\title{
IntechOpen
}

\section{Advances in \\ Landscape Architecture}

\author{
Edited by Murat Özyavuz
}

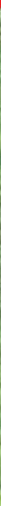





\section{ADVANCES IN LANDSCAPE ARCHITECTURE \\ Edited by Murat Özyavuz}




\section{Advances in Landscape Architecture}

http://dx.doi.org/10.5772/51738

Edited by Murat Özyavuz

\section{Contributors}

Isil Kaymaz, Murat Z. Memlük, A. Esra Cengiz, Murat Ozyavuz, Elif Ebru Sisman, Ayten Özyavuz, Aslı Korkut, Aylin Salici, Reyhan Erdogan, Ercan Gökyer, M.Kivanc Ak, Canan Cengiz, Bülent Cengiz, Filiz Çelik, Nazan Kuter, Umut Pekin Timur, Aysel Uslu, Nasim Shakouri, Aydın Özdemir, Tuğba Kiper, Engin Eroglu, Cengiz Acar, Ibrahim Turna, Özgür Burhan Timur, Nurgül Konaklı Arısoy, Habibe Acar, Aybike Ayfer Karadağ, Murat Akten, Mehmet Cetin, Gökçen Firdevs Yücel, Banu Ozturk Kurtaslan, Mustafa Ergen, Yasar Bahri Ergen, Gülhan Benli, Zuhal Dilaver, José Manuel Pagés Madrigal, Rute Matos, Desidério Batista, Candan Kuş Şahin, Yusuf Adedoyin Aina, Shuaib Garba, Ali Al-Naser

\section{(c) The Editor(s) and the Author(s) 2013}

The moral rights of the and the author(s) have been asserted.

All rights to the book as a whole are reserved by INTECH. The book as a whole (compilation) cannot be reproduced, distributed or used for commercial or non-commercial purposes without INTECH's written permission. Enquiries concerning the use of the book should be directed to INTECH rights and permissions department (permissions@intechopen.com).

Violations are liable to prosecution under the governing Copyright Law.

\section{(cc)BY}

Individual chapters of this publication are distributed under the terms of the Creative Commons Attribution 3.0 Unported License which permits commercial use, distribution and reproduction of the individual chapters, provided the original author(s) and source publication are appropriately acknowledged. If so indicated, certain images may not be included under the Creative Commons license. In such cases users will need to obtain permission from the license holder to reproduce the material. More details and guidelines concerning content reuse and adaptation can be foundat http://www.intechopen.com/copyright-policy.html.

\section{Notice}

Statements and opinions expressed in the chapters are these of the individual contributors and not necessarily those of the editors or publisher. No responsibility is accepted for the accuracy of information contained in the published chapters. The publisher assumes no responsibility for any damage or injury to persons or property arising out of the use of any materials, instructions, methods or ideas contained in the book.

First published in Croatia, 2013 by INTECH d.o.o.

eBook (PDF) Published by IN TECH d.o.o.

Place and year of publication of eBook (PDF): Rijeka, 2019.

IntechOpen is the global imprint of IN TECH d.o.o.

Printed in Croatia

Legal deposit, Croatia: National and University Library in Zagreb

Additional hard and PDF copies can be obtained from orders@intechopen.com

Advances in Landscape Architecture

Edited by Murat Özyavuz

p. $\mathrm{cm}$.

ISBN 978-953-51-1167-2

eBook (PDF) ISBN 978-953-51-5381-8 


\section{We are IntechOpen, \\ the world's leading publisher of Open Access books}

\section{Built by scientists, for scientists}

\section{$4,200+$}

Open access books available

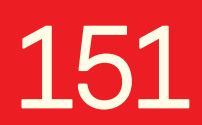

Countries delivered to

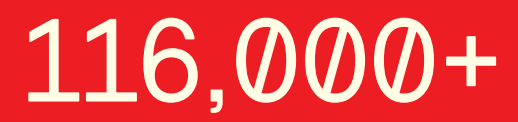

International authors and editors

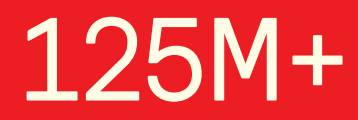

Downloads

Our authors are among the

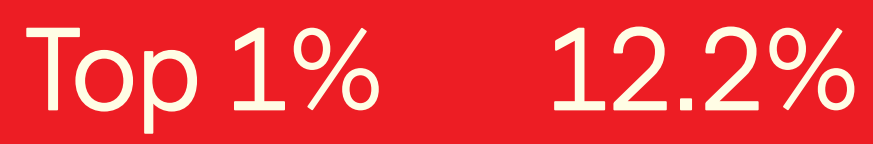

most cited scientists

Contributors from top 500 universities

\section{Interested in publishing with us? \\ Contact book.department@intechopen.com}

Numbers displayed above are based on latest data collected.

For more information visit www.intechopen.com 



\section{Meet the editor}

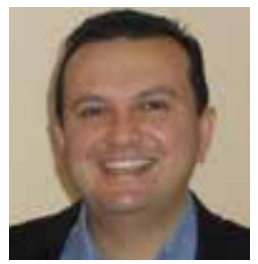

Assoc. Prof. Dr. Murat Özyavuz was born in 1976 in Turkey and lived there until coming to Ankara (Turkey) in 1999. He studied Landscape Architecture at the Ankara University and obtained B.S. degree in 1999. He obtained his M.S. and Ph.D. degrees from the Landscape Architecture Department of Institute of Natural and Applied Sciences in 2003 and July 2008, respectively (M. S.

Thesis, Arboretum Planning Principles and Thrace University Güllapoğlu Arboretum Landscape Planning Studies, Ph.D. thesis, Planning of İğneada - Demirköy Part of Yildiz Mountains as a Biosphere Reserve). During his Ph.D. studies, he mostly worked on Landscape Planning, Protected Areas, Geographic Information Systems and Remote Sensing. Now, Dr. Ozyavuz is an Associate Professor at the Department of Landscape Architecture, Faculty of Fine Arts, Design and Architect, Namık Kemal University. He has many national and international publications and has worked on many research projects. 



\section{Contents}

\section{Preface XIII}

Section 1 Landscape Planning 1

Chapter 1 Inventory and Analysis of the Landscape $\mathbf{3}$

Murat Özyavuz

Chapter 2 Impacts of Improper Land Uses in Cities on the Natural Environment and Ecological Landscape Planning 19

A. Esra Cengiz

Chapter 3 Architectures on Territories Methodologies for the Graphical Representation 53 José Manuel Pagés Madrigal

Chapter 4 Possibility to Employ AHP as a Multi-Criteria Decision Making Method in Landscape Planning Initiatives 87 Murat Akten

Chapter 5 Use of Watersheds Boundariesin the Landscape Planning 105

Aybike Ayfer Karadağ

Chapter 6 Stakeholder Involvement in Sustainable Watershed Management 131 Reyhan Erdogan

Chapter 7 Urban Waterfront Regenerations 169 Umut Pekin Timur

Section 2 Landscape Design 207

Chapter 8 Eco-Revelatory Design 209 Nurgül Konaklı Arısoy 
Chapter 9 Designing Landscapes for Child Health 227

Aydın Özdemir

Chapter 10 Integrating Ecosytem Landscapes in Cityscape:

Birds and Butterflies 263

Gökçen Firdevs Yücel

Chapter 11 Visual Quality Assessment Methods

in Landscape Architecture Studies 279

Mehmet Kıvanç Ak

Chapter 12 Landscape Design for Children

and Their Environments in Urban Context 291

Habibe Acar

Chapter 13 Ecological Landscape Design 325

Filiz Çelik

Chapter 14 Crosby Arboretum (Picayune, Mississippi):

A Natural World for All 351

Banu Ozturk Kurtaslan and Robert Brzuszek

Chapter 15 Hospital Outdoor Landscape Design $\mathbf{3 8 1}$

Gökçen Firdevs Yücel

Section 3 Urban Landscape 399

Chapter 16 Pedestrian Zones 401

Elif Ebru Sisman

Chapter 17 Urban Landscape Design and Biodiversity 427

Aysel Uslu and Nasim Shakouri

Chapter 18 Urban Agriculture: The Allotment Gardens

as Structures of Urban Sustainability 457

Rute Sousa Matos and Desidério Sales Batista

Chapter 19 Designing Urban Squares $\mathbf{5 1 3}$

Murat Z. Memluk

Chapter 20 Towards an Integrative Theory Approach to Sustainable Urban Design in Saudi Arabia: The Value of GeoDesign 531

Y.A. Aina, A. Al-Naser and S.B. Garba

Chapter 21 Urban River Landscapes $\mathbf{5 5 1}$

Bülent Cengiz 
Chapter 22 Vertical Gardens $\mathbf{5 8 7}$

Özgür Burhan Timur and Elif Karaca

Chapter 23 Street Furniture and Amenities:

Designing the User-Oriented Urban Landscape 623

Gökçen Firdevs Yücel

Chapter 24 Greenways as a Sustainable

Urban Planning Strategy $\mathbf{6 4 5}$

Aylin Salici

Section 4 Landscape Ecology 661

Chapter 25 Understanding Landscape Structure

Using Landscape Metrics 663

Ercan Gökyer

Chapter 26 Urban Ecology 677

Canan Cengiz

Chapter 27 Landscape Engineering, Protecting Soil, and Runoff Storm Water 697

Mehmet Cetin

Section 5 Geographic Information System and Remote Sensing 723

Chapter 28 Application of Geographical Information

System to the Analysis of Urban Green Areas

in Urban Development Plans

- A Case Study of Zonguldak, Turkey 725

Yasar Bahri Ergen and Mustafa Ergen

Section 6 Socio-Cultural Landscape 737

Chapter 29 Urban Landscapes and Identity 739

Isil Kaymaz

Chapter 30 Homegardens in Landscape Architecture -

A Case Study of Hazelnut Plantations 761

Engin Eroğlu, Cengiz Acar and Ibrahim Turna

Chapter 31 Role of Ecotourism in Sustainable Development $\mathbf{7 7 3}$

Tuğba Kiper

Chapter 32 The Use of Courtyards and Open Areas

in the Ottoman Period in İstanbul 803

Gülhan Benli 
Section 7 Landscape Restoration 821

Chapter 33 Reclamation of Degraded Landscapes due to Opencast Mining 823

Nazan Kuter

Section 8 Biodiversity and Plant Material 859

Chapter 34 Native Vegetation $\mathbf{8 6 1}$

Murat Özyavuz, Aslı B. Korkut and Ayten Özyavuz

Chapter 35 Conservation of Natural Plants and Their Use in Landscape Architecture $\mathbf{8 8 5}$ Zuhal Dilaver

Chapter 36 Lawns and Ground Covers in Landscape Design 905

Candan Kus Sahin 


\section{Preface}

The purpose of this book, is to reveal the landscape planning and design in recent years. For this purpose, chapters were selected on the topics of different landscape architecture study. Landscape architecture is the design of outdoor and public spaces to achieve environmental, socio-behavioral, and/or aesthetic outcomes. It involves the systematic investigation of existing social, ecological, and geological conditions and processes in the landscape, and the design of interventions that will produce the desired outcome. The scope of the profession includes: urban design; site planning; town or urban planning; environmental restoration; parks and recreation planning; visual resource management; green infrastructure planning and provision; and private estate and residence landscape master planning and design - all at varying scales of design, planning and management. Landscape planning is the key planning instrument for nature conservation and landscape management. Apart from the landscape plans at the local level, i.e. municipal level, there are landscape structure plans (Landschaftsrahmenplane) at the district or planning region level (Regierungsbezirk, Landkreis, Planungsregion) and the regional landscape program (Landschaftsprogramm) for an entire regional state (Land). The local landscape plans (Artliche Landschaftsplane) are based on the specifications contained in the regional landscape program and the landscape structure plans. At all levels landscape planning makes an important long-term contribution to the conservation of natural resources. It not only addresses the narrower areas of particularly valuable protected sites, but also devises strategies for full-coverage, sustainable conservation and the long-term development of nature and landscapes.

This book is for landscape architects; theoretical foundations, theories, methods, and applications will be essential parts of this reference book. In addition, this book addresses several very different subjects of study: landscape planning, landscape engineering, biodiversity, landscape restoration, landscape design, and urban design related to theory, practice and the results will be covered. Due to the varied usage of the term Landscape Architecture, the intended readership for this book is a broad audience including environmentalists, landscape architects, architects, environmentalists, botanists, urban and regional planners, government agencies, nongovernmental organizations, agricultural organizations, students at all levels, research organizations, international organizations and all interested parties. 
I would like to express my deep sense of gratitude and indebtedness to all the authors for their valuable contributions and also to the researchers who actually performed experiments and reported their findings. I must confess that it had been a rare privilege for me to be associated with InTech publisher. Thanks is the least word to offer to Ms. Marina Jozipovic, InTech's Publishing Process Manager, yet I shall avail this opportunity to extend my sincere gratitude for her help and co-operation at various phases of book publication. Last but not least I express my sincere thanks and affection to my wife Ayten Özyavuz and my daughter Ayza Özyavuz for their patience and cheerful. I hope this book will be beneficial to the scientific world.

\author{
Assoc. Prof. Dr. Murat Özyavuz \\ Namik Kemal University \\ Faculty of Fine Arts, Design and Architecture \\ Department of Landscape Architecture \\ Tekirdag \\ Turkey
}


Section 1

\section{Landscape Planning}





\title{
Inventory and Analysis of the Landscape
}

\author{
Murat Özyavuz
}

Additional information is available at the end of the chapter

http://dx.doi.org/10.5772/55747

\section{Introduction}

Landscape planning, often referred to as 'environmental planning' or 'ecological planning', is a way of directing or managing changes in the landscape so that human actions are in tune with nature and environment (Zaucer and Golobic, 2010).

Landscape planning is undergoing change due to new requirements. Its previous main task of controlling spatial uses and the development of nature and the landscape has extended. Implementation of the European requirements for the Natura 2000 network, for the Water Framework Directive (WFD), the Floods Directive as well as the Strategic Environmental Assessment (SEA) can be made considerably easier and can be coordinated with the help of landscape planning. It is ideally suited, for example, as the basis of the Strategic Environmental Assessment or as an extensive information base for river basin planning covering all natural resources. In addition, landscape planning increasingly supports the tasks of providing members of the public with environmental information and their participation in sustainable local community and landscape planning (Haaren, et al., 2008).

Landscape planning can be better used as a versatilely usable information basis for overall spatial planning, impact mitigation regulation or environmental assessments if the information is presented according to the requirements of this planning and these instruments. Spatial planning has always been regarded as an activity that, in seeking solutions for a certain social problem, brings a change into the territory. It primarily looks after social needs, the economical use of the resource and its fertility. Because spatial planning is essentially economic in orientation, it is generally characterized as developmental planning (Zaucer and Golobic, 2010). The basic distinction between spatial planning and landscape planning is that the former is essentially economic and developmental in orientation, while the latter is more concerned with environmental and landscape qualities and thus protective in orientation. It must be noted that landscape planning does not represent a substitute for spatial planning. With developed approaches 
and methods, it may complement a set of spatial planning approaches and methods and contribute to larger efficiency of bottom-up comprehensive planning (Zaucer and Golobic, 2010). The aim of landscape planning is thus to prevent or at least limit the degradation of the environment to a minimum while increasing, as far as possible, 'creativity' in order to meet the developmental needs. By combining approaches from the natural sciences and the planning disciplines landscape planning has developed a range of different methods and tools for integration of environmental objectives into the process of analysis and the development of planning proposals. Landscape planning approaches and methods are transparent and systematic, which makes them useful for participatory and comprehensive spatial planning (Zaucer and Golobic, 2010).

Landscape planning is currently developing away from rigid planning to a generally accessible and easy to update information base and a basis for action. By using new data processing and transfer technologies, landscape planning can be developed into an information and communication platform, which also communicates data and knowledge about nature and the landscape to the public and makes simple consultation and participation possibilities available via the internet. This development is borne by a new understanding of government action which is characterised by more proximity to citizens and transparency in politics and the administration. Landscape planning therefore supports implementation of Agenda 21 as well as the objectives of the Aarhus Convention and the associated EU Directives and federal laws for the introduction of more democracy in environmental issues. It promotes the enlightenment of members of the public and businesses as well as their commitment to their environment and homeland. Because landscape planning creates fundamentals, competence and incentives for own initiatives, resourcefulness and commitment to the integration of environmental aspects in landscape usage (Haaren, et al., 2008).

Landscape planning is also a way to effectively include the environmental requirements of different sectors into planning process. One of the most valuable approaches is vulnerability analysis, where environmental qualities are assessed from the viewpoint of potential threat resulting from planned actions. It functions as an integrating and conflict-solving tool, since it (Zaucer and Golobic, 2010):

- $\quad$ includes a whole territory (of a chosen administrative / planning unit),

- considers a whole range of diverse environmental components,

- $\quad$ supports active dialog between stakeholders,

- may embrace all interests (natural, social, economic, and political) and evaluate their consequences and thus supports crosssectoral or comprehensive planning, and

- $\quad$ supports search for an optimal solution.

Landscape planning today should not be viewed as a static plan but as a dynamic, continuously or modularly changeable information and working basis. Landscape planning is expected to be need- and problem-oriented. Against the background of fast changes in use of nature and landscape, these requirements are becoming increasingly important (Haaren, et al., 2008). Landscape planning, design and management are practised directly or 
indirectly by many others and in many sectors, including land use planning, agriculture, forestry, nature conservation, amenity land management, and so on, and we include all these in our approach. The term 'landscape' used here is also broad and includes much more than 'the appearance of the area of land which the eye can see at once' (Chambers, 1993). Landscape is an evolving cross-disciplinary area, which draws contributions from art, literature, ecology, geography and much more (Benson and London, 2000). As the legal basis of the various planning and instruments partly name natural resources as sensitive receptors, partly landscape functions, it should be possible to access landscape planning information structured both by natural resources and landscape functions.

Landscape-ecological planning is a specialization within landscape planning that focuses on spatial planning, the organization of uses and relationships of land uses to achieve explicit goals (e.g. habitat improvement, sustainability). While the landscapeecological planning approach is characterized by a focus on the linkage of ecological patterns and processes, it also includes the actions and values of humans, and social and economic dimensions (Hersperger 1994). Finally, landscape-ecological planning adopts the landscape as the principle spatial unit of research and planning recommendations (Ahern, 2006).

Landscape analysis has a significant function in the process of decision making for the future land use, organization of the space, nature protection, and rational use of the nature resources. Basic problems and tasks of the landscape analysis and planning are located in discovering and solving the conflicts among the development of the society and very complex task in nature assignment. The development covers more intensive engagement of space and more intensive land use, organization and arrangement. The features of the land and space with their entire natural and produced substratum are the significant categories for determination of future development. In this context, landscape analysis and planning appear as an activity of primary task to connect developing possibilities and tendencies for certain space (Pecova, 2000). These strategies, in essence, define the planning context with respect to the macro-drivers of change in a given landscape and the strategic nature of the planners' response. Defining these strategies also helps to place the planning activity within a broader context, which is particularly important when planning methods are transferred or adopted for use in different locations, contexts or for different applications (Ahern, 2006). Landscape planning methods can also be classified and understood according to their strategic orientation: protective, defensive, offensive or opportunistic (Ahern 1995). Planning methods can also be understood and classified according to their resource or goal orientation. The abiotic-biotic-cultural (ABC) model is useful to describe the specific goals addressed in planning and the level of integration between these goals (Ahern, 1995) (Figure 1). In this model, abiotic goals include water resources, soil and air quality. Biotic goals focus on biodiversity in general, including individual species and habitat protection and ecological restoration. Cultural goals are human-based and include: transportation, land use, recreation, historic preservation and economic goals (Ahern, 2006).

Figure 1. presents an array of planning types graphically organized within a triangle that represents the $\mathrm{ABC}$ model. In this diagram a number of planning sectors or themes are located according to their emphasis and level of integration within the $\mathrm{ABC}$ resources. The 
figure shows that an evolution is occurring towards a more integrated planning perspective as represented by the central circle (Ahern, 2006).

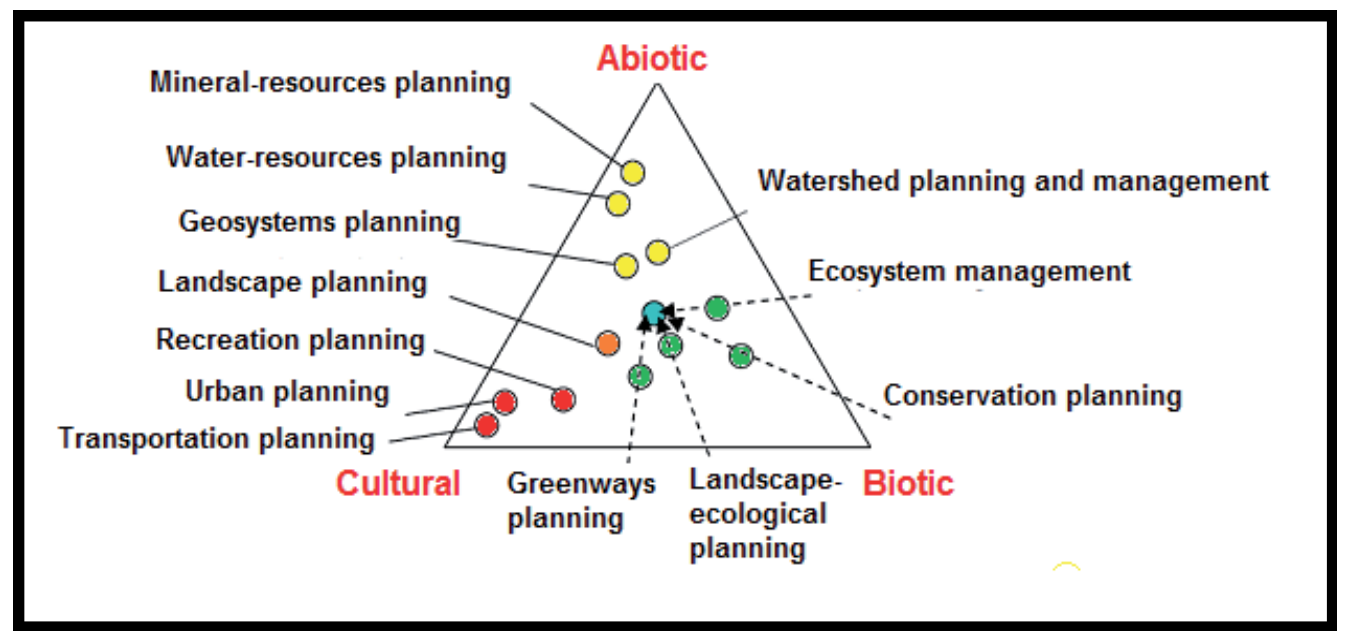

Figure 1. The abiotic, biotic and cultural resource-planning continuum (Ahern, 2006).

The combination of different landscape factors and the interactions between the natural resources are also significant for performance and ability to function. Apart from the description and assessment of the landscape functions (current condition and development potential), statements for specific areas are made on the sensitivity of distinct (sub)landscapes to impacts as well as on the ability to restore their performance and functional capability (Haaren, et al., 2008). This can be achieved by appropriate linking of standard text units in digital landscape plans. It is also advisable not only to be able to select specific individual cartographic areas but also to easily find and collate text statements on special landscape units. This service will assist the administrations or project sponsors in consolidating the respective relevant area descriptions for comments or environmental assessments. The effort spent on these preparations pay off because the information is so conveniently accessible and is easier to integrate in other planning and instruments (Haaren, et al., 2008). In landscape planning the existing condition of nature and the landscape is determined and assessed on the basis of legal and functional objectives and standards, which also include landscape planning objectives at a higher level. To this end the available data and information is collated and, where necessary, it is supplemented and updated by additional surveys. The fundamental information on the soils, geology, bodies of water, air and climate, fauna and flora is used to deduce statements regarding the performance and functions of the individual natural resources and/or the balance of nature and the landscape overall (Haaren, et al., 2008).

\section{Inventory and analysis of the landscape}

\subsection{Terrain analysis}

Topographical maps of Greek origin Topos (place) and graphics (lines formed figure) is formed from the word, used for lines shows created in the forms. These are the natural and 
cultural aspects of the land, the horizontal and vertical cases, show a horizontal plane and under a certain scale. Soil maps and other maps are used in making topographic maps as a base map (Figure 2). Soil experts determine the elevation and slope curves, positions the most benefit from relief. . Physiography deals with the physical conditions of the surface of the land. The broad physiography of an area can be determined by the knowledge of the physiographic region in which it lies. The important aspects of physiography are elevation and slope. Slope, soils, geology, hydrology, microclimate, plants, and animals may be strongly related to elevation. This means that elevation is an important feature in analyzing landscapes. Topographic contour shape on the map, the location, frequency, taking into account in an area of alluvial fans, colluvial skirt lands, valleys, mountainous-hilly areas, old terraces, alluvial flood plains, river paths, meanders, lagoons and sand dunes landforms such as defined. (Figure) Any contour of the land surface structure identifies the most understandable form. Contour curves, in order to produce a realistic and reliable planning decisions important.

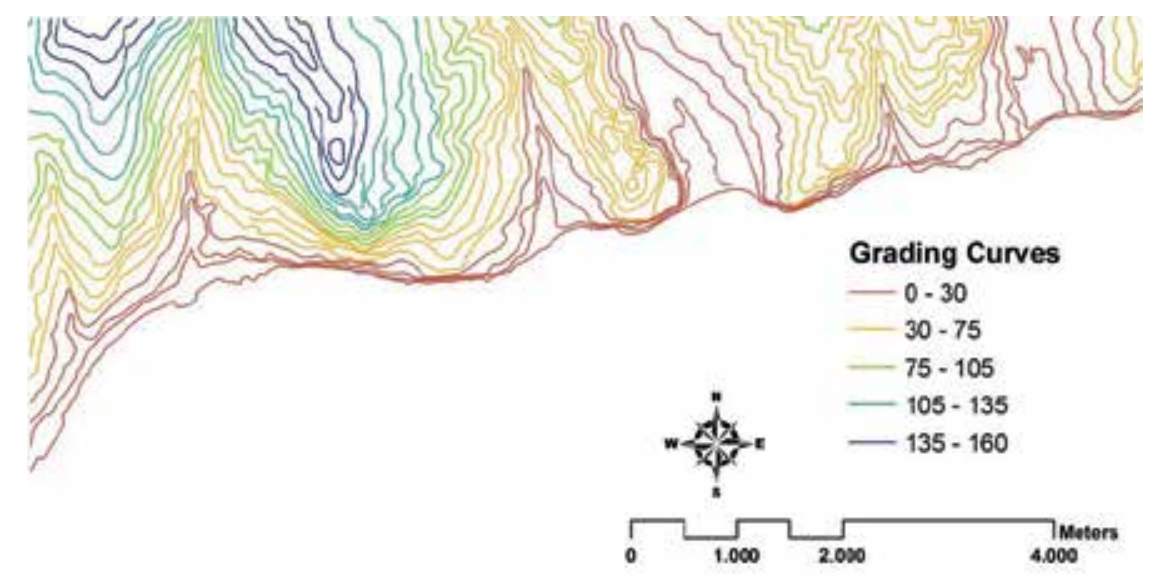

Figure 2. Grading curves for an example area

First of all, check whether the map is up to date. If the current deficiencies detected during the observations, can be added to the map. Or new information obtained from different sources (water sources, wells, dams, ponds, bridges, new uses, etc.) can be placed on the map. Horizontal and vertical cross-section for the map to be more easily interpreted. Thus, the difference in level between the high and low parts of the land surface structure and can be detected (hills, peaks, valleys, valley bottoms, slopes) (Figure 3). This is due to differences in harmful situations, measures to prevent them must be determined. The base terrain, steep slopes, private entities, such as delta, flood deposits, flood areas identified as sensitive areas. The cross sections obtained terrain, concave (depressions, valleys, depressions and so on.) And convex (ridges, hills) allows to perceive how it has developed to take shape. It is also important heights, large and small valleys, flood beds and borders determined and displayed. Accordingly, both precipitation and drainage of surface water streams flow distribution to be determined. Surface water flow intensive - is less dense areas should be considered. 


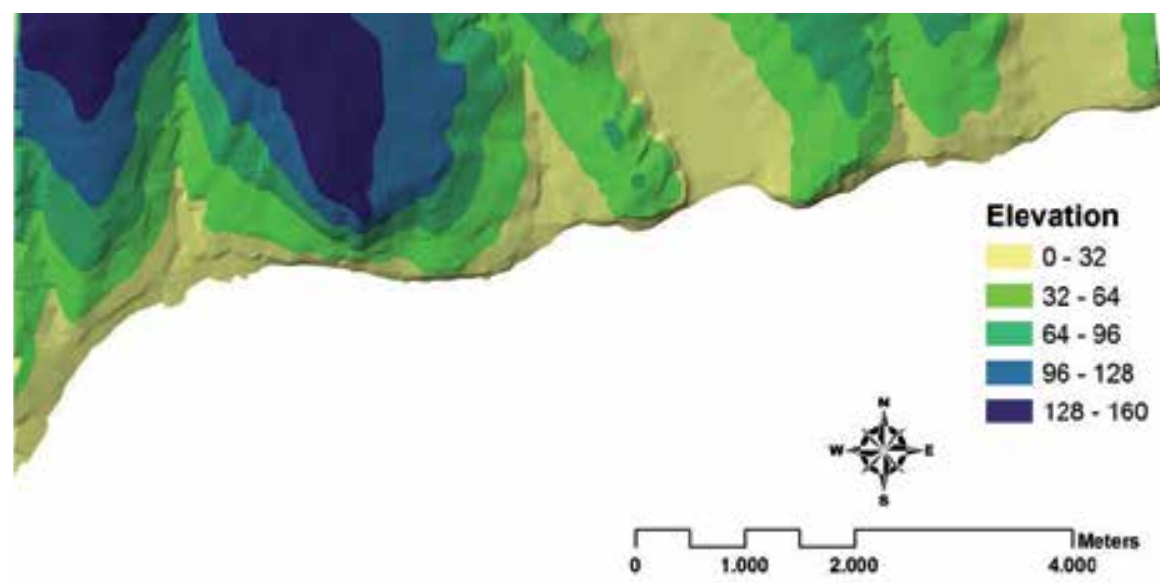

Figure 3. Elevation for an area

According to Kienast, 1993; for many countries topographic maps in the scale of 1:20'000 to 1:30'000 provide reliable monitoring data over the last 100 to 150 yrs (Hodgson and Alexander, 1990). Additionally, there are often rich collections of detailed plans in larger scales (1:5000 to 1500) that date back to the late 18th and the early 19th century (Di.int, 1990; Miiller, 1990). For the present study the main data sources are two series of topographic maps in the scale of 1:25 '000 dating back to the 1880's (Figure 4). Since topographic maps are perceptions of the environment and often rather a 'text than a mirror of reality' (Harley, 1989), definition of specific landscape elements or habitat types may vary considerably over time and the location of features is often less accurate in earlier map editions compared with today's standards (Hodgson and Alexander, 1990). Some of these misinterpretations are impossible to correct. However with a strict crossdating and a comparison of the historic maps with data from independent sources, most incompatibilities were eliminated. This was accomplished by consulting the written protocols and field notes of the topographers.

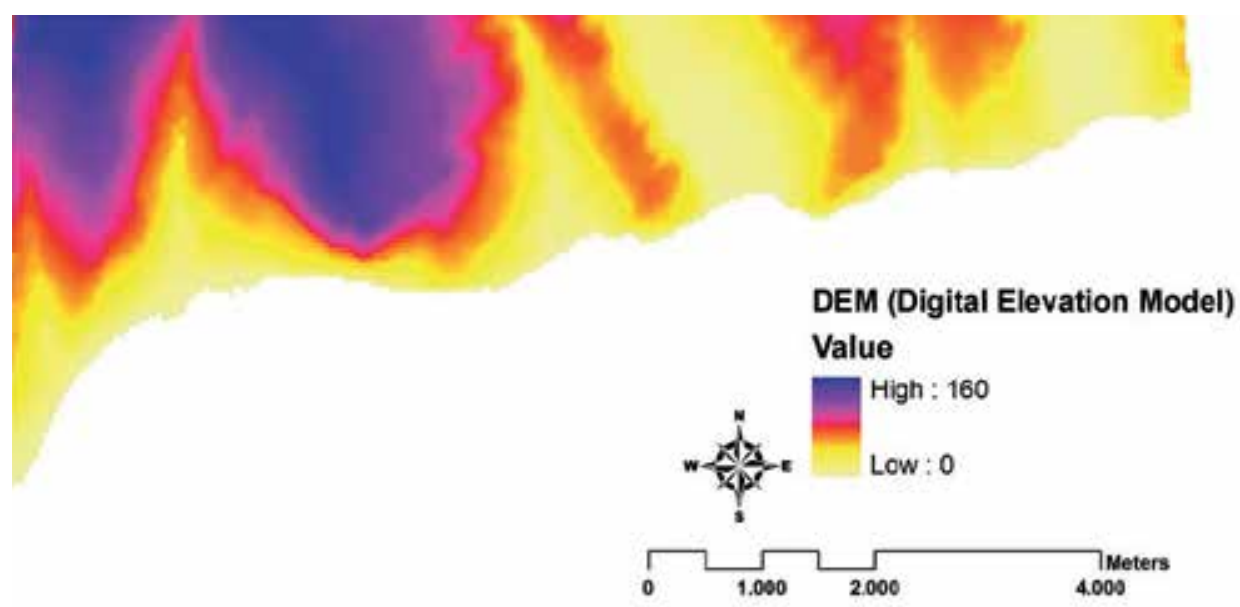

Figure 4. Dijital elevation model (for spatial analyst) 
Elevation maps are easily constructed by selecting intervals from the base maps. Altitudes can be represented by coloring spaces between topographic intervals. Elevation changes are depicted in shades of browns, yellows, or grays with felt markers, colored pencils, crayons, or through the use of computer technology, becoming lighter or darker as elevation increases

In addition, topographic maps allow visibility analysis is made from.Visibility analysis based on viewsheds is one of the most frequently used GIS analysis. This analyst ise used. This analysis is used in many studies of landscape architecture (Figure 5).

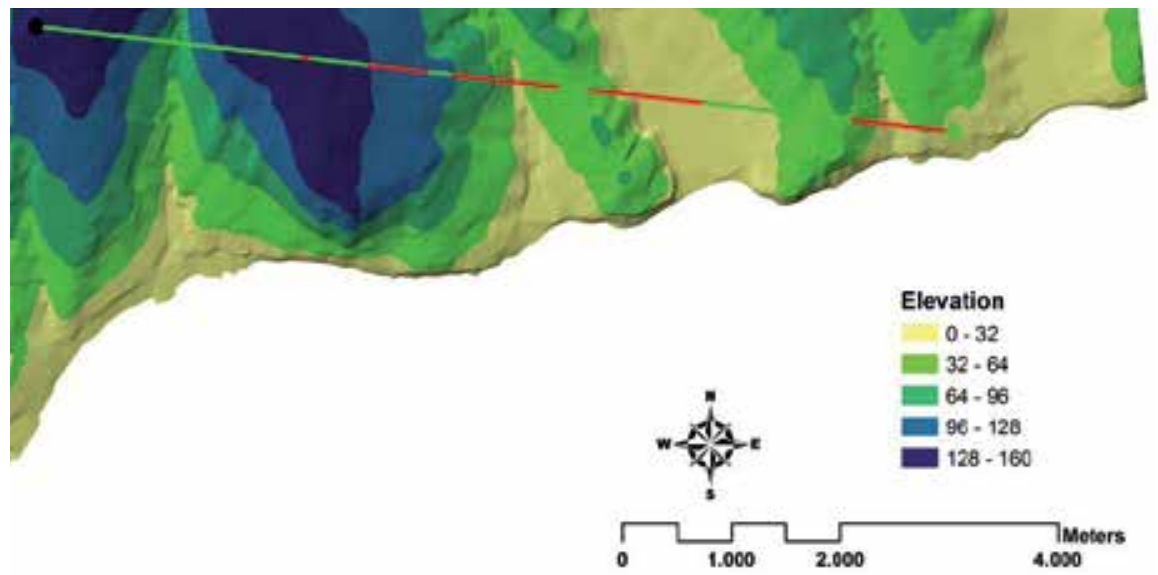

Figure 5. Visibility analysis (observer offset:120 m. and target offset:100 m.)

Contour curves are some of the features (Karadeniz, 2010):

- All points on a contour curve above are the same height above sea level,

- Each contour curve closes in on itself. Even with the edge of the map, the map will continue and close neighbors,

- A closed contour curve shows the peak or pit.

- Contour curves do not cut each other.

- The slope increases, the contour lines pass as close to each other

- In the cross-sections in order to compare the characteristic profile shapes with each other is possible to make topographic maps. (Figure

- Contour maps of curves that can be obtained; Height groups, slope, aspect maps (except that 3-D images);

- Height Groups

- Curved contour map is obtained by the separation of certain groups heights (Figure 6).

\subsection{Slope}

Slopes may be subdivided according to steepness and direction. Slope direction is referred to as aspect, or orientation (Figure 7). Steepness may be important for such activities as agriculture or the construction of buildings, while the direction of slopes is an important 
factor for such activities as siting housing for solar energy collection. Slope composition and related lithology needs to be determined. Lithology is "the soil and rock material that comprise a slope" (Marsh 1998, 80) or the physical characteristics of sedimentary materials. As with the elevation map, the division of slope categories will depend on the study.On the map using the horizontal and vertical distances are obtained and analyzed in separate groups of different units (Kienast, 1993).

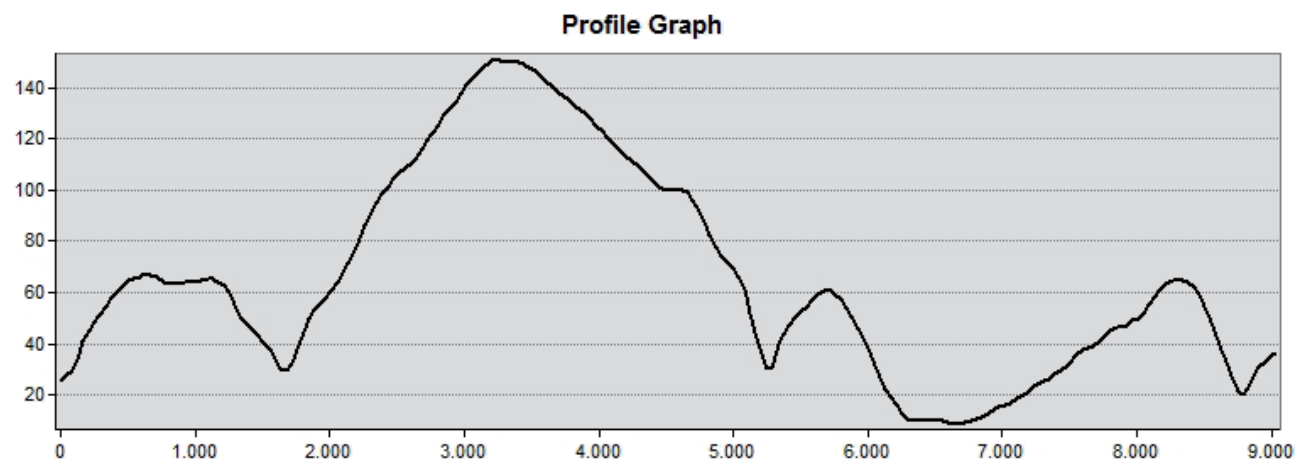

Figure 6. Land profile graph (made by DEM)

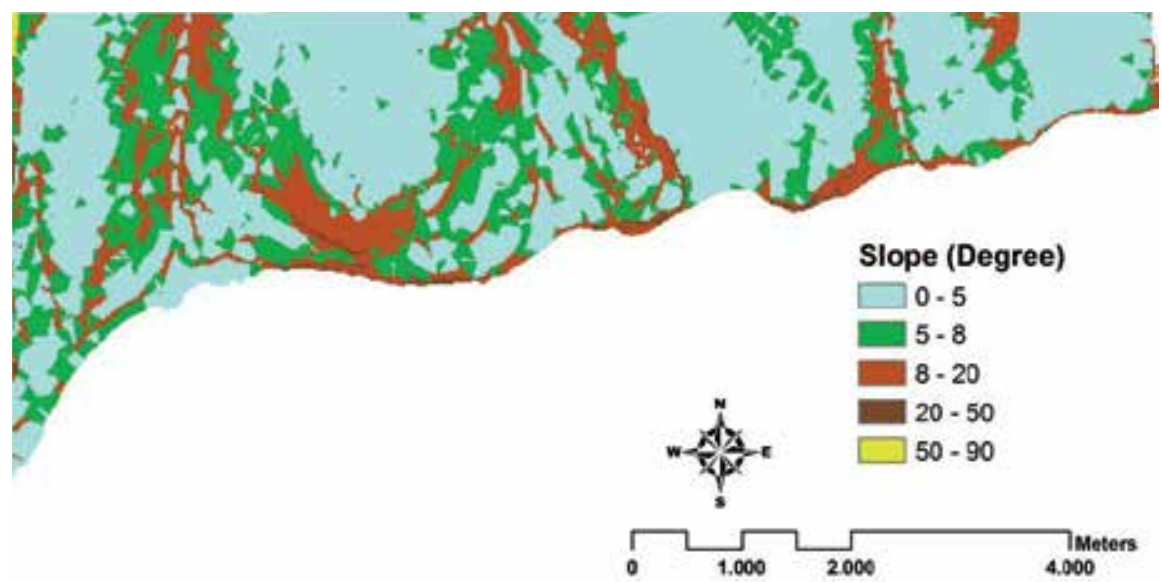

Figure 7. Slope analysis

\subsection{Aspect}

Aspect map, facing at the surface indicates in which direction. Aspect of a landscape, the climate, especially temperature and rainfall affect the amount of that place. In general, the $S$, SE, SW, and W aspect "sunny aspects,» is called. N, NE, NW, E aspects, "the shady aspects,» has been described as (Figure 8). The shaded look still water evaporation from the soil temperature is less than would be even less. Therefore, the shady aspects, the same rainfall conditions, sunny look still have a more favorable water economy 


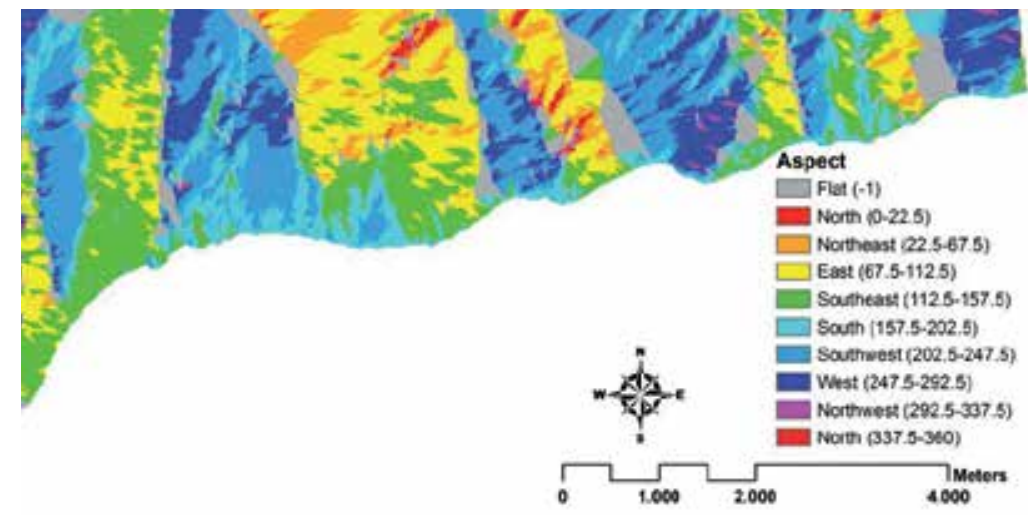

Figure 8. Aspect analysis

\subsection{Climate analysis}

Climate is the set of meteorological conditions characteristic of an area over a given length of time. It is defined as the study of extremes and long-term means of weather. The regional (or macro) climate is the big picture, the meteorological conditions and patterns over a large area. Macroclimate is affected by physical conditions such as mountains, ocean currents, prevailing winds, and latitude. It in turn affects the formation of the physiographic region through the weathering of the terrain and the amounts of precipitation that fall on the landscape. Climate states the average of the air for a long time in a specific place. Macro, meso and micro are the 3 types of climate. Long-term measurements, temperature, precipitation, air humidity and air movement and extreme values determined for the average for the region, which is characterized by a wide range of climate macroclimate is called. Climate characteristics of macro-states of different characteristics of land in the air near the surface have been described as microclimate. Shape of the face of the land, such as elevation and aspect Relief for small spaces created by the characteristics of the type of climate is called the mesoclimate. This is located between the macro and microclimate. Plant growth and biological analyzes to people about the climate are crucial in terms of comfort, they are temperature and precipitation analysis. Relative humidity, time of sun and cloud cover, wind direction and nature, frost days, and etc. factors have a significant effect on the bioclimatic comfort. Precipitation is the most important factor limiting regeneration of vegetation. The total annual rainfall is $600 \mathrm{~mm}$ but not enough for the formation of a local forest as a result of research that indicated

Heat and temperature are very different concepts. Despite the potential value of objects based on the heat, the temperature of this value emerged as a kinetic form. Therefore, the air temperature is not heat.

Bioclimatic limits of comfort with the body temperature of $15^{\circ} \mathrm{C}$ between $37^{\circ} \mathrm{C}$ ambient unless otherwise stated. Temperature of 20-24 C in the summer, optimum indoor temperature of $21 \mathrm{C}$ values of the optimal bioclimatic comfort. At night, the relative humidity of $40-70 \%$ and $18-24 \mathrm{C}$ temperature limit values. 
Climatic elements in preparing the vegetation ecological environment, climate, type of vegetation and animals living in the rural and urban areas are the limiting factor.

Analysis, planning to put up a field of plant breeding the human race in the comfort of home to learn about the conditions to create a suitable environment is important for people in planning will be done.

Therefore, the climatic comfort of people trying to manifestation of the analysis depending on the season. Bioclimatic comfort level and the amount of which should be of climatic elements allowing research on human beings endure as a medium between the lowest and highest temperatures bioclimatic comfort limits.

Meteorological elements change vertically and horizontally within short distances. Smallscale variations are brought about by changes in slope and orientation of the ground surface; soil type and moisture; variations in rock, vegetation type and height; and humanmade features. These different climates found within a small space are grouped together under the general description of microclimate. The term topoclimate is used when the effects of topographic variations of the land on the microclimate are considered. Generally, topoclimate is an extension of microclimate into the higher layers of the atmosphere and over landscapes, depending on the relief of the land. Therefore, topoclimate can be considered to occupy an intermediate level between macroclimate and microclimate. It is important to understand microclimate and topoclimate for many of the same reasons that macro, or regional, climate is important. These finer layers, however, relate more directly to building and open space design (Kienast, 1993).

\subsection{Geology}

Geology is the study of the earth. This study involves both what has happened in the past, or geological history, and what is happening on and in the earth today.

This analysis was prepared by institutions engaged in geological studies consists of the interpretation of maps and reports. As a result of this review maps and reports, forms the bedrock of physical and chemical state of the soil, water retention properties of the mass due to the hydrogeological characteristics of sedimentary or igneous efficiency, earthquake status (seismicity), the main rock formations are learned.

The inventory of a place requires an understanding of the geological history and processes of the region. Such understanding can begin with a geological map, which is "a graphic representation of the rock units and geological features that are exposed on the surface of the Earth. Accordance with the determination of the geological structure of the area in which such use is put forward. Functional characteristics of a field analysis of geological bedrock exhibits the aesthetic features can be evaluated. Underground long and wide fissures (fault lines) goes on and on. These lines are extremely sensitive to the occurrence of the earthquake areas. These areas should be on residential areas, more use should be included in nature conservation purposes. In addition to showing different types and ages of rocks, most geo- logical maps depict geologic features, such as faults, folds, and 
volcanoes. The relative timing of events can usually be determined from a geologic map, usually by the application of these principles: superposition (younger layers are above older ones); original horizontality (layers formed from deposition of sediment were originally flat); crosscutting relationships (younger features crosscut older ones; a fault will be younger than the layers or contacts it cuts); and inclusions (a rock unit is younger than the layers from which the inclusions it contains came).

Summary of geologic inventory elements; regional geographic history, depth to bedrock, outcrops, bedrock types and characteristics, cross sections, columnar sections, surficial deposits (regolith): kames, kettles, eskers, moraines, drift and till, mineral resources, major fault lines, earthquake zones, and seismic activity, rock slides and mud slides (Kienast, 1993)

\subsection{Geomorphological analysis}

Geomorphological structure, depending on the geological structure of different geological times (Era), composed of the structure of the land. Geological times, the base of the valley bottom and the plain plains, alluvial cones, low and high benches, low, medium, and high plateaus, hills, hilly and mountainous areas and etc. geomorphological formations emerge. Generally, plains, hills, high hills and highlands plateaus are around. Maps, brown hills, valleys, yellow and green, and etc.. are shown in colors. Geomorphological structure studies, microclimate, ground water, agriculture, transport, housing and construction issues during the elections helps. For example, the hills are areas that allow private construction. Dense urban developments planned, slope and valleys, parks and woods considered. Relief: mountains, hills, plains, valleys and plateaus of the surface forms of the earth's crust. Soil formation processes such as erosion and drainage efficiency of distribution and orientation plays a significant role in relief.

The following information can be produced as a result of an examination of relief

- $\quad$ the height above sea level

- according to an altitude of objects around the comparison and detection of patterns,

- certain areas, and the average slope inclination

- lands texture local formations (rocks, steep cliffs, sand dunes, karstic, etc.)

Relief, the shape of the land belonging to a landscape on a flat, recessed - ribbed, curved, is a phrase that allows the introduction of phrases such as low or high. Relief characteristics of a landscape, "altitude", "examination", "slope of the land", "shape of the earth» factors are introduced. Relief of a place, climate, vegetation and soil characteristics have a significant impact on.

\subsection{Hydrological analysis}

According to (Kienast, 1993); Water is essential for all forms of life. It is also a finite resource. Most water in the hydrosphere is salt water ( 97.20 percent). Water in the polar icecaps and other frozen areas accounts for 2.15 percent of the resource. This means only 0.65 percent of 
the water in the world is fresh, and its distribution and quality is uneven (Tarjuelo and de Juan 1999). As a result, water is an essential factor to consider in planning Water resources in conjunction with the natural function of the aquatic ecosystem at every stage of life, are needed by all living beings. Hydrological characteristics of the structure is damaged in any way connected to it will affect the life of the living.

The hydrologic cycle expresses the balance of water in its various forms in the air, on land, and in the sea. As the hydrologic cycle and water budget illustrate, hydrology deals with the movement of water through the landscape both on the surface and in the ground. Groundwater is water that fills all the unblocked pores of materials lying beneath the surface. Surface water is water that flows above the ground. Depth to water table, water quality, aquifer yields, direction of movement, and the location of wells are important groundwater factors.

Hydrological survey planned in the field;

- $\quad$ surface drainage analysis

- analysis of groundwater

- $\quad$ surface water analysis

- bottom water analyses can be performed in four different fields.

Types of Utilization of Water Resources (Karadeniz, 2008);

- $\quad$ Drinking water (surface + underground - wells)

- Agricultural activities (surface + underground - wells)

- Industrial activities

- commercial activities

- transportation

- Recreation / tourism activities

\subsection{Soils}

The skeleton of the geological structure formed by elements of the vitality of plants and animals, which have gained ground, first of all exhaustible not protected, there is no place, no longer works in the life of human nutrition, accommodation, and so on. a substance that has taken over the function of many. Soil, the water and items such as a living source. Soils occupy a unique position in the lithosphere and atmosphere. Sustainable soil use is indispensable for the development of a country. They are a transition zone that links the biotic and abiotic environments. Soil is a natural three-dimensional body on the surface of the earth that is capable of supporting plants. Its properties result from the integrated effect of climate and living matter acting upon parent material, as conditioned by relief over periods of time. Many processes are linked within the soil zone, so soils often can reveal more about an area than any other natural factor. The soil survey includes the information necessary:

- To determine the important characteristics of soils 
- To classify soils into defined types and other classificational units

- To establish and to plot on maps the boundaries among kinds of soils

- To correlate and to predict the adaptability of soils to various crops, grasses, and trees, their behavior and productivity under different management systems, and the yields of adapted crops under defined sets of management practices

The principal purposes of the soil survey are:

- To make available all the specific information about each kind of soil that is significant to its use and behavior to those who must decide how to manage it

- To provide descriptions of the mapping units so the survey can be interpreted for land uses that require the fundamental facts about soil

Summary of soils inventory elements: Soil series, permeabilit,texture, profiles, erosion potential, drainage potential, soil associations and catenas, cation and anion exchange, acidity-alkalinity

Soil maps, land capability classes and these classes determine the soil physical, chemical and biological properties of soils, as well as training courses are available. In addition, usage patterns according to these properties are stated and symbols are shown on the map.

Soil landslide, fluidity, displacement characteristics of survey plans or maps are very important in terms of processing uses reach a decision on the erroneous.

Soil, landscape planner is one of the important ecological factors affecting the decision. Should not be the decision of any plan without understanding the properties of the soil as it should be.

Soil, landscape planner is one of the important ecological factors affecting the decision. Different climatic conditions, a wide range of rocks of different plant designs at different elevations formed land, water and air, one of the indispensable elements of life. Soil is a limited natural resource. In Turkey, most of the worlds to represent the soil types have different soil types.

\subsection{Vegetation}

Plants are important to study for many reasons. They may have economic and medicinal value. They provide habitat for wildlife. They have significant influence on natural events like fires and floods and may reduce the human consequences of such events. Plants are beautiful and contribute to the scenic quality of landscapes. Plants are the source of oxygen, which humans need to survive.

Survey analysis of landscape vegetation is one of the most important works. Flora and vegetation survey done by several methods. The flora of an area of all plant species, surveying, site observations and collected in the form of plants can be identified.

Flora cannot work without knowing the vegetation. Stratification, vitality (naturalness) and the other based on qualitative and quantitative characteristics of the plants are grouped and 
named all of the vegetation. Vegetation surveys, in the form of detailed investigation, Braun /Blanquet's method and the values determined by the quality and quantity of work done with the vegetation maps we developed this method in many countries.

The vegetation plots will be determined by dividing the area of the study of flora as simple as possible. Sample plots can be created in various sizes. For example, a plot of $20 \times 20 \mathrm{~m}$ in size of all trees, shrubs, herbaceous plants is determined by the type and size. Plots more detailed surveys, $4 \times 4 \mathrm{~m}$ and $1 \times 1 \mathrm{~m}$ in size by dividing the sub-plots of plant species can be detected. These plots are given numerical values are determined by density of plant species.

Vegetation, vegetation can be classified as natural and cultural. In vegetation surveys should be examined in both studies. Vegetation can be determined by aerial photographs. Vegetation remote sensing system is also an important method used in the search. The vegetation surveys, and maps are used in planning the elections of most plant material.

Summary of vegetation inventory elements; Plant associations and communities, vegetative units, species list, species composition and distribution, physiognomic profiles, ecotone and edge profiles, rare, endangered, and threatened species, fire history (Kienast, 1993).

\subsection{Fauna}

Fauna, terrestrial and aquatic fauna can be studied in two groups. Land fauna of mammals, birds, frogs and reptiles, insects and invertebrates. These populations, habitats, and is determined in terms of activities. Results are reported with a map of a state of wild life. Within the scope of this report, the general condition of the fauna (endemic, rare, endangered, extinction, etc.). Indicated. Broadly, wildlife is considered to be animals that are neither human nor domesticated. Insects, fish, amphibians, birds, and mammals are more mobile than plants. While closely linked to vegetative units for food and shelter, wildlife often use different areas to reproduce, eat, and sleep. Like vegetation, wildlife have not been extensively inventoried except where the animals have some commercial value. Because animals are mobile, they are even more difficult to inventory than vegetation. Planners are paying increased attention to wildlife. They observe that in addition to enhancing the quality of life, wildlife protection is important for ethical and moral reasons, for recreational benefits, and for economic and tourist values.

Summary of wildlife inventory elements; Species list, species-habitat matrix, animal populations, habitat value map, habitat of rare, endangered, and threatened species

Animal migration is connected to both the ecological and genetic factors need to be taken into consideration surveying point. Migration event, both vertically and horizontally maintained. Regular vertical migration by plankton, the night side of the sea or lakes go deep into the water again in the morning takes the form of strokes. Horizontal migration of many invertebrate and vertebrate animals conducted by the immigration. Vertebrate animals are more regular migrations. Some animals are effective spread plant species. For example, birds, fruits, taking them to various places after eating the seeds of these plants are to help them develop those areas. In addition, the fauna that need to fertilize plants. 
In addition, creating a major impact on hunting fauna. Hunting generating stations was established, hunting periods, must be done regularly. Effects on fauna, there are cultural practices, improper applications, the reductions in fauna, migration, and etc. causes problems.

\subsection{Analysis of socio-culturel resources}

Landscape architecture, planning activities, as well as natural resources, cultural resources present in the area is important in the determination of planning decisions to be taken for these resources. Planning was done by the people for the people by the people are the most important criterion in planning.

In the selection of a cultural use of natural resources in an area to determine the effects of this field, if necessary, the effects on natural resources, cultural resources, and these effects should be known to be determined.

Surveys, social situation, demographics, migration and urbanization, communication and transportation, education, health and nutritional status, settlement and housing status, issues such as public-state relations under investigation. In surveys, the economic situation, land ownership, party products, credit facilities, cooperatives, marketing and market relations, forms of business power, the income levels of the families studied.

\section{Author details}

Murat Özyavuz

Namık Kemal University, Faculty of Fine Arts, Design and Architect, Department of Landscape Architecture, Turkey

\section{References}

Ahern, J., 1995. Greenways as a planning strategy. In: Fabos, J. and Ahern, J. eds. Greenways: the beginning of an international movement. Elsevier, Amsterdam, 131-155.

Ahern, J., 2006., “Theories, methods and strategies for sustainable landscape planning". In From Landscape Research to landscape Planning: Aspects of Integration, Education and Application. B. Tress, G. Tress, G. Fry, and P. Opdam, Editors. Springer. Pp. 119131.

Benson, J.F., London, M.H.R. 2000. Landscape are complex systems that require a multiscale approach to fully understand, manage, and predict their behavior. ISBN 0-419-25080-8 (Print Edition).

Haaren, C.V., Galler, C., Ott, S. 2008.Landscape planning: The basis of sustainable landscape development, Federal Agency for Nature Conservation, Hannover.

Karadeniz, N. 2008. Kaynak Envanter ve Analizi, Ankara Üniversitesi, Peyzaj Mimarlığ1 Bölümü, Ankara, Türkiye. 
Kienast, F. 1993. Analysis of historic landscape patterns with a Geographical Information System - a methodological outline, Landscape Ecology vol. 8 no. 2 pp 103-118.

Pecova, H.S., 2000. Landscape Analysis in Spatial Planning, Landscape Ecology: theory and applications for practical purposes, The Problems of Landscape Ecology Vol VI., 93-101.

Zaucer, L.B. and Golobic, M. 2010. Landscape planning and vulnerability assessment in the mediterranean, Croatia. 


\title{
Impacts of Improper Land Uses in Cities on the Natural Environment and Ecological Landscape Planning
}

\author{
A. Esra Cengiz \\ Additional information is available at the end of the chapter
}

http://dx.doi.org/10.5772/55755

\section{Introduction}

Irregular and unsound urban development is the common problem of all urban settlements today. The increasing continuation of this problem is inevitable in this order, where the economy-ecology balance is not taken into consideration and economic concerns always win.

Urban growth, the density of which is continuing increasingly with the population increase that has taken place in urban areas in the recent years, leads to the vanishing of an extremely limited number of natural resources and to the occurrence of irregular and unsound urban areas, along with impairing the agricultural lands (Brueckner et al., 2001).

When considered from another perspective, it might be stated that urbanization gained momentum with the industrial revolution. When urbanization and industrialization are evaluated together in this context, it follows that the share of industrialization in the concentration of the population in urban areas and in the environmental pressure it creates is a fact which cannot be ignored (Aksu, 2011). The technological development, the population increase and the rapid change in cities that particularly occurred upon the industrial revolution have upset the ecological balance; consequently, the process of rapid degradation of natural resources commenced. Having continued with a gradual increase in the need for new living spaces and areas of use, this process of degradation has substantially altered the working of the ecosystem with either conscious or unconscious planning.

It is impossible to make up for the natural resources which have been used up due to the degraded ecosystem; furthermore, the vital impacts of this process are increasing day by day. The cities and industrial areas (technoecosystems) which continue to develop on natural areas especially due to the shortcomings/mistakes in city planning are striking as one of the most important results of this situation. 
Technoecosystems are ecosystems which occur with the rearrangement of natural ecosystems and on which urban-industrial societies live. Being relatively new on the earth, these systems provide their power from advanced technologies and non-self-renewing energy resources. In order for urban-industrial formations to survive on the earth with limited resources, it is imperative that they be made more compatible with the natural ecosystem than that of today and that an order which benefits both parties be created without the impairment of the working of the ecosystem (Odum and Barrett, 2008).

In conclusion, upon the impairment of the working of the ecosystem, the fertile agricultural lands which are particularly impossible to reclaim have been confronted with the danger of degradation and vanishing, along with the natural areas that must absolutely be conserved within the ecosystem. Therefore, preservation of the ecological balance and the concept of ecological landscape planning that developed accordingly are the primary issues on which one must strongly dwell today.

Considering the principle of integration of the urban ecosystem with the natural ecosystem, this study dwells on the impacts of improper use due to wrong urban development on the natural environment and the concept of ecological landscape planning. Within this scope, the subjects "Improper Land Use, Planning and the Planning Hierarchy in Turkey, Ecological/Environmentally-Sensitive Landscape Planning and its Importance, and the Relationship between Sustainable Urbanization and Ecological Planning" were included in the study.

At the next stage of the study, the losses of fertile agricultural lands resulting from the lands which were opened to development at the city center of Çanakkale, selected in order to explain the matter with a concrete example, are contained in the study with numerical expressions and figures. At the final stage, an overall evaluation of the planning hierarchy on the urban scale in our country was made, and the legal and administrative gaps in the improper use of the land were investigated thoroughly. Accordingly, the reasons for, the consequences of and the solutions to improper land uses frequently taking place in urban area planning were discussed.

\section{Improper land use}

The importance attached, and the priority given, to the environment and to urban ecological planning varies by society. Furthermore, it is possible to see the variations in the perspectives of the environment at various stages. Urban development is defined with the increase in production and consumption following the industrial revolution with the assumption that the natural resources were endless and with intensive construction activities. This stage involves some extravagant energy and land use at this stage. The growth of the city against agricultural lands is regarded as an essential indication of development (Eke, 2000).

Especially the process of metropolitanization causes cities to grow rapidly in the space and sprawl over extensive areas and to predominate, economically and socially, in all surrounding urban and rural communities. As a result of this, the natural resources remaining within the metropolitan area enter the process of being used up rapidly. This manifests itself with the unplanned and uncontrolled growth particularly against the rapid population increase in the metropolises of developing countries (Sezgin and Varol, 2012). 
By the phenomenon of urbanization which appeared in this process of growth, the sprawl of cities, the absolute necessity for establishing new settlements and the fact that urban lands could easily be turned into a matter of speculation resulted in the rapid inclusion of fertile agricultural lands in urban lands (Keleş and Hamamc1, 1993).

The rapid decrease in agricultural lands upon rapid urbanization and industrialization is a phenomenon which is observed worldwide besides in our country. The construction activities of industrial establishments, roads which are their infrastructure, sports facilities and entertainment centers take place in fertile agricultural lands generally with the justification that they bring fewer economic losses (Çepel, 2008).

The reasons for improper use, meaning the use of agricultural land for nonagricultural purposes, include the gradual increase in urbanization, the rapidly developing industry and investments accordingly, and, finally, the gaps in laws and regulations. The economic earnings that develop depending on the construction of houses in rapidly growing areas where urban development is intensively felt are always higher and less risky than the yield of the activities to be carried out in agricultural lands, which manifests itself as the most primary reason why such areas are preferred as urban settlements.

Improper use generally takes place on the fertile agricultural lands which are generally Class I to Class IV agricultural lands, where any plant can grow, which are plain, which are well-drained, where the soil depth is high, and which definitely should not be used for nonagricultural purposes.

In this way, urbanization, one of the most serious threats for the world's biodiversity, most dramatically and permanently alters land use in our country, as it does worldwide (Ricketts and Imhoff, 2003; Yli-Pelkonen and Niemelä, 2006).

Upon the industrial branch which developed afterwards, the identification of these lands, which continued to exist as urban development areas, as areas convenient for any nonagricultural investment and their use for these purposes were supported. Since no laws or regulations to prevent all these things and to protect fertile agricultural lands have been made or since, even if they have been made, they lack the necessary restrictions, the improper use of fertile agricultural lands continues as a great national problem.

\section{Planning and the planning hierarchy in Turkey}

With a wide variety of definitions, planning is an integrated system which involves a series of chaotic cases in theory and practice and which depends on various laws and regulations besides being a multidirectional and comprehensive concept. According to the definition by Keleş (1972), planning is regarded as the whole of decisions about the actions in the future, whereas planning also involves the absolute necessity for the rational use of the available resources and information. The process of preparation of the series of decisions aiming at attaining the targets which have been specified regarding the activities to take place in the future as a whole via the optimum means is called planning (Akay, 2009). 
Article 166 of the 1982 Constitution is entitled "Planning" and assigns the state the task of planning which ensures "economic, social and cultural development, particularly the rapid development of industry and agriculture at the national level in a balanced and compatible way, and the efficient use of national resources by making their inventory and evaluation".

There are numerous laws, statutes, regulations and circulars which direct development in our country, with the most determinative one being the Development Law No. 3194 and the regulations affiliated to it. Depending on the variety of the objects intended to be planned, a large number of types of plans are encountered in the development law. Some of these types of plans were organized in the Development Law No. 3194, while some of them were left to Article 4 of the law and the regulations to be made with special laws. It is possible to classify the plans which arise from the provisions of the Development Law as "types of plans for general purposes" and the plans which are for special purposes and which are envisaged for the areas that are the subject of a different planning regime as "types of plans for special purposes" (Table 1) (Erdem and Coşkun, 2009). Of the following types of plans, Upper-Scale Plans, the Physical Plan of the Country, the Regional Plan and the Land Use Plan are types of socio-economic and ecological plans, while the remaining plans are called "types of physical plans".

\begin{tabular}{|c|c|}
\hline Types of Plans for General Purposes & Types of Plans for Special Purposes \\
\hline Upper-Scale Plans & $\begin{array}{l}\text { The Development Plan for Conservation } \\
(1: 5,000 \text { and } 1: 1,000)\end{array}$ \\
\hline $\begin{array}{l}\text { The Physical Plan of the Country (A five-year } \\
\text { development plan) }\end{array}$ & $\begin{array}{l}\text { The Development Plan for Tourism }(1: 5,000 \\
\text { and } 1: 1,000)\end{array}$ \\
\hline $\begin{array}{l}\text { The Regional Plan }(1: 200,000,1: 50,000,1: 25,000, \\
\text { and 1:10,000) Natural resource } \\
\text { inventory/analysis, Socio-economic resource } \\
\text { inventory/analysis }\end{array}$ & $\begin{array}{l}\text { The Plan for a Special Environmental } \\
\text { Conservation Zone }(1: 25,000,1: 5,000 \text {, and } \\
1: 1,000)\end{array}$ \\
\hline $\begin{array}{l}\text { The Land Use Plan (Conservation, Agriculture, } \\
\text { Forest, Recreation, Settlement, Industry, etc.) }\end{array}$ & $\begin{array}{l}\text { The Development Plan for Rehabilitation } \\
(1: 5,000 \text { and } 1: 1,000)\end{array}$ \\
\hline The Metropolitan Master Plan $(1: 50,000)$ & The Village Settlement Plan $(1: 1,000)$ \\
\hline The Environmental Order Plan $(1: 25,000)$ & The Forestland Development Plan \\
\hline The Master Plan $(1: 5,000)$ & The Coastal Development Plan \\
\hline $\begin{array}{l}\text { The Implementation Development Plan } \\
(1: 1,000)\end{array}$ & $\begin{array}{l}\text { The Development Plan for Mass Housing } \\
\text { Areas }\end{array}$ \\
\hline Complementary plans which bring change & Planning in Agricultural Lands \\
\hline The Additional Plan & Planning of Pastures, etc. \\
\hline The Partial Development Plan & National Park Planning \\
\hline The Revision Development Plan & Planning in Industrial Sites \\
\hline An Amendment to the Plan & Planning in Water Basins \\
\hline
\end{tabular}

Table 1. Types of plans (Atabay, 2003; Erdem and Coşkun, 2009) 
Even though most of the above-mentioned types of plans are in some way contained in the law, the majority are the types of plans with no implementation in practice. In Article 6, entitled "the Planning Hierarchy", of the second section entitled "Fundamental Principles on Development Plans" in the Development Law No. 3194 that was shaped with an understanding which was extremely far from conserving the natural resources and that was primarily organized in order to ensure the shaping of urban living spaces, it is laid down that "Plans are prepared as "Regional Plans" in terms of the area they cover and their purposes, whereas development plans are prepared as "Master Plans" and "Implementation Development Plans". In other words, spatial plans are collected in two main ranks as Upper-Scale Plans (the Regional Plan) and Lower-Scale Plans (Development Plans), although not clearly defined in the law. Development Plans are subdivided into two as "the Master Plan" and "the Implementation Development Plan". Another type of plan included in Article 5 of the law, entitled "Definitions", is "the Environmental Order Plan". This type of plan should again be regarded as an upper-scale plan type both owing to the content provided in the definition and because it is not included in the definition of "Development Plans". In conclusion, when the related articles of the Development Law are evaluated together, it is possible to speak of three main plan ranks, namely Regional Plans, Environmental Order Plans and Development Plans, although not defined systematically (Ersoy, 2006).

The types of plans and their definitions which are contained in the law are as follows (Ercoşkun et al., 2004; Erdem and Coşkun, 2009; Demirel, 2010; the Ministry of Environment and City Planning, 2012):

Regional Plan: The State Planning Organization (SPO) makes the regional plans which must reveal the socio-economic development trends and the potential of settlements for development, or it has them made, when it considers necessary. Having appeared on the agenda following the establishment of the SPO after the 1960s, this plan hierarchy did not draw significant interest. Even if it is mentioned in the Development Law, it is not definite how a plan will be made or will gain legality, and it is not obligatory to make it either.

Metropolitan Area Plans: "Metropolitan Area Plans", which are not contained in "Definitions" and "the Planning Hierarchy" in the Development Law No. 3194 but which are mentioned in Article 9 of the law although they must follow regional plans in the hierarchy of plans, are plans that must be between regional plans and environmental order plans in terms of scope and scale.

Environmental Order Plan: In Article 5 of the law, it was stated that "it is a plan which determines the decisions on settlement and land use, such as housing, industry, agriculture, tourism and transportation, in agreement with national and regional plan decisions"; however, no specific scale was mentioned. On the other hand, the scale of an Environmental Order Plan was specified as 1:25,000, 1:50,000, 1:100,000 or 1:200,000 in "the Regulation on Plan-Making" enacted depending on the same law and it was laid down that it was required to comply with regional plan decisions, if available. Aiming on the one hand to conserve natural resources and cultural, historical and environmental assets, but on the other, to guide settlement demands, this plan has a quality of directing the low-ranking plans. 
Development Plans: These plans are organized in accordance with the resolutions on the higher-level regional or environmental order plans and bring details concerning the implementation. Development plans are spatial arrangements which are developed on the present maps so as to find the best solutions that might be provided among urban functions, such as residing, working, resting and transportation, by meeting social and cultural needs in order to provide good quality of life by offering the required standards of living to the residents of a particular locality. The municipalities concerned make these plans, or have them made, and these plans come into force after having been approved by the municipal assembly. "The requirement for the ensuring of compliance of development plans with regional plan and environmental plan decisions (if available)" is mentioned in Article 8/b of the law. Development plans are basically implemented at two stages, i.e. the master plan and the implementation development plan. In Article 5 of the Development Law, it is stated that "implementation development plans will be drawn according to the fundamental principles of the master plan, and master plans will be organized to form the basis for the preparation of implementation development plans":

Master Plan: It is a plan which is recorded on the existing maps in agreement with the regional or environmental order plans, which is explained with a detailed report drawn up to form the basis for the preparation of implementation development plans, and which is prepared on the scales of 1:25,000, 1:5,000 and 1:2,000 with the new regulations. It includes the general ways of use of land pieces drawn with their cadastral status being recorded, if available, the types of regions, the future population density of regions, the building density, the development direction and size of various settlements as well as their principles, their transportation systems, and the solution to problems.

Implementation Development Plan: It is a plan on a scale of 1:1,000 which is drawn on the approved present maps - with the cadastral status being recorded, if available - according to the master plan and which shows in detail the city blocks of various regions, their density and order, the roads and the implementation stages that will form the basis for the development implementation programs required for implementation and other information. Moreover, in addition to this plan, the Revision Development Plan, the Additional Development Plan and the Partial Development Plan are also made when any type of plan on any scale fails to respond to the need or when it is impossible to implement it.

As also understood from these definitions and as also stated previously, when the recent legal regulations are read altogether, it is comprehended that the planning system in force consists of three main ranks, namely Regional Plans, Environmental Order Plans, and Development Plans. "The Physical Plan of the Country" at the top of the planning hierarchy is the planning which is not included in the law and has no implementation either. Instead, "Development Plans", which had been in five-year periods until 2009 and which have been covering a seven-year process since 2009, are prepared by the SPO. No plan concepts or approaches at the national level are included in the spatial planning system in force in our country; furthermore, the expressions about Regional Plans are extremely inadequate. Regional planning is a rank whose technical content and sanctions have entirely been left in 
uncertainty. The section which defines the plans in the Development Law in force contains no elaborate explanation with respect to "Regional Plans" that are the second upper-scale plans and that are indicated as the first step of the legal plan hierarchy. It is clearly seen that these plans, stated to be made by the SPO in the law, must be on the scales of 1:100,000 and above, despite the presence of no provisions on this matter in the law. Nevertheless, not enough plans on this scale have been made in our country; moreover, since there is no legal regulation in the materialization of the projects drawn up, no reality could be achieved about their implementation (Ersoy, 2006; Akay, 2009).

Although the concept of "Environmental Order Plan", an upper-scale plan, is very frequently considered and discussed, it has not been finalized and clarified yet by which institution it will be prepared (Demirel, 2010). Especially the development about making an "Environmental Order Plan" is continually being disrupted due to the confusion of authority between the central government and the local government (Yilmaz, 2007).

Although the master plan and the implementation development plan are completely far from ecological concern in terms of their ways of implementation in our country, these plans are made to organize the utilization of soil (Keleş, 2012). However, "the Environmental Order Plan", "the Master Plan" and "the Implementation Development Plan" should be ecological plans for environmental conservation. These plans should envisage the conservation, planning and management of sensitive ecosystems and the areas with naturally and culturally unique features. According to the existing planning system, some shortcomings and some cases which contradict with the definitions of plans occur in practice.

In fact, environmental order plans should not be the magnified copies of regional plans; master plans should not be the magnified copies of environmental order plans; and implementation development plans should not be the magnified copies of master plans. These plans must be documents whereby abstract-to-concrete plan decisions are taken and which contain different features and details (Ersoy, 2006). Thus, the inclusion of ecological planning in the planning hierarchy in the existing system (Table 2) appears an obligation (Tozar and Ayaşligil, 2008).

Brought forward as a solution to/remedy for the consequence that all of these approaches and the planning ranks also contained in the legal legislation nationwide are inadequate and up against a brick wall at some point, ecological landscape planning is one of the planning approaches, the importance of which is gradually increasing today and which might prevent the systematic destruction of natural resources.

\section{Ecological/environmentally-sensitive landscape planning and its importance}

Upon the population increase and the phenomena of urbanization and industrialization which developed accordingly, all living environments and the natural assets which must be conserved have been endangered by the intensive pressure of the unlimited use by people. It is impossible to stop this bad course with standard planning approaches. Therefore, 
ecological planning is the most important approach among the approaches set forth in order to conserve and reclaim the ecosystem which is degrading rapidly today.

\begin{tabular}{|c|c|c|c|c|c|}
\hline $\begin{array}{l}\text { Name of the } \\
\text { Plan }\end{array}$ & $\begin{array}{l}\text { Planning } \\
\text { Area }\end{array}$ & Scale & $\begin{array}{l}\text { Authority of } \\
\text { Plan-Making }\end{array}$ & $\begin{array}{l}\text { Authority of } \\
\text { Plan Approval }\end{array}$ & Legal Basis \\
\hline Regional Plan & Region & Uncertain & $\begin{array}{l}\text { The State } \\
\text { Planning } \\
\text { Organization }\end{array}$ & $\begin{array}{l}\text { The State } \\
\text { Planning } \\
\text { Organization }\end{array}$ & $\begin{array}{l}\text { Development } \\
\text { Law No. } 3194\end{array}$ \\
\hline $\begin{array}{l}\text { Provincial } \\
\text { Environmental } \\
\text { Order Plan }\end{array}$ & $\begin{array}{l}\text { The area } \\
\text { which } \\
\text { remains } \\
\text { within the } \\
\text { provincial } \\
\text { boundaries } \\
\end{array}$ & Uncertain & $\begin{array}{l}\text { The Special } \\
\text { Provincial } \\
\text { Administration }\end{array}$ & $\begin{array}{l}\text { The Special } \\
\text { Provincial } \\
\text { Administration } \\
\text { and the } \\
\text { Municipality } \\
\text { concerned }\end{array}$ & $\begin{array}{l}\text { Special } \\
\text { Provincial } \\
\text { Administration } \\
\text { Law No. } 5302\end{array}$ \\
\hline $\begin{array}{l}\text { Metropolitan } \\
\text { Development } \\
\text { Plan }\end{array}$ & $\begin{array}{l}\text { Metropolitan } \\
\text { Area }\end{array}$ & Uncertain & $\begin{array}{l}\text { The Ministry of } \\
\text { Environment } \\
\text { and City } \\
\text { Planning } \\
\end{array}$ & $\begin{array}{l}\text { The Ministry of } \\
\text { Environment } \\
\text { and City } \\
\text { Planning } \\
\end{array}$ & $\begin{array}{l}\text { Development } \\
\text { Law No. } 3194\end{array}$ \\
\hline $\begin{array}{l}\text { Environmental } \\
\text { Order Plan }\end{array}$ & $\begin{array}{l}\text { Basin and } \\
\text { Region }\end{array}$ & \begin{tabular}{l|}
$1: 50,000$ \\
$1: 100,000$
\end{tabular} & $\begin{array}{l}\text { The Ministry of } \\
\text { Forestry and } \\
\text { Water Affairs }\end{array}$ & $\begin{array}{l}\text { The Ministry of } \\
\text { Forestry and } \\
\text { Water Affairs }\end{array}$ & $\begin{array}{l}\text { Environment } \\
\text { Law No. } 2872 \\
\text { which was } \\
\text { amended by } \\
\text { Law No. } 5491 \\
\end{array}$ \\
\hline Master Plan & \begin{tabular}{|l|} 
The area \\
which \\
remains \\
within the \\
boundaries of \\
the \\
Metropolitan \\
Municipality \\
\end{tabular} & $1: 25,000$ & $\begin{array}{l}\text { Metropolitan } \\
\text { Municipality }\end{array}$ & $\begin{array}{l}\text { Metropolitan } \\
\text { Municipality }\end{array}$ & $\begin{array}{l}\text { Metropolitan } \\
\text { Municipality } \\
\text { Law No. } 5216\end{array}$ \\
\hline Master Plan & \begin{tabular}{|l|} 
The \\
Municipality \\
and the \\
Adjacent \\
Area \\
\end{tabular} & $\begin{array}{l}1: 5,000 \\
1: 2,000\end{array}$ & $\begin{array}{l}\text { All } \\
\text { Municipalities }\end{array}$ & $\begin{array}{l}\text { The } \\
\text { municipality } \\
\text { concerned }\end{array}$ & $\begin{array}{l}\text { Development } \\
\text { Law No. } 3194\end{array}$ \\
\hline $\begin{array}{l}\text { Implementation } \\
\text { Development } \\
\text { Plan }\end{array}$ & \begin{tabular}{|l} 
The \\
Municipality \\
and the \\
Adjacent \\
Area
\end{tabular} & $1: 1,000$ & $\begin{array}{l}\text { All } \\
\text { municipalities } \\
\text { other than the } \\
\text { Metropolitan } \\
\text { Municipalities }\end{array}$ & $\begin{array}{l}\text { The } \\
\text { municipality } \\
\text { concerned }\end{array}$ & $\begin{array}{l}\text { Development } \\
\text { Law No. } 3194\end{array}$ \\
\hline
\end{tabular}

Table 2. The existing planning hierarchy in our country (adapted from Ersoy, 2006) 
Elimination of the pressure on resources and the carrying out of planning that is suitable for this are prerequisites for the economical use, and sustainability, of natural resources. In the ecological landscape planning studies which have substantially developed in the recent years, it is recommended not to disregard ecological convenience in land uses by developing a multidirectional way of ecological arrangement and planning (Dramstad et al., 1996; Makhzoumi and Pungetti, 1999; Ndubisi; 2002). In ecologically-based land uses, particularly the conservation of natural resources should be the fundamental objective, and the principle of integration of natural areas into the conventional urban land use planning should be adopted. The aim of ecological planning, in which the ecology-economy balance is absolutely taken into consideration in planning studies, is to utilize a region at the optimum level according to the existing physical factors and open it to multidirectional use (Cook, 1991; McHarg, 1992; Colding, 2007).

The ecological landscape planning studies date back to very ancient times, and the first and most fundamental work on this subject is "Design with Nature" - the most important planning book of the 20th century by McHarg (Akpinar, 2008). Ecological planning differs from physical plans in that it aims at a balanced organization among land uses. This is achieved when all existing and potential uses in an area maintain the negative impacts with the environment and among themselves at the minimum level (Kocataş, 2010).

So far, various definitions and explanations have been set forth on ecological planning/urban ecological planning - the most influential means of the protection of the nature, its development, and carrying it to the future. The following are some of these definitions with common goals:

According to Stitt (2009), ecological planning is defined as "the use of natural and sociocultural information so as to suggest various probabilities and restrictions in the process of decision-making regarding the use of natural resources" (Özügül and Atabay, 2006).

Ecological landscape planning is an area of expertise within the scope of landscape planning studies and focuses on making a connection between ecological patterns and the processes. Moreover, it also encompasses social and economic dimensions in terms of human activities and cultural values. In conclusion, ecological landscape planning bases its research and plan suggestions on ecological spatial units (Akpınar, 2008).

On the one hand urbanization, industrialization and technological developments provide societies with better living conditions, but on the other, they lead to the degradation of the natural environment and cause natural resources to be used up and the environmental pollution to increase. It is these factors which make it imperative to attach more importance to cities in environmental conservation studies and to adopt an ecological approach in city planning (Eke, 2000).

The ecological planning approach in urban areas can be summarized as an approach to a sustainable urban life which prioritizes the methods and implementations that support the evaluation and development of urban data according to natural, i.e. ecological, criteria as well as conservation and reuse (Gül and Polat, 2009). 
The natural environment and landscape have been evaluated in an integrated way in physical planning in the recent years when the environmental problems have reached the most advanced dimensions. Ecological planning is a planning process in which the favorable/restrictive conditions of an area and biophysical and socio-cultural data are used when determining the optimum places for land use in areas which have not degraded yet (Tozar and Ayaşligil, 2008). In other words, it is a planning approach which provides an opportunity of choosing the living space that is optimum in terms of natural potential among our living spaces and therefore has sustainability and which entails the spatial organization of different types of land uses (Çelikyay, 2005).

Ecological landscape planning is a process which encompasses land use planning besides decision-making with respect to the way of, and strategies for, using natural resources. Additionally, it is the whole of the objectives which the society wishes to attain in planning and the process of physical change resulting from the implementation of these objectives (Marsh, 1997; Steiner, 2000).

Ecological planning is one of the basic sections of physical planning, and it is generally related to the arrangement of the physical space for ecological objectives. The primary purpose of this planning is to enhance the optimum and continuous efficiency of the natural and artificial environments in all special physical planning. In other words, it refers to filtering special plan objectives (all wishes regarding the physical structure) through the filter of ecological planning that is the complementary planning (Köseoğlu, 1982).

Çelikyay (2006) states that the aim of ecological evaluations is to determine the negative effects of human actions and physical factors on natural resources. Ecological planning both is a link between the process of spatial planning which is particularly directed to land use and the process of effect evaluation for natural resources and constitutes the foundation of the effective management of natural resources.

The ecological planning approach envisages preventing environmental problems just before they occur and arranging the spaces where one will live accordingly. In this planning approach, first of all, natural-local resources are determined and the uses are arranged considering the features of these resources. The objective is not to repress the resource with the planning made but to prevent the damage caused by the uses through planning according to the resource (Uğur, 2009). Accordingly, ecological planning is the process of examining the physical and social factors about the determination of the optimum place for the types of land uses selected in order to reveal the opportunities of, and barriers to, decision-making regarding the use of natural resources (Akpinar, 2008).

According to Atabay (2003), when there is sustainability in planning, first of all, it is necessary to set forth the sustainable development strategies which are based on the natural environment, which is only possible through ecological planning. Atabay (2005) states that particularly country-, region- and basin-based "Ecological Master Plans" are needed in order to ensure the sustainable conservation and use of natural resources.

In conclusion, the ability of urban settlements to survive is directly correlated with the concept of sustainable development that also depends on the conservation and use of natural resources 
(Cheng and $\mathrm{Hu}, 2009)$. In other words, urban sustainability can be achieved as a result of the conservation-use balance provided with ecological landscape planning.

\section{The relationship between sustainable urbanization and ecological planning}

Urbanization, expressed as the rate of people living in urban areas, displays rapid growth, with the values reaching about $80 \%$ in most European countries today (Antrop, 2004).

The population increase in the world began to manifest itself in all regions in the midst of the 18th century and went on increasing rapidly in the 1950s in particular. Recently, the world's population has approached 7 billion people, and this figure is estimated to reach 10.5 billion in 2050 (Kocataş, 2010; Aksu, 2011). Although it was expressed by Niemelä (1999) that $60 \%$ of the world's population lived in cities as of 2005, in the Sustainable Cities Development Report (2009) that was prepared by the United Nations in 2009, it was stated that urban and rural populations were first equalized in the history of the world in 2008 and that $70 \%$ of the world's population would live in urban areas in 2050 (Aydin, 2010).

Sustainable development has become an important problem of the agenda since the Conference of the United Nations that was held in Rio in 1992. According to "the Report of the Commission on Environment and Development", also known as "the Brundtland Report", prepared in 1987 by the United Nations, sustainable development is defined as "development which meets the needs of the present without compromising the ability of future generations to meet their own needs" (WCED, 1987).

According to "the Sustainable Cities Development Report" prepared in 2009 by the United Nations, it is stated that for sustainable development, far more ambitious policies are needed today for development and in order to limit the energy consumption and it is stressed that the first thing to do is to reduce pollution and conserve natural areas and arable lands (Naess, 2001).

The main problems resulting from urbanization - one of the basic features of the European civilizations - are the upsetting of the ecological balance for reasons, such as the increase in building as a result of the human activities depending on the population increase and the improper use of natural areas, and the vital changes that have developed accordingly (Antrop, 2004; Berry, 2008).

Particularly when the losses of green areas and natural resources are considered today, it is evident that urban development over the urban nature is gradually increasing and that urbanization is an issue which should be considered with care (Yli-Pelkonen and Kohl, 2005). The concept of ecological landscape planning, which occurred as the minimization of the problems urbanization caused in the natural environment and as an organization that supported a sustainable urban life and on which various studies have been made for long years, is regarded as the only solution to the problems caused by urbanization. 
Nevertheless, although the economic and ecological approaches are complementary when measuring sustainable development (Rennings and Wiggering, 1997), there has been a continuous conflict between economic gains and the ecological balance since the past. The natural areas which were opened to use with economic concerns are now confronted with many problems with the rapidly increasing urban development. Introducing a real solution to all those land uses which remain between two contradictory dimensions as ecological conservation and the economic life today, ecological planning advocates that natural resources such as water, air, soil and vegetation must definitely be conserved (Van Lier, 1998), for these natural areas are particularly in a position to be the lungs of urban ecosystems.

Urban ecosystems are able to survive by obtaining their large amounts of food, water, energy, minerals and other needs from nearby or distant agricultural lands, forests, mines and water basins. As urban areas grow, the need for resources and pollution create a gradually increasing pressure on water resources, aquatic regions, estuaries, forests, cultivated \& planted lands, and untouched rural areas (Erdem, 2000).

As also seen in Figure 1, when the relationship of cities with the environment is considered, their first-degree dependence on the neighboring ecosystems is striking. Cities meet their vital needs such as raw material, water, food and energy first of all from the ecosystems located on their fringe, and they leave their wastes again in these areas. That is to say, first of all, the conservation and continuity of these natural areas are indispensable for the continuity of cities (Aydın, 2010).

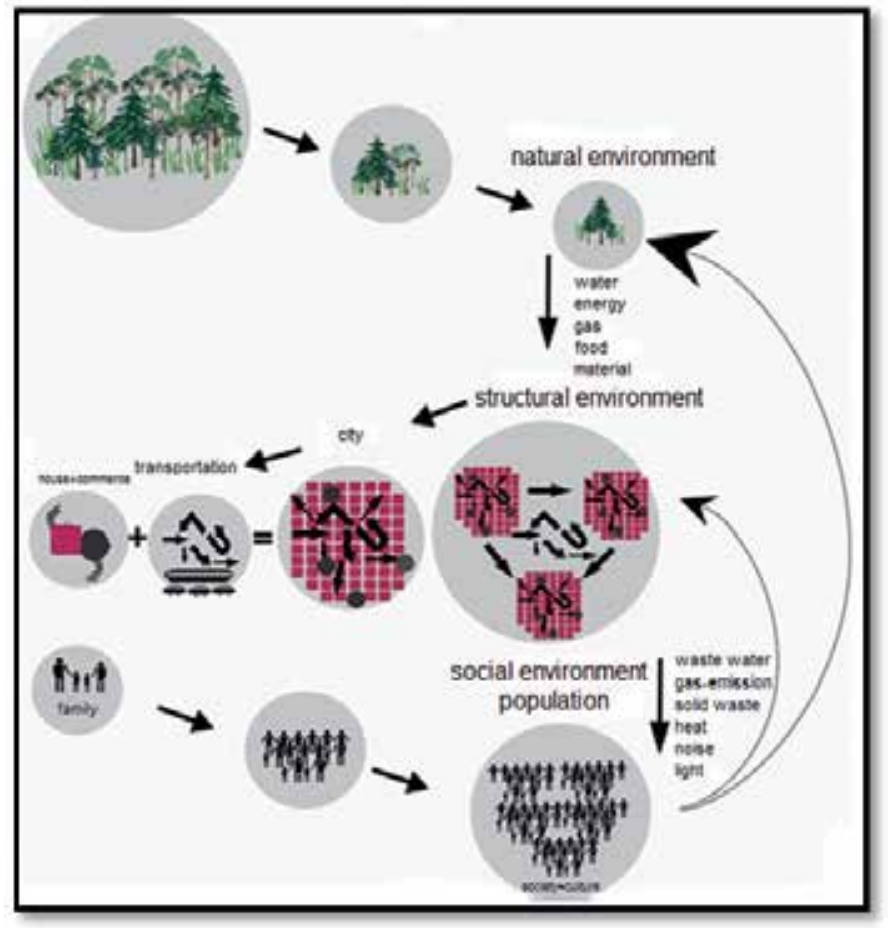

Figure 1. The relationship among natural, structural and social environments (Aydın, 2010) 
Particularly from the environmental problems cities have caused in the recent years, it follows that the city must also be in harmony with its environment and that cities must also be considered an ecosystem. Every entity that is randomly (in an unplanned and uncontrolled way) and rapidly growing without considering the bearing capacity of the life support system means that it is also preparing its own end rapidly. When the infrastructure necessary to support and carry on this rapid growth is unavailable, every rapid growth will inevitably be followed by a rapid end. As Odum and Barrett (2008) also state, the natural ecosystem and the urban ecosystem must absolutely be integrated in the understanding of sustainable city planning (Figure 2).

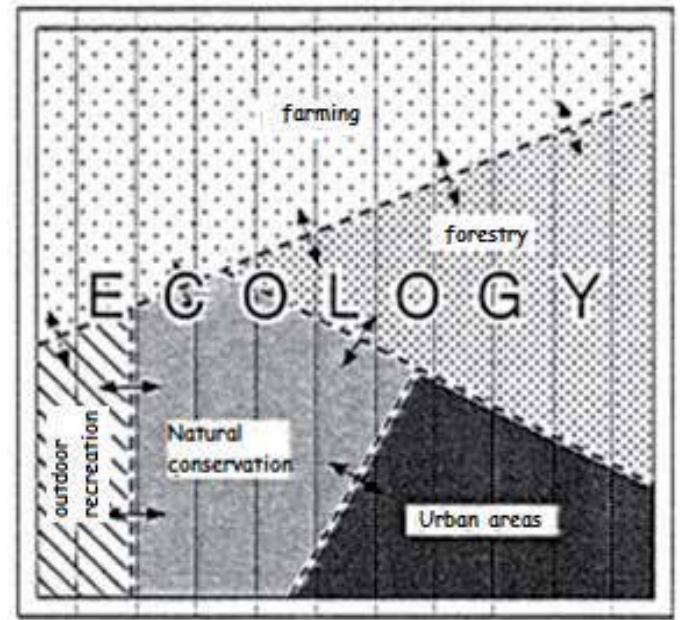

Figure 2. The schematic integration of ecologically-based land use (Van Lier, 1998)

It is impossible to speak of any sustainable society and environment with sustainable urban planning as long as it is failed to conserve and develop natural resources. The environment and natural resources are important restrictive elements today and at the point of the possibility of meeting social and economic needs of the future generations (Cheng and $\mathrm{Hu}, 2009$ ) (Figure 3).

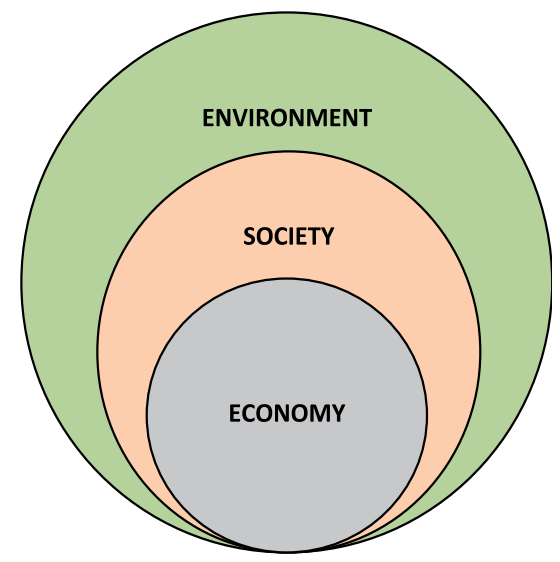

Figure 3. The relationship of the environment with economy and social development (Cheng and Hu, 2009) 
Today sustainable city planning and sustainable development are concepts which are widely used in the development of urban areas and in environmental issues (Yli-Pelkonen and Niemelä, 2005). Sustainable city planning, a phenomenon with economic and social dimensions besides its ecological dimension (Figure 4), is an understanding of planning that is developed against the use of the environment as a resource without attaching importance to its consumption and loss. It is a contemporary evaluation which considers not only the addressing of the environment only to the users of that period and its provision of the most benefits but also the right of the future generations to use the environmental resources (Ercoşkun, 2005).

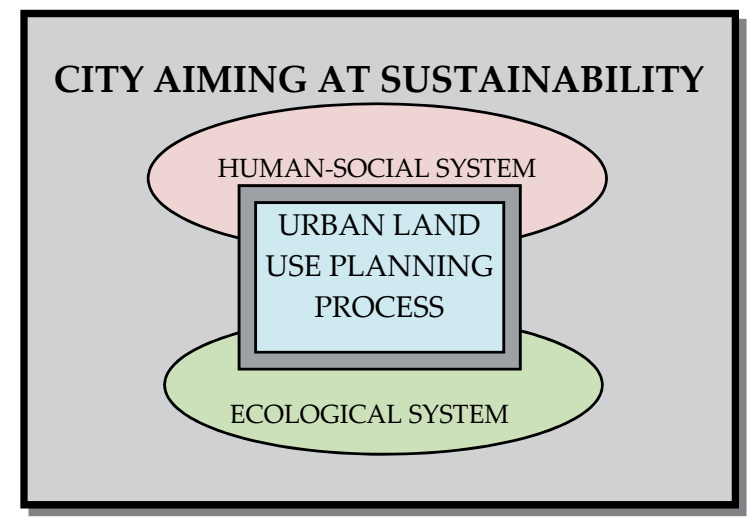

Figure 4. A simple conceptual framework to ensure urban sustainability - The connection between the human-social system and the ecological system in the planning process (Yli-Pelkonen and Niemelä, 2005)

As Lyle (1993) also states, the cities of the future must embrace the ecology of the landscape that surrounds them (Odum and Barrett, 2008). The conservation of natural habitats has gradually gained importance depending on the increase in people's sensitivity to the conservation of the natural environment particularly in the last fifty years. Accordingly, ecology and ecological landscape planning approaches have gained importance as a response to the questions of how sustainable cities can be formed and how improper land uses will be prevented.

In conclusion, the first thing to do in city planning that is based on the conservation of the ecological structure is to determine the natural and cultural resource inventory of the area and to carry out planning accordingly. An ecologically-based planning approach is also imperative for the sound development of cities besides the conservation of natural \& cultural resources (Niemelä, 1999; Termorshuizen et al., 2007).

\section{The sample area: the city center of Çanakkale}

The city center of Çanakkale, selected as the sample area, is located between $40^{\circ} 09^{\prime}$ and $40^{\circ}$ $18^{\prime}$ northern latitudes and $26^{\circ} 33^{\prime}$ and $26^{\circ} 48^{\prime}$ eastern longitudes and covers an area of about $17.83 \mathrm{~km}^{2}$ (Figure 5). The sample area was specified as the municipal boundaries of the central district of Çanakkale (Çanakkale Municipality, 2011). 


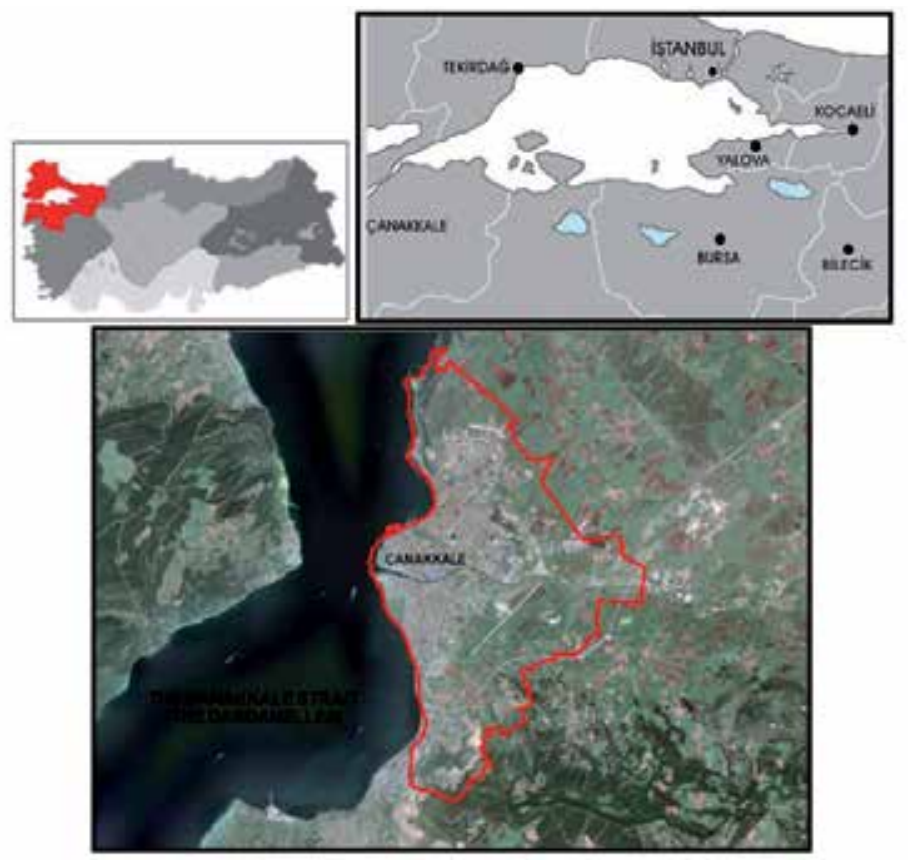

Figure 5. The geographical location of the sample area, Çanakkale, Turkey

Improperly Used Natural Areas According to the Development Plan Periods

At this stage of the study, first of all, the areas with a development plan at the city center of Çanakkale selected as the sample area, were classified into five periods by utilizing Koç (2006), and they were digitized by means of the GISs (the Geographic Information Systems) and computerized. Accordingly, the development periods in Çanakkale can be listed by date as follows (Figure 6): a) Areas with a Development Plan in the First Period (between 1949 and 1963) b) Areas with a Development Plan in the Second Period (between 1963 and 1978) c) Areas with a Development Plan in the Third Period (between 1978 and 1984) d) Areas with a Development Plan in the Fourth Period (between 1984 and 1993) e) Areas with a Development Plan in the Fifth Period (between 1993 and 1995).

Secondly, "the Previous Land Use Map" included in "the Land Inventory" on a scale of 1:100,000 in the Report on the Provincial Land Asset of Çanakkale, prepared in 1999 by the Directorate General of Village Services, was digitized by means of the GIS and computerized in order to express concretely the amount of the loss of agricultural lands according to all development periods.

At this point, attention should be drawn to the fact that the soil classification was entirely amended by "the Soil Conservation and Land Law" No. 5403, and different definitions were made under the headings of absolute agricultural lands, planted agricultural lands, marginal agricultural lands, pasture, forest, settlements, and other areas (such as rushy areas, marshes, and rocky areas). There is a "Land Asset Map" that was prepared in 2008 according to this new type of classification by the Provincial Directorate of Food, 
Agriculture and Animal Husbandry of Çanakkale. However, in order to express the loss of fertile agricultural lands more clearly at this stage, a re-classification was made according to the law concerned besides using "the Previous Land Use Map" with an earlier date, i.e. 1999. According to this classification, the uses were collected under the headings of urban area (settlement, recreation, and airport), agriculture (irrigated and rain-fed agricultural lands), planted agriculture (olive, fruit, and vineyard), forest, and pasture.

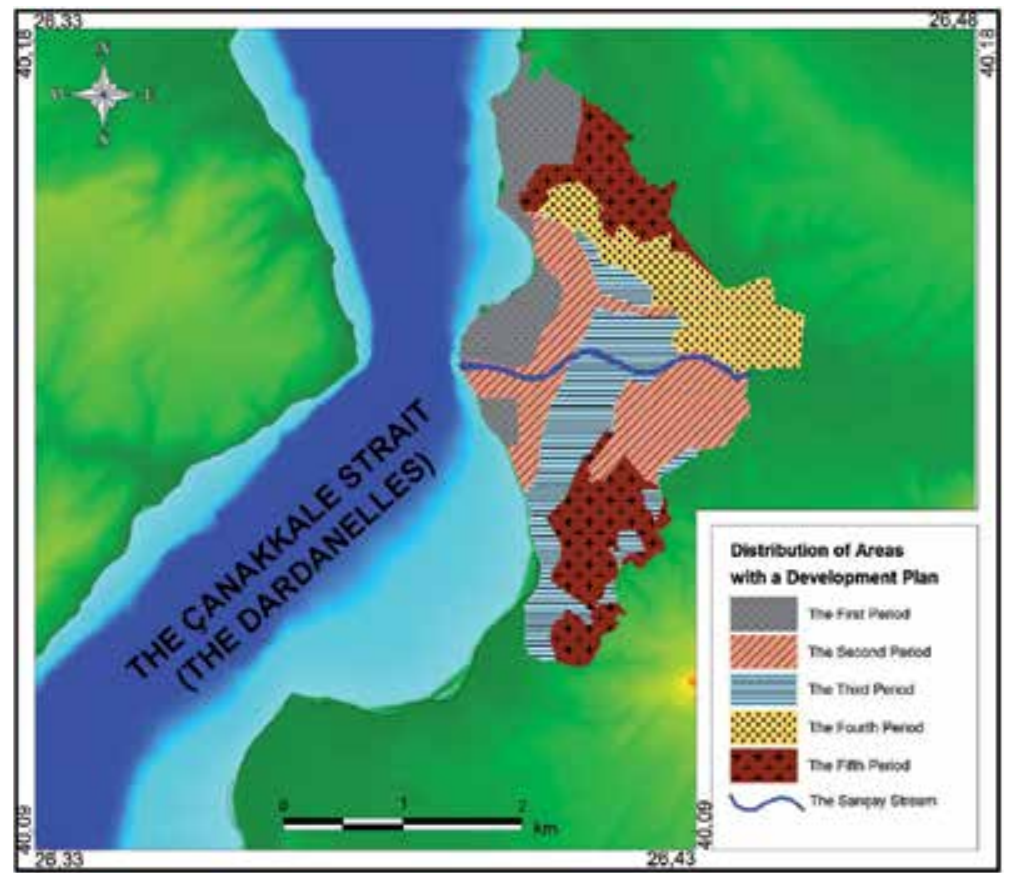

Figure 6. Distribution of the areas with a development plan by development plan period

To express the losses of fertile lands of the development periods more clearly and to show the periodic losses of each development period, the five development periods and "the Previous Land Use Map" were overlapped in the computer medium by means of the GIS. To what use the boundary of each development period corresponds on the previous land use map and their numerical values are provided in the following maps and tables (Figures 7, 8, 9, 10 and 11; Tables 3, 4, 5, 6 and 7). 


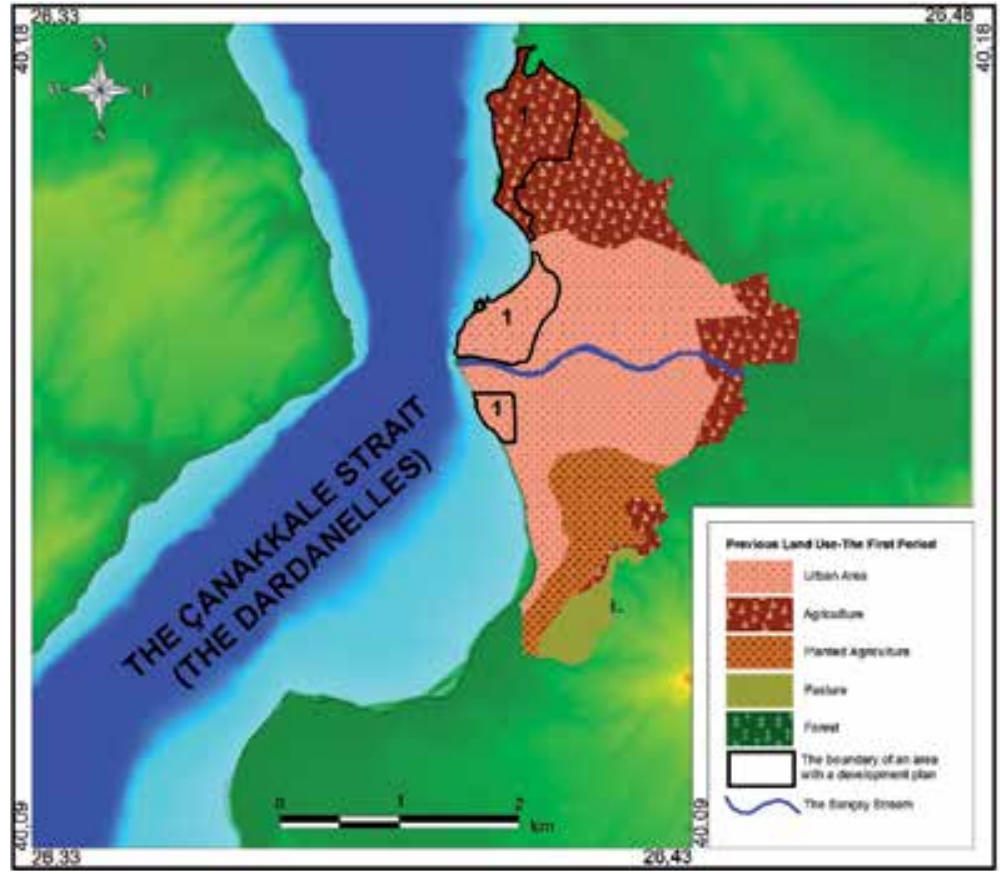

Figure 7. The loss of fertile agricultural lands in the areas with a development plan in the first period

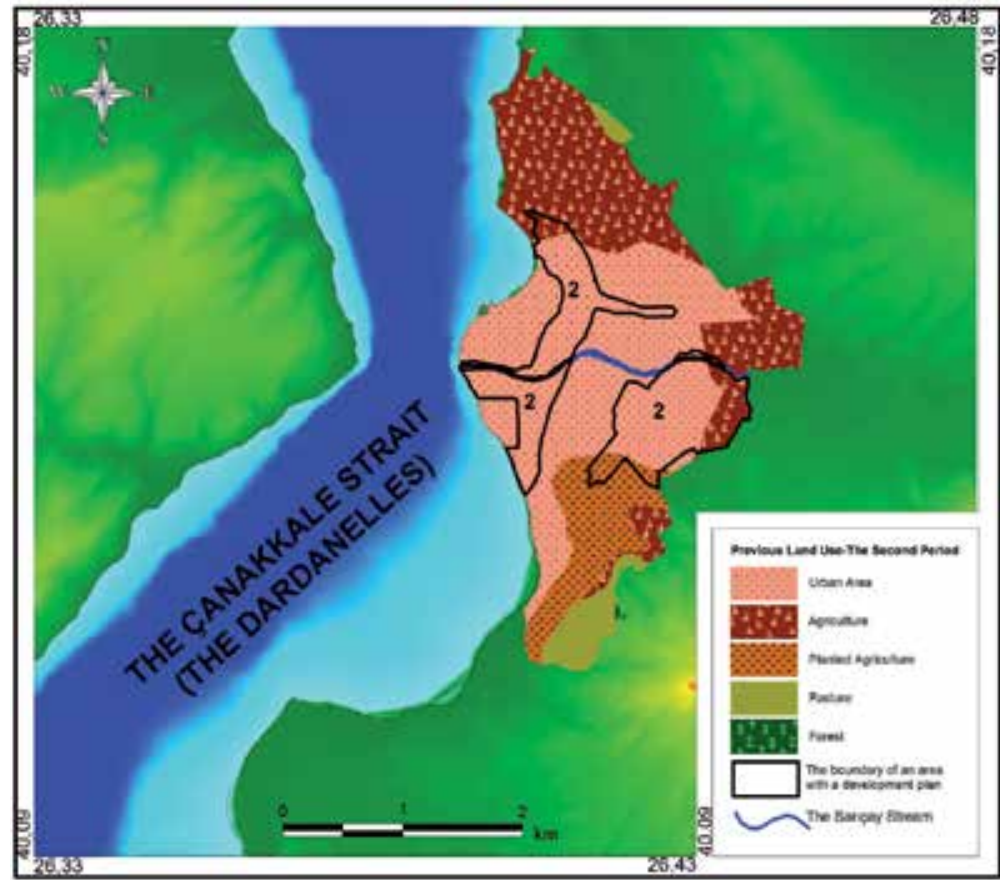

Figure 8. The loss of fertile agricultural lands in the areas with a development plan in the second period 


\begin{tabular}{|l|c|c|}
\hline Quality of the Area & Covering Area $\left.\mathbf{( k m}^{\mathbf{2}}\right)$ & Covering Percentage (\%) \\
\hline Urban Area & 1.32 & 46.48 \\
\hline Agriculture (Irrigated and rain-fed) & 1.52 & 53.52 \\
\hline Total & $\mathbf{2 . 8 4}$ & $\mathbf{1 0 0 . 0 0}$ \\
\hline
\end{tabular}

Table 3. Distribution of the losses of fertile agricultural lands in the areas with a development plan in the first period

\begin{tabular}{|l|c|c|}
\hline Quality of the Area & Covering Area $\left.\mathbf{( k m}^{\mathbf{2}}\right)$ & Covering Percentage (\%) \\
\hline Urban Area & 3.48 & 82.46 \\
\hline Agriculture (Irrigated and rain-fed) & 0.54 & 12.80 \\
\hline Planted agriculture & 0.20 & 4.74 \\
\hline Total & $\mathbf{4 . 2 2}$ & $\mathbf{1 0 0 . 0 0}$ \\
\hline
\end{tabular}

Table 4. Distribution of the losses of fertile agricultural lands in the areas with a development plan in the second period

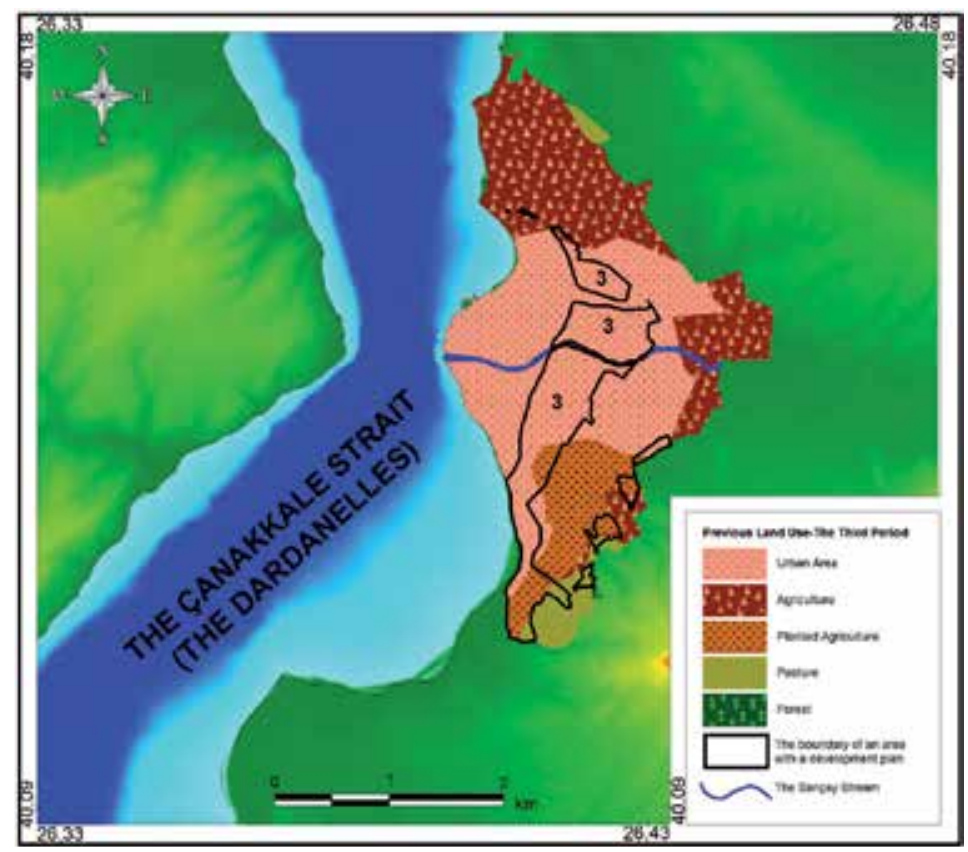

Figure 9. The loss of fertile agricultural lands in the areas with a development plan in the third period 


\begin{tabular}{|l|c|c|}
\hline Quality of the Area & Covering Area $\left.\mathbf{( k m}^{\mathbf{2}}\right)$ & Covering Percentage (\%) \\
\hline Urban Area & 2.86 & 76.68 \\
\hline Agriculture (Irrigated and rain-fed) & 0.09 & 2.41 \\
\hline Planted Agriculture & 0.61 & 16.35 \\
\hline Pasture & 0.17 & 4.56 \\
\hline Total & $\mathbf{3 . 7 3}$ & $\mathbf{1 0 0 . 0 0}$ \\
\hline
\end{tabular}

Table 5. Distribution of the losses of fertile agricultural lands in the areas with a development plan in the third period

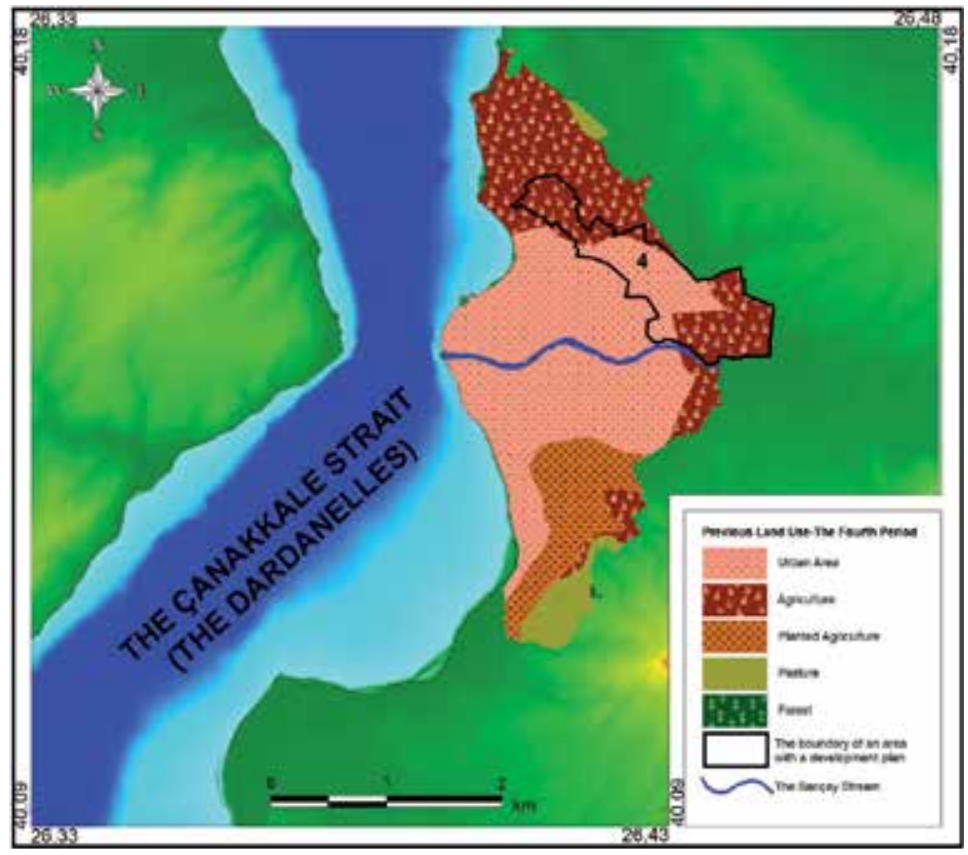

Figure 10. The loss of fertile agricultural lands in the areas with a development plan in the fourth period

\begin{tabular}{|l|c|c|}
\hline Quality of the Area & Kaplama Alanı $\left.\mathbf{( k m}^{\mathbf{2}}\right)$ & Kaplama Yüzdesi (\%) \\
\hline Urban Area & 1.17 & 40.91 \\
\hline Agriculture (Irrigated and rain-fed) & 1.69 & 59.09 \\
\hline Total & $\mathbf{2 . 8 6}$ & $\mathbf{1 0 0 . 0 0}$ \\
\hline
\end{tabular}

Table 6. Distribution of the losses of fertile agricultural lands in the areas with a development plan in the fourth period 


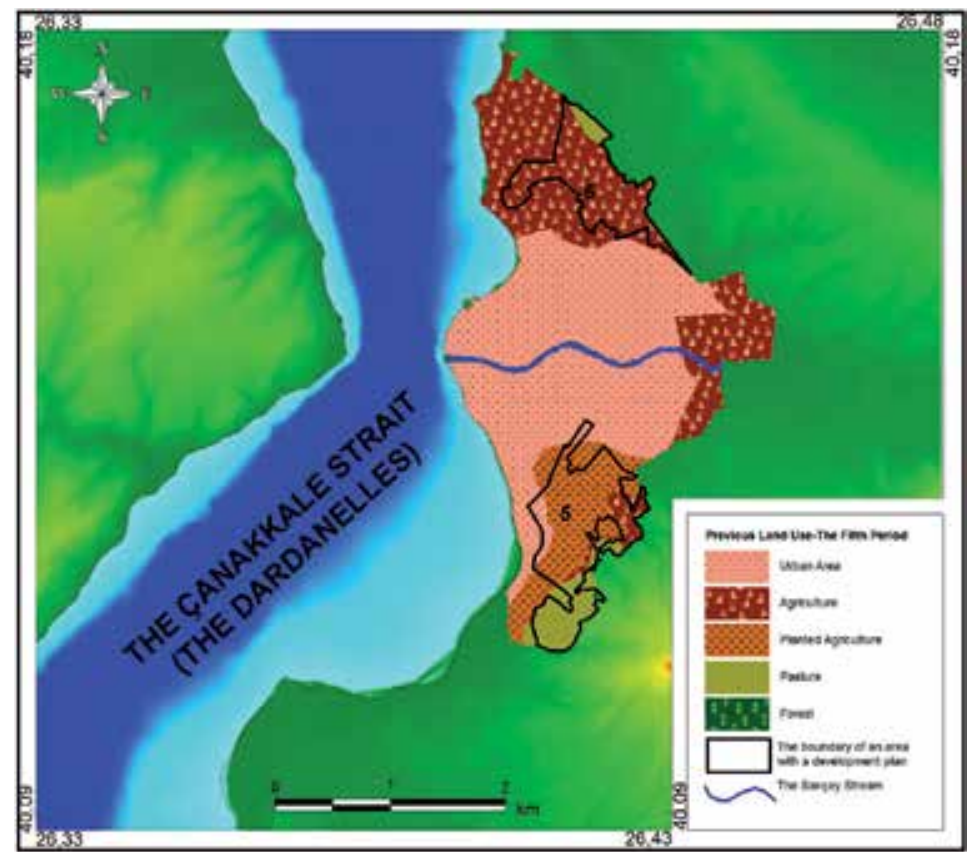

Figure 11. The loss of fertile agricultural lands in the areas with a development plan in the fifth period

\begin{tabular}{|l|c|c|}
\hline Quality of the Area & Covering Area $\left.\mathbf{( k m}^{\mathbf{2}}\right)$ & Covering Percentage (\%) \\
\hline Urban Area & 0.19 & 4.71 \\
\hline Agriculture (Irrigated and rain-fed) & 1.84 & 45.66 \\
\hline Planted Agriculture & 1.27 & 31.51 \\
\hline Pasture & 0.71 & 17.62 \\
\hline Forest & 0.02 & 0.50 \\
\hline Total & $\mathbf{4 . 0 3}$ & $\mathbf{1 0 0 . 0 0}$ \\
\hline
\end{tabular}

Table 7. Distribution of the losses of fertile agricultural lands in the areas with a development plan in the fifth period

Even though there were losses of fertile lands in the second and third periods as well, serious losses took place especially in the first, fourth and fifth development periods. While it is observed that as the city expanded towards its fringes, these losses were in irrigated and rain-fed absolute agricultural lands in particular, the planted agricultural lands also experienced significant losses, along with the areas that were opened to development.

The following is the numerical distribution of the land asset in all areas with a development plan - i.e. the sample area - according to the data by the Directorate General of Village Services (1999) (Figure 12, Table 8).

When all the areas opened to development as of 2011 are considered according to the table above, it is seen that only $50.59 \%$ of the land asset map corresponds to the urban area. When the other land uses are considered, it is seen that $31.91 \%$ are rain-fed and irrigated 
agricultural lands and $11.67 \%$ are planted agricultural (olive, vineyard, and garden) lands. There is a small amount of pasture areas in an area with a rate of $4.93 \%$.

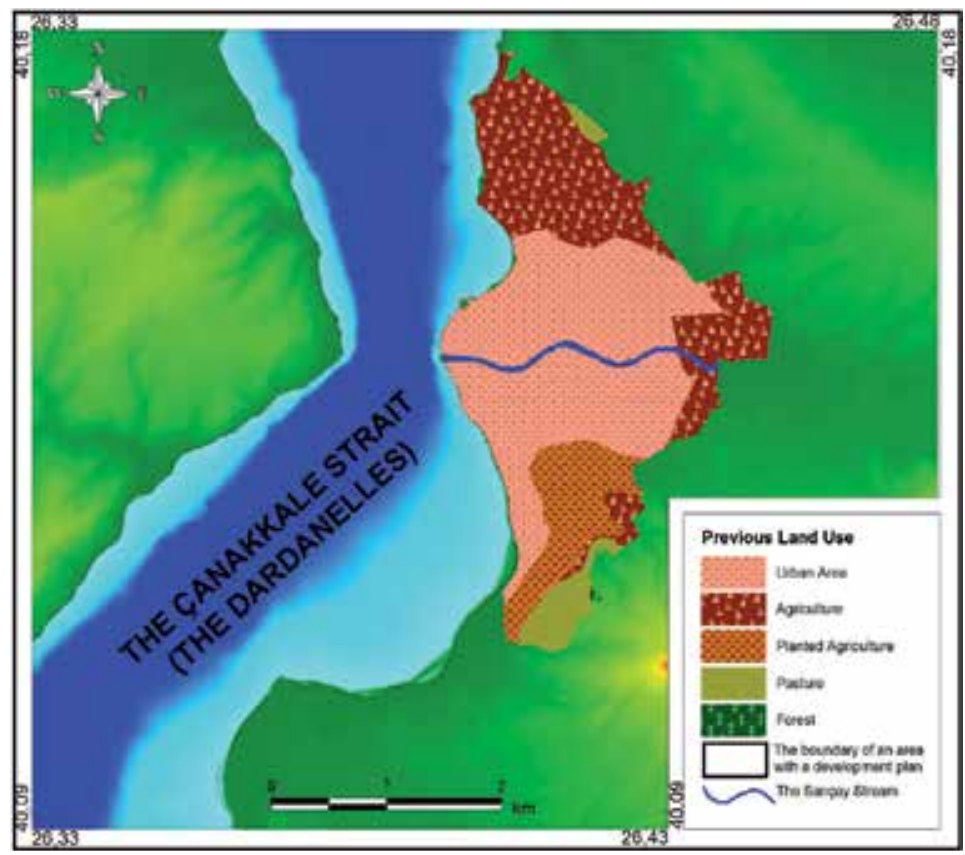

Figure 12. The previous land use in areas with a development plan

\begin{tabular}{|l|c|c|}
\hline Quality of the Area & Covering Area $\left.\mathbf{( k m}^{\mathbf{2}}\right)$ & Covering Percentage (\%) \\
\hline Urban Area & 9.02 & 50.59 \\
\hline Agriculture (Irrigated and rain-fed) & 5.69 & 31.91 \\
\hline Planted Agriculture & 2.08 & 11.67 \\
\hline Pasture & 0.88 & 4.93 \\
\hline Forest & 0.02 & 0.11 \\
\hline The Sarıçay Stream & 0.14 & 0.79 \\
\hline Total & $\mathbf{1 7 . 8 3}$ & $\mathbf{1 0 0 . 0 0}$ \\
\hline
\end{tabular}

Table 8. The previous land use at the city center of Çanakkale $\left(\mathrm{km}^{2} / \%\right)$

Accordingly, as also understood from this table, the master and implementation development plans of the entire sample area with a size of $17.83 \mathrm{~km}^{2}$ were made and, as a result, the areas transformed into an urban settlement by being used improperly are 7.77 $\mathrm{km}^{2}$ of fertile agricultural lands $(43.58 \%)-5.69 \mathrm{~km}^{2}$ of irrigated and rain-fed agriculture and 
$2.08 \mathrm{~km}^{2}$ of planted agriculture. From this result, it is understood that almost half of the entire area has a "fertile agricultural land" status and that an area with such a dimension has been transformed completely into an urban area with the master and implementation development plans prepared.

As also understood from the tables and figures, quite substantial losses of fertile agricultural lands took place in all development periods. The Master and Implementation Development Plans of all areas with a development plan, also indicated in periods above, were made and the activities of house construction are still ongoing in the agricultural lands located in these areas. Although the agricultural activities are still ongoing in the fertile lands which have remained in a small amount within the city, all of these lands have been excluded from the agricultural land status and transformed into an urban area with the development plans made (Figure 13).
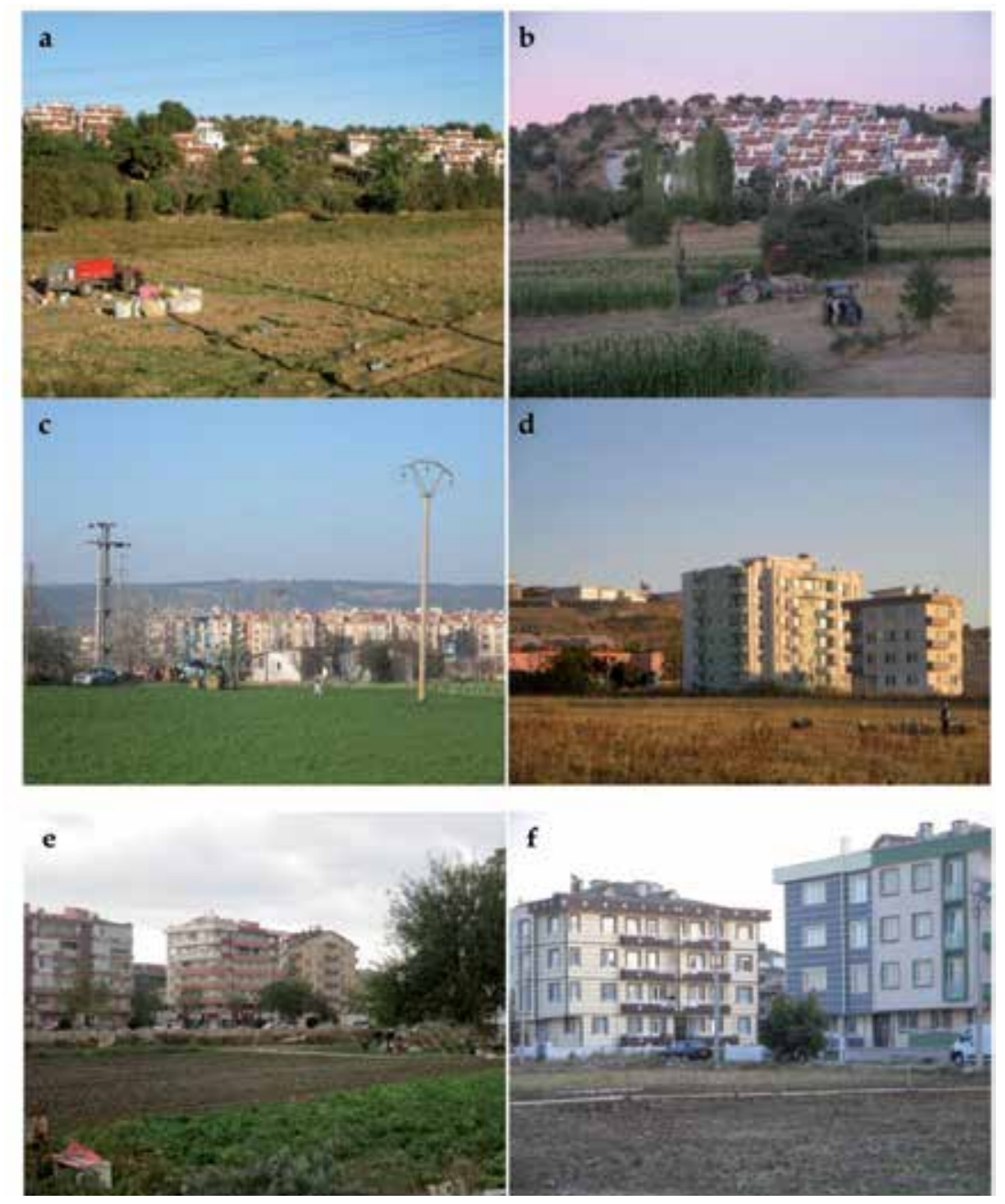

Figure 13. The agricultural lands with a development plan at the city center, Çanakkale, Turkey (a-b: on the Çanakkale-Lapseki ring road, c-d: Şekerpınar locality, e-f: around the airport in Barbaros District) 
At this stage of the study, "the Existing Land Use Map" prepared in 2011 (Çanakkale Municipality, 2011) was used as the basic data so as to make a clearer and more accurate evaluation. At the next stage, to detect the areas used improperly, the boundary of "the Previous Land Use Map (1999)" and “the Existing Land Use Map (2011)” were overlapped in the GIS medium. Accordingly, how much of the industrial and settlement areas currently in use was used improperly and excluded from the agricultural land status was expressed with concrete data (Figures 14 and 15, Table 9).

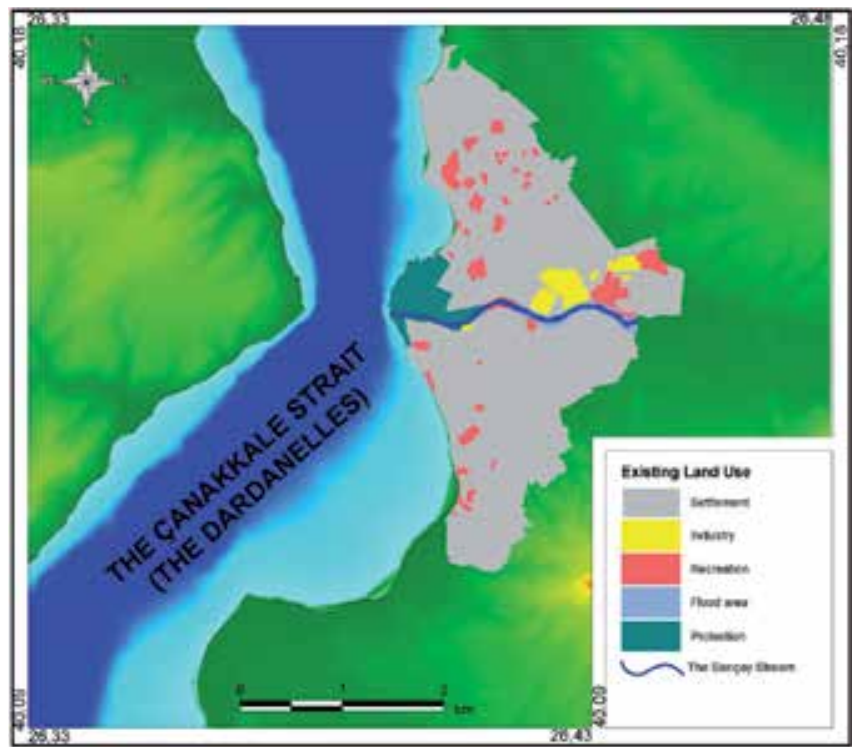

Figure 14. The existing land use

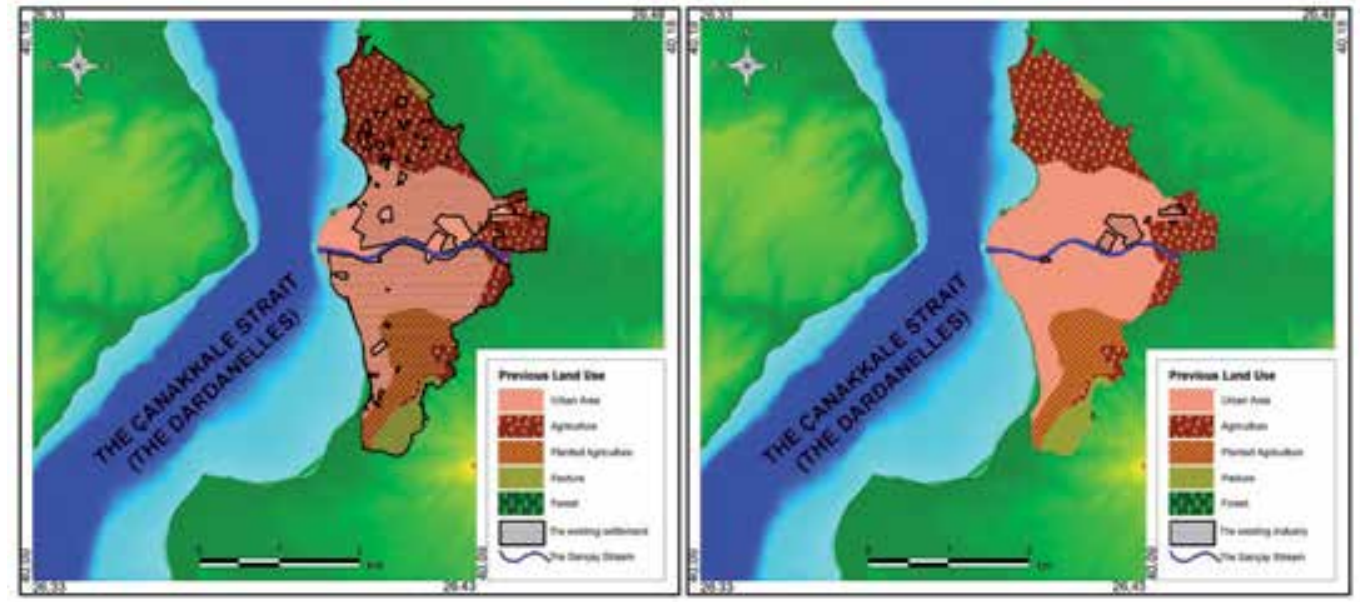

Figure 15. The previous land use and improper land uses 


\begin{tabular}{|l|c|c|c|c|}
\hline \multirow{2}{*}{$\begin{array}{l}\text { Existing land use } \\
\text { Previous land use }\end{array}$} & \multicolumn{2}{|c|}{ Settlement } & \multicolumn{2}{c|}{ Industry } \\
\cline { 2 - 5 } & $\mathbf{k m}^{\mathbf{2}}$ & $\%$ & $\mathbf{k m}^{\mathbf{2}}$ & $\%$ \\
\hline Settlement & 7.41 & 47.78 & 0.43 & 93.48 \\
\hline Agriculture (Irrigated and rain-fed) & 5.14 & 33.14 & 0.03 & 6.52 \\
\hline Planted Agriculture & 2.06 & 13.28 & - & - \\
\hline Forest & 0.02 & 0.13 & - & - \\
\hline Other & 0.88 & 5.67 & - & - \\
\hline
\end{tabular}

Table 9. Improper land uses

As understood from the figures and the table above, of the urban settlement area in current use which is totally $15.51 \mathrm{~km}^{2}, 8.20 \mathrm{~km}^{2}(46.42 \%)$ with a fertile agricultural land status have been used improperly and opened to settlement. It has been detected that of the industrial area again in current use which is $0.46 \mathrm{~km}^{2}, 0.43 \mathrm{~km}^{2}(93.48 \%)$ must indeed be used for settlement.

\section{Discussion and conclusion}

"All living things are either directly or indirectly soil-dependent for survival. In other words, soil is a natural space in which all plant species and intra-soil living things survive and a natural resource by which food is provided" (Kocataş, 2010).

As a result of the population which has piled up in cities, urbanization gave rise to the need for accommodation. This led to the use of the land for nonagricultural purposes and caused the housing sector to capture the land. The limited arable lands and the gradually increasing improper use of these lands gave rise to a serious problem of degradation and loss of agricultural lands (Keleş and Hamamc1, 1993; Ercoşkun and Karaaslan, 2009).

The perception of the concept of "Development" merely as the opening of new settlement zones to development in the process of planning of cities or settlements leads to consequences that are impossible to compensate for in the ecological dimension in terms of cities. The important thing here is the materialization of upper-scale plan decisions by local governments and the production of policies for conservation. In this context, the upper-scale plan decisions developed in line with the objectives and strategies concerning both the city and the conservation of the components of the city are of vital importance to the prevention of the consequences concerned (Erdem and Meşhur, 2005).

Today the uncontrolled growth of cities and the issue of how they can respond to the needs of the public are among the significant planning problems of countries. The most important issue that must be carried out in order for settlements to display regular and planned development is how development affairs will be done with a joint interdisciplinary study in the light of technological and scientific developments (Akay, 2007). The planning hierarchy in our country is just a ball of problems in this sense. The entry of institutions into each other's area of authority with the continually amended laws and regulations further complicates the already complicated system; consequently, our natural resource assets are being destroyed day by day. 
The most serious problem in the planning hierarchy is the absence of Regional Plans that must be made by the State Planning Organization (SPO). "The decisions \& main strategies, whose main headings are given as the ensuring of interregional balanced development by using the regional potential and the determination of where public investments and the private capital will be located and which should be decided by Regional Plans" have unfortunately been assumed by the Environmental Order Plans (Demirel, 2010). Furthermore, Environmental Order Plans are not made with a continuous and serious approach but only when they are considered necessary by the authorized institutions. However, the physical plan which is directive and binding at the highest level in Turkey is "the Environmental Order Plan" (Akay, 2007; Cengiz and Gönüz, 2011).

The fact that "the Regional Plan" and "the Environmental Order Plan", upper-scale plans, are made only when considered necessary by central governments according to the Development Law can be expressed as another serious problem. Many urban and metropolitan settlements do not have such a planning approach. This negative situation prevents the formation of an integrated and a sound strategic planning approach. For the formation of the sound planning approach concerned, the plan decisions from the upper scale to the lower scale should be consistent with each other. At this point, within the framework of the principle of "graded coexistence" of plans, each lower-scale plan must contain more information and details than the one upper-scale plan. An original plan which also encompasses the new information and data required by the respective original scale of lower-scale plans but which preserves the main decisions of the one upper scale is expected (Öztürk, 2004; Ersoy, 2006).

Atabay (2005) expressed

"the inclusion of provisions like 'The State Planning Organization makes the regional and basin plans to be prepared in order to determine socio-economic development trends, the potential of settlements for development, sectoral objectives and activities, and the distribution of infrastructural services unique to these activities, or has them made, when it considers necessary', its definition by ignoring natural resources, and its leaving of this important planning stage optional",

in Paragraph a of Article 8 in the Development Law No. 3194 with respect to regional planning, as a great shortcoming for the Development Law.

At this point, although the inclusion of some decisions in the law makes no sense, leaving of the planning decisions directly concerning the conservation of natural resources to arbitrary administration is striking as an extremely disadvantageous approach with no sanctions.

Additionally, there is quite great chaos in our country about the planning hierarchy which is a serious problem. Accordingly, "the Special Provincial Administration Law" No. 5302, which came into force in 2005, is essential in terms of the affiliating of public services to single administration and, through this law, the authority of "the Provincial Environmental Order Plan-Making and Approving" was granted to "the Special Provincial Administrations", appearing the most influential institutions today (Demirel, 2010). With 
the "Law on Environment" No. 2872, amended by Law No. 5491, the Ministry of Forestry and Water Affairs was empowered to make "the Environmental Order Plan". When the recent case in the authority of plan-making is considered, it is the Ministry of Forestry and Water Affairs which is empowered to make "the Environmental Order Plan" on the scales of 1:100,000 and 1:50,000; it is the Ministry of Environment and City Planning which is empowered to make "the Metropolitan Area Plan" on a scale of 1:50,000; and it is the Metropolitan Municipalities which are empowered to make "the Provincial Environmental Order Plan" on a scale of 1:25,000 and "the Master Plan" and "the Implementation Development Plan", which are lower-scale plans, in metropolitan provinces.

At this point, it appears an appropriate decision that the plans on a scale of 1:25,000 have been organized as an obligation particularly for metropolitan municipalities, regarding "the Provincial Environmental Order Plan" - one of the most important rings of upper-scale planning. Nevertheless, the failure to form a relationship between the authority of the central government that is empowered concerning "the Environmental Order Plan" and "the Provincial Environmental Order Plan" which local governments are empowered to make upon this recent regulation paves the way for the probability of the occurrence of some problems on this matter (Y1lmaz, 2007).

In addition, the chaos experienced in the planning hierarchy in our country worsened upon the transfer of the authority of making Master and Implementation Development Plans to metropolitan and district municipalities from the central governments with the Development Law No. 3194. With this amendment in the law, rent-based approaches in the division of city block lots and implementations of poor quality in building increased substantially.

While the need for integrated ecological planning in this process is evident, it is extremely saddening that only the understanding of city planning generally predominates in the society in general and in the governments and that the efforts remain on a personal scale. The fact that planning has been stuck between "the Master Plan" and "the Implementation Development Plan", two plans implemented only in practice, causes this vicious circle to continue. However, within the scope of the conservation and development of natural and cultural resource assets found within the settlements, the plans with a special purpose (such as the Development Plan for Conservation, the Plan for Tourism \& Recreation, the Special Environmental Conservation Plan, the Development Plan for Rehabilitation, the Agricultural Land Conservation Plan, and Land Consolidation) must absolutely be produced and materialized by the local governments concerned, along with upper-scale plans (such as the Environmental Order Plan and the Regional Plan), with adhering to the planning hierarchy and first of all with an approach that aims to conserve and carry on the ecological balance (Cengiz and Gönüz, 2011).

It should be the main goal to carry out upper-scale planning studies at a level whereby the balance between urban sprawl and the natural ecosystem can be achieved, make them widespread, and turn them into a state policy. At this point, when the legal regulations in 
the planning hierarchy are considered, there is no doubt that the confusion of authority among the institutions which results from empowering several institutions to make certain plans will soon give rise to various problems as well, although the developments about upper-scale planning in particular are promising.

The actual problem in the continuation of the chaos experienced in the legal process is experienced in the process following the completion of these plans. It is an essential and functional requirement for the creation of sustainable cities that primarily the professional group of landscape architecture have a say in taking the decisions on land use accurately, particularly in landscape and ecological planning (At1l et al., 2005). The fact that naturalists are not included in the team in these projects that are predominantly prepared for the objective of using natural and cultural resources by conserving them causes these plans, which are made in some way, to fail to attain their target in practice (Demirel, 2010). Besides, various professional disciplines about the matter (e.g. Geographer and Biologist) should also have a say in decisions and implementations when taking planning decisions and preparing plans. The necessity for target-oriented interdisciplinary studies should be kept at a high level in city planning studies which aim at preserving the ecological balance (Silaydin, 2007; Cengiz and Gönüz, 2011).

At this stage, planners must first of all regard ecology and environmental assets as an integral part of their professional ethics and disciplines in the context of their position and the task(s) they have assumed in the society (Arapkirlioğlu, 2003).

One of the most important and negative results of urbanization is the continuous increase in the need for new urban areas. The generally pursued urbanization policies pit economy and ecology against each other, and this event culminates in the destruction of the natural environment. Nevertheless, "ecology" is the element which must rank first in the formation of urban environments (Tunçer and Ercoşkun, 2007).

Economic concerns are remarkable as the primary factors in the opening of fertile agricultural lands to development. Especially the problem of opening fertile agricultural lands to development is because the professional disciplines that are specialized in the subject do not take part in the teams which prepare all these planning approaches and these plans.

Article 45 of the 1982 Constitution contains the provision

"The state is liable to prevent the improper use and destruction of agricultural lands as well as meadows and pastures".

Besides, the provision

"Agricultural lands cannot be planned in order to be used for nonagricultural purposes without obtaining the permits stated in the Soil Conservation and Land Use Law" in Paragraph c of Article 8 in the Development Law No. 3194 regarding the preparation of plans and putting them into effect supports this expression too. 
The laws and regulations enacted to ensure the prevention of the destruction of fertile agricultural lands in particular and the natural resources in our country are full of legal \& administrative gaps which will lead to extremely restricted and wrong implementations in terms of content. The recent example of this is striking with many aspects in "the Soil Conservation and Land Law" No. 5403 that came into force on 03.07.2005. Even though in the law it seems that the improper use of agricultural lands is prevented, the law actually contains various clear expressions on the facilitation of using these lands for other purposes. In fact, the first thing to do in such laws should be to determine the fundamental principles to encourage the use of agricultural land for agricultural purposes and make this widespread but not to determine the fundamental principles for the improper use of agricultural land.

It is an inevitable outcome that the phenomena of house and industry are always in front of agriculture in the urban growth patterns due to their economic yield. Thus, to increase the economic yield of agricultural land besides its conservation, new regulations should be made in "the Soil Conservation and Land Law" No. 5403 that is in force now for this purpose or various legal and administrative studies should be made on this matter.

The conservation of natural areas before all depends on the use of land in a way which is suitable for the nature. This approach basically contains the division of national territories into "Land Use Capacity Classes" in terms of suitability for various purposes of use (Kışlalığlu and Berkes, 2009). This is indeed a sound approach for the conservation of national territories and for utilizing them more accurately. Previously made by the Directorates General of Village Services, these plans have not been made for long years. Upon the establishment of the Ministry of Food, Agriculture and Animal Husbandry in 2011, it was expressed that studies such as land planning and soil classification would be carried out by the Department of Agricultural Land Utilization of the Directorate General of Agricultural Reform that was affiliated to this ministry. Nevertheless, the problems occurring in practice and their outcomes are more important than the making of such plans by the institutions concerned. That is, the articles on

"ensuring the use of an agricultural land basically in agriculture and the allocation of an agricultural land for nonagricultural purposes under the condition that this be confined to obligatory cases" and "evaluating the demands for nonagricultural land use" among the duties of the Directorate General of Agricultural Reform actually confirm that agricultural lands have not been taken under conservation yet and are in some way left to nonagricultural sectors.

It is possible to multiply such examples in the law. It is obvious that it is not enough to enact laws for an efficient implementation and a successful outcome on this matter. In conclusion, the laws and regulations on the matter are inadequate and open to exploitation to the same extent. In order for urban formation to survive, there is a need for radical change in the vision of urban planning. In this new planning vision, it should be ensured that cities form harmonious integrity with the nature and with their environment (Ercoşkun and Karaaslan, 2009). It is impossible to preserve the ecological balance with the standard understanding of city planning; moreover, this integrity is only possible through the 
integration of the phenomenon of "Ecological Planning" into the existing planning system in our country.

Especially the planning studies which remain only on the urban scale are stuck at some point and remain inadequate to produce the expected solutions. The true implementation of ecological planning is only possible within a planning system that continues systematically from the highest rank to the lowest rank and that will take place on an integrated scale. On the other hand, the ecological planning studies considered within a narrow scope by ignoring the integrated scale serve the process of postponing the problem rather than a solution. As Silaydin (2007) also states, the ecological conservation studies produced on the urban scale only become meaningful within an integrated ecological planning construct based on natural boundaries (e.g. the basin boundary).

Losses of natural areas will continue increasingly as long as urban planning decisions are defined independently of upper-scale plans and as long as upper-scale plans are not included in the planning hierarchy. At this point, the ecologically-based "Regional Plans" which preserve their place as upper-scale plans in the planning hierarchy in our country but which lack adequate implementations must be materialized comprehensively.

Besides, "the Basin Plan" is also recommended as an upper-scale plan rank in some studies. Basins define the natural boundaries required for the conservation of the water cycle and the natural resources depending on it. Basin-based planning is an important stage of the planning understanding for the conservation of natural resources. Thus, a planning rank with the mental power of comprehending the nature in an integrated way for ecological planning is formed with "the Basin Plan". Besides the fact that "Basin Plans" are of great importance to national and regional planning, it is useful to underline that "the Ecological Basin Master Plan" is an indispensable method in the context of the sustainable development of a country. The basin-based planning understanding has not been included in any planning rank yet. However, it is an issue which "the Regional Development Commission" - a working sub-commission of the State Planning Organization (SPO) strongly considers (Sılaydın, 2007; Efe and Aydın, 2009; Küçükali and Atabay, 2013).

In conclusion, the running out of natural resources is striking as one of the most serious ecological problems at the present. A wrong understanding of city planning is expressed as one of the most fundamental causes of this problem, for the selection of locations for the ways of land use in the present city planning is done without considering the existence of natural resources.

In addition, the natural areas in our country are continuing to be damaged rapidly as "Ecologically-Based Landscape Plans" have not been included in the legal processes and upper-scale plans implemented in our country yet and as the implementations in the law remain inadequate (Şahin, 2009).

Turkey has turned "the European Landscape Convention", a framework convention on the conservation, management and planning of natural and cultural landscapes as a whole, into a part of its domestic law with Law No. 4881, dated 10/06/2003. Thus, it is also extremely 
important that the environmentally-sensitive/ecological planning approach introduced by the convention to the planning understanding be integrated into the legal process and be applicable (Erdem and Coşkun, 2009).

However, although a period of nine years passed, there have not been any constructive studies that support the convention either in the plan hierarchy or in laws and regulations. This is saddening in terms of the development of the process concerned and worrisome in terms of the timeout experienced. The fact that ecological conservation now remains merely in theory postpones the solution process, and more concrete approaches are needed at this point. As Turan (2007) also states, the conditions of the European Landscape Convention and the infrastructures brought about by the conditions (such as laws and regulations and institutions) should be interpreted very carefully at the current stage and materialized rapidly. In this context, the requirements of the convention should be formulated with landscape architects, city planners, jurists, and the other disciplines concerned, and they should take their part on the regional scale.

Our country is not at an irreversible point yet with respect to the prevention of improper land uses and the allocation of the necessary place to "Ecological Landscape Planning" studies in the planning hierarchy. The prevention of improper land uses for new development areas in particular and the endeavors on the matter by local governments stand out at this point. The full inclusion of "Ecological Landscape Planning" in the plan hierarchy is an extremely important step for the sustainable city planning understanding. In this context, first of all, the phenomenon we call "Ecological Consciousness" must descend to the public level, and the nongovernmental organizations must do what falls to them regarding this matter.

\section{Author details}

A.Esra Cengiz

Çanakkale Onsekiz Mart University, Faculty of Architecture and Design, Department of Landscape Architecture, Turkey

\section{References}

Akay, A. (2007). Environmental Order Plans and Authority Problems. Journal of Public Administration, Volume: 40, Issue: 3, p: 113-148.

Akay, A. (2009). Landscape Management (Planning and the Planning Hierarchy in Turkey). Editor: (Aslı Akay and Münevver Demirbaş Özen). Publication by the Turkish and Middle Eastern Public Administration Institute, No: 354, ISBN: 978-975-8918-36-2, p: 1-30, Ankara.

Akpinar, N. (2008). Introduction to Landscape Planning, the History and DefinitionsTerminologies. Department of Landscape Architecture at Ankara University, Unpublished Course Notes, 96 p., Ankara.

Aksu, C. (2011). Sustainable Development and the Environment. A Report by the South Aegean Development Agency, 34 p.

Antrop, M. (2004). Landscape Change and the Urbanization Process in Europe. Landscape and Urban Planning, 67: 9-26. 
Arapkirlioğlu, K. (2003). Ecology and Planning. Journal of Planning, 2003/1: 4-8.

Atabay, S. (2003). The Future of Landscape Planning Education in Turkey within the Framework of Harmonization with the European Union Legislation on Education. A Book of Papers of the Symposium on the European Landscape Convention and Turkey, Editor: Prof. Dr. Semra Atabay, the Printing Center of the Faculty of Architecture at YTU, İstanbul.

Atabay, S. (2005). Strategic Environmental Effect Evaluation and Physical Planning Relationships. A Book of the First Council on Environment and Forestry, Publications of the Ministry of Environment and Forestry of the Republic of Turkey, p: 312-319, Antalya.

Atıl, A., Gülgün, B., and Yörük, İ. (2005). Sustainable Cities and Landscape Architecture. Journal of the Faculty of Agriculture at Ege University, 42 (2): 215-226.

Aydin, B. (2010). Determination of the Criteria for Ecological Urban Settlement in the Development Areas and their Interpretation within the Scope of the Development Plan: the Example of Ömerli Basin-Sancaktepe. Graduate Thesis (Unpublished). Section of Urban Design in the Institute of Natural and Applied Sciences at İstanbul Technical University, İstanbul.

Berry, B. J. L. (2008). Urbanization (Urban Ecology An International Perspective on the Interaction Between Humans and Nature). Editors: John M. Marzluff, Eric Shulenberger, Wilfried Endlicher, Marina Alberti, Gordon Bradley, Clare Ryan, Ute Simon, Craig ZumBrunnen, Online ISBN: 978-0-387-73412-5, p: 25-48, Springer Science Business Media, New York. Date of Access: 12.12.2012, Available at http://link.springer.com/chapter/10.1007\%2F978-0-387-73412-5_3?LI=true\#

Brueckner, J. K., Mills, E. and Kremer, M. (2001). Urban Sprawl: Lessons from Urban Economics (with Comments). Brookings-Wharton Papers on Urban Affairs, Brookings Institution Press, pp: 65-97. Date of Access: 13.12.2012, Available at http://www.jstor.org/stable/25058783

Cengiz, A. E. and Gönüz, A. (2011). Urban Land Uses in Ecological Sense: An Example of the City Center of Çanakkale. Journal of the Faculty of Agriculture at Atatürk University, 42 (1): 79-89.

Cheng, H. and Hu, Y. (2010). Planning for Sustainability in China's Urban Development: Status and Challenges for Dongtan Eco-City Project. Journal of Environmental Monitoring, DOI: 10.1039/b911473d, 12: 119-126. Date of Access: 02.11.2011, Available at www.rsc.org/jem

Colding, J., 2007. Ecological Land-Use Complementation for Building Resilience in Urban Ecosystems. Landscape and Urban Planning, 81 (2007): 46-55.

Cook, E. A., 1991. Urban Landscape Networks: An Ecological Planning Framework. Landscape Research, 16 (3): 7-15.

Çanakkale Municipality (2011). The Digital Development Map of Çanakkale Municipality. Directorate of Development in Çanakkale Municipality, Çanakkale.

Çelikyay, S. (2005). Determination of Land Uses with the Ecological Threshold Analysis; An Experiment in the Example of Bartın. PhD Dissertation (Unpublished). Section of City and Regional Planning in the Institute of Natural and Applied Sciences at Yildiz Technical University, İstanbul.

Çelikyay, S. (2006). Strategic Environmental Effect Evaluation in the Process of Ecological Planning and a Sample Study on Bartın. Journal of the Faculty of Forestry at Zonguldak Karaelmas University, 8 (9): 10-22. 
Çepel, N. (2008). Ecological Problems and their Solutions. Popular Science Books of TÜBİTAK (the Scientific and Technological Research Council) 180, Impress Printing Facilities, ISBN: 978-975-403-290-1, 183 p., Ankara.

Demirel, Ö. (2010). The Place of the Profession of Landscape Architecture with a Mission to Become an Ecologically-Based Discipline within the National Spatial Planning and the Things which fall to it or which it is required to do, Date of Access: 10.01.2011, Available at http://sablon.sdu.edu.tr/fakulteler/orman/pemat/sunum_5.pdf

Directorate General of Village Services (1999). A Report on the Provincial Land Asset of Çanakkale. Publications of the Directorate General of Village Services of the Prime Ministry of the Republic of Turkey, Provincial Report No: 17, Ankara.

Dramstad, W. E., Olson, J. D. and Formon, R. T. T. (1996). Landscape Ecology Principles in Landscape Architecture and Land-Use Planning. Harvard University Graduate School of Design, Island Press, ISBN: 1-55963-514-2, 80 p., Washington.

Efe, M. and Aydin, S. B. (2009). Changeability of Planning based on Administrative Boundaries and a Recommendation of Basin-Based Provincial Boundaries. Journal of Geography of Ege, 18 (1-2): 73-84.

Eke, F. (2000). Ecology in Urban Settlements. A Book of Papers of the Symposium on the Environment where we lived in the 2000s and Landscape Architecture, p: 23-31.

Erdem, Ü. (2000). Ecology-the Sustainable World. (Editor: Prof. Dr. Ümit Erdem), Publications of the Application and Research Center for Environmental Problems at Ege University, No: 1, p: 129-269, ISBN: 975-483-465-2, İzmir.

Erdem, N. and Coşkun, A. A. (2009). An Analysis of the Compliance of the Provisions of the European Landscape Convention with the Turkish Legislation on Planning. Journal of the Faculty of Forestry at İstanbul University, Series: B, 59 (2): 64-78.

Erdem, R. and Meşhur, M. Ç. (2005). Unplanned Urban Development by Development Plans. A Book of Papers of the Symposium on New Policies, Strategies, Risks and Opportunities in Planning, Publications of the Faculty of Architecture at ITU, p: 339-345, Taşkışla-İstanbul.

Ersoy, M. (2006). The Planning Hierarchy in our Legislation on Development and the Problem of Upper-Scale Planning. Symposium on Regional Development and Governance, TEPAV, Publications of the Faculty of Architecture at METU, p: 215-231, Ankara.

Ercoşkun, Y. Ö., Sat, N. A. and Varol, Ç. (2004). The Role of Geographic Information Systems in the Education of City Planning. The 3rd Informatics Days of Geographic Information Systems, p: 189-199, İstanbul.

Ercoşkun, Y. Ö. (2005). Sustainable City Plans instead of Development Plans. Journal of Natural and Applied Sciences of Gazi University, ISSN 1303-9709, 18(3): 529-544.

Ercoşkun, Y. Ö. and Karaaslan, Ş. (2009). Ecological and Technological Cities of the Future. E-Journal of the Faculty of Architecture at Yildiz Technical University, 3 (3): 283-296.

Gül, A. and Polat, E. (2009). An Obligation for the Future of Cities: An Integrated Ecological Approach. International Davraz Congress on Social and Economic Issues Shaping The World's Future: New Global Dialogue, 24-27 September 2009, p: 281-294, Isparta. Date of Access: 08.06.2010, Available at http://idc.sdu.edu.tr/tammetinler/kalkinma/kalkinma18.pdf

Keleş, R. (2012). Urbanization Policy, İmge Bookstore, 703 p., Ankara.

Keleş, R. and Hamamc1, C. (1993). Ecology. Publications by İmge Bookstore, 312 p., Ankara.

Kışlalığlu, M. and Berkes, F. (2009). Ecology and Environmental Sciences. Remzi Bookstore, ISBN: 978-975-14-0187-8, p: 255-305, İstanbul. 
Kocataş, A. (2010). Ecology-Environmental Biology. The Printing House of Ege University, 597 p., Bornova-İzmir.

Koç, T. (2006). The Relationship between the Urban Development of Çanakkale (1462-2006) and Physical Geography. A Report by the Working Group on Urban Development Areas, the Book Series of the Publications by the City Council of Çanakkale, Publication No: 2, 101 p., Çanakkale.

Köseoğlu, M. (1982). Landscape Evaluation Methods. Publications of the Faculty of Agriculture at Ege University, No: 430, Ofset Printing House, 138 p., Bornova.

Küçükali, U. F. and Atabay, S. (2013). An Ecological Approach to the Physical Planning of Basins. Journal of Turkish Scientific Anthologies, 6 (1): 180-183, ISSN: 1308-0040, E-ISSN: 2146-0132. Date of Access: 14.11.2012, Available at www.nobel.gen.tr

Makhzoumi, J. and Pungetti, G. (1999). Ecological Landscape Design and Planning. ISBN: 0-41923250-8, 330 p., London.

Marsh, W. M. (1997). Landscape Planning Environmental Applications. John Wiley\&Sons, ISBN: 0-471-24207-1, 434 p., New York.

McHarg, I. L. (1992). Design with Nature. Published for the American Museum of Natural History, 197 p., New York.

Ministry of Environment and City Planning (2012). Development Law No. 3194. Date of Access: 20.11.2012, Available at http://www.csb.gov.tr/turkce/index.php

Naess, P. (2001). Urban Planning and Sustainable Development. European Planning Studies, 9:4, 503-524. Date of Access: 07/09/2012, ISSN 0965-4313, print/ISSN 1469-5944 online/01/040503-22 Ó 2001, DOI: 10.1080/0965431012004987.

Ndubisi, F. (2002). Managing Change in the Landscape: A Synthesis of Approaches for Ecological Planning. Landscape Journal, 21 (1): 138-155.

Niemelä, J. (1999). Ecology and Urban Planning. Biodiversity and Conservation, 8 (1): 119-131.

Odum, E. P. and Barrett, G. W. (2008). Fundamental Principles of Ecology. Palme Publications: 469, Translation Editor (Prof. Dr. Kani Işık), ISBN: 978-9944-341-74-5, p: 374-412, Ankara.

Öztürk, B. (2004). Formation of an Urban Open and Green Area System: An Example of Kayseri as a Whole. PhD Dissertation (Unpublished). Section of Landscape Architecture in the Institute of Natural and Applied Sciences at Ankara University, Ankara.

Özügül, M. D. and Atabay, S. (2006). A Recommendation of the Method Likely to be used in Ecological Planning: An Example of Ömerli Drinking Water Basin. Journal of the Faculty of Architecture at Yildiz Technical University, 1 (4): 201-217.

Provincial Directorate of Food, Agriculture and Animal Husbandry of Çanakkale (2008). The Digital Map of the Provincial Land Asset of Çanakkale. Numerical Data by the Provincial Directorate of Food, Agriculture and Animal Husbandry of Çanakkale, Çanakkale.

Rennings, K. and Wiggering, H. (1997). Steps to Wards Indicators of Sustainable Development: Linking Economic and Ecological Concepts. Ecological Economics, 20 (1): 25-36. Date of Access: 19.11.2012, Available at http://dx.doi.org/10.1016/S09218009(96)00108-5

Ricketts, T. and Imhoff, M. (2003). Biodiversity, Urban Areas and Agriculture: Locating Priority Ecoregions for Conservation. Conservation Ecology, 8(2): 1. Date of Access: 19.11.2012, Available at http://www.consecol.org/vol8/iss2/art1

Sezgin, D. and Varol, Ç. (2012). The Impact of Urban Growth and Sprawl in Ankara on the Improper Use of Fertile Agricultural Lands. METU JFA, 29 (1): 273-288. DOI: 
10.4305/METU.JFA.2012.1.15. Date of Access: 19.11.2012, Available at jfa.arch.metu.edu.tr/archive/0258-5316/2012/cilt29/.../273-288.pdf

Silaydın, M. B. (2007). Ecological Planning: Is it Possible through the Planning Action and Conservation Efforts Conducted on the Urban Scale? A Book of Papers of the National Symposium on Ecological Architecture and Planning, p: 86-88, Antalya.

Steiner, F. (2000). The Living Landscape: An Ecological Approach to Landscape Planning. Arizona State University Press, 275 p., USA.

Şahin, Ş. (2009). Landscape Management (Conceptual Bases and Implementation Areas of Landscape Ecology). Editor: Aslı Akay and Münevver Demirbaş Özen. Publication of the Turkish and Middle Eastern Public Administration Institute, No: 354, ISBN: 978-975-8918-36-2, p: 31-57, Ankara.

Termorshuizen, J. W.,Opdam, P., Brink, A. (2007). Incorporating Ecological Sustainability into Landscape Planning. Landscape and Urban Planning, 79 (3-4): 374-384.

Tozar, T. and Ayaşligil, T. (2008). Methods of Ecological Planning Developed for the Sustainability of Natural Resources. Journal of the Faculty of Forestry at IU, Series A, 58 (1): 17-36. Date of Access: 20.09.2012, Available at www.iudergi.com/tr/index.php/orman/article/view/9645/8940

Tunçer, M. and Ercoşkun, Y. Ö. (2007). Ecological Planning for Antalya that is shaped under the Pressure of Urban Rent. A Book of Papers of the Symposium on Ecological Architecture and Planning, p: 102-109.

Turan, Y. B. (2007). Structuring of the Mechanism of Landscape Planning in the European Union and Turkey. Journal of Landscape Architecture, Publications of the Chamber of Landscape Architects of UCTEA (the Union of Chambers of Turkish Engineers and Architects), 2007/1-2: 44-47, Ankara.

Uğur, S. (2009). Studying the Large-Scale Parks Created around Natural Water Surfaces in terms of Ecological Criteria: An Example of Mogan Park. Graduate Thesis (Unpublished). Section of Landscape Architecture in the Institute of Natural and Applied Sciences at Ankara University, Ankara.

Van Lier, H. N. (1998). The Role of Land Use Planning in Sustainable Rural Systems. Landscape and Urban Planning. 41 (2): 83-91. Date of Access: 11.12.2012, Available at http:/ /dx.doi.org/10.1016/S0169-2046(97)00061-3

WCED (1987). World Commission on Environment and Development (Our Common Future). United Nations, 247 p. Date of Access: 20.10.2012, Available at http://www.undocuments.net/wced-ocf.htm

Yilmaz, H. (2007). Current Regulations and Problems concerning the Environmental Order Plan. TBB Journal, 72: 78-94.

Yli-Pelkonen, V. and Kohl, J. (2005). The Role of Local Ecological Knowledge in Sustainable Urban Planning: Perspectives from Finland. Sustainability: Science, Practice, E Policy, 1 (1): 3-14.

Yli-Pelkonen, V. and Niemelä, J. (2005). Linking Ecological and Social Systems in Cities: Urban Planning in Finland as a Case. Biodiversity and Conservation, DOI 10.1007/s10531004-2124-7, 14: 1947-1967.

Yli-Pelkonen, V. and Niemelä, J. (2006). Use of Ecological Information in Urban Planning: Experiences from the Helsinki Metropolitan Area, Finland. Urban Ecosyst, DOI 10.1007/s11252-006-8591-8, 9: 211-226. 


\title{
Architectures on Territories - Methodologies for the Graphical Representation
}

\author{
José Manuel Pagés Madrigal \\ Additional information is available at the end of the chapter
}

http://dx.doi.org/10.5772/55849

\section{Introduction}

Territories were always referred to their architectures in a continuous transformation's process. These architectures were based on natural materials, as a direct consequence of the agricultural functions and are essential for a right perception of the logic of territorial structuring.

This perception is always important for a territorial planning.

This chapter deals problems of the scales' study and its validity in certain areas and smallscale landscapes. Some case studies are being compared and analysis proposal prior to the territorial drafting.

The proposal is to individual redraw of territories, as a method of knowledge appropriate for the planning level. Comparisons are made between the performed methods in similar territories. In the first case an entirely hand survey is done, and in the second one the survey is based on the knowledge of computer applications. The conclusions summarize the pros and cons of each of the cases we have studied. Also the basis for a territorial approach proposed small-scale landscapes are defined.

\section{Topics for a chapter}

The main argument of this chapter is based on a certain number of topics we are introducing.

Our initial point into this discourse is the idea of considering there are architectures without architects.

From our point of view, territories were made by the Man, as the real architect of them, in a continuous process, as a dialogue between him and the surrounding environment. The 
result of this dialogue was, and continues to be, the creation of objects on these territories. This idea is not really new. It was implicit in the definition of the landscape of Webster dictionary on 1913: "A portion of land or territory which the eye can comprehend in a single view, including all the objects it contains" [1]

The identification and characterization of environments and landscapes in Europe was made taking in consideration such scale of the landscapes. In fact the European Landscape map showed us Europe as a conjunct of 2682 different landscapes as the result of a classification among the 202 types of detected landscapes. Two thousand and six hundred of theselandscape units were a dimension larger than $2500 \mathrm{Ha}$. This quantity lets know the large diversity of landscapes characteristic for specific regions as one of the key culturalheritage elements of Europe. ${ }^{[2]}$

It is important to remember that this dimension $(2500 \mathrm{Ha})$ is equivalent to the size of all Carnoedo $^{1}$ (Spain) It is one of our case studies will be presented. This dimension represents five times the extension of Bárrio ${ }^{2}$, that is the other case study into Ponte de Lima Municipality, northern region of Portugal.

These numbers can synthesize the problem we have in front of us. These two spaces are representative of so many areas into the European continent. They are so rich from a landscape point of view that so many things and changes are experimented into them. In our opinion the small scale landscapes are clearly out of the considered dimension. This chapter is based on this idea: the need to consider the various scales involved in the process of territorial structure.

The second topic we must underline is the idea of considering the territorial analysis as the ideal tool to understand their internal structuring. Each analysis has an adequate dimension, according to its goals. And this dimension is directly associated to the scale of the territory. When territories to be analyzed are out of the conventional dimensions they are usually applied we can risk to lose an important number of elements into them, not recognizable by the tools are used for developing the analysis.

The third topic is related to the existence of constants, as elements able to explain the different territorial configurations of the place. The temporal dimension becomes as a reference into it. We can confirm the existence of a number of constants that occur in any territory.

These elements, in combination, cause the different architectures on these lands, in a continuous process, in a process of transformation of the territory. It is the place where the Man is the real protagonist.

Medium and short sized scales in territories are the basis for a right perception of extended areas and regions in all around the world. We can find these characteristics in western European territories within countries as Ireland, Great Britain, Holland, Spain and Portugal.

\footnotetext{
${ }^{1}$ Carnoedo's dimension is $27,49 \mathrm{~km}^{2}$

${ }^{2}$ Barrio is a place into Ponte de Lima Municipality with an extension of 5,31 km²
} 
But this scale can be found in other territories. Lebanese country presents a clear morphological division (fig. 5):. The waterfront facing to Mediterranean Sea and the inlands. All these two regions reflect the small-medium sized scales.

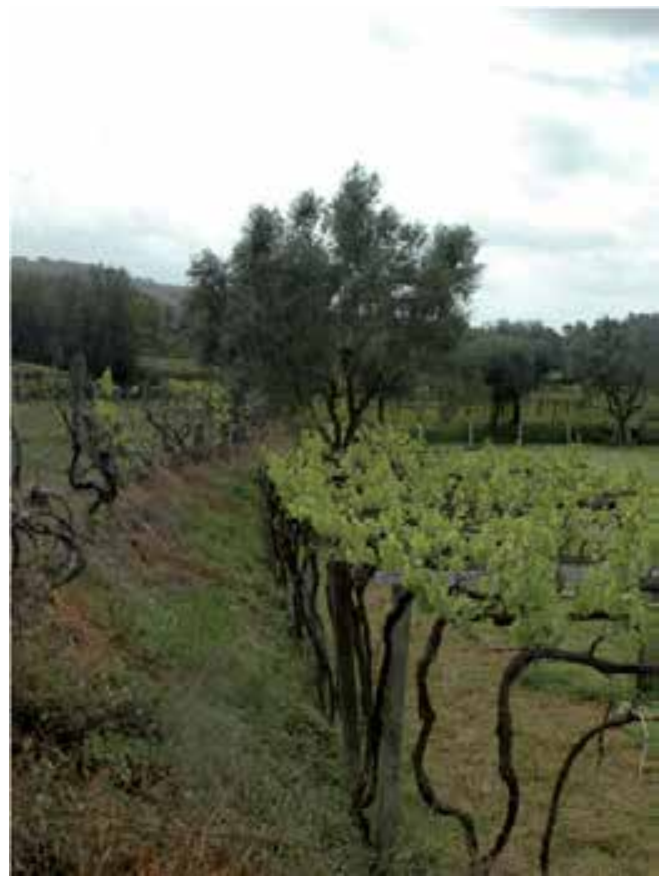

Figure 1. Bárrio-Ponte de Lima-Portugal, by author.

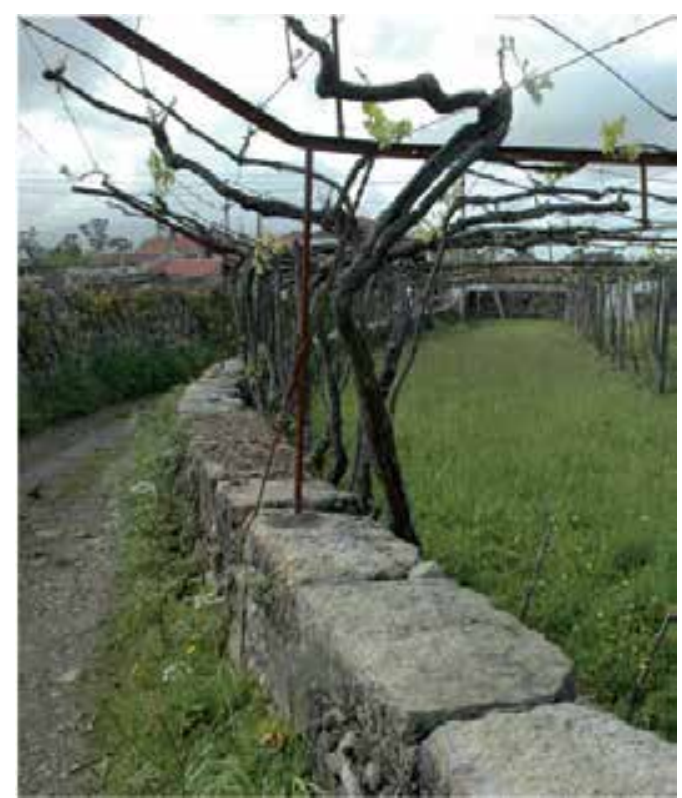

Figure 2. Correlhã-Ponte de Lima-Portugal, by author 


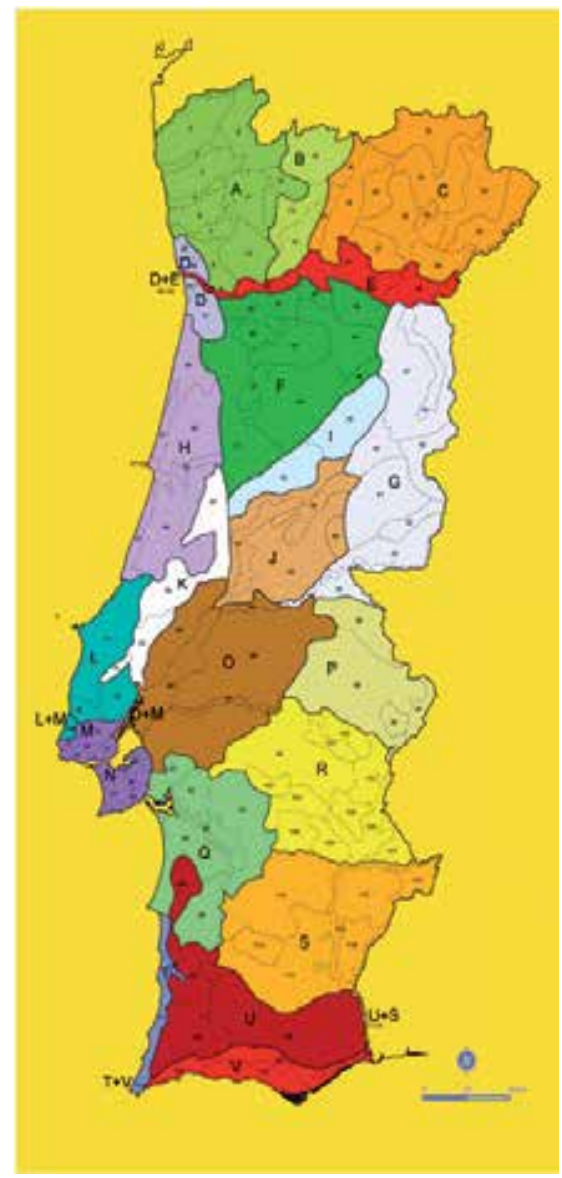

Figure 3. Landscape's Portuguese Atlas, from "Contributos para a identificação e caracterização da paisagem em Portugal continental"

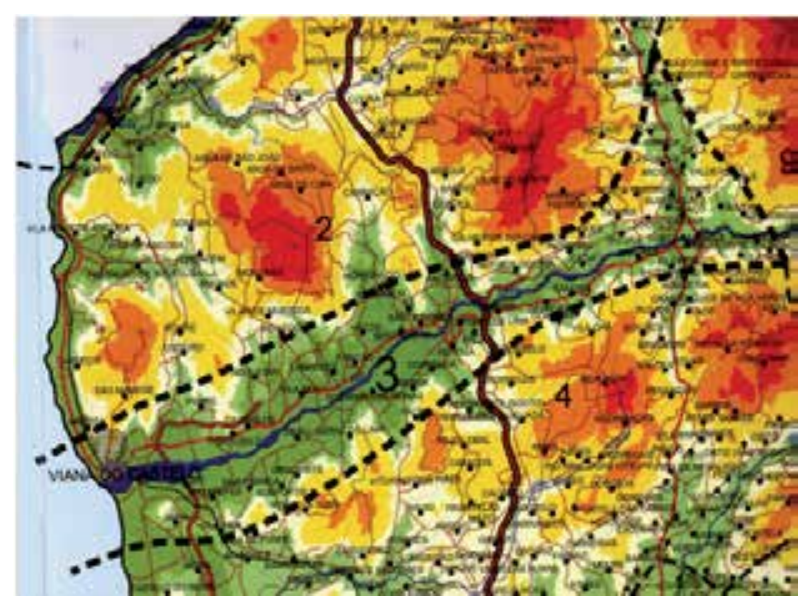

Figure 4. Lima Valley's landscape units-Portugal, from: "Contributos para a identificação e caracterização da paisagem em Portugal continental" 


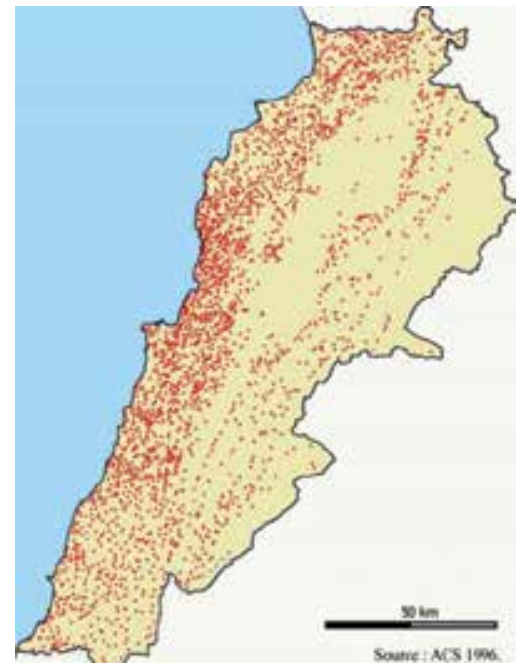

Figure 5. Lebanon's population distribution

Several actions in the way of considering the specificities of these kinds of territories can be appreciated in the last five years. We highlight last international seminar in Refóios do Lima3-Ponte de Lima-Portugal on May 2011 "Small scale landscapes in Western Europe, methodological developments in habitat recording and monitoring". (fig.6) It was possible there to identify certain alternative studies to fill the existent lacks in the normal scale for the CLC maps for Europe, when compared with other European initiatives.

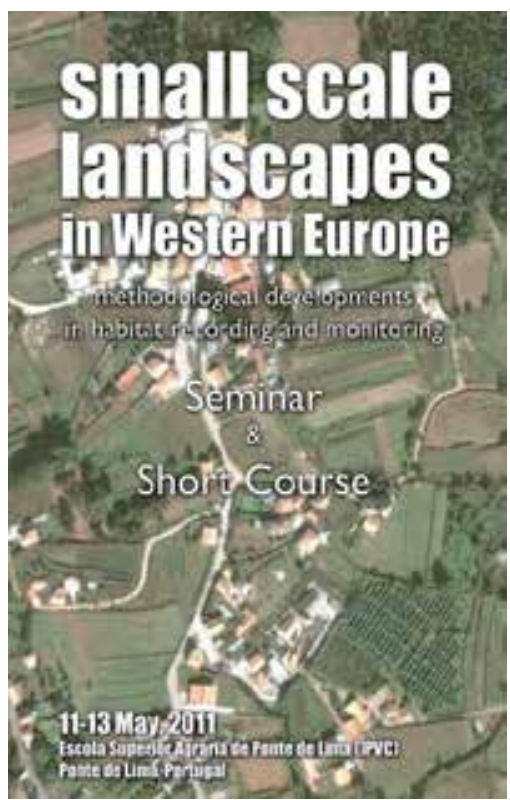

Figure 6. Flyer for the seminar

\footnotetext{
${ }^{3}$ Escola Superor Agrária. Instituto Politénico de Viana do Castelo (IPVC)-Portugal
} 


\section{CLC studies: The problems related to the land use and land cover analysis}

One of the most direct reflections of all these patterns into the landscape is the land use. ${ }^{4}$ The land use patterns in Europe could be seen as an expression of centuries of human intervention on its environment, an expression of the continuous transformation process previously referred. Historically, the development of rural areas has depended heavily on the exploitation of its natural resources

But social components are not the unique elements to define the land use patterns. Other external elements as the geographical context and the capability to produce enough resources must be considered. In a parallel way the economic evolution of the territories and the societies linked to them will depend of these concepts and its demographic evolution.

The interim report of the EU-LUPA ${ }^{5[3]}$ describes the process using the work from SOER ${ }^{6}$, as follows:

"Land use specialization (urbanization, agricultural intensification and abandonment, natural forestation) decrease of arable land and permanent crops and land artificialization (residential, economic sites and infrastructures) are major trends that could be identified in the last decades (SOER, 2010). Those trends are the result of interacting driving forces including policies."

Land uses and land covers are the trend topics for the CORINE project ${ }^{7}$. The basis of this project is the grid of $1 \mathrm{~km}^{2}$ dimension applied over all the European territory, analyzing the several functions develop on this square grid trying to identify the dominant uses can characterize this cell. Technical reasons were supporting it.

Comparative studies about the evolution of the land use in the partner countries are a reality today. Analysis on 1990, 2000 and 2006 were a strong contribution. At the same time the major image resolution has improved the analysis capability detecting a bigger and more detailed number of topics.

Use changes are always linked to several aspects, where human activities work as the engine for the changes in the economic field.

\footnotetext{
${ }^{4}$ We must remember that Land Use Functions (LUFs) express the goods and services that the use of the land provides to human society that are of economical, ecological and socio-cultural value and likely to be affected by policy changes In EU-LUPA six LUFs have been identified considering the following criteria:

- The main uses of the land in Europe are represented (i.e. agriculture, forestry ,nature conservation, tourism, urban settlement, transport and energy infrastructure);

- Ensure that all three dimensions of sustainability (economic, environmental and societal) have an equal representation;

- The functions are likely to be affected by European policies

${ }^{5}$ EU-LUPA is the acronym of European Land $\boldsymbol{U}_{\text {se }}$ Patterns

${ }^{6}$ The European environment - state and outlook 2010 (SOER 2010)

${ }^{7}$ CORINE project (Co-ORdination of INformation on the Environment) was launched in 1985 as an EU initiative. The main goal is to provide the information on the status and changes detected in the environmental fields. One of the databases integrated within this project is the CORINE land cover database (CLC). The working area is a encompassing most of the European countries
} 
The right evaluation of the detected changes about the land uses must consider these aspects.

Problems are coming for the small scale territories when the applied grid $\left(1 \mathrm{~km}^{*} 1 \mathrm{~km}\right)$ is too big to be identified with a unique dominant use. This classification is hiding other important functions being developed on the same grid. The relations among the several functions into territories with a high density use are complex and complementary.

Such of these small scale landscapes have linked their characteristics to national or regional identities $^{8}$. The main characteristics of these landscapes can be summarized as follows:

- The existence of a large number of small lots

- The extent and number of linear features.

- The overlaps between lines and areas

- The number of different habitats present within a certain agrarian unit

The property structure is helping to consider this diversity into the small scale. This heterogeneity is supported by the small patches and the different interpretations about the landscape concept. This system runs the risk of disappearing some centuries after this basic heterogeneity.

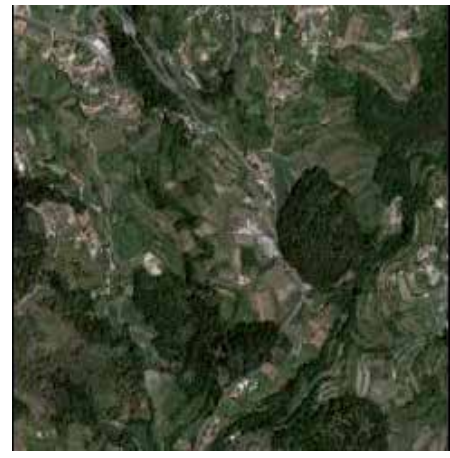

Figure 7. Bárrio-Ponte de Lima-Portugal- $1 \mathrm{~km}^{2}$ grid

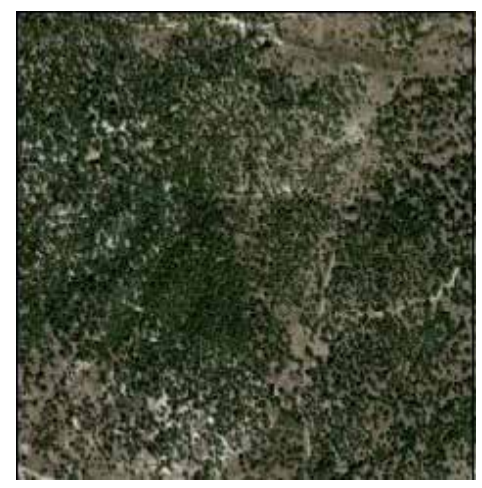

Figure 8. Évora-Portugal- $1 \mathrm{~km}^{2}$ grid

\footnotetext{
${ }^{8}$ Ireland case study can be a clear example about the national identity. Porto and Douro river are identified with a specific territory where the terraces' landscape play an important role as a "territorial branding"
} 


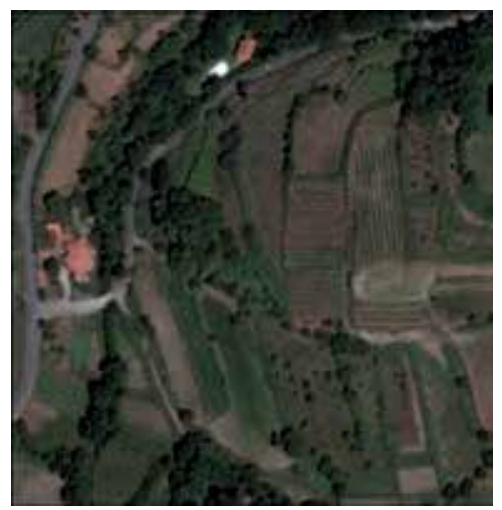

Figure 9. Bárrio-Ponte de Lima-Portugal-250m×250m grid

\section{Small agricultural landscapes - The vision of the planner}

Studies of local history, regional history, rural geography and archaeology itself reveal the strong relationship between agricultural use of the various areas and continuous transformation. In Europe we see the existence of a secular agrarian structure tied in large parts of the continent. We must look for these phenomena into an dispersed ownership structure that caused the existence of small-scale agricultural landscape. This small scale has been disappearing for several reasons. In some cases this change was abrupt: at this point a broader political project have converged with a landscape incidence. We can see it in two countries: Czechoslovakia and Portugal. In the first case, we must remember the landscapes' consequences of the socialist revolution (Fig.10) with the change of the economic system. In th second case, it is clear the Estorãos'(Portugal) and its new land parceling. On the opposite side, the fragmentation of the landscape has been seen in the new irrigation systems in the river Guadiana (Spain). In general terms, abundant water and small property usually go together.

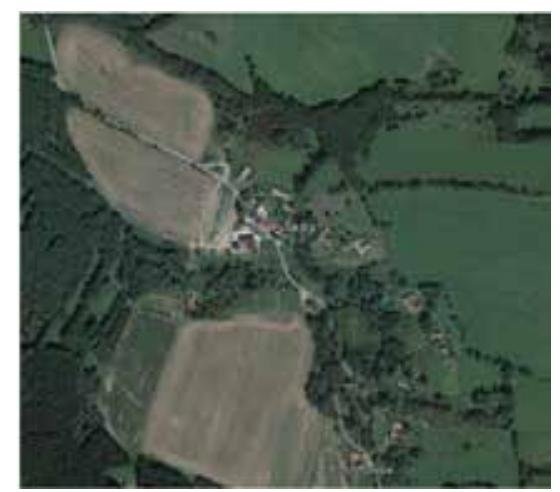

Figure 10. Sejby-Czech Republic

Central Bohemia region experienced great changes which occurred during the 40 years of socialist collectivism. The changing process of the property structure reflected important 
landscape transformations. The images below are expressing the radical different points of view about the landscape changing (fig. 12) This process was filled within a 50 years period. Aerial photographs show the effects of this controlled planning when comparisons between both sides of the border, as in the case of Sejby and Moorbad-harbach in the border between the Czech Republic and Austria (fig12) ${ }^{9}$

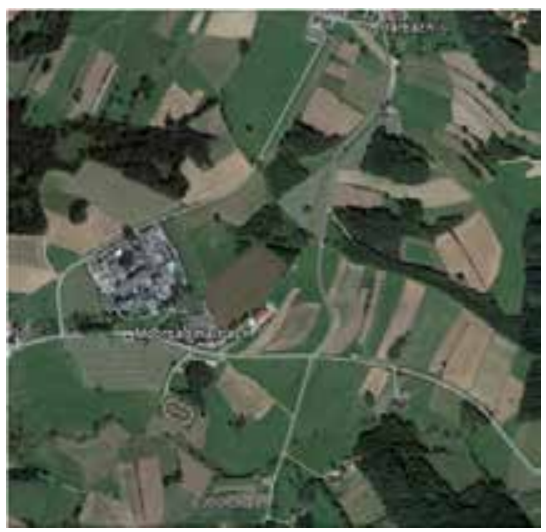

Figure 11. Moorbad-harbach- Austria

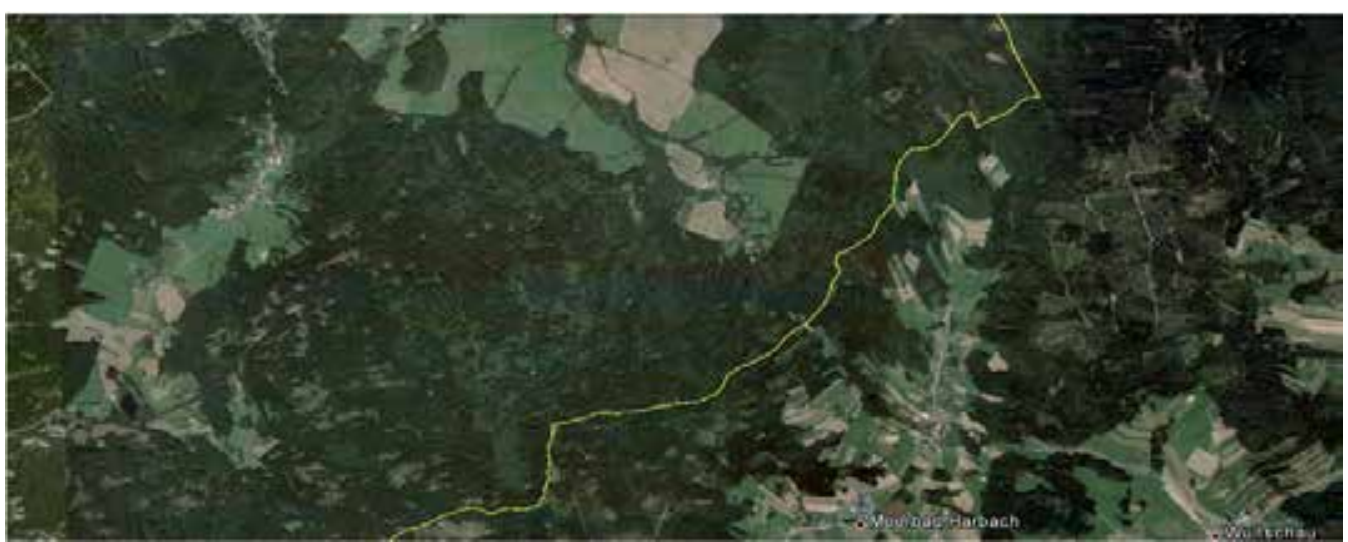

Figure 12. Border space between Moorbad-harbach and Sejby. From Google earth

Estorãos is the first developed project about the land reparcelling in Portugal, into 60's. The changes were experienced in a short period, between 1961 and 1969 (fig.13, respectively on the left and on the right). These changes were based about the maintenance of the infrastructures but grouping the smallest lots where extreme difficulties to apply new technologies for the agricultural functions existed.

Landscapes tried to be adapted to the new scale. Actors were the same, primary elements ${ }^{10}$ into the memory of the social practices continued to be the same ones. Scale alteration was

\footnotetext{
${ }^{9}$ For a more detailed information Works published by Zdeněk Lipský de Czech University of Agriculture Prague, Faculty of Forestry can be consulted.

${ }^{10}$ We take this concept from the different Aldo Rossi's works about the city, applied to territories
} 
enough for the landscape transformation. The work consisted of checking how the primary elements, once recycled and reinterpreted after the redistricting process parcel, are still conditioning the final layout of the landscape. This hypothesis was not confirmed. However it was found that the elements shaped the landscape were still present in the new landscapes resulting from land redistribution although relations were altered depending on the change of scale. This time the political territorial planning caused effects similar to found in the case of border space between Czech Republic and Austria(fig. 12).

Finally, the new process of land redistribution experienced in Badajoz-Spain province was a part of a global strategy: the new irrigation of a large tract of land along the Guadiana river.

This program included the construction of new villages and the displacement of several thousand people, the new colonists of the twentieth century. More than 40.000 colonists spread on 59 new settlements, ${ }^{11}$ together with the irrigation infrastructure, were transforming totally these territories as perceived in the comparative pictures.(fig 14 and 15).
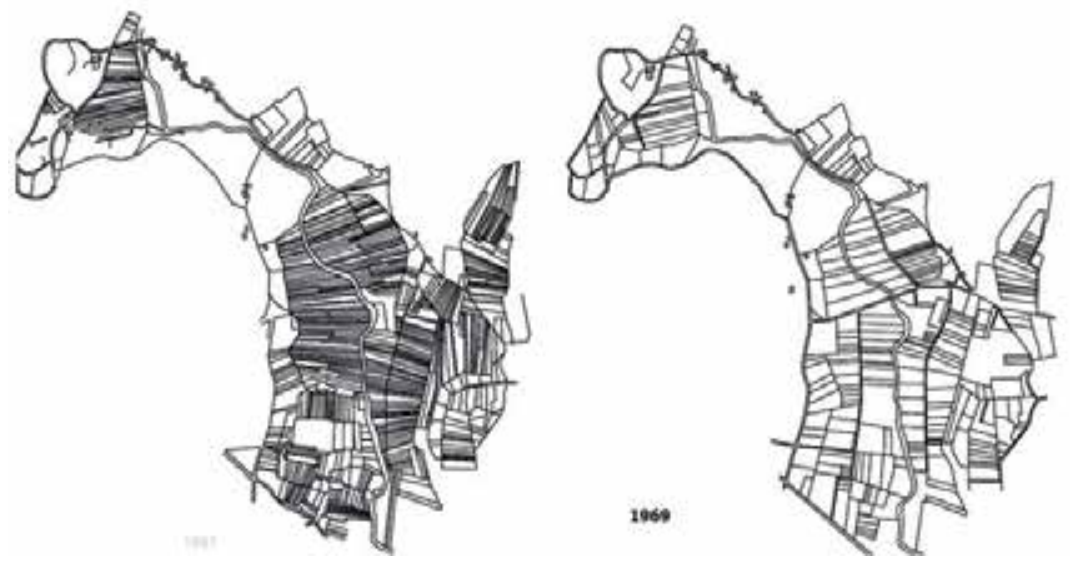

Figure 13. Estorãos-Ponte de Lima-Portugal, Land registry 1961-1969

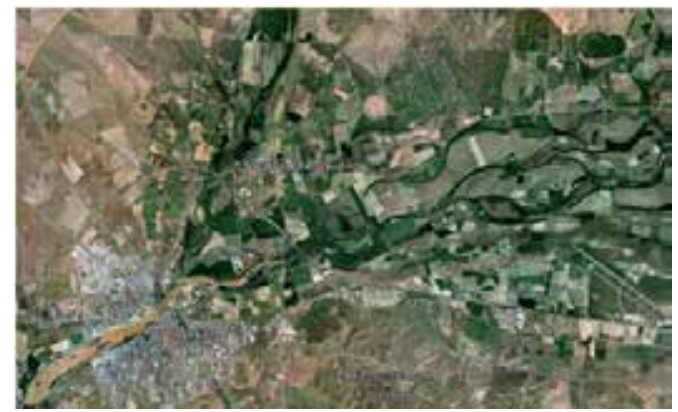

Figure 14. Badajoz's surroundings.2011

\footnotetext{
${ }^{11}$ Data on 2009, but the first settlements were built on 1956
} 


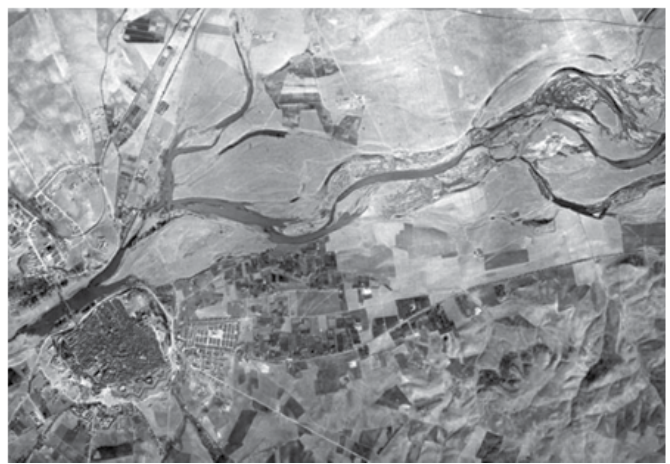

Figure 15. Badajoz's surroundings.1956

We must resume that small scales present a heterogeneity only compared between them, with own dynamics. Too many things are happening on these territories where the distance between two places can be around 200 meters. Correlhã is paradigmatic. We can see these changes occur all along the Portuguese Caminho de Santiago ${ }^{12}$, as a sequence of places. Original representation at $1 / 500$ of this continuity may reflect it. ${ }^{13}$ (fig. 16). Done work expresses the characteristics of the relationship between domestic space and land.

Through all the referred case studies we can repair that the initial situation, identified as heterogeneity, is decreasing, turning to a specialization caused by the low rates of employing in the agricultural sector and the low activity in the last years

This specialization is based on the urbanization, mixed with the short number of fixed residents, converting some areas into a second residential area, more active during the week-ends.

These questions are helping to provoke important changes in the identities of these places.

Identities are tied closely to their respective territorial morphologies. The understanding of identity cannot be separated from its territory, as tangible reference point for the development of the social practices. The maps, as mere and accurate mapping, do not express these relationships.

The conventional maps use the same criteria of intensity and representation, merely expressing formal characterizations. They confirm the reiteration of facts in one place.

But the intangibles are hardly expressed in an automatic way, impersonal, thoughtless.

The characterization of these identities is vital in order to act over these territories, regardless of the scale of the performance.

But, at the same time, this scale will be always essential for choosing the adequate tools.

${ }^{12}$ Caminho de Santiago is the Pilgrim's Route from Portugal to Santiago de Compostela

${ }^{13}$ Correlhã is a freguesia close to Ponte de Lima was studied by the students of University Fernando Pessoa in the years 2010-2011 and 2011-2012, with the goal to identify the rural morphologies understood as primary elements. 


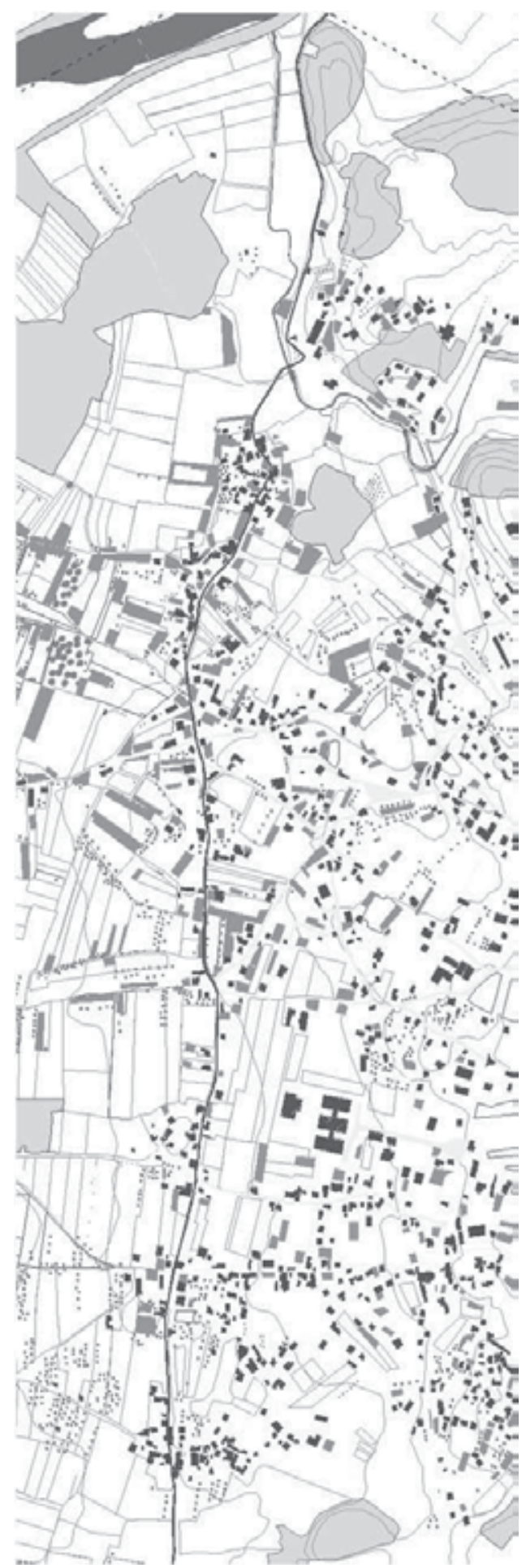

Figure 16. Portuguese Caminho de Santiago (Pilgrim's route) 


\section{Small landscapes and landscape-characters}

Such Atlantic Europe small scale landscapes are known by their rich biodiversities, but their capability to define "per se" the elements are defining the Landscape character ${ }^{14}$. Some of these elements are related to the definition of "primary element". We understand them as the elements able to define the basic structure of a territory; basic elements are repeated within the territorial morphologies.

The small scale is capable of receiving therein a larger number of events than other larger scales, a greater number of elements. A huge variety of scenarios can be checked. They are created within a small area. This phenomenon provokes a greater distinctive appearance and amount of agricultural products, into the agricultural landscapes' small scale.

These characteristics are coinciding en several cases with the definition of a national or regional identity ${ }^{[4]}$. The image of the small landscape is an important component of this identity $\left.{ }^{15}\right)$. Marketing Porto wine's example was referred previously. But this example is not the only one. "Vinho verde region" is a concept exclusively linked to Alto Minho(NUT III) region. (fig. 17) In the same way, but with specific characteristics we can talk about the virtual region of Maronite sanctuaries in Lebanon, almost all of them dedicated to the wine's culture as an identity signal confronted to other religions at Lebanon.

The heterogeneity of these spaces is coming from the numerous actors on a short space. This heterogeneity is the core of the identity. A few primary elements are composing the several visual scenarios. Monitoring of these spaces is normally more complicated than larger scales: several habitats and patches are sharing almost the same spaces; the multifunctionality of the spaces is a normal solution with two levels of agricultural practices in the Minho-Galicia region.

We can resume the general characteristics of this scale:

- [1] A relative important number of habitats in a short space

- [2] The overlapping between lines and areas, especially talking about the fences where the grape is defining the different types of fences.

- [3] A larger number or small lots (smallholding).

- [4] The extent and number of linear features, when compared with the small areas.

The knowledge of all these realities is clearly harder and more difficult. The tools for achieving this knowledge must be more precise, according the territorial scales.

The solutions coming from a right planning must be in the same level.

\footnotetext{
${ }^{14}$ Landscape character is an English term used for defining what makes an area unique. It is defined as "a distinct, recognizable and consistent pattern of elements, be it natural (soil, landform) and/or human (for example settlement and development) in the landscape that makes one landscape different from another, rather than better or worse". The Countryside Agency (2002) defines the Landscape character as "a distinct, recognizable and consistent pattern of elements in the landscape that makes one landscape different from another ,rather than better or worse"-

${ }^{15}$ Works about this issue from Natalino Martins (coordination), Estela Domingos, Félix Ribeiro and Paulo de Carvalho can be a good reference about it.
} 

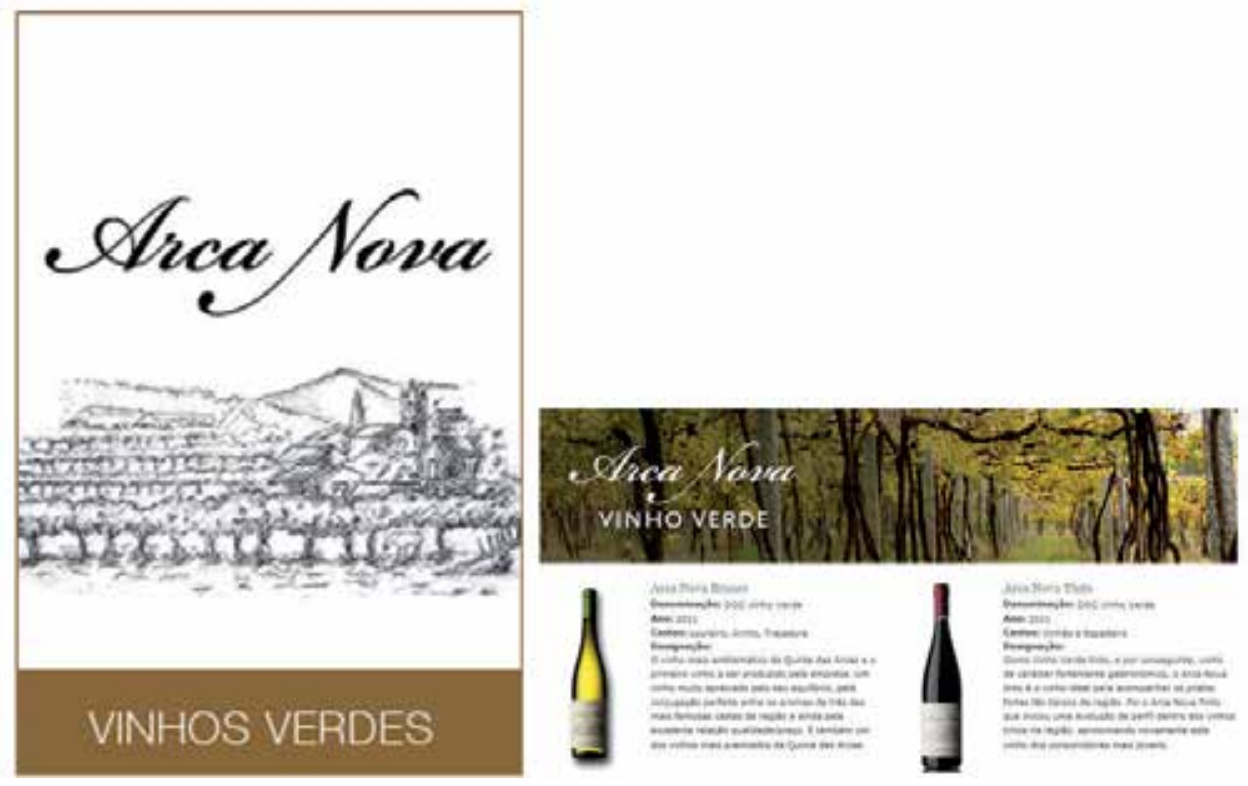

Figure 17. Territorial branding with landscapes through the different wines in Northern Portugal.

This adequate relationship between the previous concepts is crucial for the perception of these territories. Certain tools are unreflective in these processes. The $1 \mathrm{~km}^{2}$ grid used in CLC is very criticized in such small scales. Too many things are happening in these territories within this grid, where the antropization process is more evident. The choice of one dominant function, not coincident with the key one sometimes, reduces the possibilities to observe the multi-functionality of small scale landscapes.(fig. 18) This limitative problem suggests the proposal of smaller grids able to identify the several functions or characteristics into these spaces. The $0,625 \mathrm{~km}^{2}$ area $(250 \mathrm{~m} * 250 \mathrm{~m}$ grid) on fig. 9 seems more adequate to the scale and its needs. We must remember, as a reference, that the typical eira ${ }^{16}$ in some places of this region is $220 \mathrm{~m}^{2}$. (fig. 19-20) The fragmentation of these territories provokes this variety, normally associated to these phenomena:

- The existence of a strong rural concentration.

- A very scattered property structure.

- A high antropization process during a long period.

Into the opposite side we can repair the Alentejo case study. Alentejo region occupies most of the southern half of mainland Portugal. Its extension is equivalent to $35.44 \%$ of all mainland Portugal. Its 128 units are grouped in 22 sets. Five of them refer totally or partially Alentejo. Both the extent and homogeneity landscape, despite their variety, only $19.5 \%$ of the national total units are in the region.

\footnotetext{
${ }^{16}$ Eira is the name for the minimal agriculture unit normally close to the house, as a result of smallholder ownership structure
} 


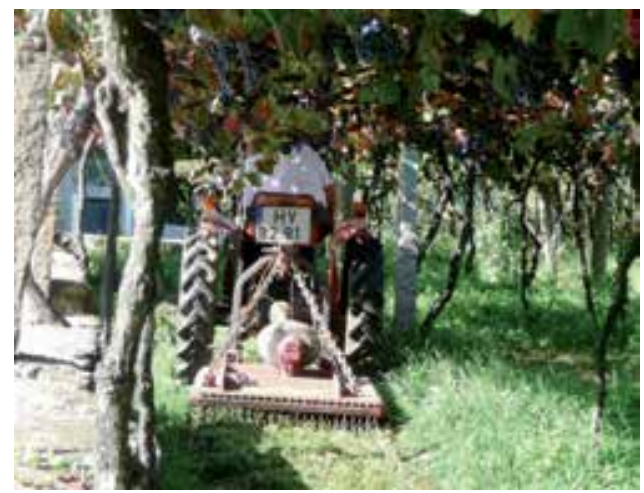

Figure 18. Several cultural on the same space. Correlhã. Ponte de Lima-Portugal

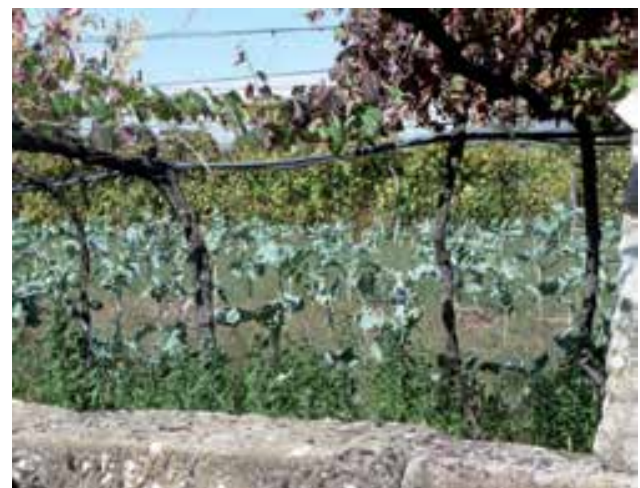

Figure 19. The formal results of the several eiras with several properties and cultures. Correlhã. Ponte de Lima. Portugal

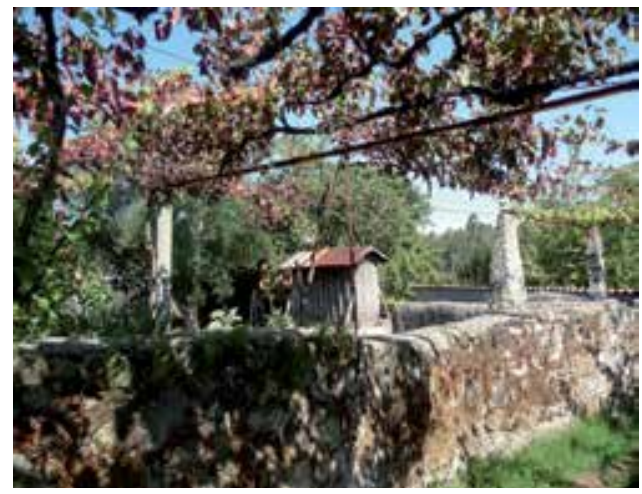

Figure 20. The espigueiro appears in the middle of this small scale as architectural reference into these landscapes

The application of $1 \mathrm{~km}^{2}$ grid is logic in certain parts of the region, especially in the landscape units whose primary elements are related to ecosystem "montado". ${ }^{17}$ We can

${ }^{17}$ Montado is a Portuguese word refers the Mediterranean grassland. 
repair in these aspects in the comparative photography of an Alentejo landscape, where it is clear that small grid is unnecessary to be applied for these purposes. Figures 7 and 8 reveal this contrast between Évora region and Ponte de Lima.

\section{Territorial design and its scales within the small landscapes}

Territorial Design is about generating value to a territory through establishing and reinforcing its identity, while revitalizing the strength of existing icons in the area.

Territorial design aims to develop a relationship among cultural, social, and economical processes, searching for references in architecture, urbanism, anthropology and design. This methodology is considered a "project approach" of strategic design, building scenarios for dealing with innovation and sustainability aspects in a territory.

We understand the need to define appropriate tools on a right approach to the problem of the various territorial scales.

It has raised the need to address the problem of small-scale with greater detail, involving more physical approach to this reality. However, we must remember that this small scale, usually in very sensitive situations, depends in turn on its regional context. In the specific case of Ponte de Lima, one can observe that the territorial branding is based on the small scale in turn survives by the peculiar structure of existent relationships between the various scales. The wine stands as a region's economic engine ${ }^{18}$, which in turn is defined by primary landscape elements associated with this activity.

But the survival of this land is related through a system of competitive territories to the existence of a territorial strategy, a territorial project. At the same time this strategy should be very respectful with the small scale, where branding marks of this land are, as the primary elements that support. It is, therefore, a two-way process. Need two parallel actions: we must get to the small-scale project from the upper levels, and proposed solutions to this small scale should be taken into account in structuring the territorial project. Applying these design tools, based on the analysis in the project, is essential to achieve these objectives.

The question would be which is the architect's role in this process. In the same way of other design's scales and maybe in a stronger and a deeper level we need to consider the identity signals as the basis for this territorial design.

The identification of these primary elements will not be enough but the perfect understanding if the relations among them.

There will be an adequate territorial design if the primary elements are preserved and improved. And this improvement must be related to the correct utilization of the existent resources. These resources must be ready to be used or recycled into regional competitiveness, but identity signals can survive.

${ }^{18}$ The Adega Cooperativa Ponte de Lima is a coop based on the wine's product of more than 200 families of the region. 
This is the reason why some actual problems need specific solutions.

One of these problems is the progressive abandonment of the "traditional" cultures. (fig. 21) This question must be lethal for the landscapes were created by day. And this problem is much better in the small scale where the accessibility to the different spaces is "enlarging" the visual impact of the problem. This problem is clear in the landscapes based on the continuous hand work of the Man. This man is not already exists. Demographics data of these areas indicate there is no generational renewal capacity. (fig.22).

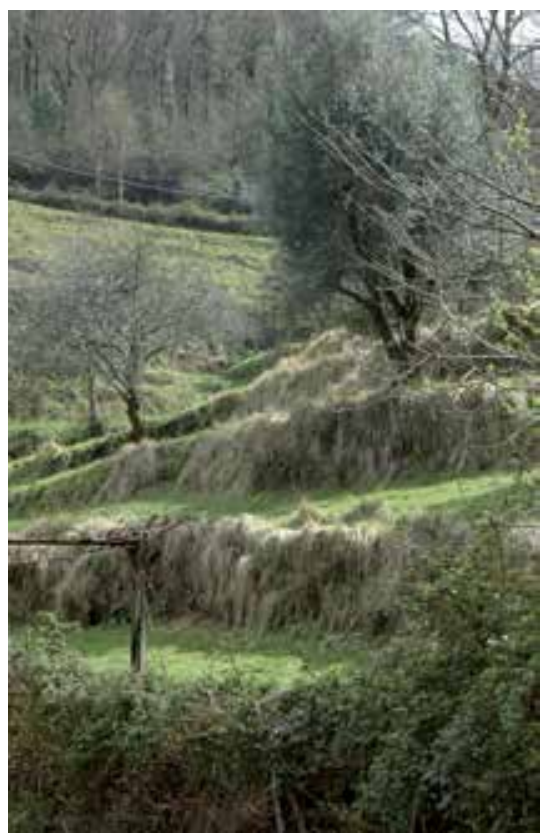

Figure 21. Abandoned lands into Bárrio freguesia.Ponte de Lima.Portugal. From the author

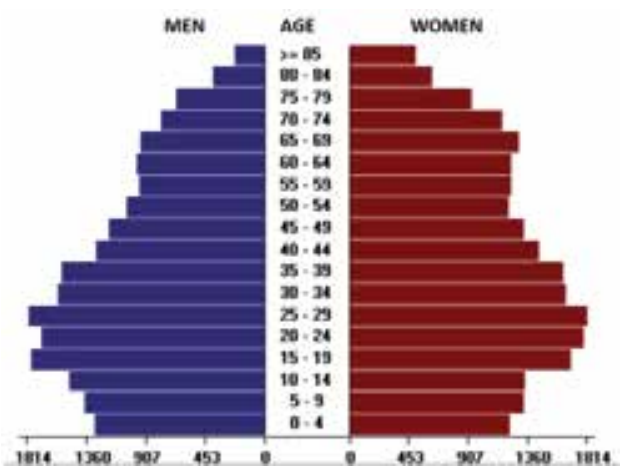

Figure 22. Populational pyramid. Ponte de Lima.2001, from Diagnostico social Conselho Local de Acção Social Ponte de Lima, 2008, adapted

But at the same time, crisis times are more reflected in the urban field. It implies a good chance for the rural areas, especially for the small landscape areas where the proximity to 
the urban areas can be a call for the return of younger population and becoming the future generations for these lands.

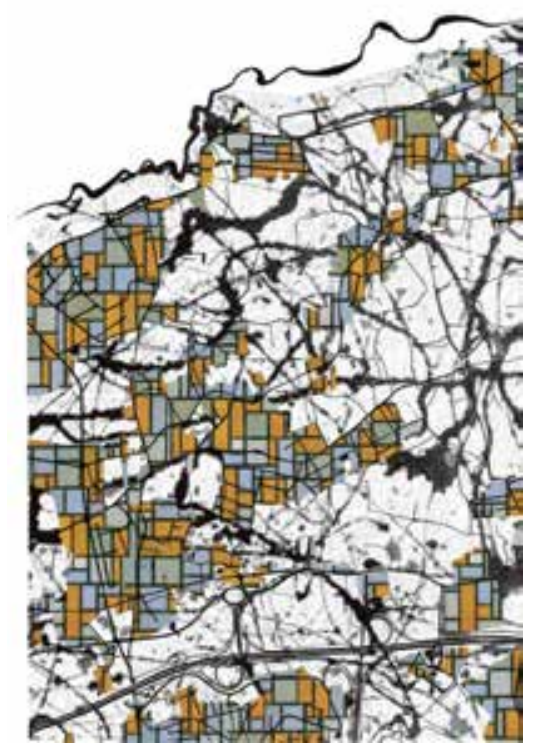

Figure 23. Territorial representation into Projecto V course. University Fernando Pessoa-Portugal-20092010. Author: Rui Pedro Silva. Original scale:1/7000

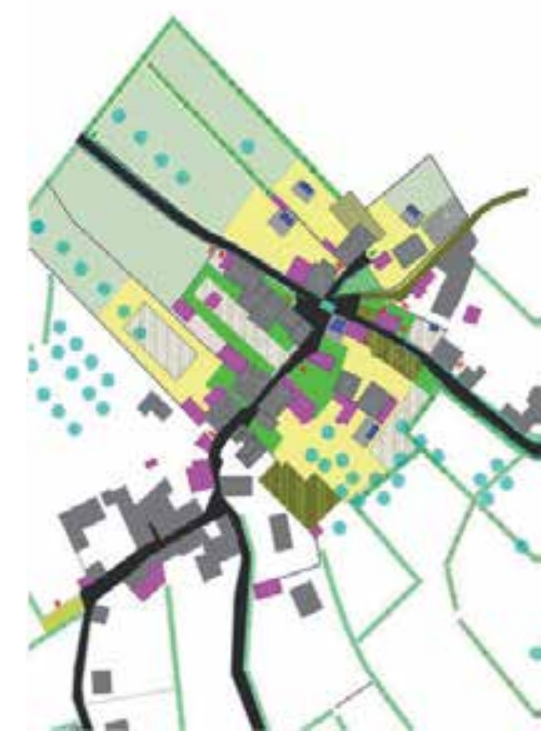

Figure 24. Anta-Correlhã.Ponte de Lima.Portugal. Representation $1 / 500$ scale in original drawing.

There seems to be a clear statement on the issue of small-scale: the approach between the territory and the Man is greater the smaller the spatial scale of perception. And many of the 
relationships are channeled through this relationship between man and land and it implies. And these group relations, as social animal that is man, implies the possible evaluation through social patterns of behavior. In 1977 Christopher Alexander published "A Pattern Language: Towns, Buildings, Construction" ${ }^{[5]}$ justifying it.

These books tried to define new structure for the understanding of the three levels were considered:

"At the core... is the idea that people should design for themselves their own houses, streets and communities. This idea... comes simply from the observation that most of the wonderful places of the world were not made by architects but by the people".[19]

At the same time this idea is linked to the definition of social patterns, including the anthropologic ones. "These are patterns in what people do, with or without interfaces designed for those purposes. These patterns are interesting and fun to talk about and they help us understand what's likely to happen,... " ${ }^{[6]}$

\section{Re-drawing territories}

Drawing territories, its representation was an obsession from earlier times. The feeling of control about territories was feeding the need to know about the form, about the conditions and potentialities form all the points of view.

Antoine Picon ${ }^{[7]}$ evokes the earlier meaning of territory for administrators, architects and engineers. They considered territories as lands that were integrated into nations or colonies by the early modern European countries. This obsession about administrative separation were dominating the perceptions of territory specially within the 18th- and 19th-century. This obsession led to a continuation of the ideas in the case of American colonization by the Spanish military engineers ${ }^{[8]}$

This desire to represent the territory as its control element is evident in the figure 25 . The author relates the main elements of territorial characterization, not as an actual approach, but as a way of understanding of the difficulties involved in Mexico's relationship with water, through the port of Veracruz, in Mexico.(Fig.26) Maps and different territorial representations were orientated in these lines. This rigorous representation was vital for achieving the referred goals.

Working on actions for territorial planning obliges to use specific tools, because territorial planning means at this case territorial project. The key steps for a right process can be the graphical representation of this territory, where the small details are so important. The various scales determine the use of specific tools of representation.

Drawing must be considered as a rational activity, basic for the development of the creative acts into a design activity. The communication of an idea would be different without this tool.

\footnotetext{
${ }^{19}$ From the book flap in the original version of this book
} 


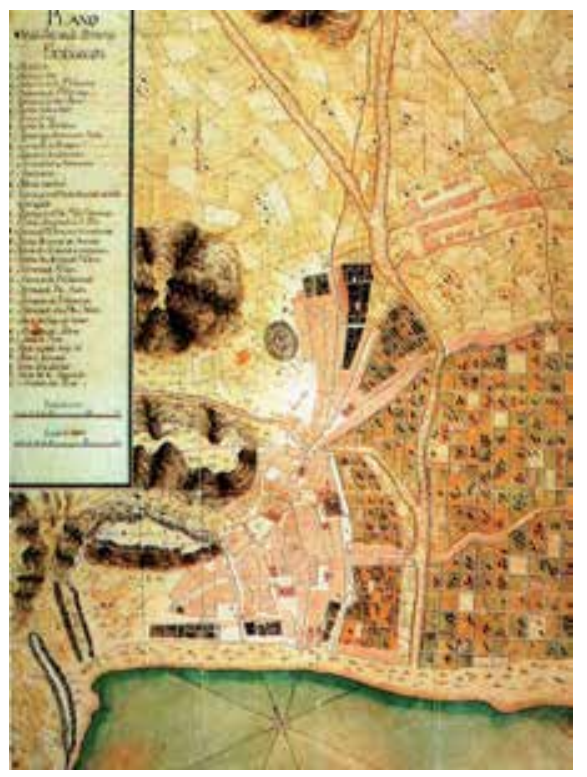

Figure 25. Almeria. Spain. 18th century from Archivo General de Simancas-Spain

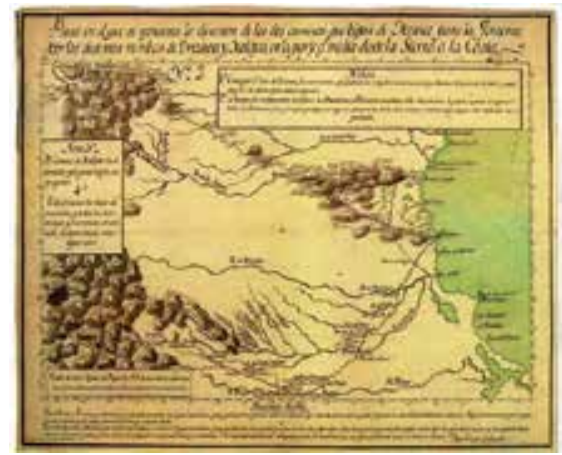

Figure 26. Diego García Cinde-1798- Plano dirección de los caminos de bajan de México a Veracruz. Biblioteca Nacional. Madrid. Spain

A methodology for the site analysis has been developed during last thirty years as the basis for an adequate territorial planning. This analysis was firstly applied to the Carnoedo case study, in northern Galicia-Spain, using a hand drawing system (1982).

The aerial photography as a first approach to the reality, confirmed or rejected by the personal ocular inspection to the place, is a classic methodology related to the hand drawing as the best way to represent the several aspects of this reality. At the same time, the representation of intagible appears when the individual interpretation of aerial photography arises from a process of personal analysis.

The drawing tells us the concept. One classical pedagogic activity into the Faculties of Architecture during the 60 's and 70's was redrawing the images of the most important works from some sacred architects. When the pen was going up photograph analysis of the 
work was more effective as a rethought drawing, as a rational act that increased the student's analytical skills.

Taking in consideration this idea, we can apply this technique to the territorial analysis. T will be a way to feel territory, overwriting territories over maps or aerial photos.

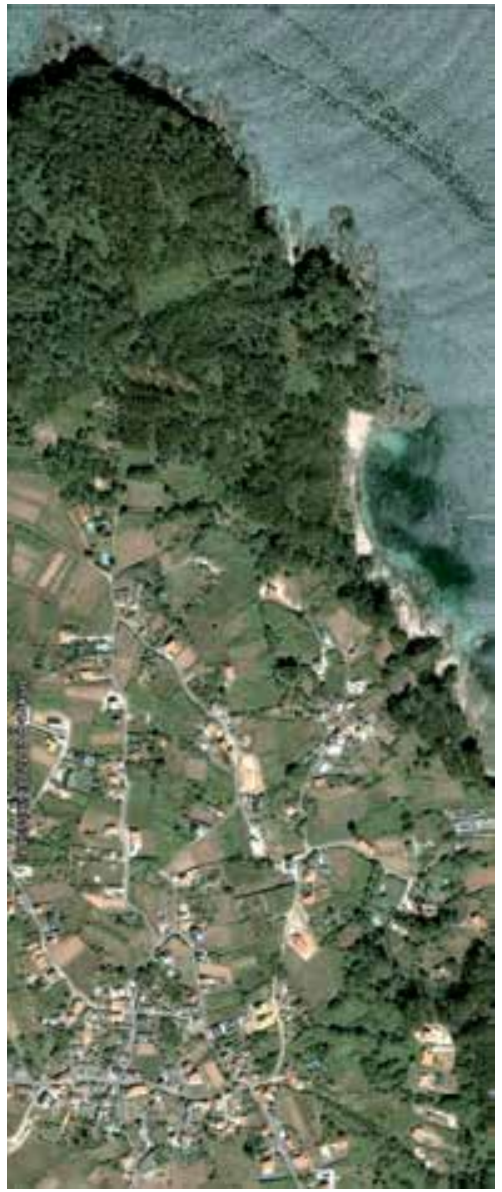

Figure 27. Carnoedo. Spain.From Google-earth

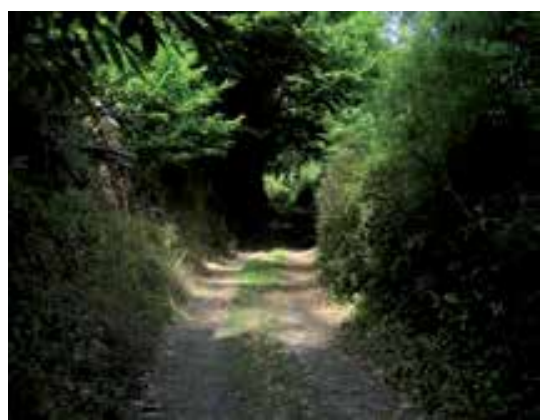

Figure 28. Path to Lobos' beach-Carnoedo-Spain 


\section{The methodology}

The work consists of taking territorial redraw as support recognition through numerous visits to the lot and the aerial photography. It dispenses with the existing conventional mapping. We understand it could be a disturbing element in the search for relationships in the analysis process. Thus establishing a direct link between the territory and its observer.

The redrawing of the territory (fig. 29) through exclusive data extraction from aerial photography work involved two levels. First, the careful observation of this photograph allowed a selection of elements that made up this country and they deserved representation, assuming a first level of analysis. There were thus identified territorial primary elements. (fig. 30)

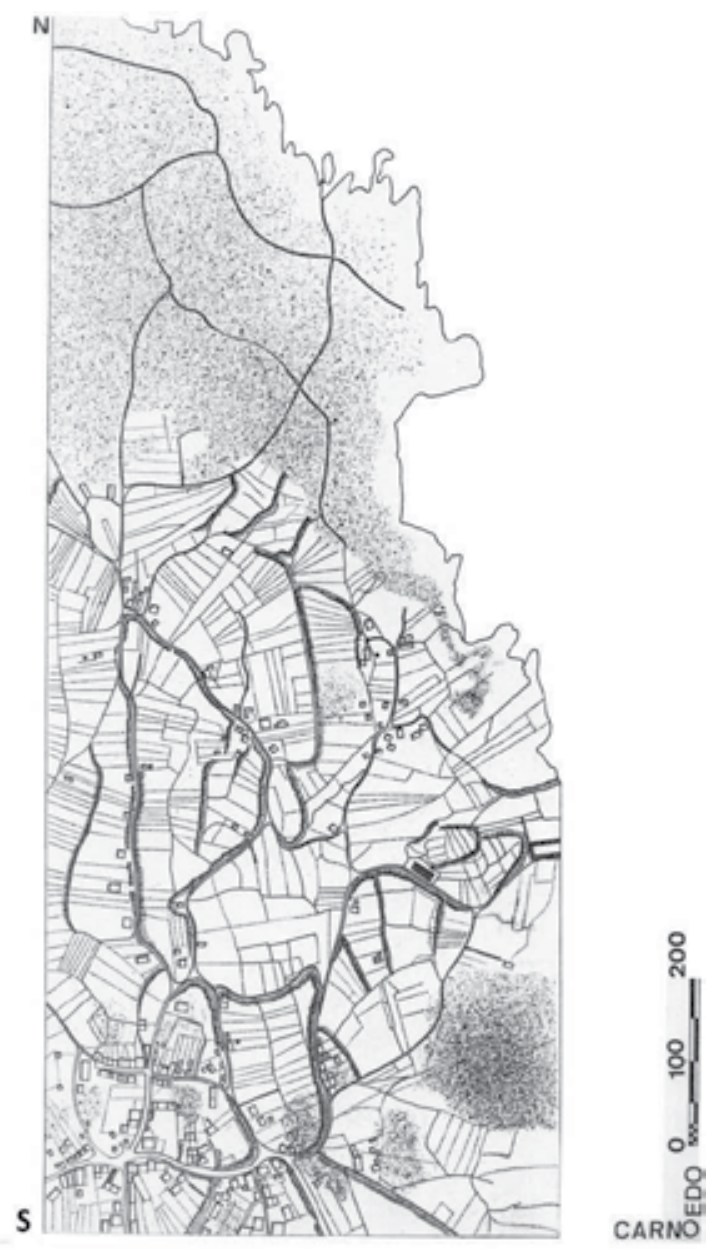

Figure 29. Handmade graphical representation Original scale 1/2000.

Second, learning techniques of representation required for recycling of previous knowledge and identifying the relationship between territorial primary elements. 
Finally, the comparison of data collected from the first phase were corroborated or rejected after the site visit, as a form of complementary knowledge of the local.

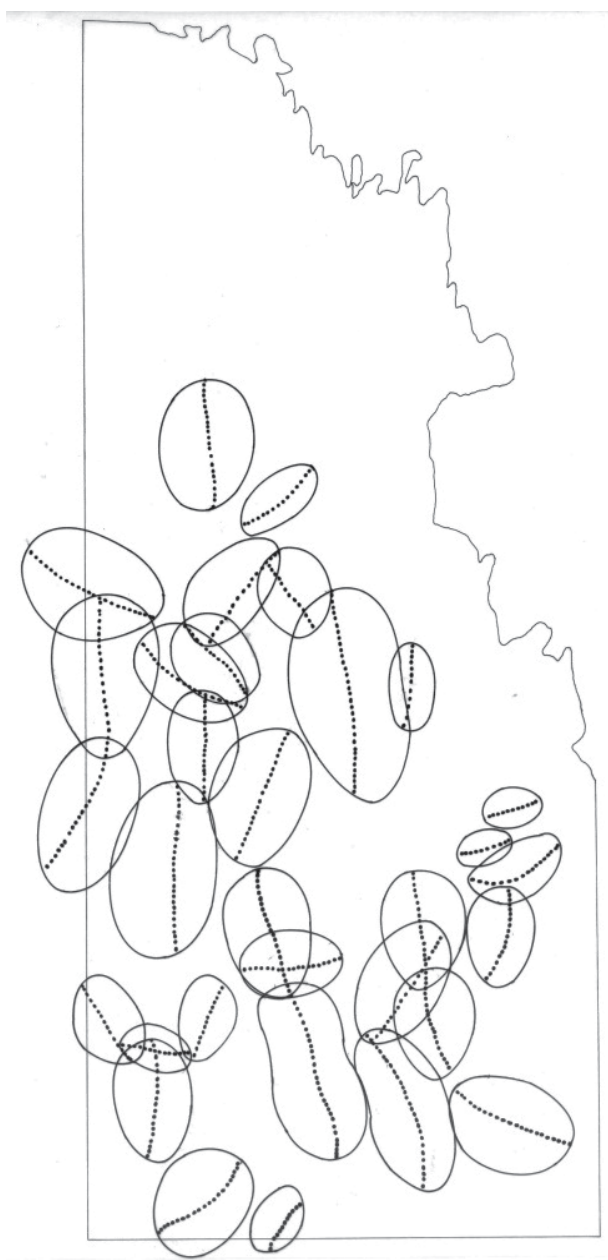

Figure 30. Identification of the primary elements Original scale 1/2000

This process contributed to the breakdown of exclusive knowledge through the plan (standard error of architecture student). Direct relationships between the plan and the third dimension were attributed through this method. For example, a shadow in the aerial photograph contributed greatly to this knowledge and assumed values for height, defining per se he third dimension. After the location of certain primary elements we define one of these areas as a landscape unit to be studied.

The choice is according to the existent topography and the primary elements previously identified. Thus, the student approaches the overall understanding of the territory where the primary elements in its structure constants, abstract territorial complexity.

The proposed work includes a number of stages, referred to below: 
- Visual recognition case study

- Personal data collection on-site.

- Understanding the process of territorial transformation, coming from the transversal knowledge.

- The identification of the primary elements

- Understanding the territorial syntax, as a result of the combination and interaction of the various primary elements previously identified.

- The definition of the forms resulting from this combination.

- Eventual classification of the various combinations detected.

- Global understanding of the territory, as the resulting object of a complex process. In this process, the man appears as an actor in this transformation slowly but steadily.

This work enables deep personal approach to the country's territorial reality. Knowledge of the various relationships between the various elements and levels of training implies territorial, while a valuable tool for future project phases.

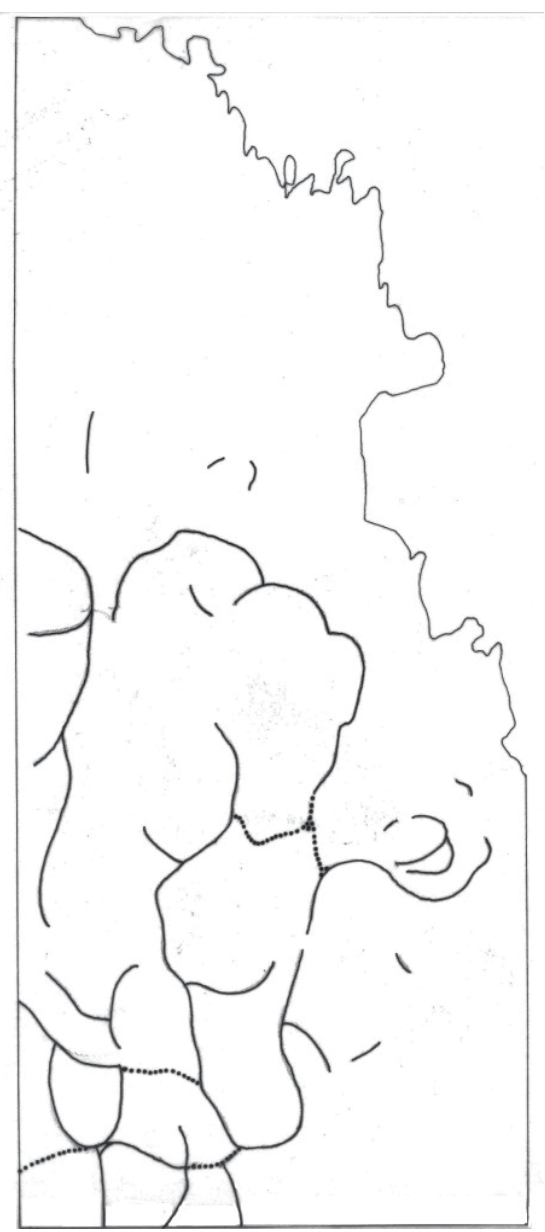

Figure 31. Interaction between primary elements and path's net. 


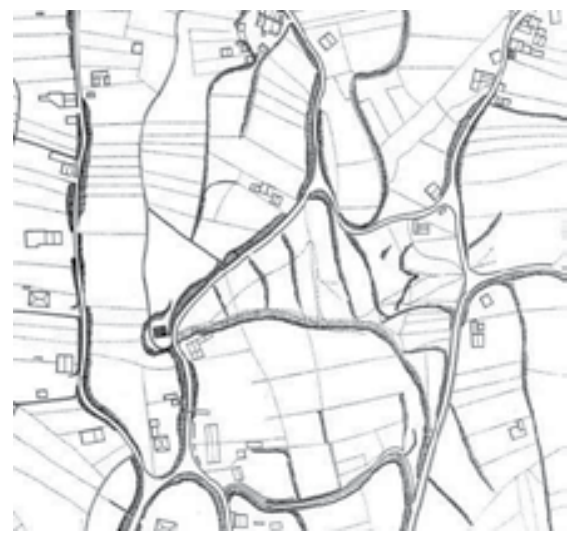

Figure 32. Detail of the whole elements, included terraces. Original scale 1/500

The different proposed stages are shown in the following:

Visual recognition case study

This first step is basic for all the process, happening after an initial analysis about the place, according the observer's background. It must occur in parallel with the second stage, as a way of approximation from the tangible, which tries to identify the fundamental joint elements of the territory. The always individual data collection is completed with the identification of these elements on the aerial photo of the site and the use of the camera as the main ally.

Personal data collection on-site.

Data relating to the territory under study, both statistical and anthropological level, are important. Knowledge of the various social practices is essential in personal and sensitive approach to the intangibles. Knowledge of these data helps the development of the state of the arts over the territory.

Understanding the process of territorial transformation, taking knowledge of science or knowledge cross.

This process arises from the combination of two strong concepts. On one side we have the knowledge collected in the state of the arts. On the other side territorial representation will be present. This phase helps the understanding of how the territory as a single complex reality.

The identification of the primary elements

The identification of the primary elements is a direct consequence of the previous phase. Primary elements concept were previously defined. In practice, the relationship between the respective elements having primary and the other elements helps perception of a first order formed by the set of elements. It was established around them a set of relationships that allow identification of relationships which typically repeat as a constant. 
Understanding the territorial syntax, as a result of the combination and interaction of the various main elements identified above.

In that sense, the primary elements are not really the most important thing in these cases, but the relationship between them. It is about understanding how to configure and interact with each other, and how they feel and express these relationships.

This issue is contrary to the consideration of individual elements. The student knows eventually that these relationships allow consideration of a territorial system, a landscape unit.

The definition of the forms resulting from this combination.

After having defined these formal systems such as landscape units, the resulting set of forms must provide a first global perception of the territory under study. This vision must come previously reinforced by the existence of different transition elements. This transition will depend on the relative position origin of the linkage to perform functions and their appearance over time. The transition elements are also subject to possible classification.

Global understanding of the territory as the resulting object of a complex process. In this process, the man appears as an actor in this transformation slowly but steadily.

We present in this chapter two versions of territorial representation. The first example draws on Carnoedo parish in the municipality of Sada (La Coruña) - Spain).This municipality reflects the characteristics of any of the lands that make up the Galician Rias Altas with significant housing density ${ }^{20}$. The landscape shows a remarkable territorial complexity from a continuous process of anthropization ${ }^{21}$.(fig. 33)

It was therefore a small-scale agrarian context, typical of the locale of Galicia and, by extension, of the ledge Northwest of the Iberian Peninsula. On that occasion the methodology used was based on hand territorial redraw at scale $1 / 1000$. The final layout is presented at scale $1 / 2000$. The study aimed, among other objectives, the definition of the primary territorial elements analyzed.(fig. 30)

Among these elements relate the terraces and Agras as territorial configurator completed by a road structure which allows high permeability. In line with both elements property system and the capillary structure of the water were analyzed.

Both elements are vital to understand the agricultural cadastre reflecting tensions between terraces, Agras, roads and water mains. (fig. 31) Last step of this analysis will refer constructed elements, superimposed to territorial building. Every stage was following a strong relationship to the outside. In the beginning there were not architectural typologies but dialogue between territory and built through the various modes of occupation on the parcel were not absent. (fig. 32)

\footnotetext{
${ }^{20}$ Available data for this area in 2011 defined a density of 540.92 inhabitants $/ \mathrm{km}^{2}$

${ }^{21}$ Technical term from the Italian (antropizzazione) that relates the work of transforming the natural environment applied by humans to meet their needs and improve quality of life, often at the expense of the ecological conditions
} 


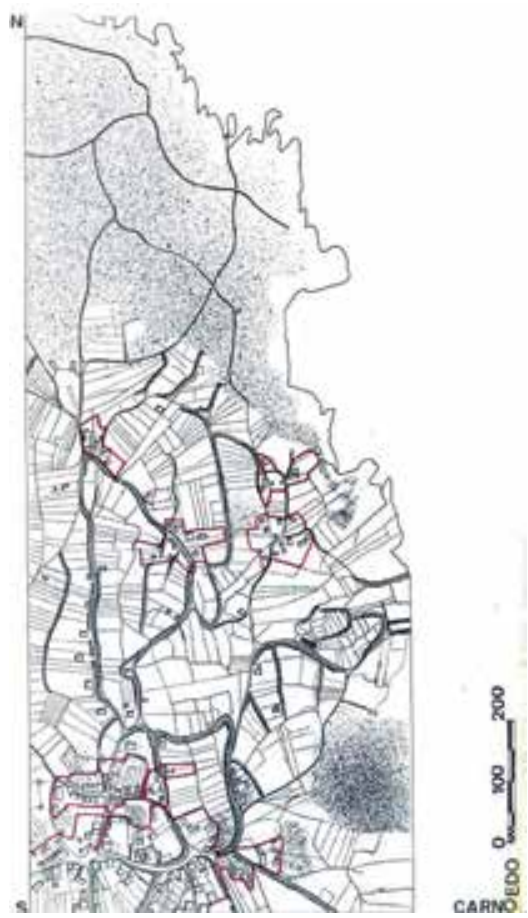

Figure 33. Whole graphic representation, with the different definition of the places.

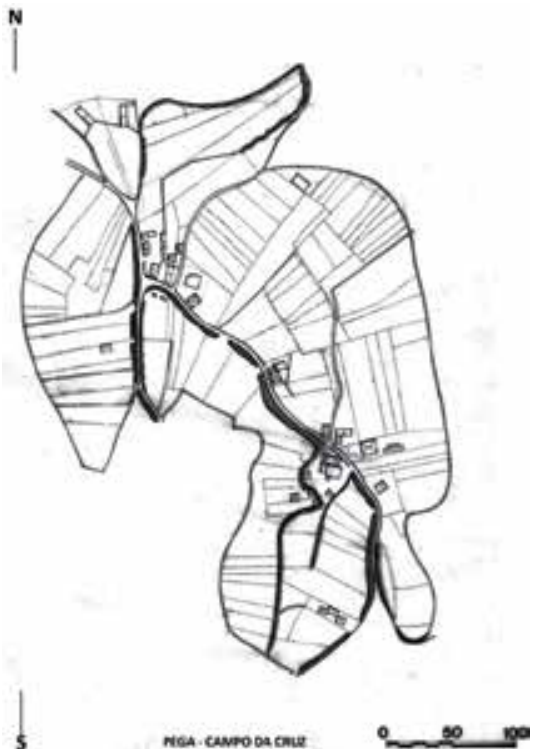

Figure 34. Campo da Cruz place.Carnoedo

Thus, it was established a direct link between the territory and its observer. After the location of certain primary elements, such as formal constants appearing in shaping the territory, one of these areas was defined, such as landscape unit to study.(fig 34) 
The choice was made based on the topography and the existence of Agras. (fig 33) Thus, the student approached the overall understanding of the territory where the trinomial, Sea, Agra, Mount summarized to territorial complexity. Road structure converged on it. It was the three scales running along only one path: The urban scale, as the road assumed his relationship with Sada; the agricultural scale, when the road was associated with the various agras and plots that make up the landscape around the different places of the Carnoedo parish and finally the scale when the extension of this road towards formalizing the corredoiras $^{22}$ going to communal forest area.

Previous experience served as a reference for the development of the work done thirty years later ${ }^{23}$. This territorial representation is about Arrestim and Ponte Nova (Igreja) sites, in the parish of Bárrio - Ponte de Lima,(fig. 35) a Portuguese town near the border between Galicia and Alto Minho. The morphology responds to the characteristics already referred to the ledge northwestern Iberian Peninsula. In this case it is a more rugged topography, predominantly terraced structure with "socalco"24 as a structuring element for the construction of the territory.

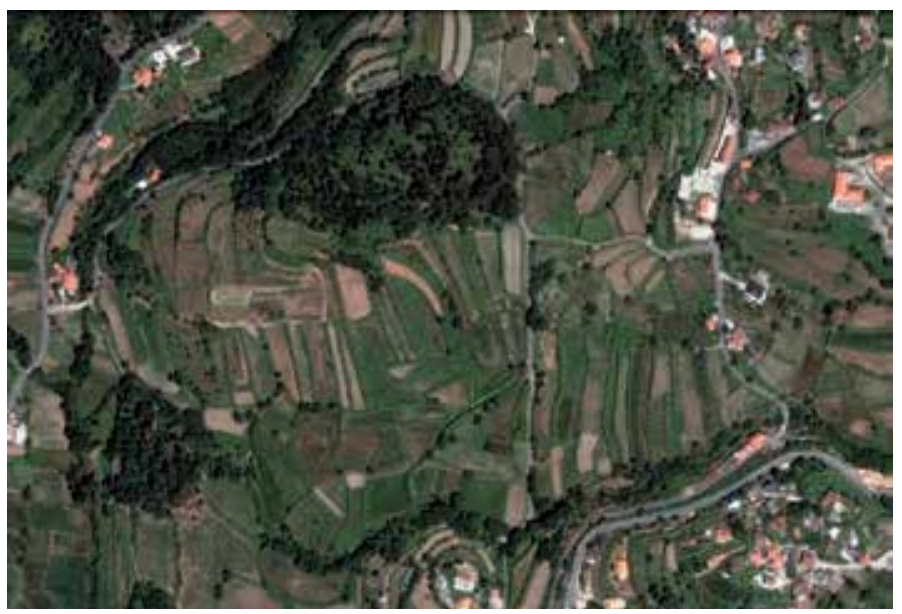

Figure 35. Bárrio-Ponte de Lima.Portugal from Google-earth

\footnotetext{
${ }^{22}$ Galician term refers specifically to the cart path.

${ }^{23}$ Work done by students Rachel Campos and Rogério Soares under supervision of the author of this article

${ }^{24}$ Socalco is the Portuguese name for the terraces.
} 


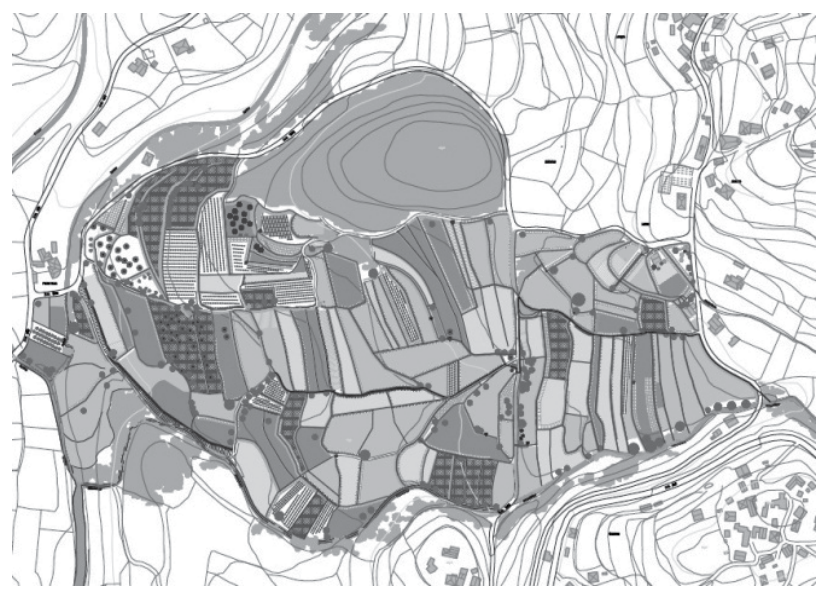

Figure 36. CAD graphical representation about Bárrio-Ponte de Lima. Portugal

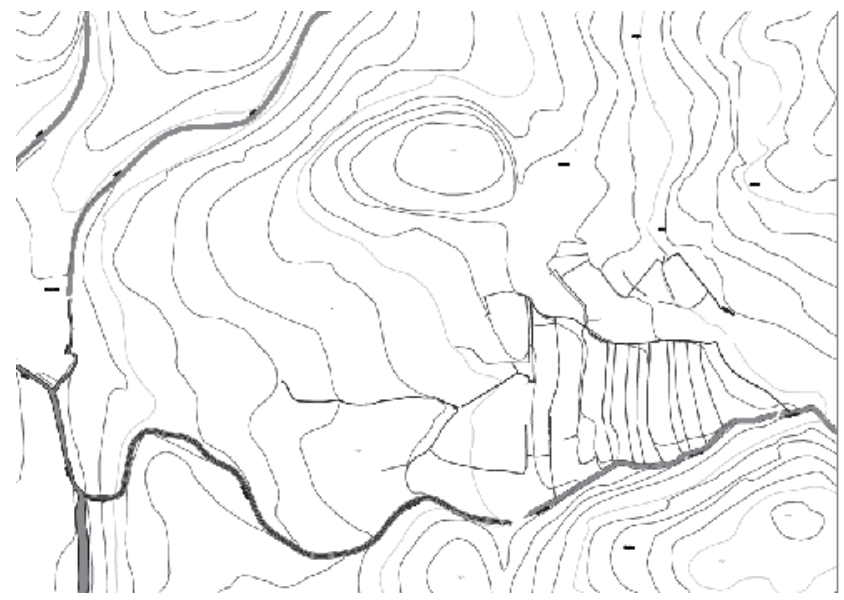

Figure 37. Topography and water structures

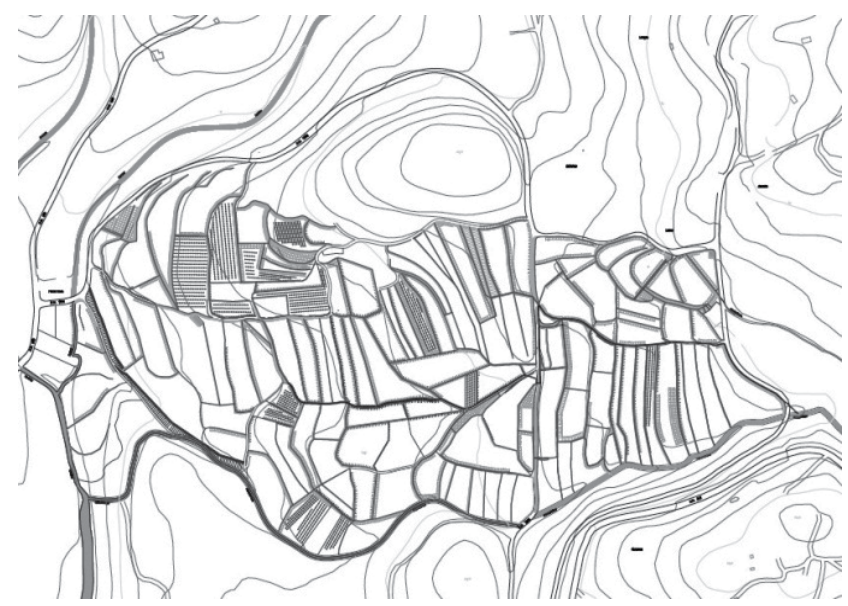

Figure 38. Primary elements into Bárrio. 


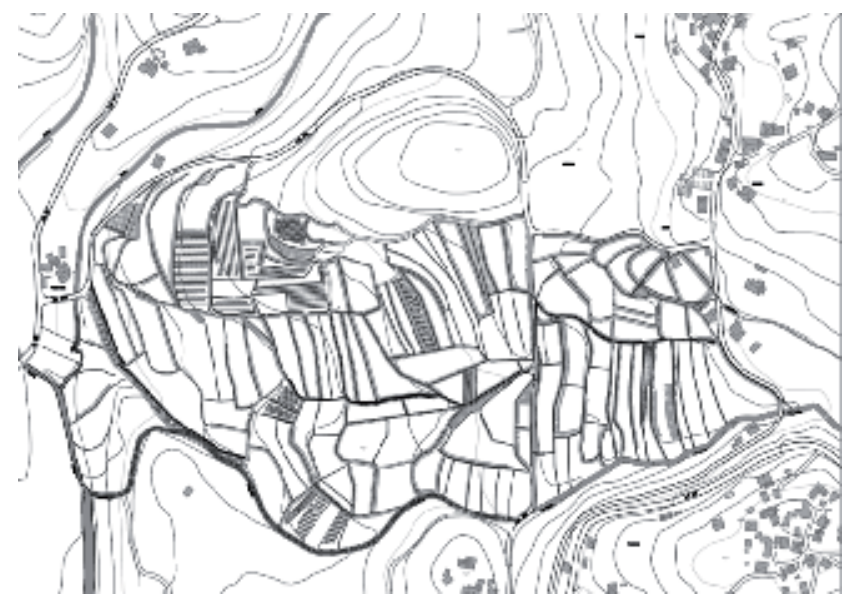

Figure 39. Topography, water structures, terraces and built elements

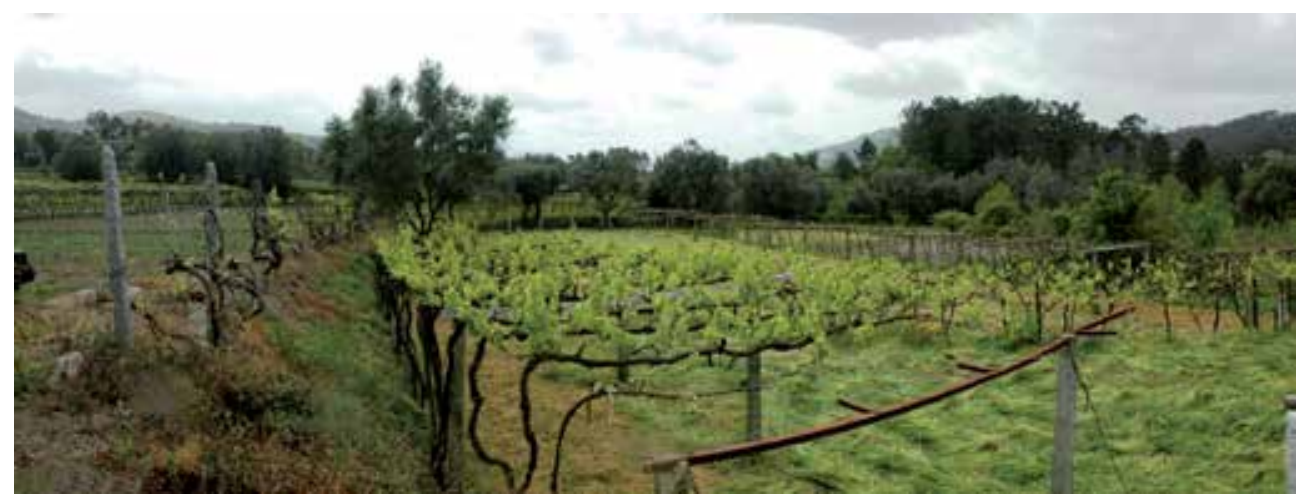

Figure 40. Socalco and ramada, as primary elements in Bárrio.

Road's scheme and water mains interact resulting in an agricultural system where wine architecture, in its various types, define the dominant landscape. The case study prevents the study of the phenomena of construction in the area in a first phase. It was only in the characterization influence of agricultural land, avoiding interference built elements. The following objectives were defined:

a. The student's approach to the territorial level, where it is expected he will develop his future professional career.

b. The identification and subsequent analysis of territorial primary elements, ie elements that make up a presence and / or lack of the territory, in turn distributed in different layers or levels of information.

c. The knowledge of syntax territorial modes how territorial these primary elements already identified are interrelated, and the results from these interactions.

d. The transdisciplinary understanding of relationships existing in this territory allowed keeping certain territorial structure till now.

e. The development process of the project. It was based on the knowledge of the scale of action and its location, as a direct consequence of the previous work. 


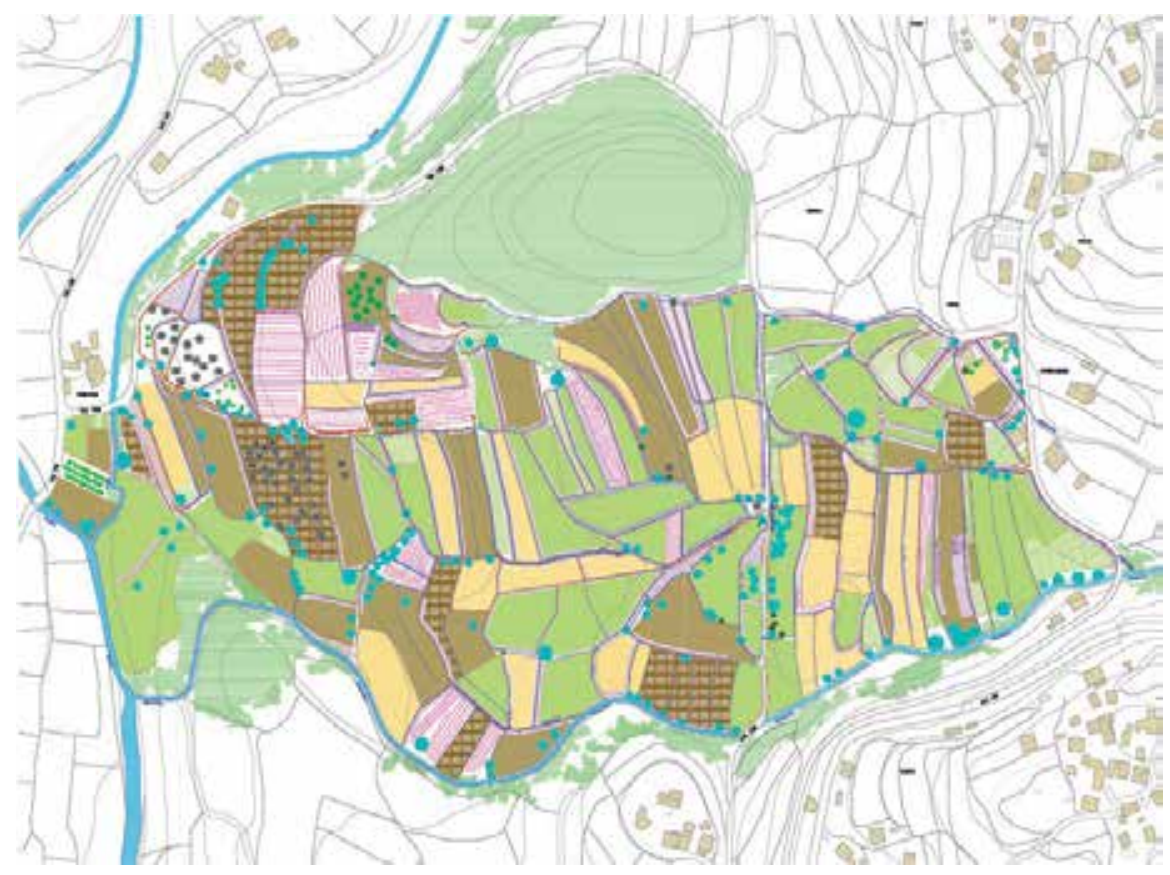

Figure 41. Whole graphical representation for Bárrio.

The development of the process took place as follows:

We started working on the municipality digital format as graphic bases at $1 / 5000$. Several visits to the site helped define at first the landscape "unit" study, with the support of existing aerial photography, always based on following conditions:

- Topography, existing land parcel boundaries

- Water structure, and natural and artificial joint are various levadas and plots affected by irrigation.(fig. 42)

- Road infrastructure linking all the above items.

- Identification of the primary elements of the study area territorial configurators

Based on the foregoing, we defined a perimeter defined by paths that are directed to the lowest point defined by the course of the riverbank Labruja ${ }^{25}$ in at Ponte Nova. So, we proceeded to the individual recognition of the terrain and extensive data collection unit and considered. This confirmed the structuring role of architectures socalcos and wine in its various variants studied before. ${ }^{[9]}$ It was also noted the role delineation of water structures, both natural, formed by the banks of San Gens, Labruja and Mestre, and the artificial one. This project, integrating the Levada do Caneiro, do Tested, do run it and do Casal, developed in previous decades to proceed to irrigate the plots studied.

The analysis took advantage of the characteristics of the CAD application to designate layers for the different levels of information.

${ }^{25}$ Labruja is the main left stream of Lima river. (Limia, while running through galician lands) 
This issue is an improvement with respect to previous work, given the correction facilities introduced in the process and the ability to interrelate two or more levels of information mechanically.

Given these results, it seems logical to make a comparative study of the two processes.

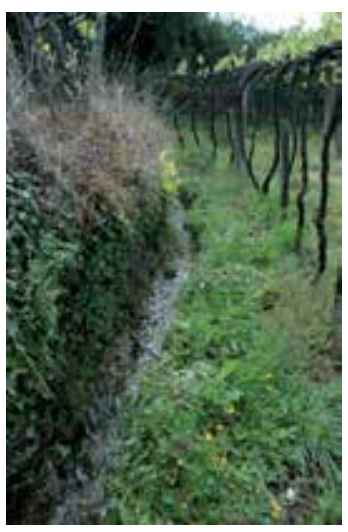

Figure 42. Levada in Bárrio-Ponte de Lima . Portugal

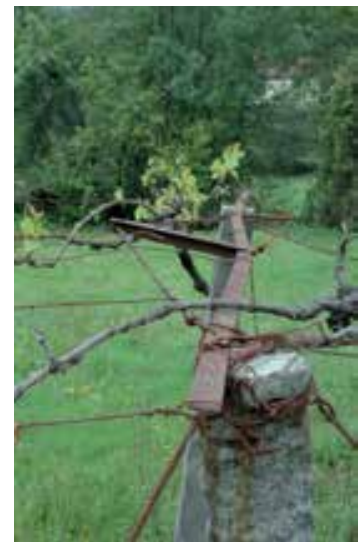

Figure 43. Detail of ramada in Bárrio-Ponte de Lima. Portugal

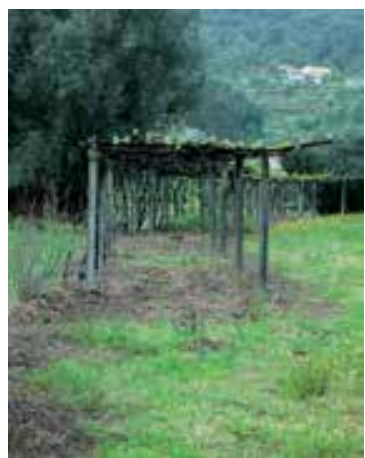

Figure 44. Ramadas in Bárrio-Ponte de Lima.Portugal 
1. The use of CAD in the redrawing of the territory has the following advantages:

a. Those are known in CAD drawing, its versatility and its ability to copy repetitive processes, and choose from several editing modes mechanically.

b. Assignment to the respective levels of information layers, leading to the possibility of establishing relations between the various levels of information in a direct and immediate.

c. The ability to reach scales of analysis hardly achievable in manual drafting

2. On the contrary, the use of these computer applications led to a series of difficulties or disadvantages with regard to analysis or manually territorial redrawing:

a. The interposition of the computer between the territorial redraw and final expression. It is a mechanical device incapable of interpreting by itself.

b. Failure to express the author's subjective attitudes into the formal territorial analysis, reducing the freshness of the final result.

c. The inability to ensure entirely personal processes. Redrawing can be the result of a joint action that disrupts the production of educational goals facing the approach to architectural design. Only except personal commitment of the students goals would be achieved.

d. The lack of agility in non mechanical processes was confirmed, where the manual process was more advantageous.

\section{Conclusions}

We can define a set of initial findings in all this work:

1. The conventional territorial representation involves a process that necessarily reduces the provided information.

2. This reduction is an important obstacle to the development of territorial project.

3. This problem becomes more complex in the small and medium scales.

4. Solving such problems can be obtained through an individual complementary survey work. Intangible items must be included somehow in this work.

5. The manual or computerized surveys methods developed according this methodology are equally valid, with specificities.

6. The manual method allows a greater voice, especially when talking about qualitative aspects of the territory, but is slower. This method allows rapid consideration of the interactions between the various layers of information.

7. The computer method loses freshness of expression, but is very effective as far as regards interaction layers.

8. In any of the cases we have studied, the method allows a very efficient approach to define the guidelines of design.

9. The method reveals its effectiveness for small and medium scale. In these cases the dimensions have ranged $27,39 \mathrm{~km}^{2}$ for Carnoedo and $5,41 \mathrm{~km}^{2}$ for Bárrio.

10. The limitations come from the spent time in performing a conventional project planning, making it difficult to extrapolate to higher dimensions. 


\section{Author details}

José Manuel Pagés Madrigal

Faculty of Architectural Engineering, Beirut Arab University, Lebanon

\section{Acknowledgement}

It is only fair to acknowledge the work done by my former students, architects today, Rui Pedro Silva, Raquel Campos and Rogério Soares that between 2009 and 2012 developed the work that became the basis for preparing this chapter.

Pictures are from the author of this cahpter, except other indications

\section{References}

[1] Porter N. editor . Webster's Revised Unabridged Dictionary. G \& C. Merriam Co.;1913.

[2] Mücher, C.A.,Bunce, R.G.H.,Jongman, R.H.G.,Klijn, J.A.,Koomen, A.J.M.,Metzger, M.J.,Wascher, D.M. Identification and characterisation of environments and landscapes in Europe (2003)Wageningen,Alterra, Green World research. Alterra Report, 832

[3] TECNALIA et altri, European Land Use Patterns. Applied Research 2013/1/8. Interim Report I Version 3rd/June/2011

[4] Pagés Madrigal,J.M. Terra Água e Homem. bases para um projecto territorial. Leción para prova de agregação.University Fernando Pessoa,2012. http://hdl.handle.net/10284/3249 accessed 12 december 2012

[5] Alexander, Ch.. A Pattern Language: Towns, Buildings, Construction. Oxford University Press, USA;1977

[6] http://www.designingsocialinterfaces.com/patterns.wiki/index.php?title=Main_Page, accessed $12^{\text {th }} / 12 / 2012$

[7] Picon, A. What Has Happened to Territory?. Architectural Design, 80:p 94-99. ;2010

[8] León G. M.C. Reconocimiento territorial y obra cartográfica de los ingenieros militares en Nueva España (segunda mitad del siglo XVIII) .Scripta nova revista electrónica de geografía y ciencias sociales universidad de Barcelona Vol. X, núm. 218 (55), 1 de agosto de 2006 . http://www.ub.edu/geocrit/sn/sn-218-55.htm

[9] Pagés Madrigal, J. M \& Malafaya Baptista,Ff. Territórios como laboratórios. Territories as Laboratories Ed List Trento.2011 


\title{
Possibility to Employ AHP as a Multi-Criteria Decision Making Method in Landscape Planning Initiatives
}

\author{
Murat Akten \\ Additional information is available at the end of the chapter
}

http://dx.doi.org/10.5772/55885

\section{Introduction}

For Ersoy (2006), planning is a process set out to solve the problem. During planning, how and within what structural relationships this problem and/or problems have appeared, and how they can be resolved through interventions is analysed. A conceptual overview of plan and planning reveals that transformation of an intellectual model into a material design creates the "plan", and the entirety of the implementing process for realizing the plan constitutes "planning" (Akay, 2009). Planning is an all-round holistic action; contains social, economical, political, psychological, anthropological and technological factors; and is a multi-disciplinary, normative, democratic occupation and a professional engagement encouraging involvement and seeking action paths for options (Bulut and Atabeyoğlu, 2010). In brief, planning is deciding on the method for utilizing limited natural and cultural resources with a view to assuring and extending life quality (economical, social, psychological) of a country on national scale (Akay, 2009).

Parameters such as ensuring sustainable development, safeguarding natural resources, costeffective nature of investments during the incorporation and operation process, stripping catastrophic nature of acts of God, availability to enhance types preferred in land utilization, etc. represent the generally disregarded, yet crucially significant facts in land utilization practices. Negligences and wrong practices along these issues lead to economical and social harm on individual and national scale, and unrecoverable loss of natural resources and cultural heritage. To avoid such losses, need to Physical Planning initiatives in depth of physical geography and relying upon ecological principles comes to sight (Turoğlu, 2005).

Sustainable use of natural and cultural resources, in other words, seating decisions for physical planning upon an ecologically acceptable base progressively gain weight in spatial 
planning strategies today. In this sense, "landscape planning concept and practices" among other spatial planning strategies come to the forefront with its mediating and guiding attitude (Ayhan and Hepcan, 2009).

\subsection{Landscape planning}

Countries plan and reflect to the physical space their socio-economical decisions on national, regional and local scale for the development and enhancement of their societies. However, decisions for land utilization assuming various functions regarding residential areas influence economical actions in particular fields, and such actions consequentially induce adverse impacts in physical space as well as natural biotopes rising thereon such as the topography, soil, flora and fauna, and increasingly the ecological composition, culminating in environmental issues. Examining the topic from the standpoint of the benefit-cost theory reveals that, such decisions and practices yielding socio-economical benefits in the short run call forth adverse ecological costs driven by fading away natural assets with implications upon the whole society in the long run (Atabay, 1991).

According to Buchwald for the sake of preserving the efficiency and attributes of the nature, enhancing the skills for utilizing natural resources, the natural herbal and animal wealth, and human recreation in nature, landscape should be safeguarded within a sustainable framework. Landscape planning takes the following measures to assure the realization of these objectives: the optimal ecological-biological, visual composition and wealth of landscape is preserved and enhanced; cross-complementary zones precious for their ecological features are incorporated into the protected zones system, and plans suggesting optimal uses in ecological and visual terms where space utilization will have minimum impact on other uses are elaborated (Uzun, 2003).

The European Landscape Convention; describes "Landscape Planning" concept as the set of forward-looking actions launched to promote the value of, improve or construct the landscape (Anonymous, 2000). According to Başal (1998), safeguarding the nature and the land we live upon, availing of its existing potential in maximum, flourishing and then offering it to the benefit of future generations is only possible by exploring and scrutinizing the available use options that do not conflict with each other and implementing them based on a particular plan as buttressed by a consistent process maintenance and audit. Landscape planning targets, with reference to the idea favouring the flourishing of human-nature interaction as aligned to the balance between the process of protection and use, the construction of an environment promising healthy, free and high-quality life conditions to the society and its members (Benliay and Yildırım, 2012). According to Ahern (2002), landscape planning is aimed at protecting rare, scarce and unique resources; avoiding the hazards; conserving limited resources through a controlled use; and identifying areas suiting development actions (Ayhan and Hepcan, 2009).

Analysing the definitions suggested by Başal, Buchwald and the European Landscape Convention reveals that some key concepts are stressed for landscape planning, and objectives are put forward across such concepts. The priority in this process is attached to 
putting forward the balance between protection and use, analysing the ecological features, assessing the uses and therefore the ecological relationships, and then identifying the actions and construction of the environment that people can avail of to the utmost, yet that induces minimal damage to other organisms.

For Lewis (1964), McHarg, (1967), Buchwald et al., (1973), Hills (1976) and Kiemstedt, (1967), landscape planning is an instrument allowing to build up an efficient balance between human and nature in terms of protection and development. Landscape planning is aimed at addressing the interactive pattern between natural and cultural resources and the people utilizing them followed by incorporation of the same into the physical planning process; minimizing adverse impacts induced by environmental conflicts through the optimum land utilization approach, and supervising zoning initiatives to ensure optimum and proper maintenance of landscapes (Yüksel, 2003).

Landscape planning does not merely constitute a special planning for a landscape arrangement in rural or urban space, but represents the process of planning the measures for flourishing, conserving and maintaining both spaces as per the laws on ecology (Köseoğlu, 1982).

The fields of action for landscape planning and landscape management target securing sustainably the balance between protection and use throughout the human-nature interaction. Planning practices where the human-nature relationships and interactions are not properly analysed and assessed are among major factors that trigger environment issues (Şahin, 2009). The demonstrated understanding in the last century is that respecting a particular system and safeguarding the balance constitutes the condition precedent for the sustainability of life (clean and accessible water, air and food) in relationships with different systems. Natural resources that human needs to sustain life are limited to the capacity of the recycling mechanisms of those resources. Optimally utilizing the available resources, respecting the rights of future generations to utilize these resources and ensuring the sustainability of natural systems is a quite tough yet inevitable approach. What makes this approach tough is associated with the requirement to handle natural systems such that no damage should be induced to them throughout the entire range spanning from the initial phase of planning up to the construction, use, post-use and depletion phase (Çetinkaya, 2012).

To secure sustainable development, enhancing the environmental strategy, establishing a hierarchy of priorities for environment, and building efficient environmental policies in making decisions for investment are also needed besides economical and social policies.

In resolving the environmental issues, an ecology-based identification is needed with a view to setting up a hierarchy in the sustainable management of natural resources in relation to the type of solutions to be produced at the lower and upper scale. This is indeed "ecological land classification" adopted by myriad of European countries under different names including the bioregion, ecoregion, ecosystem classification, etc. Ecological land classification is a hierarchic classification of the space ranging from upper scale down to the lower scale. Setting up such a hierarchy owes to the assessment of different measures from 
the upper scale down to the lower scale. The art of landscape ecology gaining a forward progress over the last years hierarchically divides landscape into various sub sections, and allows to make distinct comments on the structure, function and variation of landscape, and to identify zones in the sustainable ecological management (Uzun, 2003).

Landscape planning methods have greatly been enhanced in the course of time. Despite this however, like in all planning efforts, the planner should choose the most appropriate one among a plurality of distinct options impacted by a great number of factors in the landscape planning process. For the sake of obtaining a healthy decision support through a participatory approach, decision makers should compare and assess alternative land allocation forms according to the preferences, demands and expectations of the public, benefit-interest groups and sectoral specialists. Hence, alternative management strategies should be assessed in a multi-criteria pattern according to social, economical and environmental criteria through a participatory approach, and the most appropriate alternative should be chosen.

Such decision-making process may be quiet complicated some time, therefore multi-criteria decision making methods are employed to minimize potential errors.

\section{Multi-criteria decision making methods}

Key issue of the decision-making process is to choose the best alternative out of the alternatives set assessed by means of criteria competing and conflicting with each other (Saaty, 1986). Decision-making issue is typically choosing the most appropriate alternative out of the options set according to at least one objective or criterion. In this sense, if there is only one possible way to go, in other words if there is no possibility to make a choice, then there is no decision-making (Ünal, 2010).

Decision making is to identify and choose the alternatives that would deliver the desired condition. Decision is only the outcome of particular processes.

It is observed that decision highlights distinct aspects including the choosing action, alternatives conflicting with each other, and the process. From this point of view, we can define decision-making as the process of choosing the most appropriate one among alternatives conflicting with each other to satisfy a particular objective (Ünal 2010).

Decision making and planning concepts require the holistic perception of objectives, targets and strategies within a systematic understanding.

There are various methods, analyses and techniques employed to make informed decisions on case basis as long as the paths to follow for attaining these objectives, data sources, IT methods and other similar conditions vary.

Capability to make efficient decisions for directors owes to the use of scientific methods that can concomitantly assess myriad of qualitative and quantitative factors in the decisionmaking process. At the forefront of the methods that may be employed in this process is the 
Multi-Criteria Decision Making method. The literature involves many studies where MultiCriteria Decision Making methods are employed.

In the traditional multi-criteria decision making methods, final assessment of criteria and alternatives is expressed with real numbers and decision is made based on the customary "alternative fully satisfies the criteria or not" rationale. However, due to the complexity of the real life and our limited capacity of perception, there are various objects that we are unable to comprehend in absolute terms which can only be assessed through subjective opinions. Therefore, to cope with decision-making for complex objects, the general characteristic feature of the object (e.g. beauty) is handled as a fuzzy attribute, and then a set of attributes is defined where each attribute corresponds to a single criterion. Hence, while establishing the alternatives, the decision maker employs linguistic assets involving uncertainty based on his/her personal opinions which may be represented by fuzzy sets. Once such type of alternatives produced by the decision maker are assessed in a fully objective manner against the existing criteria, they are sorted and then the most appropriate one is identified, leading to the optimum solution (Eminov and Ballı, 2004).

It is possible to categorize by objective the huge bulk of multi-dimensional decision-making methods listed as decision-making methods in the literature in a plurality of forms based on various criteria such as optimization-consistency, reduction-classification, mathematicsstatistics, etc. (Halaç, 2001). Accordingly, classification of multi-dimensional decisionmaking methods is shown in Table 1.

In case some sub-systems with logical ties between, yet considered different from each other are handled in the decision-making process, the objectives of each sub system should be consistent with the objectives of the master system (macro objectives), in other words, they should be aligned to inflexible objectives. In such a case, we can talk about consistency, and methods employed for this purpose are called Methods Aimed at Consistency. On the other hand, there are also planning methods where consistency is replaced by accessible and proper objectives. And these methods are called Methods Aimed at Optimization. Data Reduction Methods represent the methods that describe the variation of the dataset containing variables in $\mathrm{p}$ number, and aimed at defining the data structure through a fewer number of variables $(k<p)$ with no cross correlation. Classification Methods are the methods developed to facilitate to the actions for establishing prototype sets (groups, classes) for structures with unknown population characteristics, and further to assign new units to the preliminarily defined groups. Furthermore, most significant methods out of a vast set, each with a distinctive intended use, are discussed under the heading "Other Methods".

There are also some other decision-making techniques in addition to those covered by Table 1. However, Table 1 encompasses techniques that are commonly employed for various objectives. On the other hand, given the intended use and dominant properties of some techniques in Table 1, it is understood that they may be involved in multiple classifications. For instance, some techniques aimed at consistency (PERT and CPM, Input-Output technique, etc.) may also be used for optimization purposes as well through sensitivity analyses and dynamic analyses. To display this situation, one or more of the numbers from 


\begin{tabular}{|c|c|}
\hline BY INTENDED USE METHODS & DECISION-MAKING TECHNIQUES \\
\hline $\begin{array}{l}\text { 1. METHODS AIMED AT } \\
\text { CONSISTENCY }\end{array}$ & 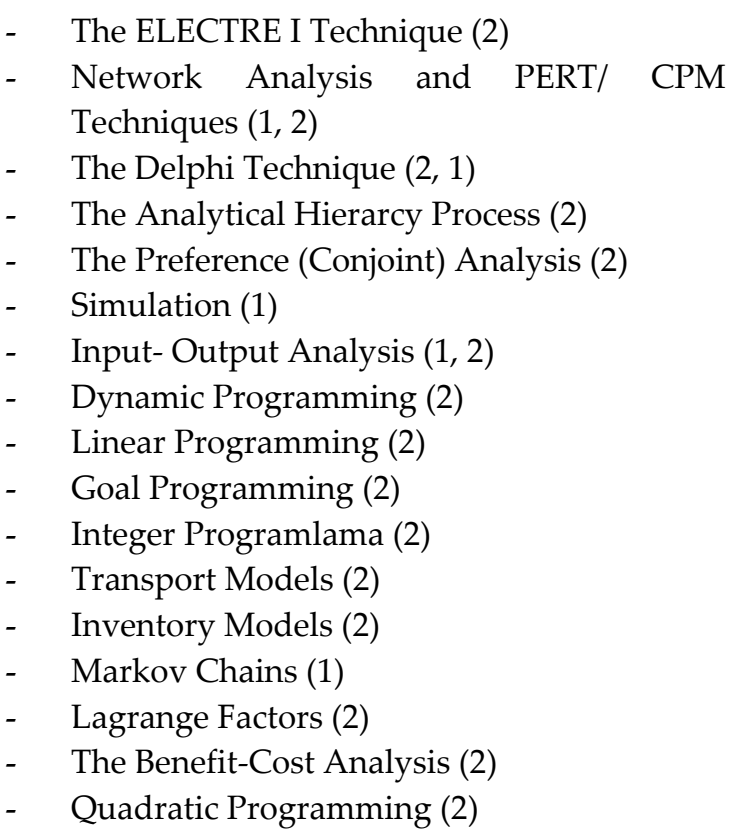 \\
\hline $\begin{array}{l}\text { 3. METHODS AIMED AT DATA } \\
\text { REDUCTION }\end{array}$ & \multirow{3}{*}{$\begin{array}{ll}\text { - } & \text { Factor Analysis }(3,4) \\
\text { - } & \text { Correspondence Analysis (3) } \\
\text { - } & \text { Discriminant Analysis (4) } \\
\text { - } & \text { Clustering Analysis (4) } \\
\text { - } & \text { Multi-Dimensional Scaling Analysis }(3,4) \\
\text { - } & \text { Multi-Dimensional Variance Analysis (5) } \\
- & \text { Canonical Correlation Analysis (5) }\end{array}$} \\
\hline $\begin{array}{l}\text { 4. METHODS AIMED AT } \\
\text { CLASSIFICATION }\end{array}$ & \\
\hline $\begin{array}{l}\text { 5. OTHER METHODS } \\
\text { (such as surveying the dependence } \\
\text { structure, building hypotheses and } \\
\text { hypothesis tests) }\end{array}$ & \\
\hline
\end{tabular}

$\left.{ }^{*}\right)$ Figures in parentheses denote the dominant intended use of the methods.

Table 1. Classification of Multi-Criteria Decision-Making Methods.

1 to 5 denoting the methodological class in which the technique has been involved according to its intended use have been supplemented to each technique in Table 1.

The decision analysis deals with using a rational process for choosing the best out of the alternatives. How "ideal" a chosen alternative is depends on the quality of the data employed to define the decision case. In this case, the decision-making process may be involved in one of the three classes below (Taha, 2000):

a. Decision-making under certainty where data are deterministically known. 
b. Decision-making under the risk where the data may be defined through the breakdowns of possibility.

c. Decision-making under uncertainty where the data cannot be assigned to relative weights representing the level of relationship in the decision process.

While data can be defined well under certainty, the data is fuzzy under uncertainty. Hence, decision-making under the risk is the "half-way" case.

In this section, the Analytical Hierarchical Process approach, one of the abovementioned models of decision-making under certainty will be discussed.

\section{Decision-making under certainty}

Linear programming methods is an example to decision-making under certainty. These methods are only suitable for cases that may be associated with mathematical linear functions where alternatives are well defined among each other. This section brings a different approach to cases where thoughts, ideas, senses and ambitions are measured such that decision alternatives are listed through a numerical scale. This approach is known as the Analytical Hierarchy Process (Taha, 2000).

\subsection{The analytical hierarchy process}

The Analytical Hierarchy Process (AHP) is one of the multi-criteria decision-making methods defined by Thomas L. Saaty (1977). The AHS method imitates the mental action process for differentiating the groups intrinsically present in the human. The core essence of AHS is concept fragmentation and synthesis. Once the problem is fragmented into tiny integral bits, the system identifies the cross-significance of two elements compared as well as the magnitude of such significance. This system plays a critical role in human perception, concept formation, classification of examples and logical judgement (Cengiz, 2003).

It is observed that the AHS method is commonly employed to solve the complex multicriteria decision-making problems. As a matter of fact, it is reported that, the process has been applied, since the date it was developed, to various decision-making problems in various fields including economy, planning, energy policies, resource allocation, health, resolution of conflicts, project selection, marketing, computer technology, budget allocation, accounting training, sociology, architecture and many else. Furthermore, there are examples as to the use of the method in complex environmental decision analyses too.

The AHS method is primarily a theory of measurement based on priority values yielded by the paired comparison of the elements. This method allows to consider both quantitative (objective) and qualitative (subjective) factors in choosing the best alternative. Thanks to its features such as simplicity, flexibility, ease of use and seamless interpretation demonstrated in the analysis of complex decision problems, the method seems to have a broad field of use in distinctive decision problems. In its current form, the method is interesting as one of the most popular multi-criteria decision-making methodologies today (Y1lmaz, 1999). 
The following steps are followed to solve a decision-making problem by means of the AHS method (Göksu and Güngör, 2008).

Step 1: A decision hierarchy is formed with the decision elements such that the decisionmaking problem is identified.

Step 2: The decision elements are compared on a pairwise basis between each other to yield a data set. While making pairwise comparisons, it is searched which of the two elements is more important and at what degree in decision making.

Step 3: The relative priority (significance, weight) values of decision elements is estimated by means of the eigenvalue method.

Step 4: Based on the relative priority of decision elements, general priority and sequence of decision alternatives is obtained.

\section{Step 1: Hierarchical Model}

A complex system with many common characteristics, yet containing myriad of elements that are hard to concurrently consider can be simplified and more conveniently analysed by splitting them into sub systems. In this respect, by arranging the system in sequenced levels where each hosts different number of elements or factors, hierarchies are obtained. These hierarchies are formed based on the assumption that system elements can be split into discrete sets. Therefore, a rational and systematic solution can be reached for the problems by assessing all factors with potential relevance.

The process of setting up the hierarchic model starts with placing the general objective of the problem on the top level. Then, criteria to be employed in the assessment of alternatives are identified, and arranged in a hierarchic layout. In this hierarchy, a level consisting of the criteria and the sub level(s) into which each criterion is split into subcriteria are found. The decision alternatives of the problem are placed on the bottommost level of the hierarchy, so the hierarchy formation process is completed. Finally, the topmost level and the bottommost level of the hierarchy is associated with each other through intermediate levels (Yilmaz, 2004). Factors at the same level are defined independently from each other (Ejder, 2000).

Creation of the decision hierarchy would vary based on the number of hierarchic levels, the complexity of the problem, and the depth of detail needed by the person undertaking the analyses to solve the problem (Y1lmaz, 1999).

\section{Step 2: Determining Priority Values}

Once the decision hierarchy is created, relative significance or the priority value of each element (criteria, sub-criteria, alternatives, etc.) at different levels of the hierarchy should be identified. In the AHS method, first pairwise comparisons are performed for this purpose.

Pairwise Comparisons: An element at any level is the relative element of the immediately upper level. The degree of impact induced by such relative elements in the immediately 
upper element is compared in pairs. Let's say $C_{1}, C_{2}, \ldots \ldots . . . . C_{n}$ represents elements at any level, and let's say $W_{1}, W_{2}, \ldots \ldots \ldots W_{n}$ is the priority of impact (weight) induced by that element in the upper element to which they are linked, where $W_{i}$, reflects the impact power/weight of $C_{i}$ on its own relative upper element. To create the weight vector $\left(\mathrm{W}_{\mathrm{i}}\right)$, first $\mathrm{n}$ number of elements should be compared in pairs in terms of their impact on the respective upper element (Yılmaz, 2004).

In these pairwise comparisons; by asking questions like "what element is preferred more (is more significant) when element 1 and element 2 are compared to the respective upper element?" and "what is degree of preference placed in favour of the more preferred element compared to the other?", the decision maker is prompted to make a judgement.

The results of these comparisons are arranged in matrix form. The prioritization scale developed by Saaty (1998) used to convert the results of such pairwise comparisons in the matrix into numerical values is presented in Table 2.

The table shows numerical values suggested for verbal preferences expressed by the person undertaking the pairwise comparisons. This scale is employed to construct the pairwise comparisons matrix.

\begin{tabular}{llc}
\hline $\begin{array}{c}\text { Judgement for } \\
\text { Verbal Preference }\end{array}$ & \multicolumn{1}{c}{ Description } & $\begin{array}{c}\text { Numerical } \\
\text { Value }\end{array}$ \\
\hline Equal Preference & $\begin{array}{l}\text { Two activities make equal contributions to the } \\
\text { objective. } \\
\text { Experience or judgement places partial preference in } \\
\text { favour of one action to the other } \\
\text { Experience or judgement places high preference in } \\
\text { favour of one action to the other }\end{array}$ & 3 \\
Very High Preference & $\begin{array}{l}\text { One action is highly preferred compared to the other } \\
\text { and its dominance is conspicuous in practice. }\end{array}$ & 7 \\
Absolute Preference & $\begin{array}{l}\text { Proofs relating to the preference of an action to the } \\
\text { other are greatly reliable }\end{array}$ & 9 \\
Average Values & $\begin{array}{l}\text { Values falling between two successive judgements to } \\
\text { be used when compromise is necessary } \\
\text { When an element is compared to the other, one of the } \\
\text { values above is assigned. When the second element is } \\
\text { compared to the first, it gains an opposite value. }\end{array}$ & $2,6,8$ \\
\hline
\end{tabular}

Table 2. The Pairwise Comparisons Scale Used for Preferences in the AHS Method (Saaty, 1980). 
Pairwise Comparisons Matrix: Values obtained from pairwise comparisons are placed in a matrix called "pairwise comparisons matrix". Hence, a matrix like in (1) is obtained (Yilmaz, 2004):

$$
A=\left[\begin{array}{cccccc}
a_{11} & a_{12} & \cdot & \cdot & \cdot & a_{1 n} \\
a_{21} & a_{22} & \cdot & \cdot & \cdot & a_{2 n} \\
\cdot & \cdot & \cdot & \cdot & \cdot & \cdot \\
\cdot & \cdot & \cdot & \cdot & \cdot & \cdot \\
\cdot & \cdot & \cdot & \cdot & \cdot & \cdot \\
a_{n 1} & a_{n 2} & \cdot & \cdot & \cdot & a_{n n}
\end{array}\right]
$$

where;

$\mathrm{A}=$ Pairwise comparisons matrix, and

$\mathrm{a}_{\mathrm{ij}}=$ the significance of the $\mathrm{i}^{\text {th }}$ element to the $\mathrm{j}^{\text {th }}$ element compared to the upper element in the hierarchy.

The values of the pairwise comparison matrix satisfy the equation in (2) and such equation is called "reciprocity function" (Saaty, 1989).

$$
a_{j i}=\frac{1}{a_{i j}}
$$

For the pairwise comparisons matrix to be fully consistent, it should satisfy the condition in (3).

$$
a_{i k}=a_{i j} a_{j k}(i, j, k=1,2, \ldots, n)
$$

To satisfy this equation is quite difficult due to the fact that values are obtained relatively from pairwise comparisons. If the judgements of pairwise comparisons are absolutely consistent, in other words, if the equation above is satisfied, then the inputs of the A pairwise comparisons matrix will not include any error, allowing it to suggest the equation in (4).

$$
a_{i j}=\frac{W_{i}}{W_{j}}(i, j=1,2, \ldots n)
$$

$\mathrm{W}_{\mathrm{i}}=$ the priority value for the element $\mathrm{i}$ as calculated through the pairwise comparisons matrix,

$\mathrm{Wj}=$ the priority value for the element $\mathrm{j}$ as calculated through the pairwise comparisons matrix,

Diagonal elements of the pairwise comparisons matrix take the value of 1 (5).

$$
\begin{gathered}
a_{i k} a_{k j}=\frac{W_{i}}{W_{k}} \frac{W_{k}}{W_{j}}=\frac{W_{i}}{W_{j}}=a_{i j}(i, j, k=1,2, \ldots, n) \\
a_{i i}=1 \quad(i=1,2, \ldots, n)
\end{gathered}
$$


Once the pairwise comparison matrices are constructed, the priority values (weights) of factors compared to the respective immediately upper factor are calculated with reference of the matrix data.

\section{Step 3: Calculation of Priority Values}

Pairwise comparisons matrices are used to calculate the priority values. During this calculation procedure, consistency of pairwise comparison judgements should be considered. Various methods have been developed for this purpose.

For fully consistent matrices, it is specified that normalizing any $\mathrm{j}^{\text {th }}$ column of the matrix $(\mathrm{j}=1,2, \ldots, \mathrm{n})$ would yield the priority vector (Y1lmaz, 2004). Accordingly, the priority vector is calculated as provided in (6):

$$
a=\frac{a_{i j}}{\sum_{k=1}^{n} a_{k j}} \quad(i=1,2, \ldots \ldots, n)
$$

where;

$\mathrm{W}_{\mathrm{i}}=$ priority value for the element $\mathrm{i}$,

$a_{i j}=$ value of the $i^{\text {th }}$ row and $j^{\text {th }}$ column of the pairwise comparisons matrix.

As another method for the calculation of priority values, normalizing the sum of values in rows of the fully-consistent pairwise comparisons matrix is suggested. Such mathematical calculation is carried out as provided in (7):

$$
W_{i}=\frac{\sum_{j=1}^{n} a_{i j}}{\sum_{i=1}^{n} \sum_{j=1}^{n} a_{i j}}(i=1,2, \ldots, n)
$$

On the other hand, the "eigenvector method" by Saaty is an important method as it suggests a measure for consistency towards pairwise comparison judgements. Descriptions on this method are presented below (Y1lmaz, 2004);

The eigenvector corresponding to the highest eigenvalue of the pairwise comparisons $\operatorname{matrix}\left(\lambda_{\max }\right)$ is the priority vector. This vector $(8)$ is represented with

$$
W=\left[W_{1}, W_{2}, \ldots, W_{n}\right]
$$

This eigenvector is also referred to as the right eigenvector. Each normalized element of this vector indicates a priority value estimate and also involves errors made during comparison. If $\mathrm{W}_{\mathrm{i}}(\mathrm{i}=1,2, \ldots, \mathrm{n})$ values are known, then pairwise comparisons are based on absolute measurements, and the pairwise comparisons matrix is absolutely consistent. So, where $\mathrm{i}$, $\mathrm{j}$, $\mathrm{k}=1,2, \ldots, \mathrm{n}$, the following equiation can be derived (9) and (10):

$$
a_{j i}=\frac{W_{j}}{W_{i}}=\frac{1}{W_{i} / W_{j}}=\frac{1}{a_{i j}}
$$

and

$$
a_{i j} \frac{W_{j}}{W_{i}}=1
$$


Summing based on $\mathrm{j}$ on both sides of the equation yields,

$$
\sum_{j=1}^{n} a_{i j} W_{j} \frac{1}{W_{i}}=n \quad(i=1,2, \ldots, n)
$$

(11) Transferring $1 / \mathrm{W}_{\mathrm{i}}$ on the lef side of the equation to the right side yields the following equation:

$$
\sum_{j=1}^{n} a_{i j} W_{j}=W_{i} n \quad(i=1,2, \ldots, n)
$$

(12). This equation is composed as

$$
W=\left[W_{1}, W_{2}, \ldots, W_{n}\right]
$$

where (13) being the priority vector composed as

$$
A W=n W
$$

(14) According to the matrix theory, $\mathrm{W}$ in this equation is the eigenvector of the pairwise comparisons matrix $A$. Solving this equation yields eigenvalues $A \lambda_{1}, \lambda_{2}, \ldots, \lambda_{n}$ of the pairwise comparisons matrix.

Indeed, since $a_{i j}$ is based on subjective judgements, deviations from the ideal $\mathrm{W}_{\mathrm{i}} / \mathrm{W}_{\mathrm{j}}$ ratio occur. Therefore, the matrix theory brings two cases to the foreground:

First, where $\lambda_{1}, \lambda_{2}, \ldots, \lambda_{n}$ are eigenvalues,

$$
A X=X \lambda
$$

if $a_{i i}=1$ for every $i$, and the eigenvalue of the matrix A above satisfying the equation (15), then

$$
\sum_{i=1}^{n} \lambda_{i}=n
$$

Therefore, when the equation $\mathrm{AW}=\mathrm{nW}$ is satisfied, only one out of the eigenvalues of the pairwise comparisons matrix $\mathrm{A} \lambda_{\mathrm{i}}$ has $\mathrm{n}$ value (equal to $\mathrm{n}$ ), and all other eigenvalues are zero. This means, when the matrix $\mathrm{A}$ is consistent, the highest eigenvalue of the matrix $\mathrm{A}$ $\left(\lambda_{\max }\right)$ is equal to $n\left(\lambda_{\max }=n\right)$.

Considering them all, if the diagonal elements of the matrix A (aii) are 1, and if the matrix A is consistent, then it is concluded that variations in aij do not lead to a change in the highest eigenvalue $\left(\lambda_{\max }\right)$ near $n$, and that the remaining eigenvalues have values near 0 . Once the pairwise comparisons matrix is actually obtained, the problem (17)

$$
A W=\lambda_{\max } W
$$

will be solved, yielding the $\mathrm{W}$ priority vector (eigenvector) satisfying this equation and constituting the unit vector.

Estimating the Consistency Ratio: While the significance or priority values of elements are calculated on the basis of the pairwise comparisons matrix in the AHS method, mistakes or 
inconsistencies may occur since pairwise comparisons are based on subjective considerations. To measure this condition, the "Consistency Ratio" is employed in the AHS method.

To create a pairwise comparisons matrix with $\mathrm{n}$ elements suggested by the AHS method, obtaining (n-1) assessments is enough. Accordingly, other assessments may be made. As a matter of fact, if element $X$ is twice the element $Y$, and has four folds of significance compared to element $Z$, then we may infer $X=2 Y, X=4 Z, 2 Y=4 Z$ ve $Y=2 Z$.

$$
C I=\frac{\lambda_{\max }-n}{n-1}
$$

\begin{tabular}{cc}
\hline Matrix Size (n) & Random Index (RI) \\
\hline 1 & 0.00 \\
2 & 0.00 \\
3 & 0.58 \\
4 & 0.90 \\
5 & 1.12 \\
6 & 1.24 \\
7 & 1.32 \\
8 & 1.41 \\
9 & 1.45 \\
10 & 1.49 \\
11 & 1.51 \\
12 & 1.48 \\
13 & 1.56 \\
14 & 1.57 \\
15 & 1.59 \\
\hline
\end{tabular}

Table 3. Random Index Values Variable by Matrix Size Used to Calculate Consistency Ratio in the AHS Method (Yılmaz, 1999). 
In this matrix, if the significance of element $Z$ compared to element $Y$ is different than 2, than this pairwise comparisons matrix will be inconsistent. This fairly common condition does not constitute a major problem in solving the problem. While making assessments as to pairwise comparisons, if the decision maker merely refers to the (n-1) key assessment and neglects other assessments, then the pairwise comparisons matrix should be expected to be inconsistent. This is a very common case, however this does not lead to major issues in solving the problem (Cengiz, 2003). In this case, the matrix consistency ratio (1.20) is measured. Normalizing this measurement through the size of the pairwise comparisons matrix (n) is defined by Saaty as the consistency index-CI (1.18) (Ejder, 2000).

To calculate the Consistency Ratio, the "Random Index (RI)" values should also be known. These values have been constructed by randomly placing 100 matrices in each node of the 115 size matrices and then averaging the Consistency Ratios calculated according to the following formula. However, as the values of random indices increase with the growing matrix size, 500 random pairwise comparisons matrices have been formed for each matrix size of 11,12,13, 14 and 15, and calculations have been repeated. Hence, RI values by matrix size as shown in Table 2 have been obtained (Y1lmaz, 1999).

$$
C R=\frac{C I}{R I}
$$

If this ratio (19) is zero, then the judgements of the decision maker are fully consistent. With this ratio approximating to 1.00 , it may be argued that the pairwise comparisons matrix based on the decision maker's judgements are not rational and consistent, but random. Furthermore, a consistency ratio of 0.10 or less indicates that the results obtained are within acceptable limits (Taha, 2000).

\section{Step 4: Determining General Priority Values}

The last stage of the AHS method is to identify the general priority values of bottommost elements of the decision hierarchy (decision alternatives) in reference to the topmost general objective. For the sake of a description clarity, this may be illustrated on a sample three-level decision hierarchy as follows (Y1lmaz, 1999).

The first level of the three-level decision hierarchy consists of a single element that represents the overall objective, and has a priority value of 1 . Let's assume that the second level of this hierarchy consists of $\mathrm{n}$ elements and third level consists of $\mathrm{m}$ elements. Accordingly;

$\mathrm{W}_{\mathrm{h}}=$ Priority value of the element at the first level (overall objective),

$\mathrm{V}_{\mathrm{i}}=$ Priority values of elements at the second level $(\mathrm{i}=1,2, \ldots, \mathrm{n})$,

$\mathrm{W}_{\mathrm{ij}}=$ Priority values of $\mathrm{j}$ elements (decision alternatives) at the third level compared to the element $\mathrm{i}$ at the second level $(\mathrm{j}=1,2, \ldots, \mathrm{m})$,

$W_{i}=$ Priority values of decision alternatives in reference to the overall objective $(i=1,2, \ldots, m)$ 
Since the priority value of the overall objective is 1 , multiplication of this value to the priority values of elements at the second level will make no difference. In other words, the priority values of elements at the second level of the hierarchy will remain the same.

Hence, priority values of decision alternatives in reference to the overall objective are obtained by multiplying the priority value of each element at the second level of the hierarchy to priority values of subordinate elements at the third level, and then by summing such weighted values of the alternatives. This procedure may be illustrated in matrix form as follows (20):

$$
\left[\begin{array}{cccccc}
W_{11} & W_{21} & \cdot & \cdot & \cdot & W_{n 1} \\
W_{12} & W_{22} & \cdot & \cdot & \cdot & W_{n 2} \\
\cdot & \cdot & \cdot & \cdot & \cdot & \cdot \\
\cdot & \cdot & \cdot & \cdot & \cdot & \cdot \\
\cdot & \cdot & \cdot & \cdot & \cdot & \cdot \\
W_{1 m} & W_{2 m} & \cdot & \cdot & \cdot & W_{n m}
\end{array}\right]\left[\begin{array}{c}
V_{1} \\
V_{2} \\
\cdot \\
\cdot \\
V_{n}
\end{array}\right]=\left[\begin{array}{llllll}
W_{1} & W_{2} & \cdot & \cdot & \cdot & W_{m}
\end{array}\right]
$$

By calculating the $\mathrm{W}_{\mathrm{i}}$ general priority values, a solution is offered to solve complex decisionmaking problems. Hence, the highest of these priority values may also be treated as the best, in other words the decision alternative to be chosen.

\section{Conclusion}

While previously associated with minor pollution issues together with short-term solutions aimed at eliminating them, environment today reveals itself as the entire set of natural, economical, social and cultural values. Comprehending this fact has triggered the abandonment of traditional development models and exploration towards new models. Therefore, the traditional unlimited development and unlimited consumption models have started to be replaced by sustainable and more balanced development models.

Safeguarding the nature and the land we live upon, availing of its existing potential in maximum, flourishing and then offering it to the benefit of future generations is only possible by exploring and scrutinizing the available use options that do not conflict with each other and implementing them based on a particular plan as buttressed by a consistent process maintenance and audit (Başal, 1998).

As a managerial instrument, Landscape Planning reveals the inventory and analysis of natural and cultural environment, and so ensures that optimum decisions can be taken for land utilization alternatives. It is clearly known today that analyses with single dimension or variable are not sufficient in solving complex problems like the landscape analysis. The major assumption in single-dimension analyses is to consider the impacts of other dimensions in the case as constant and study only one dimension (factor) every time. However, events and objects in the universe are formed not under the influence of only one factor, but under the collective influence of myriad of internal and external factors, and 
reveal a complex nature. For this reason, events and objects should be defined not based on a single variable, but on myriad of variables and their collective impacts.

When decision makers encounter a complex system formed by interrelated components (resources, outputs proposed, constraints, etc.) in landscape analyses, they first endeavour to gain a thorough insight into the composition of this system. Hence, judgements and decisions made are rather informed. In landscape analyses, particularly in identifying the criterion weights of natural data, user opinions are of great significance. However, entities proposing to solve a complex decision problem may take different decisions despite employing the same method. The reason is that people have different value judgements. And different value judgements would lead to different priorities. In other words, different decision makers may attach different priorities to the components of the system. At this point, AHS comes up as a process distinguished from other decision making approaches as it directly considers the value judgements of different decision makers.

\section{Author details}

Murat Akten

Süleyman Demirel University Faculty of Forestry, Landscape Architecture of Department, Turkey

\section{References}

[1] Eminov, M., Ballı, S., 2004. “Karmaşık Problemler İçin Belirsizlik Altında Çok Kriterli Bulanık Karar Verme". Operational Research/Industrial Engineering - XXIVth National Congress, June 15-1 Gaziantep-Adana

[2] Anonymous, 2000. "European Landscape Convention", Strasbourg Translation: Dr. Nilgül GÖRER.

[3] Atabay, S., 1991. "Doğal Çevreye Uyumlu Planlama", Cumhuriyet Newspaper, November 5, Istanbul.

[4] Atay, A., 2009. “Türkiye'de Planlama ve Planlama Hiyerarşisi. Peyzaj Yönetimi". Institute of Public Administration for Turkey and Middle East Publication No: 354, Local Administrations Central Publication No: 27, p. 1-30, Ankara.

[5] Ayhan, K.Ç., Hepcan, Ş., 2009. “Özgün Peyzaj Karakteristiklerine Sahip Mekanlara Yönelik Bir Peyzaj Planlama Yönteminin Ortaya Konulması; Bozcaada Örneği" Tekirdağ Faculty of Agriculture Journal No: 2009 6(1), Tekirdağ.

[6] Benliay, A., Yıldırım, E., 2013. "Peyzaj Planlama Çalışmalarında Peyzaj Metriklerinin Kullanımı" Turkish Journal of Scientific Reviews 6 (1): 07-11, 2013 ISSN: 1308-0040, EISSN: 2146-0132.

[7] Bulut, Y., Atabeyoglu, Ö., 2010. “Kent Planlamasında Peyzaj Mimarlarının Yeri Ve Önemi" $3^{\text {rd }}$ National Black Sea Forestry Congress, May 20-22, 2010, Volume: IV, page:1494-1593. 
[8] Cengiz, T., 2003. "Peyzaj Değerlerinin Korunmasına Yönelik Kırsal Kalkınma Modeli Üzerine Bir Araştırma: Seben İlçesi (Bolu) Alpağut Köyü Örneği”. Ankara University, Institute of Science and Technology, Phd Thesis, 301 p. Ankara.

[9] Çetinkaya, K.F., 2012. "Peyzaj Planlamada Ekolojik Parametreler" Turkish Journal of Scientific Reviews 6 (1): 55-57, 2013, SSN: 1308-0040, E-ISSN: 2146-0132.

[10] Ejder, E., 2000. “Mobilya Endüstrisinde Analitik Hiyerarşi Süreci Yöntemi İle Kuruluş Yer Seçimi". Hacettepe University, Institute of Science and Technology, Master Thesis, 103 p. Ankara.

[11] Göksu, A., Güngör, İ., 2008. “Bulanık Analitik Hiyerarşi Prosesi ve Üniversite Tercih Siralamasinda Uygulanması". Suleyman Demirel University, The Journal of Faculty of Economics and Administrative Sciences. Vol.13, No.3 pp.1-26. Isparta.

[12] Halaç, O., 2001. "Kantitatif Karar Verme Teknikleri (Yöneylem Araştırması)". (5 Edition) Alfa Press, Bursa.

[13] McHarg, I.L., 1969. "Processes As Values, In Design with Nature". Published For The American Museum of Natural History, 298 p. NewYork.

[14] Saaty, L.T., 1986. "Axiomatic Foundation of the Analytic Hierarchy Process", Management Science, Volume 32, Issue7, pages 841-855.

[15] Şahin, S., 2009. “Peyzaj Ekolojisi Kavramsal Temelleri ve Uygulama Alanları". Institute of Public Administration for Turkey and Middle East Publication No: 354, Local Administrations Central Publication No: 27, p. 31-56, Ankara.

[16] Taha, H.A., 2000. “Yöneylem Araştırması". (Translated and adapted by: Ş.A. Baray and Ş. Esnaf), Translation from the $6^{\text {th }}$ Edition, Literatür Press, ISBN: 975-8431-28-5, 910 p. Istanbul.

[17] Turoglu, H., 2005, "Fiziksel Planlama ve Coğrafi Bilgi Sistemleri", Ege University, Symposium on Ege Geographic Information Systems, 27-29 Nisan 2005, Books of Abstracts, S: 51, İzmir.

[18] Uzun, O., 2003. “Düzce Akarsuyu Havzası Peyzaj Değerlendirmesi ve Yönetim Modelinin Geliştirilmesi". Ankara University, Institute of Science and Technology, Phd Thesis, 470 p. Ankara. Ankara.

[19] Uzun, O., 2009. "Peyzaj Ekolojisi”. Institute of Public Administration for Turkey and Middle East Publication No: 354, Local Administrations Central Publication No: 27, p. 57-80, Ankara.

[20] Ünal, F.Ö., 2010. “Analitik Hiyerarşi Prosesi İle Yetkinlik Bazlı İnsan Kaynakları Yöneticisi Seçimi”. Süleyman Demirel University, Social Sciences Institute, Unpublished Phd Thesis, Isparta.

[21] Yılmaz, E., 1999. “Analitik Hiyerarşi Süreci Kullanılarak Çok Kriterli Karar Verme Problemlerinin Çözümü". East Mediterranean Forestry Research Institute, DOA Journal, Tarsus, Ministry of Forestry Publication No: 127, DOA Publication No: 16, 5 , ISSN: 1300-8544, 95-122.

[22] Y1lmaz, E., 2004. “Orman Kaynaklarının İşlevsel Bölümlemesine İlişkin Çözümlemeler”. Istanbul University, Institute of Science and Technology, Phd Thesis, 388 p. Istanbul. 
[23] Yüksel, D.Ü., 2003. “Amerika ve Avrupa'da Ekolojik Planlama Yaklaşımları”. Ankara University, Institute of Science and Technology, Phd Thesis, 23 p. Ankara. 


\title{
Use of Watersheds Boundariesin the Landscape Planning
}

\author{
Aybike Ayfer Karadağ \\ Additional information is available at the end of the chapter
}

http://dx.doi.org/10.5772/55765

\section{Introduction}

Interactions between human society, biosphere, atmosphere, and hydrosphere have increased extensively, sometimes for the welfare of mankind and environment, but frequently for their man. These interactions are characterized by increasing complexity, diversity, use, and misuse of natural resources, the latter permanently decreasing. And this holds true for any scale in space and time, from global to local and from long-term to short term. On the regional and local scale the interactions between society, hydrosphere, and biosphere are relevant (Kaden, 2003) and these interactions determine the future of the landscape.

Landscape is complex and far-reaching. People have strong ties to landscapes and use them in various ways. Thus landscape is interweaves with climate change and ecology, development, economics, politics, and culture (Bastian et al., 2006; Jones, et al., 2007). Landscape changes as a result of these relationships that human-nature interaction. The changes in landscape were brought up idea of planning for sustainable use, conservation and management. But landscape character and structure make difficult landscape planning decisions. Therefore it must be understood primarily "landscape" to successful landscape planning.

Two different approaches have emerged to defining landscape, when the definitions of landscape are evaluated. According to the first approach, landscape is ecological units. In this context Forman (1995) defined landscape as a mosaic where the mix of local ecosystems or land uses is repeated in similar form over a kilometers-wide area. A landscape manifests an ecological unity thought its area. Within a landscape several attributes tend to be similar and repeated across the whole area, including geologic land forms, soil types, vegetation types, local faunas, natural disturbance regimes, land uses, and human aggregation pattern. Thus a repeated cluster of spatial elements characterizes a landscape. Burel and Baudry 
(2003) argue that landscape is a level of organization of ecological systems that is higher than the ecosystem level (Farina et al., 2005). It is characterized essentially by its heterogeneity and its dynamics, partly governed by human activities. It exists independently of perception. Landscape is considered mainly a mosaic of geographical entities in which organisms deal with the spatial arrangement of these entities determined by complex dynamics (Farina et al., 2005). Landscape is geographic unit at second approach. Geography, where the landscape plays a central role and may be considered a fundamental unit, is of particular importance in the attempt to delineate a clear, scientifically useful concept of landscape. The definitions in geography essentially focus on the dynamic relationship between natural landforms or physiographic and human cultural groups (Forman and Godron, 1986). Landscape refers to a common perceivable part of the earth's surface. Landscape became a core topic of geography, in particular regional geography. It was seen as a unique synthesis between the natural and cultural characteristics of a region (Mander and Antrop, 2003). As Zonneveld (1979) stated, landscape is part of the spaces on the earth's surface, consisting of a complex of systems, formed by the activity of rock, water, air, plants, animals and man, and that by its physiognomy forms a recognizable entity (Forman and Godron, 1986). The European Landscape Convention defines landscape as "an area, as perceived by people, whose character is the result of the action and interaction of natural and/or human factors" (Anonymous, 2000). In this context Turner et al.(2002) indicated landscape as an area that is spatially heterogeneous in at least one factor of interest. Opdam et al. (2006) defined landscape as a "geographical unit characterized by a specific pattern of ecosystem types, formed by interaction of geographical, ecological and human-induced forces."

Regardless of how landscape is defined, landscape can be characterized by structure, function, and change (Kurum and Şahin, 2000). Structure, the spatial relationships among the distinctive ecosystems or elements present-more specifically, the distribution of energy, materials, and species in relation to the sizes, shapes, numbers, kinds, and configurations of the ecosystems. Landscape structure is generally defined in terms of "composition" and "configuration". Dunning et al. (1992), these are, respectively, the kinds of patches present in the landscape and the amount of each, and the spatial relationships among them as indices of landscape structure, landscape metrics can be used to describe the composition and spatial arrangement of a landscape (Forman and Godron, 1986). They can be applied at different levels to describe single landscape elements by such features as size, shape, number or for whole landscapes by describing the arrangement of landscape elements and the diversity of landscape (Forman and Godron, 1986; Waltz, 2011). Forman and Godron (1986) defined landscape function from a systems-theoretical point of view as "the interactions among the spatial elements, that is, the flows of energy, materials, and species among the component ecosystems". Leser (1997) emphasized that it is necessary to analyze functions and functional interactions between landscape factors and landscape components in order to understand the relationships within the system (Bastian, et al. 2006). Change, the alteration in the structure and function of the ecological mosaic over time (Baker, 1989).

Landscape change, because they are the perceivable expression of dynamic interactions between the physical and material environment and natural and cultural forces. In addition, 
Consequently, landscapes differ from place to place and different landscape types can be recognized as well as different landscape regions (Mander and Antrop, 2003). In this context three main factors can be identified in determining landscape: physical, biological and anthropic. Their interaction are continuously composing the landscape in such a way that we can distinguish between a spatial and a temporal aspect of this composition. The spatial landscape variety consists in the present interrelation of these three factors in a certain place (Kerkstra et al., as cited in Makhzoumi, 1973 and Pungetti, 1999). In addition history and ecology are essential factors in the structuring and understanding of landscapes. No reference is made to "special" landscapes such as "spectacular" or "ordinary" ones, to rural, industrial or urban ones; all landscapes should be considered equally (Antrop, 2005).

Landscape ecology provides understanding of change of landscapes. In addition landscape ecology provides a strong conceptual and theoretical basis for management and planning at the landscape level by contributing to a better understanding of the structure and function (Uzun, 2003; Ivits et al., 2005). Landscape ecology, a subdiscipline of ecology, is the study of how landscape structure affects the abundance and distribution of organisms. Landscape ecology is the study of the pattern ${ }^{1}$ and interaction between ecosystems within a region of interest, and the way the interactions affect ecological processes, especially the unique effects of spatial heterogeneity on these interactions (Clark, 2010). Landscape pattern consists of three elements: patches ${ }^{2}$, corridors ${ }^{3}$ and a matrix ${ }^{4}$. In addition, landscape ecology involves the application of these principles in the formulation and solving of real-world problems (Forman, 1995).

Landscape planning has come up in the process of understanding, maintainable usage and preservation of the landscape that changed as a result of the relationship and interaction between the man and the nature (Bastian et al., 2006; Jones, et al., 2007). Landscape planning is the key planning instrument for nature conservation. The basis for the concept of planning is formed by the idea of "balancing the needs and the sources by complying with rational priorities in the long term to reach certain goals with scarce resources" (Keleş, 2004). From upper scale to subscale, the planning includes physical environment, socio-cultural life, history on economic and political issues, decisions concerning today and future (Uzun, et al., 2012). Also, social and physical are grouped as executive and object planning (Zaimoğlu, 2003). At that point, landscape planning is evaluated as the subtopic of physical planning (Köseoğlu, 1982) and accepted as the basis for it (Zaimoğlu, 2003).

The European Landscape Convention defines landscape planning as "strong forwardlooking action to enhance, restore or create landscape" (Anonymous, 2000). Landscape planning is an activity that analyses, plans and localises landscape and environmental characteristics, resources and values (Dökmeci, 1996). Steiner (1999) used the term of

\footnotetext{
${ }^{1}$ Pattern refers to its spatial arranges of ecosystems and their type, number, size, shape, and relative relationship over the landscape (Forman, 1995).

${ }^{2}$ Patch is a wide relatively homogeneous area that differs from its surroundings. Patches have familiar attributes, such as large or small, rounded or elongated, and straight or convoluted boundaries (Forman, 1995).

${ }^{3}$ Corridors, as strips that differ from their surroundings, permeate the land (Forman, 1995).

${ }^{4}$ Matrix is the background ecological system of a landscape (Forman, 1995).
} 
landscape plan to emphasize that such as plans should incorporate natural and social consideration. Uzun et al., (2012) stated that landscape planning had two basic approaches which were "depending on a certain territory" and "directed to problem solving". The landscape planning studies that depend on a certain territory are examples of the planning studies concerning an area having a developmental potential. It contains the approaches concerning the formation of criteria about determining the territorial usage (agriculture, recreation, etc.) in the process of development of a newly developing region or a sub-region. The landscape planning studies directed to problem solving have the aim of solving the present problems in the landscape planning and the problems concerning the planned usage. Choosing places for industry, settlement, highway route, etc. and landscape renovations are examples for these planning. In addition Uzun and Gültekin (2012) emphasized landscape planning which is one of the fields of study that creates a balance between natural sciences and engineering sciences in the best possible way is also important for natural resource management. One of the main purposes is a balanced planning of people and nature, instead of people oriented planning. In landscape planning, the approaches in which landscape functions are analyzed and the structure and change of landscape is presented have been supported by ecology and landscape ecology sciences.

L. McHarg (1920-2000), the pioneer of the environmental movement, revealed that natural sciences should be evaluated in solving the problems, by focusing on the natural life processes and their determinative effects on area usage plans (Şahin, 2009a). In this context, putting preservation and usage balance forward, examining the ecological features, analysing the usages and accordingly the ecological relationships, and after these examinations, defining the actions and forming an environment which people will take the most benefit of, but will be less threat for other animals are emphasised in the landscape planning (Uzun et al., 2012). At the same time landscape planning provides a coordinated information basis for all natural resources, which enables us to rapidly obtain an overview of the nature and landscape situation within the planning areas; fragmented changes to individual parts of nature and the landscape can be assessed with respect to their effect on the whole existing condition; planning and nature conservation experts in the administration can use this as basis for quick and uncomplicated comments. The complex interaction of all the factors affecting the balance of nature such as soil, water, air and climate, plants, and animals, as well as diversity, characteristic features and beauty and the recreational value of nature and landscape as well as the effects of existing and foreseeable land usages, are analysed and assessed within the landscape planning. As a result, extensive basic information about nature and the landscape is available for the whole area. The spatial objectives, measures and requirements developed in the landscape on the protection, maintenance and development of nature and the landscape (Anonymous, 2008).

In the basis of a successful landscape planning lies understanding and knowing the landscape. In this context, landscape structure, landscape processes and the changes in landscape were effective items. Uzun et al. (2012) states that the structure and functions of landscape are evaluated, landscape processes are analysed and landscape ecology based approaches are put forward in the recent landscape planning studies. In this context 
landscape ecology have also attached great significance to the issue of scale, and the "landscape units" is more widely canvassed as a framework for analyzing inter-relationship and delivering joined-up policy within a comprehensible and identifiable space (Selman, 2006).

In this study, the concept of boundary in landscape planning is emphasized. Additionally, the use of the ArcHydro Model was described to delineate watershed boundaries.

\section{Exploring the boundaries in landscape planning}

Natural systems are usually considered parts of hierarchies - an ordering from biggest to smallest (or vice-versa). For our purposes (planning, management, etc.), ecological hierarchy will be discussed from the largest to the smallest scale.

Scale is the dimension of an object or process. It can be described as resolution and range, which indicate in how much detail the object or process has been understood (Du-ning and Xiu-Zhen, 1999). Scale is a key issue in planning. Due to the interdependencies of ecosystems, a planning approach is need that examines a site in its broader context. Scale is related to three dimensions (Selman, 2006).

- A spatial dimension: -the mostly cited component of landscape scale, based on both a rational and intuitive recognitions of distinct physical units.

- A temporal dimension: -implying a continuum from the earliest human use of a landscape into the sustainable use by future generation.

- A modification dimension: -from intensely urbanized areas, through farmland and other types of natural use, to pristine or wilderness areas, with some areas processing such intense degrees of alteration that the landscape requires human assistance to accelerate the recovery of its "regenerative" properties.

The concept of scale can allow to the analysis on the level of different hierarchal system that can be related to each other and it can be related to the hierarchy theory. Allen and Star (1982) stated that the hierarchy theory was developed as a study outline for analysis of complex systems or situations which became organized in certain types. The systems that become organised hierarchically can be divided into functional components. These elements' structure, function and characteristics related to time and space can be formed in scale or on different levels. There is no basic hierarchy in the hierarchy theory. Its focus level can change according to considered events (Hersperger, 1994 as cited in Uzun, 2009). The hierarchical theory is a useful instrument for exploring numerous patterns and processes through various scales in space and time. Considering complexity as an attribute that is intrinsic to a landscape, the hierarchy paradigm explains how the various components located on certain scales enter into contact with other ones that are visible on different scales of resolution. The hierarchical theory views a system as a component in a larger system that consists of subsystems (Allen and Starr, 1982; O'Neill et al., 1986; Allen and Hoekstra, 1992 as cited in Farina, 2001). 
The concept of boundary is a spatial expression of the scale and it can be expressed in different ways with hierarchy theory. Such as the biosphere or planet is boundary and is subdivided into continents (and oceans) within hierarchical theory. Continents are subdivided into regions, region into landscapes, and landscapes into local ecosystems or land uses. Region is a broad geographical area with a common macroclimate and sphere of human activity and interest. This concept links the physical environment of macroclimate, major soil groups, and biomes, with the human dimensions of politics, social structure, culture, and consciousness, expressed in the idea of regionalism (Forman, 1995). A region therefore almost always contains a number of landscapes (Forman and Godron, 1986; Duning and Xiu-Zhen, 1999). In addition the region is composed of patches, corridors and a matrix that vary widely in size and shape. In this case the spatial elements are whole landscapes. Unlike the recurring landscape elements in a landscape, a region does not exhibit a pattern of repeated landscape. Usually the distribution of landscape simply mirrors the typically coarse-grained, geomorphic land surface. Thus, most regions are coarse grained or variable-grained with group of small landscapes. In short, the spatial pattern or arrangement of landscape in a region is just as important functionally as the pattern of continents on the globe, local ecosystems in a landscape (Forman, 1995).

Landscape is a dynamic and hierarchical setting. Landscape comprises so many hierarchically constructed ecosystems from a single molecule to the whole Earth and even the limitless emptiness called the space (Selman, 2006). Considering complexity as an attribute that is intrinsic to a landscape, the hierarchy paradigm explains how the various components located on certain scales enter into contact with other ones that are visible on different scales of resolution (Farina, 2001). Every ecosystem has its own boundaries yet is in relation with other ecosystems through the flow of energy and data which ensure the continuity of the system. A system is theoretically in balance when the inputs and outputs required for its functions within its natural boundaries are equal. Therefore, the assessments in defining the capability, capacity and sensitivity of the area for any human activity should be performed within the natural boundaries (Şahin, 2009b). For instance, bioregionalists have argued that "nature" defines its own integral systems and that, historically, sustainability in human systems has been a consequence of close alignment between socioeconomic practices and environmental capacity. This leads to arguments, discussed more fully below, that natural, rather than political, boundaries could form the basis of many planning and management choices (Selman, 2006).

A landscape can vary in size from a few centimeters to tens of kilometers. The heterogeneity might be expressed as physically identifiable structures. At any rate, the degree of heterogeneity varies according to the spatial arrangement of the single component parts. Landscapes do not exist in isolation. Landscapes are nested within larger landscapes that are nested within larger landscapes, and so on. In other words, each landscape has a context or regional setting, regardless of scale and how the landscape is defined. The landscape context may constrain processes operating within the landscape. Landscapes are "open" systems; energy, materials, and organisms move into and out of the landscape. This is especially true in practice, where landscapes are often somewhat arbitrarily delineated. That broad-scale 
processes act to constrain or influence finer-scale phenomena is one of the key principles of hierarchy theory and "supply-side" ecology. The importance of the landscape context is dependent on the phenomenon of interest, but typically varies as a function of the "openness" of the landscape. The "openness" of the landscape depends not only on the phenomenon under consideration, but on the basis used for delineating the landscape boundary. For example, from a geomorphological or hydrological perspective, the watershed forms a natural landscape, and a landscape defined in this manner might be considered relatively "closed". Of course, energy and materials flow out of this landscape and the landscape context influences the input of energy and materials by affecting climate and so forth, but the system is nevertheless relatively closed. Conversely, from the perspective of a bird population, topographic boundaries may have little ecological relevance, and the landscape defined on the basis of watershed boundaries might be considered a relatively "open" system (Farina, 2001).

Landscape has different hierarchical systems. The classification of a landscape as one goes from lower to increasingly higher levels in the hierarchy: ecotope (the basic unit in a landscape consisting of biotic and abiotic elements); microchore (the spatial distribution of ecotopes); mesochore (the environmental system composed of a group of microchores); macrochore (a mosaic of landscapes); and megachore (a group of geographical elements covering several kilometers). A system exists independently of its components and is generally able to organize itself and to transmit information; in other words, it is able to exist as a cybernetic system. A landscape exhibits its own type of complexity, and in order to understand it fully it is necessary to focus on a certain organizational level. There are innumerable hierarchical levels and thus an equal number of systems that are nested inside them in one way or another. The behavior of a given subsystem conditions nearby systems both above and below it. The speed with which the processes unfold and thus the scales in time are specific to each level. When going from one level to another, it is therefore necessary to adjust the resolution (Farina, 2001). In the most variants of the landscape, researchers refer to something framed at the human scale. However, this is revised upwards to reveal patterns from satellites, and downwards to reveal mosaics related to the life-spaces of meso- and micro- organism. McPherson and DeStefano (2003), writing from an ecological perspective, identify landscape studies as being those undertaken at quite an extensive spatial scale: less extensive than the "biome" or biosphere", but larger than the ecosystem, community, population, organism or cell (Selman, 2006).

Landscape ecological concepts and applied metric are likely to be useful to addresses the spatial dimension of sustainable planning. The landscape ecological aspect of spatial scale has received so much attention in the literature. Landscape ecology is the study of the interactions between the temporal and spatial aspects of a landscape and its flora, fauna, and cultural components in so far as this impact on ecosystem properties. However, the subject also incorporates the study of water movements, particularly insofar as these impact on ecosystem properties. An understanding of ecological and hydrological pattern and processes not only reveals the complex web of natural interdependencies, but also enroll economic and social systems at these strongly modify the energy and materials inputs into 
landscape (Selman, 2006). In this context, watershed boundaries, for having well-defined edges make up a fundamental unit for landscape planning (Makhdoum, 2008).

A widely advocated approach to landscape planning is to steward resources on the basis of biogeographic units: that is, segments of the earth's surface defined, not on the basis of traditional political and administrative boundaries. Selman (2006) stated that landscape planning has three main reasons for the popularity of biogeographic units. First, natural systems, as watershed, often form logical units for many resources management decisions, and focusing on an integrative landscape unit may help reduce fragmentation of environmental processes and of policy delivery. Second, neither wildlife species nor hydrological systems recognize administrative boundaries, and their natural geographical range and extend must be taken into account in spatial planning, or even serve as its framework. Finally, people develop particular attachments to landscape on the basis of both physical and cultural factors, and so may possibly identify with distinctive biogeographic space more than with, say, local government districts (Selman, 2006).

Graff, 1993; Metzger and Muller, 1996; Şahin, 1996; Tangtham, 1996; Farrina 2006; Uzun, 2003; Selman, 2006; Bulley et al., 2007; Karadağ, 2007; Şahin, 2007; Makhdoum, 2008; Şahin, 2009b; Uzun, 2003 and Uzun et al., 2012 have drawn attention to the information of watershed in landscape planning. Watersheds can be considered as landscapes. It seems useful to study landscapes by applying the scale of watersheds, which can be considered as multifunctional units in which flows of water and the transfer of nutrients are distinctive processes (Farina, 2001).

\section{Watershed}

Water effects on the environmental and on life in all forms in distribution and circulation of waters (O'Callaghan, 1996). Surface flow, travel of water which is called hydrological circuit and feeding of ground waters, form the basis for ecological processes. The flow of water not only provides a unique ecological feature, but also forms geographically unique areas/spaces.

Surface flow, travel of water which is called hydrological circuit and feeding of ground waters affect landscape from different aspects. Surface flow of water and feeding of the ground waters are related to water period of landscape. Water period depends on permeability values (Uzun and Gültekin, 2013). Hydrological circuit is the process of evaporation and condensation of surface waters with the effects of climactic factors (Karadağ, 2007).

A watershed is the area drained by a river or stream and its tributaries. Generally many watersheds are included in a landscape, and a landscape boundary may or not correspond to the boundaries of watershed (Forman and Godron, 1986). A watershed is a landscape surface area that surrounds and drains into a common waterbody such as a lake, small stream or river basin system (Anonymous, 2012a). Davenport, et al. (2012) defined as watershed is an area of land that drains into a lake or river. As rainwater and melting snow run downhill, they carry sediment and other materials into streams, lakes, wetlands and 
groundwater. According to United States Environmental Protection Agency (EPA), watershed is the area of land where all of the water that is under it or drains off of it goes into the same place (Anonymous, 2012b). A watershed is a catchment basin that is bound by topographic features, such as ridge tops (Anonymous, 2012c). In addition watershed defined as a physiographic landscape (Şahin, 2007) and units of hydrologically independent areas (McHarg, 1991). In addition a functioning natural unit with interacting biotic and abiotic components in a system whose boundaries is determined by the cycles and flux of energy, materials and organisms. It is valid to describe different ecosystems with different, overlapping sets of boundaries in the same geographic area (e.g. forest ecosystems, watershed ecosystems and wetland ecosystems). A watershed is one of many types of ecosystems (O' Keefe et al., 2012).

A large numbers of terms are very frequently and loosely used to classify watershed in different sizes (micro, small, and large). "Small watersheds are those where the overland flow is the main contributor to peak runoff / flow and channel characteristic do not affect the overland flow". "Large watersheds are those give peak flows are greatly influenced by channel characteristics and basin storage". Watershed classified according to drainage systems; main river watersheds, watersheds and sub-watersheds (micro watersheds). River watersheds are the areas which all the flows on the ground (river, lake, etc.) flow into the sea through a single river mouth, an estuary or delta from a certain point on the water route. Watersheds are defined as multiple territorial areas which feed a certain water resource (river watershed). However, sub-watersheds (micro watersheds) are defined as catchment areas concerning drainage lines in various sizes which feed watersheds and river watersheds (Karadağ, 2007).

Hydrological systems have along with ecological units, long been viewed as a natural basis for division of the earth's surface. Thus the "watershed" or "catchment" has often been proposed as the most appropriate division for landscape planning. Key reasons have been: its relative self-containment in terms of flows of water, other materials and energy; its relationship to geomorphic processes and the consequent recognisability of landform characterizing individual catchments; and the importance of water, often in short or excess supply, to human settlements. Increasingly, landscape ecologists also recognize the importance of water catchments in influencing the nature and functionality of ecosystem, through their role not only in supplying moisture but also moving chemical nutrients along rivers and though ground and soil water (Selman, 2006).

Watershed classification provides a means for generalizing or grouping watersheds by characteristics such as ecological properties, or land use patterns, so that they can be managed, treated, or compared efficiently. Classification can be based on a number of attributes related to natural or anthropogenic differences in watersheds. Natural features include climate, physiography, soils, nutrient productivity, watershed size and connectivity to other aquatic ecosystems. Anthropogenic features are primarily related to land use and include land-use types (urban, agriculture, forest), the degree of hydrologic disturbance and imperviousness, water withdrawals, water quality, in stream habitat conditions, and riparian integrity (Page, et al., 1999). 
Climate, hydrology, and geomorphology are physical template to shape forces of ecosystems. The three elements of the physical template and other factors also interact significantly in determining the structure and composition of a watershed and its biotic communities. As a result of different combinations of these formative processes, different types of watersheds are created (O' Keefe et al., 2012). Besides watersheds are continually changing and evolving. Some changes are natural, or are accelerated by human activities. A watershed contains information about all the things happening and lands use history within it (Anonymous, 2012d). Because of that watersheds are frequently used to study and manage environmental resources because hydrologic boundaries define the flow of contaminants and other stressors ( $\mathrm{O}^{\prime}$ Keefe et al., 2012).

Each part of a watershed is unique, even though the characteristics of any watershed are similar. All watersheds flow from headwaters to outlets, eventually ending in an ocean. As the water flows, it passes through many parts. And like the parts of a puzzle, if one happens to be damaged, the result affects the whole picture (Anonymous, 2012d). The watersheds are complex ecosystems in which land use, surficial geology, climate, and topography are interrelated with biological components such as vegetation communities (Page, et al., 1999). Weekes (2009) believe that headwater stream flow patterns are homogenous when they have similar climate, bedrock type and hardness, topographical range, drainage area, soils and vegetation). In addition his investigations strongly support that meso-scale geomorphic processes and structures are first order drivers of hydrologic regimes. Geomorphic processes are a part of landscape function. Landscape ecology and catchment hydrology, both disciplines deal with patterns and processes as well as their interactions and functional implications (Schroder, 2006).

A watershed has three primary functions. First, it captures water from the atmosphere. Ideally, all moisture received from the atmosphere, whether in liquid or solid form, has the maximum opportunity to enter the ground where it falls. The water infiltrates the soil and percolates downward. Several factors affect the infiltration rate, including soil type, topography, climate, and vegetative cover. Percolation is also aided by the activity of burrowing animals, insects, and earthworms. Second, a watershed stores rainwater once it filters through the soil. Once the watershed's soils are saturated, water will either percolate deeper, or runoff the surface. This can result in freshwater aquifers and springs. The type and amount of vegetation, and the plant community structure, can greatly affect the storage capacity in any one watershed. The root mass associated with healthy vegetative cover keeps soil more permeable and allows the moisture to percolate deep into the soil for storage. Vegetation in the riparian zone affects both the quantity and quality of water moving through the soil. Water moves through the soil to seeps and springs, and is ultimately released into streams, rivers, and the ocean. Slow release rates are preferable to rapid release rates, which result in short and severe peaks in stream flow. Storm events which generate large amounts of run-off can lead to flooding, soil erosion and siltation of streams (Anonymous, 2012b). This situation, as Schroder (2006) stated, forms the interaction between the landscape and watershed. 
Implementing a watershed approach has environmental, financial, social and administrative benefits. As well as its potential for considerable impact on the environment, this type of approach can result in cost savings by building upon the financial resources, knowledge and the willingness of interested people in the watershed to take action. An action plan that focuses on solutions evolves from those knowing the local issues and opportunities. This can help to enhance local and regional economic viability in ways that are environmentally sound and consistent with defined watershed objectives (Anonymous, 2012b).

\section{How to delineate watershed using the archydro model}

The advantage of Geographic Information Systems (GIS) technology lies in its data synthesis, the geography simulation, and spatial analysis ability. Spatial analytical techniques, geographical analysis and modeling methods are therefore required to analyses data and to facilitate the decision process at all levels within an urban regional context. GIS approach is very efficient as a tool to facilitate the decision-making process (Laurini, 2001). GIS has emerged as a significant support tool for managingand analyzing water resources using digital elevation models (DEM) of land surface terrain.

Various methods are used in determining the river basin boundaries. The traditional methods are determining and drawing the boundaries of drainage divides, peaks, stream beds on the topographical maps by hand. However, the modern methods are determining the boundaries by digitising and analysing the contour lines developed by GIS.

Arc Hydro is a geospatial and temporal data model for water resources designed to operate within ArcGIS (Maidment, 2003). Arc Hydro is a geographical data model that describes hydrological systems. A data model is a set of conceptsexpressed in a data structure; the data model describes a simplification of reality using tables and relationships within a database. Geographic data models use database structures to describe the world or part of it usingGIS technology. The ArcHydro data model is a conceptualization of surface water systems and describes features such as river networks, watersheds and channels. The data model can be the basis for a "hydrologic information system" which is a synthesis of geospatial and temporal data supporting hydrologic analysis and modeling. Arc Hydro integrates geospatial and temporal information into a defined structure. Based on this structure analysis and modeling tools can be applied. The data model provides a common characterization and understanding of the hydrological system and this description canbe utilized by multiple models, analysis tools and decision support systems all referring to the same common structure (Kovar and Nachtnebel, 1996; Strassberg et al.,2011).

This study is going to demonstrate the use of the ArcHydroModel to determine watershed boundaries of a small stream (Köprü stream) in the Central Mediterranean Basin. The hydrologic modeling involves delineating streams network and watersheds, and getting some basic watershed properties such as area, flow length, stream network density, etc. Traditionally this was (and still is!) being done manually by using topographic/contour maps. But in ArcHydro Model analysis is performed by using DEM (Ayhan et al., 2012). DEM generation from topographic maps that derived from a 10 meter DEM from the General Command of Mapping (Turkey). 
Watershed and drainage systems can define generally with 4 stages and 11 analysis in ArcHydro module. At the first stage of the analysis, "DEM reconditioning" and "fill sink" analysis, which are confirmation and preparation processes for the given analysis, are carried out. At the second stage, "Flow direction, Flow Accumulation, Stream Definition" and "Stream Segmentation" analysis, by which evaluations concerning surface flow are made, are carried out. At the third stage, "Catchment Grid Delineation" and "Catchment Polygon Processing" analysis, by which catchment areas are determined, are carried out. At the last stage, "Drainage Line Processing", "Drainage Point Processing" and "Batch Watershed Delineation" analysis, by which watershed boundaries are defined by evaluating drainage systems according to surface flow and catchment areas, are carried out. But first of all, Archydro tools must be downloaded to the computer to start the analysis. Archydro tool 1.3 is downloaded because of ArcMap 9.3 is used in this study.

First stage of Archydro Model is Terrain Preprocessing. Arc Hydro Terrain Preprocessing should be performed in sequential order. All of the preprocessing must be completed before Watershed Processing functions can be used. DEM reconditioning and filling sinks might not be required depending on the quality of the initial DEM. DEM reconditioning involves modifying the elevation data to be more consistent with the input vector stream network. This implies an assumption that the stream network data are more reliable than the DEM data, so you need to use knowledge of the accuracy and reliability of the data sources when deciding whether to do DEM reconditioning. By doing the DEM reconditioning you can increase the degree of agreement between stream networks delineated from the DEM and the input vector stream networks (Mervade et al., 2009; Ayhan et al., 2012; Mervade, 2012).

DEM Reconditioning: This function modifies a DEM by imposing linear features onto it (burning/fencing). The function needs as input a raw dem and a linear feature class (like the river network) that both have to be present in the map document (Mervade et al., 2009; Ayhan et al., 2012; Mervade, 2012). This function is located on Terrain Preprocessing on the ArcHydro Toolbar (Terrain Preprocessing- $\bigoplus E M$ Manipulation $\bigoplus E M$ Reconditioning) (Mervade et al., 2009; Ayhan et al., 2012; Mervade, 2012).

Select the appropriate Raw DEM (köprü_dem) and AGREE stream feature (köprü_str). Set the Agree parameters as shown. You should reduce the Sharp drop/raise parameter to 10 from its default 1000. The output is a reconditioned Agree DEM (default name Agree DEM). A personal geodatabase with the same name as your ArcMap document has also been created as shown in the following ArcCatalog view (Figure 1.)(Mervade et al., 2009; Ayhan et al., 2012; Mervade, 2012).

Fill Sinks: This function fills the sinks in a grid. If cells with higher elevation surround a cell, the water is trapped in that cell and cannot flow. The Fill Sinks function modifies the elevation value to eliminate these problems. The model readjusts the height value with this stage to solve the problem. Therefore, the drainage networks' being asunder is prevented. This function is located on Terrain Preprocessing on the ArcHydrotoolbar (Terrain Preprocessing ĐataManipulation Pill Sinks) (Mervade et al., 2009; Ayhan et al., 2012; Mervade, 2012). 

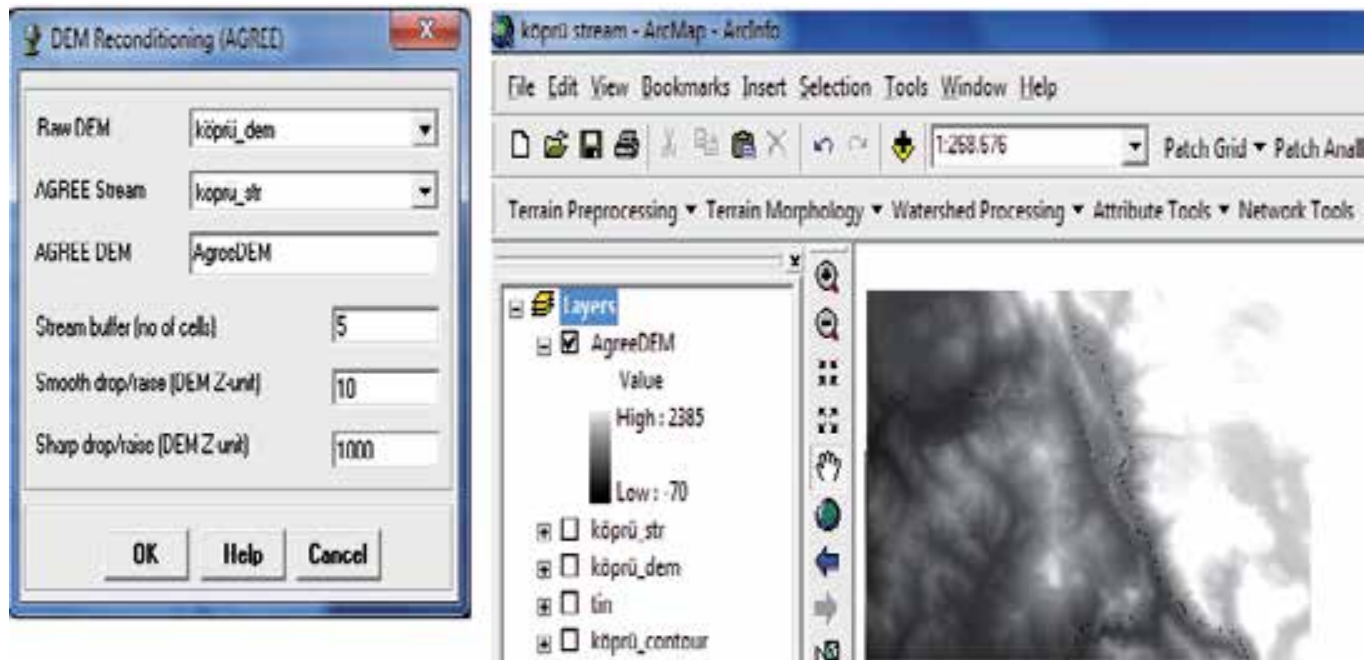

Figure 1. DEM Reconditioning menu and AgreeDEMlayer.

Confirm that the input for DEM is AgreeDEM. The output is the Hydro DEM layer, named by default Fil. This default name can be overwritten. Leave the other options unchanged. The Fil layer is added to the map, when the process completed (Figure 2.) (Mervade et al., 2009; Ayha net al., 2012; Mervade, 2012).
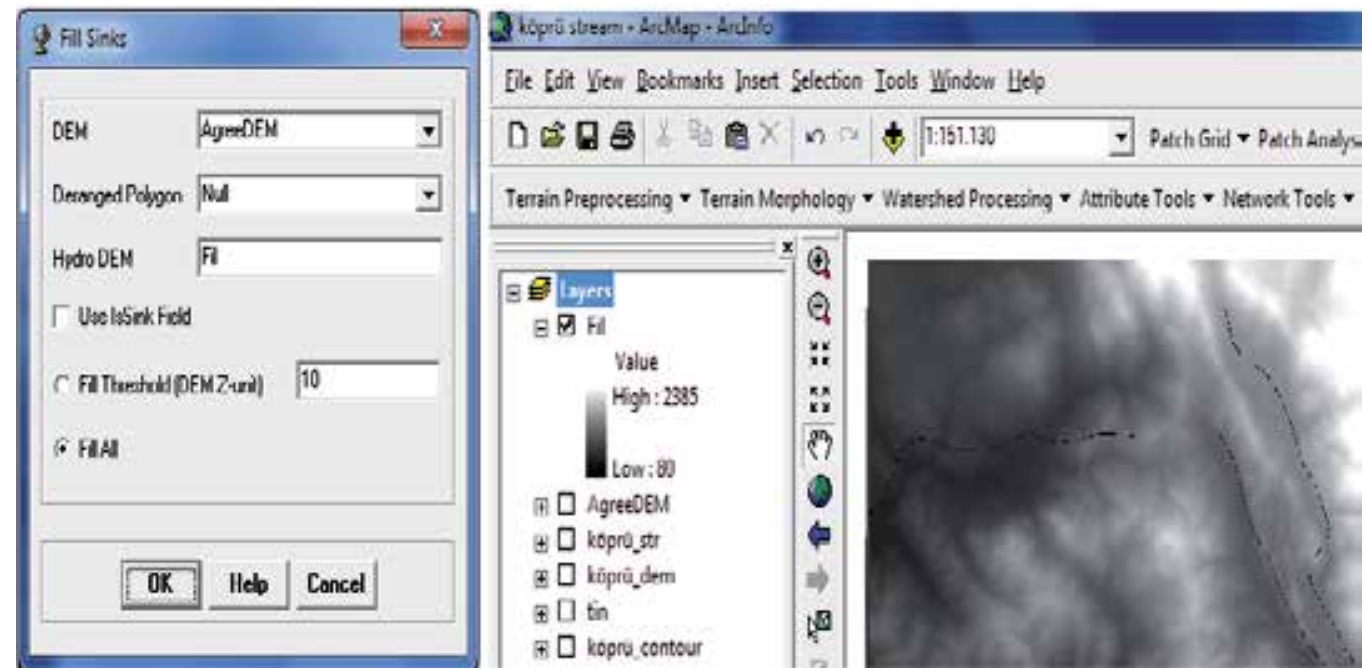

Figure 2. Fill Sinks menuand Fillayer.

Flow direction: This function computes the flow direction for a given grid. Each grid has a value of height and water flow will be towards the lowest one, by comparing the height values of 8 grids. The flow direction is defined as "8 directional flow model" in the computer environment. Digital values, which are developed depending on the directions, are used to show the flow direction of the grid in the module. This function is located on 
Terrain Preprocessing on the ArcHydro toolbar (Djokic 2008, Mervade et al., 2009; Ayhan et al., 2012; Mervade, 2012).

Confirm that the input for Hydro DEM is Fil. The output is the Flow Direction Grid, named by default Fdr. This default name can be overwritten. The flow direction grid Fdr is added to the map, when the process completed (Figure 3.) (Mervade et al., 2009; Ayhan et al., 2012; Mervade, 2012).
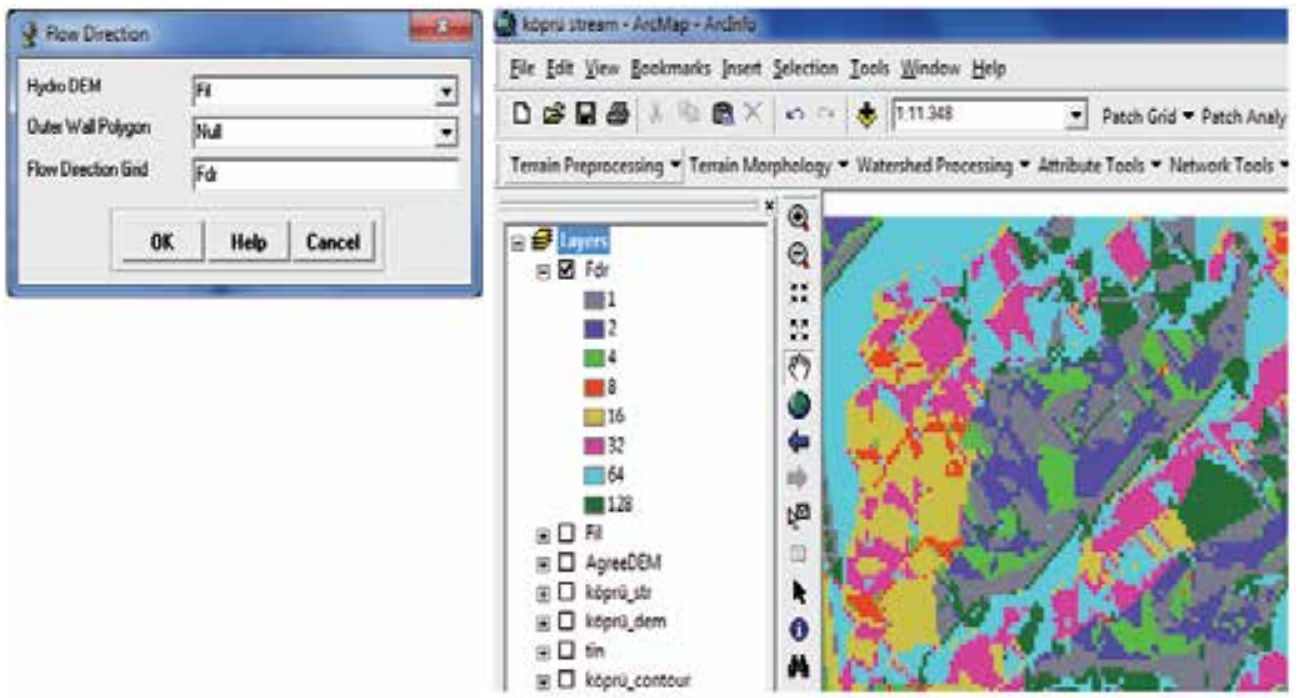

Figure 3. Flow direction menu and Fdrlayer.

Flow Accumulation: This is the stage in which the cells taking place in the catchment area of each cell are calculated. The water gathered in the lowest grade is calculated, by assuming that each cell has 1 unit of water. The system defines the value of the cells having no flow as zero, and cells in which water gathers are defined in the number of cells having flow. The flow calculation is carried out by taking 8 cells as basis. This function is located on Terrain Preprocessing on the ArcHydrotoolbar (Mervade et al., 2009; Ayhan et al., 2012; Mervade, 2012).

Confirm that the input of the Flow Direction Grid is Fdr. The output is the Flow Accumulation Grid having a default name of Fac that can be overwritten. The flow direction grid Fac is added to the map, when the process completed. Adjust the symbology of the Flow Accumulation layer Fac to a multiplicatively increasing scale to illustrate the increase of flow accumulation as one descends into the grid flow network (Mervade et al., 2009; Ayhan et al., 2012; Mervade, 2012).

Zoom-in to a stream network junction to see how the symbology changes from light to dark color as the number of upstream cells draining to a stream increase from upstream to downstream. If you click at any point along the stream network on Fac grid using the identify button you can find the area draining to that point by multiplying the Fac number by the area of each cell (cell size x cell size which is $30.89 \times 30.89$ in this case) (Figure 4.) (Mervade et al., 2009; Ayhan et al., 2012; Mervade, 2012). 

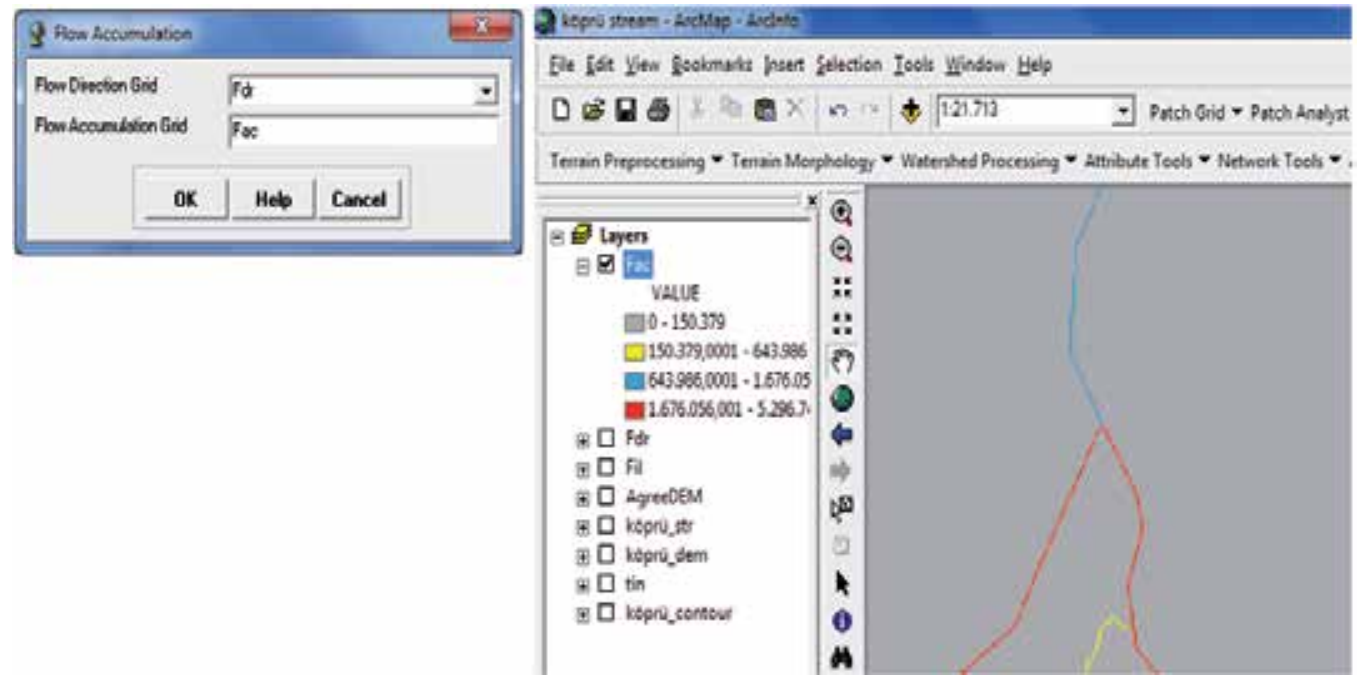

Figure 4. Flow Accumulation menu and Faclayer.

Stream Definition: This function computes a stream grid which contains a value of "1" for all the cells in the input flow accumulation grid that have a value greater than the given threshold. All other cells in the Stream Grid contain no data. This function is located on Terrain Preprocessing on the ArcHydro toolbar (Mervade et al., 2009; Ayhan et al., 2012; Mervade, 2012).

Confirm that the input for the Flow Accumulation Grid is "Fac". The output is the Stream Grid. "Str" is its default name that can be overwritten. The stream grid Str is added to the map, when the process completed (Figure 5.) (Mervade et al., 2009; Ayhan et al., 2012; Mervade, 2012).
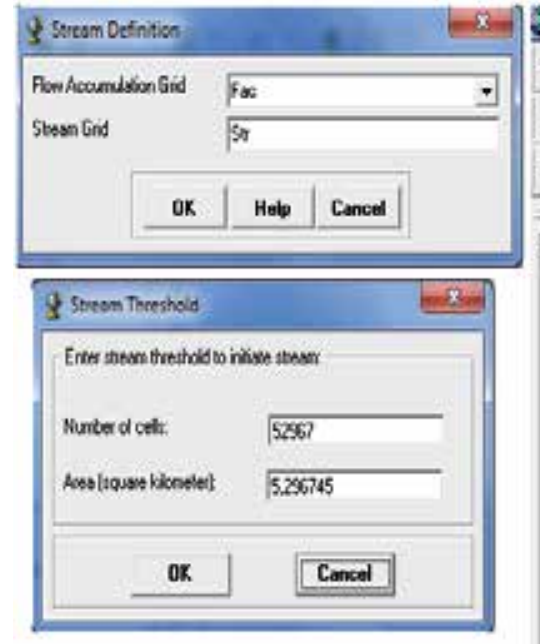

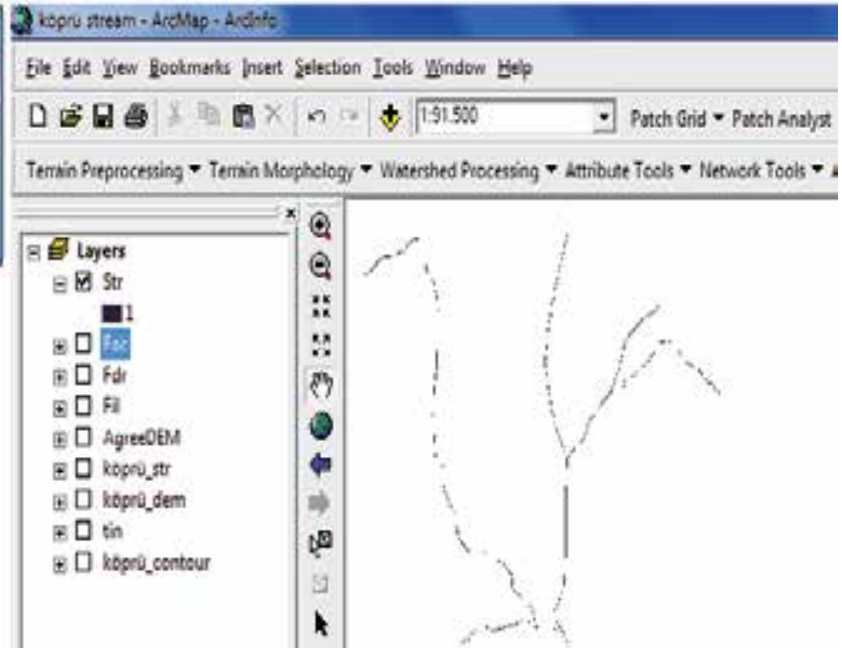

Figure 5. Stream Defination menu and Str layer. 
Stream Segmentation: This function creates a grid of stream segments that have a unique identification. Either a segment may be a head segment, or it may be defined as a segment between two segment junctions. All the cells in a particular segment have the same grid code that is specific to that segment. This function is located on Terrain Preprocessing on the ArcHydro toolbar (Mervade et al., 2009; Ayhan et al., 2012; Mervade, 2012).

Confirm that Fdr and Str are the inputs for the Flow Direction Grid and the Stream Grid respectively. Unless you are using your sinks for inclusion in the stream network delineation, the sink watershed grid and sink link grid inputs are Null. The output is the stream link grid, with the default name StrLnk that can be overwritten. The link grid StrLnk is added to the map, when the process completed (Figure 6.) (Mervade et al., 2009; Ayhan et al., 2012; Mervade, 2012).
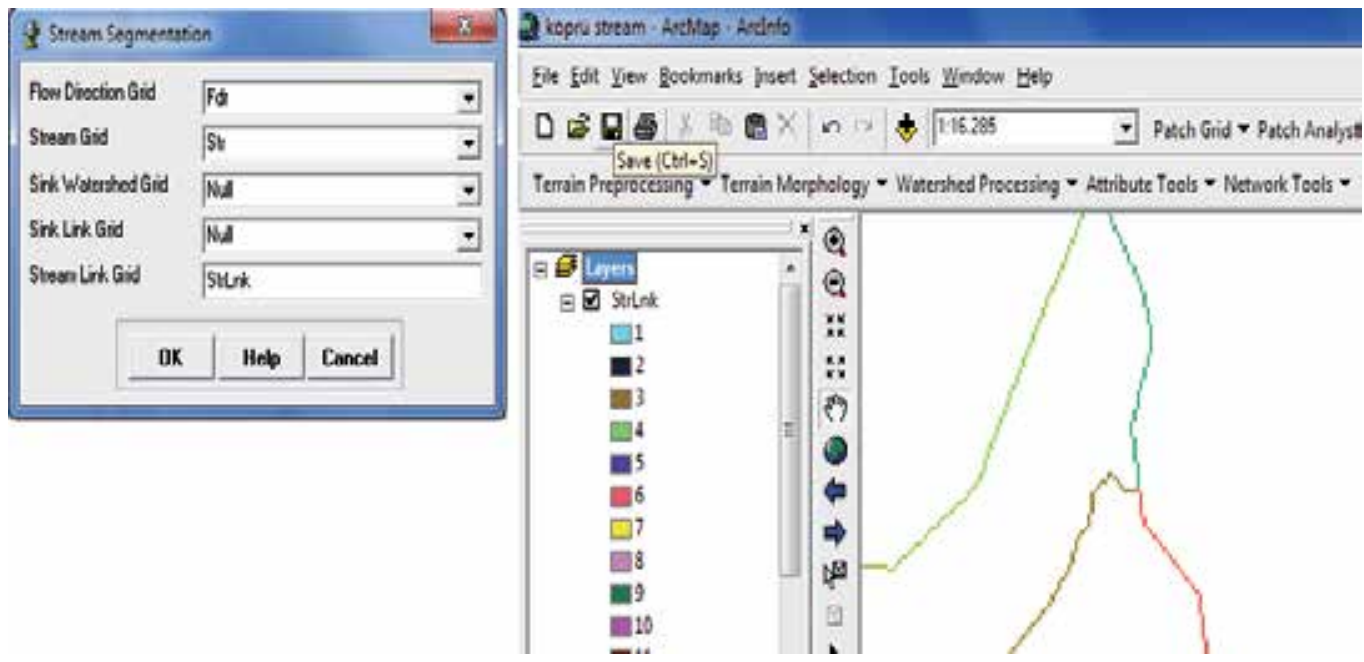

Figure 6. Stream Segmentation menu and StrLnk layer.

Catchment Grid Delination: This function creates a grid in which each cell carries a value (grid code) indicating to which catchment the cell belongs. The value corresponds to the value carried by the stream segment that drains that area, defined in the stream segment link grid. This function is located on Terrain Preprocessing on the ArcHydro toolbar (Mervade et al., 2009; Ayhan et al., 2012; Mervade, 2012).

Confirm that the input to the Flow Direction Grid and Link Grid are Fdr and Lnk respectively. The output is the Catchment Grid layer. Cat is its default name that can be overwritten by the user. The link grid StrLnk is added to the map, when the process completed. The Catchment grid Cat is added to the map, when the process completed. In addition study case will have 70 catchment (Figure 7.) (Mervade et al., 2009; Ayhan et al., 2012; Mervade, 2012).

Catchment Polygon Processing:This function converts a catchment grid into a catchment polygon feature. This function is located on Terrain Preprocessing on the ArcHydro toolbar (Mervade et al., 2009; Ayhan et al., 2012; Mervade, 2012). 

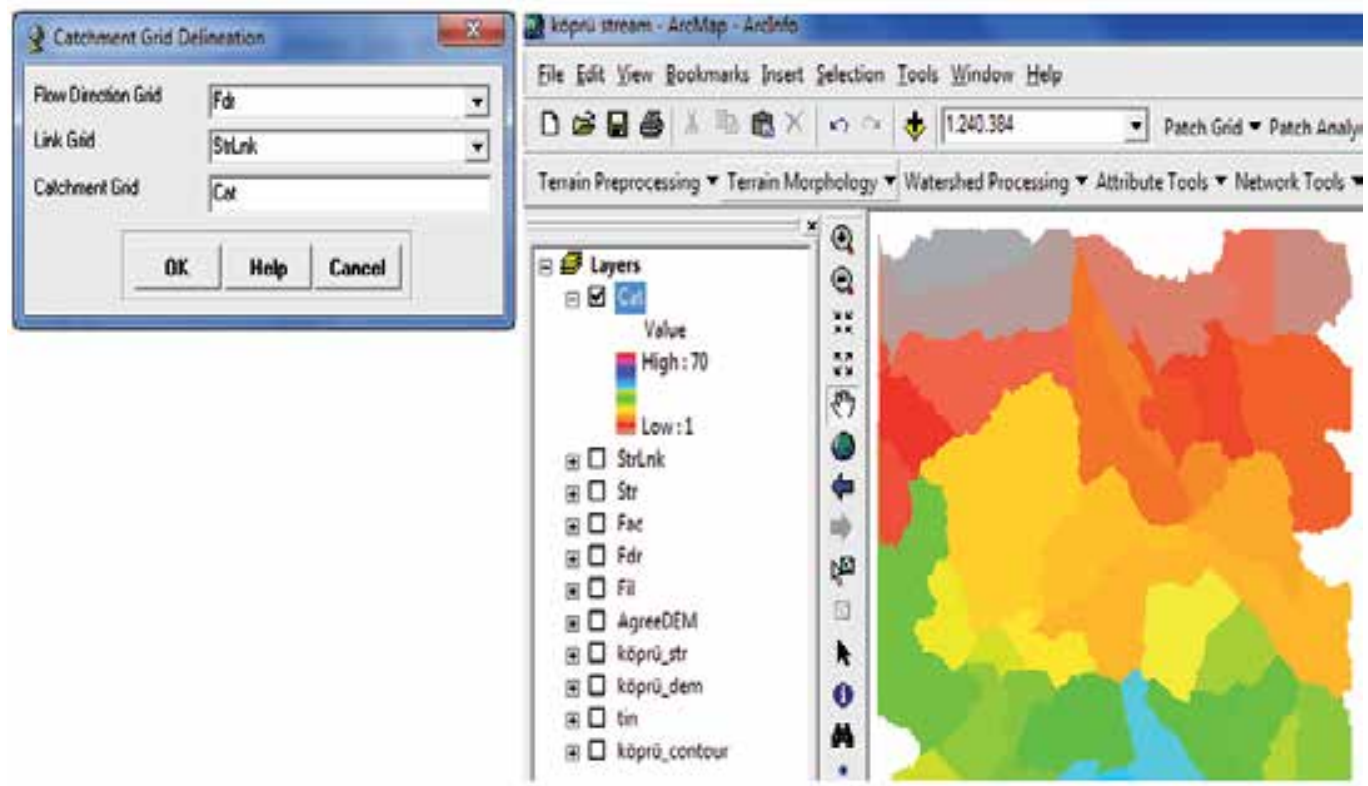

Figure 7. Catchment grid menu and Cat layer.

Confirm that the input to the CatchmentGrid is Cat. The output is the Catchment polygon feature class, having the default name Catchment that can be overwritten. The polygon feature class Catchment is added to the map, when the process completed. In addition there are important information (HydroID assigned, Length and Area attributes of catchment) in attribute table of Catchment (Figure 8.) (Mervade et al., 2009; Ayhan et al., 2012; Mervade, 2012).
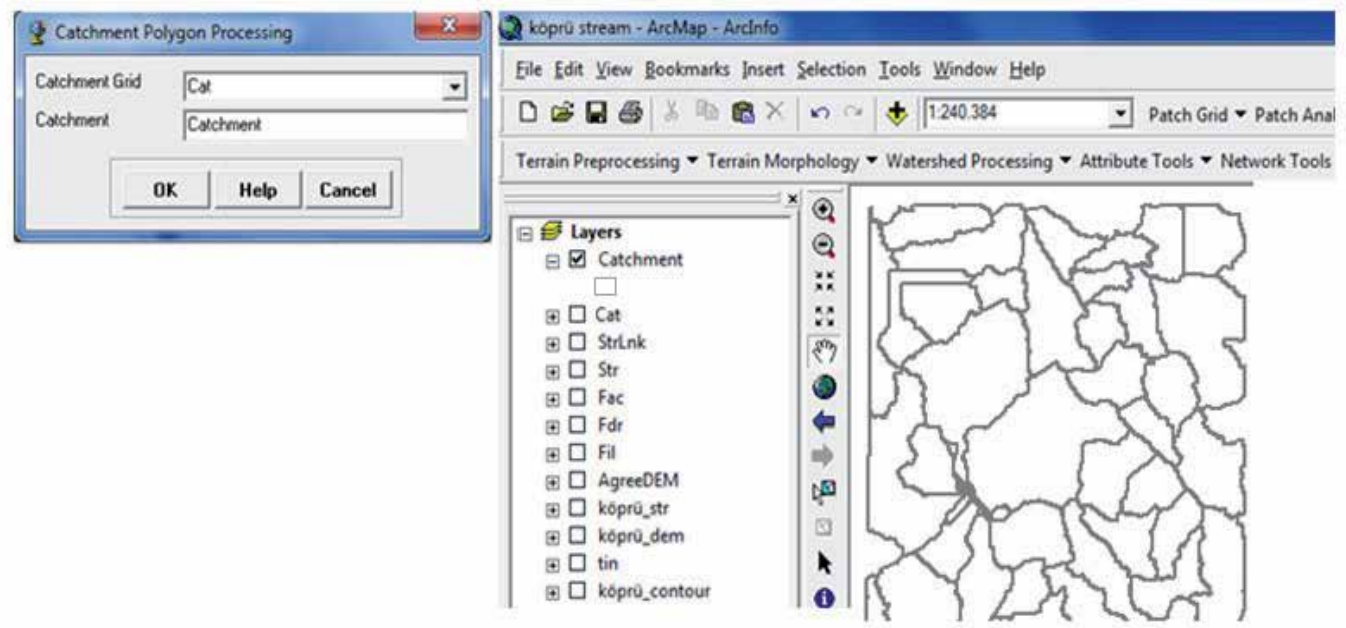

Figure 8. Catchment polygon processing menu and Catchment layer.

Drainage Line Processing: This function converts the input Stream Link grid into a Drainage Line feature class. Each line in the feature class carries the identifier of the 
catchment in which it resides. This function is located on Terrain Preprocessing on the ArcHydro toolbar (Mervade et al., 2009; Ayhan et al., 2012; Mervade, 2012).

Confirm that the input to Link Grid is Lnk and to Flow Direction Grid Fdr. The output Drainage Line has the default name DrainageLine that can be overwritten.The linear feature class DrainageLine is added to the map, when the process completed (Figure 9.) (Mervade et al., 2009; Ayhan et al., 2012; Mervade, 2012).
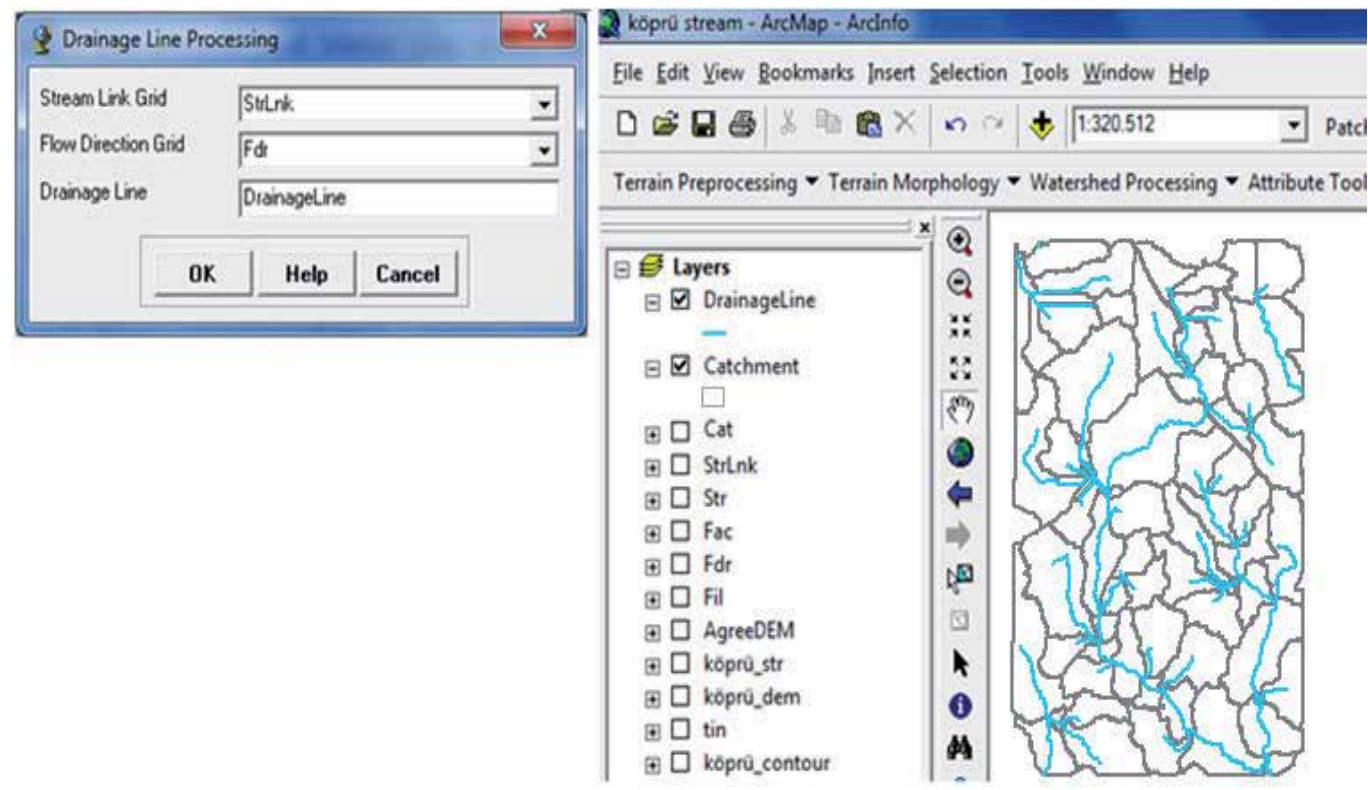

Figure 9. Drainage line processing menu and Drainageline layer.

Drainage Point Processing: This function allows generating the drainage points associated to the catchments. This function is located on Terrain Preprocessing on the ArcHydro tools(Mervade et al., 2009; Ayhan et al., 2012; Mervade, 2012).

Confirm that the inputs are as below. The output is Drainage Point with the default name DrainagePoint that can be overwritten. Upon completion of the process, the point feature class "DrainagePoint" is added to the map (Figure 10.) (Mervade et al., 2009; Ayhan et al., 2012; Mervade, 2012).

Watershed Processing: Arc Hydro toolbar also provides an extensive set of tools for delineating watersheds and subwatersheds. These tools rely on the datasets derived during terrain processing.

Batch watershed delineation function delineates the watershed upstream of each point in an input Batch Point feature class. Batch Point Generation can be used to determine the outlet of the watershed. Arrange your display so that Fac, Catchment and DrainageLine datasets are visible. Zoom-in near the outlet of the Köprü stream watershed (Figure 11.). The display should look similar to the figure shown below and be zoomed in sufficiently so you can see 
and click on individual grid cells. Our goal is to create an outlet point on the flow accumulation path indicated by Fac grid where the flow leaves the Köprü stream watershed (Mervade, 2012).
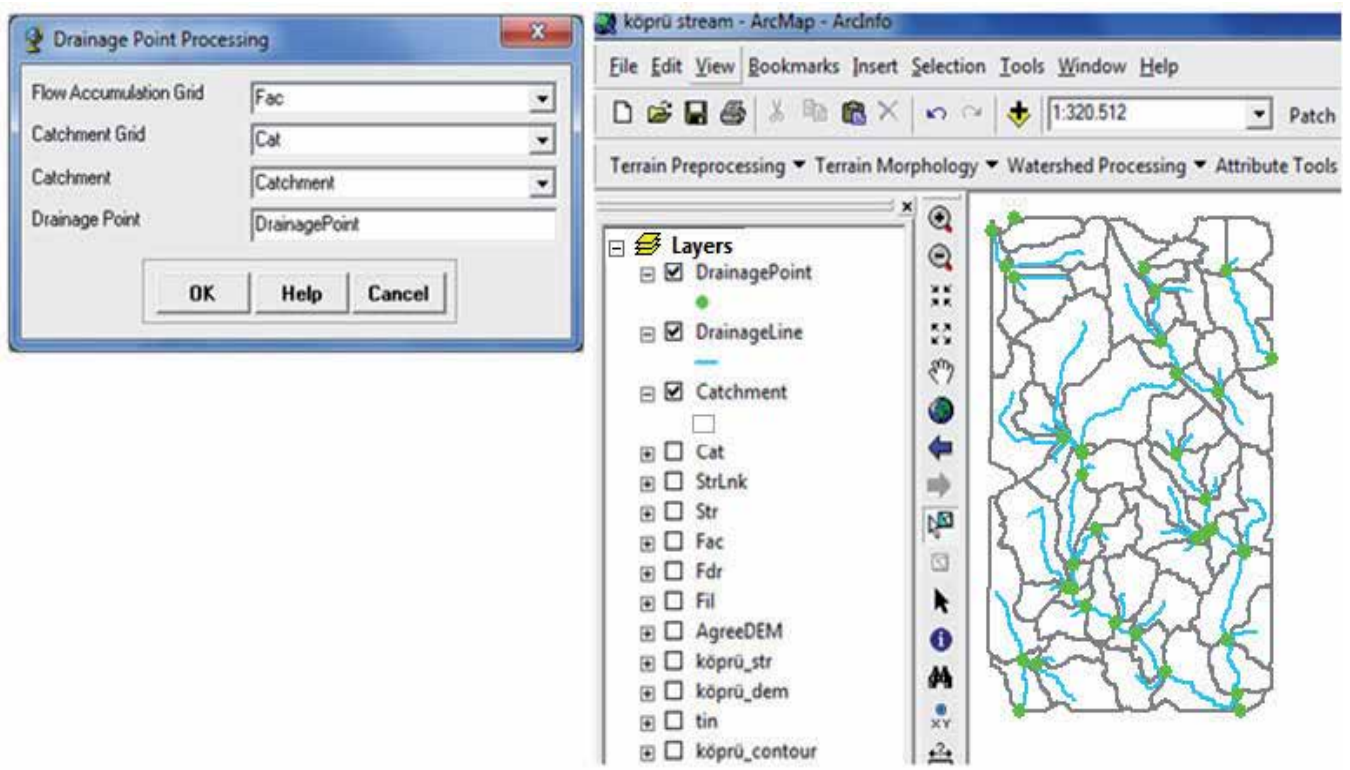

Figure 10. Point processing menu and Drainage point layer.
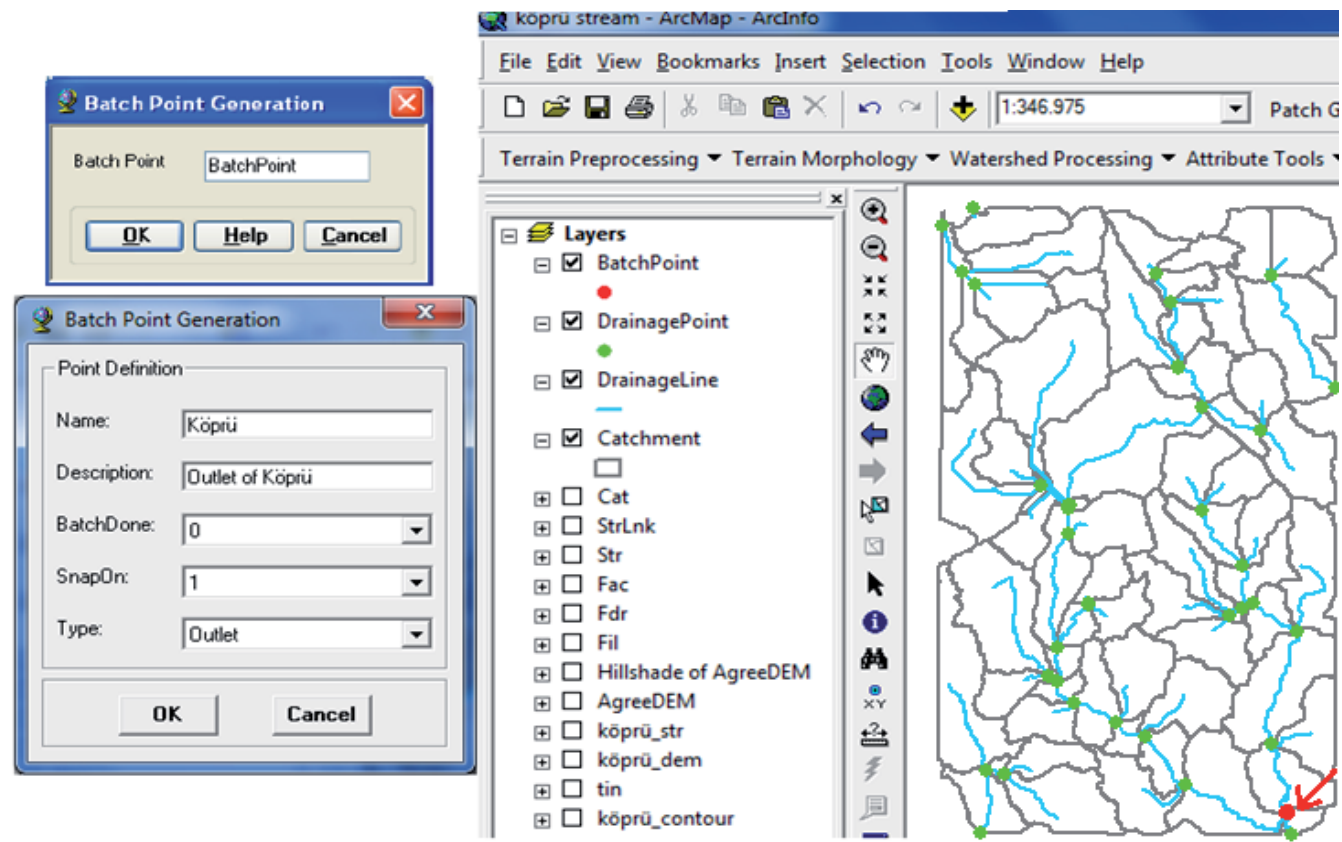

Figure 11. Batch Point generation 
Batch watershed delineation function delineates the watershed. This function is located on Watershed Processing on the ArcHydro Toolbar. Confirm that Fdr is the input to Flow Direction Grid, Str to Stream Grid, Catchment to Catchment, AdjointCatchment to AdjointCatchment, and BatchPoint to Batch Point. For output, the Watershed Point is WatershedPoint, and Watershed is Watershed (Figure 12.). WatershedPoint and Watershed are default names that can be overwritten (Mervade et al., 2009; Ayhan et al., 2012; Mervade, 2012).

You can see that area and length, if you open the attribute table of Köprü_watershed. In addition you will see that these two are related through HydroID-the DrainID of WatershedPoint is equal to the HydroID of the watershed, when you open the attribute table of catchment and DranaigePoint. At the same time you can learn length of drainage line from attributes table of DranaigeLine (Mervade et al., 2009; Mervade, 2012).
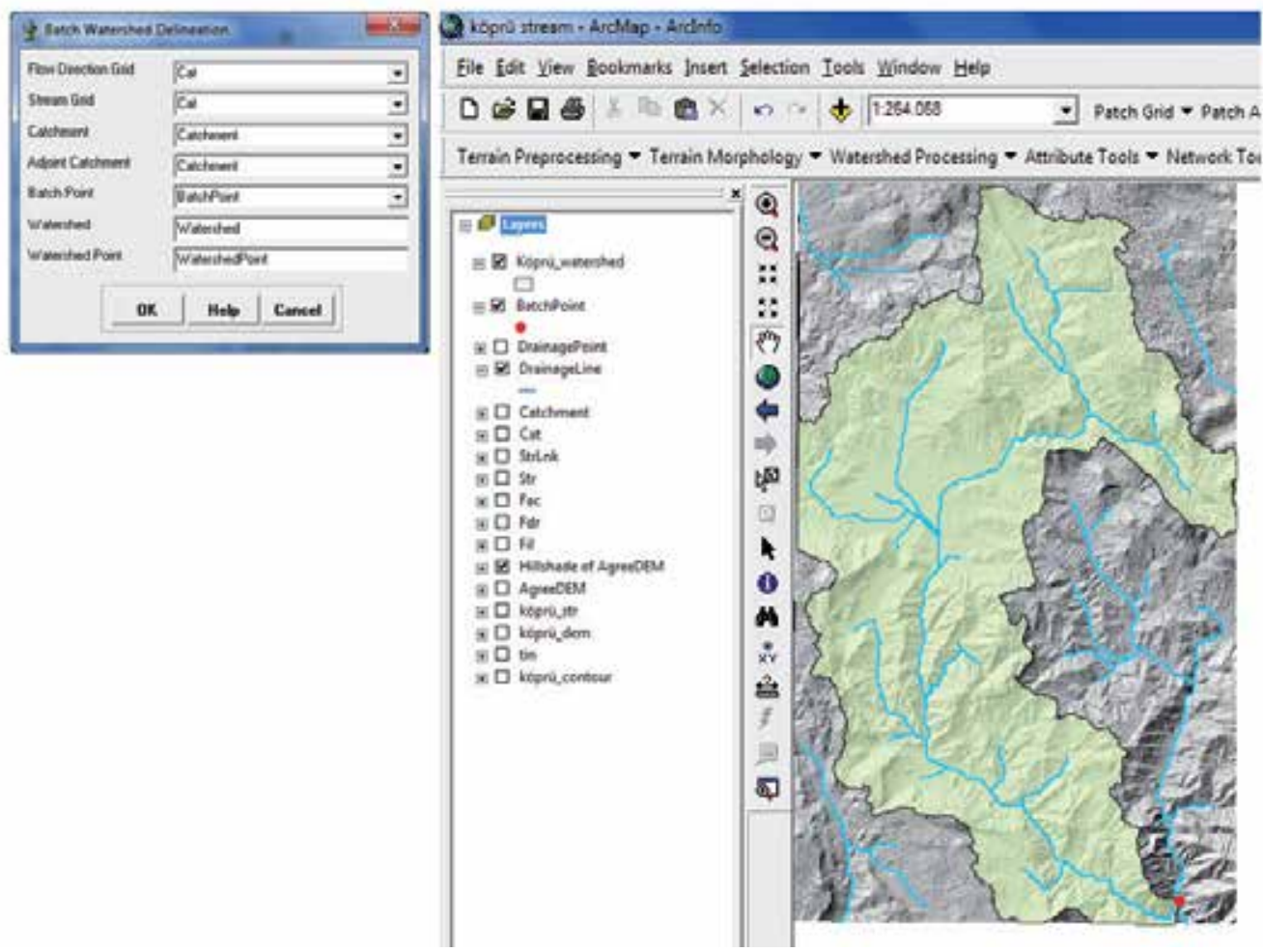

Figure 12. Batch watershed delineation and Köprü stream watershed

\section{Conclusion}

The future of our present societies is determined by environmental, social, economic and political situations and the problems and the solutions concerning these issues. Landscape, which can be defined as the interaction space or product of natural and cultural processes, puts its relation with future at this point. The concept of future brought about the concept of 
planning, which is evaluated in different topics, and transformed landscape planning into a part of the future. Therefore, ecological, aesthetic and economic importance of landscape has become a topic for many researchers and the need for landscape planning is emphasised. At last, vital importance of landscape and need for its being planned were transferred to a legal text when European Landscape Convention was signed in 20 October 2000.

The aims of European Landscape Convention are to promote landscape protection, management and planning, and to organise European co-operation on landscape issues. The Convention applies to the entire territory of the Parties and covers natural, rural, urban and peri-urban areas. It includes land, inland water and marine areas. It concerns landscapes that might be considered outstanding as well as every day or degraded landscapes. Landscape planning means strong forward-looking action to enhance, restore or create landscapes in the Convention (Anonymous, 2000). The convention intended to plan landscape with a "comprehensive, pedant, holistic, coordinated, participant, rationalist" approach. Also, with the expression "transboundary landscape", which took place in $9^{\text {th }}$ clause of the convention and which emphasised local and regional cooperation, brought about the concept of "planning boundary".

The planning, which is defined as balancing the needs and the resources in the long run by complying with the reasonable priorities to reach certain aims with limited resources (Keleş, 2004), is a versatile activity from upper scale to subscale and a body of decisions related to past, present and future integrating social, economic, political, physical, anthropogenic and technical elements, as Alipour (1996) stated (Uzun et. al. 2012). This general definition of planning requires landscape planning to be made in different scales and accordingly in certain boundaries. Also, as Uzun et. al. (2012) stated, the boundaries of the study area are the first stage of planning and are very important in clarifying the goal. The data gathering, which enables the planning to be carried out systematically and defines success (Mcharg, 1967), depends on the boundaries of the planning area. Ultimately, the management process of realising the plan will be integrated with the administrative structuring within the boundaries. All these put the importance of the question "What should be the boundary of landscape planning?" forward.

When determining the boundaries of landscape, the fact that landscape is "a space in which natural, socio-cultural and economical life come together" should not be ignored. This situation emphasises that the boundary of landscape shouldn't just describe the natural areas (eco-zone, ecoregion, habitat, etc.) or administrative spaces. Therefore, the boundary will be integrated with the body of the landscape. Within this context of approach, there are various consistent points of view about the boundary of landscape. Meijerink (1985) considered that watersheds were the best units in which the interactions of human and natural resources, and the geographical distribution of their consequences could be observed and modeled (Metzger and Muller, 1996). Gregersen et al. (1987), said watersheds can use as a physical-biological and a socioeconomic-political units for planning of natural resources (Graff, 1993). According to Farrina (2006) watersheds are examples of the hierarchical organization of the landscape. River watershed is composed of sub-watershed, 
each of which is composed of smaller-order watershed. The upper and lower limits of this hierarchy are not definitive but it is possible to move in both directions, including smaller and larger basins. Tangtham (1996) and Karadağ (2007) lay stress on watershed classification is thus anticipated as a useful tool for management and planning of natural resources. Selman (2006) emphasized the importance of watershed boundaries in landscape ecology. Makhdoum (2008) indicated that the mapping unite (or land unit) is freely derived from watershed, land system, land form units and ecosystems, at different scale level. He accepted watershed as one of mapping units in land ecology. Bulley et al. (2007) point out that watershed provides an important spatial framework to develop a classification system. Şahin (2007) and Şahin (2009) suggests that watershed can be descriptive and administrative units for landscape planning. According to EPA watershed is an example of hierarchical system in nature (Anonymous 2012a). Efe and Aydın (2009), indicated that the provincial boundaries which constitute the framework of the administrative organization where planning is currently authorized do not coincide with the natural boundaries. They suggest redefining the provincial boundaries compatible with watershed for the protection of the nature.

Actually watershed clarifies the complexity of boundary in the landscape. When we consider the importance of water in life of living things, its effect on establishing, developing and even collapsing civilisations, it is clear that watershed will be effective boundaries in landscape planning; because water turns into the interaction space of natural and cultural life while forming socio-cultural and economical life by its presence. This situation enables a watershed to turn into not only a natural boundary, but also a boundary that effects a human's life. Also, the landscape changes as nature reshapes with human life. The changing landscape gains a new character. This character is not only a product of the change of the natural structure caused by the human presence, but also can be expressed with a hierarchal system from a local scale to upper scales. Thus, the watershed supports the scale approach in the planning with its hierarchal structure (main river basin, basin, subbasin, microbasin). Along with that, the main river basins that go beyond the national boundaries will be able to easily define its collaborators in the transnational landscapes.

\section{Author details}

Aybike Ayfer Karadağ

Düzce University, Faculty of Forestry, Department of Landscape Architecture, Turkey

\section{References}

Anonymous, 2000. The European Landscape Convention. Council of European, 51p.

Anonymous, 2008. Landscape Planning the Basis of Sustainable Landscape Development. Federal Agency for Nature Conservation. Gebr Klingenberg Buchkunst Leipzing Gmbh Printed, 52p.

Anonymous, 2012a. Watershed Planning http://www.conservewy.com (Accessed on: 10.11.2012) 
Anonymous, 2012b. What is a Watershed. United States Environmental Protection Agency. www. http://www. water.epa.gov Anonymous, 2012a. (Accessed on: 2.12.2012)

Anonymous, 2012c. An Introduction to Urban Watersheds.

http://www.gdrc.org/uem/water/watershed/introduction.html (Accessed on: 12.01.2012)

Anonymous, 2012d. Getting to Know. http://www.agric.gov.ab.ca (Accessed on: 12.12.2012).

Antrop, M. 2005. From Holistic Landscape Synthesis to Transdisciplinary Landscape Management. In: Tress, B., Tress, G. Fry, G. En Opdam, P. From Landscape Research to Landscape Planning: Aspect of Integration, Education and Aplication. Wageningen, Frontis, p.27-50.

Ayhan, N. G., Seyrek, K. and Sargin, A. H., 2012. Application of Geographic Information Systems in Hydrology and Water Resources Management.Printed Course Note. ISLEM Group of Companies, Ankara, Turkey, 80p.

Baker, W. L. 1989. A Review of Models of Landscape Change. Landscape Ecology, 2(2), p.111-133.

Bastian, O. Krönert, R., and Lipsky, Z. 2006. Landscape Diagnosis on Different Space and Time Scales - A Challenge for Landscape Planning. Landscape Ecology, Vol. 21, p.359374.

Booth, B. 2000. Using ArcGIS 3D Analyst GIS by ESRİ. Environmental Systems Research Institute, Inc, USA, 212p.

Bulley, H.N. N., Merchant, J. W., Marx, D. B., Holz, J. C. and Holz, A. A.H. 2007. A GISBased Approach to Watershed Classification for Nebraska Reservoirs. Journal of The American Water Resources Association, 4(3), p.605-620.

CaO'Callaghan, J. R. 1996. Land Use: The Interaction of Economics, Ecology and Hydrology. Chapman \& Hall Publisher, London, UK, 197p.

Clark, W. 2010. Principles of Landscape Ecology. Nature Education Knowledge, 3(10), 34p.

Davenport, T., Minsch, K., Novak, C. Olsenholler, S., Sagona, F., Sprunger, E. and Warren, J. 2012. Getting to Know Your Local Watershed.

http://www.ctic.purdue.edu

Dijokic, D. 2008. Comprehensive Terrain Preprocessing Using Arc Hydro Tools. ESRI, New York, USA.

Dökmeci, V. H. 1996. Sustainable and Landscape Planning. Unprinted Master Seminar. University of Ankara, Graduate School of Natural and Applied Sciences, Department of Landscape Architecture, Ankara, Turkey.

Du-ning, X. and Xiu-Zhen, L. 1999. Core Concepts of Landscape Ecology. Journal of Environmental Sciences, 11(2), p.131-135.

Efe, M. and Aydin, B. A. 2009. Change ability of Planning Based on Administrative Boundaries and Proposal Boundaries of Provincial Based on Basin. Aegean Geographical Journal, Izmir, Turkey, 18(1-2), p.73-84.

Farina, A. 2001. Landscapes and Their Ecological Components. The Living World, Vol. 4, p.435-448.

Farina, A., Bogaert, J. and Scipani, I. 2005. Cognitive Landscape and Information: New Perspectives to Investigate the Ecological Complexity. Bio Systems, No. 79, p.235-240. 
Farina, A. 2006. Principles and Methods in Landscape Ecology. Kluwer Academic Publishers, USA, 436p.

Forman, R. T.T. and Gordon, M. 1986. Landscape Ecology.Wiley and Sons, New York, USA, $620 \mathrm{p}$.

Forman, R. T.T. 1995. Land Mosaic. The Ecology of Landscapes and Regions. Cambridge University Press, UK, 632p.

Graff, J. 1993. Soil Conservation and Sustainable Land Use. A Royal Institute Series, Amsterdam, 191p.

Ivits, E., Koch, B., Blaschke, T., Jochum, M and P. Adler, P. 2005. Landscape Structure Assessment with Image Grey-Values and Object-Based Classification at Three Spatial Resolutions. International Journal of Remote Sensing, 26 (14), p.2975-2993.

Jones, M., Howar, J., Olwing K. R., Primdahl, J. and Herlin, I. S. 2007. Multiple Interfaces of the European Landscape. Norwegian Journal of Geography, 61(4), p.207-216.

Kaden, S. 2003. GIS in Water-Related Environmental Planning and Management: Problems and Solutions. Application of Geographic Information Systems in Hydrology and Water Resources Conference, IAHS Publisher, Vietnam, No. 211, p. 385-396,

Karadağ, A. A. 2007. Development of Participatory Watershed Management Model: The Case of Kovada Lake. Ph. D. Thesis. University of Ankara, Graduate School of Natural and Applied Sciences, Department of Landscape Architecture, Ankara, Turkey, 254p.

Keleş, R. 2012. Urbanization Policy. İmge Kitapevi Press, No.8, Ankara, Turkey, 703p.

Kovar, K and Nachtnebel H.P. 1996. Application of Geographic Information Systems in Hydrology and Water Resources Management. The International Association of Hydrological Sciences, 235p.

Köseoğlu, M. 1982. Landscape Evaluation Methods. University of Ege Faculty of Agriculture. Ofset Publisher, İzmir, Turkey, No.430, 138p.

Kurum, E. and Şahin, Ş. 2000. Determination of High Landscape Value in Watershed Management Areas: Analysis of Soil-Vegetation Protection. Our Environment and Landscape Architecture in the 2000's Symposium. University of Ankara, Turkey, p.7581.

Laurini, R. 2001. Information Systems for Urban Planning.Taylor \& Francis, London and New York, 368p.

Maidment, D. R. 2002. Arc Hydro: GIS for Water Resources, ESRI Press, Redlands, 201p.

Makhdoum, M. F. 2008. Landscape Ecology or Environmental Studies (Land Ecology) (European Versus Anglo- Saxon Schools of Thought). J. Int. Environmental Application \& Science, 3 (3), p.147-160.

Makhzoumi, J. and Pungetti, G. 1999. Ecological Landscape Design and Planning: The Mediterranean Library. E\&FN Spon Publisher, New York, USA, 330p.

Mander, Ü. and Antrop, M. 2003. Multifunctional Landscapes Continuity and Change.Wit Press, USA, 289p.

McHarg, I. L. 1967. Design in Nature. John Wiley \& Sons. Washington, USA, 198p.

Mervade, V., Maidment, D. and Robayo, O. 2009. Watershed and Stream Network Delineation GIS in Water Resources. University of Texas, Center for Research in Water Resources, Printed Lecture Note, Texas, USA, 26p. 
Mervade, V. 2012. Watershed and Stream Network Delineation Using ArcHydro Tools. University of Purdue, School of Civil Engineering, Printed Lecture Note, USA, 22p.

Metzger, J. P. and Muller, E. 1996. Characterizing the Complexity of Landscape Boundaries by Remote Sensing.Landscape Ecology, 11 (2), p.65-77.

McHarg, I. L. 1991. Design With Nature. Wiley and Sons, New York, USA, 198p.

Mostaghimi, S., Park, S.W., Cooke, R.A. and Wang S. Y. 1997. Assessment of Management Alternatives On a Small Agricultural Watershed. Journal of Water Resources, 31 (8), p. 1867-1997.

Opdam, P., Steingröver, E. and Van Rooij, S. 2006. Ecological Networks: A Spatial Concept for Multi-Actor Planning of Sustainable Landscapes. Landscape and Urban Planning, 75 (3-4), p. 322-332.

O'Callaghan, J. R. 1996. Land Use: The Interaction of Economics, Ecology and Hydrology. London: Chapman \& Hall, 216p.

O' Keefe, T. C., Elliott, S. R. and Naiman, R. J. 2012. Introduction to Watershed Ecology. Watershed Academy Web Documents, Environmental Protection Agency, USA, p.1-37.

Page, N., Rood, K., Holz, T, Zandbergen, P., Horner, R. and McPhee, M. 1999. Proposed Watershed Classification System for Stormwater Management in The GVS \& DD Area. Environmental Monitoring and Assessments Task Group, Washington, USA, 125p.

Schroder, B. 2006. Pattern, Process, and Function in Landscape Ecology and Catchment Hydrology-How can Quantitative Landscape Ecology Support Predictions in Ungauged Basins (PUB). Hydrology and Earth System Sciences Discuss, p.1185-1214.

Selman, P. 2006. Planning at the Landscape Scale. Routledge Publisher, Newyork, USA, $214 p$.

Steiner, F. 1999. The Living Landscape: An Ecological Approach to Landscape Planning. McGrawHill, New York, 462p.

Strassberg, G., Jones, N.L. and Maidment, D. R. 2011. Arc Hydro Groundwater: GIS for Hydrogeology. Esri Press, USA, $160 \mathrm{p}$.

Şahin, Ş. 1996. A Research on Determining and Evaluating the Landscape Potential of Dikmen Valley. Ph. D. Thesis. Ankara University, Graduate School of Natural and Applied Sciences, Department of Landscape Architecture, Ankara, Turkey, 160p.

Şahin, Ş. 2007. Co-Operative Approach in the Implementation of European Landscape Conventionand European Water Framework Directive in Turkey: Joined up Thinking. International Congress River Basin Management, No.1, p.218-227.

Şahin, Ş. 2009a. Landscape Ecology: Concepts, Methods and Applications. Public Administration Institute for Turkey and the Middle East (TODAIE) Publisher, Ankara, Turkey, 231p.

Şahin 2009b. Sustainable Landscape Assessment of River Catchments in the Example of Dikmen Brook in Ankara, Turkey. International Journal of Geosciences, 57 (2), p.33-46.

Tangtham, N. 1996. Watershed Classification: The Macro Land-Use Planning for the Sustainable Development of Water Resources. Advances in Water Resources Management and Wastewater Treatment Technologies Workshop. Suranaree University of Technology, Bangkok, 24p. 
Turner, M. G., Gardner, R. H. And O'Neill, R.V. 2002. Landscape Ecology in Theory and Practices: Pattern and Process. Springer Verlag, New York, USA, 404p.

Uzun O. 2003. Landscape Assessment and Development of Management Model for Düzce, Asarsuyu Watershed. Ph. D. Thesis. University of Ankara, Graduate School of Natural and Applied Sciences, Department of Landscape Architecture, Ankara, Turkey, 470p.

Uzun, O. and Gültekin, P. 2012. Process Analysis in Landscape Planning, The Example of Sakarya/Kocaali, Turkey. Scientific Research and Essays, 6(2), p.313-331.

Uzun, O., İlke E. F., Çetinkaya, G., Erduran, F. and Açıksöz, S. 2012. Landscape Management: Conservation and Planning Project for Konya, Bozkır-Seydişehir-Ahırl1Yalıhüyük Districts and Suğla Lake. The Project. Ministry of Environment and Forestry, General Directorate of Nature Conservation and National Parks, Division of Landscape Conservation, Ankara, Turkey, 175p.

Waltz, U. 2011. Landscape Structure, Landscape Metrics and Biodiversity. Living Reviews in Landscape Research, 5(3), p.1-35.

Weekes, A. 2009. Process Domains as a Unifying Concept to Characterize Geohydrological Linkages in Glaciated Mountain Headwaters. Ph. D. Thesis. University of Washington, USA, $151 \mathrm{p}$.

Zaimoğlu, E. 2003. A Search on Landscape Planning of Selçuk (Izmir) and It's Around. Msc Thesis. Ege University, Graduate School of Natural and Applied Sciences, Department of Landscape Architecture, Ankara, 141p. 


\title{
Stakeholder Involvement in Sustainable Watershed Management
}

\author{
Reyhan Erdogan
}

Additional information is available at the end of the chapter

http://dx.doi.org/10.5772/55798

\section{Introduction}

\subsection{Water is a main source of life}

Water is a key element for human life and philosophy. Many of the thinkers had considered on this issue and they have produced several theories. For example, Thales' most famous belief was his cosmological thesis, which held that the world started from water. This thesis was the first try to explain how was the beginning of the creation and world, in the terms of the logical and systematical way. On the other side, Aristotle considered this belief roughly equivalent to the later ideas of Anaximenes, who held that everything in the world was composed of air. The best explanation of Thales' view is the following passage from Aristotle's Metaphysics (Anonymous, 2012a). The passage contains words from the theory of matter and form that were adopted by science with quite different meanings. "That from which is everything that exists and from which it first becomes and into which it is rendered at last, its substance remaining under it, but transforming in qualities, that they say is the element and principle of things that are." Again: "For it is necessary that there be some nature, either one or more than one, from which become the other things of the object being saved... Thales the founder of this type of philosophy says that it is water". A deeper dip into the waters of the theory of matter and form is properly reserved to other articles (Anonymous, 2012a). Thales taught as follows: "Water constituted the principle of all things." Heraclitus Homericus states that Thales drew his conclusion from seeing moist substance turn into air, slime and earth. It seems likely that Thales viewed the Earth as solidifying from the water on which it floated and which surrounded Ocean (Anonymous, 2012b). On the other hand, Heraclitus said, "everything in life is changing and will change too". He is famous for his insistence on ever-present change in the universe, as stated in the famous saying, "No man ever steps in the same river twice". This quote is the famous speech about waters and river in the philosophy. 
On the other hand, problems about the water should be necessarily solved and it is very important for human life. The main problem about water is permanent since the human history. In the right term humans are the main factor of the problems about water and rivers, they have been effected by these problems in the first hand, but in the same time humans are responsible about to solve these problems The most challenging activity about water is the shape and nature of the water. Water can break walls, buildings and cities. Besides this destructive nature of the water, humans need water for sustaining their lives too. They need it, to irrigate their fields for producing crops, to drink when they are thirsty. For solving this, problems humans need to improve their calculations and they try to find a suitable solution for these situation. A first innovative and qualitative solution in math has been established in this period, in the field of the geometry (Deauna et al., 2000). Because of them the earliest branches of Mathematics. Beginnings of the geometry can be traced before 1700 B.C. or in early ancient Egypt. Due to necessity, every time the Nile River inundated and deposited fertile soil along the bank, the early Egyptian had to solve the problem of size and boundaries of land along the Nile River. Changes happened in the contour of the land had caused confusion among landowners. Therefore, a system of making boundaries, measuring lengths and areas had to be discovered (Deauna et al., 2000). From this circumstance, the name "Geometry" has evolved. The word "Geometry" originated from the word "Geo" means "earth" in Greek and "metros" means "to measure" (Deauna et al., 2000).

Many thinkers of the western World could not be stand indifferent to these rules of the nature. They were very proud to these knowledge and they have adopted these knowledge to their societies. These situation is very ironic because today many of the eastern countries are following western World. However, nowadays the source of the knowledge is not matter; every country and every nation in the World want to solve the water problems. Water is the most important source in the World, so water problem is now a global problem and it is a key issue for every individual in the World.

\subsection{Watershed}

A watershed is an area of land where all of the water that is under it or drains off it goes into the same place. John Wesley Powell, geographer and a scientist, put it best when he said that a watershed is: "that an area of land, a bounded hydrologic system, within which all living things are inextricably linked by their common water course and where, as humans settled, simple logic demanded that they become part of a community." (USEPA, 2012). The term "watershed" is commonly used to describe an area of the earth's surface from which water flows downhill to a single outflow point (Anonymous, 2009). Watersheds come in all shapes and size. The area encompassed may either be small, such as that which an ephemeral stream drains only during precipitation events, or be large. Watersheds cross county, state, and national boundaries (Anonymous, 2009). Because of them managing of the watersheds is very sensitive political issue between countries.

Health of the watershed has directly effect on the quality of the water, which drain in the watershed area. In this situation, quality of water is important (Giri et.al,. 2012). 
Furthermore, the size and volume of the water are other important indicators of the water management. Maintaining proper water quality conditions is important to protect human, animal, and plant health, and is an on going concern in water resources (Giri et.al,. 2012). Meanwhile, anthropogenic activities such as direct industrial discharges and agricultural practices significantly interfere with natural processes, which ultimately degrade water quality (Giri et.al,. 2012). Natural systems are mainly working on the logic of life cycle. A change in a parameter can be effect all other parameters.

Water quality depends on several physical combinations (Said et al., 2006). Sustainability of these physical components is important. Basically, physical sustainability is the combination of water quality, water quantity and ecological factors (Said et al., 2006). Evaluating the water quality situation within a watershed requires information on physical, chemical, and biological water quality indicators. Unfortunately, for many constituents historical measurements do not exist for most watersheds. In these cases, estimation of these constitutes is necessary from the available data on different, related constituents (Said et al., 2006). Trends of these constituents are very important for complete evaluation and mitigation of water quality problems and in the long-term decision-making processes. Using advanced techniques that construct relationships between water quality constituents makes evaluation and mitigation of water quality problems more reliable (Said et al., 2006).

There are some international tools to protect and improve water quality. One of these tools is European water Framework. This framework is a proper way to combine countries for more sustainable management practices. There are many good examples of the plans that aim to achieve a better understanding of water bodies. To comply with the European Water Framework Directive (EWFD, 2000/60/EC), which requires a "Good Ecological Status" for all waterbodies in 2015, French policy adopted a Phyto-Pharmaceutic Products' or pesticide reduction plan (ECOPHYTO 2018 plan). This program aims at inciting farmers to halve the annual amount of pesticides used. Nevertheless, the question of pesticide transfer is not solved. Presently the "zero pesticide" solution is not achievable for technical and economical reasons. The sociological part of the study highlights the importance of a co-construction process between all involved stakeholders, even if it is time consuming. Theoretical solution should be adapted not only to hydrological aspects but also to the socio-economical context (Tournebize et al., 2011).

Altering the landscape can influence the hydrologic integrity of a watershed. Changes in water quality and quantity that can occur from storm-water runoff include but are not limited to:

- Decreased and/or lack of infiltration to groundwater recharge areas and potential aquifer depletion,

- Decreased seasonal stream base-flows,

- Increased storm water volume and velocity contributing to stream-bank erosion, stream channelization, and more frequent and severe flood events,

- Increased surface water temperatures from heated storm-water runoff and lack of shaded riparian buffers, and 
- Decreased filtration of pollutants from narrowing or damaging riparian buffers (Tournebize et al., 2011).

Mitigation of water quality problems requires a number of actions by stakeholders and regulatory agencies. In some cases, especially in locally impaired waters, stakeholders can identify and mitigate water quality problems directly. In the case of significant local or regional pollution, watershed management plans and the total maximum daily loads, issued by USEPA of the Clean Water Act, enhance the water quality situation in impaired watersheds (USEPA, 1991). The total maximum daily load establishes a set of required reductions in target parameters consistent with an implementation policy to protect in stream water quality (Benham et al., 2002). If the water quality continues to worsen or goals can not be achieved under easing condition, it may be necessary to apply point source reductions or best management practices to improve the water quality as a whole. In summary, the water quality component in watershed management integrates scientific knowledge and stakeholder supplied information regarding the watershed-scale social, economic, and environmental processes affecting water quality.

\subsection{Watershed management}

Watershed management is the integrated use of land, vegetation and water in a geographically discrete drainage area for the benefit of its residents, with the objective of protecting or conserving the hydrologic services that the watershed provides and of reducing or avoiding negative downstream or groundwater impacts (Darghouth et al., 2008).

Watershed management is dedicated to solving watershed problems on a sustainable basis. These problems can be classified into five categories: lack of water (quantity), deterioration in water quality, ecological affects, poor public participation, and low output economic value for the investment in water-related activities. The first three categories constitute physical or "natural" sustainability while the last two categories define social and economic sustainability. For successful implementation of solutions to the physical and economic issues, a broad, representative array of stakeholders should be involved (Grigg, 1998, Said et al., 2006).

Watersheds are a highly desirable unit for planning because they are physical features ubiquitous across the landscape serving as the geographic foundation for political states. As planning units, watersheds transcend political boundaries. However, prior to the 1970 's, most watershed management focused on solving localized problems without taking into account the interrelationship between those problems and the biophysical, economic and social elements of the larger watershed system (Heathcote, 1998). Furthermore, during most of the mid- to late- $20^{\text {th }}$ century, watershed management was, politically, a top-down planning process with national concern pre-empting local (National Research Council, 1999). In the mid-1990s, EPA's Risk Assessment Forum and Office of Water cosponsored the development of five-demonstration watershed ERAs to test application of the ERA Framework (USEPA, 1992) to Office of Water programs. The five watershed assessments 
were performed in the Clinch and Powell Valley, VA, Middle Snake River, ID, Waquoit Bay, MA, Big Darby Creek, $\mathrm{OH}$, and the Middle [segment of the] Platte River, NE. All five selected sites had valued ecological resources, multiple stressors, an existing data set, and willing assessment participants. Using these assessments, many key aspects of the watershed ERA process, including challenges encountered and lessons learned, documented.

Chess and Gibson (2001) stated that the attributes intrinsic to a watershed management are: scientific feasibility, social feasibility, and motivational feasibility. They considered that these feasibilities are not static attributes although they can be improved through additional efforts to deal with attributes that limit feasibility. Watershed management plans may not be implemented due to lack of support even if the planning process and proposed actions are faultless. However, watershed restoration and protection management are often a complex web of technical, legal, and economic issues involving numerous stakeholders. The ability to address these issues depends on the attributes intrinsic to the watershed and whether they provide sufficient, basis for this innovative approach to watershed management (Chess and Gibson 2001). These attributes are defined by Chess and Gibson (2001) as follows:

1. Scientific feasibility is tied to the nature of environmental problems and the scientific capacity to solve them.

2. Social feasibility encompasses public communications and engagement.

3. Motivational feasibility includes issues related to values or economic consideration (Chess and Gibson 2001).

Scientific feasibility concerns the nature of the environmental problems, the tools to track them, and the methods to improve them. Examples of scientific feasibility related issues are the engineering solutions to improve water quality or conserve water quantity, technological limitations, such as the inability to detect the source of pollution, the absence of obvious causal relationships, and the development of best management practices (Said et al., 2006). In some areas, scientific feasibility may be so limited that management of a given watershed becomes a lower priority than other watersheds in which watershed management is more likely to succeed. Research and strong leadership can increase scientific feasibility to overcome technological barriers (Said et al., 2006). In summary, environmental problems must be measurable and tractable over time in order to predict performance, achieve public awareness, indicate progress towards goals, locate hot spots, take actions when appropriate, and sustain watershed management (Said et al., 2006).

Social feasibility means getting stakeholders involved and utilizing their input in a meaningful process. The National Research Council noted the need for watershed management to "get the participation right." There are many ways to improve stakeholder partnerships (Said et al., 2006). These include recruiting participants, encouraging leadership, education, civic engagement, and exploring various structural arrangements. Watershed management can be implemented through voluntary participation or facilitated by existing statutory infrastructure. Ideally, all watershed management activities would be driven by voluntary participation because of enlightened self-interest. However, statutory 
authority is often important because of the authority it grants, the planning it may mandate, and the funding it may provide (Said et al., 2006). Collaborative approaches may not be appropriate for watersheds in which there is limited evidence of social feasibility. If there is lack of social feasibility within a watershed, Federal and state agencies need to recognize that significant effort may be required to build social capacity to compensate for this intrinsic limitation. Agencies can build social feasibility by promoting civic efforts and by following best practices for development of collaborations (Said et al., 2006).

Occurrences of flooding, drinking water contamination, or other threats may increase social feasibility. Motivational feasibility is needed when there is a lack of sufficient income or demographic composition and when tax and donation of funds and time are needed. Motives may fall into three distinct categories: rational (cost-benefit assessment), normbased (efforts to conform to norms such as pollution remediation), and affective (emotional attachments that are difficult to quantify such as protection of endangered species and nonuse values) but are powerful in watershed management. Motivational feasibility is closely linked to social feasibility. For watershed management activities to occur there must be motivation to take action. Motivation can be induced by infusing funds (incentives for watershed projects), increasing values, and improving cost benefit ratios (Said et.al, 2006).

There is some important plan at maintaining progress towards a sustainable watershed. The first one is organizational capacity for a long term. The second one is multi-disciplined, inclusive oversight group. The others are revitalization of existing planning efforts and programs as planning tools for a sustainable future; broadening the scale of future sustainability efforts in the region to include the entire Broad-head watershed; further review and analysis of the regulatory framework affecting sustainable watershed planning efforts, and continuation of an education and outreach effort through social marketing efforts.

\subsection{Identifying and including stakeholders in watershed management}

Among the various ways of identifying stakeholders, as well as in the agency, behavioral, ecological, institutional, resource dependence, and transaction cost theories of the firm, there has been found no single attribute within a given theory that can guide people to a reliably on these issues. However, it was found that one can extract from these literatures the idea that just a few attributes can be used to identify different classes of stakeholders in an environment. Analysis with Freeman's definition of stakeholder is a good point. He stated that-"any group or individual who can affect or is affected by the achievement of the organization's objectives" (Freeman, 1984) and develop a theory of stakeholder identification drawn from these various theoretical literatures. From this point, there can be a broad definition can be explained, so that no stakeholders, potential or actual, are excluded from analysis arbitrarily or a priori (Wamalwa, 2009). Stakeholders are important in the planning of the natural environment where the human activities and natural processes are multilayered combined. And then, a propose that classes of stakeholders can be identified by their possession or attributed possession of one, two, or all three of the following attributes (Wamalwa, 2009): 
1. the stakeholder's power to influence life on the watershed,

2. the legitimacy of the stakeholder's relationship with the watershed region, and

3. the urgency of the stakeholder's claim on the watershed area (Wamalwa, 2009).

This theory produces a comprehensive typology of stakeholders based on the normative assumption that these variables define the field of stakeholders: those entities to whom managers should pay attention (Wamalwa, 2009). This attention is a very important key factor that the sustainability of the watershed management.

According to Mitchell et al., (1997) stakeholders can be classified as "Latent" referring to those who are of low importance to the organization, because they posses only one of the three characteristics (urgency, power and legitimacy) or "Expectant", having a higher importance, than the latent by virtue of being in possession of two of the three qualities or "definitive" having the highest degree of importance to the organization, because they posses all the three features. The latent group of stakeholders can be further classified into three (Mitchell et. al. 1997). Dormant; involving those who have power but of no or little effect to the goal of integration, because they do not have legitimacy and urgency. Discretionary; including those who have legitimacy but have no urgency and power. Demanding; including those who may have the urgency but of low rating because they do not have legitimacy and power (Mitchell et. al. 1997). The expectant group can also be further subdivided into dominant, wielding both high influence and stake or, dependent with high stake and urgency but having low influence, or dangerous with urgency and power (Wamalwa, 2009).

The planning phase for a watershed assessment is especially complex because a watershed typically overlaps multiple jurisdictions that are managed by organizations with divergent goals and responsibilities and inhabited by numerous stakeholders with varied interests. Depending on the perspectives of the stakeholders involved, a different set of goals and objectives may emerge. Stakeholder participation may become complex if there are numerous stakeholders or some of them are interested in only a limited range of issues (Glicken, 2000).

The inadvertent exclusion of a stakeholder group may influence a group's decision to accept or reject the outcome of the process. Excluded stakeholders could even take legal actions, such as filing a citizen lawsuit under the Clean Water Act to challenge the process outcomes. Therefore, stakeholder involvement needs to be balanced against the limited resources available for watershed assessment and management (USEPA, 2001).

Participants in the watershed management process should include all regulatory or resource agencies (state, federal, local) with responsibilities for protecting and managing the water body and any parties whose authority will be needed to implement a management plan (e.g., local and county officials with zoning oversight). Nongovernmental organizations (such as watershed associations or councils, river watch citizen groups, volunteer monitoring group, educational and research institutions, industries, and agricultural associations) all have a stake in watershed management. Besides organized groups, other stakeholders include landowners, those who use the watershed, and those whose 
participation is essential to successful management. In some instances, stakeholders may be hundreds of miles away from the assessment (e.g., bird watchers concerned about migratory waterfowl). The nongovernmental and unaffiliated stakeholders may have objectives that are very different from those of the regulatory agencies (e.g., minimizing restrictions on land use, resource development, or waste disposal). Although such social, legal, and economic objectives may be in conflict with some environmental objectives, they are still relevant concerns that need to be considered (Stahl et al., 1999). To help assess these tradeoffs, it may be helpful to involve environmental economists.

Participants on a watershed assessment team contribute different resources that include socioeconomic information, historical data, scientific expertise, and assets to conduct the assessment. The Big Darby Creek assessment project is a good example of team studies in the watershed management. Team members of the Big Darby Creek assessment project included biologists, a city planner, and environmental scientists (Cormier et al., 2000). Team members performed literature reviews and frequently consulted or interviewed experts in other disciplines. The team interacted regularly with the Big Darby Partners, a group of state agencies, representatives from The Nature Conservancy, and farmers concerned about the future of the working landscape. Because of them partnership between stakeholders and planners are important factor. Integration between these two groups effect the plan and application.

\section{Watershed management approaches}

\subsection{Collaborative watershed management}

Collaborative watershed management has emerged in the last two decades as a promising approach to address non-point source pollution in waters. With such a wide variety of landuse patterns across watersheds, it is important that collaborative approaches to water resource management are tailored to local land-use planning efforts (Wang, 2001; Scott et. al., 2010). Urban and rural landscapes can have very different biological systems, leading watershed partnerships located in different areas to address different environmental issues. Moreover, collaborative management efforts in each setting can be impacted by different sets of variables, from the level of human capital (e.g., income, education) and social capital (e.g., trust, networks, norms of reciprocity) in watershed communities, to the financial, technical, and human resources made available by government agencies, NGO's, academic units, and local citizens (Hardy and Koontz, 2010).

Successful collaborative watershed management programs emphasize active stakeholder engagement, employ integrated solutions, recognize the authority of multiple agencies and jurisdictions, and build on expertise and resources across sectors. Out of bio-geophysical necessity, managing a watershed involves coordinated stewardship of the waterbody and the land area that the waterbody drains. Consequently, watershed conservation and rehabilitation is typically a function of an array of public and private programs. Representatives of local, state, and federal agencies; nonprofit group; and for-profit businesses each must bring complementary resources to the task (Golden, 1998). Ideally, 
collaborative watershed management refers to shared decision-making and implementation by public and private sector partners who share the common goal of conserving or enhancing hydrologic resources (Michaels, 2001).

The collaborative watershed approach is on the agenda of the federal government in the United States. President Clinton's 1998 Clean Water Action Plan explicitly promotes such an approach nation wide. The plan encourages states to work with watershed stakeholders, including interested citizens, to identify watersheds with critical water quality problems and to focus resources and implement strategies to solve these problems (Michaels, 2001).

By collaborating with local entities, states can facilitate ongoing learning; devise systems for measuring, monitoring, and evaluating; and disseminate best practices or model policies. They can actively engage in propagating local experiments. States have instrumental roles to play in achieving Dorf and Sabel's (1998) ideal of democratic experimentalism, where the deliberations and performance of one jurisdiction are considered in like jurisdictions. Since problems are encountered face-to-face at the local level, a critical function of the states is to build local collaborative, managerial, financial, and technical capacity (Cigler, 1998). Recognizing the political palatability of local collaborative management results in emphasizing grassroots strategies, such as community education, and local government tools, such as floodplain zoning (Blatt, 1993).

\subsection{Holistic watershed management}

Embraces the idea that all aspects of the watershed human resources, economic development, environmental quality, infrastructure development and public safety must be considered in a holistic watershed management decision-making process. Holistic watershed management's fundament approach is in a facilitated process designed for the integration of organizations and individuals having environmental knowledge, skills and resources in the water quality and comprehensive community planning.

Consider the following roles agencies could play in sustainable holistic watershed management decision-making:

1. Catalyst-incentives or regulation enforcement to improve watershed environment (Water Quality). Agency representative living in the watershed experiencing a problem.

2. Responsive/Supportive-provide technical resources as needed for sound holistic watershed management decision-making.

3. Stand back and let local people control the holistic watershed management planning process (UOEWQP, 2004).

\subsection{Integrated watershed management}

Previous water management efforts that were sectoral, technological and centralized have proved inadequate, because they failed to recognize and appreciate the intricacies and interrelations of ecosystems (Pereira, 1973). Consequently, integrated watershed Management 
has been suggested as a solution and has been tried for decades in several countries in the world (Bowden, 1999; Mitchell, 1990; Bulkley, 1995; Lant, 1999; Pereira, 1973).

An "integrated watershed management" approach should strive to create settings for collaboration and innovation by facilitating dialogue among local stakeholders. The overriding charge under the piloting of this approach is fostering a framework for dialogue among stakeholders for problem solving examining interdisciplinary solutions that are inherently multi-objective. That is, solutions able to address more than one problem simultaneously while addressing the entire resource based on local circumstances. The Integrated Watershed Management Program proposes a framework for fostering interdisciplinary on-ground implementation activities. Interdisciplinary takes on a meaning of multiple dimensions and scales. In one instance vertical dimensions: encompassing both surface water and ground water quality at the watershed scale. In the other instance, the lateral dimension considering the varied land uses and land covers associated with agriculture, silviculture, mining, and hydrologic/habitat modification activities, as well as those associated with urbanization (e.g., land development, transportation, recreation, etc.). These land uses and activities give rise to varying degrees of non-point source pollution or polluted runoff, which is the major contributor to impaired waters (National Research Council, 1999).

Over the past two decades, there have been numerous applications of integrated watershed management worldwide. For example, integrated watershed management approaches have been recently used for combating drought in the Jhabua watershed in India (Singh et al., 2002), assessing and managing water resources in the upper Chao Phraya in Thailand (Padma et al., 2001), assessing and managing agricultural phosphorus pollution on the Chesapeake Bay (Sharpley, 2000), tackling the problem of land degradation in Australia (Ewing, 1999), and managing the Truckee River in Nevada (Cobourn, 1999). Also, in the United States, the USEPA has been quite instrumental in promoting the integrated watershed approach to management (National Research Council, 1999).

The lessons learned from these and other initiatives indicate that in order to succeed, integrated watershed management must be participatory, adaptive and experimental, integrating all the relevant scientific knowledge/data and user-supplied information regarding the social, economic and environmental processes affecting natural resources at the watershed level (Steiguer et al., 2003). This is due to poor integration and coordination, which is either fostered or hindered by a complex set of environmental and socio-economic and institutional factors at various spatial levels such as "(1) legislation and regulations, (2) policies and guidelines, (3) administrative structures, (4) economic and financial arrangements, (5) political structures and processes, (6) historical and traditional customs and values and (7) key participants or actors" (Mitchell, 1990).

\section{Organizational approaches in watershed management}

With the increase in population water has became a key resources. The result of the development efforts of the countries, demand on the water has been become on maximum 
level. This situation thread clear water resources and watersheds areas were under the pressure of human activities. So that, many of the international organizations have considered on this problem. In addition to this, they have produced many protection projects to solve water issues. In this study, we compile and evaluate the state of the art, with a special focus on material, which is produced by international organizations such as the World Bank, IFAD, FAO, IWMI.

\subsection{World bank}

Over the past seven years since the World Bank's Water Resource Strategy was created, the Bank's water lending commitments have increased significantly, the quality of the water portfolio was turned around, and the outcome project rating now even outperforms the Bank average. The 2010 mid-cycle implementation progress report, "Water for All in a Changing Climate", and "The Sustainable Infrastructure Action Plan" continue to guide the Bank's strategy for managing water resources. The World Bank increasingly works with partners from multilateral and bilateral agencies, but also agencies within civil society and the private sector at the global, regional, and country levels. It's partners are Global Water Partnership (GWP), International Commission on Irrigation and Drainage (ICID), International Water Association (IWA), UN-WATER, Water Supply and Sanitation Collaborative Council (WSSCC), World Water Council (WWC).

\subsubsection{Watershed management approach before the 2000}

The watershed management approach became prominent in developing countries in the 1970 in programs designed to improve upland natural resource management in order to protect downstream resources and infrastructure, when the problems of watershed degradation first became apparent.

The origins of modern watershed management can be traced to several parallel and independent movements: the restoration of the Alps, the conservation movement in the United States in the 1930s; and the watershed rehabilitation activities of colonial governments in Africa (Dargouth et. al, 2008). National and regional programs were set up to address the damage to downstream infrastructure caused by degradation in the uplands. For instance, Indonesia created a National Watershed Development Program in 1976. From the mid-1970s, Brazil launched soil conservation programs that evolved by the mid-1980s into the Integrated Soil and Water Management Program in Microcatchments. India created the National Watershed Development Program for Rainfed Areas in 1990 (Dargouth et. al, 2008).

The watershed management projects in the 1970s and 1980s consisted on specific on-site and downstream physical outcomes, this works have been done only to protect resources by the engineer approaches. So investments were high cost and not always well justified, and the assets and benefits created often had a limited life (Dargouth et. al, 2008). And ecological dimension has never seen in these works. Because of these approaches, there is no chance to put a sustainable management approach in a holistic way. 
First generation of watershed management projects in the 1970s and 1980s were to prevent rapid runoff of water, slow down siltation of reservoirs, and limit the incidence of potentially damaging flash flooding. Targets were fixed in relation to physical outputs rather than economic and natural resource outcomes and a top-down planning approach was generally adopted (Dargouth et. al, 2008). In pratical way local people could not adapted to this planning outputs. So, general result of this top-down planning approach was a total mass on side. Nowadays, local users empty these old infrastructure buildings, which have been built by this plan and authors and scholars try to remediate this areas.

The need to improve the livelihoods of the poor upland population was not completely ignored, but the technical improvements for agricultural production introduced usually focused on costly vegetative and mechanized technologies (Dargouth et. al, 2008). Watershed planning was based on land capability rather than on the capacities and needs of

\begin{tabular}{|c|c|c|c|}
\hline & Main Purpose & Applications & Results \\
\hline $1980 \mathrm{~s}$ & $\begin{array}{l}\text {-Beyond the } \\
\text { engineering } \\
\text { approaches } \\
\text { acceptance of } \\
\text { large scale } \\
\text { collaboration } \\
\text { between national } \\
\text { and } \\
\text { international } \\
\text { organizations }\end{array}$ & $\begin{array}{l}\text {-To protect to soil, water and } \\
\text { vegetation resources } \\
\text {-To try to decrease of local } \\
\text { community poverty } \\
\text {-Ecological and institutional } \\
\text { sustainability of the resources } \\
\text { management } \\
\text {-To try watershed management } \\
\text { approaches in dry land areas }\end{array}$ & $\begin{array}{l}\text { High government staff turnover and } \\
\text { poor supervision resulted in inconsistent } \\
\text { project management and unaccountable } \\
\text { implementation arrangements. } \\
\text { Projects often ignored crucial inter- } \\
\text { sectoral linkages, resulting in lack of } \\
\text { collaboration and communication } \\
\text { across sectors. } \\
\text {-the comparative failure of the } \\
\text { "engineering-led" approach was clear } \\
\text {-lack of collaboration and } \\
\text { communication across sectors }\end{array}$ \\
\hline 1990s & $\begin{array}{l}\text {-To resource, use } \\
\text { productivity, } \\
\text { livelihood } \\
\text { improvements, } \\
\text { and poverty } \\
\text { reduction } \\
\text { objectives in } \\
\text { addition to } \\
\text { resource } \\
\text { conservation. }\end{array}$ & \begin{tabular}{|l|}
-To identify and execute \\
interventions within an \\
integrated farming systems \\
approach, including lowland \\
and upland agriculture, pasture, \\
and forest management \\
-To adopt a participatory and \\
demand-driven development \\
approach, which was influenced \\
by emerging theories of "farmer \\
first"
\end{tabular} & $\begin{array}{l}\text {-To led watershed management } \\
\text { programs to seek ways to build on } \\
\text { existing social structures and institutions } \\
\text { and to support planning and } \\
\text { implementation by community } \\
\text { institutions the promotion of low-cost } \\
\text { vegetative techniques for erosion control } \\
\text { replaced or complemented the previous } \\
\text { "mechanical" techniques that had relied } \\
\text { on heavy construction and had proved } \\
\text { expensive to build and difficult to } \\
\text { maintain }\end{array}$ \\
\hline
\end{tabular}

Table 1. Timeline of watershed management practices (Dargouth et. al, 2008; Chambers et .al. 1989) 
local people who lived there. People were hired as manual labor, and projects provided subsidies to stakeholders as incentives to participate (Dargouth et. al, 2008). There was little involvement of the communities in planning and implementation, which often resulted in weak commitment to the project. Benefits were expected to trickle down to the local population, although this generally happened only on a limited scale. It is given some information about water-sheet management studies belong to different years in the table 1 .

A number of countries as diverse as India, Kenya, and Nigeria have seen environmental rehabilitation carried out almost spontaneously as population pressure increased or environmental degradation, particularly erosion, reached high levels. For example, Tiffen, Mortimore, and Gichuki (1994) explored the relationship between increasing population density, productivity, and environmental degradation through a case study in southeast Kenya. They showed that population increase combined with market opportunities stimulated local investment and innovation in dry land farming and environmental recovery of heavily degraded land (Dargouth et. al, 2008).

\subsubsection{World bank projects}

There are many water management projects which were held by World Bank on the issue that the Participatory Watershed Management. In the same time they want to support local economies in the same time by the way, they want to protect natural sources. These projects may include financing critical economic infrastructure such as rural footpaths, sewerage, drainage, roads and water supply.

The development objective of the proposed Participatory Watershed Management Project (PWMP) is to improve the productive potential of natural resources and increase incomes of the rural households in selected watersheds in Jammu \& Kashmir using socially inclusive, institutionally and environmentally sustainable approaches. A secondary objective is to support policy and institutional development in in Jammu \& Kashmir to harmonize watershed development projects and programs across the state in accordance with best practices (Darghouth et. al., 2008).

Most of the key lessons stem from the previous project, although they are hallmarks of other successful watershed development projects in India (Darghouth et. al., 2008):

- Cost-sharing is critical for ensuring ownership and continued operations of projectfinanced assets. Hand-outs and full subsidies are to be discouraged.

- Transparency of decision-making and resource allocation is important to ensure that all community members are fully aware of project activities and benefits. Several participatory planning tools, such as social mapping and village account displayed in central places, have been used successfully in this respect.

- As a land-based approach, the watershed development project needs to take into account marginal groups (women, landless, nomadic tribes) who may not directly benefit from project interventions unless targeted efforts are made by the project to cater to their unique needs. 
- $\quad$ The proposed project should leverage its resources going beyond target watersheds and encouraging state-wise initiatives in capacity-building and policy reforms that will yield wider benefits (Darghouth et. al., 2008).

National policies on watershed management have generally been driven by program experience rather than vice versa.

Initially watershed management programs were adopted in the 1970s and 1980s by governments as pragmatic responses to natural resource degradation and the related social and economic costs. These programs developed in an iterative fashion, with early setbacks over approaches dominated by engineering being succeeded by tests of community-based approaches targeting sustainable changes in land use practices. Now, in several countries success in testing community-based approaches has led to adoption of broader policies for community-based watershed management (Darghouth et. al., 2008).

Turkey has built on local and regional experience to formulate policies for community based watershed management in poor upland areas. The Turkish rural economy has been characterized by a high incidence of poverty, particularly in upland areas. The consequent growing pressures on forests and pasture have reduced vegetative cover and diminished soil fertility and the carrying capacity of rangeland. This has contributed to reductions in infiltration rates and to increases in peak river flows, flooding, and sedimentation problems (Darghouth et. al., 2008).

Beginning in the late 1980s, Turkey tested an integrated and participatory approach to watershed management in a number of micro-watersheds, and from 2004 expanded the approach to three major river basins. Policy is now based on a community-driven approach to natural resource management, integrating forestry, soil and water conservation, and crop and livestock production. The government shares the cost of a mutually reinforcing package of resource use productivity enhancing and conservation measures. This policy has driven institutional change, particularly the coordination and integration of the activities of different government departments at the microwatershed level and the development of watershed-based forest resource management plans (Darghouth et. al. 2008).

There are some projects which has been held by World Bank in Turkey where the two continent are joined. One example of this projects is Eastern Anatolia Watershed Project. This subproject would seek to identify and establish in-situ conservation areas in Turkey, for the protection of genetic resources and wild relatives of important crops and forest tree species that originated in Turkey. It will provide for sustainable in-situ conservation of genetic resources in cereals, horticultural crops, medicinal plants, forest trees, and pasture grasses and legumes through an integrated ecosystem approach. It will also contribute to the broader objective of conserving sustainable farming and forest systems that is a key element of the Watershed Rehabilitation project. The project has been developed the institutional capacity in Turkey for preparing and implementing a national strategy for insitu conservation which could include landraces in a second phase Project. The aim was to test and develop a new approach to conservation of genetic diversity which has not been tried on a large scale anywhere in the world (Anonymous, 2012c). 
Dams influence both water quality and the very functionality of rivers, of planetary life cycle processes harming people, culture and nature, collectively. Roughly two-thirds of the world's rivers have suffered harm from the ten thousands of dams that have been built over the past century. Many of the world's great rivers such as the Indus, the Colorado, and the Yellow Rivers, no longer reach the ocean, turning once-productive deltas into biological deserts. More than tropical rainforests, marine environments, or coastal wetlands, freshwater ecosystems are experiencing the greatest loss of biodiversity, in large measure due to dams. Over the past 40 years, freshwater ecosystems have lost $50 \%$ of their populations and over a third of remaining freshwater fish species are threatened with extinction. Presently, the great river basins of the world are experiencing a new wave of damming: The Amazon, the Mesopotamia, the Congo, the Mekong are each superlative in their contributions to planetary cycles, biodiversity and cultural evolution of human civilization. Each of these basins is threatened with audacious and narrow-sighted schemes that will irreversibly disconnect rivers and cost the planet billions in lost ecosystem services. The main reason underpinning this new wave is that dams are misinterpreted as "renewable energy" and promoted as solution to climate change. Yet, as proven different parts of the world, such as Amazonia and Mesopotamia, dams do not generate renewable energy, but irreversible natural and cultural destruction. Also scientific studies indicate that dams and reservoirs are globally significant sources of the greenhouse gases carbon dioxide and, in particular, methane (Anonymous, 2012d).

Dams have significant adverse effects on heritage through the loss of local cultural and archaeological sites and resources. For instance, Ilisu Dam will destroy more than 300 archaeological sites, including the 11,000 year-old historic town of Hasankeyf that is the only place in the world that meets nine out of 10 criteria for UNESCO World Heritage Site status (Anonymous, 2012d).

Dams also cause loss or damage of cultural heritage through land reclamation and irrigation projects and the construction of power lines, roads, railways and workers towns. In most cases, no measures have been taken to minimize or mitigate the loss of cultural and archaeological resources (Anonymous, 2012d).
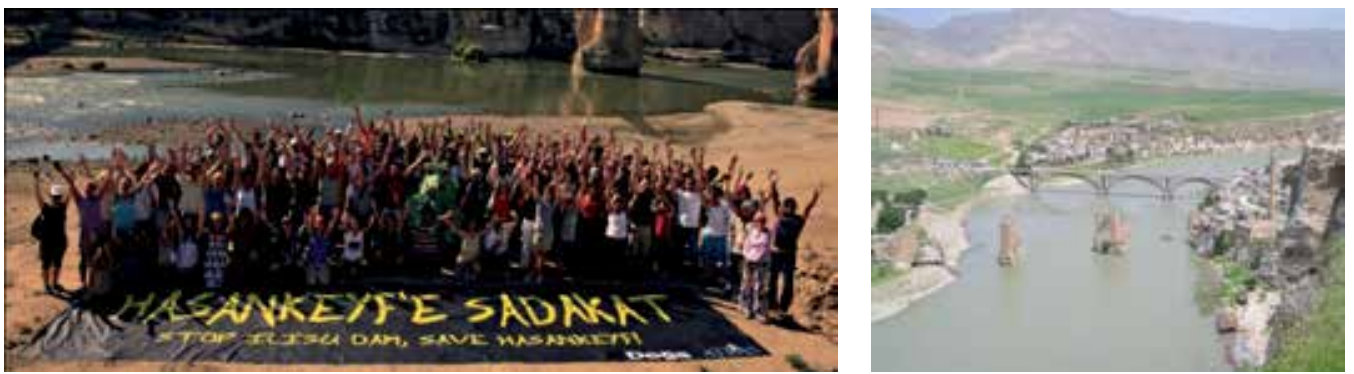

Figure 1. Hasankeyf, a demonstration against the construction of the Ilisu Dam, held by Turkish Nature Organization and general view of the area (Anonymous, 2012e and Anonymous, 2012f). 


\subsection{International Fund for Agricultural Development (IFAD)}

International Fund for Agricultural Development (IFAD), a specialized agency of the United Nations, was established as an international financial institution in 1977 as one of the major outcomes of the 1974 World Food Conference. IFAD is dedicated to eradicating rural poverty in developing countries (Anonymous, 2012g).

In recent decades, IFAD has supported changes in land and water governance as a way to improve rural poor people's access to these natural resources, and to ensure poverty reduction, increased food security and better livelihoods. This involves working through community-based and civil society organizations and NGOs to better identify the changes that are needed, and with national and local governments to change policies and legislation. The aim is to empower rural poor people to participate in managing the common property resources on which they depend.

Paid environmental or watershed services are increasingly recognized as a potential source of additional income for poor rural people. IFAD's Environmental and Social Assessment Procedures, which include operational statements, for example on irrigation, range resources, inland fisheries and wetlands, regulate exploitation of water resources and the environment.

The State of the World's Land and Water Resources for Food and Agriculture (SOLAW) analyses a variety of options for overcoming constraints and improving resource management in these areas of heightened risk. In each location, a mix of changes in institutional and policy measures will have to be combined with greater access to technologies for better management of land and water resources. Increased investments; access to novel financing mechanisms; and international cooperation and development assistance will also help overcome these constraints (Anonymous, 2012g).

This first issue of SOLAW, which complements other "State of the world" reports published regularly by FAO, is intended to inform public debate and policy-making at national and international levels. IWMI is one of 15 international research centers supported by the network of 60 governments, private foundations and international and regional organizations collectively known as the Consultative Group on International Agricultural Research (CGIAR). IWMI's Mission is to improve the management of land and water resources for food, livelihoods and the environment. IWMI targets water and land management challenges faced by poor communities in the developing world/or in developing countries and through this contributes towards the achievement of the UN Millennium Development Goals (MDGs) of reducing poverty, hunger and maintaining a sustainable environment. These are also the goals of the CGIAR (Anonymous, 2012g).

In most developing countries, agriculture accounts for more than 80 per cent of water use. An increased focus on this sector is needed to address the water crisis. For poor smallholder farmers, water and land cannot be treated as separate issues. Government and development actions targeting only land or only water governance changes are unlikely to achieve sustainable impact. For poor farmers, secure land access can lead to secure water access, and 
the reverse is also true. This in turn leads to access to credit and investment in their farms, which can improve their livelihoods, and improve agricultural water use efficiency (Anonymous, 2012g).

At local level, land and water governance structures already exist in some form, but these are not systematically recognized at higher institutional levels. If reforms are to improve the livelihoods of rural poor people, their voices and concerns need to be heard and acknowledged as part of the reform process.

Indigenous knowledge and practices need to be recognized as a strong basis for building lasting change in land and water governance (Anonymous, 2012g).

The role of women in land and water management and use must be recognized as part of the reform process.

The capacity of individuals, communities and NGOs must be developed so they can take on the responsibilities associated with reforms. Building trust in communities and among partners is an essential part of capacity development, so that they can act collectively for mutual benefit. Sufficient time must be allowed for enlisting broad support for reform. NGOs can be a useful vehicle to support the reform process, which does not always fit with time and budget constraints of development projects. External support is important. Financial support, combined with policy dialogue, can be a catalyst for NGOs, communities and governments to pursue change. International agencies also provide small communities and local and national organizations with a valuable sense of international recognition, credit and encouragement (Anonymous, 2012g).

Documenting land and water governance experiences in a country promotes better understanding of stakeholders' and IFAD partners' views. This creates opportunities for effective pro-poor advocacy and policy dialogue at all levels aimed at improved access to productive natural resources and technology (Anonymous, 2012g).

\subsection{Food And Agriculture Organization of The United Nations (FAO)}

As a knowledge organization, FAO creates and shares critical information about food, agriculture and natural resources in the form of global public goods. However, this is not a one-way flow. FAO plays a connector role, through identifying and working with different partners with established expertise, and facilitating a dialogue between those who have the knowledge and those who need it. By turning knowledge into action, FAO links the field to national, regional and global initiatives in a mutually reinforcing cycle (Anonymous, 2012h).

In assessing the anticipated impacts of climate change on agriculture and agricultural water management, it is clear that water availability (from rainfall, watercourses and aquifers) will be a critical factor. Substantial adaptation will be needed to ensure adequate supply and efficient utilization of what will, in many instances, be a declining resource (Anonymous, 2012h). By the definitions of the FAO; the world's food production depends on the availability of water, a precious but finite resource and nearly half of the world's population is affected in various ways by mountain ecology and the degradation of watershed areas. 


\subsection{International Water Management Institute (IWMI)}

IWMI is one of 15 international research centers supported by the network of 60 governments, private foundations and international and regional organizations collectively known as the Consultative Group on International Agricultural Research (CGIAR). It is a non-profit organization with a staff of 350 and offices in over 10 countries across Asia and Africa and Headquarters in Colombo, Sri Lanka (Anonymous, 20121).

IWMI's Mission is to improve the management of land and water resources for food, livelihoods and the environment. IWMI's Vision, reflected in the Strategic Plan is water for a food-secure world. IWMI targets water and land management challenges faced by poor communities in the developing world/or in developing countries and through this contributes towards the achievement of the UN Millennium Development Goals (MDGs) of reducing poverty, hunger and maintaining a sustainable environment. These are also the goals of the CGIAR (Anonymous, 20121).

Research is the core activity of IWMI. The research agenda is organized around four priority Themes including Water Availability and Access; Productive Water Use; Water Quality, Health and Environment; and Water and Society. Cross cutting activities in all themes include, assessment of land and water productivity and their relationship to poverty, identification of interventions that improve productivity as well as access to and sustainability of natural resources, assessment of the impacts of interventions on productivity, livelihoods, health and environmental sustainability.

IWMI works through collaborative research with many partners in the North and South and targets policy makers, development agencies, individual farmers and private sector organizations. IWMI's new triple approach to uptake is being implemented (Anonymous, 20121). This involves:

1. Project uptake strategies: These are targeted strategies built into projects at the beginning. They are focused on the project results and the potential users of the results.

2. Regional uptake strategies: These are particularly important to keep the momentum going when projects are completed, and to build linkages across projects to provide synthesized messages.

3. Macro uptake strategies: This involves making all information and knowledge available as broadly as possible, making it easily accessible and promoted widely (Anonymous, 20121).

IWMI supported to some project about ecosystems for water and food security. The result of water management in agroecological landscapes is remarkable.

\subsubsection{Water management in agroecological landscapes}

Managing agricultural land to deliver multiple services considerably improves values derived. This is best done at the landscape level, linking ecosystems and managing natural resources such as water and land specifically to enhance ecosystem services, thereby 
integrating all sources of water in the basin, from rain, in the soil, in aquifers and as surface water. Water is then no longer supplied to crops, trees, livestock, or fish, but to multifunctional agroecosystem linked and managed together at the river basin or landscape level. In this way, synergies can be exploited and productivity can be improved, while obtaining benefit from improved carbon storage, erosion control, water retention, waste treatment, and cultural and recreational values including tourism. Notably, most of these added services do not conflict with agricultural production but in many cases improve both its productivity and sustainability.

The recommendations are based on the findings on the various types of ecosystems and integrated ways to enhance water management for food security. In addition, principles of sustainable water management for agriculture in ecoagriculture have been incorporated (Molden et. al. 2007). As a result, the specific recommendations concerning water are only part of the larger message on how to manage natural resources sustainably and make the transition from production systems to multipurpose agroecosystems.

These guiding principles have been combined from various sources and would increase ecosystem services and sustainability while using the same resources, hence be more productive (Swift et al., 2004; Molden et al., 2007; Van der Zijpp et al., 2007; Bossio and Geheb 2008; Hajjar et al., 2008; Swallow and Meinzen-Dick 2009; World Bank 2009; Zomer et al., 2009; Garrity et al., 2010; McCartney and Smakhtin 2010):

Promote diversity within the production systems: Optimizing the diversity of the above and below ground biotic components within the production system (crop biodiversity, animal diversity, soil biodiversity, and pollinators) can increase the adaptive capacity of the cropping system to buffer against fluctuations in water availability, temperatures, pests and diseases, thereby enhancing the resilience of rural livelihoods. Synergies with livestock and aquaculture can be explored to increase resource recovery and productivity, for instance in crop livestock systems, rice-fish culture, tree-crop systems, aquaculture in reservoirs, forestpastures, or wastewater-fed aquaculture. Integration of trees can help fix nitrogen, tighten nutrient, water, and carbon cycles, and produce additional goods, such as year-round availability of fodder and biomass for use as organic fertilizer and fuel.

Promote diversity in landscapes: Landscapes with high levels of biodiversity are more resilient and better able to mitigate environmental impacts. Large mono-cropped areas can be developed into landscapes with higher levels of biodiversity by identifying and linking natural habitat patches, including aquatic ecosystems. Habitat integrity and connectivity can be maintained by incorporating hedgerows, multipurpose trees, and corridors of natural vegetation interconnecting parcels of agricultural land and natural ecosystems (such as wetlands and forests - these may need to be specifically developed where they are too far away). In large irrigated areas, canals and roads can be lined with perennial vegetation such as trees, thereby also serving as important passages and habitats for animals. Canals and other waterways can connect aquatic ecosystems and thereby maintain the connectivity of migratory routes, providing the variety in habitats required for subsequent life cycle stages such as spawning. Landscape-scale planning of strategic tree cover interventions can reduce 
flow accumulation by providing sites for water infiltration and penetration. By incorporating both fodder production and grazing land, livestock can be managed at the landscape level too, thereby enabling animals to reach otherwise inaccessible feed sources and avoiding overgrazing and trampling of vulnerable areas.

\section{Watershed management studies in developing country}

For several decades, Integrated Watershed Management has been suggested and tried in several countries in the world, as an effective way to address complex water resource challenges. However its implementation has not been successful in most cases, due to various barriers. In Kenya, this approach is new and requires appropriate strategies to overcome these barriers and stimulate effective integrated watershed management. To design suitable and effective strategies, there is need to understand institutional features at various spatial levels, which promote or hinder integration and coordination. Wamalma's paper therefore explores the prospects and barriers of integrated watershed management of Mara, by examining the existing complex set of biophysical and socio-economic conditions, stakeholders attitudes and perceptions, arrangements for participation of stakeholders, available institutional structures and financial plans, and recent policy reforms in water and forestry sectors. Empirical information was gathered from official documents, direct observations, semi-structured interviews with managers, administrators, politicians and households of Mara watershed. Results indicates that, integrated watershed management of Mara is likely to be fostered by the critical biophysical and socioeconomic conditions, suitable institutional structures that are being established, water and forestry reforms, recognition of stakeholder participation and enhanced education of stakeholders, and leverage of resources from NGOs. However this efforts are likely to be hampered by disparity of views and perspectives, egoistic tendencies of influential leaders, inadequate financial plans, lack of effective coordination mechanisms, ineffective multi-stakeholder process, unwillingness of the local community and the politicians if there interests are not addressed, and lack of legitimacy for the institutional structures that are being created. This study therefore suggests adoption of multi-stakeholder forums for building understanding and bridging the disparity of views, the need to address the legitimate interests of the local community and politicians, and enhanced level of understanding among stakeholders on the interactions and interdependencies among the variables of the ecosystem. Finally the study recommends the need for a more effective coordination arrangement such as elevation of the CAAC (Catchment Area Advisory Committee) to the level of a coordinating agency instead of relying on a single government agency like WRMA (Water Resources Management Authority) as provided for by the water act 2002 at the catchment level. In conclusion as much as the new water sector reforms provide legitimacy, impetus and a framework for integrated watershed management in Mara and other water catchments in Kenya, implementation may still remain a challenge if barriers are not identified and addressed.

Liu et al.'s study highlights two highly degraded watersheds in the semi-arid Amhara region of Ethiopia where integrated water resource management activities were carried out 
to decrease dependence on food aid through improved management of 'green' water. Whiletop-down approaches require precise and centrally available knowledge to deal with the uncertainty in engineering design of watershed management projects, bottom-up approaches can succeed without such information by making extensive use of stakeholder knowledge. This approach works best in conjunction with the development of leadership confidence within local communities. These communities typically face a number of problems, most notably poverty, that prevent them from fully investing in the protection of their natural resources, so an integrated management system is needed to suitably address the interrelated problems. Many different implementing agencies were brought together in the two study watersheds to address water scarcity, crop production, and soil erosion, but the corner stone was enabling local potential through the creation and strengthening of community watershed management organizations. Leadership training and the reinforcement of stakeholder feedback as a fundamental activity led to increased ownership and willingness to take on new responsibilities. A series of small short term successes ranging from micro-enterprise cooperatives to gully rehabilitation have resulted in the pilot communities becoming confident of their own capabilities and proud to share their successes and knowledge with other communities struggling with natural resource degradation (Liu et al., 2008).

Specifically it has learned that (1) communities have high interest in development initiatives, including sustaining natural resources; (2) only when people make real contributions of their own resources will they strive to ensure the implementation of the planned activities; (3) emphasis must be given to effective organization of communities rather than only focusing on technology development; (4) including non-technical leaders in the information loop provides great benefits at the community level. Introduced ideas, such as the fair representation of women and poor in the management process, women's micro-enterprise groups, and closing off areas to livestock, faced strong cultural opposition at the beginning but have proven very successful thanks to trial tests and continue collaboration efforts by farmers, non-technical leaders, and project personnel. It has also found that communities most at risk were also the most open to new ideas (Liu et al., 2008).

Partnerships and co-operative environmental management are increasing world wide as is the call for scientific input in the public process of ecosystem management. In Hawaii, private land owners, non-governmental organizations, and state and federal agencies have formed watershed partnerships to conserve and better manage upland forested watersheds. In this paper, findings of an international workshop convened in Hawaii to explore the strength of approaches used to assess take holder values of environmental resources and foster consensus in the public process of ecosystem management are presented. Authors draw upon field experience in projects throughout Hawaii, Southeast Asia, Africa and the US main land to derive a set of lessons learned that can be applied to Hawaiian and other watershed partnerships in an effort to promote consensus and sustainable ecosystem management. Interdisciplinary science-based models can serve as effective tools to identify areas of potential consensus in the process of ecosystem management. Effective integration of scientific input in co-operative ecosystem management depends on the role of science, the 
stakeholders and decision-makers involved, and the common language utilized to compare tradeoffs. Trust is essential to consensus building and the integration of scientific input must be transparent and inclusive of public feedback. Consideration of all relevant stakeholders and the actual benefits and costs of management activities to each stakeholder is essential. Perceptions and intuitive responses of people can be as influential as analytical processes in decision-making and must be addressed. Deliberative, dynamic and iterative decisionmaking processes all influence the level of stakeholder achievement of consensus. In Hawaii, application of lessons learned can promote more informed and democratic decision processes, quality scientific analysis that is relevant, and legitimacy and public acceptance of ecosystem management (Gutrich et. al. 2005).

Maintaining base-flows in the Pocono Creek is a particular concern. Knowing that the demand for water increases as competition for existing water resources grows with a growing number of users, concerns about sustaining the exceptional water quality and supply for future generations were raised throughout the 2003 Pocono Creek Pilot Project for Goal-based Watershed Planning (Pilot), which was funded by a PA Growing Greener grant. Local resource managers and citizens emphasized this issue during both the Pilot's goal setting (2000) and project evaluation stages (2003). The Environmental Protection Agency's Region 3 Office (EPA-3) organized and funded the current project, known as the Framework for Sustainable Watershed Management (Combe et. al. 2009).

The purpose of the Framework is to introduce a program that balances growth with natural resource protection, so that future generations can enjoy the highly valued natural resources of the region, while enjoying economic prosperity. This program is accomplished in three stages; technical, planning and watershed community outreach. The technical stage identifies the impacts of rapid growth on a watershed's water resources. The planning stage develops management strategies that balance regional growth needs with natural resource protection. The planning and watershed community outreach effort introduces an innovative approach to protecting the region's water resources through a community-wide public art event that receives extensive media coverage, has high visibility and generates enthusiastic community participation (Combe et. al. 2009).

The micro-watershed has proved a flexible and practical unit for project implementation and has reduced costs. However, the definition of a micro-watershed needs to be adapted to the social, administrative, and physical context. Best practice is that choice of scale should be driven by a participatory analysis of problems throughout the watershed, preferably within a broader watershed planning framework, as was done in the Loess II Project in China. In 1994 the World Bank funded one of the most successful conservation projects in the world, which improved the local environment, but also boosted the livelihoods of more than 1 million farmers. The number of people living in poverty in the region dropped from 59 percent in 1993 to 27 percent in 2001 and almost 3,000 square kilometers of eroded land was terraced (World Bank, 2003).

The restoration project worked closely with local farmers to build terraces, plant shrubs and trees, install irrigation and sediment control dams, and provide training and education on erosion control. 
This watershed restoration project is now being replicated across China, with continued success (World Bank, 2003).

Based on this, programs can be clear from the beginning about the proposed scale of interventions and the socioeconomic, environmental, and technical criteria for defining the micro-catchment and for selecting which micro-catchments to target. The micro-watershed approach also raises some difficulties when it comes to scaling up. Working at the microwatershed scale does not necessarily aggregate or capture upstream-downstream interactions. A patchwork of upstream interventions would only have a significant impact downstream if prioritized and planned within the larger watershed context and with understanding of the spatial and hydrological links between the perceived externalities and their causal factors (for example, land and water use). The lesson is that integration of watershed management activities beyond the micro-watershed requires higher level technical planning. In best-practice approaches, planning includes an institutional mechanism where stakeholders have a voice and are able to agree on measures from the micro-watershed scale upwards that can achieve both local and larger-scale objectives. The approach also needs to deal with institutional challenges of interagency collaboration and local-regional-level coordination.

Groetschel's (2000) study has investigated the problem situation in selected villages in Kachchh and Dahod district and looked into the institutional framework of watershed development in Gujarat. Field surveys for the target area analysis were carried out in six villages. In the five priority districts for watershed development activities, 15 NGOs and a number of Government institutions were met and assessed. The study is part of the planning process for the Indo-German Watershed Development Program (IGWDP) in Gujarat. It is geared towards providing a qualitative description of important issues for a region specific watershed development approach and gives recommendations for possible adaptations of the watershed development approach. In answer to the problem of natural resource degradation, more than 1200 watershed development projects have been implemented under different programs by the Rural Development Department in Gujarat since 1995. More than 70 percent of these are operated by NGOs. All government funded watershed development projects in Gujarat follow common guidelines, which determine implementation strategies, program content and components, principles of project management, capacity building, financial aspects and monitoring and evaluation. Major aspects of the approach include sustainability, participation, empowerment and decentralization.

In general, the spirit of the common guidelines must be considered to be appropriate. However, as nation wide guidelines, they lack considerations of regional characteristics and problems. More flexibility would be required in many aspects to ensure appropriate handling of local problems. As an integrated, but, basically land based approach, watershed development needs careful consideration of equity concerns. Soil and water conservation measures alone might otherwise further benefit the rich instead of fostering social and economic cohesion. Implementation problems also arise from cooperation difficulties among different GOs and NGOs. The treatment of forest lands and common property resources, as 
required in most cases when following the ridge to valley approach, faces many difficulties. For the last years, the emerging Joint Forest Management Program (JFM) has been trying to mitigate some of those problems. Meanwhile it is the largest program of the Forestry Department. In addition to JFM, there are other government programs, which are supplementary to and supportive of watershed development efforts. The status of NGOs in Gujarat is very strong. Many of them have been involved in watershed development related activities for a number of years already. They actively participate in policy dialogues with the Government and are a driving force in pursuing adaptation of the watershed development approach. Many of the NGOs have developed special implementation strategies, often depending on their specific field of interest or the background of their organization and staff.

Other NGOs are implementing regionally adapted solutions based, for example, on the problem of salinity in coastal areas. In 1999, the National Bank for Agriculture and Rural Development (NABARD) joined the watershed development efforts by establishing its Watershed Development Fund. The fund aims at further strengthening participatory watershed development initiatives. The selection criteria for watersheds are a significant proportion of Scheduled Castes/Scheduled Tribes (SC/ST) population, high extent of rainfed farming and a high potential for watershed development. The regional watershed management cell of NABARD, which took up work in August 1999, is planning to undertake 19 projects at the first stage. Number and staff composition will have to widen, when the program expands.

Successful project implementation demands a range of skills and attitudes at village, NGO and program management level, which are not always or not sufficiently developed. Capacity building, therefore, plays a central role. Requirements at village level include raising awareness for environmental problems and resource management. Additional training will be required in order to make best sustainable use of conserved resources. Many NGOs in Gujarat have been successfully involved in watershed development projects. They have gained ample experience with this approach. What is still needed in some cases is to balance any existing bias in their work, which in many cases is either on the social or on the technical side. However, capacity building for the proposed IGWDP in these respects will probably not require the establishment of a separate institution. There are well established networks, which take care also of capacity building requirements. Requirements at the management level will mainly comprise comprehensive supervisory and monitoring functions.

An important goal of watershed management is to ensure the sustainable development of water resources. However, since integrated watershed management is much easier said than done, this approach is going to illustrate a real watershed, the Big Lost River watershed located in south-eastern Idaho, that has suffered from practical problems and examine this watershed in terms of sustainability just before and after the implementation of this approach. The Big Lost River watershed is about $3730 \mathrm{~km}^{2}$ and drains into the Big Lost River and its tributaries, which in turn drain to the Eastern Snake River Plain. The Big Lost River is one of the largest tributaries to the Eastern Snake River Plain. Although the majority of the 
land in the Big Lost watershed are forest and grass land, agriculture, animal raising, and residential development make significant contributions to the water quality and quantity problems.

To achieve the goals of both the stakeholders and the management decision-makers under sustainability conditions, it is necessary to implement the following steps:

1. The existing characteristics of the Big Lost River watershed should be assessed. This will (a) include determining problems that can hinder the watershed management effort, (b) classifying these problems into groups (scientific, social, or motivational), and (c) determining the priorities in solving these problems.

2. Suitable solutions to solve these problems should then be proposed such as:

a. developing useful relationships among selected water quality parameters to make evaluation of the water quality situations easier by using a small number of parameters,

b. improving integrated management of surface and ground waters by estimating uncertainty in the water budgets,

c. exploring interactive methods for effective public participation, and

d. determining the impact of water quality deterioration and the increase in water demand on water-use physical sustainability.

3. These solutions should be evaluated by examining the sustainability. This approach seeks to introduce a pertinent watershed management framework that can be used to bring Together major stakeholders in a watershed in an-unified effort to protect and improve the quality and quantity of their watershed. The approach can be shared among decision-makers and stakeholders and the results can be used to evaluate and achieve water quality improvements and water quantity conservation. The study tackles watershed problems using a robust technique based on watershed management feasibilities. While this technique has scientific tools to solve watershed problems, it also uses sustainability and public participation as great issues of socio-economic values. The examination of water quality effects, especially erosion of lands and increasing sedimentation as well as increases in water demand due to population or land use changes, on the physical sustainability of water use in a watershed will be a significant benefit and can be applied for other watersheds. The proposed actions related to improving water quality and conserving water quantity, will lead to successful watershed management and encourage stakeholders to participate in the decisionmaking processes (Said et. al. 2006).

\section{Current situation of watershed management in Turkey}

\subsection{Watershed in Turkey}

Turkey has been separated into 25 different hydrologic watershed area (Table 2. Figure 2) and annual flow of these areas are nearly 186 billion cubic meters. One of third of these flow has been calculated in the Tigris watershed area which is situated in the eastern part of the 
Turkey. In the spatial terms volume of these watershed has been followed by Kizilirmak and Sakarya watershed and in the term of the rain regime these watershed has been followed by the East Blacksea, East Mediterranean and Antalya Regions (Anonymous, 2013).

Social and demographic conditions and resource usage of the watershed has been changed by the aspect of the vertical and horizontal conditions of the area and it has been showed differences by the local conditions. Upper parts of the watershed and in the east regions of the country, the general population levels are commonly low levels. Rural poverty and necessities to use of natural resources to sustain life is more common in the upper part of the watershed and eastern part of the country rather than the western parts. Upper parts of the watershed main economic activities are livestock, small agricultural production and forestry. In the contrast of these situation downstream areas are widely used for agricultural products (Anonymous, 2013).

The amount of the total water resource is 112 billion cubic meter and \%36 of these water is proper for use and 32 billion cubic meters are used for irrigation, 7 billion cubic meters are used for drinking water and 5 billion cubic meters are used for industrial proposes (Anonymous, 2013).

In the last decades, with the participation of the non-governmental organizations and universities, there is a great awareness in the public about the sustainable use of natural resources and its benefits (Such as soil protection, water volume and quality, carbon emission, protection of the biological diversity etc.). With the parallel these situation, there is an increase of the projects about rehabilitation works, soil protection barriers and action plans to protect natural biological diversity (Anonymous, 2013).

\begin{tabular}{|c|c|c|c|c|c|}
\hline \multirow{2}{*}{ Watershed name } & \multicolumn{2}{|c|}{ Rainfall area } & \multicolumn{2}{|c|}{$\begin{array}{c}\text { Avarage annual } \\
\text { flow }\end{array}$} & \multirow{2}{*}{\begin{tabular}{|c}
$\begin{array}{c}\text { Avarage } \\
\text { annual } \\
\text { productivity }\end{array}$ \\
$\left(1 / \mathrm{s} / \mathrm{km}^{2}\right)$
\end{tabular}} \\
\hline & $\left(\mathrm{km}^{2}\right)$ & $\%$ & $\left(\mathrm{~km}^{3}\right)$ & $(\%)$ & \\
\hline (01) Meric-Ergene Watershed & 14,560 & 1.9 & 1.33 & 0.7 & 2.9 \\
\hline (02) Marmara Watershed & 24,100 & 3.1 & 8.33 & 4.5 & 11.0 \\
\hline (03) Susurluk Watershed & 22,399 & 2.9 & 5.43 & 2.9 & 7.2 \\
\hline (04) North Aegean Watershed & 10,003 & 1.3 & 2.09 & 1.1 & 7.4 \\
\hline (05) Gediz Watershed & 18,000 & 2.3 & 1.95 & 1.1 & 3.6 \\
\hline (06) Kucuk Menderes Watershed & 6,907 & 0.9 & 1.19 & 0.6 & 5.3 \\
\hline (07) Buyuk Menderes Watershed & 24,976 & 3.2 & 3.03 & 1.6 & 3.9 \\
\hline (08) West Mediterranean Watershed & 20,953 & 2.7 & 8.93 & 4.8 & 12.4 \\
\hline (09) Antalya Watershed & 19,577 & 2.5 & 11.06 & 5.9 & 24.2 \\
\hline (10) Burdur Lake Watershed & 6,374 & 0.8 & 0.50 & 0.3 & 1.8 \\
\hline (11) Akarcay Watershed & 7,605 & 1.0 & 0.49 & 0.3 & 1.9 \\
\hline
\end{tabular}




\begin{tabular}{|c|c|c|c|c|c|}
\hline \multirow[t]{2}{*}{ Watershed name } & \multicolumn{2}{|c|}{ Rainfall area } & \multicolumn{2}{|c|}{$\begin{array}{l}\text { Avarage annual } \\
\text { flow }\end{array}$} & \multirow{2}{*}{$\frac{\begin{array}{c}\text { Avarage } \\
\text { annual } \\
\text { productivity }\end{array}}{\left(1 / \mathrm{s} / \mathrm{km}^{2}\right)}$} \\
\hline & $\left(\mathrm{km}^{2}\right)$ & $\%$ & $\left(\mathrm{~km}^{3}\right)$ & $(\%)$ & \\
\hline (12) Sakarya Watershed & 58,160 & 7.5 & 6.40 & 3.4 & 3.6 \\
\hline (13) West Blacksea Watershed & 29,598 & 3.8 & 9.93 & 5.3 & 10.6 \\
\hline (14) Yesilırmak Watershed & 36,114 & 4.6 & 5.80 & 3.1 & 5.1 \\
\hline (15) Kizılırmak Watershed & 78,180 & 10.0 & 6.48 & 3.5 & 2.6 \\
\hline (16) Konya Watershed & 53,850 & 6.9 & 4.52 & 2.4 & 2.5 \\
\hline (17) East Mediterranean Watershed & 22,048 & 2.8 & 11.07 & 6.0 & 15.6 \\
\hline (18) Seyhan Watershed & 20,450 & 2.6 & 8.01 & 4.3 & 12.3 \\
\hline (19) Asi Watershed & 7,796 & 1.0 & 1.17 & 0.6 & 3.4 \\
\hline (20) Ceyhan Watershed & 21,982 & 2.8 & 7.18 & 3.9 & 10.7 \\
\hline (21) Firat-Dicle Watershed & 184,918 & 23.7 & 52.94 & 28.5 & 8.3 \\
\hline (22) East Blacksea Watershed & 24,077 & 3.1 & 14.90 & 8.0 & 19.5 \\
\hline (23) Coruh Watershed & 19,872 & 2.6 & 6.30 & 3.4 & 10.1 \\
\hline (24) Aras Watershed & 27,548 & 3.5 & 4.63 & 2.5 & 5.3 \\
\hline (25) Van Lake Watershed & 19,405 & 2.5 & 2.39 & 1.3 & 5.0 \\
\hline Total & 779,452 & 100.0 & 186.05 & 100.0 & \\
\hline
\end{tabular}

Table 2. The Watershed of Turkey (Anonymous, 2013)

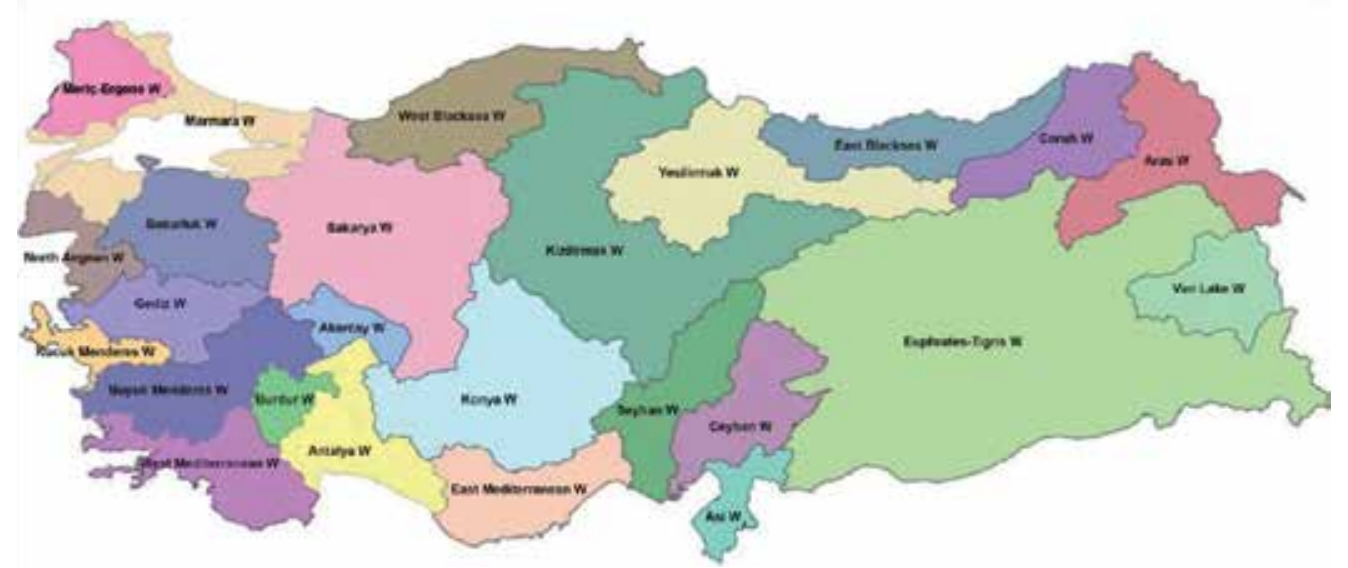

Figure 2. Watershed areas in Turkey (Anonymous, 2013)

\subsection{Stakeholders about watershed management in Turkey}

Watershed management practices in Turkey were held mainly by the governmental organizations such as ministry departments and governmental agencies. Briefly these agencies can be classified by the ministries occupation. These are include (Anonymous, 2013); 
Agencies in the Ministry of Forestry and Hydraulic Works: General Directorate of Combating Desertification and Erosion, General Directorate Of Forestry, General Directorate for State Hydraulic Works, General Directorate of Water Management, Directorate of Nature Conservation and National Parks, Directorate of Meteorological Services, Presidency of Strategy Development, Turkish Institute of Water, Presidency of Information (Anonymous, 2013).

Agencies in the Ministry of Food, Agriculture and Livestock: General Directorate of Agricultural Improvement, General Directorate of Vegetative Production, General Directorate of Agricultural Researches and Politics, General Directorate of Fishery and Water productions, Department of GIS (Anonymous, 2013).

Agencies in the Ministry of Environment and Urban Planning: General Directorate of Spatial Planning, General Directorate of Control about Environmental Impact Assessment, General Directorate of Environment Management, General Directorate of Protection about Natural Heritage, General Directorate of City Bank, General Directorate of Infrastructural Works (Anonymous, 2013).

Agencies in the Ministry of Energy and Natural Resources: General Directorate of Quarry Companies (Anonymous, 2013).

Ministry of Culture and Tourism, Ministry of National Education, Ministry of Health.

Agencies in Prime Ministry: Under secretariat of Treasury, Disaster and Emergency Management Presidency

Agencies in the Ministry of Interior: General Directorate of Local Administration

Local Administrations; governorship (Anonymous, 2013).

\section{Other Civil Stakeholders:}

Non-governmental Organizations: (Organizations, groups, activists about the issues like Soil and Water Resources, Biological Diversity and Rural Development)

Profession Chambers

Watershed Groups

Rural Societies who lives in Watershed Region

Science and Education Organizations (Universities, The Scientific and Technological Research Council of Turkey, Research Institutes)

Stakeholders from Private Sector (Anonymous, 2013).

Stakeholders of Watersheds have different views and importance about economic, ecological, social and cultural by the results product (energy management, clear water resources, irrigation water, water for industrial needs, income and productivity, conservation of the biological diversity, protection of the air cleanness, recreation needs, 
natural landscape, eco-tourism, game sports, protection of the local cultural motivations of the watershed, national income, surplus to liberal economy) (Anonymous, 2013).

\subsection{SWOT analysis of the watershed management}

There is a strong need to swot analysis for figuring out about the future goals and aims of the watershed management (Figure 3).

\section{SWOT ANALYSIS}

\begin{tabular}{ll}
\hline \multicolumn{1}{c}{ Strengths } & \multicolumn{1}{c}{ Weaknesses } \\
\hline $\begin{array}{l}\text { Organizations have gained their experience } \\
\text { about the watershed management and therefore } \\
\text { they can attempt to management in a more } \\
\text { holistic way }\end{array}$ & $\begin{array}{l}\text { Inadequacies in the terms of the watershed } \\
\text { management politics and strategies in addition } \\
\text { to these problems about coordination between } \\
\text { sectorial investments }\end{array}$ \\
$\begin{array}{l}\text { Increase in the watershed protection and } \\
\text { monitoring action plan and river region } \\
\text { management plans }\end{array}$ & $\begin{array}{l}\text { Coordination, legality, policy problems between } \\
\text { governmental agencies }\end{array}$ \\
$\begin{array}{l}\text { Increase about governmental investments for the } \\
\text { watershed organizations }\end{array}$ & $\begin{array}{l}\text { Inadequacies in the term of the participation of } \\
\text { the non-governmental organizations and local } \\
\text { people }\end{array}$ \\
$\begin{array}{l}\text { Increase in the terms of the soil protection and } \\
\text { watershed rehabilitation }\end{array}$ & $\begin{array}{l}\text { Problems about the sharing information } \\
\text { between agencies about development plans }\end{array}$ \\
$\begin{array}{l}\text { Increase in the knowledge share between } \\
\text { governmental and non-governmental } \\
\text { organizations }\end{array}$ & $\begin{array}{l}\text { Inadequacies conditions about monitoring } \\
\text { system which is caused by the lack of the } \\
\text { modern investigation systems }\end{array}$ \\
$\begin{array}{l}\text { molume } \\
\text { Biological diversity monitoring department has } \\
\text { been established a data matrix to inventory of } \\
\text { the biological resources }\end{array}$ & $\begin{array}{l}\text { Lack of national watershed monitoring data set } \\
\text { Inadequacies to set priorities about watershed }\end{array}$ \\
& $\begin{array}{l}\text { proficiencies to set rules of the watershed plans } \\
\text { for coordinating management actions } \\
\text { Deficiencies in the lack about to monitoring of } \\
\text { ecological and socio-cultural data's } \\
\text { Deficiencies in the calculation of the cost benefit } \\
\text { analysis about the stakeholder who effected both } \\
\text { positive and negative } \\
\text { Lack of the sharing information and dialog } \\
\text { between researches and applications }\end{array}$ \\
& $\begin{array}{l}\text { Lack of the stuff who should work for } \\
\text { management agencies }\end{array}$ \\
\hline &
\end{tabular}


SWOT ANALYSIS

\begin{tabular}{|c|c|}
\hline Opportunities & Threats \\
\hline $\begin{array}{l}\text { Decrease of pressure on the upper watershed by } \\
\text { stakeholders because of the mitigation }\end{array}$ & $\begin{array}{l}\text { The deterioration and extinction process on } \\
\text { limited natural resources }\end{array}$ \\
\hline $\begin{array}{l}\text { Access to data and possibilities of utilization of } \\
\text { technology }\end{array}$ & $\begin{array}{l}\text { The deterioration of population balance among } \\
\text { the downstream and upper watershed }\end{array}$ \\
\hline $\begin{array}{l}\text { Diversity and potentials of Watershed that are } \\
\text { caused by natural resources and living creature's }\end{array}$ & $\begin{array}{l}\text { Because of increasing of the population, increase } \\
\text { of demand and requirement from watershed } \\
\text { areas' products and services. }\end{array}$ \\
\hline $\begin{array}{l}\text { Increase of awareness on the society to natural } \\
\text { resources and environmental protection }\end{array}$ & Rural poverty \\
\hline Increase of NGO's effects and contributions & $\begin{array}{l}\text { Because of migration to urban, decrease of } \\
\text { young population in the term of work force in } \\
\text { rural area }\end{array}$ \\
\hline Increase of political attention and support & $\begin{array}{l}\text { Inadequacies of sensitivity and education of the } \\
\text { watershed resources value }\end{array}$ \\
\hline $\begin{array}{l}\text { Development of institutional participatory } \\
\text { approaches }\end{array}$ & Problems of ownership and right of usage \\
\hline $\begin{array}{l}\text { Increase of job opportunities to local community } \\
\text { to work in several remediation processes }\end{array}$ & Increase of industrial pollution \\
\hline $\begin{array}{l}\text { Improvements in legality and policy which was } \\
\text { started with the EU adaptation processes }\end{array}$ & $\begin{array}{l}\text { Increase of using chemical pesticides and } \\
\text { fertilizers }\end{array}$ \\
\hline $\begin{array}{l}\text { Developments in the watershed management in } \\
\text { the world. }\end{array}$ & Threats on the biological diversity \\
\hline \multirow[t]{4}{*}{ Increase of scientific research capacities. } & $\begin{array}{l}\text { Inadequacies in the terms of the legal sanction } \\
\text { about problematic application processes }\end{array}$ \\
\hline & $\begin{array}{l}\text { Negative effects on watershed which is caused } \\
\text { by climate change process }\end{array}$ \\
\hline & Increase of industry at the watershed areas \\
\hline & Increase of mining at the watershed areas \\
\hline
\end{tabular}

Figure 3. SWOT Analysis for Watershed Management in Turkey (Anonymous, 2013).

\section{Discussions and conclusion}

All the organizations is interested with poor people and dedicated to eradicating rural poverty in developing countries.

Main problem about this issue is rapid demographic chance in both rural and urban areas in developing countries. Rural areas have been emptied by the migration progress that is caused by unemployment and poverty in rural areas. Beside this situation, huge urban sprawl has been seen on many cities in developing countries. Water demand on the cities 
that has got huge reservation of the population has been become big problem for clean water resources and sustainability of this resources can not be produced by the managers and governments. However, watershed management should be collaborative. Collaborative watershed partnerships consist with different land use patterns: one in an urban environment, and the other rural. A good practice of healthy and sustainable watershed management is based on a good understanding of these two distinct territories that have different organic and fabric organization schema.

Researchers have paid particular attention to the effect of land use on water quality (Lenat and Crawford, 1994; Hall et al., 1994, Wang and Yin, 1997), a water-quality component often is missing in land-use plans and land-use planning is rarely used in water-quality management. This could be because water-quality management and land use planning often are administrated by different agencies that do not coordinate constantly. Both of planning agencies and local authorities are not use feedback datas for developing plans to monitor of extensive land use and water-quality chances. Water-quality management agencies traditionally address existing water-quality problems rather than to prevent to cause a problem in the main sources. Planners and decision-makers should pay proper attention to water-quality issues in evaluating plans and facilitating collaborations. They should pay enough attention to significancy of land and water collaboration (Wang and Yin, 1997),

Governments and development organizations worldwide are searching for new ideas on how to bring more participation that is public into environmental policy decision processes. Some social and political movements, too, are expanding their participatory outreach and organizing techniques (CIELAP, 2004). Many of the nongovernmental organizations and green activities seek to focus public opinion globally on the importance of water rights (Council of Canadians, 2006). In addition, as mentioned above, the European Water Framework Directive is pushing jurisdictions and cross-jurisdictional water basin committees to implement new participatory processes. Researchers, consultants and activists are generating practices, which can be widely discussed and shared. However, in the end, while many insights can come from hearing what worked and what did not in other places/situations, there is no substitute for locally designed and locally appropriate public participation processes, both within and outside of government (David, 2005).

As the conclusion of the European Water Framework Directive Guidance Document on Public Participation states, "The preamble of the Water Framework Directive includes a very clear statement: active public involvement is most likely the key to success with regard to achieving the desired water quality objectives." In other view, the water users and water polluters need to be turned into part of the solution, not kept outside the considerations as part of the problem. Active involvement is important, however, to take into account that no blueprint solution can be provided. Each River Basin District has to find its own way to handle this, taking into account the prevailing cultural, socio-economic, democratic and administrative traditions. Careful planning, stakeholder analysis is a particular recommendation, but each competent authority has to accept that a dynamic and learning 
process based on "trial and error" is the challenge to embark on. Experiences showed that given sufficient time it would pay off in the long run (EC,). According to Perkins (2011), government initiatives in a very positive light and ignores issues such as in what sense water users who are unserved by infrastructure or too poor to pay for water are really "stakeholders," how the "payoff" of a public learning process might be measured, and to whom this payoff accrues (Perkins, 2011).

Watershed Watershed management project results which are successful in the term of both theory and application, the role of class and gender, among other differences, as determinants of everyone's standpoint and possibilities for participation must be acknowledged. Liberal individualism is certainly not the only thing going on in any participatory process. The truly radical nature of participation only appears as and when it leads to economic redistribution - not just policy-making within existing structures of distribution. Under capitalism and due particularly to its second, ecological, contradiction ( O'Connor, 1994), the pressing need for local environmental knowledge and the contributions of diverse constituencies (Fischer, 1993; McKinney, 2002) in order to address ecological constraints has arguably loosened the controls which the state has traditionally placed on democracy. The type of policy analysis that is "antagonistic to authentic democratic participation" (Fischer, 1993) is now giving way in some instances to more democratic policy-generating processes as a means of addressing intractable environmental problems. However, the inherent open questions of gender, "race," ethnicity and class inequities remain. To address both the "top-down" and the "bottom-up" challenges to broadening public involvement in watershed decision processes as cited above, a creative combination of grassroots environmental education and community organizing is needed. Community-based environmental education initiatives, which are relevant and they are interesting for local residents and increase their knowledge of watershed issues (Fischer, 1993).

Watershed affect the daily lives of every one of many countries 's citizens and provide a powerful wall of protection for countries 's economic development. Data are scarce, but subjective understanding is clear: throughout much of the developing world watersheds are vital to the livelihoods of many millions of people.

Today issues about the water management should be appropriate to the nature as Thales had been said "water is not a just a common material besides it is a spiritual basin". Because of them water management should not be just an engineering work besides it should be a social work which should consider on the both social and cultural work too. So that, common problems can be solved easily and outputs of the projects will be more productive. Rivers are not just a natural sources for transportation, fresh water, energy or irrigation, none or the less they are the basic ground for human culture of the nearby areas. All the ancient great civilizations have been settled near the great rivers, and most of the modern civilization have a peace with their rivers. Because of them combining links between nature and society is the most important issue for sustainability. 


\section{Author details}

Reyhan Erdogan

Akdeniz University, Agricultural Faculty, Department of Landscape Architecture, Antalya, Turkey

\section{References}

[1] Anonymous, 2009. White Paper Holistic Water Resources Management: A Professional Education Plan, H2C1 Team Mississippi State University http://www.gri.msstate.edu/ publications / docs /2009 /09 /6310 WatershedCourseWP2 Sep09.pdf, Date Accessed: 21.07.2012

[2] Anonymous, 2012a. http://en.wikipedia.org/wiki/Thales Date Accessed: 21.07.2012

[3] Anonymous, 2012b. http://en.wikipedia.org/wiki/Heraclitus Date Accessed: 21.07.2012

[4] Anonymous, 2012c. http://www.worldbank.org/projects/P009023/eastern-anatoliawatershed-project?lang=en, Date Accessed: 21.07.2012

[5] Anonymous, 2012d. http://damocracy.org/?page_id=417. Date Accessed: 21.07.2012

[6] Anonymous, 2012e. http://damocracy.org/wpcontent/uploads/2012/04/hasankeyf_hasankeyfesadakat2.jpg, Date Accessed: 21.12.2012

[7] Anonymous, 2012f. http://en.wikipedia.org/wiki/File:Hasankeyf.JPG, Date Accessed: 28.12.2012

[8] Anonymous, 2012g. http://www.ifad.org/governance/index.htm, Date Accessed: 11.08.2012

[9] Anonymous, 2012h. http://www.fao.org/about/en/ Date Accessed: 11.08.2012

[10] Anonymous, 20121. http://www.iwmi.cgiar.org/About_IWMI/Overview.aspx Date Accessed: 11.08.2012

[11] Anonymous, 2013.

Ministry of Forestry and Hydraulic Works, 2012. Strategy of National Watershed Management Report. Date Accesses: 10.04.2013.

http://www.ormansu.gov.tr/osb/haberduyuru/duyurular/12-04-

19/Ulusal_Havza_Y\%C3\%B6netim_Stratejisi_Tasla\%C4\%9F\%C4\%B1.aspx?sflang=tr

[12] Benham B., Brannan K., Dillaha T., Mostaghimi S., Yagow G., 2002. TMDLs (total maximum daily loads) - terms and definitions, Blacksburg, VA: Virginia Tech.

[13] Blatt J. R., 1993. The anti-environmental backlash: The wise use movement's influence on river protection in New England. Unpublished master's thesis. Tufts University, Medford, Massachusetts.

[14] Bossio D., Geheb K., 2008. Conserving land, protecting water. Comprehensive Assessment of Water Management in Agriculture Series 6. Wallingford, UK: CAB International; Colombo, Sri Lanka: International Water Management Institute (IWMI); Colombo, Sri Lanka: CGIAR Challenge Program on Water and Food. http://www.iwmi.cgiar.org/Publications/CABI_Publications/CA_CABI_Series/Conservi ng_Land_Protecting_Water/protected/9781845933876.pdf 
[15] Bowden B. (1999) Integrated catchment management rediscovered: An essential tool for a new millennium. In: Proceedings of Manaaki Whenua Conference: A Three Day Conference on Science for Resource Management. pp.21-23.

[16] Bulkley J.W. (1995) Integrated watershed management: past, present, and future. Water resources management, 100, pp.7-18.

[17] Chambers R., Pacey, A., Thrupp L. A. 1989. Farmer first: Farmer innovation and agricultural research. London: Intermediate Technology Publications.

[18] Chess C., Gibson G., 2001. Watersheds are not equal: exploring the feasibility of watershed management. J Am Water Resour Assoc 2001;37(4):775-82.

[19] CIELAP, 2004. Public Participation in Great Lakes Management. Canadian Institute for Environmental Law and Policy, Toronto.

[20] Cigler B. A., 1998. Emerging trends in state-local relations. In R. L. Hanson (Ed.), Governing partners: State-local relations in the United States. Boulder, CO: Westview Press.

[21] Cobourn J., 1999. Integrated watershed management on the Truckee River in Nevada. Journal of the American Water Resources Association 35(3):623-632.

[22] Combe P.V., Najjar K., 2009. Framework for Sustainable Watershed Management in Pocono Creek Watershed, Delaware River Basin Commission, West Trenton, New Jersey

[23] Cormier S.M., Smith M., Norton S., 2000. Assessing ecological risk in watersheds: a case study of problem formulation in the Big Darby Creek watershed, Ohio, USA. Environ Toxicol Chem 19(2):1082-1096.

[24] Council of Canadians, 2006. Blue Planet Project. <http://www.blueplanetproject. net/Movement/index.html>. http://www.canadians.org/

[25] Darghouth S., Ward C., Gambarelli G., Styger C., Roux J. 2008. Watershed Management Approaches, Policies, and Operations: Lessons for Scaling up watersector board siscussion papaer series, Paper No:11 The World Bank, Washington, DC.

[26] David E.T., 2005. Developing Watershed Management Organizations in Pilot SubBasins of the Ping River Basin, Project Report of Participatory Watershed Management for the Ping River Basin, Thailand,

url: http://www.worldagroforestry.org/sea/Publications/files/report/RP0129-063.pdf, accessed date: 01.02.2013.

[27] Deauna M. C., Lamayo F., 2000. Introduction to analytic geometry and calculus Quezon City: SIBS Pub. House, ISBN: 9717910731, http://cristina327.hubpages.com/hub/History-of-Geometry

[28] Dorf M. C., Sabel C. F. 1998. A constitution of democratic experimentalism. Columbia Law Review 98(2):267-473.

[29] EC, 2002. Guidance on Public Participation in Relation to the Water Framework Directive: Active Involvement, Consultation, and Public Access to Information. EC Circa Website.

$<$ http://forum.europa.eu.int/Public/irc/env/wfd/library?l=/framework_directive/guidanc e_documents/participation_guidance\&vm=detailed\&sb=Title $>$ (accessed10.07.04). 
[30] Ewing S., 1999. Landcare and community-led watershed management in Victoria, Australia. Journal of the American Water Resource Association 35(3):663-674.

[31] Fischer F., 1993. Citizen participation and the democratization of policy expertise: from theoretical inquiry to practical cases. Policy Sciences 26, pp.165-187.

[32] Freeman R. E., 1984. Strategic management: A stakeholder approach. Boston: Pitman.

[33] Garrity D.P., Akinnifesi F.K., Ajayi O.C., Weldesemayat S.G., Mowo, J.G., Kalinganire A., Larwanou M., Bayala J., 2010. Evergreen agriculture: a robust approach to food security in Africa. Food Security 2(3): 197-214. http://dx.doi.org/10.1007/s12571-010 0070-7

[34] Giri S., Nejadhashemi P., Woznicki S.A., 2012. Evaluation of targeting methods for implementation of best management practices in the Saginaw River Watershed

[35] Glicken J., 2000. Getting stakeholder participation 'right': a discussion of the participatory processes and possible pitfalls. Environmental Science and Policy, 3, 305310.

[36] Golden B. F., 1998. Issues in developing and implementing a successful multiparty watershed management strategy. Pages 353-368 in R. J. Reimold (ed.), Watershed management: Practice, policies and coordination. McGraw-Hill, New York.

[37] Grigg N.S., 1998. Coordination: the key to integrated water management. Water resources. Update, Special Issue No. 111. Carbondale, IL:Universities Council on Water Resources.

[38] Groetschel A., Müller-Neuhof I., Rathmann I., Rupp H., Santillana X., Söger A., Werner J., 2000. Watershed Development in Gujarat- A problem-oriented survey for theIndoGerman Watershed Development Programme- Humboldt- Universität Zu Berlın Landwirtschaftlıch-gärtnerısche Fakultät Sle Centre for Advanced Training in Rural Development Ahmedabad/Berlin.

[39] Gutrich J.; Donovan, D., Finucane, M.; Focht, W., Hitzhusen, F.; Manopimoke, S.; McCauley, D.; Norton, B.; Sabatier, P.; Salzman, J., Sasmitawidjaja, V.; 2005. Science in the public process of ecosystem management:lessons from Hawai, Southeast Asia, Africa and the US Mainland. Journal of Environmental Management, Aug:(76(3):197209

[40] Hajjar R.; Jarvis D.I.; Gemmill-Herren B., 2008. The utility of crop genetic diversity in maintaining ecosystem services. Agriculture Ecosystems \& Environment 123: 261-270. http://dx.doi.org/10.1016/j.agee.2007.08.003

[41] Hall L. W., Fischer S. A., Killen W. D., Jr,Scott M. C., Ziegenfuss M. C., Anderson R. D., 1994. Status assessment in acid-sensitive and non-acid-sensitive Maryland coastal plain streams using an integrated biological, chemical, physical, and land-use approach. Journal of Aquatic Ecosystem Health 3, 145-167.

[42] Hardy S. D., Koontz T. M., 2010. Collaborative watershed partnerships in urban and rural areas: Different pathways to success? Landscape and Urban Planning 95: 79-90.

[43] Heathcote, Isobel W., 1998. Integrated Watershed Management: Principles and Practices. John Wiley\& Sons, Inc. New York.

[44] Lant C.L., 1999. Introduction human dimensions of watershed management. Journal of the American Water Resources Association, 35 (3), pp.483-486. 
[45] Lenat, D. R. and Crawford, J. K. (1994). Effects of land use on water quality and aquatic biota of three North Carolina Piedmont streams. Hydrobiologia 294, 185-199.

[46] Liu, B.M.; Abebe, Y.; McHugh, O.V.; Collick, A.S.; Gebrekidan, B.; Steenhuis, T.S. 2008. Overcoming limited. information through participatory watershed management: Case study in Amhara, Ethiopia. Physics and Chemistry of the Earth 33 (1-2): 13-21. http://dx.doi.org/10.1016/j.pce.2007.04.017

[47] McCartney, M.; Smakhtin, V. 2010. Water storage in an era of climate change: addressing the challenge of increasing rainfall variability. IWMI Blue Paper. Colombo: International Water Management Institute.

[48] McKinney, Matthew, Harmon, W.,2002. Public participation in environmental decision making: is it working? National Civic Review 91 (2), 149.

[49] Michael, S. 2001. Making Collaborative Watershed Management Work: The Confluence of State and Regional Initiatives. Environmental Management Vol. 27, No. 1, pp. 27-35 DOI: $10.1007 / \mathrm{s} 002670010131$

[50] Mitchell, B. 1990 Integrated water management: international experiences and perspectives. London, Belhaven Press. Mitchell, R.K., Agle, B.R. \& Wood, D.J. (1997) Toward a theory of stakeholder identification and salience: Defining the principle of who and what really counts. Academy of management review, 22 (4), pp.853-886.

[51] Mitchell, R.K., Agle, B.R. \& Wood, D.J. 1997 Toward a theory of stakeholder identification and salience: Defining the principle of who and what really counts. Academy of management review, 22 (4), pp.853-886.

[52] Molden, D.; Tharme, R.; Abdullaev, I.; Puskur, R. 2007. Irrigation. In Scherr, S.J.; McNeely, J.A. eds. Farming with nature: The science and practice of ecoagriculture. Washington, DC, USA: Island Press. pp 231-249.

[53] National Research Council, 1999. New Strategies for America's Watersheds. National Academy Press, Washington, DC.

[54] O'Connor, James, 1994. Is sustainable capitalism possible? In: O'Connor, Martin (Ed.), Is Capitalism Sustainable? Guilford Press, New York, pp.152-175.

[55] Padma, L. H. Lim-Applegate, and M. Scoccimarro. 2001. The adaptive decision-making process as a tool for integrated natural resources management: Focus, attitudes, and approach. Conservation Ecology 5(2):11. http://www.consecol.org/vol5/iss2/art11

[56] Pereira, H.C. 1973 Land use and water resources in temperate and tropical climates. London, Cambridge University Press.

[57] Perkins, E., 2011. Public participation in watershed management: International practices for inclusiveness/Physics and Chemistry of the Earth 36 (2011) 204-212

[58] Rhoades, R. E. 1999. Participatory Watershed Research and Management: Where the Shadow Falls. Gatekeeper Series No. 81. London: IIED.

[59] Said, G. Sehlke, D.K. Stevens, T. Glover, D. Sorensen, W. Walker, T. Hardy, 2006. Exploring an innovative watershed management approach: From feasibility to sustainability, Energy 31 (2006) 2373-2386

[60] Scott D.H., T. M. Koontz, 2010. Collaborative watershed partnerships in urban and rural areas: Different pathways to success? Landscape and Urban Planning 95 (2010) 79-90 
[61] Sharpley, A. N. 2000. Agriculture and phosphorus management: The Chesapeake Bay and Boca Raton FL. Lewis Publishers, London.

[62] Singh, A. K., T.J. Eldho, and D. Prinz. 2002. Integrated watershed management approach for combating drought in a semi-arid region in India: The case of Jhabua watershed. In 2nd World Water Congress: Integrated Water Resources Management pp. 85-92. Alliance House, London.

[63] Stahl, RG; Bachman, RA; Barton, AL; et al. (1999) A multi-stakeholder framework for ecological risk management: Summary of a SETAC technical workshop. Environ Toxicol and Chem 18(2):1-22.

[64] Steiguer, J.E., J. Duberstein, V. Lopes, 2003. The Analytic Hierarchy Process as a Means for Integrated Watershed Management, Proceedings of the 1st Interagency Conference on Research on the Watersheds, Oct. 27-30, Agricultural Research Service, Benson, Arizona,pp: 736-740.

[65] Swallow, B.; Meinzen-Dick, R. 2009. Payment for Environmental Services: interactions with property rights and collective action. In: Beckmann V.; Padmanabhan, M. eds. Institutions and Sustainability: Political Economy of Agriculture and the Environment. Springer. pp 243-265.

[66] Swift, M.J.; Izac, M.N.; van Noordwijk, M. 2004. Biodiversity and ecosystem services in agricultural landscapes - are we asking the right questions? Agriculture, Ecosystems \& Environment 104 (1): 113-134. http://dx.doi.org/10.1016/j.agee.2004.01.013

[67] Tiffen M., Mortimore M. and Gichuki F. 1994. More People, Less Erosion, Environmental Recovery in Kenya, African Centre for Technology Studies, Nairobi, Kenya, 326.

[68] Tournebizea, J., B. Vincenta, C. Chaumonta, C. Gramagliab, C. Margoumc, P. Mollec, N. Carluerc, J. J. Grilc, 2011. Ecological services of artificial wetland for pesticide mitigation. Socio-technical adaptation for watershed management through TRUSTEA project feedback, Procedia Environmental Sciences 9 (2011) 183-190 doi:10.1016/j.proenv.2011.11.028

[69] U.S.EPA, 1991. Guidance for water quality-based decisions: the TMDL process, EPA 444/4-91-001. Washington, DC.

[70] U.S.EPA, 1992 A framework for ecological risk assessment. Risk Assessment Forum, Washington, DC; EPA/630/R-92/001. Available online at http://www.epa.gov/ncea/raf.

[71] U.S.EPA, 2001. Improved science-based environmental stakeholder process, a commentary by the EPA science advisory board. EPA Science Advisory Board, Washington, DC; EPASAB-EC-COM-01-006. Available online at http://epa.gov/sab/pdf/eccm01006.pdf.

[72] U.S.EPA, 2012. What is a watershed? http://water.epa.gov/type/watersheds/whatis.cfm

[73] University Outreach\& Extension Water Quality Program (UOEWQP), 2004. Fostering Locally-Led Holistic Watershed Management http://www.usawaterquality.org/conferences/2004/posters/TharpMO.pdf

[74] Van der Zijpp, A.J.; Verreth, J.A.J.; Le Quang Tri; van Mensvoort, M.E.F.; Bosma, R.H.; Beveridge, M.C.M. 2007. Fishponds in farming systems. Wageningen Publishers, Netherlands. 
[75] World Bank, 2003. China Loess Plateau Watershed Rehabilitation Project Report. Report No: 25701 http:/ / www-wds.worldbank.org

[76] Wamalwa, I. W., 2009. Prospects and limitations of integrated watershed management in Kenya: a case study of mara watershed, Lund university international masters programme in environmental studies and sustainability science, A Master Thesis, Sweden p.51

[77] Wang, X. and Yin, Z.-Y. 1997. Using GIS to assess the relationship between land use on water quality at a watershed level. Environment International 23, 103-114.

[78] Wang, X., 2001. Integrating water-quality management and land-use planning in a watershed context. J. Environ. Manage. 61 (1), 25-36.

[79] Zomer, R.J.; Trabucco, A.; Coe, R.; Place, F. 2009. Trees on farm: analysis of global extent and geographical patterns of agroforestry. ICRAF Working Paper no. 89. Nairobi: World Agroforestry Centre. http:// www. worldagroforestrycentre.org/ downloads/ publications/PDFs/WP16263.PDF 


\title{
Urban Waterfront Regenerations
}

\author{
Umut Pekin Timur
}

Additional information is available at the end of the chapter

http://dx.doi.org/10.5772/55759

\section{Introduction}

"Cities seek a waterfront that is a place of public enjoyment. They want a waterfront where there is ample visual and physical public access - all day, all year - to both the water and the land. Cities also want a waterfront that serves more than one purpose :they want it to be a place to work and to live, as well as a place to play. In other words, they want a place that contributes to the quality of life in all of its aspects - economic, social, andcultural".

Remaking the Urban Waterfront, the Urban Land Institute

(Seattle Department of Planning and Design, 2012)

Water is an indispensible natural resource that is a renewable, but limited. It uses the aims of agricultural, industrial, energy generation, household, transportation, recreational and environmental. Kılıç (2001) as cited in Hamamcıoğlu (2005), water resources which have played an important role in most parts of the world throughout history in the establishment and formation of the settlements and through their getting their own identities (Pekin, 2008). Sairinen \& Kumpulainen (2006), waterfront identifies the water's edge in cities and towns. Moretti (2007), in pre-industrial cities, waterfront areas were intensely used and thriving with people and activities. Also, during this period, a close relationship was between waterfront and cities. With industrial era, this relationship was interrupted due to some uses, such as huge ports, commercial, industry, warehouses and transportation (Pekin, 2008). Through the evolution of containerization technology, port activities moved to outside the city. Accordingly, industrial plants were abandoned and forms of transportation changed (Wrenn et al., 1983). Also with the increasing environmental awareness and as a consequence of the pressure for upgrade in a urban areas, waterfronts were rediscovered in the city. So, phenomenon of waterfront regeneration emerged. Urban waterfront regeneration projects has become an effective tool for urban planning and politics an international dimension since 1980's (Sairinen \& Kumpulainen, 2006; Goddard, 2002). 
This chapter discusses waterfront, urban waterfront, its development phases, typologies of urban waterfront regenerations, advantages and disadvantage of urban waterfront regenerations, principle of sustainable and successful development for waterfront and also case studies in the world.

\section{Waterfronts and urban waterfronts definitions}

The word meaning of waterfront get through as "the part of a town or city adjoining a river, lake, harbour, etc." in the Oxford American Dictionary of Current English in English Dictionaries and Thesauruses (Dong, 2004).

Moretti (2008), the word "waterfront" means "the urban area in direct contact with water". According to the author, waterfront areas usually is occupied by port infrastructures and port activities. Yasin et al. (2010) indicated that waterfront is defined generally as the area of interaction between urban development and the water. Hou (2009), described the waterfront area as the conflux area of water and land.

Although the vocable of waterfront is clear, also it has been met using some different words instead of the term waterfront in the literature. Hoyle (2002), Hussein (2006); Mann (1973), Tunbridge and Ashworh, (1992), Vallentine (1991) and Watson (1986), these words are a city port, harbourfront, riverside, river edge, water edge and riverfront (Dong, 2004; Yassin et al., 2012).

Breen and Rigby (1994), Sairinen and Kumpulainen (2006) and Morena (2012) imply the same thing with waterfront and urban waterfront. According to these, waterfront identifies the water's edge in cities and towns or urban area of all sizes. The water body may be " $a$ river, lake, ocean, bay, creek or canal" or (e.g. in Shaziman et al., 2010) artificial.

\section{The effects of water as a planning element in urban area}

The balance is established between nature and social life for a sustainable development of cities. Urban natural water elements play an important role in the establisment of this balance. Water is the most important planning element which is comfort of human physical and psychological. In addition, it brings existing environment in a number of features in term of aesthetic and functional (Figure 1) (Önen, 2007).

One reason for the importance of natural water source in urban area is aesthetic effects whose creates on human. This effects are visual, auidal, tactual and psychological effects.

The primarily power of attracted people on waterfronts is visual landscape effects of water on relaxation. Throughout, designs related to water takes over motion and serenity factors. Moving water (Figure 2a) (waterfall, cascade rivers and etc.) adds vibrancy and excitement to a space. Stagnant water (Figure 2b) creates the mirror effect in its space as a visual (Önen, 2007).

Aksulu (2001), water is used commonly as reflection element by means of the optical properties. Wide and quiet water surfaces bring in serenity and deepness to its surronding 
or a space. Beside deepness effect of water gives more widening feeling of in living area. Also, the various light games is formed on this surface (Hattapoğlu, 2004).

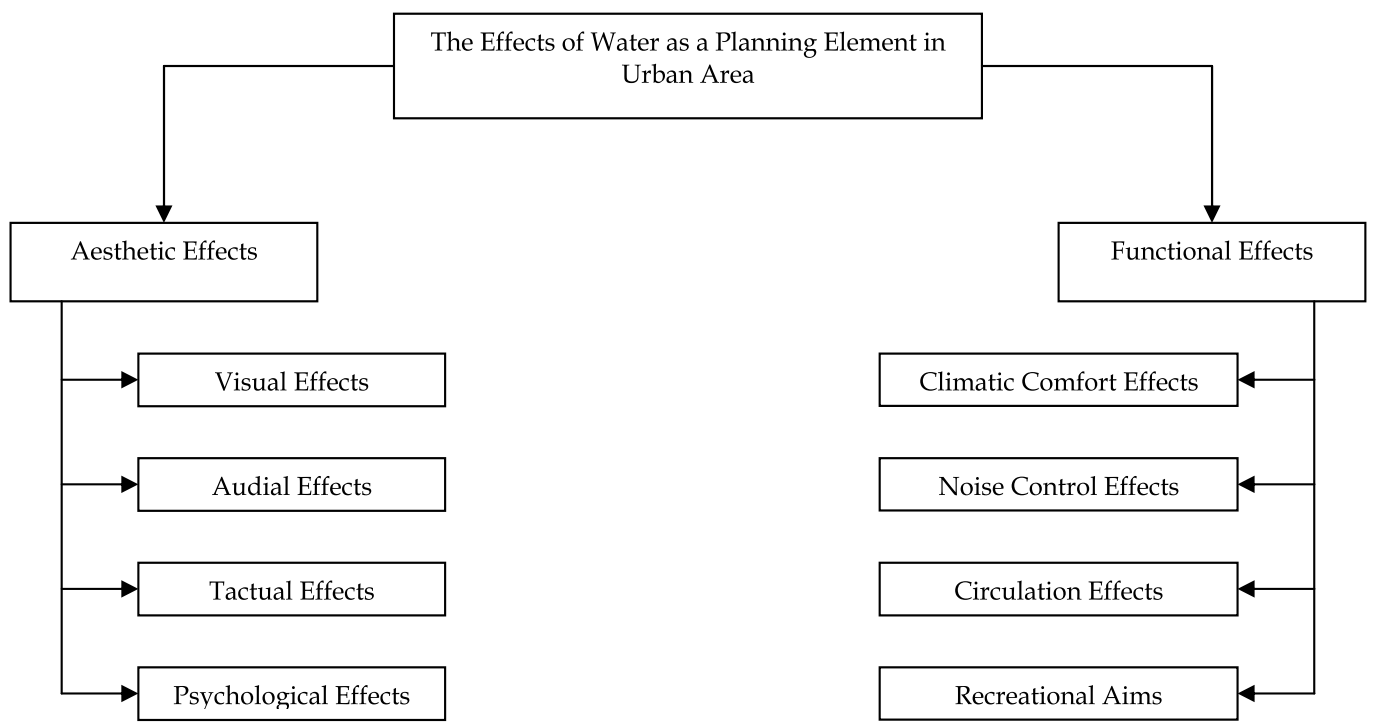

Figure 1. Adapted from Önen (2007), the effects of water as a planning element in urban area
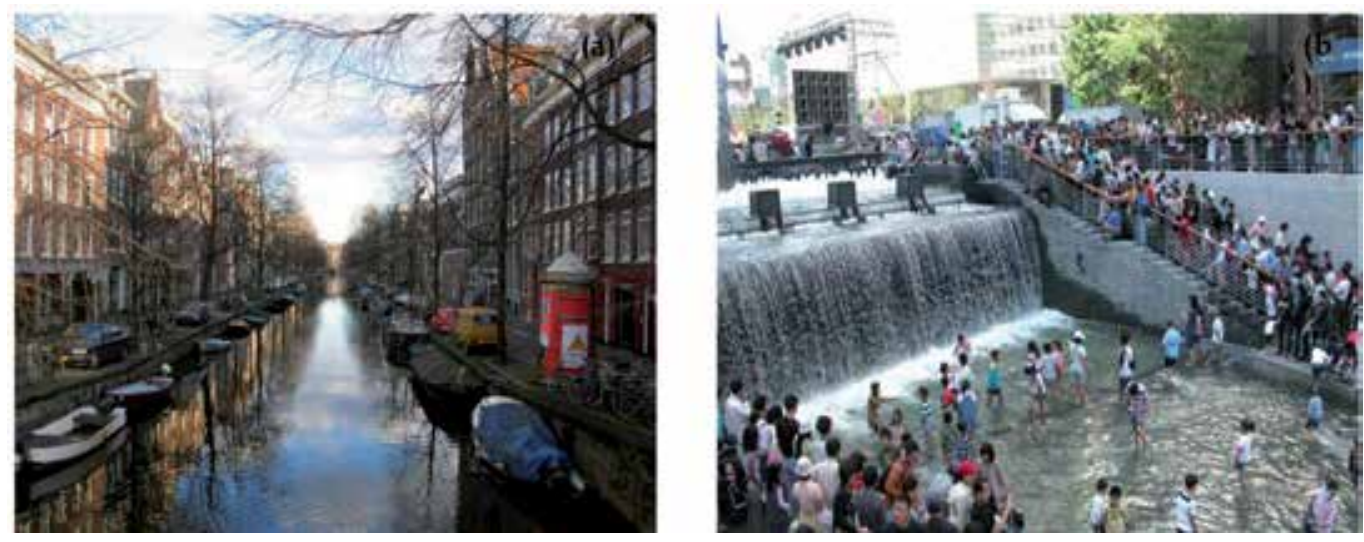

Figure 2. (a) The mirror effect of water, (b) The vibrancy effect of moving water (Önen, 2007).

Aksulu (2001), the sound of water as an audial, a symbol is in a state which exhibits continuity of life whereas it gives vibrancy and joy (Hattapoğlu, 2004). Stagnant water as an audial creates a serenity sense while moving water adds vibrancy to a space and also creates music effect (Önen, 2007).

For the tactual effects of water in planning varies from rain dropping to our face, getting wet with splashing water of waterfall to being completely submerged in pool, lake or the sea. Diving in to the water is a kind of escape from the world. Touch with water is a symbol that reach the religious serenity for many belief systems (Hattapoğlu, 2004). 
It is possible that an important effects of the aesthetic effects are psychological ones. In fact, these effects are the emotional result which is perceived with senses. In addition, there is also psychological reactions towards water which comes from people's sprits. Human being trends psychologically to water as an element which provides the continuity of life. Sound and freshness of water relax people (Önen, 2007).

Water in urban areas is aesthetic effects as well as functional effects. These are climatic comfort, noise control, circulation effects and recreational aims.

Water surfaces cool air by means of increasing the amount of moisture in an environment. Especially with continental climate, that is a great importance. Also, water is used to freshen up the outdoor's air. Wide water surfaces in regional-scale regulate air's temperature surrounding areas (Önen, 2007). Water element is an important in urban areas where is in this regions, because of its visual and climatic effects (Gençtürk 2006).

In addition, water areas in urban spaces are composed of a barrier to artificial sounds with its creating the natural sounds (Önen, 2007).

Eckbo (1950), water is in the organization of space as a limiting and concealer element. Because person has to walk around in suitable direction (Gençtürk 2006). It is possible to see mostly this effect at the riverfronts.

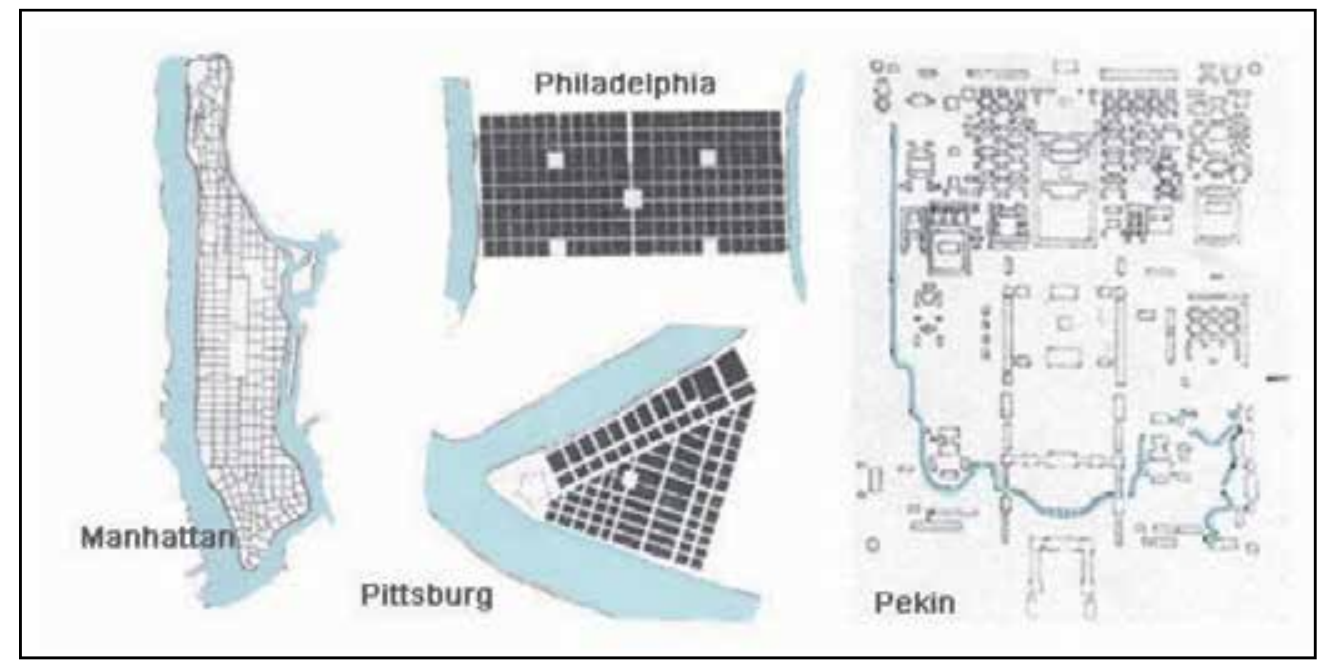

Figure 3. Moore, Lidz (1994), urban schema of Manhattan, Philadelphia, Pittsburg and Pekin (Hattapoğlu, 2004)

Rivers taked on a spine task which is established cities and in the formation of streets, parks and other urban spaces have become a major factors. For example, (Figure 3) in Manhattan, Pittsburg, Philadelphia and Pekin (Hattapoğlu, 2004).

Recreational use of water element is too varied. Natural and artificial water surfaces and its surrounding can be serve many recreational uses (Figure 4), such as swimming, fishing, boat tour, entertaiment, walking etc. 

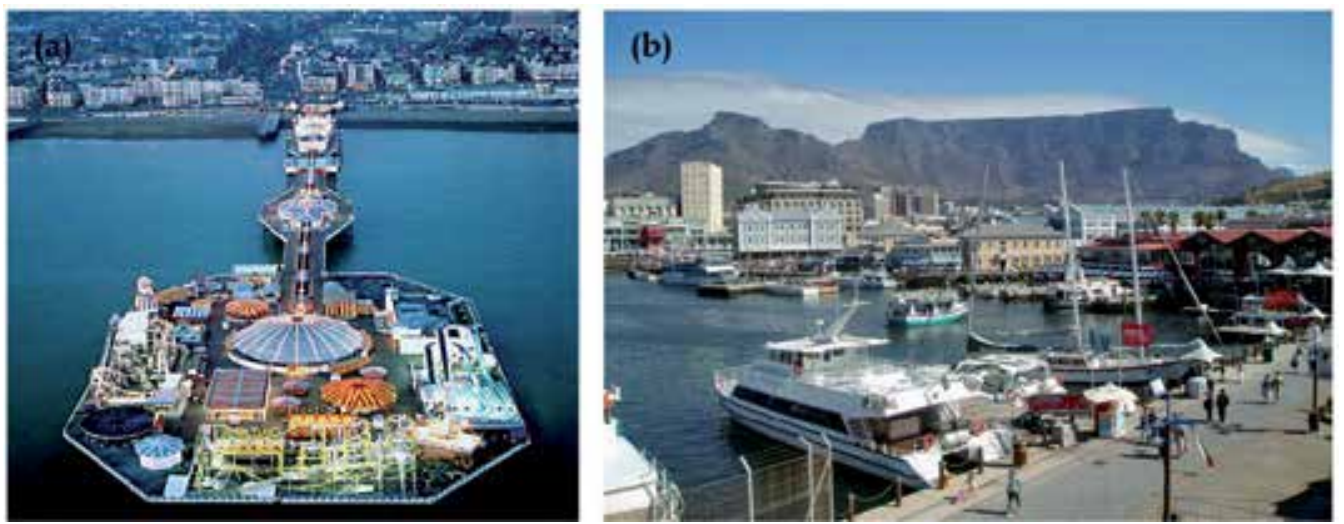

Figure 4. Recreational uses (a) (http://www.aerialarts.com/db_B_ton_Pier_Night1.jpg), Brighton Pier, (b) (www.thelances.co.uk/SA/CT12.jpg) The Victoria and Alfred Waterfront (Andini, 2011)

\section{Urban waterfronts categories}

According to Wrenn et al. (1983), urban waterfronts have been distinguished five categories to location with water. Explained below the first two line symbolize coastal cities and the latter three line symbolize inland ones (Al Ansari, 2009).

a. Urban area located on peninsula,

b. Urban area located on a bay,

c. Urban area located on banks of a river,

d. Urban area located on banks of intersecting rivers,

e. Urban area located on a large body of water.

Wrenn et al. (1983), regardless of that separation, the shoreline shape is a major influence on how the location of the city in reference to the water impacts the city-water links. Cities which are located on peninsulas, headlands or small islands benefit from longer waterfronts at a short distance from the city centre. The same could be said of cities located on the banks of intersecting rivers, estuaries and deltas. They have many long waterfronts, which increases the chance of public spaces located on the waterfront and also of these being connected to other hinterland public spaces (Al Ansari 2009).

\section{Urban waterfronts features}

Akköse (2007), three factors are more important in forming the cities. The first of these is the natural structure of the city, the second of these is physical structure of the city, and the other one is social structure of the city. These three factors constitude system of the city in interaction with each other. In the natural structure of the city, the water element of presence or absence influences the process and the image of the city. Water resources such as sea, river or lake are added value in different ways. According to Dong (2004), Yassin et al. (2010) and Seattle Department of Planning and Design (2012), certain features of waterfront is represented to below: 
- It is become an urbanized area, a important land,

- Water and land are the two essential elements of waterfront, so this area an aquatic and terrestial features,

- The "water" may be a river, lake or sea,

- It has uncertain spatial boundaries and dimensions which change from place to place,

- The waterfront area may be a historical port area or urban area for other usages close to water,

- An essential structure of mixed land uses characterizes this essential area of the city,

- It supplies oppurtunity for interaction between human settlement and nature and water,

- As an edge environment, it is a dynamic place which changes biological, chemical and geological charachter,

- It is a special area because of being productive and biologically diverse ecosystems,

- It is a natural defense area for flooding, erosion with plant cover,

- The waterfront area is a pollution moderator.

\section{Waterfront development}

Dong (2004), indicated that the meaning of the waterfornt development has differents in terms of understandings. Also he/she emphasized that the content of waterfront development varies greatly with respect to the characteristics of sites and cities. For example, in Japan urban waterfront development is one of the interrelated three waterrelated development concepts. Its location is between waterside and coastal development. Also, these development levels are comen up different field. In here, waterfront development is evaluated urban planning field.

According to Morena (2011), "the urban waterfront development is widely regarded as a frontier on contemporary urban development, attracting investment and publicity. Sydney, London, Amsterdam, Hong Kong, Tokyo, Toronto, Osaka, Kobe and Dublin are examples of cities developed through the waterfront development process ".

Yassin et al. (2012), defined ideally as "a development directly fronting on water for any purposes and the water components can include river delta, coastal plains, wetlands, beached and dunes, lagoon, and other water features". Beside, the boundary of where the water and land meet is difficult to determine and this boundary usually differ the laws and the administration of the countrys.

Wrenn (1983), the waterfront development stimulated modern development in the cities. Therefore, understanding the historical milestone of waterfront development is important (Yassin et al., 2010). This subject has been explained in the following topic.

\section{Typical pattern of waterfront development}

Throughout history, waterfronts are the most ideal living area for human being to be able to provide food, settling, reproduction, defence and learning etc. So, the many cities or towns 
are established water's edge from the history of civilization to until today. Uruk, Erudu, Ur and Babylon are an examples for early settlement about 6000 years ago (Hamamcioğlu, 2005; Morena 2011). In case nowadays, the many cities or towns in China, England, Italy and America can be given as an examples of waterfront settlement (Zhang, 2002).

Urban waterfronts have historically been the hub of transportation, trade and commerce (Letourneur, 1993). Rafferty and Holst (2004), they are always connected with close by means of reflecting immediately any change in social, economic, industrial environmental. Historically, waterfronts aren't planed carefully and consistently. Growth had been inceasing and disconnected as a result, synthezis of numerous enterprise, activities and decisions of political authority. Thus, every urban waterfront has its special history (Akköse, 2007).

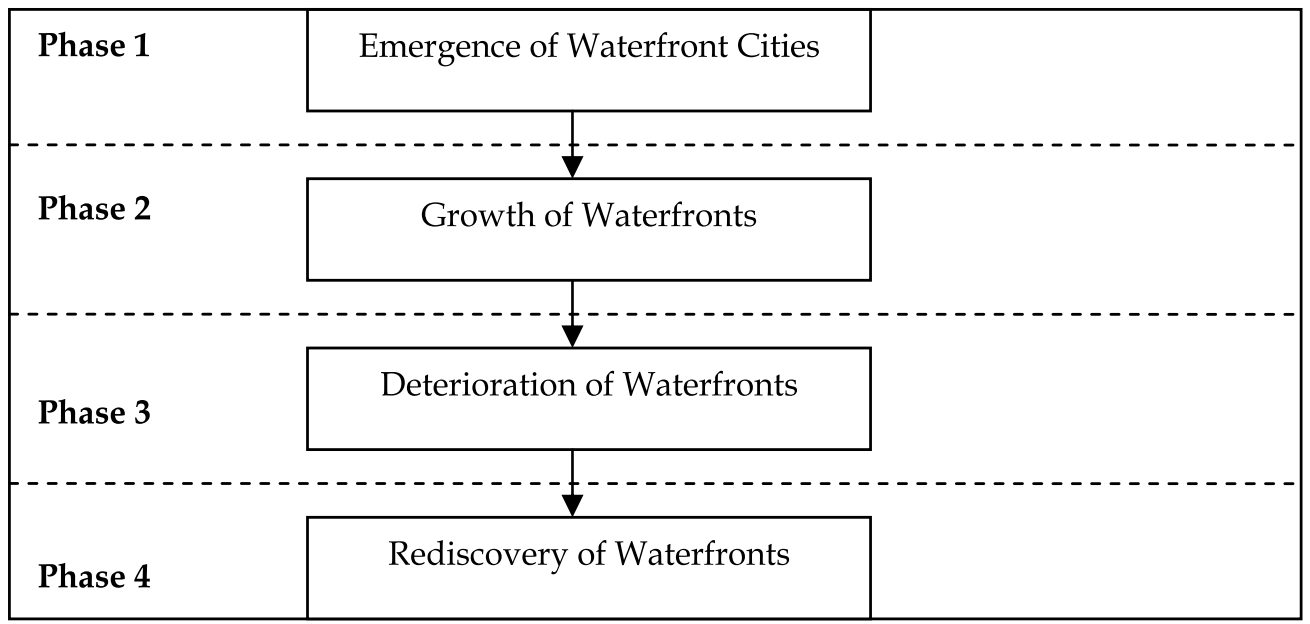

Figure 5. Adapted from Wrenn et al. (1983), typical pattern of waterfront development phases

Wrenn et al. (1983), indicated the historical evolution of waterfront into four periods (Figure 5). These are explained briefly as follows:

a. Emergence of Waterfront Cities

The early American settlements, the waterfront and the city was directly contact. Waters plays an essential role for trade activity and water tranportation. Settlements were established and European immigrant colonies arrived. The movement of production and people is provided between the two continent by sea route. A settlement's waterfront served to link the necessities of Europe with a familiar and predictable environment (Zhang, 2002; Akköse, 2007; Yassin et al., 2010).

These settlements were established around a port with safe harbor suitable for cargo and passenger ships (Figure 6). At this time, the waterfront has only a few trails converging at a jetty. After, a street pattern was slowly installed. In this period, a larger wood pier was usually established for ship. Also, buildings began to develop on the street pattern. Though the rapid growth and development, the settlement still connect with the waterfront a shoreline road (Akköse, 2007; Wrenn et al., 1983). 


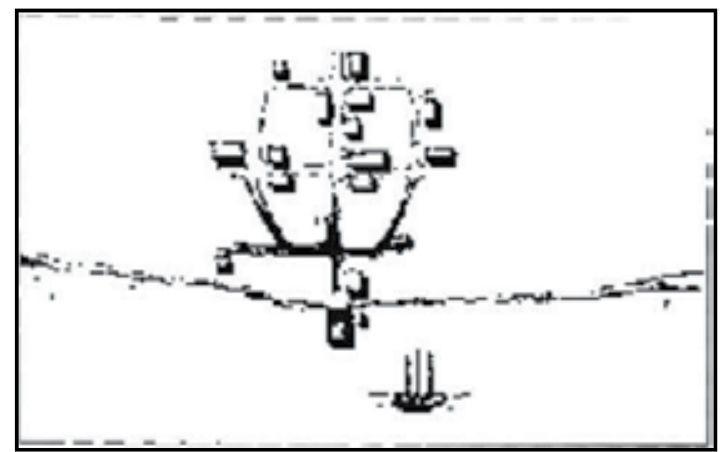

Figure 6. Typical pattern of waterfront development (Phase 1) (Seattle Department of Planning and Design, 2012)

\section{b. Growth of Waterfronts}

The first period of ports has converted contain of many functions ports with increase of economic activities. At this time, the settlement became a city and maritime trade stimulated urban development (Figure 7). The shoreline road turned into a busy street providing services, supplies, and officespace for commercial activities. The waterfronts became more important state and commerce escalated with the use of steamships. Warehouses were constructed along the waterfront and these rows of warehouses blocked the water's edge from the street. Also, in the former period used of wooden piers replace by bigger docks made of stone and fill material. By filling out into the water to expand docking and storage facilities. The rapid development waterfronts as a port facility caused the formation of a port authority for managing the port activities (Akköse, 2007; Wrenn et al., 1983).

At this period, railroad was introduced as a new mode of transportation. This required some space from waterfront to service docks and install tracks. As a result of this change, effectively severed the central city from the waterfront. Also, the waterfront became increasingly congested. Since 1930's, elevated highways and interstate freeways was built the shoreline to decrease this congestion. Offices and stores along the old shoreline road were converted to warehouses (Wrenn et al., 1983; Zhang, 2002).

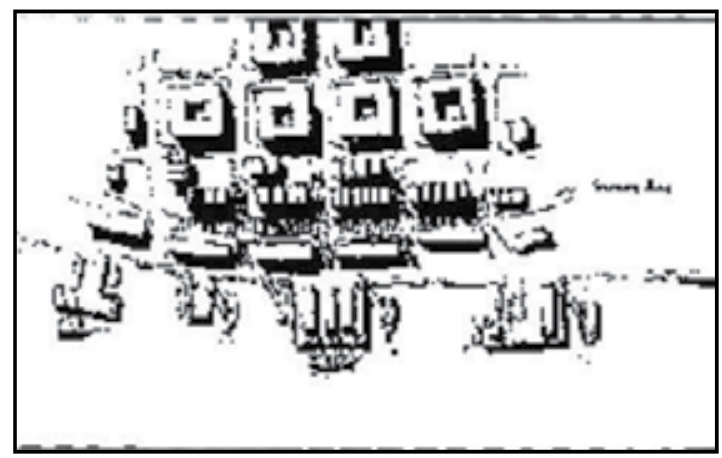

Figure 7. Typical pattern of waterfront development (Phase two) (Seattle Department of Planning and Design, 2012) 
At this time, transportation and industry become the only use of the waterfront. Beside, in the previous period contact directly with water is lost as construction of warehouses, railway and highway create a barrier to public access. In the meantime, the waterfront environment deteriorated because of the industrial pollution. The water became dirty and the waterfront began to lose its natural attraction to many urban residents. (Wrenn et al., 1983; Letourneur, 1993).

c. Deterioration of Waterfronts

Rafferty and Holst (2004), until World War II, the loading-offloading activities of ship was carried out in along time in a port areas (Figure 8). After the War, the amount of load and speed of the loading-offloading increased with the development of containerization technology (Akköse, 2007).

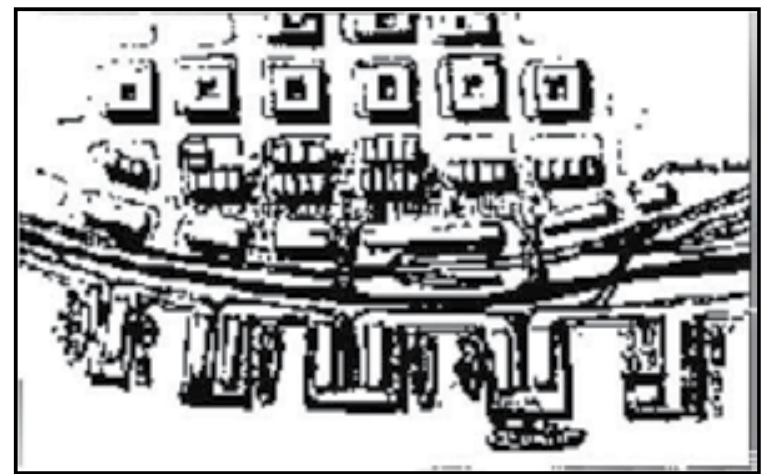

Figure 8. Typical pattern of waterfront development (Phase three) (Seattle Department of Planning and Design, 2012)

Zhang (2002), the old port areas were too constricted for modern container ships and equipment to maneuver easily, also Rafferty and Holst (2004), as cited in Akköse (2007) water depth was not enough for approaching the ships. Millspaugh (2001), after World War II, as a result of developments in maritime industry, thereby growing port actitivies started to need new areas (Akköse, 2007). Thus, port activities moved to outside the city. So, the old ports lost the role as the transportation and industry center. With the construction of highways largely changed the transportation patterns and this contributed to be abandoned the waterfronts areas. Also, people preferred the highways to railroads because of their freedom of choice. Due to fewer people chose railroad, the waterfront became even deteriorated (Zhang, 2002).

Beside these changes, increasing public interest over pollution contributed to the waterfronts demise. With the introduction of stricter air and water pollution controls, manufacturers began to leave the city. As a result, many ports fell into disuse. Also, the railroads suffered because of decline of manufacturing plants and disinvestment. Railroad yards on the waterfront were neglected. The waterfront virtually became a deserted, inaccessible and unsafe area, further separating the urban core from the water (Zhang, 2002; Wrenn et al., 1983). 
d. Rediscovery of waterfronts

In the waterfront areas of abandoned old ports was available several problems. The first of these was caused pollution by the port and industrial activities. Second problem should be obsolete infrastructure of the industrial areas which is surrounded by abandoned warehouses and other port structures. In addition, the railroad and the highway broke off the link between urban center and waterfront area and also prevented interaction eachother (Akköse, 2007). Also, in the 1960's, people became more concerned about environmental-city health and the misuse of natural resources. Locals wanted to recover the aesthetic scenery of the waterfront which had been neglected for years. As a result, the port's commercial failure caused reevolution of waterfronts by private developers and city governments (Zhang, 2002). So, U.S. Department of Commerce, NOAA and OCZM (1980), it was at this time that an opportunity exists for the public use and a mix of recreational, residential, and commercial uses were developed (Figure 9). The lost intimate connection was provided again between the city and its waterfront. In the meantime, a new port to respond to new technology was established outside the city where space was plentiful (Wrenn et al., 1983; Letourneur, 1993).

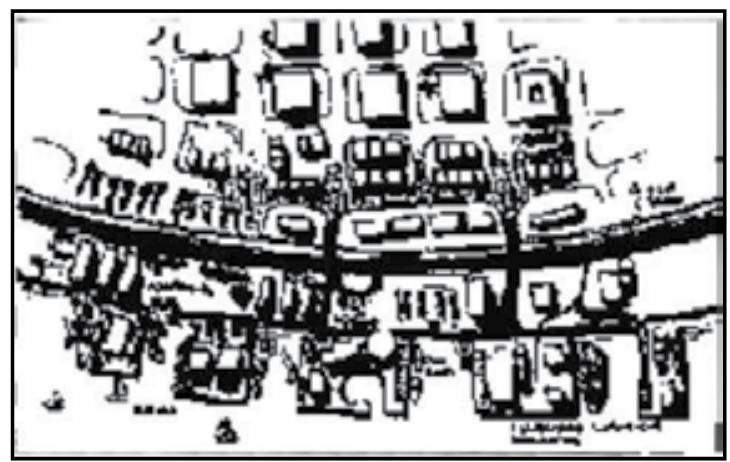

Figure 9. Typical pattern of waterfront development (Phase four) (Seattle Department of Planning and Design, 2012)

Waterfronts vary depending on many interrelated factors. These are a city's history and size, its location, land structure and climate, the diversity of water-related uses and city's management status. For this reasons, each waterfronts may be some variance in the typical waterfront evolution pattern. But, one fact is common, urban waterfronts dramatically changed because of the influence of social and technology factors. Finally, much more area has been regained public use and access (Wrenn et al., 1983; Zhang, 2002).

\section{Urban waterfront regeneration}

With the rediscovery of the urban waterfronts, Sairinen and Kumpulainen (2006), as cited in Pekin (2008) new laws were enacted to govern the structural changes in there and for this goal, new planning methods were developed. 
As most of the waterfront development projects arise in the larger context of urban renewal, for these projects a number of other expressions are used similar to this phrase. But most of these projects concentrate on the regenerating function. Such expression include "waterfront regeneration" (e.g. in Wood and Handley, 1999; McCarthy 1996), "waterfront revitalization" (e.g. in Goodwin, 1999; Hoyle, 2001), "waterfront rehabilitation" (e.g. in Hoyle \& Pinder, 1981: 83), and "waterfront redevelopment" (e.g. in Gospodini, 2001; Gordon 1999) (Dong, 2004). Also, the terms which is used in their development may vary according to study's border and as a regional domain (Koca, 2011).

The interest of waterfront regeneration phenomenon emerged from North America in the mid 1960's, with a rehabilitate of Baltimore's Inner Harbour (Figure 10), a project that transformed the degraded harbor zone to an urban leisure centre (Papatheochari, 2011; Al Ansari, 2009; Goddard, 2002; Tastsoglou \& Dimitra, 2012). Breen \& Rigby (1996), Hoyle (2001a), Shaw (2001), this phenomenon is characterized as a Baltimore Syndrome, is still in full swing (Al Ansari, 2009).

Many factors are considered more as the sources of the phenomenon, except those mentioned previously. But the two most essential are Connors (1986), Meyer (1999), Norcliffe et al. (1996), Tunbridge (1988), the economic transition from industrial to postindustrial service base and Clrake (1972), Cohen et al. (1997), Pinder and Witherick (1993), Vitousek et al. (1997), the high concentration of population at waterside (on the riverine, lacustrine, estuarine, and costal zones) locations (Al Ansari, 2009).

Tunbridge (1988), remarked that prompted a general revitalisation of US port-cities based on several factors among which are changing demography, availability of cheap, residential property, increasing heritage awareness, increasing quality of life awareness, the desire to live closer to work and the increasing importance of urban tourism (Jones, 1998).

Also Jones (1998), indicated that the movement of waterfront in US is attributed to a few of factors which have involved the following:

- The inreasing amount of leisure time and the need for more recreational area,

- The need to conserve historical and architectural heritage, because of being found old dockland areas of the first American ports,

- According to Breen \& Rigby (1998), US Federal Government support by means of urban regeneration action grants and other development tax incentives.

“Tunbridge (1988), and Malone (1996), pointed out that the movement provides a parallel thread to the overall urban regeneration process. Also, Wood (1965) suggested that waterfronts are naturally prone to renewal and regeneration because they are usually in the oldest parts of the city" (Al Ansari, 2009).

According to Shaw (2001) the regarding theoretical work has always followed the practical part of the process. Hoyle \& Pinder (1992), Hoyle et al. (1988b), explained that the main bulk of the regarding research started to accrue in North America in the 1970's and in Europe in the 1980's (Al Ansari, 2009). 

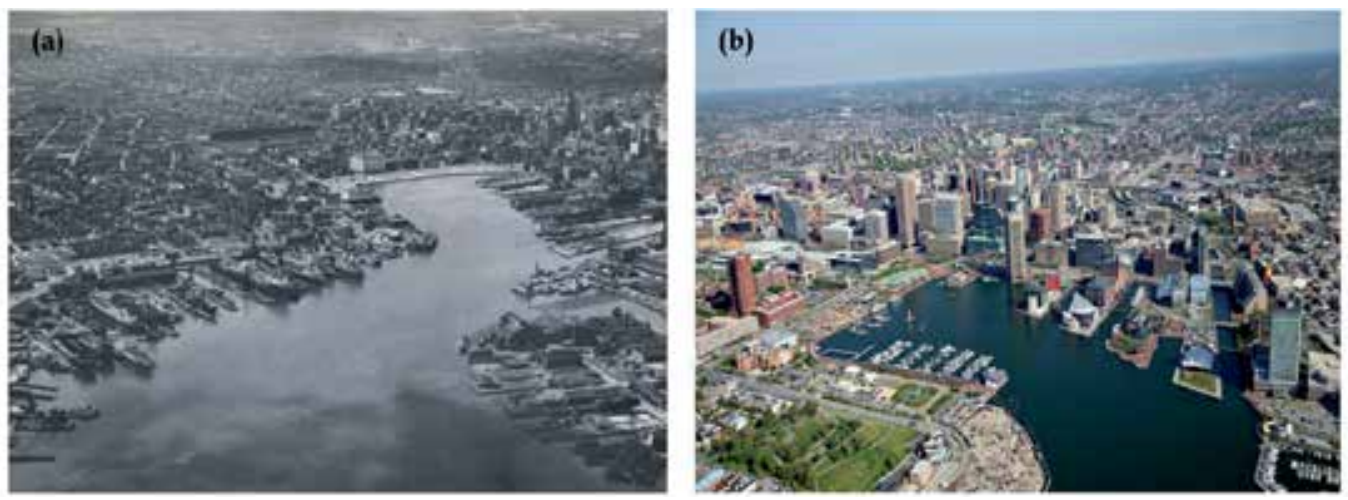

Figure 10. (a) 1960's in Baltimore Inner Harbour (Kilduffs Baltimore's Harbor, 2013), (b) Present day (Anonymous, 2013a)

The first examples of waterfront regeneration came in the 1970's from cities in the North America (Papatheochari, 2011). In case its applications became widespread in the 1980's in there (Jones, 1998; Goddard, 2002). Generally, the waterfront regeneration varied to urban interventions and politics of countries. For example, in North America Hoyle (2000), the waterfront is considered to be part of the urban renewal process in North America, whereas Hoyle (2000), (2001a), Tunbridge (1988) in Europe, it is regarded as a mere side-effect of the changes in maritime transportation, however, in the UK, it is a component part of postindustrial urban regeneration.

The American waterfront regeneration is consist of mixed uses including residential, recreational, commercial, retail, service and tourist facilities. Mainly residential, recreational and tourist-related uses were often the predominant than the others in this model. Also this largely became the typical development model within the US. and this model was widely accepted by other countries. The experience of Amerikan waterfront regeneration, especially Baltimore's Inner Harbour regeneration, influenced many in Europe (from Scandinavia, UK and the Netherlands to Spain and all southern Europe) and worldwide (Australia, Japan, Latin America, the Middle East and South Africa (Papatheochari, 2011; Jones, 1998).

English Tourist Board (1988), Hoyle et al. (1988), indicated that the most influential examples of the US waterfront regeneration projects in worldwide are The Inner Harbour Baltimore, Quincy Market Boston, The Pierhead Building New York, San Diego's waterfront village, Giradelli Square and Pier 63 San Francisco (Jones, 1998).

To Jones (1998), "since the mid 1980's the vocabulary of urban waterfront regeneration has been clearly established in the minds of developers, local authorities and national government departments".

Beside, waterfront regeneration is viewed as a standart catalyst of inner area regeneration for any city or town in the mid 1980-1990's (Goddard, 2002).

The widespread recognition of the phenomenon and its importance brought about the establishment of research centres, such as The Waterfront Centre - Washington D.C. (1981), Association Internationale Villes \& Ports - Le Havre (1988), The International Centre Cities 
on Water - Venice (1989). Aim of these enhance scientific studies and research about the planning and design stages necessary for an effective development of waterfront area. According to Waterfront Expo (2004) it is guessed that $£ 55$ billion is going to be spent on waterfront projects between 2004 and 2009 (Al Ansari, 2009; Giovinazzi \& Giovinazzi, 2008).

As a result, this phenomenon which began about fifty years ago, has been applied vigorously in recent years on many waterfronts around the world (Tastsoglou \& Dimitra, 2012).

The intensification of waterfront regeneration is really remarkable during the last decades as waterfront cities began to develop postindustrial urban development strategies throughout

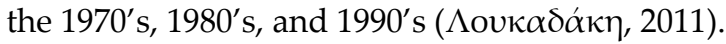

\section{Different typologies of urban waterfront regenerations}

Hoyle (2000), urban waterfront regenerations are'nt just met a phenomenon which is in post-industrial port cities. They are possible to see all kinds of waterside settlements which includes waterfronts created on reclaimed wet or foreshore lands (Al Ansari, 2009). With respect to aims of their classification is very difficult. Because, one regeneration has a few aims at the same time. Moretti (2008) indicate different typologies of waterfront regenerations as follow:

a. New Urban Expansion: This typology contains the waterfront areas which is built all over again in available areas; and reclaimed old industrial or port areas. Some examples of it can be given a Hafen City in Hamburg, and (Figure 11) on Lake Spandau and the Bay of Rummelsburg, in Berlin (Moretti, 2008a; Giovinazzi \& Giovinazzi, 2008).

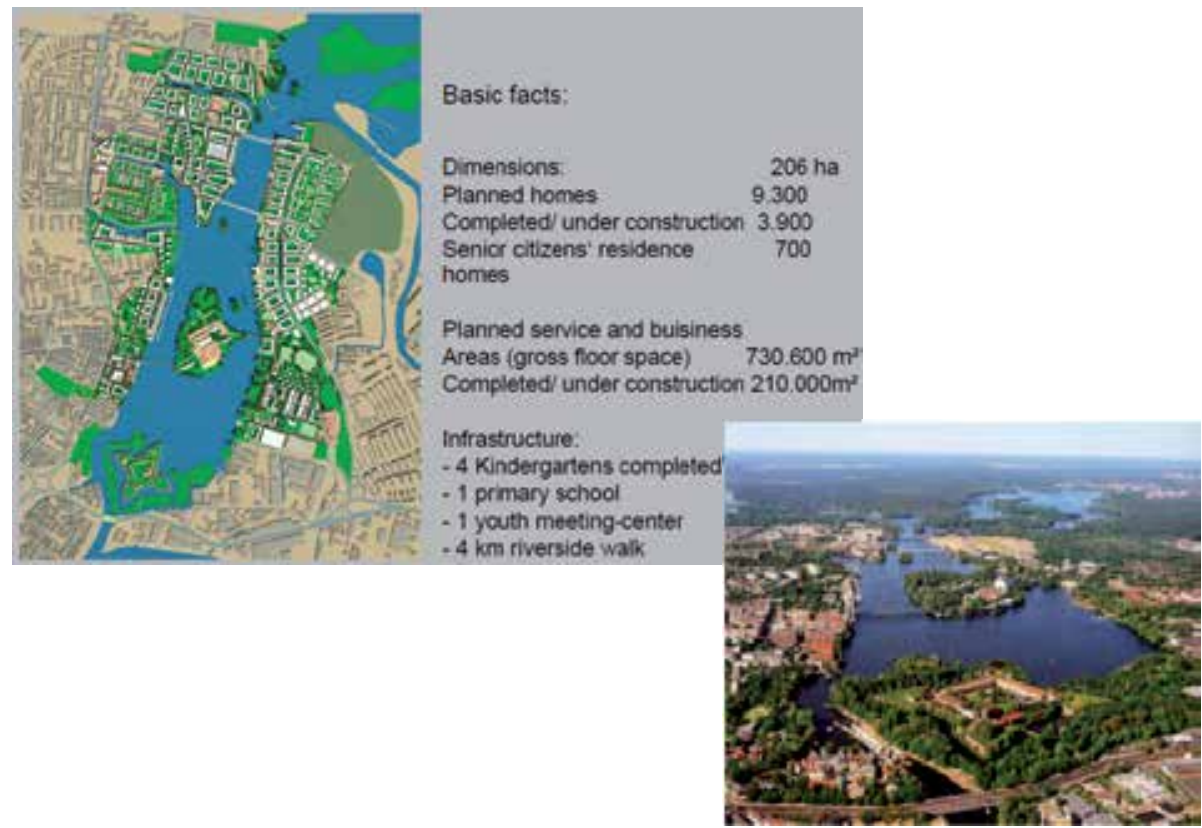

Figure 11. A view of Lake Spandau in Berlin (Hellweg, 2013) 
b. Waterfronts and Great Events: In this one is establihed as a consequence of important temporary events in the waterfront area such as the Expos (Figure 12): in Seville (1992), Barcelona (1992, 2004), Genoa (1992 and 2004), Lisbon (1998), London (2000), Zaragoza (2008). Afterward, new urban areas are developed around these areas like residental and production area (Moretti, 2010).
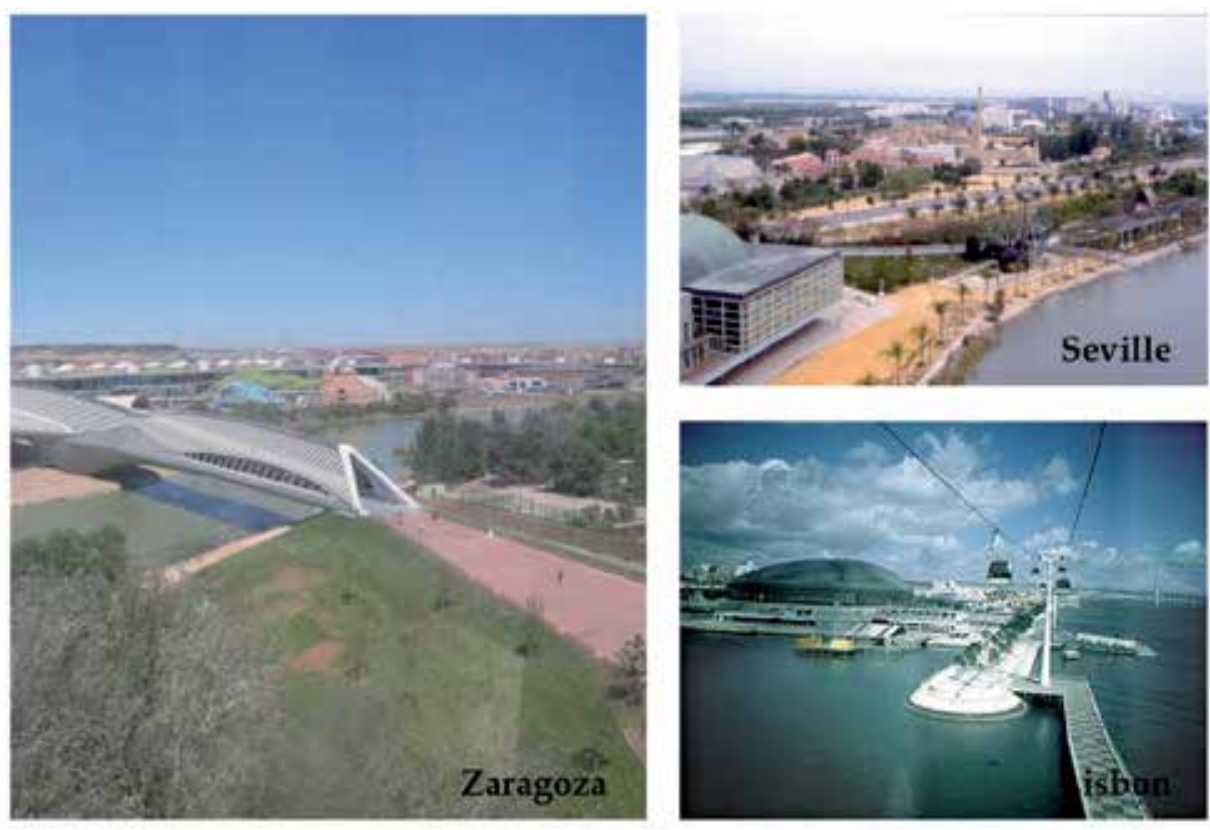

Figure 12. Example visions of Expos (Moretti, 2008b)

c. New Urban Waterfront Itineraries: The waterfront regeneration implies innovative consequences along the banks and in the surrounding areas. It provides public uses along pedestrian paths. For example, Barcelonetta Beach and its environs (Figure 13) which connects the port areas and river bank along the Thames in London (Figure 14) with public uses like a jogging, walking and cycling etc. (Aksoy, 2006; Moretti, 2008a).

d. These settlements were established around a port with safe harbor suitable for cargo and passenger ships (Figure 6). At this time, the waterfront has only a few trails converging at a jetty. After, a street pattern was slowly installed. In this period, a larger wood pier was usually established for ship. Also, buildings began to develop on the street pattern. Though the rapid growth and development, the settlement still connect with the waterfront a shoreline road (Akköse, 2007; Wrenn et al., 1983).

e. Reuse of Port Areas: This typology includes waterfront areas which is regenerated former port areas. With re-use of these areas, the water is regained the heart of cities. For instance, (Figure 15) Rotterdam (Moretti, 2008a).

f. Flood Defence: Some structures which is established for river flood defence can represent a new opportunity for city expansion and for the establishment of new urban uses. Three examples of this can be given. The first one is with green areas and 
recreational uses like an open air festival and sport activities etc. The Donauinsel (Danube Island) in Vienna (Figure 16a), as a created barrier island (Moretti 2008a). For over 20 years at the end of June a couple million people gather at the Donauinsel for to visit the biggest open air festival in Europe, the Donauinselfest (Anonim, 2013c). The others are Guadalupe River (Figure 16b) in San José, California, USA and Porsuk Stream in Eskişehir, Turkey.

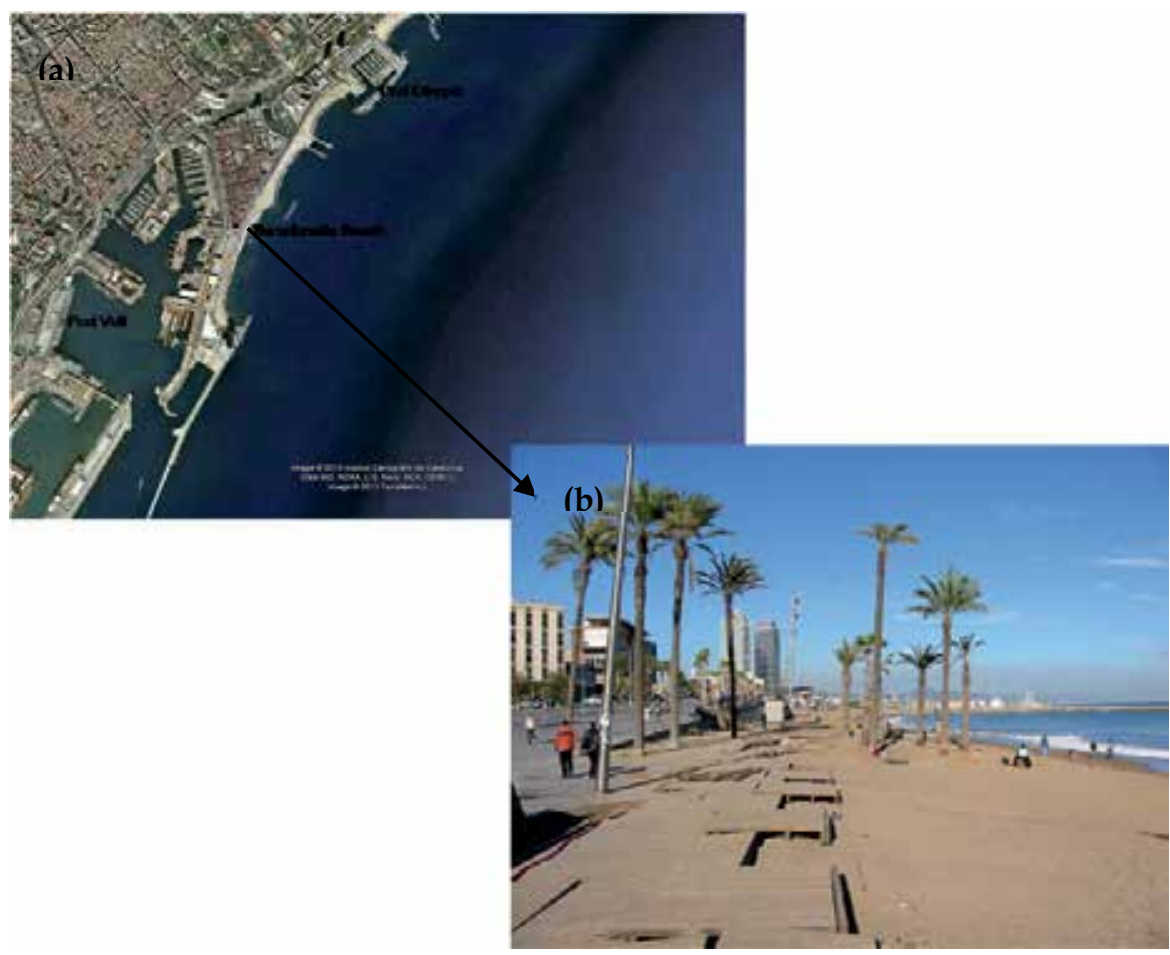

Figure 13. (a) View from above Barcelonetta Beach in Spain (Anonymous, 2013), (b) (www.leatherdevil.com) public uses in the beach (Aksoy, 2006)

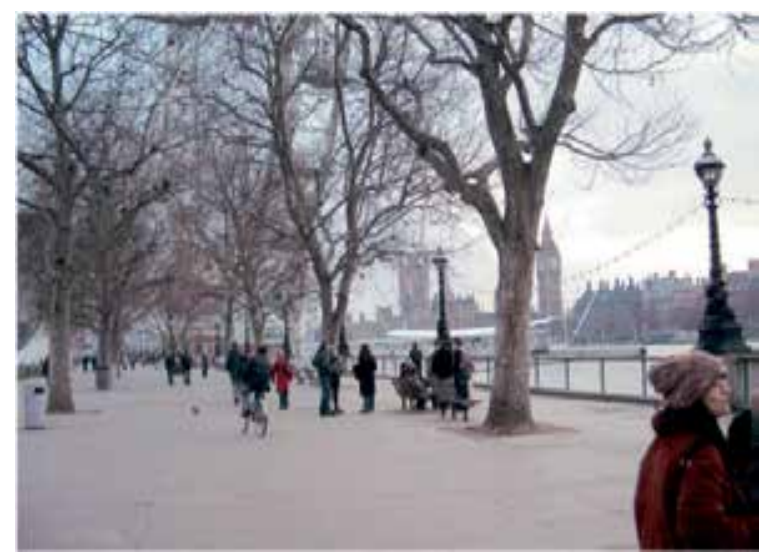

Figure 14. Thames River Bank provides public access to the river and cultural sites (Donofrio, 2007) 


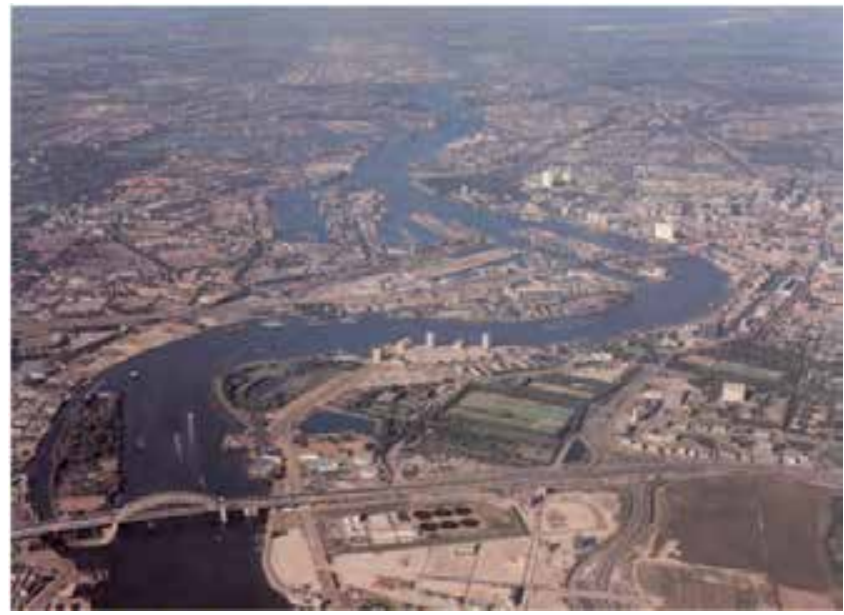

Figure 15. Reuse of port areas such as Rotterdam in Holland (Moretti, 2008a)
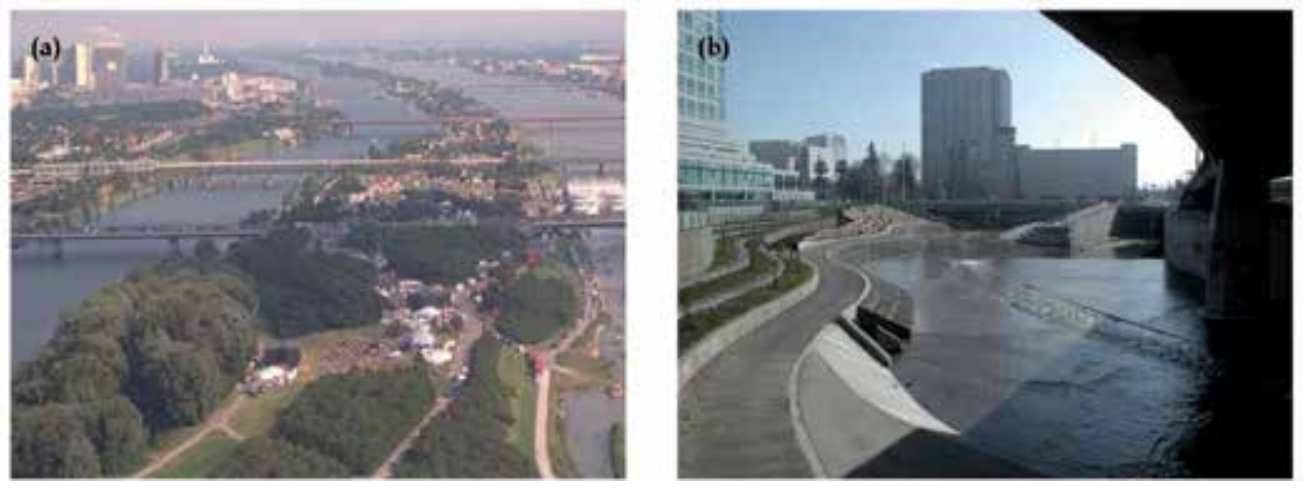

Figure 16. (a) The Donauinselfest in Vienna (Anonymous, 2013d), (b) Guadalupe River in San José, California, USA (Önen, 2007)

g. Urban Beaches: Urban beaches are described by urban planners as an artificially created environment in an urban areas. They show a distinctive and alternative mode of reusing of waterfronts. Urban beaches are relatively unfixed due to temporary and mobile. Their locations and uses may be change. They may be a seasonal (especially the warmer months) installation over a roadway or a parking lot or a public park or a site cleared by demolition. Urban beaches have a view of urban waterfronts, also in this areas sometimes can be possible access to the water. These areas are compared with to natural beach environments by using thematic objects such as a large volume of sand, beach umbrellas, setting elements, palm trees and thatched huts. The first urban beach in contemprorary was created in France. Use of urban beaches spread rapidly to major city centres throughout Europe and in North America and Australia (Anonymous, 2013e; Stevens, 2011). Urban beaches not only provide a lot of recreational and sport activities but also represent social activities as a sort of 'piazza' (Moretti 2008). For example, Strand Pauli in Hamburg, The Badeschiff on the Spree River in Berlin, Porsuk Plage in Eskişehir, Paris Plage in Paris etc. 

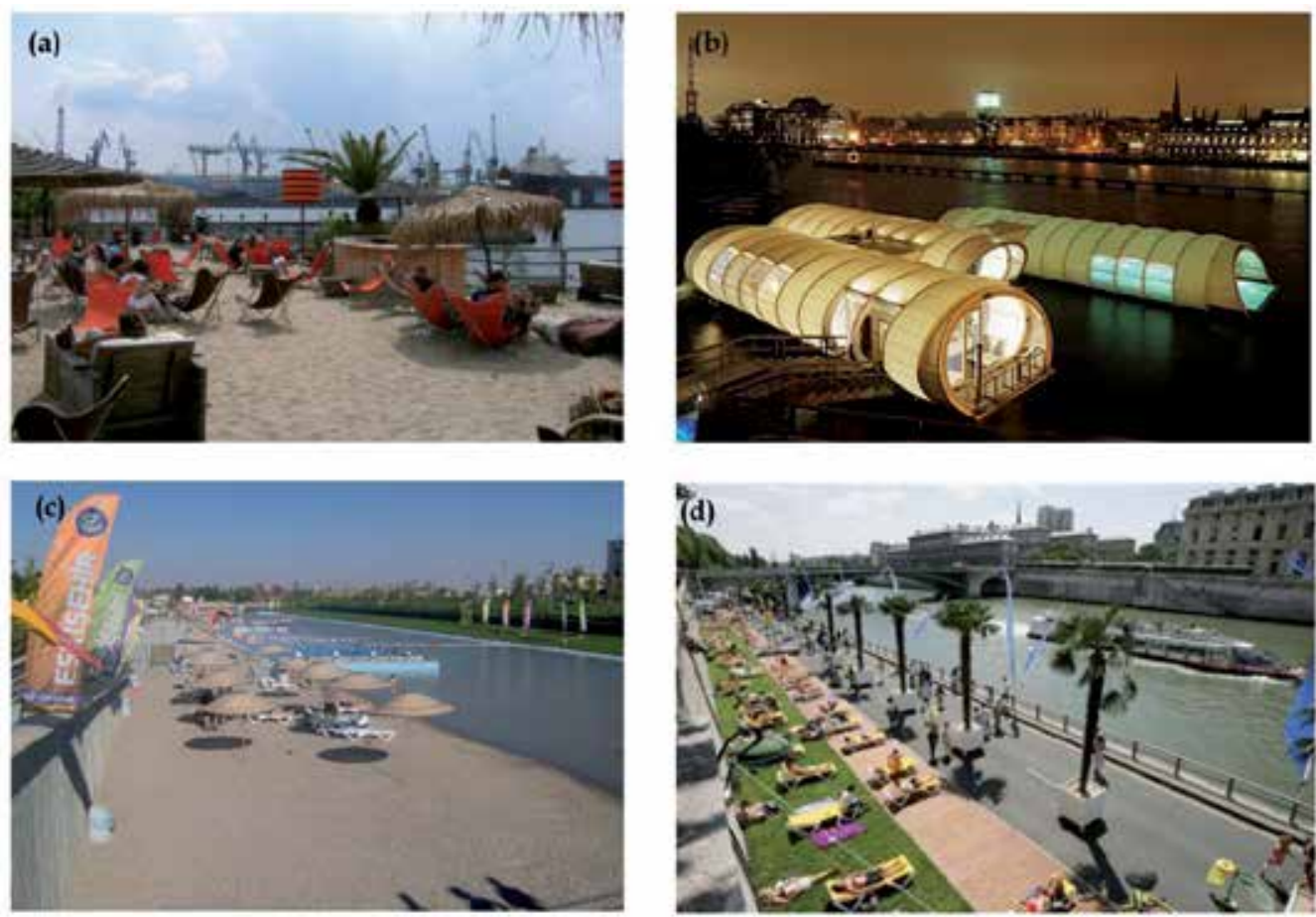

Figure 17. (a) Strand Paulion the banks of the Elbe River in Hamburg (Anonymous, 2013f), (b) The Badeschiff on the Spree River, in Berlin (Anonymous, 2013g), (c) Porsuk Plage in Eskişehir (Original, 2010) Street beachs, (a) Paris Plage (Anonymous, 2011)

Urban Riverfront Regeneration: $s$ the intersection between different aspects of urban life, the river represents a community heritage and its riverfront demonstrates a great potential for becoming a central axis in a new and articulated public space." Some examples of it can be the Cheong Gye Cheon canal in Seoul, Houtan Park Shanghai in China (Figure 18), Brda River in Poland (Figure 19a), Dark River Irwell in Manchester (Figure 19b), Hudson River Park in New York (Figure 20a), Emscher Landschaftspark in Germany (Figure 20b).
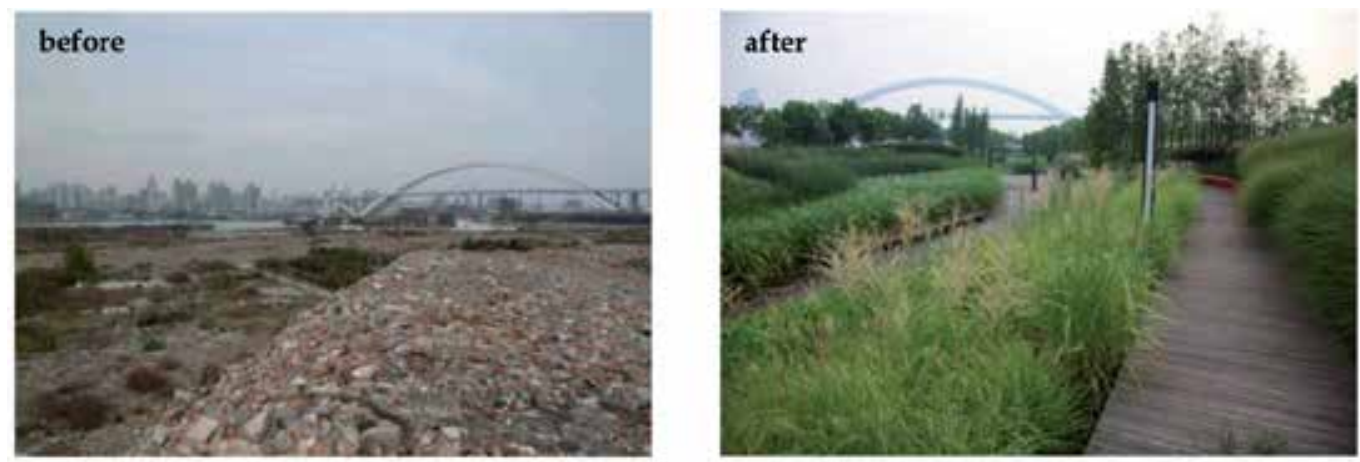

Figure 18. Houtan Park, Shanghai (Landscape Architecture Foundation, 2013) 

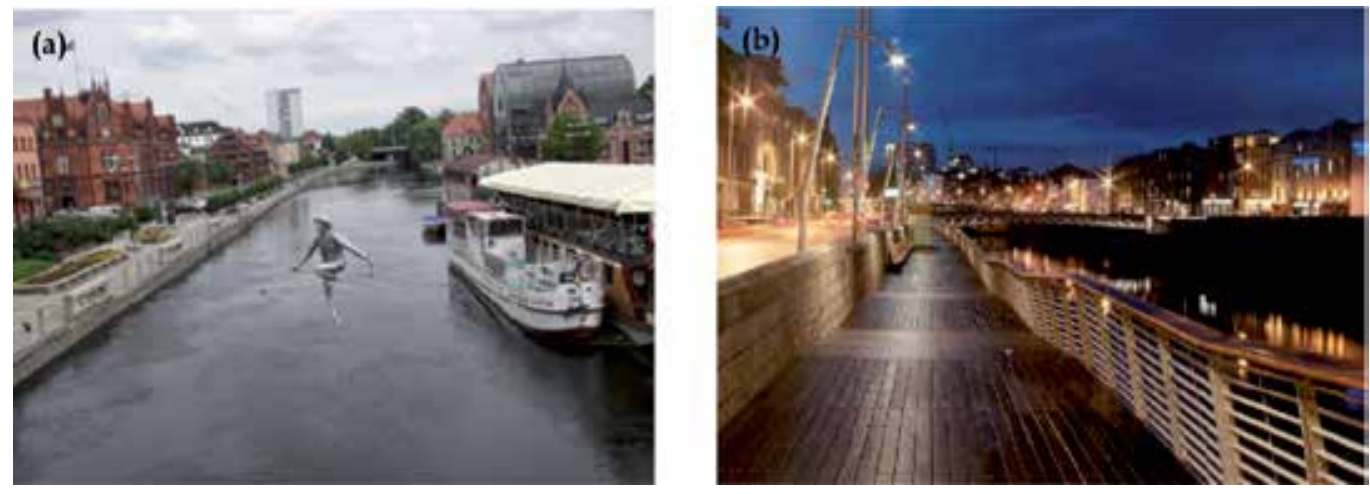

Figure 19. (a) Brda River in Bydgoszcz in Poland (Original, 2012), (b) Dark River Irwell in Manchester (APEM and Environment Agency, 2010)
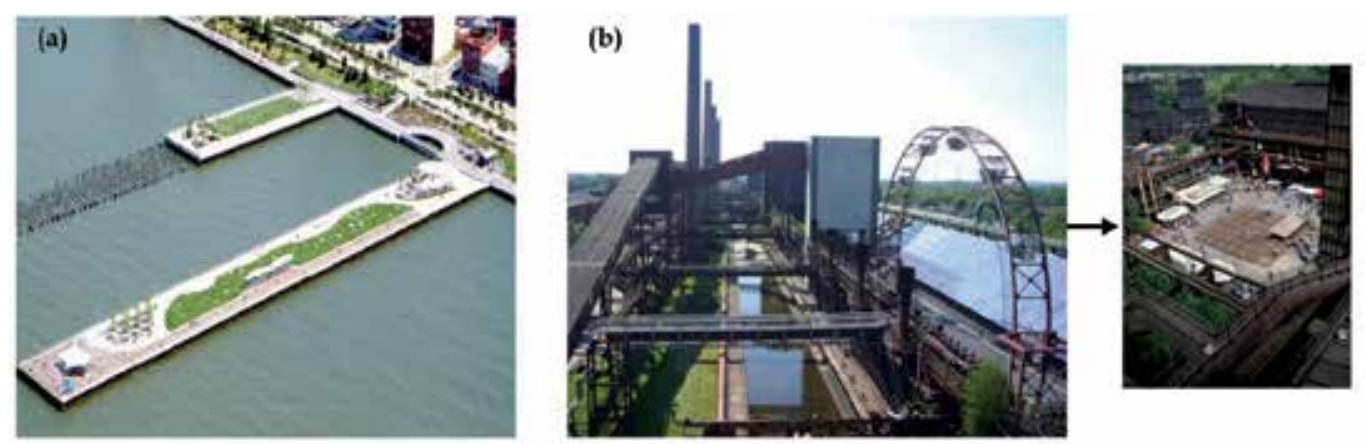

Figure 20. (a) Hudson River Park, New York (Anonymous, 2013h), (b) Emscher Landschaftspark in Germany (Anonymous, 20131; Cabe, 2010)

\section{Benefits and risks of urban waterfront regeneration}

Urban waterfront regeneration, which is phenomenon in global dimension, have a social, economic and environmental benefits to the community. According to Papatheochari (2011), Jones (2007) and Goddard (2002), the most pronounced benefits urban waterfront regenerations are:

- The increase in real estate property values,

- The preservation historical and local heritage also re-use of historic building,

- The improvement of water quality and water ecology by means of the advanced management processes,

- Providing of opportunities for new uses and activities,

- Representing of new economic regeneration opportunites for declining inner city areas,

- Attracting tourists not only at the regional level, but also nationally and internationally,

- The provision of many new homes,

- Providing new jobs,

- The improvement of the environmental conditions, 
- The advancement of better services of transport and social service,

- Providing of relationship between water and the city,

- Encouring of economic investment on degraded areas,

- With the improvement of the city's image which causes right marketing strategies.

Urban waterfront regeneration may also have some of the risks and the negative effects as well as mentioned these benefits. The risks and negative effects of waterfront regeneration explain as follow according to Morena (2011).

- Standardization of the invertensions; When a regeneration invertension is a planned, one of the greatest risks is to select. In short, models can be unconnected with area under evaluation. The result often leads to a kind of disorientation where the identity of the place is lost.

- Little room to real estate logics; "Sometimes, the final outcome does not correspond to the project's initial objectives, and the the 'common good' in terms of spaces, enjoyment and access, is partly neglected in favour of property interests" (Morena, 2011).

- An excessively commercial-tourist functions; Domination of these functions over residential and productive ones are an important risk. Because, these areas are usually used a few hours a day and in the weekends. While about the project area is done planing, in order to provide long term use of this area should be also added residential use as an extra commercial-tourist (Morena, 2011).

- The surronding of residental areas should be mixed both functionally and socially (Giovinazzi \& Moretti, 2010).

- Aim of high profit level; The achievement of high profit level is considered important rather than the quest for a high quality (Moretti, 2008a).

- Free access to the waterfront; The aim in this project is provided relationship between people and waterfront. So access of this areas should be free and indiscriminate. Recently, such transformation have produced new bans and new areas reserved for just a few categories (Morena, 2011).

Principles for successful development of urban waterfront areas

Waterfront plans are of vital importance to waterfront developments. According to Acosta (1990) while the plan makes, three elements are considered: public access, walkways and open spaces; urban design and landscaping; and land uses along the river's edge (Dong, 2004).

The base of waterfront regeneration are integrated with water and city. So, public access and open spaces more important for successful development of urban waterfront areas.

Accesibility of the water can be evaluated three formats: City-waterfront connectivity, interwaterfront zone continuity and waterfront-water connectivity. These were presented in Figure 21.

Acosta (1990), urban design guidelines can protect the public interest by spelling out basic standards for private development. In addition, criteria that are given out for urban design guidelines should be simple and clearly stated; fully illustrated; remain consistent over time. Adair et al., (2000) maintained that a master plan approach is essential so that investors can realize the long-term commitment to a particular scheme (Dong, 2004). 


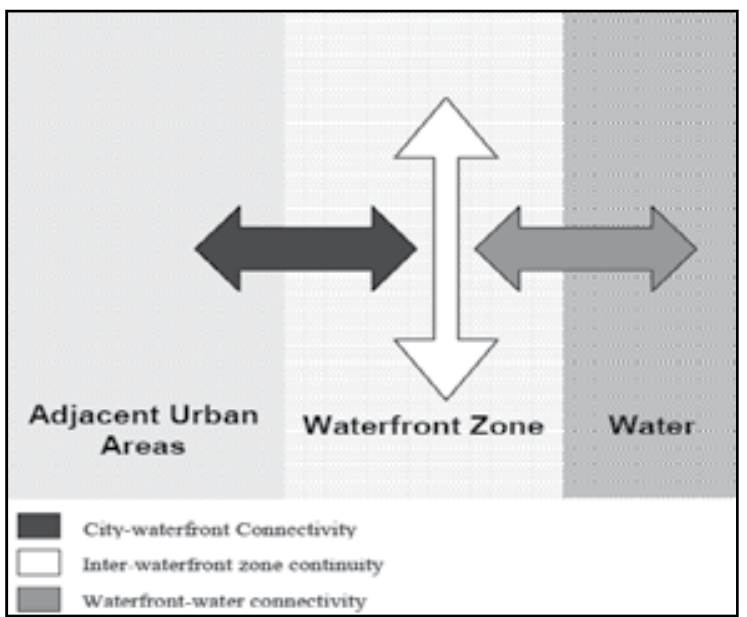

Figure 21. Figure 20. Accessibility of the Waterfront (Al Ansari, 2009)

Furthermore, aesthetic and functional effects of water should be gotten rich with plantal and structural designs in urban waterfront regeneration plans.

Lynch, Spence, and Pearson (1976), land uses in urban waterfront areas should be categorized by degree of integration with water (Dong, 2004). In this context water dependcy is also important. Sairinen \& Kumpulainen (2006) and Erdoğan (2006), indicated that a threefold classification of it is dependency is possible:

1. Water-dependent uses: Waterfront location is indispensable. Like a field of ferryboat, marine terminals, ship repair and construction works, commercial huntings can be given examples to this group.

2. Water-related uses: Because of in waterfront areas are uses that are in the condition of advantageous. For example, industrial production fields, some storage facilities and public spaces.

3. Water-independent uses: This group uses are neither dependent nor related to waterfront. For instance, public parks, some commercial and service complexs.

Torre (1989) identified that the success of a waterfront development is only achieved once it can function on all levels and benefit all stakeholders. Also, he/she point outed that 10 elements recommended to be taken into consideration while planning a waterfront development to achieve the specific aims of a successful waterfront development (Yassin, Bond and McDonagh, 2012). These were presented in Figure 22.

In addition, Bertsch (2008) recommended several principles that must be included while developing plans for waterfront areas: (i) accessibility, (ii) integrated, (iii) sharing benefits, (iv) stakeholder participation, (v) construction phase (Yassin et al., 2012).

Also Wang (2008), have examined samples of waterfront regeneration in USA, UK and Europe. According to this, he/she suggested that the waterfront regeneration will be succeeded if the following aspects have been followed: 
i. Waterfront should be define and the future role of waterfront in the city should be think,

ii. The master plan should be make, the participation of the communities and developers in the earliest stage,

iii. Physical and economic conditions should be fostered for the waterfront regeneration,

iv. Public authorities, private organisations and community groups should be worked together,

v. The master plan shoul be reviewed in order to to respond the market change and to reduce the financial risk.

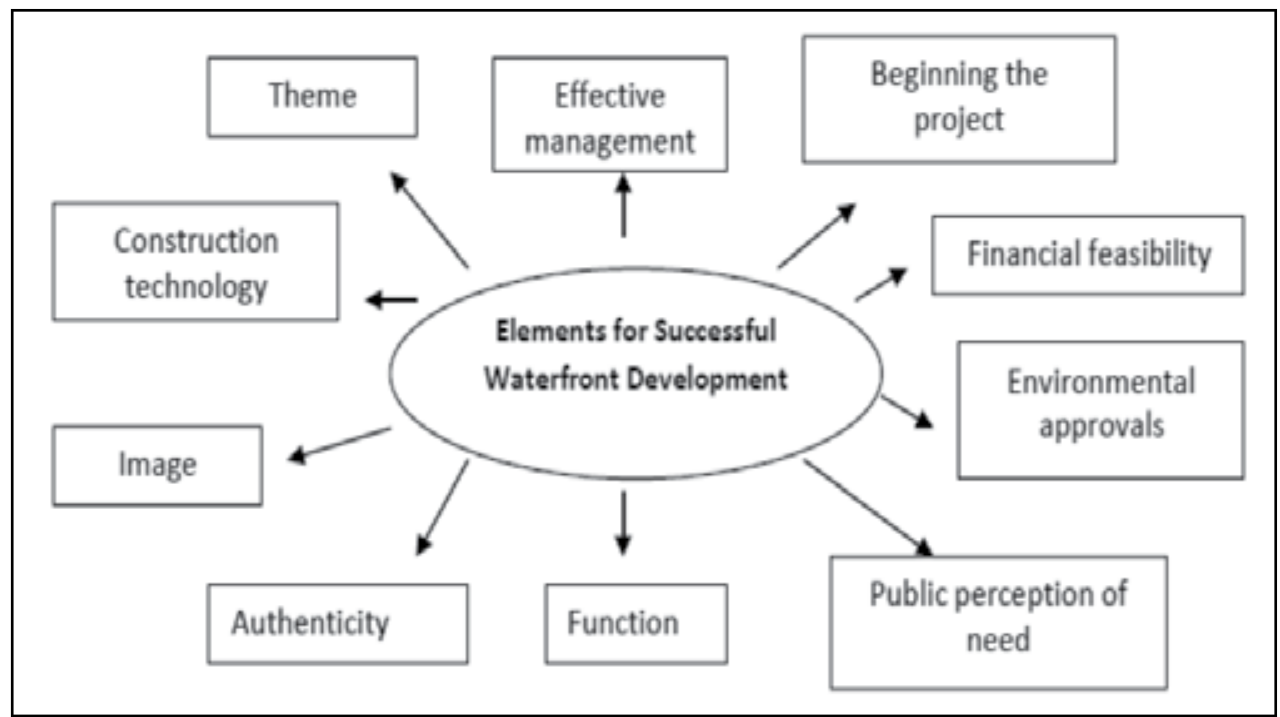

Figure 22. Figure 21. Torre (1989), elements for successful waterfront development (Yassin et al., 2012)

Principles for a sustainable development of urban waterfront areas

In the present day, to Thomas (2003), 2.8 billion people worldwide live in urban areas. They are great magnets to most humans with offered social and economic opportunities as well as facing several problems such as air, water and noise pollution, lack of open and green areas and inadequate transportation. It is predicted that by the end of the 21st century threequarters of the world's population will be urban. There is no doubt that this demographic trend will increase more the existing negative effects on urban environment. These urban issues are handled within the framework of sustainability (Vasconcelos Silva, 2006).

Water is basic source of life for the living. At the same time, it is an ecological, economic and social benefits for the cities.

Areas which is seen these benefits are waterfronts. To be benefited from those should be provided a sustainable developments in these areas.

Sustainability is evaluated three dimensions: economic, environmental and social. These three dimensions must be combined at all levels (Vasconcelos Silva, 2006). 
Giovinazzi \& Moretti (2010) indicated the 10 principles, which were developed by Cities on Water in collaboration by Wasserstadt $\mathrm{GmbH}$, Berlin, in the course of international seminars, were approved in the context of the initiatives for the Global Conference on the Urban Future (URBAN 21) held in Berlin in July 2000 and in the course of the EXPO 2000 World Exhibition, for a sustainable develpoment of urban waterfront areas. Also, Benson (2002), highlighted 9 lessons, which were experience of the Waterfront Regeneration Trust in The Lake Ontario Waterfront Trail, for success in regeneration. The some of these lessons overlaped with sustainability principles.

According to them, principles for a sustainable development of urban waterfront area were explained as follow.

1. Secure the quality of water and the environment

Bruttomesso (2001), Krieger (2004), Locklin (1999), White (1991), the quality of the water is an important dimension that could affect the waterfront, particularly its accessibility and the variety of its uses (Al Ansari, 2009). For this reasons, the quality of water in the system of streams, rivers, canals, lakes, bays and the sea is a prerequisite for all waterfront developments. So, the water need to be treated to achieve good water quality and also, create better sense of smell for the public. Aspect of quality environment is an important element in dealing space for public comfort and health (Giovinazzi \& Moretti 2010; Shaziman et al., 2010).

The municipalities (local managements) are responsible for the sustainable recovery of derelict and neglect banks and contaminated water (Giovinazzi \& Moretti 2010).

2. Waterfronts are part of the existing urban fabric

Waterfront development plans must ensure that waterfronts are reconnected to urban fabric. That is to say new waterfronts should be considered as an integral part of the existing city and contribute to its vitality. So, these plans should be based to develop on overall urban planning and also conserved the qualities of public areas (Benson, 2002; Giovinazzi \& Moretti, 2010; Hou, 2009). Beside, waterfront green areas should be considered whole city system (Kaynak!!)

Furthermore, water is a part of the urban landscape and should be used for specific functions such as waterborne transport, recreation, culture and aesthetic etc. (Giovinazzi \& Moretti, 2010).

3. The historic identity gives character

Collective heritage of water and city, of events, landmarks, existing architecture and nature should be utilised to give the waterfront redevelopment character and meaning. Especially, the preservation of the industrial past is an integral element of sustainable redevelopment for in post-industrial port cities (Giovinazzi \& Moretti, 2010). So, natural and cultural landscape should be conceived together. 
With these aims, while waterfront green areas plan, they should be combined with cultural landscape. In this manner, continuity of urban historical context will be provided. Beside, the vitality of waterfront landscape will be enhanced (Anonymous, 2013i).

4. Mixed use is a priority

Urban waterfronts are the interface between water and land (Wrenn et al., 1983). While apply uses select, uses that require access the water should be priority as water function is in the foreground. Waterfronts should celebrate water by offering a diversity of cultural, commercial and housing uses (Giovinazzi \& Moretti, 2010).

5. Public access is a prerequisite

Bertsch (2008), as cited in Yassin et al. (2012), the urban waterfront should not be isolated or separated from the development, so that the public can access the waterfront easily.

Waterfronts should be both physically and visually accessible for locals and tourists of all ages and income at any time. Visual access to the waterfront area is enhanced by providing series of view corridors. The accessibility to the waterfront for pedestrians is maximized by providing physical linkages from the urban core areas. Also, public areas should constructed in high quality (Figure 23) to allow intensive use (Giovinazzi \& Moretti, 2010; Al Ansari, 2009; Shaziman, et al., 2010). As technology develop, it is subject use of lots new kind of material (Figure 1) in this area (Hou, 2009). So, that should be considered in planning and designing phase.
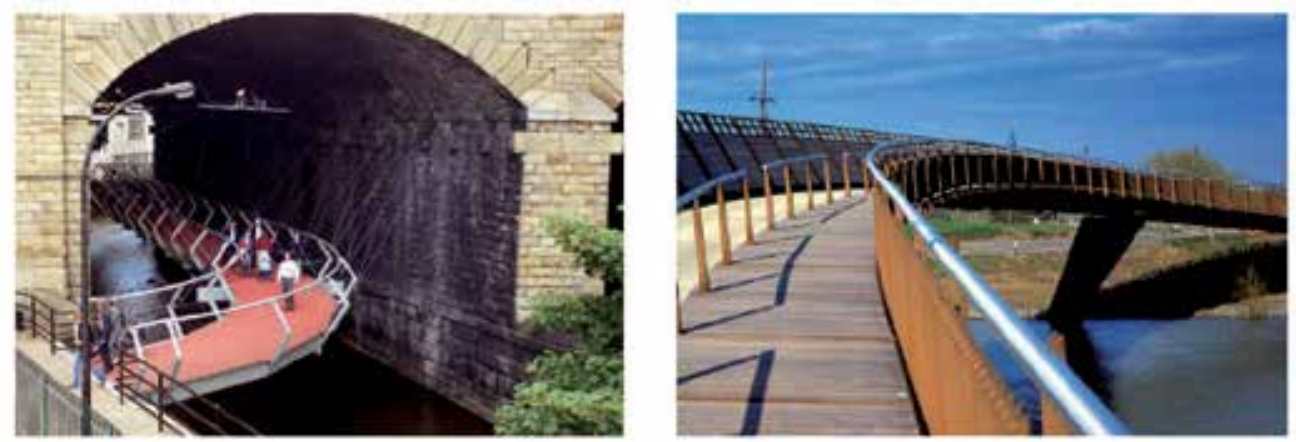

Figure 23. An examples of innovative designs, Dark River Irvel in Manchester (APEM and Environment Agency, 2010)

6. Make the waterfront a community priority

Once a vision for the waterfront is determined and development (or regeneration) should be handled not just for local residents and businesses but essentially for the community as its priority (Benson, 2002).

7. Planning in public private partnerships speeds the process

Waterfront development connects people and spaces. It requires cooperation to reach a common objective (Benson, 2002). So, new waterfront developments should be planned in 
form of public-private partnerships. "Public authorities must guarantee the quality of the design, supply infrastructure and generate social equilibrium. Private developers should be involved from the start to insure knowledge of the markets and to speed the development" (Giovinazzi \& Moretti, 2010).

8. Secure strategic public investment and attract private resources

Preservation of strategic public investments and luring private resources would have an increasing effect on utilization of waterfronts in long term. Entrepreneurial leadership, and strong, strategic planning attract investment of private sectors (Benson, 2002).

9. Public participation is an element of sustainability

Sustainable waterfront development should be developed not only in ecological and economical aspects but also socially. For this reason, the planning processes must be transparent and they must provide meaningful opportunities for the involvement of people. In other words the community should be informed and involved in discussions continuously from the start (Figure 24). Such an approach should be necessarily taken into consideration as an important element for sustainability and good planning of waterfront development (Giovinazzi \& Moretti, 2010; Benson, 2002).
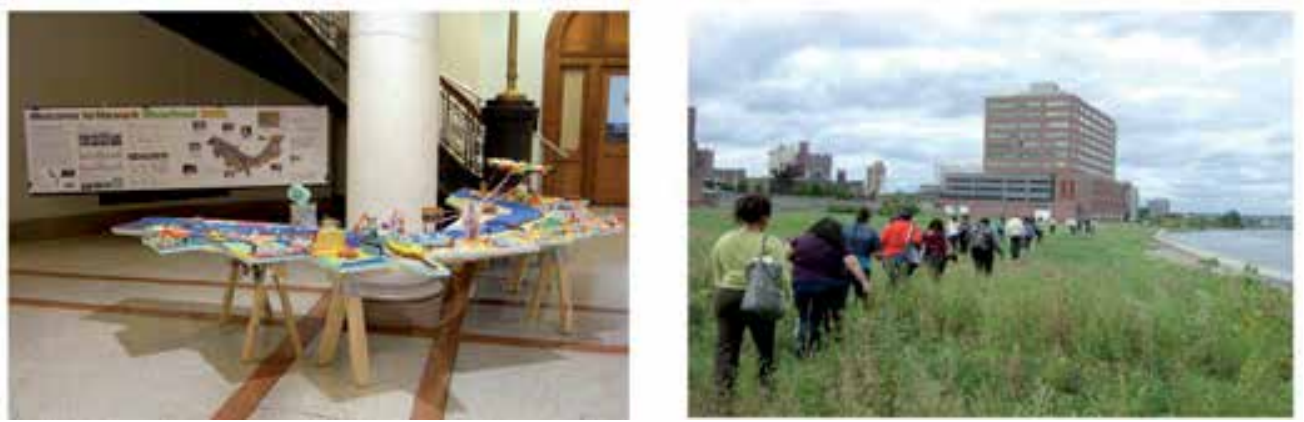

Figure 24. Public involvement in Newark Riverfront Regeneration Plan (Booker, Pryor and Rich, 2010)

10. Waterfronts are long term projects

"Waterfronts need to be regenerated step by step so the entire city can benefit from their potentials. They are a challenge for more than one generation and need a variety of characters both in architecture, public space and art. Public administration must give impulses on a political level to ensure that the objectives are realized independently of economic cycles or shortterm interests" (Giovinazzi \& Moretti, 2010).

11. Regeneration is an ongoing process

All master planning must be based on the detailed analysis of the principle functions and meanings the waterfront is concerned. Plans should be flexible, adapt to change and incorporate all relevant disciplines. To encourage a system of sustainable growth, the management and operation of waterfronts during the day and at night must have equal priority to building them (Giovinazzi \& Moretti, 2010). 


\section{It requires a multidisciplinary work}

The regeneration of waterfronts is a highly complex task. For this reason, participation and collaboration of several occupational disciplines is required both in its planning and application (Giovinazzi \& Moretti, 2010).

\section{Look beyond your boundaries}

According to Spirn (1994), although problems caused by urbanization may differ from city to city and from country to country, they have a lot in common (Arslan 1996). Approach of the countries and cities which succeeded in solving those problems should be examined and considered. Accordingly, when waterfront regeneration is also concerned, data, service and products at both national and international level should be shared and exchanged by means of a vision overreaching the borders. This reality means that the waterfront has become a place of international interest and significance. That's a vital economic reality and also a huge opportunity for the country or city to attract new investment, and to continue to learn from others engaged in regeneration (Benson, 2002).

\section{Case studies}

\subsection{Porsuk Stream, Eskişehir, Turkey}

According to Anonim (2005), Ulu (2005), Eskişehir which was only a small settlement with under 30.000 residents until the period of the Republic increased the number of its population to 706.009 by 2000 with a rise of 4,5 times. Until 2001, Porsuk Stream and its banks within the city of Eskisehir has been exposed to intensive pressures because of the increasing number of the city population, and the following inaccurate use of the related lands. As a result, the stream has become almost an open sewage running through the city (Pekin, 2008).

Eskisehir Greater Municipality took into consideration the fact that a city with a river running through is always under threat of possible floods and also the recent earthquake disaster (August 17, 1999) the city experienced and so initiated the Project of Porsuk Stream in 2001 (Figure 24) with the support of European Investment Bank with the aim of protecting the city from the damages of natural disasters and also minimizing the effects. This project is performed as the Project to Lessen the Damages of the Natural Disasters (Component 2) which is part of the Urban Development Projects with three main components (Büyükerşen \& Efelerli, 2005). This project includes the $12 \mathrm{~km}$ long part of Porsuk Stream running through the city center.

This project is basically project of flood defence, river rehabilitation was done to get over flood in a manner safe. The issue of floods in Eskişehir was examined by State Water Affairs in the frame of Porsuk Basin Water Administration Plan. In addition to this study, Porsuk Stream Urban Transition Rehabilitation Project was prepared. The according precautions may be summed up as follows (1) Building Sarısu Flood Detention Dam since Sarısu Stream which flows into Porsuk Stream within the city has an increasing effect on flood risk, 
Construction of Sarısu and Porsuk sand traps in order to detent swept down dregs and dirt and also cleaning of these traps before and after the flood season (3) Restoration of $9.6 \mathrm{~km}$ part of Porsuk Stream bed (4) Building nine bridges for vehicles, examination of four bridges for pedestrians against earthquake risk and building four new bridges for pedestrians (5) Construction of eight buildings for controlling water level in order to render the regulation of the river flow uniform in the restored parts and maintain full flow (6) Equipping water level buildings with automatic sensors which make them mobile in order to prevent those buildings to become any handicap during floods, (7) Rehabilitation of main irrigation canals that consists $3408 \mathrm{~m}$. left bank and $5100 \mathrm{~m}$. right bank (Büyükerşen \& Efelerli 2005). Anonim (2006c), Beside, the stream flow is regulated by Porsuk Dam (Pekin, 2008). Also, it has been necessary to equip the water level buildings with boat transfer shutters in order not to prevent the waterborne transport within the stream (Büyükerşen \& Efelerli 2005).

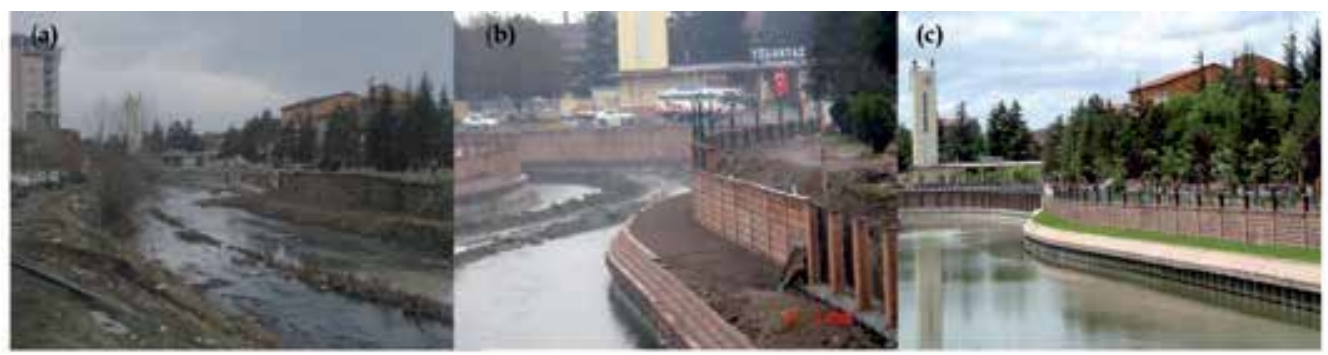

Figure 25. Porsuk Stream in Eskişehir in Turkey Porsuk Çayı (a) before; (b) in application; (c) now (Eskişehir Greater Municipality, 2006)

Smooth parts revived after the restoration process made waterborne transport on the stream possible. In addition, a comprehensive landscape project was prepared to accommodate the restoration to the very surrounding of the stream (Figure 26). According to this, a footpaths, recreational areas and parks was done on the banks and its environs (Büyükerşen \& Efelerli 2005).

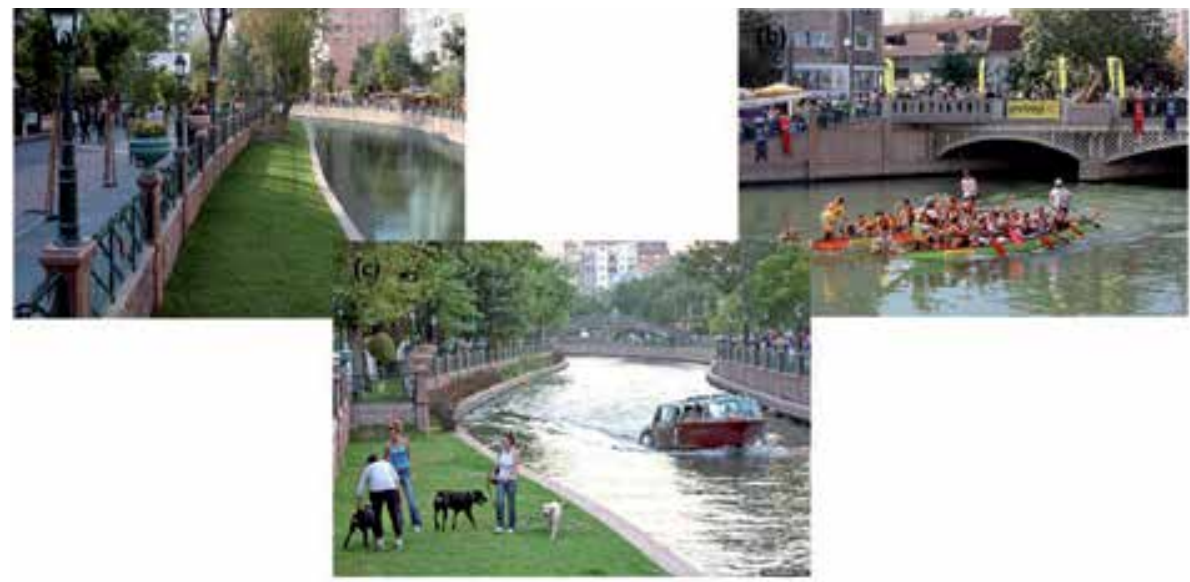

Figure 26. (a) The water transport (Eskişehir Greater Municipality, 2006), and (b) Canoe competitions on the Porsuk Stream (Anonymous, 2013j), (c) Footpaths Eskişehir Greater Municipality, 2006). 


\subsection{Hafen City, Hamburg, Germany}

The city of Hamburg is located on the river Elbe which flows into the North Sea as Germany's second largest city and host to Europe's second-largest port (Waterfront Communities Project, 2007). While the important parts of the port are now located on the south bank of the river Elbe, most of the northwestern bank has become disused for port functions until 1997 and has thus been regenerated for urban use (Hans, 2008; Erkök, 2009).

This regeneration area described as Hafen City. The Hafencity or harbour city Project (Figure 27) offers an amazing opportunity on the banks of the river Elbe. Because of its proximity to the central area, the project has the potential to become a comfortable extension to the city centre (Appleton, 2005). This project area (http://www.hafencity.com) takes place between the historic Speicherstadt warehouse district and the River Elbe, there will be a new city with a mixed uses. According to Hafencity Hamburg GmbH (2006), the area occasionally getting flooded required a smart solution for this problem, not cutting off land from water by high defenses. With the exception of the waterfront promenades, the entire area will be raised by 7.50 to 8.00 meters above mean sea level, creating a new and distinctive topography while preserving access to the water (Erkök, 2009). Beside, residental areas and promenades will be fixed on concrete piles (Mimdaporg, 2008). In the Project area, elevated footpaths, waterproof parking basements and the accessible waterfronts, as part of the new emergency infrastructure, have provided a successful combination of safety and spatial quality of urban spaces. As a solution for the accessibility of water at all tides in the very high quays, Enric Miralles designed a descending 'landscape' of surfaces (Figure 28, 29) (Erkök, 2009).

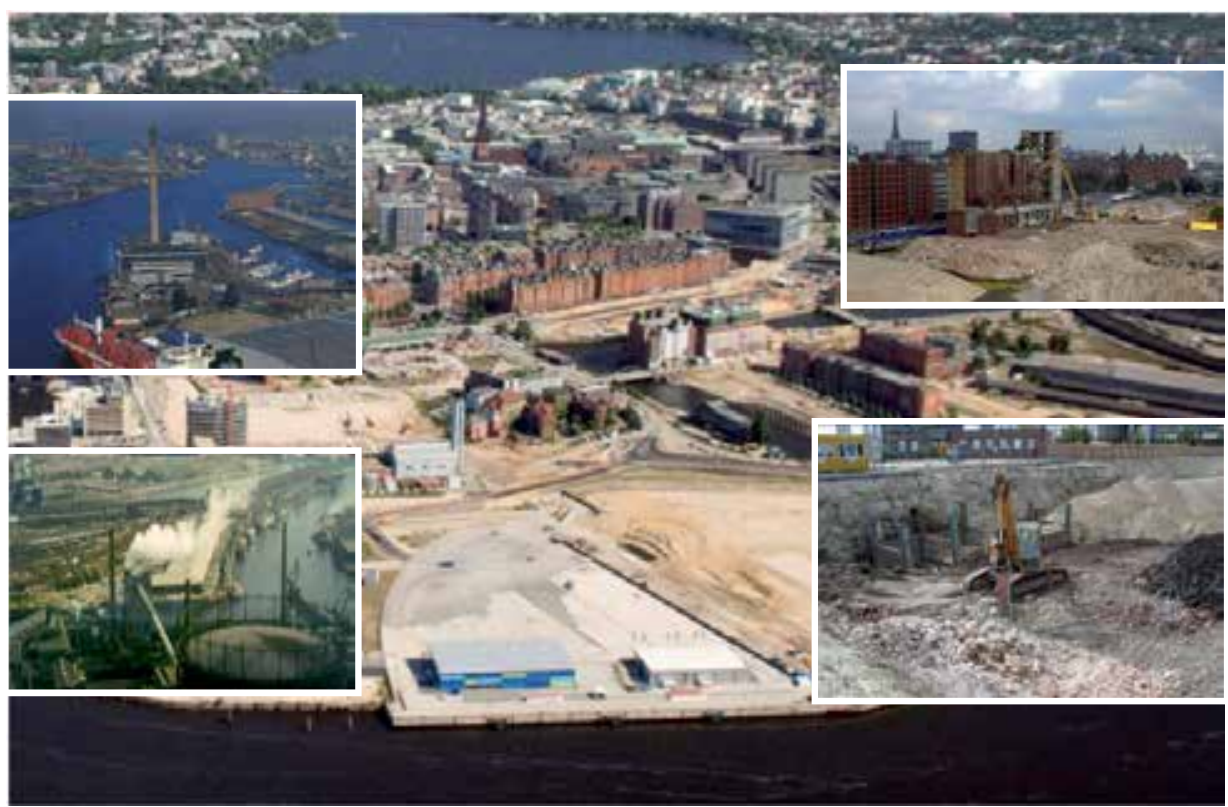

Figure 27. In application River Elbe, Hafencity in Hamburg (Bruns, 2012) 
The project which includes an area of 155 hectares, is currently under construction and application of it includes an ambitious 25 years period. When it is fully realised, Hafencity will have 5,500 apartments, 20,000 work places, 20 hectares of public open space and major cultural facilities to this waterfront. Also it involves approximately $10 \mathrm{~km}$ of quayside promenades (Appleton, 2005; Erkök, 2009).

It is the largest inner city development project in Europe. With Hafencity project will be enlarged city center by $40 \%$ and also it will be home 10000-12000 inhabitants (Erkök, 2009; Hans, 2008).
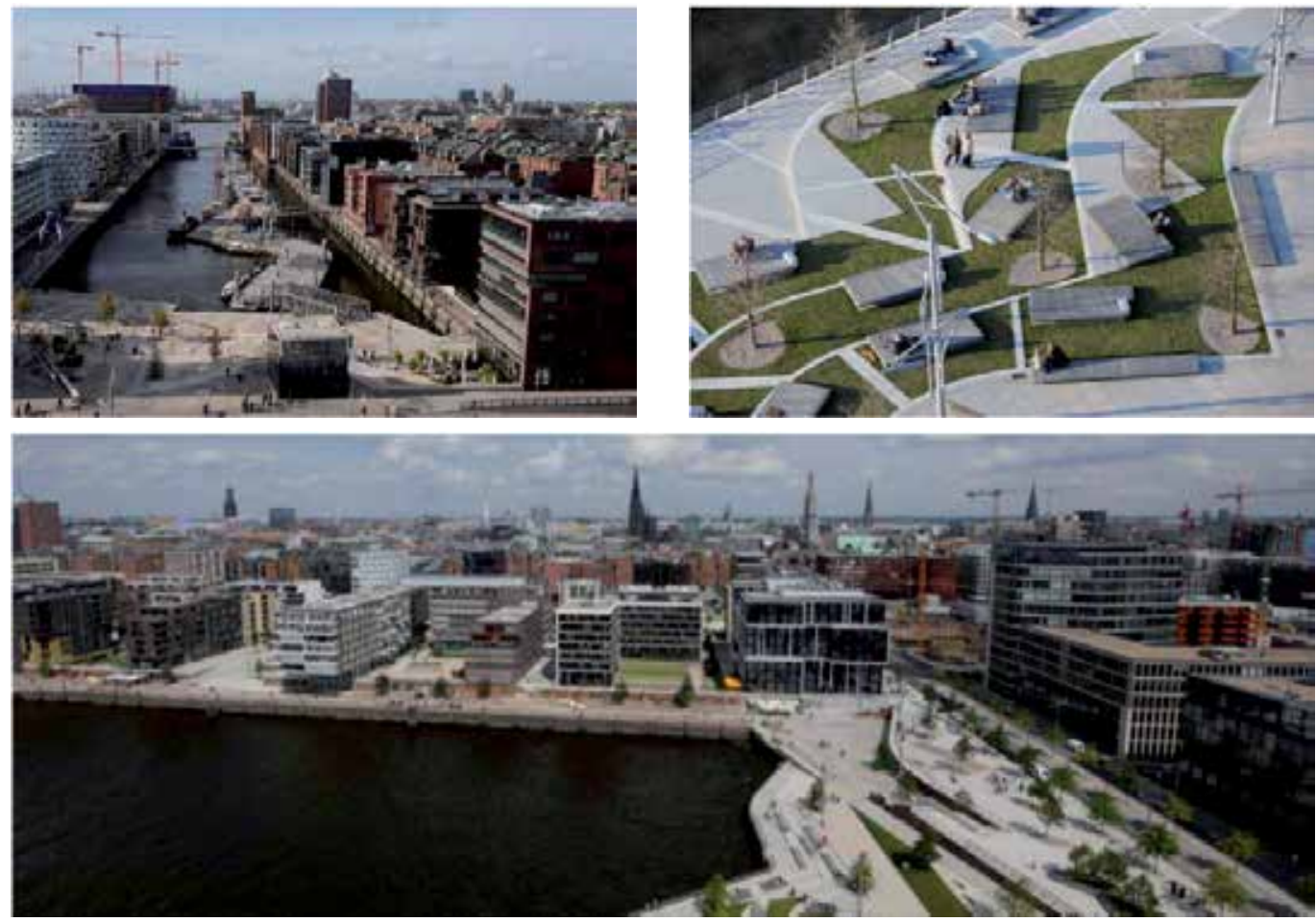

Figure 28. A waterfront terraces and the descending 'landscape' of surfaces (Schneider, 2010)

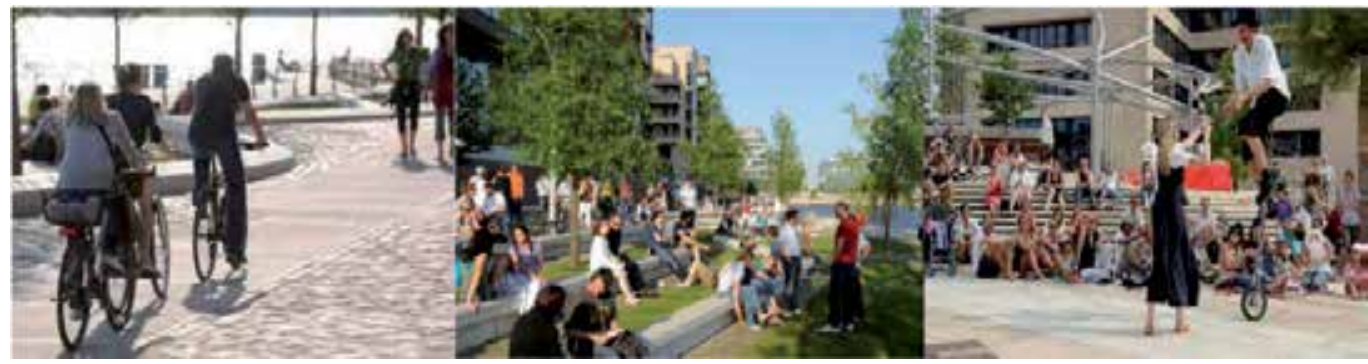

Figure 29. A views of public uses in Hafencity (Bruns, 2012) 
Beside, in Hafencity Project points out with a highly attractive public transport system. According to this, pedestrian ways (Figure 29) are more dominant than vehicle ways. Also $70 \%$ of pedestrian ways are away from the streets and bicycle paths take place in the area (Hans, 2008; Mimdaporg, 2008).

In this project was considered sustainability principles. There was noticed economic use of energy. In this context, eco-friendly building materials were used (Mimdaporg, 2008).

Numereous Projects which are developed by different architects, are together in Hafencity (Mimdap, 2008). Cultural highlights of the project range from the striking landmark Elbphilarmonie Concert Hall (Figure 30a), to International Maritime Museum of Hamburg (Figure 30b) and the new urban plazas being used for smaller events (Erkök, 2009). Beside, with reuse of warehouse, bridge and cranes were provided to integrate the historical texture and waterfront (Waterfront Communities Project, 2007).
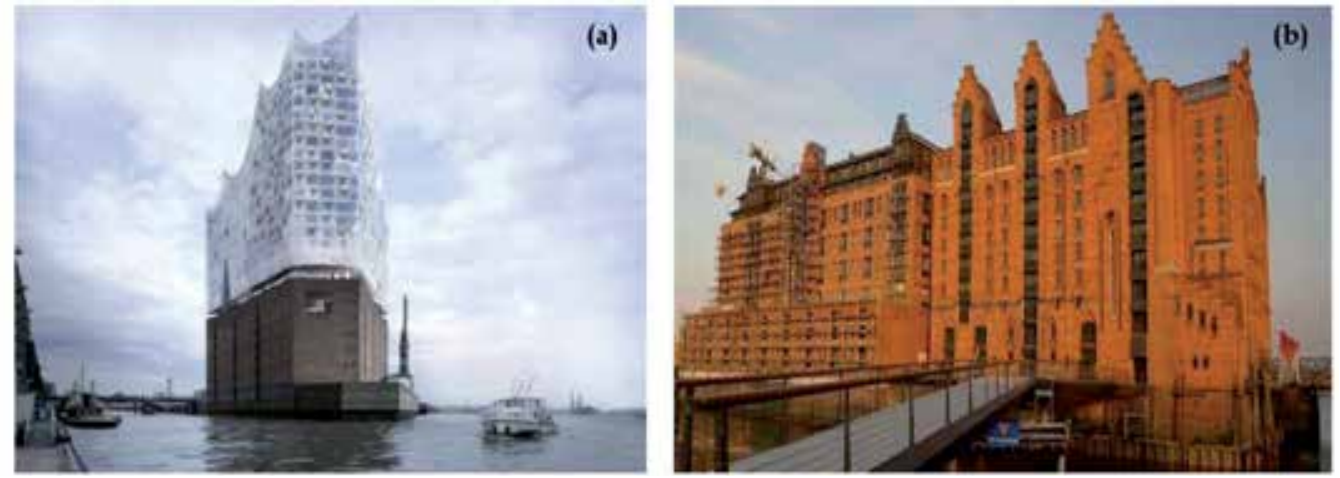

Figure 30. (a) Elbphilarmonie Concert Hall, (b) International Maritime Museum of Hamburg (Schneider, 2010)

\subsection{The Cheonggyecheon Canal in Seoul}

Cheonggyecheon ("clear valley stream") (Figure 31) is a former seasonal waterway in the city center of Seoul, South Korea and fallen into Han River. Between 1958 and 1976, the stream was covered and Cheonggye Road and Elevated Expressway were built above it. Per day, combined traffic counts on both roads were approximately 168000 vehicles and stream have continued to exist as a sewage canal (Seattle Urban Mobility Plan, 2008; Önen, 2007).

In the year 2000, a study by the Korean Society of Civil Engineering discovered that serious repair works should be done for three years to adress deficiencies of the road and elevated structure. Also the Cheonggye area become the most congested and noisy part of Seoul. When Lee Myung-bak was elected Mayor of Seoul in 2001, one of his key campaign promises was to remove this freeway and restore the Cheonggyecheon Stream. So, instead of repairing the elevated highway structure, the politicians at the time decided to restore the historical stream underneath the structure. Thus, a project studies was begun in July 2003 and it became the largest urban reneval project underteaken in Korean history (Martires, 2007; The Preservation Institute, 2007). 

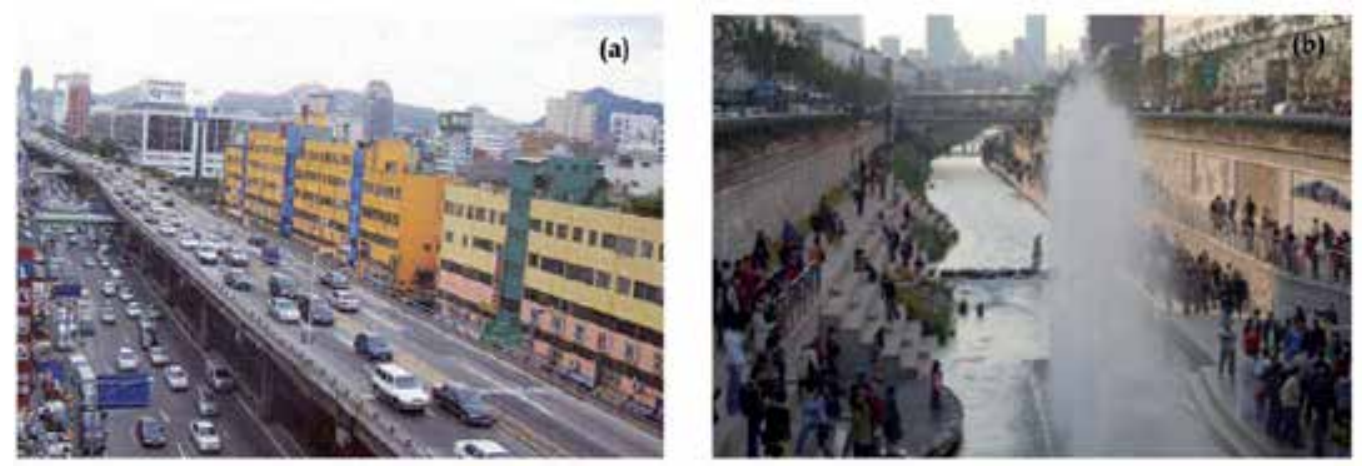

Figure 31. Before (a) and after (b) Cheonggye Expressway (Seattle Urban Mobility Plan, 2008)

According to Martires (2007), Seoul Metropolitan Government (2009) the aims of the Project are as follow:

- Creation of environment-friendly urban space,

- Restoration of historicity and culture of Seoul,

- Solution for safety problem of deteriorating structure over Cheonggyecheon,

- Balanced regional development between north and south of Seoul,

- To improve the city's water quality,

- Stimulate economic growth.

There was a two problem related to in application the Project. One of the problem is being lived congestion in North Seoul with the replacement of roads which is in position of main artery. And the other that closed stream is dry except during summer months (Önen, 2007).

Between 2003 and 2005, the highway was removed and stream recovered. As a result, the problem of drought was solved by bringing water from Han River and water depth was 40 $\mathrm{cm}$. The stream is the center piece of a 5,8 km linear park. New two lane, one-way streets are on each side of the park (Önen, 2007; Seattle Urban Mobility Plan, 2008).

The Project divided into three sections (Figure 32) and planning each section with specific themes, history (tradition), culture-urban (present age), and nature (future). Also, Three each teams which was civil engineering, landscape architecture and other disciplines worked together in the each sections (Seoul Metropolitan Government, 2009; Lee, 2006; Önen, 2007).

New Cheonggyecheon provides an uninterrupted tract of green space covering $276650 \mathrm{~m}^{2}$ along $5.8 \mathrm{~km}$ of the stream. The Project based on technology and creativity. The basic concept of the landscape design is to implement the image of 'Urban Stream with Nature'. Main Concepts of Landscape Arragments are considered as follows (Önen, 2007; Lee, 2013).

- To create green areas with concept of continuous space along $5.8 \mathrm{~km}$ of the stream,

- To transform from urban landscape to natural structure as gradual,

- To create thematic areas like ecological parks, fountain and waterfall,

- To provide the optimal balance between exploitation and ecology, 


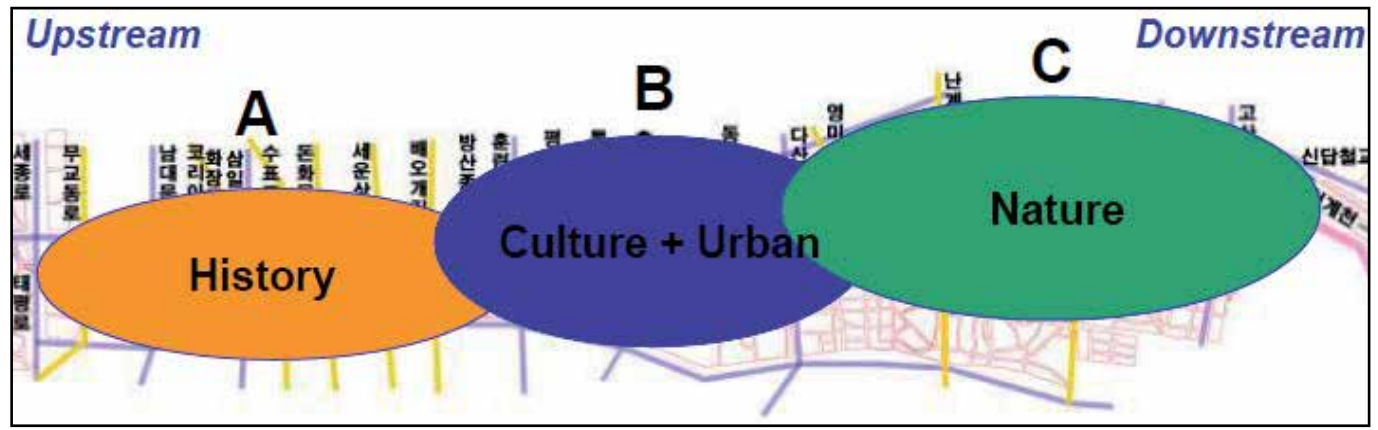

Figure 32. Three sections of the Project (Lee, 2006)

A number of 22 bridges take place over stream. The seven of their are only pedestrian way, the others are mixed as pedestrian and vehicle way. And also historic bridges (e.g. Gwanggyo Bridge) were restored. The bridges that span the restored waterway have been designed to reflect the character of their neighborhoods ((Martires, 2007; Önen, 2007).

The lighting scheme has been designed to give the stream and neighborhood a distinctive character (Figure 33) at night (Martires, 2007).

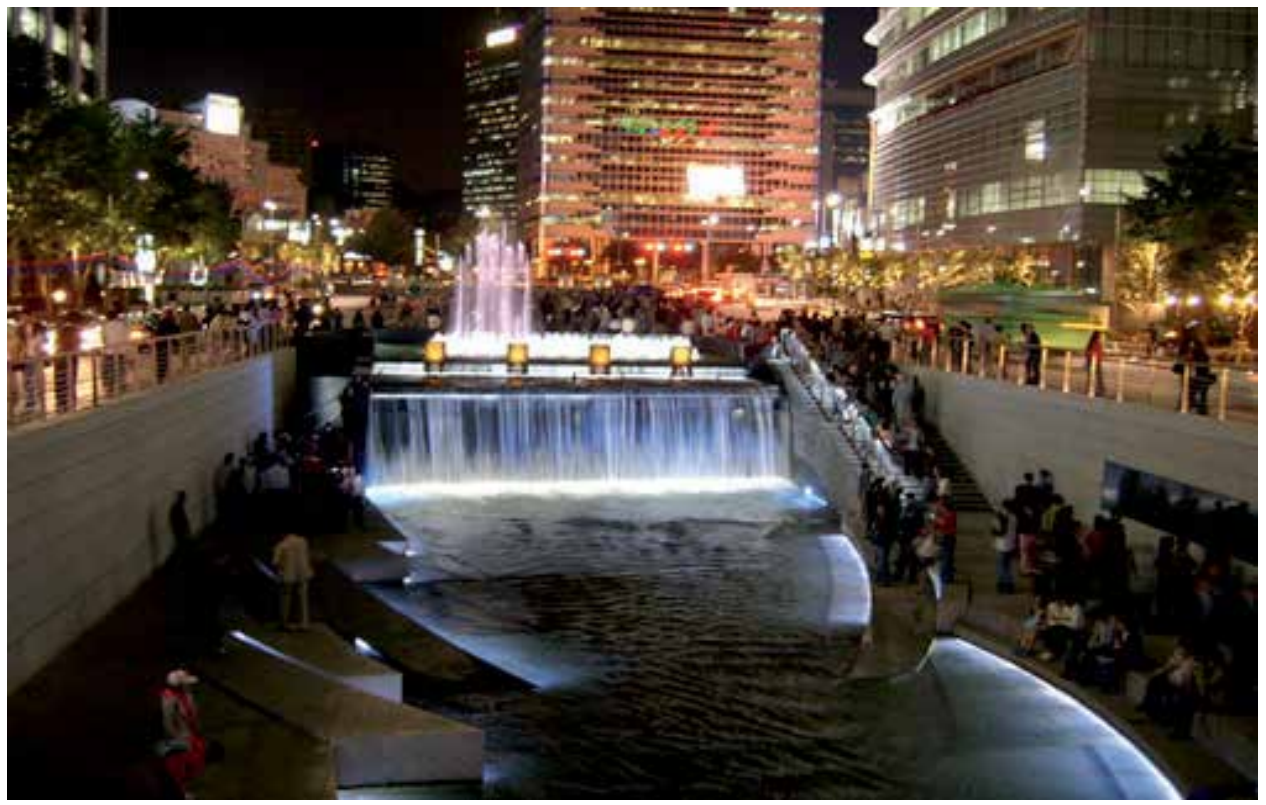

Figure 33. The Cheonggyecheon Canal at night (The Preservation Institute, 2007)

Along the stream (Figure 34), small squares, art works, waterfront decks were built for citizens and biotopes were introduced for plants, fishes and birds. The streambed of upper reach is mostly built with stone to resist scouring. Slope walls of $41,889 \mathrm{~m}^{2}$ separating roads from the stream with a height of 2 to $6.5 \mathrm{~m}$ were newly built, and the surface of the wall was covered with granite plate to recreate the past image of masonry wall. 
The construction cost was 386 million (USD). In the 15 months after its opening, the park attracted approximately 90,000 visitors per day, 30\% of them from outside the metropolitan area (Lee, 2013; Seattle Urban Mobility Plan, 2008).
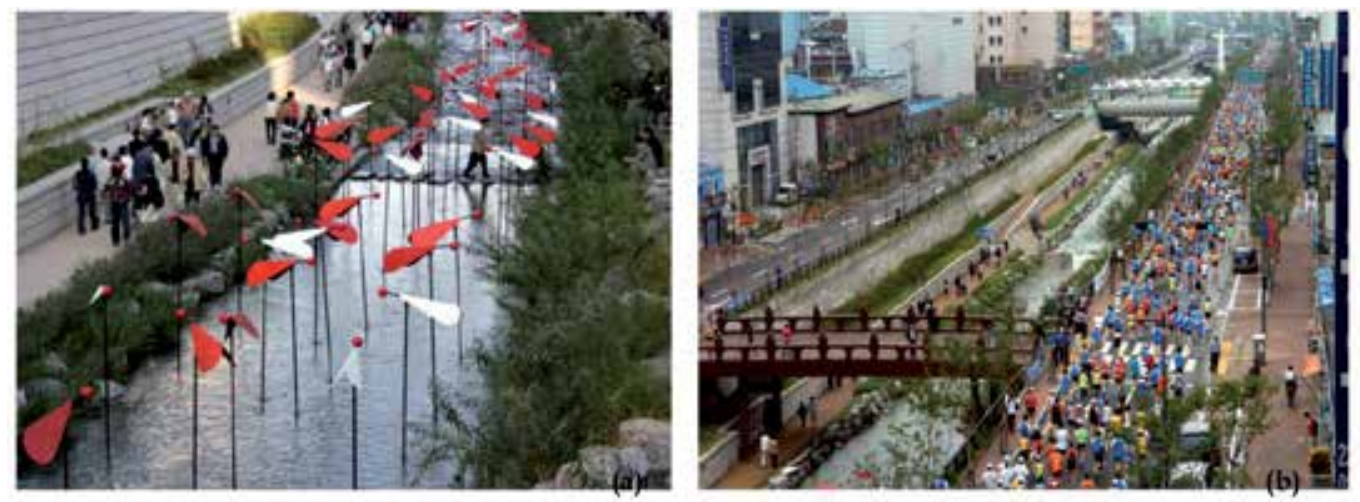

Figure 34. Cheonggyecheon: (a) Art installation, (b) Marathon (Martires, 2007)

\section{Author details}

Umut Pekin Timur

Çankırı Karatekin University, Faculty of Forestry,

Department of Landscape Architecture,

Çankırı, Turkey

\section{References}

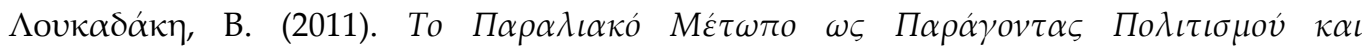

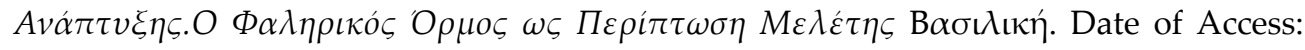
10.01.2013, Available from:

http://dspace.lib.ntua.gr/..//loukadakiv_faliron.pdf

Akköse, A. C. (2007). The Analysis of Istinye Shipyard Area Within The Context of Redevelopment of Urban Waterfront Areas. Master Thesis, Istanbul Technical University, Institute of Science And Technology, 131 p., İstanbul.

Aksoy, C. O. (2006). The Evaluation of City Beaches And Their Design Criteria. Master Thesis, Ankara University The Graduate School of Natural and Applied Sciences, 91 p., Ankara.

Al Ansari, F. (2009). Public Open Space on the Transforming Urban Waterfronts of Bahrain The Case of Manama City. Ph.D. Newcastle University School of Architecture, Planning and Landscape, 353 p., Newcastle.

APEM and Environment Agency. (2010). Urban River Regeneration in Manchester Transforming: The Dark River Irwell. Date of Access: 12.10.2012, Available from: 
http://www.merseybasin.org.uk/archive/assets/60/original/60_APEM_River_Irwell_rep ort_EA.pdf

Andini, D. (2011). Public Space For People On New Urban Waterfronts: A Literature Exploration on Socio-spatial Issues in Post-industrial Waterfronts. End Report Msc Thesis Socio-Spatial Analysis, Landscape Architecture and Planning Wageningen Unıversity, 67 p. Wageningen.

Anonymous. (2011). Paris Plage until August 21. Date of Access: 19.10.2012, Available from: http://blog.lecitizenhotel.com/2011/08/04/paris-plage-until-august-21st/

Anonymous. (2013a). Baltimore Inner Harbour. Date of Access: 14.01.2013, Available from: http://www.wrtdesign.com/projects/detail/Baltimore-Inner-Harbor/157

Anonymous. (2013b). Barceloneta, Barcelona, Spain. Date of Access: 09.01.2013, Available from: http://www.earth.google.com

Anonymous. (2013c). Artificial Island. Date of Access: 07.01.2013, Available from: https://www.ead.ae/Tacsoft/FileManager/Quarterly/Artificial\%20Islands/Artificial\%20Is lands\%20of\%20the\%20World\%20FINAL.pdf

Anonymous. (2013d). Accordion Worldwide. Date of Access: 07.01.2013, Available from: http://www.accordions.com/index/squ/ru_squ_08_09_05.shtml

Anonymous. (2013e). Urban Beach. Date of Access:05.01.2013, Available from:http://en.wikipedia.org/wiki/Urban_beach

Anonymous. 2013f. Triplib Reisen nicht vergessen. Date of Access: 03.01.2013, Available from: http://www.triplib.de/fotos/ansicht/17670

Anonymous. (2013g). Appendix 8. Date of Access: 02.01.2013, Available from:

http://www.ddda.ie/files/business/planning/20090202032305_05_3\%20Human\%20Being s.pdf

Anonymous. (2013h). Halcrow United States of America. Date of Access: 05.01.2013, Available from: http://www.halcrow.com/Where-we-work/United-States-of-America/

Anonymous. (20131). Ruhr Bölgesi'ni Başarıyla Dönüştüren Projenin Sırları. Date of Access: 05.01.2013, Available from: http://www.arkitera.com/haber/index/detay/ruhr-bolgesi-nibasariyla-donusturen-projenin-sirlari/4907

Anonymous. (2013i). Waterfront Green Space in Urban Ecological Planning and Design of the Contents and Methods. Date of Access: 04.01.2013, Available from: http://www.docstoc.com/docs/52295113/Waterfront-Green-Space-in-Urban-EcologicalPlanning-and-Design-of-th-contents-and-methods

Anonymous. (2013j). Eskişehir Büyükşehir Belediyesi. Date of Access: 10.01.2013, Available from:

http://www.eskisehir-bld.gov.tr/haber_dvm.php?resim_id=346758

Arslan, M. (1996). Yeşil Yol Planlaması: Ankara Örneği. Çevre Planlama ve Tasarımına Bütüncül Yaklaşım Sempozyumu, 277-285 p., Ankara.

Benson, E. (2002). Rivers as Urban Landscapes: Renaissance of the Waterfront. Water Science and Tecnology, Vol 45, No:11 pp. 65-70, IWA Publishing. 
Booker, C. A., Pryor, S. and Rich, D. (2010). The Riverfront That Newark Wants Progress Report: 2009-2010, Date of Access: 08.01.2013, Available from:

http://pages.csam.montclair.edu/pri/symposium2010/Rich,Damon_Newark.pdf

Breen, A. and Rigby, D. (1994). Waterfronts: Cities Reclaim Their Edge. McGraw-Hill, Inc., 256 p. New York.

Bruns, J. (2012). Hafencity Hamburg: Making a New Downtown. Date of Access: 02.02.2013, Available from: http://learningcitiesplatform.files.wordpress.com/2012/07/lcp-hafencityhamburg-june-2012s.pdf

Büyükerşen, Y. \& Efelerli, S. S. 2005. Doğal afet zararlarını azaltma yaklaşımı EskişehirPorsuk Projesi. 4.Kentsel Altyapı Ulusal Sempozyumu, TMMOB İnşaat Mühendisleri Odası Eskişehir Şubesi, pp. 161-171, Eskişehir.

Cabe. (2010). Urban Rivers-Planning and Regeneration. River corridors in the Urban Environment. Date of Access: 10.01.2013, Available from: http://www.ursula.ac.uk/upload/Inner/News_other/Vandergert.pdf

Dong, L. (2004). Waterfront Development: A Case Study of Dalian. Master of Applied Environmental Studies in Local Economic Development - Tourism Policy and Planning, University of Waterloo, 159 p., Canada.

Donofrio, J. T. (2007). Preservation as a Tool for Waterfront Revitalization: Design, Management and Financing Solutions from Vancouver, Boston, and London. Master Thesis, University of Pennsylvania, 164 p., Pennsylvania.

Erdoğan, Z. (2006). The Role of Tourism in Waterfront Redevelopment Projects Feasibility Analysis of Galataport Project. Master Thesis, Istanbul Technical University, Institute of Science And Technology, 110 p., İstanbul.

Erkök, F. (2009). Waterfronts: Potentials for Improving the Quality of Urban Life, ITU AIZ Vol: 6, No: 1, pp. 126-145.

Eskişehir Greater Municipality. (2006). Başlanan vizyon projeler sunum CD’si. Eskişehir Büyükşehir Belediyesi, Eskişehir, Türkiye.

Gençtürk, I. Z. (2006). Design of Water Features in Squares: A Case Study on Sultanahmet and Beyazit Squares. Master Thesis, Istanbul Technical University, Institute of Science And Technology, 163 p., İstanbul.

Giovinazzi, O. \& Giovinazzi, S. (2008).Waterfront Planning: a Window of Opportunities for Post-disaster Reconstruction.

Date of Access: 11.01.2013, Available from:

http://ir.canterbury.ac.nz/bitstream/10092/3987/2/12625558_iRec_Dr\%20Oriana\%20Giov inazzi\%20\%26\%20Dr\%20Sonia\%20Giovinazzi.pdf

Giovinazzi, O. \& Moretti, M. (2010). Port Cities and Urban Waterfront: Transformations and Opportunities. TeMALab Journal, Date of Access: 01.02.2013, Available from: www.tema.unina.it ISSN 1970-9870 Vol 3 - SP - March (57 - 64).

Goddard, C. (2002). Waterfront Regeneration, Geo Factsheet. Date of Access: 01.02.2013, Available from http://ebookbrowse.com/135-waterfront-regeneration-pdf-d224946024 
Hamamcıoğlu, C. (2005). Kentlerin Su Yolu Girişlerinde Geçmişten Günümüze Yaşanan Aşamalar ve Kentsel Tasarım. Planlama Dergisi, TMMOB Şehir Plancıları Odası Yayını, 3, pp. 104-113.

Hans H, (2008). Changes on the Waterfront - Transforming Harbor Areas: Comparison and Evaluation of Waterfront Developments in Two Contexts: San Francisco Bay Area and Hamburg, Germany, IURD Working Paper Series, Institute of Urban and Regional Development, pp. 37-48, UC Berkeley.

Hattapoğlu, M. Z. (2004). Place of Water Phenomenan in Evoluation of Settlements and Teinterpretation of it as an Urban Design Element, Mimar Sinan Arts of University, Institute of Science And Technology 164 p., İstanbul.

Hellweg, U. (2013). Floating Homes at Rummelsburg Bay in Berlin. Date of Access: 02.02.2013, Available from:

ftp://ftp.cs.kun.nl/pub/faf/Bart\%20Swanevleugel/PPTs_FaF_Conf_KA_June_06/Round\% 20table\%202/Floating\%20Homes\%20Hellweg.pdf

Hou, D. (2009). Urban Waterfront Landscape Planning. Master thesis, Blekinge Institute of Technology Karlskrona, 53 p. Sweden.

Jones, A. (2008). Issues in Waterfront Regeneration: More Soberin Thoughts-A UK Perspective, Planning Practice \& Research, Vol. 13, No. 4, pp. 433 \pm 442, London.

Jones, L. J. (2007). On the Water's Edge: Developing Cultural Regeneration Paradigms for Urban Waterfronts. (Edited by Smith, M. K.), CABI, pp. 143-150, Oxsfordshire, UK.

Kilduffs Baltimore's Harbor. (2013). Date of Access: 05.02.2013, Available from: http://www.kilduffs.com/Harbor.html

Koca, F. (2011). Sustainability Analysis on The Transformation of Waterfronts: The Case of Haydarpasa. Master Thesis,

Istanbul Technical University, Institute of Science And Technology, 237 p., İstanbul.

Landscape Architecture Foundation. (2013). Date of Access: 01.02.2013, Available from: http://www.lafoundation.org/research/landscape-performance-series/case-studies/casestudy/424/

Lee, I. K. (2006). Cheong Gye Cheon Restoration Project-a Revolution in Seoul, Date of Access:01.02.2013, Available from: 04.02.2013. http://worldcongress2006.iclei.org/uploads/media/K_LEEInKeun_Seoul__River_Project.pdf

Lee, I. K. (2013). Cheong Gye Cheon Restoration Project, Date of Access: 11.01.2013, Available from:

http://www.ufrgs.br\%2Farroiodiluvio\%2Fa-bacia-hidrografica\%2Foutrosexemplos\%2Fcheongyecheon $\% 2 \mathrm{Fcgc} \% 2520$ restoration $\% 2520$ projetct $\% 2520$ lee.pdf

Letourneur, C. C. (1993). Life at the Water's Edge: An Analysis of Human Behaviour and Urban Design of Public Open Space at the Water's Edge. Master Thesis, The University of British Columbia, 350 p., Vancouver, Canada. 
Martires, L. (2007). Waterways in Urban Tokyo. Date of Access: 11.01.2013, Available from: 05.01.2013.http://repository.dl.itc.u-tokyo.ac.jp/dspace/bitstream/2261/15318/1/K-014051.pdf

Mimdaporg, (2008). Hafencity'e ziyaret. Date of Access: 15.01.2013, Available from: http://www.mimdap.org/?p=11312

Morena, M. (2011). Morphological, Technological and Functional Characteristics of Infrastructures as a Vital Sector for The Competitiveness of a Country System. ISBN: 8838760772,195 p., Milano.

Moretti, M. (2010). Valorisation of Waterfronts and Waterways for Sustainable Development. International Scientific Conference about Poltva River RenewingLviv, Ukraine, November 19th-20th 2010. Date of Access: 10.05.2012, Available from:

http://www.urbanproject.lviv.ua/php_uploads/data/articles/ArticleFiles_84_Moretti_en. pdf

Moretti, M. (2008a). Cities on Water and Waterfront Regeneration:A Strategic Challenge for the Future. Grundtvig, II meeting Rivers of Change-River//Cities Warsaw, Poland, July 24th 27th 2008. Date of Access:10.05.2012,Available from:

http://www.river-cities.nazwa.pl/www/download/m.moretti_warsaw2008.pdf

Moretti, M. (2008b). Cities on Water and Waterfront Regeneration: The Role of Culture and Events. Grundtvig, III meeting Rivers of Change-iver//Cities Wien, Austria, September 5th 7th2008. Date of Access:10.05.2012, Available from:

http://www.river-cities.nazwa.pl/www/download/m.moretti_vienna2008.pdf

Önen, M. (2007). Examination Rivers' Recreational Potantial As An Urban Coastal Space: Case Study, Eskişehır Porsuk Creek and İstanbul Kurbağalıdere. Master Thesis, Istanbul Technical University, Institute of Science And Technology, 204 p., İstanbul.

Papatheochari, D, (2011). Examination of Best Practices for Waterfront Regeneration. Littoral 2010. Date of Access:10.05.2012, Available from: 10.10.2012.

http://coastnetlittoral2010.edpsciences.org/index.php?option=com_article\&access=stand ard\&Itemid=129\&url=/articles/litt/abs/2011/01/litt-02003/litt-02003.html

Pekin, U. (2008). Urban Waterfronts Regeneration: A Model of Porsuk Stream in Eskişehir. Proceeding of the 6. International Symposium Agro Environ "Natural Resources Conversation, Use \& Sustainability", pp. 410-413, Antalya, Turkey.

Sairinen, R. \& Kumpulainen, S. (2006). Assessing Social Impacts in Urban Waterfront Regeneration. Environmental Impact Assessment Review, 26, pp. 120-135.

Schneider, H. (2010). HafenCity Hamburg-Sustainable Development for a New Downtown. Date of Access:10.10.2012, Available from:

http://mestrado.otpa.dcea.fct.unl.pt/files//1273829592_HafenCity_HPS_Lissabon.pdf

Seattle Department of Planning and Design. (2012). Waterfronts Open Spaces and Interfaces of Edge Environments. Date of Access: 02.01.2012, Available from: 
http://depts.washington.edu/open2100/pdf/2_OpenSpaceTypes/Open_Space_Types/wat erfront.pdf

Seattle Urban Mobility Plan. (2008). 6 Case Studies in Urban Freeway Removal, Date of Access: 05.09.2012, Available from:

http://www.seattle.gov/transportation/docs/ump/06\%20SEATTLE\%20Case\%20studies\% 20in\%20urban\%20freeway\%20removal.pdfwark

Shaziman, S., Umsan, I. M. S., Tahir, M. M. (2010). Waterfront as Public Space Case

Study; Klang River between Masjid Jamek and Central Market, Kuala Lumpur.

Selected Topics in Energy, Environment, Sustainable Development and Landscaping, WSEAS Pres, ISSN: 1792-5924 / ISSN: 1792-5940, ISBN: 978-960-474237-0, pp. 344-349.

Stevens, Q. (2011). The German "City Beach" as a New Approach to Waterfront

Development. (Edited by Desfor, G., Laidley, J., Stevens, Q., and Schubert, D.), by Routledge, pp.234-254, New York.

Yassin, A. B., Bond, S., McDonagh, J. (2012). Principles for Sustainable Riverfront Development for Malaysia. Journal of Techno-Social Vol.4 No.1 ISSN:2229-8940, pp. 2136.

Yassin, A. B., Eves, C. and McDonagh, J. (2010). An Evolution of Waterfront Development in Malaysia. 16th Pacific Rim Real Estate Society Conference Wellington pp. 1-17.

Zhang, L. (2002). An Evaluation of an Urban Riverfront Park Riverfront Park, Spokane,

Washington Experiences and Lessons for Designers. Master of Science in Landscape Architecture Washington State University. Date of Access: 02.01.2013, Available from:

https://research.wsulibs.wsu.edu:8443/xmlui/bitstream/handle/2376/75/L_Zhang_05060

2.pdf.txt;jsessionid=6EE534F1691D9BB953EB40FAC2350F22? sequence=2

Tastsoglou A \& Vagiona D, 2012. Urban Waterfront Regeneration: The Thessaloniki-Greece

Case Study. Protection and Restoration of The Environment XI, Sustainable Landscape Architecture, Management and Restoration, pp. 2224-2233.

The Preservation Institute. (2007). Removing Freeways-Restoring Cities : Seoul, South Korea

Cheonggye Freeway. Date of Access: 02.01.2013, Available from:

http://www.preservenet.com/freeways/FreewaysCheonggye.html

Waterfront Communities Project. (2007). The Cool Sea-waterfront Communities Project Toolkit, Date of Access: 02.01.2013, Available from:

http://www.waterfrontcommunitiesproject.org/downloads/The_cool_Sea_part3.pdf

Wang, C. (2008). Waterfront Regeneration, MSc in City and Regional Planning Cardiff University. Date of Access: 02.01.2013, Available from:

http://www.scribd.com/doc/7222338/Waterfront-Regeneration

Wrenn, D. M., Casazza, J. A., Smart, J. E., (1983). Urban Waterfront Development, Urban Land Institute, 218 p., Washington. 
Vasconcelos Silva, P. (2006). Greenways, a path towards urban sustainability. Master's Thesis. Faculdade de Ciências e Tecnologia da Universidade Nova de Lisboa, Portugal. Date of Access: 02.01.2011, Available from:

http://www.ece.auckland.ac.nz/ sinnen/VasconcelosSilva2006.pdf 
Section 2

\section{Landscape Design}





\title{
Eco-Revelatory Design
}

\author{
Nurgül Konaklı Arısoy
}

Additional information is available at the end of the chapter

http://dx.doi.org/10.5772/55764

\section{Introduction}

Built environments ignore people's need and their potential for learning. The negative effects related to the ignorance of natural systems in human development are evident. Making natural cycles and processes visible bring the designed environment back to life. Effective design helps inform us of our place within nature. Landscape architects have developed theories and methodologies which represent a new, ecologically oriented approach to design.

Eco-revelatory design (ERD) is an ecological design concept in the field of landscape architecture means "a design strategy that attempts to enhance site ecosystems as well as engage users by revealing ecological and cultural phenomena, processes and relationships affecting a site " [1]. Landscape architects reveal nature through their form, materials and formation, and they also reveal the nature of the person who designed them. ERD is a new approach to landscape architecture, one where ecological processes and the environment is a fundamental determinant of the design.

ERD is a different exposition and interpretation -updated version- of design. It is an integrative and ecologically responsible design. It is a partnership between people and nature. ERD attempts to enhance site ecosystems and engage users by revealing ecological and cultural phenomena, processes, and relationships affecting a site. It aspires to reveal endemic ecological process and affords a more direct connection between fundamental ecological process and the phenomenological experience of landscape. It is important to involve using knowledge about how interact with environment to form objects and spaces with skill and artistry [4]. This approach to design should be applied not only to urban sides, but also to nonurban sides such as wetlands, arboretums. The theory has received heavy criticism about its ability to absorb an audience in ecological understanding or improve site conditions [2,3].

Another criticism about ERD is some designs make tangible improvements in local ecological health while others are symbolic gestures [2]. It is adequate for people to develop 
ecological perception by means of the visibility of ecological process in design. The theory has received heavy criticism about its ability to absorb an audience in ecological understanding or improve site conditions.

It aspires to reveal endemic ecological process and affords a more direct connection between fundamental ecological process and the phenomenological experience of landscape. It is important to involve using knowledge about how interact with environment to form objects and spaces with skill and artistry (Ndubisi, 2002). This approach to design should be applied not only to urban sides, but also to non-urban sides such as wetlands, arboretums.

They are typically designed landscapes that elucidate natural phenomenon such as the cleansing action of wetlands. Ecorevelatory landscapes have also been referred to as "educational and enlightening". They are reference sites for what we understand about our environment and its workings. Designs can convey knowledge through direct experience as well as by interpretation. Interpretation seeks to create connections between the resources that are being interpreted and relevant everyday knowledge that everyone has by engaging emotions, creating experiences, and entertaining ideas through engagement [5]. By highlighting the particular ecological relationships at any given site, such design can punctuate and enliven our environment and sensitize us to what is known about its interlocking complexities" [1]. These sites often still use traditional interpretive media such as wayside exhibits and publications to fully convey their meaning and function, but ecorevelatory design can bring to light processes that usually remain unseen and forgotten.

\section{History}

This study explores descriptive theory, principals, techniques and practice of eco-revelatory design, can help to plan a sustainable development, which uses and reveals natural systems to reconciling human systems and its effects on the surrounding environment. The goal of this study, therefore, is to generate ideas and to begin a discussion about how the design within an eco-revelatory framework will be.

Most of the "eco" prefixes such as eco-city, eco-technique, eco-efficient was began to used nineties; also ERD emerged in 1998 as a new theory within the field of landscape architecture.

The term and practice of ERD was coined from an exhibit Nature Constructed/Nature Revealed sponsored by the University of Illinois at Urbana-Champaign. Two predominant schools of thought, one insistently cultural and the other assertively ecological, reigned over the conceptual and theoretical dialog in landscape design and planning. In 1998 a group of practitioners and landscape scholars published a special issue of Landscape Journal as a catalogue and record of the exhibition Eco-Revelatory Design: Nature Constructed/Nature Revealed. Brenda Brown, Terry Harkness, and Douglas Johnston chaired the exhibition and served as guest editors of the journal (Figure 1). The exhibit opened at the University of Illinois in 1998 and closed at the Washington DC's National Building Museum in 2000.

Brown identifies three areas of investigation on landscapes as/of sound: listening gardens, sound, or listening trails, and sound designs [3]. She is particularly interested in what she 
calls "the reciprocal revelations of landscapes and sounds, how sounds can reveal landscapes and how landscapes can reveal sounds." She is therefore also concerned with how people perceive, understand and engage with landscapes.

ERD roots are based on ecologically minded landscape architects such as Ian McHarg and Frederick Law Olmsted but they didn't use the term as ERD. These landscape architects created works to foster function in natural systems and processes aesthetically. Ian McHarg was accepted as the first person who to apply his ecological knowledge into design. He began advocating the use of ecology as a basis for design in the early 1960s. He accomplished his goal of merging design with ecology. He gave importance of ecological principles in design.

Thirty years ago, in Design with Nature, McHarg proposed a system of ecological inventories to help explain the way natural processes may influence regional and urban planning and design [6]. Also, it makes the case for an ecological approach to design. McHarg gave a new dimension to the historical goal of 'imitating nature' (mimesis). He was concerned both with

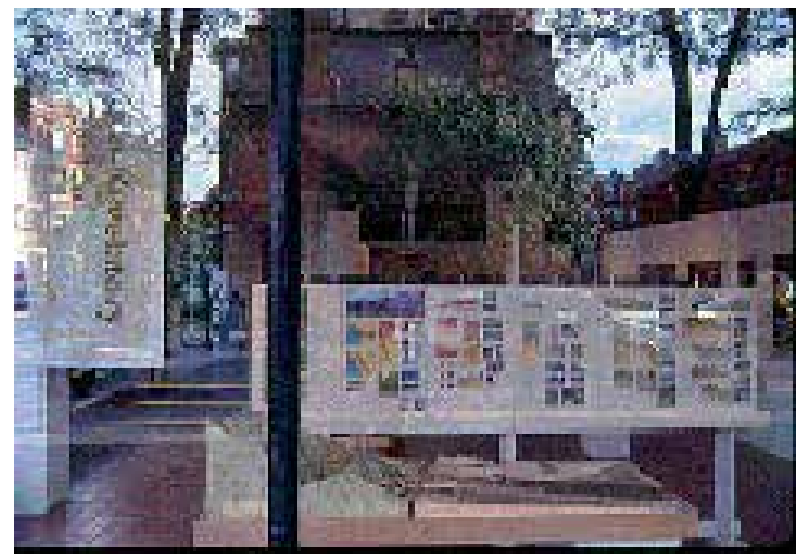

Figure 1. Eco-revelatory design exhibit

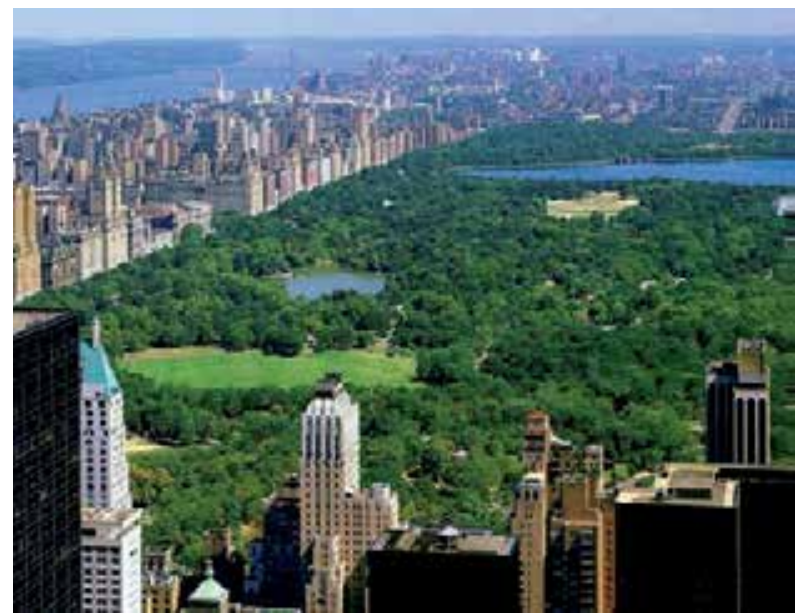

Figure 2. Central Park, NYC 
the practicalities of 'design with nature' and with the aesthetic results of a naturalist approach to landscape and garden design. It was demanded that local landscapes should follow ecological principles that implied that landscape could not represent some particular claim of social identity.

In the second half of the 19th century, Frederick Law Olmsted completed a series of parks which continue to have a huge influence on the practices of Landscape Architecture today. Among these were Central Park in New York City (Figure 2), Prospect Park in Brooklyn (Figure3), New York and Boston's Emerald Necklace park system (Figure 4).

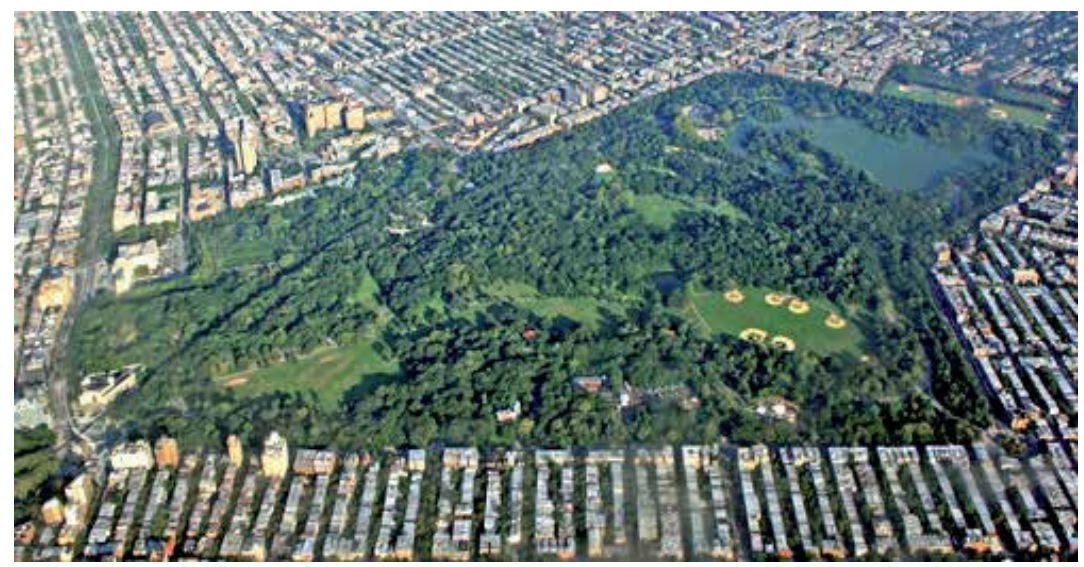

Figure 3. Prospect Park in Brooklyn

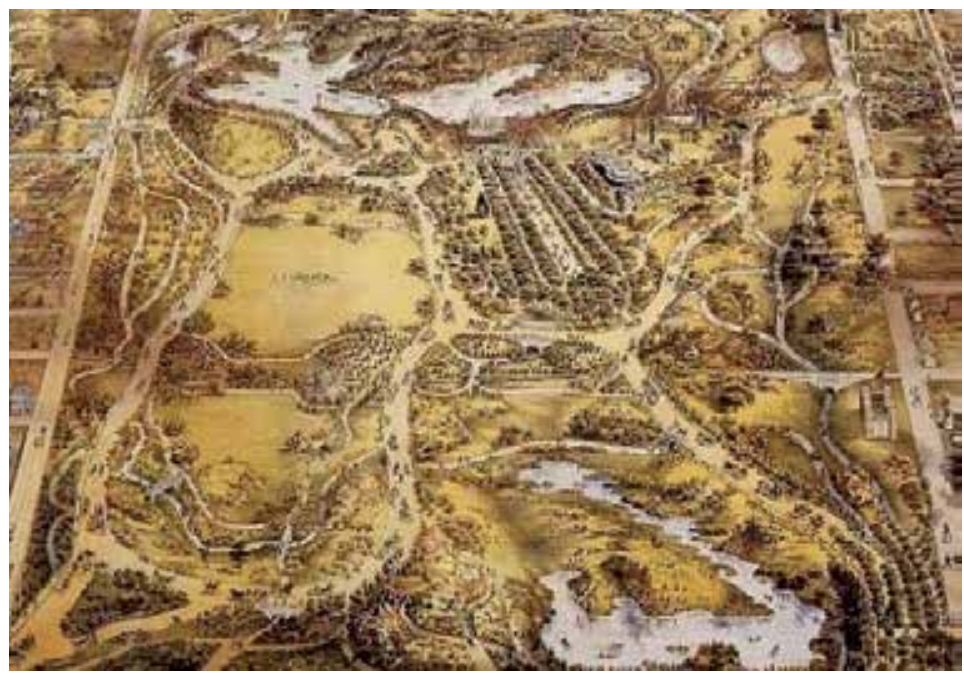

Figure 4. Boston's Emerald Necklace park system

The Emerald Necklace consists of a 1,100-acre $\left(4.5 \mathrm{~km}^{2}\right)$ chain of parks linked by parkways and waterways in Boston and Brookline, Massachusetts. 
Several components of the Emerald Necklace pre-date the plan to unite them. Some links of the Emerald Necklace not only offer an opportunity for recreation in a wooded environment, but are also ecologically important urban wilds that provide nesting places for migratory birds, fishes and other animals and improve the air quality of the city. The Emerald Necklace Project successfully ties together conservation, land restoration, sewage treatment, solid waste disposal, recreation, transportation, and water and visual quality [7]. The park system provides opportunities for people to learn about natural systems by enjoying, observing, and appreciating these systems.

Today, landscape architects recognize the effects of ignorance on natural systems in human development. So they coined a new design approaches.

Arcata Marsh is one of the ERD examples of today design approach. The Arcata Marsh and Wildlife Sanctuary was constructed in 1981 (Figure 5). The City of Arcata incorporated wastewater treatment to the system in 1986. The City of Arcata's unique wastewater treatment facility, marsh, and wildlife sanctuary attracts approximately 150,000 visitors per year [8]. Arcata's wastewater treatment plant is an example of a community involvement in environmental politics, innovative uses of land, and applications of appropriate technology in a small urban community. The Arcata Wastewater Treatment Plant combined with the Arcata Marsh and Wildlife Sanctuary has multiple uses, including wastewater treatment, recreation, wildlife habitat, education, and research. The residents of Arcata who stroll by the wetland can, for instance; see that wastewater treatment wetlands can be important habitat for fish and birds, as well as an energy-efficient, biologically based method of controlling water pollution. The experience of the Arcata wetland shows that ecological processes can be brought into a constructive partnership with human settlements.
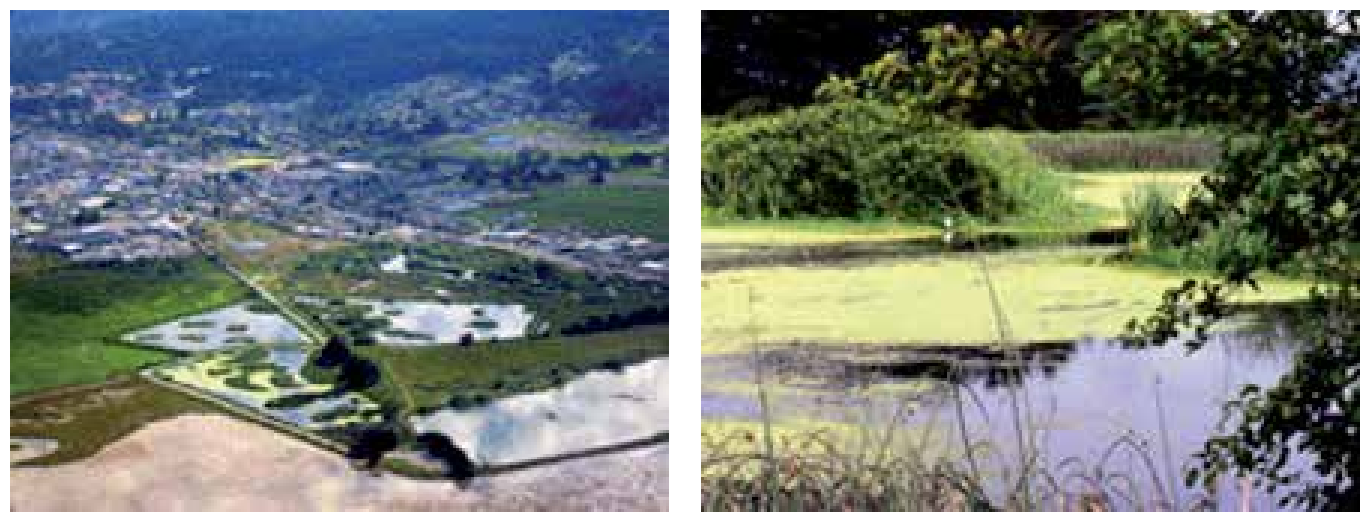

Figure 5. The Arcata Marsh and Wildlife Sanctuary (source: http://www.humboldt.edu/engineering/graduate/facilities)

Students are centrally involved in the original design and development of the Marsh's constructed wetland water treatment system, and they continue to play a key role through projects and research geared towards the continued optimization of the system. 
The second example for ERD is the Gateway Business Center - post-industrial area- is a 25acre site consisting of 10 industrial tilt-up buildings located at the San Gabriel Mountain foothills on a great alluvial fan that crosses the San Gabriel Valley on its way to the Pacific Ocean. The site concept transformed an industrial building environment into a sustainable and nature-inspiring experience. The layout of cairns act as way finding and directional markers and add to the overall landscape display and experience of bioswales, infiltration zones, rain harvesting, solar canopies and an array of recycled materials.

The site landscape is designed to mimic the natural feel of the local native landscape character and capture it into the renovated industrial complex. The goal is to create "biophilia" (an instinctive bond between man and nature). The bioswale has taken the place of the previous concrete swale, while the concrete catch basin remains to collect any additional runoff in a deluge, and as a reminder of the previous form of site storm water drainage. More than 95 percent of the runoff water in this parking lot is captured.

The storm garden is irrigated by the adjacent rain harvesting tanks. A natural wash picks up excess rainwater and roof water not captured by the parking lot bioswale. [9] (Figure 6)

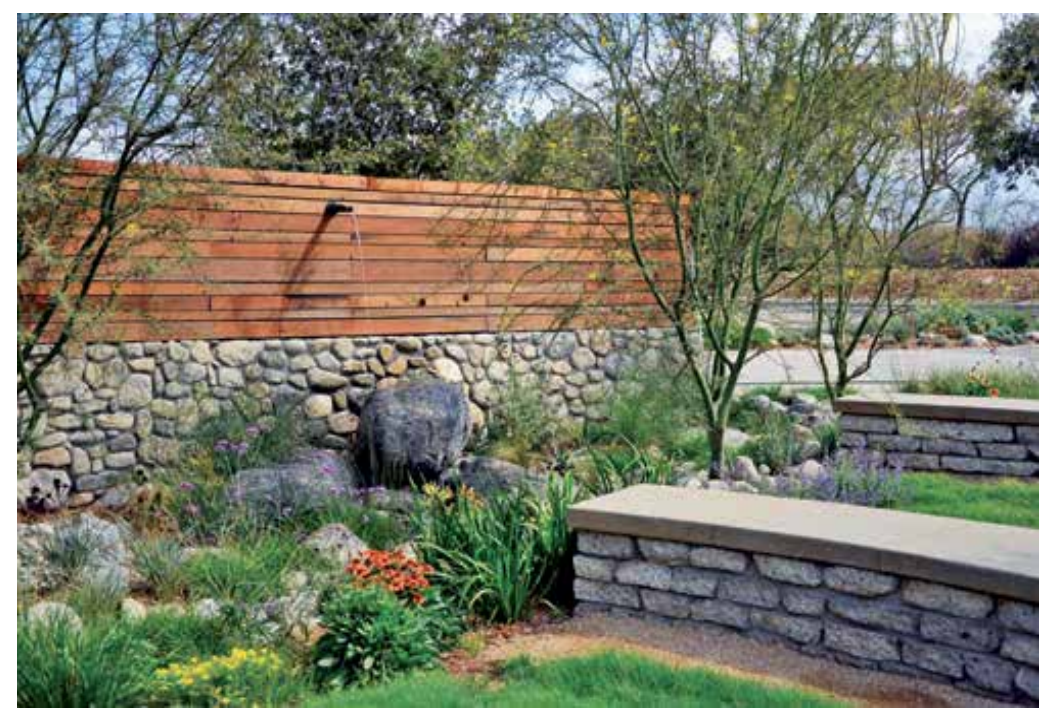

Figure 6. The Storm Garden of Gateway Business Center

\section{Design and ecology relationship}

Design is the intention that redefines how we relate to each other and our environment. The process of designing places and artefacts are opportunities to reimagine a new relationship with our environment, especially when it seems remote or difficult to create. Design that reveals hidden systems, whether ecological or economic, is a powerful way to meet the challenges of ecologically benign communities. Landscape design is a discipline which transfer the knowledge developed in landscape ecology to application [10]. 
The term ecology, like the term landscape, has multiple meanings. Ecology has historically focused on pristine, natural environments, however, by the 1970's many ecologists began to turn their interest towards the ecological interactions taking place in, and caused by urban environments. Urban ecology is recognized as a diverse and complex concept which differs in application between North America and Europe. The European concept of urban ecology examines the biota of urban areas while to the North American concept which has traditionally examined the social sciences of the urban landscape as well as the ecosystem fluxes and processes.

Environmental knowledge have been part of the intent of design in landscape architecture and various conceptions and methodologies have been improved for measuring the environmental consequences of design.

Nassauer and Opdam define design as intentional change of landscape pattern, for the purpose of sustainably providing ecosystem services while recognizably meeting societal needs and respecting societal values [11]. Design is both a product, landscape pattern changed by intention, and the activity of deciding what that pattern could be.

Ecology plays a big role in ERD. Disciplines in applied ecology such as urban ecology, landscape ecology etc. helps planning and design practice in landscape architecture. These disciplines help put theories into practice. The most important thing is to find how to use ecological thinking in design.

\section{Landscape architecture and landscape ecology}

Landscape architecture is informed by scientific knowledge and aspires to provide aesthetic expressions in landscapes across a range of spatial scales. Landscape ecology has been defined as the study of the effect of landscape pattern on process, in heterogeneous landscapes, across a range of spatial and temporal scales [12]. The logical reasons for integrating these two fields are clear and compelling, with a great potential to support sustainable landscapes through ecologically based planning and design.

Proponents of ERD recognized that landscape architecture alters and directs both cultural and ecological systems. Furthermore, they acknowledged landscape architects' capacity to direct human experience and reveal, through design, aspects of ecology and culture. This integrated approach provides opportunity for people to place themselves in and as part of an interconnected socio-ecologic world, reinforcing the relationships between humans and the bio-geosphere.

Landscape ecology is defined as a problem-oriented science [13]. It has developed from the growing awareness of environmental problems since the nineteen seventies. Spatial planning and landscape design are disciplines which transfer the knowledge developed in landscape ecology to application. To optimize this process of knowledge transfer, landscape ecology must co-evolve with spatial planning [14]. The development of ecologically sustainable landscapes requires that patterns of future landscapes sustain the necessary 
ecological processes in the landscape. Therefore, we must know how landscape patterns relate to these processes.

Humans are the driving force behind urban ecology and influence the environment in a variety of ways, such as modifying and altering land surfaces and waterways, introducing foreign species. In this context, changes between human-environment affect the styles of landscape design directly.

However, the present concept of ecological design and its interpretation in this sense does not refer to information charts or written explanations, which people encounter at places like zoological gardens or arboretums.

Generally, "ecological designs blend with their contexts and results in a diffuse visual pattern" [15]. Consequently, this perceptual subtlety can make ecological landscapes difficult for inhabitants to recognize and care about. ERD make ecological considerations perceivably a "visible part of landscape experience". It achieve this is by benefiting from the contrast between cultural and ecological domains. One way to achieve this is by exploiting the power of contrast, particularly the contrast between cultural and ecological domains. Ecological design has tended to diffuse edges to provide transition.

We can use basic principles of landscape ecology in landscape design. Such as linear parks, neighbourhood parks, playgrounds as for patch, greenways for corridor.

Every human directly or indirectly contributes towards enriching as well as degrading the quality and experience of cities. In order to create a successful ecological design it is important to recognize and interpret the historic and cultural significance of the landscape. In other words, "eco-revelatory design expands by hitching human habitat and their inevitable cultural determinants in to an environmentally inclusive vision" [16].

Farina observed that landscape design is an important component in practical landscape ecology as it expresses the relationship of spatial patterns and processes in a practical manner [17]. It provides in depth understanding on wildlife habitats and movements and biological interdependency within a region. The two disciplines should be complementary [17].

People use land for its scenic and recreational uses. Thus, the aesthetic use is important for them. However, natural systems are the important part of the designing decisions.

It is important to understand the social and cultural backgrounds and expectations of the society who use the land are determinant. It depends on two factors [18], in how people experience and use their landscapes, and their understanding of ecological processes.

It is important to organize a linkage between cultural expectations and ecological process. Man made land uses affect the ecological system activities such as wildlife crossing and subsurface water movement. Lyle has explained the following six basic ecological processes that are vital for operational integrity of natural systems [19].

In order to participate creatively in natural processes and to do so with reasonable hope of success, we need to include as subject of design the inner workings of the landscape, the 
systems that motivate and maintain it, and reveal them through creative, imaginative, and visible form of the landscape [19].

\section{Theory}

A design theory is a procedure for how to set about a design project. The classical twentieth century approach to landscape design has been Survey-Analysis- Design (SAD). It has been elevated to the status of a design methodology and cruelly overworked. The resultant places lacked clarity of intention. The intention of ERD is to "connect people with the natural environment". A dynamic balance between natural environment and society, intended to reveal and interpret (resolve and educate the relationship between user and the designed area ) and finally to provide awareness on ecological understanding.

Most of the landscape designers' style ignores natural systems and have only one purpose, primarily focused on aesthetics. ERD has to combine aesthetics and science. It is one of the endeavours that contribute to rediscovering aesthetics. It is hard to measure aesthetics outcome statistically or collectively. But can measure the environmental effects in numbers. So you can measure the sustainability by its effects on environment not by aesthetics.

\section{Method}

It is important to choose a method that is most compatible design strategy. It depends on the design intent, the place and the designer. How methods fit into design process should be determined clearly.

Generally two methods are used at ERD as follows;
a. Mimic the nature
b. Use the nature

a. We need to design a natural area to show the ecological processes and relationships. Artificial waterfalls can perfectly mimic the nature a way that highlight the system of the real one (Figure 7). Native trees and shrubs mimic the adjacent natural areas. The site landscape is designed to mimic the natural feel of the local native landscape character.

b. ERD utilizes the natural capabilities of the environment. In an ecorevelatory approach the pre-existing natural, structural and functional characteristics of the place are integrated into design and made them observable and understandable.

There are a lot of methods for ERD that landscape architecture can use such as environmental method, man centred method, evaluation method, interpretive analogy method. The design method is up to designer's idea and knowledge.

Through our senses, we form concrete relationships, we reconciliate, with the world. With this understanding, phenomenology can be used as a method for eco-revelatory design. Suitability analysis is also one of the approaches for ERD. 


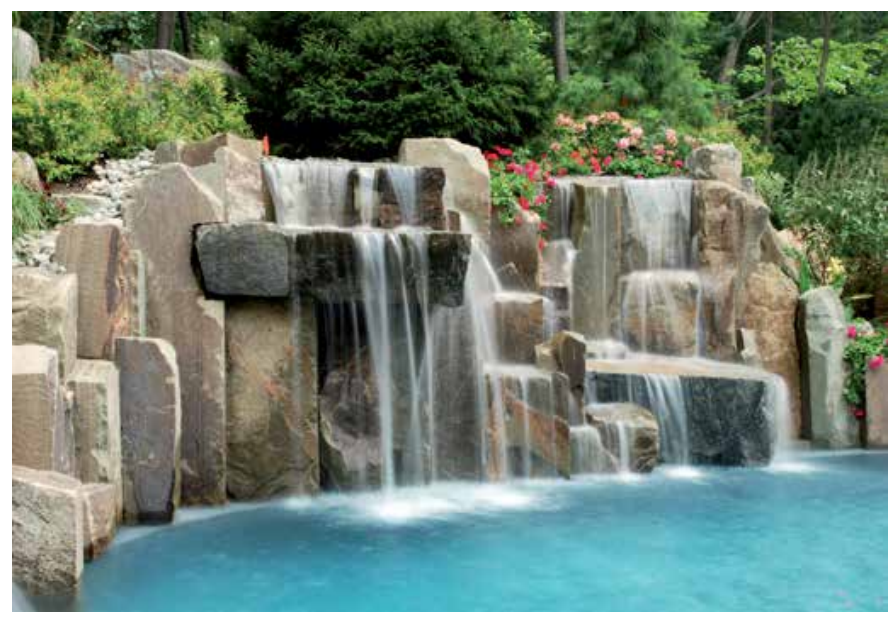

Figure 7. Artificial Waterfalls

\section{Design process}

When we examine the literature about ERD we can't see any knowledge about the design process. Landscape ecology principles integrate to design process. How can we adopt the ecology approach and principles into design process? We can use basic principles of landscape ecology in landscape design such as linear parks, neighbourhood parks, playgrounds as for patch, greenways for corridor. Landscape ecology principles influence every stage of landscape design process such as site planning.

One of the design processes is traditional design process that landscape architects undertake. It typically starts with the selection of a site based on a set of criteria. Once a site is selected, the typical design process will move through a series of phase including site inventory, site analysis, conceptual design, design development, construction documentation and finally implementation [20].

Landscape designers need to understand how natural and human systems work and design as an integral part of a nature and establish relationship with nature. They can achieve this by combining those with new technology to meet changing cultural and ecological needs.

\section{Principles (Design strategy)}

The hosts of the exhibit, Barbara Brown, Terry Harkness and Doug Johnston, take great care in describing what deserves to be called eco-revelatory design, and stressed stringent and ambitious goals for the competition. Those chosen for the exhibit represent rigorous application of eco-revelatory design, and utilize some or all of the following strategies [1]:

- Abstraction and simulation of natural processes

- New uses of landscapes producing deeper caring for life and ecological processes

- Signifying features that speak for natural/cultural processes that might otherwise remain invisible 
- $\quad$ Expose infrastructure and process

- Reclaim landscapes so that the past is remembered

- Change perspectives by structuring how we interact with the Landscape.

Interpretation of ecological processes refers to the ability of the design to reveal ecological processes at work. This process of revealing can only be successful if the environments created are visible, observable, legible, and have the ability to raise curiosity in visitors to explore and understand the complexity of the landscape. Principles for ERD are described generally as follows:

\section{Visibility}

Visibility is a cardinal point for ERD. Many designers and planners have become concerned in recent years with "revealing" ecological processes in their designs so that the users of the environment may experience, learn about, and appreciate those processes. In practice, "revelation" of ecological process has meant everything from capturing stormwater on the surface of the land before it drains away to the storm sewers. In addition, the ecological processes that are revealed may themselves be truly "natural," in the sense that they could continue to exist without the management of humans, or they may be highly artificial, engineered systems that need constant supervision if they are to persist in an urbanized context.

"Most of the time, natural systems themselves are not visible and readily engaging. What are visible are the surface manifestations and the material conclusions of these natural systems, for example layers of rocks are not ecological process, but the result of it" [21]. Thus the most important challenge for designers is to recognize which ecological processes can actually be made visible and how they can interpret these dynamic processes or their material conclusions to form and inform landscapes.

The Arcata Marsh and Wildlife Sanctuary, a real-world example of eco-revelatory design, highlights some of the positive potential of using visibility as a design strategy (Figure 8).

Some ERDs, for example, have sought to bring ecological processes (such as water flows) into the open, but then blend them in with the surrounding landscape as much as possible. Many proposals to capture rainfall in grassy areas and infiltrate it into the soil before it runs off into the storm sewers would use either parks or front lawns for this purpose. Although this strategy reveals an ecological process occurring during and just after a rainfall, the rest of the time these spaces would simply look like what they have always looked like--large grassy expanses--and would forfeit an opportunity to communicate a clear, consistent, and meaningful landscape message. Making natural cycles and processes visible bring the designed environment back to life.

In reference [22] the quantitative interpretation challenges aesthetics by rendering it negative, segregated and unstable. Under this "hegemony" various endeavours in which eco-revelatory design played a part involved in. It is important for people to "read" or "experienced" the ecological knowledge tried to given. This attempt is achieved by visibility. 


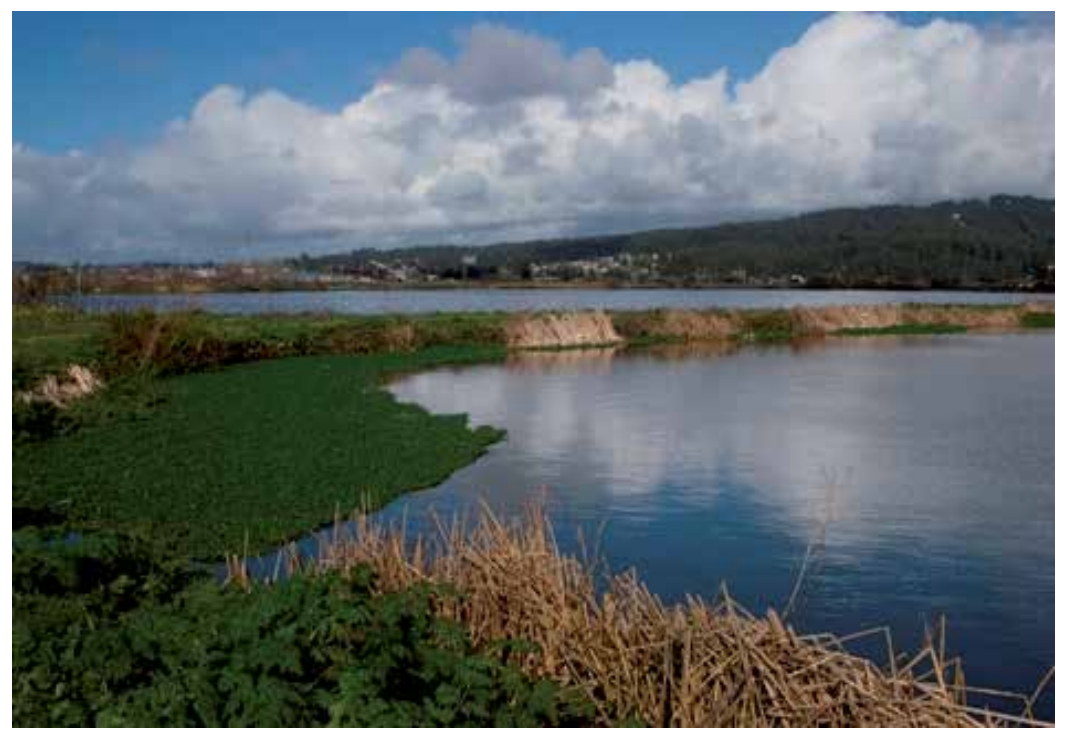

Figure 8. An Oxidation Pond at the Arcata Wastewater Treatment Plant

\section{Sustainability}

The second concern for ERD is to provide sustainability. The term sustainability was first used in 1980 in IUCN's World Conservation Strategy. The sustainability concept is arguably relevant to systems from the global to the local scale. Sustainable ecologically-based approaches to design are desirable but their application is not widely seen.

Sustainability reshapes environmental ethics, available technologies, planning techniques, and assessment criteria, which in turn influence environmental design disciplines. This approach suggests a need to contemplate spiritual aspects of sustainable design. A set of criteria is developed for sustainability to evaluate the environmental performance. In this context, sustainability becomes the key consideration in design.

If we propose to use ecological design of urban places to promote cultural change in the human relationship to the environment, then, we should be thinking about how to create physical settings with cues for sustainable behaviour.

The design of sustainable systems is consistent with ecological principles, which integrate human society with its natural environment for the benefit of both. There are many compelling reasons why environmental and resource problems should be placed in a dynamic perspective. It is important to provide sustainability by using moderate and efficient resource use. ERD strives for moderation and efficiency in resource use.

\section{The use of native plants (Naturalness)}

Naturalness provide to "sustainability" and "knowledge" about native plants. It also engages people and nature as it used to be. We can see the usage of native plants example 
on stormwater garden (Figure 9). It gives opportunity to people to have information about their native plants. Native trees and shrubs mimic the adjacent natural riparian areas, native plant communities and wildlife habitat. Natural water sources and planting zones will be considered when choosing plant material to minimize the need for irrigation.

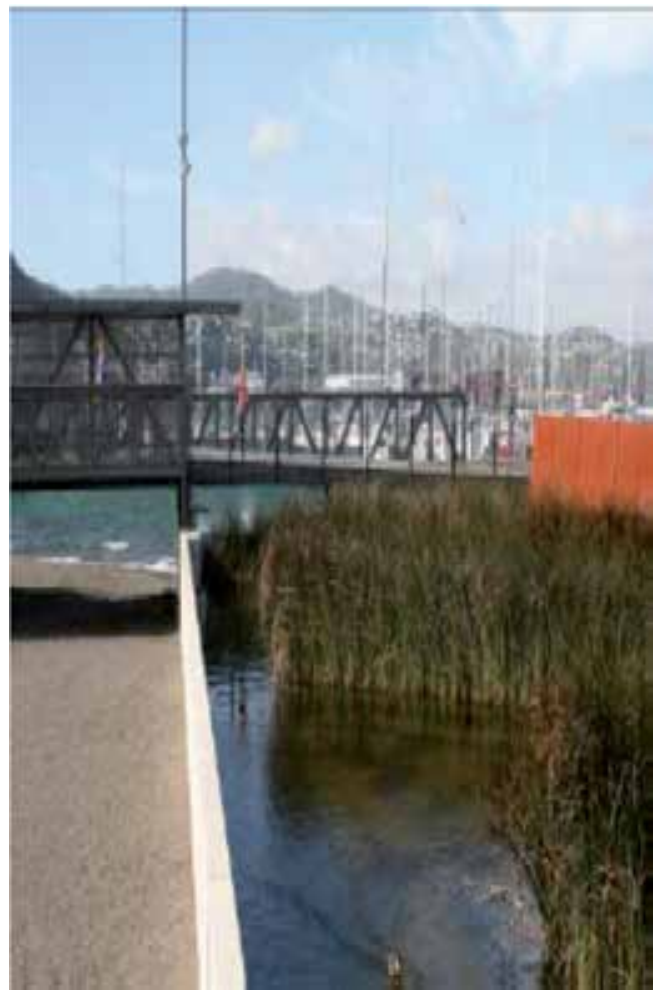

Figure 9. Stormwater management- the use of native plants

You can help stop the exotic plant invasion by using and nurturing native plants around your home and on your property. Native plants generally grow well and require less care than exotic species when grown on the proper soils under the right environmental conditions.

- $\quad$ Protective cover for most animals.

- $\quad$ Seeds, nuts, and fruits for squirrels and other mammals.

- $\quad$ Seeds, fruits, and insects for birds. add beauty to the landscape and preserve our natural heritage provide food and habitat for native wildlife

- $\quad$ serve as an important genetic resource for future food crops or other plant-derived products

If you enjoy observing nature, are concerned about the environment, or wish to make a long-term contribution to your community's ecosystem, then using native plants is a 
responsible, money-saving, long-term, positive investment to both your property and your community.

Landscaping with native plants improves the environment. Native plants are hardy because they have adapted to the local conditions. The native plants increase our connection to nature, help educate our neighbours, and provide a beautiful, peaceful place to relax.

The interest in the preservation and restoration of native plant communities increases as the public becomes more concerned about the environment. Native plants are valued for their economic, ecological, genetic, and aesthetic benefits in addition to the growing societal belief in their intrinsic value as living species.

\section{Observability}

It is relevant with visibility. People observe the design by hearing, listening and seeing. It makes awareness about the nature.

When ecological design incorporates "visibility" [23] and "observability" [24] it reveals ecological phenomena and processes and can be referred to as ERD.

\section{Multifunctionality}

Multifunctionality is the most important characteristics of this design strategy. It serves people multifunctional activities such as recreation, protection and education together. For instance, The Arcata Wastewater Treatment Plant combined with the Arcata Marsh and Wildlife Sanctuary has multiple uses, including wastewater treatment, recreation, wildlife habitat, education, and research.

Some people come to learn about the innovative wastewater treatment that enhances the community. Other people come to see the more than 270 species of birds that make use of the habitat provided by the Marsh [8]. Even more people come to exercise on the trails while enjoying the natural experience.

Multifunctionality is fundamental for sustainability. Multi-functionality is generally desirable, as it encourages efficient use of land, delivers wider public benefit and builds partnerships of user groups, leading to better stewardship. [25].

A designed land has many layers for visitors such as place for leisure activities, resting areas, conservation areas, fish and wildlife areas, sports activities and educational areas together. People gain social, environmental, economical advantage from multifunctional places.

\section{Legibility}

The design gives its mission to the visitor clearly. ERD purpose is "educate" and illumine". In this context, the messages have to be understandable. Effective design helps inform us about our place within nature. 
Legibility was interpreted as the understanding of how the landscape worked from its manifestation based on coherence between climate, soil, water and human occupation; or "understanding relationships between process and material, form and space" [26].

The spatial organization of design was utilized to clarify the ecological and cultural phenomena for people. People accompany the space by their senses. It gives people to create a spiritual connection with their environment and to have an educational consciousness.

\section{Ability to raise curiosity}

If the design does not take attention it can not to carry out its mission. To make people curious about the design shows its success. The perception is the most important element of design that its comprehensibleness and arouse curiosity.

It is important for people to "read" or "experienced" the ecological knowledge tried to given. This attempt is achieved by rising curiosity. If people wonder, they can learn the ecological awareness. Designers should enhance visitor's experience by encouraging interaction to interpret the ecological processes.

Effective design solutions or distinctive features are chosen as the general publics' ability to gain ecological information from their environment is limited. By using and revealing natural systems to spread consciousness and earn attention and care for our environment.

ERD overlap cultural needs and ecological processes to raise curiosity in visitors to explore and understand the complexity of the landscape.

\section{Conclusion}

ERD is a new approach in subdiscipline of design for landscape architecture, one where ecological process, the environment and the cultural awareness of people is a fundamental determinant of the design. Landscape architects should enhance visitor's experience by encouraging interaction to interpret the ecological processes. In this context, the ecological knowledge of them should be enough for interpretation of ecological processes on their designs. Also, it is important to be understood that the ecological phenomena helps people understand their environment and its cycles by their senses.

The present concept of ERD enriches the landscapes by incorporating visibility and observability. In this context, it reveals ecological phenomena and process. This process of revealing can only be successful if the environments created are visible, observable, legible, and have the ability to raise curiosity in visitors to explore and understand the complexity of the landscape.

In order to create a successful ecological design it is important to recognize and interpret the historic and cultural significance of the landscape. In other words, "ERD expands by hitching human habitat and their inevitable cultural determinants in to an environmentally inclusive vision" [16]. 
The Eco-Revelatory Design Exhibit, summarized in the 1998 special issue of Landscape Journal [1], clearly articulates an open challenge for landscape architects to work as environmental educators and to help heal the relationship between society and natural systems.

Explaining this new philosophy as distinctly different and complementary to ecological design, a more technical approach for designing with natural processes, ERD reveals the significant ecological aspects of a site and helps visitors build meaning and connection between the landscape and their own lives. In this sense, eco-revelatory designs are educative landscapes, pushing their visitors to think, gain perspective, and internalize new information [1].

ERD serves as a lens for reading the landscape's story. This design idea was resulted from environmental and ecological degradation, and the erosion of spiritual connections with the land.

Most of the projects have only one purpose: they are planned for recreation that ignores natural system usually or planned for protection. However, ERD is a multifunctional design that reveals natural systems and meets the cultural and ecological needs of human systems. By revealing natural systems earn people consciousness attention, and care for their environment. The basis for ERD is to create a landscape that is ecologically as well as culturally sustainable. It provides people educational and recreational opportunities.

The technology and the conditions of life break people's connections with nature. Landscape architecture can play a major role in the mission to bring together again nature and people and reveal the ecological processes by design.

\section{Author details}

Nurgül Konaklı Arısoy

Selçuk University, Agricultural Faculty, Department of Landscape Architecture, Turkey

\section{References}

[1] Brown B Harkness T Johnston D. Eco-Revelatory Design: Nature Constructed/Nature Revealed: Guest Editors' Introduction. Landscape Journal. 1998 Special Issue: x-xi.

[2] Eisenstein W. Ecological design, urban places and the culture of sustainability: Can citybuilding foster a culture of sustainability? Retrieved 8/23/2009, from SPUR. 2001. http://www.spur.org/publications/library/article/ecologicaldesign09012001

[3] Brown B. Holding moving landscapes. Landscape Journal 1998 (Special issue):53-68.

[4] Ndubisi F.. Ecological planning: a historical and comparative synthesis. Johns Hopkins University Press, Baltimore; 2002

[5] Cox Von Ins R E. Designing for Interpretatıon: Nanny's Mountain Park, Master Of Landscape Architecture. Maureen Grasso Dean of the Graduate School The University of Georgia, Athens; 2006. 
[6] McHarg I L. Design with Nature. Doubleday/Natural History Press, Garden City, NJ; 1969

[7] Forman R T. The Missing Catalyst: Design and Planning with Ecology Roots. Washington Covelo London:Island Press; 2002

[8] The Ashford Borough Council. 2008

[9] http://www.landscapeonline.com/research/article/15739

[10] Opdam P Verboom J and Reijnen R.. Landscape cohesion assessment: determining the conservation potential of landscapes for biodiversity (submitted); 2002

[11] Nassauer J I Opdam P.. Design in science: extending the landscape ecology paradigm, Landscape Ecol, Springer 2008: 23:633-644, DOI 10.1007/s10980-008-9226-7

[12] Turner M G. Landscape ecology: The effect of pattern on process. Annu. Rev. Ecol. Syst 1989: 20: 171-197.

[13] IALE Executive Committee, 1998. IALE Mission Statement. IALE Bulletin 16:1

[14] Ahern J. Integration of landscape ecology and landscape design: An evolutionary process. Edited by J. A. Wiens and M. R. Moss. International Association for Landscape Ecology, Guelph, Ontario, Canada.Landscape Ecology 1999: 119-123.

[15] Lyle J T. Regenerative Design for Sustainable Development. New York: John Wiley \& Sons;1994.

[16] Mozingo L A. The Aesthetics of Ecological Design: Seeing Science as Culture Landscape Journa,1 Spring, 1997 (16) 146-59 DOI: 10.3368/lj.16.1.46

[17] Farina A. Principles and methods in landscape ecology. London: Chapman \& Hall; 1998

[18] Deshpande A M. Design Process to Integrate Natural and Human Systems, Landscape Architecture, State University, Ms Thesis, Blacksburg, VA.; 2003

[19] Lyle J T. Design for human ecosystems. Landscape, land use, and natural resources. New York: Van Nostrand Reinhold Company Inc ; 1985

[20] LaGro J A. Site analysis. Linking program and concept in land planning and design. New York: John Wiley and Sons: 2001

[21] Nassauer J I. The appearance of ecological systems as a matter of policy. Landscape Ecology 1992: (6) 239-250

[22] Zhang B. Technicalization of Environmental Aesthetics and a Resolution of Spirituality, Architecture, Culture, and Spirituality Symposium. JUne29-July 1 2011, Serenbe, Georgia, USA

[23] Hough M. Cities and Natural Process, London: Routledge; 1995

[24] Thayer R L. The experience of sustainable landscapes. Landscape Journal 1989: 8 (2):101-110.

[25] Selman P. Community Essay. Department of Landscape, University of Sheffield, Crookesmoor Building, Conduit Road, Sheffield S10 1FL United Kingdom, Planning for landscape multifunctionality, Sustinnability: Science, Practice \&Policy 2009: 5 (2)

[26] Spirn A W. The language of landscape. New Haven and London, Yale University Press; 1998. 
226 Advances in Landscape Architecture

[27] Lyle J T. Regenerative Design for Sustainable Development. New York: John Wiley \& Sons; 1994 


\title{
Designing Landscapes for Child Health
}

\author{
Aydın Özdemir
}

Additional information is available at the end of the chapter

http://dx.doi.org/10.5772/55762

\section{Introduction}

Childhood obesity has reached epidemic proportions and is a major public health problem globally (Ebbeling et al., 2002; Pate et al., 2008), which causes many serious health-related problems (van Emmerik et al., 2012; Daniels et al., 2005; Din-Dzietham et al., 2007; Lorch and Sharkey, 2007) such as coronary heart disease, diabetes, osteoporosis (Sallis and Owen 1999; Pate et al. 1995; Hume et al. 2005; Raitakari et al., 1997; Teixeira et al., 2001; Bailey, 1995; Berenson, 1986; Van Mechelen et al., 2000), sleep apnea syndrome (Wabitsch, 2000) and psychological problems (Dietz, 1998; Daniels, 2006). Obesity is caused by a higher energy intake than energy expenditure, resulting in excessive weight gain (Koezuka et al., 2006). Theory implies that energy balance is maintained by energy expenditure, and physical activity helps to improve energy expenditure resulting weight loss (Weinsier et al., 1998; Lambert and Goedecke, 2004; Chaput et al., 2011). Physical activity helps to improve metabolic profile, muscular and bone health (Anderson and Butcher, 2006; Ekelund et al., 2008; Hind and Burrows, 2007; Biddle et al., 1998), mental health and academic performance (Singh et al., 2012; Strong et al., 2005). For a healthy living, it is recommended that children should participate to at least $60 \mathrm{~min} /$ day of physical activity and include vigorous physical activity at least 3 days/week (Strong et al., 2008). Daily walking is a useful activity for healthy living (Shultz et al., 2011) and children should accumulate at least 12.000 steps per day to maintain a healthy weight (Tudor-Locke et al., 2011).

Environmental factors, which discourage energy expenditure and thus limit the availability of facilities for physical activity, have potential to influence body weight and healthy behavior (Lachowycz and Jones, 2011; Feng et al., 2010; Papas et al., 2007; Sallis et al., 2000). Studies reported a positive relationship between access to greenspaces and physical activity (Lachowycz and Jones, 2011; Kaczynski and Henderson, 2007; Kaczynski et al., 2008). Increased vegetation was associated with reduced weight among children (Liu et al., 2007) and neighborhood greenness influenced less weight gain in children (Bell et al., 2008). Promoting physical activity among children, therefore, should be a public health priority, 
and studies should focus on the determinants of the environmental variables of physical activity.

Previous reviews found associations between aesthetic attributes of the physical environment with physical activity (Sallis and Owen, 1999; Sallis et al., 1998; Owen et al., 2000; Humpel et al., 2002). Models developed from such research help to explain environment-behavior relationships that can play a key role in linking research, policy and practice. In this context, there is a need for high-quality empirical evidence supporting environmental influences on health (Humpel et al., 2002) and an understanding of how these environmental attributes are related to promoting more physical activity.

Within the extant literature there are many models and theories which help to conceptualize a potential way of mapping ecological, social and biological frameworks. Ecological model implies that behavior is influenced by the environmental factors, and changes in the environment-positive or negative-will have effects on health (McLeroy et al., 1988). The evidence shows that the built environment-the office environments (Chao et al., 2003), healing environments such as hospitals and day care centers (Whitehouse et al., 2001; Cooper-Marcus and Barnes, 1999), school buildings (Cradock, et al., 2007; Everett Jones et al., 2003), outdoor school environments (Rivkin, 1997; Dyment et al., 2009; Dyment and Bell, 2007; Tranter and Malone, 2004; Brink et al., 2010; Özdemir and Y1lmaz, 2008), housing and home environments (Shaw, 2004; Wigle, 2003; Evans et al., 2003; Saegert, 1982), recreation facilities and access to green spaces (Wells and Evans, 2003; Maller et al., 2006; Stigsdotter et al., 2010; Sugiyama et al., 2008), greening vacant urban space (Branas et al., 2011), the design of neighborhoods (Wells and Yang, 2008) and store locations (Holsten, 2009) - will affect health and well-being of users.

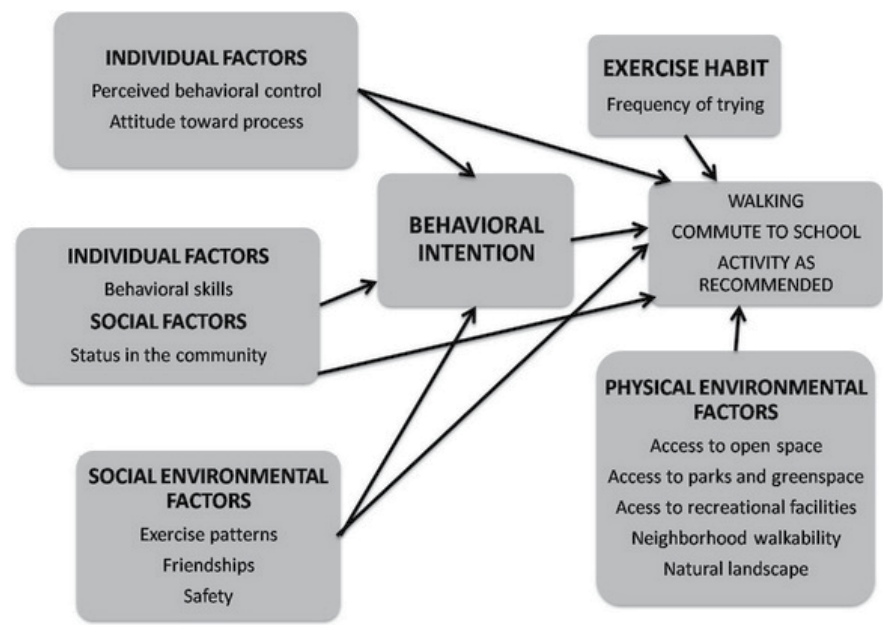

Figure 1. Model of environment health relation (Adapted from Pikora et al., 2003).

Established links between health and environment suggest that individual, social and physical environmental factors are related to behavioral intention, thus, shape our way of activities (Figure 1). As a result, improvements in the physical environment might lead to a number of 
long-term health outcomes: decrease in obesity, increase in physical activity, and decrease in serious health problems. Several studies have linked urban green space to fewer health complaints (Maas et al., 2009; Takano et al., 2002; Mitchell and Popham, 2008; Richardson and Mitchell, 2010; Mitchell et al., 2011). Based on these numerous health outcomes, planning and design decisions should take into consideration these public health impacts.

\subsection{Environmental characteristics and health outcomes}

Research on the determinants of potential environmental variables of physical activity is a growing trend (Carnegie et al., 2002; Sallis et al., 1990; Brug et al., 2005; Humpel et al., 2002; Owen et al., 2004; Trost et al., 2002; Saelens et al., 2003; Cunningham and Michael 2004; Wendel-Vos et al., 2007). Despite extensive research, the determinants of physical activity are not fully understood (Dishman and Sallis, 1994; Sallis and Owen, 1997; Vita and Owen, 1995). In order to promote planned and systematic physical activity among children, the key issue should be to gain insight into environmental factors that facilitate or obstruct physical activity among children (Baranowski and Jago, 2005; Wendel-Vos et al., 2004).

The social model of health conceptualizes health in environmental and social rather than just physical or individual terms (Figure 2). Research on the determinants of healthy child development showed that studies should include a mix of social and environmental factors-income, education, health and everyday environments-and all levels of society (Bonnefoy, et al., 2007). Healthy children will be those who are enabled to satisfy their needs and change, and cope with the urban environment (Davis and Jones, 1996; Black and Krishnakumar, 1998). However there is no systematic analysis of health effects of environments (Davis and Jones, 1996). Physical activity researchers, on the other hand, have not seriously addressed how the wider social and physical environment influences children's play and mobility.

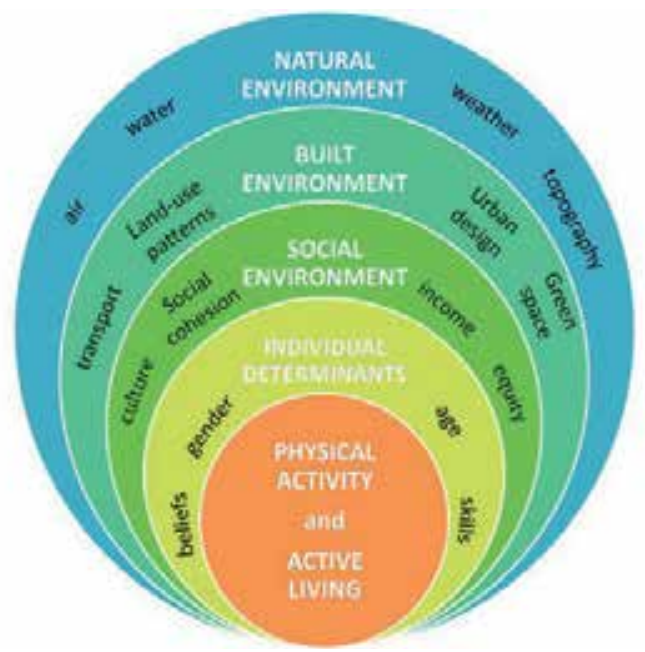

Figure 2. Factors influencing physical activity in communities (Adapted from Dahlgren and Whitehead, 1991). 


\subsection{Outdoor school environments and health outcomes}

Despite the fact that most physical activity by children is undertaken outside of the school building (Sallis et al., 1993; Vicent and Pangrazi, 2002), schools have not been recognized as key settings both to promote and to contribute to physical activity guidelines (Zimring et al., 2005; Zask et al., 2001; Iverson et al., 1985; Biddle et al., 1998) because children spend a large proportion of their time there (Biddle et al., 1998; Iverson et al., 1985).

School environments and policies have been studied for their effects on healthy behavior and obesity prevention (Trudeau and Shepherd, 2005; Story et al., 2006; Wechsler et al., 2000). Additionally, school building and campus characteristics have been associated with objective measures of physical activity (Cradock et al., 2007). Effects of school recess time (Ridgers et al., 2006), type and size of space and fixed outdoor equipments (Sallis et al., 2001), school size and available number of balls (Zask et al., 2001), size of schoolyards (Özdemir and Y1lmaz, 2008), the provision of extra equipment (Sallis et al., 2003; Verstraete et al., 2006), school ground paintings (Stratton and Mullan, 2005; Ridgers et al., 2007) and school environment improvements (Haug et al., 2010) have been found to be associated with physical activity. Past studies concentrated on environmental influences on health outcomes, however, found limited and ambiguous results (Ferreira et al., 2007; Davison and Lawson, 2006). Children were found to be healthier in large schoolyards (Özdemir and Yılmaz, 2008); however, children were more active in small schoolyards (Özdemir and Çorakçı, 2010). Additionally, limited outdoor play time and short recess were associated with a higher body mass index levels in young children (Ernst and Pangrazi, 1999; Alhassan et al., 2007; Ridgers et al., 2006).

Access to urban parks and recreational facilities, schoolyard renovations, type and quality of play spaces have been studied for their effects on increased physical activity in children (Sallis et al., 2009; Stucky-Ropp and DiLorenzo, 1993; Sallis et al., 1993). Some studies reported a significant association between active commuting to school and weight status (Faulkner et al., 2009; Lee et al., 2008; Lee and Tudor-Locke, 2005; Heelan et al., 2005; Pabayo et al., 2011; Rosenberg, et al., 2006; Mendoza et al., 2011), and children who actively commute to school are healthier than passive commuters (Heelan et al., 2005; Özdemir and Yilmaz, 2008; Lee and Tudor-Locke, 2005). In a comparison between cycling and non-cycling children, after 6 years of observations, children who cycle to school were found healthier (Cooper et al., 2008).

In order to develop school-based interventions, it is crucial to better understand the ways by which the school environment may promote or inhibit children's physical activity (van Sluijs et al., 2012). For a sustainable and a successful transition of school grounds from a conventional asphalt surface to a natural educational setting, outdoor school environments need to be conducive to health promotion with an integrated and a participatory approach.

\subsection{Neighborhood characteristics and health outcomes}

Active behaviors should be promoted with city planning and infrastructure by creating safe and accessible urban environments (Lopez and Hynes, 2006; Frank et al., 2005; Badland and 
Schofield, 2005; Handy et al., 2002), which in turn enhance energy expenditure. Environmental factors are influential in type and frequency of activity, such as climate of the region, terrains, neighborhood and traffic safety, and parents' perceptions of their children's activities outdoors (Saelens et al., 2003; Leslie et al., 2005). Sociocultural background (Flavia et al., 2010; Fredriks, 2005) and neighborhood characteristics are effective in obesity prevention; children in deprived neighborhoods are more likely to be overweight (deJong et al., 2011; Janssen et al., 2006; Lackshman et al., 2010; Veugelers and Fitzgerald, 2005). Several reviews indicate that people with low income are more likely to live in poor quality built environments, and this contributes to poor health (Lavin et al., 2006; Sallis et al., 2009). Parents in lower income neighborhoods reported the highest rates of unpleasant walking environments (van Lenthe et al., 2005). Neighborhood violent crime may be a significant environmental barrier to outdoor physical activity for urban dwelling (Bennett et al., 2007; Gomez, 2004).

Studies reported a positive relationship between access to greenspaces and physical activity (Kaczynski and Henderson, 2007; Lachowycz and Jones, 2011; Lee and Maheswaran, 2010). Children living in neighborhoods with playgrounds, parks and other recreational facilities engage in more physical activities and are less likely to be obese (Veugelers et al., 2008; Gordon-Larsen et al., 2006). Increased vegetation was associated with reduced weight among children (Liu et al., 2007) and neighborhood greenness influenced less weight gain in children (Kaczynski and Henderson, 2007; Roemmich et al., 2006; Bell et al., 2008). Park playgrounds were influential in reduced BMI values in children (Potwarka et al., 2008). A cross-sectional survey of adults in 8 European cities found that people in the greenest areas are less likely to be obese (Ellaway et al., 2005). Parents complained about the heavy traffic streets and the absence of a park nearby, which limited their children's play outside. Additionally, some parents indicated that their children never play outside of their home, even during the weekend due to the lack of nearby park (Aarts et al., 2012).

\subsection{Measurement techniques of physical activity}

The assessment techniques of physical activity can be grouped into two categories: subjective and objective. Subjective techniques include observations, questionnaires, interviews, physical activity logs and activity diaries. Objective techniques include physiological indices such as heart rate monitoring and electronic motion sensors (accelerometry, pedometer measurements), and tracking movement with Global Positioning Systems (GPS).

\subsubsection{Subjective assessments}

Assessment of children's physical activity levels is a research-priority (Trost et al., 2000) and several tools have been developed for this assessment (Welk, 2002; Ekelund et al., 2001). The most common technique is the subjectively measurement of child physical activity by survey techniques with self-reports (Loprinzi and Cardinal, 2011). Sallis et al. (2002) discussed self-report techniques that are defined as inexpensive and easy to administer. 
However, accuracy and reliability of self-report data are discussed, since young children may have difficulties in recalling their activity behaviors (Pate et al., 1995; Welk et al., 2000; Affuso et al., 2011), which calls for a response bias that affect the quality of data (Klesges et al., 2004).

Some studies included parental reports of their children's height and weight (Hinkley et al., 2008; Oliver et al., 2007; Eiser and Morse, 2001), which are often inaccurate (Rowland, 1990). Indirect subjective measures such as parent and teacher questionnaires were also administered to assess child physical activity (Oliver et al., 2007) and health related quality of life (Eiser et al., 2000).

The evaluation of the children's perception of the environment and its effect on behavior should be provided by multi-method approach. Focus groups are useful techniques in research with children (Hoppe et al., 1995; Morgan et al., 2002; O'Dea, 2003; Vaughn et al., 1996), and discussing topics in groups in schools is an appropriate method to gain insight into child views on several topics. Focus group method has been used for providing data which are deeper, more qualified and appropriate to the purpose of the research. Focus group is one of the rapid scanning methods which provide qualitative information in a short time. It is generally realized with 10-12 participants. The moderator provides the different/same opinion, comment or information to occur via questions which help to discuss. It is one of the most frequently used information gathering methods, because it provides convenience to reach different information in a short time, enables the flexible, unexpected and unknown findings to occur, catches extreme points and is cost-effective (Babbie, 2006; Debus, 1990; Engelbrektsson, 2002; Krueger and King, 1998; Krueger and Casey, 2000).

\subsubsection{Objective measurements}

Direct measures with objective tools such as accelerometers, pedometers, heart-rate monitoring (Oliver et al., 2007; Sirard and Pate, 2001; Trost et al., 2000) and GPS techniques can be used to monitor, measure and assess childhood physical activity. The use of these tools reduces the bias commonly associated with self-report measures. The objective assessment with measurement tools has high practical utility, high reliability and high validity relative to subjective measurements (King et al., 2011; Corder et al., 2008).

\section{Pedometers and accelerometers}

Accelerometer-based devices provide valid and objective information on physical activity with several outputs such as calories and fat burnt during a period of time, time spent in moderate and vigorous activity, distance walked and total step counts (Bassett and John, 2010). They are battery-operated devices that are attached to the wrists or ankles of the subjects to measure the number of steps during activities. Pedometers enable translating physical activity recommendations into pedometer-based step goals and commonly used in research with children (Pate et al., 2010; Mitre et al., 2009; Marshall et al., 2009; Tudor-Locke et al., 2011; Tudor-Locke and Bassett, 2004). They are widely used in medical research to 
compare descriptive data (steps per day) for specific age groups, cultures and environmental contexts (Whitt et al., 2004). However, they fail to capture data of seated activity (Berlin et al., 2006) and they only measure horizontal activities such as walking and running.

Accelerometers are also useful, reliable and valid tools with motion sensors to assess the intensity, frequency, pattern and duration of activity, which is an advantage over the pedometers (Berlin et al., 2006). Data collected by these devices should be processed on a computer. Research that included pedometer measurements found that obese children have lower pedometer counts than non-obese children (Tudor-Locke and Bassett, 2004; Eisenmann et al., 2007; Al-Hazzaa, 2007). Tudor-Locke and Bassett (2004) proposed a system used to classify healthy adults based on their activity levels: $<5,000$ steps a day for sedentary lifestyle, 5,000 to 7,499 steps a day for low activity, 7,500 to 9,999 steps a day for somewhat active, 10,000 to 12,499 steps a day for active, and $>12,500$ steps a day for highly active.

\section{Heart rate monitoring}

Heart rate (HR) monitoring is an objective, inexpensive and unobtrusive assessment tool providing indirect, intensity and duration data of physical activity among children (Loprinzi and Cardinal, 2011). HR monitoring provides information about total energy expenditure and about the amount of time spent in high-intensity activity (Ainslie et al., 2003). This tool has provided a valid and reliable objective estimate of physical activity (Rowlands and Eston, 2007) however, the link between heart rate measurements and energy expenditure is not as strong as other objective techniques (Trost et al., 2001). Heart rate can be measured easily with monitors attached to the wrists and the beltline. The resting and maximal heart rate is compared to gauge exercise and activity intensity. According to the American College of Sports Medicine Position Stand (1998), physical activity intensity according to frequency of heart rate is calculated for practical purposes as shown in Table 1 below:

\begin{tabular}{ccc}
\hline \multirow{2}{*}{ Intensity descriptor } & \multicolumn{2}{c}{ Relative Intensity } \\
\cline { 2 - 3 } & \% Heart rate reserve & Rating of perceived exertion \\
\hline Very light & $<20$ & $<10$ \\
Light & $20-39$ & $10-11$ \\
Moderate & $40-59$ & $12-13$ \\
Vigorous & $60-84$ & $14-16$ \\
Very vigorous & $>85$ & $17-19$ \\
\hline
\end{tabular}

*Adapted from American College of Sports Medicine Position Stand (1998).

Table 1. Physical activity intensity according to frequency of heart rate

Heart rate also has a significant relationship with energy expenditure and has been widely used in studies of physical activity in children (Eston et al., 1998; Spurr et al., 1988; Ceesay et al., 1989; Livingstone et al., 1992). HR monitoring reports much lower levels of physical activity and is based on small sample groups (Livingstone et al., 2003). However there are a 
number of limitations to the use of this technique (Armstrong and Welsman, 2006; Rowlands et al., 1997). Since HR is influenced not only by physical activity, reliability of this measurement is questionable. A child with low levels of physical activity may have high heart rates due to the influence of other parameters such as emotional stress, anxiety, hydration and environment (Armstrong and Welsman, 2006; Rowlands et al., 1997). In this respect, heart rate monitoring should be considered to measure moderate to vigorous physical activity, and heart rates below $120 \mathrm{bpm}$ would be considered to be valid measures of physical activity.

\section{GIS/GPS Tools}

Transportation, urban design and planning studies include Geographic Information Systems (GIS) to support the hypothesis that neighborhood environment is associated with physical activity in the form of walking and biking for transport (Frumkin, 2002; Saelens et al., 2003). GIS tools have been used to describe the associations between objective measures of the built environment and walking and transportation activity (McGinn et al., 2007). In the public health literature, the relationship between the built environment and physical activity was assessed by measuring the frequency, intensity and duration of activity. In such studies, objective measures of the environment were collected and mapped using GIS tools (McGinn et al., 2007). Global positioning system (GPS) is also used to track areas in a settlement or a space in a district where physical activity is promoted (Wheeler et al., 2010; Fjörtoft et al., 2009; Fjörtoft et al., 2010). GPS system was used to record children's movement patterns, which was transferred to GIS systems for further analysis (Fjörtoft et al., 2009; Fjörtoft et al., 2010). The purpose of the studies using GPS tools is to describe the interaction between environment and physical activity; based on the GPS data, designers explore and determine how space may interact with physical activity in children. However, GPS devices fail to record position indoors, under heavy tree canopy and in dense urban areas (Maddison and Ni Mhurchu, 2009) and they have limited accuracy in sensing stationary device location (Chen et al., 2012).

\section{Photography}

Studies of children's geography and social behavior concluded that children's physical activity and use of public spaces have been constricted and controlled (Blades et al., 1998; Matthews et al., 1998). In order to include views of children as key informants of research for their health and well-being, qualitative approaches have been employed (Darbyshire et al., 2005). It is important to offer children the opportunity to portray their own environments and one of the methods used for this purpose is photography, which is commonly accepted and validated by many researchers (Booth and Booth, 2003; Sharples et al., 2003; Wang and Burris, 1997) aiming to generate different and complementary visual information (Darbyshire et al, 2005). In a current study, children were asked to take pictures with disposable cameras (Özdemir, 2010). This visual data production strategy enabled children to relate their everyday life with their activities and environmental perceptions. There is extensive research with children using photography (Aitken and Wingate, 1993; Dodman, 2003; Morrow, 2001; Young and Barrett, 2001). However, there limits of this 
technique; the method of photography did not include children's talk about their taken pictures and the reasons of taking those pictures. Children took pictures and we defined and discussed them as adults.

\section{Schoolyard design to promote physical activity: An exploratory study}

\subsection{Methodology}

This study aims to assess outdoor school environments for their possible association with healthy behavior of children. For this purpose, children's total step counts were associated with the schoolyard size and 1115 students in 4 primary schools were surveyed. The aim of the project is to examine whether size and design of the outdoor school environments affect child physical activity. In addition, gender and age were selected to be variables to determine their relation to physical activity.

A random stratified sampling of primary schools from various districts of the city was used to represent a cross-section of the population. The schools, which have the adequate open space for the renewal projects, are located in different districts in terms of socio-culture and economy, have different numbers of students and need their schoolyards to be renewed, have been selected from a list of elementary schools provided from the Provincial Directorate for National Education (Table 2).

\begin{tabular}{ll}
\hline District & School \\
\hline Çankaya & Kavaklidere Primary School \\
Mamak & Çocuk Sevenler Primary School \\
Keçiören & Kamil Ocak Primary School \\
Akyurt & TOKİ Primary School \\
\hline
\end{tabular}

Table 2. The primary schools subject to the research and their districts

\subsubsection{Defining landscape characteristics of schoolyards}

For each schoolyard, ordinal categories were used as being applied for the classification of landscape quality. Aerial images and photo surveys were used to assess outdoor school environments; total area, usable area, landscaped-vegetated areas and hard surfaces were measured. The reliability tests of these measurements showed that both measurements on aerial images and hand measurements of a selected schoolyard gave specific and similar results. The photographs describe a variety of outdoor settings suggesting the need for a more spacious space per student after the calculation of the open space standards for school population for each case. Outdoor environments and the adjacent areas were assessed with respect to physical and landscape qualities (i.e. vegetation, material, size). A group of reviewers, which includes landscape architects and architects, reviewed the photographs and scored the schoolyards based on the features such as size, material, vegetation cover, vegetation quality, maintenance and spaciousness. Environments with low physical qualities scored 1. Environments with advanced features scored 2. 


\subsubsection{Focus groups}

The study also included 30 minutes meetings that were held with the students in each school. These focus groups, targeting children, included discussions on the current problems and future developments of the schoolyards; children's attitudes towards the school settings and the parents' views on their children's use of the schoolyards were discussed. Teachers did not attend the meetings; students had the chance to express their opinions freely.

\subsubsection{Pedometer measurements and BMI value assessments}

Intensity of children's school time activities was measured with electronic pedometers (Omron HJ-12). Pedometers were attached to randomly selected students. Average step counts of 10 children in each school were determined. Measurements also included distance covered, the amount of calorie (kcal) and body oil (gram) burnt during activities. It was assumed that the measurements would be distributed according to age groups, gender and schoolyard size.

Students were asked to indicate their weight and height on the questionnaire sheets to assess their nutritional status. In order to ensure reliability of self-reports, we weighed a group of students using a standard electronic scale, and their heights were measured with a wooden measuring board. Self-reported and objectively measured height and weight status were compared and it was found that self-reports were reliable. The height and weight information obtained in the surveys were used to calculate the BMI, which was computed as weight in kilograms divided by height in meters squared $\left(\mathrm{kg} / \mathrm{m}^{2}\right)$.

BMI values according to age groups are shown below (Table 3) (Uluocak et al., 2006; Şimşek et al., 2005; Öner et al., 2004; Altunkaynak and Özbek, 2007; Uğuz ve Bodur, 2007).

\begin{tabular}{cccccc}
\hline \multirow{3}{*}{ Primary School } & Grade & Age & Underweight & Normal & Overweight \\
\cline { 2 - 6 } & 3 and 4 & $9-10$ & $<14.0$ & $14.0-20.0$ & $>20$ \\
& 5 and 6 & $11-12$ & $<14.6$ & $14.6-23.1$ & $>23.1$ \\
\hline
\end{tabular}

Table 3. BMI values according to age groups

\subsubsection{Photography}

Children's perception of environment was evaluated with photography technique. In this scope, students, selected randomly from each school, were given disposable cameras and were asked to take pictures of places they visit during weekend. It was assumed that children would take pictures of a number of scenes such as greenery, plants, open views, pets, buildings and structures, traffic, indoors and their daily activities. Children's environmental perception would differ according to places they visit such as an urban park or an indoor environment. Based on the picture characteristics, potential perceptual variables were listed after expert ratings of scenes; experts included landscape architects and graduate students. 


\subsubsection{Workshops}

Researchers offered a variety of workshops for school-aged children, teachers and parents. These workshops were oriented towards the respective target audience and based on participatory methods, providing insight into the design process. The aim was to increase environmental awareness among children and to inspire creative thinking. In these workshops, children were introduced to landscape design through presentation, design drawings, sketches and 3D models.

In this case study, after the presentations to the school community, workshops were organized with the voluntary students. Firstly, borders of the schoolyards on the layout plans and draft drawings, entrances, current uses (parking, playfield, etc.) and green fields were shown to the students and they became familiar with the plan. Alternative uses, requested by the students in the schoolyard, were listed. Group of students prepared their own designs. In this process, the researchers assisted the children regarding the drawing techniques. Each project was developed in line with different concepts such as "adventure" or "blossom." First group made an adventure road strolling along the schoolyard. Each member of the second group named her/himself after a flower name and requested these flowers to be planted to the different parts of the schoolyard. The authentic design examples provided at the end of nearly half-hour study were displayed and presented by the group representatives (Figure 3).

Each group prepared a draft plan with sketches and colored markings. The final version of these projects, including before and after images, was displayed on the school boards in order to get feedback from students and teachers (Figure 4 and 5).
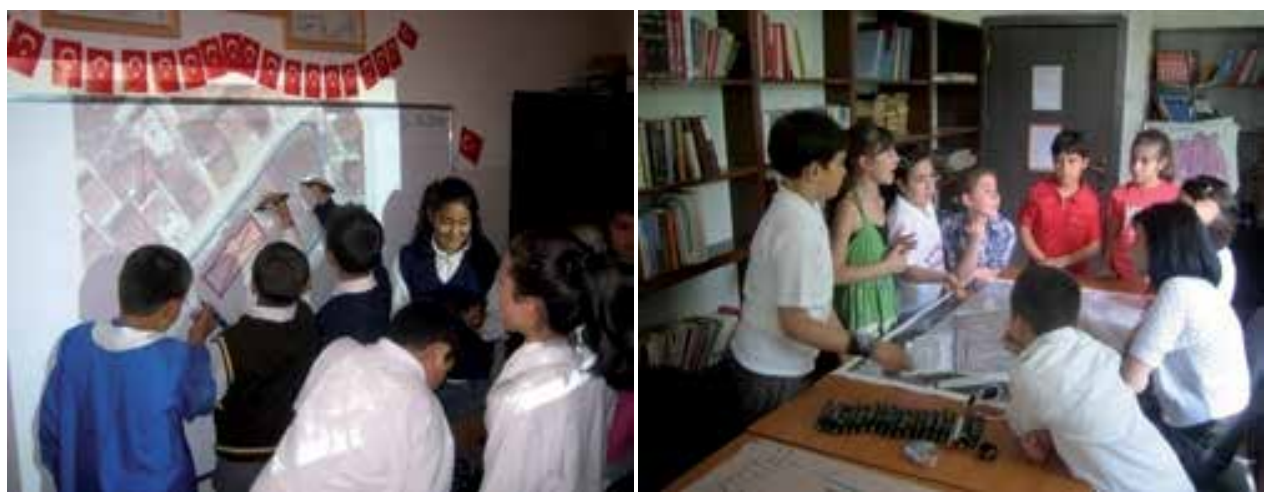

Figure 3. Views from the workshops 

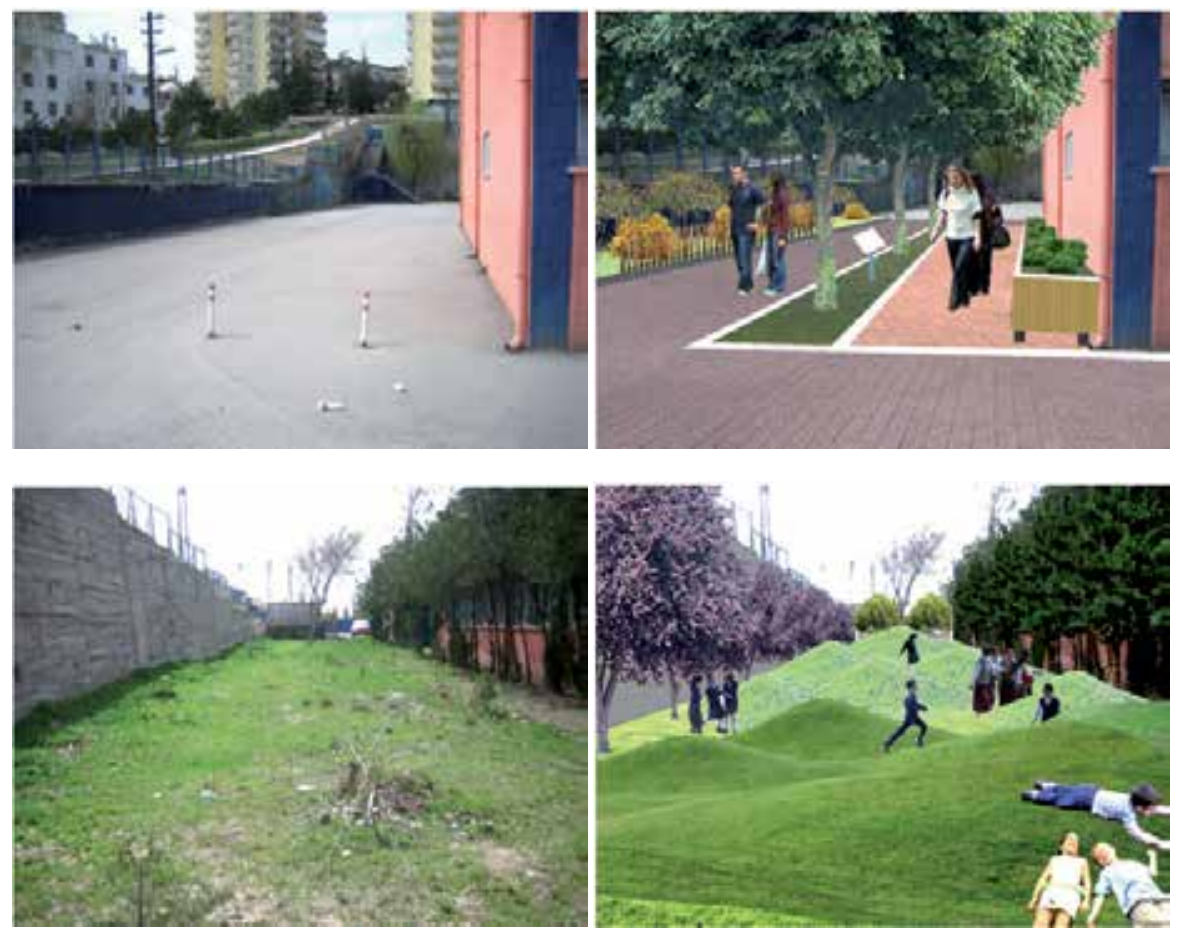

Figure 4. Current status of the schoolyards and the views after the arrangement

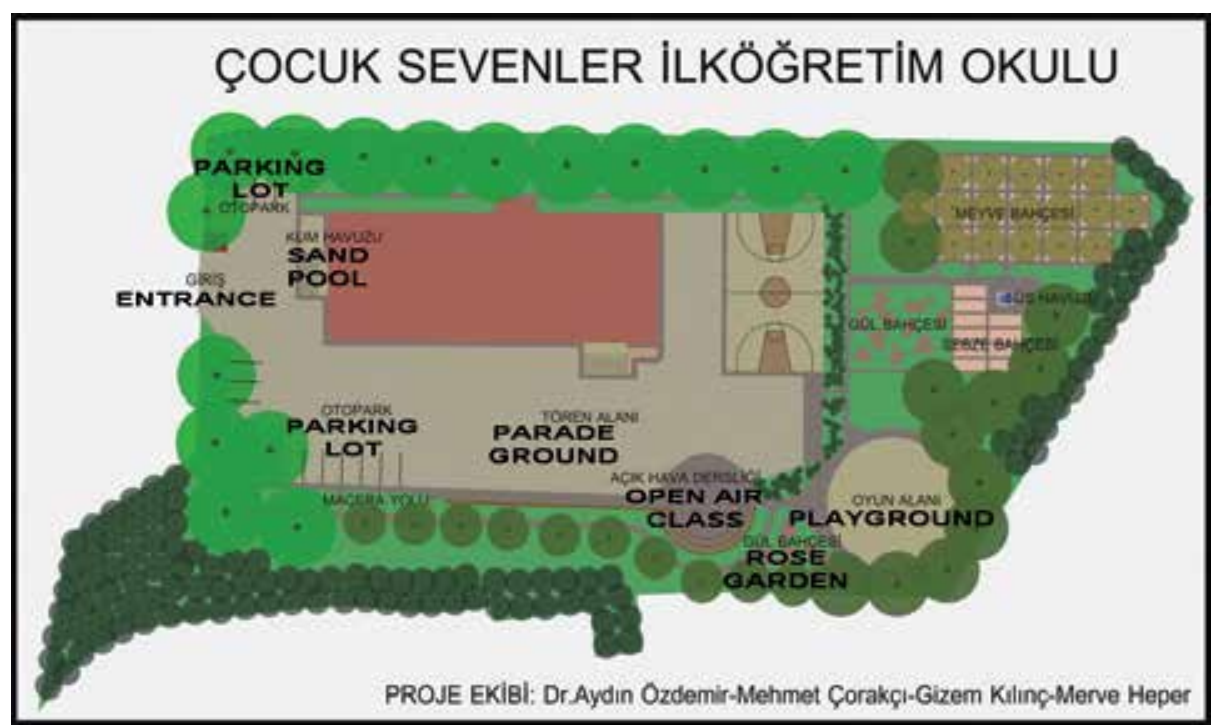

Figure 5. One of the alternative projects include sport facilities, fruit and vegetable gardens, rose garden, parking lot, open-air class, play field and walking trail, as proposed by the children 


\subsection{Results}

Physical and landscape characteristics of schoolyards were defined according to total yard size, total school size, and available space per students as shown in Table 4.

\begin{tabular}{cccccc}
\hline District & School & $\begin{array}{c}\text { Number of } \\
\text { students }\end{array}$ & $\begin{array}{c}\text { Total school } \\
\text { area }\end{array}$ & $\begin{array}{c}\text { Total yard } \\
\text { area }\end{array}$ & $\begin{array}{c}\text { Usable yard } \\
\text { space per } \\
\text { student }\end{array}$ \\
\hline Çankaya & Kavaklıdere PS & $650^{*}$ & $2050 \mathrm{~m}^{2}$ & $1350 \mathrm{~m}^{2}$ & $2.08 \mathrm{~m}^{2}$ \\
Mamak & Çocuk Sevenler PS & $580^{*}$ & $5500 \mathrm{~m}^{2}$ & $4750 \mathrm{~m}^{2}$ & $8.19 \mathrm{~m}^{2}$ \\
Keçiören & Kamil Ocak PS & $1300^{*}$ & $9300 \mathrm{~m}^{2}$ & $6800 \mathrm{~m}^{2}$ & $5.23 \mathrm{~m}^{2}$ \\
Akyurt & TOKI PS & 720 & $6100 \mathrm{~m}^{2}$ & $4525 \mathrm{~m}^{2}$ & $6.28 \mathrm{~m}^{2}$ \\
\hline
\end{tabular}

*The number shows only the morning shift students

Table 4. Physical assessment of schoolyards

Kamil Ocak Primary School has the largest yard; however, the available area per student is not adequate. According to zoning standards in Turkey, child play spaces should have at least $10 \mathrm{~m}^{2}$ usable area per child. This standard is also applicable to schoolyards; however, none of the schools provide sufficient space for child activities in this study (Table 4). Çocuk Sevenler Primary School, which has the largest usable space per student, received the best expert rating score. On the other hand, Kavaklidere Primary School, which has the smallest and inadequate space per student, received the lowest expert rating score. It is assumed that spatial conditions such as spaciousness influence expert ratings. Kamil Ocak Primary School yard received one of the lowest scores due to the confined feeling and the existence of a high retaining wall that divides the yard into separate lots. This wall was defined as dangerous and useless. Green spaces that have the potential for recreational purposes are out of reach of children and they are not accessible. There is the scarcity of shaded seating spaces and most of the ground is covered with hard material such as asphalt.

\subsubsection{Questionnaires}

Almost half of the respondents were boys (49,4\%) and 4 th and 5 th graders $(55,6 \%)$. Most of the students have spent at least two years in their school. We may conclude that these students are familiar with the school settings. More than half of the students $(54,8 \%)$ reside in the same neighborhood where the school is located, and most of the students prefer to walk to their schools. Only $22,3 \%$ of respondents commute to school with a vehicle.

There is variability in type of activities during recess. A considerable amount of children spend their recess time inside the school $(13,5 \%)$. More than half of students spend their recess time both indoors and outdoors (59\%). Most of the students prefer to walk in the schoolyard (43,5\%) and $21,2 \%$ of them behave active during recess. On the other hand, only $13,3 \%$ of children in these four schools prefer passive behaviors such as eating and sitting during recess (Figure 6). 


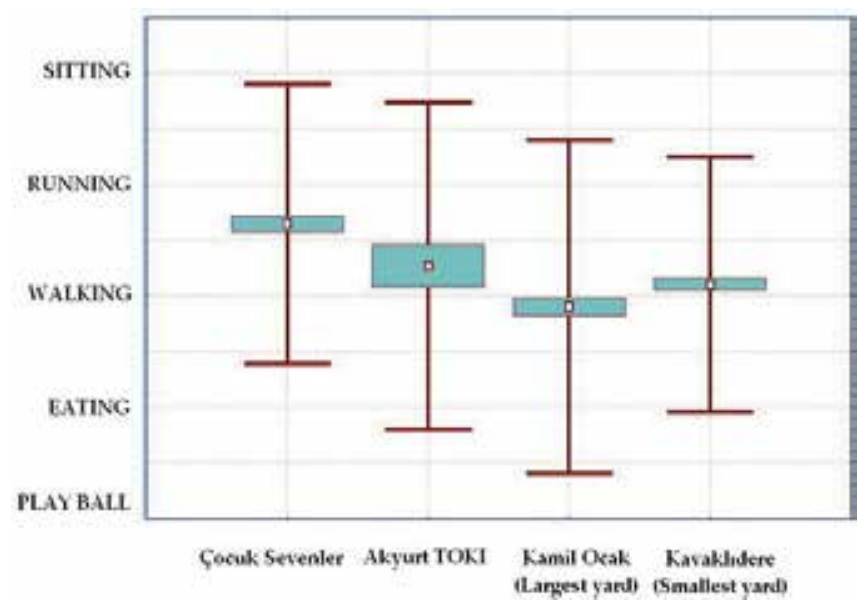

Figure 6. Scatter-plot diagram showing the distribution of type of activities across schools

More than half of respondents define their schoolyards as inadequate for any of the activities (59\%). Regardless of the size of schoolyards, this relationship was found statistically significant $(\mathrm{F}=113.05, \mathrm{df}=3, \mathrm{p}<0.005, \mathrm{R}=0.48)$ (Figure 7).

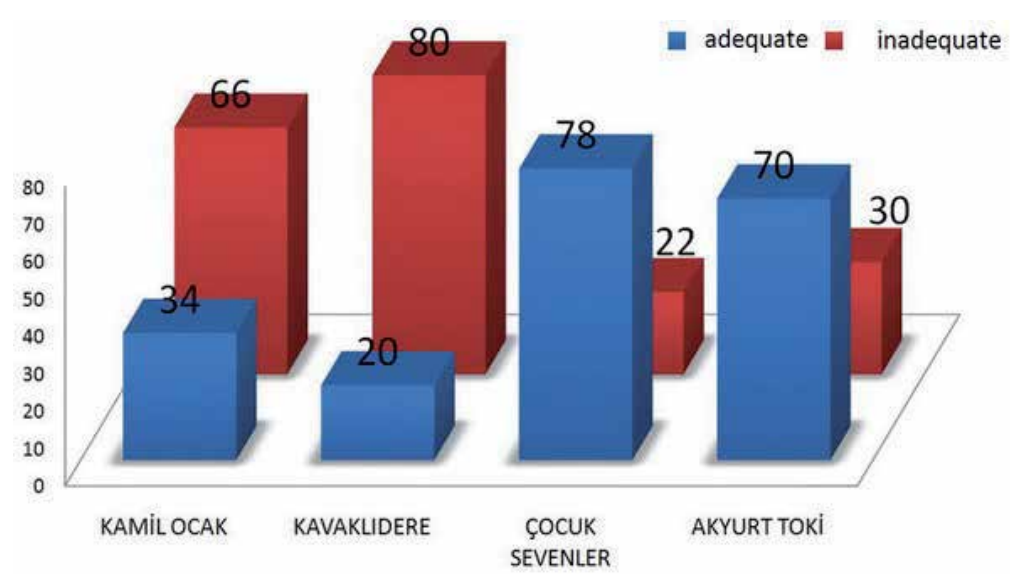

Figure 7. Adequacy of schoolyards

There is a statistical significance among number of students who liked yards; most of the students preferred the larger yards $(\mathrm{F}=226.6, \mathrm{df}=3, \mathrm{p}<0.005, \mathrm{R}=0.60)$. Similar results were identified between the expert ratings and students' responses; children liked the yards which were also highly rated by the experts $(\mathrm{F}=226.6, \mathrm{df}=3, \mathrm{p}<0.005, \mathrm{R}=0.60)$ (Figure 8).

Most of the students (65\%) were not satisfied with the yards. Responses indicated that the size of the yards was a major contributor of this result; most of the children $(34,2 \%)$ did not enjoy the small yards $(\mathrm{F}=16.1, \mathrm{p}<0.05)$. Other reasons included inadequacy of sport facilities and limited green spaces. 


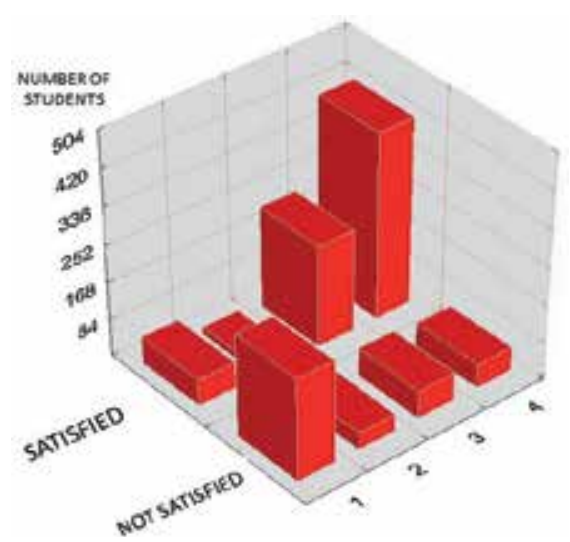

Figure 8. Students' satisfaction of schoolyards among scored yards (Quality scores - 1: High quality; 4: Low quality)

\subsubsection{BMI distribution among schools}

As a result of BMI distribution among schools, 16,2\% of children were defined as overweight $(\mathrm{N}=181)$. Most of the students were in the normal range of BMI values $(78,6 \%$, $\mathrm{N}=876$ ). Boys had higher BMI values than girls, and as expected, BMI values raised according to age groups, except 3rd grade students, which had lower BMI values than 2nd grade students (Table 5).

\begin{tabular}{llcccc}
\hline Domain & & N & Percentage & Mean & sd \\
\hline Gender & Female & 564 & 50.6 & 17.89 & 2.88 \\
& Male & 551 & 49.4 & 18.64 & 2.96 \\
\hline Grade & 2 & 70 & 6.3 & 17.86 & 2.71 \\
& 3 & 215 & 19.2 & 17.30 & 2.79 \\
& 4 & 303 & 27.2 & 18.15 & 2.86 \\
& 5 & 317 & 28.4 & 18.62 & 2.98 \\
& 6 & 210 & 18.8 & 18.99 & 2.93 \\
\hline BMI & Underweight & 58 & 5.2 & & \\
& Normal & 876 & 78.6 & & \\
& Overweight & 181 & 16.2 & & \\
\hline Type of & Walk & 866 & 77.7 & 18.20 & 2.95 \\
& & & & & \\
& Vehicle & 249 & 22.3 & 18.47 & 2.87 \\
\hline Yard size & Kamil Ocak (Largest yard) & 293 & & 18.17 & 2.75 \\
& Çocuk Sevenler & 293 & & 17.58 & 2.88 \\
& TOKI Akyurt & 55 & & 18.13 & 2.73 \\
& Kavaklidere (Smallest yard) & 474 & & 18.75 & 3.02 \\
\hline
\end{tabular}

Table 5. Subject characteristics and BMI values 
Results showed that there is a statistical significance between type of activities and BMI values ( $\mathrm{F}=2.67, \mathrm{P}=0.032)$. Students who were active during recess had lower $\mathrm{BMI}$ values than passive students. This was similar with the active school commuters; children who actively commute to school have lower BMI values, and this result is statistically significant $(\mathrm{F}=3.78$, $\mathrm{df}=1, \mathrm{p}=0.013$ ). Interestingly, large schoolyards have limited influence on decreased BMI values. Children in smaller schoolyards were more active and had lower BMI values. This finding is assessed by the relationship between total step counts and yard sizes, which is presented in the next section.

\subsubsection{Pedometer measurements}

A total of 120 measurements were made to indicate the variations in daily step counts, distance covered, burnt calories and fat among children at ages between 9 and 11 (Table 6).

\begin{tabular}{|c|c|c|c|c|c|c|c|c|c|c|c|}
\hline & & $\mathbf{N}$ & $\%$ & $\begin{array}{l}\text { Step } \\
\text { count }\end{array}$ & sd & $\begin{array}{c}\text { Distance } \\
(\mathbf{k m})\end{array}$ & sd & $\begin{array}{c}\text { Burnt calorie } \\
\text { (Kcal) }\end{array}$ & sd & $\begin{array}{l}\text { Burnt } \\
\text { fat (gr) }\end{array}$ & sd \\
\hline \multirow{2}{*}{ 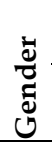 } & Female & 65 & 55 & 4201.7 & 1971 & 2.43 & 1.19 & 66.6 & 33.9 & 3.75 & 2.01 \\
\hline & Male & 55 & 45 & 4609.5 & 2068 & 2.75 & 1.25 & 84.1 & 41.8 & 4.71 & 2.48 \\
\hline \multirow{4}{*}{$\begin{array}{l}\tilde{J} \\
\tilde{J} \\
\end{array}$} & 3 & 10 & 8 & 5605 & 2970.8 & 3.32 & 1.91 & 82.5 & 51.1 & 4.85 & 3.2 \\
\hline & 4 & 40 & 34 & 4839 & 2041.7 & 2.81 & 1.32 & 74.6 & 34.3 & 4.17 & 1.95 \\
\hline & 5 & 70 & 58 & 3957 & 1734.4 & 2.34 & 0.96 & 73.4 & 39.3 & 4.1 & 2.32 \\
\hline & $\begin{array}{l}\text { Kamil Ocak } \\
\text { (Largest yard) }\end{array}$ & 40 & 33 & 3645.8 & 2171.6 & 2.23 & 1.34 & 61.18 & 36.9 & 3.46 & 2.24 \\
\hline \multirow{2}{*}{ 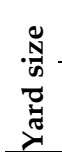 } & Çocuk Sevenler & 40 & 33 & 4173.7 & 1585.7 & 2.49 & 1.02 & 61.1 & 27.3 & 3.6 & 1.54 \\
\hline & $\begin{array}{l}\text { Kavaklidere } \\
\text { (Smallest yard) }\end{array}$ & 40 & 33 & 5346.4 & 1914.7 & 3.01 & 1.76 & 97.5 & 40.1 & 5.5 & 2.4 \\
\hline
\end{tabular}

Table 6. Step counts, distance, burnt fat and calorie across gender, grades, and yard sizes

Average step counts were 5346 in Kavaklıdere, 4174 in Çocuk sevenler, 3646 in Kamil Ocak primay schools. Boys were more active than girls, and small children were more active than older ones. Similar results were found for values of energy expenditure; boys and small children burnt more calorie and fat than girls and older students. The most interesting outcome of the study was the statistical significant and inverse relationship between schoolyard size and pedometer counts. Children in small schoolyards walked more $(\mathrm{F}=4.47, \mathrm{df}=2, \mathrm{p}=0.013)$, and burnt more calories $(\mathrm{F}=12.83, \mathrm{df}=2, \mathrm{p}<0.05)$ and fat $(\mathrm{F}=11.78, \mathrm{df}=2$, $\mathrm{p}<0.05)$. 


\subsubsection{Assessment of student pictures}

Total of 472 pictures taken by students were assessed as shown in Table 7. Experts defined type of images and visible elements in the pictures. As a control group, researcher took pictures with a disposable camera and included these images within other groups of images for a random presentation. Both control group images and student images were similarly assessed, which conclude that assessments are reliable and valid.

\begin{tabular}{|c|c|c|c|c|c|c|c|c|}
\hline School & Gender & Total & Built & Planting & Enclosed & $\begin{array}{l}\text { Open } \\
\text { scene }\end{array}$ & $\begin{array}{l}\text { Scene- } \\
\text { plants }\end{array}$ & Animals \\
\hline \multirow{7}{*}{ 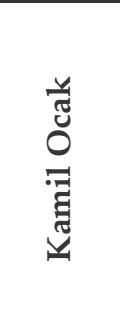 } & $F$ & 19 & 4 & & 5 & 2 & 8 & \\
\hline & $\mathbf{F}$ & 15 & 2 & 7 & 1 & 2 & 3 & \\
\hline & F & 20 & 3 & 8 & 1 & & 8 & \\
\hline & F & 27 & 5 & 3 & & 1 & 13 & 5 \\
\hline & $\mathbf{F}$ & 20 & 3 & 8 & 1 & & 8 & \\
\hline & M & 22 & 1 & 7 & 1 & & 8 & 5 \\
\hline & $\mathrm{M}$ & 25 & 1 & 16 & & 3 & 4 & 1 \\
\hline \multirow{9}{*}{ 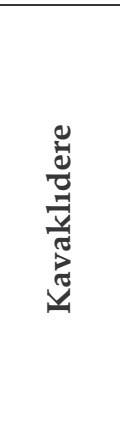 } & F & 25 & 2 & 19 & & & & 4 \\
\hline & F & 22 & 1 & 6 & 5 & & 5 & 5 \\
\hline & F & 25 & 1 & 3 & 1 & & 20 & \\
\hline & F & 23 & & 7 & 4 & & 9 & 3 \\
\hline & F & 18 & 3 & 8 & 4 & & 3 & \\
\hline & F & 25 & 1 & 14 & 2 & 1 & 4 & 3 \\
\hline & $\mathrm{F}$ & 15 & 4 & 4 & 5 & 1 & 1 & \\
\hline & M & 20 & & 10 & 1 & 3 & & 6 \\
\hline & $M$ & 21 & 1 & 6 & 2 & & 7 & 5 \\
\hline \multirow{6}{*}{ 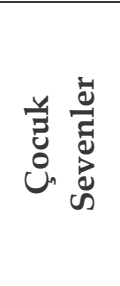 } & $\mathrm{F}$ & 23 & 2 & 11 & 2 & & 8 & \\
\hline & F & 16 & 1 & 8 & 4 & 1 & 2 & \\
\hline & $\mathrm{F}$ & 20 & & 3 & 6 & 7 & 4 & \\
\hline & $\mathrm{F}$ & 17 & & & 1 & 5 & 8 & 3 \\
\hline & $\mathrm{F}$ & 27 & 1 & 10 & 9 & 4 & 3 & \\
\hline & M & 27 & 2 & 8 & 5 & 12 & & \\
\hline
\end{tabular}

Table 7. Number of pictures according to the picture character across schools

Most of the students took pictures of plants and plant groups (35\%). A considerable number of students took landscape images (27\%). Only $12 \%$ of children captured interior spaces such as their home environments and school interiors. The most frequent type of images was captured from a vantage point-balcony or a terrace-looking toward the green spaces and plant groups. Although most of the images were captured during weekend, most of the pictures included home environments and local parks. We may conclude that children spend their weekend time at home and in the neighborhood. 
Distribution of image properties are associated with regional locations (Figure 9). Kavaklidere Primary School is located in a highly dense region with dense traffic and limited green spaces. Local parks in the district are scarce and limited front yards of apartments are used for parking cars. Kamil Ocak Primary School, on the other hand, is located in a district with lower dense housing distribution. This neighborhood with lower income families has more open spaces and green lots. Students' perceptions of environment, therefore, may vary according to the neighborhood characteristics. Most of the students in Kavaklidere Primary School took pictures of plants in their homes. On the other hand, Kamil Ocak and Çocuk Sevenler students took pictures of open spaces and open vistas. These results can be associated with neighborhood characteristics. However, these assumptions should be based on valid and systematic research that should include significant comparisons of children's environmental perceptions and spatial characteristics of neighborhoods.

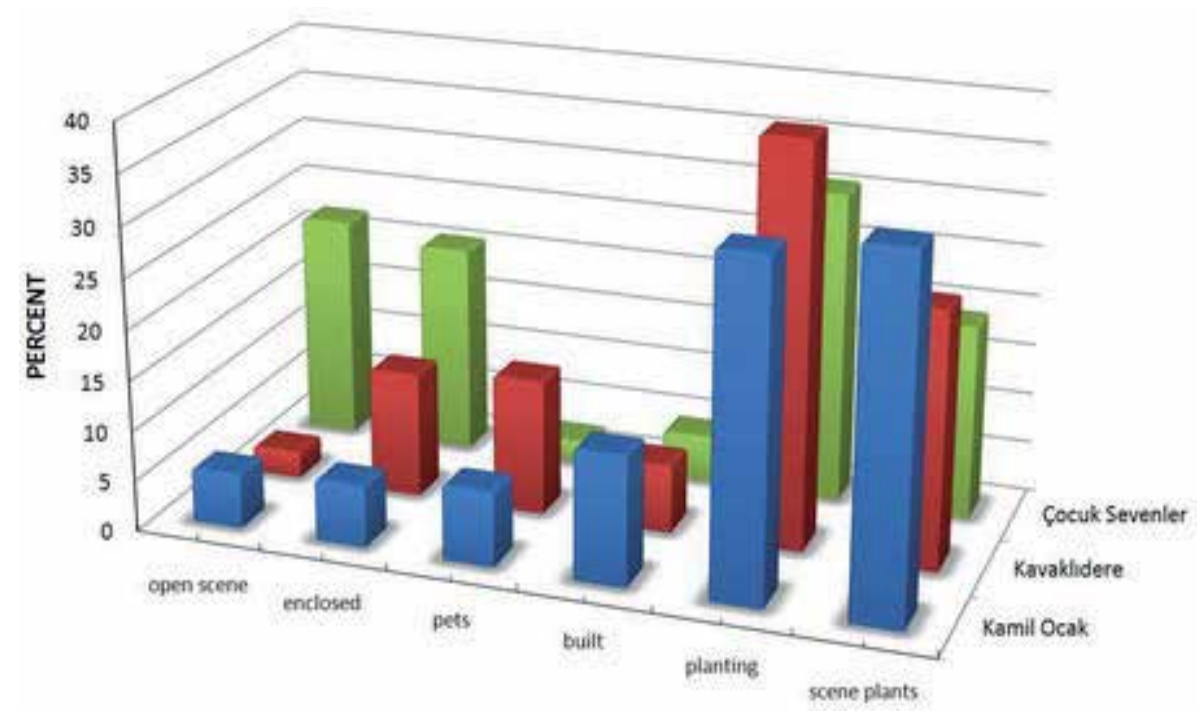

Figure 9. Distribution of picture properties across schools

\subsection{Discussion}

The results of this study contribute to both health and design professionals; environmental variables are effective in health promotion. In terms of design outcomes, this study provides evidence indicating the spatial effects of school environments on child health. Although most schools lack spacious schoolyards that were defined as mostly crowded and congested during recess, children were more active in small yards. Students generally complain about limited outdoor space for both play and physical activities; most students requested more spacious and green space for attraction and comfort. On the contrary of the expectations, pedometer measurements provided support that space distribution rather than the size is effective in health promotion. As many children attend to public schools, improvement the quality of the schoolyards to promote more physical activities is recommended. 
It was expected that larger yards would improve health of students with lower BMI values, which was found in the study of Özdemir and Yilmaz (2008). However, this study found a statistical significant and inverse relationship between schoolyard size and pedometer counts. Children in smaller schoolyards were more active with more step counts. The findings from the questionnaires, which included assessment of BMI values showed similar results; children in schools with smaller yards are more active and have lower BMI values.

The schools are considered for the purpose of this study in the small to medium size bracket. The current study questionnaire sample would appear to be representative in terms of school size and regional distribution. Data in the present study indicate that small schools reported more positive physical activity promoting practices than larger schools. Small schools experienced fewer barriers than larger schools specifically with respect to restricted areas, accessibility, supervision, security and availability of play equipments. Small schoolyards may provide more opportunities for mixed and group plays and the limited availability of space may promote children to be more active. Children in small schoolyards all play together, rather than being in separate groups in larger yards. However, these factors were not included in this study, which requires further investigation.

On the other hand, larger schoolyards were more likely to permit children to play on the green areas, which are generally allocated for cars. These schools also permit the free-play of children during recess for security and health reasons; teachers are generally worried about the possible injury of children on vast and vacant yards. Meanwhile in larger schoolyards, children were more likely to engage in group activities. Since these schools lack fixed equipments and playground markings, children stroll around during recess. Barriers in the large yards such as walls, fences and parked cars limit the active behavior of children.

The findings of this study are relevant to Zask et al. (2001)'s results that as schools got larger children became less active. On the other hand, the pedometer measurements of Cardon et al. (2008) and Louie and Chan (2003) indicated that more space per child was found to be associated with more PA during recess; children in schools with large outdoor space were significantly more active than children at schools with smaller outdoor space. The present study would indicate that the comparison of yard sizes exhibit different challenges in relation to play habits, yard organization, and availability of play equipments, crowding, landscaping, maintenance and most importantly effects on physical activity and child health. More research is needed to investigate possible relations between these factors in order to overcome these challenges and to decide whether yard size is influential on child health.

Children who were active during recess had lower BMI values than passive students. This finding is similar with the active school commuters; children who actively commute to school have lower BMI values. The study also found gender and age differences; boys have higher BMI values than girls, and as expected, BMI values rise according to age groups, except 3rd grade students, which have lower BMI values than 2nd grade students. Boys and small children burnt more calorie and fat than girls and older students. More boys were engaged in active behavior than girls and similar findings were consistently reported in 
other studies (Myers et al., 1996; Sallis et al., 2000; Mota et al., 2005; Tudor-Locke et al., 2006; Özdemir and Yilmaz, 2008).

\subsection{Conclusions}

Given the increasing rates of childhood obesity, energy expenditure is a research priority to improve settings promoting more activity. The effect of the built environment on health is a current research agenda and research has found associations between environmental features and physical activity and body mass. However, the examination of physical environments to explain and promote physical activity is an important yet underinvestigated area of research inquiry, and research on health outcomes of the physical environment has been limited by insufficient data regarding the role of the environment.

Many factors contribute to obesity, and the physical environment in particular can have a strong influence on children's opportunities for regular physical activity. Decisions made at the local level regarding planning and design of school environments can have a significant impact on child health. By recognizing these links, communities can help reverse obesity trends and build healthy environments. Young children appear to engage in low levels of physical activity at school. With more than 25 millions of children attending schools in Turkey, it is important to better understand factors inherent in school environment that influence physical activity behaviors of young children.

Major critical factor emerged from this investigation was the spaciousness is not a critical measure for an active behavior as well as for play and learning. Almost all students had complaints about the lack of adequate space for play due to the crowded schoolyard in all recess time. However small spaces may promote more active behavior and public schools with limited space inside the city centers can better develop design guidelines to improve the physical qualities of these yards.

Previous studies have shown the impact of outdoor environments on physical activity and prevention from obesity in various nations, and the recognition of such approach may lead to the advancement of the outdoor school environments. Encouraging students to be active in safe and attractive outdoor environments may be accomplished by careful and systematic landscape designs, but the major concerns are the finance and the maintenance.

The urban environment is not built to suit child needs and to accommodate child play behaviors in a safe environment. The most natural way to be active and to develop healthy attitudes in PA among children is to play outside in a safe and open environment (Caroli et al., 2011), and the school environment is one of the settings to provide safe and healthy environment for children. School setting is a valuable resource contributing improved PA and this type of environment should be studied to find ways of reducing obesity by improving active behavior. Research should include identification of environmental variables of schools contributing to high levels of obesity in children. Schools in neighborhoods with high risks of obesity should be the focus of future studies; those school settings should be re-developed and re-designed to encourage PA in children. 
It is assumed that findings would reinforce the need to provide and support school physical environments related to physical activity. The results of exploratory studies indicate support for the contention that child spaces should be thought of as a part of a viable strategy for health promotion. The hypothesis is that outdoor environments with more natural landscape characteristics are a viable context for health promotion activities such as physical activity.

A conceptual framework should be outlined that addresses the complexity of the relationship between spatial characteristics of outdoor environments and students' physical activity behavior, which should be structured to guide future policy and research.

Active behaviors should be promoted with city planning and infrastructure by creating safe and accessible urban environments. Changes in neighborhood characteristics, adding more parks, safe walking routes and playgrounds and recreational facilities will have positive effects on health of children and adults.

\subsection{Future directions}

Research is needed to develop effective interventions to increase daily physical activity via active commute to school, monitoring daily physical activity behaviors, promoting school activity programs and promoting healthy curriculum and dietary habits. Studies should include more objective measurements of physical activity among different age groups and the specific roles of environmental factors should be defined that are related to preventing childhood obesity (Lobstein et al., 2004). School environment represents a fundamental opportunity for children to gain active lifestyle through the use of spaces that promote active behavior (Pate et al., 2006; Wagner and Kirch, 2006). Schools are ideal places for health promotion by including healthy school programs, curriculums and making availability of daily exercise (Stice et al., 2006; Doak et al., 2006; Brown et al., 2009). Research should include identification of environmental variables of schools contributing to high levels of obesity in children. Schools in neighborhoods with high risks of obesity should be the focus of future studies; those school settings should be re-developed and re-designed to encourage physical activity focusing on minority and disadvantaged groups and communities.

Research should include longitudinal approach to track changes in children's activities, and include sample from rural and remote areas with disadvantaged neighborhoods. Changes in neighborhood characteristics, adding more parks, safe walking routes and playgrounds and recreational facilities will have positive effects on health of children. Promoting physical activity in urban neighborhoods, especially lower income ones, must address concerns about the physical and social environment.

\subsection{Strengths and limitations}

The key strengths of this study are the use of measured height and weight for the calculation of BMI, the objective measurement of the PA by pedometers and the adoption of 
BMI cut-off points for children. This use of objective measurement of PA reduces the bias commonly associated with self-report measures. The sample selected is a good representative of the population; schools were randomly selected according to regions and a considerable number of students were included in the study in each school.

This study was conducted during spring season only, and children were more likely to be outside with active behaviors which resulted with limited variability in the outcomes. Another limitation of our study is the presentation of results from a single time point, which limits the casual directions in the relationships between overweight and well-being. In our study, there may be too many other external factors in the setting - the schoolyards - which are difficult to measure and available to include as independent factors affecting health of children.

As with all questionnaire-based surveys, social desirability bias in the responses is a problem; children may have difficulties in recalling types of behavior they participated in the last two weeks.

Studies that define the casual relationships between environmental interventions and health behaviors with empirical associations usually lack definitions on how and why these variables influence health behaviors, which is one of the limitations of this study.

Based on these limitations, more systematic research is needed on developing strategies to prevent childhood obesity, to find ways in promoting more active behavior and to better design environments for improving child health.

\section{Author details}

Aydın Özdemir

Ankara University, Faculty of Agriculture, Department of Landscape Architecture, Turkey

\section{Acknowledgement}

This study; "Schoolyard Design to Promote Physical Activity: An Exploratory Study" was supported by a grant from the Scientific Research Projects Coordination Unit, Ankara University, Turkey (BAP-09Ö4347001). The author is grateful for the help and support of Mehmet Çorakçı, Gizem Kılınç, Merve Heper and Filiz Uncu who worked with the author in the development and design of this case study.

\section{References}

Aarts, M.J., de Vries, S.I., van Oers, H.A. and Schuit, A.J. (2012). Outdoor play among children in relation to neighborhood characteristics: a cross-sectional neighborhood observation study. International Journal of Behavioral Nutrition and Physical Activity, 17(9), 98. 
Affuso, O., Stevens, J., Catellier, D., McMurray, R.G., Ward, D.S., Lytle, L., et al. (2011). Validity of self-reported leisure-time sedentary behavior in adolescents. Journal of Negative Results in Biomedicine, 10, 2.

Ainslie, P.N., Reilly, T. and Westerterp, K.R. (2003). Estimating human energy expenditure: a review of techniques with particular reference to doubly labelled water. Sports Medicine, 33(9), 683-698.

Aitken, S.C. and Wingate, J. (1993). A preliminary-study of the self-directed photography of middle-class, homeless, and mobility-impaired children. Professional Geographer, 45(1), 65-72.

Alhassan, S., Sirard, J. R. and Robinson, T. N. (2007). The effects of increasing outdoor play time on physical activity in Latino preschool children. International Journal of Pediatric Obesity, 2, 153-158.

Al-Hazzaa, H. (2007). Pedometer-determined physical activity in obese and non-obese boys 8-12 years. Journal of Physiological Anthropology, 26, 459-465.

Altunkaynak, B.Z. and Özbek, E. (2007). Obezite: nedenleri ve tedavi seçenekleri. Dicle Tıp Dergisi, 34(2), 144-149.

American College of Sports Medicine Position Stand. (1998). The recommended quantity and quality of exercise for developing and maintaining cardiorespiratory and muscular fitness, and flexibility in healthy adults. Medicine and Science in Sports and Exercise, 30(6), 975-991.

Anderson, P.M. and Butcher, K.E. (2006). Childhood obesity: trends and potential causes. The Future of Children, 16(1), 19-45.

Armstrong, N. and Welsman, J.R. (2006). The physical activity patterns of European youth with reference to methods of assessment. Sports Medicine, 36(12), 1067-1086.

Babbie, E. (2006). The Practice of Social Research. New York: Wadsworth Publishing.

Badland, H. and Schofield, G. (2005). Transport, urban design, and physical activity: an evidence-based update. Transportation Research Part D: Transport and Environment, 10(3), 177-196.

Bailey, D.A. (1995). The role of mechanical loading in the regulation of skeletal development during growth. In: C.J.R. Blimkie and O. Bar-Or (Eds.), New Horizons in Pediatric Exercise Science (pp. 97-108). Champaign, IL: Human Kinetics.

Baranowski, T. and Jago, R. (2005). Understanding the mechanisms of change in children's physical activity programs. Exercise and Sport Sciences Reviews, 33(4), 163-168.

Bassett, D.R. and John, D. (2010). Use of pedometers and accelerometers in clinical populations: validity and reliability issues. Physical Therapy Reviews, 15(3), 135-142.

Bell, J.F., Wilson, J.S. and Liu, G.C. (2008). Neighborhood greenness and 2-year changes in body mass index of children and youth. American Journal of Preventive Medicine, 35(6), 547-553.

Bennett, G.G., McNeill, L.H., Wolin, K.Y., Duncan, D.T., Puleo, E. and Emmons, K.M. (2007). Safe to walk? Neighborhood safety and physical activity among public housing residents. PLoS Medicine, 4(10), e306.

Berenson, G.S. (1986). Evolution of cardiovascular risk factors in early life: perspectives on causation. In: G.S. Berenson (ed.), Causation of Cardiovascular Risk Factors in Children, New York: Raven Press, pp. 1 -26. 
Berlin, J.E., Storti, K.L. and Brach, J.S. (2006). Using activity monitors to measure physical activity in free-living conditions. Physical Therapy, 86(8), 1137-1145.

Biddle, S., Sallis, J.F. and Cavill, N.A. (1998). Young and active? Young People and Health Enhancing Physical Activity: Evidence and Implications. London: Health Education Authority.

Black, M.M. and Krishnakumar, A. (1998). Children in low-income, urban settings: interventions to promote mental health and well-being. American Psychologists, 53(6), 635-646.

Blades, M., Blaut, J.M., Darvizeh, Z., Elguea, S., Sowden, S., Soni, D., Spencer, C., Stea, D., Surajpaul, R. and Uttal, D. (1998). A cross-cultural study of young children's mapping abilities. Transactions of the Institute of British Geographer, 23(2), 269-277.

Bonnefoy, J., Morgan, A., Kelly, M.P., Butt, J. and Bergman, V. (2007). Constructing the evidence base on the social determinants of health: a guide. National Institute for Health and Clinical Excellence. Retrieved on December, 18, 2012. http://www.who.int/social_determinants/knowledge_networks/add_documents/mekn_ final_guide_112007.pdf

Booth, T. and Booth, W. (2003). In the frame: photovoice and mothers with learning difficulties. Disability and Society, 18(4), 431-42.

Branas, C.C., Cheney, R.A., MacDonald, J.M., Tam, V.W., Jackson, T.D. and Ten Have, T.R. (2011). A difference-in-difference analysis of health, safety, and greening vacant urban space. American Journal of Epidemiology, 174(11), 1296-1306.

Brink, L.A., Nigg, C.R., Lampe, S.M., Kingston, B.A., Mootz, A.L. and van Vliet, W. (2010). Influence of schoolyard renovations on children's physical activity: the Learning Landscapes Program. American Journal of Public Health, 100(9), 1672-1678.

Brown, W.J., Bauman, A.E. and Owen, N. (2009). Stand up, sit down, keep moving: turning circles in physical activity research? British Medical Journal, 43(2), 86.

Brug, J., Oenema, A. and Ferreira, I. (2005). Theory, evidence and Intervention Mapping to improve behavior nutrition and physical activity interventions. International Journal of Behavioral Nutrition and Physical Activity, 2(1), 2.

Cardon, G., Van Cauwenberghe, E., Labarque, V., Haerens, L. and De Bourdeaudhuij, I. (2008). The contribution of preschool playground factors in explaining children's physical activity during recess. International Journal of Behavioral Nutrition and Physical Activity, 5(1), 11.

Carnegie, M.A., Bauman, A., Marshall, A.L., Mohsin, M., Westley-Wise, V. and Booth, M.L. (2002). Perceptions of the physical environment, stage of change for physical activity, and walking among Australian adults. Research Quarterly for Exercise and Sport, 73(2), 146-155.

Ceesay, S.M., Prentice, A.M., Day, K.C., Murgatroyd, P.R., Goldberg, G.R., Scott, W. and Spurr, G.B. (1989). The use of heart rate monitoring in the estimation of energy expenditure: a validation study using indirect whole-body calorimetry. British Journal of Nutrition, 61(2), 175-186.

Chao, H.J., Schwartz, J., Milton, D.K. and Burge, H.A. (2003). The work environment and workers' health in four large office buildings. Environmental Health Perspectives, 111(9), 1242. 
Chaput, J.P., Klingenberg, L., Astrup, A. and Sjodin, A.M. (2011). Modern sedentary activities promote overconsumption of food in our current obesogenic environment. Obesity Reviews, 12(5), 12-20.

Chen, K.Y., Janz, K.F., Zhu, W. and Brychta, R.J. (2012). Re-defining the roles of sensors in objective physical activity monitoring. Medicine and Science in Sports and Exercise, 44(1), 13-23.

Cooper, A.R., Wedderkopp, N., Jago, R., Kristensen, P.L., Moller, N.C., Froberg, K., Page, A.S. and Andersen, L.B. (2008). Longitudinal associations of cycling to school with adolescent fitness. Preventive Medicine, 47(3), 324-328.

Cooper-Marcus, C. and Barnes, M. (1999). Healing Gardens: Therapeutic Benefits and Design Recommendations. New York: John Wiley and Sons.

Corder, K., Ekelund, U., Steele, R.M., Wareham, N.J. and Søren Brage, S. (2008). Assessment of physical activity in youth. Journal of Applied Physiology, 105(3), 977-987.

Cradock, A.L., Melly, S.J., Allen, J.G., Morris, J.S. and Gortmaker, S.L. (2007). Characteristics of school campuses and physical activity among youth. American Journal of Preventive Medicine, 33(2), 106-113.

Cunningham, G.O. and Michael, Y.L. (2004). Concepts guiding the study of the impact of the built environment on physical activity for older adults: a review of the literature. American Journal of Health Promotion, 18(6), 435-443.

Dahlgren, G. and Whitehead, M. (1991). Policies and Strategies to Promote Equity in Health. Stockholm : Institute for Future Studies.

Daniels, S.R. (2006). The consequences of childhood overweight and obesity. Future Child, 16(1), 47-67.

Daniels, S.R., Arnett, D.K., Eckel, R.H., Gidding, S.S., Hayman, L.L., Kumanyika, S. and Williams, C.L. (2005). Overweight in children and adolescents pathophysiology, consequences, prevention, and treatment.Circulation, 111(15), 1999-2012.

Darbyshire, P., MacDougall, C. and Schiller, W. (2005). Multiple methods in qualitative research with children: more insight or just more? Qualitative research, 5(4), 417-436.

Davis, A. and Jones, L.J. (1996). Children in the urban environment: an issue for the new public agenda. Health and Place, 2(2), 107-113.

Davison, K.K. and Lawson, C.T. (2006). Do attributes in the physical environment influence children's physical activity? A review of the literature. International Journal of Behavioral Nutrition and Physical Activity, 3(1), 19.

Debus, M. (1990). Handbook for Excellence in Focus Group Research. Washington, DC: Academy for Educational Development.

De Jong, K., Albin, M., Skärbäck, E., Grahn, P., Wadbro, J., Merlo, J. and Björk, J. (2011). Area-aggregated assessments of perceived environmental attributes may overcome single-source bias in studies of green environments and health: results from a crosssectional survey in southern Sweden. Environmental Health, 10(1), 4.

Dietz, W.H. (1998). Health consequences of obesity in youth: childhood predictors of adult disease. Pediatrics, 101(3 Pt 2), 518-525.

Din-Dzietham, R., Liu, Y., Bielo, M.V. and Shamsa, F. (2007). High blood pressure trends in children and adolescents in national surveys, 1963 to 2002. Circulation, 116(13), 14881496. 
Dishman, R.K. and Sallis, J.F. (1994). Determinants and interventions for physical activity and exercise. In: C. Bouchard, R.J. Shephard and T. Stephens (Eds.), Physical Activity, Fitness and Health: International Proceedings and Consensus Statement (pp. 214-238). Champaign, IL: Human Kinetics.

Doak, C.M., Visscher, T.L.S., Renders, C.M. and Seidell, J.C. (2006). The prevention of overweight and obesity in children and adolescents: a review of interventions and programs. Obesity Reviews, 7(1), 111-136.

Dodman, D.R. (2003). Shooting in the city: an autophotographic exploration of the urban environment in Kingston, Jamaica. Area, 35(3), 293-304.

Dyment, J.E. and Bell, A.C. (2007). Active by design: promoting physical activity through school ground greening. Children's Geographies, 5(4), 463-477.

Dyment, J.E., Bell, A.C. and Lucas, A.J. (2009). The relationship between school ground design and intensity of physical activity. Children's Geographies, 7(3), 261-276.

Ebbeling, C.B., Pawlak, D.B. and Ludwig, D.S. (2002). Childhood obesity: public-health crisis, common sense cure. Lancet, 360(9331), 473-482.

Eisenmann, J.C., Laurson, K.R., Wickel, E.E., Gentile, D. and Walsh, D. (2007). Utility of pedometer step recommendations for predicting overweight in children. International Journal of Obesity, 31(7), 1179-1182.

Eiser, C. and Morse, R. (2001). Can parents rate their child's health related quality of life? Results of a systematic review. Quality of Life, 10(4), 347-357.

Eiser, C., Mohay, H. and Morse, R. (2000). The measurement of quality of life in young children. Child: Care, Health and Development, 26(5), 401-414.

Ekelund, U., Sjostrom, M., Yngve, A., Poortvliet, E., Nilsson, A., Froberg, K., Wedderkopp, N. and Westerterp, K. (2001). Physical activity assessed by activity monitor and doubly labelled water in children. Medicine and Science in Sports and Exercise, 33(2), 275-281.

Ellaway, A., Macintyre, S. and Bonnefoy, X. (2005). Graffiti, greenery, and obesity in adults: secondary analysis of European cross-sectional survey. British Medical Journal, 331(7517), 611-612.

Engelbrektsson, P. (2002). Effects of product experience and product presentations in focus group interviews. Journal of Engineering Design, 13(3), 215-221

Ernst, M. P. and Pangrazi, R. P. (1999). Effects of a physical activity program on children's activity levels and attraction to physical activity. Pediatric Exercise Science, 11, 393-405.

Eston, R. G., Rowlands, A. V. and Ingledew, D. K. (1998). Validity of heart rate, pedometry, and accelerometry for predicting the energy cost of children's activities. International Journal of Applied Physiology, 84 (1), 362-371.

Evans, G.W., Wells, N.M. and Moch, A. (2003). Housing and mental health: A review of the evidence and a methodological and conceptual critique. Journal of Social Issues, 59(3), 475-500.

Everett Jones, S., Brener, N.D. and McManus, T. (2003). Prevalence of school policies, programs, and facilities that promote a healthy physical school environment. American Journal of Public Health, 93(9), 1570-1575.

Faulkner, G.E.J., Buliung, R.N., Flora, P.K. and Fusco, C. (2009). Active school transport, physical activity levels and body weight of children and youth: a systematic review. Preventive Medicine, 48(1), 3-8. 
Feng, J., Glass, T.A., Curriero, F.C., Stewart, W.F. and Schwartz, B.S. (2010). The built environment and obesity: a systematic review of the epidemiologic evidence. Health Place, 16(2), 175-190.

Ferreira, I., Van der Horst, K., Wendel-Vos, W., Kremers, S., Van Lenthe, F.J. and Brug, J. (2007). Environmental correlates of physical activity in youth: a review and update. Obesity Reviews,8(2), 129-154.

Fjörtoft, I., Kristoffersen, B. and Sageie, J. (2009). Children in schoolyards: tracking movement patterns and physical activity using global positioning system and heart rate monitoring. Landscape Urban Planning, 93(3-4), 210-217.

Fjörtoft, I., Lofman, O. and Halvorsen Thoren, K. (2010). Schoolyard physical activity in 14year-old adolescents assessed by mobile GPS and heart rate monitoring analyzed by GIS. Scandinavian Journal of Public Health, 38(5), 28-37.

Flavia, B., Meyer, U., Niederer, I., Ebenegger, V., Marques-Vidal, P., Granacher, U. and Koebnick, C. (2010). Socio-cultural determinants of adiposity and physical activity in preschool children: A cross-sectional study. BMC Public Health, 10.

Frank, L., Schmid, T., Sallis, J., Chapman, J. and Saelens, B. (2005). Linking objectively measured physical activity with objectively measured urban form: findings from SMARTRAQ. American Journal of Preventive Medicine, 28(2S2), 117-125.

Fredriks, A.M., Buuren, S., Van Hirasing, R.A., Wit, J.M. and Verloove-Vanhorick, S.P. (2005). Alarming prevalences of overweight and obesity for children of Turkish, Moroccan and Dutch origin in The Netherlands according to international standards. Acta Paediatrica, 94(4), 496-498.

Frumkin, H. (2002). Urban sprawl and public health. Public Health Reports, 117(3), 201-217.

Gomez, J.E. (2004). Violent crime and outdoor physical activity among inner-city youth. Preventive Medicine, 39, 876-881.

Gordon-Larsen, P., Nelson, M. C., Page, P. and Popkin, B.M. (2006). Inequality in the built environment underlies key health disparities in physical activity and obesity. Pediatrics, 117(2), 417-424.

Handy, S.L., Boarnet, M.G., Ewing, R. and Killingsworth, R. E. (2002). How the built environment affects physical activity. American Journal of Preventive Medicine, 23(2), 6473.

Haug, E., Torsheim, T., Sallis, J. F. and Samdal, O. (2010). The characteristics of the outdoor school environment associated with physical activity. Health Education Research, 25(2), 248-256.

Heelan, K. A., Donnelly, J. E., Jacobsen, D. J., Mayo, M. S., Washburn, R. and Greene, L. (2005). Active commuting to and from school and BMI in elementary school childrenpreliminary data. Child: Care, Health and Development, 31(3), 341-349.

Hind, K. and Burrows, M. (2007). Weight-bearing exercise and bone mineral accrual in children and adolescents: a review of controlled trials. Bone, 40(1), 14-27.

Hinkley, T., Crawford, D., Salmon, J., Okely, A.D. and Hesketh, K. (2008). Preschool children and physical activity: a review of correlates. American Journal of Preventive Medicine, 34(5), 435-441.

Holsten, J.E. (2009). Obesity and the community food environment: a systematic review. Public Health Nutrition, 12(3), 397-405. 
Hoppe, M.J., Wells, E.A., Morrison, D.M., Gillmore, M.R. and Wilsdon, A. (1995). Using focus groups to discuss sensitive topics with children. Evaluation Review, 19(1), 102-14.

Hume, C., Salmon, J. and Ball, K. (2005). Children's perceptions of their home and neighborhood environments, and their association with objectively measured physical activity: a qualitative and quantitative study. Health Education Research, 20 (1), 1-13.

Humpel, N., Owen, N. and Leslie, E. (2002). Environmental factors associated with adults' participation in physical activity: a review. American Journal of Preventive Medicine, 22(3), 188-199.

Iverson, D. C., Fielding, J. E., Crow, R. S. and Christenson, G. M. (1985). The promotion of physical activity in the United States population: the status of programs in medical, worksite, community, and school settings. Public Health Reports, 100(2), 212 - 214.

Janssen, I., Boyce, W. F., Simpson, K. and Pickett, W. (2006). Influence of individual- and area-level measures of socio-economic status on obesity, unhealthy eating, and physical inactivity in Canadian adolescents. American Journal of Clinical Nutrition, 83(1), 139-145.

Janz, K.F., Letuchy, E.M., Gilmore, J.M.E., Burns, T.L., Torner, J.C., Willing, M.C. and Levy, S.M. (2010). Early physical activity provides sustained bone health benefits later in childhood. Medicine and Science in Sports and Exercise, 42(6), 1072.

Kaczynski, A.T. and Henderson, K.A. (2007). Environmental correlates of physical activity: A review of evidence about parks and recreation. Leisure Sciences, 29(4), 315-354

Kaczynski, A.T., Potwarka, L.R. and Saelens, B.E. (2008). Association of park size, distance, and features with physical activity in neighborhood parks. American Journal of Public Health, 98(8), 1451-1456.

King, A.C., Parkinson, K.N., Adamson, A.J., Murray, L., Besson, H., Reilly, J.J. and Basterfield, L. (2011). Correlates of objectively measured physical activity and sedentary behavior in English children. European Journal of Public Health, 21(4), 424-431.

Klesges, L., Baranowski, T., Beech, B., Cullen, K.,Murray, D., Rochon, J. and Pratt, C. (2004). Social desirability bias in self-reported dietary, physical activity and weight concerns measures in 8 to 10-year old African-American girls: results from the Girls Health Enrichment Multisite Studies (GEMS). Preventive Medicine, 38(Supp), 78-87.

Koezuka, N., Koo, M., Allison, K.R., Adlaf, E.M., Dwyer, J.J., Faulkner, G. and Goodman, J. (2006). The relationship between sedentary activities and physical inactivity among adolescents: results from the Canadian Community Health Survey. Journal of Adolescent Health, 39(4), 515-522.

Krueger, R.A. and King, J.A. (1998). Involving Community Members in Focus Groups. SAGE: Thousand Oaks, CA.

Krueger, R.A. and Casey, M. (2000). Focus Groups: A Practical Guide for Applied Research. SAGE: Thousand Oaks, CA.

Lachowycz, K. and Jones, A.P. (2011). Greenspace and obesity: a systematic review of the evidence. Obesity Reviews, 12(5), 183-189.

Lackshman, R., McConville, A., How, S., Flowers, J., Wareham, N. and Cosford, P. (2010). Association between area-level socioeconomic deprivation and a cluster of behavioral risk factors: cross-sectional, population-based study. Journal of Public Health, 33(2), 234245. 
Lambert, E.V. and Goedecke, J.H. (2004). Energy balance and energy expenditure in obesityis obesity a disease of inactivity? South African Journal of Sports Medicine, 15(1), 21-25.

Lavin, T., Higgins, C., Metcalfe, O. and Jordan, A. (2006). Health effects of the built environment. Dublin, Institute of Public Health. Retrieved on December, 18, 2012. http://www.publichealth.ie/publications/healthimpactsofthebuiltenvironmentareview

Lee, A.C. and Maheswaran, R. (2010). The health benefits of urban green spaces: a review of the evidence. Journal of Public Health, 33(2), 212-222.

Lee, M.C., Orenstein, M.R. and Richardson, M.J. (2008). Systematic review of active commuting to school and children's physical activity and weight. Journal of Physical Activity and Health, 5(6), 930-949.

Lee, S.M. and Tudor-Locke, C. (2005). Active versus passive commuting to school: what children say. American Journal of Health Studies, 20(3/4), 212.

Leslie, A., Saelens, B., Frank, L., Owen, N., Baumand, A., Coffee, N. and Hugo, G. (2005). Residents' perceptions of walkability attributes in objectively different neighbourhoods: a pilot study. Health and Place, 11, 227-236.

Liu, G.G., Wilson, J.S., Qi, R. and Ying, R (2007). Green neighborhoods, food retail and childhood overweight: differences by population density. American Journal of Health Promotion, 21(4), 317-25.

Livingstone, M.B.E., Robson, P.J., Black, A.E., Coward, W.A., Wallace, J.M.W., McKinley, M. C. and McKenna, P.G. (2003). An evaluation of the sensitivity and specificity of energy expenditure measured by heart rate and the Goldberg cut-off for energy intake: basal metabolic rate for identifying mis-reporting of energy intake by adults and children: a retrospective analysis. European Journal of Clinical Nutrition, 57(3), 455-463.

Livingstone, M.B., Coward, W.A., Prentice, A.M., Davies, P.S., Strain, J.J., McKenna, P.G. and Kerr, M.J. (1992). Daily energy expenditure in free-living children: comparison of heart-rate monitoring with the doubly-labelled water (2H2 (18) O) method. The American Journal of Clinical Nutrition, 56(2), 343-352.

Lopez R.P. and Hynes, H.P. (2006). Obesity, physical activity and the urban environment: public health research needs. Environmental Health, 5(1), 25-35.

Loprinzi, P.D. and Cardinal, B.J. (2011). Measuring children's physical activity and sedentary behaviors. Journal of Exercise Science and Fitness, 9(1), 15-23.

Lorch, S.M. and Sharkey, A. (2007). Myocardial velocity, strain, and strain rate abnormalities in healthy obese children. Journal of Cardiometabolic Syndrome, 2(1),30-34.

Louie, L. and Chan, L. (2003). The use of pedometry to evaluate the physical activity levels among preschool children in Hong Kong. Early Child Development and Care, 173(1), 97107.

Maas, J., Verheij, R.A., de Vries, S., Spreeuwenberg, P., Schellevis, F.G. and Groenewegen, P.P. (2009). Morbidity is related to a green living environment. Journal of Epidemiology and Community Health, 63(12), 967-973.

Maddison, R. and Ni Mhurchu, C. (2009). Global positioning system: a new opportunity in physical activity measurement. International Journal of Behavioral Nutrition and Physical Activity, 6(1), 73. 
Maller, C., Townsend, M., Pryor, A., Brown, P. and St Leger, L. (2006). Healthy nature healthy people: 'contact with nature' as an upstream health promotion intervention for populations. Health Promotion International, 21(1), 45-54

Marshall, S.J., Levy, S.S., Tudor-Locke, C.E., Kolkhorst, F.W., Wooten, K.M., Ji, M., Macera, C.A. and Ainsworth, B.E. (2009). Translating physical activity recommendations into a pedometer-based step goal: 3000 steps in 30 minutes. American Journal of Preventive Medicine, 36(5), 410-415.

Matthews, H., Limb, M. and Taylor, M. (1998). The geography of children: some ethical and methodological considerations for project and dissertation work. Journal of Geography in Higher Education, 22(3), 311-324.

McGinn, A.P., Evenson, K.R., Herring, A.H., Huston, S.L. and Rodriguez, D.A. (2007). Exploring associations between physical activity and perceived and objective measures of the built environment. Journal of Urban Health, 84(2), 162-184.

McLeroy, K.R., Bibeau, D., Steckler, A. and Glanz, K. (1988). An ecological perspective on health promotion programs. Health Education Quarterly, 15(4), 351-377.

Mendoza, J.A., Watson, K., Nguyen, N., Cerin, E., Baranowski, T. and Nicklas, T.A. (2011). Active commuting to school and association with physical activity and adiposity among US youth. Journal of Physical Activity and Health, 8(4), 488-495.

Mitchell, R. and Popham, F. (2008). Effect of exposure to natural environment on health inequalities: an observational population study. Lancet, 372(9650), 1655-1660.

Mitchell, R., Astell-Burt, T. and Richardson, E.A. (2011). A comparison of green space indicators for epidemiological research. Journal of Epidemiology and Community Health, $10,1-6$.

Mitre, N., Lanningham-Foster, L., Foster, R. and Levine, J.A. (2009). Pedometer accuracy for children: can we recommend them for our obese population? Pediatrics, 123(1), 127-131.

Morgan, M., Gibbs, S., Maxwell, K. and Britten, N. (2002). Hearing children's voices: methodological issues in conducting focus groups with children aged 7-11 years. Qualitative Research, 2(1), 5-20.

Morrow, V. (2001). Using qualitative methods to elicit young people's perspectives on their environments: some ideas for community health initiatives. Health Education Research, 16(3), 255-268.

Mota, J., Silva, P., Santos, M.P., Ribeiro, J.C., Oliveira, J. and Duarte, J.A. (2005). Physical activity and school recess time: differences between the sexes and the relationship between children's playground physical activity and habitual physical activity. Journal of Sports Sciences, 23(3), $269-275$.

O'Dea, J.A. (2003). Why do kids eat healthful food? Perceived benefits of and barriers to healthful eating and physical activity among children and adolescents. Journal of the American Dietetic Association, 103(4), 497-501.

Oliver, M., Schofield, G.M., Grant, M. and Gregory, S. (2007). Physical activity in preschoolers: understanding prevalence and measurement issues. Sports Medicine, 37(12), 1045-1070.

Owen, N., Humpel, N., Leslie, E., Bauman, A. and Sallis, J.F. (2004). Understanding environmental influences on walking: review and research agenda. American Journal of Preventive Medicine, 27, 67-76. 
Owen, N., Leslie, E., Salmon, J. and Fotheringham, M.J. (2000). Environmental determinants of physical activity and sedentary behavior. Exercise and Sport Sciences Reviews, 28(4), 153-158.

Öner, N, Vatansever, Ü. and Sarı, A. (2004). Prevalence of underweight, overweight and obesity in Turkish adolescents. Swiss Medical Weekly, 134, 529-533.

Özdemir, A. (2010). The Authentic Landscape Design of Primary School's Yards. Ankara University Scientific Research Projects Unit, Final Report for the Project No: 09 Ö4347001.

Özdemir, A. and Yilmaz, O. (2008). Assessment of outdoor school environments and physical activity in Ankara's primary schools. Journal of Environmental Psychology, 28(3), 287-300.

Özdemir, A. and Çorakçı, M. (2010). Participation in the greening of schoolyards in the Ankara public school system. Scientific Research and Essays, 5(15), 2065-2077.

Pabayo, R., Gauvin, L. and Barnett, T.A. (2011). Longitudinal changes in active transportation to school in Canadian youth aged 6 through 16 years. Pediatrics, 128(2), 404-413.

Papas, M.A., Alberg, A.J., Ewing, R., Helzlsouer, K.J., Gary, T.L. and Klassen, A.C. (2007). The built environment and obesity. Epidemiologic Reviews, 29(1), 129-143.

Pate, R.R., Pratt, M., Blair, S.N., Haskell, W.L., Macera, C.A., Bouchard, C., et al. (1995). Physical activity and public health. A recommendation from the Centers for Disease Control and Prevention and the American College of Sports Medicine. Journal of the American Medical Association, 273(5), 402-407.

Pate, R.R., O'Neill, J.R., and Lobelo, F. (2008). The evolving definition of 'sedentary'. Exercises and Sport Sciences Reviews, 36(4), 173-178.

Pate, R.R., O'Neill, J.R. and Mitchell, J. (2010). Measurement of physical activity in preschool children. Medicine and Science in Sports and Exercise, 42(3), 508-512.

Pikora, T., Giles-Corti, B., Bull, F., Jamrozik, K. and Donovan, R. (2003). Developing a framework for assessment of the environmental determinants of walking and cycling. Social Science and Medicine, 56(8), 1693-1704.

Potwarka, L.R., Kaczynski, A.T. and Flack, A.L. (2008). Places to play: association of park space and facilities with healthy weight status among children. Journal of Community Health, 33(5), 344-350.

Raitakari, O. T., Taimela, S., Porkka, K. V., Telama, R., Valimaki, I., Akerblom, H. K. and Viikari, J. S. (1997). Association between physical activity and risk factors for coronary heart disease: The Cardiovascular Risk in Young Finns Study. Medicine and Science in Sports and Exercise, 29(8), 1055-1061.

Richardson, E.A. and Mitchell, R. (2010). Gender differences in relationships between urban green space and health in the United Kingdom. Social Science and Medicine, 71(3), 568575.

Ridgers, N.D., Stratton, G., Fairclough, S.J. and Twisk, T.W. (2007). Long-term effects of playground markings and physical structures on children's recess physical activity levels. Preventive Medicine, 44(5), 393-397. 
Ridgers, N.D., Stratton, G., Clark, E., Fairclough, S.J. and Richardson, D.J. (2006). Day-to-day and seasonal variability of physical activity during school recess. Preventive Medicine, 42(5), 372-374.

Ridgers, N.D., Stratton, G. and Fairclough, S.J. (2006). Physical activity levels of children during school playtime. Sports Medicine, 36(4), 359-371.

Rivkin, M. (1997). The schoolyard habitat movement: What it is and why children need it. Early Childhood Education, 25(1), 61-66.

Roemmich, J.N., Epstein, L.H., Raja, S., Yin, L., Robinson, J. and Winiewicz, D. (2006). Association of access to parks and recreational facilities with the physical activity of young children. Preventive Medicine, 43(6), 437-441.

Rosenberg, D.E., Sallis, J.F., Conway, T.L., Cain, K.L. and McKenzie, T.L. (2006). Active transportation to school over 2 years in relation to weight status and physical activity. Obesity, 14(10), 1771-1776.

Rowland, T.W. (1990). Exercise and Children's Health. Champaign, IL: Human Kinetics.

Rowlands, A.V. and Eston, R.G. (2007). The measurement and interpretation of children's physical activity. Journal of Sports Science and Exercise, 6, 270-276.

Rowlands, A.V., Eston, R.G. and Ingledew, D.K. (1997). Measurement of physical activity in children with particular reference to the use of heart rate and pedometry. Sports Medicine, 24, 258-272.

Saegert, S. (1982). Environments and children's mental health: residential density and low income children. In: A. Baum and J.E. Singer (Eds.), Handbook of Psychology and Health (pp. 247-271). Hillsdale, NJ: Erlbaum.

Saelens, B.E., Sallis, J.F., Black, J.B. and Chen, D. (2003). Neighborhood-based differences in physical activity: an environment scale evaluation. American Journal of Public Health, 93(9), 1552-1558.

Saelens, B.E., Sallis, J.F. and Frank, L.D. (2003). Environmental correlates of walking and cycling: findings from the transportation, urban design, and planning literatures. Annals of Behavioral Medicine, 25(2), 80-91.

Sallis, J.F., Hovell, M.F., Hofstetter, C.R., Elder, J.P., Hackley, M., Caspersen, C.J. and Powell, K.E. (1990). Distance between homes and exercise facilities related to the frequency of exercise among San Diego residents. Public Health Reports, 105(2), 179-185.

Sallis, J.F., Nader, P., Broyles, S., Berry, C., Elder, J., McKenzie, T. and Nelson, J. (1993). Correlates of physical activity at home in Mexican-American and Anglo-American preschool children. Health Psychology, 12(5), 390-400.

Sallis, J.F. and Owen, N. (1997). Ecological models. In: K. Glanz, F.M. Lewis and B.K. Rimer (Eds.), Health Behavior and Health Education: Theory, Research and Practice (pp.403-424). San Francisco: Jossey-Bass.

Sallis, J.F., Bauman, A. and Pratt, M. (1998). Environmental and policy interventions to promote physical activity. American Journal of Preventive Medicine, 15(4), 379-397.

Sallis, J.F. and Owen, N. (1999). Physical Activity and Behavioral Medicine. Thousand Oaks, CA: Sage Publications.

Sallis, J.F., Judith P. and Wendell, T. (2000). A review of correlates of physical activity of children and adolescents. Medicine and Science in Sports and Exercise, 32(5), 963-75. 
Sallis, J.F., Conway, T.L., Prochaska, J.J., McKenzie, T.L., Marshall, S.J. and Brown, M. (2001). The association of school environments with youth physical activity. American Journal of Public Health, 91(4), 618.

Sallis, J.F., McKenzie, T.L., Conway, T.L., Elder, J.P., Prochaska, J.J., Brown, M., et al. (2003). Environmental interventions for eating and physical activity - a randomized controlled trial in middle schools. American Journal of Preventive Medicine, 24(3), 209-217.

Sallis, J.F., Saelens, B.E., Frank, L.D., Conway, T.L., Slymen, D.J., Cain, K.L., et al. (2009). Neighborhood built environment and income: examining multiple health outcomes. Social Science and Medicine, 68(7), 1285-1293.

Sallis, J.F., Taylor, W.C., Dowda, M., Freedson, P.S. and Pate, R.R. (2002). Correlates of vigorous physical activity for children in grades 1 through 12: comparing parentreported and objectively measured physical activity. Pediatric Exercise Science, 14(1), 3044.

Sallis, J.F., Kraft, K., Cutter, C.L., Kerr, J., Weitzel, J. and Wilson, A. (2009). The active living research program. American Journal of Preventive Medicine, 36(2), 10-21.

Sharples, M., Davison, L., Thomas, G. and Rudman, P. (2003). Children as photographers: an analysis of children's photographic behavior and intentions at three age levels. Visual Communication, 2(3), 303-30.

Shaw, M. (2004). Housing and public health. Annual Review of Public Health, 25, 397-418.

Shultz, S.P., Browning, R.C., Schutz, Y., Maffeis, C. and Hills, A.P. (2011). Childhood obesity and walking: guidelines and challenges. International Journal of Pediatric Obesity, 6(5-6), 332-341.

Singh, A., Uijtdewilligen, L., Twisk, J.W., Van Mechelen, W. and Chinapaw, M.J. (2012). Physical activity and performance at school: a systematic review of the literature including a methodological quality assessment. Archives of Pediatrics and Adolescent Medicine, 166(1), 49-55.

Sirard, J. and Pate, R. (2001). Physical activity assessment in children and adolescents. Sports Medicine, 31(6), 439-454.

Spurr, G.B., Prentice, A.M., Murgatroyd, P.R., Goldberg, G.R., Reina, J.C. and Christman, N.T. (1988). Energy expenditure from minute-by-minute heart-rate recording: comparison with indirect calorimetry. American Journal of Clinical Nutrition, 48(3), 552559.

Stice, E., Shaw, H. and Marti, C.N. (2006). A meta-analytic review of obesity prevention programs for children and adolescents: the skinny on interventions that work. Psychological Bulletin, 132(5), 667-691.

Stigsdotter, U.K., Ekholm, O., Schipperijn, J., Toftager, M., Kamper-Jørgensen, F. and Randrup, T.B. (2010). Health promoting outdoor environments: associations between green space, and health, health-related quality of life and stress based on a Danish national representative survey. Scandinavian Journal of Public Health, 38(4), 411-417.

Story, M., Kaphingst, K.M. and French, S. (2006). The role of schools in obesity prevention. Future of Children, 16(1), 109-142.

Stratton, G. and Mullan, E. (2005). The effect of multicolor playground markings on children's physical activity level during recess. Preventive Medicine, 41, 828-833. 
Strong, W.B., Malina, R.M., Blimkie, C.J., Daniels, S.R., Dishman, R.K., Gutin, B., Hergenroeder, A.C., Must, A., Nixon, P.A., Pivarnik, J.M. et al (2005). Evidence based physical activity for school-age youth. Journal of Pediatrics, 146(6), 732-737.

Strong, K.A., Parks, S.L., Anderson, E., Winett, R. and Davy, B.M. (2008). Weight gain prevention: identifying theory-based targets for health behavior change in young adults. Journal of the American Dietetic Association, 108(10), 1708-1715.

Stucky-Ropp, R. and DiLorenzo, T.M. (1993). Determinants of exercise in children. Preventive Medicine, 22(6), 880-889.

Sugiyama, T., Leslie, E., Giles-Corti, B. and Owen, N. (2008). Associations of neighborhood greenness with physical and mental health: do walking, social coherence and local social interaction explain the relationships? Journal of Epidemiology and Community Health, 62(5), e9.

Şimşek, F., Ulukol, B., Berberoğlu, M. and Gülnar, S.B. (2005). Ankara'da bir ilköğretim okulu ve lisede obezite sıklığı. Ankara Üniversitesi Tıp Fakültesi Dergisi, 58, 163-166.

Takano, T., Nakamura, K. and Watanabe, M. (2002). Urban residential environments and senior citizens' longevity in megacity areas: the importance of walkable green spaces. Journal of Epidemiology and Community Health, 56(12), 913-918.

Teixeira, P.J., Sardinha, L.B., Going, S.B. and Lohman, T.G. (2001). Total and regional fat and serum cardiovascular disease risk factors in lean and obese children and adolescents. Obesity Research, 9(8), $432-442$.

Tranter, P.J. and Malone, K. (2004). Geographies of environmental learning: an exploration of children's use of school grounds. Children's Geographies, 2(1), 131-155.

Trudeau, F. and Shepherd, R.J. (2005). Contribution of school programs to physical activity levels and attitudes in children and adults. Sports Medicine, 35(2), 89-105.

Trost, S.G., Pate, R.R., Freedson, P.S., Sallis, J.F. and Taylor, W.C. (2000). Using objective physical activity measures with youth: how many days of monitoring are needed? Medicine and Science in Sports and Exercise, 32(2), 426-431.

Trost, S.G., Kerr, L.M., Ward, D.S. and Pate, R.R. (2001). Physical activity and determinates of physical activity in obese and non-obese children. International Journal of Obesity, 25(6), 822-829.

Trost, S.G., Owen, N., Bauman, A.E., Sallis, J.F. and Brown, W. (2002). Correlates of adults' participation in physical activity: review and update. Medicine and Science in Sports and Exercise, 34(12), 1996-2001.

Tudor-Locke, C.E. and Bassett, D.R. (2004). How many steps are enough? Pedometerdetermined physical activity indices. Sports Medicine, 34(1), 1-8.

Tudor-Locke, C., Craig, C.L., Beets, M.W., Belton, S., Cardon, G.M., Duncan, S., Hatano, Y., Lubans, D.R., Olds, T.S., Raustorp, A. et al. (2011). How many steps/day are enough? for children and adolescents. International Journal of Behavioral Nutrition and Physical Activity, 8(1), 78.

Uğuz, M. and Bodur, S. (2007). Konya il merkezindeki ergenlik öncesi ve ergen çocuklarda aşırı ağırlık ve şişmanlık durumunun demografik özelliklerle ilişkisi. Genel Tıp Dergisi, 17(1), 1-7. 
Uluocak, N., Parlaktaş, B.S., Erdemir, F. and Çağlar, M.N. (2006). Sağlıklı okul çağ çocukalrında böbrek boyutlarının vücut kitle indeksi ve cinsiyet ile olan ilişkisi. Çocuk Ürolojisi, 32(3), 370-374.

Van Emmerik, N.M., Renders, C.M., van deVeer, M., van Buuren, S., van der Baan-Slootweg, O.H., Kist-van Holthe, J.E. and Hirasing, R.A. (2012). High cardiovascular risk in severely obese young children and adolescents. Archives of Disease in Childhood, 97(9), 818-821.

Van Lenthe, F., Brug, J. and Mackenbach, J. (2005). Neighborhood inequalities in physical inactivity: the role of neighborhood attractiveness, proximity to local facilities and safety in the Netherlands. Social Science and Medicine, 60(4), 763-775.

Van Mechelen, W., Twisk, J.W., Post, G.B., Snel, J.A.N. and Kemper, H.C. (2000). Physical activity of young people: The Amsterdam Longitudinal Growth and Health Study. Medicine and Science in Sports and Exercise, 32(9), 1610-1616.

Van Sluijs, E.M., Jones, N.R., Jones, A.P., Sharp, S.J., Harrison, F. and Griffin, S.J. (2012). School-level correlates of physical activity intensity in 10-year-old children. International Journal of Pediatric Obesity, 6(2Part2), 574-581.

Vaughn, S., Schumm, J.S. and Sinagub, J. (1996). Use of focus groups with children and adolescents. In: J.M. Sinagub, S. Vaughn and J.S. Schumm (Eds.), Focus Group Interviews in Education and Psychology (pp. 128-142). Thousand Oaks, CA: Sage.

Verstraete, S.J., Cardon, G.M., De Clercq, D.L.R. and De Bourdeaudhuij, I.M.M. (2006). Increasing children's physical activity levels during recess periods in elementary schools: the effects of providing game equipment. European Journal of Public Health, 16(4), 415-419.

Veugelers, P.J., Sithole, F., Zhang, S. and Muhajarine, N. (2008). Neighborhood characteristics in relation to diet, physical activity and overweight of Canadian children. International Journal of Pediatric Obesity, 3(3), 152-159.

Veugelers, P.J. and Fitzgerald, A.L. (2005). Prevalence of and risk factors for childhood overweight and obesity. Canadian Medical Association Journal, 173(6), 607-613.

Vincent, S.D. and Pangrazi, R.P. (2002). An examination of the activity patterns of elementary school children. Pediatric Exercise Science, 14(4), 432-441.

Vita, P. and Owen, N. (1995). A perspective on the behavioral epidemiology: the determinants and the stages of exercise involvement. Australian Psychologist, 30(2), 135140.

Wabitsch, M. (2000). Overweight and obesity in European children and adolescents: causes and consequences, treatment and prevention: an introduction. European Journal of Pediatrics, 159(3), 8-13.

Wang, C. and Burris, M.A. (1997). Photovoice: concept, methodology, and use for participatory needs assessment. Health Education and Behavior, 24(3), 369-387.

Weick, K.E. and Quinn, R.E. (1999). Organizational change and development. Annual Review of Psychology, 50(1), 361-386.

Weinsier, R.L., Hunter, G.R., Heini, A.F., Goran, M.I. and Sell, S.M. (1998). The etiology of obesity: relative contribution of metabolic factors, diet, and physical activity. American Journal of Medicine, 105(2), 145-150. 
Wechsler, H., Devereaux, A.B., Davis, M. and Collins, J. (2000). Using the school environment to promote physical activity and healthy eating. Preventive Medicine, 31(2), 121-137.

Welk, G.J. (2002). Physical Activity Assessments for Health-Related Research. Champaign, IL: Human Kinetics Publishers.

Welk, G.J., Corbin, C.B. and Dale, D. (2000). Measurement issues in the assessment of physical activity in children. Research Quarterly for Exercise and Sport, 71, 59-73.

Wells, N.M. and Evans, G.W. (2003). Nearby Nature: A Buffer of Life Stress among Rural Children. Environment and Behavior, 35(3), 311-330

Wells, N.M. and Yang, Y. (2008). Neighborhood design and walking: a quasi-experimental longitudinal study, American Journal of Preventive Medicine, 34(4), 313-318.

Wendel-Vos, W., Droomers, M., Kremers, S., Brug, J. and Van Lenthe, F. (2007). Potential environmental determinants of physical activity in adults: a systematic review. Obesity reviews, 8(5), 425-440.

Wendel-Vos, G.C., Schuit, A.J., de Niet, R., Boshuizen, H.C., Saris, W.H. and Kromhout, D. (2004). Factors of the physical environment associated with walking and bicycling. Medicine and Science in Sports and Exercise, 36, 725-730.

Wheeler, B.W., Cooper, A.R., Page, A.S. and Jago, R. (2010). Greenspace and children's physical activity: A GPS/GIS analysis of the PEACH project. Preventive Medicine, 51(2), 148-152.

Whitehouse, S., Varni, J.W., Seid, M., Cooper-Marcus, C., Ensberg, M.J., Jacobs, J.R. and Mehlenbeck, R.S. (2001). Evaluating a children's hospital garden environment: utilisation and consumer satisfaction. Journal of Environmental Psychology, 21, 301-314.

Whitt, M.C., DuBose, K.D., Ainsworth, B.E. and Tudor-Locke, C. (2004). Walking patterns in a sample of African American, Native American, and Caucasian women: the crosscultural activity participation study. Health Education and Behavior, 31(Suppl 4), 45-56.

Wigle, D.T. (2003). Child Health and the Environment. New York: Oxford University Press.

Young, L. and Barrett, H. (2001). Adapting visual methods: action research with Kampala street children. Area, 33(2), 141-52.

Zask, A., Van Beurden, E., Barnett, L.M., Brooks, L.O. and Dietrich, U.C. (2001). Active school playgrounds-myth or reality? Results of the 'Move It Groove It' project. Preventive Medicine, 33(5), 402-408.

Zimring, C., Joseph, A., Nicoll, G. L. and Tsepas, S. (2005). Influences of building design and site design on physical activity: research and intervention opportunities. American Journal of Preventive Medicine, 28(2), 186-193. 


\title{
Integrating Ecosytem Landscapes in Cityscape: Birds and Butterflies
}

\author{
Gökçen Firdevs Yücel \\ Additional information is available at the end of the chapter
}

http://dx.doi.org/10.5772/55753

\section{Introduction}

Today, with the rapid growth of cities, sustainable landscape planning and design are a serious concern, because within the urban context, green areas such as parks, gardens, green belts, and road reserves enable positive human interaction with nature, help maintain natural resources, and form environments that bring in wildlife, including, in particular, birds and butterflies [1]. Such eco-friendly urban gardens increase people's appreciation of nature, which can be a source of pleasure, and also make it possible for the behavior and ecology of these species of wildlife to be studied [2].

In urban environments which are not ecologically designed, the practices of mowing lawns, clipping shrubs and raking up organic material from borders, as well as the widespread use of deadheaded flowers, eliminate food sources, nesting grounds and places of shelter for wildlife. Typically, gardens designed with open populations of birds and butterflies in mind are found in urban and suburban areas, and those with closed populations are found in parks and in public or private lots [3]. These gardens help to create and maintain communities which are essentially urban ecosystems where human beings interact with nature.

Gardens in urban ecosystems may have co-existing bird and butterfly species, although the kinds of vegetation and habitats that various species require, as well as their life cycles, may differ [4]. Australian researchers have noted relationships between endemic vegetation and the presence of endemic bird species (French et al., 2005; Daniels and Kirkpatrick, 2006), and Burghardt et.al. (2009) found larger populations of endemic birds and butterflies in areas designed with endemic landscaping [5].

Birds and butterflies have simple needs: consistent food and water sources, safety, and shelter. It is therefore critical that urban gardens designed to attract them should have 
appropriate vegetation, water features, feeding areas, and also areas where they can take cover from predators and thrive in safety and security.

\subsection{Benefits of bird and butterfly gardening}

The primary benefits of designing bird and butterfly gardens as part of urban ecosystems are, for the wildlife, flower pollination, food sharing, and environmental conservation, as well as public education. Additional benefits for people include pest and weed control, the stress relief provided by the natural environment, and financial gain as a result of the increasing value of eco-friendly property.

\section{Issues in urban ecosytem landscape design}

\subsection{Bird gardens}

\section{Site Selection}

Bird gardens are easy to create, since birds' requirements are flexible; however, they should be open to sunlight as well as have ample areas of shade; and vegetation that affords shelter should be available.

\subsubsection{Criterias for structural design in bird gardens}

Paths

Rigid, linear paths are less attractive to wildlife than natural, organic paths, and animals are attracted to unexpected twists and turns, where they can explore new areas. Organically curved and narrow pathways in a garden make it easy for birds to visit a wide range of shrubs and flowers.

Slopes

Certain kinds of birds forage for food on the ground, and they are attracted to uneven slopes, such as one finds in low, rocky hills where there are fallen trees and underbrush. This environment can be provided for them in the form of rock walls or rock gardens with vegetation covering them.

Water

Liquid water is an essential requirement for birds in the winter months, when natural sources are frozen, and also during the summer, when they use it to cool down [6]. Sources may include bird baths, misters, ponds, waterfalls or streams; but flowing water is safer than the static pool of a traditional bird bath, from where diseases may be spread [7]. Interestingly, birds such as robins, flickers, and hummingbirds are highly attuned to the sound of flowing water, and may hear it even if the source is very small. Robins are particularly attracted to the steady spray from lawn sprinklers [8]. Some plants, such as Hosta spp. and Cornus spp., have concave leaf surfaces where water accumulates, and these are used as baths by small birds, including warblers and hummingbirds. 


\section{Bird baths}

Bird baths are made of various substances, including concrete, metal, ceramic and plastic, and come in various sizes and shapes. A bird bath should be set up at least $4.5 \mathrm{~m}$ away from the feeding station, and near plants or shrubs that afford shelter, since birds do not fly efficiently immediately after bathing. It should also be surrounded by a clearing about three meters in diameter, so that while they are drinking, the birds will have time to escape from approaching predators. Several birds can use a bird bath at the same time if it is at least $60 \mathrm{~cm}$ in diameter; however, the depth of the water in it should not exceed $5 \mathrm{~cm}$. The ideal depth of bath is sloping from $1.25 \mathrm{~cm}-2.5 \mathrm{~cm}$ at the edges, down to between $6 \mathrm{~cm}$ and $7.5 \mathrm{~cm}$ in the middle [9].

\section{Safety and shelter}

Appropriate plants need to be planted in urban gardens, because birds use them as a means of escape or to seek cover from predators, to perch and rest on, to nest in during the summer, and to shelter in during the winter months. In the winter, when the leaves have fallen from other trees, evergreens such as Magnolia spp., Ilex spp., and Rhododenron spp., and conifers such as the juniper tree provide essential shelter. Landscaping features frequented by birds seeking shelter include shade arbors, pergolas, arches, and trellises.

Food

Sources of nutrition must be made available throughout the year; birds are more likely to visit gardens where supplementary food sources are available, especially during the winter [11]. The saps, buds, and seeds of some plants are also used as food sources [10]. Food sources and the times they are sought vary depending on the species: chickadees and nuthatches, for example, tend to eat during daylight hours; some birds eat berries and other fruits from trees and shrubs; others, such as woodpeckers and many songbirds, hunt for insect eggs and larvae in tree trunks and branches [12]. In the case of hummingbirds, there ought to be several feeders available, each at least $180 \mathrm{~cm}$ away from the others; this is because these territorial birds do not share food unless there is competition between large numbers of them, and having several feeders will prevent one hummingbird from dominating the entire garden [13].

\section{Bird garden equipments}

\section{Bird houses}

Bird houses are shelters, usually made of wood or more durable composite materials, that can be set up for birds to nest and roost in. They are quite simple, consisting of four sides, a base or bottom, and an overhanging sloping roof (this should be watertight to prevent rainwater entering); the birds go in and out either through a hole or the front side (if this is left open) under the roof [14]. Bird houses should be fixed to trees, walls or fences, at a height of about $2-5 \mathrm{~m}$, and well insulated to provide shelter; if they are wooden, the walls should be at least $1.5 \mathrm{~cm}$ thick. Holes may be drilled in the bottom to drain out any water that may get in, and these same holes will also provide ventilation. Bird houses should not 
be set up in direct sunlight [15]; they should face northeast-southeast, affording protection from the sun and wet winds [16].

\section{Bird feeders}

Providing food to garden birds at feeding stations with bird feeders can increase urban bird populations in the landscape as a whole [17]. The water in the feeders needs to be changed at least once a week in hot weather, and the feeders need to be washed regularly with soap and hot water [18].

Dead trees (snags)

Birds tend to defend their territories by finding perches, such as dead trees, and using them as singing posts. For this reason, dead trees are particularly useful as supports for bird houses [6].

\subsubsection{Criterias for planting design in bird gardens}

The most useful way to plan a bird garden is to start by finding out which bird species already exist in the area, and which are to be attracted to the birdscape. Each species adapts to different parts of the habitat, depending on its needs, so native vegetation will provide the best types and ranges of food and shelter that the birds need at different times of the year.

For the same reasons, diversity in the vegetation will attract a broader range of bird species: some will be ground foragers, and others bush and shrub feeders; some may prefer nesting at lower levels, and others higher up. The habits of a single species may include using different types and layers of vegetation for feeding, roosting and nesting, and these habits also need to be taken into account.

The landscaping should include trees which afford protection from winds, especially during the winter months - for example, rows of evergreens or a mixture of evergreens and deciduous trees (a 50:50 mix would be ideal); and if the typical winds are northwesterly, the trees should line the north and west sides of the garden. These tall trees will also have the added advantage of attracting birds and providing a high perch for them from which they can look out for any possible danger before descending into the garden [19].

In addition, the landscaping should provide a variety of levels of vegetation to be used as food sources and nesting sites, This can be done by layering in smaller trees and shrubs, such as Malus trees, Rosa, Amelanchier spp., and deciduous Ilex spp., planted in front of the windbreaks created by the taller trees. Perennials and annuals, whose seeds and nectar are an excellent food source, can form yet another layer in front [12]; birds are drawn to the bright colors of wild flowers and fruit, in particular when they are migrating, and Salvia coccinea, Penstemon spp., and Campsis radicans will attract a wide range of species [20].

Another essential part of a good birdscape is grasses, which are resilient, tolerate extremes of heat and dryness as well as the winter cold, and are easily sustainable. Song and game birds that feed at low levels use the grass seeds as a food source, and the blades of grass to 
build nests; dried grasses during the winter also enable them to hide from predators. For successful urban ecosystems to flourish, then, this type of landscape should be increased at the expense of mowed lawn and turf areas, which are unproductive habitats and tend to attract less desirable species, such as Columba livia, the Sturnidae family, the Molothrus genus and Quiscalus quiscula [20]. These turf areas provide little in the way of nutrition or habitable environment, and may also be maintained by fertilizers and pesticides which have a detrimental effect on birds, as well as on other wildlife [7].

There are two main categories of vegetation that are appropriate for bird gardens: nectar plants and fruit plants.

Nectar plants

As for this category of plants, it is essential to have diversity, as each species of bird feeds on different food at different times of the year; at the same time, there should be a sufficient quantity of plant species that produce visible masses of fruit, so these can be recognized by the birds (Table 1). However, this diversity should not extend to exotic trees and shrubs, which can invade and take over endemic habitats.

\section{Fruit plants}

In their natural habitats, birds have a wide variety of fruits to choose from during the year, as different fruits ripen in each season; among the most appealing are: Prunus, Sorbus, Ilex, Amalanchier, Cornus and Juniper. Vines are also a good food source; and they provide nesting sites and shelter for birds (Table 1).

Many bird species are attracted to the fruit of Cornus and Juniper; for example, Cornus florida draws bluebirds, robins, thrushes, and 30 other species. The dogwood tree is colorful in spring, has beautiful leaves in the autumn, and then produces bright red fruit. Junipers, many of which have attractive red bark, can be incorporated practically anywhere in an ecofriendly garden; Juniperus virginiana attracts some 54 bird species, and can tolerate a wide range of environmental conditions (only the female plant bears fruit, but both male and female plants are required for fruit to be produced) [8].

\begin{tabular}{|l|l|l|}
\hline Botanical Name & Birds Attracted & Plant Appeal \\
\hline Trees & $\begin{array}{l}\text { Cardinalidae family, Carduelis pinus, Passerina } \\
\text { caerulea, Parulidae family, Pheucticus } \\
\text { melanocephalus, Pheucticus ludovicianus, Poecile } \\
\text { carolinensis, Sitta europaea, Troglodytes } \\
\text { troglodytes and many others }\end{array}$ & Seeds, nesting \\
\hline Amelanchier spp. & $\begin{array}{l}\text { 40+ species, including genus Ailuroedus, } \\
\text { Cardinalidae family, genus Carduelis, Erithacus } \\
\text { rubecula }\end{array}$ & Fruits \\
\hline Betula nigra & $\begin{array}{l}\text { 35 + species, including songbirds, genus } \\
\text { Bombycilla, Fringilla coelebs, Garrulus } \\
\text { glandarius, genus Junco, Poecile carolinensis }\end{array}$ & $\begin{array}{l}\text { Seeds; flower buds; } \\
\text { insects on foliage }\end{array}$ \\
\hline
\end{tabular}




\begin{tabular}{|c|c|c|}
\hline Botanical Name & Birds Attracted & Plant Appeal \\
\hline Carpinus spp. & $\begin{array}{l}\text { Songbirds, especially Cardinalidae family, } \\
\text { Carduelis carduelis, Passerina caerulea, Pheucticus } \\
\text { melanocephalus, Pheucticus ludovicianus }\end{array}$ & Nutlets; shelter \\
\hline Celtis occidentalis & $\begin{array}{l}48+\text { species, including Erithacus rubecula, Picidae } \\
\text { family and Toxostoma rufum }\end{array}$ & $\begin{array}{l}\text { Fruits ripen in late } \\
\text { summer, nesting; shelter }\end{array}$ \\
\hline Malus spp. & $\begin{array}{l}29+\text { species, including songbirds, Erithacus } \\
\text { rubecula and Picidae family }\end{array}$ & Fruit; nesting site \\
\hline Morus spp. & 40+ species. & $\begin{array}{l}\text { Fruit ripens July- } \\
\text { August; nesting site }\end{array}$ \\
\hline Picea spp. & $\begin{array}{l}\text { 25+ species, including genus Loxia, Sitta europaea, } \\
\text { Poecile carolinensis }\end{array}$ & $\begin{array}{l}\text { Cones; shelter; nesting } \\
\text { site }\end{array}$ \\
\hline Pinus spp. & $\begin{array}{l}\text { Carduelis spinus, Fringilla coelebs, Garrulus } \\
\text { glandarius, Loxia curvirostra, Picidae family and } \\
\text { Sitta europaea }\end{array}$ & $\begin{array}{l}\text { Cones on trees } 10+\text { years } \\
\text { old; shelter; nesting site }\end{array}$ \\
\hline Prunus spp. & $\begin{array}{l}\text { 84+ species, including genus Bombycilla, Passerina } \\
\text { caerulea, Pheucticus melanocephalus, Pheucticus } \\
\text { ludovicianus, Pheucticus ludovicianus, Picidae } \\
\text { family }\end{array}$ & Fruit \\
\hline Quercus spp. & $\begin{array}{l}\text { 60+ species, including Cyanocitta cristata, Picidae } \\
\text { family, Sitta europaea, Toxostoma rufum }\end{array}$ & $\begin{array}{l}\text { Acorns; insects; shelter; } \\
\text { nesting site }\end{array}$ \\
\hline Sorbus spp. & $\begin{array}{l}20+\text { species, including genus Bombycilla, } \\
\text { Erithacus rubecula, Icteridae family, Picidae } \\
\text { family and genus Sialia, Turdus migratorius } \\
\end{array}$ & $\begin{array}{l}\text { Fruit ripens in late } \\
\text { August- September }\end{array}$ \\
\hline $\begin{array}{l}\text { Taxodium } \\
\text { distichum }\end{array}$ & Anatidae family & Seeds; shelter \\
\hline Taxus cuspidata & $\begin{array}{l}\text { Genus Bombycilla, Cardinalidae family, Turdidae } \\
\text { family and many others }\end{array}$ & $\begin{array}{l}\text { Cones; shelter; nesting } \\
\text { site }\end{array}$ \\
\hline Thuja plicata & $\begin{array}{l}\text { Cardinalidae family, Erithacus rubecula, } \\
\text { Passeridae family, Passerina caerulea, Pheucticus } \\
\text { melanocephalus, Pheucticus ludovicianus and } \\
\text { Poecile carolinensis }\end{array}$ & $\begin{array}{l}\text { Cones; shelter; nesting } \\
\text { site }\end{array}$ \\
\hline \multicolumn{3}{|l|}{ Shrubs } \\
\hline Berberis ssp. & Many species & $\begin{array}{l}\text { Berries ripen in fall; } \\
\text { shelter }\end{array}$ \\
\hline Cornus spp. & $\begin{array}{l}\text { 93+ species, including Empidonax minimus, } \\
\text { Picidae family }\end{array}$ & $\begin{array}{l}\text { Fruits ripen in late } \\
\text { summer. }\end{array}$ \\
\hline Cotoneaster spp. & $\begin{array}{l}\text { Genus Ailuroedus, Cardinalidae family, Erithacus } \\
\text { rubecula, Fringillidae family, Garrulus glandarius, } \\
\text { Turdus migratorius and many others }\end{array}$ & Fruit; shelter \\
\hline Crataegus spp. & Bombycilla cedrorum, Cardinalidae family & $\begin{array}{l}\text { Fruits; insects on foliage; } \\
\text { nesting site }\end{array}$ \\
\hline Ilex decidua & $\begin{array}{l}\text { 49+ species including genus Ailuroedus, genus } \\
\text { Bombycilla and Erithacus rubecula }\end{array}$ & $\begin{array}{l}\text { Fruit matures in autumn } \\
\text { and persists through } \\
\text { winter; nesting site }\end{array}$ \\
\hline
\end{tabular}




\begin{tabular}{|c|c|c|}
\hline Botanical Name & Birds Attracted & Plant Appeal \\
\hline Juniperus species & $\begin{array}{l}\text { Bombycilla cedrorum, Coccothraustes vespertinus, } \\
\text { Erithacus rubecula, genus Junco, Melospiza } \\
\text { melodia, Toxostoma rufum, Turdus migratorius, } \\
\text { Spizella passerina }\end{array}$ & $\begin{array}{l}\text { Fruit; shelter; nesting } \\
\text { site }\end{array}$ \\
\hline Rhus typhina & $\begin{array}{l}\text { 98+ species, including genus Colaptes, Erithacus } \\
\text { rubecula, Passeridae family, Picidae family, genus } \\
\text { Pipilo and Thraupidae family }\end{array}$ & $\begin{array}{l}\text { Fruit ripens in August - } \\
\text { September and persists } \\
\text { into spring; shelter }\end{array}$ \\
\hline Ribes spp. & $\begin{array}{l}\text { 98+ species, including Erithacus rubecula, } \\
\text { Passeridae family, genus Pipilo and Thraupidae } \\
\text { family }\end{array}$ & $\begin{array}{l}\text { Fruits ripen in June-July } \\
\text { on female plants }\end{array}$ \\
\hline Rosa spp. & $\begin{array}{l}\text { 42+ species, including genus Bombycilla, Passerina } \\
\text { caerulea, Pheucticus melanocephalus, Pheucticus } \\
\text { ludovicianus and Poecile carolinensis }\end{array}$ & $\begin{array}{l}\text { Fruit ripens in August, } \\
\text { often persisting into } \\
\text { winter, nesting site }\end{array}$ \\
\hline $\begin{array}{l}\text { Rubus } \\
\text { allegheniensis }\end{array}$ & $\begin{array}{l}\text { 149+, including genus Ailuroedus, Picidae } \\
\text { families, genus Tyrannus, Thraupidae family, } \\
\text { Zonotrichia leucophrys and Zonotrichia albicollis }\end{array}$ & $\begin{array}{l}\text { Berries ripen from late } \\
\text { August into fall }\end{array}$ \\
\hline Sambucus spp. & $\begin{array}{l}\text { 120+ species including genus Ailuroedus, genus } \\
\text { Bombycilla, Fringillidae family, Parulidae family, } \\
\text { Picidae family and genus Regulus }\end{array}$ & $\begin{array}{l}\text { Fruit ripens July- } \\
\text { September; nesting site }\end{array}$ \\
\hline Syringa spp. & $\begin{array}{l}\text { Cardinalidae family, Fringilla coelebs and Poecile } \\
\text { carolinensis. }\end{array}$ & Nesting site \\
\hline $\begin{array}{l}\text { Symphoricarpos } \\
\text { orbiculatus }\end{array}$ & $\begin{array}{l}\text { Erithacus rubecula, Poecile carolinensis and } \\
\text { Cardinalidae }\end{array}$ & $\begin{array}{l}\text { Berries ripen in October, } \\
\text { persisting late into } \\
\text { winter }\end{array}$ \\
\hline Viburnum spp. & $\begin{array}{l}\text { Cardinalidae family, Genus Sialia, Mimidae } \\
\text { family }\end{array}$ & $\begin{array}{l}\text { Berries ripen in fall; } \\
\text { nesting site }\end{array}$ \\
\hline
\end{tabular}

Other attracting plants for birds:

Vines: Hedera helix, Lonicera spp., Vitis spp.,

Annuals: Cosmos spp., Helianthus spp., Zinnia spp.,

Perennials: Aster spp., Centaurea cyanus, Echinacea spp.

Grasses: Carex spp., Digitaria spp., Panicum spp.

Water plants: Hosta spp., Polygonum spp., Typha spp.,

Table 1. Bird Garden Plant List $[8,12,28,30]$

\subsection{Butterfly gardens}

"Butterfly gardening" is the term used to describe the development and maintenance of a tract of land as a butterfly habitat. It involves attracting and retaining populations of butterflies, which, apart from their being beautiful, enable plant reproduction through pollination [14] . Butterfly gardening is believed to have begun in England in the 1970s, as an expression of the British love of gardening and nature; the Butterfly World habitat was inaugurated at Coconut Creek in Florida, in the USA, in 1988. 


\section{Site selection}

One factor that affects butterflies' activities is wind; strong winds tend to work against them, so a windbreak will be crucial if the chosen site is an open area. Of course, a site surrounded by trees or houses will not need wind protection [21]; however, the site should not be shaded: butterflies need warmth to fly and most plants preferred by butterflies also thrive in sunlight. The ideal site would have a southern exposure and get no less than six hours of sunlight daily [22].

\section{Climate}

Sunlight is a critical factor, both for flowers and for butterflies. Butterflies can only fly efficiently when their body temperature is about 85-100F. This is why they tend to rest in the early morning on rocks, bricks or gravel paths that have been heated by the sun. When the temperatures rise during the day, they seek out flowers for their nectar, but only in areas where there is warm sunlight.

\subsubsection{Criterias for structural design in butterfly gardens}

The area allocated for a butterfly garden can be as small as a $1.5 \times 3 \mathrm{~m}$ strip of land by a path, or as large as a naturally landscaped garden, but drainage and walkways around the beds of plants must be taken into consideration; materials ranging from boards to railroad ties, rocks, bricks, etc., can be used to create a raised-bed butterfly garden.

\section{Open areas}

Because of their need for warmth in order to fly, butterflies need sunny open areas, and these can be supplied by designing open lawns with groundcover and clover, as well as flat surfaces such as rocks or paving stones for the butterflies to rest on; in addition, the clover will provide nectar for adult butterflies, and help the lawns to grow by fixing soil nitrogen.

\section{Water}

Butterflies are unable to drink directly from open water; instead, they "mud-puddle," which means they take in water from the moist areas near open water. This situation can be catered for by leaving a bowl of wet sand or creating a mud puddle in the garden where the butterflies can drink. [23]. If sand is used, ideally it should be salt-saturated beach sand, because the salt helps the male butterflies produce sperm; an added advantage is that the salt keeps away slugs and snails which attack the butterflies' host plants and kill caterpillars [24]. Adding a few rocks or sticks to the bowl or puddle will allow the butterflies to perch on them while they are drinking, and as the male butterfies need extra sodium in the mating season, a little salt can be added to the puddle [25].

\section{Shelter}

Like most fauna, butterflies need shelter from wind and rain, and will tend to take cover in protected areas [26]. They also tend to feed and lay their eggs in warm areas sheltered from the wind. For these reasons, the design of the butterfly garden might well include a row of 
taller trees or shrubs serving as a windbreak, with another inner layer of tall plants for further protection [23].

Food

Butterflies begin their life cycle as eggs, which are laid on plants and adult hatch into larvae or caterpillars, which first eat their egg shells and then feed on the leaves of their host plant. This is different from the case of the adult butterflies, which feed on primarily on liquid nectar from flowers [27].

Some butterfly larvae, such as tent caterpillars, cutworms, and the tobacco hornworm, are seen as pests; most, however, are not, and emerge as beautiful adult butterflies. It is therefore essential that a butterfly garden have plants which will serve as food for different kinds of butterfly larvae, such as flowering plants with long blooming periods and life cycles covering different months. This diversity will create a source of nutrients for a range of species, and also conceal damaged leaves. In any case, the larvae usually do little harm to plants; they also feed on tree sap, organic detritus and animal waste, and adults are often attracted by fruit which has fallen off plants and lies rotting on the ground.

Rocks

Butterflies tend to sit and warm themselves on rocks that have been heated by the sun.

\section{Fences}

Fences or corner nooks and crannies may be used by butterflies as shelters in strong winds and rainstorms.

Butterfly garden equipments

Butterfly houses

In adverse weather conditions, migrating butterflies usually take shelter in cracks in buildings or trees. A butterfly house is a shelter created specifically to assist migrating and hibernating butterflies by providing them a place to stay.

Wood piles

Wood piles also offer butterflies shelter and a place where they can hibernate [31].

\subsubsection{Criterias for planting design in butterfly gardens}

As noted earlier, in a butterfly garden there should be an appropriate range of plants that will support both the larvae and the adult butterflies [7]. The location of the flowering plants is not simply a matter of aesthetics; they should be planted in clusters, with taller plants in the background and shorter ones in the front, so that the butterflies can have access to the widest possible range of flowers. If the garden is in the middle of an open area, taller plants should be placed in the center and shorter ones at the outer edge, with the shortest flowering plants closer to the center. 
The types of flowering plant selected are also significant, because the sizes and shapes of flowers may determine the kinds of butterflies that visit them: large butterflies like Papilio machaon, for instance, have a tendency to alight on flowers with large compact heads, on which they can rest their bodies while feeding.

The two basic types of plants that butterflies look for are: first, those that provide nectar for food; and second, host plants, on which the females lay their eggs, and which also serve, when the eggs hatch, as food for the caterpillars.

\section{Nectar plants}

The butterfly garden can include a wide range of nectar plants, comprising a mixture of annuals, perennials, herbs, shrubs and endemic wildflowers (Table 2). Such colorful flowering plants are key to attracting and maintaining butterfly populations [32], for when the female finds these food sources, she will deposit her eggs [24].

\section{Host plants}

Having sufficient host plants in the garden will maintain the butterfly population: when the female is ready to lay, she searches for and locates host plants with leaves that the caterpillars will eat when the eggs hatch. Many species of larvae eat only the flowering parts and ignore the leaves; some feed on the leaves [33]; others feed on the reproductive parts of flowers or seeds. Caterpillars typically spend most of their time feeding on their host plant (Table 2); many starve to death if they cannot find the right plant [25]; and in the end, only about $5 \%$ of the $60-150$ eggs the female lays will survive to the adult phase.

\begin{tabular}{|l|l|l|}
\hline Botanical Name & $\begin{array}{l}\text { Butterfly Caterpillar/Larval } \\
\text { Host }\end{array}$ & $\begin{array}{l}\text { Nectar Source/Butterflies } \\
\text { Attracted }\end{array}$ \\
\hline Trees & Satyrium liparops & \\
\hline Amelanchier spp. & $\begin{array}{l}\text { Nymphalis antiopa, N. } \\
\text { Vaualbum; Papilio glaucas, }\end{array}$ & Enodia anthedon \\
\hline Betula spp. & Hesperia comma & \\
\hline Gleditsia triacanthos & Limenitis arthemis & \\
\hline Carpinus spp. & Satyrium calanus & \\
\hline Carya spp. & $\begin{array}{l}\text { Asterocampa celtis, A.clyton; } \\
\text { Libytheana carinenta, } \\
\text { Nymphalis antiopa, Polygonia } \\
\text { interrogationis }\end{array}$ & \\
\hline Celtis occidentalis & Satyrium calanus & \\
\hline Juglans nigra & Papilio glaucas & Enodia anthedon \\
\hline Liriodendron tulipifera & Limenitis, Papilio glaucas & $\begin{array}{l}\text { Limenitis arthemis, Nymphalis } \\
\text { antiopa, Rubidus Hybrid, } \\
\text { Satyrium liparops }\end{array}$ \\
\hline Malus spp. &
\end{tabular}




\begin{tabular}{|c|c|c|}
\hline Botanical Name & $\begin{array}{l}\text { Butterfly Caterpillar/Larval } \\
\text { Host }\end{array}$ & $\begin{array}{l}\text { Nectar Source/Butterflies } \\
\text { Attracted }\end{array}$ \\
\hline Prunus spp. & $\begin{array}{l}\text { Celastrina ladon, genus of } \\
\text { Limenitis, Papilio glaucas, } \\
\text { Satyrium liparops } \\
\end{array}$ & \\
\hline Quercus spp. & Satyrium liparops & \\
\hline Salix spp. & $\begin{array}{l}\text { Satyrium liparops, Limenitis } \\
\text { arthemis, L. archippus, Papilio } \\
\text { glaucas, Nymphalis antiopa, N. } \\
\text { vaualbum }\end{array}$ & $\begin{array}{l}\text { Enodia anthedon, Nymphalis } \\
\text { antiopa }\end{array}$ \\
\hline Tilia spp. & Polygonia interrogationis & \\
\hline Ulmus hybrids & $\begin{array}{l}\text { Nymphalis antiopa, Polygonia } \\
\text { interrogationis, Polygonia c- } \\
\text { album }\end{array}$ & \\
\hline \multicolumn{3}{|l|}{ Shrubs } \\
\hline Buddleja davidii & & $\begin{array}{l}\text { Battus philenor, } \\
\text { Danaus plexippus, } \\
\text { Junonia coenia, } \\
\text { Libytheana carinenta, } \\
\text { Nymphalidae families, } \\
\text { Papilio polyxenes, } \\
\text { Papilio glaucas, Phyciodes tharos, } \\
\text { Pyrgus communis, } \\
\text { Speyeria cybele, Vanessa atalanta }\end{array}$ \\
\hline Cornus sericea spp. & Celastrina ladon & Libytheana carinenta \\
\hline Crataegus spp. & $\begin{array}{l}\text { Limenitis arthemis, Satyrium } \\
\text { liparops }\end{array}$ & \\
\hline Hamamelis virginiana & Celastrina ladon & \\
\hline $\begin{array}{l}\text { Hydrangea paniculata } \\
\text { 'Tardiva' }\end{array}$ & & Danaus plexippus \\
\hline Lantana spp. & & $\begin{array}{l}\text { Papilio glaucas, Papilio troilus } \\
\text { Papilio zelicaon }\end{array}$ \\
\hline Lavandula angustifolia & & $\begin{array}{l}\text { Cupido comyntas, Danaus } \\
\text { plexippus, Papilio machaon }\end{array}$ \\
\hline Lonicera spp. & & $\begin{array}{l}\text { Hesperia comma, Papilio } \\
\text { cresphontes, Papilio glaucas, } \\
\text { Papilio cresphontes }\end{array}$ \\
\hline Rhododendron spp. & & $\begin{array}{l}\text { Battus philenor, Papilio } \\
\text { cresphontes, Papilio cresphontes }\end{array}$ \\
\hline Syringa vulgaris & & $\begin{array}{l}\text { Battus philenor, Danaus } \\
\text { plexippus, Nymphalidae family, } \\
\text { Papilio machaon, }\end{array}$ \\
\hline
\end{tabular}




\begin{tabular}{|l|l|l|}
\hline Botanical Name & $\begin{array}{l}\text { Butterfly Caterpillar/Larval } \\
\text { Host }\end{array}$ & $\begin{array}{l}\text { Nectar Source/Butterflies } \\
\text { Attracted }\end{array}$ \\
\hline Viburnum dentatum & Macroglossum stellatarum & $\begin{array}{l}\text { Polygonia interrogationis, Vanessa } \\
\text { atalanta }\end{array}$ \\
\hline Viburnum lentago & Celastrina ladon & \\
\hline
\end{tabular}

Other attracting plants for butterfly:

Annuals: Antirrhinum spp., Cleome spp., Echium vulgare, Helianthus spp., Tropaeolum majus.

Perennials: Asclepias spp., Aster spp., Carex spp., Centaurea spp., Coreopsis spp., Echinops ritro, Rudbeckia hirta, Solidago spp., Viola odorata, Verbena spp.

Herbs: Anethum graveolens, Artemisia dracunculus, Humulus lupulus, Levisticum officinale, Mentha spp., Origanum vulgare, Salvia officinalis.

Weeds: Boehmeria spp., Plantago spp., Trifolium spp., Urtica spp.

Table 2. Butterfly Garden Plant List [24, 34, 35, 36]

\section{Color}

The flowers selected for a butterfly garden should have a variety of colors [32]. Each butterfly species has its own preferences as regards color, but they usually tend to prefer warm colors such as reds, yellows, and oranges, and especially purple, white, yellow, and pink [27].

\section{Fragrance}

Yet another factor that affects butterflies' choice of habitat is fragrance, which may surpass color in significance [2]. Butterflies' antennae are speckled with thousands of minute holes that absorb scents so intensely that they can pick up the fragrance of flowers up to two miles away. Flowers such as Lavandula, Syringa and Lonicera emit strong scents to attract butterflies for pollination [25], as do the wild flowers that grow in fields, meadows, and beside roads [29].

\subsection{Maintenance of butterfly and bird gardens}

These gardens should be maintained in much the same way as any other flower garden. Applying 5-7.5cm of a coarse wood chip mulch enhances the soil, prevents weed growth, helps the soil to retain moisture, and also provides cover for butterfly pupae and beneficial insects.

The greatest problem for butterfly gardens is the growth of undesirable plants such as weeds and grasses that might crowd out the adult butterflies' nectar plants and the larvae's host plants [3]. During weeding and pruning, care should be taken not to damage or destroy butterfly eggs, which are frequently laid on the undersides of leaves and other parts of host plants [2]. Pesticides should be avoided [25]; organic pest control in the form of insectrepelling plants should be used instead.

\section{Conclusion}

Butterflies and birds, in contrast to most fauna, are not restricted in their habitat to distant natural environments; they live in both rural and urban environments, and their 
populations can easily be increased and maintained with some basic knowledge and organization. Urban ecological environments for them do not need much land; indeed, existing gardens can be modified for this purpose [32].

Urban ecological gardens can be created by carrying out an analysis of the proposed site, and selecting and arranging the planting of appropriate vegetation and other design elements. Birds and butterflies have the same fundamental needs - food, water, safety, and shelter - and these needs can be met through the creation of simple constructions such as water features and feeding stations, as well as through basic procedures that afford protection from predators, and privacy.

There are some design differences in the construction of gardens for birds and those for butterflies: while butterflies need what is provided by particular plants, birds tend to need particular kinds of habitat structures which facilitate sheltering, roosting, nesting, and foodfinding. These structures may range from open plains, to deep woods, to a combination of both [37]. Butterflies prefer, and indeed need, the warmth of the sun, whereas birds make use of both sun and shade. Water features (e.g. the bird bath) are more important for bird gardens than for butterfly gardens, because birds need to drink more to cool themselves.

Food is, of course, important for both birds and butterflies; increasing its availability. will result in larger populations of both in the cityscape [11]. For butterflies, the food source of the host plant is needed for the larval phase, and nectar for the adult. Food sources like berries will attract the birds; fragrant flowers will draw in the butterflies. Certain types of equipment can also enhance the appeal and sustenance provided by both types of urban ecological garden: these include bird houses, feeders and dead trees for bird gardens; and butterfly houses and wood piles for butterfly gardens.

The design and organization of vegetation plays a critical role in both types of garden; in each case the garden should be seen as comprised of three basic areas: the background, middleground and foreground. The background area, comprising purpose-planted trees and shrubs, functions as a windbreak, and also as a backdrop for the flowers. The middleground, comprising clusters of colorful, medium to tall flowers, is the central focus of the garden; and the foreground, with low-growing plants, marks its front boundary. Unmowed areas of gardens where nature is left to itself may have more diverse plant species than are found in mowed areas, and so form better habitats with more food sources. Because adult butterflies are more likely to recognize plant masses than individual plants, there should be relatively more massed vegetation in butterfly gardens than in bird gardens.

In the planning of ecological urban gardens, it should be reiterated that plants that produce seeds, berries, fruit, or nuts tend to attract birds, while fragrant and nectar-producing flowers attract butterflies; and that host plants are also critical for butterflies, especially in the larval period. Nectar plants which also serve as food sources are the main desirable plants for both birds and butterflies. Ecological urban gardens usually contain a mixture of such plants, both endemic and non-endemic [38], and the landscape should be designed to reflect the natural environment. Research indicates that the range of bird species seen in these gardens increases the more endemic plants they contain, and the greater the total plant biomass [39]. 
Today in the cityscape context, landscaping based on ecological principles is increasing in importance, and the successful creation, development and maintenance of sustainable environments requires both the construction of natural habitats, and the attraction to these habitats of compatible and balanced populations of wildlife species. Bird and butterfly gardens are paradigms for the new eco-friendly city.

\section{Author details}

Gökçen Firdevs Yücel

Faculty of Engineering and Architecture, Istanbul Aydin University, Istanbul, Turkey

\section{References}

[1] Lex, Hes and Roy, Tredler. Attracting Birds to Your Garden in Southern Africa, Publisher: Struik Publishers; 2nd Revised edition edition; 2000.

[2] Gochfeld, Michael and Burger, Joanna. Butterflies of New Jersey: A Guide to Their Status, Distribution, and Appreciation, Publisher: Rutgers University Press; 1996.

[3] Shepard, John and Guppy, Crispin. Butterflies of British Columbia: Including Western Alberta, Southern Yukon, the Alaska Panhandle, Washington, Northern Oregon, Northern Idaho, and Northwestern Montana, University of British Columbia Press;2001.

[4] Ortho. Ortho's All About Attracting Hummingbirds and Butterflies, Publisher: Ortho; 1st edition; 2001.

[5] Gaston, Kevin. J.Urban Ecology (Ecological Reviews), Cambridge University Press; 2010.

[6] Kress, Stephen W. Bird Gardens (21st Century Gardening), Publisher: Brooklyn Botanic Garden; 1998.

[7] Livingston, Margaret. Landscape design for attracting wildlife in southwestern urban environments, Proceedings 4th International Urban Wildlife Symposium; 2004.

[8] Zickefoose, Julie. The Bird-Friendly Backyard: Natural Gardening for Birds: Simple Ways to Create a Bird Haven (Rodale Organic Gardening Book), Publisher: Rodale Pr. ; 2001.

[9] Adams, George. Birdscaping Your Garden: A Practical Guide to Backyard Birds and the Plants That Attract Them, Publisher: Rodale Pr; First Edition edition; 1994.

[10] Marinelli, Janet. The Wildlife Gardener's Guide (Brooklyn Botanic Garden All-Region Guides), Publisher: Brooklyn Botanic Garden; 2008.

[11] Fuller, Richard A. and Warren, Philip H.and Armsworth, Paul R. And Barbosa, Olga and Gaston, Kevin J. Garden bird feeding predicts the structure of urban avian assemblages, Diversity and Distributions; 2008, 14, 1, 131-137

[12] Ellis, Barbara W. Attracting Birds and Butterflies (Taylor's Guides), Publisher: Houghton Mifflin (Trade); 1997.

[13] Newfield, Nancy L. Hummingbird Gardens - Attracting Nature's Jewels to Your Backyard, Publisher: W. W. Norton \& Co; 1996. 
[14] Moss, Stephen. The Garden Bird Handbook: How to Attract, Identify and Watch the Birds in Your Garden, New Hollond Publishers(UK); 2006.

[15] Whittley, Sarah and Cole, Dan. The Garden Bird Book, Publisher: New Holland Publishers Ltd; 2006.

[16] Golley, Mark and Moss, Stephen and Daly, Dave. The Complete Garden Bird Book: How to Identify and Attract Birds to Your Garden, New Holland Publishers (UK); 2001.

[17] Fuller, Richard A. and Warren, Philip H.and Armsworth, Paul R.and Barbosa, Olga, and Gaston, Kevin. Garden bird feeding predicts the structure of urban avian assemblages, Biodiversity Research, Diversity and Distributions (Diversity Distrib.) 2008;14, 131-137

[18] Hostetler, Mark E. and Klowden, Gregg and Miller, Sarah Webb and Youngentob Kara N. Landscaping Backyards for Wildlife: Top Ten Tips for Success, University of Florida IFAS Extension; 2012, http://manatee.ifas.ufl.edu/lawn_and_garden/mastergardener/gardening-manatee-style/b/backyard-wildlife-habitats.pdf $\quad$ (accessed 20 January 2013)

[19] Rose, Tui. Green, Healthy \& Thrifty Gardening Helpful Hints: A Practical Guidebook of 1001 Wholesome Living Solutions to Make Life Easier \& Save Money with Safe \& Natural Non-Toxic Tips, CCB Publishing; 2012.

[20] Bender, Kelly Conrad. Texas Wildscapes: Gardening for Wildlife, The Texas A \& M Nature Guides Edition, Texas A\&M University Press; 2009.

[21] Schlicht, Dennis W. and Downey, John C. and Nekola, Jeffrey C. The Butterflies of Iowa, University of Iowa Press; 2007.

[22] Lewis, Alcinda and Buchanan, Steve. Butterfly Gardens: Luring Nature's Loveliest Pollinators to Your Yard (21st Century Gardening), Publisher: Brooklyn Botanic Garden; 2007.

[23] Krischik, Vera. Creating a Butterfly Garden From Butterfly Gardening, Regents of the University of Minnesota; 2012.

[24] Mikula, Rick. Garden Butterflies of North America: A Gallery of Garden Butterflies \& How to Attract Them, Publisher: Willow Creek Press; 2001.

[25] Lamb, S. and Chambers, S. and Allen N. Create a Butterfly Garden, The Wildlife Garden, Oregon State University Extension Service Press; 2002.

[26] Harris, Linda, D. Gardens for Birds, Hummingbirds \& Butterflies (Black \& Decker Outdoor Home), Creative Publishing International, US; illustrated edition edition; 2001.

[27] Barnes, Thomas, G. Gardening for the Birds, The University Press of Kentucky; 1999.

[28] Trees and shrubs that attract birds, http://www.mortonarb.org/?option=com_content\&view=article\&id=868\&Itemid=6 (accessed 20 January 2013)

[29] Malam, John. Grow Your Own Butterfly Farm, Publisher: Raintree; 2012.

[30] Oddie, Bill, Beddard, Roy. The Garden Bird Year: A Seasonal Guide to Enjoying the Birds in Your Garden New Holland Publishers Ltd; 2007. 
[31] Sprenkel, Richard. Getting Started in Butterfly Gardening, Entomology and Nematology Department, Florida Cooperative Extension Service, Institute of Food and Agricultural Sciences, University of Florida, 2005.

http://edis.ifas.ufl.edu/pdffiles/IN/IN56400.pdf (accessed 20 January 2013)

[32] Capinera, John L. Encyclopedia of Entomology, Springer Press; 2008.

[33] Allen, Thomas J. Caterpillars in the Field and Garden - A field guide to the butterfly caterpillar of North America, Oxford University Press; 2005.

[34] Roth, Sally. Attracting Butterflies \& Hummingbirds to Your Backyard: Watch Your Garden Come Alive with Beauty on the Wing (Rodale Organic Gardening Books), Publisher: Rodale Press; 2002.

[35] Shalaway, Scott. Butterflies in the Backyard, Publisher: Stackpole Books; 2004.

[36] Plants that Attract Butterflies, http://www.mortonarb.org/tree-plant-advice/article/889/plants-that-attractbutterflies.html (accessed 20 January 2013)

[37] Lowry, Judith Larner. Gardening With a Wild Heart: Restoring California's Native Landscapes at Home, University of California Press; 2007.

[38] Bauer, Nancy. The California Wildlife Habitat Garden: How to Attract Bees, Butterflies, Birds, and Other Animals, University of California Press; 2012.

[39] Day, Tim D. Bird species composition and abundance in relation to native plants in urban gardens, Hamilton, New Zealand, Notornis;1995, 42, 3, 172-186. 


\title{
Visual Quality Assessment Methods in Landscape Architecture Studies
}

\author{
Mehmet Kıvanç Ak \\ Additional information is available at the end of the chapter
}

http://dx.doi.org/10.5772/55769

\section{Introduction}

In our day, the continuous rise in population density and technological developments make urban life attractive. However, this situation has inevitable negative influences on human factors. The psychological pressure which is a result of these negative influences alienates human from natural life and makes human beings' admirations and expectations different.

The visual problems, which are the reflection of changes in urban landscape design, causes loss of prestige for many settlements and decreases the values of natural-cultural landscape (Coşkun and Kaplan, 2001).

While environmental issues are becoming more and more problematic and the size of green areas is decreasing day by day, the importance of natural resources are comprehended more seriously in today's conditions. Therefore, it can be accepted that the landscape is not just an economic issue but also an aesthetic one to evaluate and discuss about (Erdönmez and Kaptanoğlu, 2007). "Visual quality assessment" becomes an indispensable research topic when landscape is discussed as an aesthetic entity.

This point depends on visual perception and it can be called as "visual quality" in cities and "scenery beauty" in rural areas. Similar to the natural and cultural landscape areas, perceiving a space in recreational areas in terms of visuality influences the active or passive usage of these areas (Polat et al, 2012). Therefore, in order to develop the quality of recreational areas and increase users' satisfaction, specifying users' demographical characteristics is important in studies about "visual quality assessment" in landscape design.

When more than half of the last century is taken into account, landscape quality assessment can be seen as a contest between expert or design approach and public perceptual approach. 
The previous studies mostly developed perception-centred approaches. These studies are usually used in sustainable environmental perception and landscape assessment research. Furthermore, the same studies are developed for public land administration practice. Both approaches put forward the fundamental idea which claims that biophysical characteristics are in interaction with the components of environment, human perception or experience. Landscape quality consists of the relationship between the characteristics of landscape and the influence of these characteristics on the users (Daniel, 2001).

Visual assessment studies focus on evaluating the visual characteristics, locational installation, and social life of a place or a route on a perceptual basis (including all sense organs, especially the eyes) within a functional relationship. These assessments become operative in urban settlements such as a broad place which includes a whole city or a division of a settlement or a route (boulevard, main road, street). The findings from the assessments also shape people's daily life, physical planning and design works (Kaplan and Hepcan, 2004).

This study presents an analysis of quality assessment and assessment approaches in landscape architecture, together with conducting a broad literature review and how the was used in practice. "Landscape quality assessment" studies claim that users' admirations and expectations have an influence on their awareness. Therefore, the studies put forward that landscape should not only be evaluated with design rules, and argue that the users' admirations should also be taken into account together with these rules.

\section{Landscape architecture and visual quality}

It is immensely important to explain what 'landscape' means in order to better analyse the work of 'visual quality assessment' within the profession discipline of landscape architecture. This is because visual quality works can be a research topic for different profession disciplines.

In this context,

- $\quad$ Landscape concept

Landscape is the view which situates in an observable frame and is composed of natural and cultural substances. At the same time, the notion refers to our capacity of how and how much we perceive the materials that surround us and how we setup a relationship with them. Landscapes are the most important aspects in setting up our locational identities. By the help of nature and history, landscapes provide the fundamental interaction amongst human (L.C.A., 2008).

Moreover, the lexical meaning of 'landscape' refers to a scene which comprises the natural beauties of a region or an area. In other words, it refers to the total land form or shape of a region. According to another definition, landscape can be described as a piece of area which is positioned in a certain view frame. It also refers to a composition of all natural and cultural environments within the aforementioned frame (Acar, 2003). 
- Visual quality concept

Even though the literature shows that there are different definitions of visual quality concept in landscape design, it can be argued that the implied concept and the elements that is served for are similar.

Landscape visual quality is simply defined as 'the aesthetical perfection of landscape' (Polat and Önder, 2011). According to Daniel (2001), landscape visual quality is a common product of the observer's psychological (perceptual, cognitive, emotional) process which is in an interaction with apparent (visible) landscape characteristics. According to Kalın (2004), visual quality for an environment has a remarkable perceptual and objective structure as it includes many variables inside of it. Because of this characteristic, 'visual quality' is probably one of the hardest phenomenons that can be analysed and measured in an environment.

In general, visual quality is a concept which shows the degrees of people's opinions and aesthetic admirations about living creatures, objects and the view around them.

- The concept of aesthetic

According to Porteous (1996), the concept of aesthetic originates from the Greek words "aisthanesthai" which means 'to perceive', and "aistheta" which means 'perceivable objects'. The lexical meaning of aesthetic is defined as the knowledge which was derived from senses (Çakc1, 2007).

When its theoretical aspects are taken into account, aesthetics is one of the environmental design criteria which influences the protection and development of the 'landscape visual quality' for an ecological and sustainable landscaping (Kamicaityte and Janusatis, 2004). In this context, researchers' work would become easier by using the analyses on spatial applications. Photographic images and digital drawings are usually used as a method in order to evaluate the environmental quality. Most research projects showed that there are clear similarities between the actual land and the photographs which were employed in the surveys for the users. This means that objective results can be gathered even if the participants in the survey only make comments by looking at the images instead of going to the actual land. In addition to landscape designers and expert resource managers, different professionals such as ecologists, geographers, environmental experts and psychologists also use visual quality assessment in their research projects. Each profession discipline looks for a different method. 'Visual quality assessment' in landscape design are usually named as the perceptual interactivity of people (Lu et al., 2012).

When the approaches on aesthetic perception are considered, it can be seen that different methods were used concerning the studies on 'visual quality assessment'. Table 1 below categorised these approaches in brief.

While the expert approach is particularly powerful in environmental management applications, the approaches which are based on user perception are dominant in research 
projects. Both approaches accept that landscape quality originates from the interaction between the landscape's biological and the observer's perceptual process. The difference between the two approaches is the mutual dominancy of expert and user. In today's approach model, it is internalised that the first two approaches should be applied in parallel. This research, which prefers to evaluate the users' preferences and the experts' ideas together, is preferred more as it allows analysis and investigation in landscape planning and design (Erdönmez and Kaptanoğlu, 2007).

\begin{tabular}{|l|l|}
\hline \multicolumn{1}{|c|}{ APPROACHES } & \multicolumn{1}{c|}{ APPLICATION AREAS } \\
\hline $\begin{array}{l}\text { The evaluation approach which is based on } \\
\text { experts' opinion }\end{array}$ & Environmental management applications \\
\hline $\begin{array}{l}\text { The evaluation approach which is based on } \\
\text { the perception of users. }\end{array}$ & Research projects, academic works, etc. \\
\hline $\begin{array}{l}\text { The visual quality assessment approach } \\
\text { which is based on the convergence of users' } \\
\text { preferences and experts' opinions. }\end{array}$ & $\begin{array}{l}\text { Environmental management applications, } \\
\text { research projects, academic works, etc }\end{array}$ \\
\hline
\end{tabular}

Table 1. The approaches which are used in visual quality assessment studies

\section{Visual quality assessment}

In visual landscape assessments -in accordance with landscape planning, design and management objectives- there are several inventory analysis and assessments for different visual characteristics of landscape (Palmer and Hoffmann, 2000). Systematic visual landscape quality assessment developed and manifested in the second half of the 20th century. It started to be an actor in environmental management and policies, and became a scientific research area with its important literature (Özhancı and Yılmaz, 2011).

In this sense, the fundamental of today's 'visual quality assessment' studies originates from Kevin Lynch who published the book "The Image of the City" in 1960. The factors concerning the production of 'urban images', listed in Lynch's book (1960), light the way for many studies in the field.

Urban landscape is an important concept which mobilises people's joy and emotions, keeps them away from their daily life's stress, and psychologically refreshes them. For this purpose, renovating a city and its environment by a systematic way is only possible by using 'visual quality assessment' studies (Lynch, 1960). In this context, Nasar (1998) emphasised that the users' preferences can be measured in order to designate the likability degree of the elements that people like or not in different sectors of their cities (Chon, 2004).

In order to understand the importance of environment, investigating how people react to different characteristics of the environment is required. Therefore, experts want to know 
whether the salient criteria, which were evaluated by the users, are statistically meaningful or not.

Visual quality studies directly address the users and they have an impact on the users. Therefore, it is important that planners and designers take into account the public opinion before a decision-making process in order to conduct the research in an objective way. According to the current literature, collaborating with the users and providing a good communication with them by employing photomontage and simulation techniques on the users have a positive impact on decision-making process in environmental design (Mahdjoubi and Wiltshire, 2001). It is observed that the visual techniques (photomontage, simulation, etc) that are used in research projects encourage the users' participation in the decision making process. This kind of comparison work lets the participants imagine their living space beforehand which is beneficial for us to perceive the participants' impressions. These impressions gathered from the participants are interpreted together with the experts' views. Accordingly, this provides a more objective evaluation in scientific research about visual quality (Chon, 2004).

The previous research also shows that the planning and design decisions which were supported by simulation and photomontage methods, carried out by the users, are more reliable and practical knowledge (Kaplan and Kaplan, 1989; Nasar, 1988; Nasar 1998; Purcell, 1986; Zube 1980). While Chon (2004) argues that the research related to environmental preference is usually presented with one criterion to the users, Moore (1989) claims that the preference of more than one user supports an interactive view. As a result of the interactivity of users' perception and aesthetics, 'environment' occurs.

Likability represents a psychological construction which includes subjective assessments about environment (Nasar, 1998). Likability includes two types of variables. They are:

- Physical environment,

- User's reaction

According to Lothian (2012), evaluation and mapping works in Australia was conducted by 'National Trust'. In their work, soil-geology, bio-diversity - geomorphology, rivers-lakes and the characteristics which were emphasised by those were analysed. The aim of the analysis was to explore the quality of landscape. However, the biggest shortcoming of their work was the exclusion of the public in the research. Therefore, the studies were by and large unsuccessful.

The method which was used in their studies are summarised in Figure 1 below.

In order to carry out the landscape analysis work in an objective way, the studies should include observation, analysis and synthesis, and these should undergo the cognitive process of human brain. On the other hand -within the scope of assessing qualitative values- visual quality, including the liked and not liked, is an emotional process which consist of people's preferences. Therefore, in this context, the components are analysed and the preferences are evaluated. Lothian's work about 'visual landscape quality' (2012) underlines that the participation of the local users brought more objective results in the Figure 2 below. 


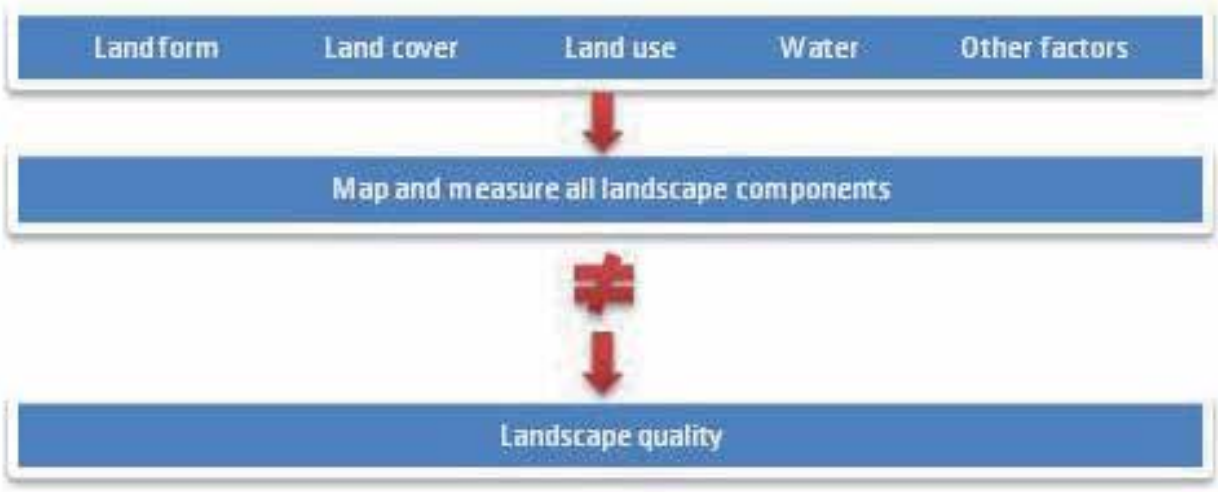

Figure 1. Traditional landscape quality assessment method - the wrong approach (Lothian, 2012). 


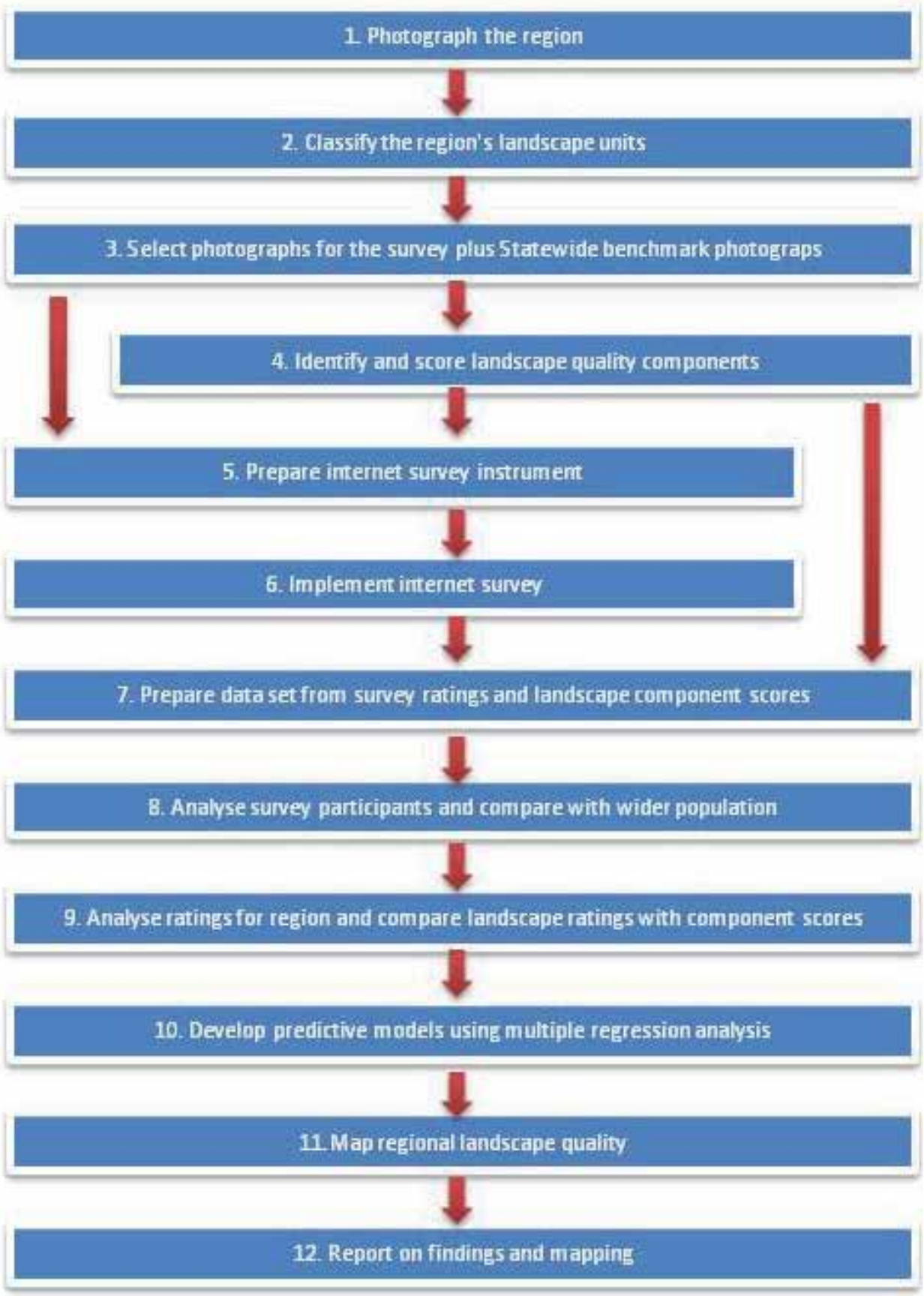

Figure 2. Landscape quality assessment method (Lothian, 2012).

Table 2., illustrates this by showing the influence of familiarity with the Flinders Ranges in South Australia. Being very familiar lifted the average rating for those persons by $12.5 \%$, or 0.8 on the $1-10$ scale. Even being slightly familiar enhanced ratings by $8 \%$ or 0.5 . 


\begin{tabular}{lll} 
Familiarity & Mean & $\%$ \\
\hline Not familiar & 6.07 & 100.0 \\
\hline Slightly familiar & 6.57 & 108.3 \\
\hline Very familiar & 6.83 & 112.5
\end{tabular}

Table 2. Influence of familiarity - Flinders Ranges (Lothian, 2012).

\section{Some of visual quality assessment studies and the employed methods}

Lynch developed a fundamental method which seeks to evaluate the urban form and improve the urban images (Coşkun and Kaplan, 2001). By the distinct model he established, Lynch claimed that any environment has the possibility to create a powerful quality and this was defined as 'imageability'. Lynch worked on this presumption by the quality assignation programme he conducted in the downtowns of Boston, New Jersey and Los Angeles. After these applications, the method proposed by Lynch includes two parallel study. In the first step, the analysed area is scanned and the observations are listed in a report. In parallel with this, a survey is conducted on a group of people which is large enough to represent the general characteristics of the society. The questionnaire includes questions related to important routes and locations. In addition to these two parallel studies, the strong and weak aspects of environment are analysed. In the second step, the important elements selected from another group will be placed, virtual travels will be performed, and the impression of experimental subjects by preparing the rough copies will be presented (Ak, 2010). By preparing a map and a report, the general quality of environment, its visual weakness and powerful aspects, characteristics and changing possibilities were determined.

In their research, Özhanc1 and Yilmaz (2011) focussed on 120 people and conducted a survey about a visual quality analysis of the area they chose. For this purpose, 48 pictures which can represent the area were selected and the participants were asked to evaluate the area in the pictures. Before the questionnaire, the participants were informed about the topic. Accordingly, parameters which are based on perception (naturality, diversity, consistency, openness, mystery, perspective, confidence, order, the beauty of view) and recreation value parameters were used. In the second evaluation step, expert evaluations which focus on landscape characteristics were considered.

In Daniel's (2001) research called "Whither Scenic beauty? Visual landscape quality assessment in the 21st Century", reliability of individual expert evaluations was mentioned. The research found out that the consistency is not stable and different experts have different opinions on the same landscape. Studies in the field do not examine whether the abstract design parameters, which are based on expert evaluations, are related to landscape quality or perception-centred measurements.

In brief, it was not proved that the expert views were completely confidential in visual landscape quality assessments. 
James' (2000) study called "Reliability of Rating Visible Landscape Qualities" looked at the reliability of evaluating the apprehended landscape characteristics by using perception. It was emphasised that the methods which were used in quality assessments should include the evaluation forms (questionnaires) which were approved by visual presentations. Moreover, the requirement to use the pictures while explaining the visual quality criteria was also mentioned.

Bishop and Rohrmann's (2003) study looks at the comparison of actual images and animation images. The study evaluated an actual and an animation view of a park at night and in day time together with the participants' perceptual reactions on these views. The conceptual framework of the study is shown in Figure.3.

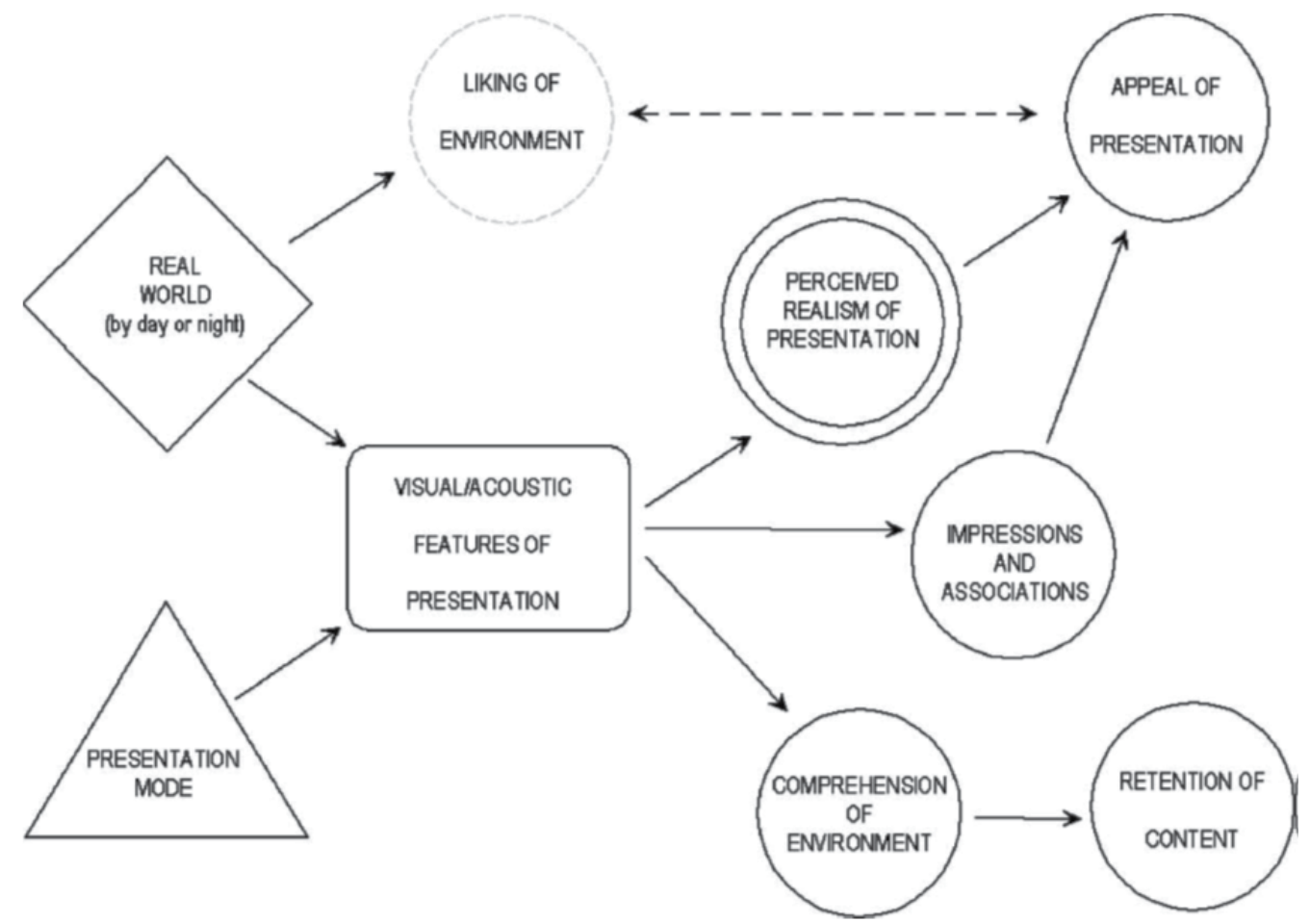

Figure 3. Conceptual framework of the study. Participant responses to the presentations are shown in circles. The presentations are a combination of the actual features of the environment and the chosen means of presentation (Bishop and Rohrmann, 2003).

In another study, Kaltenborn and Bjerke (2002) put forward the relationship between different landscape preferences and the living area. Local people were asked to evaluate the visual aspects of 24 different pictures which show different areas in the local people's area.

Kaplan and Hepcan's (2004) work focuses on visual quality assessments of the places where vehicles and pedestrians' way are used together. The study is based on the physical structure that shapes the location, and the visual analysis and assessment of senses which were gathered from social life. As the perceived senses differentiate during the day because 
of climate, the fieldwork was conducted in İzmir, Turkey where this differentiation clearly appears in June in different times of the day. According to the method, the first section of the study looks at the typology of views which were perceived from important locations. The second section deals with the visual experiences and psychological senses which were gathered on the move and these were transformed into a set of statistical data and then evaluated. Then, the study presented some findings by ranking the values that were gathered in morning, noon and evening time. Finally, comparisons on these different rankings and a discussion were presented.

\section{Conclusion}

Studies on environmental quality assessment developed in the last 50 years. Researchers are active and influential in measuring the locational quality of environment, and preparing reliable visual quality maps about urban and rural environments. The quest for new methods in recent years in research projects shows how much important the visual quality studies are in perceiving the environment.

When 'visual quality assessment' studies are examined, there is no study which accepts the quality among the studies that were conducted only by referring to expert evaluations. Again, no study verified quality among the studies that were conducted only by the evaluations of public/users. In this context, the evaluations of experts and the perceptions and evaluations of public/users should be investigated in order to see how much they are in line with real aesthetic values.

Until recently, the evaluations were mainly about physical characteristics. In recent years, because of the aesthetic concerns on landscape, user-centred method selections were also added to these evaluations. In order to put forward the correct data regarding visual quality assessments, the physical, biological and social characteristics of environment should be considered together.

In particular, as long as expert/design approach continues to be unsuccessful in providing the correct and reliable criteria, the problem of deciding whether this approach is valid or not will be a continuous discussion.

According to most studies, if objective results are expected in 'visual quality assessment' studies, expert's view should not be the only source and the view of people who live in the area should also be taken into account. In this context, the analysis studies which are continuously renewed and corrected provide a basis for the plan which is going to shape the visual configuration of environment in the future.

\section{Author details}

Mehmet Kivanç Ak

Düzce University, Faculty of Forestry, Department of Landscape Architecture, Düzce / Turkey 


\section{References}

Acar, C., 2003. Dağ Ekosistemlerinde Görsel Kalite ve Görsel Kaynak Yönetimi-Ekolojik ve Görsel İndikatörler. Kaçkar Dağları Milli Parkı Çevre Eğitimi, Ayder-Çamlıhemşin, Rize.

Ak, K., 2010. Akçakoca Kıyı Bandı Örneğinde Görsel Kalitenin Belirlenmesi ve Değerlendirilmesi Üzerine Bir Araştırma. Doktora Tezi.Ankara.

Bishop, I.D., Rohrmann, B., 2003. Subjective Responses to Simulated and Real Environments: A Comparison. Landscape and Urban Planning. 65(2003)261-277.

Chon, J.H., 2004. Aesthetic Responses to Urban Greenway Trail Corridors: Implications for Sustainable Development in Tourism and Recreation Settings. Ph.D Thesis. Texas A\&M University.

Coşkun, Ç., Kaplan, A., 2001. Urla (İzmir) Kent Merkezi ve Yakın Çevresi Örneğinde Görsel Etki Değerlendirme Çalışması. Ege Üniversitesi Araştırma Projesi, ZRF-36, İzmir

Çakcı, I., 2007. Peyzaj Planlama Çalışmalarında Görsel Peyzaj Değerlendirmesine Yönelik Bir Yöntem Araştırması. Ankara Üniversitesi Fen Bilimleri Enstitüsü, Doktora Tezi, Ankara.

Daniel, T.C., 2001. Whitherscenic beauty? Visual landscape quality assessment in the 21st century. Landscape and Planning, 54(2001) 267-281.

Erdönmez, M.Ö., Kaptanoğlu, A.Y.Ç., 2007. Peyzaj Estetiği ve Görsel Kalite Değerlendirmesi. İstanbul Üniversitesi Orman Fakültesi Yayınları, Seri B, Cilt 58, Sayı:1, Sayfa:39-51.

James, F.P., 2000. Reliability of Rating Visible Landscape Qualities. Landscape Journal. 19(12):166-178.

Kalın, A., 2004., Çevre Tercih ve Değerlendirmesinde Görsel Kalitenin Belirlenmesi ve Geliştirilmiş: Trabzon Sahil Bandı Örneği. K.T.Ü. Fen Bilimleri Enstitüsü. Doktora Tezi, Trabzon.

Kaltenborn, B.P., Bjerke, T., 2002. Associations Between Landscape Preferences and Place Attachment: A Study in Roros, Southern Norway. Landscape Research, Vol. 27, No:4, 381-396.

Kamicaityte, J.V., Janusatis, R., 2004. Some Methodical Aspects of Landscape Visual Quality Preferences Analysis. Environmental research, engineering and management, ISSN 1392-1649 No.3(29).P.51-60.

Kaplan, A., Hepcan, Ç.C., 2004. Ege Üniversitesi Kampüsü 'Sevgi Yolu'nun Görsel (Etki) Değerlendirme Çalışması. Ege Üniversitesi Ziraat Fakültesi Dergisi. 41(1):159-167 ISSN 1018-8851.

Kaplan, R. Kaplan, S., 1989. Experience of nature. New York: Cambridge University Press.

L.C.A., 2008. Landscape Character Assessment. http://www.landscapecharacter.org.uk. (accessed 12.October.2012).

Lothian, A., 2012. Measuring and Mapping Landscape Quality Using the Community Preferences Method. New Zealand Planning Institute Annual Conference, Blenheim.

Lu, D., Burley, J., Crawford, P., Schutzki, R., Loures, L., 2012. Quantitative Methods in Environmental and Visual Quality Mapping and Assessment: A Muskegon, Michigan 
Watershed Case Study with Urban Planning Implications.Advances in Spatial Planning. ISBN: 978-953-51-0377-6, InTech, DOI: 10.5772/33400.

Lynch, K., 1960. The Image of the City, Twenty First Printing, The MIT Press, USA.

Mahdjoubi, L., Wiltshire, J., 2001. Towards a framework for evaluation of computer visual simulations in environmental design. Design Studies, 22(2), 193-209.

Moore, G.T., 1989. Environmental and behavior research in North America: History, development, and unresolved issues. In D. Stokols \& I. Altman (Eds.), Handbook of environmental psychology (pp.1359-1410). New York: John Wiley.

Nasar, J.L., 1988. Perception and evaluation of residential street scenes. In J.L. Nasar (Ed.), Environmental aesthetics (pp.275-289). Cambridge: Cambridge University Press.

Nasar, J.L., 1998. The evaluative image of the city. Thousand Oaks, CA: Sage Publications.

Nasar, J.L., 1998. The evaluative image of the city. Thousand Oaks, CA: Sage Publications.

Özhanc1, E., Yılmaz, H., 2011. Evaluation of Recreation Areas for Visual Landscape Quality;Sample of Erzurum, Turkey. Iğdır Univ. J. Inst. Sci. \& Tech. 1(2): 67-76.

Palmer, J.F., Hoffman, R.E. 2000. Rating Reliability and Representation Validity in Scenic Landscape Assessment. Landscape and Urban Planning. 54 (2001) 149-161.

Polat, A.T., Güngör, S., Adıyaman, S., 2012. The Relationships between and the Visual Quality of Urban Recreation Areas near by the city of Konya and Demographic Characteristics of their Users KSU J. Nat. Sci., Special Issue.

Polat, A.T., Önder, S., 2011. Konya İli Kent Parklarının Görsel Kalitesinin Belirlenmesi. I. Konya Kent Sempozyumu. 26-27 Kasim.

Porteous, J.D., 1996. Environmental Aesthetics: ideas, politics and planning. Routledge, 290 p., London.

Purcell, A.T., 1986. Environmental perception and affect: A schema discrepancy model. Environment and Behavior, 18(1), 3-30.

Zube, E.H., 1980. Environmental evaluation: Perception and public policy. Monterey, CA: Brooks/Cole. 


\title{
Landscape Design for Children and Their Environments in Urban Context
}

\author{
Habibe Acar \\ Additional information is available at the end of the chapter
}

http://dx.doi.org/10.5772/55751

\section{Introduction}

One of the most important topics of landscape architecture profession is to design highquality open spaces for people to meet their needs and expectation. These open spaces range from smaller-scale residential gardens, used by certain number of people, to large city parks, used by people with different age groups and the crowded masses. These different open spaces and differences in uses lead to changes in the needs and expectations. Therefore, it is necessary to know well about the needs and expectations of people when designing spaces for them.

Children constitute a significant part of users in urban open spaces. Because children's time, spent in open spaces with play during the development, is extremely important and necessary in terms of physical social, emotional, and cognitive aspects. Therefore, nature of the play space is very important. Because, the elements, facilities and quality of a space also affect the quality of the play. As it will be discussed in the following sections of this text, when importance of play for children is considered, the design of open spaces for children becomes an extremely important issue.

Today cities are getting crowded due to the variety of business and social opportunities offered to the people. Due to the increasing population density and intensive construction, open spaces that children can use are decreasing. In this context, introducing new and alternative play spaces and play options are a solution. It is extremely important that designed play areas should be qualified to meet children's needs and desires and to make positive contributions to their development.

This chapter focuses on landscape designs for children, particularly in urban spaces. At this point, the subject will be discussed in terms of landscape design, children, and urban context. First, it will be focused on the general definition of landscape design, interests, and 
the place of children's play areas among them. Second, the concept of play, the relationship of the child with their environment, open spaces, natural areas and their importance, the differences between environmental perceptions of children and adults will be mentioned. Children's needs and expectations in urban open spaces will also be discussed. Third, all of above mentioned issues will be evaluated in terms of urban context with playgrounds examples selected from around the world. Finally, in the light of all this information and assessments, children's expectations from open spaces, design process of children's play areas and considerations to design an ideal playground will be presented.

\section{Landscape design}

"Landscape, originates from French word "paysage" which means scenery. Nowadays, the word encompasses a wider and deeper meaning. While in the medieval period, "landscape" was used as a synonym for "region" and "territory" in most of the Germanic languages, beginning from the 15th century landscape became a pictorial genre. The use of landscape as a term in science is relatively new. Today, landscape refers to not only a phenomenon described and analyzed by scientific methods, but also a subjective experience which has perspective, aesthetical, artistic and existential meaning" (Memlük, 2012).

Design is the creative process of responding to conditions and concentrating meaning; and landscape design is the creation of responsive, evocative, meaningful, sustainable, and regenerative landscapes (Motloch, 2000). In other words "landscape design is the art and science of organizing and enriching outdoor space through the placement of plants and structures in agreeable and useful relationship with the natural environment" (Van Der Zanden and Rodie, 2008, Adapted from the Nebraska Master Gardener Handbook, 1994).

A designer must handle both aesthetics and function at the same time in the designs. Because one cannot exist without the other in quality design (VanDerZanden and Rodie, 2008). Especially, when the area is considered for children, function is more important. Because children evaluate the environment with its functional rather than its esthetical features. The aim of the landscape design is to build up qualified spaces in open areas for people. Open areas that are the interest of landscape design may be urban or rural and private or public. In this article urban landscape will be emphasized. "From a wider perspective, urban landscape is a part of urban matrix. Therefore design of urban landscapes should be considered as an integral part of urban design. Urban landscape design is clearly not urban design, but a crucial part of it. Hence, factors influencing urban design also influence the form and functioning of urban landscapes (Memlük, 2012).

There are lots of spaces, having different functions, that can be subject of landscape design in urban. Some of them may be ranged as urban squares, public gardens, playgrounds, open areas of public institutes such as education, health...etc. and yards. Each of these spaces requires different activity fields according to their users and locations. Among these spaces, children's play areas have an important place because playing in open areas in the childhood period is extremely important for children's healthy development. 


\section{Children}

When designing places for people, the first necessary thing is to know the users of these places. In this way, it would be possible to determine the user's needs and expectations. Places to meet these needs are preferred and used by users. Therefore, design for children requires to know the child, to understand the importance and necessity of play for child, and to know activities children do and want to do especially in public areas.

Play and importance of play for children

When you think of a child, the first thing that comes to mind is play. The play is a concept of universal that extremely important for the development of child's personality. There are many definitions of play in the literature.

According to the Winnicott 'to play is to use imagination, the most important thing a person can do...Play is always an experience of creating, also of uniting time and space- so is fundamental to how we live'(Day and Midbjer, 2007).

Moore (1990) states that "play lies at the heart of childhood, limited in its boundaries only by the opportunities afforded by physical settings and by the attitudes and commitment of those whose business it is to manage them" (Jones, 1997).

According to Piaget, play is not a condition of mental, but is a behavior or action and it causes the child makes effort about what to do. According to him, the play is necessary for the development of intelligence (Piaget and Inhelder, 1971).

Play is a form of behavior which has many definition, description and developmental theories (Piaget and Inhelder, 1971; Jones, 1997). As a result, if we need to briefly mention, the play refers to a unscheduled, spontaneous situation. It is possible to mention the four assumptions about the play (Jones, 1997). These are listed as follows;

1. children learn during the play and play is necessary for the child's development and growth,

2. the play is not limited to younger children, it is an important concept in adults' lifecycle,

3. to play outside is an important need because it offers opportunities not found anywhere else,

4. play environments are educational areas

Children obtain feelings of achievement and self-security, of being together with others, respect for themselves and others as a result of playing the play (Day and Midbjer, 2007).

Play is an extremely important concept in terms of children's rights. The International Play Association (IPA) Declaration of the Child's Right to Play was introduced in November 1977 at the IPA Malta Consultation held in preparation for the International Year of Child (1979) (Clements and Fiorentino, 2004). Play was emphasized that nutrition, health, housing and education, as well as of vital importance for the development potential of each child in this declaration (Yilmaz and Bulut, 2003). 
Experts working on childhood states that the best learning is provided through play and exploration for children (Vicki and Stoecklin, 2004). A child learns and discovers himself and his environment during the play. During the play, children use objects to learn how to use them, perform activities with them and recognize them. Children should change the places of them, create compositions, bring together, separate, take a piece of them, and reinstall the missing part (Piaget and Inhelder, 1971). In this way, children find the opportunity to learn by trying different things. Therefore play is the child's experiment tool.

Benefits of play on the development of children can be classified under two headings. These are; the benefits of playing during the play, the benefits of playing over time. In 1978, Jones and Prescott stated that "through play, children (and bigger people, too) learn a great deal about the variety and complexity of the world, and about themselves as self-directed learners" (Jones and Prescott, in Jones, 1997).

There are also benefits that bring to the play over time, summarized as follows:

- Children gain a sense of freedom and self-confidence

- When a child's respect for other individuals increases, sharing also increases

- Children become an healthy individual both physically and mentally, the learning ability of children develop

\section{- Children's creativity increases}

Recognizing the importance of play and playing game will provide to better understand the importance of play spaces as well. Because the nature of space and its components affects children's play. As we live in an environment that surrounds us, outdoor areas where children play are not possible to think independently from the environment. In this context, the relationship between the child and their environment is important.

\section{Child and Environment}

The physical environment influences everybody's behavior (Proshansky et al., 1976; Day and Midbjer, 2007) and supports the formation of self-identity during childhood years. Children obtain information about environment and interact socially as a result of their experiences in the physical environment. In order to learn about the environment children need actively use and explore the environment. They invest certain meanings and names in special environments for themselves. The importance of these special environments continues through adulthood period. This sense of attachment and meaning of color, smell and texture of special places has been studied by educators and designers (Francis, C. 1997). Studies on this subject and the remaining images in the minds of children about their environment can be evaluated in future play space design.

Individuals' motivation, behavior and mental health are affected between individual characteristics from the environment and the characteristics of the environment (Özdemir and Yilmaz, 2008). When we look at it in terms of children, if an environment meets the psychological needs of children, it provides satisfaction, if it does not meet, it provides dissatisfaction. In addition, motion is required in order the children get to know a place and to explore it. "Before they can locomote or move from place to place (crawl, walk, run, etc.) 
independently, infants are interested in many of things that fall within their reach" (Bell, 2008). Environments that offer opportunity for movement and that offer diversity for children are more preferred. At the same time, as this kind of environment will provide an opportunity to explore, it will make positive contributions to the development of children.

Studies on children's needs and the experiences in the environment can be found in the environmental psychology literature (Spencer and Woolley, 2000). Environmental psychology is a branch of discipline developed by Proshansky, Rivlin and Ittelson. This interdisciplinary work area includes specific research topics such as perception, cognition and social learning in the relationship between the environment and human (Loebach, 2004). In the field of environmental psychology, the best concept to assessment the child's relationship with the environment, the opportunities presented by the environment and its elements is "affordance" theory. Affordance generally refers to functional facilities offered by the environment. Firstly, it has been developed by James J. Gibson in the late 1970 's. Later, the concept of affordance used to identify children's environment's opportunities by many researchers particularly in Harry Heft (1988) and Marketta Kyttä (2002, 2003, 2004) (Loebach, 2004; Clark and Uzzell, 2008; Acar, 2009). Functional possibilities offered by the environment create opportunities for different activities for children (figure 1, 2, 3).

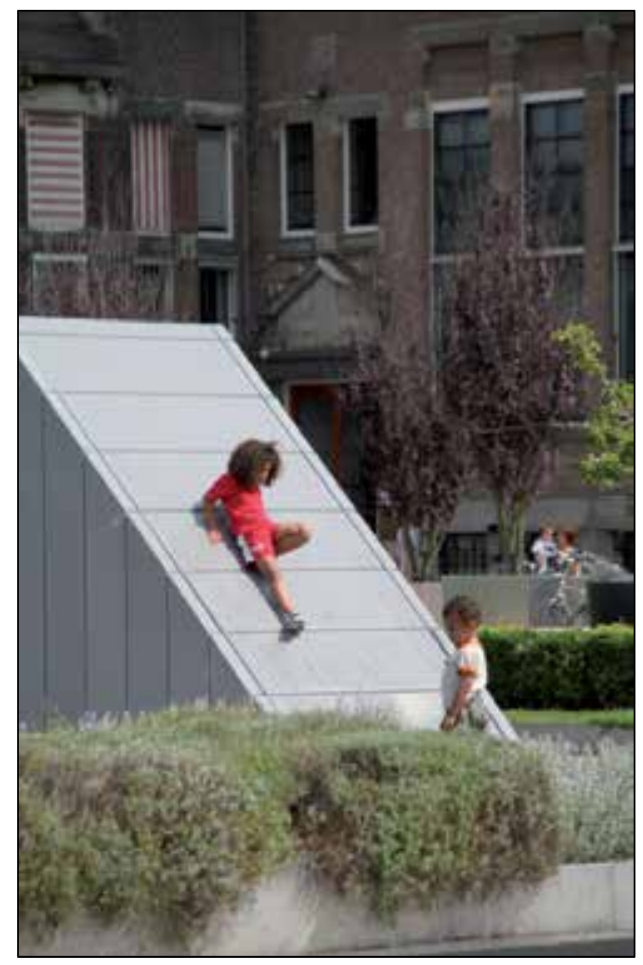

Figure 1. Sloping surfaces in any area are used to slide by children (Photo Acar, H., Rotterdam, Netherland). 


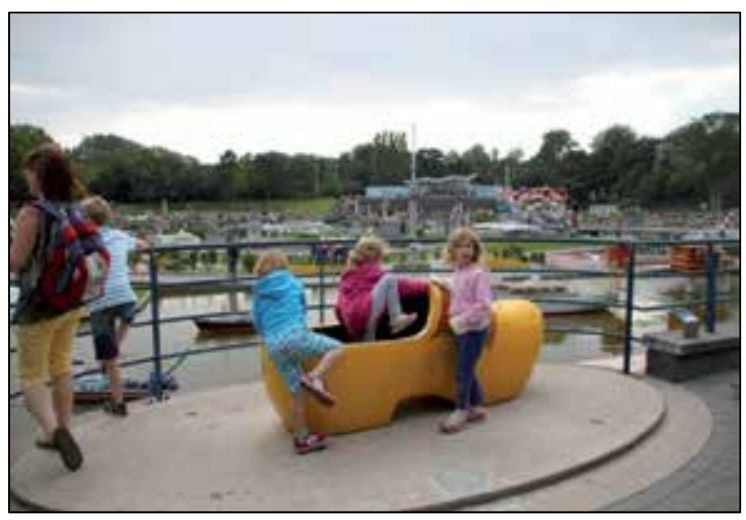

Figure 2. Any object that children can enter might be a play space for them (Photo Acar, H., Den Haag, Netherland).

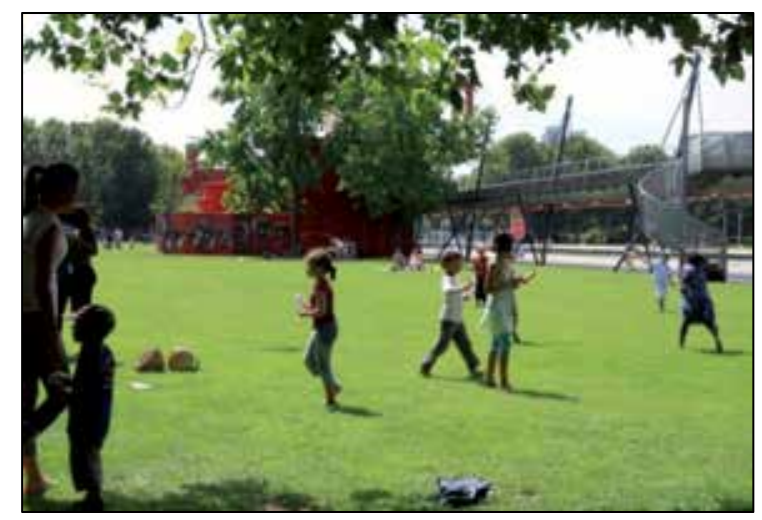

Figure 3. Open green spaces provide opportunities for different activities (Photo Acar, H., Paris, France).

Children use these opportunities according to their own imagination, creativity, or purposes (figure 4).

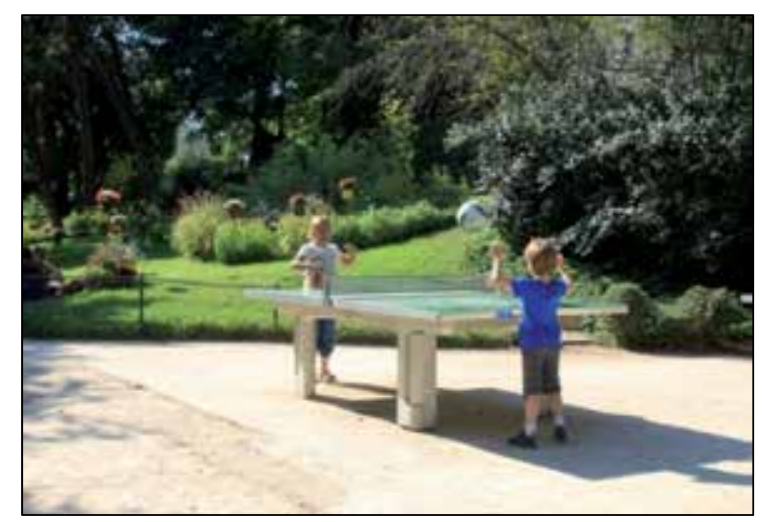

Figure 4. Children use materials in the environments according to their own purposes (Photo Acar, H., Paris, France). 
These activity opportunities may be in open or closed spaces. But open areas are more important for children than closed areas.

Opportunities offered by open spaces for children

Children need environment-related experiences during the character decisive years of their life. Environmental experiences helps children prepare for their life and provide positive contributions to their development. Open spaces are important places for obtaining these experiences because play outside offers a direct relation with environment and makes children discover their environment. Therefore open areas must be provided for children to play. Outside play areas contribute to the development of children's gross motor, allow them to play freely and noisier plays, and also help them to learn about the natural environment (Wilson, 2004).

Open spaces provide more opportunity than the closed spaces with the materials they have (Heerwagen and Orians, 2002; Day and Midbjer, 2007; Acar, 2009). First of all, these spaces experimentally allow children to contact with their environment, to make observation and to learn natural events (change of the seasons and so on). Also, it helps children to become social because it presents the opportunity of being together with other children (figure 5, 6).

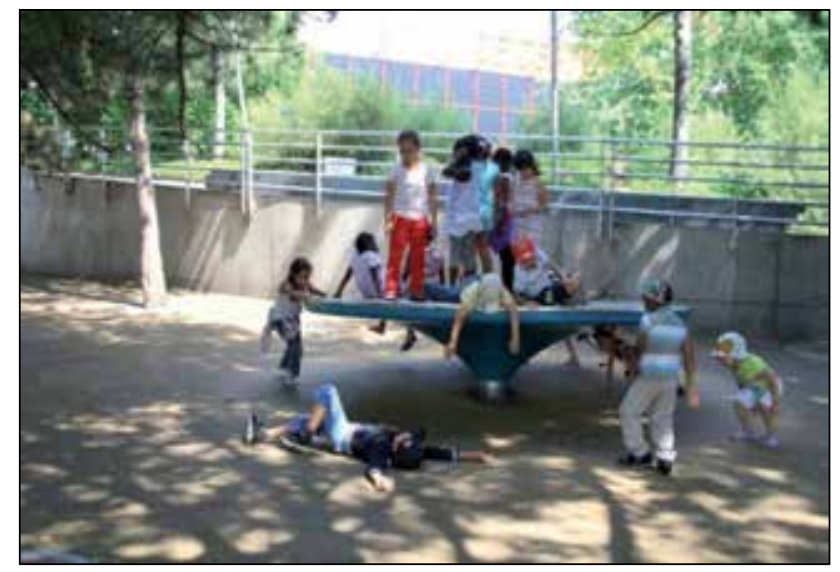

Figure 5. Open spaces provide the opportunity to be together with other children (Photo Acar, H., Paris, France).

It is possible to increase these opportunities offered by open spaces for children. The importance of children's use of open spaces is more valuable, especially in urban areas. Children's opportunity to benefit from and access to open areas is less than in the rural areas than urban areas due to security, traffic and intensive construction. Therefore, it has become more important to make the existing places more qualified. 


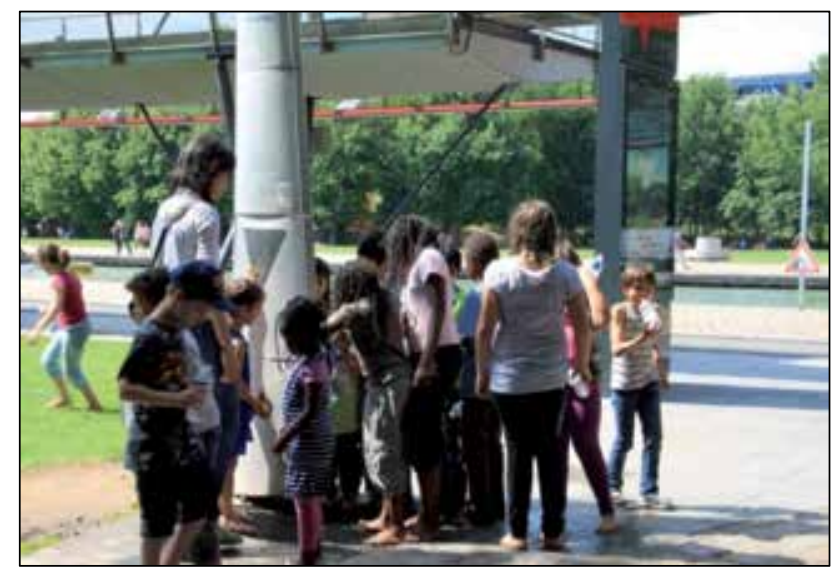

Figure 6. Even a fountain allows children come together, to communicate, to socialize. At the same time helps them to learn issues such as to respect the rights of others and their right to self-defense (Photo Acar, H., Paris, France).

\section{Natural materials and play potential}

Natural areas, one of the open spaces, and the materials they have can provide lots of opportunity for different activities when they are used in accordance with the creativity and imagination of children. Some researchers state that experiences in natural areas play an important role on children's cognitive and affective development (Pyle, 2002; Derr, 2008). Actually these studies show that this situation is a reflection of adults' childhood experience (Derr, 2008). That is, adult's childhood experiences affect attitudes of their adulthood. Therefore, being in interaction with nature and natural materials in childhood contribute to getting information about this subject in future, being sensitive and conscious towards the environment and handing down this experience to the next generations.

Childhood is a period for exploring and it is wonderful, powerful and life-changing discoveries for many children. In this process, period of 6-12 years is considered as middle childhood (Tai et al., 2006). Especially during middle childhood, children get significant experiences and skills that they can use throughout their lives. Therefore, interaction with nature is extremely important for people during this period (Bixler et al., 2002; Tai et al., 2006; Acar, 2009).

Studies show that children have a tendency to more natural materials and these materials provides a positive contribution to their healthy development (Fjørtoft and Sageie, 2000; Fjørtoft , 2004; Taylor and Kuo, 2008; Louv, 2008). For this reason, these materials should be used in the play areas by considering their utility situations in plays and activity facilities. Especially these materials must be used in play spaces in urban areas where it is difficult to find natural areas and materials. But, it cannot be provided just by taking these materials into the playground. The important thing is that these materials should support children's activities. For example, if the climbing activity will be done by a tree instead of a climbing wall, the tree should be appropriate for children's dimensions and in an appropriate form to climb. 
"As childhood has become more restricted, opportunities for interaction with nature and natural experience are even more critical" (Mark Francis, in Lyle, 1997). Interaction with nature and natural materials contribute children's physical, mental, moral and emotional development. There are strong evidences that constant change and growth in nature have a strong effect on the development of intelligence. Also, when human beings and animals are in dynamic environment containing natural areas, neural connections in the brain increase and start to be more complex. Being deprived of such rich environments can cause lack of energy and violent behavior (Tai et al., 2006).

Diversity and complexity offered by the environment support children's play. This complexity and diversity creates opportunities for social interaction and problem solving. If a play environment contains complexity and diversity, this environment will continue to attract the attention of children over time (Jones, 1997). These complexity, diversity and richness in the environment can be created more with the natural materials. Because natural materials can be evaluated in different ways in the extent of children's creativity due to their variability. Therefore, areas that have such elements will attract the attention of children for a long time.

In addition, nature's contributions to the development of children are frequently mentioned in the literature. These can be grouped under the following headings (Acar, 2009);

- Nature contributes in terms of psychological, cognitive, and emotional health, treatment of attention deficit and hyperactivity disorder, motor development, play quality, increased sensitivity to the environment, socialization

- Nature develops the imagination, creativity and social play

- Nature evokes positive emotions, sense of place

- Nature has a stimulating effect

- Nature allows thinking, observation and research

- Natural environments are rich, tutorial, educational and informative environments

Stephen R. Kellert who is social ecology expert express that children can relate to nature in three ways. These are (Kellert, 2002);

- Direct; there is physical contact with nature and children recognize the nature more closely.

- Indirect; physical contact with nature is limited and is programmed, such as zoos, botanical gardens.

- Symbolically; there is no physical contact with nature, children recognize the nature with materials such as book and computer.

The most ideal of these for children is direct contact with nature (figure 7). But today establishing a direct relationship with nature and access to nature's facilities are limited for children in their daily experiences. The most important factor of this is the vast majority of the population has begun to live in urban and suburban areas. In this case children see the natural areas in their environment less than children live in rural or even they cannot see, they usually go to school by service or other vehicles, they cannot have the experience or the 
opportunity to explore their environment, children use more open areas under adult supervision due to security matters or they are recommended to use closed areas to play and due to the increasing constructions children can use limited areas for play. Studies about subject show that all of them effect the healthy development of children negatively. Considering we don't have a chance to change our living conditions and after that these conditions would change more against the children, especially designers who design open spaces for children have important role from now on.

"Study nature, love nature, stay close to nature. It will never fail you" Frank Lloyd Wright (Tai et al., 2006). This expression of Wright explicitly refers to the result of being in relationship with nature.

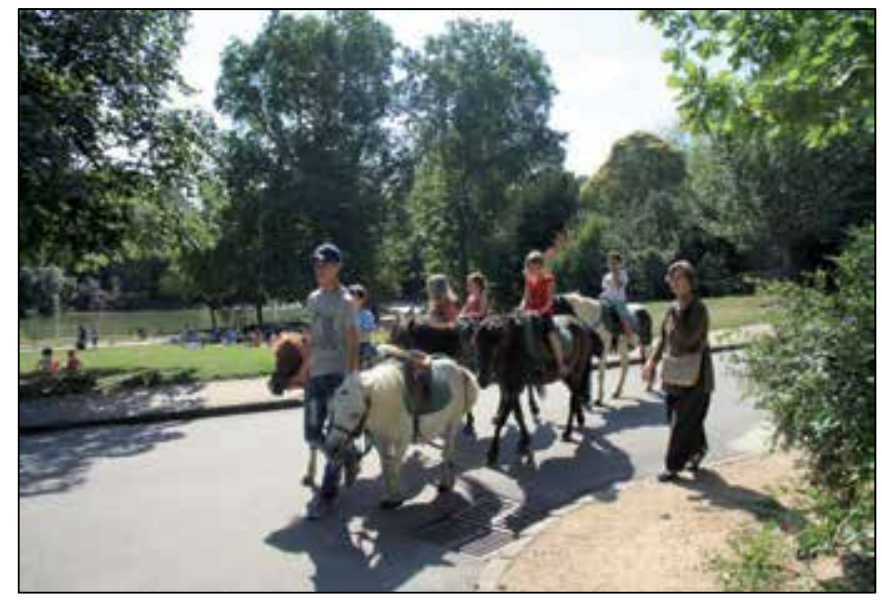

Figure 7. An activity allowing direct contact with nature- pony ride on the area- (Photo Acar, H., Paris, France)

Differences in the perceptions and expectations of children and adults about the environment

Children and adults see and perceive the world differently (Day and Midbjer, 2007) and use open spaces differently (Moore, 1991). Therefore, while making a decision about the design of open spaces we should not forget that there are differences between children's and adults' perspectives. Functional features of the environment are more important than the aesthetic features for children (figure 8). Therefore, when designing areas for children we should determine according to children's needs and desires.

Adults just focus on how to use space and they know what it is. On the other hand, for children what the space means and how they meet and experience it is more important (figure 9). "Paula Lillard distinguishes these approaches: 'children use the environment to improve themselves; adults use themselves to improve the environment. Children work for the sake of process; adults work to achieve and result. This means places-for adults-are for pre-defined purposes; but to children, they offer opportunities for things to do. Adults live (mostly) in a world of material facts-'known' and unchanging. For children, the 'real' world is often servant to an imaginary world" (Day and Midbjer, 2007). 


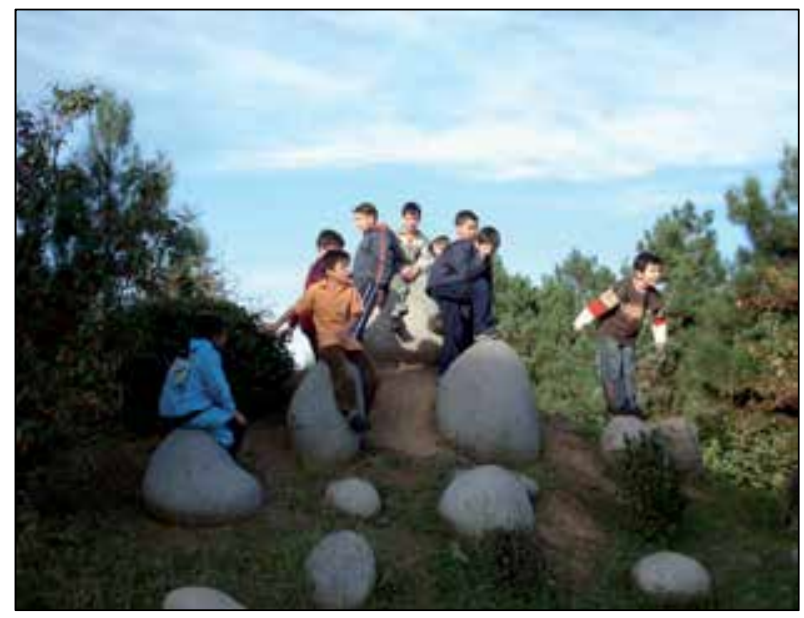

Figure 8. Figure 8. A rock garden and rocks in the garden designed aesthetically for adults are elements seating, climbing, over and around the watch for children (Photo Acar, H., Trabzon, Turkey)

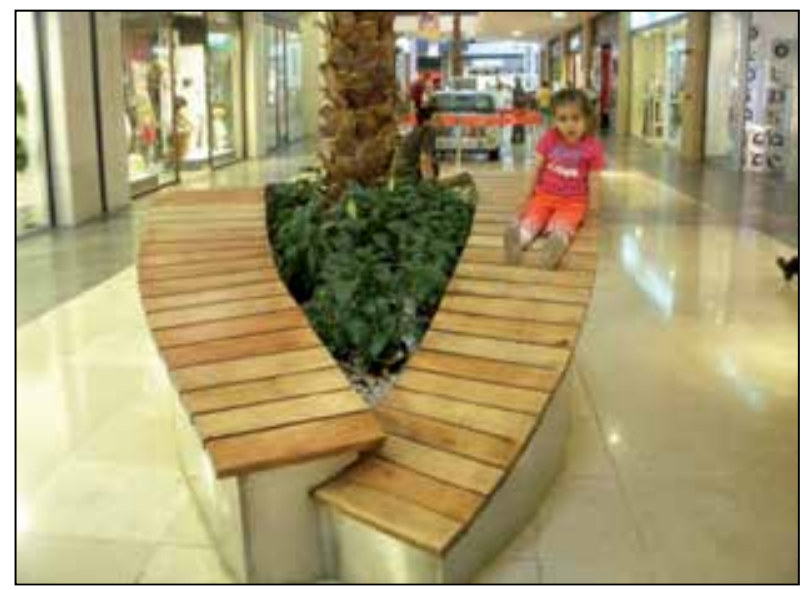

Figure 9. Figure 9. A curved equipment designed by adults for aesthetically or sitting in the shopping center can be play element to slide for a child (Photo Acar, H., Trabzon, Turkey)

For example, while adults enjoy looking at a lake, trees, the grass, these must be a tactile auditory, oral and olfactory experience for children. "It is through body contact, direct and often disorderly, that need to experience their world". Puddles of water that adults avoid are funny places splashing when pressed for children. Lush green hills adults likes looking at is a place to roll down, feel the wet soft grass, smell its green smell for a child, an experience the free fall of tumbling round and round. Adults prefer visually clean and well maintained places instead of irregular and wet grass in open spaces. However, children as one of the players that use the environment are "place-messers" (Francis, M. 1997).

The streets have always been one of the important and attractive play spaces for children (figure 10). Children meet their friends around there, get to know each other and explore the environment. The most important feature that makes streets attractive is its accessibility for 
both sexes and all age groups. However, streets are thought as a transportation routes used to go from a point to $b$ point or parking areas for vehicles by adults (Moore, 1991).
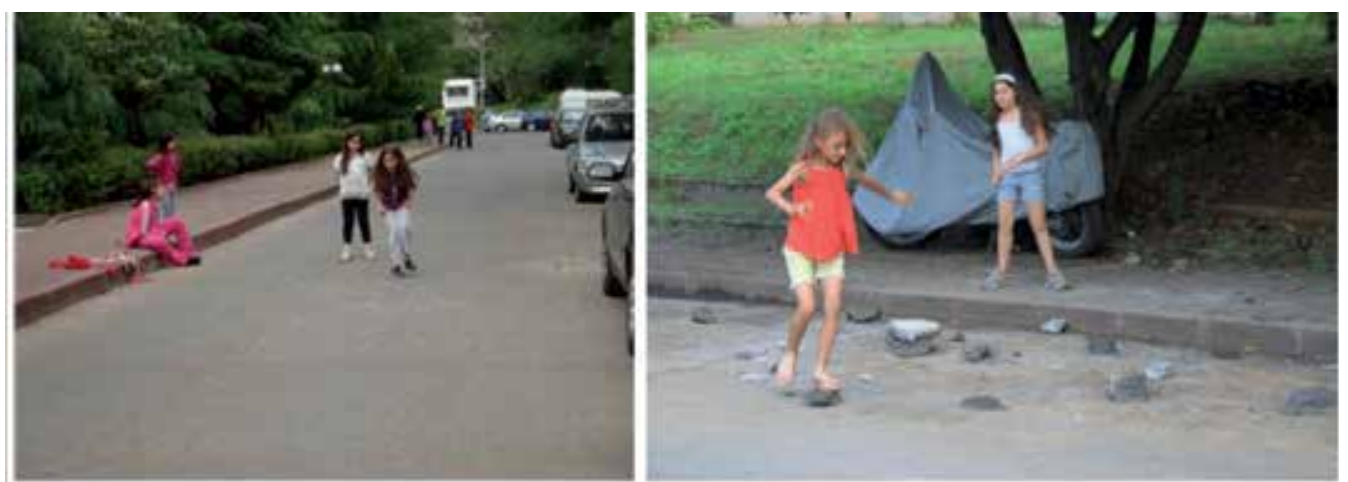

Figure 10. Figure 10. Streets are play spaces for children near their home (Photos Acar, H., Trabzon, Turkey)

One way to understand how children use the environment and what kind of environment they want is observing them. If the user of area that is designed for the child is apparent - for example a school or daycare garden- in order to learn the expectations of children we should observe children's behavior in the area instead of learning by interviews. In this way, it can be determined that which points in the area, when, how often, with how many people and finally and most importantly, for which activity children use. Also, children can build special places such as wooden houses, clubhouses built with waste materials, cottages, and so on, for their own needs in their environments. These places built by the children are an important indicator of their expectations from the environment. These special places are not very aesthetically pleasing but it is important for the development of children's creativity. Therefore, designers should learn to look at the environment through children's eyes or listen them while designing the spaces for children.

\section{Urban context}

Human has needed spaces that have different functions for various needs and wishes since the transition of urban life. These can be either open or closed spaces. Space, with the simplest definition, is place of a person or group. Space is a place which has human, human relations, and equipment required for these relations and the boundaries of a space is defined according to the structure and characteristics of activity (Gür, 1996). Urban is a settlement consists of these spaces and people using them.

While Norberg Schulz defines the urban as a "meeting place" in which people come together and a "microcosm" surrounding the people (Erdönmez and Ak1, 2005), Lynch (1960) defines the urban as a place of a communication in which there are open and closed symbols, religious symbols, signs and plates, towers, columns, entries and rural areas. Urban have a different user segments together with the diversity of this place. So, all of the city's open 
spaces especially in public spaces are used by different age groups. Children are one of the most important of these user groups.

Churchman (2003) began his research with a question "Is there a place for children in the city?". In fact, we should ask this question for all cities and even all the settlements where children are in. Because unfortunately open green spaces decreases in parallel with an increase in the population and the number of structural elements such as residential and business centers increases in urban areas with the process of urbanization. Decrease in open areas also causes a decrease in outside play areas for children. Whereas as mentioned in the previous sections playing in open spaces is really important and necessary for the healthy development of the children.

\section{Being Child in the City}

Nowadays childhood has shown a change through over-controlled by families rather than child-centered (Francis and Lorenzo, 2008). Especially changing environmental conditions in urban areas-traffic density, lack of security- have significant impact on this change. As a result of this, while children spend less time in open areas, they spend more time with individual plays in their homes, in virtual environments such as computers and television and with technological devices such as mobile phone, portable play station, play station (Heerwagen and Orians, 2002; Onur, 2007; Acar, 2009). Eventually, problematic children who cannot interact with nature and with their peers, cannot develop talents and creativity and have limited knowledge about their environment are brought up. This also means problematic adults (Francis and Lorenzo, 2008). Whereas former children were playing in the gardens of their houses or in vacant fields near their homes, on the streets or special places they created. They could find opportunity to be with the same or different age groups and friends in there. Today this condition disappeared in urban areas although it continues in rural areas. This case is not special only for Turkey but for the world-wide (Francis and Lorenzo, 2008; Acar, 2009).

Especially in the last four decades of childhood both negative and positive changes have been occurred. The most alarming cause of these changes is developed cities. Children are increasingly disappearing in density and the chaos of the cities. They are often under the control of the adults while using open spaces. Researchers refer that this situation prevents the needs and the rights of living and enjoying the city of children (Francis and Lorenzo, 2008). Therefore, it is very important to find solutions that will allow children to use open spaces freely and happily for their needs in advanced and crowded cities. Because kids are the same everywhere and need opportunities for healthy development. According to Ellen Ruppel Shell (2001) the title of her article "Kids don't need equipment, they need opportunity".

There are open spaces that have different qualities in the urban centers. These areas provide opportunities for children and are grouped under the following headings;

- Private residential gardens

- Schools' and daycare centers' open spaces 
- Shopping centers'-plazas' open spaces and courtyards

- Play areas in urban parks

- Playgrounds

- Streets

- Urban forests

- Vacant fields and natural areas

- Cities

Some of these open areas used by children designed especially for children, some of them are not designed (such as natural areas, streets). Needs of each designed areas can show diversity according to the state of the user and usage. While designing these places, designers should pay attention to these needs and children's desires. There are studies on the design of these open spaces in the literature (Moore et al., 1997; Francis, 1998; Spencer and Woolley, 2000). Generally issue of "how urban open spaces should be designed for children" will be discussed under the next heading.

How cities should be for the children?

Issues such as how cities should be for children, design criteria for urban open spaces designed for children, and specific points need to be considered in design are classified under specific headings by experts who design open space for children and work on these issues.

Elizabeth Jones (1997), classified specific design elements of spaces under the 9 titles including children play activities depending on the design requirements. These are:

1. Accessible-Inaccessible

2. Active-Passive

3. Challenge/Risk-Repetition/Security

4. Hard-Soft

5. Natural-People/Built

6. Open-Closed

7. Permanence-Change

8. Private-Public

9. Simple-Complex

"They all are essential in the creation of outdoor settings offering guidance in meeting the needs of children intellectually, socially, cognitively and physically" (Jones, 1997).

Owen (1988) determined the qualities required for children in urban design in accordance with the relevant experts and children's statements to define best cities. Francis and Lorenzo (2008) also determined characteristics of better urban places for children based on their design experiences and Owen's (1988) suggestions. These characteristics are;

1. Accessibility: Play areas (if far away from children's home), especially for small children, should be separated from traffic flow, and be connected to their home or school with a good link or be within reach by bike. 
2. Mixed use and mixed users: Children do not like mono-functional zoning. These ideas are consistent with the mixed use and zoning idea of urban designers and planners today. Children want to be together with individuals with different age groups and cultures rather than special places for themselves. They want to try events and functions, and make observations without limitation of adults in a space.

3. Sociability: Children want to be together with different age groups of children and young people autonomously. Besides, children and youth want to be involved in management of some places.

4. Small, feasible, flexible: Children often prefer small-scale constructions formed by recycled, low-cost materials, and natural and green components.

5. Natural, environmentally healthy, growing and in movement: Natural elements, especially plants are preferred by children and are responded to their expectations as they are living materials and reflect seasonal changes. Natural elements, therefore, used for different activities by children and should be included in the design of children places. In addition, other living materials and water should be considered.

6. Urban and place identity: Disorder in scale, function and form in children's place, especially in urban areas, cause perception of space, as a market place. Whereas children know that places need to be identifiable. Signals and signs can be designed into the physical plan. Their design solutions are colors, materials, plantings, etc.

7. Places and opportunities for participation: Children want to contribute to the ongoing, flexible, and permanent design in the process. Children feel good about themselves and have protective attitudes when they have a voice and contribute to the design of the environment they live in.

Tai et al. (2006) classified the design process in a play area under the titles such as research (the inventory and analysis, program development and user needs, design) and construction documentation (cost estimating, implementation). Considerations for determining user needs in this process are listed as follows;

- Five senses: Designs to outdoor areas used by children should contribute to the use and are aware of their feelings. Scientifically, unchanging and unchangeable environments is not ideal for the senses. When diversity is not exist in the environment, the brain searches for other ways to stimulate such as self-introspection or goes to sleep, concentration deteriorates, attention fluctuates and lapses. In contrast, varying stimuli provides attention and awareness keeps you awake (Day and Midbjer, 2007).

- Scale: While adults see the world on a larger scale, children are more cautious about the details. Studies in this area also support this idea. Gary Nabha, one of the authors of The Geography of Childhood, saw his photographs are different, looking at the photos taken by his son in western National parks travels. While his photographs present interesting vistas, his son took more photos with rocks, twigs, lizards and other more tactile, small-scale objects. Therefore, when an adult designs a space for children, he should care for the child's point of view.

- Safety: Creating a play space, safety is one of the most important design principles to be considered. At this point, there are two important elements that children like to see 
around; the water and the high elements. Therefore they should be used in children places by taking the necessary safety precautions.

- Retreat: Although children are different from adults, it should be noted that they are also individuals and there are similarities between adult and kids. Adults need special places that they will be alone for relaxing and escaping. Children need spaces away from the control of adult, feeling secure and playing privately. These spaces should be in a safe environment and close to adults so the security of children should be guaranteed. Such areas can be form in bounded tree house or a building, such as plastic game tubes.

- Play: Play is an activity that is important to explore the world through the eyes of a child. There are many theories and classifications for play. One of them is contributing to the child's physical development and active movement. Another one is contributing to the development of the child's mind and the discovery of creative environment.

- Active play: Active play, in essence, includes a lot of action. These are extremely important for the development of physical health and motor skills. However, it should be noted that children having different needs have different expectations. This situation is related to different skill levels and preferences of the children. In this case, play spaces should be funny and comfortable for physical and active play. These places should also be versatile for the different needs and abilities of children.

- Creative play: Creative play is one of the most important experiences in the childhood period. Children's creativity develops when stimulated in a healthy play environment. The natural environments are the best areas to stimulate creativity and to encourage children. In such areas, twigs, leaves, rocks, provide opportunities for different play. When a child is given any material to create a new world, possibilities are endless.

- Plants: The selection of plant materials in the play area requires care. Dangerous, poisonous, thorny, and allergic species should not be used.

- Wildlife: Plants, necessary for play areas, is also important for wildlife. Monitoring these habitats is necessary for childhood learning.

- Food: While plants provide habitat for wildlife, they also provide information about ecology for children with the features such as acorns, nuts, berries, or other seeds.

- Water: All animals need water to drink or bathe. A water feature in the garden guarantees that birds will come into this area in the future. In this way, children can be ensured to see birds.

- Shelter: To attract wildlife and keep them in the area, shelters, especially on plants, can be made for animals. Brush piles, fallen logs, rock piles and other natural elements can provide animals safety and shelter.

- $\quad$ Place to rise the young: Wildlife has benefits both for adults and children. Children can learn about wildlife by observing the natural environments.

There are different elements around that we can use to draw children's attention. These elements should be utilized in the designed areas for children. Water is one of these elements. Water, either artificially created or with natural surroundings (a river, lake or sea), in the city are always offers unlimited opportunities for children to explore (figure 11). Similarly, blankets, pillows and boxes can be used to create places to hide. Trikes and bikes 
encourage children to be active. All of these and other similar elements can contribute to the development of children's physical ability, motion, coordination, balance and testing skill, and encourages them to play. The setting that include "attractive materials" can be a clue when designing play spaces for kids (Jones, 1997).

As a part of biological diversity, plants, animals, water elements (lake, river, ...) that provide habitat for a particular species, and natural areas that include a portion or all of them in urban areas, can be a source of inspiration for play (Acar, 2010 ) (figure 12). Even if not completely natural, these should be used in the design of children spaces. As discussed in detail in the previous sections, contact with natural areas and natural elements in childhood is extremely important for children. As Robin Moore pointed out, "green" alone is not enough as well as. Spaces created for children should be child-centered, recollective and inviting, and should continuously be effective on the development of children (Tai et al., 2006).

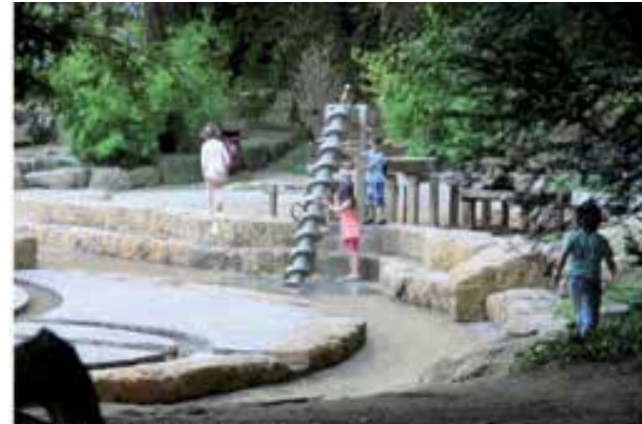

Lixemburg, Luxeminurg

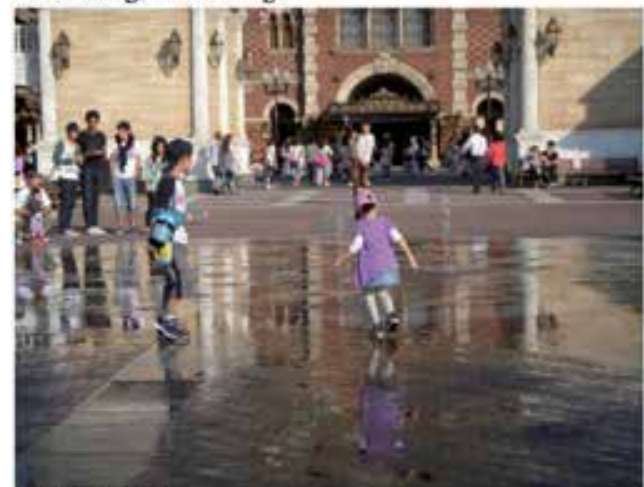

Tokyo, Japan

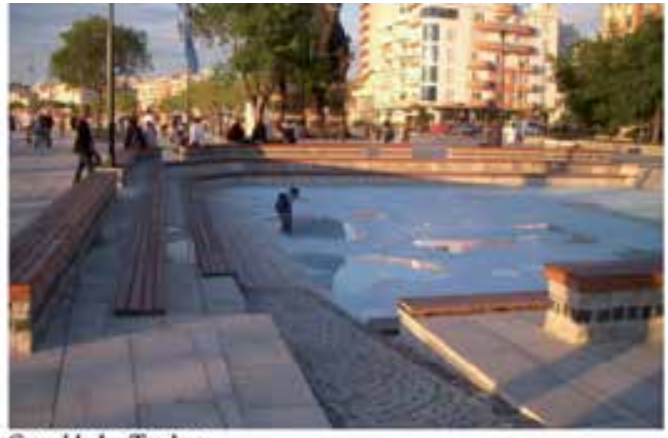

Canakkale, Turkey

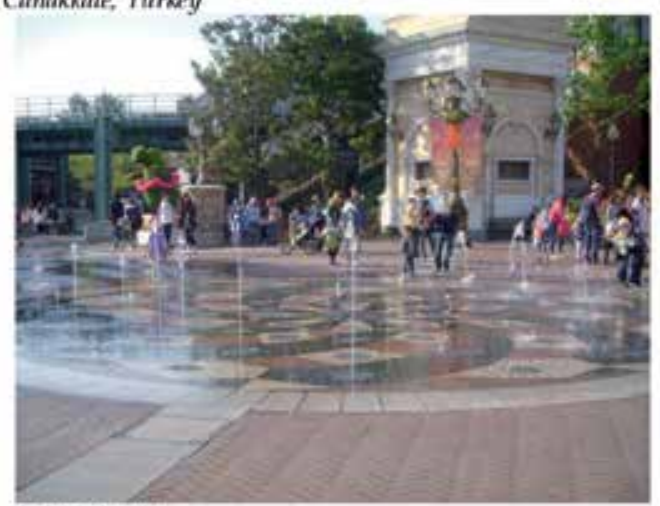

Tokyo, Japain

Figure 11. Playing with water have always been attractive and exciting for children (Photos Acar, H.)

Gender differences should be taken into account in play space design. Girls and boys are different from each other physically, and activity elements should be suitable for both sexes. Although the reason is not always clear, girls and boys are attracted to different places. Boys' plays can often last over days even weeks to complete. While boys usually construct unused buildings (especially tower), the girls usually construct rooms with people in them. 
Girls are often pay attention to the aesthetics of the environment and like colorful and beautiful flowers. Girls particularly 13-15 aged ones, have a variety of definition about the space when compared to boys (Day and Midbjer, 2007). It is observed, that girls prefer, for example, flowers and butterflies and trees, whereas boys prefer more active play such as sliding and playing hide and seek. However, they all need quite places to rest, talk, and socialize (Simonic et al., 2005).

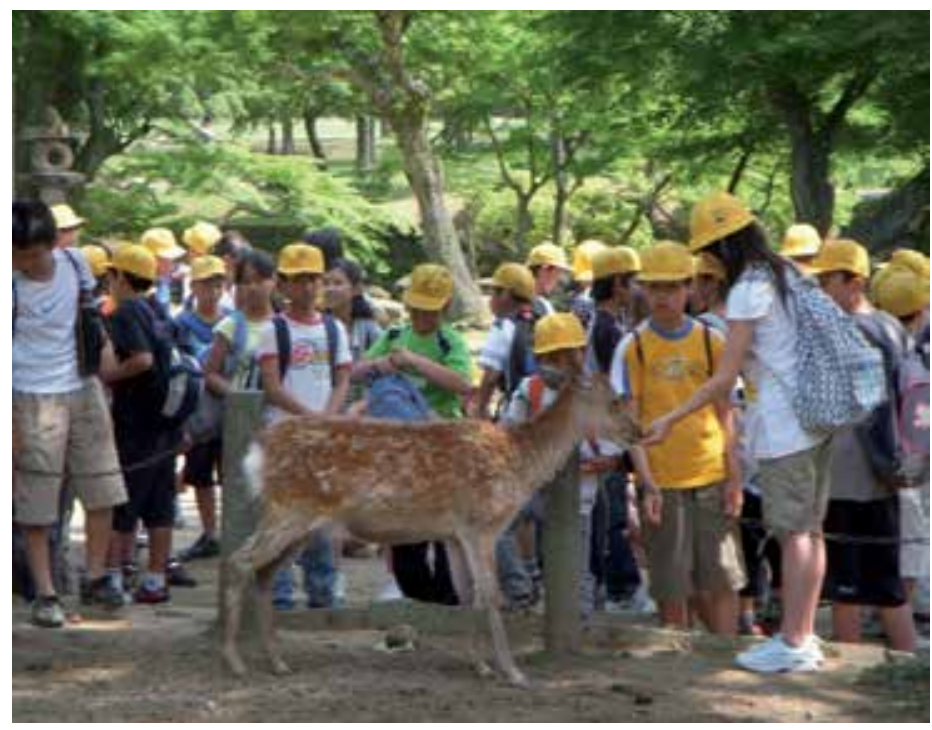

Figure 12. Figure 12. The opportunity of interaction with animals allows children to have information about the animals (Photo Acar, H., Nara, Japan)

Color is an important factor in the children's preferences. Color preferences are personal. Young children love bright colors. In the 1960s, some educationalists were considering that children can only perceive main colors. Today, it is believed that they are over-stimulating. Strong colors can be used in small spaces. But, in large spaces in which we spend more time, it would be better to use muted colors or mood stabilizers. Distinct and warm colors (red, yellow, and orange) are preferred by children over 6 years old. This is not surprising. At this age, they are activity-led, not feeling- or thought-led. Boys preferred red color more than girls that is compatible with their behavior. Older children prefer blue color. Beyond the personal preferences, there are also powerful therapeutic effects of the color (Day and Midbjer, 2007). The color choice seems to change according to age. H. Friedling, in his study performed in 1974, showed the color preferences of children according to age. According to this study, popular and unpopular colors vary as follows (Gür and Zorlu, 2002):

- Popular colors:

5-8 ages - pinkish purple, red, pink, lilac, lemon yellow

9-10 ages - purples, pink, red, turquoise, reddish orange, coffee,

11-12 ages - green, light blue, red, purple

13-14 ages - light blue (masculine), red (feminine), blue, green, orange, dark orange 
- Unpopular colors:

5-8 ages - black, white, gray, dark brown

9-10 ages - gray, dark brown, black, rust green, rust blue

11-12 ages - olive green, rust green, purple, lilac

13-14 ages - rust green, brown, dark brown

Children would like to see plants that can be used for play. For this purpose, plants can also be used to serve a variety of outdoor activities in open spaces designed for children. Trees, shrubs, flowers, vegetables and parts of these plants, such as branches, leaves, pinecones are important elements of children's environments and plays (figure 13,14, 15). Plants in child environments are used with the objectives of enclosure, identity, movement, climbing, play props, programmed activities/education, accessibility/integration, landmarks, seasonal change, wildlife enhancement, climate modification, and environmental quality (Moore, 2002). Plants offer different color options in different seasons with their colorful leaves, flowers and fruits. Results of the author's master thesis that focused on the plant preferences for children play spaces revealed that children like red, yellow, mottled, blue and orange colored leafs while they do not like yellow and green colored leafs. Study also revealed that purple, pink and white flowers were favorite, while red and white colors were unfavourable. In terms of fruit color, study also found that red and blue were favorite, while yellow and orange colors were unfavourable (Acar, 2003).

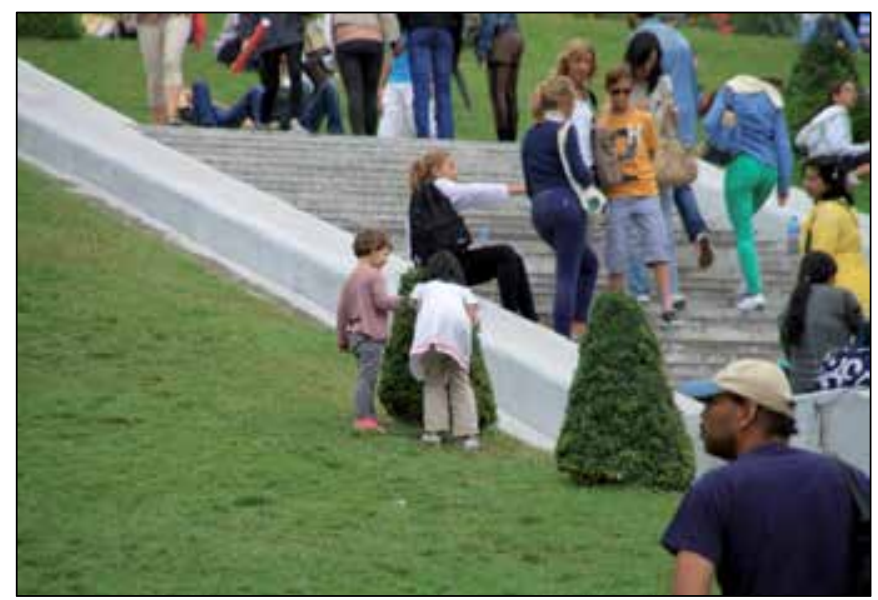

Figure 13. Plants are interesting materials for children (Photo Acar, H., Paris, France)

The functional properties of the plants can be assessed by children in addition to the esthetic properties such as color, form, etc. As mentioned in previous sections, to evaluate existing elements, such as the functional point of view is more important for children. In this respect, children use plants in the playground depending on the features that they have for activities such as climbing, hiding, symbolic games (branch and leaf-like parts of the imaginary cone), and swinging (Acar, 2009). For these purposes, appropriate species selection is needed depending on, function and usage of the space, and the activities that will take place (e.g. size, form, texture, evergreen-deciduous, coniferous-broadleaved, fruit-fruitless, etc.) 
(Moore, 2002). In addition, care must be taken for children's health and safety according to selected species (allergens, toxic, barbed should not be used).

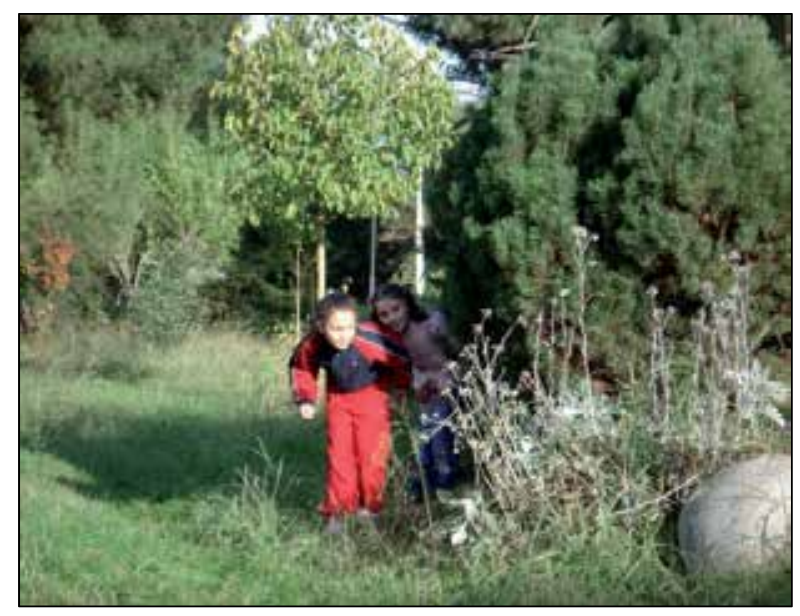

Figure 14. Figure 14. Plants are ideal materials to hide behind (Photo Acar, H., Trabzon, Turkey)

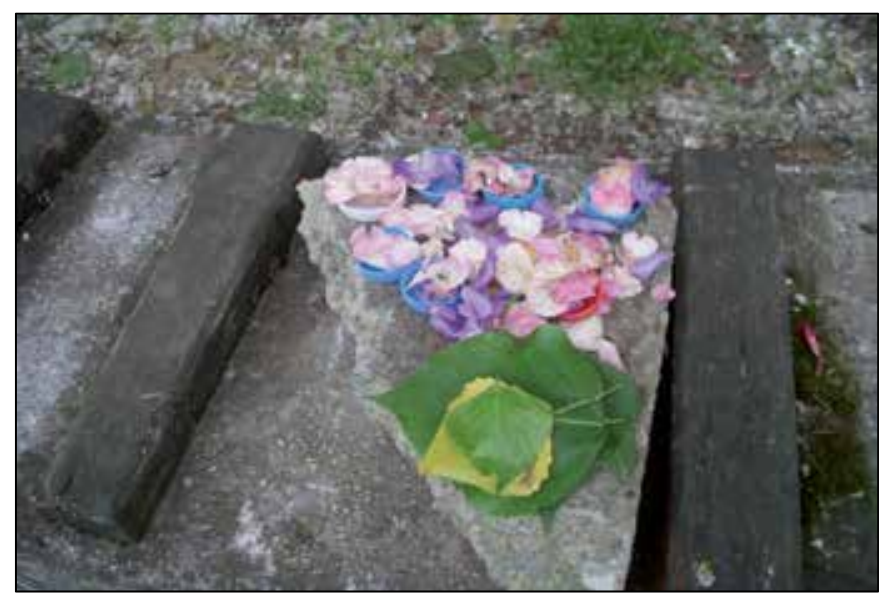

Figure 15. Figure 15. Plant parts are important play materials (Photo Acar, H., Trabzon, Turkey)

Finally, White and Stoecklin (1998), cited the following features that children likes to see in public areas;

- water

- $\quad$ vegetation including trees, bushes, flowers and the long grass

- animals, creatures living in ponds

- sand and water

- natural colors, diversity and change

- $\quad$ places to sit under, in, and on, and sheltered places

- $\quad$ hidden, and private, places and places providing good view

- $\quad$ especially replaceable structures, materials, and equipment that they imagine 
These features and everything mentioned so far are important clues for the design of open space for the children Needs and preferences can vary depending on the individual; however, the knowledge of the general trend provides a significant contribution for space design.

\section{Children's participation in the design process}

Overall, by definition, "participation" refers to that the active participation in decisions affecting one's self and has a say. This is also the right of individual citizens in a democracy. A meaningful participation in the design of open space can be achieved by the participation of individuals from all ages on the subject that includes designed field evaluation, identification of problems, evaluation of the available data, solution proposals, needs and the development of alternatives and by combining all of these on a common plan for a conclusion. Participation is local, transparent, inclusive, interactive, responsive, relevant, educational, reflective, transformative, sustainable, personal and voluntary (Driskell, 2002).

Children should be included in the design of kid play areas through the design process, if possible. Children participation in the decision-making process has advantages for both designers and practitioners. In this way, their needs will be met and their contribution to the construction process leads to a protective attitudes towards these areas among them. "Local Agenda 21" action plan that was introduced in the United Nations Conference on Environment and Development held in Rio de Janeiro in 1992 and accepted by the UN members, strongly supports the involvement of children in the planning of local environments.

A meeting was held in Bologna (Italy) in May 1994 to contribute the identification of childfriendly cities. Approximately more than 300 children from 100 primary and secondary schools in different cities of Italy, educators, planners, and administrations all have described the problems of the cities. All of the children supported by WWF Italy took part in participatory design projects. As a result of these activities, The Children's Manifesto: How to Win Back Our Cities gives clues for future urban design. According to this, the children's ideas are grouped under following headings: "needs in general, expectations from the city, needs regarding urban green spaces, needs in school, needs related to whelming traffic, and needs for the future" (Francis and Lorenzo, 2002). Some of their expectations are;

- to interact with nature in cities which means: playing, climbing, building huts, listening, looking and understanding,

- to have different experiences, sleeping out of doors, strolling together, 'kites between the houses', bridges between the windows, etc.

- more sport activities and children's theaters,

- $\quad$ areas for cycling

- to be heard by others

- to establish children's council to participate decision-making

- quiet environments 
- colourful and beautiful schools

- $\quad$ secure traffic

- a lot of trees, shrubs and grasses,

- collect fruit trees

These are very important as it reflects the expectations of children's requests.

Francis and Lorenzo (2002) stated that children should be included into the process of urban design. In this context, they identified seven realms for children's participation in urban design and planning.

1. Romantic

2. Advocacy

3. Needs

4. Learning

5. Rights

6. Institutionalization

7. Proactive

A new approach is on the agenda in line with the participatory design to re-planning of cities which are not suitable for children to meet their needs. This approach is a proactive process that is including idea of children, adults and professional designers. This approach is fundamentally different approach to the participation of children, which indicates multifaceted perspective and multi-faceted participation. It is based on listening and learning the ideas of children, adults, designers, planners and decision-makers. Differences of opinion between children and adults are negotiated. In the design process, the concepts of equality, justice, and sustainability are important. This process is also based on social science methods that adults re-remember their childhood experiences and share them as their own children. In addition, this involves the use of Internet and Digital Media interactively. This approach claims that the work of children in other age groups, will contribute to the formation of livable, ecologically sustainable and child-and adult friendly cities (Francis and Lorenzo, 2008). In this process, children can participate to the design of children's play areas.

\section{Examples from the world}

In order to make an overall assessment of selected samples around the world, it is important to see the different perspectives and approaches for the design of children's play. It is possible to increase the number of samples.

\section{Rotterdam, Netherland}

This example is a play space in which space's boundaries are defined with color differences on the ground in the city. This area is composed of artificial equipment completely and is quite small. Despite this, it allows more than one activities (figure 16). 

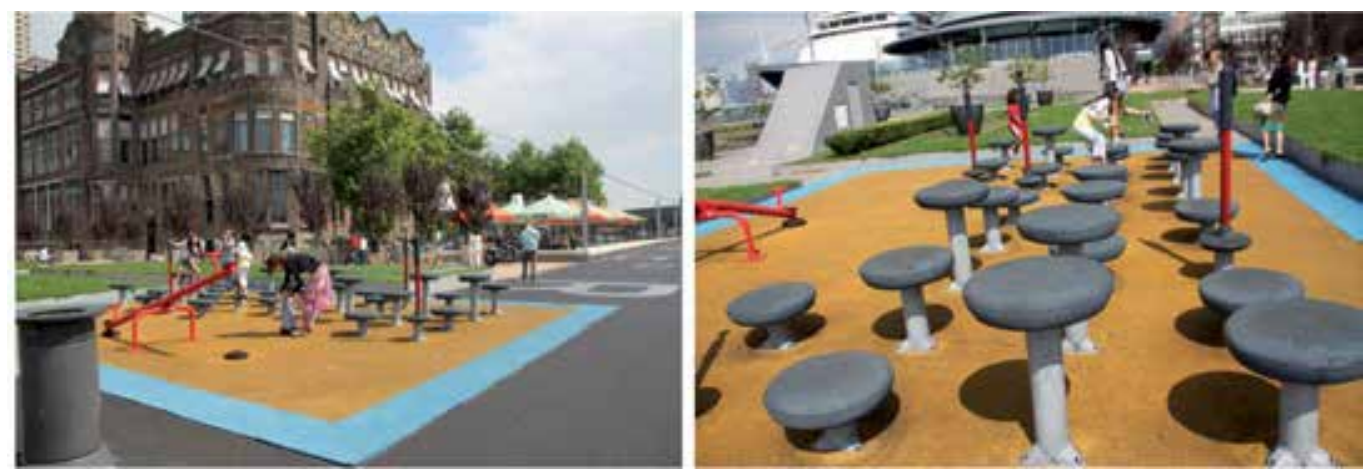

Figure 16. Play space from Rotterdam, Netherland (Photos Acar, H.)

\section{Brussels, Belgium}

This area was designed in woodland in the city. It is particularly suitable for disabled people with ramp play equipment. It provides an opportunity to contact with nature for children as it is in a woodland area (figure 17).
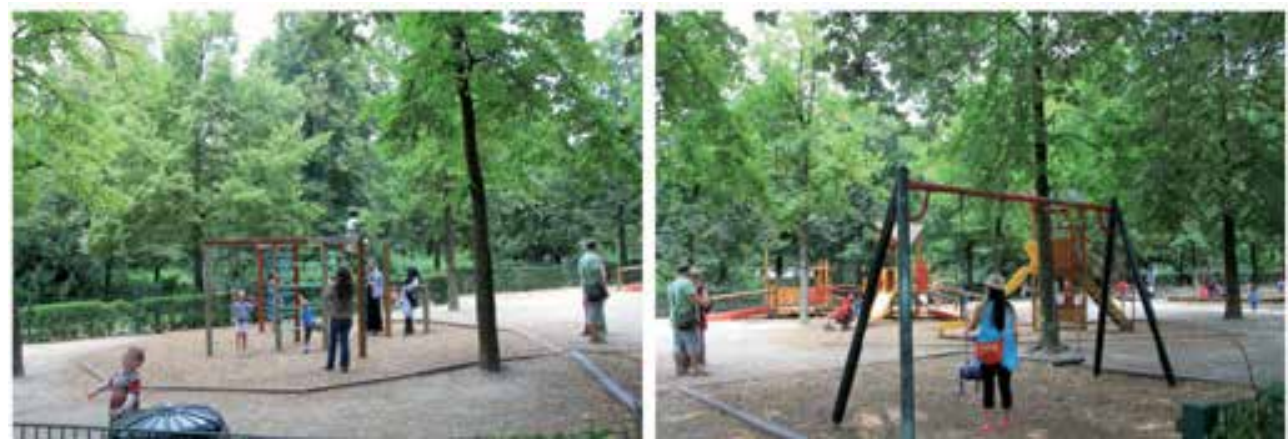

Figure 17. Figure 17. Play space from Brussels, Belgium (Photos Acar, H.)

\section{Luxemburg, Luxemburg}

Ship is a play element that is frequently used in playgrounds and is also attractive in any time for children. It evokes discovery and adventure. The figure of the ship, located in the city offers many activities (sliding, hiding, stable standing, monitoring around, climbing, etc.) for children. Timber materials are used in the area and their colour are in a harmony with wooded area. Animal figures are used as sitting equipment. Although they are artificial, they give an opportunity to children to see and touch the turtle. Water-related spaces that children would like to see were designed in a wide range. In addition, there are towers offering different height options in this play spaces (figure 18). 

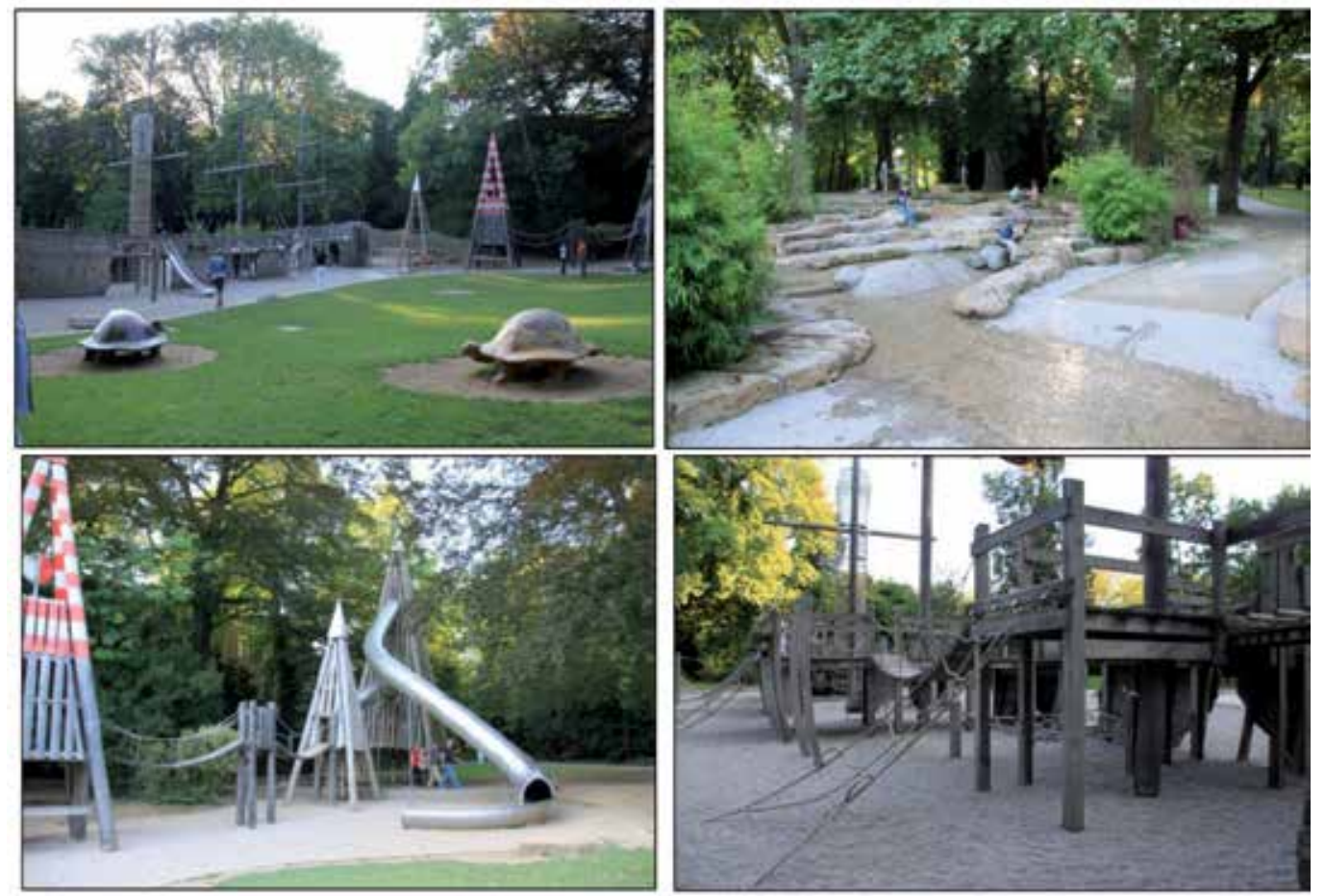

Figure 18. Figure 18. Play space from Luxemburg, Luxemburg (Photos Acar, H.)

\section{Den Haag, Netherland}

There is also a ship figure in this play space. In addition, there are different equipment for different activities such as swinging, sliding, balancing, jumping, and playing with sand. Seating areas were also designed around the playground for parents together with the children (figure 19, 20).
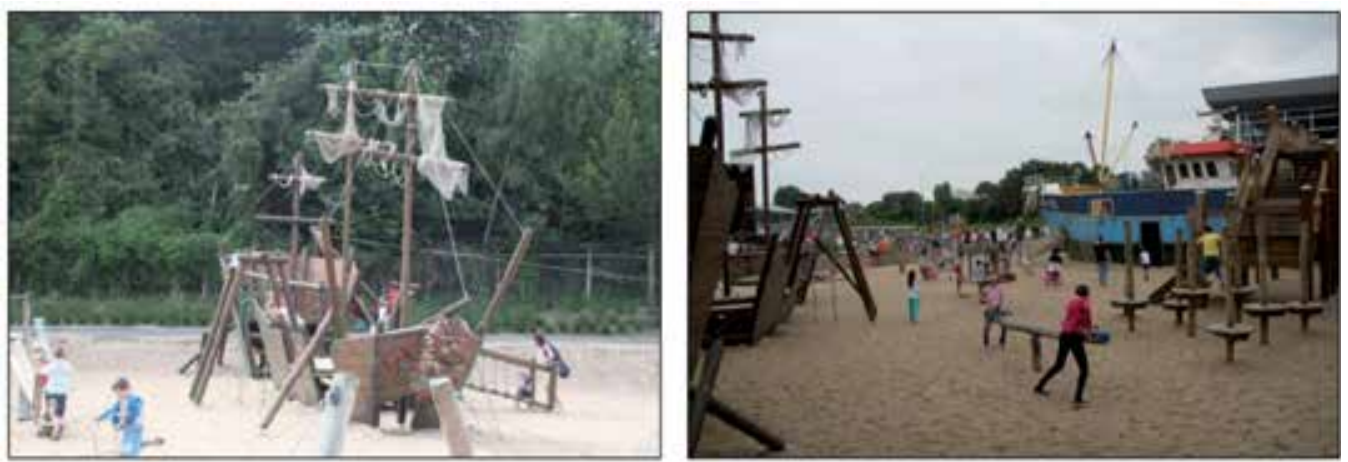

Figure 19. Figure 19. Play space from Den Haag, Netherland (Photos Acar, H.) 

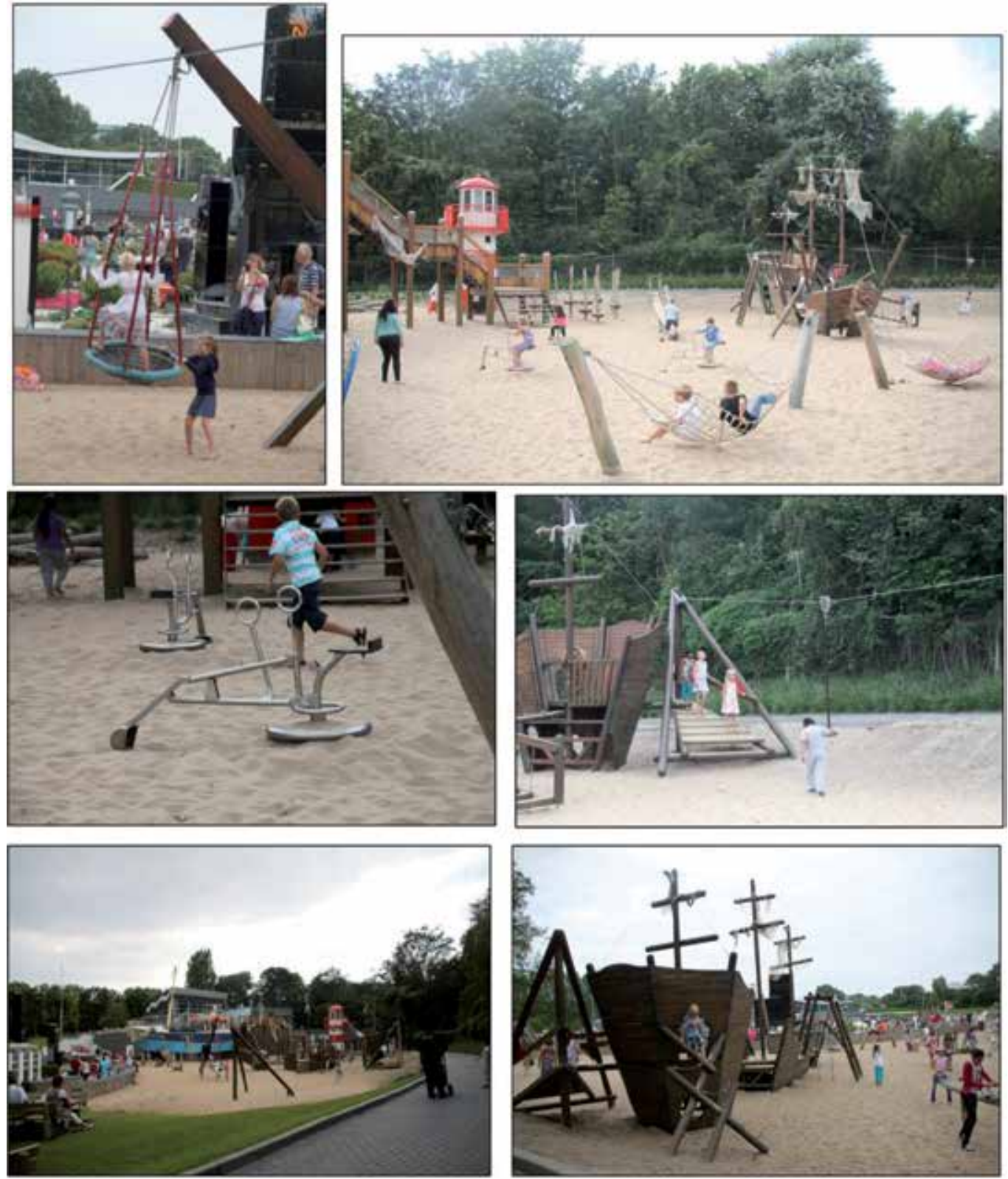

Figure 20. Play space from Den Haag, Netherland (Photos Acar, H.)

\section{Istanbul, Turkey}

This example is in woodland of the city. There are only artificial equipment offering different activities in this play space. Because these play spaces located in a natural area, they provide the opportunity to become intimate with nature for children (figure 21). 

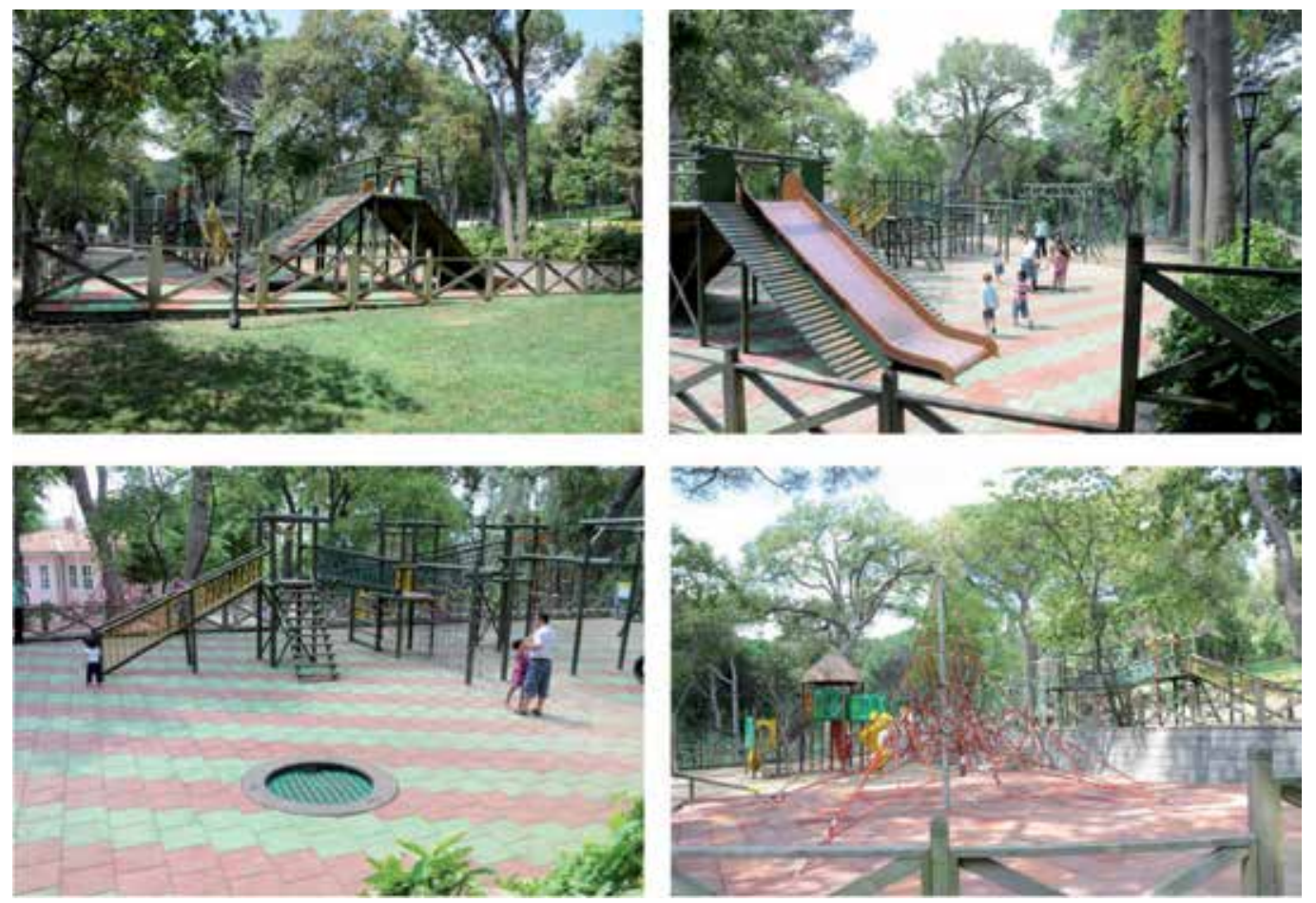

Figure 21. Play space from Istanbul, Turkey (Photos Acar, H.)

\section{Paris, France}

This play area located in Paris is an extremely good example in terms of different topography options. The existing slope in this area was evaluated without too much intervention. As described in affordance theory, curved surfaces afford to climb or slid. So, there is more climbing activity provided with different equipment such as rope in this play area. In addition, this play space is suitable for sliding. Also, although this is a fairly curved area, the safety of children is provided by safety barriers. Boundary elements are also suitable to sit (figure 22, 23).
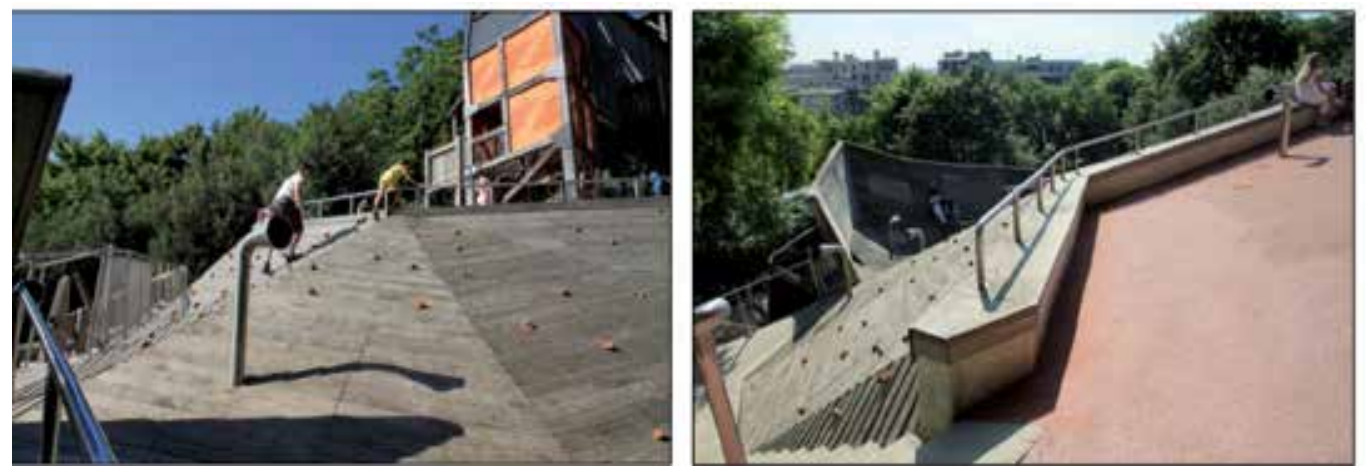

Figure 22. Play space from Paris, France (Photos Acar, H.) 

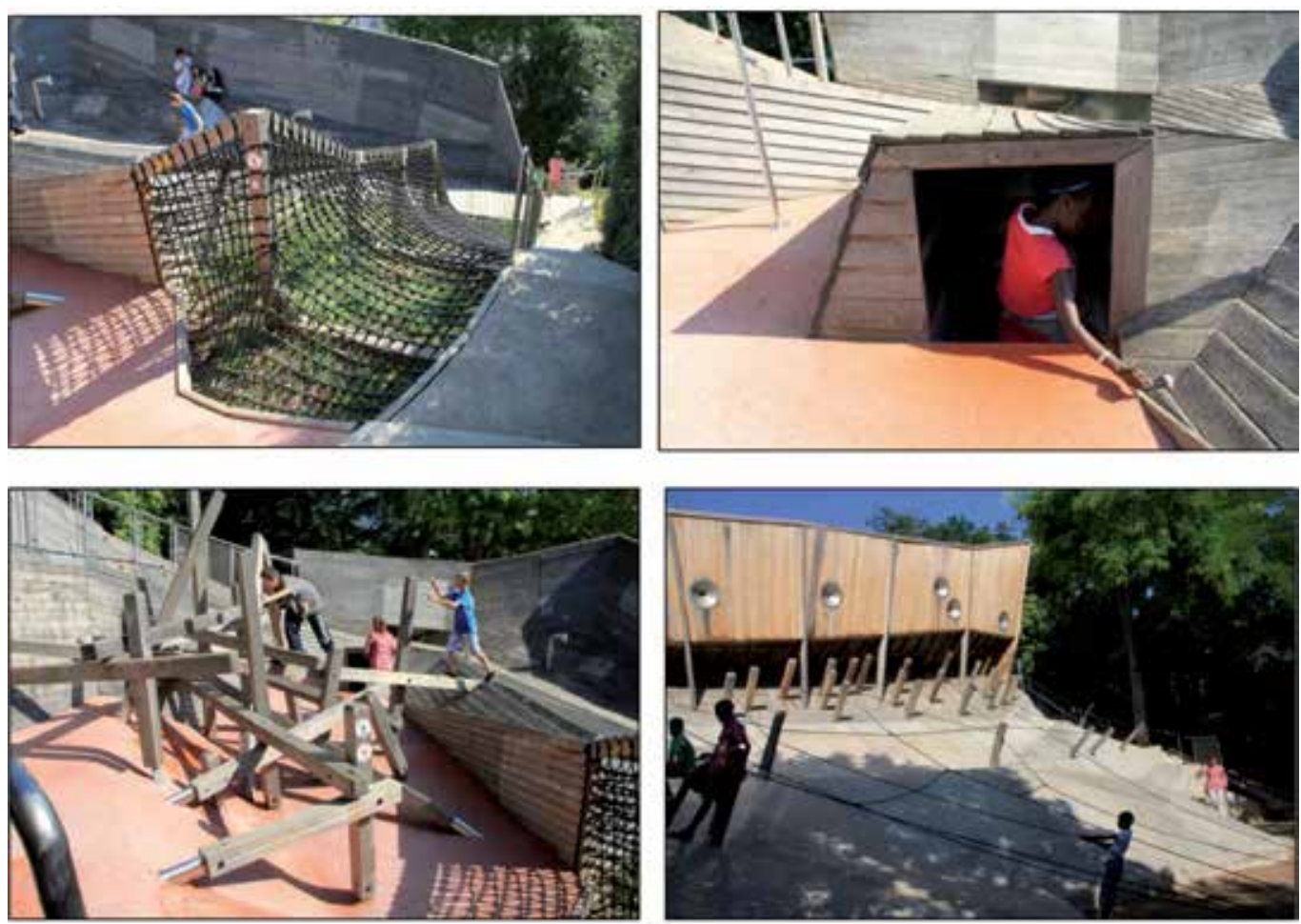

Figure 23. Play space from Paris, France (Photos Acar, H.)

\section{Conclusion}

As a result, looking at the subject in the light of information covered so far in general, the design process in outdoor play space for children in urban areas can be classified under the following headings.

- Site analysis and data collection

- To form main design decisions in accordance with the field opportunities and the needs and preferences of children

- Producing scenario

- Selection of ideal scenarios and detailing

- Application

In this process, the design considerations of play spaces in urban areas can be grouped under the following headings.

The nature of the site and facilities:

Designed area: The location of designed area in the city, the relationship of space with its surroundings and the possible means of transportation and routes of people expected to use this area should be determined. 
The usage status: The place that will be designed as play space or its surroundings and the purpose of use should be evaluated. For example, the school, city park, playground, and so on. Accordingly, the users (age group), as well as the needs and demands of these users should be determined. For example, if the designed area is a primary school, intensive use depending on the number of students at certain intervals such as break hours; areas of application that can be made for courses such as science or nature experiences; areas for active movement such as physical education courses should be considered.

Site facilities: The whole data during the site analysis and information gathering about field (topography, climate, existing vegetation types, soil, space and constructions around the pedestrian-vehicle transport) should be reviewed and evaluated. The positive ones (plant species evaluated in case of the protection, different topography options) should be evaluated in the designs by maintaining or strengthening. In this way, the area will be completely unmodified and untreated, so the existing facilities will be evaluated. The negative features (bad images, features that constitute a threat to children) should be removed from the area or improved.

The needs of children:

User profile: The user group of the area is extremely important. Because when the development, changes in physical measurements, sense and mental capacities and motion abilities of children according to their age is considered, the change of needs and desires is inevitable. Therefore, the varieties of activity and capacities of spaces should be determined appropriately for the age groups of children that will use these areas.

Expectations: The preferences of people vary according their personal expectations, environments and cultures. This situation is also same for children. However, the needs and desires of children about open spaces have been shown by some investigations. It is possible to determine on the basis of their general tendency. It will give useful results if some interviews are made with the users of the area to determine their direct expectations and even by including the children to the designing process. In this way, children's expectations will be fulfilled by mutual consultations. In this way, designed play spaces can be used by children for a long time. Apart from this, if there will be a revision to the design area, giving design decisions would be more healthy after observing the behaviors of children using the area for a while before design it from the beginning.

Activities: Before you design an environment, you need to determine the activities which are expected to be implemented in that area. Because, spaces are designed depending on the particular activities. When designing the space for the child, users' requests, the age groups of children are kept in mind to decide which activities would be done. These activities may be active or passive. The form, capacity and equipment of space are designed according to the type of determined activity and number of people performing this activity. Suggested activities for children in outdoor areas should contribute to their physical, mental, emotional and social developments. In addition, it is essential to suggest some areas for the parents to sit and rest since they need to be near their children. 
Safety: Safety is one of the most important issues in children's play spaces. If a field is not safe, no matter how many different activities it suggests, the children will not favour them. Or their families will not allow their children to use that space. Security in play areas should be ensured in terms of accessories used in the play space as well as its relationships with its environment.

Nature: As it is mentioned the contribution of natural areas and materials for to the development of children are extremely high. For this reason, the natural elements designed children's play spaces must be provided transportation. Therefore in designs, natural materials such as plant, rock, and water should be used so that they allow for children to use the appropriate size in playing.

Plant: Plants and parts such as branches, leaves, and pinecones are very good play materials for children. They are preferred especially when children can use them with different aims due to their creativity during their plays if they are open to be changed. For this reason, they contribute to children's intellectual development and the development of their power of creativity. In addition, the use of nature enables the children to learn the natural cycle since they are alive seasonal changes, leafing, flowering and fructification time. However to manage this it is necessary to ensure the appropriate planting for play area. For example, for climbing activity, species that has branching structure which are not so high and are appropriate for climbing should be selected. To show seasonal variations, species showing coloration in autumn and having leaved broad can be selected. Species with edible fruits may be included where appropriate. For the development of children's visual senses, leaves, wind, sound-producing species should be suggested. These examples can be multiplied. If the existing plant species in the area will be used for these purposes, they should be protected. In addition, those which have psychologically negative affect or which are harmful for children with, such as barbed or very tall species should be avoided.

Water: Water which always attracts the attention of children is a very important material. It should be used necessarily in play areas. It can be used such as a fountain, water gushing from the ground, pied feet of small puddles of water, with sand in different forms.

Animal: Animals always attract the attention of children because of they are living organisms and acting. Children tend to touch or examine a small ant whenever they see them. Seeing animals around themselves will be affective to understand and have information on their roles in the life cycle, their nutrition their habitats. Zoos are open areas offering children a chance to see animals in nearly natural environments. However, arrangements can be made in smaller areas to provide the opportunity to see animals which do not need special care such as ant, bird, butterfly. For example, to manage this, plant species which attract birds and butterflies can be used.

Topography: Topography of the area can be used for different activities. For example, curved surfaces enable children to climb and slide, high places do the same for going on around the watch, the hills are good for rolling over and hiding behind. If these and similar topography options are present in field, they should be established or improved in the different options. Because children prefer very irregular forms than a uniform backgrounds. 
Socialization: Open spaces allow children to be associated with ones at the same or different ages. It is important for the socialization of children. Therefore, you need to design areas to ensure children to have time together with other children. These places may include activities that meet large groups of people, and activities in large areas. Moreover, there should be relatively small-scale spaces allowing two children to sit and chat in more quiet corners of the field, either.

The use of the senses: The play spaces should contribute to the development of the senses of children. Therefore, designs and accessories that we can collect data from environment by five senses in the play should be used. For example, plant species with fragrant flowers to smell, different sound-producing musical instruments to hear, different display mirrors offering a choice of perceive to see by looking at the outside environment, edible plant species to taste, different textured surfaces or plants created by offering a choice of vertical and horizontal planes or different textures to touch should be used.

Creativity: Outdoor play areas contribute to the development of children's creativity. However, for this, environment elements can be modified and used for different purposes. These can be different materials such as water with sand, or non-constant materials to build a structure in the field, flowers and leaves to make a symbolic meal in children's plays, the boat leaves to refloat, the plant parts to ride a horse and so on. Children use them in playing in accordance with their creativity and imagination.

The materials that is to be used:

Safety: Security is the most important criteria in playgrounds design. For this reason, safety should come first both for the designed play areas, its surroundings and the material; we should avoid the life-threatening risks for children.

Soundness: All the materials to be used in play space should be sound, convenient and ergonomic in terms of anthropometric measurements of children. For more use, the deformed space and accessories should be renewed or replaced as soon as possible. Wooden materials that will be used should not be cracked or rough.

Health: Plant material that will be used in the play space should not be constituted a threat to the health of children. To do this, toxic, allergenic pollen, with thorny species should be avoided. In addition, horizontal, vertical, or other artificial materials used in contact with reinforcement made of materials should be non-toxic.

Natural-Artificial: Based on the studies on the subject, most of them appear to prefer natural areas or natural materials. And this material provides a positive contribution to their development. However, this does not indicate the need for children's play spaces using only natural materials. Because, artificial materials with color, texture and potential in different sizes attract children. For this reason, natural materials, as well as artificial materials should be included in the designs.

Free materials: In play areas, there should be portable free standing, unstable materials that allow children to change their places and take them together to build new things. These 
enable children to build up the objects in their dreams and to learn while doing and trying so and to be in cooperation with other children also.

Design for Everyone: The right of every citizen is to take advantages of urban open spaces equally. Therefore, in the play places designed for children in cities all children (disabled, non-disabled) should take advantage of them. Therefore, non-impaired persons with disabilities at the beginning of the design process needs to be considered. Both efficacy and regulations (space and reinforcement measures) should be considered.

As a result this article deals with children's play areas' design in urban open space. It should not be forgotten that children's preferences and expectations may vary according to the individual, the society and the culture. However, scientific studies on children, children's environment and children's preferences, observations and experiences show us that the general trend is in this direction. In addition, all the types referred to in a play space, variety of activity areas or equipment may not be able to use together. In particular concept (such as water gardens, water gardens or sense) of one or a few of them in the play area may be considered. In addition, the above mentioned information is considered to be an important resource for those working with children and general open space designer for children.

Finally, "a child's play space should ideally never be finished, it should be in a constant state of change" (Goltsman, in Loughlin and Suina, 1997).

\section{Author details}

Habibe Acar

Karadeniz Technical University, Faculty of Forestry, Department of Landscape Architecture, Trabzon, Turkey

\section{References}

Acar, H., 2003. A study on determining plant preferences of users in children playgrounds: An example of Trabzon city, (In Turkish: Çocuk oyun alanlarında kullanıcıların bitki tercihlerinin belirlenmesi üzerine bir araştırma: Trabzon kenti örneği), Master Thesis, Karadeniz Technical University, The Graduate School of Natural and Applied Sciences, Department of Landscape Architecture, Trabzon, Turkey.

Acar, H., 2009. Assessment of natural landscape elements' play affordances, (In Turkish: Doğal peyzaj elemanlarının oyun olanaklılıklarının değerlendirilmesi), PhD Thesis, Karadeniz Technical University, The Graduate School of Natural and Applied Sciences, Department of Landscape Architecture, Trabzon, Turkey.

Acar, H., 2010. Contribution of urban biodiversity to children's play, Proceeding of the $2^{\text {nd }}$ International Conference of Urban Biodiversity and Design, p. 323, Nagoya, Japan, 1822 May, 2010. 
Bell, S., 2008. Scale in children's experience with the environment, (in: Children and Their Environments, Edited by Christopher Spencer and Mark Blades), Cambridge University Press, New York, 13-25.

Bixler, R. D., Floyd, M. F., Hammitt, W. E., 2002. Environmental socialization: Quantitative tests of the childhood play hypothesis, Environment and Behavior, 34, 6, 795-818.

Churchman, A., 2003. Is there a place for children in the city?, Journal of Urban Design, 8, 2, 99-111.

Clark, C., Uzzell D.L., 2008. The socio-environmental affordances of adolescent's environments, (in: Children and Their Environments, Edited by Christopher Spencer and Mark Blades), Cambridge University Press, New York, 176-195.

Clements, R.L., Fiorentino, L., 2004. The child's right to play, Greenwood Publishing Group, USA.

Day, C., Midbjer, A., 2007. Environment and children: Passive lessons from the everyday environment, Architectural Press, Oxford.

Derr, T., 2008. 'Sometimes birds sound like fish': Perspectives on children's place experiences, (in: Children and Their Environments, Edited by Christopher Spencer and Mark Blades), Cambridge University Press, New York, 108-123.

Driskell, D., 2002. Creating better cities with children and youth: A manual for participation, UNESCO and Earthscan Publications Ltd., UK.

Erdönmez, M.E., Akı, A., 2005. Açık kamusal kent mekanlarının toplum ilişkilerindeki etkileri, YTÜ Mimarlık Fakültesi e-Dergisi, Cilt 1, Sayı 1.

Fjørtoft, I. ve Sageie, J., 2000. The natural environment as a playground for children landscape description and analyses of a natural playscape, Landscape and Urban Planning, 48, 83-97.

Fjørtoft, I., 2004. Landscape as a playscape: The effects of natural environments on children's play and motor development, Children, Youth and Environments, 14, 2, 21-44.

Francis, C., 1997. Particular places: School environments over time, (in: Landscapes for Learning: Creating Outdoor Environments for Children and Youth, Edited by Sharon Stine), John Wiley\&Sons, Inc., New York, 45-87.

Francis, C., 1998. Child care outdoor spaces, (in: People Places: Design Guidelines for Urban Open Space, Second Edition, Edited by Clare Cooper Marcus and Carolyn Francis) John Wiley\&Sons, New York, 259-310.

Francis, M., Lorenzo, R., 2002. Seven realms of children's participation, Journal of Environmental Psychology, 22, 157-169.

Francis, M., 1997. The players, (in: Landscapes for Learning: Creating Outdoor Environments for Children and Youth, Edited by Sharon Stine), John Wiley\&Sons, Inc., New York, 1-11.

Gür, Ş., Ö., Zorlu, T., 2002. Çocuk mekanları, 1. Baskı, Mas Matbaacılık, YEM Yayın-75, İstanbul, Turkey.

Gür, Ş.Ö., 1996. Mekan örgütlenmesi, Kare Reklam, Ankara, Turkey.

Heerwagen, J., H., Orians, G., H., 2002. The ecological world of children, (in: Children and Nature: Psychological, Sociocultural, and Evolutionary Investigations, Edited by Peter H. Kahn, Jr. and Stephen R. Kellert), The MIT Press, London, 29-63. 
Heft, H., 1988. Affordances of children's environments: A functional approach to environmental description, Children's Environments Quarterly, 5, 3, 29-37.

Jones, E., 1997. Basics, (in: Landscapes for Learning: Creating Outdoor Environments for Children and Youth, Edited by Sharon Stine), John Wiley\&Sons, Inc., New York, 13-43

Katcher, A., 2002. Animals in therapeutic education: Guides into the luminal state, (in: Children and Nature: Psychological, Sociocultural, and Evolutionary Investigations, Edited by Peter H. Kahn, Jr. and Stephen R. Kellert), The MIT Press, London, 179-198.

Kellert, S., R., 2002. Experiencing nature: Affective, cognitive, and evaluative development in children, (in: Children and Nature: Psychological, Sociocultural, and Evolutionary Investigations, Edited by Peter H. Kahn, Jr. and Stephen R. Kellert), The MIT Press, London, 117-151.

Kyttä, M., 2002. Affordances of children's environments in the context of cities, small towns, suburbs and rural, villages in Finland and Belarus, Journal of Environmental Psychology, 22, 109-123.

Kyttä, M., 2003. Children in outdoor contexts: Affordances and independent mobility in the assessment of environmental child friendliness, Doctor of Philosophy, Helsinki University of Tehncology Centre for Urban Regional Studies, Espoo.

Kyttä, M., 2004. The Extent of children's independent mobility and the number of actualized affordances as criteria for child-friendly environments, Journal of Environmental Psychology, 24, 179-198.

Loebach, J., 2004. Designing learning environments for children: An affordance-based approach to providing developmentally appropriate settings, Master of Environmental Design Studies, Dalhousie University, Halifax, Nova Scotia.

Louighan, C., Suina, J., 1997. Congruence, (in: Landscapes for Learning: Creating Outdoor Environments for Children and Youth, Edited by Sharon Stine), John Wiley\&Sons, Inc., New York, 89-135.

Louv, R., 2008. Last child in the woods: Saving our children from nature-deficit disorder, Algonquin Books, USA.

Lyle, J., 1997. Ode to the outdoors, (in: Landscapes for Learning: Creating Outdoor Environments for Children and Youth, Edited by Sharon Stine), John Wiley\&Sons, Inc., New York, 187-229.

Lynch, K., 1960. The image of the city, Mit Press, Cambridge.

Memlük, M.Z., 2012. Urban landscape design, (in: Landscape Planning, Edited by Murat Özyavuz) InTech, Croatia, 277-298.

Moore, R. C., 2002. Plants for play: A plant selection guide for children's outdoor environments, MIG Communications, Berkeley, California.

Moore, R. C., 1991. Streets as playgrounds, (in: Public Streets for Public Use, Edited by Anne Vernez Moudan with a foreword by Donald Appleyard,) Columbia University Press, New York, 45-62.

Moore, R. C., Goltsman S.M., Iacofano, D.S., 1997. Play for all guidelines: Planning, design and management of outdoor play settings for all children, Second Edition, MIG Communications, Berkeley, California. 
Motloch, J.L., 2000. Introduction to landscape design, Second Edition, John Wiley \& Sons, USA.

Onur, B., 2007. Çocuk, tarih ve toplum, 1. Baskı, Pelin Ofset, İmge Kitabevi, Ankara, Turkey.

Özdemir, A., Yilmaz, O., 2008. Assessment of outdoor school environments and physical activity in Ankara's primary schools, Journal of Environmental Psychology, 28, 287-300.

Piaget, J., Inhelder, B., 1971. The child's conception of space, Langdon, $4^{\text {th }}$ Edition, Compton Printing Ltd., London.

Proshansky, H. M., Ittelson, W., H. ve Rivlin, L., G., 1976. Environmental psychology: People and their physical settings, Second Edition, Holt, Rinehart and Winston, USA.

Pyle, R. M., 2002. Eden in a vacant lot: Special places, species, and kids in the neighborhood of life, (in: Children and Nature: Psychological, Sociocultural, and Evolutionary Investigations, Edited by Peter H. Kahn, Jr. and Stephen R. Kellert) The MIT Press, London, 305-327.

Shell, E. R., 2001. "Kids don't need equipments, they need opportunities", Lifestyle Information Network, September/October, 34-35.

Simonic, T., Gostincar, R., Recer, S., Luznik, J., 2005. Design initiatives for children play in urban environment, International Conference for Integrating Urban Knowledge \& Practice Gothenburg, Sweden. May 29 - June 3.

Spencer, C., Woolley, H., 2000. Children and the city: a summary of recent environmental psychology research, Child: Care, Health and Development, 26, 3, 181-197.

Tai, L., Haque, M.T., McLellan, G.K., Knight, E.J., 2006. Designing outdoor environments for children: Landscaping, schoolyards, gardens, and playgrounds, McGraww-Hill Companies, USA.

Taylor, A. F., Kuo, F.E., Is contact with nature for healthy child development? State of evidence, (in: Children and Their Environments, Edited by Christopher Spencer and Mark Blades), Cambridge University Press, New York, 124-140.

VanDerZanden, A.M., Rodie S.N., 2008. Landscape design, Theory and application, Thomson Delmar Learning, Canada.

Vicki, L., Stoecklin, M., 2004. Creating playgrounds kids love, http://www.whitehutchinson.com/children/articles/playgrndkidslove.shtml, 16.12.2004.

White, R., Stoecklin, V., 1998. Children's outdoor play \& learning environments: Returning to nature, Early Childhood News Magazine, March/April.

http://www.whitehutchinson.com/children/articles/outdoor.shtml, 19.12.2012.

Wilson, R., 2004. Why children play under the bushes, http:/ / www.earlychildhood.com/Articles/index.cfm?A=412\&FuseAction=Article, 16.12.2004. 


\section{Ecological Landscape Design}

Filiz Çelik

Additional information is available at the end of the chapter

http://dx.doi.org/10.5772/55760

"Choose only one master-Nature"

Rembrandt Harmenszoon van Rijn (1606-1669)

\section{Introduction}

The most critical changes in the world over the last century have been derived from the variety of environmental problems. Growing environmental problems now affect entire the world. The majority of environmental problems originates in human greed and interference.

It is well known that planet Earth is experiencing a so-called environmental crisis (ecological crisis). This crisis is characterized by three major themes:

- Rapid growth of the human population and its associated economic activity,

- The depletion of both non-renewable and renewable resources, and

- Extensive and intensive damage caused to ecosystems and biodiversity.

The environmental crisis is a predicament of inappropriate design-it is a consequence of how cities have been developed, industrialization undertaken, and ecoscapes used. Fundamentally, the problem has been one of inadequate integration of ecological concerns into planning (Shu-Yang et al., 2004).

In many ways, the environmental crisis is a design crisis. It is clear that design has not been given a rich enough context. Design is a hinge that inevitably connects culture and nature through exchanges of materials, flow of energy, and choices of land use. The every world of buildings, artifacts, and domesticated landscape is a design world, one shaped by human (Van Der Ryn and Cowan, 1996).

Some environmental problems have arisen from design problems. Design can have a crucial impact upon the environment in many different ways. This is because every design decision is an environmental decision. Design is a consequence of how things are made, and the world has been shaped by the designers. The present forms of everything in the world have been 
derived from design. It is clear that design has been previously used only to meet human needs. Unfortunately, in many past situations environmental effects were ignored during the design stage. Design has not been taught in the context of its ecological impact. Many practices in the design field have been done with unsustainable design principles. The environmental problems have boosted the sustainable explorations necessary for protecting ecological system in order to address and find solutions to the problems. Scientists, planners and designers have questioned the effectiveness of design and have suggested incentives as alternatives. At the end of 20th century, the power of design for to solve the problem and the potential of design for sustainability have been noticed; an integration that goes from ecological processes and functions to design has started. Design and its potential have been regarded a creative problem solving activity. While ecological sciences provide the knowledge and guidance, design provides creative solutions for the environmental problems.

In a world facing a future characterized both by expanding metropolitan regions and by ecological crisis, it is imperative that we re-think the relationship of urban dwellers to the natural environment. The 21st century is expected to be the first in history in which a majority of humanity lives in cities, and if present trends continue, it may also be the one in which those urban populations inflict irreversible damage on the earth's living systems (Eisensten, 2001).

Designers and design critics are increasingly emphasizing the actual or, potentially, radical nature of an ecological approach to design which implies a new critique-a recognition of the fact that to adopt an ecological approach to design is, by definition, to question and oppose the status quo (Madge, 1997). In this context design has a crucial role to play in achieving sustainability and to provide solutions for environmental problems. In parts of the world dominated by humans, landscape design can have significant and positive environmental effects (Helfand et al., 2006).

Ecological design explicitly addresses the design dimension of the environmental crisis. It is not a style. It is a form of engagement and partnership with nature that is not bound to a particular design profession (Van Der Ryn and Cowan, 1996).

In recent years ecological design has been applied to an increasingly diverse range of technologies and innovative solutions for the management of resources. Ecological technologies have been created for the food sector, waste conversion industries, architecture and landscape design, and to the field of environmental protection and restoration (Todd et al., 2003).

As environmental problems escalate, ecological design in landscape architecture has increasing in academia and practice. Ecological design is an integrative ecologically responsible design discipline. Ecological design has been emerged as a means to model ecological processes and functions, and therefore as a model for sustainability. Today's ecological landscape design movement tends to address design problems.

\section{The relationship between ecology, sustainability and design}

Ecology, sustainability and design are different fields, but they have been merged together in recent years. This is because human lifestyle is having an increasingly negative impact on the surrounding environments. 
Ecology, in the 100 years since its inception, has increasingly provided the scientific foundation for understanding natural processes, managing environmental resources and achieving sustainable development. By the 1960s, ecology's association with the environmental movement popularized the science and introduced it to the design professions (e.g. landscape architecture, urban design and architecture) (Makhzoumi, 2000).

"Ecology" in the profession of landscape architecture and planning can't be understood solely as meaning the relationship between nonhuman life forms and their environment. The term ecology is traditionally used as shorthand for the sum of the biophysical forces that have shaped and continue to shape the physical world. Thus there are other dimensions to be recognized if we are to understand the key nature of ecology: that of process, integration, and humanity (Ahern et al., 2001).

The relationship between design and ecology is a very close one, and makes for some unexpected complexities (Papanek, 1995). Ecology explains how the natural world is and how it behaves, and design is also the key intervention point for making sustainability in ecology (Figure 1.). The knowledge gained from ecology can influence landscape design.

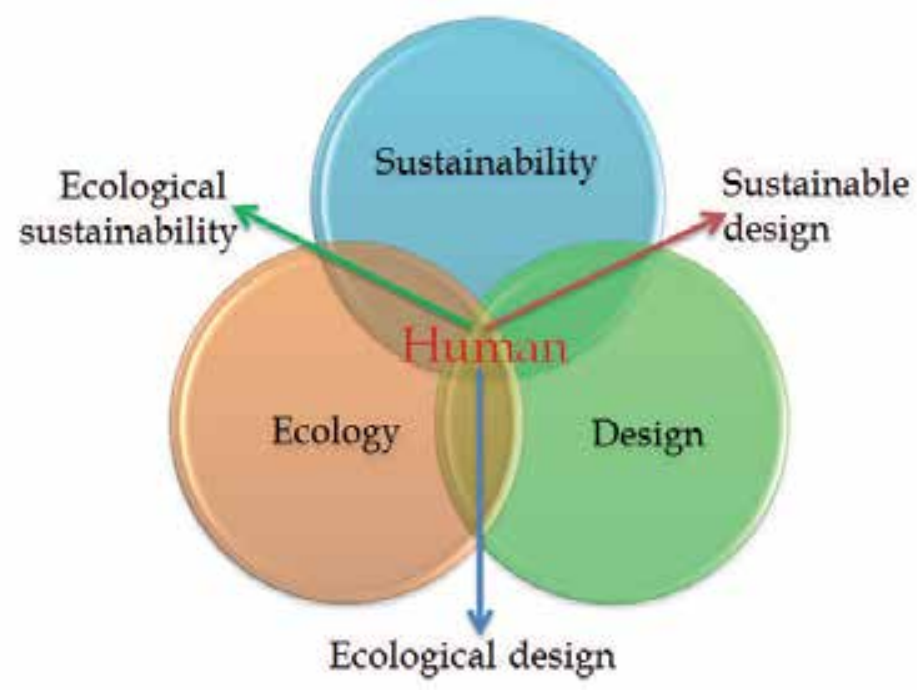

Figure 1. The relationship between ecology, sustainability and design

In landscape architecture ecology's emphasis on natural processes and the interrelatedness of landscape components influenced outlook and method and prompted an ecological approach to design (Makhzuomi and Pungetti, 1999). The ecological component is crucial in landscape design according to the principles of sustainability.

The typical relationship of designer and scientist presumes that most of what can be known is known. The designer is the creative partner; the scientist is an interactive book. Since the scientific base for ecological design is nascent, the nature of this relationship is flawed. 
Science and design are complementary ways to generate knowledge (and therefore both are creative endeavors). Scientists solve problems inductively, forming generalized principles from specific observations (Figure 2.). Designers use general principles to solve specific problems deductively. The knowledge available for ecological design would greatly increase if designed landscapes were used as ecological research sites. Designed landscapes that are typical of the surrounding region, with one to a few clear themes and repeated patterns (replication), are potential ecological research sites (Galatowitsch, 1998).

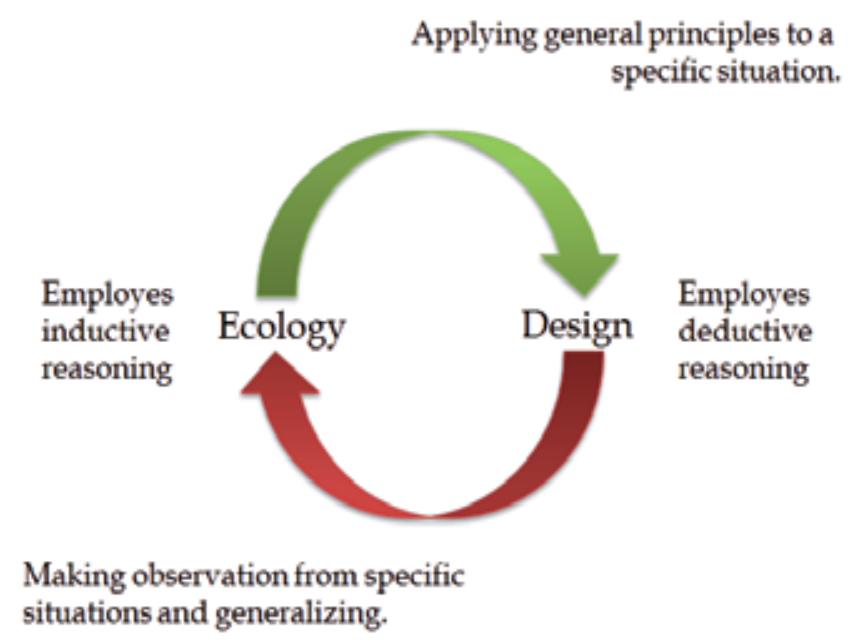

Figure 2. Design and ecology are complementary problem-solving techniques (Galatowitsch, 1998)

\section{Ecological sustainability}

Sustainability is not a single movement or approach. It is varied as the communities and interests currently grappling with the issues it raises. One the one hand, sustainability is the province of global policy makers and environmental experts. One the one hand, sustainability is also the domain of grassroots environmental and social groups, indigenous peoples preserving traditional practices, and people committed to changing their own communities. The environmental educator David W. Orr calls these two approaches technological sustainability and ecological sustainability. While both are coherent responses to the environmental crisis, they are far apart in their specifics. Technological sustainability, which seems to get most of the airtime, may be characterized this way: "every problem has either a technological answer or a market solution. There are no dilemmas to be avoided, no domains where angels fear to tread." Ecological sustainability is the task of finding alternatives to the practices that got us into trouble in the first place; it is necessary to rethink agriculture, shelter, energy use, urban design, transportation, economics, community pattern, resource use, forestry, the importance of wilderness, and our central values. While the two approaches have important points of contact, including a shared awareness of the extent of the global environmental crisis, they embody two very different visions of a sustainable society (Van Der Ryn and Cowan, 1996). 
A goal of ecological design is to help meet this vision of ecological sustainability, by finding ways of manufacturing goods, constructing buildings, and planning more complex enterprises, such as business and industrial parks, while reducing resource consumption and avoiding ecological damage to the degree possible (Shu-Yang et al., 2004).

Ecological design strives to achieve an increasing reliance on renewable sources of energy and materials, while maintaining standards of quality of goods and services and reducing overall resource consumption, waste generation, and ecological damage through efficiencies of use, re-use, and recycling.

Ecological design provides a framework for uniting conventional perspectives on design and management with environmental ones, by incorporating the consideration of ecological concerns at relevant spatial and temporal scales. If the principles of ecological design are rigorously applied, important progress will be made towards ecological sustainability (ShuYang et al., 2004).

Landscape design mostly depends on natural resources, so ecological sustainability is very important. Landscape design contributes to the ecological sustainability.

\section{Sustainable design}

There is no verifiable starting point for the current sustainable design movement. It seems to have converged from several different broad ideas concerning our relationship with the natural world. Some of the key figures who have contributed to the discussion include Frederick Law Olmsted and Calvert Vaux, John Muir, Theodore Roosevelt and Gifford Pinchot, Aldo Leopold, Rachel Carson, and Ian McHarg (Cook and VanDerZanden, 2011).

Sustainability is an ecological term that has been used since the early 1970s to mean: "the capacity of a system to maintain a continuous flow of whatever each part of that system needs for a healthy existence," and when applied to ecosystems containing human beings refers to the limitations imposed by the ability of the biosphere to absorb the effects of human activities. The term sustainable development was first used in the early ' 80 s, but was popularized by the Brundtland Report of 1987. "Sustainable" has become the buzzword of the '90s in the same way "green" was in the '80s, and is equally open to different interpretations and misuse. The Brundtland Report adopted a global perspective on the consumption of energy and resources, and emphasized the imbalance between rich and poor parts of the world, arguing that: "Sustainable development requires that those who are more affluent adopt lifestyles within the planet's ecological means." However, because the report also argued that economic growth or development is still possible as long as it is green growth, this has been interpreted by many to endorse a "business as usual" approach, with just a nod in the direction of environmental protection. This ignores the real meaning of sustainable development, which is enshrined in the widely quoted concept of "futurity": ..."meeting the needs of the present without compromising the ability of future generations to meet their own needs." 
When applied to design, this not only introduces or reintroduces the ideas of ethical and social responsibility, but also the notion of time and timescale. Thinking about the life cycle of products through time, and considerations about design for recycling, have led to the concept of DfD (Design for Disassembly) followed by the idea of going Beyond recycling towards the design of long-life, durable products. These two concepts are not as contradictory as they sound, as Victor Papanek has recently remarked: "To design durable goods for eventual disassembly may sound like an oxymoron, yet it is profoundly important in a sustainable world. The term "sustainable design" has begun to be used in the last 15 years or so to refer to a broader, longer-term vision of ecological design. At the Centre for Sustainable Design, established at the Surrey Institute of Art and Design in July 1995, sustainable design means "analyzing and changing the 'systems' in which we make, use, and dispose of products," as opposed to more limited, short-term DFE. The ECO2 group makes a similar distinction between "green design, project-based, single issue and relatively shortterm; and sustainable' design, which is system-based, long-term" ethical design. Emma Dewberry and Phillip Goggin have also explored the distinctions between ecological design and sustainable design; arguing that, whereas ecological design can be applied to all products and used as a suitable guide for designing at product level: "The concept of sustainable design, however, is much more complex and moves the interface of design outwards toward societal conditions, development, and ethics.... This suggests changes in design and the role of design, including an inevitable move from a product to a systemsbased approach, from hardware to software, from ownership to service, and will involve concepts such as dematerialization and "a general shift from physiological to psychological needs." Finally, they emphasize the extent to which consumption patterns must change, and refer to the inequality between developed and developing nations, the fact that 20 percent of the world's population consumes \%80 of the world's resources and conclude that ecological design does fit into a global move toward sustainability, but has many limitations in this context. This is the point made by Gui Bonsiepe, who has expressed the fear that ecological design will remain the luxury of the affluent countries while "the cost of environmental standards would be shifted onto the shoulders of the Third World." (Madge, 1997).

Sustainability can be viewed as the long-term outcome of maintaining landscape integrity. Designing for sustainable landscapes necessitates a holistic and integrative outlook that is based on ecological understanding and awareness of the potentialities and limitations of a given landscape. Such understanding ensures that in accommodating future uses their impact on existing ecosystems and essential ecological processes and biological and landscape diversity is anticipated. This will allow for healthy ecosystems and long-term ecological stability (Makhzuomi and Pungetti, 1999).

Designs that promote sustainable landscapes should be simultaneously aware of local values and resources as well as regional and national ones, as sustainability is the domain of both. Further, achieving landscape sustainability requires patience, humility and a design approach that attends to scale, community, self-reliance, traditional knowledge and the wisdom of nature's own (Van der Ryn and Cowan, 1996). 
Whereas maintaining landscape integrity and designing for sustainability can be seen as the practical objectives of ecological landscape design, the design of creative and meaningful places addresses aesthetic concerns.

The following is a palette of terms that in some way define or refer to sustainable design:

- Design for environment,

- Ecological design (ecodesign/eco-design),

- Environmental design,

- Environmentally oriented design,

- Ecologically oriented design,

- Environmentally responsible design,

- Socially responsible design,

- Environmentally sensitive product design,

- Sustainable product development,

- Green design,

- Life-cycle design,

- Dematerialization,

- Eco-efficiency design,

- Energy efficient design, and

- Biodesign (Deniz, 2002).

\section{The role of technology in ecological design}

Environmental problems become an increasingly important aspect of the designer's work to minimize the risks and to solve the problems. Because of the rapid technological development, environmental problems increase day by day. On the other hand, new technologies often tend to be less dangerous than what they replace, and hence designers may find themselves in the forefront of identifying problems which must be addressed by technology. Sometimes, existing technologies may not be able to provide the solution, and the designer may have to influence the development of a new technological approach. Designers must also follow technological developments in order to be sure of incorporating the most environmentally advanced technologies (Deniz, 2002).

Technology has been the principal method by which we intervene on the land and modify the ecosystems to ensure our existence, yet its various manifestations are most often ignored in discussions of the designed landscape. In fact, much of the rationale for this exhibit might be based upon the obfuscation of ecological clarity by technology and the subsequent employment of more benign and expressive techniques for bringing back such clarity. In the ordinary landscape, the instances in which intentional land design aims at a higher, symbolic meaning in some decipherable form are few when compared with the countless millions of ordinary landscape structured by the dominant, operative, contemporary technological paradigms. In one sense, we have covered up our ecosystems with our technologies; we have obscured a degree of innate clarity of the former with the vast 
complexities of the latter. While science and technology have made it possible to comprehend deeper levels of ecosystem knowledge, they have also enabled the physical cover-up and subsequent concealment of dimensions of the landscape once readily accessible to more primal peoples. With technological hegemony, our ecosystems have gained little and lost a lot (Thayer Jr., 1998).

This raises the whole issue of the relationship between design and the "Appropriate Technology" (AT) movement in the last twenty to thirty years. Schumacher (1973) coined the term "intermediate technology" to signify "technology of production by the masses, making use of the best of modern knowledge and experience, conducive to decentralization, compatible with the laws of ecology, gentle in its use of scarce resources, and designed to serve the human person instead of making him the servant of machines". The central tenet of appropriate technology is that a technology should be designed to be compatible with its local setting. Examples of current projects that are generally classified as appropriate technology include passive solar design, active solar collectors for heating and cooling, small windmills to provide electricity, roof-top gardens and hydroponic greenhouses, permaculture, and worker-managed craft industries. There is general agreement, however, that the main goal of the appropriate technology movement is to enhance the self reliance of people on local level. Characteristics of self reliant communities that appropriate technology can help facilitate include: low resource usage coupled with the extensive recycling; preference for renewable over nonrenewable resources; emphasis on environmental harmony; emphasis on small-scale industries; and a high degree of social cohesion and sense of community (Roseland, 1997).

\section{Emerge of ecological landscape design}

Landscape architecture is a multi-disciplinary field, incorporating aspects of; botany, horticulture, the fine arts, architecture, industrial design, geology and the earth sciences, environmental psychology, geography, and ecology.

Landscape architecture has ecological thinking at the core of its legacy (Mozingo, 1997). As a result of a trend favoring ecological perspectives in design, significant changes have occurred in the landscape architecture profession in recent decades through the move to integrate ecological perspectives (Hooper et al., 2008).

Thinking ecologically about design is certainly not a "new" idea. Since ancient times "designers" looked to nature for "solutions" to their common problems; they saw nature as the perfect model to follow. Even though, in recent times, an increase in ecological education and environmental awareness is apparent among design professionals, there is still the need to better understand the expression of ecology through design (Lomba-Ortiz, 2003). In the face of the environmental problems new approaches to reconciling the divide between ecology and design have been explored in landscape architecture.

Since the 1960s, ecology has increasingly influenced the design professions, providing for a holistic and dynamic outlook on nature, environment and landscape. The different 
dimensions of ecology have come to imply the ability to think broadly, to search for patterns that connect and to observe nature with insight. Alternatively, ecological knowledge allows a comprehensive understanding of landscape as the outcome of interacting natural and cultural evolutionary processes which account for pattern, diversity, sustainability and stability (Makhzuomi and Pungetti, 1999).

To date, however, ecological design has been principally concerned with the realistic emulation of ecological form, function, and, where possible, process. As an outgrowth of, and to some degree, a fusion between landscape architecture, ecology, environmental planning, and the building science aspects of architecture, there is a distinctive functional emphasis in the discipline. Ironically, artistic elements and visual aesthetics have not been a priority in a discipline that bears the label of "design." I would attribute this principally to the dominance of landscape architecture in influencing ecological design, itself (until recently) a discipline characterized by a schism between garden design and horticulture in one domain, and technical ecologists concerned with ecological restoration and reconstruction in the other. This remediative, reactive "applied ecology" practice of landscape architecture along with related environmental professions have understandably been the progenitors of the new discipline of ecological design, largely (and understandably) as a response to global environmental crises (Lister, 2005).

Motivated by environmental values, landscape architects became increasingly knowledgeable about ecological principles and systems (Meyer, 2000). Ecology, the study of interactions between organisms and their environments, has long been a compelling theme for faculty, practitioners, and students of landscape design and planning. Frederick Law Olmsted's visionary public designs, Jens Jensen's native plantings, May Watt's observations of vernacular landscapes, and Ian McHarg's book, Design with Nature, are all milestones of ecological thinking in landscape design and planning (Johnson and Hill, 2001). McHarg (1969), Spirn (1984) and Hough (1995) played seminal roles in applying theories and principles of ecological landscape design to urban areas (Özgüner et al., 2007). lan McHarg who, perhaps more than any other, popularized ecology in landscape architecture. Patrick Geddes is the initiator of an ecological approach in design and planning and because he offered an integrative view of the environment that embraced urban design, landscape design and planning. John Tillman Lyle offers a comprehensive approach embracing theory, practice and method (Makhzuomi and Pungetti, 1999).

In the late 1860's Frederick Law Olmstead supported the idea that landscape architects were stewards of the land. Olmstead's designed landscapes borrowed aesthetically from the picturesque but he was overtly conscious of ecological processes playing a critical role in the function and design of landscape spaces (Ware, 2004).

The early influence of ecology can be traced to the work of late nineteenth century visionary biologist Patrick Geddes, the conceptual initiator of an ecological approach to urban and landscape design and landscape planning. Patrick Geddes had a clear, overall conceptual strategy for improving the manmade environment and for advocating a sympathetic coexistence with the natural environment. In his 'biological principles of economics' he came closest to the present day concept of sustainability (Makhzuomi and Pungetti, 1999). 
Ecological thinking was only resumed with the publication of lan McHarg's (1969) 'Design with Nature'. The significance of McHarg's work, however, lies elsewhere, namely in introducing ecological understanding to the profession. McHarg believed that ecology had the potential to emancipate landscape architects from the static scenic images of ornamental horticulture by steering them away from arbitrary and capricious designs (Makhzuomi and Pungetti, 1999). Ian McHarg's work fore grounded much of the early sustainable design discussions of the 1970's and into the 1980's. Carl Steinz's, Fred Steiner's, and Rob Thayer's earliest work was a critique of McHarg's methods (Ware, 2004).

John Tillman Lyle's (1985) 'Design for Human Ecosystems' is a comprehensive integration of ecological concepts and landscape design. The term human ecosystems is proposed by Lyle to signify the totality of the landscape at hand as a warning against a strongly visual notion of landscape assessment and as a reminder that the landscape needs to be evaluated as the outcome of natural and cultural processes. Lyle argues the necessity of making full use of ecological understanding in the process of designing ecosystems; only then can "we shape ecosystems that manage to fulfill all their inherent potentials for contributing to human purposes, that are sustainable, and that support nonhuman communities as well".

Three aspects of Lyle's (1985) work are of direct relevance in establishing the conceptual foundation for ecological design. The first is that he attempts to tackle the complexity of design method and offers a critical investigation of the design process in the context of ecosystem, its function, structure and ecological (rather than economic) rationality. The second is that he includes 'management' as an integral part of ecosystem design, arguing that ecosystems like any organic entity have a variable future and as such, their design should be probabilistic; it is difficult to predict the changes that will take place. The implication here is that design is an ongoing process and that the final product of design is only one stage in this process; it should not be the objective. It also implies that design is interactive because it takes into account future change resulting from the designed system's interaction with its environment. A third aspect of Lyle's work is that he breaches the professional categorization of landscape architecture and landscape planning. The terms 'landscape design' and 'landscape planning' are often used interchangeably, however, uses 'design' as giving form to physical phenomena 'to represent such activity at every scale'. In this he follows others (Steinitz, 1979 and McHarg, 1969) who refer to the regional planning scale while using 'design'. Lyle viewed landscape planning's focus on the rational as inevitably excluding the intuitive (Makhzuomi and Pungetti, 1999).

More recently, designers such as Le Corbusier and Frank Lloyd Wright, among many others, have attempted, with some degree of success, to address ecological issues through their designs. "Green Architecture," "Alternative Architecture," "Sustainable Design," and "Ecological Design," are some of the terms commonly used today to describe a special expression of design that takes as its primary driving force nature's processes. Van Der Ryn and Cowan (Ecological Design, 1996) defined this form of expression as "any form of design that minimizes environmentally destructive impacts by integrating itself with living processes." A "new" movement among design professionals has been developing for some 
time now with many of its principles synthesized by the current "green" movement in design (Lomba-Ortiz, 2003).

Ecological design is an emerging interdisciplinary field of study and practice. In fact, many would argue that it is a transdisciplinary field, concerned with the creation of entirely new applications that may emerge from its progenitor disciplines or arise from a synthesis of several. Influenced principally by ecology, the environmental sciences, environmental planning, architecture, and landscape studies, ecological design is one of several rapidly evolving (theoretical and practical) approaches to more sustainable, humane, and environmentally responsible development. As such, it may also be considered a critical approach to navigating the interface between culture and nature. In the broadest sense, ecological design emerges from the interdependent and dynamic relationship between ecology and decision making.

Van Der Ryn and Cowan (1996) described ecological design as a hinge that connects culture and nature, allowing humans to adapt and integrate nature's processes with human creations. In modern industrialized societies, human culture and nature are perceived and treated as separate realms, yet their interface offers fertile ground for the creation of new, hybridized natural/cultural ecologies and the rehabilitation and re(dis)covery of others. Ecological design is inspired by the nexus of these worlds and the urgent need to blur the boundary between them; it seizes on the creative tensions between them and, as such, may offer opportunities for and insights to a re(dis)covered place of "living lightly" with the land (Lister, 2007).

By the beginning of the 21st century, ecological design had emerged as an expression of a sustainability world-view, which seeks to integrate the human enterprise with a sustainable harvest of resources, while ensuring that stresses caused to natural ecosystems are within the bounds of viability. If this can be achieved, the integrity of both the human economy and of natural ecosystems can be maintained. As such, ecological design is an all-encompassing concept, as it deals with the sustainability of:

- The enterprises of families, neighborhoods, and cities;

- The construction of buildings in a manner that decreases resource use and environmental damage to the degree possible;

- The manufacturing of certifiably green products;

- The organic production of foods and other renewable resources;

- The integration of these various activities within ecologically planned mutualisms, such as industrial and business parks, which are designed to maintain high production while reducing the use of resources and minimizing waste; and

- The maintenance of indigenous biodiversity (Shu-Yang et al., 2004).

Landscape architects continue to speculate how we can design with the materials of nature and not have the result be confused for nature itself (Ware, 2004). Beth Meyer asserts, 'to some it might seem odd that landscape architects looked toward art and design theory and practice when seeking direction about folding ecological principles and environmental values into their creative processes. But this simultaneous look to art as well as science and 
to theories of site specificity and phenomenology as well as ecology was critical to the successful integration of environmentalism into landscape architectural design.' (Meyer, 2002).

\section{Ecological landscape design}

Ecological landscape design is based on an ecological understanding of landscape which ensures a holistic, dynamic, responsive and intuitive approach (Figure 3.). It is holistic because it simultaneously considers past and present as well as local and regional landscape patterns and processes. It is responsive because it develops from a realization of the constraints and opportunities of context whether natural, cultural or a combination of both. Ecological landscape design is guided by three fundamental, mutually inclusive objectives: the maintenance of landscape integrity; promoting landscape sustainability; and reinforcing the natural and cultural spirit of place. Ecological landscape design engages the designer's rational, intellectual, emotional and creative capabilities (Makhzoumi and Pungetti, 1999).

Ecological design develops out of two areas of inquiry. On the one hand, it is the outcome of ecology's interface with the environmental design professions. Despite the differing perspectives and focus of interest, a number of common concepts have been outlined. On the other hand, ecological landscape design also utilizes fundamental ecological. Input from these two areas of inquiry forms the foundation for ecological landscape design which is here seen as integrating four overlapping attributes (Figure 3.).

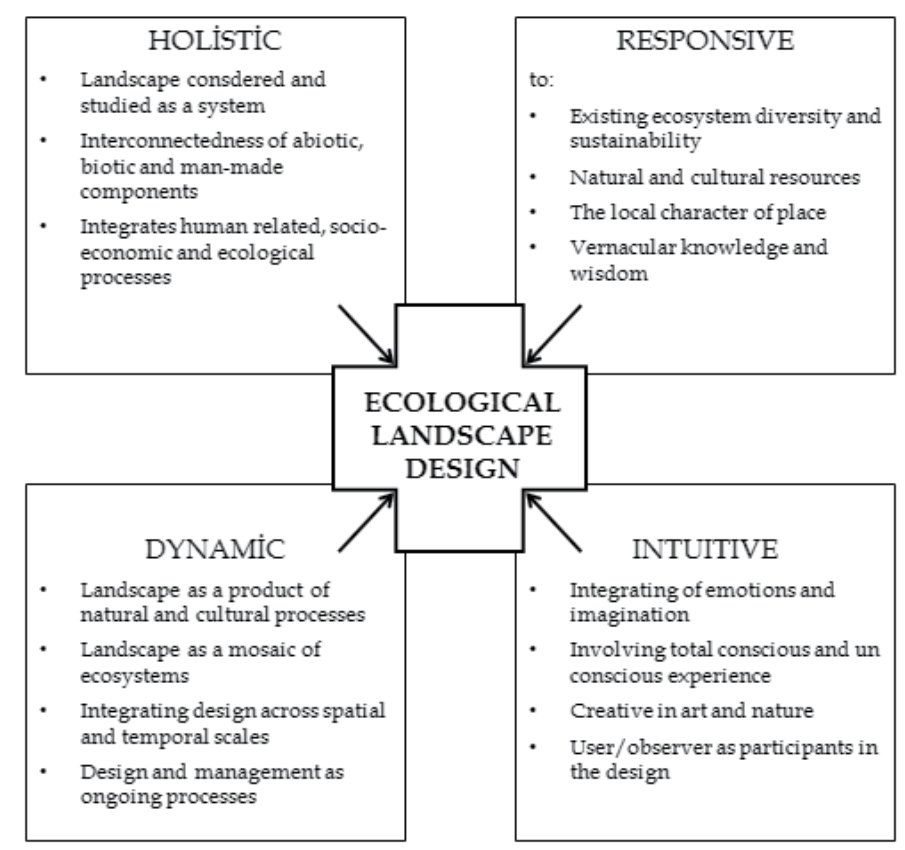

Figure 3. Framework for ecological landscape design, drawing on concepts from ecology (left) and ecological design (right) 
The first is a holistic approach to landscape understanding, integrating abiotic, biotic and cultural landscape components. The second is a dynamic approach in which landscape is investigated along two continuums: a spatial one, i.e. movement between a larger scale and a local one; and a temporal one representing the evolutionary historical development of the landscape. The third is ecological landscape design's responsiveness to the constraints and opportunities of context whether natural, cultural or a combination of both. Responsiveness also dictates an anticipatory approach that considers the impact of the design on existing ecosystems and resources. Finally, ecological landscape design is intuitive, encompassing not only the rationality of the outer world but also the neglected 'intangible relationships' of the inner world. This intuitive approach embraces a new definition of creativity that departs from the formal, i.e. object-centered, appearance-oriented aesthetics to a phenomenological participatory aesthetics where the emphasis is on the totality of human experience of the object (Makhzuomi and Pungetti, 1999).

Reviewing ecology's interaction with the environmental design professions reveals a wide range of concepts, solutions and approaches (Figure 4.). The contributions in architecture and the urban landscape design include practical strategies (e.g. energy conservation, ecological networks) and design solutions to specific problems (e.g. earth-sheltered architecture and bioclimatic design). The interaction of ecology and landscape architecture has been more extensive, leading to a holistic approach to landscape design. All the contributions, however, find inspiration in nature and aim to shape man's environment sustainably and 'beautifully'.

Ecological landscape design integrates input from landscape ecology and design, both of which are seen as providing parallel and complementary, albeit different methodological approaches. The analytic and descriptive nature of landscape ecology, the science, provides for a holistic understanding of existing landscapes, while the intuitive and creative problemsolving capabilities of design prescribe alternative courses for future landscape development (Makhzoumi, 2000).

In the different steps of the design process a lot of information has been needed to analyze and evaluate ecological processes and functions. Thus ecological design has been interdisciplinary field of study and practice.

Over the past 20 years landscape architecture has re-invested in ecologically driven design. Ware (2004) investigates the following typologies:

- Interpretation and Environmental Education

- Environmental Remediation/Re-vegetation

- $\quad$ Re-Use/Re-programming

- Eco-Revelatory Design

- The Art of Landscape Function

- Intertwining Ecologies

- Constructed Ecologies

- Simulated 'natural' Attractions 
The typological framework aims to illustrate and differentiate current methods of approaching ecological design in landscape architecture. The eight categories include a critical reflection as to how the work itself may not be addressing much of the dynamic, ecological processes that the projects are predicated upon (Ware, 2004).

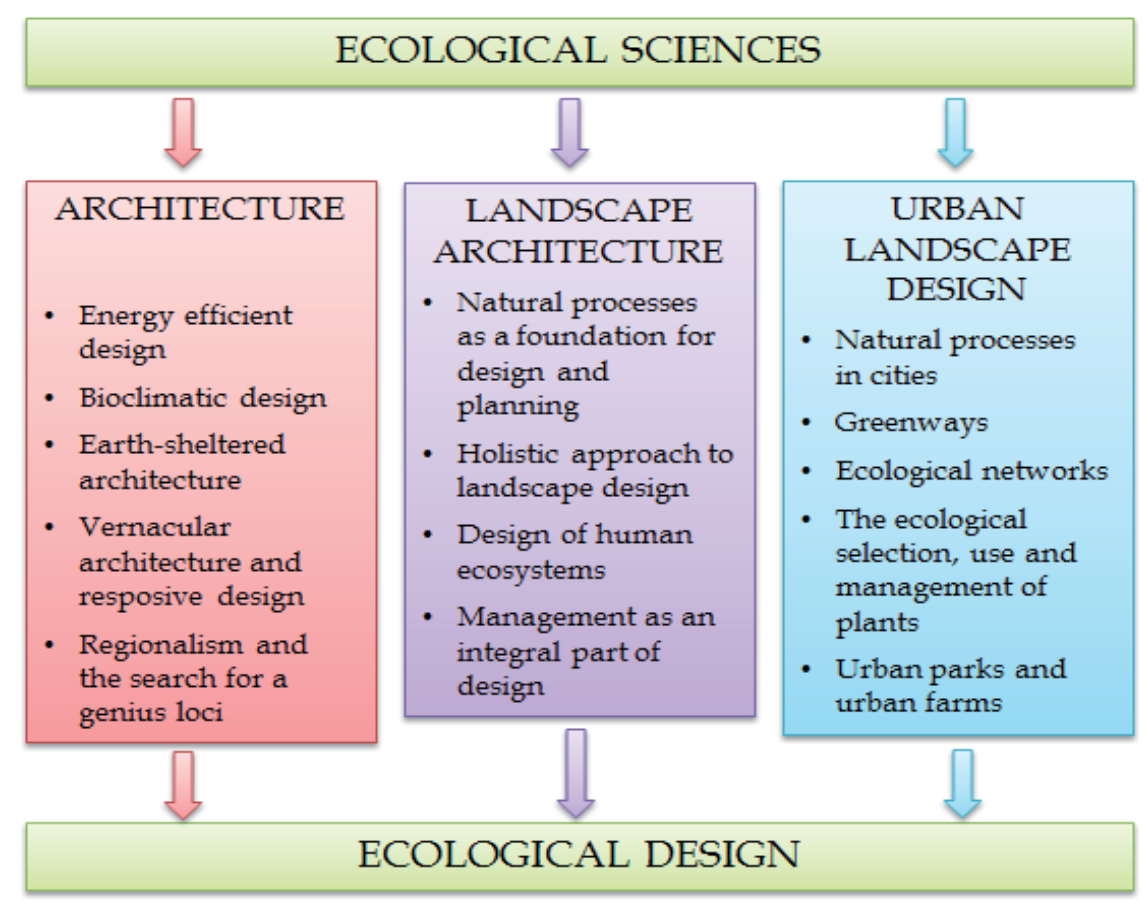

Figure 4. The interface of ecology with architecture, landscape architecture and urban landscape design (Makhzuomi and Pungetti, 1999)

\subsection{Principles of ecological landscape design}

The main ecological principles concerning cities are that:

- Cities are ecosystems;

- Cities are spatially heterogeneous;

- Cities are dynamic;

- Human and natural processes interact in cities; and

- Ecological processes are still at work and are important in cities.

The first three principles address the structure of cities and the change in structure through time. The remaining two principles focus on ecological processes in cities (Table 1.).

The first principle suggests that landscape design theory and management practice must address all the components of such systems. Urban ecosystems include four broad kinds of components (organisms, a physical setting and conditions, social structures, and the built environment) all interacting with one another. Landscape designs and management 
strategies that are aimed at one or two of these components or interactions, in reality have the potential to affect them all. Landscape designs that acknowledge and work with the connections between the social, biological, physical, and built components of the system are much less likely to produce unintended negative consequences, and are more likely to contribute to ecological sustainability. Furthermore, enhanced quality of urban life depends on all components of the urban ecosystem, not just some of them (Cadenasso and Pickett, 2008)

\begin{tabular}{l|l} 
Principles & Summary of Implication for Landscape Design \\
\hline Cities are ecosystems & Design affects all four components of human ecosystems. \\
\hline Cities are heterogeneous & $\begin{array}{l}\text { Design should enhance heterogeneity, and its ecological } \\
\text { functions. }\end{array}$ \\
\hline Cities are dynamic & $\begin{array}{l}\text { Design must accommodate internal and external changes } \\
\text { projects can experience. }\end{array}$ \\
\hline $\begin{array}{l}\text { Human and natural } \\
\text { processes interact in } \\
\text { cities }\end{array}$ & $\begin{array}{l}\text { Design should recognize and plan for feedbacks between } \\
\text { social and natural processes. }\end{array}$ \\
\hline $\begin{array}{l}\text { Ecological processes } \\
\text { remain important in } \\
\text { cities }\end{array}$ & $\begin{array}{l}\text { Remnant ecological processes yielding ecological services } \\
\text { should be maintained or restored. }\end{array}$ \\
\hline
\end{tabular}

Table 1. A brief summary of the general implications of each of the five principles of urban ecology for ecologically motivated landscape design and management

The second principle suggests that interactions and transfers among patches within the urban matrix are affected by landscape design and management. Urban landscape design should carefully consider the heterogeneity and its role in maintaining desirable functions such as biodiversity, storm water retention, microclimate mitigation, and carbon sequestration. The interaction between a particular landscape project and adjacent patches of similar or contrasting landscape structure can enhance the function and value of individual projects. This may mean paying particular attention to the boundaries between contrasts within or between projects to enhance or protect from exchanges.

The third principle means that landscape designs should accommodate change. Natural disturbances, extreme climate events, shifting economic investment or disinvestment, the maturation of households, and the aging of or renovation of infrastructure are but some of the examples of the kinds of dynamism that landscape designs and management will have to respond to. Persistent equilibrium in cities is unlikely. Designs that plan for successional changes in vegetation have redundancies in the face of disturbance, or that encourage use by different age groups may be more resilient in changing cities.

The fourth principle suggests that both of these major categories must be addressed as landscape design goals. A design that satisfies only obvious social criteria, such as recreation or efficiency of commerce, misses an opportunity to contribute to ecosystem services that 
may ultimately have great social value. All landscape designs and management schemes should be judged for their ability to contribute to both social and ecological goods and services, and to reduce both social and ecological risks and vulnerabilities.

The fifth principle means that landscape designs and management practices have the opportunity to preserve and promote those basic biological processes upon which human health and well-being depend. It will be important to provide for these functions even in areas beyond the large green parcels usually targeted for this kind of benefit. The control of water flow and infiltration, the retention of limiting and hence potentially polluting nutrients, the sequestration of carbon dioxide, the neutralization of toxics, the maintenance of soil respiration, the production of biomass, the amelioration of climate extremes, the mitigation of natural disturbance, and the preservation of biodiversity, are but some of the processes that can exist in various places in designed systems. Landscape designs and management protocols can be purposefully planned so as to maintain, or in some cases restore, as many of these kinds of natural processes as possible throughout the urban matrix. As such, landscape design and management can provide creative new ways to insinuate ecological processes in cities (Cadenasso and Pickett, 2008).

Ecologically designed urban landscapes are ones that can use both ecological processes and human values as form-giving elements. In addition to their many environmental benefits, these landscapes -which include systems such as energy efficient buildings, storm water infiltration, sewage treatment wetlands, and urban forests- can also contribute to local cultures of sustainability that, like all cultures, both shape and are shaped by the built and designed environment. If they are to do so, however, their designers must think clearly about the experience of the users of the urban landscape, and particularly about the meanings and lessons that they derive from their surroundings. The ways that people learn from and respond to the urban environment are critical to the prospects for sustainability, if for no other reason than that for most of us, it is the landscape of the city that helps to shape our view of nature and our relation to it (Eisenstein, 2001).

Ecological landscape designs fall into four categories:

1. Preservation of existing, functioning ecological systems;

2. Enhancement or re-establishment of degraded ecological systems;

3. Intensification of ecological processes to mitigate potential or existing ecological degradation; and

4. Environmental interventions which reduce nonrenewable resource consumption (Mozingo, 1997).

Van Der Ryn and Cowan (1996) have pointed out principles of ecological design Table 2.. The first principle grounds the design in the details of place. In the words of Wendell Berry, we need to ask, "What is here? What will nature permit us to do here? What will nature help us to do here?" The The second principle provides criteria for evaluating the ecological impacts of a given design. The third principle suggest that these impacts can be minimized by working in partnership with nature. The fourth principle implies that ecological design is 
the work not just of experts, but of entire communities. The fifth principle tells us that effective design transforms awareness by providing ongoing possibilities for learning and participation. Taken together, these five principles help us to think about the integration of ecology and design.

\begin{tabular}{l|l} 
Principles & Summary of Implication for Landscape Design \\
\hline $\begin{array}{l}\text { Solutions grow from } \\
\text { place }\end{array}$ & $\begin{array}{l}\text { Ecological design grows from an intimate, detailed knowledge } \\
\text { of the place and its nuances. }\end{array}$ \\
\hline Make nature visible & $\begin{array}{l}\text { Make sure natural cycles and processes are visible to bring the } \\
\text { designed environment back to life. }\end{array}$ \\
\hline Design with nature & $\begin{array}{l}\text { Nature's living processes offer opportunities to design using } \\
\text { natural cycles, natural waste, and regeneration as part of the } \\
\text { total design. }\end{array}$ \\
\hline $\begin{array}{l}\text { Ecological accounting } \\
\text { informs design }\end{array}$ & $\begin{array}{l}\text { By tracing the environmental impacts of a design, we can } \\
\text { discover the more ecologically sound options. }\end{array}$ \\
\hline Everyone is a designer & Listen to every voice in the design process. \\
\hline
\end{tabular}

Table 2. Principles of ecological design

\subsection{Examples of ecological landscape design}

\subsubsection{The West Davis Pond}

The West Davis Pond in Davis, California, is exemplary of the new landscape space of ecological design. The subdivision of a single family and low-rise apartment neighborhood required capacity improvement of an existing storm-water-treatment settling pond. This prosaic infrastructure requirement innovatively integrates a constructed habitat for numerous over-wintering migratory birds and resident wildlife whose wetland habitats have largely been destroyed in the Central Valley.

The pond had pre-existing development on three sides: an arterial roadway edged by backyard fences, a long edge of directly adjacent backyard fences, and warehouse commercial uses. On the fourth side, the project developers and their team of engineers, environmental scientists, and landscape architects conceived of the pond as integral to the open space of the new development. In lieu of a more typical suburban park, between the housing and the pond, a bike path, part of a famous city-wide system, incorporates two pond overlooks and a constructed arroyo channel as a children's play area. Between the manicured, exotic landscape of the housing and the habitat planting of the pond, transitional "native planting" envelopes the bike path, overlooks, and play area (Figure 5.). Most of the species are not native to this part of California, and many are unhealthy or dying.

As one of the first storm-water-treatment wildlife ponds in the Central Valley, and one of the first wetland restoration projects within an urban context, the project is laudable in ways-it is based on sound ecological science, it achieves its clearly stated ecological goals, it 
is innovative, and it manifests strong community support. The project was done with conscience, care, and the considerable risk that precedents always entail (Mozingo, 1997).

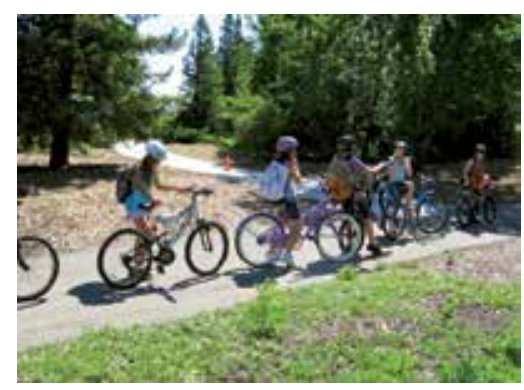

Bike path

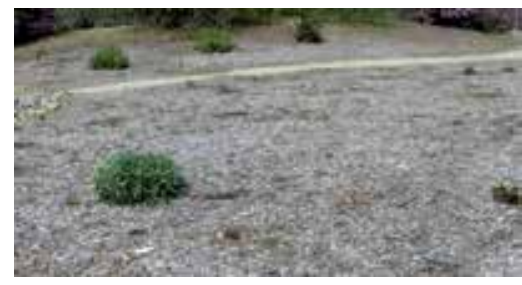

How it looked in 2007

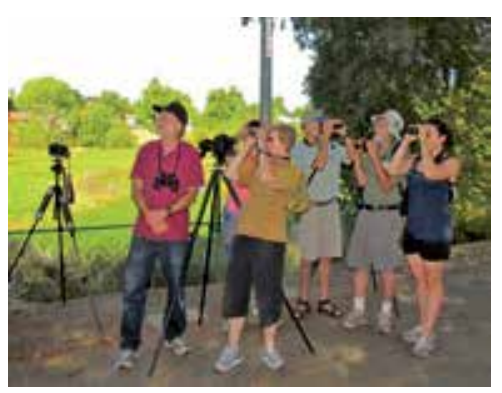

Birding walks

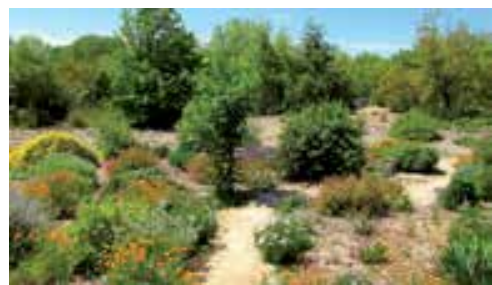

How it looked in 2010

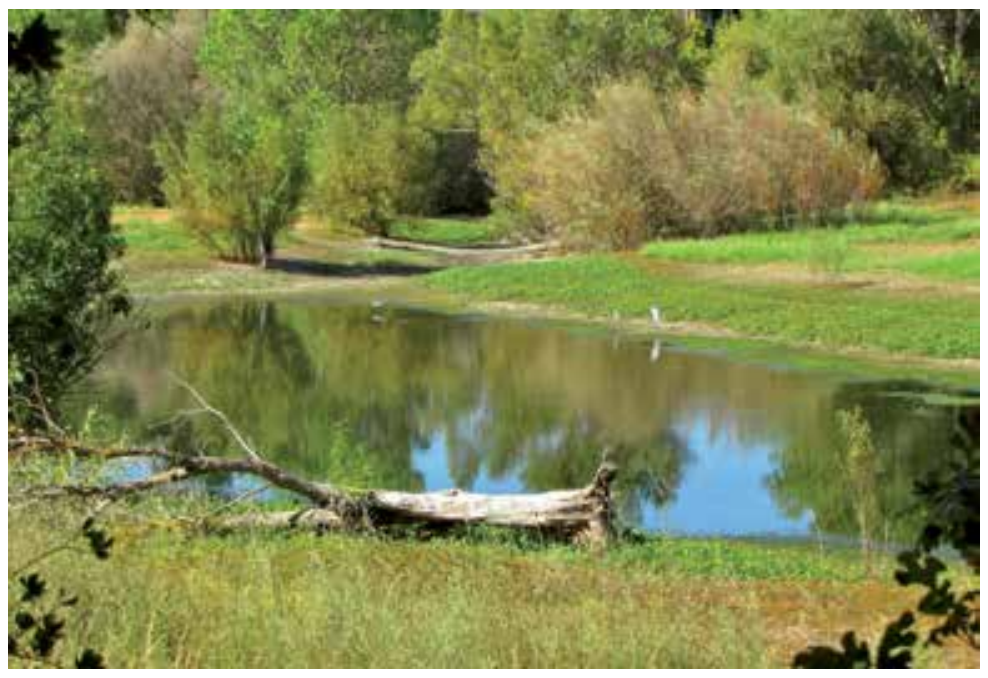

Early fall at the pond

Figure 5. The West Davis Pond (Anonymous, 2012)

The West Davis Pond is a new kind of ecologically integrated project, with measurable ecological benefits that we want to increasingly infiltrate into the landscape. The Pond is an enhanced wetland wildlife habitat, while its primary purpose is to retain storm water runoff and help prevent flooding. In the dry months, water is provided by a supplementary well. 
The Pond is enclosed by a security fence and is designated a "Wildlife Preserve" and "Sensitive Habitat Area" by the City of Davis. Native trees and shrubs grow on the slopes around the Pond and provide habitat for a diversity of wildlife (Anonymous, 2012).

\subsubsection{The Glenn W. Daniel King Estate Park}

The Glenn W. Daniel King Estate Park encompasses eighty acres of a north-south ridge overlooking the East Bay Hills and an expansive panorama of the San Francisco Bay. The park is the largest open space and only urban wild land west of Interstate 580, the city's social and physical divide. The Glenn W. Daniel King Estate Park is not blueprint for a park constructed as a single project. Rather, it is a guide for a sustained effort to bring to fruition a park that is ecologically healthy and well integrated into the social life of its community (Figure 6.). The park lies within a home owning, middle-class, primarily African American neighborhood considerably integrated with European American, Latino and Asian American residents (Mozingo et al., 1998).

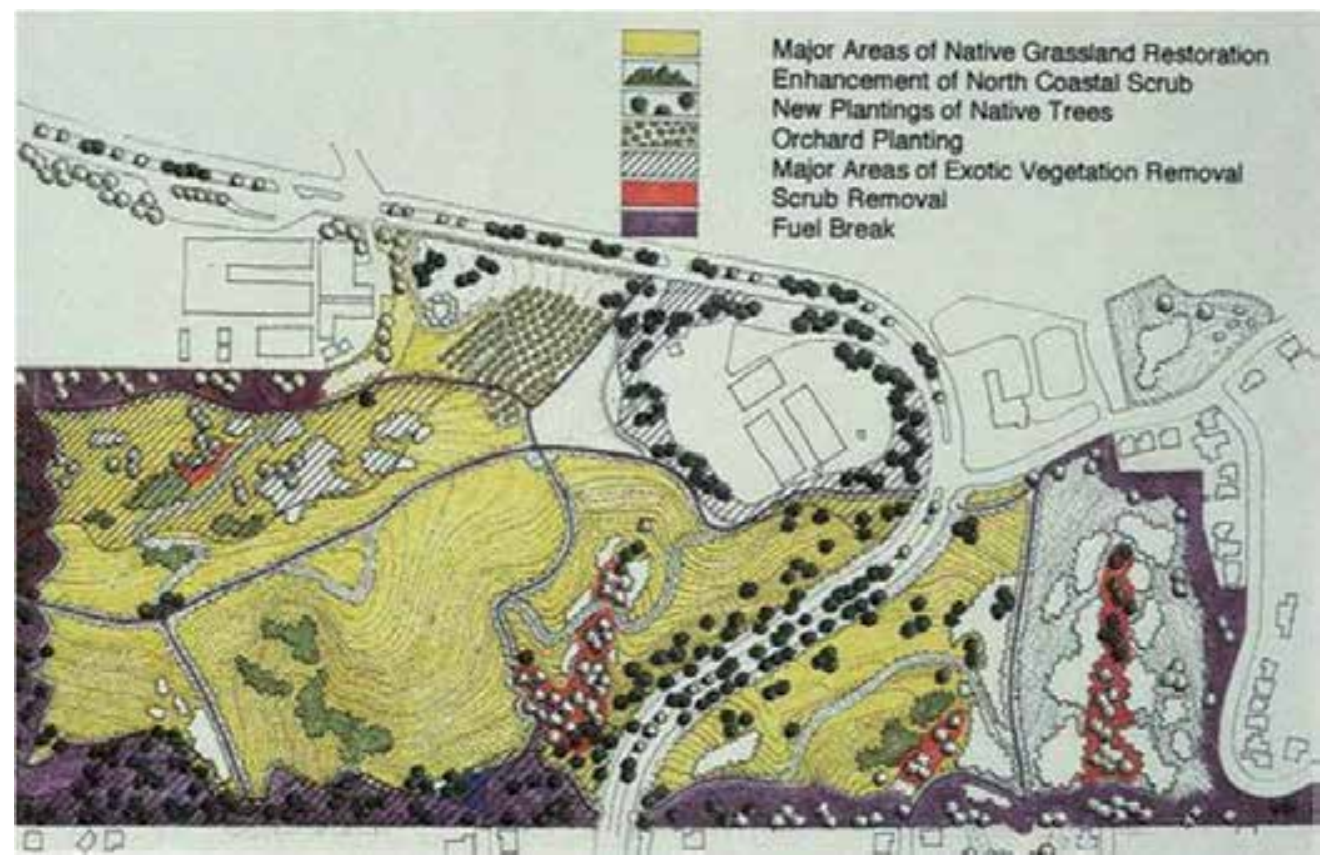

Figure 6. The Glenn W. Daniel King Estate Park Master plan (Mozingo et al., 1998)

A partnership ethic respects both cultural diversity and biodiversity. In the hills above Oakland, California, a culturally diverse middle-class neighborhood consisting of a majority of African Americana along with many European, Asian, and Latin Americans worked in partnership with the each other and with landscape architect Louise Mozingo of the University of California, Berkeley. The goal was to restore biodiversity to the oak groves from which the city derived its name and ecological heritage. Together they devised a plan to develop the neighborhood's The Glenn W. Daniel King Estate Park to benefit from the 
diversity of perennials grasses, oak savannahs, and brushy chaparral indigenous to the area. At the same time, they revamped hiking trails, added a recreation center, and increased security. The resulting master plan provided "a template for how communities can become active partners in the fulfillment of their own environmental visions" (Merchant, 2004).

\subsubsection{Village of Yorkville Park}

The idea of this urban park dates back to the late 1950s when a block of Victorian-era row houses was demolished along Cumberland Street to allow for the construction of the Bloor Danforth subway line. The park sits at the cusp of two neighborhoods: the small-scale old Yorkville neighborhood with its late 19th and early 20th century row houses, and the highrise commercial core that has built up along the Bloor Street corridor since the subway opened. For years, this highly visible site remained a parking lot. Activist neighbors fought to build a public place to bring the neighborhood together rather than to divide it. Finally, in 1991, the City of Toronto Department of Parks, Forestry and Recreation announced an international design competition (Figure 7.).

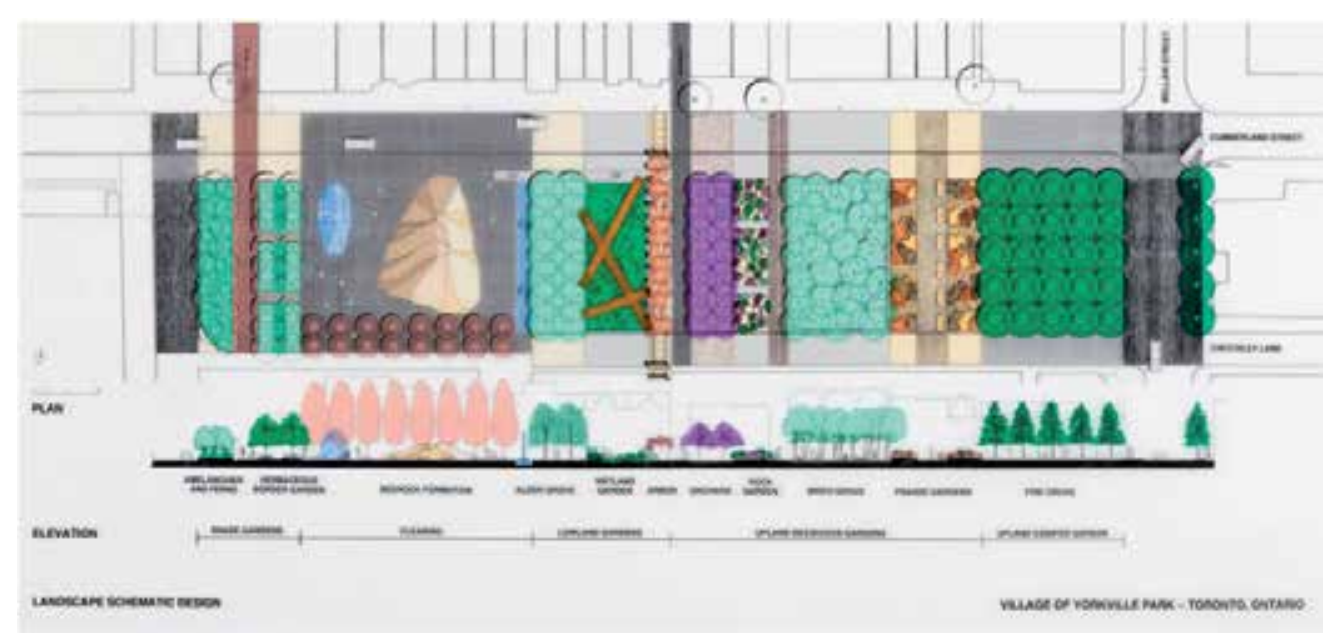

Figure 7. Village of Yorkville Park landscape schematic design (Anonymous, 2012a)

The community wanted a park that reflected the scale and context of the neighborhood, incorporated the native ecology of the surrounding region, and made connections with the circulation of local streets and a system of midblock passageways. The design strategy for the competition was to design the park to express the Victorian style of collecting. In this case, "collecting" landscapes of Ontario -pine groves, prairies, marshes, orchards, alder woods, rock outcroppings and so on -and arranging them in the pattern of the nineteenth century row houses.

The park design creates a series of linear subdivisions with contextual alignments to the building lot lines across the street and connections to mid-block passageways in the 
adjoining blocks. Each linear park segment is distinct in character but related to the next, creating a park of diversity and unity. To anchor this space with an element of regional glacial geology, a large 700-ton bedrock outcrop of native Muskoka granite was taken apart along natural crevices, moved 150 miles south, and reconstructed on site. Immense yet inviting, the outcrop has a wonderful tactile surface for sitting and absorbs warmth on cool sunny days. Moveable tables and chairs next to the boulder offer a nice contrast of permanence and flexibility (Figure 8.).
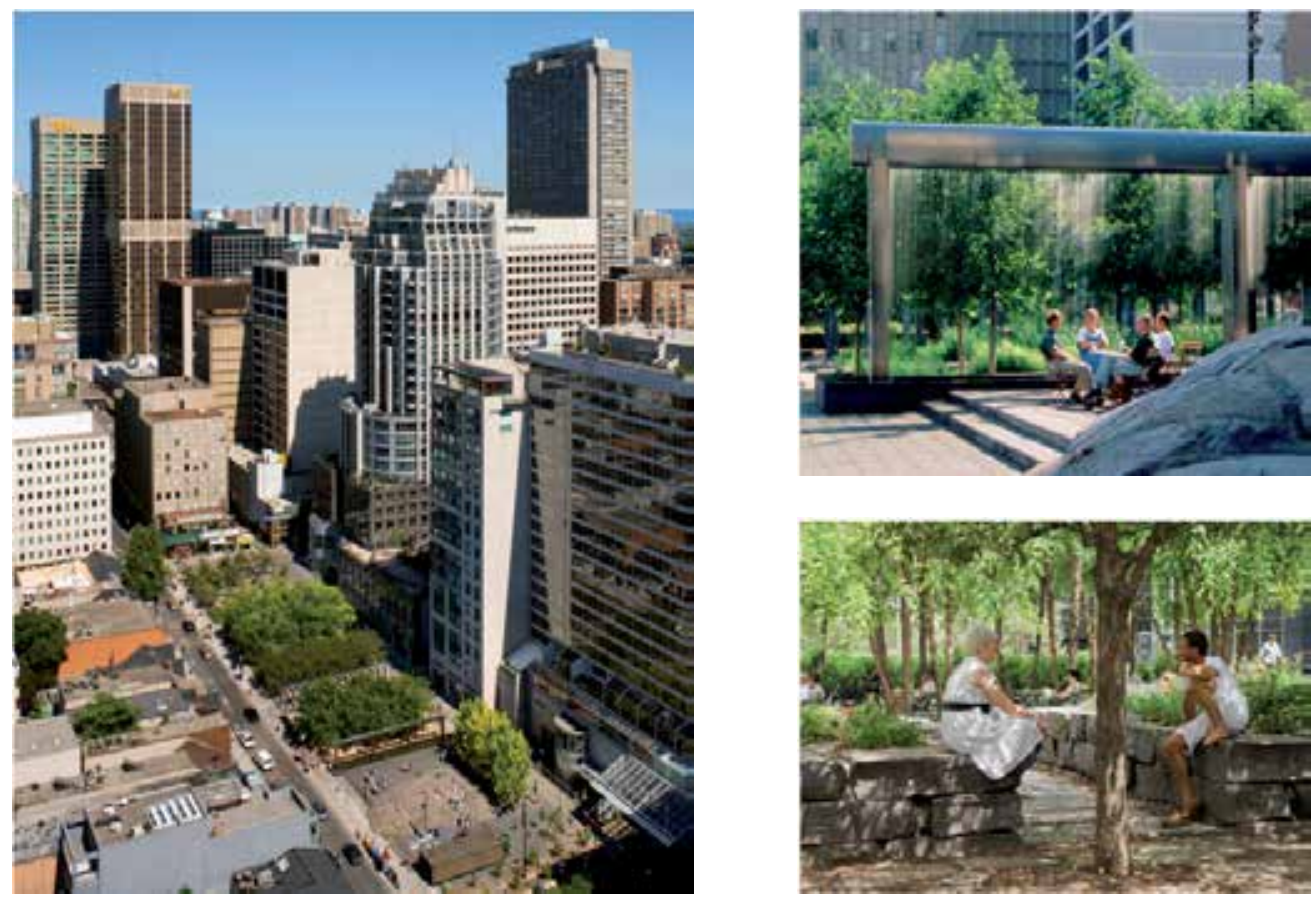

Figure 8. Village of Yorkville Park

The park has become a local landmark. While small in size, Yorkville's park has played an important role in the revitalization of the neighborhood since its completion in 1994. The neighborhood has continued its redevelopment with several new high-rise buildings rising along the edge or near the park. Recently, the park underwent some restoration work, but its original design integrity as a distillation of regional ecology, along with its role as a neighborhood connection point, remain as strong as ever. The park is owned and maintained by the City of Toronto Department of Parks, Forestry and Recreation. The BloorYorkville Business Improvement Area takes an active role in the management and programming of the park (Anonymous, 2012a).

\subsubsection{Downsview Park}

In 1999, the Parc Downsview Park announced an International Design Competition in attempt to turn Downsview Park into an urban park, and potentially one of the largest ones 
in the world, in which Bruce Mau Design, Rem Koolhaas, Oleson Worland, and Petra Blaisse submitted the winning design scheme, known as "Tree City." Parc Downsview Park has since come up with a new plan to construct commercial and residential developments instead (Anonymous, 2012b). This 320-acre federal park will provide natural and formal garden environments, offering both passive and active recreation while promoting such themes as environmental sustainability, new ecologies, and the rich heritage of the site. Contributors to this volume analyze the entries of the competition finalists and consider a range of issues raised by the competition, including landscape architecture, geography, landscape ecology, and contemporary urbanism (Czerniac, 2002).

Downsview Park is designed to support environmental, social and economic sustainability. The vision for the park is the creation of a recreational space incorporating expansive open space areas, as well as the repurposing of an inventory of historic aviation-related buildings to create a year-round setting (Figure 9.). Downsview Park is a model development demonstrating sustainable practices in its design, construction, operation and maintenance. It is intended to be a recreational, educational and cultural amenity for all Canadians (Figure 10.); a diverse, healthy and livable community for its occupants, visitors and neighbors; and an educational demonstration project of international significance. In addition to creating a unique park on the majority of the lands, portions of the property will be developed to facilitate creating and maintaining Downsview Park. More than \$20 million has been spent to date on construction, improvements to infrastructure and renovations of older buildings. The investment that Downsview Park is making in the public realm will have a significant impact well beyond its 231.5 hectares ( 572 acres) -job creation, increased real estate values, social and cultural engagement and numerous environmental benefits are all a direct result of the work being performed in the creation of the Park (Anonymous, 2012c).

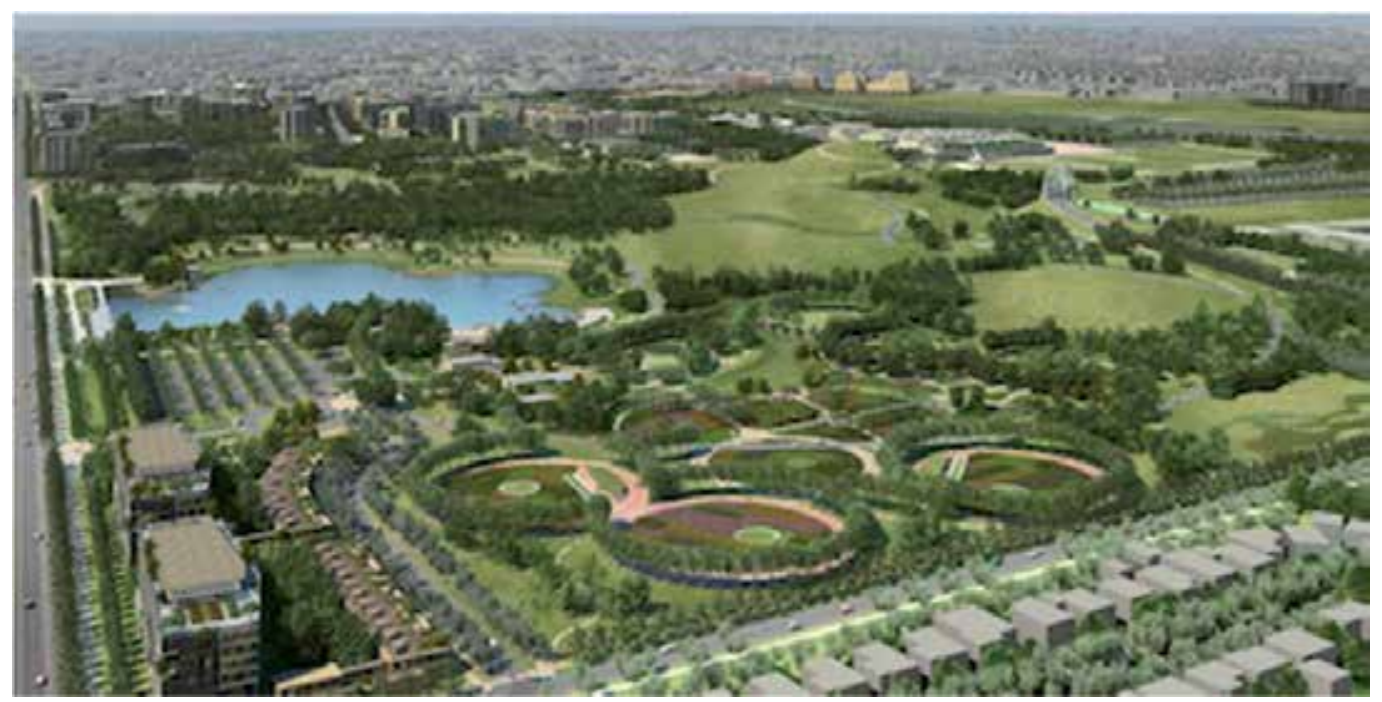

Figure 9. Downsview Park (Anonymous, 2012b) 


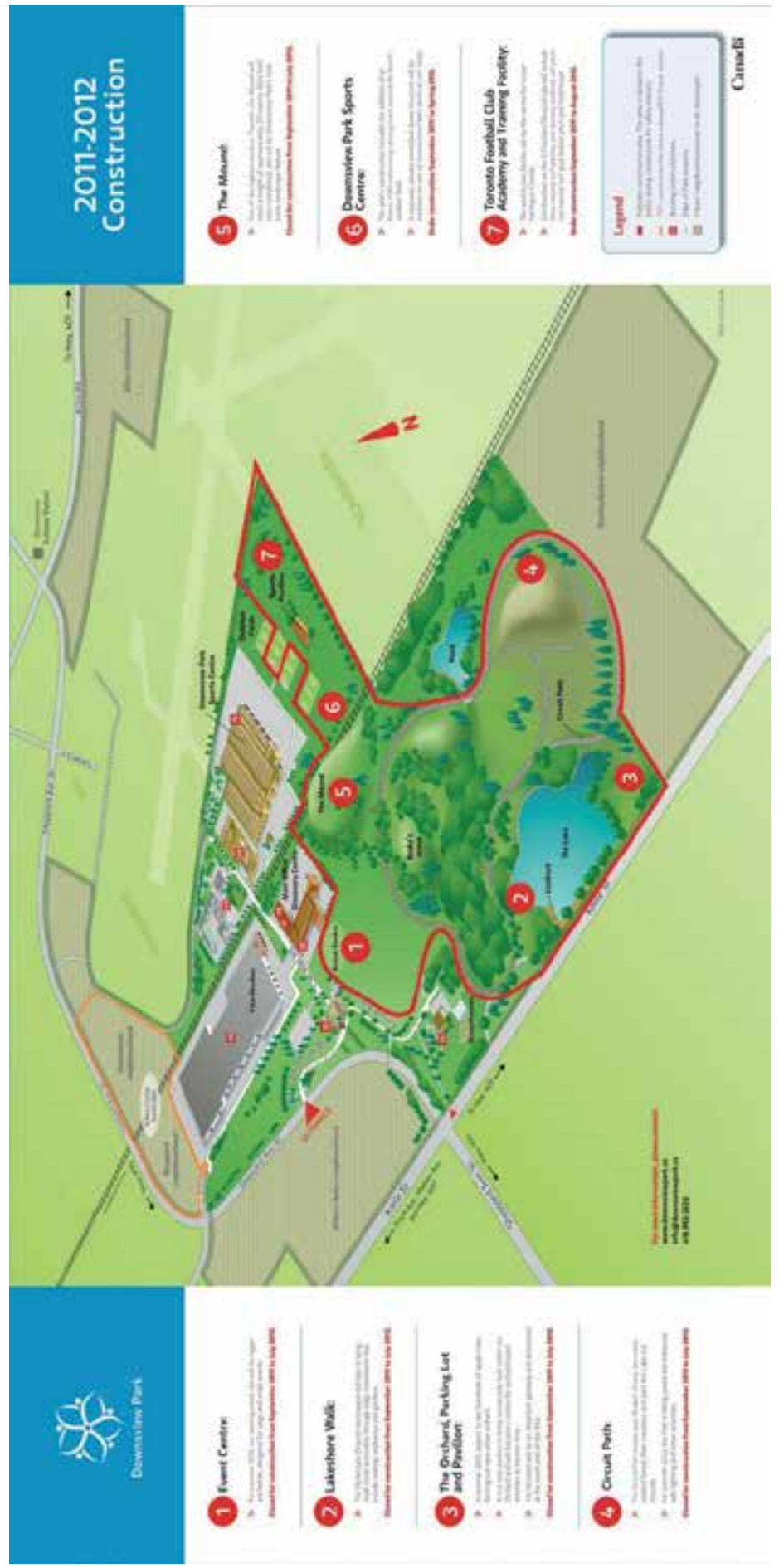

Figure 10. Recreational, educational and cultural amenities in the Downsview Park (Anonymous, 2012d) 


\section{Author details}

Filiz Çelik

Selçuk University, Faculty of Agriculture, Department of Landscape Architecture, Konya, Turkey

\section{References}

Ahern, J., France, R., Hough, M., Burley, J., Turner, W., Schmidt, S., Hulse, D., Badenhope, J. and Jones, G. 2001. Integration Ecology "across" the Curriculum of Landscape Architecture. B. R. Johnson and K. Hill (eds). Ecology and Design Frameworks for Learning, Island Press, ISBN: 1-55963-813-3, USA.

Anonymous, 2012. http://daviswiki.org/Friends_of_West_Pond (accessed 15 October 2012).

Anonymous, 2012a. http://www.asla.org/2012awards/034.html (accessed 15 October 2012).

Anonymous, 2012b. http://www.cicadadesign.ca/portfolio/downsviewpark.html (accessed 22 November 2012).

Anonymous, 2012c. http://en.wikipedia.org/wiki/Downsview_Park (accessed 22 November 2012).

Anonymous, 2012d. http:/ / downsviewtownhomes.com/wpcontent/uploads/2011/12/constructionmap_nov2011_EN.jpg (accessed 22 November 2012).

Cadenasso, M. L. and Pickett. S. T. A., 2008. Urban Principles for Ecological Landscape Design and Management: Scientific Fundamentals. Cities and the Environment, vol: 1(2), p.16.

Czerniak, J., 2002. Downsview Park Toronto. Prestel, USA.

Cook, T. W. and VanDerZanden, A. M., 2011. Sustainable Landscape Management: Design, Construction, and Maintenance, John Wiley \& Sons, Inc., USA.

Deniz, D., 2002. Sustainability and Environmental Issues in Industrial Product Design, Izmir Institute of Technology. Master Thesis on Industrial Design, Turkey.

Eisenstein, W. 2001. Ecological Design, Urban Places, and the Culture of Sustainability. San Francisco Planning and Urban Research Association, http://www.spur.org/documents/pdf/010901_article_02.pdf (accessed 02 October 2012).

Galatowitsch, S. M., 1998. Ecological Design for Environmental Problem Solving. Landscape Journal, Fall 98, vol: 17, no: 2, p. 99-107.

Helfand, G. E., Park, J. S., Nassauer, J. I. and Kosek, S. 2006. The Economics of Native Plants in Residential Landscape Designs. Landscape and Urban Planning, vol: 78, p. 229-240.

Hooper, V. H., Endter-Wada, J. and Johnson C. W. 2008. Theory and Practice Related to Native Plants: A Case Study of Utah Landscape Professionals. Landscape Journal, vol: 27, p. 127-141. 
Johnson, B. R. and Hill, K. 2001. Ecology and Design Frameworks for Learning, Island Press, ISBN: 1-55963-813-3, USA.

Lister, N. M. 2007. Sustainable Large Parks: Ecological Design or Designer Ecology?. In: J. Czerniak \& G. Hargreaves (eds.), Large Parks. Princeton NJ: Princeton Architectural Press, p. 31-51.

Lister, N. M. 2005. Industrial Ecology as Ecological Design: Opportunities for Re(dis)covery, In R. Coté, J. Tansey and A. Dale (eds). Linking Industry and Ecology: A Question of Design. Vancouver: UBC Press, pp. 15-28.

Lomba-Ortiz, E. A., 2003. Questioning Ecological Design: A Deep Ecology Perspective. Ecotecture, http://www.ecotecture.com/library_eco/appropriate_tech/lomba-ortiz_ questioningeco.html (accessed 04 December 2012).

Madge, P., 1997. Ecological Design: A New Critique. Design Issues, vol: 13, no: 2, A Critical Condition: Design and Its Criticism (Summer, 1997), p. 44-54.

Makhzoumi, J. M. 2000. Landscape Ecology as a Foundation for Landscape Architecture: Application in Malta. Landscape and Urban Planning, vol: 50 (2000), p. 167-177.

Makhzuomi, J. M. and Pungetti, G. 1999. Ecological Landscape Design and Planning, Taylor \& Francis, ISBN-13: 978-0419232506, USA.

McHarg, I. L. 1969. Design with Nature, Natural History Press, New York.

Merchant, C., 2004. Reinventing Eden: the Fate of Naturein Western Culture, Taylor \& Franchis Books, Inc., p. 238, USA.

Meyer, E. K. 2000. The Post-Earth Day Conundrum: Translating Environmental Values into Landscape Design, Environmentalism in Landscape Architecture (Edt: Michel Conan), Dumbarton Oaks Research Library and Collection, vol: 22, p. 187-244, USA.

Mozingo, L. A., 1997. The Aesthetics of Ecological Design: Seeing Science as Culture, Landscape Journal, Spring 97, vol: 1, p. 46-59.

Mozingo L. A., Baker, A., London, J., Ancel, N., Cheng, I. and Dohi, M. 1998. The Glenn W. Daniel King Estate Park Master Plan. Landscape Journal, vol: 17, p.12-14.

Özgüner, H., Kandle, A. D. and Bisgrove, R. J. 2007. Attitudes of Landscape Professionals

Towards Naturalistic Versus Formal Urban Landscapes in the UK. Landscape and Urban Planning, vol: 81, p.34-45.

Papanek, V. 1995. The Green Imperative, Ecology and Ethics in Design and Architecture. Thames and Hudson, p. 256, London.

Roseland, M., 1997. Dimensions of the Eco-city. Cities, vol: 14, no: 4, p. 197-2002.

Shu-Yang, F., Freedman, B. and Cote, R. (2004). Principles and Practice of Ecological Design. Environmental Review, vol: 12, p. 97-112, doi: 10.1139/A04-005, Canada.

Thayer Jr., R. L. 1998. Landscape as an Ecologically Revealing Language. Landscape Journal, vol: 17 , isuue: 2 , p. 118- 129.

Todd, J., Brown, E. J. G. and Wells, E., 2003. Ecological Design Applied. Ecological Engineering, vol: 20, p. 421-440.

Van Der Ryn, S. and Cowan S. 1996. Ecological Design. ISBN: 1-55963-389-1, USA. 
Ware, S., 2004. The Nature of Design, 2004 AILA Nationla Conference (200 MILE CITY), Landscape Architecture Online: an online magazin published by the Australian Institute of Landscape Architects, Australia. 


\title{
Crosby Arboretum (Picayune, Mississippi): A Natural World for All
}

\author{
Banu Ozturk Kurtaslan and Robert Brzuszek \\ Additional information is available at the end of the chapter
}

http://dx.doi.org/10.5772/55815

"At the Crosby Arboretum, Picayune, Mississippi, I listened for and found my voice..." Edward L. Blake Jr.

\section{Introduction}

Arboretums are living plant museums where mainly the taxa of trees and other wood-like plants of known origin and age, each of which are gathered in a correct and careful manner for the purposes of scientific research and observation, are cultivated, exhibited and introduced in suitable selected habitats [1].

Arboretums are garden abstractions for interpreting the natural landscape. These gardens offer biological and ecological diversity of collections, serve as conservation of soil, water and biological resources, demonstration of environmentally responsible landscape design, and restoration of degraded landscapes.

Being of vital importance for the protection of the nature in the present day urban life, arboretums at the same time have important roles in terms of esthetical and recreational aspects. In addition to providing scientific data regarding plants, arboretums also assume the function of presenting their natural beauties, esthetical qualities (size, form, texture, line and color characteristics) and introducing rich species of plants [2].

The functions of arboretums, whose formation on the earth dates back centuries ago, shows variety. These functions are giving information to all the students from elementary and secondary education to the university level and to the local community primarily about wood-like plants and secondly if they desire, about herbaceous plants, introducing these plants in their habitats and contributing to the development of a consciousness of protecting the environment. Besides, other functions of arboretums can be listed as introducing the natural, endemic and exotic plants from all corners of the world without having to go on 
long and expensive trips through gathering them as climate allows, giving people the opportunity to select the plants with esthetical value, taking endangered species under preservation, conducting studies on the adaptation of the species of foreign origin to the country. Furthermore, the functions of special-purpose arboretums will certainly be different. Arboretums that are organized to maintain the cultivation of a limited number of species can be given as an example to such places [3].

In the beginning, botanical gardens and arboretums were generally created for the introduction and production of newly discovered plants. Big botanical gardens, such as Arnold Arboretum or Kew Botanical Garden in London, collect plant species from all around the world and maintain the affluence of these species by developing and reproducing them. In recent times, this function has become of secondary importance. This is because the number of newly discovered plants is not as much as it was in the 19th century. However, there are still travels for discovering new species [4].

The functions of arboretums can be summarized as follows:

- They maintain the physical balance of the city. They create buffer areas in cities by eliminating the disharmonies and mutual negative effects among different areas of use such as housing, commerce and industry,

- $\quad$ They have positive effects on human psychology through providing an opportunity for recreation,

- They are the oxygen sources of cities,

- They bring in positive microclimatic characteristics to the city. Wide green areas considerably improve the air circulation in cities, provide clean air to the city and they are effective in increasing atmospheric moisture. It was determined that the temperature in open and green areas was 6.5 degrees cooler in winter and 10 degrees cooler in summer compared to the temperature in the city. Green areas humidify the air through transpiration, thus the dust in the humid air either settles as suspended particles or are taken away through the wind [4].

It is a necessity that arboretums are planned and designed through an ecological approach in order that they can perform their assumed ecological functions. In landscape architecture, "ecological design" is one of the significant aplication of sustainibility. According to Van der Ryn and Cowan (1996) ecological design is "any form of design that minimizes environmentally destructive impacts by integrating itself with living processes." Ecological design can apply to many design systems such as architecture, agriculture, engineering and many other fields. In the scope of this chapter, which is about an arboretum, ecological design is an important concept in terms of "sustainable landscape design" [5] [6] [7].

In the XIX century ecological awarenes was reflected to modern urban landscape design and planning by theorists and practitioners. For instance Frederic Law Olmsted produced projects such as Central Park (New York), Emerald Necklace (Boston) and other national parks, and was a pioneer of landscape architecture. This ecological sensitivity continued with Jens Jensen, Ian Mc Harg, Anne Winston Spirn and Michael Hough [8] [9]. 
An example of early ecological design and planning, "Crosby Arboretum is one of the substantial ecological design works in terms of contributions on the urban/nature context and the development of natural settings in cities. It was established in 1978 as a living memorial to L.O. Crosby Jr., a prominent Mississippi timber owner and philantropist. The idea of his immediate family was to create an arboretum and form a board of directors to fully explore the concept of ecological design. The Crosby family donated a 26-ha (64-acre) site on which to establish the arboretum. The primarily wetland site was formerly a working strawberry farm in the 1940s, complete with drainage ditches and old farm roads, that had been converted to a pine plantation shortly thereafter " [10].

The arboretum purchased and leased nearby lands containing pristine examples of local native plant communities, realizing that nearby natural plant communities would become important research models for the exhibit design of the arboretum, as well as to fulfill the preservation aspect of their mission statement. So it was designed by abstracting the natural habitats of plants and animals, within the Pearl River Basin. The Pearl River is a 444-mile long major watershed in west Mississippi that Arboretum lands lie within. Each exhibit illustrates a combination of past human influences and natural succession that reveals the drama and beauty of the regional flora. During a 10-y period, 11 sites comprising more than 685 ha $(1700 \mathrm{ac})$ would become the satellite natural areas of the arboretum, and they were systematically inventoried by biologists. Detailed topographical surveys were conducted on the mostly flat site, and subtle moisture gradients and drainage areas were recorded [10].

The mission of the arboretum is preserving, protecting, and displaying plants native to the Pearl River Drainage Basin ecosystem, providing environmental and botanical research opportunities, and offering cultural, scientific, and recreational programs [11].

The Crosby Arboretum is a not-for-profit institution dedicated to educating the public about their environment by:

- Preserving, protecting, and displaying plants native to the Pearl River Drainage Basin in Mississippi and Louisiana

- Providing environmental and horticultural research opportunities

- Offering cultural, educational, scientific, and recreational programs

(http://www.crosbyarboretum.msstate.edu/pages/mission.php)

The arboretum located in Picayune, Mississippi is administered by the Mississippi State University Extension (Figure 1). These lands provides habitats for 300 native plant species and animals, some of which are endangered or threatened.

With increasing value being placed on our natural heritage, The Crosby Arboretum is the premier native plant conservatory in the southeast United States. The Arboretum has expanded to become a resource for education in the region and the world. Today, it provides for the protection of the region's biological diversity and also a place for the public's enjoyment of plant species native to the Pearl River Drainage Basin of south-central Mississippi and Louisiana. People can study and learn about plants and plant products so that they may use them to their best advantage and ensure their continuous propagation in 


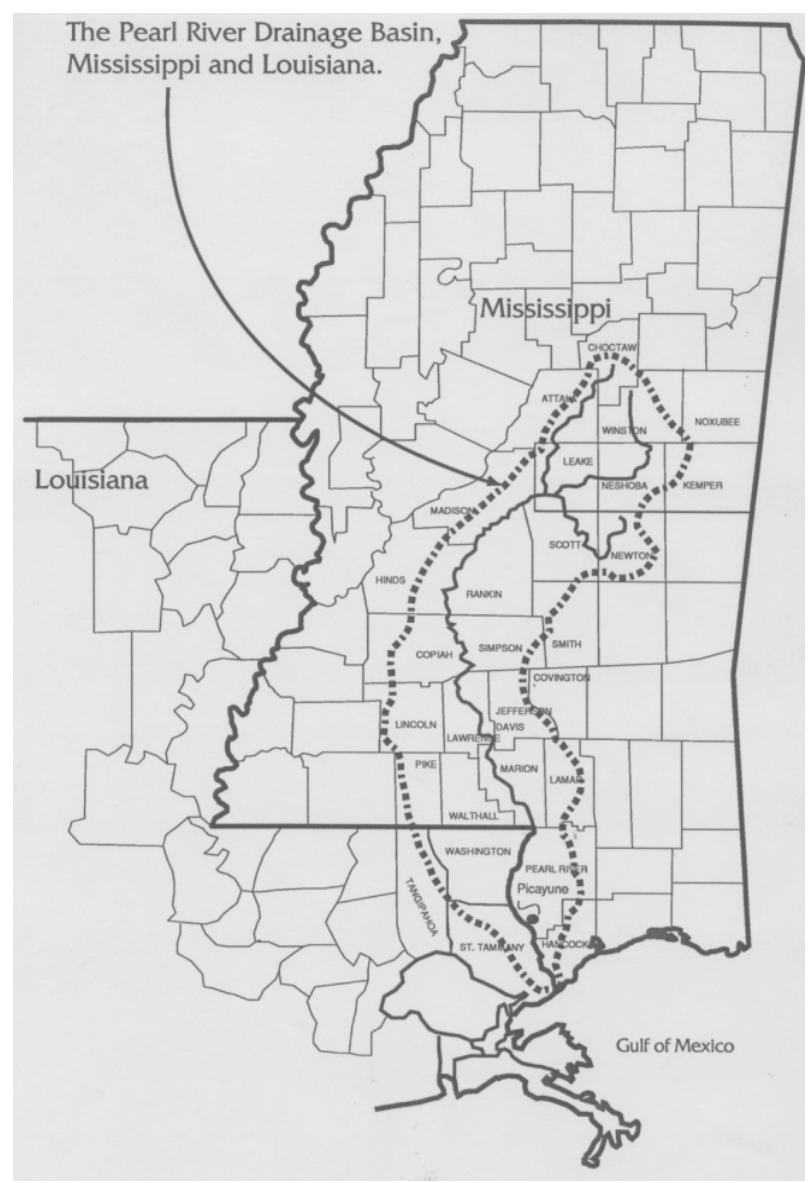

Figure 1. Location of the Crosby Arboretum.

the future. Aesthetic, agricultural, scientific, and industrial contributions of native plant species and ecosystems can be examined in a real-life setting at the Arboretum.

The arboretum has a 104-acre Native Plant Center and it serves as the focus of Arboretum activities and development. The Pinecote Pavilion and the Piney Woods Lake at the arboretum display native water plants in their natural setting. The Pinecote Pavilion and the many wooden bridges that complement the lake were designed by award-winning architect Fay Jones, of Fayetteville, Arkansas to enhance the artistic and functional aspects of the Arboretum.

(http://www.crosbyarboretum.msstate.edu/pages/about.php)

The Crosby Aboretum has 6000 visitors annually. Pinecote, the name of the Arboretum site, was designed to weave the activities and needs of human into an evolving living mosaic of "woodland, aquatic and pine savanna" habitats. This 64 acre former strawberry farm and pine plantation is being transformed to display and interpret the native plant communities found in our natural areas. 
The Arboretum was designed to be an evolving landscape that abstracts the natural habitats of plants and animals within the Pearl River Basin. Each exhibit illustrates a combination of past human influences and natural succession that reveals the drama and beauty of the regional flora. The pond, slough, pathways, bridges, landscape features and pavilion weave together into a seamless whole, fortifying each other's presence (Figure 2).

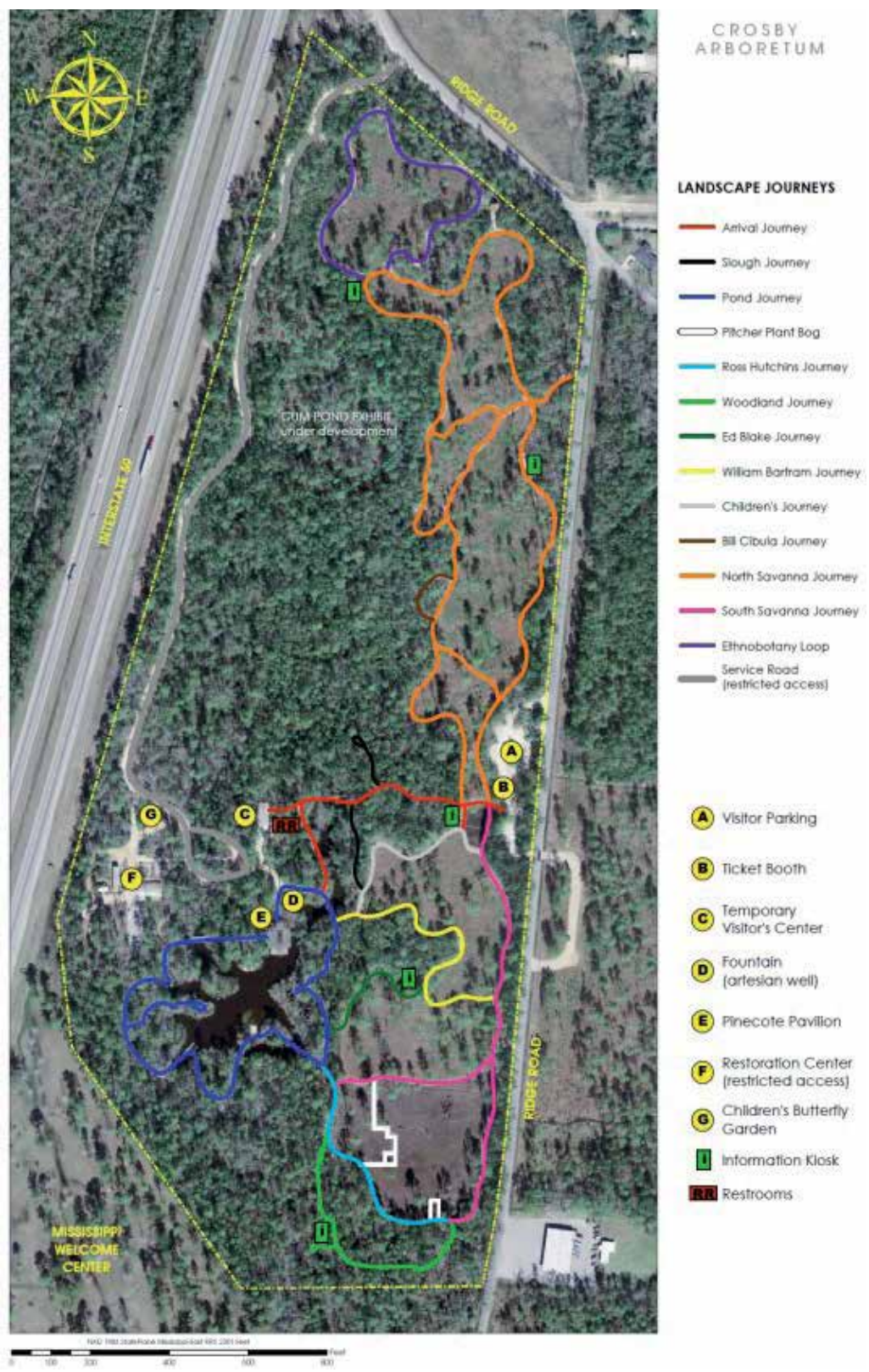

Figure 2. Crosby Arboretum trails and other uses (http://www.crosbyarboretum.msstate.edu/pages/map.php) 
The Crosby Arboretum Master Plan was completed in 1994. The Schematic Master Plan outlined the following design principles to the Arboretum's Interpretive Center (Pinecote) site development:

- Displaying habitats as well as flora

- Creating displays that enhance the character of the native landscape

- Fostering a sense of place appropriate to the Piney Woods region of Mississippi

- Interpreting how perceptions of landscape by industry, agriculture, and forestry have resulted in changes in landscape appearance and land use patterns

- Developing a holistic approach to interpreting what we see

- Encouraging a synthesis to develop between the arts, sciences, and humanities

- Focusing on doing a few things well and emphasizing quality

- Interpreting the role of fire as a major determinant of landscape form

- Displaying the arboretum landscape as a process rather than product

Andropogon Associates Ltd articulated the design at Pinecote as "a new synthesis of the artistic values of drama and beauty, with the scientific values of correct relationships between plant and plant and plant and place. This design is based on 3 premises:

1. The Pinecote site will be treated as an entire coherent unit.

2. The site design at Pinecote will accurately reflect the major natural processes of the site.

3. Planting design should reflect Plant Community Structure." [10].

"In spring 2011, a graduate class in the department of landscape architecture at Mississippi State University, was assigned by one of the authors (Brzuszek) the task of conducting the research and to develop the conceptual designs for the Forested Stream exhibit. The semester-long project included studying the research literature for small streams and stream restoration; site visits to small streams near the Arboretum site to measure and map their wetland configurations; study the plant species and spatial configurations of small stream corridors; to host a design charrette to consider possible conceptual designs; and the resolution of conceptual ideas into a proposed exhibit design. To fund the exhibit construction, a federal grant was applied for and awarded through the National Fish and Wildlife Foundation's 5-Star Grant. The grant awarded $\$ 38,870$ with a complementary match by the Crosby Arboretum and its partners, and the period required construction of the exhibit to be completed by June 2013" [12]. The small stream swamp exhibit covers approximately four acres and connects the Gum Pond in the northern part of the site to the Slough and Beaver Pond to the south. This wetland exhibit improves habitat for fish, amphibians, reptiles, and birds that are indigenous to the Pearl River Drainage Basin. The forested stream channel offers a unique opportunity to teach visitors about the importance of forested wetlands by demonstrating the value of its function [10]. Dead Tiger Creek, a natural stream which is near the arboretum, served as a reference site to closely examine the regional features of water corridors. The class studied vegetative patterns and aquatic habitats to aid in understanding the dynamics of small stream swamp forests. With collective effort, the class created field sketches and detailed notes on various characteristics of the creek. Reviewing this information provided vital intelligence and was relevant to future implementation of the Crosby Arboretum exhibit [13]. 


\section{The ecological significance of the Arboretum}

The Crosby Arboretum is preserving existing ecosystems in its natural areas and at the Interpretive Center site. [14][15] [16]. The designers enabled the site to "express itself" by introducing periodic fire to maintain the savanna exhibit (fire is an important component of the Piney Woods ecosystem) and it displays native plants within the context of regionally occurring native plant communities (Figure 3) [10] [17]. The arboretum is an environmental intervention and it is the first truly regenerative arboretum in the U.S. because the entire site, and all of its sites are based solely upon the environment [18] [19]. With these qualities, Crosby Arboretum is involved in four ecological landscape design categories which were determined by Mozingo (1997) [20]: "preservation of existing, functioning ecological systems; enhancement or re-establishment of degraded ecological systems; intensification of ecological processes to mitigate potential or existing ecological degradation; and environmental interventions which reduce nonrenewable resource consumption."

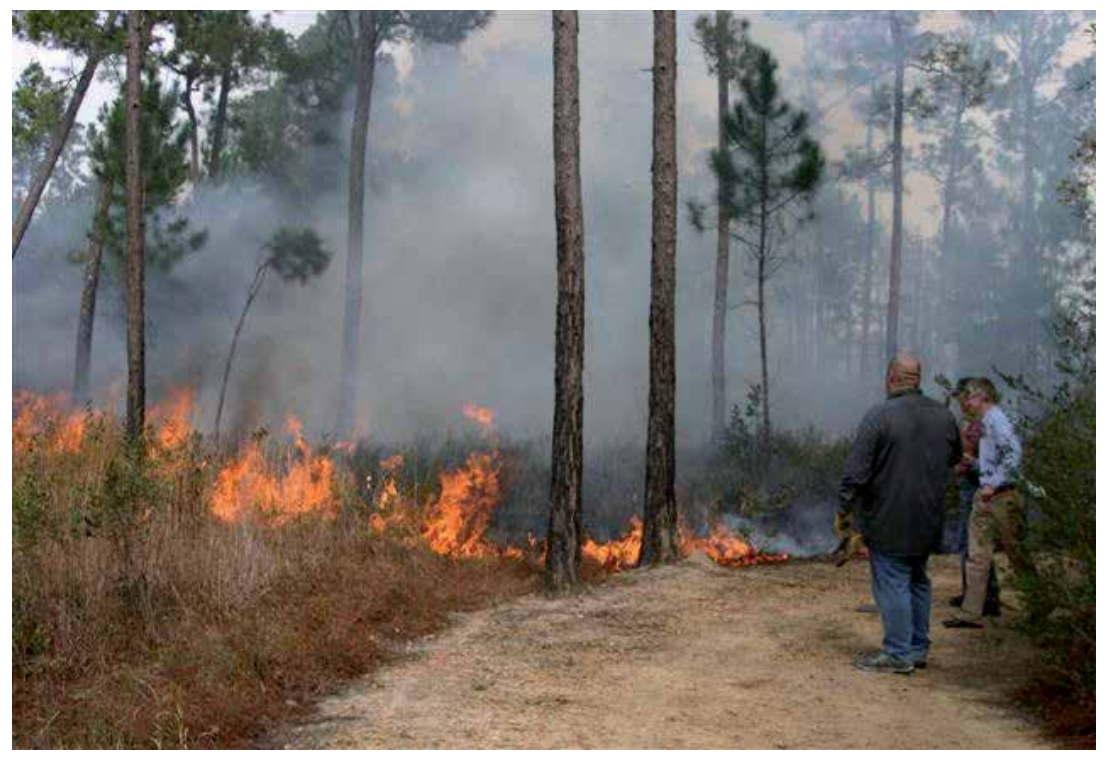

Figure 3. Precribed fires at te arboretum

The assemblages of carefully selected and protected lands nurtures the species of indigenous trees, shrubs, wildflowers, and grasses. Together with the rare, or endangered species of plants and wildlife throughout the Arboretum's preserves, unusual plants have their place as well. The Arboretum protects and manages several pitcher plant bogs both on site and within the natural areas. Edible, poisonous, and aromatic plants, too, are found at the Arboretum. As the seasons unfold their splendor, the Arboretum provides a clear, unobstructed view of the variety and beauty of our natural resources.

While constituting the master plan of the arboretum; through observation and research, first the staff uncovered the wet, mesic and dry zones of the site and their associated plants. This information guided the form of Pinecote's master plan (awarded an honour award by the 
American Society of Landscape Architects in 1992). At the Arboretum, each exhibit is modeled after natural habitats found and oriented at appropriate locations. Predominant plant species found in these habitats are then planted among the existing vegetation structure of Pinecote. These "introduced" species are located with scientific accuracy and designer's eye so that visitors have an opportunity to understand the process that shape plant communities as well as to experience the heightened drama and beauty of the Piney Woods.

The Pearl River Basin is at the hearth of the Arboretum's mission, which is to interpret, promote and preserve the native plant communities along its boundaries. Pinecote has no irrigation lines or other artificial life support systems, thus existing site hydrology plays a crucial role in the survival and management of all plant community exhibits. So from this standpoint, it paid attention to the water related designs in the arboretum constituting process. The Master Plan identifies the construction of four main wetland exhibits that are based upon regional water features. These include;

- a two-acre pond called Piney Woods Lake that abstracts the form and function of locallly-occurring beaver ponds;

- a half-acre Slough Exhibit based upon local bayous;

- a one acre Gum Pond exhibit that features a Gulf Coast waterbody primarily composed of tupelo gum trees (Nyssa sylvatica var. biflora), (Figure 4) and

- a 970' small stream corridor entitled the Forested Stream Exibit. The Piney Woods Lake, Slough, and Gum Pond exhibits have already been constructed prior to 2011.

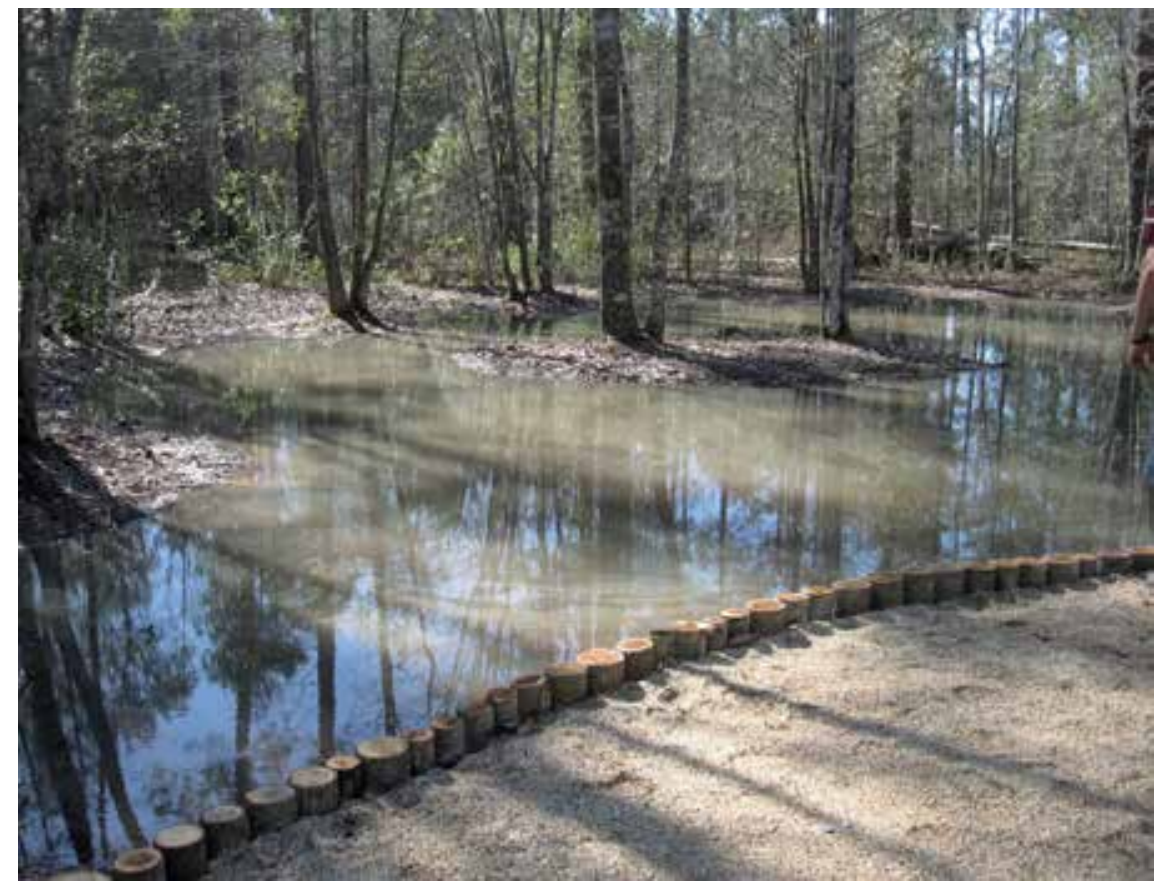

Figure 4. Gum Pond Exhibit area (Photo :Banu Ozturk Kurtaslan, 2011). 
After the completion of Beaver Pond, the success of the pond was demonstrated when beavers moved in and cut down every Taxodium tree that had been freshly planted along the pond's margin. Since then a fence has been constructed along the drainage outlet to reduce the number of problem animal species (Figure 5).

The Mississippi River system alone drains more than 40 percent of the United States and portions of southern Canada. The original plant community of Pinecote was essentially wetland in character, a wet pine savanna. Pinus palustris once dominated the dry rises of the site, supported with a understory of Aristida, Andropogon and a host of wild flowers. Even after row-cropping in the 1930s, mant native wetland plants such as Sarracenia alata, Ericaulon decangulare and Habenaria ciliaris reappeared at Pinecote, sustained by periodic fires set for forestry purposes. These wetland species continue to survive today and their locations form the basis for the design of Pinecote's plant displays [21].

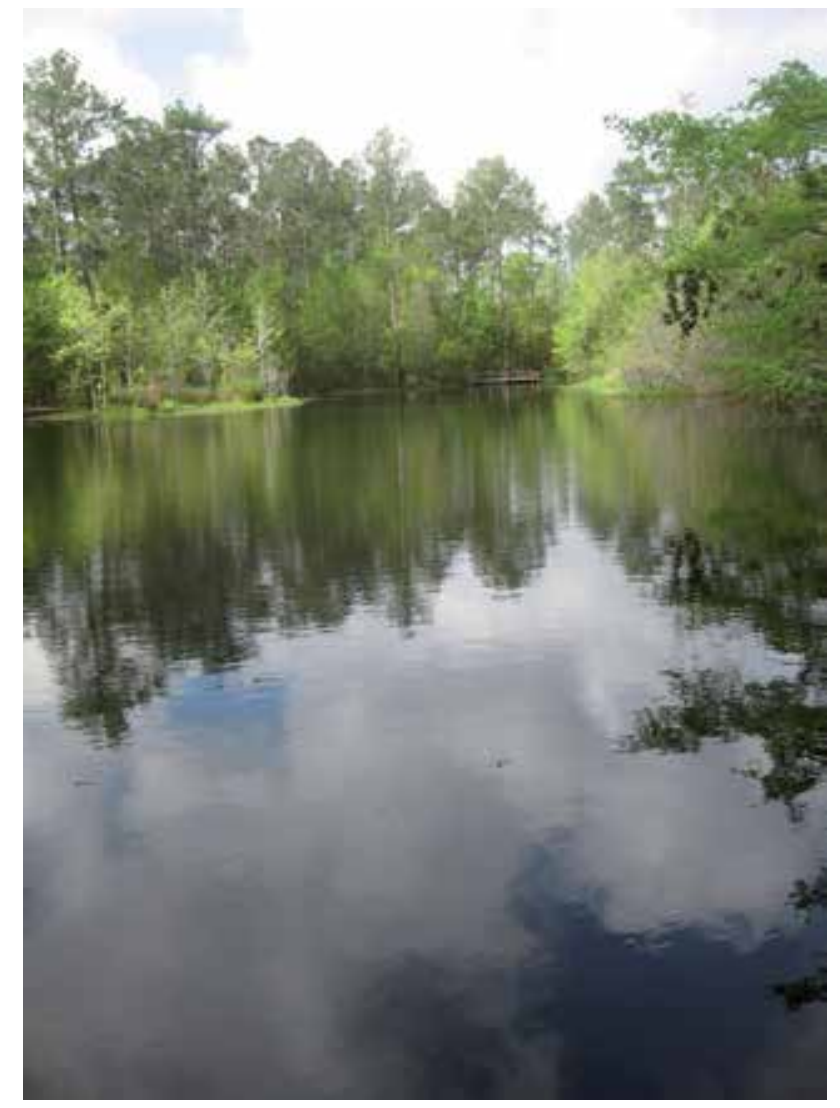

Figure 5. Beaver Pond Exhibit area (Photo :Banu Ozturk Kurtaslan, 2011).

In its early years, The Crosby Arboretum conducted biological surveys for all of the plants that existed on site. In order to do this, Arboretum managers had the property surveyed and established permanent reference markers across the site. These reference markers would framework the entire site into a grid of one hundred foot square plots that could then be 
individually studied. Brass stakes were tamped into the ground at each corner of each grid section. At the top of each stake, a brass plate was stamped with the unique identifiers for that location. In addition to becoming permanent reference markers for subsequent floristic surveys, the brass markers became key alignment points for the locations of structures at the arboretum's Master Plan [12].

On the Table 1, the list of the rich plant species can be seen.

\begin{tabular}{|c|c|c|c|c|c|}
\hline Scientific Name & Common Name & Duration & Habit & Sun & Water \\
\hline Acalypha gracilen & Slender threeseed mercury & Annual & Herb & & \\
\hline Acer barbatum & $\begin{array}{l}\text { Southern sugar maple, Florida maple, Caddo } \\
\text { maple }\end{array}$ & Perennial & Tree & Part-shade & Dry \\
\hline Acer rubrum & Red maple, Scarlet maple & Perennial & Tree & Sun, Part-shade & Moist \\
\hline $\begin{array}{l}\text { Acer rubrum var. } \\
\text { drummondii }\end{array}$ & $\begin{array}{l}\text { Drummond's maple, Drummond red maple, } \\
\text { Swamp maple }\end{array}$ & Perennial & Tree & Part shade & Wet, moist \\
\hline Aesculus pavia & $\begin{array}{l}\text { Scarlet Buckeye, Red buckeye, Firecracker } \\
\text { plant }\end{array}$ & Perennial & Shrub,Tree & Part shade & Wet, moist \\
\hline Agalinis fasciculata & Beach false foxglove & Annual & Herb & & \\
\hline Agalinis purpurea & $\begin{array}{l}\text { Purple false foxglove, Purple gerardia, } \\
\text { Gerardia }\end{array}$ & Annual & Herb & $\begin{array}{l}\text { Sun, Shade, } \\
\text { Part-shade }\end{array}$ & Wet, Moist \\
\hline Agalinis tenuifolia & Slenderleaf false foxglove & Annual & Herb & & \\
\hline Aletris aurea & $\begin{array}{l}\text { Golden colicroot, Colicroot, Star grass, Yellow } \\
\text { colic root }\end{array}$ & Perennial & Herb & & \\
\hline Aletris farinosa & White colicroot, Colic root, Unicorn root & Perennial & Herb & Sun & Moist, Dry \\
\hline Alnus serrulata & $\begin{array}{l}\text { Hazel alder, Brookside alder, Tag alder, } \\
\text { Common alder } \\
\text { Common serviceberry, Downy serviceberry, }\end{array}$ & Perennial & Shrub & $\begin{array}{l}\text { Sun, Shade, } \\
\text { Part-shade } \\
\text { Sun, Shade, }\end{array}$ & Wet, Moist \\
\hline Amelanchier arborea & $\begin{array}{l}\text { Shadbush, Juneberry } \\
\text { Indigo bush, False indigo bush, False indigo, }\end{array}$ & Perennial & Shrub & Part-shade & Dry \\
\hline Amorpha fruticosa & Desert false indigo & Perennial & $\begin{array}{l}\text { Shrub } \\
\text { Grass/Grass- }\end{array}$ & Sun, Part-shade & Moist \\
\hline Andropogon virginicus & $\begin{array}{l}\text { Broomsedge bluestem, Broom-sedge } \\
\text { Devil's walkingstick, Devil's walking-stick, }\end{array}$ & Perennial & like & Part-shade & Moist \\
\hline Aralia spinosa & Prickly Ash, Hercules & Perennial & $\begin{array}{l}\text { Tree } \\
\text { Grass/Grass- }\end{array}$ & Part-shade & Moist \\
\hline Arundinaria gigantea & $\begin{array}{l}\text { Giant cane } \\
\text { Fewflower milkweed, Few-flower milkweed, }\end{array}$ & Perennial & like & Part-shade & Wet \\
\hline Asclepias lanceolata & Red milkweed & Perennial & Herb & Sun & Wet \\
\hline Asclepias longifolia & $\begin{array}{l}\text { Longleaf milkweed } \\
\text { Groundseltree, Sea-myrtle, } \\
\text { Consumptionweed, Eastern baccharis, } \\
\text { Groundsel, Groundsel bush, Salt marsh-elder, }\end{array}$ & Perennial & Herb & & \\
\hline Baccharis halimifolia & Salt bush, Florida groundsel bush & Perennial & Shrub & Part-shade & Wet \\
\hline \multicolumn{6}{|l|}{ Baccharis halimifolia } \\
\hline Balduina uniflora & Oneflower honeycombhead & Perennial & Herb & & \\
\hline Bartonia paniculata & Twining screwstem & Annual & Vine & & \\
\hline Betula nigra & River birch & Perennial & Tree & Part-shade & Moist \\
\hline Bidens aristosa & Bearded beggarticks, Tickseed sunflower & Annual & Herb & & \\
\hline Buchnera americana & American bluehearts, Bluehearts & Annual & Herb & Sun & Moist \\
\hline Callicarpa americana & American beautyberry, French mulberry & Perennial & Shrub & Part-shade & Moist \\
\hline Calopogon pallidus & Pale grasspink & Perennial & Herb & & \\
\hline Calopogon tuberosus & Tuberous grasspink, Grass pink & Perennial & Herb & & \\
\hline Canna flaccida & Bandanna of the Everglades, Golden canna & Perennial & Herb & Sun & Wet \\
\hline
\end{tabular}




\begin{tabular}{|c|c|c|c|c|c|}
\hline Scientific Name & Common Name & Duration & Habit & Sun & Water \\
\hline Carex glaucescens & Southern waxy sedge & Perennial & $\begin{array}{l}\text { Grass/Grass- } \\
\text { like }\end{array}$ & & \\
\hline Carphephorus odoratissimus & Vanillaleaf, Vanilla Plant & Perennial & Herb & & \\
\hline Carpinus caroliniana & $\begin{array}{l}\text { American hornbeam, Blue beech, } \\
\text { Musclewood, Ironwood }\end{array}$ & Perennial & Tree & $\begin{array}{l}\text { Shade, Part- } \\
\text { shade } \\
\text { Sun, Shade, }\end{array}$ & Moist \\
\hline Carya glabra & Pignut hickory & Perennial & Tree & Part-shade & Dry \\
\hline Castanea pumila & $\begin{array}{l}\text { Chinkapin, Allegheny chinquapin, Allegheny- } \\
\text { chinkapin, Chinquapin }\end{array}$ & Perennial & Shrub & $\begin{array}{l}\text { Part-shade } \\
\text { Shade, Part- }\end{array}$ & Dry \\
\hline Ceanothus americanus & New Jersey tea, Redroot & Perennial & Shrub & shade & Moist, Dry \\
\hline Cephalanthus occidentalis & $\begin{array}{l}\text { Common buttonbush, Buttonbush, Button } \\
\text { willow }\end{array}$ & Perennial & Shrub & $\begin{array}{l}\text { Shade, Part- } \\
\text { shade } \\
\text { Shade, Part- }\end{array}$ & Wet, Moist \\
\hline Cercis canadensis & Eastern redbud, Redbud & Perennial & Tree & shade & Moist \\
\hline Chamaecrista fasciculata & Partridge pea, Sleepingplant, Sensitive plant & Annual & Herb & Sun, Part-shade & Moist, Dry \\
\hline Chamaecrista fasciculata & Partridge pea, Sleepingplant, Sensitive plant & Annual & Herb & Sun, Part-shade & Moist, Dry \\
\hline Chaptalia tomentosa & Woolly sunbonnets & Perennial & Herb & & \\
\hline Chionanthus virginicus & White fringetree, Fringe tree & Perennial & Tree & Part-shade & Moist \\
\hline Chrysopsis mariana & Maryland goldenaster, Maryland golden-aster & Perennial & Herb & Sun & Wet \\
\hline Cirsium muticum & Swamp thistle & Biennial & Herb & & \\
\hline Cleistes divaricata & Rosebud orchid & Perennial & Herb & & \\
\hline Clematis crispa & $\begin{array}{l}\text { Swamp leatherflower, Curly clematis, Blue } \\
\text { jasmine, Curlflower } \\
\text { Coastal sweet pepperbush, Clethra, Summer }\end{array}$ & Perennial & Vine & $\begin{array}{l}\text { Sun, Part-shade } \\
\text { Sun, Shade, }\end{array}$ & Wet, Moist \\
\hline Clethra alnifolia & sweet & Perennial & Shrub & Part-shade & Wet, Moist \\
\hline Cliftonia monophylla & Buckwheat tree, Buckwheat bush & Perennial & Shrub & Sun & Wet \\
\hline $\begin{array}{l}\text { Cnidoscolus urens var. } \\
\text { stimulosus }\end{array}$ & Finger rot, Tread Softly & Perennial & Herb & & \\
\hline Coreopsis lanceolata & Lanceleaf coreopsis, Lanceleaf tickseed, & Perennial & Herb & $\begin{array}{l}\text { Sun, Shade, } \\
\text { Part-shade }\end{array}$ & Dry \\
\hline Coreopsis linifolia & Texas tickseed & Perennial & Herb & & \\
\hline Cornus florida & Flowering dogwood, Virginia dogwood & Perennial & Tree & $\begin{array}{l}\text { Shade, Part- } \\
\text { shade }\end{array}$ & Moist, Dry \\
\hline Crataegus marshallii & Parsley hawthorn & Perennial & Tree & Part-shade & Dry \\
\hline Crataegus opaca & $\begin{array}{l}\text { Mayhaw, Riverflat hawthorn, Western } \\
\text { mayhaw } \\
\text { Crinum lily, Seven sisters, Swamp lily, }\end{array}$ & Perennial & Tree & Part-shade & Wet \\
\hline Crinum americanum & Southern swamp lily, String lily & Perennial & Shrub & Part-shade & Wet \\
\hline Croton capitatus & Hogwort & Annual & Herb & & \\
\hline Cuscuta pentagona & Fiveangled dodder & Annual & Vine & & \\
\hline Cyrilla racemiflora & $\begin{array}{l}\text { Swamp titi, Titi, Leatherwood, Swamp cyrilla, } \\
\text { Palo colorado }\end{array}$ & Perennial & Tree & Part-shade & Wet \\
\hline Diodia teres & Poorjoe & Annual & Herb & & \\
\hline Diospyros virginiana & Common persimmon, Eastern persimmon & Perennial & Tree & Part-shade & Dry \\
\hline Drosera brevifolia & Dwarf sundew, Spatulate-leaved sundew & Perennial & Herb & & \\
\hline Drosera capillaris & Pink sundew & Annual & Herb & & \\
\hline Drosera intermedia & Spoonleaf sundew & Perennial & $\begin{array}{l}\text { Herb } \\
\text { Grass/Grass- }\end{array}$ & Sun & \\
\hline Eleocharis ovata & Ovate spikerush & Annual & like & Sun & \\
\hline Erigeron philadelphicus & Philadelphia fleabane, Fleabane daisy & Biennial & Herb & Part-shade & \\
\hline Erigeron vernus & Early whitetop fleabane & Perennial & Herb & & \\
\hline Eriocaulon compressum & Flattened pipewort, Hat pins & Perennial & Herb & Part-shade & Wet \\
\hline
\end{tabular}




\begin{tabular}{|c|c|c|c|c|c|}
\hline Scientific Name & Common Name & Duration & Habit & Sun & Water \\
\hline Eriocaulon decangulare & Tenangle pipewort, Pipewort & Perennial & Herb & Sun & \\
\hline Erythrina herbacea & $\begin{array}{l}\text { Coralbean, Cherokee bean, Red cardinal } \\
\text { American strawberry-bush, Strawberry bush, } \\
\text { Brook euonymus, Hearts-a-burstin, Bursting- }\end{array}$ & Perennial & Shrub & Sun, Part-shade & Dry \\
\hline Euonymus americanus & $\begin{array}{l}\text { heart, Wahoo } \\
\text { Trumpetweed, Queen of the meadow, Hollow }\end{array}$ & Perennial & Shrub & Part-shade & Moist \\
\hline Eupatoriadelphus fistulosus & Joe-pye weed, Joe-pye weed & Perennial & Herb & Sun & Wet, Moist \\
\hline Eupatorium capillifolium & Dog Fennel, Dogfennel & Perennial & Herb & & \\
\hline Eupatorium perfoliatum & Common boneset & Perennial & Herb & $\begin{array}{l}\text { Sun, Shade, } \\
\text { Part-shade }\end{array}$ & Wet, Moist \\
\hline Eupatorium rotundifolium & Roundleaf thoroughwort & Perennial & Herb & & \\
\hline Fagus grandifolia & American beech & Perennial & Tree & $\begin{array}{l}\text { Shade, Part- } \\
\text { shade }\end{array}$ & Moist \\
\hline Galium tinctorium & Stiff marsh bedstraw & Perennial & Herb & Part-shade & \\
\hline Gaylussacia dumosa & Dwarf huckleberry & Perennial & Shrub & Part-shade & \\
\hline Gelsemium sempervirens & $\begin{array}{l}\text { Carolina jessamine, Yellow jessamine, Evening } \\
\text { trumpetflower, Poor man's rope }\end{array}$ & Perennial & Vine & $\begin{array}{l}\text { Sun, Part-shade } \\
\text { Shade, Part- }\end{array}$ & Moist \\
\hline Geranium maculatum & Spotted geranium, Wild geranium, Cranesbill & Perennial & Herb & shade & Moist \\
\hline Gordonia lasianthus & Gordonia, Loblolly bay & Perennial & Shrub & Sun & Moist \\
\hline & $\begin{array}{l}\text { Two-wing silverbell, Silver bell, Two-winged } \\
\text { silverbell, Snowdrop tree, American }\end{array}$ & & & & \\
\hline Halesia diptera & snowdrop tree & Perennial & Shrub, Tree & Part-shade & Dry \\
\hline Hamamelis virginiana & Witch hazel, American witch hazel & Perennial & Tree & shade & Moist, Dry \\
\hline Helenium vernale & Savannah sneezeweed & Perennial & Herb & & \\
\hline Helianthus angustifolius & Swamp sunflower & Perennial & Herb & Part-shade & Wet \\
\hline Hibiscus aculeatus & $\begin{array}{l}\text { Comfortroot, Big thicket hibiscus, Pineland } \\
\text { hibiscus }\end{array}$ & Perennial & Herb & Sun, Part-shade & Moist \\
\hline Hibiscus lasiocarpos & $\begin{array}{l}\text { Rose-mallow, Rosemallow, Woolly mallow, } \\
\text { Wooly Rose-mallow }\end{array}$ & Perennial & Shrub & Sun & Wet \\
\hline Hydrangea quercifolia & Oakleaf hydrangea, Oak-leaf hydrangea & Perennial & Shrub & Shade & Moist \\
\hline Hypericum crux-andreae & St. Peterswort & Perennial & Subshrub & Part-shade & \\
\hline Hypericum gentianoides & Orangegrass, Pineweed & Annual & Herb & Part-shade & \\
\hline Hypericum gymnanthum & Claspingleaf St. Johnswort & Perennial & Herb & & \\
\hline Hypericum tetrapetalum & Fourpetal St. Johnswort & Perennial & Subshrub & & \\
\hline Hypoxis hirsuta & $\begin{array}{l}\text { Common goldstar, Eastern yellow star-grass, } \\
\text { Yellow star-grass }\end{array}$ & Perennial & Herb & $\begin{array}{l}\text { Sun, Shade, } \\
\text { Part-shade }\end{array}$ & Dry \\
\hline Ilex amelanchier & Sarvis holly, Swamp holly & Perennial & Shrub & Part-shade & Wet \\
\hline Ilex coriacea & $\begin{array}{l}\text { Large gallberry, Bay-gall bush, Ink-berry holly } \\
\text { Possumhaw, Possumhaw Holly, Deciduous }\end{array}$ & Perennial & Shrub & Part-shade & Moist \\
\hline Ilex decidua & Holly, Winterberry, Deciduous yaupon & Perennial & Shrub & Sun, Part-shade & Moist \\
\hline Ilex glabra & Inkberry, Gallberry & Perennial & Shrub & Part-shade & Wet, Moist \\
\hline Ilex myrtifolia & Myrtle dahoon, Myrtle leaf holly, Myrtle holly & Perennial & Shrub & $\begin{array}{l}\text { Part-shade } \\
\text { Sun, Shade, }\end{array}$ & Moist \\
\hline Ilex opaca & American holly, Christmas holly & Perennial & Tree & Part-shade & Wet, Dry \\
\hline Ilex verticillata & $\begin{array}{l}\text { Common winterberry, Michigan holly, Black } \\
\text { alder }\end{array}$ & Perennial & Tree & $\begin{array}{l}\text { Sun, Shade, } \\
\text { Part-shade }\end{array}$ & $\begin{array}{l}\text { Wet, } \\
\text { Moist, Dry }\end{array}$ \\
\hline Ilex vomitoria & Yaupon, Yaupon holly, Cassina & Perennial & Shrub, Tree & $\begin{array}{l}\text { Sun, Shade, } \\
\text { Part-shade }\end{array}$ & Moist, Dry \\
\hline Illicium floridanum & $\begin{array}{l}\text { Florida anisetree, Florida anise, Anise tree, } \\
\text { Stinkbush } \\
\text { Man of the earth, Wild Potato, Wild sweet }\end{array}$ & Perennial & Shrub & $\begin{array}{l}\text { Part-shade } \\
\text { Sun, Shade, }\end{array}$ & \\
\hline Ipomoea pandurata & potato & Perennial & Herb & Part-shade & Moist \\
\hline
\end{tabular}




\begin{tabular}{|c|c|c|c|c|c|}
\hline Scientific Name & Common Name & Duration & Habit & Sun & Water \\
\hline Iris fulva & Copper iris, Red iris & Perennial & Herb & Sun, Part-shade & Wet, Moist \\
\hline Iris virginica & Virginia iris, Great Blue Flag & Perennial & Herb & Sun & Wet \\
\hline Itea virginica & Virginia sweetspire, Tassel-white & Perennial & $\begin{array}{l}\text { Shrub } \\
\text { Grass/Grass- }\end{array}$ & Part-shade & Moist \\
\hline Juncus effusus & Common rush, Soft Rush & Perennial & $\begin{array}{l}\text { like } \\
\text { Grass/Grass- }\end{array}$ & Sun & Wet, Moist \\
\hline Juncus tenuis & Poverty rush, Path rush & Perennial & like & Part-shade & \\
\hline Kalmia latifolia & Mountain laurel, Calico bush & Perennial & Shrub & Part-shade & Moist \\
\hline Lachnanthes caroliana & Carolina redroot, Paint root & Perennial & Herb & Sun, Part-Shade & Moist \\
\hline Lespedeza capitata & $\begin{array}{l}\text { Roundhead lespedeza, Roundhead bush- } \\
\text { clover }\end{array}$ & Perennial & Herb & $\begin{array}{l}\text { Sun } \\
\text { Shade, Part- }\end{array}$ & Dry \\
\hline Leucothoe axillaris & $\begin{array}{l}\text { Coastal doghobble, Coast leucothoe } \\
\text { Tall blazing star, Tall gayfeather, Rough }\end{array}$ & Perennial & Shrub & shade & Moist \\
\hline Liatris aspera & $\begin{array}{l}\text { blazing star, Button snakeroot } \\
\text { Dense blazing star, Dense gayfeather, Marsh }\end{array}$ & Perennial & Herb & Sun & Dry \\
\hline Liatris spicata & $\begin{array}{l}\text { blazing star } \\
\text { Blazing star, Scaly blazing star, Scaly }\end{array}$ & Perennial & Herb & Sun & Moist \\
\hline Liatris squarrosa & gayfeather & Perennial & Herb & Sun & Dry \\
\hline Lilium catesbaei & Pine lily, Southern red lily, Catesby's lily & Perennial & Herb & Part-shade & Wet, Moist \\
\hline Liquidambar styraciflua & Sweetgum, American sweetgum & Perennial & Tree & Part-shade & Moist \\
\hline Liriodendron tulipifera & Tuliptree, Tulip poplar & Perennial & Tree & $\begin{array}{l}\text { Part-shade } \\
\text { Sun, Shade, }\end{array}$ & Moist \\
\hline Lobelia cardinalis & Cardinal flower & Perennial & Herb & Part-shade & Wet, Moist \\
\hline Lobelia floridana & Florida lobelia & Perennial & Herb & & \\
\hline Lobelia puberula & Downy lobelia & Perennial & Herb & & \\
\hline Lobelia spicata & $\begin{array}{l}\text { Palespike lobelia, Pale-spike lobelia } \\
\text { Creeping water-primrose, Floating primr }\end{array}$ & Perennial & Herb & $\begin{array}{l}\text { Sun, Shade, } \\
\text { Part-shade }\end{array}$ & Moist, Dry \\
\hline Ludwigia peploides & $\begin{array}{l}\text { willow, Water-primrose } \\
\text { Fetterbush lyonia, Shinyleaf, Fetterbush, }\end{array}$ & Perennial & Herb & $\begin{array}{l}\text { Sun } \\
\text { Shade, Part- }\end{array}$ & \\
\hline Lyonia lucida & Staggerbush & Perennial & Shrub & $\begin{array}{l}\text { shade } \\
\text { Sun, Shade, }\end{array}$ & Moist \\
\hline Magnolia acuminata & $\begin{array}{l}\text { Cucumbertree, Cucumber tree } \\
\text { Southern magnolia, Evergreen magnolia, Bull }\end{array}$ & Perennial & Tree & Part-shade & Wet, Moist \\
\hline Magnolia grandiflora & bay & Perennial & Tree & Part-shade & Dry \\
\hline Magnolia macrophylla & Bigleaf magnolia & Perennial & Tree & Part-shade & \\
\hline Magnolia virginiana & Sweetbay, Sweetbay magnolia, Swampbay & Perennial & Tree & Part-shade & Moist \\
\hline Malus angustifolia & Southern crabapple, Wild crabapple & Perennial & Tree & Part-shade & Moist \\
\hline Mikania scandens & Climbing hempvine, Climbing hempweed & Perennial & Vine & Shade & Wet \\
\hline Morella cerifera & Wax myrtle, Southern bayberry, Candleberry & Perennial & Shrub & Sun, Part-shade & Wet, Moist \\
\hline Nothoscordum bivalve & $\begin{array}{l}\text { Crow poison, Crowpoison, False garlic } \\
\text { Yellow pond-lily, Cow lily, Spatter dock, }\end{array}$ & Perennial & Herb & Sun & \\
\hline Nuphar lutea & $\begin{array}{l}\text { Yellow cow lily } \\
\text { American white waterlily, American white }\end{array}$ & Perennial & Herb & & Wet \\
\hline Nymphaea odorata & $\begin{array}{l}\text { water-lily, Fragrant white water lily, White } \\
\text { water lily, Fragrant water lily, White water lily }\end{array}$ & Perennial & Herb & $\begin{array}{l}\text { Sun, Shade, } \\
\text { Part-shade }\end{array}$ & Wet \\
\hline Nymphoides aquatica & Big floatingheart, Floating hearts & Perennial & Herb & Part-shade & Wet \\
\hline Nyssa ogeche & Ogeechee tupelo, Ogeechee lime & Perennial & Tree & $\begin{array}{l}\text { Part-shade } \\
\text { Sun, Shade, }\end{array}$ & Wet \\
\hline Nyssa sylvatica & Blackgum, Black tupelo, Sourgum, Tupelo & Perennial & Tree & Part-shade & Moist \\
\hline Orontium aquaticum & Goldenclub & Perennial & Herb & Part-shade & Wet \\
\hline Osmanthus americanus & Devilwood, Wild olive & Perennial & Tree & Part-shade & Moist \\
\hline
\end{tabular}




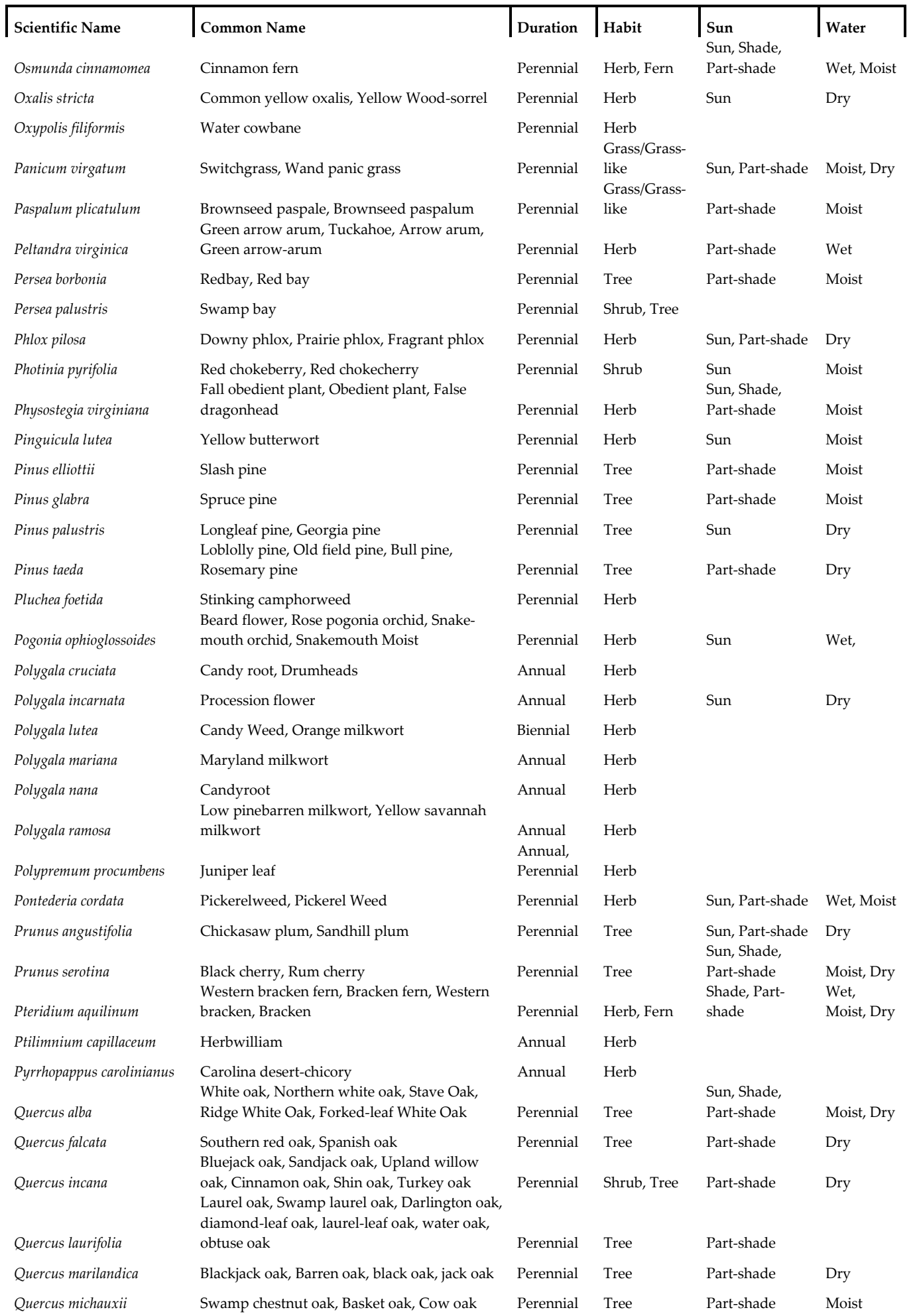




\begin{tabular}{|c|c|c|c|c|c|}
\hline Scientific Name & Common Name & Duration & Habit & Sun & Water \\
\hline Quercus nigra & Water oak & Perennial & Tree & Part-shade & Wet \\
\hline Quercus pagoda & Cherrybark oak & Perennial & Tree & & \\
\hline Quercus phellos & Willow oak & Perennial & Tree & Part-shade & Moist \\
\hline Quercus virginiana & Coastal live oak, Southern live oak, Live oak & Perennial & Tree & Sun, Part-shade & Moist \\
\hline Rhapidophyllum hystrix & Needle palm, Blue palmetto & Perennial & Shrub & Part-shade & \\
\hline Rhexia alifanus & Savannah meadowbeauty & Perennial & Herb & & \\
\hline Rhexia lutea & $\begin{array}{l}\text { Yellow meadow beauty, Yellow } \\
\text { meadowbeauty }\end{array}$ & Perennial & Herb & & \\
\hline Rhexia mariana & $\begin{array}{l}\text { Maryland meadowbeauty, Maryland } \\
\text { meadow-beauty, Meadow beauty }\end{array}$ & Perennial & Herb & Part-shade & Moist \\
\hline Rhexia petiolata & Fringed meadowbeauty & Perennial & Herb & & \\
\hline Rhexia virginica & Meadow beauty, Handsome Harry & Perennial & Herb & Part-shade & Wet \\
\hline Rhododendron austrinum & $\begin{array}{l}\text { Orange azalea, Florida azalea, Yellow azalea } \\
\text { Mountain azalea, Wild azalea, Honeysuckle } \\
\text { azalea, Piedmont azalea, Sweet azalea, Hoary } \\
\text { azalea, Southern pinxterflower }\end{array}$ & Perennial & Shrub & Part-shade & Dry \\
\hline Rhus copallinum & $\begin{array}{l}\text { Winged sumac, Shining sumac, Flameleaf } \\
\text { sumac } \\
\text { Starrush whitetop, Star sedge, White-topped }\end{array}$ & Perennial & $\begin{array}{l}\text { Shrub } \\
\text { Grass/Grass- }\end{array}$ & Sun & Dry \\
\hline Rhynchospora colorata & $\begin{array}{l}\text { sedge, Whitetop sedge } \\
\text { Shortbristle horned beaksedge, Horned }\end{array}$ & Perennial & $\begin{array}{l}\text { like } \\
\text { Grass/Grass- }\end{array}$ & Sun, Part-shade & Wet \\
\hline Rhynchospora corniculata & Beakrush & Perennial & $\begin{array}{l}\text { like } \\
\text { Grass/Grass- }\end{array}$ & Sun & \\
\hline Rhynchospora glomerata & Clustered beaksedge, Cluster Beak-rush & Perennial & like & & \\
\hline Rubus argutus & Sawtooth blackberry & Perennial & Shrub & & \\
\hline Rubus trivialis & $\begin{array}{l}\text { Dewberry, Southern dewberry } \\
\text { Black-eyed Susan, Common black-eyed Susan, }\end{array}$ & Perennial & Herb & $\begin{array}{l}\text { Sun, Part-shade } \\
\text { Sun, Shade, }\end{array}$ & Moist, Dry \\
\hline Rudbeckia hirta & Brown-eyed Susan & Annual & Herb & $\begin{array}{l}\text { Part-shade } \\
\text { Sun, Shade, }\end{array}$ & Moist, Dry \\
\hline Sabal minor & Dwarf palmetto, Palmetto, Bush palmetto & Perennial & Shrub & Part-shade & Moist, Dry \\
\hline Sabatia brachiata & Narrowleaf rose gentian & Biennial & Herb & & \\
\hline Sabatia campestris & $\begin{array}{l}\text { Texas star, Rose gentian, Meadow pink, } \\
\text { Prairie rose-gentian, Prairie sabatia }\end{array}$ & Annual & Herb & Part-shade & Dry \\
\hline Sagittaria graminea & Grassy arrowhead, Grass-leaf arrowhead & Perennial & Herb & & \\
\hline Salix nigra & $\begin{array}{l}\text { Black willow, Gulf black willow } \\
\text { Pitcher sage, Big blue sage, Azure sage, Giant }\end{array}$ & Perennial & Tree & $\begin{array}{l}\text { Sun, Shade, } \\
\text { Part-shade }\end{array}$ & Wet, Moist \\
\hline Salvia azurea & blue sage, Blue sage & Perennial & Herb & $\begin{array}{l}\text { Part-shade } \\
\text { Sun, }\end{array}$ & Dry \\
\hline Salvia lyrata & Lyreleaf sage, Cancer weed & Perennial & Herb & $\begin{array}{l}\text { Shade,Part- } \\
\text { shade }\end{array}$ & Moist,Dry \\
\hline Sarracenia alata & $\begin{array}{l}\text { Flycatcher, Yellow pitcher plant, Yellow } \\
\text { trumpet, Yellow trumpets }\end{array}$ & Perennial & Herb & Wet & \\
\hline Sarracenia psittacina & Parrot pitcherplant & Perennial & Subshrub & & \\
\hline Sassafras albidum & Sassafras & Perennial & Tree & $\begin{array}{l}\text { Sun, Shade, } \\
\text { Part-shade } \\
\text { Shade, Part- }\end{array}$ & Moist \\
\hline Saururus cernuus & $\begin{array}{l}\text { Lizard's tail, Lizard's-tail, Breast weed } \\
\text { Woolgrass, Cottongrass bulrush, Marsh }\end{array}$ & Perennial & $\begin{array}{l}\text { Herb } \\
\text { Grass/Grass- }\end{array}$ & shade & Wet, Moist \\
\hline Scirpus cyperinus & $\begin{array}{l}\text { bulrush, Teddybear paws } \\
\text { Helmet-flower, Rough Skullcap, Common }\end{array}$ & Perennial & like & Sun & Wet \\
\hline Scutellaria integrifolia & Large Skullcap, Tall Skullcap & Perennial & Herb & Sun & Wet \\
\hline Serenoa repens & Saw palmetto & Perennial & Shrub & Part-shade & \\
\hline Sisyrinchium angustifolium & $\begin{array}{l}\text { Narrowleaf blue-eyed grass, Narrow-leaf } \\
\text { blue-eyed-grass, Bermuda blue-eyed grass, }\end{array}$ & Perennial & Herb & Sun, Part-shade & Wet, Moist \\
\hline
\end{tabular}




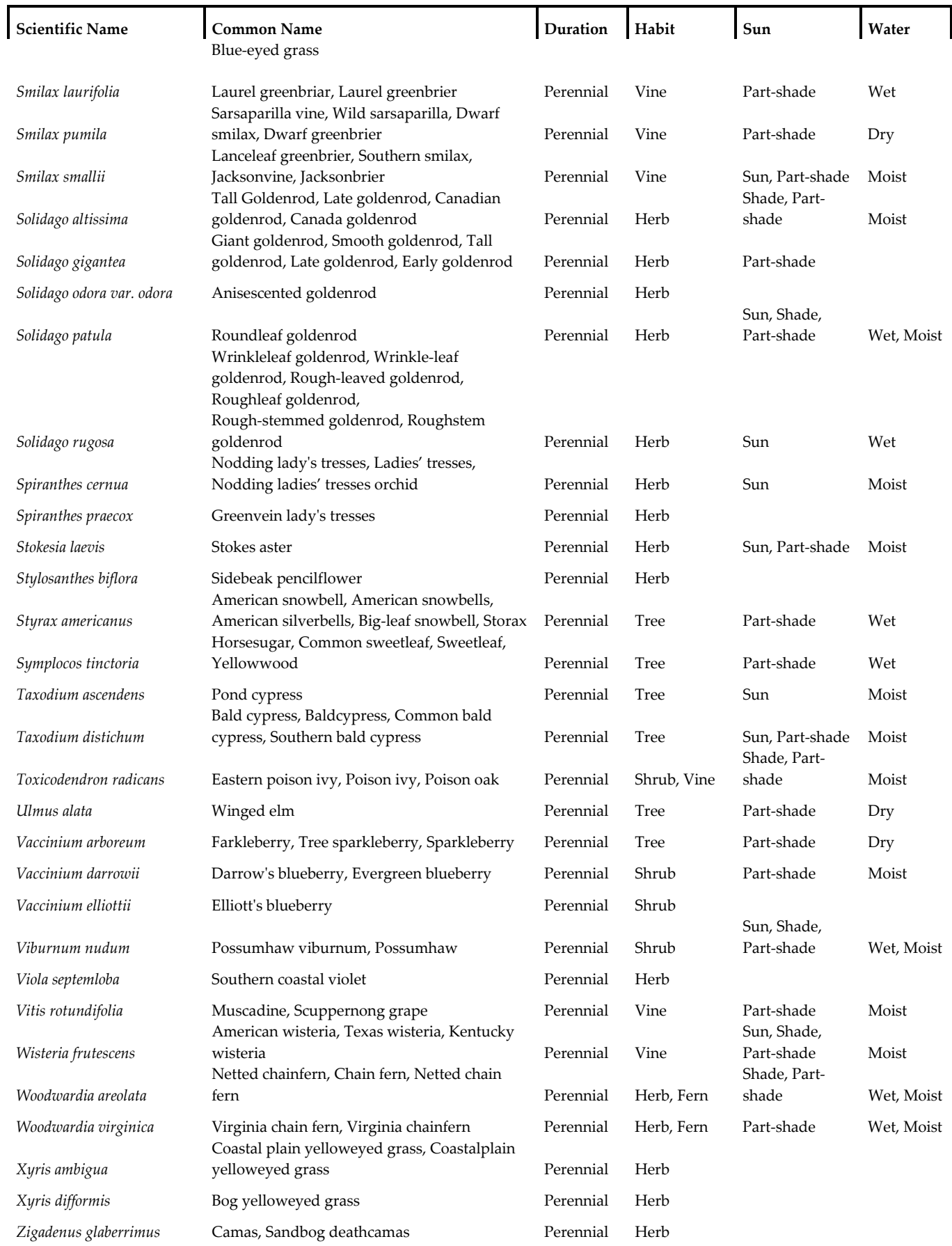

Table 1. The list of the plant species at the Crosby Arboretum (http://www.wildflower.org/collections/printable.php?collection=Organization_817) 
The wildlife patterns at the arboretum as below:

\section{Animals:}

Rabbit

Beaver

Muscrat

Opposum (sign)

Raccoon (sign)

Skunk (sign)

Fox (sign)

Coyote (reported from neighbours)

Feral (\& pet) dogs \& cats

Squirrel

Rat (spp. unknown)

Mice (spp. unknown)

Shrew (spp. unknown)

Rat snake (spp. unknown)

Diamond-Backed water snake

Copperhead Snake

Water Moccasin Snake

Garter Snake

Box Turtle

\section{Birds:}

\section{Waterfowl}

Bobwhite Quail

Turkey

Woodcock

Great Blue Heron

Little Blue Heron

Kingfisher

Red-tailed Hawk

English Sparrow

Starling

Red-Headed Woodpecker

Mourning Dove

Bobwhite quail

Mockingbird

Robin

Brown Thrasher

\section{Other:}

Crayfish (probably more than one species)

Insects ad infinitum 


\section{The esthetic significance of the arboretum}

Gardener William Robinson (1838-1935) was one of the first to abstract nature in garden designs. Within natural environments, Robinson was very sensitive to landscape design characteristics, including vegetation colors, forms, and textures. Robinson advocated studying the spatial composition of a natural landscape in his book The Wild Garden by observing how boundaries of a space were contained by the trees and shrubs. Similarly, Winston Spirn (1984) and further stipulates that landscape architects play a role in creating "conspicuous expression and visible interpretation" of landscape, and that the use of artistic interpretation plays an important role. Spirn states that "the current understanding of nature and culture as comprising interwoven processes that exhibit a complex, underlying order which holds across vast scales of space and time, not only demands a new aesthetic, new forms, and new modes of design, construction, and cultivation, but also prompts a fresh appreciation for the forms of the past and the processes by which they were created." Calling for a new design aesthetic meant its acceptance and embracement by the general public was needed as well.

In recent years, considerable debate within the design profession about aesthetics and values of ecological design, particularly for urban systems. On one hand, landscape architects are challenged to develop more ecologically sensitive projects, while one the other hand, they are drawing on the richly established tradition of visually aesthetic design. According to Mozingo (1997) [20] ecological designers must consider cultural needs and to incorporate current perceptions of aesthetics and beauty.

As it is mentioned above, there are some water exhibits in the Crosby Arboretum. For ecosystems that feature riparian or wetland systems, water is an important element in ecological design interpretation. It's surface, color, form, reflectiveness or movement are landscape elements in terms of bio-physical perspectives. With its aesthetic quality and the image and symbol that it offers [12]. It creates a sense of a place. I is often used to symbolize things in iterature. Water is a universal symbol of change and is often present at turning points in a story. Since water is often sign of life many times water represents life. Fresh water can represent good health and bad water symbolizes bad health. Water can also mean "purity and cleansing" (http:// symbolis.wikia.com/wiki/Water). For developing the relationships of people with water, every form of land use must be based upon a clear understanding of the relationships of the water within the physical characteristics unique to each place [23].

Art elements and principles can be found near natural small streams. While there is some degree of presence of all of design principles (balance, proportion, rhythm, emphasis, and unity) and elements (point, line, form, shape and space, movement, color, pattern, and texture) found within areas of small streams, the artistic elements such as line and rhythm dominate this landscape type more strongly than others. "Line" is one of the more apparent design elements of a channelized water system. Most small streams have a clearly defined bank edge where the water travels. Stream lines which are horizontal features, contrast strongly vertical lines of adjacent mature trees. These line forms create a different emotional 
experience for the viewer, as straight streams provide a distant vanishing point and meandering streams create a sense of mystery as to what is around the next bend. Like this, many natural features such as tree trunks in a dense forest create a sense of "rhythm," as a design principal. In a forested system, a creek becomes a contrast as it is a different material from the surrounding vegetation, rocks or soil. But it also serves importantly as a rhythmic item which literally flows from one part of the landscape scene to the next. The "size" of a landscape element in proportion to its surrounding features is an important principle of design. Small creek systems not only need to serve their hydrological role, but also serve their aesthetic parameters. The design principles such as line, rhythm, and scale are permanent features for small creeks and streams but many of these can be temporal in nature. However, in the fall season "colors" can change to brightly colored reds and oranges for deciduous trees and shrubs. Seasonal changes affect the qualities of other design criteria, especially spatial formations and scale. When leaves fall in the winter months the spatial dynamics of the landscapes change from dense layers of shrub and ground vegetation to an open landscape type. The surrounding land is more easily viewed and the ground plane is much more apparent. "Scale" also changes in winter months, and a small stream channel becomes even smaller in the greater landscape [12].

Mozingo (1997) [20] writes that "examining ecological design in tandem with landscapes of notable aesthetic quality elucidates tbe difficulties in reconciling their conception of visibility, temporality, reiterated form, expression and metaphor." She neatly summarizes their premises into these 5 clearly defined principles. She stipulates that ecological landscapes have inherent social acceptance problems on their own accord and must become an accepted icon or symbol by the general public to become broadly accepted. In the study of Brzuszek and Clark (2009) [10], for the Crosby Arboretum visitors, a questionnaire was designed by deriving from Mozingo's principles. It aimed to examine some qualities of Crosby arboretum such as visibility, care, orderliness, human presence, meaning were analyzed for the correlation between their value and perception for each. According to the results, visitors;

1. Believe that a landscape should blend into its surrounding environment and see this at Crosby;

2. Believe that a landscape should appear cared for and find Crosby to be well cared for;

3. Believe that landscapes need not be necessarily orderly in their appearance and find Crosby to be somewhat too orderly;

4. Are somewhat neutral on the question of having human forms of expression in the landscape but detected a modest presence at Crosby; and

5. Place high value on the need for meaning in the landscape and give Crosby high marks.

Crosby Arboretum's project designers merged a symbiotic interplay between the vegetation patterns and physical processes of the arboretum site with the patterns and processes found in local plant communities. Selecting its local watershed as its genius loci, the landscape exhibits of Pinecote (the public interpretive center of the arboretum) are designed to be "compressed, dramatic expressions of the natural features common to the Piney Woods of the Deep South" [11]. To accomplish this, project designers, Andropogon Associates Ltd. 
and Edward L. Blake Jr., merged a symbiotic interplay between the site's vegetation patterns and physical processes with natural patterns found in local plant communities [10].

While analyzing the aesthetic qualities of the Crosby Arboretum, it is useful to take a look at the design principles of Pinecote Pavilion: Pinecote Pavilion is recognized by the Mississippi Department of Archives and History as a Mississippi Landmark (http://www.crosbyarboretum.msstate.edu/ pages/pinecote.php). Euine Fay Jones (19212004), the architect of Pinecote Pavilion described the architectural qualities and design principles of the pavilion by this means: "Architecturally, the Pavilion is a symmetrical shed, resting on a base of earth-toned brick, surrounded by earth, water, and trees. The brick pattern expresses the basic building module-the composition and arrangement of all the vertical columns. The all-wood structure is built of indigenous material, native pine, and is fastened together with nails, dowels, and metal connections. There is complete exposure of every construction element, all visible from within and without. Every framing member, every beam, brace, and connection is absolutely necessary to achieve structural stability. The building is ordered by a geometric theme-a step-edged pattern that defines the outline of the base and the roof's outer edges. Many smaller elements, for lighting and display, are shaped and detailed to reflect and reinforce the characteristic geometry-to build a strong relationship of each part to the whole and to achieve organic unity. As the vertical supports rise from the brick pavement, there is a spreading-out of structural members and a progressively thinning-out of roof decking toward the edges of the hovering roof. There is a transition in the sheltering overhead arrangement, accented by a central skylight, from close and dense to open and fragile. This is analogous to the organic unfolding or blossoming of so many forms of botanical growth. The imbricated pattern of wood shingles also emulate and recall many of natures' surfaces-the bark of trees and the wings of birds. All wood is stained and the metal painted in colors that harmonize with the earth and plants. Nothing has been added to the structure as mere decoration. Ornamentation or decorative enrichment will come from the ever-changing patterns of light and shadows that play on the closely-spaced structural elements as the sun and moon move across the sky. Time of day and seasonal changes will modify the shadows that frame the light and will keep the spaces in and around the Pavilion vital and alive, continuously enhancing the poetics of revealed construction."

E. Fay Jones, FAIA, of Fayetteville, Arkansas, designed all of Pinecote's original buildings. His modest but stunning Pinecote Pavilion won an Honor Award from the American Institute of Architects (AIA) in 1990. That same year, the AIA recognized Fay Jones with its highest individual honor, the Gold Medal. (http://www.crosbyarboretum.msstate.edu/ pages/visitors.php)

\section{The recreational significance of the arboretum}

Green areas stand out with their qualities of meeting the recreational needs of the people, both in the city and its vicinity. Especially, arboretums serve various recreational opportunities which are related to education and nature conservation. When these activities 
are combined with the other attractive activities and events which are for every age groups succesful results.

The variety and richness of flora and fauna living together in different habitats at arboretums provides dynamic tools and resources creating great opportunities for crosscurricular learning. Knowing an outdoor site and identifying the resources available are important to insure the success of this type of program. Nature teaches many lessons about diversity and learning to live together and science helps people investigate questions [24]. The Crosby Arboretum is dedicated to educating the public about their environment as well. Pinecote, serves as the arboretum's public interpretive center. It provide environmental and botanical research opportunities and offer cultural, scientific and recreational programs. The Crosby Arboretum offers a continual schedule of programs and events designed to educate the public about their environment, and to celebrate nature. A festival called "Piney Woods Heritage Festival" is organized at the arboretum each November. Quarterly native plant sales are held. The Arboretum also offers guided and self-guided tours. So that people can observe the threatened or endangered species of plants and wildlife are present at throughout the Arboretum's preserves.

Arboretum website, entry signage and interpretive trail information prepares visitors to the exhibition of native plants in respective plant communities, by setting this tone, visitors understand the context of the facility and better appreciate the educational mission [10]. So, ecologically designed facilities conveys their purpose in promotional literature and interpretive signage this way, the inherent value of those landscapes is conveyed to the visitors. This is an important point for ecologically designed facilities [12].

Central to the arboretum's educational mission was the decision to display native plants in representative plant communities suitable to the site. The Schematic Master Plan outlined the some design principles and almost all the principles serve the educational mission.

At the arboretum, trail systems throughout the site allow visitors to experience more than 50 naturally occurring and human-created regional plant habitats. As the Master Plan stipulates, "Pinecote, a place where the land expresses itself, is the exhibit. Its Master Plan is the organizing framework for the needs and actions off all who use its landscape. This interplay between man and the land organizes the thematic composition of Pinecote's landscape exhibits" [21] [10]. On the walking journey at The Crosby Arboretum the visitor could experience and learn about Gulf Coast landscape. They can take a stroll around the Pond Journey to discover the diversity of life in wetland habitats, visit the South Savanna Exhibit to see carnivorous pitcher plants, and enjoy the wonder of the Pinecote Pavilion, a Mississippi Landmark. Interpretative signs along the trails describe the flora, fauna and cultural history of the Piney Woods region of Mississippi (Figure 6).

At Crosby, the Pavilion is a gathering place. This simple, open building marks a place to be used for many activities. It is a starting point for nature walks, for talks and discussions about important things in the environment and natural world, a place for exhibits and artistic performance, and a setting for social gatherings. (http://www.crosbyarboretum. msstate.edu/pages/pinecote.php). However, a new education building, designed by 
Mississippi architect Tom Howorth, at the arboretum is being built for educational activities (Figure 7).

\section{Some of the recreational events at Crosby Arboretum (2012):}

\section{Special events:}

- $\quad$ Forge Day - January

- Quarterly Native Plant Sales

- $\quad$ Arbor Day Plant Sale (February)

- $\quad$ Spring Plant Sale (April)

- $\quad$ Aquatic Plant Sale (July)

- $\quad$ Fall Plant Sale (October)

- Wildlife Day (March)
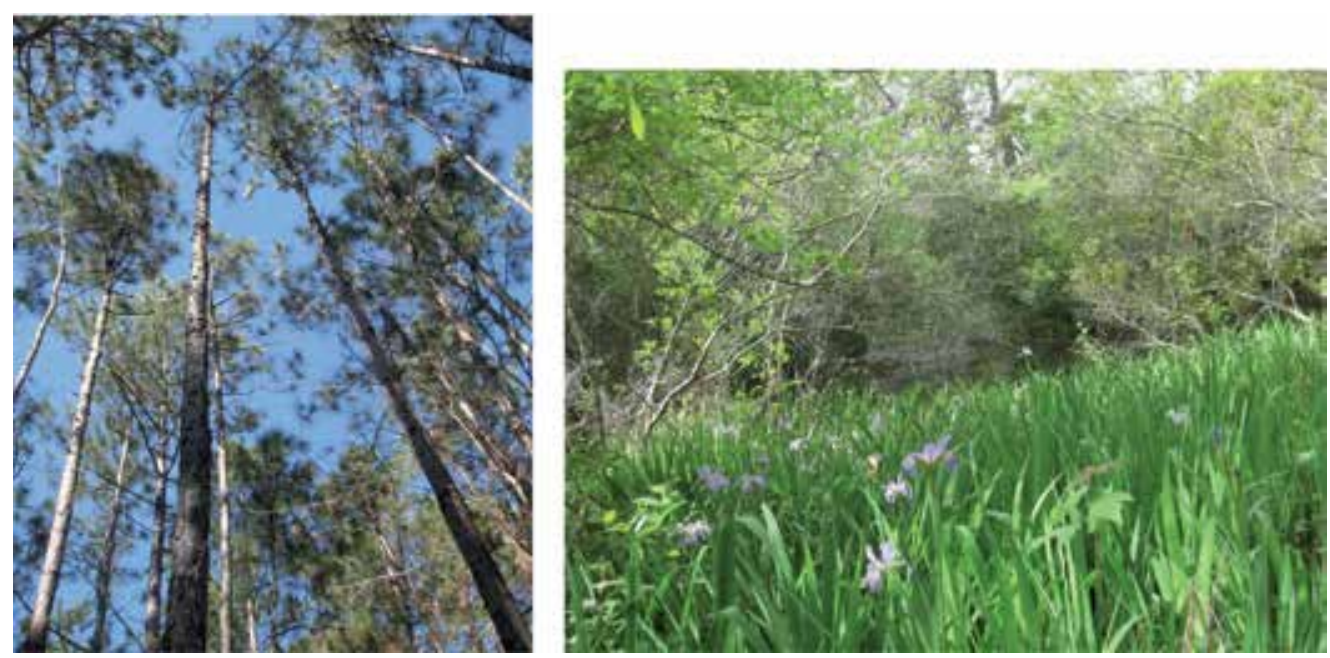

Figure 6. Some views from South Savanna Exhibit (Photos: Banu Ozturk Kurtaslan, 2011).

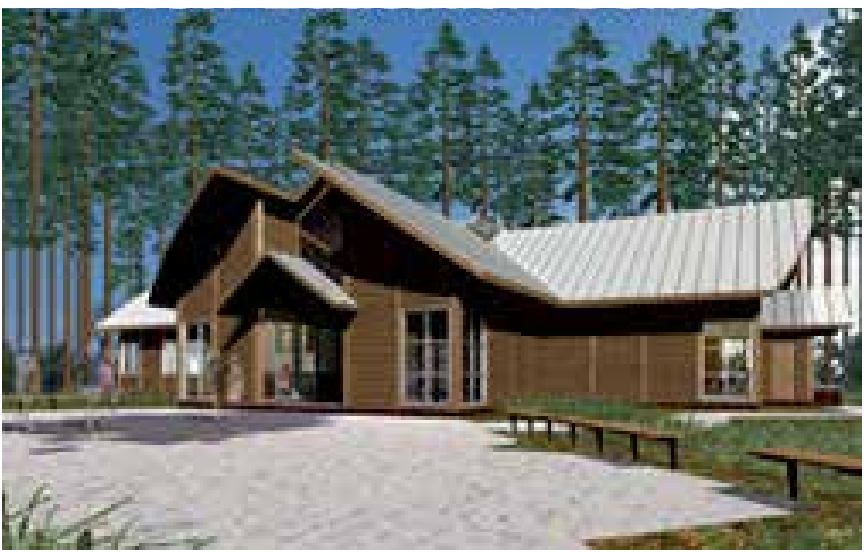

Figure 7. New Education Center building

(http://www.crosbyarboretum.msstate.edu/pages/visitors.php) 
- $\quad$ Strawberries and Cream - April

- $\quad$ Summer Nature Camp - June

- $\quad$ Bugfest - Third Weekend in September

- $\quad$ Piney Woods Heritage Festival - Second Weekend in November (Figure 8).

- $\quad$ Arboretum Open House - December

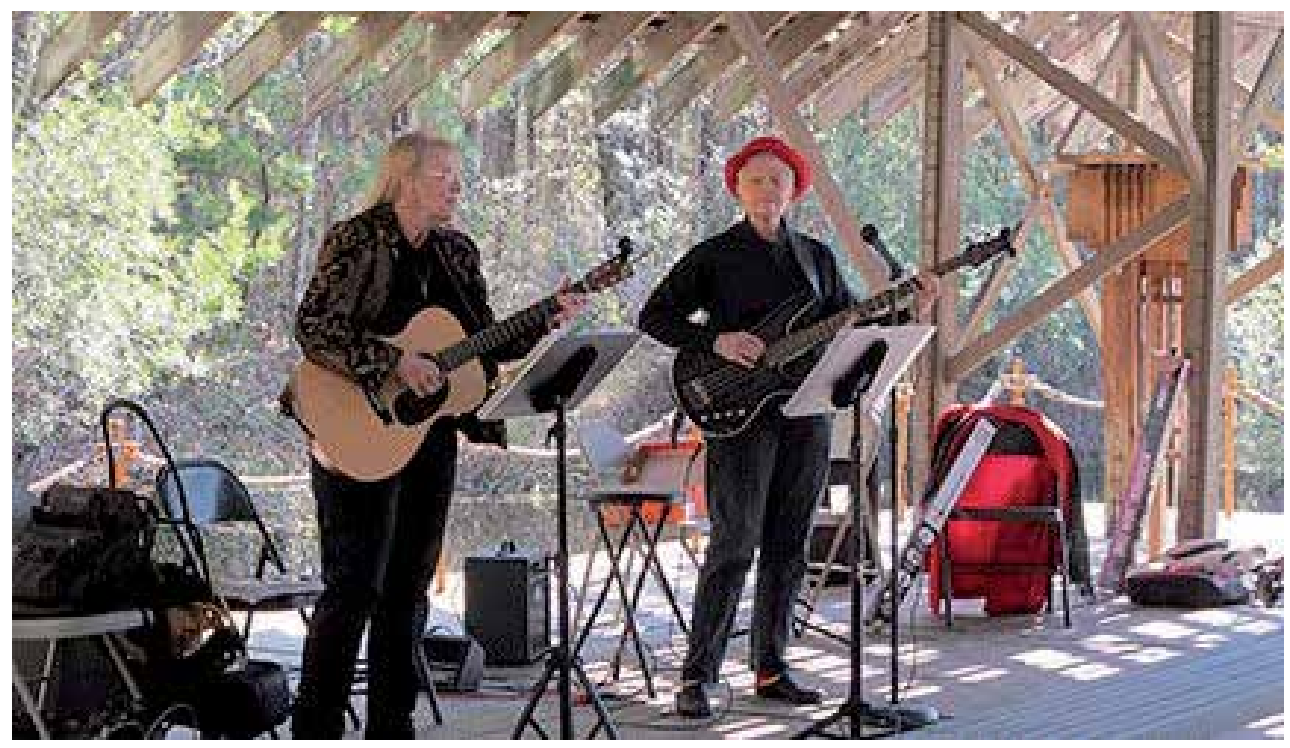

Figure 8. A concert as part of Piney Woods Heritage Festival

\section{WINTER 2012:}

- Winter sparrow banding field walk: A coastal bird biologist, MSU Coastal Research \& Extension Center, will conduct this field walk and workshop that will focus on mist netting winter sparrows (primarily Henslow's sparrows) and give participants an opportunity to observe and handle wild birds.

- Holiday ornaments for backyard wildlife-Kids: Birds and other critters often need extra food in the winter for fuel and warmth. Children will enjoy making tasty delights such as peanut butter pinecone feeders and popcorn-cranberry garlands that will attract birds and wildlife to your backyard.

- Arboretum open house

- Introduction to birding-family: An avid birder and writer, will discuss the fun aspects of birding, including feeding and identification tips. Learn about our resident birds and migrants that visit each year, books, equipment, materials, and other birding resources.

- Wild about winter: The advanced Project Wild workshop will focus on native Mississippi winter wildlife and how to incorporate seasonal wildlife, particularly migratory species and organisms' winter adaptations, into the classroom.

- Forge day: blacksmthing and metalworking: A chance to learn techniques and tips to get started in metalworking. The demonstrations, or try the hand at the forge (Figure 9)

- Arbor day native plant sale 
- Winter botany field walk - Family: With a Mississippi Department of Wildlife, Fisheries, \& Parks Botanist, in an exploration of the Pond and Savanna Habitats of the Crosby Arboretum.

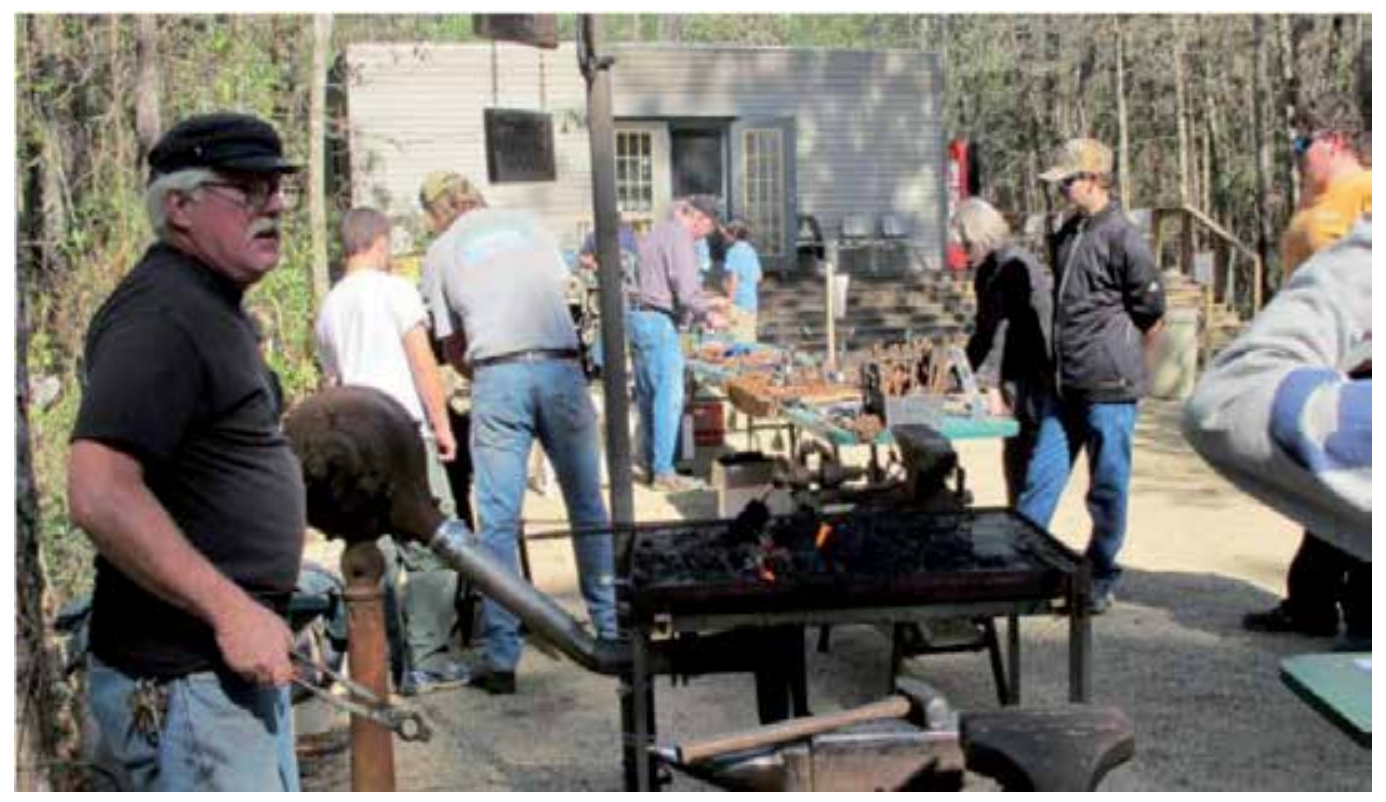

Figure 9. Forge day at the arboretum

\section{SPRING 2012:}

- "Flying wild": project wild teacher's workshop: Flying wild is designed to inspire young people to discover more about conservation and the natural world, and to get involved in activities that promote environmental learning and stewardship.

- Firewise event: "how to have a firewise home"- Adults: Information will be presented on how to design, construct, landscape, and maintain home or community so as to withstand a wildfire without the aid of firefighting resources on scene.

- Wildlife day-School Day-: Children will be thrilled to see the array of exhibitors displaying live and preserved animals, while learning how to protect and maintain wildlife in a field day open to area K-12 schools and homeschool groups.

- The Jean Chisholm Lindsey lecture in landscape design -Adults-: at the Welty House Garden featuring authors of One Writer's Garden: Eudora Welty's Home Place.

- Strawberries \& Cream festival: To celebrate the history of the old strawberry farm on the Pinecote Pavilion. Ice cream, fresh strawberries, and Picayune Frog Lemonade will be served.

- Spring plant sale

- $\quad$ Spider day- Family: 10:00 a.m. - 2:00 p.m. MSU Entomology Student will begin the day with a 30-minute tarantula presentation in the Pinecote Pavilion. A 30 minute talk on venomous spiders will be conducted. 
- Spring field walk: native plants for the home landscape: Join Director for a field walk through the Aquatic, Woodland, and Savanna Exhibits to discuss the plants growing in these habitats and how to use them in your home landscape.

- Earth day at the arboretum: A program, or visit exhibits that focus on nature and sustainable gardening. Programs: Earth day strategies used to protect Mississippi's coastal habitat, get to know native azaleas.

- Painted pots -kids: Decorating a clay pot and design a Mother's Day Card using recycled materials (Figure 10).

- The native orchids of south Mississippi - Adults: Learning to recognize and enjoy many of the thirty species of orchids native to the Gulf Coast.

- "Walking with Kim": A walk while enjoying the great outdoors.

\section{SUMMER 2012}

- Green Fire Film and Discussion: Viewing the new documentary, Green Fire: Aldo Leopold and a Land Ethic for Our Time. An extension Forestry Professor, will lead an interesting and lively discussion about the documentary from the perspective of "Aldo" Suited to ages 7 and up.

- Kid's summer nature camp: Children ages 6 through 12 will enjoy this four-day camp, learning about the outdoors with fun hands-on lessons, games, and activities.

- Teachers' workshop-wild about art and math: This interdisciplinary workshop is open to teachers and homeschool educators. A fun-filled, hands-on Project Wild workshop emphasizing art and math, conducted by Mississippi Museum of Natural Science Educational Outreach Biologist.

- Crosby arboretum's summer aquatic plant sale

- Hummingbirds: Understanding Ruby-throated Hummingbirdsin your yard: James Bell, Hummingbird Bander, of the Hummer / Bird Study Group Inc. will explain what is going on in the hummingbirds life, how they feed, why they fight so much, how to overcome that one bad bird that thinks he owns the feeder, simple tips and tricks that will insure you see more hummingbirds, and enjoy the beauty of one of nature's most dazzling creations.

- Teachers' workshop: wild About Creepy Crawlies: The Project Wild workshop will focus on native Mississippi "creepy crawlies" and will be conducted by Crystie Baker, Mississippi Museum of Natural Science Educational Outreach Biologist.

- Field walk \& clay class: Children will journey down the Arboretum pathways with director to collect natural materials they will use to impress into clay and form lasting memories.

- Summer arboretum field work: Trees, shrubs, and herbaceous plant material native to the region will be discussed, including uses in the home landscape.

FALL 2012

- Mushroom walk: Learning about fungi's fascinating ecology, taxonomy, and relationship to mankind with a professor in Biology from the University of South Alabama (Figure 11). 


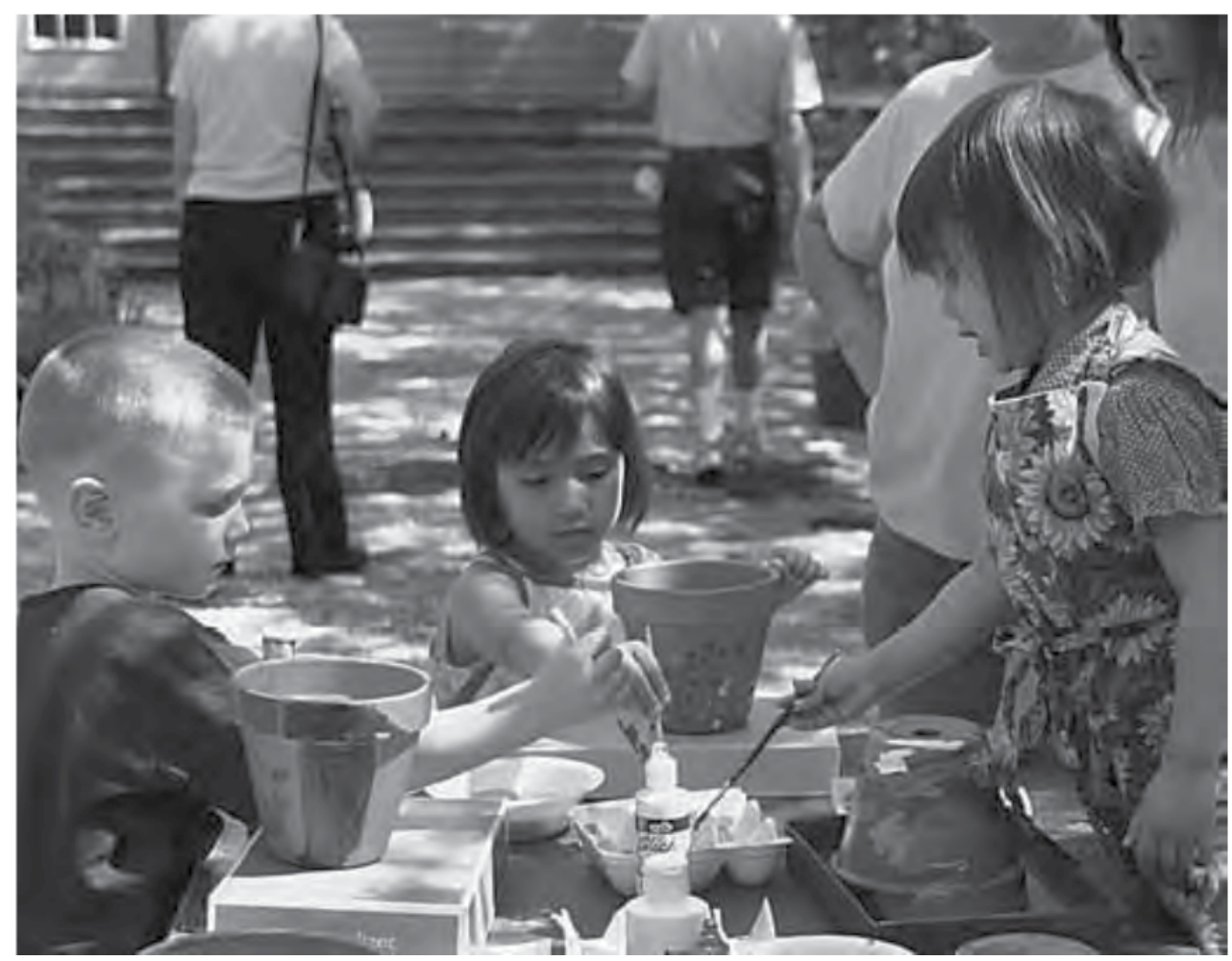

Figure 10. Decorating a clay pot for Mother's Day (http://www.crosbyarboretum.msstate.edu/pdf/2011\%20Crosby\%20Summer\%202011_WE Bsmall.pdf)

- Bugfest family event: Insect collecting by school and homeschool groups (groups over 20 persons must call to pre-register for an arrival time).

- $\quad$ Fall native plants sale

- Winter Sparrow Banding Field Walk

- Wildlife ornaments-Kids

- Arboretum Open House

- Project Learning Tree workshop: One of the oldest and most successful environmental education programs in the world. PLT activities are unbiased, interdisciplinary, fun, hands-on lesson plans, based on sound science. The goal is to "teach students how to think not what to think about environmental issues." For early childhood.

- The Annual Piney Woods Heritage Festival: Offers visitors a chance to see, hear, taste, learn, and participate in all sorts of crafts and activities from the Piney Woods region. Celebrating the early days of the Piney Woods in this 10th annual festival with exhibits and demonstrations of traditional skills such as blacksmithing, quilting, spinning, basket-making, and more.

- $\quad$ Learn the art of bonsai

- Painted Pumpkins - Kids

- Yoga at Pinecote Pavilion - Adults (Figure 12). 


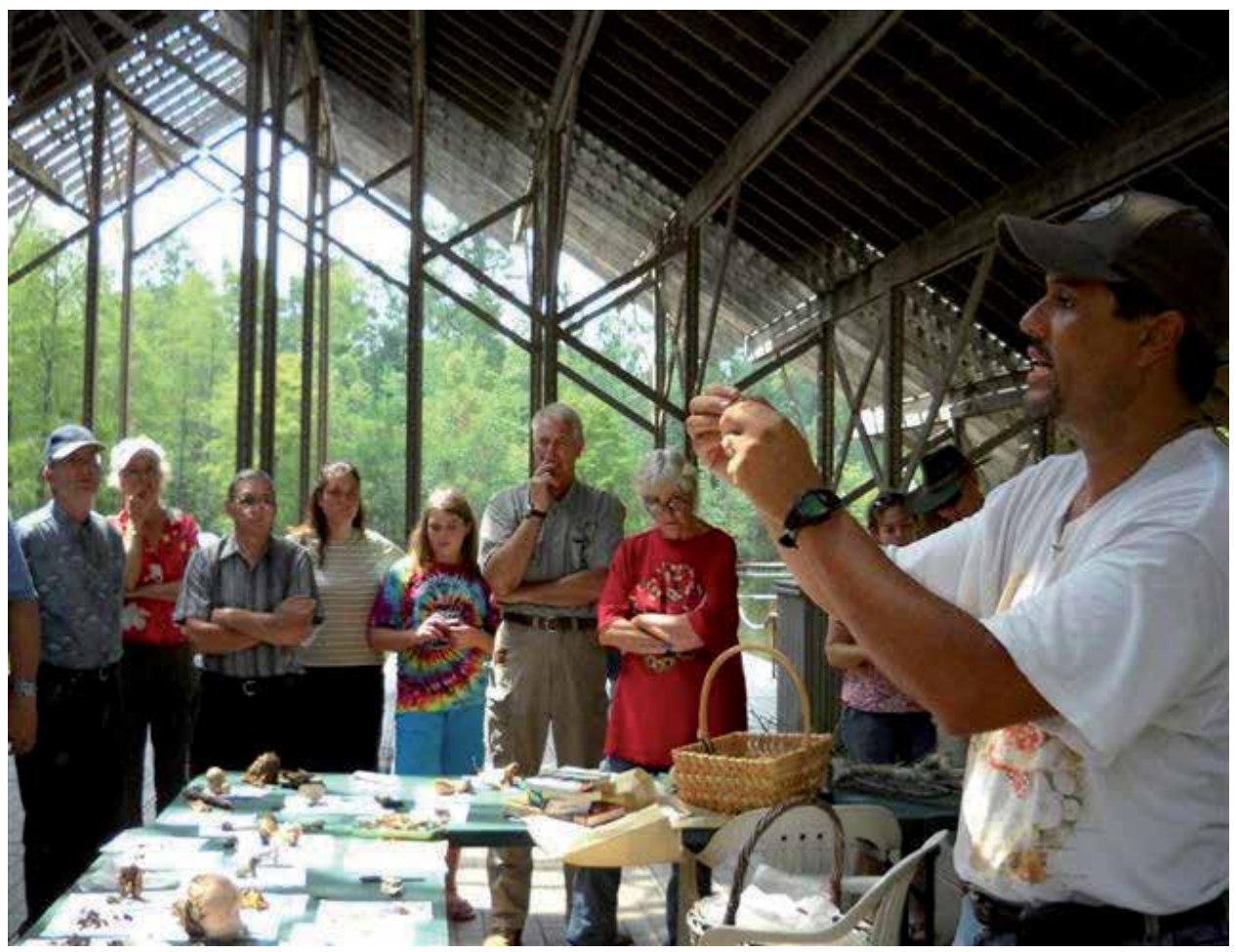

Figure 11. A wiew from "mushroom walk" activity

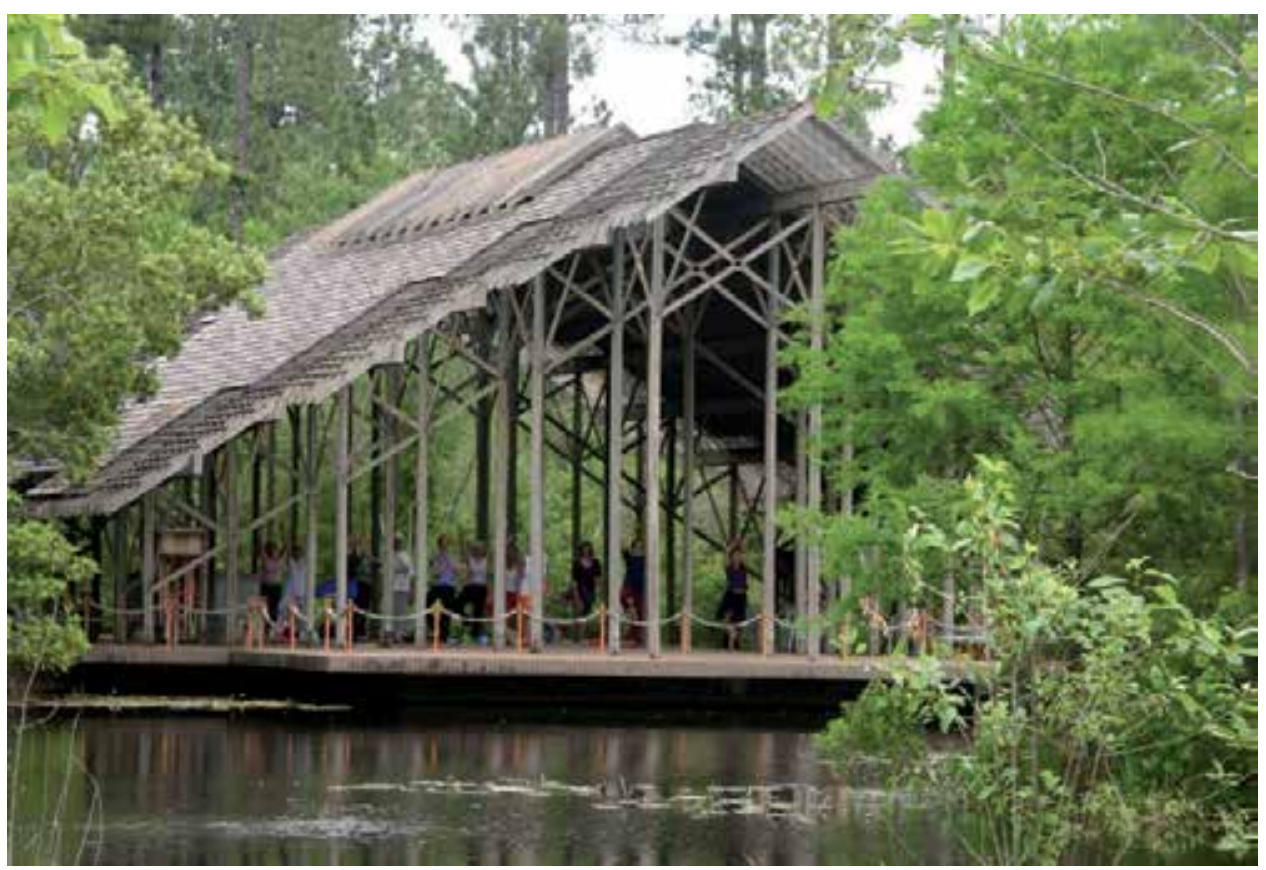

Figure 12. Yoga class at Pinecote Pavillion 
- Fall field walk: Native plants for the home landscape

- Girl scout environmental badges day: Scouting groups may picnic before or after program times on the grounds as part of their visit.

In addition to these activities and events, every Friday arboretum volunteers meet. Volunteering presents very important contributions for the arboretum (Figure 14).

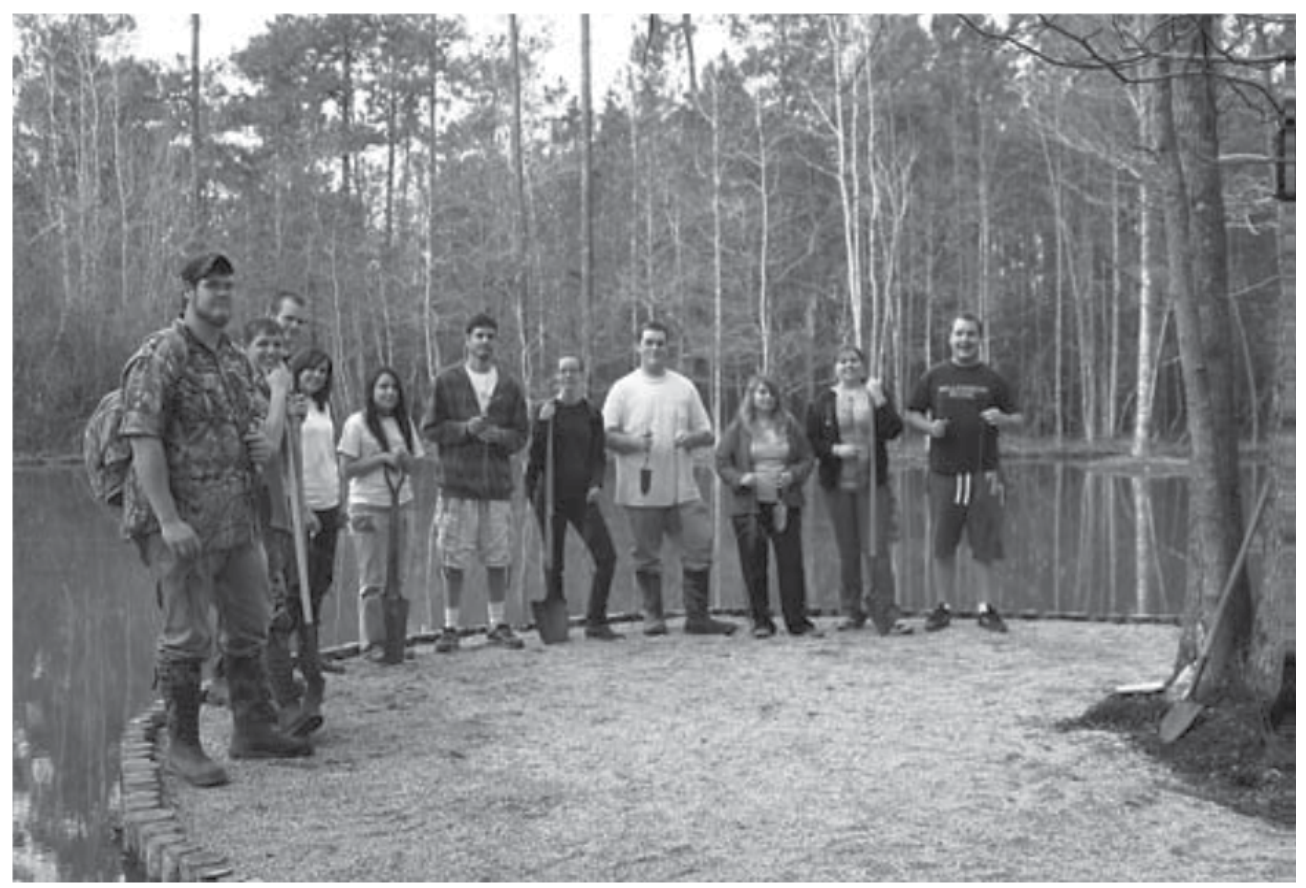

Figure 13. Joyce Applegate's Pearl River Community College botany class planted swamp gum trees on February 16, 2011 as volunteer

(http://www.crosbyarboretum.msstate.edu/pdf/2011\%20Crosby\%20Spring\%202011_Web.pdf)

\section{Conclusions}

Crosby Arboretum is a public garden that has constituted with the efforts of ecological design. The ecological, recreational and esthesic values has been attracting a number of people both from its own site and the world. Especially, Pinecote's aquatic displays serves visitors to Southern Mississippi a rich taste of the diversity of ife that resides here. The displays in the arboretum are designed to educate visitors with lots of activities and events. The goal of the arboretum staff is try to show the importance of these environmental processes both in natural areas and around all human development. So the unique sense of the place is preserved and celebrated with all other people. Crosby is fulfilling its missions of "preserving, protecting, and displaying plants native to the Pearl River Drainage Basin ecosystem, providing environmental and botanical research opportunities, and offering cultural, scientific, and recreational programs" with a succesful planninng, design and management. 


\section{Author details}

Banu Ozturk Kurtaslan

Selcuk University Faculty of Agriculture, Department of Landscape Architecture, Turkey

Robert Brzuszek

Mississippi State University, Department of Landscape Architeture, USA

\section{References}

[1] Yaltirik, F., 1969. Canli ve Kurutulmus Bitki Muzeleri (Arboretum, Botanik Bahcesi, Herbaryum), Istanbul Universitesi Orman Fakultesi Dergisi, Seri B, !9. Cilt, Sayi:1.

[2] Sertkaya, S. 1997. Bartin Orman Fakultesi Arboretumu'nun Kurulmasina Yönelik Bir Arastirma. Yüksek Lisans Tezi. Zonguldak Karaelmas Universitesi Peyzaj Mimarligi Anabilim Dali Zonguldak.

[3] Francis, J. K., 1989. The Luquillo Experimental Forest Arboretum. United States Department of Agricultry, Forest Service, Southern Forest Experiment Station, pp. 1-8. USA.

[4] Sat, B., 2002. Doga Koruma ve Cevre Egitimi Acisindan Arboretumlarin Islevleri ve Ataturk Arboretumu. Istanbul Universitesi Peyzaj Mimarligi Bolumu. Istanbul.

[5] McHarg, I., 1969. Design with Nature. Doubleday/Natural History Press, Garden City, NY.

[6] Mozingo, L. 1997. The Esthetics of Ecological Design: Seeing science as a culture. Landscape Journal. 16 (2): 46-59.

[7] Van der Ryan, S., and Cowan, S., 1996. Ecological Design. Island Pres. Washington D.C. 1996. pp. 200.

[8] Spirn, A.W., 1984. The Granite Garden: Urban Nature and Human Design. Basic Books, New York.

[9] Hough, M., 1995. Cities and Natural Process. Routledge, New York.

[10] Brzuszek, B. and Clark, J., 2009. The Crosby Arboretum. Native Plants. 10:2. Summer.

[11] Anonymus, 1984. Crosby Arboretum Quarterly News Journal. Vol. 2.1

[12] Brzuszek, B. 2012. Interview. The Curator of Pinecote, Crosby Arboretum. Mississippi State University Landscape Architecture Department. Starkville, USA.

[13] Anonymus 2011. Crosby Arboretum-The Small Stream Swamp Forest Exhibit Master Plan. Booklet by the graduate class in the department of landscape architecture at Mississippi State University. Starkville.

[14] Brzuszek, R., 2010. Artful Disturbance in The Piney Woods Landscape-The Crosby Arboretum.New Directions in American Landscape. Power Point Presentation. Connecticut College, Connecticut.

[15] Templeton, K. and Templeton, B., 2009. Crosby Arboretum: A Celebration of Nature. The Crosby Arboretum- Mississippi State University Extension Service. Quarterly News Journal. Spring 2009. pp. 8-9. USA. 
[16] Randall L. Meador, 2010. The Crosby Arboretum- Mississippi State University Extention Service. Quarterly News Journal. Spring.24.2. MSU Masters of Landscape Architecture student and civil engineer, Neel Schaffer, Inc.

[17] Anonymus, 2006. The Crosby Arboretum- Mississippi State University Extension Service. Quarterly News Journal. Spring 2006. pp. 223-229. USA.

[18] Brzuszek, R., 2011. Interview. The Curator of Pinecote, Crosby Arboretum. Mississippi State University Landscape Architecture Department. Starkville, USA.

[19] American Society of Landscape Architects, 1991. Landscape Architecture Magazine, November 1991.

[20] Mozingo, L., 1997. The Esthetics of Ecological Design: Seeing science as a culture. Landscape Journal. 16 (2): 46-59.

[21] Brzuszek, R., 1994. Celebrating Water at the Crosby Arboretum. Crosby Arboretum Quarterly News Journal. October 1994.

[22] Spirn, A.W., 1984. The Granite Garden: Urban Nature and Human Design. Basic Books, New York.

[23] Patchett,J. M. And Wilhelm, G.S. Conservation Design Forum, Inc. James M. Patchett \& Gerould S. Wilhelm. Conservation Design Forum, Inc. USA.

[24] Betz, S. 2004. Kids, Gardens and Art. A Natural Connection. The Herbarist. Issue 70.pp 45-48. 


\title{
Hospital Outdoor Landscape Design
}

\author{
Gökçen Firdevs Yücel
}

Additional information is available at the end of the chapter

http://dx.doi.org/10.5772/55766

\section{Introduction}

Among public institutions, the large buildings and complicated intervening and surrounding areas of hospitals usually tend to be seen by the public as removed from the urban context, as spaces to be feared, which one only accesses in emergencies or out of necessity. However, this psychological perception of their distance and separation can be decreased by today's more hospitable approaches to their content and design [1].

With a growing understanding of the importance of the physical environment for the quality of hospital care and the health and safety of patients and staff, the outdoor spaces of hospitals are beginning to be considered, particularly in scenic and more green areas, as a productive complement to the interior areas which are reserved for patient treatment and have traditionally been prioritized.

As a result of this new, holistic approach to medicine which entails alleviating the fears and disorientation of patients that may hinder medical treatment, the hospital has come to be seen today as a necessarily comforting and stress-free environment, created with a broader, patient-oriented sense that encompasses both master planning and landscaping [2].

This means that the outdoor as well as the indoor spaces of hospitals are understood as crucial to patients' physical, psychological and social recuperation and wellness $[1,3,4,5,6]$ : appropriately designed active and passive hospital landscapes enhance patients' interaction with nature and so reduce stress, facilitating interaction with others in ways compatible with and complementary to those found in the urban environment $[7,4]$.

\subsection{Benefits of natural environments within hospitals}

\section{Physical benefits}

Research shows that rehabilitative structures and procedures enhance both the physical endurance and the physical well-being of patients. Interaction with a natural environment 
has a positive effect on patients' feeling of well-being, which in turn has a salutary effect on their physical health. In addition to anecdotal evidence, there are theoretical and practical studies illustrating the positive effects of interaction with nature on blood pressure, cholesterol levels and stress-reduction [8, 9, 10, 11, 12]: a study by Robert Ulrich concluded that patients recovering from operations were discharged earlier, took fewer analgesics and were evaluated less negatively by nurses when they had windows in their rooms overlooking nature, compared to patients in similar rooms facing brick walls [7, 13]; and a study of the home environment similarly found that a living context with windows overlooking a natural scene produced "micro-restorative experiences" that enhanced a sense of well-being, as against a context with views of built elements [9].

\section{Psychological benefits}

Being able to choose between having privacy and interacting socially may assist in the process of recovery of patients, for most of whom the rigid regulation of time and activity in the hospital can have negative psychological effects, such as loss of self-esteem or the feeling of control, and a resulting increase in stress.

Research shows that high blood pressure and heart activity caused by stress can be decreased if patients are exposed to natural scenes, because such scenes engage them, draw their focus away from themselves and disturbing thoughts, and so contribute to their recovery $[5,14,8]$. Research conducted in London by the Bow Centre has used flower and cutting gardens for horticultural therapy; patients are overwhelmingly in favor of welldesigned hospital landscapes, because of their positive psychological effects and the chance to pass time there [15].

\section{Social benefits}

Everyone, regardless of age or ailment, needs recreation and social support; participation in social activities may also be the only means of family and community interaction and integration, and of sharing similar experiences, for the physically disabled. Studies have shown that patients with strong social support networks typically experience less stress and better health, as well as better recovery and survival rates for various conditions, than those who are isolated [8]. Social support improves immune functions and moods, and results in better compliance with treatment [16].

Natural environments in health care facilities contribute to social integration by providing spaces for social interaction and support; evidence indicates that they significantly help increase access to social support for patients, families, and staff [3].

\section{Outdoor hospital spaces}

\subsection{Typology of outdoor spaces in hospitals}

\subsubsection{Landscaped grounds}

Green areas between buildings, primarily used for waiting and eating in, link the architecture with walking paths; however, they may be expensive to maintain. 


\subsubsection{Landscaped setbacks}

These are usually planted areas in front of the main entrance, which are visually pleasant and serve to separate the hospital building from the street.

\subsubsection{Front porches}

These may include overhangs or porch roofs, an area where vehicles can pick up or drop off passengers, sitting areas, signs with directions, a mailbox, telephone booth, bus stop, etc.

\subsubsection{Entry gardens}

These are visually pleasant green spaces designed like gardens and located near hospital entrances.

\subsubsection{Courtyards}

Courtyards are the central and most often used spaces in a hospital building complex, because of their proximity to the dining area; they tend to be used more by visitors and patients if they are easily visible, and should be sufficiently large to prevent overcrowding [1]. Courtyard features may include landscaped tree-shaded areas, water features, flowerbeds and moveable seats; for reasons of privacy and security as well as aesthetics, they may be fenced around (especially if designed for care of the mentally ill) up to a height of $4.27 \mathrm{~m}$ [17].

\subsubsection{Plazas}

These outdoor areas, which are typically paved and furnished, should allow easy access to wheelchairs, walkers and crutches. They should include shade from flowering trees or spreading evergreens, and at least a quarter of the trees should be above the minimum specified size. A plaza should have shaded seating areas decorated with plants, colored shrubs and ground cover, and perhaps a water feature. Because these areas are largely paved, landscaping and gardening maintenance costs are low.

\subsubsection{Roof terraces}

A roof terrace is usually a long, narrow balcony occupying one side of the roof of a hospital building. The elements it is comprised of (plants and seating) and the surface finish are designed to minimize observation from from higher buildings overlooking it. Roof terraces are sometimes too exposed to wind, heat or shade, and for this reason care must be taken in selecting their location [3].

\subsubsection{Roof gardens}

Gardens located on roofs are visually attractive, enabling patients to look out from their rooms and have a comforting view of grass, paving stones, benches and people, rather than 
roofing material or medical equipment. Depending on how much planting material is used and to what depth, green roofs generally weigh between $6.82 \mathrm{~kg}$ and $22.73 \mathrm{~kg}$ per square foot. They are a practical and sustainable way of regulating the quantity and speed of run-off, as they retain $70-90 \%$ of the rainwater that falls on them in the summer, and $35-40 \%$ of the precipitation in winter [18]. Roof gardens enable major energy savings that will more than compensate, in time, for the costs of building, structure, waterproofing, and landscape maintenance; and they also minimize the environmental impact of a health care facility.

\subsubsection{Healing gardens}

Gardens which serve as safe and meditative environments for healing and recuperation date back to the medieval period, and have traditionally been features of hospitals, hospices, rehabilitation centers, and nursing homes [19]. The wide range of activities related to healing gardens may be passive or active: looking at the garden from a window, sitting, eating reading, doing paperwork or taking a nap in the garden, prayer and meditation, walking to a preferred spot, gardening, exercise and sports, and children's play [20]. The gardens are conducive to stress relief, relieving physical symptoms, and enhancing the feeling of well-being of hospital staff and patients.

Successful healing gardens make use of certain fundamental design principles [21]:

Enhance feelings of control: People should be aware that there is a garden and be able to find, enter and use its space. The garden should have private areas which cannot be seen from overlooking windows, and different kinds of spaces so users can feel they are making choices; if users are also consulted in designing the garden, this will also add to their feeling of control. All or some of the five senses can be chosen as focal stimuli in the garden's construction [22].

Have a prevalence of green material and areas: Patients' sense of well-being is enhanced by soft landscapes, so plant material should be dominant and hardscaping reduced to a minimum: trees, shrubs and flowers should make up about $70 \%$ of the garden, with $30 \%$ in walkways and plazas [23].

Encourage exercise: Designs should provide easy access and independence, as well as stressreducing structural elements such as walking paths for patients to encourage exercise, and play areas for children [24].

Provide positive distractions: Stress levels among patients have been shown to decrease when they are in the presence of plants, flowers, and water features as well as when they are engaged in gardening. In the Child and Adolescent Mental Health Unit at Great Ormond Street Hospital, growing vegetables has been seen to have therapeutic value for young people with eating disorders; and, as mentioned earlier, flower and cutting gardens are being utilized for horticultural therapy at London's Bow Centre [25].

Minimize intrusions: Gardens should be designed to minimize negative factors like urban noise, smoke, and artificial lighting, in favor of natural lighting and sounds. Gardens that 
appeal to the different senses are ideal (although strongly scented flowers and other scents should be avoided for chemotherapy patients) [23].

Minimize ambiguity: Complex or mysterious settings that provide a challenge might be of interest to the healthy, but research shows show that abstract design may be contraindicated for patients who are ill or undergoing stress. For this reason, the use of abstract art may be unsuitable, and design should focus on clearly identifiable elements.

\subsubsection{Meditation gardens}

This type of small, enclosed, quiet garden is designed with a central focal point to help patients (often a single patient at any given time, depending on the size) concentrate and relax as part of the healing process. It is a space for quiet contemplation, removed from distractions and private - that is, not visible from other indoor spaces. Meditation gardens are labeled as such and purpose-designed, and their layout is usually simple and minimalist, comprising, for example, a circle representing life, a square symbolizing order, or symbols such as the Celtic knot, which represents travel [3]. They usually have a lawn and/or a comfortable seating area with a focal point, typically a water feature, to encourage meditation. The vegetation should provide cool colors such as violets, blues and greens, rather than bright, warm or contrasting colors [26].

\subsubsection{Viewing gardens}

Some health care facilities with limited space and budgets feature a small, enclosed garden that can be seen but not entered. Such gardens cost little to maintain, provide some green space, flowers, perhaps a water feature, and they can be seen from sheltered indoor seating areas; however, the elements of nature they provide are removed from the senses, as they cannot be approached smelled, heard or touched.

\subsubsection{The viewing/walk-in garden}

In this variation on a viewing garden, the green space can actually be entered from a corridor or waiting room: because it has limited space and seating, it remains a quiet area which does not disturb the privacy of any nearby rooms or offices, and also provides a comforting view for people waiting or passing by in the corridor. The main disadvantage is that people using the space may feel a lack of privacy, as they can be watched by others [3].

\subsubsection{Edible gardens}

A healing garden can be developed to a new dimension if herbs, fruit plants and vegetables are grown together with the usual planted vegetation in an easily accessible space. This "edible garden" should be simple and balanced, but designed in a repeating pattern with wandering paths demarcating public and private spaces [27]. The vegetation would favor annuals over perennials; and the garden could feature a large number and variety of plants, such as, for example, Nasturtium spp., the flowers of which are beautiful and can also be eaten. 


\subsection{User groups}

\subsubsection{Patients}

The health-care environment should be designed taking into account patients' psychological as well as physical needs, disabilities, and duration of stay [28]; long-term inpatients or outpatients will have more varied requirements than short-term ones, and their holistic treatment will be enhanced by access to gardens, sheltered outdoor plazas, common social areas, and reading resource areas [29]. In addition, patients undergoing different kinds of treatment may use these areas for different purposes: for example, othopedics patients may need to use walking aids in the gardens; facilities for seniors may need handrails and more shaded areas; physical therapy patients may need to tend to plants at different heights; and psychiatric patients may need "memory cues" and planted areas which minimize the risk of injury.

\subsubsection{Visitors}

A supportive and distractive environment is also essential for people visiting friends or relatives in the health-care facility, because while visiting patients can be salutary, it may also be emotionally draining [30].

\subsubsection{Staff}

Outdoor spaces are especially important for health-care staff, who spend most of their time in the facility, and need designated and accessible areas removed from their daily activities, where they can wander, collect themselves, and adjust to the stress of their work [31]. While administrative staff tend to have the most free time to use outdoor spaces, as they typically have a one-hour lunch and regular breaks [1], nurses are the staff who have to keep patients constantly in view and help them go outdoors. However, nurses generally do not have time to stay with patients outside, and cannot leave them alone, so their responsibilities, as well as the distances from nursing stations to the outdoor spaces, have a negative effect on the use of these spaces by both patients and nurses.

\section{Outdoor design criteria for hospitals}

When creating a garden for a health-care facility, the focus should be on location, accessibility, patients' requirements and preferences, and the design elements to be included [32]. The garden should have opportunities for mobility and exercise, present a choice between social and solitary spaces, and facilitate beneficial distraction and direct or indirect interaction with nature [8].

\section{Accessibility}

This is an essential requirement, both within the hospital and in its environment. Gardens may be designed and set up attractively, but people need to be aware that they exist, that they are easily accessible through entrances and paths and useable regardless of people's 
age or disability, and that they facilitate certain activities. Within the garden, visitors follow internal circulation routes, typically between walls, but occasionally crossing open spaces. Paths help people to find their way in hospitals, and differentiating them can help patients and visitors find their way [33].

\section{Visibility}

The more a garden is visible and people are aware of it, the more its activity areas and paths will be preferred. At least one outdoor space should be visible or its location clearly indicated from the main entrance [34]. Patients' rooms should have views of the garden so they can enjoy it even if they are unable to visit it [35].

\section{Feeling of Control}

Research shows that a feeling of lack of control can lead to or aggravate depression, passivity, elevated blood pressure, and decreased immune system operation [9]. A sense of control in the garden can be enhanced by getting users involved in its design; and different types of spaces and layouts can enable them to make their own choices - for example, a variety of pathways, of types of nooks where they can sit, of furniture (if some is moveable), or of views, ranging from close to distant [36].

\section{Feeling of Security}

Patients often feel both physically and psychologically vulnerable in hospitals, and a feeling of security should be provided. This includes sufficient lighting and public telephones in isolated areas so people can call for help, and other facilities and design elements in the garden that make them feel safe. Broadly speaking, there should be a feeling of enclosure but without the feeling that one is being watched. Features should include handrails and seating at frequent intervals, particularly near the entrance, to assist the elderly, the disabled or mobility-impaired, and an avoidance of paving materials like asphalt that reflect a strong glare [5].

\section{Physiological comfort}

As hospital patients are often sensitive to temperature (burn patients, for example, generally have to keep out of direct sunlight), options such as sunny and shady areas should be provided [8], as well as seating shielded from breeze by plants or structures. Various medications require patients taking them to avoid sunlight; some patients might be afraid of catching a chill if they go outdoors. Others patients have trouble getting up on their feet, so the garden should have garden seats with arms and backs, and also benches one can sprawl or lie on.

\section{Quiet}

Research on four hospital gardens showed that users were disturbed by sounds of machines like air conditioners and traffic noise; areas to be used as garden spaces should be planned in advance, away from traffic, parking areas, delivery driveways, and helicopter landing pads [20]. A garden designed for therapeutic purposes should be quiet and removed from 
sounds inside the hospital, which range from public announcements, to television sets to catering trolleys and gurneys; visitors to the garden should feel calm, and be able to hear reassuring sounds such as birdsong, wind chimes, or flowing water.

\section{Familiarity}

Hospitals may cause stress for patients and their families, as they are unfamiliar environments, and they can be made more comforting and familiar if they include aspects of nature [37]. People working in hospitals similarly experience stress, and need to have access to familiar and relaxing garden settings. The aesthetic of the health-care environment should therefore be based on this fundamental need and provide spaces on a human or domestic scale as well as familiar-looking plants and furniture; this is particularly important in facilities for Alzheimer's patients and the terminally ill.

\section{Flexibility}

Exterior spaces should attract people, invite them in and engage them; they should be designed based on when (i.e. at what times and in what weather conditions) by whom (i.e. what groups), and how they are currently used (for example, for a lunch break, exercise, or socializing), and also on how their usage may be shaped in the future. To maintain interest and year-round interaction, for instance, they should be studied to see how they are used in different seasons, and then designed with different seasonal blooms and colors and different weather conditions taken into account.

\section{Sustainability}

Resources should be allocated intelligently when designing outdoor spaces: every material used does not have to be green, and some hard surfaces like concrete can help prevent storm water run-off. Wild grasses and Sedum spp. create ground cover which reduces domestic grass, decreasing the cost of maintaining lawns. Xeriscaping (designing with low water-use plants) together with native vegetation also helps reduce water use and maintenance. Nature trails enable users to have exercise, education and a natural aesthetic at a minimal cost; and solar-powered lights and water features that recycle rainwater can also be costeffective and sustainable.

\subsection{Hard landscape design}

\subsubsection{Gateways and entrances}

Gateways and entrances welcome people on arrival and provide cues for them to find their way around the site; they can perform this function if a comprehensive network of connecting paths is planned, specified, and followed up to ensure they are properly constructed [25]. The main entrance should be accessed logically by the most direct path, and the entry way to the outdoor space should have no ramps or steps [1]. Landscaping, artwork and detailing can prioritize the main access points and create a sense of place, and benches should be available for people arriving or waiting for rides to sit on [38]. Entrances must be sufficiently wide to accommodate people with special mobility requirements; for 
the visually impaired, different kinds of surfacing materials can be helpful, and tactile elements should indicate thresholds [39].

\subsubsection{Parking areas}

Parking areas should be sufficient to accommodate staff and employees, and parking should ideally be reserved for staff at the back of the hospital so they do not have to deal with heavy traffic when they come to work [40]. Parking for patients, especially those with disabilities should be as close as possible to the entrance [6]. Patients and visitors unfamiliar with the hospital may easily be confused if parking space is difficult to find; this can be solved by using directional signs that can be altered or moved as conditions change [41].

\subsubsection{Paths}

Large hospital or medical complexes should be organized within a clear circulation hierarchy: main roads, shopping streets, neighborhood streets and service alleys. Each of these, as well as intersections and destinations, should be indicated by a consistent system of spatial cues [33]. This circulation in the health-care facility should be independent of public roadways, and public (nonsecured) and private (secured) zones should be distinct, preferably with patient intake and outdoor recreational areas in the private zone. Traffic circulation should be organized so that individuals and ambulances can directly access emergency facilities [29].

The main circulation routes should be clearly indicated, for example by giving easily understood names to the main corridors like "Hospital Street" or "Blue Corridor" (here the walls and floor should be predominantly blue in color); or having colored lines along the walls or floor to designate main routes; or using lighting along a route [42]. Primary routes should be accessible to everyone; however, some people will prefer to experience the natural environment unmodified and will not expect easy access everywhere [25].

Minor walkways should be at least $1.5 \mathrm{~m}$ wide, with drainage that will get rid of rainwater quickly. One-way traffic routes should be at least $1.5 \mathrm{~m}$ wide to allow for the turning circle of a wheelchair; while two-way traffic routes should be at least $2.1 \mathrm{~m}$ wide. There is a risk of tripping if the edges of a path are raised [26]; and handrails or balustrades and wheelchair barriers will preclude people's falling where surface levels change, or from entering uneven ground beside paths and paved areas.

In the garden, clear links with different facilities and direct routes are essential. Right-angled corners in paths should be avoided, and slopes designed as follows: a walkway's slope should not exceed $5 \%$ (i.e. $30.48 \mathrm{~cm}$ of rise for a length of $6.1 \mathrm{~m}$ ); cross slopes should not exceed $2 \%(30.48 \mathrm{~cm}$ of rise for a length of $15.24 \mathrm{~m})$. Where the slope does exceed $1 / 20$, there should be a support railing to preclude slipping. The surfaces of paths should be firm, smooth and level, and provide traction; they should reflect the context, with "softer" materials used for informal settings. Paving surfaces should be smooth enough to be used by wheelchairs and gurneys [3]; but grooved paving may be unsuitable for them. Different 
materials have different pros and cons: concrete is suitable, but costly; asphalt absorbs and radiates heat, and may be too hot in the summer; decomposed granite may be suitable for wheelchairs, but is not for users of crutches. More recently developed rubberized paving materials are firm enough to support wheelchairs, and also absorb the force of a fall.

Outdoor areas should be designed so they can be used throughout the year; snow- or icemelting devices should be in place for walkways during the winter.

\subsubsection{Children's gardens}

Children are usually discouraged from moving around in hospital environments lest they disturb the health-care workers or patients; there should be spaces set apart for them where they can move as freely as they need or wish to [43], as they need to engage in imaginative play regardless of the condition of their health. Children need to feel they can create and make changes by interacting with their environment and moving objects and parts; as a result, flexible play areas should be designed to stimulate their imaginations [44] and give them the pleasure and therapeutic benefit of creative activity.

A children's area might, in addition to using primary colors and providing climbing structures, include a path maze, a chalkboard masonry wall, child-sized sculptures, or a miniature bridge traversing a faux rock stream, which can also be crossed on stepping stones. Routes should be stable and made of surfaces like decomposed granite, asphalt, wooden boardwalk, resilient mats, and concrete, to resist slipping. There might be platforms so children in wheelchairs can safely move onto and off play structures; and sand play areas may be made available at different heights, so they can be used on the ground or from a wheelchair [45].

\subsubsection{Dining areas}

Because the dining area is used by more people than any other hospital area, there are more potential outdoor space users in it; having an outdoor space near the dining area is essential [1]. There should be tables in the space for eating, reading, and writing activities, and to serve as territorial markers, as people rarely intrude on a table that is being used. Shade and semiprivate group spaces can also be provided by umbrella tables with chairs.

\subsubsection{Art}

Artworks form part of the healing environment, and works of art in health-care facilities featuring images of nature have been linked with stress relief in diverse groups of people. In hospital spaces which can easily be accessed, artworks which create inviting, habitable spaces should be incorporated into the design.

The type of artwork used is also important; it should have what Niedenthal et al. (1994) describe as "emotional congruence", which means that when confronted with a collection of environmental stimuli, the viewer will tend to focus on the parts that correspond to his or 
her emotional state. For example, abstract art might be seen as interesting by a relaxed person, but as frightening or threatening by a person in a state of anxiety [8]. As the hospital environment tends to increase stress, artworks, sculptures and other design elements should provide an unambiguously positive message; complex or abstract art is therefore not suitable for this kind of setting.

Appropriate artworks can create an engaging focal point for a hospital space. In terms of genre, Ulrich has shown that postoperative patients preferred representational pictures, which tend to incorporate the subdued colors of nature, as opposed to abstract art, which often features unexpected color combinations; another study found that people in a state of anxiety prefer less saturated colors [46]. The artworks should therefore be selected with these effects in mind.

\subsubsection{Water}

Hearing water running in a fountain, or seeing fish in a pond or sunlight reflecting on water, can be meaningful for a patient [44]; the sound of running water in particular can mask other noises which negatively affect the therapeutic value of a space. Such sights and sounds create sensory focal points for garden spaces which attract all ages and abilities.

Water should be available, close to the garden site, and in a paved area to prevent muddying. The spigot should be $61-91.5 \mathrm{~cm}$ above ground, and hand levers (not round spigot handles) and snap connectors should be used. Soaker hoses and mulch can decrease the water requirements of the garden. "Bubble" fountains may be appropriate, as they are tactile and make use of shallow water, raising fewer health and safety issues.

\subsubsection{Site furniture}

This term refers to free-standing elements such as seating, litter bins, lighting and signs, which should be selected to meet the needs of users. Furniture should be anchored to concrete pads or too heavy to be moved, and in cases where there is a risk of users running away, it should not be placed near fences or walls [32].

\subsubsection{Seating}

Seating should be available where people would actually want to use it, typically enclosed and towards the back, facing an attractive view or focal point, and not obstructing people on the path. Comfortable, movable, and varied seating can increase usage of the garden, especially by hospital staff; there should be benches and chairs for individuals, and more social seating arrangements for groups [38]. Social seating arrangements (right-angled or centripetal benches, or movable chairs) should be conveniently located near the garden entrance, where they are most likely to be used by staff for short breaks [3]. In addition to semiprivate areas there should be some benches arranged in a line rather than in a group, facing a view or circulation area. 
Benches are usually situated at rest places or corridors with an exterior view [44]. Space should be left beside a seat to accommodate a wheelchair or electric scooter. Raised features can help wheelchair users and people who cannot easily bend down, and should attract others as well, for example if the edge can serve as an informal seat. The thinnest construction materials should be used as long as they are stable, to increase the area of the garden: seating ledges should be $20-45 \mathrm{~cm}$ wide, and the sides may range from $45 \mathrm{~cm}$ high for a child, to $60 \mathrm{~cm}$ for a visitor sitting by a bed, to $75 \mathrm{~cm}$ or more for those who cannot bend easily.

Seats can be artworks in themselves. The material used should not retain heat or cold, so concrete, aluminium and steel should not be used: wood or hard plastic are preferable. Moveable chairs can be rearranged depending on the sun or shade, and to adjust the size of the seated group. In general, seats should have arm and back support, but their height and depth, as well as their supporting structure, will affect their usefulness to people with special needs, and this should be taken into consideration [25].

\subsubsection{Signage}

Being able to choose whether or not to follow or avoid a route that might have rough paths is essential; appropriate, approachable and welcoming signs are a must. Site signage should indicate, among other things, directional or one-way traffic, restrictions, parking, deliveries, patient entry points, entrances to facilities, and so on [32]. Tactile signs should be fixed at a height of $150 \mathrm{~cm}(120 \mathrm{~cm}$ for children) [45]. Other sensory indictors, such as audible water features and wind chimes may also be used to assist wayfinding for the visually impaired in the garden.

\subsubsection{Lighting}

The primary purpose of lighting is to enhance safety and security. Exterior lighting deters thieves or vandals; while lights on stairs, walkways or approach roads both increase safety from attackers and help prevent accidental falls. Parking areas, entrance and service roads, and also isolated or dark areas need to be clearly defined and lit; bollards or bulkheads are usually used for this purpose. Lighting along pedestrian routes should be mounted at a height where faces can be seen and recognized, and any entrances, intersections or hazards such as changes in path level, should be indicated by beacons. An added therapeutical benefit of night-time lighting is that it enables safe use of the space at night, and viewing of the garden from indoors [3].

\subsubsection{Receptacles}

The locations of trash containers should be considered as an essential element of health-care facility planning, as they allow for easy disposal of food and paper products outdoors. The number of receptacles required depends on the population density and the activity level in an area, as well as how often they are emptied; overflowing litter bins indicate a need either for more of them or for more frequent service. There should be litter containers at all transition areas such as doors, building entries, parking access points and social and pedestrian spaces. To provide a less disturbing environment, receptacles should be placed at least $3.6 \mathrm{~m}$ away from where people tend to socialize [38]. 


\subsection{Planting design}

As noted earlier, plants which require little water beyond the establishment period and can tolerate the urban environment and climate changes should take precedence in hospital garden planning. Other types of vegetation with varied densities should be used to connect greenways and wildlife corridors; and native vegetation should be mixed with compatible new plants in such a way as to sustain both. Native trees are particularly useful as they attract local wildlife: plant species that attract butterflies bring an atmosphere of gentleness; while additional features (fountains or birdbaths, a bird feeder, trees appropriate for roosting or nesting) may be used to attract birds, which stimulate the senses with their colors and sounds and raise people's morale.

A dark woodland environment might feel oppressive, so open, sunny glades and generous paths are preferable for the health-care environment: they help wild flowers to grow, and enhance the sensory aspects of nature [25]. Seasonally changing flowering trees, shrubs and perennials bring a comforting awareness of life's rhythms and cycles; and using vegetation that provides contrast and harmony through textures, forms, colors and arrangements draws people's attention and and focus away from themselves [8].

Large canopy trees create shade in summer and provide shelter in winter; they can help modify the local climate and reduce the air temperature. Trees with foliage that moves in the breeze attract the gaze to patterns of colors, shadows, light, and movement, providing a soothing and meditative experience [3]. In mental health facilities with high security, trees can soften and screen off the sight of security fences, and can also be planted in areas that patients can access under supervision. Shrubs should be trimmed to emphasize their natural form, so the space looks well cared for and sends the implied message that patients are also well cared for.

For all users of the garden, including the partially sighted, scented and brightly coloured flowers and leaves provide an attractive sensory experience. The olfactory sense is closely associated with memories and feelings, so scents can suddenly stimulate memories and responses, aiding those with memory loss. Sensory stimulation is particularly important for the visually impaired and for patients with reduced cognitive function, and this can be assisted by plants that are colorful throughout the year, are scented (e.g. Lavandula spp. and Echinacea spp.), and have tactile qualities (e.g. Festuca caesia). Fruit trees can be good for smaller spaces, and offer seasonal attractions.

The edible garden is a useful concept, particularly if the produce can be used in the facility's kitchens. Long-term residents will be able to experience the seasonal development of the garden, and patients in day centers will be able to participate in tending the garden at any time of the year; an activities program might focus on food-growing - for example, eating fruit crumble, or painting berries [25]. Planting an orchard also puts a site which is only available for a short time to good use.

Precautions should be taken in planting to ensure that there are no hazardous or thorny plants, especially in gardens for children or psychiatric patients, and also no plants that 
drop slippery fruit or leaves that might constitute a hazard [39]. Low shrubs and dense, dark vegetated "walls" that obscure the view should not be planted near sidewalks; instead, these areas should be planted with year-round screens whose appearance is softened by varied deciduous plants and open spaces.

Elevated gardens can be designed for the use of patients in wheelchairs; here pots and planters should be raised to a height of at least $61 \mathrm{~cm}$ and should be accessible from all sides if they exceed this depth. This kind of vertical garden can be used easily by both ambulatory and seated patients.

Raised planter boxes can be set up in some areas and looked after by patients in wheelchairs or on motorized scooters; this adds area to the garden at minimal cost. The width of the plant beds should be at most $1.5 \mathrm{~m}$ if they can be accessed from all sides, or $0.75 \mathrm{~m}$ if they are used from one side. More area can also be added to the raised bed through the use of structural extensions.

Table planters are shallow, soil-filled trays supported on legs. These raised planters, which are the same width as raised planters, need a height of about $70 \mathrm{~cm}$ of free space below them (including knee clearance) to allow people to sit on chairs and tend them. The soil containers should be $20-25 \mathrm{~cm}$ deep, so the total height of the structure is about $87.5-92.5 \mathrm{~cm}$, with the top of the planter no higher than the rib cage of the seated person [45].

\subsection{Maintenance of hospital landscape areas}

The site should be well manitained, for therapeutic as well as physical safety reasons [47]. In comparison with patio structures and spaces, shrubs, trees, and flowers are more difficult to maintain, but they provide the most therapeutic benefits. Suitable fertilizing, selective thinning rather than shearing, and the use of seasonal color are important factors conducive to the characteristics of the garden that users prefer [3]; hand weeding, mulching, companion planting, and the proper spacing of plants will decrease the the use of chemical fertilizers. In short, a poorly maintained environment offends their dignity and has a negative effect on the morale of patients.

\section{Conclusion}

While gardens had been used in the service of health care for centuries, modern medicine, beginning in the early 20th century, disregarded their therapeutic value [48]. In recent years, however, there has been a resurgence of interest in the contribution to healing provided by outdoor garden environments in healthcare facilities. The hours spent in a hospital can be stressful for patients, staff and visitors, and going out into a garden provides an escape; as one patient commented: "It's a good escape from what they put me through. I come out here between appointments... I feel much calmer, less stressed." [5].

Easy access to a natural environment can contribute to stress management and potentially improve health outcomes: physiological studies indicate that 3-5 minutes spent in such 
environments reduces anger, anxiety and pain and induces relaxation. Research also shows that "positive distractions" can reduce stress [7, 4, 45, 49], and their visual forms include gardens, scenic views and artwork, which play a critical role in modern hospital design: gardens, fountains, fish tanks, rooftop gardens, and water features provide patients, staff and visitors with restorative experiences of nature. Sensory stimulation through design elements or atmospheric features like labyrinths and reflecting pools, seasonal vegetation that attracts birds, and found objects of art and other elements of surprise and delight, also contribute to positive distraction.

Green areas outside hospitals are today seen as both beneficial and necessary, and specialized gardens have now been designed to meet the needs of particular patient groups such as children, cancer patients, those undergoing rehabilitation, burn patients, the elderly and Alzheimer's patients, among others. In order to afford the greatest therapeutic benefits, the health-care garden should have a broad variety of vegetation, including seasonal flowering species, plants that attract small, safe fauna (birds, squirrels, butterflies), and leaves or grasses that move in the breeze. There should be views open to the sky and clouds, and if possible to the horizon; reflecting pools with fish or water lilies; and moving water features that can be seen and heard.

The benefits of gardens in health-care facilities may be limited by various factors. The first of these is lack of information on a garden's location, accessibility and purpose: hospital staff should be educated as to its purpose and users, and on how to make use of it in patient and family care; and continual feedback to staff from users is essential. To ensure that patients and their visitors are aware of the garden and can access it, colorful brochures with pictures, information, and maps should be distributed, and posters about it put up in frequented areas such as elevators [14]. Other limiting factors may include lack of sensitivity to patients' specific mobility needs; disturbing sensory stimuli (e.g. noise and allergic pollens); lack of facilities for competing user needs (such as the wish to smoke or the desire for fresh air); and ambiguous design elements [32].

It is vital that the garden be easily maintainable, to inspire confidence in patients that they are being well taken care of by the staff. Water-efficient, low-maintenance landscaping should be used, with water conservation achieved by managing storm water runoff in the site. Keeping up and using green spaces around hospitals lowers the costs associated with recovery and also contributes positively to patients' survival chances and quality of life during their stay. Hospitals should landscape and improve their existing green spaces, and then restructure their facilities and patient care practices to provide maximal interaction between patients, visitors, staff and these natural environments.

Today the requirements of some specific patient groups are being taken into account when planning and designing outdoor hospital spaces [36]; there is now a need for gardens to be designed for other patient groups, such as children with autism, cystic fibrosis or cerebral palsy; patients with schizophrenia or Parkinson's disease; and heart surgery patients. 


\section{Author details}

Gökçen Firdevs Yücel

Architecture Department İstanbul Aydın University, İstanbul, Turkey

\section{References}

[1] Marcus Clare Cooper, Francis Carolyn. People Places: Design Guidelines for Urban Open Space, John Wiley \& Sons; 1997.

[2] Fang, Eric C.Y. The Hospital and the City, International Academy for Design and Health WCDH; 2000.

[3] Marcus, Clare Cooper and Barnes, Marni. Gardens in healthcare facilities: Uses, therapeutic benefits, and design recommendations. The Center for Health Design, Inc.; 1995.

[4] Ulrich, R. S. Health Benefits of Gardens in Hospitals. Plants for People Conference, International Exhibition Floriade; 2002.

[5] Marcus, Clare Cooper. Gardens and Health, (IADH) International Academy for Design and Health; 2000.

[6] Gupta, Kant and Gupta, Shakti Kumar. Modern Trends in Planning and Designing of Hospitals: Principles and Practice, Jaypee Brothers; 2007.

[7] Ulrich, R. S. View through a window may influence recovery from surgery, Science, 1984; 224 (4647): 420-421.

[8] Marcus, Clare Cooper and Barnes, Marni. Healing Gardens: Therapeutic Benefits and Design Recommendations, John Wiley \& Sons; 1999.

[9] Ulrich, R. S. Effects of interior design on wellness: Theory and recent scientific research. Journal of Healthcare Design, 1991; 3, 97-109.

[10] Parsons, R. The potential influences of environmental perception on human health. Journal of Environmental Psychology,1991; 11, 1-23.

[11] Ulrich R. S. Evidence based environmental design for improving medical outcomes. Proceedings of the Healing by Design: Building for Health Care in the 21st Century Conference. Montreal, Quebec, Canada, March 1-10; 2000.

[12] Kaplan, R. The psychological benefits of nearby nature. In Relf, D. (ed.) Role of Horticulture in Human Well-being and Social Development: A National Symposium. Timber Press, Arlington, Virginia; 1992.

[13] Design of hospital gardens can promote health, ProLandscaper Magazine; 2012, July 13. http://prolandscapermagazine.com/?p=3166 (accessed January 2013)

[14] Whitehouse, S. and Varni, James, W. and Seid, MichaeI and Cooper Marcus, C. and Ensberg, M.J. and Jacobs, J.R. and Mehlenbeck, R.S. Evaluating a children's hospital garden environment: Utilization and consumer satisfaction, Journal of Environmental Psychology, 2001; 21 (3) 301-314.

[15] Julia, Nerangia and Georgi, Anthopoulos Petros. Landscape Preference Evaluation for Therapeutical Gardens, 2011; 2 (5) 639-647 
[16] Kaplan, R. The nature of the view from home: psychological benefits. Environment and Behavior, 2001; 33, 507-542.

[17] Mental Health Facilities Design Guide. Department of Veterans Affairs; 2010 www.cfm.va.gov/til/dGuide/dgMH.pdf (accessed January 2013)

[18] Schucker, Robert. Hospitals Adding Rooftop Gardens to Improve Patient Care; 2010. http://www.beckershospitalreview.com/news-analysis/hospitals-adding-roof-gardensto-improve-patient-care.html (accessed January 2013).

[19] Gerlach-Spriggs, Nancy and Kaufman, Richard Enoch and Warner, Jr. Sam Bass. Restorative Gardens, Yale University Press, New Haven and London; 2004.

[20] Marcus, Clare Cooper. Healing Gardens in Hospital. Interdisciplinary Design and Research, 2007; 1 (1). http://test.spokane.wsu.edu/academics/Design/IDRP2/Vol_1/Cooper_Marcus.pdf (accessed January 2013)

[21] Mitrione, Steve and Larson, Jean. Healing by Design: Healing Gardens and Therapeutic Landscapes, Implications, 2007; 2 (10).

[22] Vapaa, Annalisa Gartman. Healing Gardens: Creating Places for Restoration, Meditation, and Sanctuary, What are the defining characteristics that make a healing garden? Master's thesis. Virginia Polytechnic Institute and State University College of Architecture and Urban Studies; 2002.

[23] Franklin, Deborah. How Hospital Gardens Help Patients Heal, Scientific American Magazine, 2012; 3.

[24] Severtsen, Betsy. Healing Gardens, Gardens, 2006; 3.

http://www.majorfoundation.org/campaign-for-the-beautiful.htm (accessed January 2013).

[25] Shackell, Aileen and Walter, Robin. Practice Guide Greenspace design for health and

[26] well being, Forestry Commission: Edinburgh; 2012.

[27] Furgeson, Molly. Healing Gardens, University of Minnesota Department of Horticultural -Science; 2012. http://www.sustland.umn.edu/design/healinggardens.html (accessed January 2013).

[28] Parcell, Stacy. Healing Garden's New Dimension: Edible Gardens, Healthcare Design Magazine, Chicago, USA, 2012; 5.

[29] Smith, Jerry. Health and Nature: The influence of nature on design of the environment of care, The Center for Health Design; 2007.

http://www.healthdesign.org/chd/research/health-and-nature-influence-nature-designenvironment-care (accessed January 2013).

[30] American Planning Association. Planning and Urban Design Standards, John Wiley \& Sons; 2012.

[31] Neducin, Dejana and Krklješ, Milena and Kurtović-Folić, Nađa. Hospital outdoor spaces- Therapeutic benefits and design considerations, Facta Universitatis Series: Architecture and Civil Engineering, 2010; 8 (3) 293-305.

[32] Tyson, Martha, M. The Healing Landscape, Therapeutic Outdoor Environments, University of Wisconsin-Madison, Libraries Parallel Press, USA. 2007. 
[33] Epstein, Mark. Hospital gardens help patients heal, Seattle Daily Journal Health Care Design \& Construction, 2006; 11.

[34] Allison, David. Hospital as city, Health Facilities Management Magazine; 2007. http://www.hfmmagazine.com/hfmmagazine/jsp/articledisplay.jsp?dcrpath=HFMMAG AZINE/Article/data/06JUN2007/0706HFM_DEPT_ARCH_Design\&domain=HFMMAG AZINE (accessed January 2013).

[35] Piotrowsk, Christine M. Designing Commercial Interiors, Wiley; 2007.

[36] Sadler, Charles King. Design Guidelines for Effective Hospice Gardens Using Japanese Garden Principles, Master's Thesis, Faculty of Landscape Architecture Suny College of Environmental Sciences and Forestry, Syracuse, New York; 2007.

[37] Marcus, C.C. Landscape design: Patient-specific healing gardens. World Health Design; 2010. http://www.worldhealthdesign.com/Patient-specific-Healing-Gardens.aspx (accessed January 2013).

[38] Kaplan, R. and Kaplan, S. Cognition and Environment: Functioning in an Uncertain World. New York, Praeger; 1983.

[39] Main, Bill and Hannah, Gail Greet. Site Furnishings: A Complete Guide to the Planning, Selection and Use of Landscape Furniture and Amenities, John Wiley \& Sons, USA; 2010.

[40] Queensland Health. Design Guidelines for Queensland Aged Care Facilities; 1999

[41] http://www.health.qld.gov.au/cwamb/agedguide/13037.pdf (accessed January 2013)

[42] Kunders, G. D. Hospitals: Facilities Planning and Management, Tata McGraw-Hill Education; 2008.

[43] International Parking Institute. Hospital Parking: A Proactive Approach for Managing, The Parking Professional Magazine, 2009; October: 33-35.

[44] NHS Estates. Wayfinding, Effective Wayfinding and Signing Systems, Guidance for Healthcare Facilities, Stationery Office Books; 2nd edition; 2005.

[45] Nord, R. Del. The Culture for the Future of Healthcare Architecture. Proceedings of the 28th International Public Health Seminar; 2009.

[46] Verderber, Stephen and Refuerzo, Ben J. Innovations in Hospice Architecture, Taylor \& Francis; 2006.

[47] Cynthia A. Leibrock and Debra Harris. Design Details for Health: Making the Most of Design's Healing Potential, 2nd Edition, New York: John Wiley \& Sons, Inc.; 2011.

[48] Shepley, M. McCuskey. The role of positive distraction in neonatal intensive care unit settings, Journal of Perinatology, 2006; 26: 34-37.

[49] Leibrock, Cynthia A. and Harris Debra D. Design Details for Health: Making the Most of Design's Healing Potential, Wiley; 2011.

[50] Verdeber, Stephen F. and Refuerzo, Ben J. Innovations in Hospice Architecture, Taylor \& Francis; 2006.

[51] Bruce, Hank and Folk, Tomi Jill. Gardens for the Senses, Gardening as Therapy, Petals \& Pages Press; 1999. 
Section 3

\section{Urban Landscape}





\title{
Pedestrian Zones
}

\author{
Elif Ebru Sisman
}

Additional information is available at the end of the chapter

http://dx.doi.org/10.5772/55748

\section{Introduction}

Walking is the oldest form of human transportation. With the exception of devices to enhance the mobility of the disabled, walking demands no special equipment. Thus, walking is the most affordable and accessible of modes. Walking is clean, easy on the infrastructure, healthy for the individual and integral to community livability. People who walk know their neighbors and their neighborhood. A community that is designed to support walking is livable and attractive.

Every trip begins and ends as a pedestrian action, so everyone is a pedestrian at regular and various times and places in their lives. Pedestrians can be grouped in a similar manner as cyclists, but the classifications have less effect on facility design. Adult commuters walk daily to work or college, and require reasonably direct routes to keep travel time down. General pedestrians include all people who are walking through shopping and service areas, from home to a friend's house, and typically on short, purposeful trips. They require safe access to multiple services. Special pedestrians include children and those with impairments. This group may require special facilities or assistance when traveling, and facility improvements for these travelers are generally helpful to everyone. No matter what type of pedestrian or purpose of trip, however, all pedestrians have basic needs. Safety is the primary need for pedestrians, who are often the most exposed to the dangers of high speed traffic. A safe system includes designated separate space for pedestrians that is free of potentially dangerous obstacles and keeps the pedestrian visible to other traffic. Width and surface of facilities is important depending on setting. Urban areas should have solid surface walks with adequate room for many users at one time. Only an aware and educated individual will act in a safe manner when presented with the numerous decision points along any given pedestrian route. Information and training programs are essential to any community striving for safe walking conditions. Because automobile traffic is the largest threat to pedestrians, both educational and physical improvements should include drivers. 
Population and urban living is increasing globally. We have to learn to build new and regenerated sustainable cities to address global issues at a local level.

Today, people are restrained from walking comfortably around especially in the city centre due to rapid urbanization and increasing vehicle traffic. It is socially, aesthetically and economically important to provide people restrained by the urbanization movements with open spaces that are secure, comfortable, partly or totally cleansed from vehicle traffic. In order to specify the needs and suggestions of people, it is important to incorporate them into the processes of planning and designing pedestrian spaces which target to revitalize the historical urban fabric.

\section{History of Pedestrianization}

In ancient times, the basic form of transportation was to walk. The relationship between urban design and transportation dates back to ancient times. City design in the ancient cities of Mesopotamia, Egypt, and India stressed the laying out proper roads and triumphal avenues as a key ingredient for good design. Later, Greeks and Roman stressed the importance of laying out adequate roads (Sen, 1999).

Beginning the ancient times, pedestrian zones have been the mark of bustling, prosperous cities. Past civilizations banned vehicular and animal traffic from crowded areas, because of reduce pollution, alleviate congestion in the interests of safety and order, and create aesthetically pleasing urban areas. Until the automobile age, two types of pollution from vehicles were noise and manure (Rosen, 2006).

In the classical age, the order minded Romans used the pedestrian zones to solve design problems throughout their empire. During the middle Ages, Northern Italy was the most heavily urbanized area of Europe, claiming Europe's largest and wealthiest cities (Rosen, 2006). Street design became an integral feature of Roman cities, which had paved streets with elevated sidewalks. Concern for aesthetics of street design resurfaced during the Renaissance in fifteenth century Europe (Sen, 1999). The density of the industrial revolution greatly exacerbated the problems stemming from city life. Some of municipal government prohibited cart and wagons transporting merchandise on selected central streets during most daytime hours (Rosen, 2006).

Since the Second World War, down towns in which automobile access was restricted retained or saw increased activity for more often than downtown areas which were not pedestrianized. The modern pedestrian zone was born in Kassel, Germany, at the close of Second World War. With $80 \%$ of the city destroyed, urban planners saw once-in- a-lifetime opportunity.

Over the next few years, most German cities and many in other European countries built pedestrian zones.

The Dutch invented a compromise pedestrian zone for residential areas, known as the woonerf that is popular throughout northern Europe. Cars and pedestrians share the 
roadway. Pedestrians are the priority users the area. Automobiles are permitted at all times provided they do not exceed walking speed.

\section{Definition of pedestrian zones}

Happy and healthy living in towns is related to the extent that town's open green space system is enough for the requirements. Today, pedestrian zones have been achieved to increase rapidly disappearing open space and to provide comfortable and safe circulation for pedestrians.

A pedestrian zone is simply an area where vehicles are restricted and reserved for pedestrians who are free to occupy the entire space. The zone entrances and exits are often designated with signage to make all users of the road aware when they are entering or exiting such an area.

As pointed out by Rubenstein (1992); three types of pedestrian malls have commonly been implemented in the United States. The first type consists of a traditional pedestrian street designed for exclusive pedestrian use (Full mall) (Figure2). The second type is the shared mall that permits limited automobile use such as one lane of one-way traffic (Semi mall) (Figure3). The third type is the transit mall which accommodates both pedestrian and transit use (Figure 4).

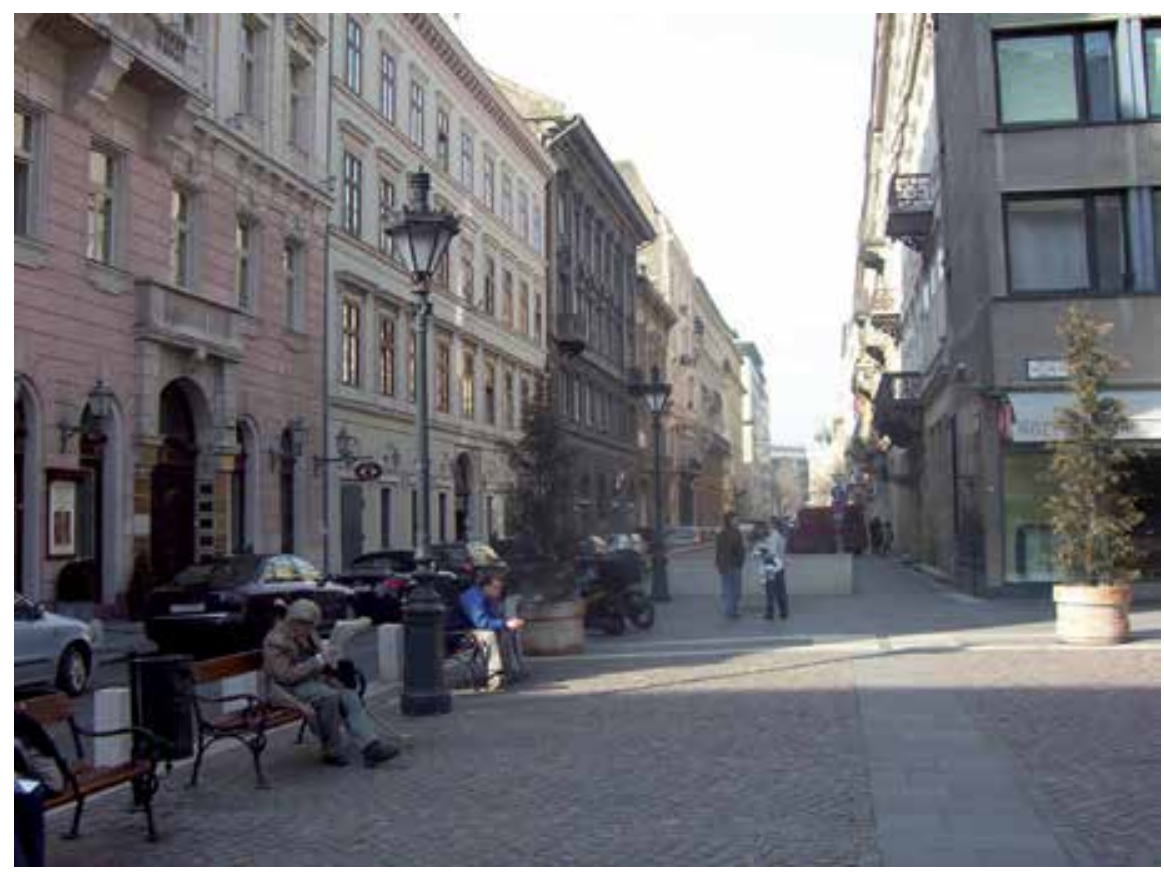

Figure 1. Pedestrian Zones (Budapest, Hungary) 


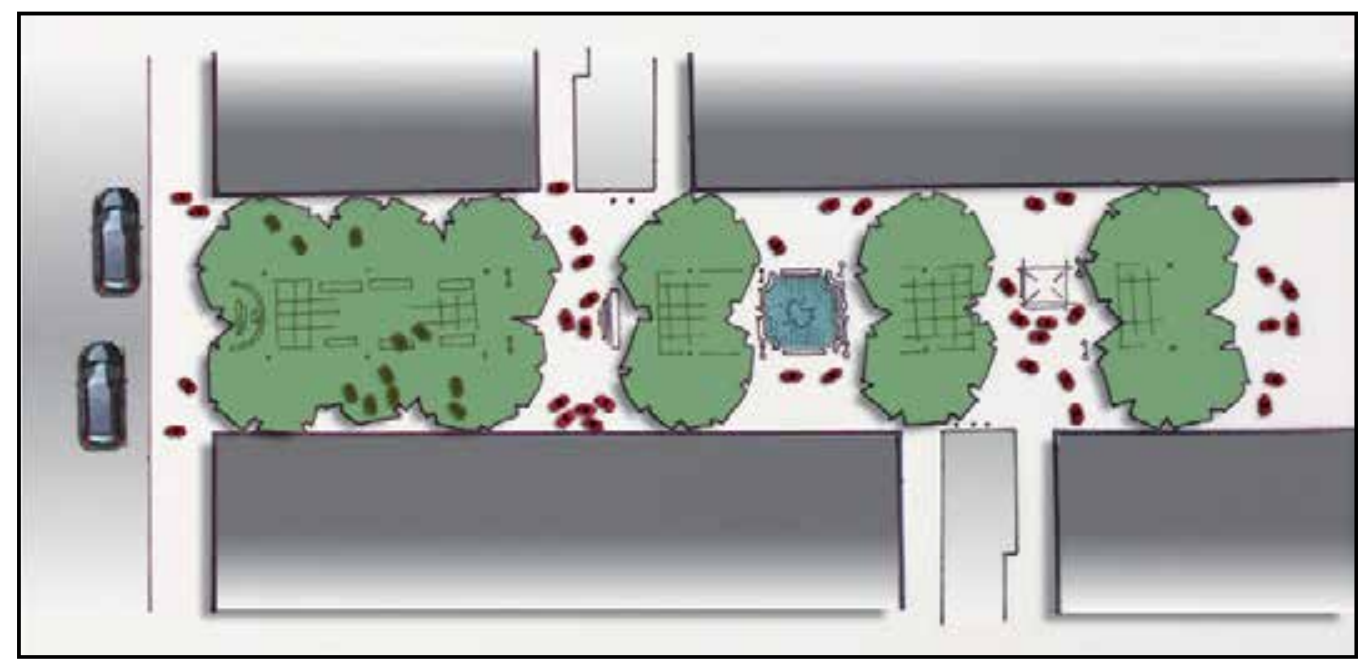

Figure 2. Full mall

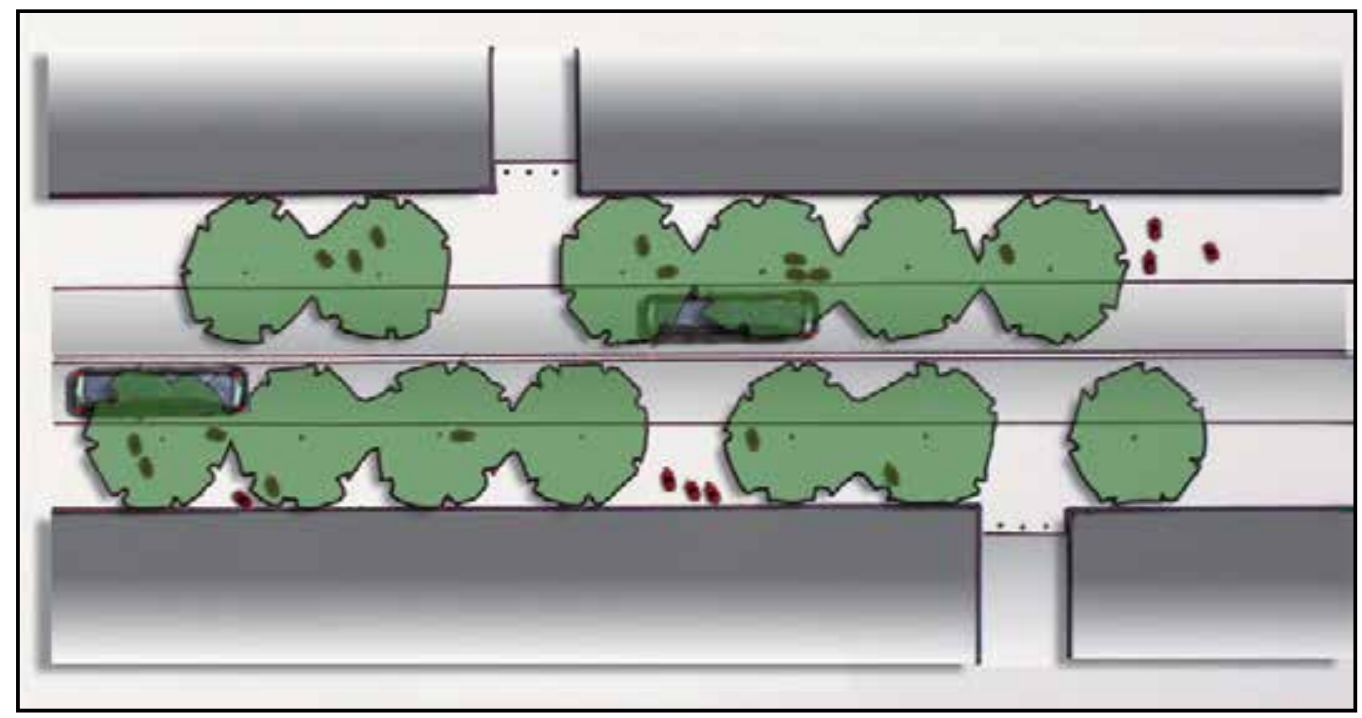

Figure 3. Transit mall 


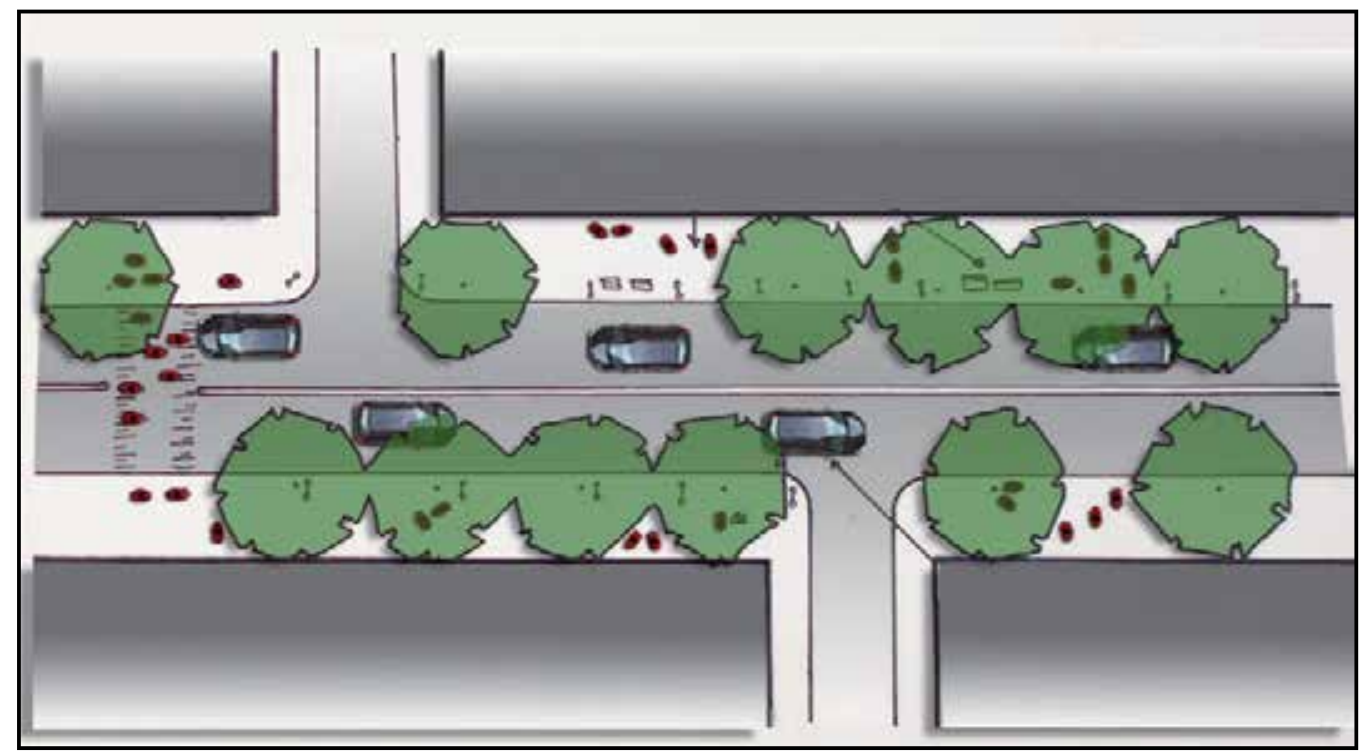

Figure 4. Semi-mall

Research shows that pedestrian zones have some of characteristics (Melia et al, 2010; Ornetzeder et al, 2008).

Characteristics to the development of pedestrian zones were:

- $\quad$ high rates of walking and cycling.

- more independent movement and active play amongst children

- less land taken for parking and roads - more available green or social space

- very low levels of car use, resulting in much less traffic on surrounding roads

The main benefits found for pedestrian zone developments:

- Low atmospheric emissions.

- Low road accident rates.

- Better built environment conditions.

- Discouragement of private car and other motorized vehicles (measure of travel demand management).

- Encouragement of active modes.

The main problem of pedestrian zones is related to parking management. Where parking is not controlled in the surrounding area, this often results in complaints from neighbors about overspill parking.

\section{Principles for pedestrian facility design}

Landscaping can add value to the aesthetics of the walking environment but they must be placed carefully since high shrubs and trees might also obscure from view (of drivers) the 
presence of vulnerable road users such as children (O'Flaherty, 1997; IHT, 1997). However, strategically located trees and greenery can be used instead of bollards to act as a marking for the entrance to the pedestrian area. Innovative design concepts can be used to hide roadside utilities from view to form a seating area for pedestrians (KonSULT).

The following design principles represent a set of ideals which should be incorporated, to some degree, into every pedestrian improvement. They are ordered roughly in terms of relative importance (Portland Transportation Office, 1998)

1. The pedestrian system should be safe. Sidewalks, walkways and crossing should be designed to minimize conflicts with motorized and non motorized vehicle traffic, minimize tripping hazards and protruding objects, and promote a reality and perception of personal safety (Figure 5).

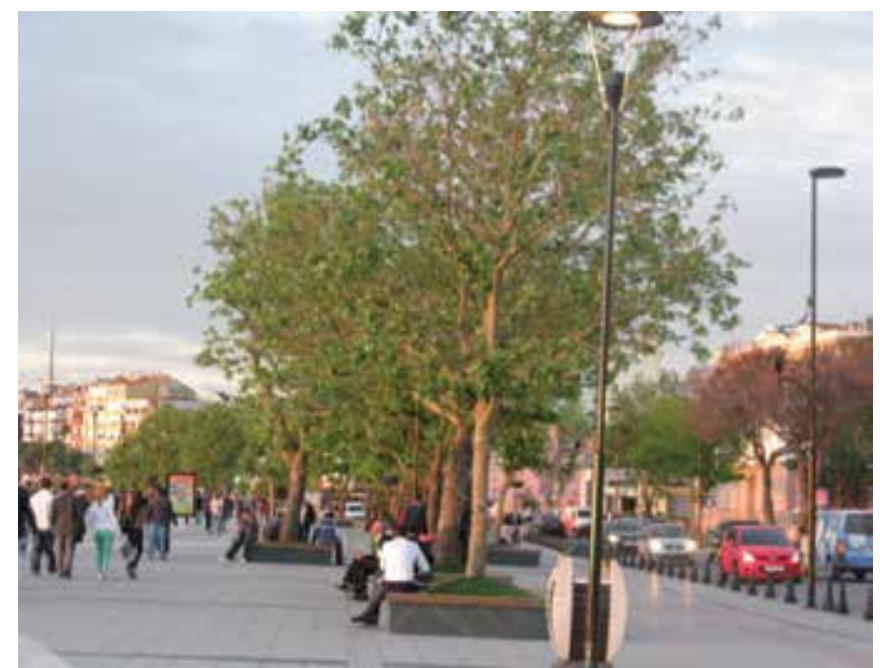

Figure 5. Safety in pedestrian zone (Canakkale, Turkey)

2. The pedestrian system should be accessible to all. Pedestrians of all ages and ability levels need to be able to safely and conveniently travel on foot or with a mobility device.

3. The pedestrian system should provide direct and convenient connections.

4. The pedestrian system should provide comfortable place to walk (Figure 6).

5. The pedestrian system should enhance the public realm of the city. The pedestrian system should be designed not only to serve a transportation function, but also to provide public spaces that enhance community, interaction, economic vitality, and the image of the city. Good design should enhance the look and feel of the pedestrian environment. The pedestrian environment includes open spaces such as plazas, courtyards, and squares, as well as the building facades that give shape to the space of the street (Figure 7). Amenities such as street furniture, banners, art, plantings and special paving, along with historical elements and cultural references, should promote a sense of place. 


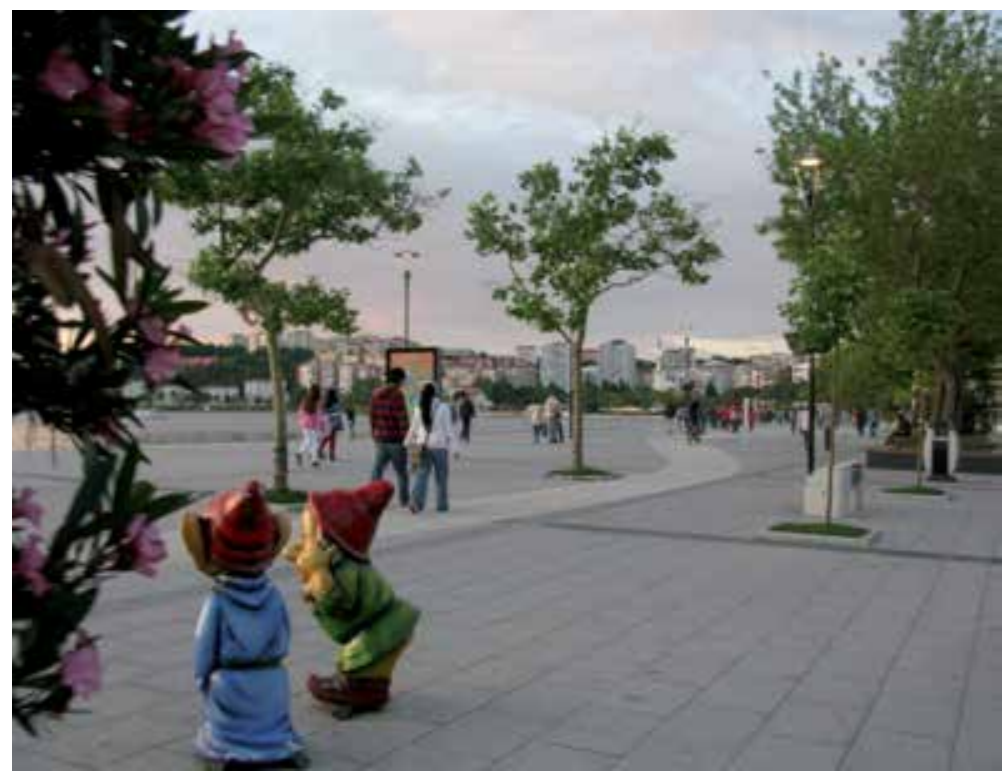

Figure 6. Comfortable pedestrian zones (Canakkale, Turkey)

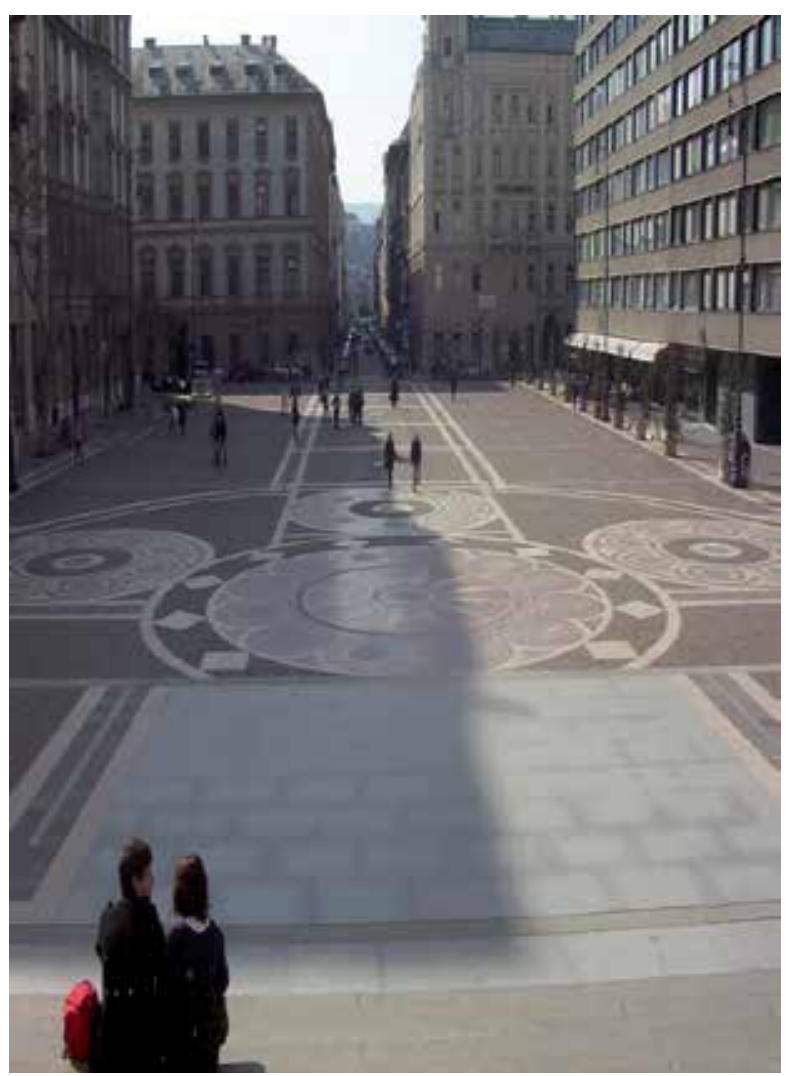

Figure 7. The basilica on Szent Istvan Squares ( Budapest, Hungary) 
6. Pedestrian improvements should be cost-effective and financially sustainable.

7. The pedestrian environment should be used for many things. The pedestrian environment should be a place where public activities are encouraged. Commercial activities such as dining, vending and advertising may be permitted when they do not interfere with safety and accessibility (Figure 8).

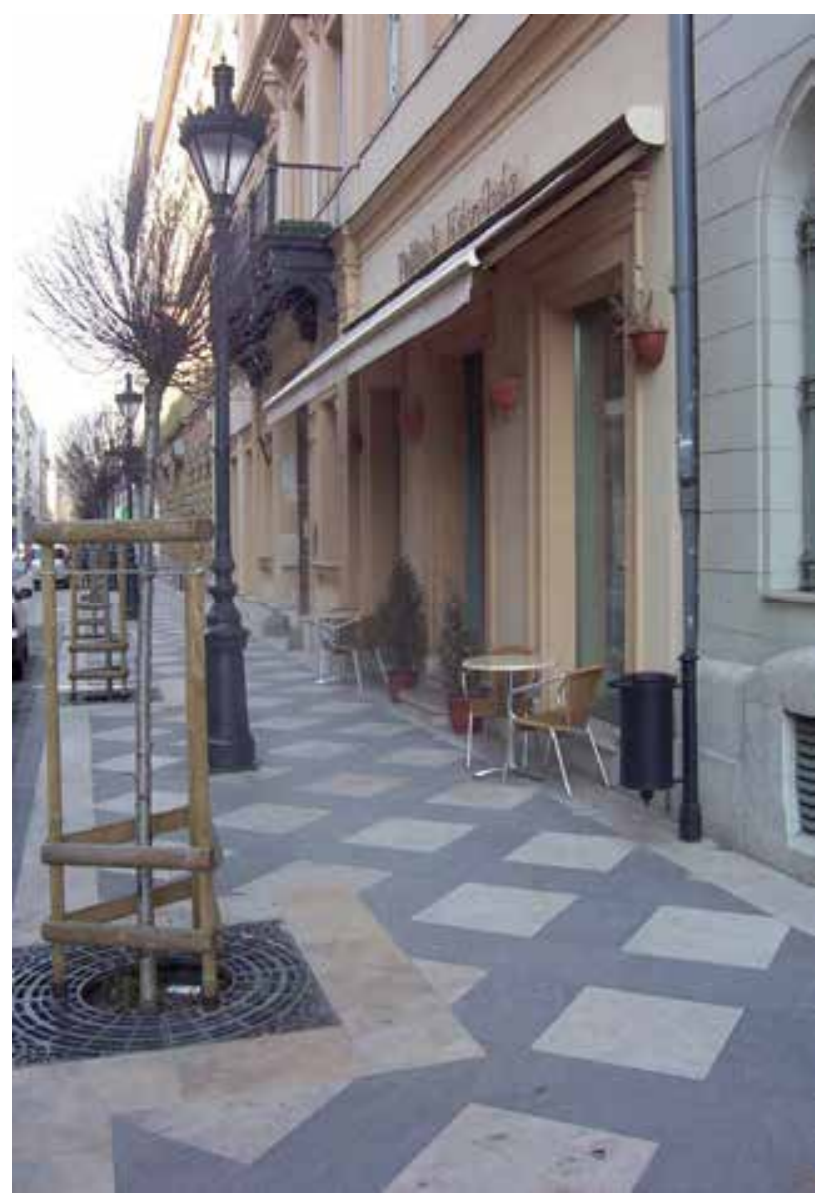

Figure 8. Sidewalk (Budapest, Hungary)

Pedestrian safety, accessibility, mobility and comfort are enhanced by:

- Slower traffic speeds

- Fewer traffic lanes

- Narrower traffic lanes

- Shorter street crossing

- Clear visibility between pedestrian and vehicle at intersections

- A buffer from traffic provided by winder sidewalks, curbside bike lanes and street parking

- $\quad$ Tighter corner radii 
- $\quad$ Space in the sidewalk corridor for trees planted boulevards, transit shelters, and other street furniture.

\section{Pedestrian zone design}

The pedestrian zone should be organized into four distinct subzones that maintain an accessible walking path and organize the placement of elements. The four subzones are the; Kerb Zone, The Planting/Street Furniture Zone, the Through Walk Zone, and the Frontage Zone (Figure 9). Minimum subzone dimension is given in below Table 1.

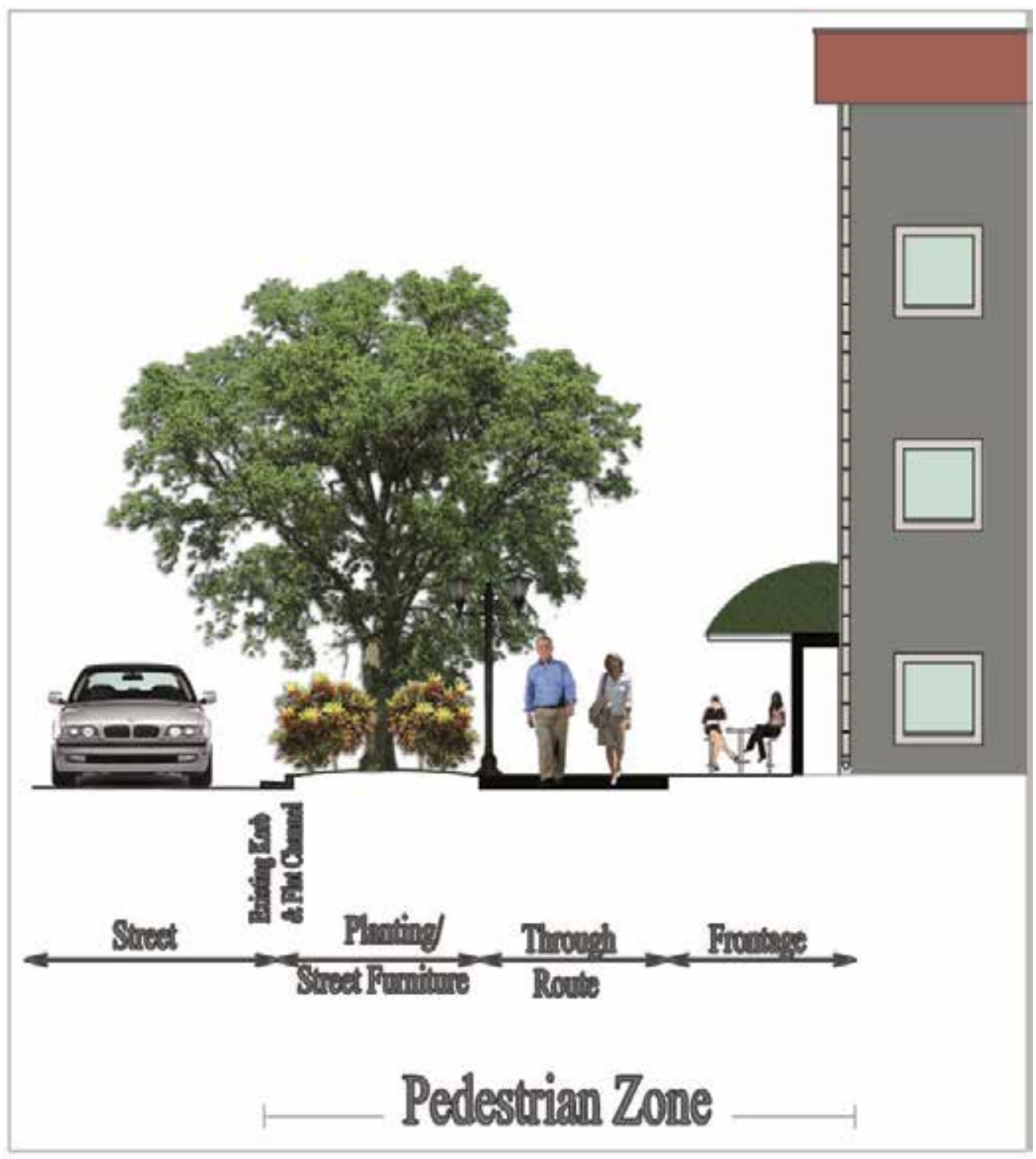

Figure 9. Subzone of Pedestrian Zone 


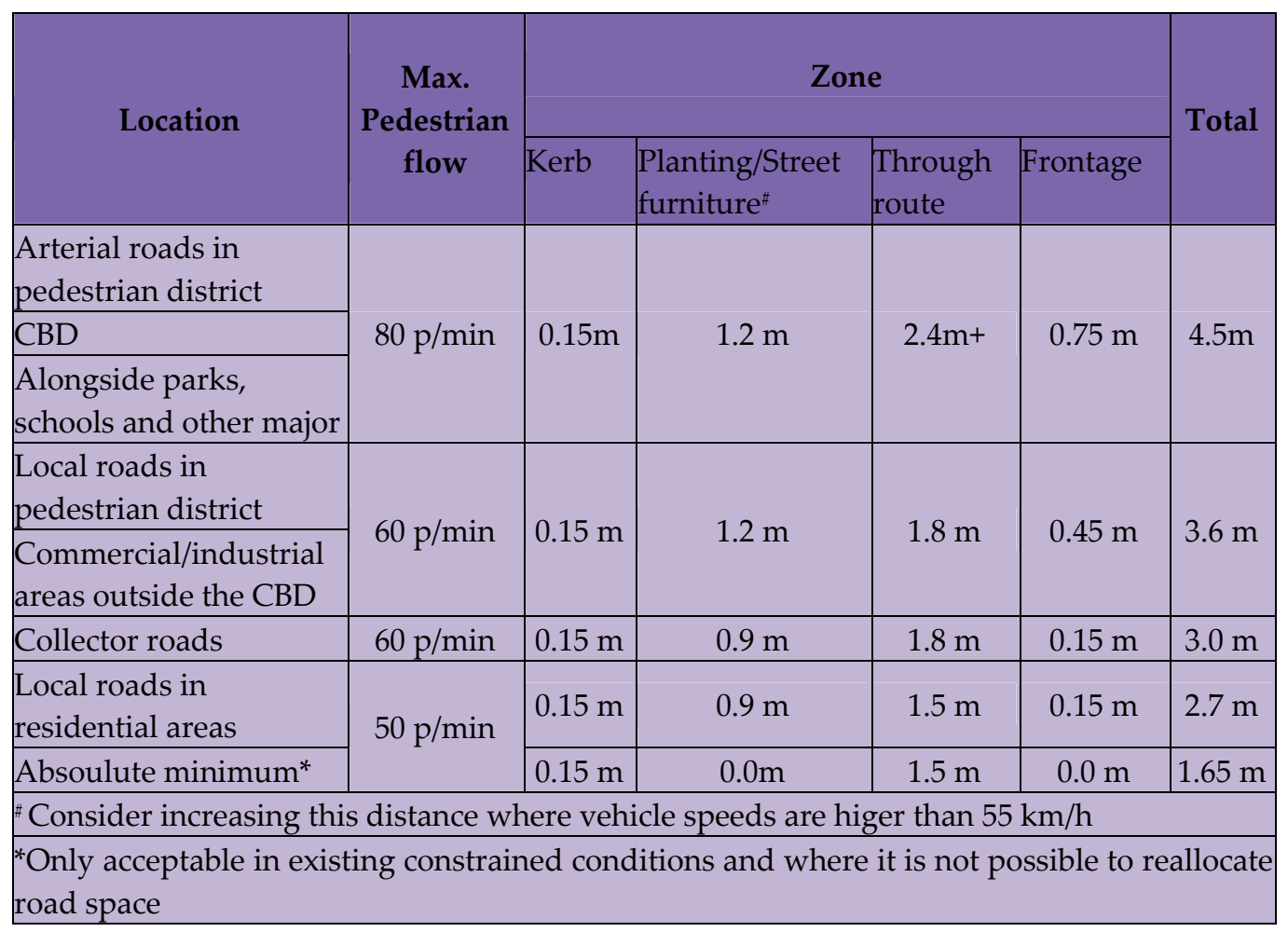

Table 1. Minimum Subzone dimensions (NZ Transport Agency, 2009)

\section{Kerb zone}

The zone is comprised of the top of kerb adjacent to the side walk. The kerb used primarily for drainage and discourage motorists from driving onto the pedestrian zone. The zone prevents roadway water run-off entering the footpath. The zone defines the limit of the pedestrian environment.

\section{The planting/Street furniture zone}

The zone creates a psychological buffer between motorized vehicles and pedestrians. The zone contains trees, signs, street lights, seats and parking meters, bicycle parking and other furniture. Trees benefit from as much space as possible. The minimum width required for tree planting is 4 feet; yet this is not desirable for long term tree health and vitality.

\section{Through route (or clear width)}

This area should be kept free of obstructions at all times. The area contains the basic sidewalk width or clear area for pedestrian travel and is sized to provide for two directions of pedestrian travel. The area should have a safe and accessible walking surface and free of vertical obstructions and protruding objects (Figure 10,11). 
The width of the footpath is dependent on the location, purpose and expected demand. The operating space for pedestrians with impairments or mobility devices needs to be considered. The minimum and desired width for the pedestrian through-route zones in various situations are summarized below. Wider path widths should be provided where possible, rather than simply designing for the minimum through-route width (Department of Transport, 2012).

- $1.2 \mathrm{~m}$ is the absolute minimum through-route width allowing passage for a single wheelchair (this minimum width should only be used for a short distance in constrained environments).

- $\quad 1.8 \mathrm{~m}$ is the desired minimum path width (1.5 $\mathrm{m}$ absolute minimum) to allow for two wheelchairs to comfortably pass, widened to $2 \mathrm{~m}$ near schools and small local shops.

- $\quad 1.54 \mathrm{~m}$ wide clearance should be maintained between a bus shelter and the kerb, as specified in the Public Transport Bus Stop Layout Guidelines, where insufficient space is available the absolute minimum through route width is $1.2 \mathrm{~m}$.

- $2.4 \mathrm{~m}$ desirable minimum through-route width(or higher based on demand) for commercial or shopping environments

- In busy alfresco dining areas such as the central city area, a minimum through-route of $3 \mathrm{~m}-4 \mathrm{~m}$ should be provided, reduced to $2.5 \mathrm{~m}$ in areas with less pedestrian traffic.

\section{Frontage zone}

The zone is the space at the edge of walkway adjacent to property line. The area that pedestrians naturally tend not to enter, as it may contain retaining walls, fences, pedestrians emerging from buildings, 'window shoppers' or overhanging vegetation.

The Frontage Zone may also be used as a secondary area for plantings, street furniture and social activities.

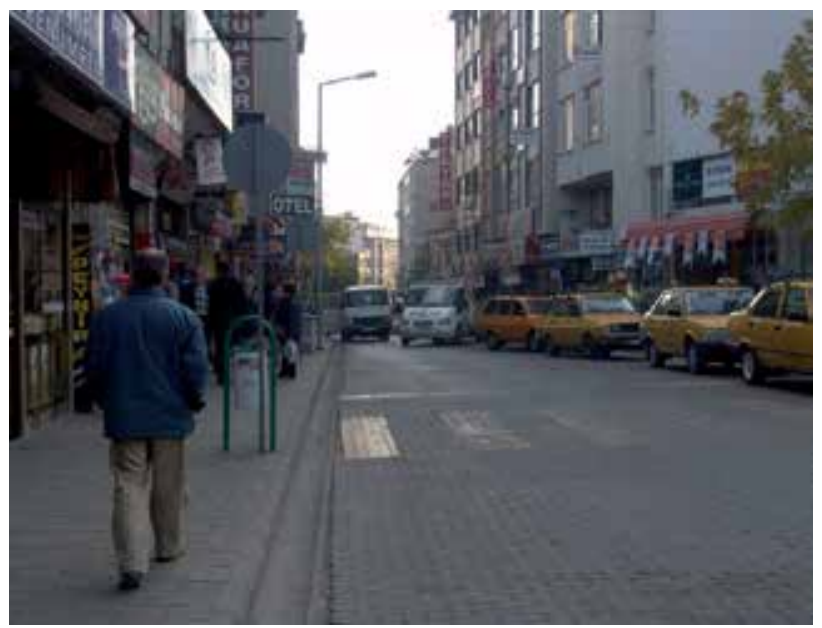

Figure 10. Without a Through Pedestrian Zone, the sidewalk corridor loses its essential function (Tekirdag,Turkey) 


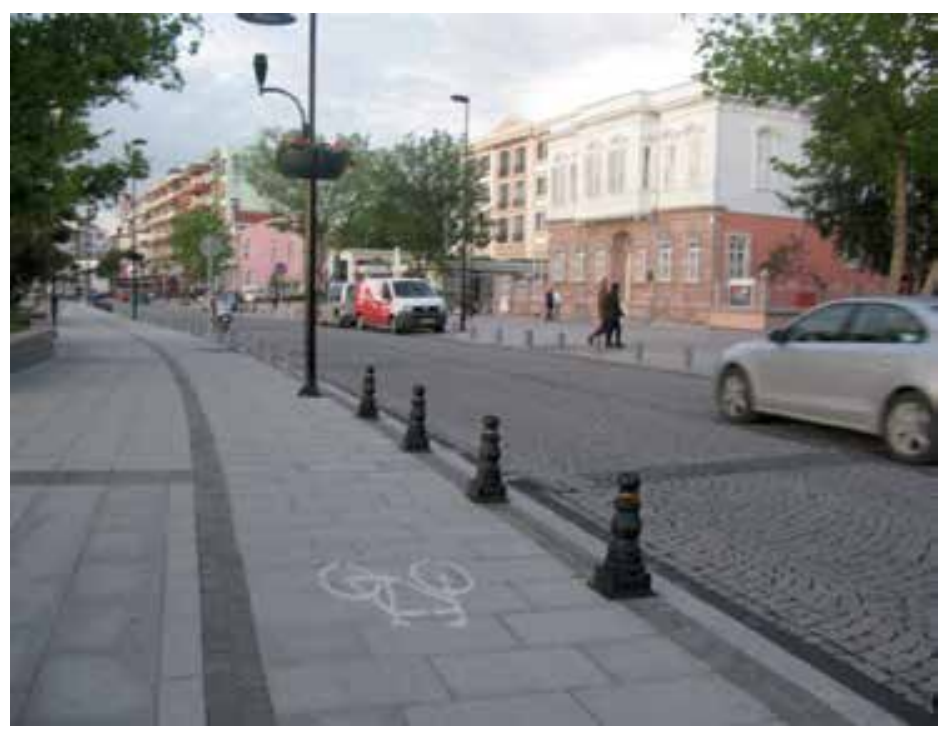

Figure 11. The Through Pedestrian Zone is the area of the sidewalk corridor intended for pedestrian travel (Canakkale, Turkey)

\section{Planting of pedestrian zone}

Plantings in the pedestrian zone should create desirable microclimates and should contribute to the psychological and visual comfort of users.

Planting design and plant choices for areas surrounding pedestrian areas play a big role in the overall appearance and environmental impact of the pedestrian area installation or new development. Trees and other landscaped areas near streets, sidewalks, and parking lots can reduce storm water runoff and adverse impacts to water resources. Trees and vegetation intercept rainfall, and the exposed soils associated with plants absorb water that will be returned to ground water systems or used by plants.

Use of native plants and shrubs help restore our natural ecosystems and help insure the survival of the full range of wildlife native to the area.

Planting trees in the strip of land between sidewalk and the edge of the road can be attractive and provide a security buffer between pedestrians and automobiles. But this strip of land is referred to by professional arborists as "the death zone" because it is so hostile to trees.

The absolute minimum width of the planting strip should be fully $1.2 \mathrm{~m}$. A planting strip of $3 \mathrm{~m}$ in width is much more reasonable. This gives enough mass and strength to the trunk to shrug off snow loads, and should be tall enough to be upbranched to provide clearance for pedestrians and vehicles.

Evergreen plants are not suitable for sidewalk planting except in very rare circumstances, such as behind a sidewalk for a buffer hedge. They tend to be low branched, causing 
clearance problems, they cast shade in winter, causing icing problems, and most are very salt intolerant (Figure 12).

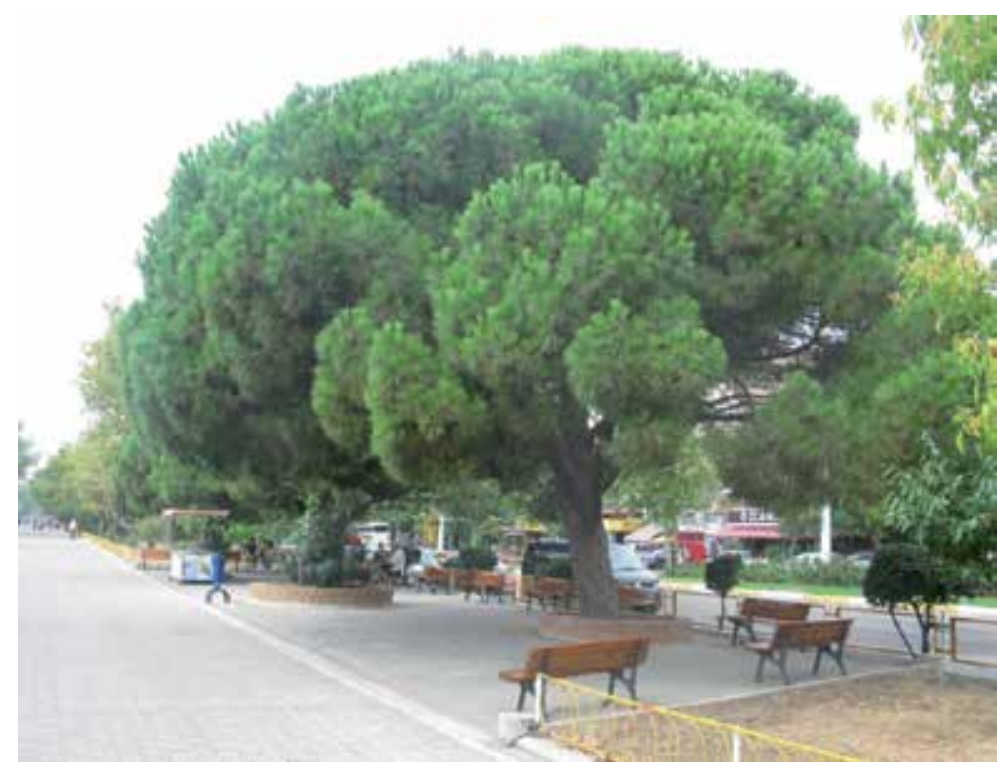

Figure 12. Evergreen plants are not suitable for planting (Tekirdag,Turkey)

The tree stock in any one area should not exceed more than $10 \%$ of any one species. Monocultures can lead to widespread tree loss when the population is attached by an alien invasive insect or disease.

Trees and vegetation help cool urban climates through shading and evapotranspiration. Trees will provide shade and, if placed between the sidewalk and the road, an additional level of pedestrian protection (US Environmental Protection Agency).

Planting materials should be chosen which provide visual interest, support the local ecology, require little or no watering or maintenance, and make the pedestrian experience more pleasant. Care should be taken to choose plants whose growth will not create obstructions for the pedestrian nor damage the sidewalk (as certain tree roots may do).

Grass is generally the easiest and least expensive to install but may be harder to maintain over time where mowing is difficult, such as on slopes or near walls. Alternatives should be considered, especially when caretakers can be identified who can provide plants and/or who will care for the area until plants are established (i.e. the property owner or a neighborhood group).

A mix of native, low-growing ground covers will provide an alternative to grass that will not need mowing or frequent watering to survive and remain attractive. Flowers and leaves from native plants will also provide food and habitat for insects that contribute to the natural life cycle of butterflies, birds, and bees, and therefore play indispensable roles in the health of our environment. 
The nature of the planting materials should be in keeping with the site. Mown grass or compact shrubs may be more in keeping with a commercial district or town center. Wildflowers and grasses may be suitable for certain residential areas and more open landscapes. Larger shrubs can be placed to block undesirable views while not obstructing important sight lines or snow clearing.

Street trees are a significant component of the green areas, and deliver (social, economic and environmental) benefits to the city. Studies of urban trees benefits tend to categorize them as either: social (including both human health and well-being, deeper spiritual and psychological significance); economic and environmental (including ecological benefits) (Sommer and Sommer, 1989; Tarran, 2006; Flannigan, 2005). Street trees have aesthetic value and attractiveness. Tree size is an important variable within this with the general preference for large, spreading, globular or round trees. Height has also been found to be an important variable (Kalmbach and Kielbaso, 1979; Williams, 2002).

\section{Social benefits}

The planting of street trees can provide an opportunity to promote the importance of preserving remnant vegetation and the need to plant more trees in the urban environment. Trees can improve the aesthetic of a streetscape thus encouraging walking and increasing the chance of social encounters and providing health benefits. A well designed and connected road and path network will optimize walking trips and all abilities access. Planting in the nature strip delineates the pedestrian space from the vehicular space which improves the sense of safety.

Furthermore, tree canopies engender a human scale to the street helping to slow vehicles and create a more pleasant street environment. Trees form a significant component of the cultural and historical value of an area. Protection of existing trees will ensure a legacy for future generations. Trees soften the harsh angularities of urban structures, aid healing and help satisfy the need to recognize seasonal differences. Street trees can enhance historical areas with plantings that are appropriate to the particular historical period and reflective of local residential garden and park plantings. A sense of place and local identity can be created by trees for local residents and visitors to the City. Direction and movement can be emphasized by trees. By manipulating planting arrangement and spacing to provide a continuous visual experience, trees can emphasis direction and movement.

\section{Environmental benefits}

Trees can improve local microclimate, and reduce the "urban heat island effect" where the air and surface temperature of urban areas are much higher than these of surrounding rural or forest areas. Trees naturally purify the air by diluting and absorbing pollution and collecting airborne particles on their leaves. Trees also reduce carbon dioxide gas in the atmosphere by direct absorption and oxygen gas production. Furthermore, the provision of pleasant street environments will encourage more walking, potentially reducing the number 
car trips taken and pollution produced. Trees can provide seasonal shade for pedestrians, cyclists and motorists and reduce the light reflection or glare from buildings and other surfaces. Trees assist in reducing the extreme temperatures by trapping heat in winter and by filtering heat and increasing the humidity during summer. Trees are ideal for reducing wind velocity in streets. The porous structure of trees allows them to temper turbulence and reduce wind tunnel effects without creating eddy currents that can occur against solid structures. Linear plantings of appropriate native trees act as valuable flight paths and habitat corridors for birds and small native mammals and provides shelter, food and nesting hollows (Moonee Valley City Council 2007).

The visual and aesthetic benefits of street trees as usually classified under social benefits, but appear to have received less attention in recent years with the focus on quantifying the measurable social, economic and environmental services provided by the urban forest. These somewhat "intangible" benefits may be less well understood, and less easily measured by researchers from the biological or social science with little research published by landscape architects and urban designer (Ely, 2010).

\section{Economic benefits}

Improved amenity and connectivity of the street network, (particularly walking routes between public transport and major activity centers) can support and improve the viability of commercial activities within the City. Street trees and in particular avenue plantings are known to markedly increase property values and to attract industry and new residents to the City. Appropriate street tree planting along commercial strips can improve the economic viability of the strip by improving customer comfort and therefore business diversity.

Street trees can reduce energy expenditure by providing shade to houses and cars and reducing energy consumption. Other aspects of street trees which have been considered in the development of this Strategy include litter drop, lifting footpaths and other property damage, obstruction of sight lines for traffic (especially when trees are young), blocking views and light, competition with other vegetation such as grass or garden plants, and potential to exacerbate allergies (Moonee Valley City Council 2007).

Acorrding to O'Brien (1993) identifies a number of functional and aesthetic contributions to urban streetscapes. Street trees; (Ely, 2010)

- Creating or reinforcing identity in a street (Figure 13)

- Complementing historic or culturally significant buildings or streetscape (Figure 14)

- Enhancing pedestrian or vehicular orientation legibility and way finding. Street trees can emphasize direction and directional change by accentuating road lines (Figure 15). They can emphasize a sense of movement, and their spacing can be manipulated to create a desired ambience, with closer spacing emphasizing a sense of speed. Trees can also be used to emphasize road junctions and focal points, and to reinforce the hierarchy of streets within the city. 


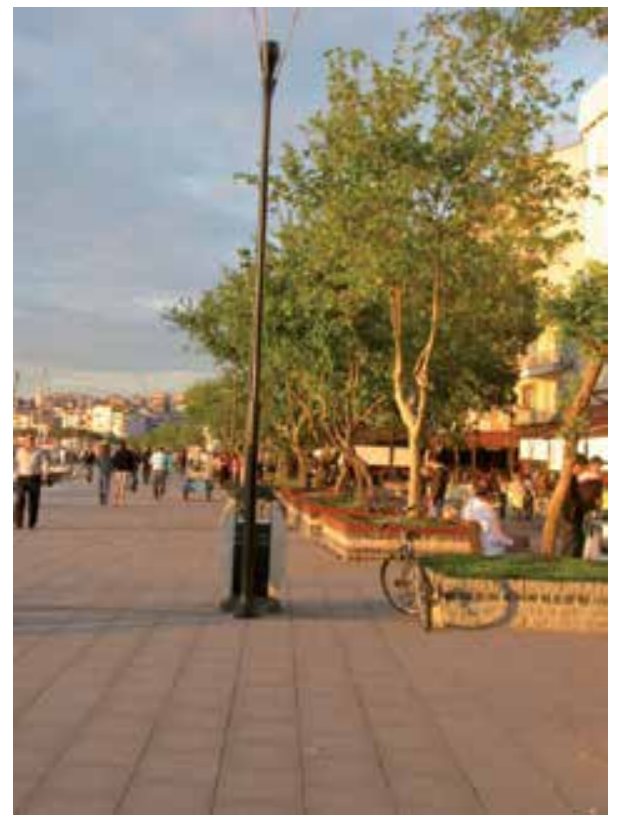

Figure 13. Trees reinforcing identity in a street (Canakkale, Turkey)

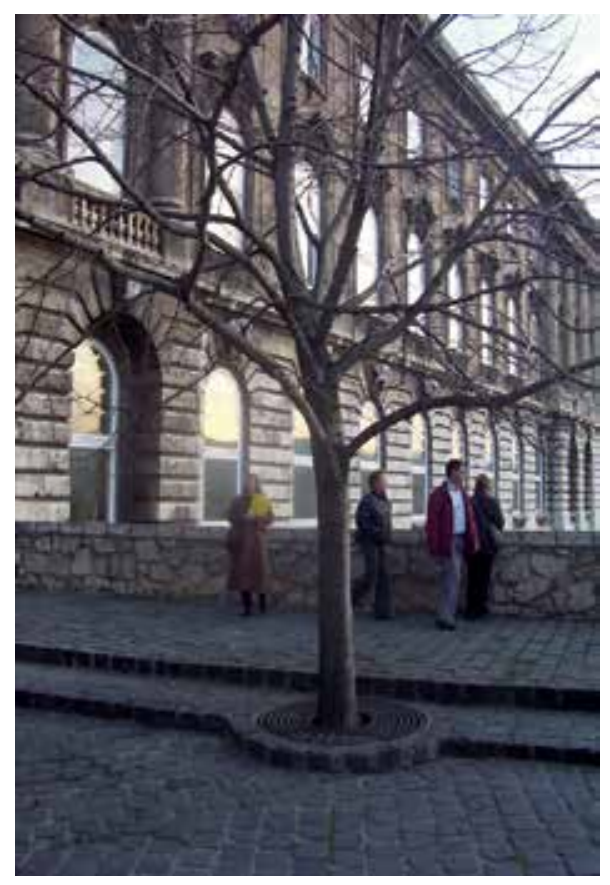

Figure 14. (Budapest, Hungary) 


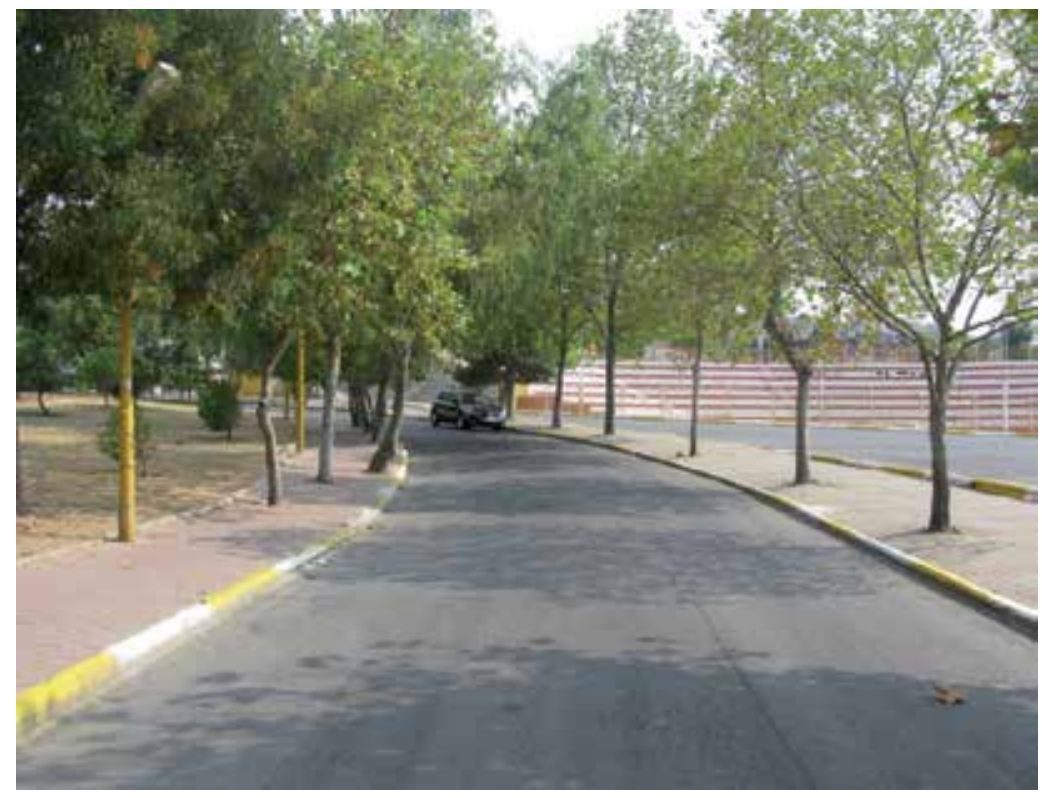

Figure 15. Street trees can emphasize direction and directional change (Tekirdag,Turkey)

- Trees can play a symbolic or monumental role, for example in major boulevards and city gateway (Figure 16).

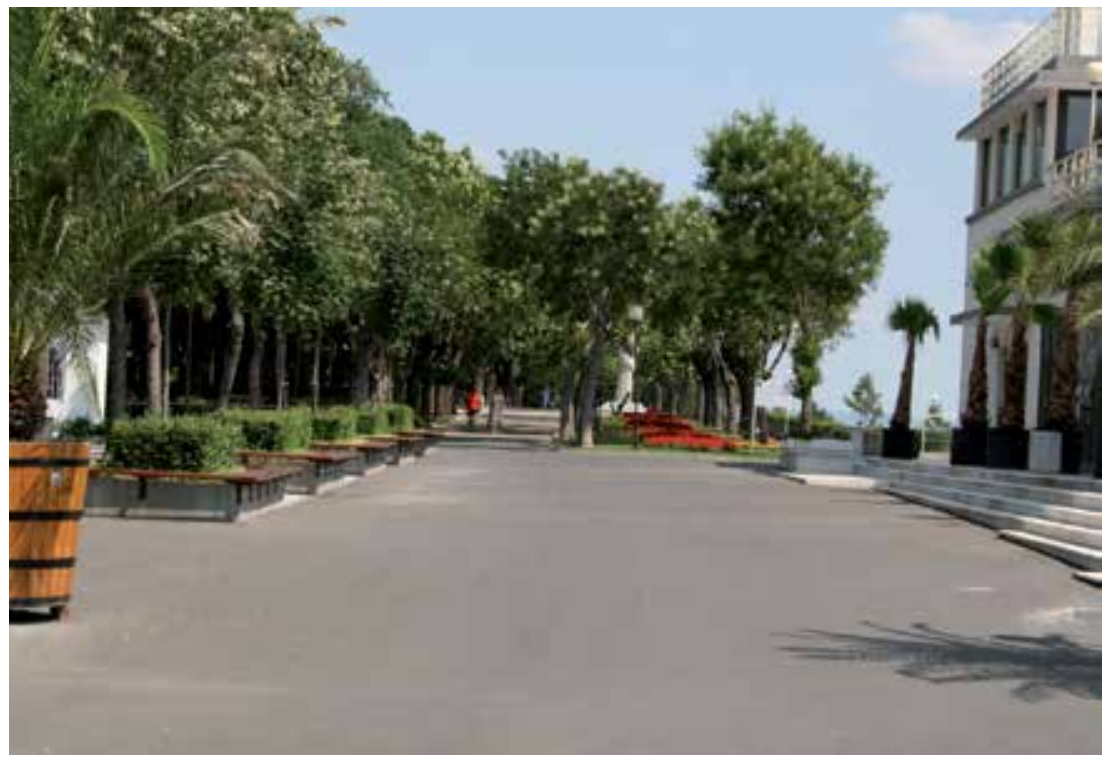

Figure 16. Tree's Symbolic or monumental role (Burgaz, Bulgaria)

- Enhancing visual amenity through screening unsightly views, softening the mass of large buildings, and reducing the apparent width of streets (especially if trees are planted adjacent to the kerb) (Figure 17). 


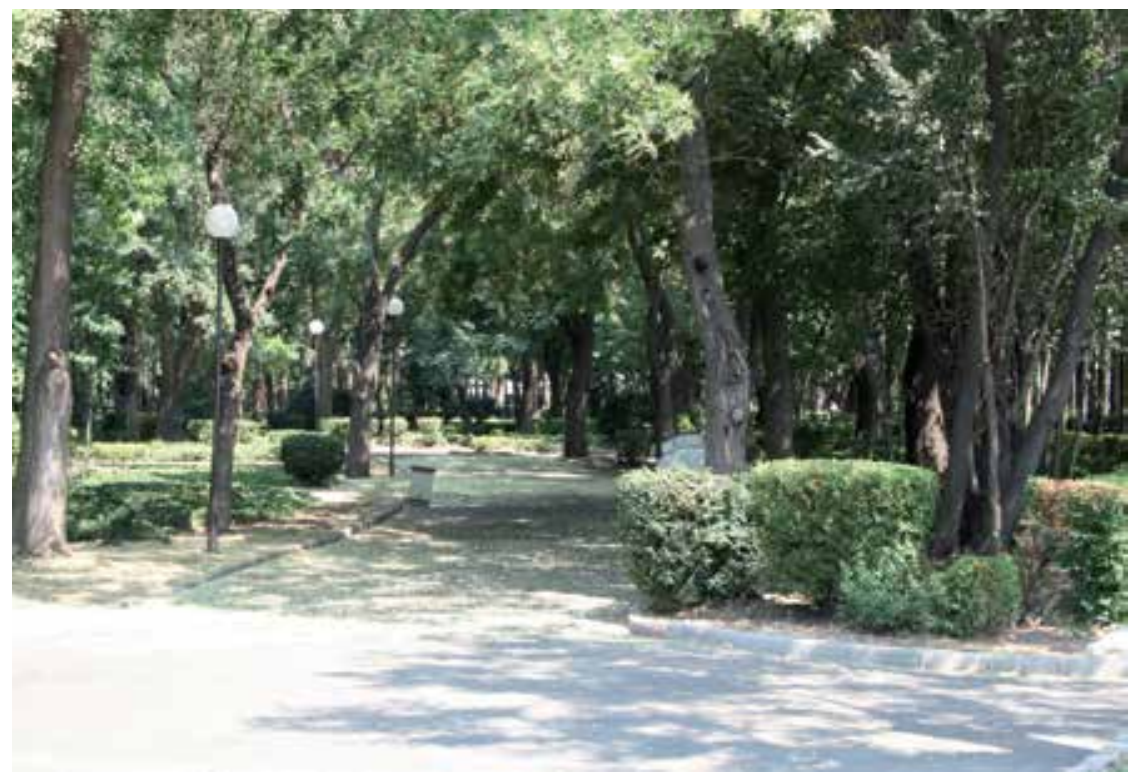

Figure 17. Enhancing visual amenity through screening unsightly views (Burgaz, Bulgaria)

- $\quad$ Providing visual interest, color and a sense of movement in urban setting (Figure 18).

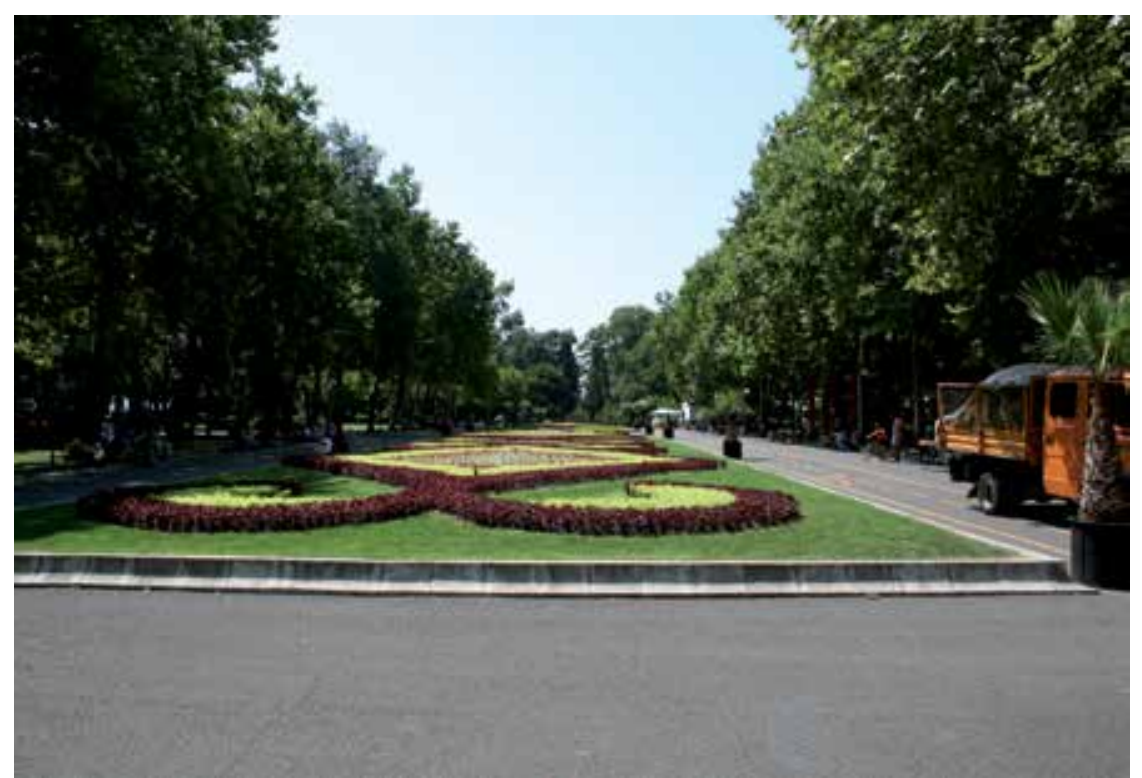

Figure 18. Providing visual interest (Burgaz, Bulgaria)

- Providing awareness of seasonal change

- Providing a sense of human scale by creating smaller space within the wider streetscape, both vertically (by creating "walls" of tree trunks), and horizontally (by creating "roofs" of tree canopies) (Figure 19, 20). 


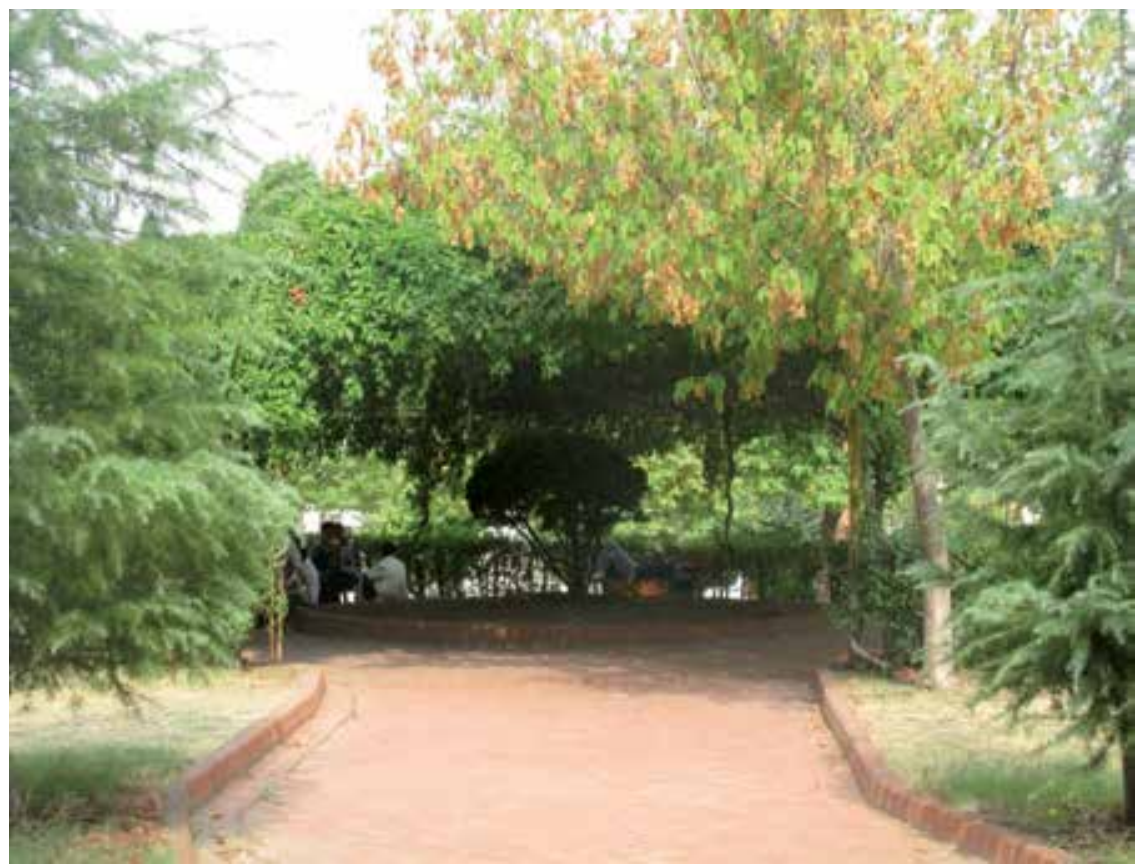

Figure 19. Street plants create a space by trunks and canopies(Tekirdag,Turkey)

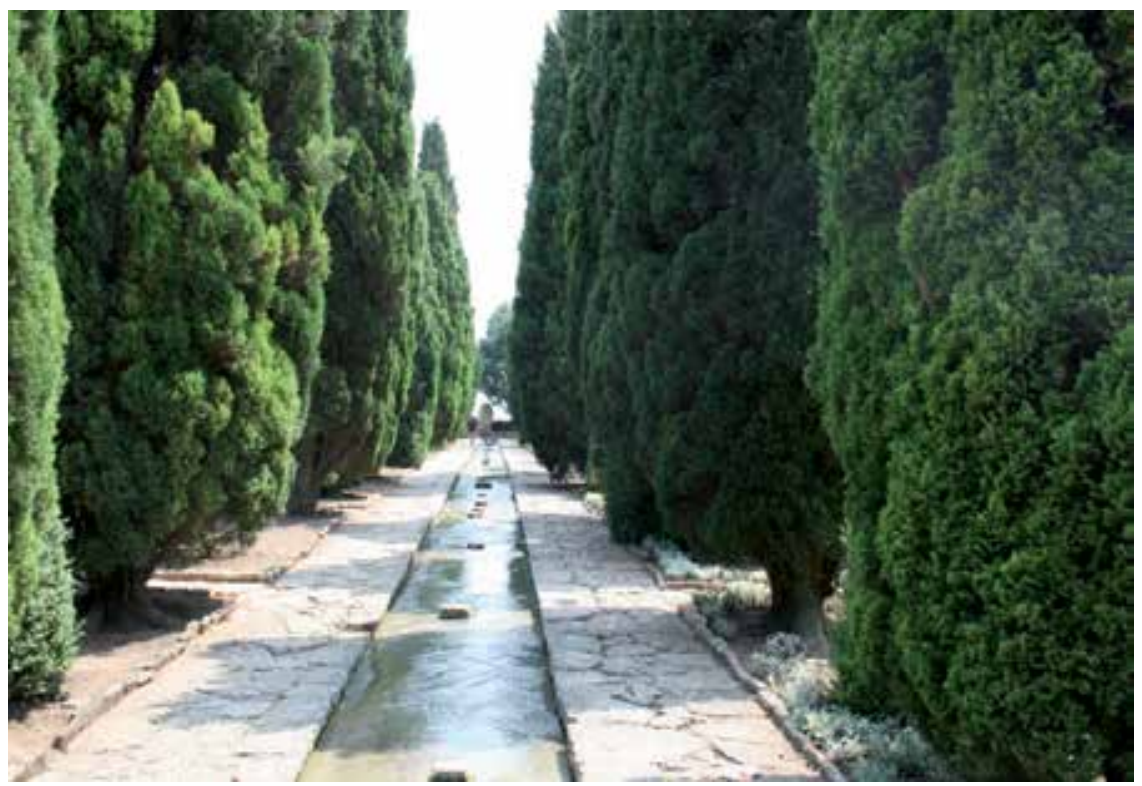

Figure 20. Creating "walls" of tree trunks (Balchık, Bulgaria)

- Providing clear spatial definition in streets, for example by separating pedestrian and vehicular zones, both physically and psychologically (Figure 21). 


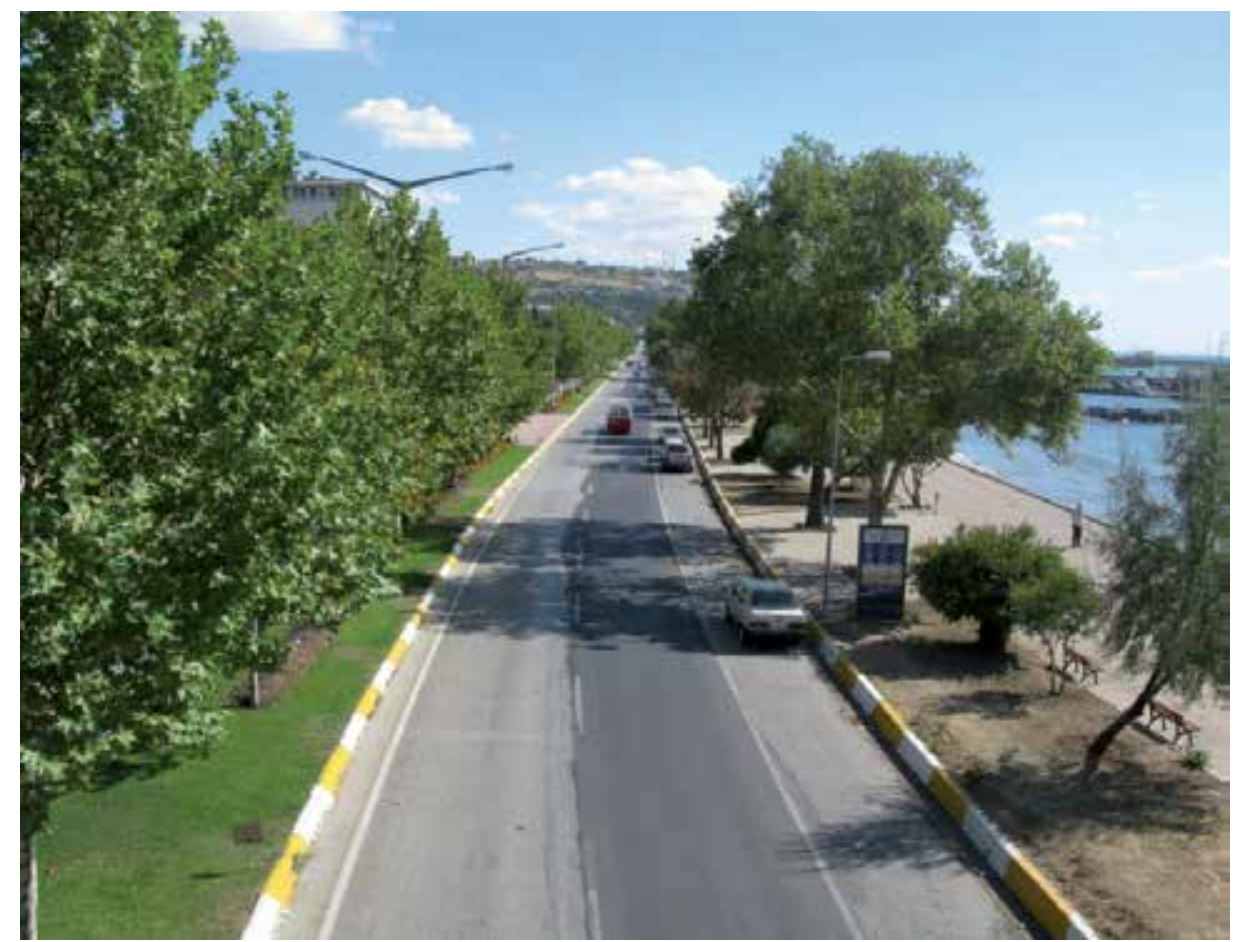

Figure 21. Street trees separating pedestrian and vehicular zones (Tekirdag,Turkey)

- Most significantly, street trees can provide a unifying element in an often visually diverse and sometimes chaotic urban streetscape.

\section{Street tree selection}

The choice of tree for a particular street or area is guided by a wide range of factors, including the ability of the species to withstand various environmental and physical constraints as well as the type of street environment that is to be created or preserved. These factors include (Moonee Valley City Council 2007):

Existing tree planting

- Species type

- Location ( nature/median strip, road, path)

- $\quad$ Planting density (number of gaps)

- Quality (age, form etc)

Street reserve

- $\quad$ Road reserve width

- Presence and width of footpath

- Presence and width of nature strip and median strip

- Overhead or underground services 
Other notable features

- $\quad$ Surrounding land use (residential, commercial, industrial, open space)

- Planting limitations (retail strips, narrow reserves)

- $\quad$ Stage of housing development (in new residential areas)

- Connections to nearby public open space

- Parking and traffic limitations

- Site topography and quality of views

- $\quad$ Proportion of recent plantings

Proposed tree species

- Physical characteristics ( height, spread, shape, ornamental value, etc)

- Evergreen or deciduous

- Rate of growth and longevity

- Resistance to pests and diseases

- Tolerances to climatic conditions (periods of drought), soil compaction, poor drainage, pollution, tree pruning and damage caused by vandalism

- Degree of limb shed

- Value of tree as a wildlife habitat

\begin{tabular}{|l|l|l|}
\hline Latin name & Latin name & Latin name \\
\hline Acer campestre & Corylus colura & Quercus rubra \\
\hline Acer negundo & Ginkgo biloba & Quercus cocinea \\
\hline Acer platonoides & Gleditsia triacanthos & Tilia tomentosa \\
\hline Acer pseudoplatanus & Ligustrum ovalifolium & Robinia pseudoacacia \\
\hline Aesculus carnea & Liriodendron tulipifera & $\begin{array}{l}\text { Robinia pseudoacacia } \\
\text { Umbracaulifera }\end{array}$ \\
\hline Alnus cordata & Morus alba & Schinus molle \\
\hline Betula pendula & Platanus orientalis & Sorbus araia \\
\hline Catalpa bignonioides & Populus sp. & Ulmus glabra \\
\hline
\end{tabular}

Table 2. Suggested Sidewalk Plants

\section{Maintenance of street tree}

Street tree maintenance includes the inspection, pruning, removal and replacement of trees.

Pruning

Street trees are to be pruned using a combination of hazard reduction pruning and maintenance pruning objectives (Figure 22).

Hazard Reduction Pruning

Primary objective is to reduce the danger to a specific target caused by visibly defined hazards in a tree. Hazard pruning consists of the removal of dead, dying, diseased, decayed and obviously weak branches, two inches in diameter or greater. 


\section{Maintenance Pruning}

Primary objective is to maintain or improve tree health and structure. Maintenance pruning may include one or all of the pruning types, crown cleaning, crown thinning and crown raising.

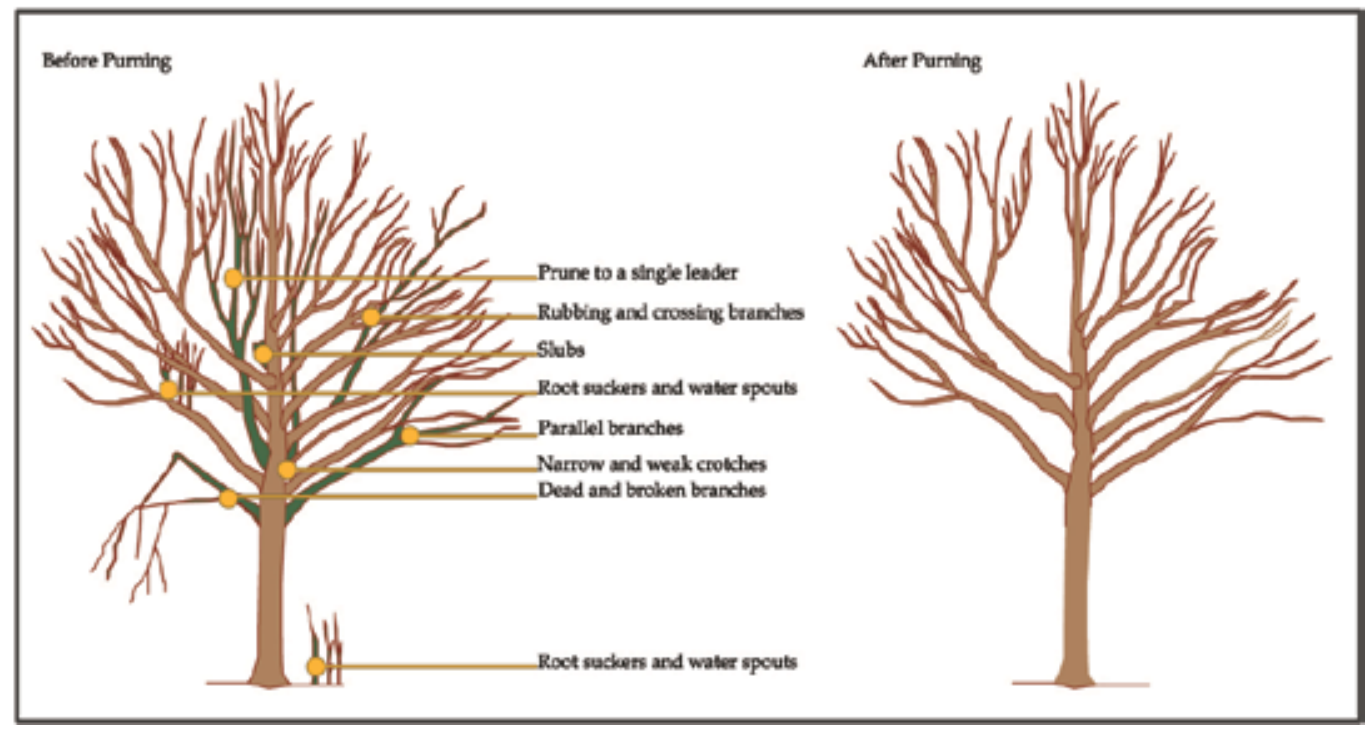

Figure 22. Pruning of trees

\section{Types of pruning}

Crown Cleaning - Consists of the selective removal of one or more of the following items; dead, dying, diseased, or weak branches and water sprouts from a tree's crown.

Crown Thinning - Consists of the selective removal of branches to increase light penetration, air movement and reduce weight.

Crown Raising - Consists of the removal of the lower branches of a tree in order to provide clearance for pedestrians and vehicles. Crown raising should be performed with the intent of providing clearance of eight feet over sidewalks and thirteen and one half feet over streets. A crown to trunk ratio of two thirds to one third should be maintained. Care must be taken to eliminate vision obstructions of oncoming traffic, stop signs, stop lights, street signs, school signs, traffic signs and any other signs or lights that affect public safety.

Crown Reduction - Consists of removing limbs to reduce the height and/or spread of a tree. Crown reduction pruning should only be done in situations where branches interfere with utility lines, where there has been significant crown dieback, or due to storm damage it is appropriate to prune for safety and aesthetic reasons (Figure 23, 24).

Crown Restoration - Improves the structure, form and appearance of trees that have been severely headed, vandalized or storm damaged. 
Training Pruning - Pruning a young tree to develop a strong scaffold branch structure. Branches that are crossing, interfering with scaffold branches or have included bark should be removed. Large growing branches with narrow attachments may need removed. Low limbs should be removed to provide clearance over streets and sidewalks. Young trees should receive a training pruning at four years after initial planting. Scaffold branches should be selected with the intent of eventually providing the above mentioned clearances. A crown to trunk ratio of two thirds to one third should be maintained. Care must be taken to eliminate vision obstructions of oncoming traffic, stop signs, stop lights, street signs, school signs, traffic signs and any other signs or lights that affect public safety.

Pruning in late autumn and early winter can lead to winter injury. The pruning wounds may not have time to "harden off" or prepare for winter. This can lead to deeper freezing in the tissues around the wound and in essence a larger wound can be created that the tree will have difficulty dealing with. During the late winter months (February and March), harmful pathogens are at a minimum, mostly inactive; therefore, this is a safe pruning environment from that standpoint. During this season, deciduous trees have hardened off and when the growing season begins the wounds will be sealed and the callusing process will begin.

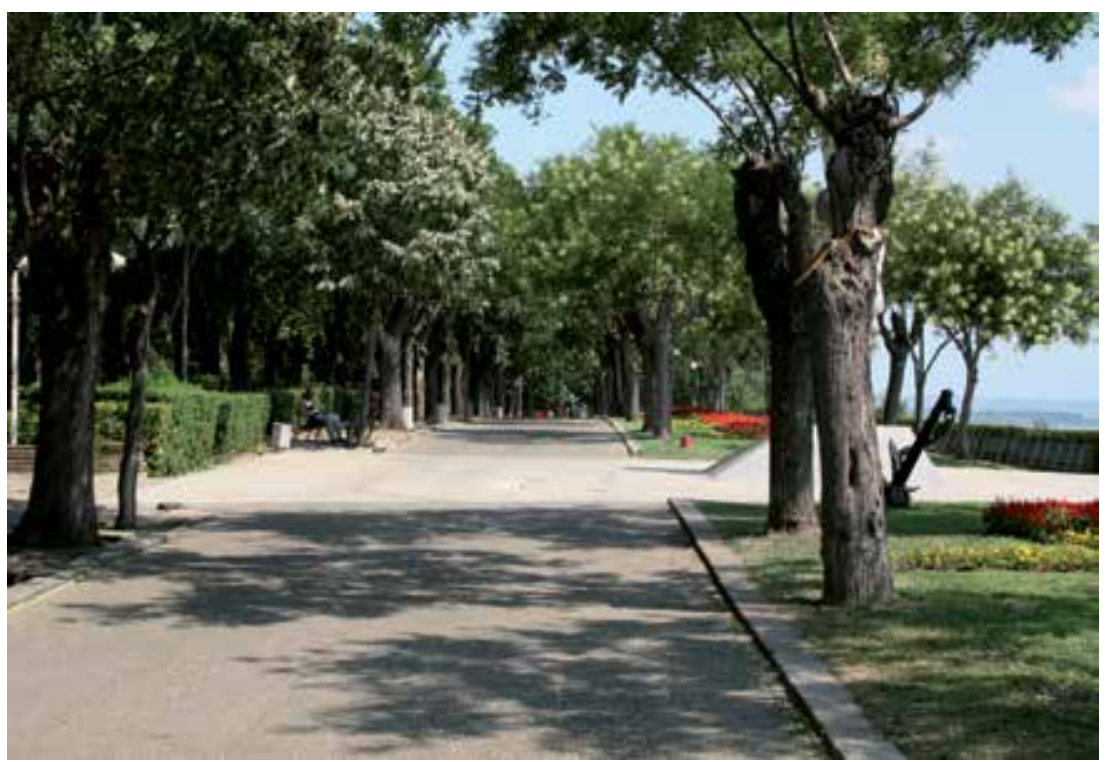

Figure 23. Incorrect pruning (Burgaz, Bulgaria) 


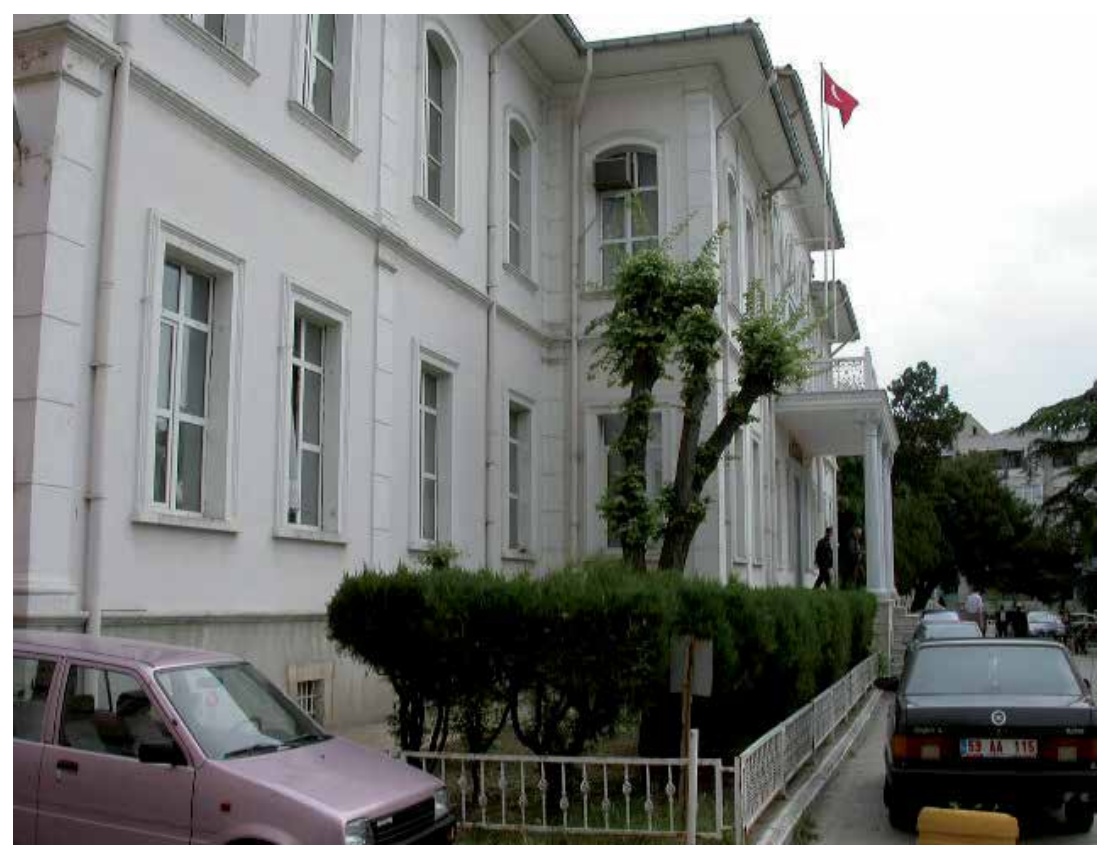

Figure 24. Incorrect pruning (Tekirdag Turkey)

\section{Author details}

Elif Ebru Sisman

Namık Kemal University, Faculty of Fine Arts, Design and Architect, Department of Landscape Architecture, Turkey

\section{References}

Department of Transport, 2012. Planning and Designing for Pedestrians: Guidelines, Western Australia.

http://www.transport.wa.gov.au/mediaFiles/AT_WALK_P_plan_design_pedestrians_g uidelines.pdf

Design Guidelines for Streets and Sidewalks 2009. Chapter 10: Pedestrian Facility Design Minneapolis. http://www.slideshare.net/Sarah17/chapter-10-pedestrian-facility-design 
Ely, M. E., 2010. Integrating Trees Into the Design of the City: Expert Opinions on Developing More Sustainable Practices for Planting Street Trees in Australian Cities, Ph. Thesis, p:483, School of Architecture, landscape Architecture and Urban Design Faculty of the Professions, The University of Adelaide.

Flannigan, J., 2005. An evaluation of residents' attitudes to street trees in southwest England. Arboricultural Journal 28, 219-241.

Guidelines for Action Sidewalk Design Transportation Advisory Committee and Town Citizens. http://www.acton-ma.gov/DocumentCenter/Home/View/856

KonSULT, the Knowledgebase on Sustainable Urban Land use and Transport. Institute for Transport Studies, University of Leeds, Leeds LS2 9JT

http://www.konsult.leeds.ac.uk/private/level2/instruments/instrument049/12_049a.htm

Melia, S., Barton, H. and Parkhurst, G., 2010. Carfree, Low Car - What's the Difference? World Transport Policy \& Practice 16 (2), 24-32.

Mineapolis Pedestrian Master Plan 2009. Access Mineapolis Ten Year Transportation Action Plan.

http://www.minneapolismn.gov/www/groups/public/@publicworks/documents/webco ntent/convert_286149.pdf

Moonee Valley City Council 2007. Street Planting Strategy.

http://www.mvcc.vic.gov.au/forresidents/environmentprograms/ /media/Files/ForResidents /Environment/EW_2008_StreetPlantingStrat_LR.ashx

NZ Transport Agency, 2009. Pedestrian Planning and Design Guide. ISBN 978-0-478-352283 (online), New Zealand.

O'Brien, D. 1993. Street Trees for Cities and Towns, Sydney, Imago Press.

Ornetzeder, M., Hertwich, E.G., Hubacek, K., Korytarova, K. and Haas, W., 2008. The environmental effect of car-free housing: A case in Vienna. Ecological Economics 65 (3), 516-530.

Portland Transportation Office, 1998. Portland Pedestrian Design Guide City of Portland Office of Transportation Engineering and Development Pedestrian Transportation Program. http://www.portlandoregon.gov/transportation/article/84048

Rosen, S.B., 2006. The success and failure of pedestrian malls in Europe and America. Senior Project, City and Regional Planning Department California Polytechnic State University San Luis Obispo.

Rubenstein, H.M., 1992. Pedestrian Malls, Streetscapes and Urban Spaces. John Wiley\&Sons, Inc.

Sen, S., 1999. Toward A Typology of Transportation-Related Urban Design Problems and Solutions: Case Studies of Small And Medium Sized Cities in The Eastern United States. National Transportation Center Morgan State.

Sommer, R. and Sommer, B., 1989. The factor structure of street tree attributes. Journal of Arboriculture 15, 243-246.

US Environmental Protection Agency, Heat Island Effect, See:

http://www.epa.gov/heatisland/mitigation/trees.htm 
Tarran, J., 2006. Trees, Urban Ecology and Community Health. TREENET Proceeding of the $7^{\text {th }}$ National Street Tree Symposium: $7^{\text {th }}-8^{\text {th }}$ September, Adelaide, TREENET Inc. 


\title{
Urban Landscape Design and Biodiversity
}

\author{
Aysel Uslu and Nasim Shakouri \\ Additional information is available at the end of the chapter
}

http://dx.doi.org/10.5772/55761

\section{Introduction}

Nowadays, cities are focal points of interaction between urbanization and nature. During the recent years, the density of buildings and other hard surfaces have dramatically increased by population growth in urban area and urbanization becomes the phenomena in our century both in developed and developing countries.

Today, more than half of the of the world's population lives in cities which is increasing by time (Tratalos et al., 2007). Research indicates that by 2030, 1.75 billion new urban residents are expected in urban area (Mcdonald et al., 2008). Also, by 2050, more than two-third of the significantly larger world will be living in urban area (Muller et al., 2010).

Although, cities cover $2 \%$ of the world's surface (Muller et al., 2010), they have an enormous impact on the earth environment. Urban areas consume $75 \%$ of global natural resources and cause $80 \%$ of 'greenhouse' gas emission. Also, urbanization modifies the ecology and features of urban landscape. There are some of the ecological impacts of the urbanization on environment such as fragmentation of open and natural areas, degradation of water resources, loss of free natural services (Benedict \& Macmahon 2002), alteration of habitat, loss and dismemberment of natural vegetation and the creation of novel habitat types (Tratalos et al. 2007). These rapid changes cause concerns about the future of life in cities. Therefore, sustainable approach towards use of the earth's natural resources and biodiversity in urban area become vital to ensure the next generations life.

Alberti et al. (2003) claimed that cities are both complex ecological entities which have their own unique internal rules of behavior, growth and evaluation and important global ecological forcing functions.

During the last few decades, the topic of urban biodiversity as a component of urban ecology has been discussed in many researches. These researches indicate that urbanization, land use and land cover (Muller et al. 2010) are the main factors threat of biodiversity by direct habitat conversion or indirect effects of human population growth on local, regional 
and global scales (Clergeau et al. 1998, Blair 1999, McKinney 2002; Ricketts and Imhoff 2003). Over the years, an approximately species decline by $10-15 \%$ caused just by habitat lost. These figures will increase by pollution, climate change and other environmental problems caused by urbanization (Zitkovic 2008).

The distribution of people across the Earth's surface is not an equal one. Therefore the pressure of population growth on balancing the conservation and the use of natural resources varies in different parts of the world (Kohsaka 2010).

Generally, the levels of urbanization are high in developing countries which most of the protected areas are located in. In addition, the distance between protected areas and cities is reducing that brings with it, significant conservation challenges (Mcdonald et al. 2008; Oliveira et al. 2011).

This situation is not better in developed countries. According to Muller \& Warner (2010), the number of vascular plant species decreases from more than 400 species per $\mathrm{km}^{2}$ at urban fringe to less than 50 species per $\mathrm{km}^{2}$ in city center, in central European cities. That's why urbanization and its impacts on environment are global issue for human future. However, there is still a glimmer of hope for preserving the urban biodiversity because there is a growing awareness that the health of the planet's biological diversity is essential for determination of human own destiny. Therefore, more protection is required for biodiversity than what has occurred to date (Millennium Ecosystem Assessment 2005; Connery 2010). In Addtion, nature in the city and studies of urban biodiversity become more vital because of rapid urbanization growth in the world.

In this case, landscape architects have significant role in designing the cities as a healthy and aesthetically pleasing living environments while conserving biodiversity. Preserving and improving the natural areas in parallel with biodiversity is an important concept in urban landscape planning and design.

Towards these objectives, this chapter focuses on the urban biodiversity and the opportunities and conflict of improving urban biodiversity. First section of chapter as a conceptual framework starts by reviewing some important concepts related with urban biodiversity. Consequently, the opportunities for improving urban biodiversity are identified. Also, the planning, management and design of urban landscape have been discussed as a tool of development, protection and creation of biodiversity. In addition, planting and constructional urban landscape design has been explained in order to creation and protection of biodiversity in urban areas. Finally, some of the conflicts in preserving and improving urban biodiversity are discussed.

\section{Conceptual framework}

\subsection{Definitions of urban biodiversity}

The concept of biodiversity is general term that can occur at any levels of life. Savard et al. (2000) explained that life is structured in a hierarchical manner which start by cells that 
constitute individuals, then form the populations, which regroup into species and as a results end as a communities.

Biodiversity is usually defined as living diversity of nature and as a component of environment. It involved all form of life, the structural and functional aspects together. Biodiversity is not only the quantity. Therefore, as assessment criteria; richness and its spatial distribution, significant and rare characteristics, homogenization and hybridization factors will be considered.

The concept of urban biodiversity is specific part of living diversity of nature. Zitkovic (2008) describes it as plants and animals that are living in the built environment. It also consists of patches of land that have survived during city expansion and represent the area before dense human settlement. In another definition by Muller et al. (2010), the urban biodiversity is explained as "the variety and richness of living organisms (including genetic variation and habitat diversity found in and on the edge of human settlements".

Through the history of human life, a lot of factors affected biodiversity. Permanent settlement, agriculture revolution, cultivates plants and domesticates animals influenced the urban biodiversity. In addition the manner that land is used and built up, economic, social and cultural dynamics affected urban biodiversity. Beside that the cities' development impacts directly urban biodiversity. It also influence how biodiversity is distributed among the different groups of the population (Oliveira et al.2011).Therefore, in the urban areas with less dense of population and shorter history of human impact original natural areas and species can be found. However, in mega-cities or more densely populated areas urban biodiversity includes only the species that can survive or adapted to the character and quality of urban ecosystems.

Today, urban biodiversity is not only the important part of urban ecosystem but also, it is a substantial ecological and cultural integrating element. Furthermore the native flora and fauna are important tools for urban ecological and cultural identity.

There is variety of biodiversity from rural borders to urban core according to the different types of habitats. Muller et al. (2010) categorized urban landscape and habitat levels as follows;

- Remnants of pristine natural landscape (e.g. leftovers of primeval forests rock faces);

- Agricultural landscapes (e.g. meadows, areas of arable land);

- Urban-industrial landscape (e.g. city canters, residential areas, industrial parks, railways areas, formal parks and gardens, brownfields).

It must be highlighted that the concept of urban biodiversity is not include just native species. Urban biodiversity may not accommodate the native biodiversity of the surroundings as this may not be compatible with the urban environment or the connivance of urban residents. For example, Manaus in Brazil is surrounded by the Amazon jungle, but its citizens do not expect to share their daily life environment with local fauna including boas or piranhas. Some native trees may not be suitable for urban environment due to the natural limitations (e.g., the need for space, clean air, water or certain species to survive) or management constraints (e.g., the frequent need for trimming or cleaning beyond local 
capacity). Indeed, removal of some species from cities, like mosquitoes, can add to the quality of life in those cities. As for desert cities, citizens may want to have trees and other non-native species. Therefore, the role of cities to foster biodiversity will vary according to its individual context. For one city, the urban biodiversity may comport with the surrounding biodiversity and the city can leave a corridor for this biodiversity thus intertwining the urban fabric with local habitats. For another city (like Manaus), this may not be possible, or at least for some species (Oliveira et al. 2011).

The modern concepts of biodiversity and ecosystems have the potential to remedy this misconception. Ecosystems show that components within any geographical unit are connected, including nature, human beings and cities. Biodiversity reflects the interconnectivity of all life on Earth.

\subsection{The importance of urban biodiversity}

The urban environment is ecologically highly dynamic (Gilbert, 1989; Adams, 1994; Savard et al. 2000) and can provide opportunities for improving the biodiversity and ensure beneficial insights into the management of biodiversity in other ecosystems. The existence of urban biodiversity can have positive impacts on quality of life as well as environmental improvement. Green areas such as parks can provide interactions between human and nature (Figure 1). It can also influence the form of the city and its inhabitants. Furthermore, the conservation of urban biodiversity is an important issue in managing urban landscape especially in mega-cities (Qureshi \& Breuste 2010).

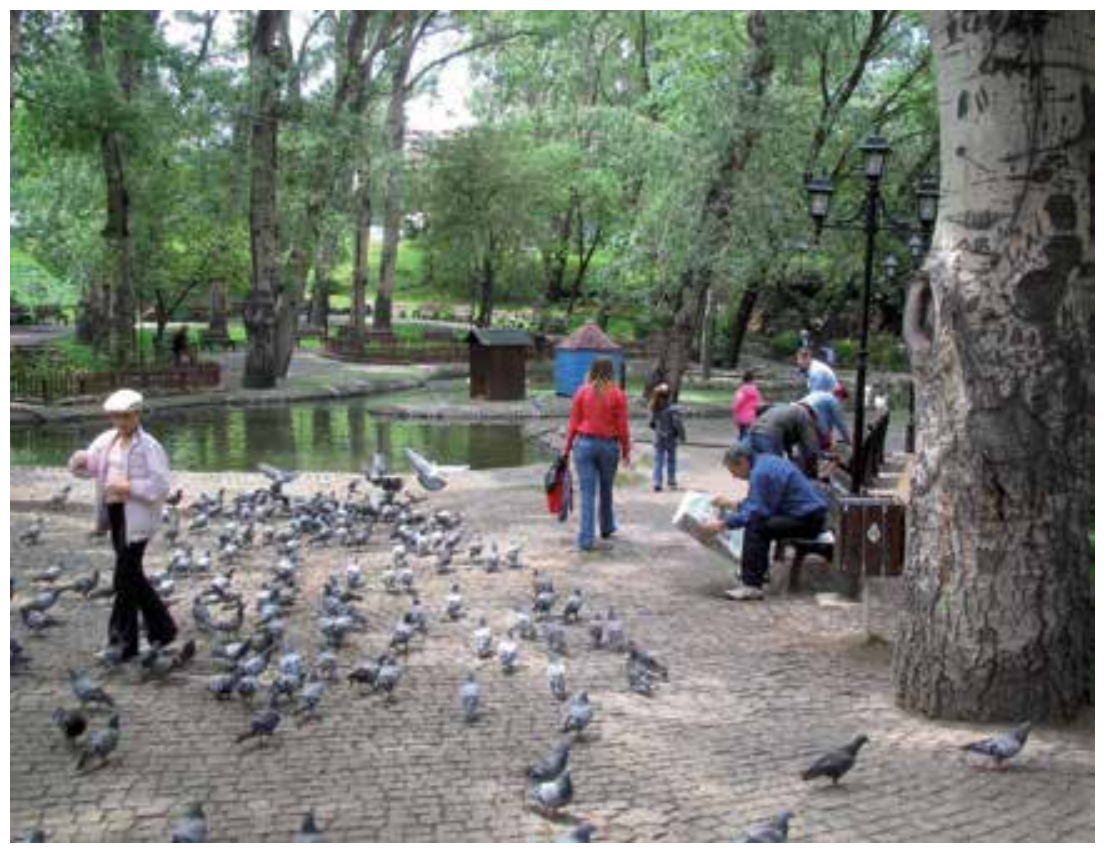

Figure 1. Green areas such as parks can provide interactions between human and nature as well as improving biodiversity (Photo from Ankara-Turkey taken by Aysel Uslu) 
Also, urban ecosystem can make favorable condition for improving biodiversity. Many researches indicate that there is a variety of species living in urban area that are welladapted to the urban life (Oliveira et al. 2011). Also, some research has produced substantial evidence indicating that biodiversity in urban area can be more than rural areas surrounding (Qureshi \& Breuste 2010). The reason is that, there are unique physical and ecological conditions in urban area. These are mixed and small-scale habitat mosaic, different from of landscapes and land uses, the various influences of people that result in habitat types and plant and animal associations or communities (Muller \& Werner 2010). Muller (2007) justified the reasons for high biodiversity in cities as follows:

- Cities often include relics of natural habitats- forests, rivers...

- Cities often include relics of semi-natural habitats - meadows, arable fields...

- The variety and distinctness of urban habitats - residential areas, gardens, parks, industrial areas, railway areas, brownfields

- Cities are centers of immigration

- Cities are centers of importation, naturalization and spread of exotic species.

Therefore, the urban ecosystem is valuable for biodiversity including population structure, genetic diversity. Savard et al. (2000) explained an excellent example for these advantages. Planting rare vegetable or rare form of plants in backyards can sustain a source for genetic variability. Additionally creation of pools and wetland can reproduce variety of aquatic organisms. Cultivation of flowering plants in cities parks and even private lots can attract butterfly and birds and consequently increase the diversity of these species. For example, in 2010 as part of the Landscape Urbanism biennale, an area was planted up to reintroduce butterflies back into the city Bat Yam Israel.

\subsection{Urban ecosystem and biodiversity}

Urban ecosystems are similar from different perspectives such as structure, function and constraints. The geographical location, size and the type of landscape they modify are the factors of their difference. One of the important element influences plant and wildlife species which can be found in urban built environment is the landscape surrounding the city. Therefore it has a significant role in the management of urban biodiversity (Savard et al. 2000).

There are lots of examples indicate immigration of animals and plants to urban areas from their natural habitats. The reason of this immigration in most cases is food supply and lack of predators (Muller \& Werner 2010).

There is a general agreement that cities are characterized by high species richness in terms of vascular plants and most animal groups. This is the result of the high beta-diversity that means the large variety of habitats present and variation in vertical and habitat structure, the considerable variation in the type and intensities of land use, the range of material used and the huge array of micro-habitants, and the most varied habitant mosaic configurations (Muller \& Werner 2010). 
According to Muller \& Werner (2010), during the $19^{\text {th }}$ and $20^{\text {th }}$ centuries, the number of naturalized species (tree, shrubs and herbaceous plants) increased significantly. The urbanization is shown as basic reason of this biotic homogenization. During these years, planting small number of nonnative species and cultivars in gardens caused biotic homogenization of these species. By the time, these species spread as invasive species into their surroundings (Muller \& Werner 2010). Beside these plant species, some of the animal species also become naturalized in urban area. As a result of biotic homogenization process, the biodiversity increase in urban areas.

Urban biodiversity have positive impact on human wellbeing. Expanding the urban green areas and contributing the natural areas development in cities not only promotes species richness, but also bring better quality of life for the residents. Curitiba Declaration on Cities and Biodiversity (2007; Connery 2009) emphasized the importance of urban biodiversity signaling the need "to integrate biodiversity concerns into urban planning and development, with a view to improving the lives of urban residents ..."

Urban biodiversity provide recreational areas in artificial urban environment, so, it is essential for resident's health (Niemela 1999).The biological diversity also helps people, shape their "sense of place."(Connery 2009). Existance of varaiety of plants or animals as characteristics of places can present a memorable picture from different sites and led to the identification of places.

Additionally, urban biodiversity as a key component of ecosystems have positive effect on ecological service function. Several ecological services having significant role and human wellbeing are the direct products of urban biodiversity. On the other hand, biodiversity loss can influence almost all services provided by ecosystems (MA, 2005; Oliveira et al. 2011). These ecological services range from provisioning services (e.g. food, fuel, water) to regulating (e.g. climate/air pollution regulation, waste assimilation, flood and fire regulation) and cultural services (Oliveira et al. 2011). Using the local diverse vegetation can be more effective improving ecological services.

Furthermore, urban biodiversity can play a significant role in improving the green infrastructure that influences the human health and climate changes and heat islands positively (Vergnes et al. 2012).

Conservation of urban biodiversity is an important global issue because urban environment have a significant role in preserving the local species and maintaina platform for urban citizens to understand the natural process. For a long time, urban planning effort was to establish protected area and corridors in cities (Hostetler et al. 2011). However today, most of the biologists and ecologists believed that creating the connection between parks, preserves and other important ecological areas and establishing green infrastructure is the key concept for pereserving biological diversity and ecological process (Benedict ve Macmahon 2002).

Benedict \& Macmahon (2002) describes green infrastructure as an ecological framework needed for environmental, social and economic sustainability. It can also be defined as 
protected natural open space and corridors (adjoining residential yards or sections) (Hostetler et al. 2011).

Green infrastructures consist of a system of hubs and link. Hubs are "destinations for the wildlife and ecological processes moving to or through them" and links are a "connections tying the system together and enabling green infrastructure networks to work".

The corridors have significant role suporting biodiversity because they allowing some species, especially the less mobile ones, to disperse to distant locations and limit the negative impacts of fragmentation (Vergnes et al. 2012).

Vergnes et al. (2012) analyzed the effect of corridors on the variety of species, the number of individuals, the means by which species disperse (in the air or on the ground) and the main habitats in which the species are typically found. The results of this research indicate that, not only do corridors affect the dispersal of individual species; they also allow species to maintain community structure. Furthermore, corridors can connect urban areas with new city regions locating in rural areas surround the main city.

During the history of life, cities often occur in unique and valuable natural ecosystems such as the River side and delta. Urbanization in these areas fragments the natural and original habitats (Schaefer 2003). Over the time, continued urbanization isolates these areas. However, in some cases these areas are protected as natural parks, but their biodiversity decreasing as a result of isolation. Planning green infrastructure and green links enables these areas to act as more viable larger units, thereby helping to protect their biodiversity.

Most of the time the growth of population in cities cause spreading to rural areas surrounding where original vegetation is exist. These areas have an opportunity for its use as parts of the urban infrastructure in the new city regions (Breuste, 2004; Florgard 2010). Planning the green infrastructure will connect these areas to urban areas and can improve the biological diversity indirectly.

One of the challenges in urban planning and design is the habitat fragmentation caused by urbanization. Connectivity is the product of green infrastructure in urban environment that ties the island biogeography and conservation biology and unable them to function as larger units containing larger breeding populations and more complex food webs (Schaefer 2003).

Habitat fragments are the nodes of this web and corridors are the connection between them. Linehan et al. (1995; Schaefer 2003) determined the strength and impact of network connectivity by the number of network in region, the dimensions of the links within the networks and the number and sizes of the nodes.

Many researchers accepted the value of connectivity in forestry conservation and founding the movement of wildlife between habitat patches (Harris 1984; Noss 1987; Schaefer 2003).

Wildlife movement through the corridors can range small to large mammals (e.g Wegner and Merriam 1979) and birds (e.g. Dmowski and Kozakiewicz 1990; Schaefer 2003). Some criteria can examine the quality of corridors in green infrastructure such as vegetation 
layering, diversity of plant life and a minimum of invasive alien species (Thorne 1993; Schaefer 2003).

Today, there are a lot of examples of ccorridors and ecological connection in European cities that bringing nature into city centers and developing physical and ecological connection between built-up areas and natural and greens paces (Beatley 2000).

In many of the urban areas, there is generally one or more open and green spaces with large size that presenting as a mother habitat patch for preserving biodiversity. But, preserving and protecting these habitat patches is not enough for improving urban biodiversity. The reason is that without the connection between them, isolation and loss of genetic diversity is unavoidable. Corridors of urban green infrastructure connect different size of habitat patches such as backyards, hedgerows, green roofs to parks.

Population increasingly grows in urban area and human life still depends on the nature and the ecosystem that they live in. An ecosystem generally can be defined as "a set of interacting species and their local, non-biological environment functioning together to sustain life" (Moll and Petit, 1994; Bolund and Hunhammar 1999). Cities are depending on the ecosystems beyond the city limits. In the study of 29 largest cities by Bolund \& Hunhammar (1999), in Baltic Sea region, it was estimated that the cities claimed ecosystem support areas at least 500-1000 times larger than the area of the cities themselves. But, in this chapter the concept of urban ecosystem is focused and the effects of ecosystem inside the borders of cities.

Ecosystems usually differ in size, borders and location. In the case of urban environment, it can be defined as a single large ecosystem including all the individual ecosystems like parks, lakes and etc. or can investigate as several individual ecosystems (Rebele, 1994; Bolund and Hunhammar 1999). In this chapter the concept of urban ecosystem consist of all ecosystems located in urban area.

The concept of 'ecosystem services' refers to benefits human populations derive from ecosystems. Bolund and Hunhammar (1999) identified seven urban ecosystems including;

Street trees; lawns: parks; urban forests; cultivated land; wetlands; lakes: sea; and streams.

Then, they range the ecosystem services generated by these systems as: air filtration, micro climate regulation, noise reduction, rain water drainage, sewage treatment, and recreational and cultural values. Finally, they emphasized the locally generated ecosystem services have a substantial impact on the quality-of-life in urban areas and should be addressed in landuse planning. Now, what the relations of urban biodiversity and the urban ecosystem services is.

Urban biodiversity can provide series of benefits in urban ecosystem by improving the ecosystem services ranging from the more directly perceived, such as water supplies and recreation facilities (parks) to less tangible effects of large bio diverse areas, such as hosting species which may help cure diseases or contribute to long term climate stability. 
Nowadays one of the important challenges in urban area is the problems caused by the climate change. The increasing growth of structural areas and fragmentation of natural and open spaces is the main reason of the urban heat islands and climate changes (Baris et al. 2010). Today, it becomes vital to create micro climatically comfortable spaces within the artificial urban environment both for human thermal comfort and for enabling the conservation of biodiversity that can still be called the native flora of the region (Hagen \& Stiles 2010).

In a variety of studies, the significant impact of vegetation in urban climate, its ecological balance and effects on citizen's comfort is documented (e.g. Bolund \&Hunhammar, 1999; Dimoudi \& Nikolopoulou, 2003; Gill et al. 2007; Hagen \& Stiles, 2010). Also as Ong (2003; Hagen \& Stiles, 2010) emphasized sustainability of city depends on the urban vegetation.

There is lots of evidence that vegetation can reduce the air pollution in urban area (Svensson and Eliasson, 1997; Bolund and Hunhammar 1999). Also, research represents the effective role of the vegetation on air filtering than water or open spaces (Bolund and Hunhammar 1999). Different component are affective on the level of pollution reduction provided by vegetation. Plants can filter the pollution and particulates in the air using their leaf. Therefore, filtering capacity increases with more leaf area and using the trees in urban design. Using trees can be more effective in air pollution reduction than the bushes and grassland.

Complex species assemblages also can improve the soil health. They can decrease the capacity of soil for absorbing the flood water. Also they can have positive impact on water filtering. Using the various species of plants specially trees can filter air and reduce the amount of carbon in the air causing the greenhouse effect in urban area. It must be noted that using local vegetation has advantages of cutting costs in many cases. The reason is that these species live several years without requiring little human attendance or input of water.

Green space in the urban landscape helps in overcoming fundamental environmental problem, further enabling and easing conservation efforts from local and regional authorities and others.

Biodiversity and healthy ecosystems within city limits support the quality of life of citizens, facilitate municipal services and aid in restoring a positive and integrated perception of the environment to citizen.

\section{Preserving and restoring urban biodiversity}

For decades, preservation of biological diversity restricted just for protected areas where biodiversity is guarded from human threats. Today, protected areas cover approximately $15 \%$ of earth whole land surfaces (Mcdonal et al. 2008). Although having such a small rate, the protected areas still have significant role on preserving biodiversity. In addition, the protected area, the concept of preserving biodiversity in urban area gets importance in last years. There are a few causes for the importance of this issue.

The reason is that the urban areas consist of different habitats and ecosystems allowing many species to grow and expand as we mentioned before. Therefore, the richness of the 
species proliferates in these areas. On the other hand, cities consume a large amount of natural resources of places, far away from cities and indirectly affect the bio diversities' of these areas. In addition, most of the cities' activities generate air pollution, solid waste and so on that directly has negative impact on cities biodiversity.

That's why; it is essential to develop methods for identifying where the human threats and biodiversity coincide (Ricketts et al. 1999; Rickettes \& Imhoff 2006) to decrease the negative impacts of urbanization on urban biodiversity and preserve the existing species while restoring the damaged areas.

According to these objectives in this section, the opportunities for preserving biodiversity in urban areas are firstly evaluated. Because preserving a functional biotope and ecosystem are a basic step in sustainable development in cities and towns. Also, it can provide aesthetical and functional advantages that can ensure many social and economic benefits in cities.

In second part, the relation between urban landscape design and biodiversity is discussed. Also, the methods of planning and design of urban landscape that can improve urban biodiversity are defined. Furthermore, the effective method for improving urban biodiversity is recommended.

Finally, the conflicts and challenges in preserving and improving urban biodiversity are investigated. The problems related to preserving urban biodiversity are emphasized in this part because if the obstructions identified, better solutions will emerged and elimination of problems will accelerate the improvement of urban biodiversity.

\subsection{Opportunities to promoting urban biodiversity}

Cities are the parts of larger ecosystems and don't exist isolated. Therefore, investigating opportunities to promote urban biodiversity can impress the richness of species not only inside the urban borders but also in areas surrounding the cities. However, while perusing these opportunities, it must be highlighted that all of the species are not equal in urban area.

Most of the species existing in urban area are different in many features such as size, shape, abundance, distribution, trophic position, ecological function, feeding habits and desirability. It is substantial to identify which species have more important role in the community and their absence will affect other species while evaluating the opportunities for promoting species life.

Urban structure consists of different natural corridors such as waterways and green ways. These natural habitats inside the urban borders accommodate many species and generally are connected to the areas out of the urban boundaries. So, they are important features for biodiversity both as stable and as transient habitats (McIntyre, 2000; McIntyre et al., 2001; Angold et al. 2006).

Therefore, evaluating the opportunities in preserving biodiversity in these areas can increase the urban biodiversity richness as well as near rural and natural areas species diversity. Any 
vegetated corridors linking urban green areas to each other or connecting these areas with rural habitats are important to maintain and enhance urban biodiversity (Flink and Searns, 1993; Savard et al. 2000). The reason is that, they facilitate the movements of species between the different habitats. Consequently, they insure the colonization of natural areas.

Streams and other waterways as natural corridors in urban areas are another opportunities for promoting biodiversity. If these corridors are well managed, they can improve biodiversity not only in the habitats beside the land but also can have positive effects on the proliferation of aquatic species (Figure 2).

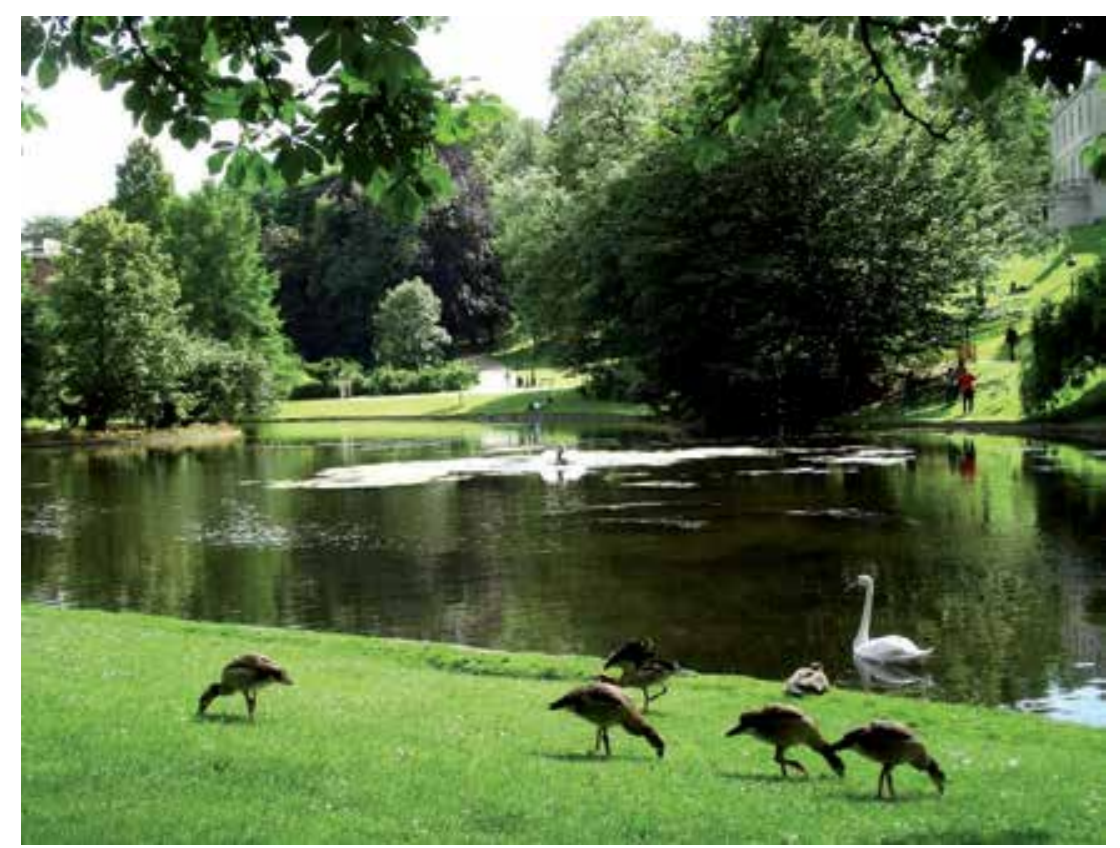

Figure 2. Waterways in urban areas as opportunity for promoting biodiversity (photo from BrusselsBelgium taken by Aysel Uslu)

In addition to urban corridors, urban landscape consists of natural areas covered by local species of plants. These plants constitute habitats for many other animal species. Therefore, protecting these natural areas inside the cities, results many benefits especially those influencing biodiversity. They also help preservation of local habitats and species that are in peril of extinction (Figure 3).

Beyond supporting a variety of species and habitats, other advantages of protecting natural areas in cities are contributing the essential services including water filtration and absorption, nutrient cycling, air filtration that can improve biodiversity indirectly. In addition, they can bring nature closer to city dwellers. As a result, the native species will recognized and be familiar for inhabitants. Therefore, urban residents will protect these species by rising awareness of environmental issues and importance of urban biodiversity. 


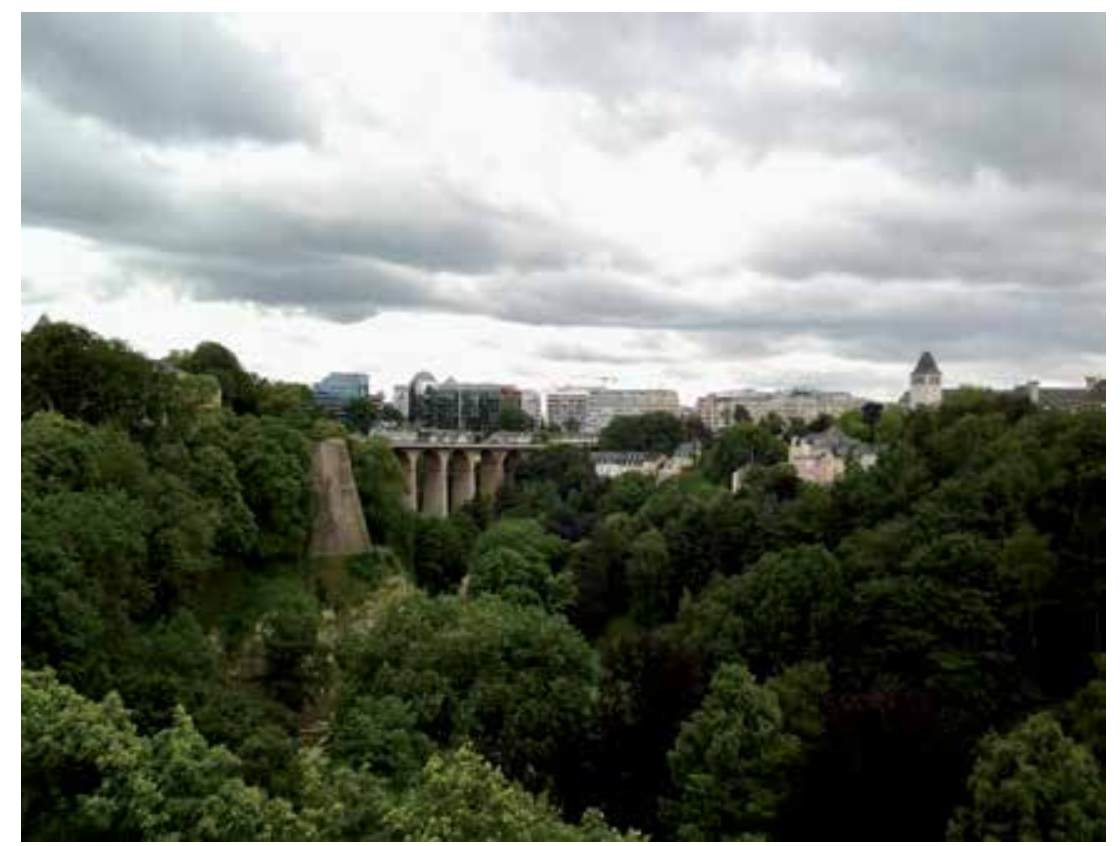

Figure 3. Natural green spaces can support the life cycle of local species (photo from Luxembourg taken by Aysel Uslu).

Also there are series of open public areas inside the cities that have potential for improving biodiversity. If these areas including; parks and public gardens, outdoor sports activity areas, playground, squares, hobby gardens and urban farms are well-designed and managed, then they will provide life habitats for many plant and animal species.

Apart from preserving and linking of existing green spaces, creating new green spaces inside the cities is essential to complete green network and sustainable urban development (Hagen \& Stiles, 2010). New green spaces can increase the potential of species to move through urban areas and colonize the surrounding habitats. Residential areas gardens can have a significant role in this concept. According to Savard (1978), well vegetated residential areas can establish aerial corridors through their tree canopy. These areas are beneficial for migrating birds which use them extensively as they provide food and protection against aerial predators.

Besides the gardens and greening the courtyard, any other green strategies such as green roof are essential for improving urban biodiversity. Rapid urbanization caused most of the natural green spaces inside the cities to be destroyed and fragmented. Consequently of these modifications, the natural habitats of many species are damaged. Therefore, creating new green areas can improve these habitats supporting urban biodiversity.

Unused land within cities and brownfield sites are the other parts of urban landscape structure that can have significant role on rehabilitating the urban natural biodiversity. One example for unused land within cities is railways. Railway sidings with vegetation can connect different green spaces within cities and play as a network enhancing habitat for 
biodiversity as well as improving its capacity to provide ecosystem services. They also can connect cities to the surroundings area and facilitate the movement of different species of insects and animals depending to the plant species.

An example for brownfield is unused industrial areas inside the cities. If these areas were abandoned for a long time, natural plants begin to grow without any intervention. As a result of this vegetation, several species of insects and other animals will attract to the area and if this habitat modification managed properly, it will be transformed into new habitat for many species. In some cases these areas turned to man-made parks that have positive impact on urban biodiversity as well as natural vegetation. The research of Strauss and Biedermann (2006; Haase\& Schetke 2010) indicate the positive response of different species to large area of inner-city grassy brownfields and negative reaction to the absence of them. In addition to brownfield, some researchers reported considerable potential of shrinking cities for biodiversity and the improvement of urban green system. The residential and commercial properties and their subsequent demolition area provide opportunities enlargement of urban green space as well as the ecological restoration of cities. Therefore, identifying these areas and investigating their potential for improving urban green space will have significant role in increasing urban biodiversity (Haas \& Schetke 2010).

Beside the opportunities related to land use, constructional elements in cities can provide opportunities for promoting urban biodiversity. Walls are one of these noticeable constructional elements in cities that can support biodiversity and provide other environmental benefits as well. As a result of population growth and decrease in land area available for urbanization, the vertical dimension in urban areas expanded. Utilizing these elements as a habitat for different species can improve urban biodiversity.

In general three types of walls in urban area can be observed; free standing (boundary) walls, buildings walls and retaining walls. Different vascular plant species have the ability to grow on these types of walls. Most of the studies on walls vegetation have focused on old walls maintaining an interesting flora, sufficient to attract some initial botanical attention. As a result, some walls are identified as worthy of conservation because they have some biodiversity value as well as historical and cultural value (Darlington, 1981; Gilbert, 1992; Jim and Chen, 2010; Francis 2010).

However, establishment of more plants on walls depends on the physical and ecological features of walls allowing the trapping and germination of seeds (Darlington, 1981; Francis and Hoggart, 2009; Segal, 1969; Francis 2010). Other factors such as physical substrate, moisture, nutrients, micro climate are also decisive factors on walls biodiversity. Freestanding walls are often the common location for vegetation in urban areas. But maintaining the other vegetation species on the buildings wall still require new technologies and constructional materials development (Figure 4).

Finally, it must be highlighted that urbanization provided appropriate environments for many exotic species to grow inside the city's boundaries. If these advantages are wellmanaged, the biological diversity of urban areas will improve with native species as well as exotic species. Thus, urban government must plan, design urban environment in such way 
that outcomes of urbanization influences on the biodiversity can have positive impact on quality and quantity of urban biodiversity.

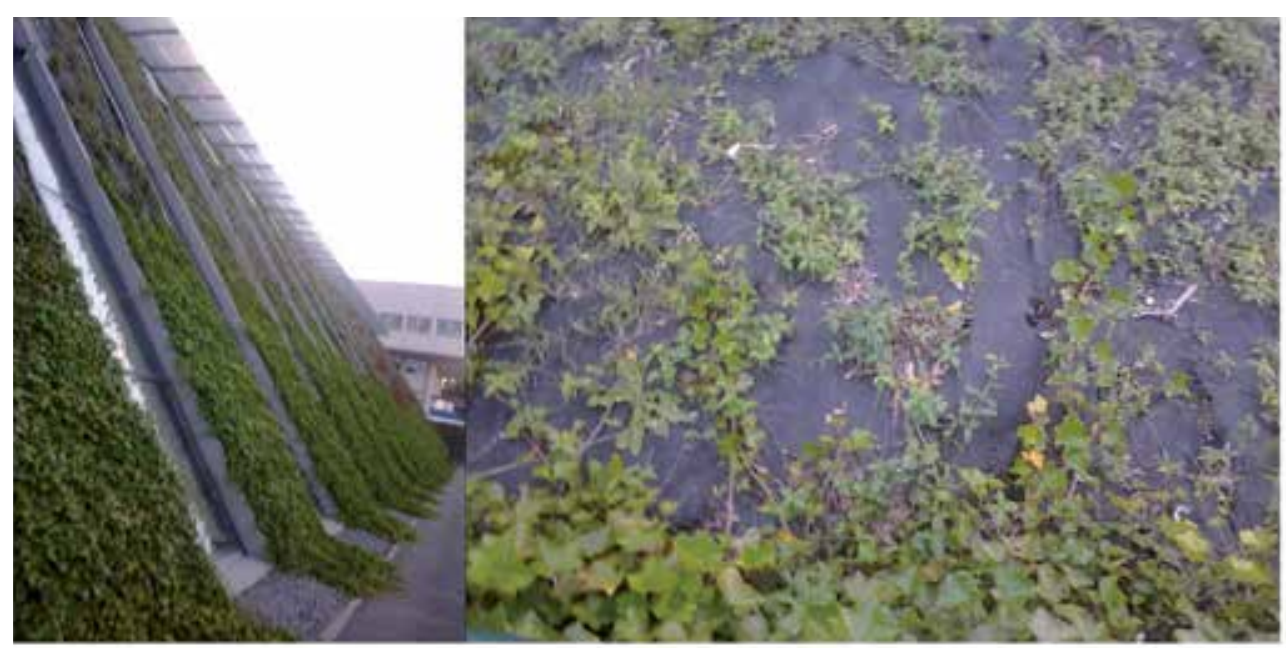

Figure 4. New technologies for maintaining vegetation species on the buildings walls (photo from Brussels-Belgium taken by Aysel Uslu).

\subsection{Urban landscape design and biodiversity}

Through the history of civilization, most of the attempts to increase the urban biodiversity restricted just to managing the particular green areas or conserving and restoring certain habitats inside the cities. Also, it must be highlighted that the main goal of these activities was providing recreation areas for urban residents like urban parks and green belts rather than improving urban biodiversity. As a result, most of planning process and managing urban land use policies were based on the immediate issues and ignore the wider ecological patterns in urban area.

Recently, emphasizing the importance of urban biodiversity in many research and increasing environmental awareness caused urban biological diversity to be slightly considered in urban planning and designing process to have sustainable and more resilience environment. However, for the implementation of this concept in comprehensive manner, more effective urban planning and design policies are required. Therefore, for shedding light to this issue, in this part some of the planning and design methods for improving urban biodiversity will be identified and recommended.

According to Angold et al. (2006), better understanding of the interplay between landscape and local factors that affect urban biological diversity is first step for managing urban environment. Therefore, identifying the existing biological diversity potential and protecting these areas is essential for improving biodiversity. Accordingly, local planning and design practices yields better results in the term of urban biological preservation. Also, local planners having more information about biodiversity potential of specific area can make better decision for improving biodiversity and react better facing to particular challenges. 
Urban planners must determine the inventory resources with in cities and organize them by unique structure, corridors. Therefore the landscape characteristics of the area must be considered in land-use decision. For example, valley or streams can be considered as natural corridors. Also, during the urban growth process it must be considered that these areas must remain as natural as possible (Figure 5).

For example a simple meadow containing wildflowers is valuable from the biological preserving point of view. However, shearing these flowers before their blooming can cause the loss of biological diversity values. Therefore, these potential zones, must integrate social and ecological considerations to avoid conflicts.

Today, there are many examples of strategies for bringing cities and nature more closely all over the world. The use of native species for ornamental purposes, establishment of conservation areas, revitalization of the nearby water river basin, planning for tree lined streets and linear parks are some of these strategies. European cities offer many examples of these kinds of efforts to incorporate green features and nature into the design of the built environment in urban areas.

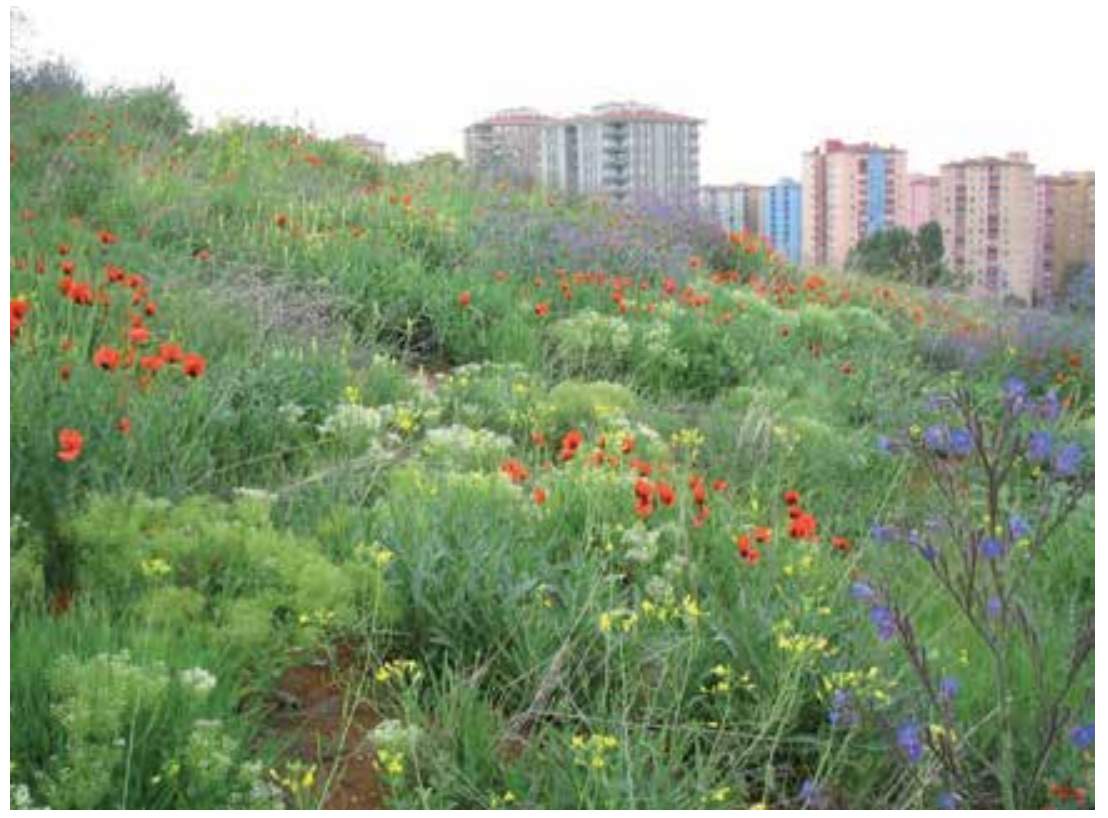

Figure 5. An area with wildflower inside the city borders is valuable for urban biodiversity (photo from Ankara-Turkey taken by Aysel Uslu).

Also, it is important that urban planners act on large scales including entire city or smaller scale including neighborhoods. Local action and regional action are equally important in the concept of improving biodiversity. It is critically important that urban planners and other related professionals such as landscape designers or urban designers consider the protection and conservation areas inside the cities in their urban planning and design strategies. In addition, continuous network of these protected zones together with other 
urban greenery must be determined. For this purpose as Niemela (1999), emphasized, 'green belts' surrounding cities and 'green corridors' running through cities are the effective strategies. Because these areas, prevent urban sprawl and ensure the connection between green and natural patches (Oliveira et al. 2011). The surrounding areas of different cities in world include lawns, grove and forest areas. These areas contain large amount of biological diversity. Creating network between these areas and inner cities green and open areas is one of the most effective instruments to preserve and enhance urban biodiversity in large scale.

Also, large scale green spaces inside the city has significant role on improving biodiversity. The reason is that small parks or green areas are scattered inside the cities without connectivity to other green spaces. So, they can have slight contributions to preserving biodiversity in urban area (Figure 6).

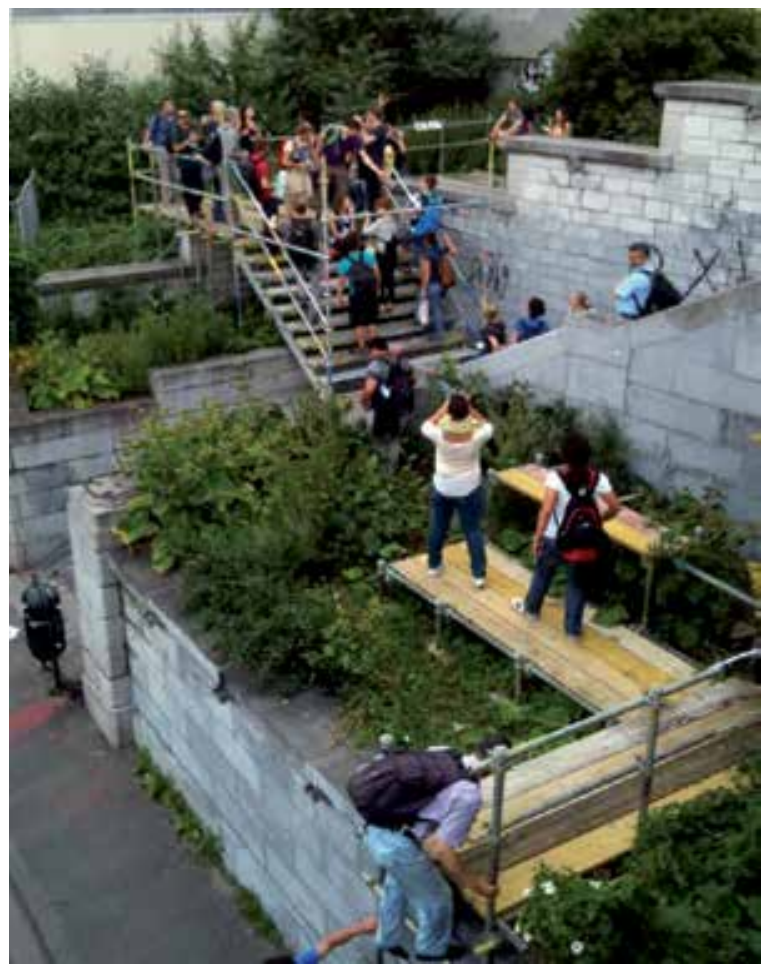

(photo from Brussels taken by Oguz Yilmz).

Figure 6. Low-maintenance green area design to promote urban biodiversity in small scale designed by Christine Guerard \& Almuth Bennett

Beside the green spaces, in large scale, planning and design strategies for aquatic urban habitats are so important for improving urban biodiversity. Therefore, the sustainable design, planning and management of urban streams, canals, rivers, ponds, reservoirs, lakes and other water bodies, constitutes can have significant role on aquatic biodiversity inside the cities. One of the examples for sustainable management of urban aquatic habitats is Urban Biosphere Reserve (UBR) approach in Istanbul (Tezer, 2005; Oliveira et al. 2011). 
Another important point that must be noted for preserving biological diversity in large scale is housing programs in urban areas. Designing more natural built environment to have minimal impact on surrounding landscape and existing biodiversity is a key concept in urban design according to the goals of preserving urban biodiversity. For these purpose, during the construction phase and the process following that, the cooperation of ecologist with urban planners and designers is very important to protect existing local biodiversity and improving flora and fauna diversity in future. One of the positive initiative according to these objectives is Eco-housing a program developed jointly by UNEP and UN-HABITAT, a concept of sustainable principle for entire lifecycle of a housing project. Eco-housing in urban area will have positive impacts on biodiversity conservation by reducing footprint and the environmental pollution caused by urbanization (Oliveira et al. 2011).

The concerted efforts at various scales on improving urban biodiversity can produce best results. Designing with biodiversity in mind must be an important part of sustainable design strategies at a neighbourhood level such as micro district, subdivision, housing complexes. In small scale, home-owners can take various actions for improving urban biodiversity. It is important that home owners realize that their individual effort can contribute to a larger collective effort that would culminate in the creation of a real biological corridor. Such a corridor can facilitate the movements of several species throughout the city and improve urban biodiversity (Laurence and Palmaerts, 1991; Savard et al. 2000). Plantings on balconies, in window boxes and on roofs beside promote residential gardens including decorative or vegetable gardens can have positive impact on improving urban biological diversity (Figure 7).

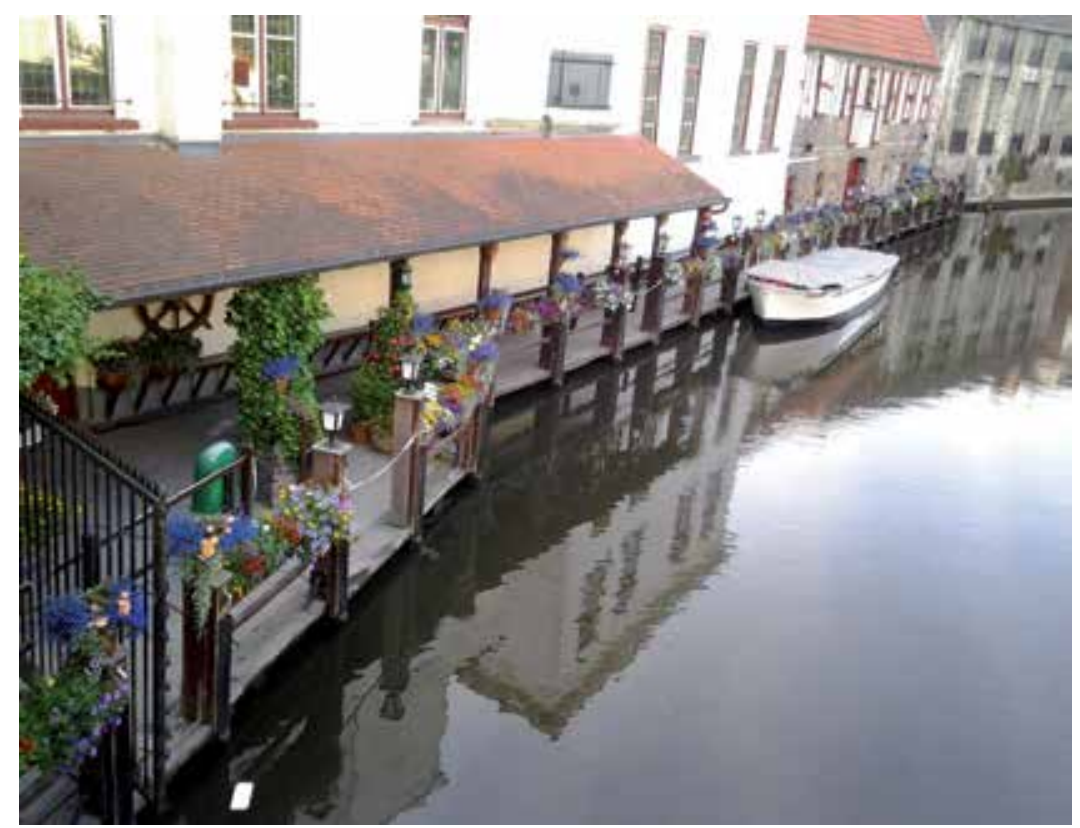

Figure 7. Flowerboxes containing various flowers diverse (photo from Brussels-Belgium taken by Aysel Uslu). 
In all large and small scale cases, the qualities of plants species used in green spaces are determinant factor for the habitat that these species provide. The reason is that these habitats encourage the particular species of animals. Generally, vegetation with a diversity of native plant species especially in areas, where land development is intensive, is recommended for increasing animal biodiversity (McKinney, 2002; Oliveir et al. 2011). For example planting trees in private gardens or cities' street provide the opportunities for improving bird biodiversity in urban area. The main problem in this case is that, after the urbanization development, most of the animals and plants do not ensure compliance with city life. But, widely use of native plants can have positive impact on improving the original habitats. Beside that, many other human efforts can help animals to adapt themselves to these new conditions. For example, by provision of artificial nesting or feeding structure inside private gardens or public green spaces in the cities, most of the birds and other animals are encouraged to live inside the city (Figure 8).

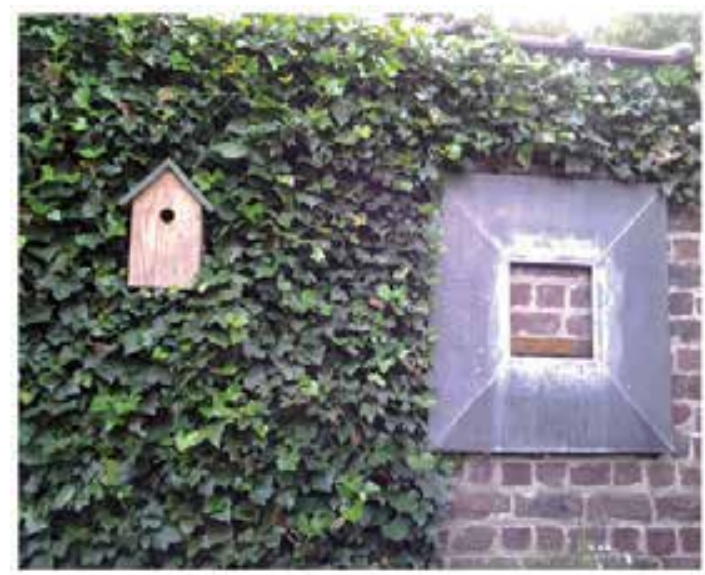

(a)

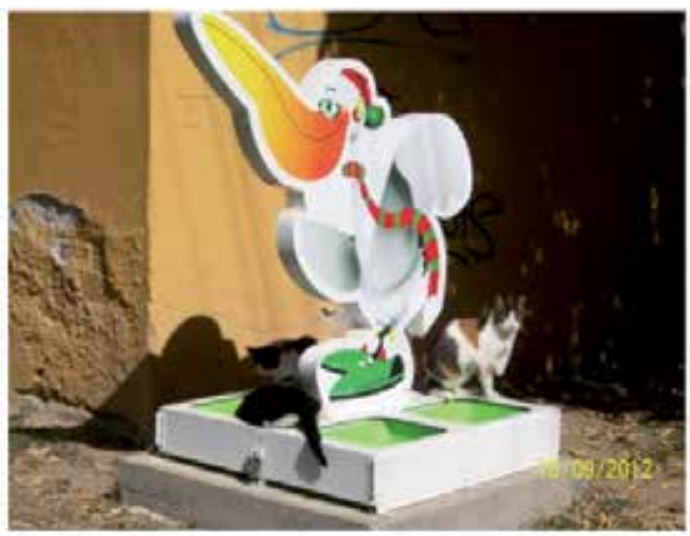

(b)

Figure 8. Artificial nesting or feeding structure for improving urban biodiversity (a) Photo from Pol Ghekiere's house garden in Belgium taken by Aysel Uslu (b) Watering cup for street animals in Izmir 
Tree planting issue is an important to promote biodiversity. Also, the maintenance of green area should promote some specific animals. For example birds use the branches of trees in their nesting season. So, cutting of these branches may disturb the life cycle of the bird and decrease the urban biodiversity. Therefore municipality or the owners of private gardens must manage their green area maintenance programs according to the biodiversity management.

One of the important opportunities for improving biodiversity in urban area is that, urban environment has potential for naturalization of non-native species. Generally the term alien species are used for these types of plants and animals coming from outside a set area. When these species adapted to their new environment, they can be able to spread and improve biological diversity of the area. Therefore particular strategies in planting design of the green areas inside the cities can help new species to be adapted and existing of these species beside the local one can help to increase the biological diversity in cities.

Most of the time in planting design of urban areas the designers utilize particular species of trees, flowers and other plants. But, diversifying plant design can support many animal species life inside the cities. For example, using different species wildflowers encourage more insects depending on the nectar feeding these insects. As a result, instead of using a small number of plants, using large number of plant species increase the opportunities for improving urban biodiversity.

Also, bringing together different types of habitats can provide shelter and feeding opportunities for wildlife, therefore can have positive impact on urban biodiversity. Combination of forest trees, shrubs and meadow can create nesting opportunities for different animals. Also, diversity in the combination of trees, shrubs, wild flowers, dead trees inside the public open areas creates more habitats for wildlife in urban areas. These rich mosaics of different habitats are attractive for urban residents too. The reason is that diversity of habitat creates different views inside the cities pleasuring the urban residents.

In addition, biological diversity usually increases in the junction point of the habitats borders. Therefore, these areas constitute habitats with different environmental characteristics. Thus, it is necessary in urban landscape design to bring different types of habitats beside each other (Figure 9). For example, Using shrubs beside the meadow area provide opportunities for life of diverse plants and animal's species.

As described above, with various methods of planting design in urban area, the biological diversity can be improved. On the other hand, there are some incorrect assumptions in urban landscape design and management that must be modified for getting better result in biodiversity improvement. One of them is that utilizing plants and vegetation having attracting fruit or seed for birds and butterfly or any other insects is not applicable in planting design of urban public open areas and parks. The reason is that, these plants and animals may cause environmental pollution that can disturb urban residents. But, the fact is that, these plants can provide habitats for birds and other animals improving urban biodiversity. Therefore, any kind of plants ensuring the life of animals and birds species 
must be identified and the methods of utilizing these plants in the urban area should be developed.

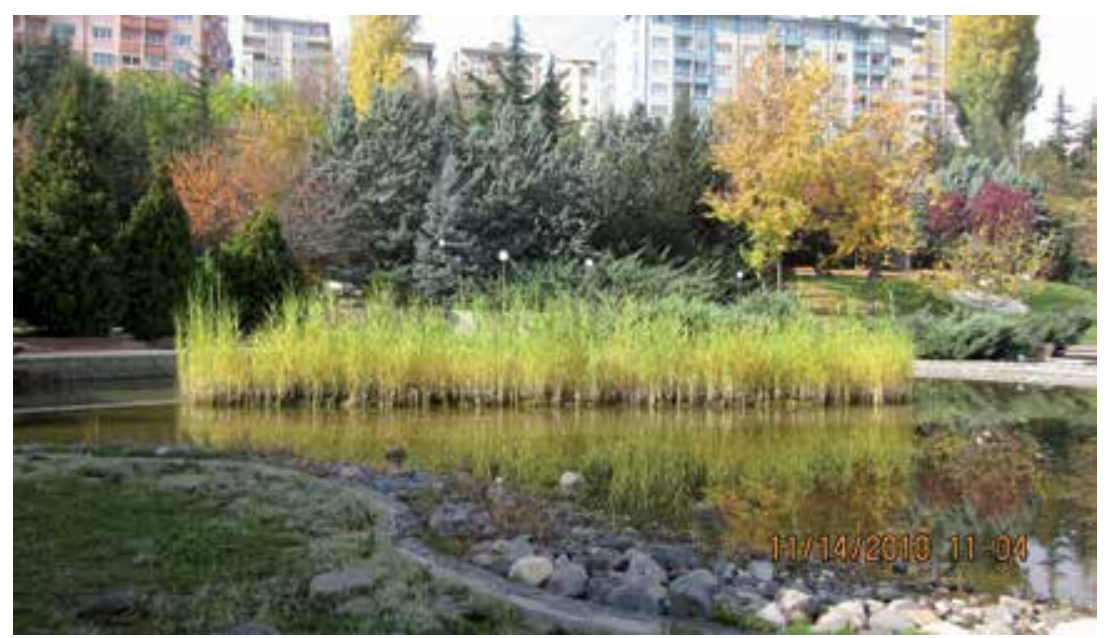

Figure 9. Bringing different type of habitats inside the urban park- Ankara(photo from Ankara-Turkey taken by Nasim Shakouri).

Besides the visible impacts of biological diversity in urban areas, after the death of animals and plants, they provide many habitats for fungus, micro-organism and degrading organisms as well. The reason is that, these corpses are nutrient for many organisms. Therefore, supporting urban biodiversity improve natural life cycle inside the cities too.

It must be noted that it is essential in urban landscape planning and design to make biodiversity more viable, more visible and sensible for urban residents (Figure 10). By engaging with those who design the places where people live and work, human habitats can be modified to places providing life requirements for wild species, a form of conservation biology that calls 'reconciliation ecology'(Rosenzweig, 2001, Rosenzweig, 2003; Miller 2005). These efforts can restore the human connections with the natural world by closing the places where people live and work to the places having the potential for improving urban biological diversity, increase public environment awareness and facilitate participation of urban residents in preserving urban biodiversity.

Another way for reproducing urban biodiversity as well as restoring human connection with nature is urban agriculture program in public lands. According to these programs, urban open areas are used for production of organic food while contributing to environmental education of local residents. These methods can improve biological diversity by creating spaces for growth of various species of plants inside the city. Also, it contributes urban residents to participate in agriculture activities that increasing plant cultivation and preservation knowledge. For better result, urban government, planners and designers must identify appreciate open places inside the cities and analyzed their potential for vegetation growth, then utilize these areas by applicable design for agriculture purposes. 


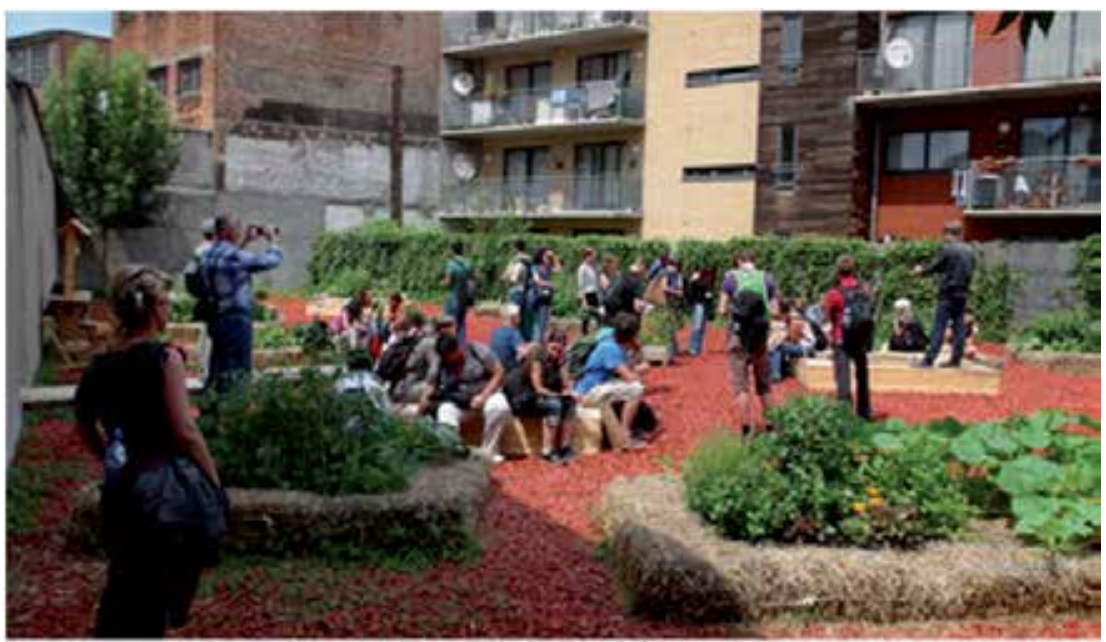

Figure 10. Biodiversity management should create benefits for poor communities and more visible and sensible for urban residents A sample of edible landscape design in urban area Belgium.

Finally, it must be noted that, creation and improvement of urban biological diversity processes require time. Therefore, the programs and design methods should be based on characteristics of the local ecology considering the time required for each stage. Also, it must be highlighted that, to be successful in conserving biodiversity, the value of nature in public mind must be made clear. Also, by using different levels of environmental education, government raises environmental awareness of urban residents to ensure the next generation life in cities. The reason is that most of the biological diversity restoration and improvement work would not have been possible without the participation of volunteers and urban residents (Figure 11).

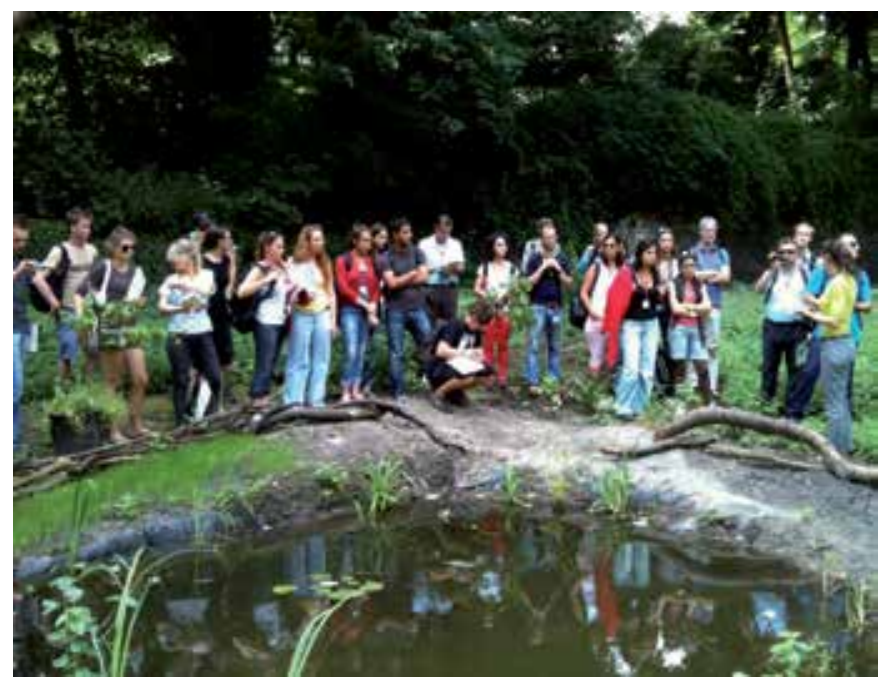

Figure 11. Promoting awareness of biodiversity to local communities (photo from Brussels in Belgium taken by Oguz Yilmaz) 
In addition, the establishment of networks for city governments, scientific and researchers is essential for cooperation, knowledge sharing, critical debate, monitoring and evaluation of the factors effecting urban biodiversity. Integration of biodiversity into urban plan should be considered.

\subsection{The conflicts in order to improvement of biodiversity in the cities}

While investigating methods and opportunities for preserving the urban biodiversity has gained importance, the challenges and conflicts of achieving these goals are more emerged. That's why, in this part, the conflicts of improving urban biodiversity is determined and discussed.

As described before, urban ecosystem is highly dynamic and beside human beings involves wildlife communities too. While the proportion of urban residents increasing, the nature and properties of urban ecosystem gain importance. The reason is that, urban ecosystem is the determining factor in quality of human life as well as other living creatures. Also, the scale and speed of urban growth is the main reason of urbanization and transformation of the spatial configuration and ecological process in urban area (Alberti 2005, Dale et al. 2000, McDonnell et al. 1997, Dramstad et al. 1996, McDonnel and Pickett 1990; Connery 2009). Therefore, planning the urban growth and applying the principles used for managing or enhancing biodiversity not only can be effective in increasing the quality of human life but also can have positive impact on natural life diversity in urban ecosystem. This section investigates the difficulties and challenges in enhancing the urban biodiversity from different points of view.

Nowadays, the words 'nature' and 'biodiversity' remained images of areas that are located far from the cities. For many people these areas are places that are unaffected by human impact. Therefore, when the concept of biodiversity is discussed in urban area, the idea of preserving and improving urban biodiversity is not familiar for them. The reason is that over the years as the urbanization expands, human being grows more and more distinct from the natural world. So, the wedge between people and nature is driven deeper. Miller research (2005) indicates that people spend most of their daily life for indoor activities. It is not applied just for adults but also it is a tendency for children to spend fewer hours outdoors as well.

The fact is that, the environment encountered during childhood becomes the baseline against which environmental degradation is measured later in life. Therefore, one of the fundamental solutions for preserving urban biodiversity is to bring people closer to the nature beginning from their childhood and give the opportunities for recognizing the natural values to preserve them in future (Figure 12).

In addition to these, there is still lack of environmental awareness. People do not understand the importance of the natural biodiversity of their region. For example, trees that are established in natural areas and buffers may be cut down by adjoining residents because of facing conflicted values such as the trees interfering with their "view" (Hostetler at el. 2011). 
Raising the awareness of biodiversity is an important part of maximizing urban biodiversity conservation.

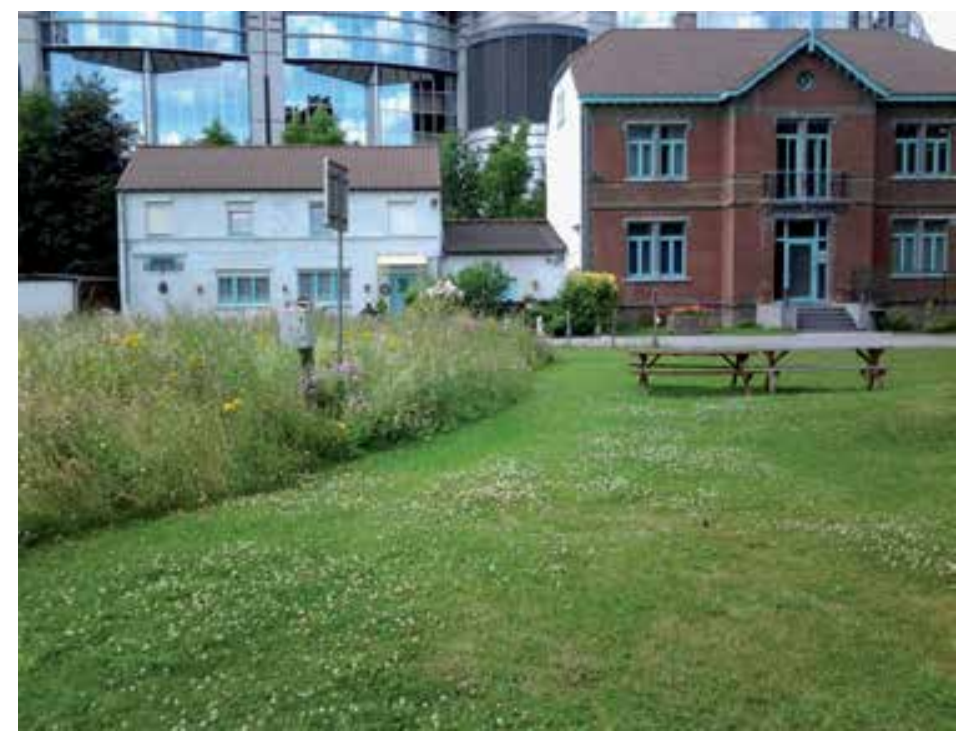

Figure 12. Creating natural areas inside the cities can be effective for bringing together urban residents and nature (photo from Brussels-Belgium taken by Aysel Uslu).

Furthermore, most of the time the urban residents don't perceive the attempts by planners and scientists to protect nature in urban environments (Breuste, 2004; Oliveira et al. 2011). Therefore, they don't participate in the implementation of the strategies for improving biodiversity. The major problems especially appear when the government and urban planning neglect the principle of urban biodiversity preservation and improvement in their urban planning and design strategies.

The other problem relating to preserving urban biodiversity is misperception the concept of natural areas that are protected inside the cities borders. Most of the people believe that these areas are squalid and unsafe regions for residents (Figure 13). Therefore they prefere these areas have particular design and form such as urban park. It is not a problem for residents but also most of the urban planners and municipalities officials have the same idea. Therefore, environmental education and defining the value of natural biodiversity is vital for straighten of this incorrect opinion.

Another problem related to human behavior, is that people do not know about the native species and they unconsciously influence the spread of non-native species. Urban ecosystem makes opportunities for growth and the replacement of native species with alien (nonnative) species (Mckinney 2002; Oliveira et al. 2011). Heightened air and surface temperature in urban areas compering to surrounding areas create new habitat in urban ecosystem. Consequently, this modification in habitat type can make opportunities for nonnative species to growth and disperse. Also it has a homogenizing effect on biodiversity as native habitats (McKinney and Lockwood 1999, McKinney 2002; Miller 2005). Urban-rural 
gradient research in many cities emphasized that the number of native species decreases in central parts of cities, where the ratio of built spaces to green spaces and the proportion of impervious surfaces are high (Zerbe et al., 2003, McKinney, 2002; Oliveira et al. 2011). Also, most of the native species that remain in cities have tendency to be segregated from the neighborhoods where most of the human residential areas are located (Turner 2004; Miller 2005). In a research on the conservation value of clustered subdivisions, the result indicate that plant community within the open space was dominated by exotics because these areas did not have proper land stewardship to maintain native plant communities (Lenth et al. 2006; Hostetler et al. 2011).

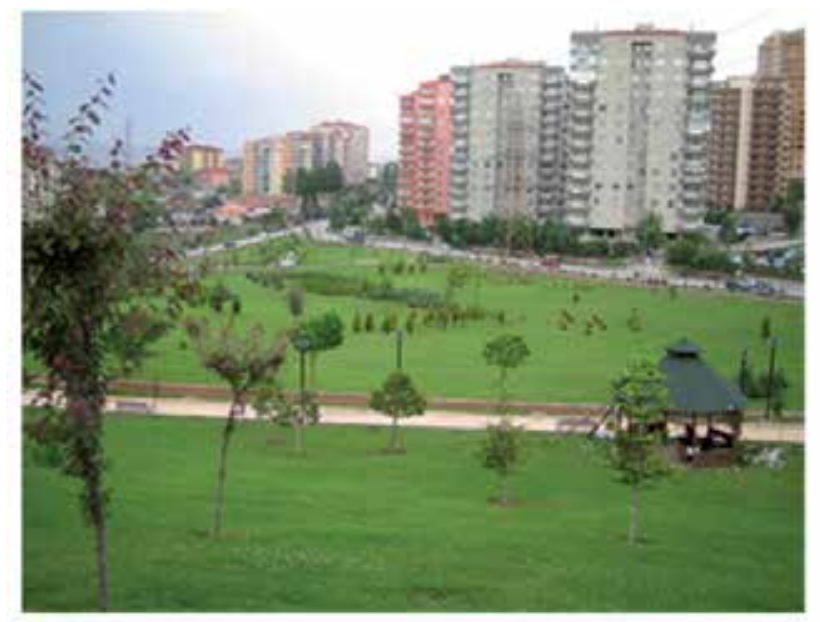

(a)

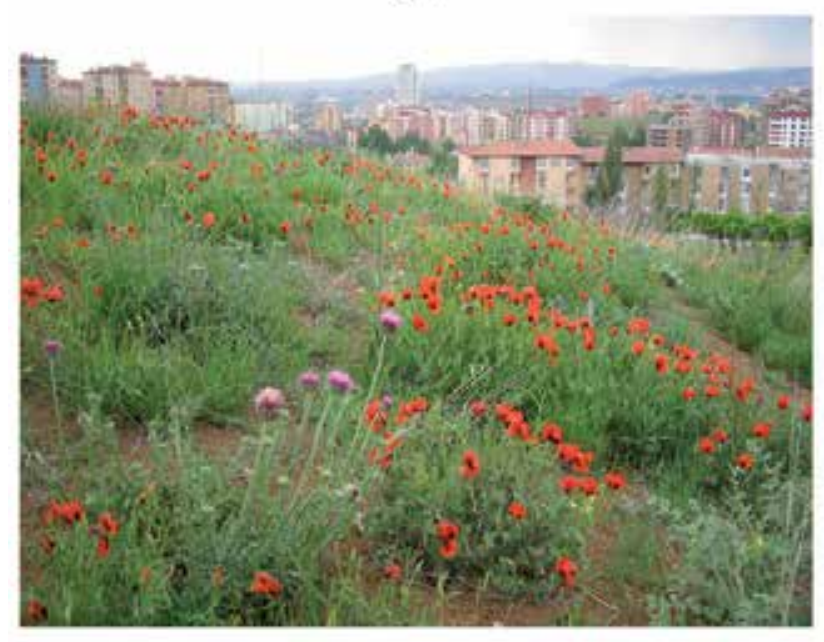

(b)

Figure 13. Residents prefer the condition of photo (a) inside the cities. However, preserving the local biodiversity on (b) is more sustainable (photos taken by Aysel Uslu from Ankara-Turkey). 
As a result, the increase in the number of non-native species in cities causes recognition of these species as native species by many people and shapes the people's view about native biodiversity incorrectly. Therefore, when the concept of preserving urban biodiversity is discussed, most of the people misunderstand this concept. For figure out such problems, considering the dynamic of urban ecosystem, the native species of every urban region must be identify and document, to prevent the unexpected result of non-native species distribution.

The other challenge relating to distribution of non-native species is hazards of invasion of aggressive species. In recent years, several Scientifics have discovered that increasing urbanization results in large proportion of existing plant species in urban areas being replaced by small number of wide spread and aggressive species. In some regions of the world, most of the invasive spices are non-native, which were first introduced into cities where they got established and naturalized, and spread. Thus, cities were the principle starting points from where many of these aggressive species spread (Muller et. al 2010).

Also it should be noted that many other factors can have unfavorable impact on native species. For example, storm water runoff can contain an excessive amount of nutrients, causing algal blooms in water bodies, fish kills, and the growth of invasive exotic plants. Therefore, urban planners must consider these hazards and manage them in such a way that the native species gets least vulnerability.

The other perception by urban resident related to biological diversity is the hazards of the illnesses causing by birds for human. Therefore most of the urban residents do not want to share their daily life environment with the birds or other animals. In these cases, urban inhabitant's behavior may influence the life of animals and birds adversely.

In addition to human behavior, biodiversity loss can be linked to the urban planning or lack of it. The fact is that, there is still a lack of proper instruments to deal with biodiversity at the city level.

Cities originally include natural areas with native flora and fauna. From the biological point of view these natural areas contain greater biodiversity than plantations (Mcdonnell, 1988; Gilbert, 1989; Florgard 2010). A critical problem relating these areas is that if the native vegetation lost, it can't be replaced by planting replacement species (Florgard 2010). However in most of the city planning strategies in developing countries this issue is ignored. As a result, fragmentation of the natural areas has occurred and causes the loss of native species.

Also, in most of the developing countries the need for housing put stress on surrounding ecology and cause unplanned and informal city plans. These plans have negative impacts on highly biodiversity ecosystems such as forests and mangroves. Rio de Janeiro is one of the top examples for this type of urban biodiversity loss. Research shows that the city lost a large part of its forests and mangroves due to the expansion of favelas (slums). Approximately $9 \%$ of the sandbank mangroves were lost during the last 3 years alone (Rocha et al., 2010; Oliveira et al.2011). 
This situation in developed countries is not better than developing country. Suburban lifestyles by middle- and high-income groups in developed and developing countries caused the urban sprawl and suburbanization. Due to the increasing spread of suburban housing the rate of structural areas to the lands preserved as parks or conservation areas is accrued (Oliveira et al. 2011).

The reports of the Secretariat of the CBD (Convention on biological diversity) indicate that many of the fundamental threats to biodiversity loss in cities associated with public services and infrastructure planning and design policy that local government are responsible for these loss (SCBD, 2007; Savard et al 2000). Therefore, making the right decision in urban planning and design polices can preserve urban biodiversity as well as restoring the losses. Establishing extensive biotope and habitat mapping and protection programs will have positive impact on identifying important areas of wildlife habitat in and around cities and protecting and enhancing these areas. Also, coordination among different levels of government and among local governments for joint action is vital for getting better result. Furthermore, addressing the residential issues is vital for controling the cities' ecological footprints. Also, polices of urban development must focus on compact urban forms and strong housing management to avoid the urban biodiversity losses.

Another issue must be underlined is that the process of urbanization influences habitats of species typical of open landscape adversely. Also, few local governments establish planning frameworks and implementation strategies through preserving urban biodiversity. For example, in central Europe, change in land use caused decrease in calcareous grassland belongs to the habitat types with the highest species richness (Joas et al. 2010). Therefore, maintaining high-quality natural areas in urbanizing regions or preserving natural areas containing high levels of biodiversity will require many municipal governments to change their perspectives and improve their urban planning according to the goals of urban biodiversity preservation and improvement.

Also, it must be highlighted that, planning open spaces and greenways are not luxury. However, they are the essential for preserving urban biodiversity and making connection between habitats with different species. Fortunately, in North America some local governments have begun to preserve and improve the urban biodiversity in their planning framework based in large part on Landscape Ecology's patch-corridor-matrix principles (Forman 1995; Connery 2009).

Finally, it must be emphasized that the researches and studies about urban biodiversity are still inadequate and limited. Generally, most of the studies analyses focus on only one or a few groups of species (e.g., Scott et al. 1993, Sisk et al. 1994; Ricketts and Imhoff 2003). Therefore, the authors evaluate data without considering the role of other species and the features of their habitat on the growth and distribution of the sample species. As a result the methods of preserving and improvement of the species community is not comprehensive and applicable. Also, many assessments include subjective information to measure threats to 
biodiversity (Olson and Dinerstein 1998, Ricketts et al. 1999, Myers et al. 2000; Ricketts and Imhoff 2003). Thus, the results cannot be applied in the actual conditions.

However, urbanized areas function within a hierarchical decision system, managing is key concept for extending biodiversity. It must be highlighted that every nation is responsible for its own characteristic biotopes and species. Thus, the development plans of cities definitely affect biodiversity conservation and improvement. Therefore, for getting best result in conserving biological diversity; all issues related to urban biodiversity should be considered. Also, the importance of local biodiversity must be emphasized until then, with the cooperation of residents, scientific and governments, sustainable solution and plans will be emerged.

Biodiversity is not only an issue of the quantity of species and their habitats, but of the quality of areas and processes. This relates very much to the local scale because much of biodiversity's quality exists in its locality, referred to as in situ biodiversity. Biodiversity existing in its natural setting is considered most valuable, as opposed to specimens in zoos and botanical gardens. For instance, an assemblage of plants and animals that has occurred in an area for millennia may not have a comparatively high number of species, but may have special characteristics as an integrated system together. Targeting single species is nonetheless often an easier task for cities (Zitkovic 2008).

Finally, urban landscape design issues must have been considered ecological objective; protecting environment and our planet in contemporary world. It must be noted that the quality of landscape design must depend on the quality of green areas as a habitat. Urban green areas and landscape design should contain the subjects of landscape ecology knowledge which have been successfully implemented in reality.

\section{Author details}

Aysel Uslu and Nasim Shakouri

Ankara University, Faculty of Agriculture, Department of Landscape Architecture, Turkey

\section{References}

Alberti, M., Marzluff, J. M., Shulenberger, E., Bradley, G., Ryan, C., Zumbrunnen, C., 2003. Integrating Humans into Ecology: Opportunities and Challenges for Studying Urban Ecosystems. BioScience, Vol. 53, No. 12 (Dec., 2003), pp. 1169-1179.

Angold, P.G., Sadler, J.P, Hill, M.O., Pullin, A., Rushton, S., Austin, K., Small, E., Wood, B., Wadsworth, R., Sanderson, R., Thampson, K. 2006. Biodiversity in urban habitat patches. Science of the Total Environment 360 (2006) 196- 204.

Barış, M.E. Shakouri, N. Zolnoun, S. (2012). Green roof: the suggestion project of Ankamall commercial building. Journal of Tekirdag Agricultural Faculty 2012 9(1) - 33-44. 
Beatley, T. 2000. Green urbanism learning from European cities. Island Press, 2000 - Business \& Economics - 491 pages.

Benedict, M. A. \& Macmahon, E.T.2002. Green Infrastructure: Smart Conservation for the 21st Century, Renewable Resources Journal, Volume 20, Number3, Autumn 2002, Pages 12-17. Maryland, USA.

Bolund, P. Hunhammar, S. 1999. Analysis Ecosystem services in urban areas. Ecological Economics 29 (1999) 293-301.

Colding, J. 2007. Ecological land-use complementation' for building resilience in urban ecosystems. Landscape and Urban Planning 81 (2007) 46-55.

Connery, K. (2009) Biodiversity and Urban Design: Seeking an Integrated Solution. Journal of Green Building: Spring 2009, Vol. 4, No. 2, pp. 23-38.

Cook, E. D. 2002. Landscape structure indices for assessing urban ecological networks. Landscape and Urban Planning 58 (2002) 269-280. doi: http://dx.doi.org/10.3992/jgb.4.2.23.

Dunnett, N. Swanwick, C. and Wooley, H.2002 Improving Urban Parks, Play Areas and Open Spaces, Urban Research Report, DTLR,, May 2002.

European Communities, 2008. The European Union's Biodiversity Action Plan. "Halting The Loss of Biodiversity by 2010 and Beyond" http://www.europea.eu.

Florgard, C. 2010. Integration of natural vegetation in urban design- information, personal determination and commitment. Urban biodiversity and design $1^{\text {st }}$ edition. Edited by $\mathrm{N}$. Muller, P. Warner and John G. Kelcey. (C2010 Blackwell Publishing Ltd.

Flores, A. Pickett, A. Zipperer, S. Pouyat, W. Pirani, R. 1998. Adopting a modern ecological view of the metropolitan landscape: the case of a greenspace system for the New York City region. Landscape and Urban Planning 39-1998. 295-308.

Francis R. A. 2010. Wall ecology: A frontier for urban biodiversity and ecological engineering, Progress in Physical Geography 2011 35: 43 originally published online 18 November 2010. http://ppg.sagepub.com/content/35/1/43.

Goddard, M.A. Dougill A.J. Benton, T.G. 2009. Scaling up from gardens: biodiversity conservation in urban environments. Trends in Ecology and Evolution Vol.25 No.2

Haase, D. \& Schetke S. 2010. Potential of biodiversity and recreation in shrinking cities: contextualization and operationalization. Urban biodiversity and design $1^{\text {st }}$ edition. Edited by N. Muller, P. Warner and John G. Kelcey. (C2010 Blackwell Publishing Ltd.

Hagen, K. Stiles, R. 2010. Contribution of landscape design to changing urban climate conditions. . Urban biodiversity and design $1^{\text {st }}$ edition. Edited by N. Muller, P. Warner and John G. Kelcey. (C2010 Blackwell Publishing Ltd.

Hostetler, M., Allen, W., Meurk, C. 2011. Conserving urban biodiversity Creating green infrastructure is only the first step. Landscape and Urban Planning (2011), doi:10.1016/j.landurbplan.2011.01.011.

ICLEI. 2008. Partnerships \& networks for urban biodiversity. Local and regional Authorities for biodiversity 2010. 
Ignatieva, M. Design and Future of Urban Biodiversity. Urban biodiversity and design $1^{\text {st }}$ edition. Edited by N. Muller, P. Warner and John G. Kelcey. @2010 Blackwell Publishing Ltd. 118-144.

Joas, Ch. Gnadinger, J. Wiesinger, K. Haase, R. Kiehl, K. 2010. Restoration and design of calcareous grasslands in urban and suburban area: examples from the Munich plain. Urban biodiversity and design $1^{\text {st }}$ edition. Edited by N. Muller, P. Warner and John G. Kelcey. (C2010 Blackwell Publishing Ltd.

Kendle, T . 1997.Urban Nature Conservation: Landscape Management in the Urban Countryside, E and F Spon.

Kohsaka, R. 2010. Economics and the convention on biodiversity: financial incentives for encouraging biodiversity in Nagoya. Urban biodiversity and design $1^{\text {st }}$ edition. Edited by N. Muller, P. Warner and John G. Kelcey. (C2010 Blackwell Publishing Ltd.

Mcdonald, R. Kareiva, P. Forman, R.T.T. 2008. The implications of current and future urbanization for global protected areas and biodiversity conservation, Biological conservation 141.

Miller, J. R. 2005. Biodiversity conservation and the extinction of experience, TRENDS in Ecology and Evolution Vol.20 No.8 August 2005.

Muller N., Werner p., Kelcey J.G. 2010. Urban Biodiversity and Design. John Wiley \& Sons, Mar 5, 2010 - 648 pages.

Muller. N. 2007. Distinctive characteristics of urban biodiversity. Cities and Biodiversity: Achieving the 2010 Biodiversity Target". Curitiba, 26. - 28. March 2007.

Müller, N. Most Frequently Occurring Vascular Plants and the Role of Non-native Species in Urban Areas - a Comparison of Selected Cities in the Old and the New World. Urban biodiversity and design $1^{\text {st }}$ edition. Edited by N. Muller, P. Warner and John G. Kelcey. (C)2010 Blackwell Publishing Ltd. 227-242.

Niemela, J.1999. Ecology and urban planning. Biodiversity and Conservation 8: 119 \pm 131 , Kluwer Academic Publishers. Printed in the Netherlands. 1999.

Oliveira, J.A., Balaban, O., Doll, C.N.H., Peñaranda, R. M., Gasparatos, A., Iossifova, D., Suwa, A. 2011. Cities and biodiversity: Perspectives and governance challenges for implementing the convention on biological diversity (CBD) at the city level. Biological Conservation 144 (2011) 1302-1313.

Opdam, P. 2002. Assessing the Conservation Potential of Habitat Networks, in gutzwiller, K.J., (ed). Applying Landscape Ecology in Biological Conservation, Springer(2002), p.381.

Qureshi, S. \& Breuste, Jurgen H. 2010. Prospects of biodiversity in mega city of Karachi, Pakistan: potentials, Constraints and implications. Urban biodiversity and design $1^{\text {st }}$ edition. Edited by N. Muller, P. Warner and John G. Kelcey. (02010 Blackwell Publishing Ltd.

Ricketts, T. and M. Imhoff. 2003. Biodiversity, urban areas, and agriculture: locating priority ecoregions for conservation. Conservation Ecology 8(2): 1. [online] URL: http://www.consecol.org/vol8/iss2/art1. 
Savard, L. Clergeaub,Ph., Mennechez, G., 2000. Biodiversity concepts and urban ecosystems. Landscape and Urban Planning 48 (2000) 131 142.

Schaefer, V. 2003. Green Links and Urban Biodiversity-an Experiment in Connectivity 2003 Georgia Basin/Puget Sound Research Conference.

http://planet.botany.uwc.ac.za/nisl/Conservation\%20Biology/Conservation_CCT/2c_sch ae.pdf.

Town and Country Planning Association, 2004. Biodiversity by Design: A guide for sustainable communities. http://www.tcpa.org.uk/data/files/bd_biodiversity.pdf

Tratalos, J., Fuller, R.A., Warren, Ph. H., Davies R.G., Gaston, K.J. 2007. Urban form, biodiversity potential and ecosystem services. Landscape and Urban Planning 83 (2007)

Vergnes, A., Le Viol, I., Clergeau, P. (2012) Green corridors in urban landscapes affect the arthropod communities of domestic gardens. Biological Conservation. 145: 171-178. Doi:10.1016/j.biocon.2011.11.002.

Yang, F. S., Freedman, B., Cote, R. 2004. Principles and practice of ecological design. Environ. Rev. Vol. 12, 2004. NRC Canada.

Werner, P. Zahner, R. Urban Patterns and Biological Diversity: A Review, Urban biodiversity and design $1^{\text {st }}$ edition. Edited by N. Muller, P. Warner and John G. Kelcey. (C2010 Blackwell Publishing Ltd. 37-55 145-176.

Zitkovic, M. 2008. Managing green spaces for urban biodiversity. Local and regional Authorities for biodiversity 2010.

http://www.countdown2010.net/2010/wp-content/uploads/FS7Greenspace_small.PDF. 


\title{
Urban Agriculture: The Allotment Gardens as Structures of Urban Sustainability
}

\author{
Rute Sousa Matos and Desidério Sales Batista
}

Additional information is available at the end of the chapter

http://dx.doi.org/10.5772/55892

\section{Introduction}

This reflexion comes from a look over the city, particularly the relationship between the built and the open spaces that constitute it. In this look we came across the enormous importance that the system of open spaces has and has always had on the construction of the city, its balance, its identity and its experience. On a closer approach to the system of open spaces of the city, we were confronted with the existence of typologically qualified spaces and of spaces without any typological attribution but that are, by no means, less important than the former. Open spaces, interstices between the built fabric of the contemporary city, that present a certain continuity and that allow the flow of air, of water and matter, simultaneously with the flow of residents or casual users. Sometimes, besides that flow, an informal appropriation of these spaces as spaces for fun, games and socializing is verified, emphasizing the enormous potential presented in the structure and cohesion of the city as support of the urban experience, of social interaction and, of the development of the sense of community. About these spaces, several questions have been raised concerning its quality and diversity, namely its lack of integration in a recognized urban typology and all the consequences that this determines. However, we considered that this fact, on its own, does not constitute a negative factor, but a distinct reality determined by the ever-accelerating rhythm of the technological, economical, social, cultural and demographic chances.

The need to understand the presence of these spaces leads us to a study and analysis of the evolution of the city and of the transformation process that has been occurring, not only in the conceptual and ideological point of view, but also in morphological terms determined by different social-economical and cultural contexts.

During this project we verified that the characteristic discontinuity of the suburbs was the result of an urban model that, since the 60's of the 20th century, has given birth to a new concept of city and, in a disorderly growing process, allowed a landscape of problematic 
suburbs to arise, anarchically, in an unqualified territory. The interstices over which we lean are the consequence of this extensive growth of cities and its suburbs.

Aware of the existence of these unnamed intervals, in the city, the open space continues, frequently, to be called green and to, still, play a secondary role on the construction of the urban landscape. Despite its high potential in the structure and cohesion of the city, these spaces - the interstices and the greens - and the attitude of indifference that has been verified towards its qualitative definition tends to reduce them to nothing more than another index in the city's statistics.

Thus, it is necessary a new understanding on the urban condition of the interstitial spaces and on the importance of the quality of the landscape. We consider fundamental to implement an intentional and adequate use of these spaces, as a vital condition to its defense, in a positive way, guaranteed by its comprehension and enjoyment, recognizing them as the true potential to the development and experience of the city. They should, then, be acknowledged as spaces of urban cohesion, fundamental and complementary to the built space and its articulation with the surrounding, ecologically, aesthetically, culturally, socially, economically and technologically.

With the purpose of obtaining a bigger understanding on the quality of the landscape, and based on the idea that this should appear as a fundamental structure and a cornerstone on the qualification of the city, we leaned on its inherent multifunctionality.

From here starts the conscious notion that the landscape is a recent conquest in the western culture, being considered as such from the moment Man inscribes it in a determined culture and epoch. Intrinsic to the concept of landscape come the concept of multifunctionality to which the concepts and the practices of production, leisure and protection have always been associated. However, this dimension and multifunctional look are lost with the modern movement where, the sectoral zoning does not allow the coexistence of several roles thus appearing the vague concept of green space, that stretches throughout the entire city homogeneously, amorphous and residually.

It becomes, then, urgent and primordial the return to that concept of landscape. Several authors, searching for new strategies that lead to the multifunctionality of the landscape and its understanding, defend that in the open spaces of the city it should be implanted a continuous and structuring fabric where landscape would appear as a fundamental structure of this continuum, having as a principle the systemic vision of the landscape, long implicit in practice and in the philosophy of landscape architecture, from the continuous system of public parks designed by Olmsted, to the concept of continuum naturale, introduced and developed, in Portugal, by Professor Caldeira Cabral, in the middle of the last century, covering all the projects that include the concepts of green corridors and of green or ecological structures, all of them essential, since they allow the occurrence of ecological processes, fundamental to the growth and sustainable development of the city.

As well in the recent current, designated as Landscape Urbanism (1996), that appears with the rekindle of environmental and ecological concerns, such as the growth of tourism and the questions connected with it, with the sense of oneness and entity, as well as with the impact 
that the massive growth of cities has over the rural space, the landscape is proposed as model to the urbanism, and it is recommended the integration of public landscapes with the infra-structural systems, formalizing and leading the urban development, similarly to what happened with Central Park in New York and the continuous system of the Boston Parks by Frederick Olmsted, where the landscape lead the process of the formation of the city.

In this search for the lost multifunctionality it is frequent the reference to the aesthetic, social, ecological, economical and cultural components and consequently, the role of protection, production and leisure.

It then begins to take shape, in this study, the idea of production associated with leisure as a fundamental component of landscape that structures, qualifies, and gives continuity to the urban fabric through its interstitial spaces, open spaces and suburbs, all the way to the countryside, promoting an articulated relationship between this old city-countryside dichotomy.

Our main purpose is the proposal of a new project approach that provides the creation of a multifunctional structure of landscape dedicated to production and leisure in an urban context. In this perspective, the interstitial spaces, object of this study, can and should be a current expression of the landscape continuum, given that it allows the occurrence of the ecological processes and of the fundamental biological cycles to the harmonious and balanced development of the city.

This desideratum is accomplished, or can consubstantiate itself, through urban agriculture, which is perfectly compatible with recreational and leisure activities, as has been long advocated by Ribeiro Telles, and it is even proposed in his "Plano Verde de Lisboa" Lisbon's Green Plan [1]-, and how it has been proved by the "quintas de recreio" (recreational farms), in Portugal.

Although urban agriculture refers, in general, to activities connected to the production of fresh vegetables in the city, it does not mean that it has to be strictly related with production; urban agriculture is also fundamental on including ecological, cultural, recreational and aesthetic concerns, related to the landscape. This means, urban agriculture can integrate, and be, a structuring continuum that assures the occurrence of the processes and flows of the various systems that constitute the landscape. This structure should be ecologically justified, as well as it should be developed according to the holistic view that the landscape demands in and for its understanding. In it, there should be present the ecological, aesthetic, social, economical and cultural components and from it there should result spaces and economical, social, cultural, aesthetic and ecologically balanced structures.

Urban agriculture can be based in the ecological principles of life and on the necessary space to process its actions, reactions and interactions. It can be considered, even, as other elements of the urban infra-structure: wide and complex, and demanding planning and design, management and maintenance. This means, it is perfectly compatible with the holistic concerns of landscape architecture.

In this sense, urban agriculture is considered, in this study, in its several dimensions ecological, cultural, social, economical and aesthetic - as a constituent of the natural and 
cultural continuous that structures the urban and suburban fabric, through its open spaces and interstices, making the articulation and establishing an inter-relationship with the countryside.

We consider that this option is based on three pillars: one with a historical and temporal character - the multifunctionality (promiscuity) of the Mediterranean landscape, from which the meridional Portuguese landscape is a part; another of a conceptual and practical character, that concerns the theory and the praxis of landscape architecture and of the landscape urbanism; and lastly, in our own opinion, the answer that may be given by the urban agriculture to the global crisis situation and to the growth of the estimated urban population (already felt) in the next decades, which lead us to approach the theme of urban agriculture in a more general way.

According to Food and Agriculture Organization (FAO) (2009), for the first time in the history of humanity, there is a bigger concentration of population in the cities than in the countryside. This urbanization process determines big challenges to the planning, management, maintenance and conservation of the urban areas.

In the beginning of the third millennium we inhabit a world with an unprecedented number of population. There are currently around 6.3 billion people, a number that it is expected to rise to 9 billion, in 2050 (FAO, 2009). Around half of the world population lives in cities, and this estimation is expected to rise to two thirds by 2030. A great number of cities grow over agricultural terrains, a fact that certainly reduces the capability to produce a considerable amount of the food necessary to the auto-sustainability of the city. It is estimated that if the developing countries follow the western lifestyle - in terms of the usage of food, forest and energy products - three whole planets will be needed. It is, then, of crucial matter that the city becomes much more efficient in the way it utilizes its resources, which includes, obviously, the production of food. Urban agriculture constitutes, in this case, a fundamental contribution to the auto-sustainability of the city. Moreover, urban agriculture will be a practice that won't compromise uses or future options, thus becoming a guaranty of soil preservation, a scarce and fundamental resource.

This chapter is centered on the theme of urban agriculture, namely its definition, identification and characterization, emphasizing three of its typologies based on relevance and inclusion in the objectives of this study. They are: the urban allotment garden, the continuous productive landscapes and the urban field. In this context, we leaned over its relevance and the need in the contemporary city when facing the current social-economical crisis and the estimated urban growth in a near future. The benefits that can be brought and the obstacles that can occur are presented, either at a food and nutritional safety level, either at a health and local development level, or even at a social-cultural and urban environmental management level. The politics that regulate urban agriculture in its social, economical and ecological dimensions are addressed, and how it has influenced its practice, as well as the economical issues associated. We considered fundamental the study of agriculture throughout history and its evolution in the city, its relationship with the countryside, as well as the possibility of its integration in the interstitial urban spaces and, 
consequently the relevance of its contextualization, in the landscape urbanism, something that it is not the happening today.

Lastly, we concluded with the proposal of integrating urban agriculture in a new approach to the landscape design in an urban context, but also in conceptual terms. And, with the presentation of strategies to the development of a sustainable urban agriculture, in order to contribute to a return to the multifunctionality of the landscape, which promotes the existence of a structure of continuous landscape where the recreation, the production and protection should be present and inseparable, thus contributing to urban sustainability.

\section{Materials and methods}

The clear relevance of the presently discussed subject, namely the existence of open spaces in the city, and the need to revitalize its periphery, the multifunctionality of landscapes, the concept of landscape as structure, and the pertinence of agriculture through the creation of allotment gardens, has led many authors from different fields to produce literature, critical studies, and research on these important matters. Our theoretical support are those authors who consider open spaces and urban voids as work material, full of potential and value for the creation of new socially, culturally, economically, ecologically, and aesthetically viable spaces, as well as those studies centered on the best tools to act on the urban voids, as urban resources. The rigid building fabric rejects these manageable, flexible spaces, which are highly adaptable, in constant change, and well articulated with the different systems of city, and its design.

In recent years, there have been some studies both on the importance of landscape in urban spaces, and on the ecological systems and their associated aesthetic issues. Some studies and projects have also been done on urban agriculture and its pertinence, ecological integration and significance as network, system, and infrastructure.

Therefore, this project is based on a bibliographical review of theoretical studies about the themes we seek to develop, and about the proposition of Plano Verde de Lisboa, which includes many interventions on the landscape architecture integrating the design of the development of allotment gardens.

\section{What is urban agriculture?}

Where human beings exist, there is an associated food market. To the eyes of planners, architects, politicians and investors, to practice agriculture in the city was considered all over the world, and mainly in the previous century, a practice not to be done or to be simply ignored. However the production of local food was always quite popular appearing, frequently, in confined spaces given that those with access to land and water would do it, independently of the political restrictions. Recently, researchers, politicians, urban planners and landscape architects have given it a growing importance - turning a neglected activity, in the last seventy years, in a great potential to create forms of sustainable subsistence. 
If we look to the history of agriculture, in the European context, many have considered agriculture and city in a different way. However, according to several authors this does not correspond to reality. ${ }^{1}$

Urban agriculture always existed. As we know, the first human settlements are located near fertile and arable land to assure a close food source. As cities grew, they were occupying those agricultural lands, necessitating, consequently, of more sources of food.

The definition of urban agriculture in [2], classical and widely used, refers that "urban agriculture is an industry located inside or in the outskirts of the city, the growth of which, processes and distributes a diversity of food and other products, widely re-utilizing human and material resources, products and services found inside and in the outskirts of the urban area, and providing, in turn, material and human resources, products and services to that urban area".

This definition articulates production in confined spaces, related economical activities, localization, destination markets (or just for the consumption inside the house) and the types of products made in a dynamic interaction that may vary from one urban area to the other. Urban agriculture does not only present research associated to the natural sciences (agronomy, pollution, water and soil quality, among others), but also important questions of social and economical nature (land markets, migration from the rural space to the urban and social integration among others. $)^{2}$, not counting the questions associated to urban planning and the architectures.

Also according to [3], urban agriculture can be defined as the cultivation of plants and the raising of animals with food purposes, inside and around the cities including, even, other uses and activities related such as the production and the delivery of inputs, and the processing and commercialization of the products. Urban agriculture is located inside or in the outskirts of the city and it comprehends a variety of different production systems, different from the subsistence production, processing, at the level of the aggregate, a completely commercialized agriculture. ${ }^{3}$

This activity is generally characterized: by the proximity to the markets, by a high competitiveness for the land, by being a limited space, by the utilization of organic resources namely solid organic residues and residual waters, by having a low degree of organization, by its products being mainly perishable, and by having a high degree of specialization, among others. Due to the provision of perishable products such as vegetables, fresh milk, and poultry products, urban agriculture complements, to some extent, rural agriculture and heightens the efficiency of national and regional food systems.

\footnotetext{
${ }^{1}$ Henri Bava, Joaquin Sabaté, Pablo Arias Sierra, Pierre Donadieu and Ribeiro Telles, among others, argue the coexistence and the simultaneous development of both.

${ }^{2}$ Currently, the research on urban agriculture is also applicable to the study of politics and is offered as an answer to the technocratic vision of the way of planning and legislating.

${ }^{3}$ The population capacity to generate income is necessary and profoundly satisfactory. Using the surface, and the land itself, is one of the most ancient ways of generating income, mainly under the form of food production. It also allows the so much desired work in and with natural conditions.
} 
In [4] is referred that the most important characteristic that distinguishes urban agriculture from any other kind of agriculture, is not so much the location, but the fact that it constitutes a part of the urban economy and the ecological and social systems: it utilizes urban resources (land, work, solid organic residues and water); produces for the citizens; it is strongly influenced by the urban conditions (politics, competition for the land, markets and urban prices) and causes an impact on the urban system (the effects on food safety, poverty, ecology and health).

Also in [5] urban agriculture may have place in any part of the city - in spaces of different topography, defined, or undefined typology, brown-fields, green spaces, parks, roadsides, highway slopes, in wide spaces or hidden corners. ${ }^{4}$ It can appear wherever inside the urban context, leading many cities to stimulate their multiple use keeping the spaces, inside the city, simultaneously valuable and free of buildings. In most cases it is high yielding allotment gardens where fruit and vegetables grow and, if the economical situation is tough, it can include small animals and/or aquaculture.

Peri-urban agriculture is the agriculture that occurs in the urban-rural borderline or in low density sub-urban areas, similar to urban agriculture despite the size of the allotment being frequently bigger. Despite this vast coverage of urban agriculture, typologically and spatially speaking, we want to make reference to three theoretically distinct types, although perfectly compatible and complementary in morphological and practical terms.

- The first referring to urban allotment gardens, protagonist typology of the urban agriculture in the city, and that is why it stands out, and which importance should be crucial on a productive, economical, ecological, social, and recreational point of view.

- The second refers to the concept of Continuous Productive Urban Landscape - CPULs for its analogy with the concepts of Natural Continuum and Cultural Continuum, perfectly inclusive of landscape architecture in Portugal and it seems important to us from the point of view of a possible design strategy of landscape to the urban space.

- The third is the concept of urban countryside of Pierre Donadieu that implies a duality between ecology and identity, constituting necessarily an urban rurality, similarly to what succeeded with the Quintas de Recreio (Recreational Farms) in Portugal. In this concept is implied a project intentionality that we consider fundamental as a strategy to be implemented.

\subsection{Allotment gardens}

Allotment gardens are a unique contribution to urban space. It's a contribution challenging the conventional notion of urban space and of open space design. These spaces are an echo, and a memory of how the countryside might have been - a humanized landscape but with a peaceful feeling, a shared space with a touch of inner silence.

However, urban/rural conflict has been a consistent source of difficulties for urban designers because it contradicts imposed rankings of what is, or should be the urban space -

\footnotetext{
${ }^{4}$ The Continuous Productive Urban Landscapes - CPULs may appear in any space of variable shape, dimension and scale.
} 
expressed through particular notions of order and control, purity of shape, and clear limits. Still, the users and the public in general seem to prize this contradiction of rules. The feeling many people have about living, working, strolling, and bicycle riding through allotment gardens is an evidence both of their vital, psychological and physical value and of the need to involve more people in the debate about the future of these spaces.

\subsubsection{Brief historical evolution}

Food production is linked to the history of cities, since their origins [6]: the lack of an efficient transportation system and of sophisticated food preservation techniques before the Industrial Revolution inevitably meant that the population had to grow vegetables near their place of residence. In the 18th century, allotment gardens acquired a deliberate social character to compensate the rural population that had migrated to the city. The purpose of those allotment gardens was to provide a nutritional and economical safety net against unemployment or, to supplement reduced incomes. The necessity of urban allotment gardens quickly rose, occupying the city. At this point, the display and the supply of the allotment gardens was widely private and ad hoc.

At the end of the 19th century, the power and the rising responsibilities of the local governments reflected in the appearance of the first law to urban allotment gardens, in England, that required local authorities to provide allotment gardens to the workers that showed economical needs. Similar proceedings occurred in other parts of Europe, for example, the introduction of the Schrebergarten in Germany [5].

Until the third decade of the 20th century, the urban growth of food meant an important part of the city's consumption. The fresh products, legumes and vegetables came from the allotment gardens along the streams and rivers of the city. The importance of these ruralurban bonds transcended the merely economical plan and the environmental issues that today we are faced with.

The former allotment gardens' zones started to be occupied with highways, residential areas, railroads and other infra-structures necessary to the growth of the city. ${ }^{5}$. Throughout the ages transformations to the agricultural activities in the urban areas occurred as a result of the new industrial culture of the cities as well as of speculative interests associated with the improvement of transportation that allowed a quicker and more economical supply of the central markets. At the same time, the contamination of the waters of the rivers by the industry represented one of the greatest ecological catastrophes resulting in the abandonment of the agricultural activity in urban areas.

\footnotetext{
${ }^{5}$ Metropolization is the major cause of the loss of agriculture in the city. Attests to the supremacy of the terciary function: commercial, financial, of decision and of command; it depends on a modality of urban growth founded under the automobile, under the consentment of the urban public administration and, consequently, under the form of local government. A second series of motives is related with a negative view for sanitary reasons and public health. A third series has to do with the disadvantages to which the farmers are subjected (the incompatibility of tractors with the urban traffic, lach of irrigation water (...) [7]
} 
Between 1900 and 1945 the bigger stimulant to the production of food in Europe was the War: the real threat of famine caused by the blockages originated campaigns to increase the local food production, a lot of which was coming from urban agriculture.

During the First World War, with fear of harming the citizens' morale, the British government's campaign to increase food production, as well as the rationing, started from 1917. Despite all this, the results of the campaign were outstanding. In [5], the number of 250m2 allotments increased, approximately, from 450000 to 600000 in 1913, and from 1300 000 to 1500000 in 1917, having been produced 2000000 tonnes of vegetables.

Between wars, the public's interest in allotments and in other forms of urban food production declined in Europe, although to levels never lower to those recorded in 1914. The mass unemployment, verified since 1920, revived the interest in allotment gardens as a valuable means of social-economical aide. Philanthropic Groups of the most varied origins, namely the Society of Friends, in England, developed plans providing fertilizers, seeds and tools. Currently, similar supporting mechanisms are used in Cuba, in its national program of urban agriculture. During the Second World War the production of fruits and vegetables inside the cities of the UK was shown to have an important value in times of need. The production in family allotment gardens, making use of gardens in public and private places, exceeded more than $10 \%$ of the country's total needs in terms of fresh vegetables [8].

According to the data in [9], during war time, not only the agricultural activities but also the livestock and poultry production reached high values. In 1942 there were registered, in urban zones in England, more than 90000 poultry farmers with a production of 16000000 specimens. In 1944 the allotment gardens, alongside gardens and other portions of land including parks transformed into agricultural fields, amounted to a total $10 \%$ of the country's food needs and half the fruit and vegetable's needs. The end of the campaign Dig for Victory, in England, was followed by a harsh decline of the urban food production. The recent state of well-being, the existence of jobs and a rising prosperity, made that the food production was no longer a necessity. Also an image problem had a negative effect on the allotment gardens: people associated them to war, and a time of austerity that no longer was in line with a time destined to the scientific progress [5].

Among progress and setbacks, in periods of crisis, the strategic value of allotment gardens has always been emphasized. The 1970's were a turning point for allotment gardens, with the emergence of new production means. This seemed to be due to a new environmental ethics, developed in the 1960's as an alternative lifestyle, and a notion of self-sufficiency based on renewable energies. After the crisis, the urban dynamics of developing societies brought new freezing techniques, allowing the possibility to find any product regardless of the season and at a minimal distance. Nevertheless, old urban markets inside the cities are very significant as a means to re-establish the citizens' natural links with nature [10]. This requires a redefinition of the methods and purposes in the design of open spaces within the cities, with new roles and goals allowing new urban activities.

It is evident that the new diffuse city carries, in a way, a certain desire of a relationship between the citizen and nature and, it seems clear that in this context, it is physically easier to establish this bond through urban agriculture. 
It is also to be noted that the settlements from where the great metropolitan areas arose, in the west, came from rural areas. The will to maintain this old cultural heritage had important effects in certain working suburbs, in big urban areas not only European, but also American [8]. The ethnic and cultural variety in the European Union, made of populations that came from rural cultures and that made sure that, in certain suburban areas, the patios and the open spaces of the house were used to their full potential with the cultivation of vegetables, keeping the bond with their origins and, at the same time, helping the family's economy. This practice can be considered an example for the open spaces of the city that, frequently, with their standardized treatment, keep the citizen and the city with their backs turned against nature.

In Portugal, the strong migration movements from the 60s and 70s, of population coming from rural areas towards the big cities [11], lead as well to the appearance of certain ways of urban and suburban agriculture that answered to a new type o urban space, called in [12] as a third space, that showed a bond from the new industrial population to the memory of their old rural habits.

Still today, in our great metropolitan areas, there are small agricultural explorations in the interstitial spaces, or of difficult use, in suburban areas that, inside their precariousness, have an exceptional interest as a sociological phenomenon, and that we believe to exceed what would be a mere mechanism of transition as an adaptation of migrant populations to the new culture of the urban space ${ }^{6}$.

The sub-metropolitan allotment gardens appear in the big cities (take a look at Lisbon) as very representative places, even from the sociological, geographical, and anthropological point of view, which has been studying them with obvious interest. These studies show us what they mean as an expression of a way of understanding the urban space as the habitat of Man: the sub-metropolitan allotment gardens mean more than just bridges towards adaptation, being the expression of what the city could be in its definitive form and that that form is both easy and possible to be accomplished.

In the case of the metropolitan area of Lisbon, the important peri-urban agricultural areas that had some significant production capability, since the 60s of the 20th century, started to progressively lose importance as a consequence of the destruction of the agricultural soil, not only due to the new industrial and residential developments that invaded these peripheral spaces, but also due to the construction of powerful infrastructures and networks of services that destroyed the productive space of a primary sector that, on the other hand, was also losing its manpower, given the new employment opportunities.

Nowadays, it is frequent that the nature and origin of those allotment gardens, either because of where it came from, or because of its situation, do not have a relationship with

\footnotetext{
${ }^{6}$ Institutional areas (belonging to hospitals, schools and churches), riverbanks and road edges, parks, terrains under high voltage power lines, areas that can not be used for construction and its surroundings constitute a great part of municipal terrain. The planning of the use and exploration of these spaces requires the record of the localization, as a first step, and then the evaluation of its potential. It is important to evaluate the availability of the land for urban agriculture in a certain city in a short, medium or long term. The land may not be available due to the rapid growth of the city and the expansion of built areas [3].
} 
the conventional agricultural activity that existed or still exists in a determined area. They are, often, activities done outside the commercial circuits, in small allotments or allotment gardens that justify themselves, as an activity, with their own reasons more linked to the urban world, than to the rural one. On the other hand, the agricultural practice by the working class has survived at the expense of the low cost food available.

Currently, urban agriculture continues to be useful as a means of providing some food and financial income for the citizens, as well as having some other important benefits [13]:

- Social (leisure, fomenting local groups, therapy for individuals with special needs, rehabilitation of youngsters).

- Environmental (renewal of abandoned urban spaces, diversification of the usage of urban land, increase of biodiversity, preservation of the water, soil and air cycle, reduction of the carbon footprint).

- Human (promotion of sociability through the encouragement of personal qualities such as altruism, the improvement of the quality of life through social interaction, health benefits through physical exercise, better food quality and bigger diversity)

- Economical (stimulus of the local economies, creation of employment and wealth, directly or indirectly).

- Emotional (due to the pause that it can provide to the monotonous and gray everyday of the citizens, allowing them to realize the real dimension of time).

In England and in Northern Europe in general, a community allotment garden or an urban farm, are local projects run by and for local community groups. Sometimes they are run in a partnership with the local authorities but, its main characteristic is the strong local involvement. These allotment gardens exist mainly in densely built areas where its creation has been the answer of the community to the lack of a project and/or adequate management to and of the open spaces.

The urban farms are also known as pedagogical farms or community farms. The agricultural allotments are not generally run by a community, but there is a rising movement for the formation of an association of groups of parcels with the objective of practicing a decentralized management from the Local Authority that will move from the statutory sector (although with legal protection) towards the run by the community sector. Inside the movement of the allotments it is verified as well that there is a rising number of groups that are consciously establishing work run by the community with innovative schemes to obtain more community support [14].The majority of the projects is centered on food production activities, formation courses on the area, field trips from schools to community allotments and the undertaking of community businesses related to the urban agricultural practice. Some advance with the proposal of recreational and sporting equipments, of free time activities and vacation schemes.

The community allotment gardens ${ }^{7}$ and the urban farms are extremely flexible and adapt to the requirements of the local community. They have in common the encouragement of

\footnotetext{
${ }^{7}$ Relatively to their location and marking of the allotment it is necessary to bear in mind if its objective is therapeutic or recreational, commercial, for self-consumption or mix use. The gardening allotments are of the most popular for
} 
social participation and of the creation of sustainable communities. The projects contribute directly to the development of the community generating social participation and promoting urban regeneration through:

- More open spaces built from living materials (water, soil, vegetation) in the urban environment;

- More educational, formal and informal opportunities;

- More pedagogical information concerning food and animal production;

- Adult formation in a series of subjects, namely gardening, horticulture and livestock;

- School field trips and educational, didactic and pedagogical activities;

- Preschool activities;

- $\quad$ Gaming and sporting activities;

- Leisure occupation and vacation schemes;

- Integration of people with deficiencies in learning and/or other special needs;

- Development of the practice of community companies, such as cafes, markets of horticultural products, horsemanship centers, gardening centers and/or other community businesses.

In [15] is considered that the expression agricultural allotment should be replaced by the concept of recreational gardens because the first one has an historical stigma of low yielding and relative poverty. Additionally, the tracing and localization of the allotments should consider not only the individual parcels, but also the community areas, shelters, recreational areas and even some occasional spaces for orchards and groves. The recreational gardens should be strategically placed near the requirements and as far way as possible from sources of known contamination, such as old railroad tracks and some empty spaces resultant from polluting industries.

In [16] is understood the presence of these sub-metropolitan allotment gardens as the result of a marginal occupation of soils that comes as the result of problems due to the crisis and of the industrial stop that in the decade of 1970 affected the working economy. The exploration of these small parcels serves to grant some additional funds to the families' economies and to give jobs to young unemployed people with no expectations whatsoever.

This diagnosis, as to the origin and justification of existence of sub-metropolitan allotment gardens, is not entirely shared in [17] after deeply analyzing the sociological components of the existing allotment gardens in suburban areas of the city. $\operatorname{In}[17]$, the origin of the metropolitan allotment gardens can not be related to the issue of industrial deactivation, given that the origin of the allotment gardens is prior to it. Thus, its origin has to be explained in variables of some other nature.

It does not seem valid, as well, to relate these allotment gardens with factors of economical benefits to their cultivators. In fact, the greens and vegetables produced do no enter in any kind of commercialization. The only gains are the occasional family consumption or the satisfaction of offering the products to friends of acquaintances.

leisure reasons and spare time in England. In fact the management of the allotments is considered by many as a leisure activity more than a means of producing food. 
The same author refers that the cultivated parcels lack market value. They are precariously occupied with their owners aware that they can be evicted at any moment. These terrains were never bought or sold and, if those who cultivate them can no longer enjoy them due to the age or any familiar reasons, they give them to those that show some interest in cultivating them. Also, it does not seem common the presence of youngsters in the cultivation of the allotment gardens; those who work there, occasionally, are men, of mature age, from 50 to 70 years old, in their majority retired, that use their free time, to fill the emptiness of their leisure. This dedication is never too intense, nor has any economical expectations, a fact almost impossible due to being a low quality piece of land, to using elementary tools and to not having the adequate support.

\subsubsection{The reality in Portugal}

Relatively to the Portuguese reality, in 2004 the Culturgest issued a challenge for the attribution of urban allotment gardens in Lisbon. The contestants were all (or almost all) retired people and migrants in the city. According to the Commissary of Town Hall of Lisbon (CML) to this contest, the Landscape Architect Rosário Salema, the children of the contestants would not carry on this activity, simultaneously productive (because they sell the products they cultivate) and recreational. Relatively to the community allotment gardens, it was verified that they covered technical staff (qualified active population), at least in the medium class neighborhoods, for example Telheiras.

According to the Landscape Architect Maria José Fundevila, current commissary for the legalization of community allotment gardens, the Town Hall of Lisbon, the Heritage and Investment Division of the CML is finally making a record of urban allotment gardens, with that information still unavailable. Relatively to the age groups and professional situations of the farmers, it would depend on the areas in question: in the more marginal zones, socially speaking, you have a wide variety of farmers being hard to establish a global pattern for the urban allotment gardens - the allotment gardens are very connected to the social and economical aspect in the city, at least that appeared spontaneously, so that they are directly related to the social typology of the area in which they are inserted.

The Commissary referred two distinct examples: Quinta da Granja, in front of the Colombo Shopping Center, and the Parque Hortícola de Chelas, near the J Zone neighborhood in Chelas: in the first one there is a predominance of retired people, at a 60 to $70 \%$ rate, that have cultivated the area for a long time. The oldest one has done it for 38 years and is 97 years old today. In this case, the number of people that initiate the cultivation already in retirement is really low. Many have occupied these areas for a long time and have, meanwhile, retired. The main reason to cultivate the allotment gardens is the fondness for the cultivation of the land as well as the distraction it provides and the leisure occupation.

In Parque de Chelas the situation is completely different. The age group ranges from 30 to 70 and here, predominate the professionally active individuals or, at least, in this age group, given that many are unemployed. Here, the main reason for the cultivation of allotment gardens is the complement to the family income. These farmers sell their products illegally, 
unlike those from Quinta da Granja that cultivate solely for themselves. In this case a severe problem arises which is the watering of the allotment gardens, in the summer, with residual waters from domestic or industrial origin, and that are improper for such use. They are, however, ready to be initiated the works of the first phase of a horticultural park, in this area, that consists precisely in endowing the area with accesses and water for irrigation.

As for the municipal politics, in Lisbon, lately there have been promoted the urban allotment gardens, which until now, had not yet happened, despite all the continued effort made by some, trying to rekindle this practice.

About six years ago, a Commission was created, with the purpose of legalizing urban allotment gardens. It was then proposed a regulation that legitimates the existence of these spaces conferring some safety to the farmers that, in the last 12 years, have already received two eviction notices. This proposal has not yet been juridically seen but, however, it is already being applied. It consists basically in a classification, in order to protect the economical and social allotment gardens that correspond to $90 \%$ of all of the existing allotment gardens.

Aside from all the economical expectation, the suburban allotment gardens have an indubitable interest as an urban phenomenon given that it is an activity situated besides the space offer that the city provides to its citizens. They signify a way of passing time that the city had not foreseen. In this sense, they constitute an in between space, between their homes and the cafe as a place of reunion and leisure for the inhabitants. As it was already referred, in [12] the third space is considered interpreting allotment gardens as a place of leisure, with no equivalent in what is offered by the cities in a standard way.

In [17] those allotment gardens are linked to the transition of the rural to the urban space, as a manifestation of the persistence of a rural-agrarian encysted in a urban habitat, understanding that they constitute a symbol loaded with values, rooted in the interior of the new citizen. In this sense, they put it inside resistance and protection against hostility schemes that the city transmits to ethnic groups or cultural misfits. This assimilation of the sub-metropolitan allotment gardens in the context of the slums does not seem well-thought to us. The underlying problem in these urban-rural spaces is not only the creation of a safety space of reunion with their own identity and with the land of origin. It is also the expression of a will of permanence, an intention to integrate in the urban space something that, with no apparent reason, disappeared from the city.

Ribeiro Telles, that in Portugal has always been a fervent supporter of the existence of the urban allotment gardens, says that the new city farmers bring an intelligent message, in a spontaneous and naïve way and, without dogmas nor impositions, show the evidence of the possible, achieved without political support or public demonstrations. The new energy and wisdom sap, that the urban context brings, is the result of not only remembering rural values, but also of recognizing and feeling the urban needs. The suburban allotment gardens are not ways of socializing that are contradictory and opposite to the urban lifestyle, instead they are paradigms of the needs that no longer justify themselves in the urban space. 
The in-between space, halfway from the domestic and the pure leisure, considered in [12], is something that the city has had, in some way and, today, the new neo-liberal city of the post-modernism has definitely lost allowing as the only option the commercialization of virtual gadgets. But this third space of life is not commercial nor a mere alienating hobby, having as a background everything that the city and Man need from Nature. This means the relationship Man/Nature and includes the understanding of the landscape with all of its multifunctionality.

In [17] is warned that there is a confrontation between sub-metropolitan allotment gardens and planning policy. The insensitivity of the planning about this space is something more than just ignorance: it is the result of the fear of the same foundations that rules planning, an image of order, from the social, functional and also aesthetic point of view. The allotment gardens have little meaning in today's virtual world where the way of existing and of connecting, given that the understanding of the city-nature does not have a market value.

\subsubsection{Other concepts related to the allotment gardens: Continuous Productive Urban Landscape (CPULs) and Urban Countryside}

\section{Continuous Productive Urban Landscape (CPULs)}

Viljoen introduced the concept of Urban and Peri-Urban Agriculture and with the concept of CPULs - Continuous Productive Urban Landscape (CPULs) ${ }^{8}$ in 2005, and it sounds quite interesting to us given the proximity of concepts with the concepts of Natural Landscape Continuum and Cultural Continuum, profoundly rooted in landscape architecture in Portugal and with concepts of the current landscape architecture: it consists in a coherently planned and conceived combination of Continuous Landscape ${ }^{9}$ with Productive Urban Landscape ${ }^{10}$.

\footnotetext{
8 Continuous Productive Landscape (CPUL) is a concept of project design that advocates the coherent introduction of productive landscapes. Crucial in the concept of CPUL it is the creation of a network of multifunctional open spaces that include urban agriculture as a complement and support of the constructed environment.

This concept grew in the project design investigation and explores the role that urban agriculture may play in urban design. It was thought and articulated for the first time in 1998 by workshop Bohn and Viljoen - Architects, followed by a publication of the book Continuous Productive Landscapes: Designing Urban Agriculture for Sustainable Cities. This concept was the center of international attention and is, currently, part of the contemporary speech project. André Viljoen and Katrin Bohn are currently developing this concept in Brighton University - Faculty of Arts, through the said workshop.

${ }_{9}$ Continuous Landscape, similarly to the concept introduced by Caldeira Cabral, in Portugal, in the 50s - Continuum naturale - it is a current idea in the theories of architecture and urbanism that has already started to be implemented, not in a global way but partially, in some cities of the world. It consists in a network of open spaces, predominantly porous and made of vegetation, namely parks, or inter-connected green spaces, oftentimes referred as an eco-structure or infra-structure. They are free of automobile circulation, allowing pedestrian movement in the urban open space. They are an alternative to the use of the urban open space if we compare them with the existing spatial qualities of the utilized and underutilized disperse parcels of the urban open space. They should constitute an enormous (infra) structure of walkable landscape that runs through the city. Example of this continuum is the green corridor of Monsanto.

${ }^{10}$ Productive Urban Landscape is an open space made of vegetation and run in an economical way and to be ecologically productive, for example, providing food through urban agriculture, the absorption of pollution, the refreshing effects of the trees or the increase of biodiversity in the green corridors.
} 
It corresponds to a non-built and urban landscape, economically, social-culturally and ecologically productive, situated in a landscaping strategy to a metropolitan scale, built to include living and natural elements; thought to encourage and allow the urban inhabitants the contact with the activities and processes normally related to the countryside.

Overlapping the sustainable concept of Productive Urban Landscape with the spatial concept of Continuous Landscapes it is possible to propose a new strategy of urban design that will change the appearance of the contemporary cities towards the understanding of the city as a natural system, similarly to what is pretended with Lisbon's Green Plan and its Green Structure. ${ }^{11}$

The CPULs will divulge the productive landscapes economically, social-culturally and environmentally. They will be inserted in the concept of landscape on an urban scale and, in the current context can be transposed to a territorial scale, offering the city a variety of advantages, lifestyles and few, if any, inconveniences or unsustainable aspects. This system of continuity shall cross the city through the built space, connecting all the open spaces inside it articulating them, finally, with the surrounding rural space.

In [19], the CPULs will expand to the countryside, enriching the urban fabric and the lifestyles and actively contributing to the resolution of environmental and urban problems. Either being different or similar, these productive landscapes will exist on pair with other urban open spaces. The CPULs will function as a strategy of urban design, hence, being able to act as moderators between the wishes of the local users and the strategies for urban planning; between social and economical feasibility; between sustainable ideas and urban productivity; between short term advantages and long term benefits.

Formally they can be very similar to the urban parks given that they both present a materiality and spatiality predominantly built with living and natural structures and elements, and are design with determined spatial criteria, formal and functional. They are as well, for several reasons, similar to urban forests. The urban parks and groves, being agriculturally less productive allow, however, a bigger freedom on the utilization of the space, given that there is not the protection of the cultures condition. In what refers to countryside, the CPULs can be considered similar to gardens given that they both follow the same sequences and patterns of plantation.

In comparison with other open kinds of urban open space, in reference [19] are referred three criteria that cover the most important qualities of a CPUL:

- $\quad$ The time and space amplitude - as heritage, legacy and identity;

\footnotetext{
${ }^{11}$ Included in the Urban Green Structure, Magalhães [18] defends, the existence of an Urban Ecological Structure, in which it is pretended to assure a bigger biological richness and to safeguard the fundamental systems to the ecological balance of the city. With this Structure it is pretended the creation of a continuum naturale integrated in the urban space, as it was congratulated in the Environmental Bases Law, providing the city, in an homogenous way, of a system constituted by different biotopes and corridors that connect them, represented either by natural occurrences, either by existing or created spaces for the purpose, that serve as a support to wildlife. To this ecological structure we add a productive structure, also a subset of the Green Structure.
} 
- Utilization - as the present reality;

- $\quad$ Ecology - as its gift for the future.

The amplitude describes the space, in its extension, its width and breath. It means more than size, but the dimension is its basic element, its beginning. There is no qualitative judgment connected to dimension ${ }^{12}$. The size is considered influential in the designation of the space and in its capability to proportion certain programs and occupations. The sense of openness $^{13}$, given that it is connected to the size, reflects this manipulation providing a much more sensitive measure for the qualitative success of the urban open space.

The utilization/occupation of the space is one of the first concerns when planning the contemporary open space. It means, frequently, to put in perspective the success of the new project with designs with criteria, also quantifiable, as for example, the cargo capacity, or the financial volume obtained by the offer capacity of the place (leisure centers, stores, restaurants, spas, among others). A more holistic vision of the current occupation of the open spaces may include more stable and qualifying criteria, namely education, health, the potential for integration or enrichment of the self, the satisfaction over individual actions and its importance to a wider urban community ${ }^{14}$.

Ecology, in this case, gives importance to the open urban space for the connection of the present drawing project to the program of a more desirable and sustainable future, proposing, as well, a strategy for the management of this process. The ecological concept of gradient, in particular, clarifies the idea of gradation in the process of formation and transformation of the shape, and of the natural processes, of the organization of the materials in nature according to a stricter set of rules following the formal creative device, but coherent with the ecological limit principle. A second type of movement is that of the misfit, that continuously changes the shape, position and appearance.

\section{The Urban countryside}

In [20] is introduced the concept of urban countryside, in which is accepted as valid the definition of the French rural code, which defines as agricultural every activity of control and management of a biological cycle of either plant or animal nature, together with the activity developed by a farmer in the prosecution of the act of production or sustained by the companies. The concept of urban countryside puts itself in the relationship of movement

\footnotetext{
${ }^{12}$ A small open space is not a bad open space, neither is a big open space for that matter. They are valued for being open, exterior, non-built.

${ }^{13}$ Although related to the place, the sense of openness reflects manipulation promoting a qualitative measure more consensual to the success of the urban open spaces. It is related to the occupation and function of the space as well as with its position in the urban thread, reinforcing the importance of the open space in the urban net. The potential to this movement encourages occupation and the occupiers as well as it models the shape and appearance of the urban open spaces. It also introduces change and renovation in the space, offering with that a particular visual stimulus. The stimulus can be extracted from a number of sources (events, activities, movement, etc.), but it is, predominantly, connected to the material and natural processes: the vegetation submitted to a seasonal variation, to the growth and change of plantation patterns, to water, wind, sun, rain, etc.

${ }^{14}$ Depending on their programs and the tolerance to change, an open space providing social interactions will certainly accommodate a great variety of occupiers that seem less interested in the dimension of the space or its location, than in its potential to integrate and participate.
} 
between process and product, between agriculture of the urban space and desagriculture of the rural space.

Considered as a social project, capable of improving the urban life conditions, the urban countryside is not reduced to a social-economical process that varies according to the greatness or richness of the city. Not wanting to renounce to its goal - to feed the citizens - it is a part of territory of the city without necessarily transforming into a green space or natural park, unless the park takes on the content and duties as an experimentation place of the urban countryside. In this case, we talk about an urban rurality - different from the agricultural rurality - similarly to Quintas de Recreio (recreational farms), in Portugal, where the population does not waive the agriculture but that should be coherent between two possible paradoxes: to lose agriculture but not the shape of the allotment garden, or to keep the field with no agriculture similar to the idea of a garden that evokes the agricultural image, without producing.

Urban countryside (campagne urbaine) - coined by Donadieu in 1998 and title of one of his most well-known works - two words that seemingly oppose and create movement fighting the sedentariness of the thought. But, urban countryside are also two coordinated words in a single concept through which it is easier to promote the project and an action.

The countryside space infiltrated in the disperse city may be a part of the urban space taking on rules for the contemporary city project from the new cultural, ecological and social values that build an inhabitable society. In [20] it is not proposed as an unprecedented space typology, as a new standard for green, but is aspired to create an inhabitable space, given that, together with agriculture, a new ecology is proposed, new myths and new symbols to share with their inhabitants - a new landscape.

The goal of Donadieu is that the peri-urban agricultural space, which will tend to be more extensive in the coming years, never again has to be subjected to the fatality of a next transformation, but that it shall be a witness of the history, given that it will outlive it. This countryside, inhabited by a society that combines the practice of the city with landsmen from several origins, asks to participate in the definition of the urban space given that their inhabitants do not want to let go of the city, confirming a life choice where a bigger contact with nature is privileged ${ }^{15}$.

The hypothesis that the new city of the urban countryside organizes itself around an habitability project, or better put of sustainable urbanity, can be put. However, for this new countryside to become a landscape and, consequently, to acquire a relative perpetuity, it is obvious that it should be created with the quality that it does not currently have ${ }^{16}$. It is the

\footnotetext{
${ }^{15}$ The risk that the peri-urban society takes is alienation, the loss of an horizon of meaning and the feeling of belonging to a community confused with the place, the attribution of a social category to a stable and immutable context.

${ }^{16}$ In [21] is emphasized that, without the cultural scheme of landscape, the citizen can not understand the countryside:

"How can you understand the agricultural logic if you are unacquainted with the subjects of fieldwork and livestock? And looking to the ecological thought, how can you accept that absolute protection allows the conservation of biodiversity, when everyone knows that the second natura, once abandoned, can leave the place a lot less diversified than what ecologists think? And how not to protest against the horticultural academicism that proposes to cover countries and cities of flowers, to produce nothing more than commonplaces. What the aestheticians say, without
} 
job of a landscape design - to build and design the landscape structure that will build the Eco-symbols. The innovation will consist in associating the agricultural and the built spaces, in a project that binds them forever. The inhabitable city will be constructed at the expenses of creative imagination, over the ruins of conformism and preconceived ideas. The multicultural concept of nature and the new attribution of the natural sense to the natural objects can create the foundation to the political project of the urban field.

According to Donadieu the realistic utopia of the urban countryside voluntarily attributes to the space a spiritual condition, more than reducing it to a lifeless support of equipment and social practices. Some will participate and will recognize themselves in this project; others won't, because the constructive tension of the project is that same source of social differentiation, adhesion, expectancy or denial.

As for us, we consider that the challenge of territorial appropriation is remarkable: first it includes in the social territory in question, some spaces exclusive for the inhabitants given that, through a work that involves major actors - farmers, associations or municipal staff - it questions the ideal of social organization and discusses that aesthetic job. The virtues of the dialog are certainly known but, its achievement depends, majorly, from the capability of society to recognize their own mythical horizons, be them ancient or modern.

It is indispensable to reclaim the myths of nature that, in the urban countryside project, send us to the founding values of society. The myths and rites keep the group together, gather it when it falls apart, be it a problem of public order, be it of collective health or of the future of the planet. Acting in such a way, the interlocutors of the project gather around rites meetings, expositions, media messages - indicating the symbols, spaces or objects, land or agricultural products, stimulating the processes of socialization where individual dispersion is the rule.

To say that the habitability of a territory passes through the social appropriation of the public and private places, mean to enunciate a necessary condition but probably not enough because the creation of social legacies through founding myths - as solidarity or health benefits - makes the social-political regulating system to recognize the collective project and to accompany it; otherwise it won't be nothing more than pure fantasy. In [20] the communal administration should, for example, buy agricultural fields to guaranty the continuity of the cultivation, to systematize leisure routes in the agricultural parks or to subsidize the farmers in case of prolonged price fall. It is not rare that local administrators subscribe to the common opinions, making their own the aspirations of society: living in the countryside, for example, is a slogan that accompanies the farms' policies and local revivalism.

compromise, is that the ecological sciences should concern themselves about the natural processes, inventory and environmental sustainability and living species, while nature and landscape pay attention to the perception of this environment and its representation."

The countryside is, in fact, the second nature made a show, in territory where urbanity and rurality are intimately connected and still opposed. In [20] the countryside is a concept we need to keep mentally representing to be able to reach reality. 
Localization can be enunciated under the form of a paradox: the more social groups find in the urban countryside the attributes of nature, the more complex should the social and technical processes be to produce this way of nature connected dialectically to the central urban area. The more the countryside becomes inhabitable, offering pleasure and comfort to its users, the more the collective myths should be renewable.

We can then consider, as being of general consensus that, although it may be placed inside urban agriculture, given that it refers to activities related to food production in the city, being able to occur in several situations, the urban countryside allows other activities besides this one, namely new social and economical practices (ponds, rural tourism, sale of quality food products, horse raising, among others) carriers of an innovative proposition of sustainability and of new ways of spatiality. The urban countryside can be that of a more urban and rural city that will result from the articulation of the natural, urban and rural systems, that will result in turn in a new idea of space where its appropriation makes it inhabitable and of identity.

\subsection{Why allotment gardens?}

Nowadays, half the world population lives in cities. According to the United Nations Human Settlements Program - UN Habitat 2004, State of the World Cities, in 2030, this proportion will be of $60 \%$ (UN-Habitat, 2004).

Many cities cannot stand this massive population growth. Authorities face many challenges: creating enough employment; providing basic services, such as water supply and sanitation, health care, education; planning and maintaining open spaces; managing urban waste and sewage; decentralizing and creating a new efficient local autonomy

Poverty accompanies the urbanization process, gradually affecting urban areas [22]. This is an indication that cities are quickly becoming the focus of intervention and strategy planning to eradicate famine and poverty, as well as to improve subsistence means, which requires new ways to encourage local economies and strengthening nourishment and food safety. We think urban farming is one of those strategies.

The growth of urban poverty, famine and unemployment, as well as the special opportunities that the city provides to the farmers ${ }^{17}$, have stimulated the development of a diversity of production of the agricultural systems inside and in the outskirts of the city, frequently specialized in perishable products like fresh vegetables, milk, eggs and meat, taking advantage of the interstices inside and in the peripheries of the cities. Even though some ways of urban and peri-urban agriculture are based in a temporary use of these empty spaces, urban agriculture is a permanent characteristic of many cities, either in developing countries, either in the so-called developed ones. Also, the meaning of urban agriculture inside the contemporary open space varies according to the city in question. The environmental benefits of urban agriculture have only recently been identified and

\footnotetext{
${ }^{17}$ Namely the rising demand for food, greens and vegetables, the proximity to the markets and the availability of cheap resources, namely the urban solid residues and residual waters.
} 
recognized, with very different meanings in the developing countries and in the developed ones. In the developing countries, urban agriculture is largely oriented around the economical needs, as in the developed countries it provides, mainly, answer to wishes and social and recreational needs. Besides the social reasons presented, urban agriculture reflects and comprehends the multifunctional dimension intrinsic to the concept of landscape.

In Europe the interest on urban agricultural exploration - whatever the typology - has constantly been increasing in the last few years resulting in an upwelling of food production in the urban space.

In [23] agriculture tends to define itself as a bottom-up activity, a movement of timeless roots to the top-down elitism of landscape design professionals. The policies - the questions and practices - whatever the perspective in which they are seen, require top-down and bottom-up initiatives. To free or reclassify the land for urban agriculture requires more than a simple desire of holding hands and planting vegetables. It requires a top-down intervention, by the planners and local authorities. If urban agriculture is seen as one of the various ways to make an environmentally productive landscape inside, and around and out of the cities, then the professionals of the field of the urban project - open spaces and built fabric - are vital allies in this project.

The urban agriculture in Western Europe can not be reproduced in the same molds as in countries like China, with a much more rooted and generalized connection to the traditional agriculture, or even in the United States, with its new immigrant population, that come from agricultural economies. For urban agriculture in Western Europe to be a part of its own citycountryside, it needs a wider coalition in the groups of interest: it needs not only to be tolerated, but to be welcomed. Any interest in the promotion of more complex models of development already introduced by Geddes and McHarg should pass by finding a place for urban agriculture.

As it has been referred, urban agriculture never stopped being present in the city, adapting to the different situations. The inhabitants of the cities have developed different strategies to improve their subsistence having urban agriculture been one of them.

In [3] urban agriculture answers in three ways to the urban dynamics:

- The first is the answer of the economically disadvantaged and unemployed population to urban poverty, to food insecurity and malnourishment. Sometimes, it is due to a temporary crisis like for example a natural disaster, a war or an epidemic. However, many of these problems related to famine and poverty have become common and structural showing that urban agriculture will have a much more extended expiration date as a social safety net for poor urban aggregates and at disadvantage.

- The second is the answer of the economically disadvantaged population, as well as of other social classes, to the opportunities and relative advantages that the urban environment provides to farmers. ${ }^{18}$ Direct access to the points of consume and markets,

\footnotetext{
${ }^{18}$ The cities accumulate nutrients through the concentration of human population and their organic residues, be it solid or liquid. These nutrients may frequently be acquired without costs or at a low cost and can be converted into edible
} 
availability of cheap inputs such as urban solid residues and residual waters, proximity to the institutions that provide information on the markets, credits and technical advices and new urban solicitations, among others.

- The third adaptation of urban agriculture is a direct answer of the urban farmers to the urban policies and programs, stimulating and enabling the urban agriculture to fill in certain requirements for the sustainable development of the city namely: the balance of the water, air and soil cycle, local economical development and food supply, as well as the recycling of residues, the promotion and maintenance of urban open spaces, the promotion of recreational and leisure services, social inclusion of minorities.

While some of the functions can be financially evaluated, others will have a tough time such as the emotional and aesthetic values. The sustainability of urban agriculture is connected with this multifunctional dimension. Urban agriculture adapts and develops together with the city according to the wishes of its users that represent the different functions. So, new ways of government, institutions and policies need to be implemented through processes that seek synergies and involve different actors [24].

Other city dynamics namely the urban and industrial traffic (that take a negative toll on the quality of the soils and irrigation waters), the new demands of the citizens (the need for recreational spaces and new products), changes in urban planning, in its norms and rules and, changes in the urban work market, among others, directly influence the development of urban agriculture and the way and where it is practiced.

These dynamics take place in a world increasingly open and global but that at the same time, searches for a bigger local focus, a greater decentralization and a larger maintenance of the social-cultural identity [22]. Both tendencies influence urban agriculture - globalization leads to new products entering the market, to more available information, in a general way, and to transformations in the consumer's preferences, which leads to an increase in the consumption in supermarkets; the focus on local tendencies leads to the preference on locally produced fresh food and to direct relationships of producer/consumer.

Since 2005 the prices of food items have skyrocketed to alarming values. Several values have contributed for this situation namely: the idea that agricultural products appear as an alternative fuel source; the rising need of food from developing countries, like China or India; a bigger cost for the transportation of the products; and the floods and droughts. The attention given to urban agriculture has increased considerably during the last two decades. The number of activities to promote urban agriculture internationally, nationally and locally, rose, but urban farmers still fight, in many cities of the world, to have their main strategy of survival recognized by the municipal authorities. Also the demand, by politicians and local practitioners, of inspiring examples of policies and successful actions is increasing.

products, vegetable or animal. On the other hand, while cities develop, there is an increasing demand of habitation buildings and of services that compete with the agricultural space. The producers need to adapt to these increasingly awkward conditions, while trying to maintain productivity through intensive production techniques. 
Farming influences a great variety of urban themes, being accepted and used as a sustainable development tool for the city. Today, farming faces the challenge of being part of the city planning and of being easily accessible so that urban citizens can enjoy its multiple benefits [3].

The rising attention of political deciders and local and national practitioners is also reflected in the rising demand (to the members of - Resource Centres on Urban Agriculture and Food Security - RUAF) for inspiring examples of policies and successful programs at the level of urban agriculture, as well as practices and co-financing of programs of investigation. This fact can be attributed to several factors, namely:

- To the quick urbanization process and to the discovery that both urban poverty and insecurity about urban food are increasing. The consumption and waste landscapes, resulting from fast urbanization processes have created big problems to the urban authorities. The majority of the cities were not capable of creating enough job opportunities to its population leading to a fast development of informal occupations from which urban agriculture is a part.

- To the rising investigation staff in urban agriculture that provides data on its presence and persistence in the cities, its importance for the safety of urban food and, in the future to the urban economically disadvantaged classes. Since the beginning of the 90s, the Cities Feeding People Programme has encouraged an action of investigation in urban agriculture. In the beginning of 2000, the international research organizations that belong to the Consultative Group on International Agricultural Research, included urban agriculture in the investigation agenda and initiated a broad investigation program, the field of urban agriculture, under the name of Urban Harvest with activities in several countries. From that point, several research organizations included urban agriculture in their regular programs (Argentina, Kenya, Senegal and Nigeria).

- To the crescent attention given to urban agriculture and urban food safety by the international organizations such as Food and Agriculture Organization (FAO) and the UN - Habitat, and the crescent attention given to these subjects in International Summits. In 1996, forty international organizations involved in urban agriculture created the International Support Group on Urban Agriculture (SGUA) to establish a joint agenda and coordinate activities. The United Nations Development Programme (UNDP) and the UN Habitat, included urban agriculture in the Urban Management Programme (in the Latin America section) and have been working with regional town halls to integrate urban agriculture in urban policies and planning. Recently, this initiative was also undertaken by the African Network of Urban Management Institutions (ANUMI, 2005). FAO has also integrated urban agriculture in its agenda and created an inter-departmental work group about urban agriculture and food safety (now called PAIA Food for the cities).

- To the increasing capabilities, locally and regionally, of thinking about urban agriculture. The RUAF established regional research centers on urban agriculture and food safety that have been crucial on adjusting interests and on disseminating the increasingly bigger corpus of knowledge in this matter, facilitating networking and the developing capability in terms of the city and region. 
As a result of these developments, as well as of the pressure of the economically disadvantaged local groups, urban farmers, the Non-governmental Organizations (NGOs) and several municipal authorities have recognized the potential of urban agriculture and are collaborating with other actors in an effort to maximize the benefits of urban agriculture while reducing the risks associated to it [3]. In [5], food production where food is being consumed, establishes a sustainable and healthy balance between production and consumption. It's an effective, practical, and beneficial way to reduce the energy currently being wasted in Western food production. This energy reduction in food production is vital for many reasons: that energy - mainly non-renewable - is currently used in the conventional food production; for instance, Europe greatly exceeds the energy use in the consumption of the food it produces. The unlimited daily use of non-renewable energy makes a significant contribution to the reduction of global resources, through the emission of greenhouse gases that generate global warming.

\subsection{The benefits of allotment gardens}

Over at least the last 50 years, green policies have been opposing the city growth, or limiting its disadvantages, through the preservation of nature spaces within the city. In Europe, those policies have safeguarded untouchable spaces in the green belt, as an expression of an ever growing interest for farming spaces for the services they render the city. On one hand because their public management costs less than that of parks and gardens, and on the other, because citizens seek specific goods and services - fresh produce, pedagogic centers, urban waste recycling capacities, and a healthy living environment.

Considered as a social project capable of improving the conditions of the urban life, agriculture is not reduced to the economical processes that vary according to the wealth of city, but has important motivations to convince the constructors and organisms of city management of the third millennium. Urban agriculture can and should feed and nourish the citizens bound to be increasingly numerous. However, it is not the same in every country $^{19}$. In the developing nations it is not necessary to show the importance of this function, conditioned, however, by the real-estate pressure that puts farther and farther away from the urban centers the productive agricultural belt of the gardens, allotment gardens and orchards. The agriculture practiced in African cities withstands even the competition from rural agriculture and of the mass markets.

In the developed countries, on the other hand, besides rural agriculture, indifferent to the city, are appearing in new ways of horticultural production, orchards and flower cultivation that answer directly to the needs of the citizens, in particular to the demand of buying fresh food products, with known provenance and quality, or of searching for ornamental products, especially trees, perennial plants and seeds. These are new urban lifestyles.

\footnotetext{
${ }^{19}$ Urban agriculture is frequently tabulated by western standards. In the totality of Chinese cities, $85 \%$ of the consumed vegetables by the residents are produced inside the cities - Shanghai and Beijing are self-sufficient in vegetable production. This information may seem irrelevant to the rich European countries. However, the attitudes relative to food production are based in cultural aspects more than in health aspects as, for example, the Hong Kong case demonstrates. There, the vegetables to satisfy $45 \%$ of local demand are produced in $5-6 \%$ of the total land area [23].
} 
This is the fundamental difference between rich and poor countries. Once satisfied the feeding needs, it gives way to a new question: the quality of the individual and collective lifestyles that should have never been separated. That is, it creates urbanity in the sense of better living the city.

Urban farming has many significant benefits, such as improving the environment and helping develop ecologically balanced areas, as well as at the social and economic level, for the community, and in terms of health.

Allotment gardens frequently connect areas with different occupations, establishing a visible physical link between two spaces. In this approach, they frequently define hidden or forgotten spaces within the city that may undoubtedly react to the landscape's multifunctionality.

Urban agriculture also gives scale to landscape. The way these farming surfaces are changed to accommodate planted surface links and gives visibility to the underlying topography. The dimension of crops and cultivated fields offers another standard from which to measure landscape, allowing people to locate and position themselves within a particular territory. This capacity to read the landscape, and locate oneself becomes critical, as contemporary globalization produces more uniform, compact, and timeless landscapes.

Despite the undeniable existence of these benefits, the positive impact of urban agriculture in the character and quality of the landscape is not shared by everyone. Landscapes that result from urban agricultural projects tend to share some common characteristics that are not included in the dominant approaches to the project design of the urban space held by landscape architects, architects and urban planners.

These characteristics include a subtlety, an introvert character and frequently non-planned and the constant transformation of the landscape. To some they are understood as detractors of the quality of the urban landscape. But to others they are some of the most desired and necessary landscapes.

It is a fact that urban agriculture is crucial to the existence of several poor cities in the world. However, just recently, the wealthy industrial nations of the world and its politicians started to consider the potential benefits of urban agriculture. Nowadays, in all European cities, food production faces a severe competition with the other uses of the land, namely habitation, commerce and industry that frequently have a high profile and financial payback.

While a great quantity of information on the design of low energy consumption buildings is available, including examples that take into account the impacts in the life cycle due to the embodied and operational energy, little bibliography is commonly made available relatively to urban agriculture. It is not that surprising that professions connected with the built environment have so little to do with urban agriculture. If the planning is supposed to be related with the coordination of the use and of land development and public interest, then the value of food production needs to be more publicized and, even included in the curricula of studies related to this theme. 
The contribution of urban agriculture to food safety and healthy nourishment is, likely, its most important point. Food production in the city is, in many cases, an answer of the urban poverty to an inadequate, irregular and insecure access to food, as well as to the lack of purchasing power. In the urban areas the lack of income translates itself more directly in a lack of food than in the rural areas (the economical income is necessary to buy food). The costs of supply and distribution of food from the rural areas to the urban ones, or the import of food to the cities, are constantly rising and its supply in the cities is irregular. As a consequence, urban food insecurity will continue to rise [25]. To add to the reinforcement of food safety and nourishment in urban farmers [26], urban agriculture produces large quantities of food to other sectors of the population. It was estimated that 200 million urban residents produce food for the urban market providing $15 \%$ to $20 \%$ of the food in the world [27].

The improved access to fresh food is directly linked with health improvement. The production of food in the cities can and should help improve the diet of the population allowing it the access to fresh fruit and vegetables, particularly that population with low income. To add to the diet, urban agriculture can provide an useful way out for the quantity of regular exercise that health professionals argue to be necessary to avoid health problems like obesity. Also the practice of gardening or horticulture has been widely recognized for its beneficial effects in the treatment of mental illnesses.

Urban agriculture is an important income source to a substantial number of aggregates. To add to the income of the sales of the surplus, the families of the farmers save in household expenses when cultivating their own food. Given that the economically disadvantaged classes normally spend a substantial part of their income in food (60-80\%) [4], the savings can be substantial. Urban agriculture also stimulates the development of micro-companies for the production of the agricultural inputs needed (forage, compound and worms); to the processing, packing and product marketing and other services (animal health services, commercial accounting, transportation). In the developing countries it can proportion an orientation for the economical life.

The economical value of urban agriculture can not be simply compared to the type of financial flux caused by the exchange of money for agricultural products in supermarkets. From a small or medium production, preferably organic and seasonal and with aim at the local market, urban agriculture is a different approach to life and food that, more than to compete, supplements the already existing products in the supermarkets.

Urban agriculture can function as an important strategy for the attenuation of poverty and social integration of the disadvantaged groups (like immigrants, families affected by AIDS, people with deficiency, aggregates lead by women with children, elders without pensions, youth without jobs) providing them with a stronger way of integration in the urban network, a decent subsistence and preventing social problems $[28]^{20}$. The urban and peri-

\footnotetext{
${ }^{20} \mathrm{It}$ is a merit that the inhabitants attribute to the neighboring agriculture of the city, the permission for the existence of family gardens, the integration of social marginal groups, for example immigrant workers or unemployed people. In
} 
urban farms can also have an important role having a leisure and educational play in for the citizens, having a role in biodiversity and landscape management, a bigger proximity with the natural cycles, as well as with the perceptive development of a different dimension of time.

Also emphasized in the urban agriculture related bibliography is its importance in terms of community development and as an agent for social regeneration, reducing the discrimination, fighting crime and generating economical benefits. In terms of urban regeneration, one of the strong points in urban agriculture, identified both in the Europe and North America related bibliography [29], is its capability of making a highly visible and practical difference in the life of the population.

The waste elimination has become a serious problem in several cities. Urban agriculture can contribute to solve this problem turning urban waste into a productive resource through the production of compound, worm culture and irrigation with residual waters.

Urban agriculture and forest can also have a positive impact in the open spaces of the cities, in the improvement of the urban micro-climate (windbreakers; dust reduction and the existence of shadow) and in the maintenance of biodiversity as well as in the reduction of the carbon footprint in the city with the production of fresh food near the consumers reducing, consequently, the energy consumption caused by transportation, packing, refrigeration, etc.

Investigation developed in Holland showed that the existence of agricultural spaces, and thus built with vegetation, near the houses, has a positive effect in people's health [3].

\subsection{Policy and allotment gardens}

Due to the multifunctional and improvising nature of allotment gardens, policy development and planning actions must involve many sectors and disciplines: agriculture, health, waste management, community development, nature and parks management, and others.

On the other hand, urban farmers, as well as the organizations supporting them, must be involved in the planning process. In [30], the most important thing in strategic planning is the involvement of the underprivileged populations in the assessment of the situation, property definition, and the process of action planning and enforcement. These advisory processes result from development policies and planning actions, not only comprehensive, but also sustainable. These facts are increasingly acknowledged and included in urban planning approaches, as planning methodologies of the many players adopted by the Agenda 21, and by the Sustainable Cities Programme.

Public power has many reasons for wanting to keep farming spaces and farmers in urban areas. First of all, for food safety reasons in countries with scarce farming areas. Then, for

these domestic allotment gardens, original ways of socializing are developed, particularly on weekends and holidays. You go to the garden, mainly for food reasons, but also for the regular render-vous with other people and, with their families, bonds are created, talk, trade and invite. 
civil safety reasons (fire hazards due to dry vegetation). There are also economical and social reasons: the producers' geographical distance (due to costs, and also to local food safety in a crisis situation), requiring short commercial circuits; the diversity of farming products and their geographical origins, leading public power, for instance in Europe, to distinguish quality brands in defined territories - registered designation of origin (DOC), factory products or organic products; farming tourism also plays a significant role spreading these products.

There are other environmental and landscaping reasons: landscape design, multifunctional use, and identity preservation, amongst others. Under controlled conditions, urban farmers should recycle a part of urban water and organic waste. Farming landscape structure, such as productive farmland plots, wind hedges, wells, channels, supports, routes - these are all ways to break the agglomerate density of buildings. There are other vegetable or water surfaces, which also help purify urban micro-climate; farming spaces are leisure areas. Most of all, they offer the population public recreational spaces kept by farmers, so long as the safety of goods and people is guaranteed. Matching Donadieu's urban field [20], this image is not spontaneously born but comes from the collective action of farmers, the population, and urban public power.

These spaces are emerging as farming parks in South Milan, as orchards by Palermo, vegetable gardens and orchards in Baix Llobregat, in the Aubagne community not far from Marseille, in Delft, Holland, and as system of farming parks in Almada, also projected in Estrutura Verde and Plano Verde de Lisboa. This happens in all cities re-acknowledging the multifunctionality of landscapes.

Despite the already referred relevance of the existence of urban agricultural practices, its integration in the contemporary urban economy is still a flaw in the urban policies and planning.

Urban agriculture is an economical activity practiced for commercial reasons, by an estimated number of 200 million people and informally by 600 million people around the world. The innovative book United Nations Development Programmes (UNDP), Urban Agriculture; foods, jobs and sustainable cities, identify three economical benefits in urban agriculture: employment for the future generations and business development; the improvement of the national agricultural sector and the supply of urban food; and the economy of land use.

Even though urban agriculture significantly contributes to the feeding necessities of several urban populations, the United Nation's Food and Agriculture Organization (FAO) informed that, in the future, the 12 mega-cities (with more than 10 million inhabitants) will experience an increased difficulty in their feeding. (FAO, 1998).

The land portion necessary for the urban agricultural activities that are commercially viable will depend of a number of factors that include [31]: the quality of the land; the use of natural and artificial micro-climates including greenhouses and polyethylene tunnels; the type of crop growth; the combination of animals and plants, the prices of the products in the 
markets, including the products from rural and overseas areas; its inputs including work and fertilizers; and the distance from the place to the urban markets.

The urban producers can obtain a bigger efficiency with the utilization of underutilized resources in the cities such as the interstitial spaces, the city compound and the labor coming from unemployed people. The productivity of urban agriculture can be 15 times bigger than that of rural agriculture although the incomes can suffer some inputs, and insufficient municipal support (FAO, 1998).

The macro-economical effects of urban agriculture can be improved on the level of food safety and of a reduction in food prices, inducing the increase of employment and contributing to the industries related to the activity. It is presented as a way out for the current social-economical problems.

\subsection{Allotment gardens in the periphery}

The rapid urbanization process, verified along the last half of the 19th century, has lead to a continuous expansion of the city towards the rural suburbs, leaving big areas under the direct influence of the urban centers. However, the current problem of the peri-urban space, understood as a new way, a disperse way, of the construction of the city, corresponds to a phenomenon that started developing two centuries ago ${ }^{21}$.

The process of progressive democratization brought the destruction of the traditional system of symbolic value and the continuous collocation of new values and references in the collective imagination. Relatively to the urban space, to its periphery and the diffuse territory of the city, democracy brought not so much the destruction of the places or their context, as it brought the trivialization of the shape of the public space and the repetition and reproduction of the shape of the private space, favoring the appearance of a separation of the idea of common good 22 .

It's common knowledge that cities go through a constant process of construction and decadence. Open spaces are filled with buildings and their formal or informal temporary uses are eliminated. Meanwhile, degenerate areas are demolished, creating new open spaces that can stay empty for a long while, until they're given a new use with the corresponding investment. These new spaces are often occupied by urban investors [3].

\footnotetext{
${ }^{21}$ To be noted that even walled cities looked to, however they could, integrate inside them an area for that purpose only. For example, the Fernandine wall, in Lisbon, built in the 14th century, covered a wide area (a little bit over 100ha), to assure some supply autonomy in case of prolonged siege.

Also the Ebenezer Howard model, about the creation of new cities, predicted that each one of them would integrate a surrounding agricultural zone.

However, if we consider that it starts in the search for the countryside by the citizens we can say for sure that it has always existed, not only for the needs of agricultural supply, but also for leisure and contact with nature and, for sanitary and health reasons [32].

${ }^{22}$ A perspective of the defense of the common good is particularly worthy when we talk about the Mediterranean landscape, especially the coast, where the need for a social solidarity is stronger and an environmental valuation policy without the reconstruction of a civic tradition that establishes a connection of society with that place is unthinkable.
} 
As for this crescent peri-urbanization, some say that, "the city-countryside dichotomy should give way to spatial integration, which process must not be seen as the countryside urbanized or as the city ruralized, but as a new way of social reorganization, that should reflect complementarities" 23 .

In that same sense - of spatial integration and social reorganization - Secchi [33] revalues peripheries, stating that it is less and less certain that the periphery is the place for subordinated activities of degradation better representing the best place for exchange between the city and the rest of the world.

Such opinions reflect from the start the reality of the city-countryside relationship that, with the increasing dispersion, occurs in the urban surroundings. This new territorial localization and the specific social relationships to it associated indicate a new way of organizing the city. In its surroundings dynamic zones in expansion are seen, zones of interaction between the urban and rural areas.

This peri-urban interface [34] is characterized by rapid transformations in the use of the land and in the way of living of the populations. The traditional systems of local agriculture and land distribution are interrupted by new citizens looking to acquire land ${ }^{24}$ leading to a raising in its price.

As an answer, some traditional farmers give up their activity ${ }^{25}$ and sell the land looking for more profitable and lucrative activities ${ }^{26}$.

The interdependence between urban areas and their rural surroundings creates the need of the existence of approaches of integrated development appealing to rethought areas of interest, institutional changes and innovative planning approaches [35].

None of this happens in the peri-urban space. The old inhabitants will still have some connection to agriculture, an increasingly smaller one, and shall keep social relationships of proximity, but the new inhabitants are essentially urban ones. Many of these come from the city, of collective habitation areas; they work in the city, in the services or in the industry and live car-dependent; their leisure and realities of reference are based on television and superstores; perhaps practicing some gardening; they value individuality and establish few neighborly connections; sometimes relationship problems occur between younger and elder residents.

The economical, social and demographic decomposition of the rural space makes the countryside increasingly oriented towards and by the city. The countryside around the city is, almost always, the most unstable place of the territory and more propitious to processes

\footnotetext{
${ }^{23}$ Carvalho [11] p. 189.

${ }^{24}$ To speculate: to the exploration of sand and stone, to the development of infra-structures, to the construction of instalation of more urbanized types of agriculture.

${ }^{25}$ The general devaluation of agriculture is a fact and Portugal is an example of it.

${ }^{26}$ Jobs in the city; the intensification of their agricultural systems of production to a bigger adaptation to the new urban conditions - cultural changes, market orientation, the use of new technologies, namely greenhouse production, direct market, use of urban waste or residual water, among others.
} 
of transformation - the soil of the future periphery, conditioning of the next votes in the process of real-estate valuation, of highways, interstitial area hard to interpret. In most cases, the destiny of the fields is the one of being defined by the dynamics of transformation of the city $[7]^{27}$.

The relationships of the new residents with the space that they occupy, little has to do with rurality (although they can feel sympathetic about it). Even the older residents, with the crescent abandonment of agriculture, new jobs and displacements, will eventually be turned into citizens of this wider city, of this city territory. The peri-urban space, presented as a return to the field is, before anything else, a new process of urbanization.

This peri-urban interface is defined as land in an advanced state of transition from rural use to urban use - land in construction, land to which the plans for subdivision have been approved - in the end, land where there are little doubts about its orientation to and conversion into urban uses, where it is not predicted a multifunctional use of the landscape, but where it is fundamental [36].

Oftentimes the urban periphery is referred more as a phase than as a place [37]; the rural activities are considered as activities to disappear in the next few years, while urban activities are simply understood as precursory of the city. The substitution of a rural inclusive space for a completely urbanized area is stipulated and, the disordered landscapes of the periphery, characterized by a mixture of rural and urban activities, are regarded according to this determined succession and established as places in transition that are soon bound to disappear ${ }^{28}$. The notion that urban development is the best use of the non-urban land is written in the lexicon of any urban planner or politician. The ignorance of the concept of multifunctionality and of the concept of landscape lead to the transformation of a the scenery of periphery and the notion of no place that accompanies it, turned into a battlefield between the efforts to preserve the rural soil and the ruthless forces of urbanization.

Periphery can then be characterized, by many, simply as the grave to the countryside and a birthplace to the city, while the intermediate phases of the landscape and of life have been ignored. The periphery landscape, complex and sometimes chaotic is merely described as a temporary void. Due to the landscapes in transition being neglected and simplified according to the urban-rural conflict, the transforming side of the landscape is put aside or severely reduced ${ }^{29}$.

These hybrid spaces of the city and the countryside, or spaces outside the order are common in the periphery [37]. Vast areas of the periphery are waiting for projects, often for a long time,

\footnotetext{
${ }^{27}$ When the contemporary city breaks the rules of construction of its growth interrupting the continuity and adjacency with the pre-existing urban fabric, it simplifies the rules of construction of the boundary space, the in-between space, isolating the new settlements inside a landscape less and less recognizable as countrysde, but already altered by a transformation which objectives will be real-estate valuation, a goal to which the owner aspires be it farmer or citizen.

${ }^{28} \mathrm{In}$ [38] is referred that the periphery of the city has been, for a long time, the destination of the rural landscape of the periphery of the city, the natural material to the subdivision for residential and industrial lots and trailer parks

${ }^{29} \mathrm{In}[39]$ is referred the artificial division between urban and rural as the primary reason for the existing difficulties when running the periphery.
} 
that contribute for the qualification of the landscape. The planning, the development, and the rehabilitation of spaces are part of the contemporary society; an intermediate phase of abandonment is an inevitable stage of the contemporary city, as well as of the countryside, that also is transformed [40] $]^{30}$; the peri-urban territory is clearly in the process of social rehabilitation.

The use of similar definitions, that refer the transition/indecision of a rural/urban use (and often the conflict between farmers and the population of the disperse city) have been long referred to in literature on planning, as well as the discussion around the old question of considering this as urbanized countryside or ruralized city.

It is certain that in both definitions it is included the idea that this space should contribute to the supply of food to the city. It is an obvious reality in developing countries, but much more complex when around the western city, where there is a type of agriculture that supplies to the big supermarkets and shopping centers, with which urban agriculture can not compete. In the peri-urban agricultural spaces there are many diverse ways of agriculture, from the intensive one to the extensive, from commercial to productive, from traditional to hobby.

This abundance of ways is quite positive because it indicates that, independently of any global project, these are the differentiation processes that are happening and that farmers are reacting to the demands of the new markets. The rapid advances of agrifood technology and modern rural economy management allowed to obtain benefits capable of transforming and making competitive the peri-urban space as a way of organization of the New Diffuse City. This new generation of dispersion landscape is related to the territory of peri-urbanity. In this figure, through discontinuity, a new agricultural space is introduced with unprecedented form and function. If we consider this space as a part of the new landscape, then territory and landscape must converge towards an innovative notion of values, nonmeasurable as trading values or economical goods, but as use values, that attribute weight to pragmatics implying a familiarity through the places they inhabit, carrying rhetorical and aesthetic values, as a premiss to an identity construction or the symbol of a renewed society.

The resistance of the farming space to the absorbing pressure of the neo-liberal city will depend, almost exclusively, on its own means and on the management of its resources and possibilities, as well as on the revitalization of its equipment levels and on the effectiveness of its means of transportation.

The enhancement and the creation of new techniques, as well as, in many cases, the farming units fragmentation, also beyond the commercial aspect, as in the case of the Hobby Farm movement and of some family vegetable gardens, generate a dynamic in which part-time farming includes a double occupation as social and economic reality. This generates a stable relationship between farming spaces and urban space economy. On the other hand, besides economic matters, this relationship between farming spaces and urban spaces has also come

\footnotetext{
${ }^{30}$ Witness of this process are the hesitations of local administrators, the disbelief of the farmers, the pressure of the new inhabitants and the different lobbys, as defended by ecologists and hunters.
} 
to imply social motivations rooted in certain urban population sectors with smallholdings and small family vegetable gardens. These are often marginal and not profit oriented, which indicates to a tendency to recover connected ways of life, contrary to what we have now.

From an ecological point of view, nowadays, this proximity between farming and urban reality may be the most efficient vector to achieving a sustainable city, capable of giving a better use to waste production and to the growing energy consumption.

A policy of maximum reduction of agricultural exploration uncertainties, under the dominant influence of the urban space, does not connect well with a new neo-liberal culture utilized as convincing proof of little solidary attitudes. Nevertheless, the maximum reduction of these uncertainties on agricultural explorations is in the recommendations of the OCDE. Before this organism agriculture must assume a decisive role in the organization of the peri-urban areas.

The management of European space policy inscribed in the European Spatial Development Perspective - Postdam 1999 - had the merit of putting between the primary objectives the orientation of the territorial community strategy towards a balanced urban system, reachable through new ways of city-countryside relationship, aiming to the integration of the poly-centric urban space of the metropolitan areas and peri-urban agricultural space, opposing to the union of the built fabric. The challenge of the contemporary city should start from the peri-urban agricultural space, which surface varies according to the greatness of the city, and which urbanity is more reinforced the more the urban center presents itself as a cohesive space, getting closer to the peripheries, including sections of field.

The peri-urban field landscape, for a long time seen as productive agriculture, can become again, as in the image of the English countryside of Humphrey Repton and Capability Brown, a place of new symbols and renewed aesthetic values, with no nostalgic intention and innovative activities, be it from the city, be it from agriculture, that do not refute the city but embrace the advantages of this closeness and its inter-relationship-.The urban periphery can simultaneously be a space of predominantly rural use that assumes some urban functions without losing its sense and its agricultural economy. Transformed space that had and has, almost permanently, the necessity to adapt to technological innovations and the increases in production being in this improving capability its shot at survival. In this sequence, it can include not only small or medium explorations but also those of bigger dimension that have been and is protagonist of the metamorphism of the peripheries, important to understand its evolution in time.

The history of peri-urban agriculture shows that, in the beginning of the 19th century, it was responsible for the production of food of the city. In the end of the said century with the big developments in transportation, peri-urban agriculture was responsible for the production of food of the city and neighboring cities (golden age of the horticultural periphery).

In the European market of the 60s of the 20th century, an enormous real-estate speculation takes place with the peri-urban agriculture. From the end of the 90s, the peri-urban agriculture painting varies a lot from region to region, with a bigger concern in this sense 
due to, in part, the enormous increase of the urban population and the economic crisis that is globally felt.

The peri-urban space is today, without a doubt, the most representative landscape of our post-industrial culture, setting a new expression that, in Europe, occupies almost the totality of the cultivable spaces, as it were the already natural form of expression of the agricultural spaces that need a high technological level and acquaintanceship with certain populations and activities [8].

The city demands a new culture concerning landscape. The expectations rural spaces create as to the location of activities already surpass peri-urban situations and the debate city/periphery/rural space, revealing a growing recovery of the landscape's multifunctionality, and implying a new understanding of their possible meaning as urban space support. What matters most is to surpass the notion of dependency of the rural space relatively to urban space. We believe that viewing the farming space as equal to any other soil use is the greatest contribution our time will leave as a legacy for the city's future.

Just as the proposition of landscape urbanism, concerning the relationship between the landscape and the city - landscape as an (infra)-structure determining urban planning and development - Donadieu, and also Ribeiro Telles, suggest - instead of trying in vain to control the city's growth through grids, belts, front sides, and green spaces - building the urban fabric from the farming and forest space.

Like many other authors - namely Corner, Donadieu, Hargreaves, Waldheim, and others - Marot [41] also says contemporary context has put landscape architects in the convergence of farming and urban traditions. This means they are at the core of an awareness directed to both viewing public spaces (urban projects) as landscapes and viewing landscapes (rural extensions) as public spaces and consequently as the projects' possible goals.

\subsection{Allotment gardens in urban voids}

The process of city growth, almost always over the rural space, has produced new peripheries, hiding with new urban fronts the view over the countryside, introducing in it the city vocabulary, the houses, the roads, the infra-structures, substituting the agricultural parceling for the regular strokes of pathways, for a hard and waterproof surface that overlaps the irregular, porous and topographical surface.

The roles played by the countryside in their proximity to the cities were canceled, modified or appropriated accordingly to meet the necessities of the city, often conflicting with the diverse logic of space occupation and urban methods, nature regulators.

The environmental question that appeared in the second half of the 19th century, in the sequence of the industrial city, was, as we have seen, target of thinkers like Howard, Unwin, and Geddes, that re-elaborated an innovative culture of inhabiting, finding inspiration in the poetic of the green. 
The modern society interrupted the dialog with the territory introducing the notion of void understood as the abstract plan of the urban stereometry, imagined isolated in a space regarded as isotropic. Newton was the motivator of the space of modern society - the space of abstraction, with no time, a space that is already between the filled ones but that is neglected. But the sanitarian question, after the First War, with the valuing of the free area and the sun that, paradoxically inspired the spatiality of the modern city nullifying the values of composition that are preponderant still today in many cities, or at least parts of them.

The theory of modern movement on the relationship between the city and the countryside was often misunderstood. With the image of the tabula rasa ended an articulated reflection that proposed the recovery of the urban green as a social value of rurality.

The word play country-cities in city-countries with which Walter Gropius pretended to rebuild the urban city in the countryside; the carefree workers that found job in the countryside; the meticulous design of the cultivation of Adolf Loos's allotment gardens in the houses of Siedlung Huberg in Vienna ${ }^{31}$; the socialization programs of the urban green aiming at the auto sustainability of the family centers promoted by Leberecht Miggie and of the Gartenkultur to the attribution of terrains attached to the house; the narrow complementarity between the urban thread and the agricultural space thought by Fritz Shumacher to the metropolitan area of Hamburg and Köln; these are just some examples that show the poetical roots of the garden-city in the modern movement knocking down the traditional relationship of dependence between the center and the periphery.

The possibility of food supply of the citizens in the planning of the countryside in the margins of the Siedlungen rediscovered the rural space as a part of the city and the allotment garden as new urban material.

The contemporary city recomposed the separation between the city and the countryside occupying the territory again, densifying the chosen places by the rich bourgeoisie, in the last century - the vacation houses, the sea, the lake, the mountain - appropriating itself of the rural space, building an enormous new city in the countryside, continuing to leave empty great portions of land in which the contemporary city project can and should take advantage of the potentiality of these empty interstitial spaces reestablishing their historic and topological value, comprising them inside a new urban space [43]. The discontinuity of the new urban territories can start with the reconnaissance of the genesis of these interstitial spaces that can be transformed to any use.

As it was referred, the category of the interstitial space has been an emerging problem to contemporaneity: the interstitial void renegades urbanization, it is not inserted in a project, or becomes a new product, or it is rejected by the countryside and becomes a non-cultivated and abandoned space. It results, generally, from the neglect that derives from the uncertainty of the way and the indefiniteness of the composition, left to an arbitrariness of a

\footnotetext{
31 "It is necessary to start from the garden. The garden is of almost importance, the house is secondary." In reference [42] (p. 109).
} 
flexible pretense made infraction from the collective interest point of view and of a mono functional vision. The interstitial space calls for a vacant spot, the abandonment, being able to contain, however, the promise of valuing.

Similarly to the Third Landscape by Gilles Clément, ecology approaches the interstitial space as a space where nature applies its projectuality, returning to the uncultivated the evolutionary dynamic of a natural habitat, more effective if it is near or inside the city, enabling the existence of a series of species of urban flora and fauna that encounter some naturalness in the inhospitable urban environment.

The theory of Gilles Clément has the merit of keeping the spaces empty, regardless of its destiny of use, dissociating the value of the space from its functionality, rushing the nature in the abandoned area and educating a new strategy of the uncultivated.

Also, the studies of urban ecology indicate the importance of safeguarding margins and interstitial areas, contributing to define rules and fundamental principles, namely to the construction of the urban countryside ${ }^{32}$ [20] or of the CPULs.

The emerging city is developed through multiple places of life, public or private, where the pulsating of the natural systems constitutes a third dimension of the city.

The hypothesis of construction either of the urban countryside, or of a CPUL (underlying the practice of agriculture) can found over the new idea of emerging city, given that it invites to consider the interstitial void as a positive property of the space and, consequently to favor every means of occupation that will provide value to this void, assuming it as a structuring element of the landscape and integrating part of the urban fabric. To the citizen, nature is first of all, the desire of a non-city or of another city, of a providential refuge, of a break. The city-nature project implies that the countryside turns into city, that the nature-countryside urbanizes itself and that the city naturalizes itself or ruralizes itself.

Outside of the built space, the emerging city-nature territory is composed by the three naturas, bound by singular ties, and that haven found over the centuries, namely in the roman villae and in the Portuguese Quintas de Recreio (recreational farms).

Interpreted according to this model, the voids constitute the interstices of the city and can be considered an evolutionary and reversible system, where its natural shape assumes a spatial and social importance that varies according to the production of the space, of the local policies and of the users - for example the family garden becomes, sometimes, the frontier of transition between the second and the third natura; the open space that is along the road network depends, almost always, of the urban functionality and the public parks are, often, stage of decorative intention.

\footnotetext{
32 Urban countryside or rural city? Two different points of view to two complementary and inseparable concepts - citycountryside and countryside-city: a countryside that is built with the city or a city that takes form with the countryside. The peri-urban countryside shoud provide the city. In the urban countryside a multiple activity should be developed (multifunctionality) that satisfies simultaneously the agricultural needs of the city provisioning and the recreational activities necessary to the quality of life of the populations.
} 
It is reinforced the idea that urban interstices are ideal spaces to include open spaces' projects that may contain urban agriculture and, simultaneously, spaces of ecological and social multifunctionality that are characterized by the continuity, polarity, differences in gradient and social diversity.

As it has been referred, urban agriculture is a term that refers to a description of what is pretended to be done but, can be, as well, quite conditioning. In an apparently radical idea it continues the western tendency to create meaning and to make decisions through the creation of opposite binaries [23].

Urban agriculture is innovative given that it is in contrast with rural agriculture. The interstices are left out of this opposition - the exterior rings of the cities, frequently neglecting and rudimentary, as well as the suburbs besides them, are often underutilized, producing a feeling of restlessness that guaranties, once again, the garbage deposit, the persistence of industrial parks with low rent warehouses, of abandoned allotments and of the existence of underutilized and insecure urban parks.

If we are capable of thinking in these interstices and other spaces as intense as, if not as more intense than, than consolidated areas with which they are related and connected, then the urban agriculture becomes one of the several intensification strategies, without being necessarily exclusive. It is one among many interventions of landscaping architecture.

The chances of building a productive landscape infra-structure may be based upon the new idea of an emerging city, for it invites us to view urban voids as a positive property of space, and consequently, to favor all occupation means valuing that void and setting it both as a structuring element of landscape and as part of the urban fabric.

Therefore, the notion that urban voids are the perfect spots for open space projects allowing urban farming and, at the same time, ecologic multifunctionality spaces characterized by continuity, polarity, gradient differences, and social diversity is strengthened.

In order for these allotment gardens to be successful, it is vital to create simple regulations ensuring that society will protect the value of natural processes, and itself. At the conceptual level, these spaces will provide an open space source essential to metropolitan areas, given the absolutely irresponsible way urbanization has been occurring (concerning natural processes and their values), generally, through the increase of the density of buildings inside the cities and extension to the peripheries, always at the cost of open spaces.

\subsection{Allotment gardens in the context of landscape urbanism}

Despite the strong structuralism potential offered by the design of allotment gardens, the matter of urban agriculture is not included in the landscape urbanism debate. The most frequent typologies of this current concern the rehabilitation of old infra-structures and brownfields, favoring leisure and recreational activities for the benefit of users, and a deep ecological rehabilitation of these spaces. 
However, given the potential of farming practices in urban space and their strong capability to support a conceptual structure, the subject of landscape design, reference must be made to allotment gardens, and to their inclusion in the scope of landscape urbanism.

We must also emphasize that, although this current does not include the productive dimension of landscape, and always keeping in mind our present goal to include the productive landscape system of urban space as well as, above all, the recovery of the landscape's multifunctionality, it's important to consider it in this project, for many different reasons:

- Because some landscape urbanism projects have successfully resisted the private sector's speculative mindset and the highly bureaucratic and technically oriented public sector.

- Due to the relationship between landscape and infra-structures being promoted.

- Because the strategies of landscape urbanism have given a voice to the territories' restoring of social and cultural formations - and the landscape's evocative power.

- Due to the criticism of landscape urbanism concerning the compromise of the classic design of urban project and planning and the need for an alternative to a new urbanism.

- Because landscape urbanism has emerged from landscape architecture, which explains its concerns extending to processes that include both the cultural and historical scope, and the natural and ecological scope [44], an idea that the emerging concept of ecological urbanism aims to enforce and potentiate [45].

- $\quad$ Because emerging practices involving landscape urbanism concepts teach many lessons to urban project design authors who wish to connect specific structures and flows of the population, activities, building materials, and time [46].

- Because it offers a complex program, at different levels filled with environmental, urban planning, social, cultural, ecological, technological, functional, and logistical mechanisms, and framings [47].

- $\quad$ Because it requires a new model of flexible and framed public spaces, caught in the web of social political, economical, and ecological currents in which they operate [48]

- Because these projects have the potential to unite the gap between ecology, creativity, and project design, so persistent since the impact of Ian McHarg's work.

- Because it opposes the random and opportunistic space composition that often rejects the landscape's organic structure.

- $\quad$ Because landscape urbanism identifies urban voids as urban space potential [49].

- And also because, in our opinion, landscape urbanism is a promising alternative available for the emergence of urban project design in the next decades, despite Diedrich's opinion [50] that considers that the development of the city from the landscape constitutes a practice to highlight in Europe, reason for which European landscape architects have never felt the need to, maybe wrongly, emphasize and utilize the concept of landscape urbanism.

The most clear proof of this are the countless prominent international landscape architects who coordinate projects proposing a great scale development in which landscape assumes ecological roles and is both a cultural authority reference and an identity mark. Among 
these landscape urbanisms' examples, we can refer Adriaan Geuze, Christine Dalnoky, Florian Beigel, James Corner, Joaquin Sabaté, McGregor+Partners, Michel Desvigne, Philip Christou, and Teresa Galí.

The landscape design appear as an essential motor in an urban and regional sustainable development and, the landscape architects, through their holistic and synthetic attitude, should appear as the major actors in an emerging approach to the system of spaces of collective use. In these spaces the landscape architect recognizes their organizing and structuring skills and their qualities, that can be flexibility, reversibility, inclusiveness and, above all, multifunctionality.

From the above mentioned principles we can therefore say that, nowadays, open space projects respond to a great variety of wishes and programs, and their themes do not vary as much as their users - occasional or permanent -, culminating in a multitude of approaches and solutions. Urban space has many different types of open space: fantastic new and old squares, urban parks, riverfronts, forests, and urban beaches. Nevertheless, the idea of a productive and continual structure is rare [5]. However, both, as well as other urban agriculture models, namely urban allotment gardens, community or pedagogical gardens, allow a centered approach in the management of urban spaces in a notable way.

In [20] is referred that the fact of describing urban space as an urban surface does not mean that it is relative only to the spaces between buildings, namely parking lots, plantation areas or residual spaces. Nor just the so-called urban parks, the neighborhoods or the few remaining natural spaces.

The landscape present in the urban space corresponds to the living and energetic structure that organizes and supports a vast range of fixed and transformable activities in the city. The landscape is dynamic and literally makes events happen in time. In this sense, the urban surface can be considered similar to an agricultural field, assuming different roles and geometries, distributive regimes and appearances, as the circumstances demand it. This adaptability will be conditioned, in part, by the topography, for a smooth and uninterrupted continuity to be achieved, but also for the equipment and services existent. This way, if the purpose of the project design of the urban surface is to increase the support and diversify activities in time - even activities that could not be determined from the start - then one of the first strategies of the urban drawing is to broaden its continuity while it diversifies its range of services. That is, fewer project design as passive improvement and understood more as an active accelerator, establishing and creating new conditions to the uncertainty of the future.

For the character presented by urban agriculture, for its potentialities and its pertinence we think that we can consider the agricultural space, in the broadest sense of the term, as a natural infra-structure of public interest, in the same level of roads, dams, or electrical networks; in the same level of public or private woods, for social, economical and ecological reasons. The structure of the agricultural landscape, namely the productive allotments, the hedges for the wind, wells, canals, pathways, vegetable and aquatic surfaces, are other ways that break the mineral compactness of the agglomerate, contributing to the purification of the urban micro-climate, among many other benefits. 
The agricultural space creates the necessary voids to the comfort of their inhabitants or to their safety in case of a fire, for example. Its reversibility allows, mainly, the possibility of an open project, making available public opens spaces for leisure purposes, with the condition of being guaranteed the safety of people and their goods. It makes available a cultivated area from which the citizens can make a collective use, in the same way of a public park, that still produces food, offers walking routes and pedagogical services to the schools; and allows to recycle urban residues, namely a part of the water and urban organic garbage.

If they are not coordinated, these uses and utilizations are not spontaneously compatible and may even exclude one another. It is important to think in articulating them and accepting a juxtaposition by exclusion. The concept of spatial agricultural infra-structure, CPULs, or, we can say, of urban countryside - as it is understood by Pierre Donadieu - is not spontaneously born, it requires involvement and joint action of public administration, farmers and inhabitants. These services provide collectivity with a price that should be payed proportionally to the objectives of public interest, of private companies that provide it and of the farmers. In practical terms, the public and private services play a complementary role to keep this infra-structure in time and, mostly to attribute the one function deemed as a priority by the administrators: natural area, leisure space, agricultural terrain, etc. To be able to persist, the cooperation between public organizations and communities should be integrated in a contract.

For us, agriculture and less dense urbanization, together with the ecological and infrastructure tendencies, are part of the landscape architecture's contemporary discourse and, in this sense we corroborate the thoughts of Michel Hough, Richard Forman, Denis Delbaere and Pierre Donadieu, among others. The agriculture and gardens analogy is linked to an underlying quantifiable and infra-structural support, in which cultures follow the movements and dynamics of energy transfer demands, ever since the comprehensive and integrative conception of landscape architecture. This agricultural analogy shares similarities with landscape urbanism that can be very interesting at the theoretical and practical level.

\section{Results}

\subsection{Allotment gardens as a new approach to landscape project in urban space}

The lack of a clear reference to urban agriculture as a way to establish a clear relationship between production, safety, and leisure, and the fact that it is an essential activity in the face of the present and expected future energy and food crisis, has led us to see urban farming, not only as a production factor, but also as having a great recreational potential, under a social, economical, ecological, cultural, and aesthetic point of view. As such, we see it as an essential structure in the re-conceptualization of urban space project.

The project of the urban whole, an extensive metropolis, from which emerge small forest or rural islands, and the project of the city's strict containment facing a dying and inanimate countryside, are no longer sustainable nor realistic. The old utopia of the garden-city no longer promises Mumfordian functionality, and the city in the countryside reflecting 
rurality adapted to the urban need of leisure is no longer an attraction. There's an alternative based on two compromising and not very changeable tendencies - on one hand, the urbanization of Western culture and its need of countryside as an alternative to urban environment; and, on the other hand, the farming economy diversification in response to an urban question not exclusively connected to food.

A project such as this generally and effectively contradicts the principles of open space planning that usually eliminate agriculture in urban areas, replacing it with public parks and gardens. In addition, it contradicts the principles of a planning that divides urban spaces in many specialized areas with apparently incompatible roles (farming production, leisure, industrial and commercial activity, among others). To make things worse, local entities are always less capable of sustaining the high costs of the creation and maintenance of new green spaces, and the social damages of urban planning zoning are very clear - space segregation, social ghettos, functional inconsistencies, urban identity crisis, among other.

We firmly believe that allotment gardens could and should integrate a continual structure of production and recreation. The arguments to give planning technicians and managers favoring a city with farming areas in an assumed form instead of a dense urban center, should present farming spaces, in a broader sense, as a public interest natural infra-structure at the same level of roads, dams, or electrical networks, and of public and private forest, for social, economic and ecological reasons [20].

The concept of farming spatial infrastructure requires cooperation between public administration and farmers. The price of these services to society from private companies supplying them, and from farmers is set according to public interest goals.

In practical terms, public and private services should assume a supplementary role to keep that infrastructure in time, and most of all, to confer the role privileged by administrators: natural areas, leisure space, farmland, etc. In order to last, the cooperation between public organizations and communities must be ruled by an agreement.

Both the concepts of urban field in [20], and of continual productive urban landscapes in [5], are included in this concept of farming spatial infrastructure, in turn approaching the concept of landscape urbanism and, consequently, of landscape architecture philosophy and practice.

Although the implementation of productive landscapes can start at a small scale, the goal is to develop a productive and continual urban city. At the largest scale, it should include a network of open spaces throughout the urban fabric, which in turn includes farmlands in the continual landscape, as suggested in Plano Verde de Lisboa (Figure 1).

Mainly following models of gardening centers, and gardens, and influenced in the last 20 years by the concept that links the ecology paradigm, open spaces, and the system they form, they should be now the tissue and the net on which the organization of continual productive urban landscapes or the urban field are based [20]. Not as inert spaces, but as living farmland, and forests, in a slow or quick, cyclic or continual future. The tool to build that future is the landscape project capable of mobilizing the people's community in that sense [52]. 


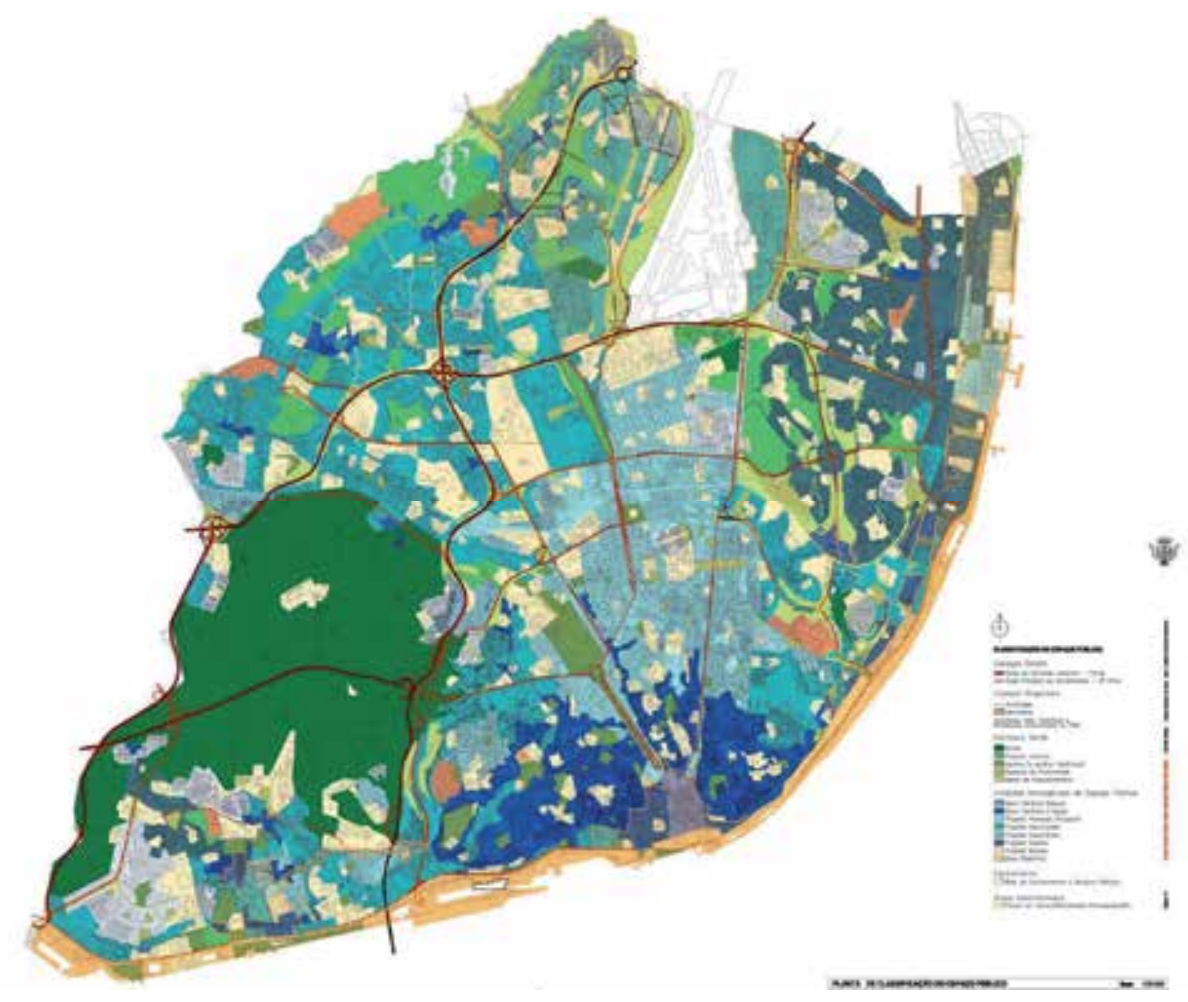

Source: Lisbon City Hall (CML)

Figure 1. Lisbon's Green Plan - Strategic masterplan for the open spaces.

\subsection{Practical examples - Plano Verde de Lisboa}

Presented in 1997 by the landscape architect Ribeiro Telles [1] and now set in motion, Plano Verde de Lisboa is a system of corridors connecting recreational and production areas seeking the establishment of a continuum naturale (Figure 2). 


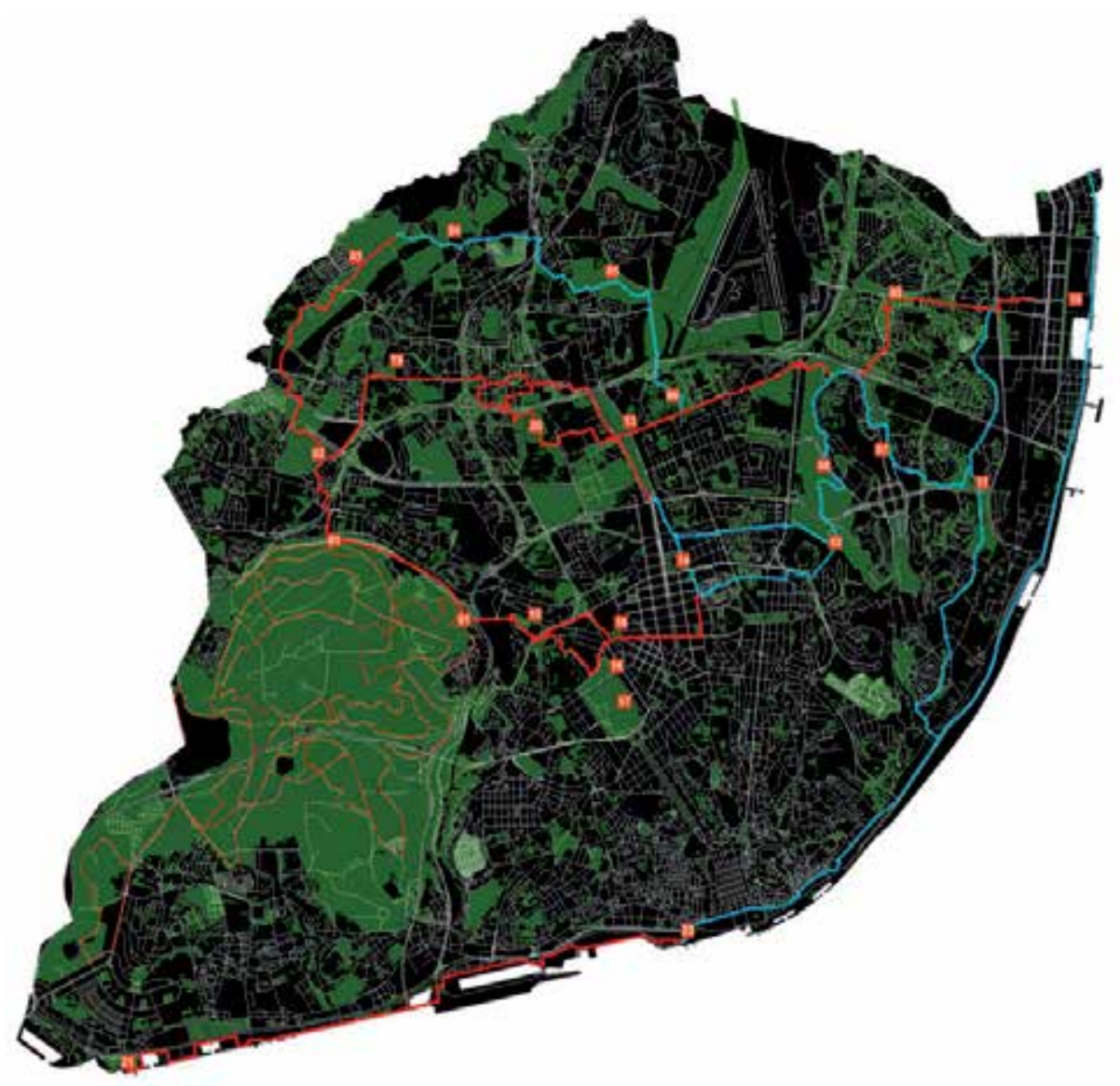

Source: Lisbon City Hall (CML)

Figure 2. Lisbon's Green Plan - Articulation between pathways and open spaces

This plan makes it possible to obtain a continual landscape in which the productive aspect is strongly considered with the inclusion of existing urban vegetable fields and suggested farming parks, namely Quinta da Granja (Figure 3 and 4) and the Parque Hortícola de Chelas (Figure 5 and 6). This productive side is articulated with recreation and circulation, in a structure of open spaces extending all over the city. 


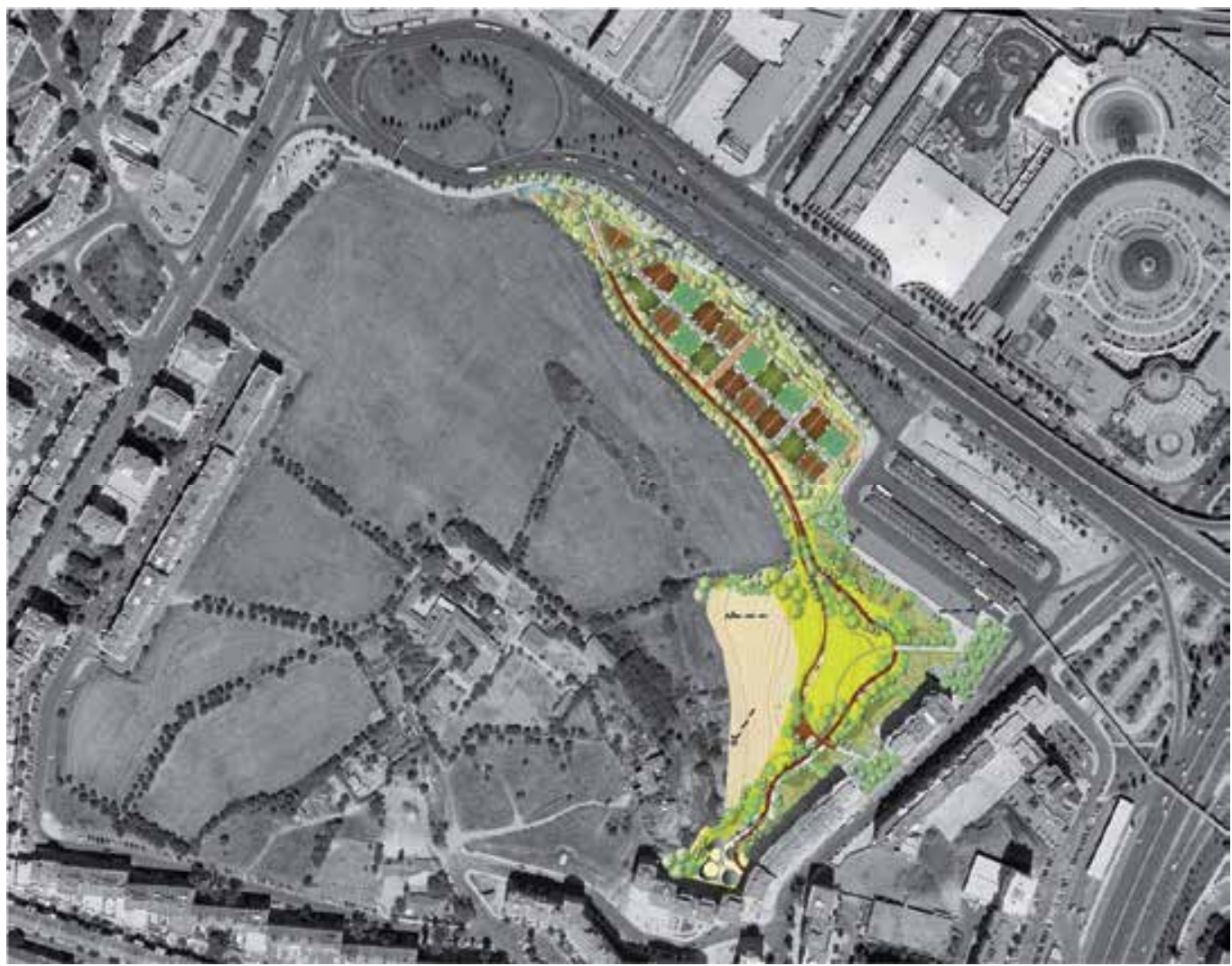

Source: Lisbon City Hall (CML)

Figure 3. Figure 3 - Landscape design masterplan for Quinta da Granja

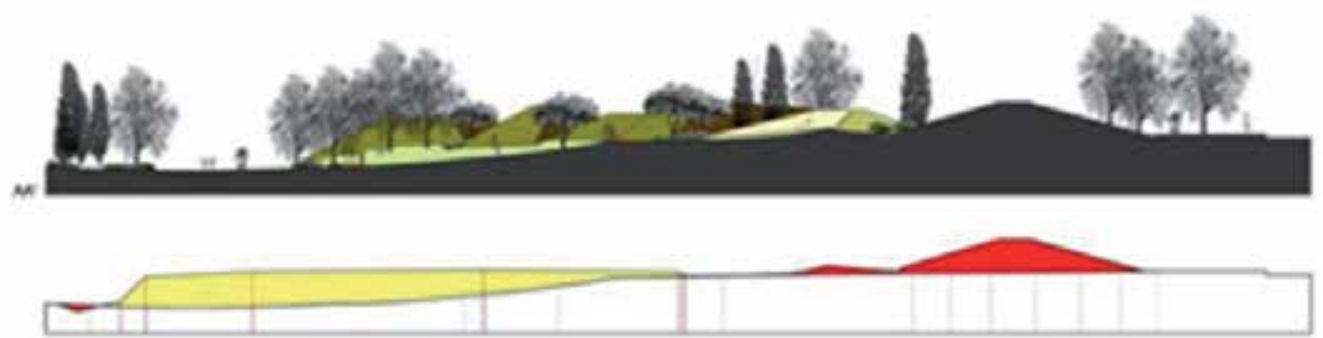

Source: Lisbon City Hall (CML)

Figure 4. Section of Quinta da Granja landscape design 


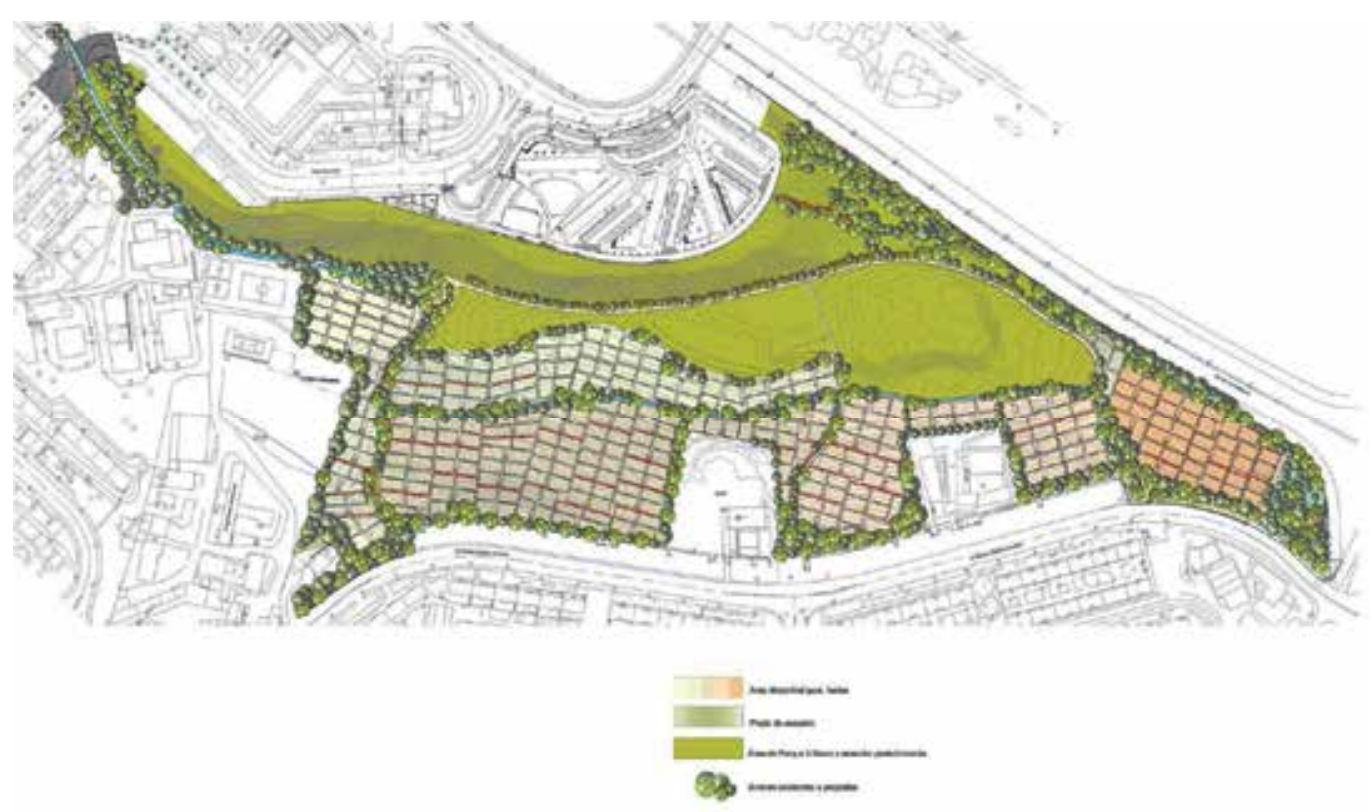

Source: Lisbon City Hall (CML)

Figure 5. Landscape design masterplan for Horticultural Park of Chelas

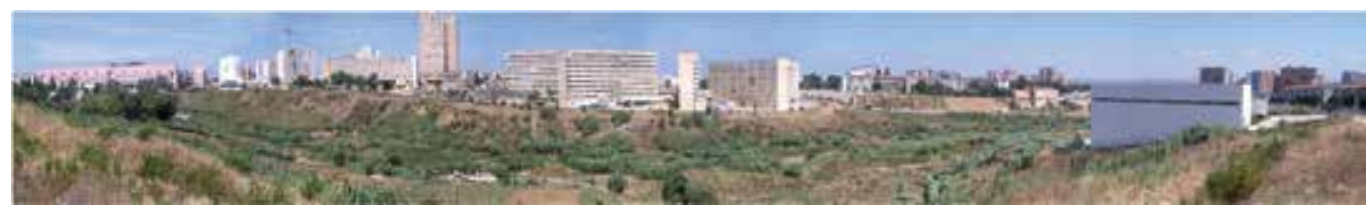

Figure 6. Section of Chelas valley

In the first stages of the implementation of these landscapes, a series of interventions leading to a network of linked spaces were made. In time, this approach will create a sense of opening inside the urban space that would otherwise be uniformly occupied by buildings. The implementation of this strategy makes underused and/or abandoned spaces become active and used in a socially and environmentally productive way. A new meaning and sense of opening are locally introduced through the definition of outward sights and great panoramic views, as opposed to the series of isolated, disconnected, and largely underused land plots they would form.

The benefits occur regardless of the intervention scale. Linear spaces can provide routes connecting different public or private spaces. Making that connection visible encourages movement among them. The relationship between the routes and the landscape can be seen as an intervention emphasizing it and highlighting. In Quinta da Granja and in Parque Hortícola de Chelas, daily routes become adjacent to spaces where food is grown (Figure 7). 


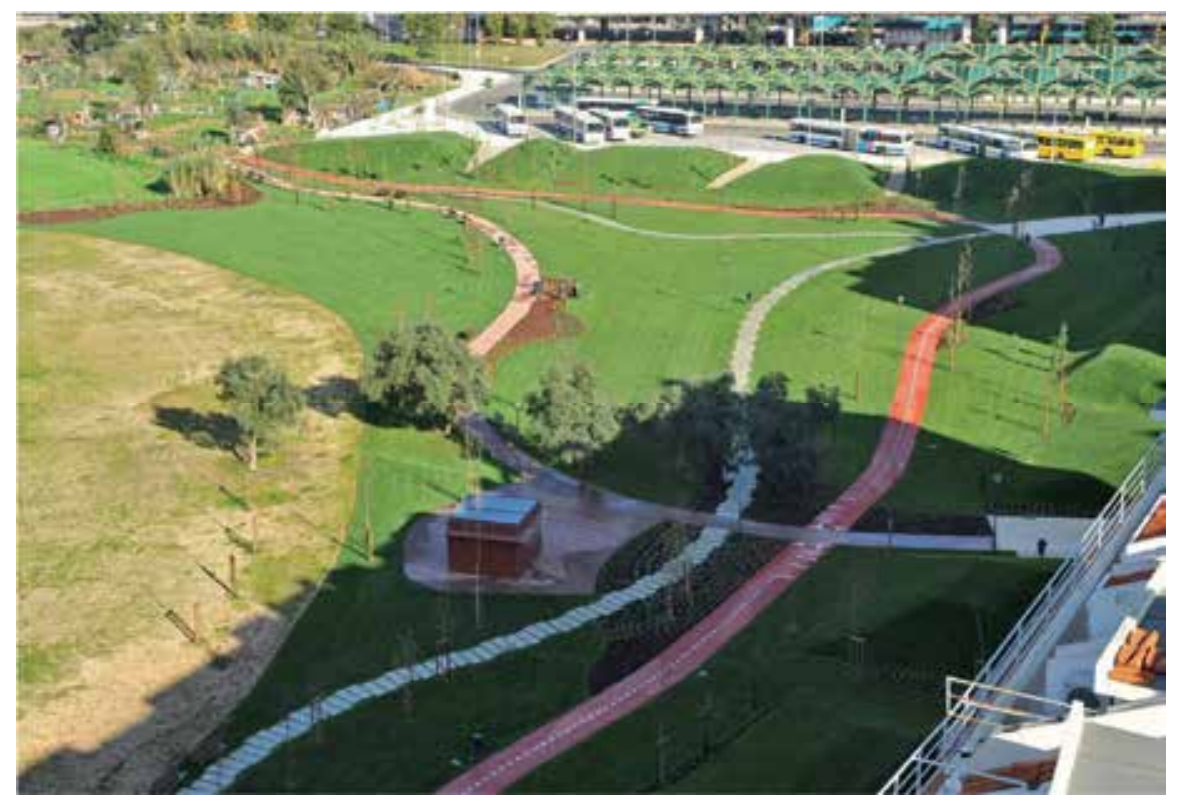

Figure 7. Pathways on Quinta da Granja

Each walk among cultures accentuates the experience of seasonality and intensifies the notion of time, due to the density of space where nature is experienced. Time is intensified - more nature for its time.

Productive urban landscapes will be part of the idea of building from the natural, like parks and gardens, which are frequently understood as natural. Allotment gardens in particular will represent the idea of countryside, of rural life, and through that image, nature is also represented.

One of the most important characteristics of these landscapes is the way in which a great variety of occupations occur simultaneously, such as gardening, farming, sports, and leisure activities (Figure 8), practiced by many occupants, that can be articulated with one or more occupations found. The variety of possible permutations between an individual occupant and their activity, or the several activities or occupations is generally larger than in many public types of facilities, namely leisure centers. Continual productive landscapes combine the peaceful qualities of a park with physical activities. They expect to be occupied, both by someone looking for a place to relax and read, and by someone who wants to practice physical exercise.

The economical profits of land use can be measured in two ways: first, by the direct quantification of economical benefits, resulting from new jobs and companies; secondly, and following an argument that becomes more relevant in the long run, by measuring the reduction of environmental degradations through the action of productive urban landscapes. These benefits result from the reduced environmental impact and cut future costs of environmental correction work. 


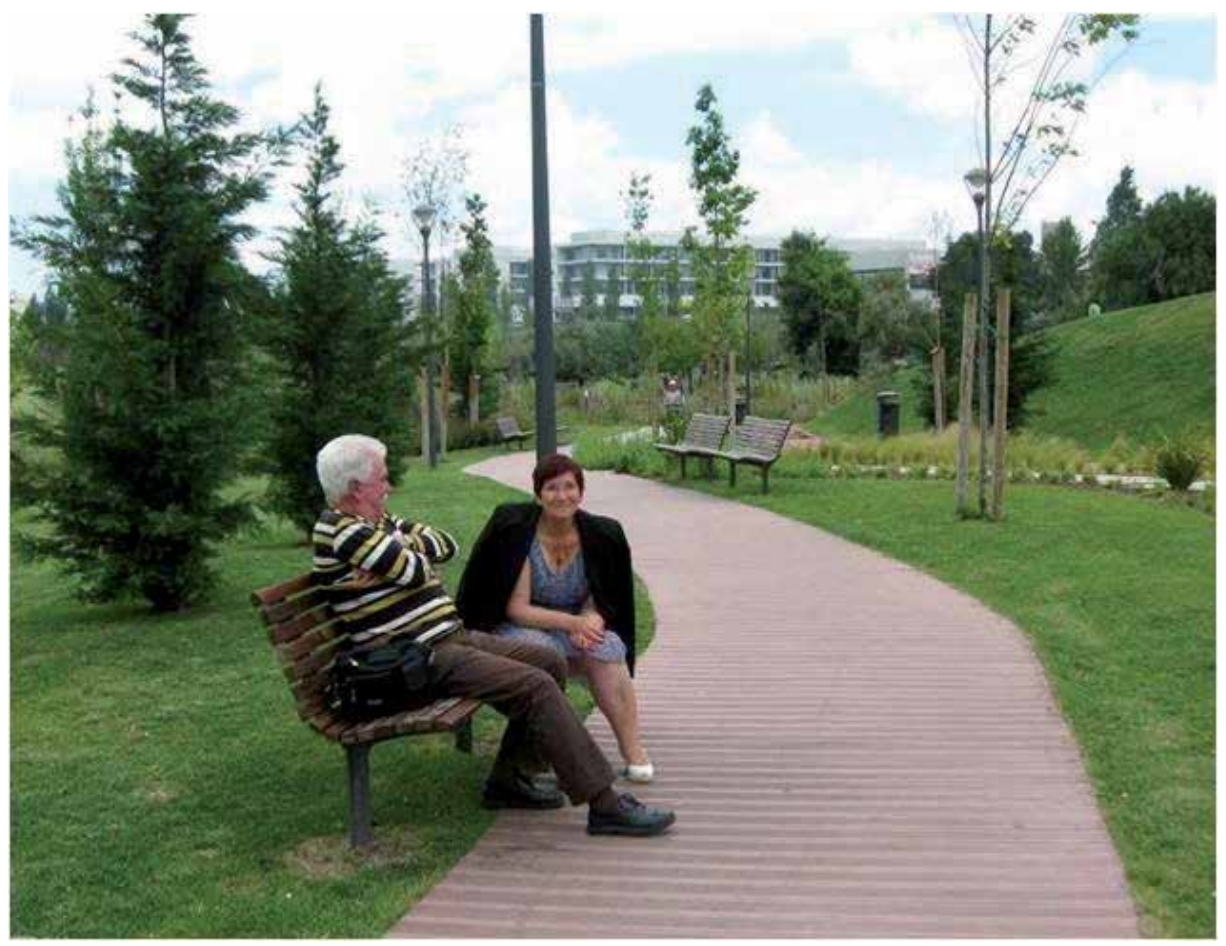

Figure 8. Pathway and sitting on Quinta da Granja

Farming practices can generally be used as part of a strategy to increase development. Consequently, the increase of development will combine economical and environmental strategies. Those strategies are acquired by surveying, planning, designing, and articulating urban voids, parks, and recreational areas.

The introduction of these landscapes will increase the number of habitats for animals and, therefore, biodiversity - an example of ecological intensification. At the same time, the development of composting systems as the base of organic farming will improve the soil and reduce the traffic of cars. Therefore, the improvement of biodiversity will reintroduce the chirping of birds, the buzzing of insects, and the sounds of nature in general.

\subsection{Implementation strategies}

The open spaces of a city embracing a continual productive landscape infrastructure will change the physical landscape and its occupation. Superficially, farmers will sculpt a new urban infrastructure, constantly changing, but always familiar, as crops come and go (Figure 9).

At the same time, a landscape of circulation and movement, and multifunctional, emerges as the populations move and interact in and with the farming landscape. Theoretical studies and practical applications will be adjacently rediscovered, not to destroy the city or let nature be conquered, but to enhance both sides through the acknowledgment of their interdependence. 


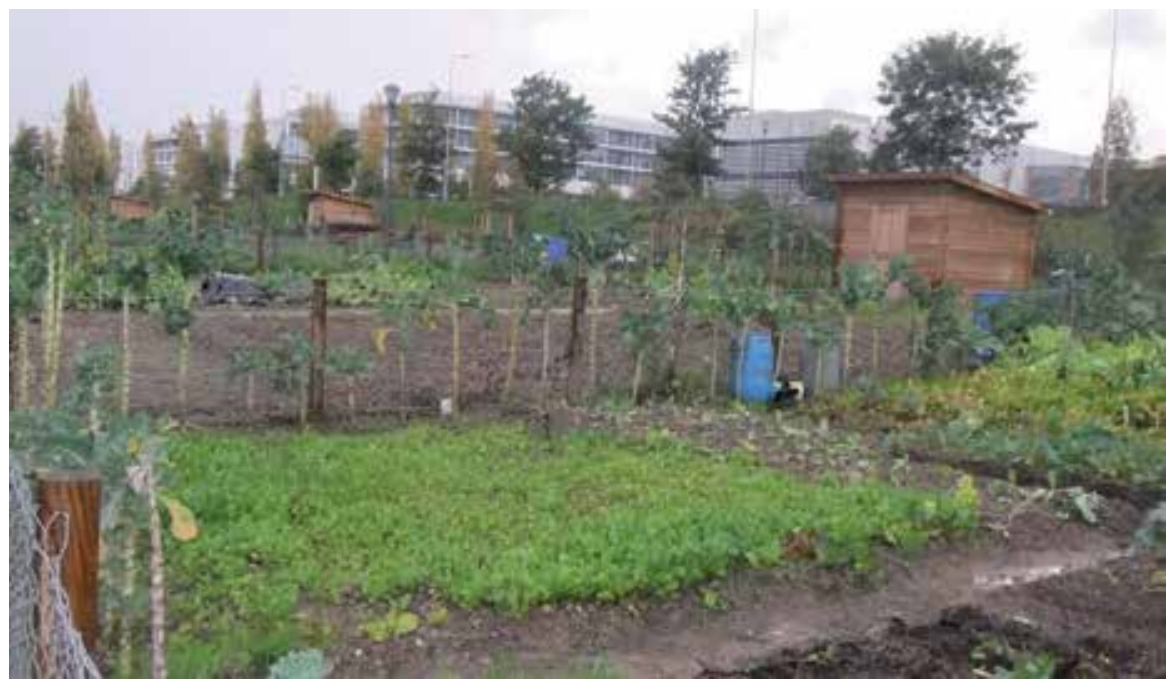

Figure 9. Allotment gardens on Quinta da Granja

In this context and in order to assure and increased the chances of success, farming in urban spaces requires:

- A considerable organization to acquire adequate lands and its farming, so as to allow lands not used or underused to be turned into areas with environmentally productive uses, namely the production of bio-fuel. The essential prerequisite of any attempt to change in that sense is to start understanding the city, the periphery, the suburbs, and the countryside as part of a continuum extending from the more densely populated areas but still ecologically active to the less densely populated areas and therefore more ecologically active.

- Simple regulations ensuring the safety of the community and of the values of natural processes. In a well-thought way (the lands where those processes occur) will provide a source of open spaces for the metropolitan areas. Ideally, the metropolitan area should include two systems - on one hand, the natural process preserved in the open space, and on the other hand, urban development. The fusing of these two systems could satisfy the provision of space for the population [53].

Although urban farming is conditioned by many social and political circumstances and political regimes, urban legislators and support institutions may make a substantial contribution to the development of a safe and sustainable farming through:

- $\quad$-The creation of a guiding environmental policy and the formal acceptance of allotment gardens as an urban feature;

- $\quad$ The strengthening of the access to urban voids and to the safety of farming use;

- The strengthening of productivity and economic viability of allotment gardens, by improving the access of urban farmers to training, technical advice, and credit;

- The support of the establishment and the strengthening of urban farmers' organizations; 
- Measures preventing environmental and health hazards associated to farming.

As we have already seen here, and contrary to the common belief, in densely urbanized areas a surprising number of urban voids can be found and used for farming on a temporary or permanent basis. City governments can ease the access of urban farmers to these interstitial spaces by several means:

- $\quad$ Surveying the number of the city's urban voids and studying their farming potential;

- Creating a Municipal Land Bank connecting those who need farmland to the landowners who need to give a temporary or permanent use to their properties.

- Encouraging the owners of urban voids (including institutional owners) to offer their lands in a mid-term concession to organized groups of farmers, with tax benefits.

- $\quad$ Creating regulations to organize the (temporary) use of voids in the city.

- $\quad$ Granting the use of municipal urban voids to organized groups of farmers.

- Taking steps to improve the availability and the conditions of the land (for instance, removing debris or providing access to drinkable water for irrigation).

- Defining areas for allotment gardens in a permanent basis and integrating them in the city planning. Those areas will usually be more sustainable when located in lands not destined for construction or not adequate for construction, namely wetlands, under high voltage lines, and in parks and nature conservancy areas. Effective guidelines should be created with the active involvement of farmers, including management practices to be adopted by urban farming in several locations.

- Giving assistance to relocate urban farmers, especially those who are not in a favorable position and, therefore, who are exposed to serious health or environmental hazards.

- Including space for individual or community gardens in the new public housing projects, and upgrading plans for poor neighborhoods.

Government organizations and the private sector should be encouraged to provide training, technical advice, and services to urban farmers, with a strong emphasis on ecological farming, adequate health risk management, farming development (for instance, intensification and diversification), company management and advertising. Cost sharing systems (among farmers, local authorities, sector organizations, and private companies) will be needed to ensure the system's sustainability.

Municipalities can also encourage the city's universities, non-governmental organizations, and community organizations, to actively support farmers' organizations, their development capabilities, and their connections to other groups of farmers, private companies, consumption organizations, and support organizations.

The municipalities and other local participants can communicate the research and technology development needs of their urban farmers to research institutes and to the national government. On the other hand, there should be a better promotion of the coordination of research institutes, farming organizations, non-governmental organizations, and urban farmers groups.

An increasing number of Portuguese cities are creating urban farming policies and programs, with the establishment of multi partnerships in planning approaches to find 
effective ways to integrate it in urban planning and sector policies and to promote the development of safe, sustainable and multifunctional farming practices. An example of these initiatives is the regulation made by Lisbon's City Council legitimizing the existence of its vegetable gardens in order to safeguard them from political whim.

Besides measures such as these, we think it's necessary to explore the relationship between urban agriculture multifunctionality and sustainability. This involves the positive or negative study of environmental roles, as well as their collective impact. In [3] , it is also important for the effectiveness of farming in urban spaces: to research and develop subjects such as land ownership, legislation, and planning, concerning urban land use; to develop work methodologies with all the participants, namely research actions with urban farmers or planners to include agriculture in planning (as part of green belts, city parks, and open spaces); to create new institutions or institutional structures, such as urban and peri-urban institutions; and to create means of support (commercial and of subsistence) for horticulture, aquaculture, and systems involving animal raising.

Such research and development actions require an institutional framework providing allotment gardens with an institutional foundation, and involving active direct or indirect players in the formulation and implementation of urban farming policies and action programs.

Once accepted, urban farming will become sustainable and adapt to the ever-changing urban conditions, and to its demands, strengthening its productivity and diversifying its roles in the city, while reducing the associated health and environmental hazards. This is the way to win political and social acceptance. In certain parts of the city, the typologies of the existing farming practices can fade away or drastically change their methods and actions, while new methods may develop in other parts of that same city (Figure 10).

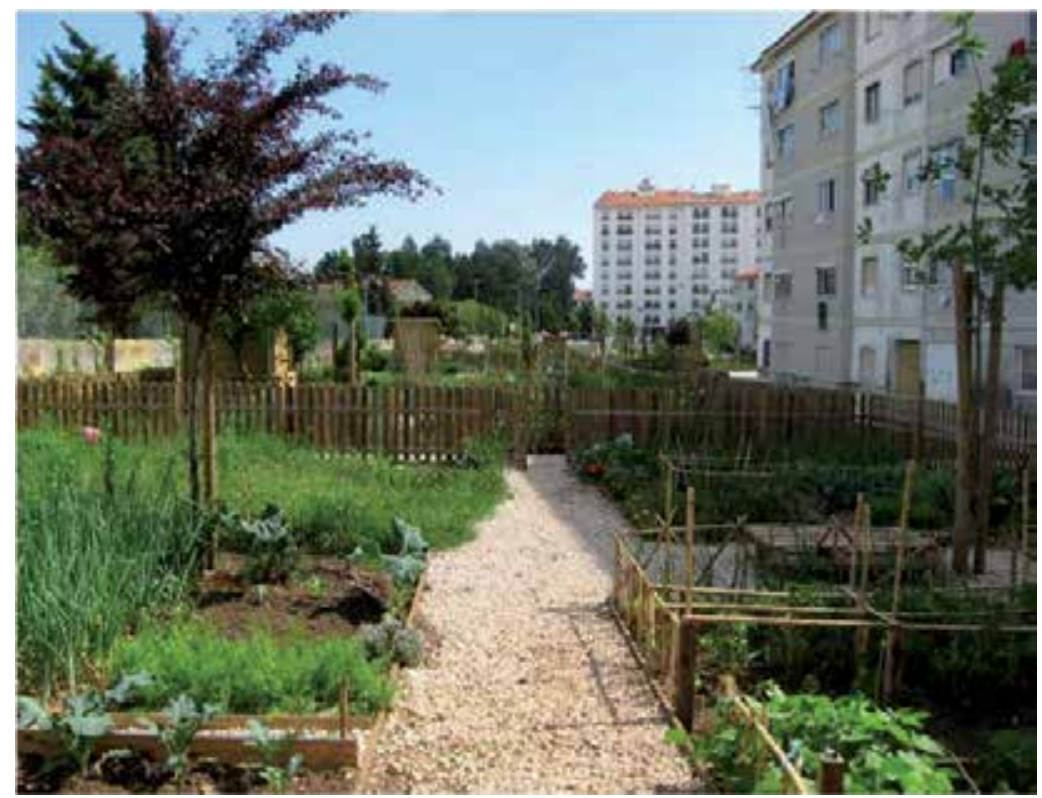

Figure 10. Organic allotment gardens on Cascais 
In the long run, allotment gardens become sustainable through the acknowledgment and the full development of their multifunctional use potential. Their sustainability is strongly connected to the development of a sustainable city, that is, an inclusive city, ensuring food safety, productivity, and a healthy environment [54].

\section{Conclusion}

In short, urban areas are generally characterized by their organic growth, resulting in a multitude of different public and private open spaces. The design and management of those spaces depend on many factors. Although some have been planned and continue being positively managed, others were forgotten in terms of a clear sense of ownership and responsibility, and are left in a natural or artificial wild state, requiring respect and protection. These are transitional, landscapes, made of time, and registering its passage. The past becomes the present, and as the future draws near, acquiring larger and larger dimensions, we see a magnificent and silent presence, which is a kind of empty spot within the storm.

Finding positive uses for these spaces has been one of the challenges facing urban planning from the late 20th century on, with a growing number of architecture, landscape architecture, and landscape urbanism projects now proposing the inclusion of urban farming.

We need to go towards more efficient, and cyclic urban systems; a perspective which naturally includes land use within the cities and in their peripheries for food production.

We also believe the inclusion of allotment gardens in landscape projects reflects a new landscape, new symbols, and renewed aesthetic values, setting new patterns reaching from the memory of the past to the future, where nature, culture, leisure, and production are present, mutually complementary, and giving birth to public spaces with a strong involvement of the population. The development of these spaces may be suggested as a reference illustrating a seemingly contradictory response to contemporary callings, and which is both the cultural strengthening of the truthfulness of humanization processes, and the creation of a nature that is simultaneously wild and familiar, near and distant, planned and spontaneous, dangerous and comfortable, tedious and ordained, alive and waste free.

Our approach to urban design is founded on a global and multifunctional concept of landscape, through the fulfillment of the idea of cultural and natural continuum, and its intermingling with the built space, materialized in a complex and dynamic landscape, structured both by technological networks, and by heritage, ecological, continual, productive, and active networks. Therefore, it matches a global design inspired by nature, culture, and landscape, with the fundamental goal to recreate the city-countryside unity, to reinvent the landscape multifunctionality, and to develop forces allowing life, in the sense of an ever-growing biologic activity of systems integrated in the landscape, and responding to the aesthetic restlessness and to current social and cultural needs.

In urban configurations, and the resulting landscapes, through an active interpretation, the system of urban voids and the city peripheries matches the genuine infrastructure of the city, 
through which it's structured and organized. Those spaces are no longer considered fragments, residual elements, or discontinuities, and are acknowledged as spaces that being part of the new model of organization and territorial management, unite, interconnect, create continuity and articulation. They're active.

Therefore, the strength and vitality of the urban void and the periphery emerge, not as abandoned areas - a residual space of buildings and urbanizations - but as continual, adequate, felt, and experienced spaces with ecological, cultural, recreational, aesthetic, productive and economical purposes, as valuable as the spaces with buildings, articulating different parts and promoting connections in the urban area [55].

Capable of significantly changing current mobility trends, and of integrating the existing urban fabric without causing a great impact, this new approach is directly linked to urban sustainability and to landscape sustainability and multifunctionality. The employment of the sustainability and multifunctionality concept and principles underlying the advised design model implies a process in which the continued use and preservation of resources, the spatial organization and management, and the associated institutional changes are consistent with the goal to perpetuate in time the quality of life and the environment, the cultural heritage, the landscape identity and balance, and the ecosystems' social, and economic roles.

By sharing the idea that the world includes complex, interdependent, and interlinked social and natural systems that, reconciled and sustainable, provide a set of principles centered in the organization of soil uses according to their ecological capability which help preserve natural systems and resources in the long run, and create strong, well-knit social communities, we seek a systemic view of a multifunctional, productive, and recreational landscape, emphasizing the multifunctional landscape. The landscape is transformed into something different: a place sensitive to different transformations that records the movements and the events that occur. An active entity structuring conditions to new relationships and interactions between the elements that constitute it. In this new concept the landscape is no longer based on a naturalist image, suggesting instead a continuous structure where we can operate through the occurrence of different activities. It is not only the space between the two buildings or the platform in which the process of construction is organized, but a true energy field, a sensitive and dynamic membrane. It is constituted of systems that establish relationships, flows and process that occur there [55].

On the other hand, 21st century urban design should start by getting closer to the design of natural ecosystems. We should learn with the natural systems' metabolism, where all waste is recycled in resources for future growth [56]. This is a matter for politicians to deal with, but that also concerns the public in general, because we all need to pressure central and local governments as well as investors to adopt practical views.

\section{Author details}

Rute Sousa Matos

CHAIA (Center of Art History and Artistic Investigation), University of Évora, Évora, Portugal 
Desidério Sales Batista

CHAIA (Center of Art History and Artistic Investigation), University of Algarve, Faro, Portugal

\section{References}

[1] Ribeiro Telles, G. Plano verde de Lisboa. Lisboa: Edições Colibri;1997.

[2] Mougeot, L. Urban agriculture: definition, presence, potentials and risks. In Bakker, Dubbeling, Gundel, Sabel-Koschella \& Zeeuw, (eds) Growing Cities, Growing Food: Urban Agriculture on the Policy Agenda, Feldafing: German Foundation for International Development (DSE), 2000, pp. 1-42.

[3] Veenhuizen, R. van. Cities farming for the future. Urban agriculture for green and productive cities. Philippines : International Institute of Rural Reconstruction and ETC Urban Agriculture. 2006.

[4] Mougeot, L. AGROPOLIS, the social, political, and environmental dimensions of urban agriculture. London: Earthscan. 2005.

[5] Viljoen, A. CPULs, continuous productive urban landscapes - designing urban agriculture for sustainable cities. Oxford: Architectural Press. Elsevier. 2005.

[6] Southall, A. The city in time and space. Cambridge, UK: Cambridge University Press; 2001.

[7] Mininni, M. Abitare il territorio e costruire paesaggi. In: P. Donadieu (Ed.) Campagne urbane, una nuova proposta di paesaggio della città. Roma: Donzelli Editore. 2006, pp. 22.

[8] Sierra, P. Periferias y nueva ciudad - el problema del paisage en los procesos de dispersión urbana. Sevilla: Universidad de Sevilla, Departamento de Urbanística y Ordenación del Territorio. 2003.

[9] Hough, M. Naturaleza y ciudad. Planificación urbana y procesos ecológicos. Barcelona: Editorial Gustavo Gili. Coleção Arquitectura y Diseño+Ecologia. 1998.

[10] Shane, G. Recombinant landscapes in the American city. In: M. Spens (Ed.). Landscape architecture: site/non-site. AD Architectural Design. Wiley InterScience. 2007, March/April. Vol. 77, n. 2, 24-35.

[11] Carvalho, J. (2003). Ordenar a cidade. Coimbra: Quarteto Editora.

[12] Remy, J., \& Voyé, L. La ville: vers une nouvelle definition. Paris: Hartmattan. 1992.

[13] Cook, H., Lee, H., \& Perez-Vasquez, A. Allotments, plots and crops in Britain. In A.Viljoen (Ed.). CPULs, continuous productive urban landscapes - designing urban agriculture for sustainable cities. Oxford: Architectural Press. Elsevier. 2005, pp. 206-216.

[14] Iles, J. The social role of community farms and gardens in the city. In A. Viljoen (Ed.). CPULs, continuous productive urban landscapes - designing urban agriculture for sustainable cities. Oxford: Architectural Press. Elsevier. 2005, pp. 82-88.

[15] Thorpe, H. The homely allotment: from rural dole to urban amenity. Geography 1975 ; (268)169-183.

[16] Urruela, E. Dinâmica agrária en la crisis industrial. El microfundio periurbano del Gran Bilbao y las Encartaciones. II Congreso Mundial Vasco de Geografia. Espacios rurales y urbanos en áreas industrializadas. AA.VV. Vitoria, Brasil. 1988. 
[17] Carrasqueno, M. (1996). Espacio urbano y socialidad: un analisis de las huertas submetropolitanas en el barrio bilbaíno de Bolueta. Ciudad y território. Estudios territoriales 1996; (110) 765-783.

[18] Magalhães, M. A arquitectura paisagista, morfologia e complexidade. Lisboa: Editorial Estampa. 2001.

[19] Bohn, K., \& Viljoen, A. More space with less Space: an urban design strategy. In A. Viljoen, (Ed.). CPULs, continuous productive urban landscapes - designing urban agriculture for sustainable cities. Oxford: Architectural Press. Elsevier. 2005. pp. 10-16.

[20] Donadieu, P. Campagne urbane, una nuova proposta di paesaggio della città. Roma: Donzelli Editore. (Original publication in French, in 1998). 2006.

[21] Burckhardt, L. Esthétique et Écologie. In : L. Burckhardt (Ed.). Le Design au-delà du Visible. Paris : Éditions du Centre Georges-Pompidou. 1991. pp - 53-60

[22] Baud, I. Coping with globalisation. The need for research concerning the local response to globalization in developing countries. Den Haag: RAWOO. 2000.

[23] Hagan, S. Plant it: an inclusive approach to environmentally sustainable planning. In A. Viljoen (Ed.). CPULs, continuous productive urban landscapes - designing urban agriculture for sustainable cities. Oxford: Architectural Press. Elsevier. 2005. pp. 52-55

[24] Berg L. van den \& Veenhuizen R. van (2005). Multiple functions of urban agriculture. Editorial. Urban agriculture magazine 2005 ; (15).

[25] Argenti, O. Food for the cities: food supply and distribution policies to reduce urban food insecurity. Rome: FAO. 2000.

[26] Nugent, R. The impact of urban agriculture on the household and local economies. In N. Bakker; M. Dubbeling; S. Gündel.; U. Sabel-Koschella; H. de Zeeuw. Growing cities, growing food: urban agriculture on the policy agenda. A reader on urban agriculture. DSE/ETC, Feldafing. 2000. pp.67-99.

[27] Armar-Klemesu, M., \& Maxwell, D. Urban agriculture as an asset strategy, supplementing income and diets. A case study of Accra. In N. Bakker, M. Dubbeling, S. Gündel, U. Sabel-Koschella, \& H. Zeeuw (Ed.). Growing cities, growing food: urban agriculture on the policy agenda. A reader on urban agriculture. Feldafing: DSE/ETC. 2000. pp. 99-117.

[28] Gonzalez, N., \& Murphy, C. Urban agriculture in the city of Havana: a popular response to crisis. In N. Bakker, S. Dubbeling, U. Guendel, K. Sabel \& H. de Zeeuw (Ed.). Growing cities, growing food, urban agriculture on the policy agenda. Feldafing: DSE. 2000. pp. 329-348.

[29] Howe, J., Bohn, K., \& Viljoen, A. Food in time: the history of english open urban space as a european example. In: A. Viljoen, (Ed.). CPULs, continuous productive urban landscapes - designing urban agriculture for sustainable cities. Oxford: Architectural Press. Elsevier. 2005. pp. 95-107.

[30] Allen, A. Environmental planning and management of the peri-urban interface. In : Managing the Environment of the Peri-urban interface: proceedings of Conference Rural-Urban Encounters: London. 2001. 
[31] Petts, J. The economics of urban and peri-urban agriculture. In: A. Viljoen, (Ed.). CPULs, continuous productive urban landscapes - designing urban agriculture for sustainable cities. Oxford: Architectural Press. Elsevier. 2005. pp. 65-73.

[32] Mumford, L. La cité à travers l'histoire. Paris: Le Seuil. 1994.

[33] Secchi, B. Urban scenarios and policies. In: N. Portas, A Domingues, J. Cabral (Eds.). Políticas urbanas. Tendências, estratégias e oportunidades. Lisboa: Fundação Calouste Gulbenkian. 2003b. pp. 275-283.

[34] Brook, R., \& Davila, J. (Ed.). The peri-urban interface, a tale of two cities. Bethesda, Wales: School of Agricultural and Forest Sciences. University of Wales and Development Planning Unit. University College London. 2000.

[35] Sangeetha, P., Brook R., \& Purohit, S. Transcending rural-urban boundaries. Habitat Debate (Forum): Cities, Engines of Rural Development 2004; 10 (3).

[36] Bryant, C. R., Russwurm, L., \& McLellan, G. The city's countryside: land and its management in the rural-urban fringe. London: Longman. 1982.

[37] Qvistrom, M. Landscapes out of order: studying the inner urban fringe beyond the rural urban divide. Journal Compilation. Swedish Society for Anthropology and Geography 2007 (269-282).

[38] Hough, M. Out of place. Restoring identity to the regional landscape. New Haven/London: Yale University Press. 1990.

[39] Allen, A. Environmental planning and management of the peri-urban interface: perspectives on an emerging field. Environment and Urbanization $2003 ; 15$ (1) ,135.

[40] Jakle, J. A., \& Wilson, D. Derelict landscapes: the wasting of America's built environment. Lanham, MD: Rowman \&Littlefield. 1992.

[41] Marot, S. The reclaiming of sites. In J. Corner (ed.), Recovering landscape. New York: Princeton Architectural Press. 1999. p.45-57.

[42] Gravagnolo, B. La progettazione urbana in Europa. 1750-1960. Roma-Bari: Laterza. (a tradução é nossa). 1991.

[43] Donadieu, P. Landscape urbanism in Europe: from brownfields to sustainable urban development. JoLA, Journal of landscape Architecture 2006; (2) 36-45.

[44] Weller, R. An art of instrumentality: thinking through landscape urbanism. In: C. Waldheim (Ed.). The landscape urbanism reader. New York: Princeton Architectural Press. 2006. p.69-86.

[45] Mostafavi, M. (Ed.) with Doherty, G. Ecologycal Urbanism. Baden: Lars Muller Publishers. 2010.

[46] Shane, G. The emergence of landscape urbanism. In C. Waldheim (ed.). The landscape urbanism reader. New York: Princeton Architectural Press; 2006. p.55-68.

[47] Corner, J. Terra Fluxus. In: C. Waldheim (ed.). The landscape urbanism reader. New York: Princeton Architectural Press; 2006. Pp. 21-32.

[48] Reed, P. Groundswell. Constructing the contemporary landscape. New York: The Museum of Modern Art. 2006.

[49] Beigel, F., \& Christou, P. (cited in M. Mostafavi, \& C. Najle, (Ed.). Landscape urbanism: a manual for the machinic landscape. London: AA Publications. 2004. 
[50] Diedrich, L. Hacia el paisaje!. In: Diedrich, L. (Ed.). On Site. Arquitectura del paisaje en Europa. Barcelona: Gustavo Gili; 2009, pp.256-261.

[51] Wall, A. Programming the urban surface. In J. Corner, James (Ed.) Recovering landscape. Essays in contemporary landscape architecture. New York: Princeton Architectural Press. 1999. pp. 233-249.

[52] Arosemena, G. Urban agriculture. Spaces of cultivation for a sustainable city. Barcelona : Gustavo Gili. 2012.

[53] McHarg, I. Design with nature, (25th aniversary edition). USA: John Wiley and Sons. 1995.

[54] Battle, E. El jardín de la metrópoli. Del paisaje romántico al espacio libre para una ciudad sostenible. Barcelona. Gustavo Gili. 2011.

[55] Matos, R. Urban Landscape: Interstitial Spaces. Landscape Review 2009 ; 13(1) 61-71.

[56] Girardet, H. Urban agriculture and sustainable urban development. In A.Viljoen (ed.). CPULs, continuous productive urban landscapes - designing urban agriculture for sustainable cities. Oxford: Architectural Press. Elsevier. 2005. p. 32-39. 


\title{
Designing Urban Squares
}

\author{
Murat Z. Memluk
}

Additional information is available at the end of the chapter

http://dx.doi.org/10.5772/55826

\section{Introduction}

The effects of fast changing economic and social conditions have increasingly become significant on how people use and shape their environments. The urban population has been dramatically increasing worldwide and consequently physical structure of the cities changes constantly, mostly in negative ways. As the population increases, the demand for infrastructure and facilities also increases. Privatization and decentralization are the two major concerns on the future of the cities and open public spaces.

Contemporary urban environment is complex in many ways. It is more heterogeneous; more multicultural and more multiethnic. Increasing mobility, communication technologies and globalization leads to expansion of urban areas causing life style changes, thus use of public spaces. Carmona groups critiques of public space issues in two categories; (i) undermanagement of public spaces, and (ii) over-management of public spaces [1]. The first group focuses on poor design and function loss of public spaces. Increasing vehicle traffic, segregation of the user groups, neglecting public space, increasing private relations of individuals are among the reasons why "public life" declines and public spaces degrade. On the other hand the second group criticizes designers and authorities for undermining "publicness" of public spaces through commodification and homogenization. However, despite there is a dichotomy in criticism of public space issues, Carmona also states "these critiques represent two sides of the same coin" [2].

Public squares are one of the significant public spaces in an urban environment. Urban squares are open public spaces which reflect the cities' identity and the communities' cultural background. They are where people of the community gather and "urban life" takes place since the ancient times. As the fundamental component of the city structure, urban squares contribute to the image and prestige of the city. According to Levy (2012), the main difference between a public park and a public square is that "on a square, citizens are not connected to manifestations of nature, but to the heart of urban culture, history and memory" [3]. In the last few decades, many urban squares have lost their function and role due to the 
changes in use of public spaces. Hence, designing urban squares as both public and open spaces now require more importance and attention.

Designing urban squares should be a part of urban design. Otherwise they become disconnected and meaningless, rather than being an integral part of the city. This chapter aims to investigate the current role and situation of urban squares and to develop design strategies in context of landscape architecture. First, I will begin with the history of public squares, and then explain the role of urban squares as open spaces. Finally, I will discuss design strategies for contemporary urban squares with design examples.

\subsection{History of public squares}

The first city formations appeared 6000 years ago and city squares were established at the crossroads of important trade routes [4].

A well-known earliest example of today's public squares is Greek's "Agora". Democracy played an important role in shaping Greek cities. The Agora was an open place in the city center where political, social and economic activities took place. Greek agoras were public spaces for all kinds of gatherings; such as political meetings, athletic and musical games, theatre performances and commercial activities [5]. The geometrical form of the agora was usually square or rectangle [6] (Figure 1).

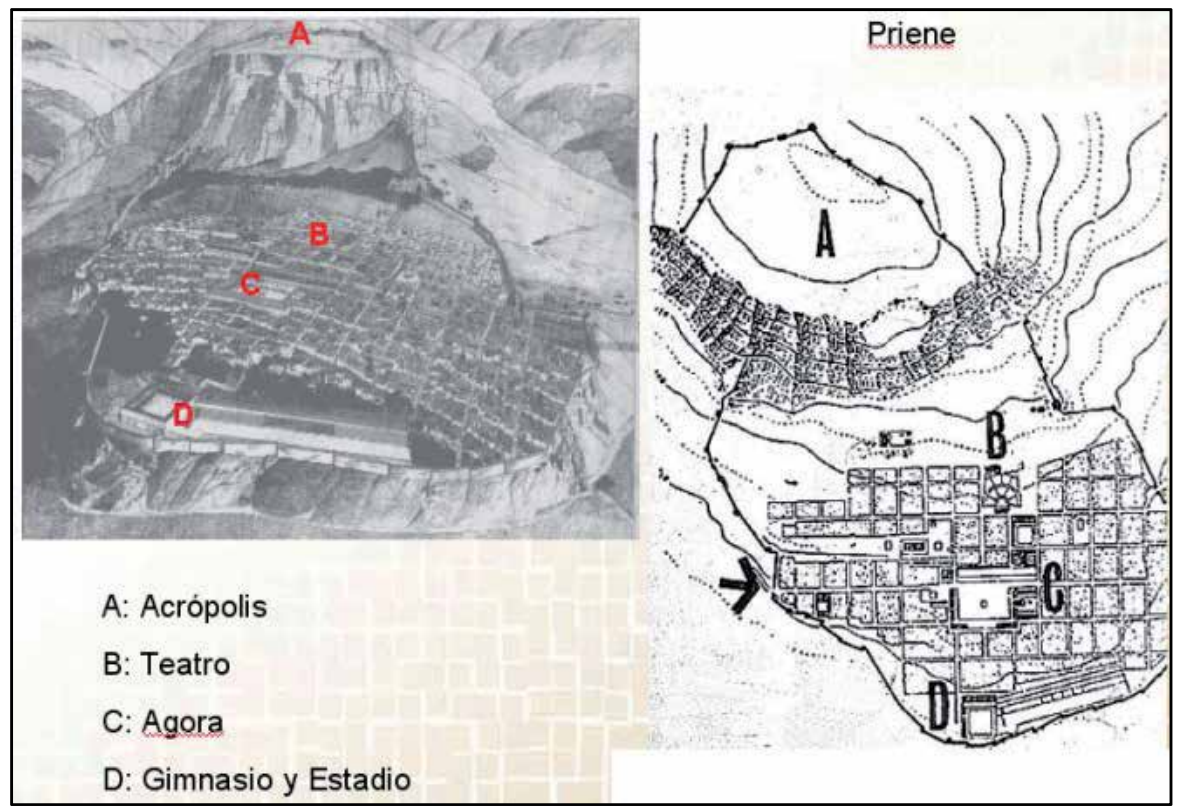

Figure 1. Agora of Priene (Aydın, Turkey) [7].

Similarly, the Roman Forum was a large open space where people gather for political, economic and social activities (Figure 2). According to Mumford (1961) the Roman forum was the combination of agora and acropolis since it included more activities (such as 
shrines, temples, the hall of justice and the council houses) with more formal order [8]. Especially, during the republican period, the forum was the heart of the city. In the last years of the Roman Empire the Roman Forum lost its importance and was used less by the public.

Following the collapse of Roman Empire, basilicas were transformed into churches and both cathedrals and churches became the focus of daily life in the middle ages. Most of the open public spaces were shaped around religious buildings. During this period commercial activities took place also in public spaces [8]. Therefore in middle ages, open public spaces were used mainly for religious ceremonies, and as marketplaces. In some European countries civic squares and piazzas emerged during this period [10].

In the neo-classical period (the Renaissance and Baroque period), there were some apparent changes in city morphology. With the changing economical, political and philosophical perspectives, approaches to planning and design of the towns shifted with the influence of rationalization during the Renaissance. Formal designs and plans were very common in this period. Symmetry and order were the essential principles in design of the squares. Italian piazzas are the very well-known examples of the Renaissance public squares. Monuments and fountains were added to the design to create aesthetically pleasant environments (Figure 3).

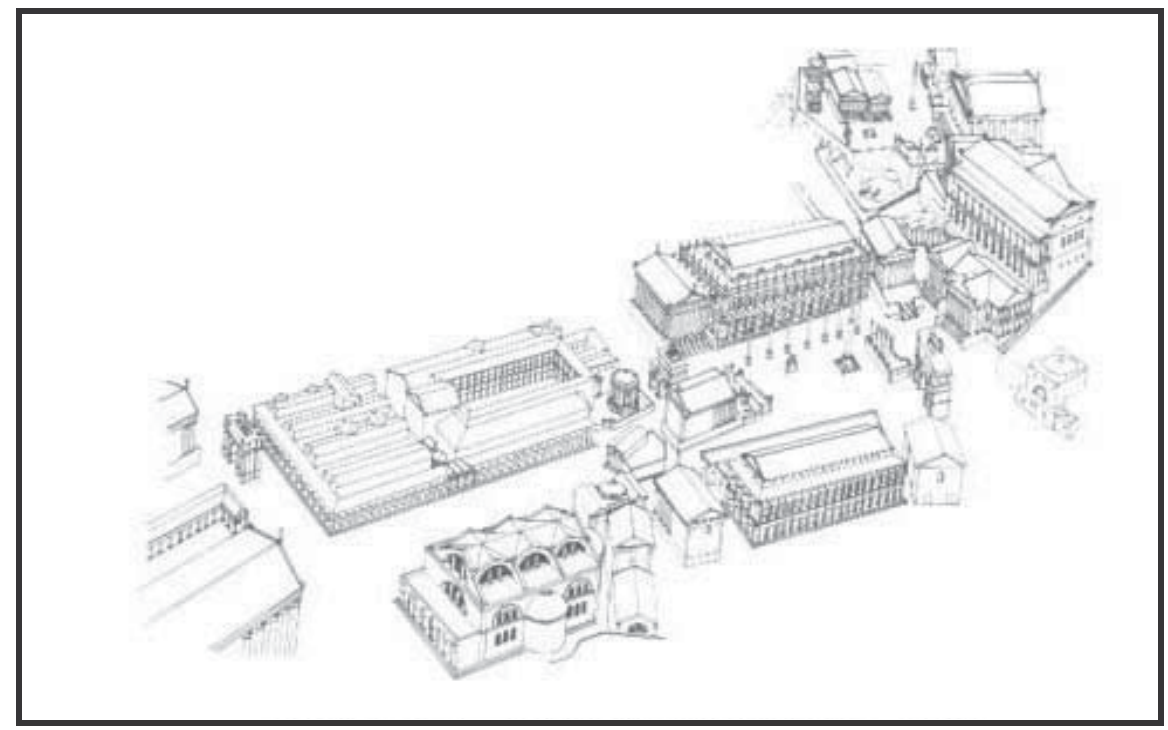

Figure 2. The Roman Forum [9].

Axial order, balance and hierarchy became main design principles during the Baroque period. In this period, open spaces were designed to create visual and ceramonial effects [6]. Piazza del Campidoglio, designed by Michelangelo, is one of the earliest examples of Baroques style open spaces. According to Zeka, the Baroque concept of "dynamic motion in space" was introduced in piazza del Campidoglio [6] (Figure 4). 


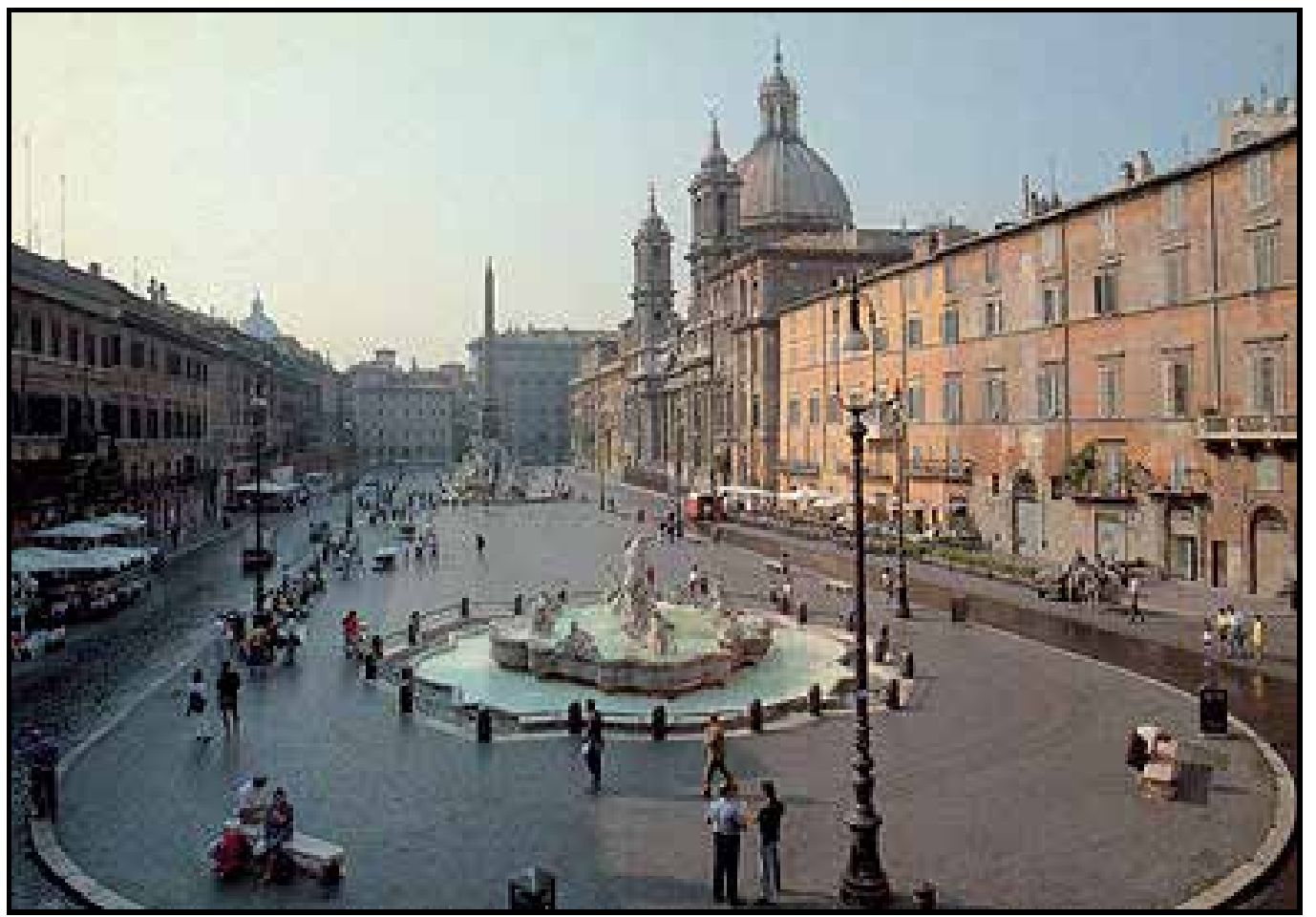

Figure 3. Piazza Navona, Italy [11].

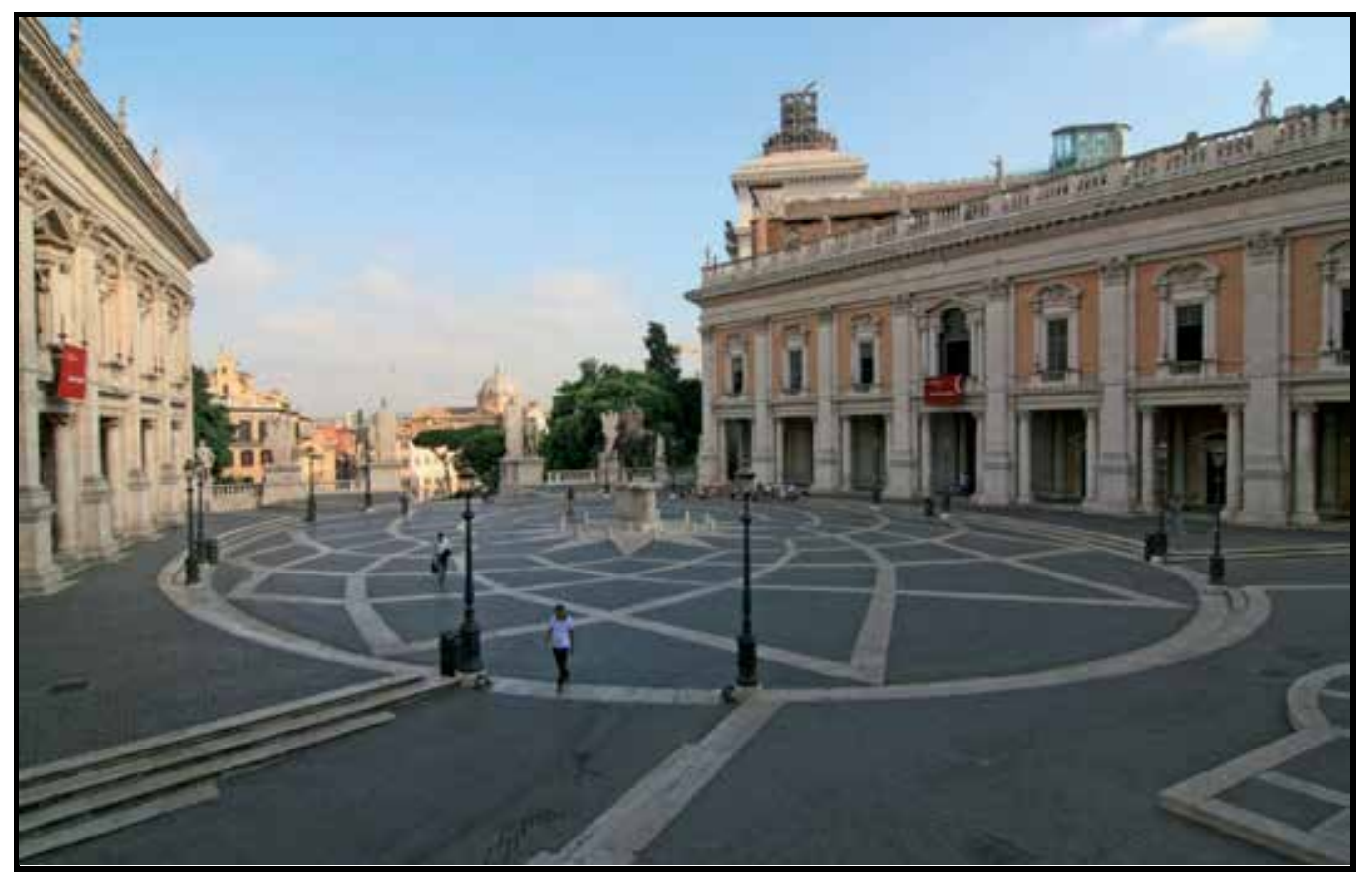

Figure 4. Piazza del Campidoglio [12]. 
In 19th century, industrial revolution caused a dramatic changes in urban design and planning. The establishment of broad railway networks leaded to population increase in urban areas which stimulated growth of cities. New industrial areas were developed near cities and labor class began to move into cities to dwell. As the bourgeoisie raised, women became more participant in the city life. The emerge of shopping arcades, shopping streets, bazaars and department stores created a new form of public space, especially for women [10]. The changing social, economical and political structure of the city also affected city morphology. Increased population meant more needs, more services and more waste. The city structure began to deteriorate. At the end of 19th century, concerns for environmental deterioration and community well-being triggered the parks movement. Instead of streets and squares, huge green areas emerged as new public places [13]. Population increase in urban areas continued during $20^{\text {th }}$ century and cities become more and more expanded, heterogeneous, and fragmented. Private automobile ownership showed a rapid increase and cities become motor vehicle dominant environments. As a result pedestrian movement and freedom were limited. In the second half of the $20^{\text {th }}$ century, many urban squares turned into crossroads especially in developing countries (Figure 5). New consumer habits and trends also caused decline in open public space use. Shopping malls have become new leisure centers. At the end of the $20^{\text {th }}$ century, following the spread of internet use, virtual environments appeared as new "social platforms".

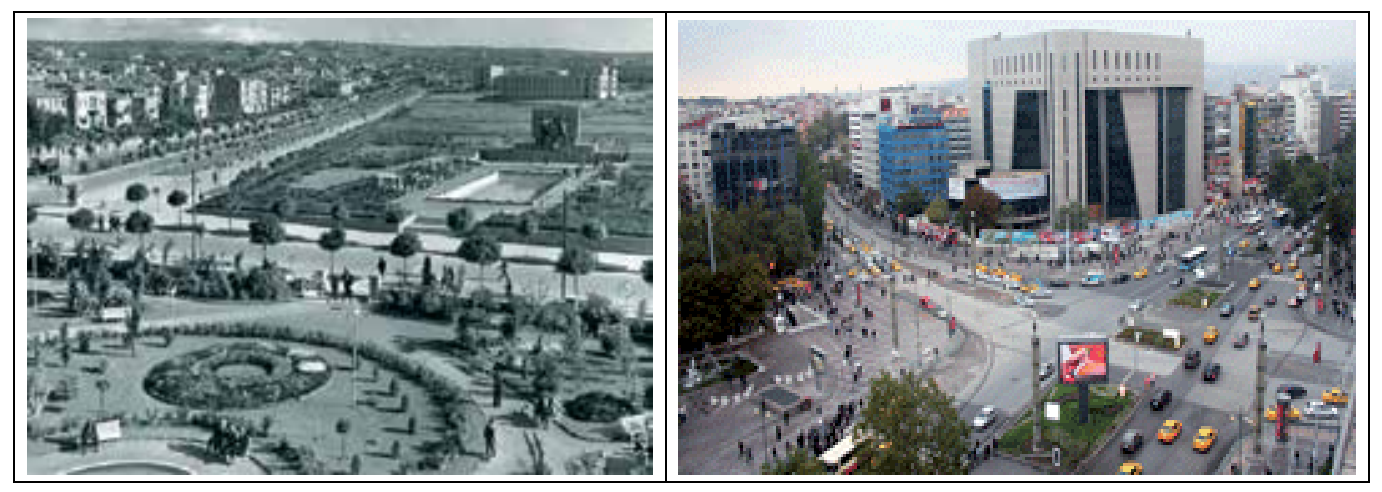

Figure 5. Left:Kızılay Square, Ankara in 1940s [14], Right: Kızılay Square, Ankara today [15].

In Islamic countries, religion has had an important influence on development and use of open public spaces. The mosque has been the centre of the social life and examples of the western style of urban squares cannot be seen in Islamic countries. Similarly throughout the history of Turkish settlements, the squares were formed around the mosques. Since markets and commercial regions were also located around mosques, these squares were where the social life took place, especially in Ottoman Empire period. Although one can easily find the traces of Roman/Byzantine influence in İstanbul's current city structure, still urban squares are located near mosques and other religious buildings. For instance, today's Sultanahmet square which was once known as hippodrome of Constantinople is surrounded by religious buildings such as Sultanahmet Mosque and Hagia Sofia Museum (Figure 6). In relatively 
smaller Anatolian cities, squares have also been used to celebrate wedding ceremonies, feasts and festivals.

During the early republican period, new urban squares were established around administrative and government buildings where national ceremonies took place. After 1950 's, urbanization increased dramatically in Turkey. City centres gradually became more and more crowded and cramped with people and cars. In metropolitan areas, new city centres emerged and cities expanded uncontrollably. Political developments also influenced the use of open public spaces. During 1970s the city squares, especially in Ankara and İstanbul, witnessed many protests and gatherings of different groups of the society. However after 1980 military coup in Turkey, urban squares were transformed to "nonpolitical" and more passive places. After 1990's globalization has a massive impact on both life styles and use of public space. People have begun to prefer to spend their spare time more indoors, rather than open public spaces. As a result, Turkish urban squares have lost their importance and functions within the city, like in many other countries worldwide.

\section{Roles and functions of urban squares}

According to Lewis Mumford, primary function of cities is the acculturation and humanization of its inhabitants [17] and for these purposes public spaces are the essential tools in the city. Kostof (1992) defines some basic functions of the urban squares as [18];

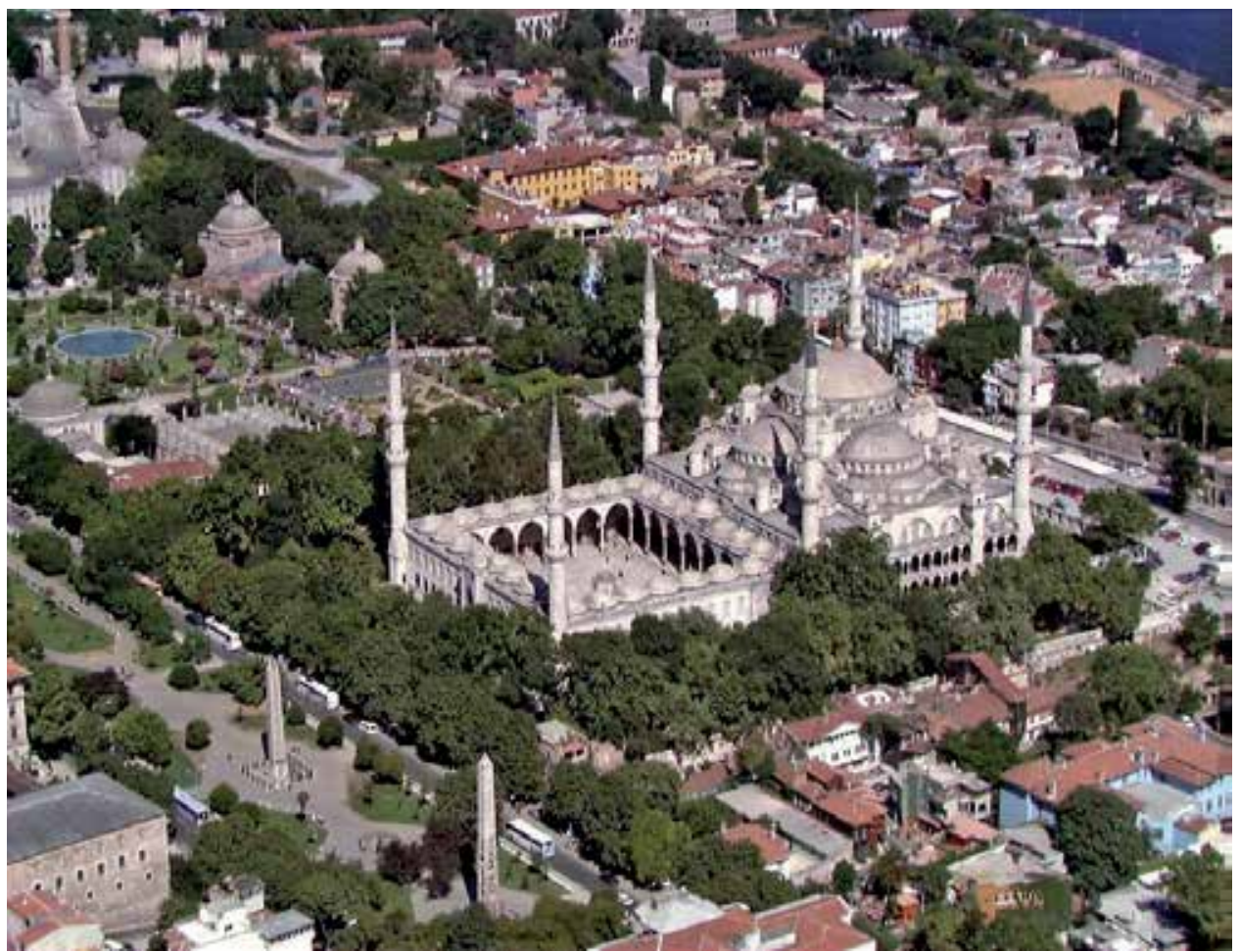

Figure 6. Sultanahmet Mosque and Sultanahmet square [16]. 
Being a part of transport system: public squares are the intersection, gathering and waiting points for both the pedestrian and vehicle traffic.

Commercial activities: public squares are civic centers where citizens engage in commercial activities. Markets have been one of the essential elements of the public squares throughout the history.

Games and sports: games and sports activities have always been an important part of public life and there have been many examples in the history where games and sports activities took place in public squares.

Kostof also believed that the links between public squares within a city forms a "system". He also stated that this approach was one of the primary issues in city planning and design during the Renaissance and Baroque periods [18].

Urban public squares are open spaces surrounded by buildings and other structures within a city. Therefore they play an important role in the context of mass and void composition of a city. Cities are formed of combination of masses and voids. The amount and ratio of masses and voids determine the structure of a city. Too many masses (e.g. buildings and structures) without connection to any voids (e.g. streets, parks and squares) would make a city cramped, illegible and chaotic. Hence, urban public squares serve as a stabilizing force especially in contemporary crowded cities.

Public squares provide citizens with places for various leisure and outdoor activities. People of the city can relax, sit, read a book, play games, meet with friends etc. in these public areas. The activities are not predefined or limited in the urban squares. Public squares can also be used for ceremonies, rituals, political activities, musical events, even theatre, and as marketplaces.

Public squares have also ecological benefits to the urban environment. Green areas and water surfaces within a square provide habitat for living organisms. Existence of green areas within a public square also helps to improve air quality, lessen surface water runoff, reduce noise levels and screen unwanted or undesirable views, and reduce negative effects of urban heat islands.

Well-designed public squares increase the visual landscape value and contribute to environmental aesthetics. While contributing to the overall city image, visual landscapes appreciated by individuals also have positive psychological impacts on the users of the place. Another psychological benefit that urban squares provide is that they are where people can relax and enjoy their spare time during their busy urban daily lives.

Urban public squares might also provide some economic benefits for the community. It is a well-known fact that existence of open and green spaces increases the real estate prices nearby [19]. Urban squares can also be used as marketplaces or they can be a part of commercial activities, such as shopping malls. There are also examples of squares where marketing is the dominating feature. Times Square in New York City is one of the wellknown examples (Figure 7). It is also one of the most famous and visited tourist attractions 
in the world. Located in Manhattan, it has a busy pedestrian traffic and density all year. Times Square also hosts various activities and ceremonies throughout the year such as annual New Year's celebrations. It is one of the landmarks of the New York City and an important part of the city image.

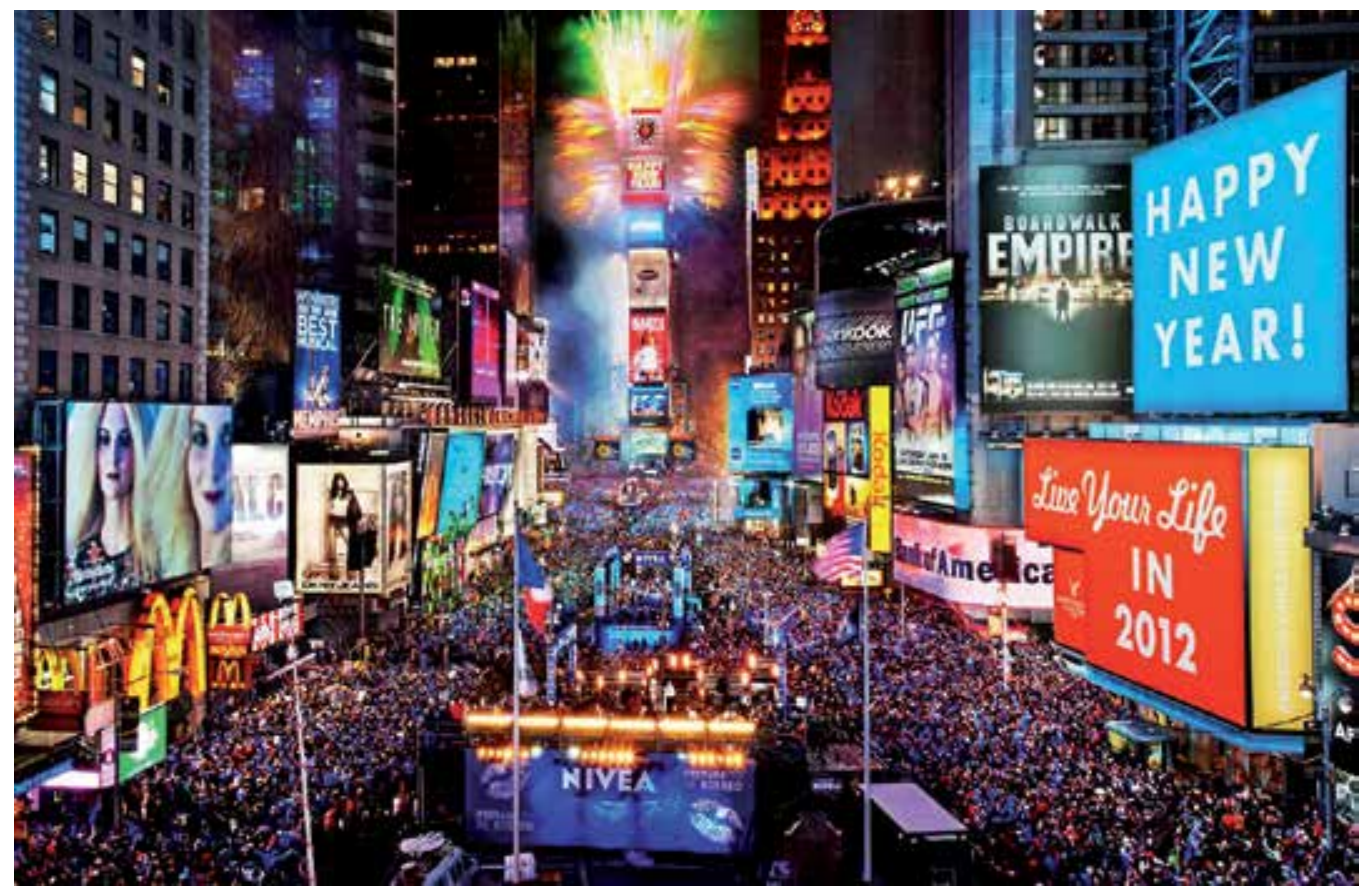

Figure 7. Times Square, New York City, USA [20].

Besides their physical and ecological roles, public squares contribute hugely to the social cohesion and local identity. They act like social catalysts. The main function of urban squares is gathering citizens together for various reasons and activities. They have a symbolic meaning of "coexistence". Hence, urban public squares are the essential elements of the city in terms of democracy. Citizens from different social, economic, and cultural backgrounds, age groups, etc. all have equal accessibility to the public spaces. Urban squares are one of these public spaces where individuals and groups learn to respect and tolerate "others". Hence, urban squares are the places where the social interaction and social cohesion occurs. The way and context of this social interaction displays the local identity. Many public squares have also historical importance for the city's identity and they usually reflect the collective values of the community.

All the roles and functions of urban public squares mentioned above also contribute to the well-being of individuals and communities. Thus, it is important to reconsider and review urban public square design approaches in order to sustain and improve our existing squares or create enjoyable new ones. 


\section{Designing urban squares}

It is quite challenging to define universal design principles that would fit for all the squares in the world. On the other hand it is possible to identify some basics that would help designers and planners through the design process. However, it is necessary to know and understand the modern city concept first. Therefore, it might be a good idea to consider the characteristics of contemporary urban environments before focusing on the design of the squares.

Today's urban environments are discontinuous, diverse and multipolar as Ascher states [21]. Changing economic and social structure, triggered by globalization, has led to expansion of urban areas uncontrollably and decentralization of cities. Globalization has been one of the significant factors that shape our physical and social environments worldwide during the last few decades. Social and spatial segregation have been increased in today's metropolitan areas because of globalization [21]. Another consequence of globalization process is that today's cities are multi-cultural and multi-ethnical more than ever. Therefore public realm is more heterogeneous today and designers and planners need to find ways to create places that serve for "everyone" in these culturally diverse communities. Finally one of the major and significant challenges of globalizing cities is the loss of identity in public spaces. Urban designers, planners and authorities should be aware of the future threats on local identity in decision making, design and planning processes.

Keeping in mind that today's urban environments are more complex and diverse, some design strategies for public squares are presented below.

Design of urban public realm involves two dimensions; functionality and visual appearance. Functionality refers to the activities and the degree of activities fitting to that place. On the other hand visual appearance is about form, image and aesthetics. While some researchers focus on the spatial arrangement of public spaces, others suggest that functionality comes first in urban space design. However, neither of them should be neglected in the design process. In fact, the relationship between these two dimensions determines the character and success of the urban space.

Many researchers have tried to identify the criteria of the ideal and successful urban space. Some of them might be useful mentioning here. For example, Carr et al. believe that public places should be [22]:

1. Responsive: a public place should serve the needs of the community; provide the citizens with spaces that allow relaxation, discovery, and active and passive engagement.

2. Democratic: Public spaces need to be accessible to all groups.

3. Meaningful: People should be able to make connections between the place, their lives and the world.

Rogers define successful public places as the places which pay dividends for cities, build civic pride, increase tourism and economic investment, and contribute to health and quality of life [23]. 


\section{Form}

A public squares form is influenced by the surrounding environment. Even though the word "square" points out a form itself, a public square can be in any form such as rectangle, square, circle, triangle or amorphous.

Camillo Sitte, in his work "City Planning According to Artistic Principles" focuses on the visual appearance rather than the functionality and defines the ideal morphologicalaesthetic criteria of the urban square as [3]:

- Enclosure; closed and protected space,

- The center should be free,

- Monuments that are placed on the perimeter,

- Existence of the elements of surprise,

- Attractiveness of architectural façades,

- Concavity and aesthetic pavement.

Sitte also emphasizes that the main requirement of a square is "the sense of enclosure" [6]. Enclosure is one of the perceptual organization principles of the Gestalt psychology. Grouping is the fundamental concept of the Gestalt approach. People tend to group objects that look similar and close to each other. Furthermore enclosure or closure helps us to perceive objects as a whole. The easiest and straightforward way of creating enclosure is grouping buildings around a central space [24].

One of the well-known works based on enclosure in the public squares is Rob Krier's work. In contrast to Sitte, Krier focused on elementary geometry when developing a typology of urban squares [24]. Krier introduces concepts of angling, segment, addition, overlapping, and distortion as modulating factors in context of urban space typology (Figure 8). According to Krier, combining these modulating factors with basic shapes of urban space (square, circle and triangle) results in either regular or irregular urban space forms [6]. Figure 9 shows some of the Krier's typologies of the urban square. On the other hand Hsu criticizes Krier's approach for ignoring the social and historical context of public squares [25].

Zucker suggests five types of urban square forms [24];

The closed square: it often has a regular geometric form. The only interruption to the closed square is the streets that are leading to it.

The dominated square: the space is directed to a building or a group of buildings.

The nuclear square: it has a central feature which creates a tension that keeps the whole together.

Grouped squares: individual squares linked organically and/or aesthetically.

The amorphous square: it is unorganized and formless when compared to other types.

\section{Location and size}

The first factor to be considered in design of urban squares is the location and the size of the square. Throughout the history squares and plazas have always been at the intersection of 


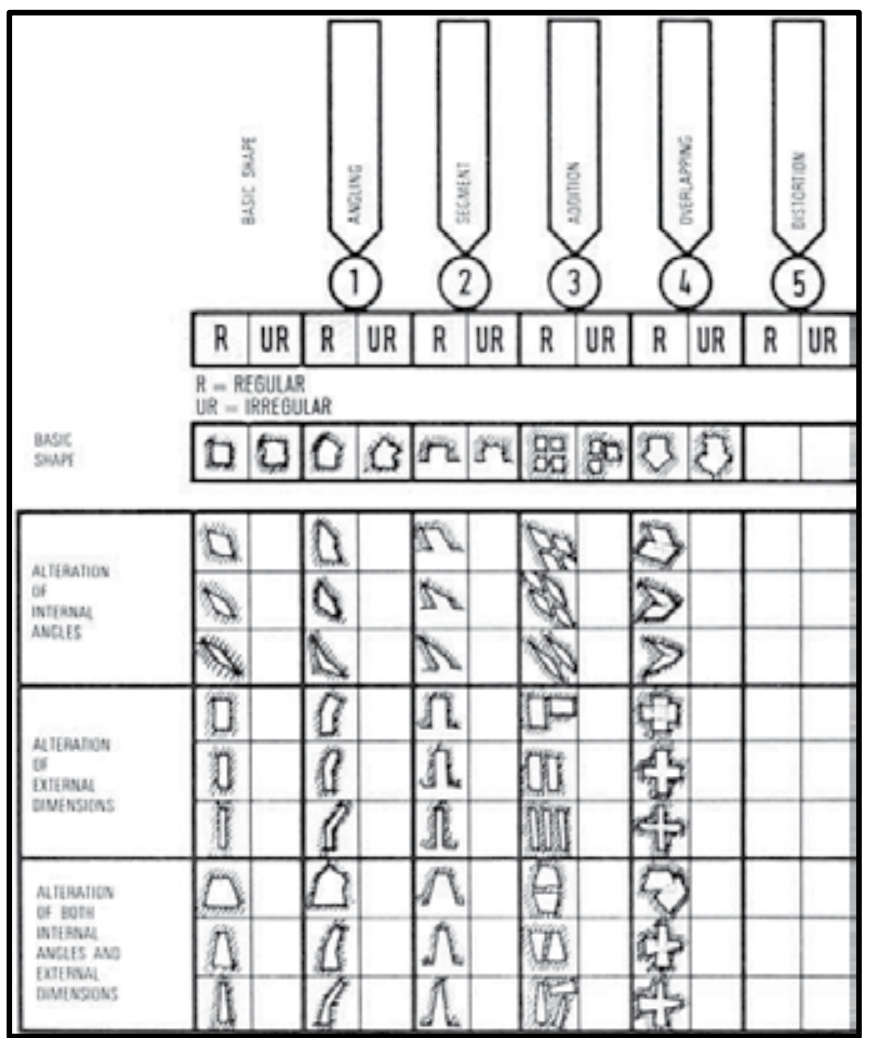

Figure 8. Modulating factors of urban space [26].

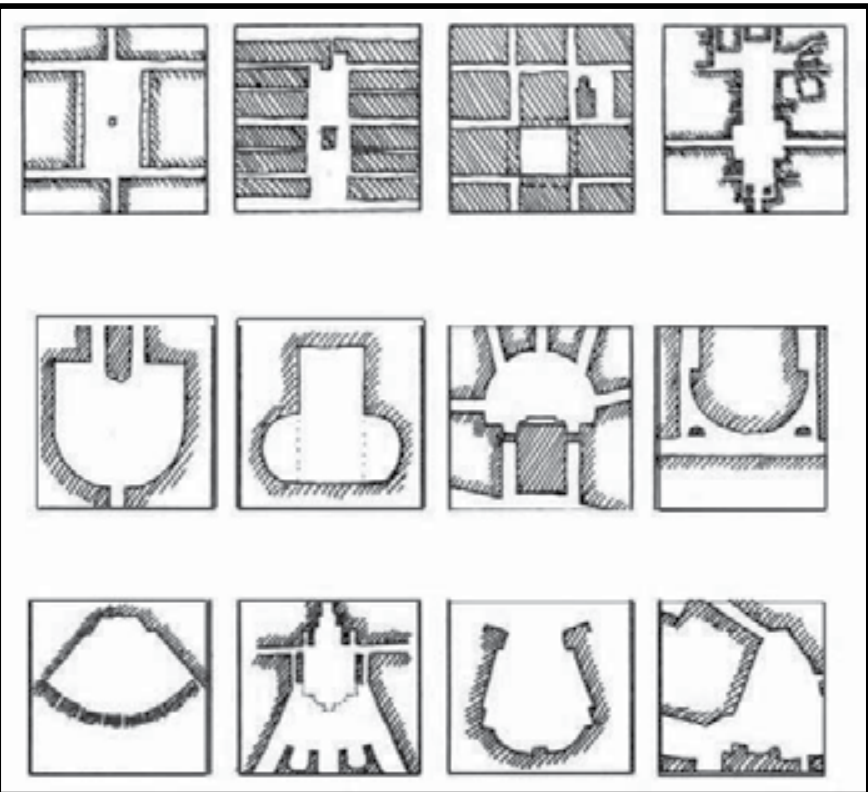

Figure 9. Some typologies of Krier's urban spaces [adopted from 26]. 
main routes of transportation and pedestrian traffic. Moreover, as Dewitte states the public squares' main function is to symbolize the archetype of human encounters and encourage urban contemplation [3] .Since human presence and activity is the essence of public squares; they should be easily accessible (both physically and visually) to public and should be created in central locations within the city.

On the other hand decentralization is one of the problems faced in contemporary cities, which makes it difficult to select central locations, since there are too many. Therefore it should also be noted that links and connections between different squares within the city should be established in order to sustain continuity of urban form.

Traditionally, squares were located next to religious and government buildings which are central to "public" life. However, as life styles change, today's cities involve many other focuses. For many, work is the central issue in our daily lives with a limited time to spare for other activities. Emerge of shopping malls also have changed/or a consequence of changing leisure patterns. Besides shopping activity, shopping malls offer many other recreational activities and facilities in one place. Therefore, people tend to prefer going to such places where they can meet their various needs in one facility. As a result, people spend their spare times more indoors than outdoors and public spaces today. There are many examples of public squares which are located around shopping malls or commercial centers/buildings in contemporary cities. Hence, designers and planners should consider the ways of bringing public squares to people when selecting the location.

Size is another aspect of urban public square design. It is often thought that public squares must be large in size. However, the size should be determined according to the location, surrounding uses, and activities nearby. The most and conventional way of determining size of a square is to calculate the number of possible users. Thus, designers and planners should focus on the "concept" of the place and possible user activity before determination of the size. Several researchers attempted to identify the ideal size of public squares. For instance according to Lynch 12 to 24 meters along each side and 100 meters for larger squares are ideal for successful urban squares, while Alexander suggests a maximum of 22 meters for small squares [6]. On the other hand Gehl suggests a dimension of 30-35 meters for the optimum size of a square in order to enable people being able to recognize the other people in the space from one side to other [27].

When determining the size of an urban square, visual perception should also be taken into account. The scale and density of the surrounding buildings and structures of a square might affect the perceived size. Squares surrounded by taller and dense buildings may appear smaller than they actually are. A ratio of 1:2 and a maximum of 1.5:2 between building height and space width can be successful to create a strong sense of definition of space [26]. Edges are also important in creating the sense of definition of an urban square. According to Alexander et al. (1977) "if the edge fails, then the space never becomes lively" [6].

\section{Activities}

Urban public squares are venues for various activities that help social cohesion and individual restoration. Generally, urban public squares are not designed to serve for any 
special type of activity. On the contrary they should be designed to provide opportunity for different kinds of activities at any time. Location and scale of a public square might also affect the activity types associated with a square. For instance, larger squares near to government buildings might be preferred to be used for protests or national celebrations by the public or squares near commercial centers might be mainly used as meeting points, performing arts venues or as marketplaces. Designers should well analyze possible user profile, their needs and expectations as well as surrounding environment's character. Some other activities might be associated with the square during design phase to attract people. For instance, nearby places to eat and drink may increase the use of space. Or placing an underground parking place might encourage people from different neighborhoods or districts using the space. However, activities aiming to attract people should never dominate the character of the square. Besides, designers should ensure involvement and participation of all social groups within a public space.

"Successful urban squares are designed for people to walk in, stand in, sit in, dance in and to perform in, and to look at other people participating in these activities" [27].

\section{Landscaping}

Generally, hard surface dominates the landscape of an urban square. Therefore selection of pavement materials is great of importance in the design phase in terms of both visual appearance and functionality. Various materials (e.g. stone, concrete, brick etc.) can be used in public square design. Pavement materials must be durable and aesthetically appealing. Durability degree of the materials can decrease or increase the maintenance costs. Surrounding architecture and streetscape should also be taken into account to ensure continuity of the character and coherence. Focal areas can be created by changing the color, form or texture, as well as pavement material itself. Similarly, by using the same strategy different uses within a square (such as seating areas) might be separated. Pavement material should be non-slippery, and suitable for walking or standing. Reflection of heat and glare should also be noted when selecting the material. Handicapped or elderly people should not be forgotten in the design phase in terms of accessibility. Drainage is another factor that should be taken into account to provide comfort in different weather conditions.

Different kinds of plants (trees, shrubs, flowers, grass etc.) can be used in the design of urban squares for different purposes such as aesthetics, shading, or visual screening. Plants also help to soften the strong and sometimes disturbing effects of hard surfaces or sharp lines. Flowering plants may also add variety to the perceived environment in terms of color and scent. Green is known for its calming and relaxing effect; hence plants might be used in order to create places for relaxation and resting. In hot climates, trees provide users with shade areas. If there is a focal point within the square like a monument, plants can be used to create a background to emphasize its visual effect. However designers should avoid using too many plants to preserve the square's main character.

Plant material should be selected based on the climate. This will reduce the maintenance costs and increase the success of plantation. There are many plants which present aesthetically pleasing and attractive changes in color and texture (like Acer species), in 
different seasons. Some trees have appealing visual effects in winter because of their geometry or color of trunks and branches, such as Betula alba and Cornus alba. Plants with poisonous fruits (e.g. Taxus baccata, Aucuba japonica, Viburnum lantana etc.) should not be used, especially within the reach of children. Plants can also be used for creating enclosure or dividing the space into subareas.

Water surfaces are landscape elements commonly used in public squares to create a focal point or aesthetically pleasing views. Water can be used in different types; as still water, running water, fountains, or combination of these. Still water surfaces create a more relaxing and tranquil environment while fountains, cascades and other running water surfaces add movement, vibrancy and dynamism to the space. For environmentally sustainable and lowcost maintenance, use of recycled water and rain-water systems should be integrated into the design. Together with lighting, water bodies and plants can be very attractive for users at night time (Figure 10).

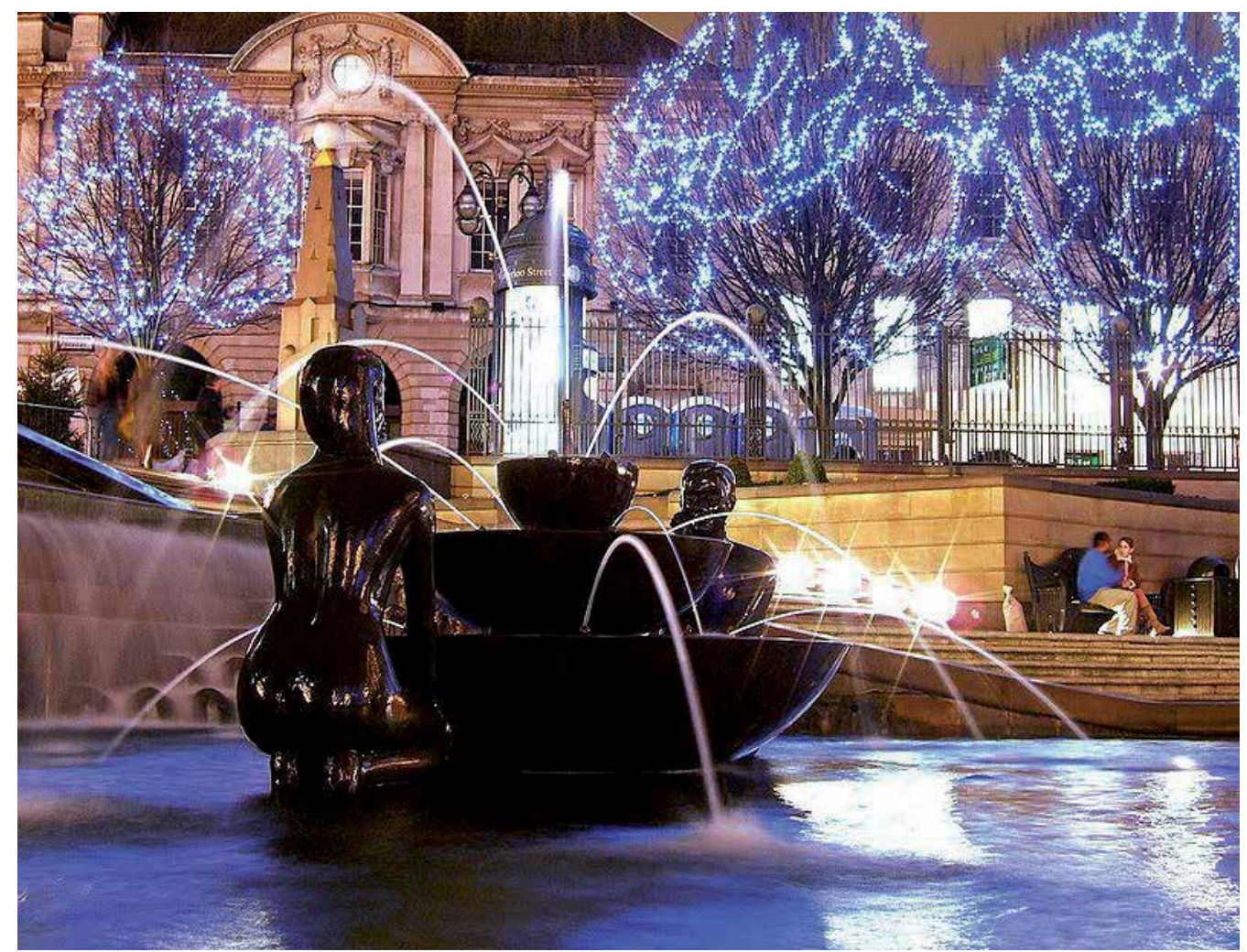

Figure 10. Victoria square, Birmingham, UK [28].

\section{Site furniture}

Seats/benches, outdoor luminaries, trash bins, direction signs are the most used site furniture items in open public spaces. Functionality comes first when selecting or designing the right site furniture. Materials used must be durable to outdoor and changing climate 
conditions. Sharp corners or edges may harm people. The surrounding architectural character should also be considered when selecting the materials and forms. Designers should avoid selecting too many different materials for different items. All site furniture should be harmonious with each other in order to provide integrity in design.

Seats can be placed either at regular intervals or as groups in different parts of the urban square. Moveable chairs or seats may make it more fun and enjoyable. They can also allow use of space for different activities at different times. Benches or seats are not necessary for providing users with a place to sit on. Walls or steps can also be used as seating places.

Seating is one of the key elements in a public square. Seating makes it possible for users to view, observe, and enjoy the environment. It also increases the users' time spent within the space. Therefore view of the space and orientation should be taken into account in the placement of seats. Seats should not be back directly to roads or passing users [27]. Designers should keep in mind that seating can act like social catalyst when well-designed. Social comfort enables spontaneous social interactions and activities [29].

Good quality lighting is necessary for users' safety and comfort at night. Lighting can also be combined with other design elements to create attractive and visually appealing environments. Direction signs should be legible and clear. Too many direction signs may cause confusion and create a chaotic environment.

Site furniture should be placed carefully and in coherence with the overall space design. Pedestrian movement and activity areas should not be obstructed. Site furniture contributes to the quality of overall design, but they should not be the dominant items in the square.

\section{Focal Point Elements}

Focal points elements might be useful to attract users while contributing to the square's identity and image. A focal point can be created by using any design element (e.g. water fountain) or public art works (e.g. sculptures, monuments). However, placing focal point elements at the center of the square is not always necessary. Sitte (1965) suggests that the centre of the squares should be kept free and focal elements should be placed along to edge, close to pedestrian routes [6].

\section{Conclusions}

Today as public spaces decline, concerns for the vitality and liveability of the cities increase. People are the main ingredients of the city and without public spaces it is impossible to establish a physical and mental connection between public and urban environment. Urban public spaces have been negatively affected by globalization and privatization. Furthermore increasing individualism has caused social fragmantation within the communities which presents itself in the changing use of public spaces. Internet has become a major component of our daily lives. Besides its economical, educational and time saving benefits, it has also dramatically changed public life. Internet has created virtual environments where people prefer to spend their time rather than going out. Social relations are necessary for the 
cohesion of communities, and local and national identity. In this context, urban public spaces are important venues for creating social relations between people.

Besides the social dimension, urban open spaces also contribute to the city image and overall quality of the physical environment. Decentralization and urban expansion are major issues in the sustainability of contemporary urban environments. If urban public spaces had not been ignored by urban designers and planners, decentralization might have been prevented to some point.

As one of the significant open public spaces, urban squares are fundamental city elements in democratic and livable cities. Therefore it is needed to recreate and design urban squares to enliven the public life and establish social cohesion. In this chapter besides the literature review, I recommended some design basics in creating successful urban public squares. Besides the physical dimension of design process, psychological aspects should also be taken into account by urban designers and planners. Physical design of urban public spaces can only be successful if safety, comfort, engagement and satisfaction of users are provided. In summary basic design principles for urban squares can be listed as:

- To create identity, sense of place and contribute to the overall city image,

- To promote public use and participation,

- To encourage social activities, communication and social integration,

- To enhance the character of the environment,

- To create a public square which is legible, enjoyable and long-lasting,

- To create both physically and socially accessible environments,

- To achieve environmental sustainability and low-cost maintenance through environmental friendly design strategies.

- To promote art, cultural activities and entertainment.

Urban public squares are more than just physical spaces; they have symbolic meaning for people. They are vibrant, active and interesting places. Most of the contemporary urban squares involve a historical value or importance for the community, as well as for the tourists and visitors. Hence, authorities should realize that urban public squares are essential for enhancing city image and community development.

Unfortunately, modern Turkey couldn't preserve many of its public squares, especially in metropolitan areas. What is now called a "square" often functions as crossroads and is occupied by vehicle traffic. Although traditional public squares in Turkish cities differ from European examples, they still have a cultural and social importance in public life. Hence, it is urgently needed to develop design and management strategies for urban public squares in order to prevent losing a vital part of the city and the community.

\section{Author details}

Murat Z. Memluk

Department of Landscape Architecture, Ankara University, Ankara, Turkey 


\section{References}

[1] Carmona M. Contemporary public space: critique and classification, Part one: critique. Journal of Urban Design 2010; 15(1) 123-148.

[2] Carmona M. Contemporary public space, Part two: classification. Journal of Urban Design 2010; 15(2) 157-173.

[3] Levy B. Urban Square as the Place of History, Memory, Identity, In : Dusica Drazic, Slavica Radisic, Marijana Simu (eds), Memory of the City, Kulturklammer, Belgrade, 2012; 156-173.

[4] www.urbansquares.com/images/resources/lecturetext.pdf, (Accessed:01.11.2012).

[5] Hölscher T. Urban Spaces and Central Places, Classical Archeology, Ed:Susan E. Alcock and Robin Osborne, Blackwell Publishing, 2007; 164-181.

[6] Zeka B. The humanistic meaning of urban squares: the case of Çayyolu urban square project. MSc Thesis, Middle East Technical University, Ankara. 2011; 241 pages.

[7] http://www.upf.edu/materials/fhuma/portal_geos/tag/t2/t2.htm, (Accessed:15.11.2012).

[8] Xing N. and Siu KWM. Historic definitions of public space: Inspiration for high quality public space. The International Journal of Humanities, 2010; 7(11) 39-56.

[9] http://courses.umass.edu/latour/Italy/RomanForum/index.html, (Accessed:13.11.2012).

[10] İlkay Y. The political struggle on and at public space. Master of Science thesis, Middle East Technical University, 2007.

[11] http://webs.wofford.edu/davisgr/i2006/intinerary.htm, (Accessed:13.11.2012).

[12] http://unicaroma2010.it/drupal6/content/contact-us, (Accessed:13.11.2012).

[13] Sedláková M. Social Meaning of a Market on Husitská Street in Brno. Diploma Work, Masaryk University, http://is.muni.cz/th/103165/fss_m/diploma_final.pdf, Accessed:15.11.2012.

[14] http://www.sozluk.org/p/415, (Accessed:13.11.2012).

[15] http:// hurriyet.com.tr\# (Accessed:13.11.2012).

[16] The Greater Municipality of İstanbul. http://www.ibb.gov.tr/sites/ks/Gallery/IstanbulGallery/_w/sultanahmet_camii_1_jpg.jp g, (Accessed:13.11.2012).

[17] The European Square Conference Report, 2002, http://www.livablecities.org/articles/european-square-conference-report, (Accessed:13.11.2012).

[18] Büyükcivelek A.B. Meydan- Kent Meydanı (Square- Urban square). In: Ersoy M. (ed.) Kentsel Planlama Ansiklopedik Sözlük. Ankara: Ninova Publishing; 2012. p.342-344.

[19] Morris N. Health, well-being and open open space: literature review. Edinburgh College of Art and Heriot-Watt University: 2003.

[20] Times Square Alliance. http://www.timessquarenyc.org/index.aspx (accessed:01.12.2012).

[21] Hamel P. Contemporary cities and the renewal of local democracy. In: Booth P. and Jouve B. (eds.) Metropolitan Democracies: transformations of the state and urban policy in Canada, France and Great Britain. England: Ashgate; 2005. p.31-46. 
[22] Carr S., Francis M., Rivlin, L. and Stone, A. Public Space. Cambridge: University Press: 1992. 400 pages.

[23] Pasaogulları N. and Doratli N. measuring accessibility and utilization of public spaces in Famagusta. Cities 2004; 21 (3): 225-32.

[24] Carmona M., Tiesdell S., Heath T., Oc T. Public Places Urban Spaces, $2^{\text {nd }}$ Edition. UK and USA: Elsevier; 2010.

[25] Hsu B. urban Square as a Theatre: Issues of continuity and discontinuity in urban design. Master of Science Thesis. Massachusetts institute of technology: 1993.

[26] Anonymous. http://predmet.fa.uni-lj.si/siwinds/s1/u2/su1/ (accessed:01.12.2012)

[27] Anonymous. Urban Squares. 2009. Available from:

http://www.healthyplaces.org.au/userfiles/file/Development\%20type/Development $\% 20$ Type\%20-\%20Urban\%20Squares.pdf (accessed: 03.12.2012).

[28] http://en.wikipedia.org/wiki/File:Victoria_Square_at_Night.jpg (accessed 07.12.2012)

[29] http://www.pps.org/reference/generalseating/ (accessed 07.12.2012) 


\title{
Towards an Integrative Theory Approach to Sustainable Urban Design in Saudi Arabia: The Value of GeoDesign
}

\author{
Y.A. Aina, A. Al-Naser and S.B. Garba \\ Additional information is available at the end of the chapter
}

http://dx.doi.org/10.5772/55888

\section{Introduction}

Sustainable urban design connotes a new relationship between the natural environment, urban form and structure, economic and institutional processes, and social livelihood. It requires a transformation of the existing socio-economic, environmental and urban design settings. Atkinson and Ting (2002) conceptualize sustainable urban design as an attempt to recognize the complex and hitherto-neglected relationship between the natural environment (sustainable) and the city as artefact (urban design). It seeks to enable the natural processes that sustain life to remain intact and to continue functioning alongside initiatives for the improvement of individual quality of life and the well being of the society. Sustainable urban design adopts a systemic and synergistic reorganization of environmental, economic and socio-economic goals that enhances the long-term health of natural systems and the vitality of urban communities (Wheeler, 1998). The concept of sustainable urban design requires a comprehensive framework of new urban design ethic to promote sustainable cities. Different authors have elaborated on the frameworks and guidelines of incorporating the principles of sustainable development in urban design (Carmona, 2001; Frey, 1999; Jenks and Burgess, 2000; Jabareen, 2006; Adhya et al., 2010). However, there is no agreed straitjacket framework of sustainable urban design. The context in which the principle is applied determines the form of sustainable urban design. The challenge is to develop the appropriate urban design guidelines for a particular local context.

In Saudi Arabia, the spate of modernization has led to the replacement of traditional urban structure and form by Western models of urban form and design. This has resulted in problematic urban development (Fathy, 1973; Brown, 1973; Alshuwaikhat and Khaled, 1993; Al-Hathloul, 1981; Elaraby, 1996; Bianca, 2000; Al-Hemaidi, 2001; Eben Saleh, 2002) as 
Western models are adopted without recourse to the underlying principles and sociocultural background of the traditional form. In the drive towards sustainable cities through design, the challenge is to develop a framework that will adapt traditional urban form to changes in the face of Western models of urban form. This chapter proposes that there is a need to reorient the approach to urban design and development in favour of an approach that is integrative in terms of theory and provides for sustainable development. It examines the urban design problems in Saudi urban development, highlights the sustainability issues, proposes an integrative framework to address the issues and lays out the basic parameters of the framework and some cases of its application.

\section{The integrative theory approach}

The integrative theory approach was suggested by Sternberg (2000) in an effort to establish a theoretical foundation for urban design. Sternberg (2000) observed that urban design had been relying on techniques and ideas that have no clear theoretical basis and suggested an integrative approach to defining the foundations of urban design. He posited that "ideas that inform urban design usually coalesce around contending approaches" and shared principles of these approaches should be integrated to establish a general theory of urban design. Sternberg (2000) highlighted four elements of integrative urban design that include good form, legibility, vitality and meaning. The principles are mainly related to the substantive aspect of urban design due to the need for "a complement to procedural theory: a substantive planning theory that sheds light on the specific concerns of the urban designer" (Sternberg, 2000).

In his article, Sternberg (2000) highlighted some criteria (referred to as challenges) that an integrative theory should fulfill. The set of criteria include highlighting the underlying principles of contending approaches, addressing substantive urban design issues, awareness of the "constituents of human experience of built form", unifying economic and architectural traditions and being realistic and practical. These criteria are used as reference in developing an integrative framework for sustainable urban design in Saudi Arabia. Urban design principles in Saudi could be considered to be generating from, at least, three sources; traditional urban design principles, contemporary or conventional urban design principles and recently emerging sustainable urban design principles. The idea is to integrate the underlying principles of these sources.

\section{Sustainable urban design: A paradigm shift}

\subsection{The rationale for sustainable urban design}

The spatial organization of cities in terms of structure and forms is rapidly being influenced by economic forces at the detriment of social and environmental factors. For this reason, cities are characterized by physical and environmental problems in terms of inadequate infrastructure, deteriorating environmental quality and congestion. Urban problems do not arise from the inherent nature of the cities but due to the absence of effective urban 
governance and management (Jenks and Burgess, 2000). Planning and urban design are interlinked with the dynamics of urban transformation and have been recognized as having a vital role in the management of urban development. Land use planning and urban design influence urban structure and form which eventually generate social and economic activities within the city. The BEQUEST framework for sustainable urban development identified urban design as one of the activities that influence sustainability (Deakin et al., 2002). Jenks and Burgess (2000) also observed that the manipulation of urban form, and the provision of better forms of governance, may go some way to overcome city problems. In addition, the study by Banister et al. (1997) concluded that significant relationship exists between energy use in transport and physical characteristics of the city such as density, size and amount of open space.

Further empirical studies have shown that urban form and structure influence the social configuration (Burton, 2000), economic efficiency (Cervero, 2001) and environmental performance (Adolphe, 2001) of the city. Adolphe (2001) asserted that urban configuration influences outdoor climate conditions, energy balance of building and diffusion of pollutants while Burton (2000) highlighted the negative and positive influences of urban compactness on social equity. The findings by Cervero (2001) suggested that the urban form and mobility characteristics of metropolitan areas have some bearing on economic performance. In essence, there is an interrelationship between the spatial, physical, and structural characteristics of a city and its functional, socio-economic and environmental qualities and this relationship should be explored to foster liveable cities (Frey, 1999).

Traditionally, urban design considers the relationship between urban structural elements, socio-economic activities and environmental quality. Lynch (1960) elaborated on the visual quality of the city and highlighted elements that are crucial to the imageability of a city. His emphasis on the interrelationship of these elements and the physical environmental quality of the city became analytical means of promoting city liveability. Gosling and Maitland (1984) lucidly stated that the physical design of the city cannot be isolated from the problematic context of existing cities and highlighted the problems that concern designers as economic, engineering considerations, social and ecological. Evidently, the emergence of the concept of sustainable development has boosted the incorporation of social, economic and environmental dimensions in urban design process. The principles of sustainable development require a balance consideration of social, economic and environmental implications of development activities. Urban designers seek to incorporate the principles of sustainability into urban design through sustainable urban design.

In Saudi Arabia, like other Middle East countries, there is growing awareness of the unsustainable water and energy consumption. Domestic energy demand is increasing due to automobile dependence and use of energy dependent air conditioners for cooling (Elgendy, 2011; Taleb and Sharples, 2011; Almatawa et al., 2012). Saudi Arabia consumes about one third of its oil production (Elgendy, 2011) and buildings are consuming about $30 \%$ of domestic usage (Almatawa et al., 2012). Water production by desalination depends on fossil energy and high water demand influences energy demand. There are indications that the usage of water has not been efficient due to wastage (Garba, 2004; Elgendy, 2011) 
and high energy consumption and automobile dependence might have led to air and noise pollution in a typical Saudi city (Alshuwaikhat and Aina, 2006). Therefore, there is the imperative to charter a new course that is more sustainable. Elgendy (2010) and Mills et al. (2012) highlighted the recent drive by Middle East governments to start initiatives that will foster sustainable built environment.

\subsection{Saudi pattern of urban development}

\subsubsection{Traditional urban form in Saudi Arabia}

The traditional urban form in Saudi Arabia is similar to that of most traditional Muslim cities. The traditional urban fabric is characterized by organic narrow winding street pattern, with homogeneous arrangement of housing plots. The houses open inward in form of courtyards (Fig. 1) and are centred on mosques, markets 'suqs' and madrassas. As noted by Bianca (2000), "the formation of the urban structure is not subject to the purely quantitative division of large space into smaller fragments but based on an incremental or 'organic' aggregation process, originating in the definition of socially relevant micro-spaces which are then connected into larger units. The enclosure of voids by correlated solids, repeated in countless variations, is the generating principle of urban form". Pacione (2001) highlighted the elements of traditional Islamic city as the obviation of the need for public buildings; the centring of city on mosques that provide a range of welfare and education functions; the bazaar or 'suq'; the residential fabric that is composed of a compact structure of open courtyard houses; and the irregular street pattern. The irregularity of forms of the traditional urban fabric does not necessarily connote lack of order but depicts coherent and harmonious integration of diverse elements to make a whole.

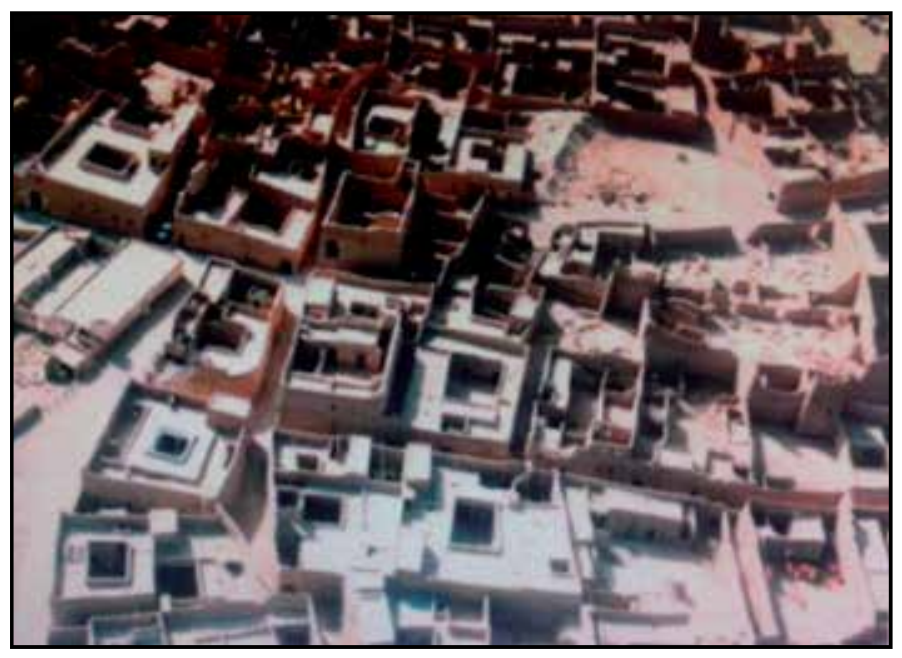

Figure 1. Traditional courtyards (Source: Arriyadh Development Authority)

In spite of the general elements attributed to the traditional urban fabric, there are notable variations from place to place. The old Jeddah as a typical example of traditional town in 
Saudi Arabia does have some specific characteristics that are peculiar to it. The old Jeddah town was significantly different from other Islamic cities by its lack of central space allocated to governmental or religious institutions (Fig. 2). The core of old Jeddah emerged around the central 'suq' or market surrounded by residential quarters (Khan, 1981). Nevertheless, the social and communal activity still centred on the mosque. The main arteries are very few numbering about five, including the major axis along the 'suq' or market. The width of the roads varied according to function and location. The narrower lanes were located within residential quarter (Fig. 3) while the wider streets served the shopping areas and transportation of goods.

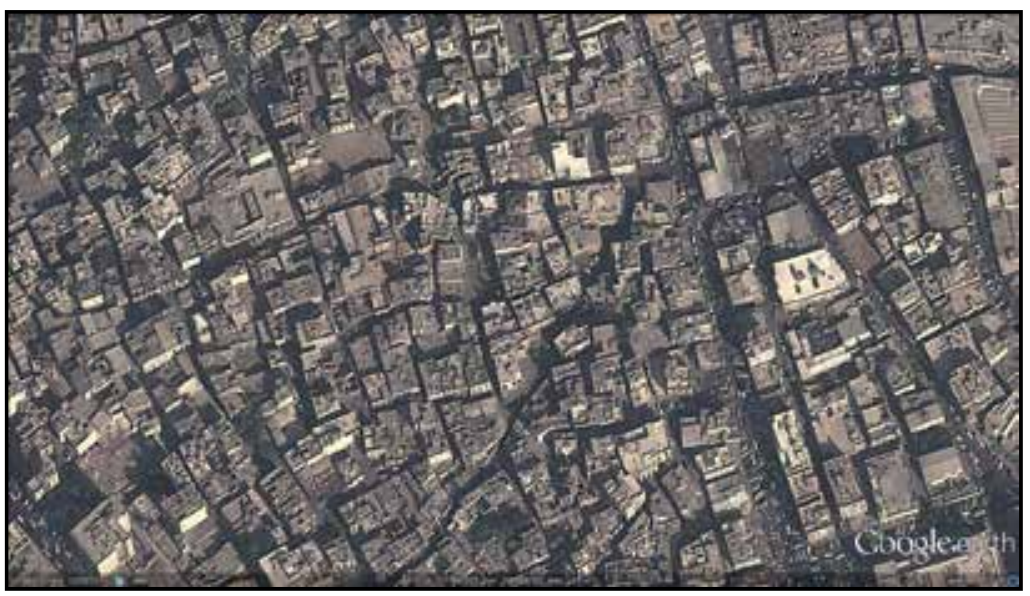

Figure 2. Street patterns in old Jeddah (Source: Google earth)

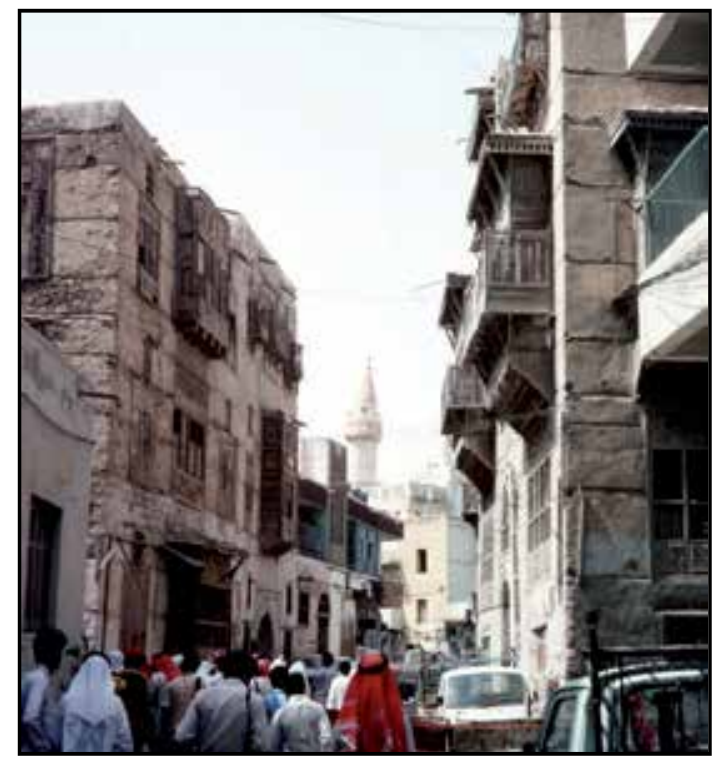

Figure 3. A narrow street in Old Jeddah (buildings have traditional wooden window screen "Mashrabiyah" for privacy) 
Religious, environmental, socio-economic and cultural factors have been cited as having influences on the elements of the traditional urban fabric. For instance, the introverted housing pattern of courtyards have stemmed from the religious concept of privacy and adaptation to the local climate. Also, the irregular street pattern reflects an adaptation to the local climate by maximizing shade. In essence the traditional urban fabric exemplified adaptation to local environment, integration of socio-economic and religious-cultural principles in developing harmonious and liveable society. The balance of socio-economic, environmental, religious and cultural factors in development of traditional urban fabric is exemplary and noteworthy. In the first instance, the origin of the city could be based on environmental, socio-economic or religious considerations. Availability of water or good agricultural land could serve as considerable environmental factor for locating traditional cities. After which the city is developed in an incremental manner without a 'formalized' planning but with a general concept of harmony, coherence and liveability.

The spatial geometry of the traditional urban fabric seems to have developed from lack of planning. Far from that, the structures are planned but the planning principles are flexible enough to allow for acceptable diversity and the principles are applied by the individuals in the society as there was limited civic planning. The main sources of these principles are the religious tenets derived from the Shari'ah (Qur'an and Sunnah). Examples are the principles of privacy, private and public space. The principle of privacy might have contributed to the development of the narrow and winding streets apart from the climatic adaptation by "shading".

\subsubsection{Contemporary urban form in Saudi Arabia}

The emergence of contemporary urban form in Saudi Arabia started in the 1930's when building regulations were enacted to guide building construction and street patterns. During this period, imported modern technologies and planning models were introduced to the country without due consideration of the local traditions and socio-cultural factors. Notable among the contemporary building regulations were the 1358/1938 King Abdulaziz's order to found Alkhobar city, the 1371/1951 ARAMCO home ownership plan and the 1960 circular by the Deputy Ministry of Interior for Municipalities. These orders and regulations set the background for the contemporary urban fabric in Saudi Arabia and the structure and pattern of cities and towns are influenced by the different regulations. Greater degree of urban transformation set in during the 1970's as a result of the economic boom and the inauguration of the Five Year Development Planning. Then, the government began a campaign of modern urban planning and systematic intervention in urban production (Eben Saleh, 2002). The new urban form was established with the grid-iron patterns and building regulations and zoning outlined compulsory setbacks and site-coverage limits. The new spatial models engendered the construction of freestanding, low-density "villa" dwellings (Eben Saleh, 2002).

Al-Malaz neighbourhood in Riyadh represents a typical Saudi contemporary urban structure. The neighbourhood, which is located $4.5 \mathrm{~km}$ north east of Riaydh, was planned in 
1373/1957 when government headquarters was moved from Makkah to Riyadh. Al-Malaz was planned following a grid-iron pattern with an hierarchy of streets, rectangular blocks, and large lots which in most cases are square in shape (Fig. 4) (Al-Said, 1992). The main thoroughfares are 30 meters in width, secondary streets 20 meters, and minor streets or access streets of 10 and 15 meters. The block areas are 100 by 50 meters. The typical lot size is 25 by 25 meters, with some variations in width (Al-Said, 1992). The Al-Malaz neighbourhood structural pattern was consequent upon the contemporary building requirements which stipulated the planning of the land, subdivision with cement poles, heights of the buildings, setbacks and square lot ratio of the buildings.

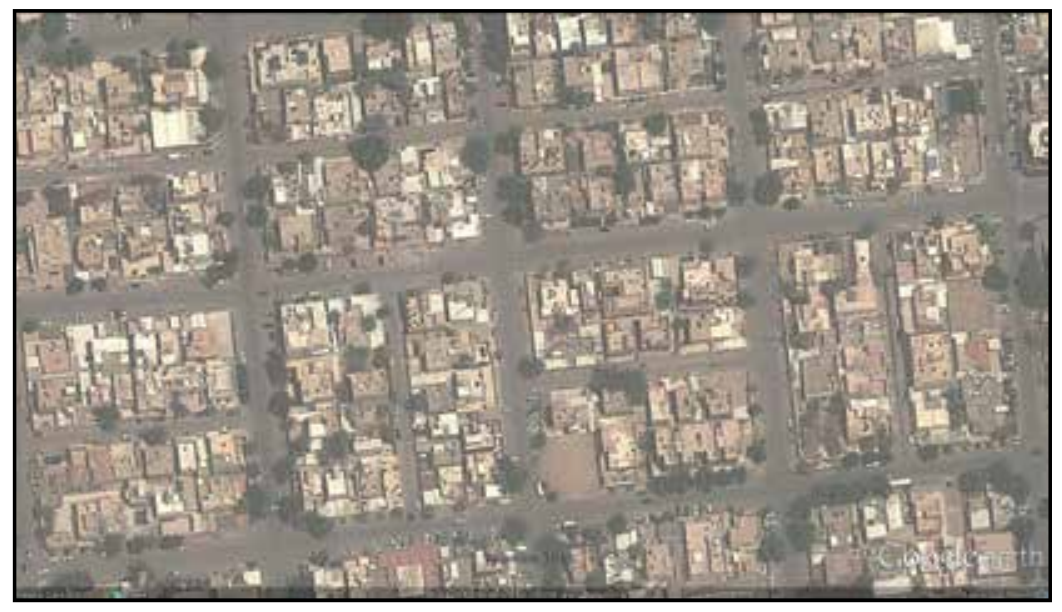

Figure 4. Structural pattern of Al-Malaz neighbourhood (Source: Google earth)

\subsubsection{Issues and problems in contemporary urban form}

The contemporary urban pattern is mainly driven by economic considerations and formalized planning legislations. The streets are widened (Fig. 5) to maintain fast connectivity among different sectors of the city through the automobile. Urban development activities are evaluated mainly by economic efficiency and traffic considerations with the neglect of socio-cultural and environmental dimensions. The contemporary model of urban design encourages the extensive use of space and the fragmentation of functional spaces. In essence, the contemporary model contrasts the traditional model by being dynamic and mechanical while the traditional model is static and human in scale.

The contemporary/modern model of urban form has been found to be in conflict with some indigenous socio-cultural, environmental, economic and structural concepts. For instance, in the traditional Arab-Islamic society privacy was very important but the introduction of setbacks allowed adjoining buildings to open their windows outward thereby infringing on the privacy of other dwellings (Eben Saleh, 2002). Also, the introduction of glazed glasses as building materials results in additional costs of cooling and heating during the extremes of climate in summer and winter. These notable conflicts rendered contemporary model of urban design to be problematic. The residents have rejected contemporary urban form by 
erecting additional structures over fences to ensure privacy and by not using their yards for female activities (Al-Hemaidi, 2001). Social sustainability is also affected by the use of cars for movements within neighbourhood such as going to school, mosque or shops instead of walking (Al-Hemaidi, 2001). Thus, Elaraby (1996) opined that the new mix of Western styles of design and characters that have appeared recently have changed the spatial environment of many Islamic countries for worse. The challenge is to develop a framework of adopting the modern technology and design principles without jeopardizing the elements of traditional values, forms and design.

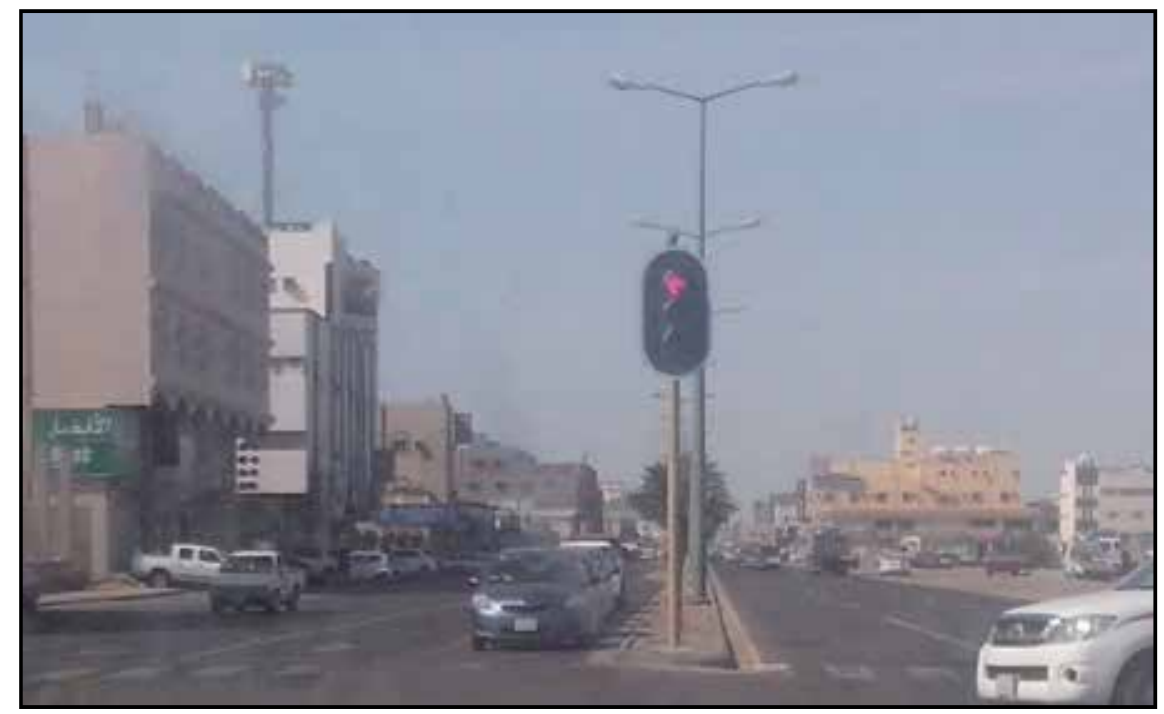

Figure 5. A wide street of the contemporary urban form

\subsection{Overview of sustainable urban design principles}

It is recognized that urban design could foster sustainability by incorporating the principles of sustainable development with urban design guidelines and process. Different research studies have elaborated on the key principles that should be incorporated into urban design to promote sustainability. Selman (1996) and Carmona (2001) highlighted the major tenets of sustainable development that should be integrated with urban design. These principles include intergenerational equity, public trust doctrine (maintaining environmental diversity and carrying capacity), precautionary principle, intra-generational equity, participation and polluter pays principle. Atkinson and Ting (2002) proposed a framework of transformative sustainable urban design with the following principles: acknowledgement of fundamental ecological patterns and limits, environmental and social restoration and regeneration, seeking better quality of life through liveability, employing integrative and holistic strategies and solutions and recognizing sustainable urban design as a process and product. Adhya et al. (2010) opined that sustainable urban design should be able to provide adequate answers to questions on the aesthetics of the urban form, functionality of the built environment and the sustainability of the social and economic processes. 
In a bid to present the sustainable urban design principles in an applicable manner, Carmona (2001) elaborated on the key principles and highlighted ten basic tenets of sustainable urban design that are found in expounded literature. These include:

- $\quad$ stewardship - integrated planning, enhancement through change and town centre rejuvenation;

- resource efficiency - economy of means, minimal environmental harm, reducing travel/energy reduction and recycling;

- diversity and choice - variety, permeability, mixed development and hierarchy of services and facilities;

- human needs - legibility, aesthetics, security, low crime, social mix and imageability;

- $\quad$ resilience - flexibility and ability to adapt to change;

- pollution reduction - low pollution and noise, water strategy, climate and air quality;

- concentration - polycentric city, compact intensification and support services;

- distinctiveness - heritage, creative relationship, sense of place and regional identity;

- biotic support - urban greening, open space, biotic support and symbiotic town/country;

- self-sufficiency - environmental literacy, local autonomy, consultation and participation.

He also noted that the spatial scale of urban design (from local to metropolitan) should be considered in applying urban design principles. In the same vein, Frey (1999) suggested three levels of urban design interventions that include individual space, city district and city/conurbation levels. In order to be effective, urban design interventions should have development frameworks generated at these levels. Choguill (2008) argued for paying more attention to the development of sustainable neighbourhood since the city cannot be sustainable with unsustainable neighbourhood.

Jabareen (2006) identified seven concepts of sustainable design that are similar to the ones developed by Carmona (2001). His principles are more specific about the issues to be addressed in fostering sustainable urban design. The concepts include:

- $\quad$ compactness - intensification of built form

- $\quad$ sustainable transport - design that promotes walking, cycling and transit-oriented development

- density - high density development

- $\quad$ mixed land uses - diversity of functional land uses

- diversity - diversity of land uses, rents and architectural styles

- passive solar design - reduction of fossil fuel consumption

- greening - provision of adequate urban green areas

A number of the sustainable urban design principles enunciated above need further research to clarify effect of applying the principles on the urban environment and the direction (increasing or decreasing) of application. For instance, although different authors have tried to document the negative effects of sprawl development, the principle of concentration in form of compact city development is still debatable. As noted by Frey 
(1999) that the exact forms and structure that would render the city more sustainable remain elusive and the claims in support of one or the other urban structure are not substantiated. The compactness of the city must be decided with due consideration to the cultural, social and environmental context of the city.

The principles highlighted above are substantive, in line with the criteria by Sternberg (2000), and might not achieve sustainability without sustainable design procedure. The design process and the outcome of design should be sustainable. Alshuwaikhat and Nkwenti (2002) and Abdulgader and Aina (2005) suggested frameworks for ensuring sustainability in the urban design process. Abdulgader and Aina (2005) identified five aspects of the urban design process that should be integrated. The aspects include substantive, procedural, methodological, policy and institutional. Alshuwaikhat and Nkwenti (2002) expatiated on the procedural aspect by suggesting a design framework that is within a balanced structure of "Top-Down" and "Down-Top" dialoguing with reflection of various components of the society. The sustainable design process approach consists of five principal stages: sustainable design objectives, sustainable design guidelines, sustainable design statements, preliminary design and sustainable design scheme. This framework has to be integrated with the planning process to promote sustainability of cities. The planning and urban design process should be incremental and adaptive due to the need for flexibility and adaptation to changes in social, economic and environmental contexts. The section below includes further discussion on sustainable design process.

\section{The integrated approach to sustainable urban design}

As illustrated in the sections above, there are at least three contending issues/concepts of urban form and design in Saudi Arabia; the heritage of the traditional urban form, modern concept of urban pattern and the emerging and overarching concept of sustainable urban design. Contemporary urban design cannot be based solely on the traditional models as the variables that have contribution to the development of urban development are fast changing and it could be very difficult and impracticable to conceptualize these changes in the light of traditional concepts alone. On the other hand, indiscriminate adoption of modern models has been found to be problematic and incompatible with the traditional city forms. "The total neglect of the traditional forms, and the implications of their meanings and values, will cause us to lose forever our heritage and architectural identity" (Al-Hemaidi, 2001). Sustainable urban design could provide the opportunity of integrating the traditional and contemporary models in a resourceful manner, as some of the relevant elements of both models are embedded in the principles of sustainable design. As noted by Liddell and Mackie (2002) that the more sustainability principles are applied to design and planning (in Northern Europe) the more these tend to take on traditional forms. However, there should be a framework that lays emphasis on the consideration of traditional concepts for the appropriate integration of these concepts in the principles of sustainable urban design.

The integrated approach to sustainable urban design should have at least three dimensions; substantive, procedural and methodological. The other two dimensions, policies and 
institutional aspects (Abdulgader and Aina, 2005), are not directly under the control of urban designers. Yet, urban designers need the skills to manoeuvre the institutional framework and also promote the implementation of sustainable policies. The procedural dimension that is adapted from the study of Alshuwaikhat and Nkwenti (2002) has been highlighted above. That is, the procedure should consist of at least five principal stages of objective, guidelines, statements, design and scheme. The integration of sustainability in urban design process is necessary because the process of urban design determines the transformation of the design and the process cannot be divorced from the product. If the design process is sustainable there is likelihood that the design itself will be sustainable and consequently the community will advance towards sustainability. The issue of implementation is very important in the procedural aspect and efforts should be made to monitor and improve the efficiency and effectiveness of the implementation mechanism.

\subsection{Substantive dimension - a synergy of principles}

The substantive dimension proceeds from the idea of Sternberg (2000), as mentioned in section two above, that the underlying principles of the contending approaches be integrated. Thus, the underlying substantive principles of sustainable urban design should be integrated with the traditional values and principles of urban form. Elaraby (1996) expatiated on the underlying principles of traditional Islamic design and highlighted six principles which are fundamental to traditional design. These principles include:

- Unity - functional and aesthetic forms that expresses an integrated, indivisible whole (unity in space and pattern, in light and colour and in space and form);

- Openness of space - positive, active spaces interact with negative spaces to express interrelationship between form and space;

- Simplicity of form and design - use of basic geometric shape and a pure modification and abstraction of geometrical form;

- Simplicity of structural expression - organic relationship between structural components;

- $\quad$ Scale - respect for human scale in both the whole environment and particular buildings;

- Harmony, compatibility and balance - harmonious integration of structure and form; and

- Privacy - respect individual right to privacy.

The traditional urban and legislative elements which interacted to shape the urban form and spatial structure should also be integrated into the design process. Some of these elements are identified by Hakim (1988) as Hisba institution, Waqf, allocation of land, traditional energy saving techniques, symbolic manifestations, water extraction and surveying and construction techniques.

A set of principles and elements from traditional and contemporary design are selected to be integrated with the principles of sustainable urban design to engender better urban form and design (Fig. 6). As shown in figure 6, the sustainability principles include mainly the 
concepts from Jabareen (2006) and some issues that were not explicitly mentioned in his framework. For example, resilience to climate change and natural hazards has become an important issue in recent time due to global environmental change. Human needs such as social relationship are also very important. So, these concepts are selected from Carmona's (2001) principles. The traditional principles are deduced from issues raised by Al-Hathloul (1981), Hakim (1988), Al-Hemaidi (2001) and Eben Saleh (2002).

The process issues such as public participation and institutional framework are not substantive but they are also important. So, they are shown in red boxes outside the substantive triangle (Fig. 6). Some of the issues feature in more than one set of principles to

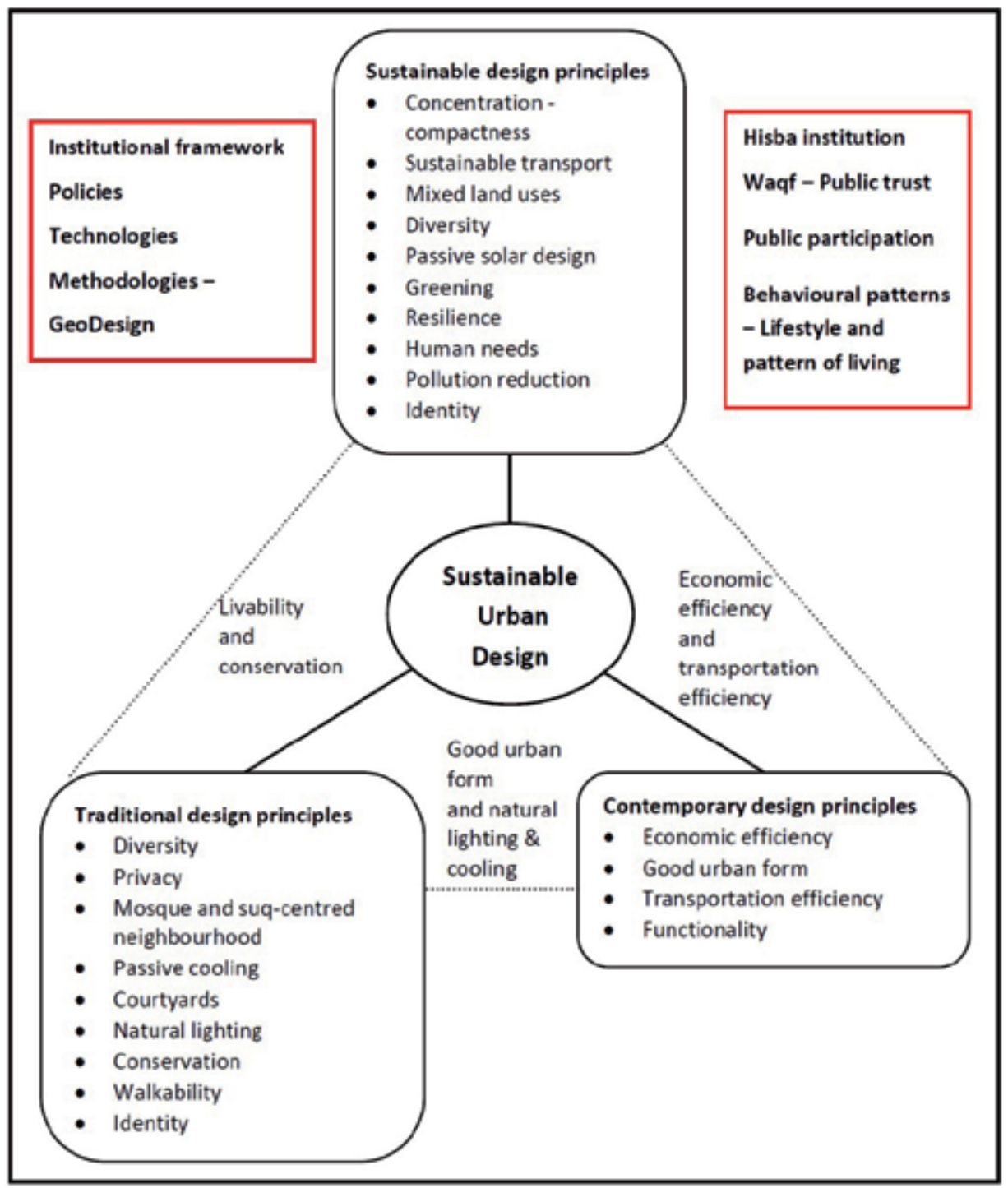

Figure 6. Conceptualization of the integrative theory approach 
show the overlap between some of the contending principles. Some challenges might arise from the issues that are conflicting among the principles. For example, promoting urban greening might conflict with conservation in a desert environment. Maintaining green areas require a lot of water and it might impact on energy demand. Also, it might be difficult to achieve high density neighbourhood with design of courtyards. The principles highlighted in this study are not conclusive and other principles could still be valid and relevant. In essence, the paper proposes that different principles of traditional, modern and the overarching sustainable urban design should be applied in an integrative approach to achieve better and liveable cities.

\subsection{Methodological dimension - a case for GeoDesign}

The methodological dimension involves the utilization of different analytical, descriptive and modelling techniques to fully grasp the complexity of different factors involved in sustainable urban design. No single method is capable of analyzing the components of urban systems in a comprehensive manner. Thus, there is the need to integrate different methods of analysis with a view to further understand and model the urban system. Efforts have been made in this direction with the development of space syntax, cellular automata, GIS and the collaborative planning support systems. It has been noted by Batty et al. (1998) that the advances in computer models and information systems have hardly been fully utilized in urban design. It is highly pertinent now to find ways of utilizing the powerful potentials of different computer models and information systems to support urban design. Batty et al. (1998) identified about four ways in which urban system can be represented (by the information systems) at the level of urban design. These include the representations of socio-economic, functional, behavioural and physical information. Virtually all the information can be stored and analyzed digitally by the current level of technology. There is just the need to fully integrate the available information systems and make them amenable to supporting sustainable urban design process and product.

Efforts towards the integration of information systems for urban design have led to the emerging concept of GeoDesign. It is the adaptation of geography, geographic information system and other information systems in a synergetic way to support urban design. That is, "integrating geospatial technologies into the design process with the goal of living more harmoniously with nature" (Artz, 2010). Goodchild (2010) defined GeoDesign as "planning informed by scientific knowledge of how the world works, expressed in GIS-based simulations". Apart from utilizing the sketching and simulation capability of GIS (Goodchild, 2010), with geographic reference, GeoDesign uses web and visualization technologies to enhance collaboration and stakeholders participation during the design process. The broad idea is to have all design related technologies, such as computer-aided design (CAD) and building information modelling (BIM), integrated into GIS to be able to design in a spatially aware environment.

GeoDesign has been demonstrated to include the following essential elements (Dangermond, 2009; Abukhater and Walker, 2010; Goodchild, 2010, Wheeler, 2010):

- $\quad$ Sketching - drawing proposed designs or plans 
- $\quad$ Spatially aware simulations - modelling different systems (environmental, economic and so on) and how they will respond to proposed design in terms of impacts and change (with geographic reference)

- $\quad$ Fast feedback - supporting collaboration

- Iteration - trying and visualizing different alternatives

- $3 \mathrm{D}$ visualization - presenting design alternatives and impacts in three dimension

In their article, Abukhater and Walker (2010) exemplified how GeoDesign can be used in making cities grow smarter. GeoDesign has also been applied in planning new electricity networks (Moreno-Marimbaldo et al., 2012), green infrastructure design (Hehl-lange et al., 2012) and landscape planning (Pietsch, 2012). The capabilities of GeoDesign make it a valuable tool for urban designers in promoting sustainable built environment. Urban designers need capable analytical, modelling and visualization tools to synthesize the varying issues of urban complexity, climate change and human social needs.

A model by Dangermond (2009) successfully highlighted the importance of GeoDesign in design process (Fig. 7). The model incorporates the design process with the elements of GeoDesign such as designing, sketching and geo-accounting. It showed that Geodesign could be a veritable box of tools that enables "a rapid and adaptive process for creating a sustainable future" (Dangermond, 2009). In terms of usage, most of the applications of GeoDesign are still in Europe and North America but there is a growing adoption in other

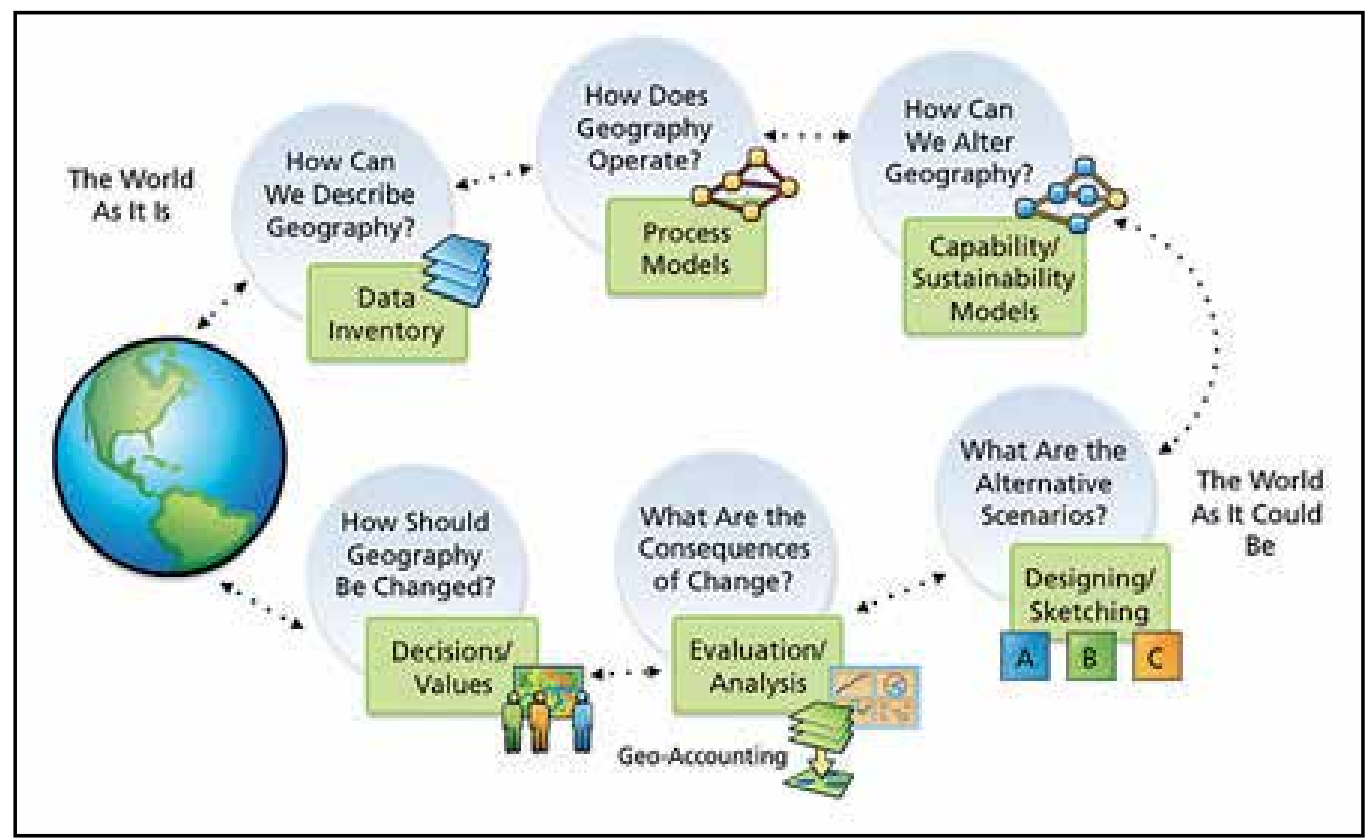

Figure 7. GeoDesign in the sustainable design process (Source: Dangermond, 2009) Graphic used by permission. Copyright (C) Esri. All rights reserved. 
countries. In Saudi Arabia, GeoDesign is gaining momentum because GIS technology (backbone of GeoDesign) is already being used in the kingdom to solve different geospatial and design problems. Aina (2012) highlighted some of the recent applications of GIS in Saudi Arabia and affirmed that the utilization of the technology is growing in the Kingdom. Another indicator of the growing application of GIS and GeoDesign is the GeoDesign conference that took place in Riyadh in 2011. The conference (http://www.iqpc.com/ Event.aspx?id=554952) recognized the need to enhance Saudi's GeoDesign capabilities to support the increasing infrastructure expansion projects.

\subsection{Case studies - Mashair metro and KAUST campus}

Saudi Arabia has carried out some projects that are exemplary for sustainable urban design. One of the projects is the Mashair metro project, which was inaugurated to improve transportation system during the yearly pilgrimage (Hajj). The Mashair trains have the capacity to transport about 550,000 pilgrims between the holy sites (Arab News, 2012). The project could promote sustainable urban design, by reducing carbon emissions and encouraging transit-oriented development, as the trains will replace about 53,000 buses (Barry, 2009). Due to the initial success of the project, other metro projects have been initiated for Jeddah and Riyadh cities and to link Makkah with Madinah (Haramain Metro). Another prominent design project is King Abdullah University of Science and Technology (KAUST) campus project. This is the first project to be awarded LEED certificate in Saudi Arabia (Almatawa et al., 2012). The project was based on sustainability principles from the scratch and they implemented a sort of GeoDesign for the design of the campus and monitoring of different sustainability parameters (Elgendy, 2010). The sustainable and traditional design principles implemented in the project include; compact city planning, traditional suq (market), traditional passive ventilation, mashrabiyah (Fig. 8), passive design, energy and water conservation (Elgendy, 2010).

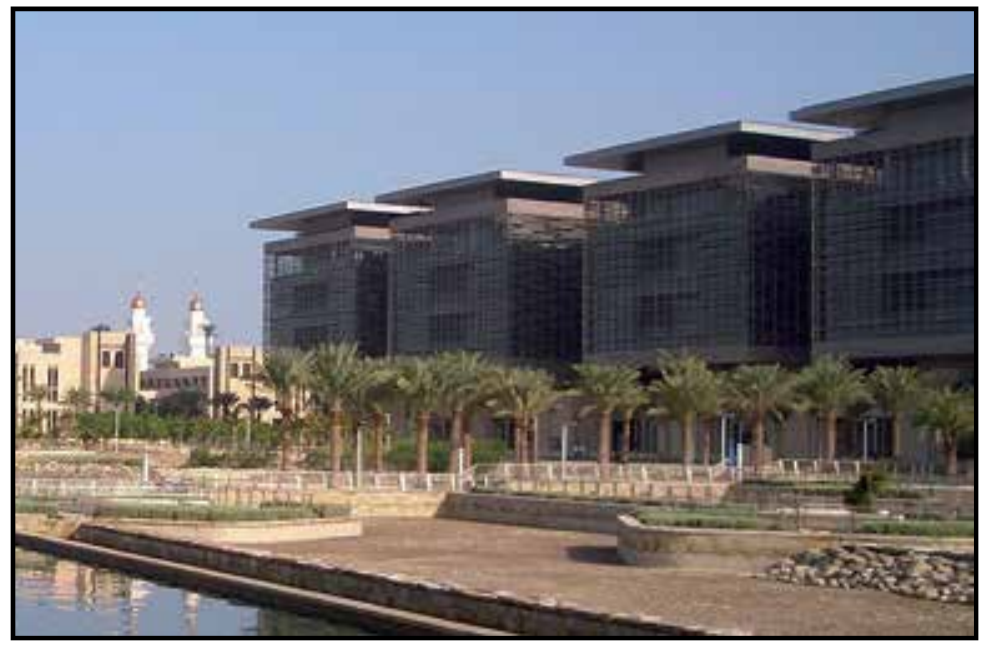

Figure 8. Building facade with window screen similar to traditional mashrabiyah (Source: A. T. Service - Wikimedia commons) 
These highlighted constitute a very bold start in embracing the principles of sustainable urban design in the Kingdom. The challenge is in replicating such projects across the Kingdom and making the adoption of sustainability principle the norm. Al-Hemaidi (2001) noted that there few promising traditional designs here and there but there is no coordinated effort to implement them on a general level. Another challenge is the ability to change the behavioural pattern of the populace. Authors like Abdulgader and Aina (2005) and Choguill (2008) have noted the requirement and importance of changing living pattern to achieving sustainability. Implementing sustainability principles is necessary but not enough for sustainable urban development (Choguill, 2008).

\section{Conclusion}

The concept of sustainable urban design is an overarching concept that can serve as a platform to resolve the conflicting values of the traditional urban form and modern design models. However, the principles of these models both traditional and modern should be integrated with the sustainable urban design principles to effectively incorporate them in urban planning and development. This chapter has tried to highlight some of the pertinent and core principles of traditional urban form and sustainable urban design that should be integrated to foster liveable cities. It also highlights the importance and value of GeoDesign to sustainable urban design. Although the approach that has been proposed by this chapter evolves from the analysis of Saudi Arabian urban design context, it could be applied in any other planning and design environment with little variations. As it is evident that the tendency in almost every society is to follow the new trend of the globalization of cities, by which forces that are 'alien' to cities dictate their structure and morphology. There is the need to further examine how to operationalize these integrated principles especially in the local context of the Kingdom of Saudi Arabia.

\section{Author details}

Y.A. Aina

Geomatics Technologies Department, Yanbu Industrial College, Yanbu, Saudi Arabia
A. Al-Naser
Department of City and Regional Planning, King Fahd University of Petroleum and Minerals, Dhahran, Saudi Arabia
S.B. Garba
Department of Civil and Architectural Engineering, Sultan Qaboos University, Muscat, Oman

\section{Acknowledgement}

The authors acknowledge the support of King Fahd University of Petroleum and Minerals for the research. The authors are also grateful to the editorial board for its comments. 


\section{References}

Abdulgader, A. \& Aina, Y. A. (2005). Sustainable cities: An integrated approach to sustainable urban design. In: Sustainable Development and Planning II: Volume 1, A. Kungolos, C. A. Brebbia \& E. Beriatos, (Ed.), WIT Press, UK, pp. 15-24

Abukhater, A. \& Walker, D. (2010). Making smart growth smarter with GeoDesign. Directions Magazine, Available from http://www.directionsmag.com/articles/makingsmart-growth-smarter-with-geodesign/122336

Adolphe, L. (2001). A simplified model of urban morphology: Application to an analysis of the environmental performance of cities. Environment and Planning B: Planning and Design, 28, pp. 183-200

Adhya, A.; Plowright, P. \& Stevens, J. (2010). Defining sustainable urbanism: Towards a responsive urban design. In: Proceedings of the Conference on Sustainability and the Built Environment, pp. 2-4, King Saud University, Riyadh, Saudi Arabia

Aina, Y. A. (2012). Applications of geospatial technologies for practitioners: An emerging perspective of geospatial education, In: Emerging informatics - Innovative concepts and applications, S. J. Miah, (Ed.), InTech, Rijeka, Croatia, pp. 3-20, Available from http://www.intechopen.com/download/pdf/35692

Al-Hathloul, S. A. (1981). Tradition, continuity and change in the physical environment: the Arab-Muslim city. PhD Thesis, Massachusetts Institute of Technology, USA

Al-Hemaidi, W. K. (2001). The metamorphosis of the urban fabric in Arab-Muslim city: Riyadh, Saudi Arabia, Journal of Housing and the Built Environment, Vol.16, No.2, pp. 179201

Al-Said, F. A. M. (1992). Territorial behaviour and the built environment: The case of ArabMuslim towns, Saudi Arabia. PhD Thesis, University of Glasgow, UK

Almatawa, M. S.; Elmualim, A. A. \& Essah, E. A. (2012). Passive and active hybrid approach to building design in Saudi Arabia. In: Eco-architecture IV: Harmonisation Between Architecture and Nature, C. A. Brebbia, (Ed.), WIT Press, UK, pp. 163-174

Arab News, (2012). Mashair train service ready to serve Hajis. Arab News, Available from http://www.arabnews.com/mashair-train-service-ready-serve-hajis

Alshuwaikhat, H. \& Khaled, N. (1993). Appropriateness of traditional neighbourhood concept for planning contemporary neighbourhood units. Geojournal, Vol.31, No.4, pp. 393-400

Alshuwaikhat, H. M. \& Nkwenti, D. I. (2002). Developing sustainable cities in arid regions. Cities, Vol.19, No.2, pp. 85-94

Alshuwaikhat, H. M. \& Aina, Y. A. (2006). GIS-based urban sustainability assessment: The case of Dammam city, Saudi Arabia. Local Environment, Vol.11, No.2, pp. 141162

Artz, M. (2010). GeoDesign: Changing geography by design. Directions Magazine, Available from 
http://www.directionsmag.com/articles/geodesign-changing-geography-bydesign/122394

Atkinson, R. \& Ting, J. (2002). Sustainable urban design - Saving the status quo or transforming the future? International Cities and Town Centres Conference, Caloundra, Australia, 18-21 August, 2002

Banister, D.; Watson, S. \& Wood, C. (1997). Sustainable cities: transport, energy, and urban form. Environment and Planning B: Planning and Design, 24, pp. 125-143

Barry, K. (2009). Take the monorail to Mecca. Wired Magazine, Available from http://www.wired.com/autopia/2009/09/take-the-monorail-to-mecca/

Batty, M.; Dodge, M.; Jiang, B. \& Smith, A. (1998). GIS and urban design. Working Paper Series, 3, CASA, University College London, UK

Bianca, S. (2000). Urban form in the Arab world: Past and present. Thames and Hudson Ltd, London, UK

Brown, L. C. (Ed.) (1973). From Madina to metropolis. The Darwin Press, New Jersey

Burton, E. (2000). The compact city: Just or just compact? A preliminary analysis. Urban Studies, Vol.37, No.11, pp. 1969-2001

Carmona, M. (2001). Sustainable urban design - A possible agenda, In: Planning for sustainable future, A. Layard, S. Davoudi \& S. Batty, (Ed.), Spon Press, London, UK

Cervero, R. (2001). Efficient urbanization: Economic performance and the shape of the metropolis. Urban Studies, Vol.38, No.10, pp. 1651-1671

Choguill, C. L. (2008). Developing sustainable neighbourhoods. Habitat International, Vol.32, No.1, pp. 41-48

Dangermond, J. (2009). GIS, design, and evolving technology. ArcNews, Fall 2009, Available from

http://www.esri.com/news/arcnews/fall09articles/tofc-fall09.html

Deakin, M.; Curwell, S.; \& Lombardi, P. (2002). Sustainable urban development: The framework and directory of assessment methods. Journal of Environmental Assessment Policy and Management, Vol.4, No.2, pp.171-197

Eben Saleh, M. A. (2002). A vision for directing future planning efforts: the case of villages of southwestern Saudi Arabia. Habitat International, 26, pp. 51-72

Elaraby, K. M. G. (1996). Neo-Islamic architecture and urban design in the Middle East: From threshold to adaptive design. Built Environment, Vol.22, No.2, pp.138-150

Elgendy, K. (2010). KAUST: A sustainable campus in Saudi Arabia. Carboun Journal, Available from http://www.carboun.com/sustainable-design/kaust-a-sustainablecampus-by-the-red-sea/

Elgendy, K. (2011). Sustainability in the desert. Detail Green Magazine, Issue 2, Available from

http://www.carboun.com/wp-content/uploads/2011/09/14-19_background_elgendy_ENcopy.pdf

Fathy, H. (1973). Architecture of the poor. University of Chicago Press, Chicago, USA 
Frey, H. (1999). Designing the city: Towards a more sustainable urban form. Routledge, New York, USA

Garba, S. B. (2004). Managing urban growth and development in the Riyadh metropolitan area, Saudi Arabia. Habitat International, Vol.28, No.4, pp. 593-608

Goodchild, M. F. (2010). Towards GeoDesign: Repurposing cartography and GIS ? Cartographic Perspectives, 66, pp. 55-69

Gosling, D. \& Maitland, B. (1984). Concepts of urban design. St. Martins Press, New York, US

Hakim, B. (1988). Recycling the experience of traditional Islamic urbanism. In: Preservation of Islamic architecture heritage, Arab Urban Development Institute, Riyadh.

Hehl-Lange, S.; Gill, L.; Henneberry, J.; Keskin, B.; LAnge, E.; Mell, I. C.; \& Morgan, E. (2012). Using 3D virtual GeoDesigns for exploring the economic value of alternative green infrastructure options, In: GeoDesign, 3D-Modelling and Visualization, E. Buhmann, S. Ervin \& M. Pietsch, (Ed.), Heidelberg, Wichmann

Jabareen, Y. R. (2006). Sustainable urban forms their typologies, models, and concepts. Journal of Planning Education and Research, Vol.26, No.1, pp. 38-52

Jenks, M. \& Burgess, R. (2000). Compact cities: Sustainable urban forms for developing countries. Spon Press, London, UK

Khan, S. M. (1981). The influence of Arabian tradition on the old city of Jeddah: The urban setting, In: The Arab city: Its character and Islamic cultural heritage, I. Serageldin \& S. ElSadek, (Ed.), Arab Urban Development Institute, Riyadh, Saudi Arabia

Liddell, H. \& Mackie, D. (2002). Forward to the past. Proceedings of International Conference on Sustainable Building, Oslo, Norway

Lynch, K. (1960). The image of the city. MIT Press, Cambridge, MA, USA

Mills, F.; Lawrence, T.; Rakheja, A. \& Darwiche, A. K. (2012). Green building practices around the world. ASHRAE Journal, Vol.54, No.1, pp. 48-55

Moreno-Marimbaldo, F. J.; Gutierrez-Corea, F. V. \& Manso-Callejo, M. Á. (2012). Using 3D GeoDesign for planning of new electricity networks in Spain. Computational Science and Its Applications-ICCSA 2012, pp. 262-274

Pacione, M. (2001). Urban geography: A global perspective. Routledge, London, UK

Pietsch, M. (2012). GIS in Landscape Planning, In: Landscape Planning, M. Ozyavuz (Ed.), InTech, Rijeka, Croatia, pp. 55-84, Available from

http://www.intechopen.com/books/landscape-planning/gis-in-landscape-planning

Selman, P. (1996). Local sustainability - Managing and planning ecologically sound places. Paul Chapman Publishing, London, UK

Sternberg, E. (2000). An integrative theory of urban design. Journal of American Planning Association, Vol.66, No.3, pp. 265-278

Taleb, H. M. \& Sharples, S. (2011). Developing sustainable residential buildings in Saudi Arabia: A case study. Applied Energy, Vol.88, No.1, pp. 383-391

Wheeler, S. (1998). Planning sustainable and livable cities, In: The city reader, R. T. LeGates \& F. Stout, (Ed.), Routledge, London, UK 
Wheeler, C. (2010). Designing GeoDesign: Next steps in GeoDesign. ArcUser, Spring 2010, pp. 16-19 Available from

http://www.esri.com/news/arcuser/0410/files/geodesign.pdf 


\title{
Chapter 21
}

\section{Urban River Landscapes}

\author{
Bülent Cengiz
}

Additional information is available at the end of the chapter

http://dx.doi.org/10.5772/56156

\section{Introduction}

The importance of urban rivers have always been recognized [1-6] for water resources, protection of nature, fisheries and recreation in view of their considerable contributions to landscape [3, 7]. In addition, rivers have certain definite environmental, social, cultural and economic values, as well. They are used by humans on a wide variety of purposes such as drinking water, irrigation, industry, power production, transportation, flood control, fishing, boating, swimming and aesthetic enjoyment [8].

Rivers have many functions like providing connection between landscapes and communities and they also gather people around the same idea for a creative and sustainable environment. People from all parts of society should and also private and public stakeholders should be included in the development of river management plan in order to find effective solutions for the use of natural resources [8].

There is an apparent interaction between cultural level of societies and the use of water in all fields [9]. Many cities in the world have been established along the river banks [6, 9-10]. For instance, many civilizations settled along the Euphrates- the Tigris Rivers in Mesopotamia, the Nile in Egypt, the Ganges in India, the Indus in Pakistan and the Huang-Ho in China throughout the history [11]. The current examples of cities include the Thames in London, the Seine in Paris, the Tiber in Rome, the Vlvata in Prague, the Danube in Budapest [12-13], the Hudson in New York, the Yarra in Melbourne [6] and Turkish cities as the Seyhan in Adana, the Yeşilırmak in Amasya, the Asi in Antakya, the Tigris in Diyarbakır, the Meriç in Edirne, the Porsuk in Eskişehir and the Bartın River in Bartın [9].

On the other hand, besides their advantages, this kind of settlement also has some disadvantages. Floodplains are susceptible to dangers of flooding in relation with the human and natural activities. Loss of life and property and damages to wildlife habitats can be cited among the risks caused by civilization on water sides [10]. Past uses of rivers and social tendencies are effective on the present condition of rivers. Despite the unsatisfactory 
conditions of water sources in many parts, the increasing efficacy of sewage treatment systems provides new opportunities for inhabitants and improvement of rivers in morphological and economic sense. For attaining a normal level of life quality along river banks, necessary consideration and importance should be given to flood control systems and water quality in urban areas. In this regard, there is an increasing concern in the world over rivers in urban areas in terms of green spaces, urban ecology and life quality [14]. The major part of works conducted on urban rivers has been carried out in North America (mainly the USA), Asia (mainly China) and Europe (mainly western Europe) [6].

In this chapter, the main emphasis has put on the understanding of floodplain resources, principles for an ecologically sound riverfront design, baselines of urban water rehabilitation and some samples of urban river landscape throughout the world. In line with the obtained results, certain recommendations have been made for planning of urban river landscapes in Turkey.

\section{Floodplain resources}

\subsection{Understanding floodplain resources}

In this section, floodplain natural resources are introduced with an explanation of floodplains, watersheds, ecosystems and natural communities.

A typical river corridor has several features brought by geological and hydrological processes effective on landscapes (Figure 1). The river channel wanders through the landscape, carving through the terrain and depositing sediment on places where it goes. Sediment deposits and depressions on water banks might form wetlands, which are always or periodically flooded with water [10].

Floodplains are the areas bordering rivers and streams. These parts in river valleys are frequently defined as areas where the likelihood of flooding is high in a given year. Therefore, the term of "100-year" flood is used to define the flood with $1 \%$ of occurrence possibility in any given year (Similar definitions can be expanded to include 25-or 50-year floods). As a river goes downward in an area, it may leave terraces, formed in time as the river flows at higher elevations. These landforms are part of a larger river corridor and play an extremely important role in the functioning of floodplain ecosystems [10].

Floods are natural outcomes of river ecology. Therefore, it is important to be ready for floods. The job of flood experts is focused on determining the size of floods in statistical terms to present the frequency of water flow that passes through a stream channel in a certain period of time. The frequency of floods is calculated as the time between the same or greater levels of floods. For instance, a 10-year flood is used to represent the event of flood occurring about every 10 years. Based on this calculation, there is a 1-in-10 change of occurrence for a 10-year flood. Historical data is considered in calculation of flood frequencies such as 10-year flood, 25-year flood and 100-year flood. From this regard, there is a 1-percent chance of occurrence for a 100-year flood event for any given year, and 


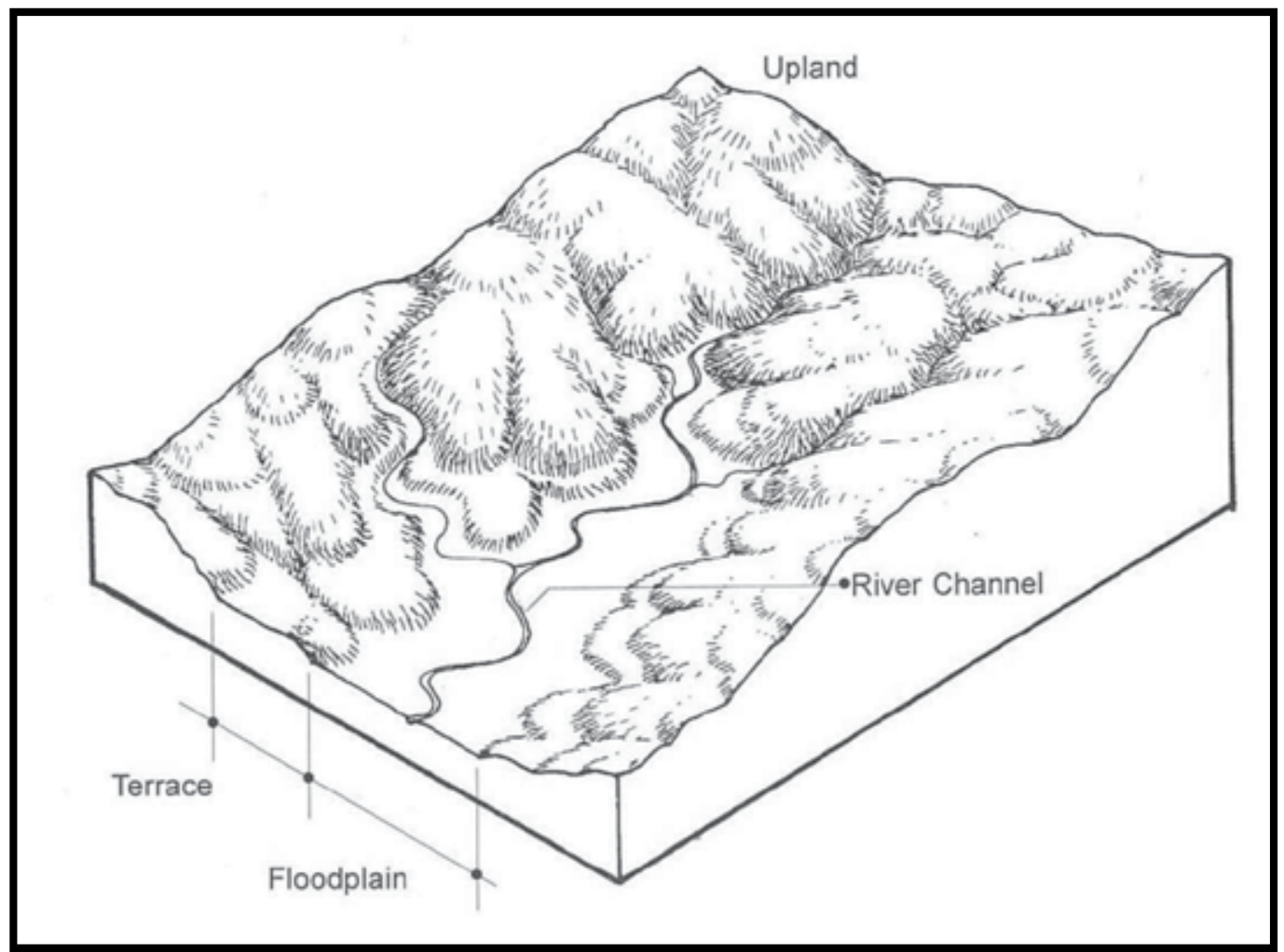

Figure 1. Major physiographic elements of a typical floodplain [10].

similarly, there is a 5-percent chance of occurrence for a 20-year flood event. Many factors including the years of high rainfall and changes in land use are effective for the frequency of these flood events [8], (Figure 2).

The definition of 100-year floodplain is considered as the basis in the U.S. National Flood Insurance Program. The boundaries of this zone are drawn by associating the discharge data and flow elevations to the topography of the stream valley. In this program, two main zones are defined: the first of which is floodway, lowest part in floodplain where flood flows deepest and most frequently; and the second of which is floodway fringe, an area on the margin of regulatory floodway and less frequently and lightly flooded in 100-year flood. Settlements along regulatory floodway are not found qualified for flood insurance; on the other hand, settlements on floodway fringe are qualified for insurance if a certain amount of flood proofing is established (Figure 3) [15].

A developed landscape is confined to the river channel or wider flood-channel. Buildings and roads are flooded in the event of a 10-year or 100-year flood, which is not a pleasant situation for users and residents, but their inconvenience should be compared with other considerations. The preventive efforts for flood events are quite costly from both financial and environmental considerations, and it is also possible that these events will worsen the downstream flood problems [16]. 


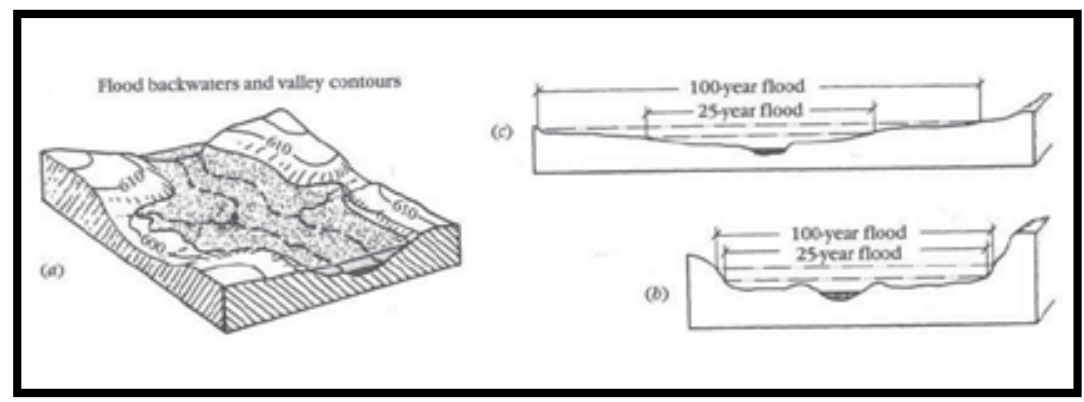

Figure 2. Flood backwaters in relation to valley contours. (b) The influence of valley shape on the extent of the 25-year and 100-year floods [15].

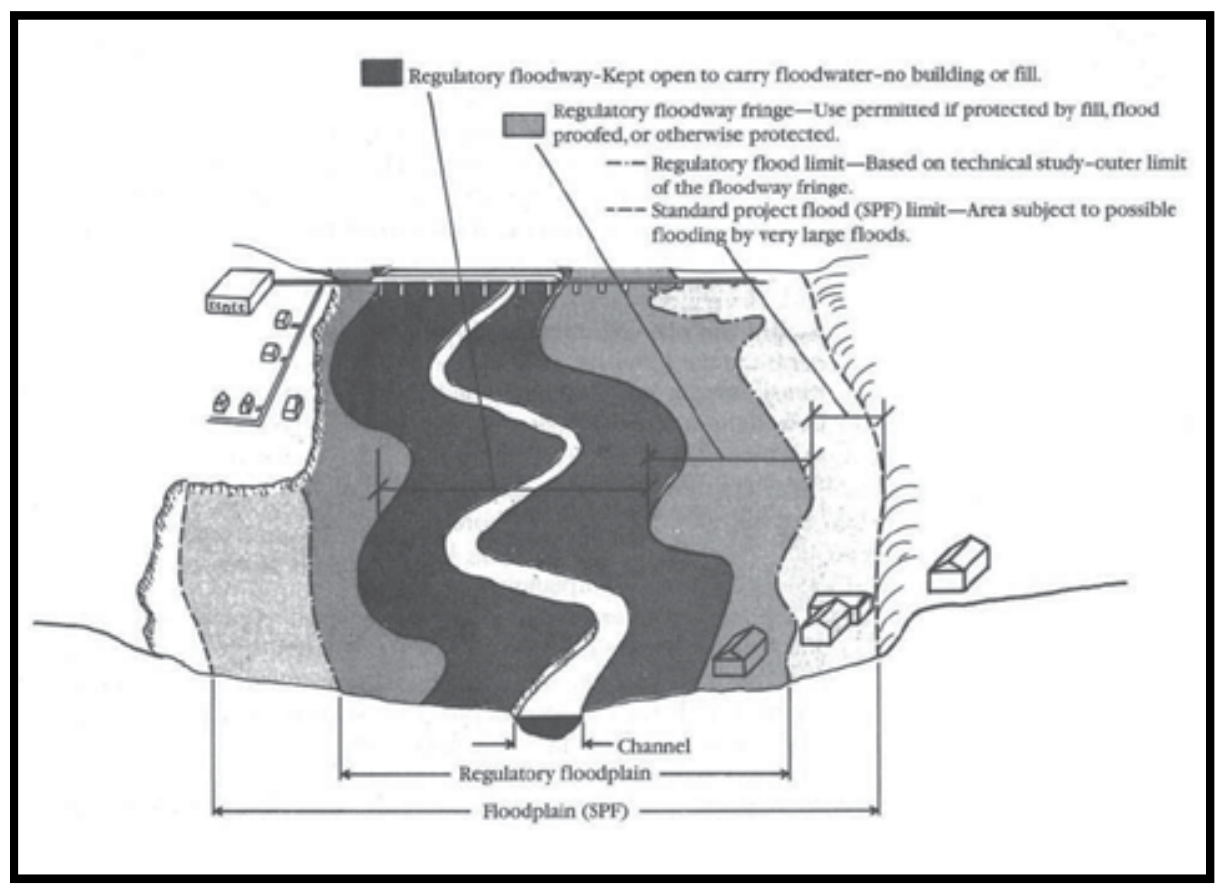

Figure 3. Presentation of the regulator floodway and floodway fringe by U.S. National Flood Insurance Program [15].

As a solution, management of flood events can be integrated into the land-use planning system. The present and recommended contours for each flood event can be drawn for each town:

- Half-year: natural reserves, playgrounds, gardens;

- One-year: needless car parks, light traffic roads, flood-tolerant buildings.

- 25-year: many roads and car-parks, the ground floors of needless buildings.

- 100-year: large urban areas, excluding hospitals or other essential services [16]. The effective areas of river form the overflow boundary, which was evaluated considering the following studies in the literature on landscape planning: [2, 4, 8, 10, 15-21]. 
Watersheds: Watersheds have an important place in understanding and managing the resources in floodplains. Watershed is an area drained by a river and its tributaries. Different watersheds are separated with ridges or divides. Similar to floodplains, they are formed in time with the effects of various climatic, hydrological and geological processes. On the other hand, watershed differs from floodplain with its much larger size, and therefore, it can be more difficult to manage because larger areas are usually covered by various municipalities that have different governments and land-use strategies. However, it should be understood that upstream uses of land and water in a watershed have negative effects on downstream areas and bring along the potential for increased flooding [10] (see Figure 4).

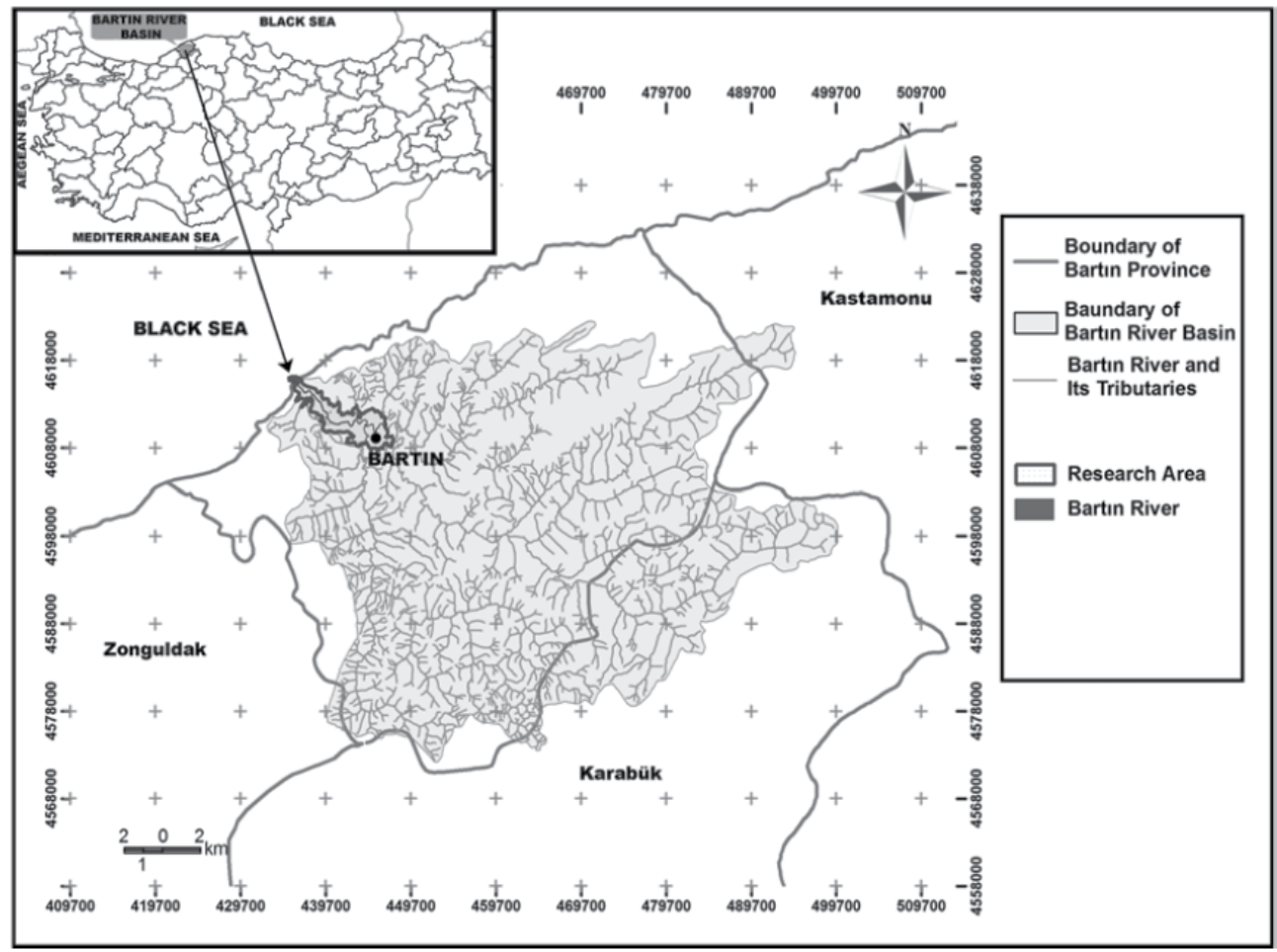

Figure 4. The Bartın River Watershed and stream orders [4, 9, 22].

Natural Resources and Ecosystems: Not only the hydrological features of landscape but also the geological characteristics have an important role in determining the type of vegetation in the area. There are a number of plant species grown in floodplains and adapted to the specific conditions of soil types and water flow cycles, which are the characteristics of river corridors. In turn, vegetation becomes important to determine how water flows in land and it is an indispensable factor in the management of erosion and sediment deposits that can alter the appearance of the landscape [10].

The living and non-living components of natural floodplains are interrelated with each other and create a dynamic system where one helps another to maintain the properties of 
the environment to sustain them in a mutually supportive cycle. These interrelated systems forming both commercial and recreational sides of physical and biological worlds are known as ecosystems. These components of floodplain ecosystem work together in storing and conveying floodwaters, protecting water quality, preventing erosion and sustaining rich habitats of fish and wildlife. The recognition of these relations among hydrological, geological and biological characteristics of these systems, one can comprehend how changing one character can significantly change an entire system [10].

Natural Communities: There can be many different ecological communities, groups of plant and animal species existing together in a certain area along the floodplain and its adjacent landforms. Various types of plant species in an ecological community might need the same type of soil or level of soil moisture available only in a particular area in the floodplain. Wet meadows, bottomland hardwood forests, and riparian shrub wetlands can be cited among the examples of such communities. Landform, soil and plant types present in a certain part of floodplain can identify the boundaries of these ecological communities [10].

\subsection{Natural resources and functions of floodplain}

The three main categories of floodplain resources and functions include water resources, biological resources and societal resources (Table 1) [10].

\subsection{Multiple uses of floodplain}

Different levels of settlement development and disturbance to natural systems have various effects on natural resources. For instance, the management objectives can be different for an already fully developed floodplain community than a community with large open spaces [10].

There are four main levels with corresponding considerations [10].

- Urban Areas: The floodplain in an urban community is probably highly developed already. Restoration of natural areas and the relocation of structures particularly threatened by flood hazards are included in the management options for these areas.

- Suburban Areas/Urban Fringe: Urban fringe areas are frequently threatened by great development pressures, but there might be enough open spaces to work with. Effective planning is of critical importance in these communities, and a special focus can be put on maintaining existing open areas along waterways and restoration of vegetation.

- Rural Areas: Agricultural communities have different concerns of floodplain. The large open spaces in the floodplain of these areas are an advantage. In these areas, management strategies should focus on controlling erosion and excessive nutrient loadings, as well as vegetation of stream banks to restore natural ecosystem functions.

- Wild-lands: The natural system in these communities with very low-density development and much more open spaces should already be functioning. In these areas, there is the opportunity to safeguard floodplain functions at the outset and to maintain valuable habitats and superior water quality. 


\begin{tabular}{|c|c|c|}
\hline \multirow{3}{*}{$\begin{array}{c}\text { Water } \\
\text { Resources }\end{array}$} & $\begin{array}{l}\text { Natural Flood and } \\
\text { Erosion Control }\end{array}$ & $\begin{array}{l}\text { - Provide flood storage and conveyance } \\
\text { - Reduce flood velocities } \\
\text { - Reduce peak floods } \\
\text { - Reduce sedimentation }\end{array}$ \\
\hline & $\begin{array}{l}\text { Water Quality } \\
\text { Maintenance }\end{array}$ & $\begin{array}{l}\text { - Filter nutrients and impurities from runoff } \\
\text { - Process organic wastes } \\
\text { - Moderate temperature fluctuations }\end{array}$ \\
\hline & $\begin{array}{l}\text { Groundwater } \\
\text { Recharge }\end{array}$ & $\begin{array}{l}\text { - Improve infiltration and aquifer recharge } \\
\text { - Reduce the frequency and duration of low } \\
\text { surface flows }\end{array}$ \\
\hline \multirow{2}{*}{$\begin{array}{l}\text { Biological } \\
\text { Resources }\end{array}$} & $\begin{array}{c}\text { Biological } \\
\text { Productivity }\end{array}$ & $\begin{array}{l}\text { - Support high rate of plant growth } \\
\text { - Maintain biodiversity } \\
\text { - Sustain the integrity of ecosystems }\end{array}$ \\
\hline & $\begin{array}{c}\text { Fish and Wildlife } \\
\text { Habitats }\end{array}$ & $\begin{array}{l}\text { - Provide breeding and feeding grounds } \\
\text { - Create and improve waterfowl habitat } \\
\text { - Protect habitats of rare and endangered species }\end{array}$ \\
\hline \multirow{3}{*}{$\begin{array}{c}\text { Social } \\
\text { Resources }\end{array}$} & $\begin{array}{c}\text { Harvests of Wild and } \\
\text { Cultivated Products }\end{array}$ & $\begin{array}{l}\text { - Improve agricultural lands } \\
\text { - Provide sites for aquaculture } \\
\text { - Restore and improve forest lands }\end{array}$ \\
\hline & $\begin{array}{l}\text { Recreational } \\
\text { Opportunities }\end{array}$ & $\begin{array}{l}\text { - Provide areas for active and passive usage } \\
\text { - Provide open spaces } \\
\text { - Provide aesthetic pleasure }\end{array}$ \\
\hline & $\begin{array}{l}\text { Areas for Scientific } \\
\text { Study and Outdoor } \\
\quad \text { Education }\end{array}$ & $\begin{array}{l}\text { - Support cultural resources (historical and } \\
\text { archeological sites) } \\
\text { - Provide opportunities for environmental and } \\
\text { other studies }\end{array}$ \\
\hline
\end{tabular}

*Adopted from: A Unified Program for Floodplain Management, 1994.

Table 1. Natural resources and functions of floodplain [10].

\section{Principles for an ecologically sound riverfront design}

The following three main parts in this section demonstrate concrete examples of principles in planning and design (Table 2) [21].

\section{GENERAL PRINCIPLES}

General Principle 1: $\quad$ Ecological targets and economic development targets should be mutually beneficial

General Principle 2: $\quad$ Protect and restore the characteristics and functions of natural rivers

General Principle 3: Regenerate the riverfront as a human realm

General Principle 4: $\quad$ Compromises are necessary to achieve multiple objectives

General Principle 5: Obtain broad participation in the process of planning and designing riverfront 


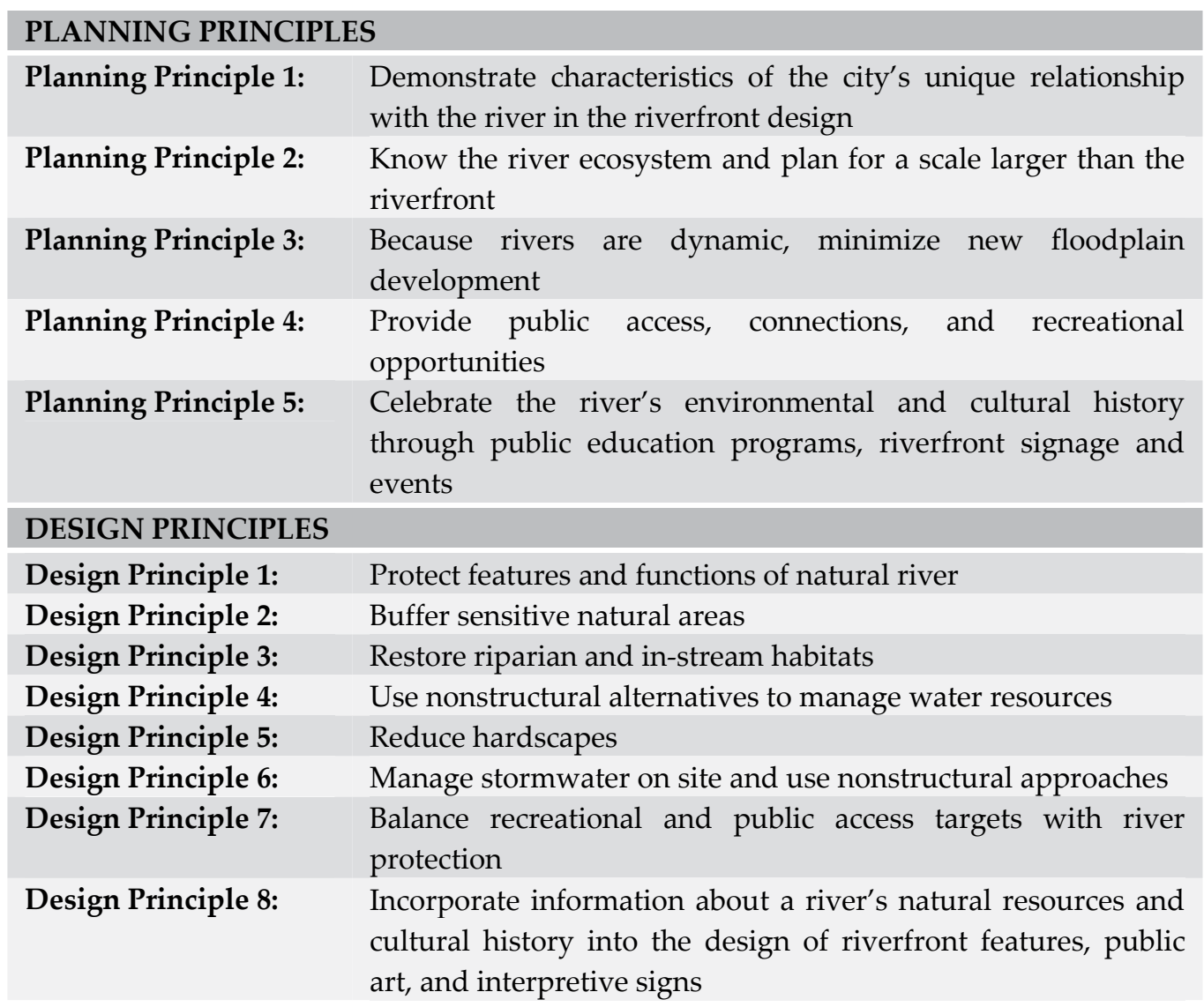

Table 2. Principles for an ecologically sound riverfront design [21].

\subsection{General principles for an ecologically sound riverfront design}

Five general principles set the stage for the success of planning [21].

\subsubsection{Ecological goals and economic development targets should be mutually beneficial}

Public and private developments build a sense of connection and stewardship for the river by attracting people to the waterfront live, eat, shop, relax, recreate, and participate in cultural events.

Healthy and functioning river systems are appealing and attractive to residents and businesses. A society engaged in enjoying riverfront features and activities also cares about the long-term sustainability of river systems. Communities have started to understand the appeal of a more natural riverfront for residents and visitors. Apart from touristic advantages, there are some other benefits as well, including cost-effective flood control, improved water quality, reduced infrastructure costs and increased property values and tax base. 


\subsubsection{Protect and restore the characteristics and functions of natural rivers}

Rivers provide their regions with some natural benefits of critical importance and therefore that must be protected. Natural characteristics of river like meanders, backwaters, wetlands, and gradually sloped banks have important ecological functions. There are also benefits for inhabitant such as cleaner water and flood storage. It might not be possible to restore these features in many urban areas, but even a little effort can bring about a positive effect. Environmental improvements can be achieved on even the most heavily impacted rivers.

\subsubsection{Regenerate the riverfront as a human realm}

There could be some obstacles including physical, political, social and economic barriers for a riverfront project to overcome and increase public use and enjoyment of these public resources. There have been many successful projects designed to include spaces that specially accommodate parks, walkways, docks, and special events such as concerts and festivals. In a good riverfront design, the need of all neighborhoods, ages, and cultures in the community should be taken into account. Community members should be enabled to experience the river closely. In turn, these physical and visual experiences will help creating lively and diverse places to encourage a sense of community and an appreciation for nature.

\subsubsection{Compromises are necessary to achieve multiple objectives}

Sometimes, there could be competing interests in urban waterfronts. Recreational trails and wetlands are often linked to waterfront condos and port facilities. It cannot be always possible to give special focus on economic development and environmental concerns on urban river banks. On account of the present structures, only a few cities can really achieve to create a fully natural river environment. On the other hand, a development project of riverfront to enhance economic livelihood of a city should not rule out natural features, compound riverfront damage, or limit public access. Communities of a riverfront should take advantage of integrating and balancing ecological, social and economic concerns, as well.

\subsubsection{Obtain broad participation in the process of planning and designing riverfront}

The design and planning processes of riverfront should obtain the participation of a wide variety of community members. The process should be extended beyond the identification of traditional stakeholders groups and include the neighborhoods that might not have used the riverfront in the past. There can be different needs of various neighborhoods and constituencies. Riverfront can be designed more lively, inclusive, and successful if these different priorities are taken into account. The participation of local officials, developers, and planning staff in public meetings should be acquired to ensure that everyone aims for the same vision, and that all important thoughts are known. 


\subsection{Planning principles}

Some important aspects such as regional development patterns, natural and cultural history, flood control, public access, recreation and education should be taken into account in planning the revitalization of a riverfront. The five principles below must be incorporated into master plans and conducted by zoning and building codes, engineering standards and site plans and designs [21].

\subsubsection{Demonstrate characteristics of the city's unique relationship to the river in the riverfront design}

Any river city has a unique relation and a nested history with its river. There should a special feel and appearance of riverfronts that is directly associated with the history of city and inspires and celebrates city's character.

It should be known by inhabitants that the river in their city grants the identity of their region and also provides wildlife habitat, recreation, drinking water and jobs in their area. Once these values are appreciated by inhabitants, they become supporters for protecting and restoring their riverfronts.

\subsubsection{Know the river ecosystem and plan for a scale larger than the riverfront}

Planners must regard riverfront development from the aspects of the natural structures of river, which includes:

- Characteristics of the watershed (the land area drained by a river and its tributaries);

- The floodplain and the river channel with the structure of its bed and banks;

- Hydrology (water flows and timing);

- Water chemistry, and

- The biological needs of wildlife, such as insects, fish, amphibians, reptiles, birds, and mammals.

Another important point is to understand how the structure of a river has been altered and how it might change in the future. Rivers are affected by any events occurring in their watersheds and riverfront activity, in turn, they affect areas beyond the edge of river. Planners should not disregard the possible effects of design and activities of riverfront on all areas of the watershed.

\subsubsection{Because rivers are dynamic, minimize new floodplain development}

Rivers are in a constant change by their nature. For instance, spring flood elevations might exceed nonflood levels by $30 \mathrm{~cm}$ or more on some rivers and some rivers freeze in winter, while some others show little seasonal change. These natural variations can be considerably affected by the changes in upstream and the surrounding watershed, often causing 
disastrous results. Extreme flooding events, often intensified by settlement developments in floodplain, are among the most destructive natural disasters.

Undeveloped and connected floodplains are of crucial importance for river health. Future developments on riverfront like trails and parks should be designed to minimize floodplain intrusions. From this regard, structures and facilities must be designed to ensure that there will be no release of contaminants during flooding, no decrease in flood storage capacity, and no flooding or other downstream impacts.

There should be no large permanent structure built in 100-year floodplain as they increase the size of resistant surface, aggravate runoff problems, and increase the risk of costly flooding damages.

\subsubsection{Provide public access, connections, and recreational opportunities}

Easy access is necessary to attract people to a riverfront. Another important point is visual connection to the river from nearby commercial and residential areas. Physical and visual access should not be confined only to the selected neighborhoods or businesses along the redeveloped river. Riverfronts might offer many recreational usages, like bicycling and bird watching. Riverfront communities should be provided with areas or facilities offering a large variety of usage possibilities.

Weather it is through wading, fishing, launching a boat, or sitting on the riverfront, people should be given opportunities to touch and interact with the river in appropriate locations. Economic revitalization projects on riverfronts like new developments of mixed-usage with housing, restaurants or cafes and open spaces become more successful when visual and physical access to the water is included.

\subsubsection{Celebrate the river's environmental and cultural history through public education programs, riverfront signage, and events}

Riverfronts have a rich human and natural history. Informative and path-finding systems can define the river, its environment and how river and city history are connected. Certain activities like educational and cultural programs, performances and public art events can be organized to attract people to the riverfront.

Ecological education is especially meaningful along urban rivers because most of the original forms of ecosystems have been damaged. Rivers can be used as a powerful tool in science and nature education thanks to their active and visually rich environments. Raising awareness of public about rivers and their natural systems will provide a sense of stewardship and connection to the history of rivers.

\subsection{Design principles}

Eight general principles set the stage for design success [21]. 


\subsubsection{Protect natural river features and functions}

The water flow and sediment supply are controlled by natural equilibrium in stable streams and rivers. However, dams and flood control systems have dramatically changed the structure of many urban rivers. Protection of natural river features and functions necessitates avoiding the use of new dams and other engineering solutions, such as a straightening, channelizing, or placing streams in underground pipes and culverts.

It might be possible to fully restore the ecological features and functions in most urban rivers and streams. However, there are many other opportunities for communities to protect the critical areas to provide a more natural riverfront. There are surprisingly rich and extensive predevelopment features in many urban rivers, including forested banks, fish and bird habitat, and wetlands. Preservation of these properties of natural watershed can also be cost saving.

\subsubsection{Buffer sensitive natural areas}

Buffer zones are areas situated next to a shoreline, wetland, or stream where development is restricted or prohibited. They facilitate the protection of ecological integrity of rivers, enhance connections between wildlife habitats, and allow rivers to function more naturally. A buffer network serves as "right-of-way" for a river or stream and it is an indispensable part of the stream ecosystem. Various sizes of buffers help protecting the natural areas close to rivers and streams, and especially fragile zone like steep slopes and wetlands.

They also reduce the impermeability of an area and filter sediments and storm-water pollutants like fertilizers and pesticides. They act like a filter and reduce the cost of water treatment systems by preventing pollutants from entering in the sources of potable water. Through the protection of open spaces along the river as buffer zones, storm-water and flood control can be achieved in a cost-effective way. Buffers also play an important role in reducing the risk of erosion caused by uncontrolled runoff and stabilize riverbanks with vegetation.

A well designed buffer zone helps protecting the quality of water and habitats for plant and wildlife. Buffers also provide shadow areas which decrease the temperature of water and thus protect aquatic habitat. With trees, shrubs, grasses and other native plants, they provide cover and food for birds, mammals, and other animals along the river. There are also benefits for humans as flourishing buffers are visually appealing and can often be used as greenbelts, parks and recreation areas.

On the other hand, the traditional norm of "attractive" can be abandoned to create buffer zones beneficial to river ecosystem. There is no advantage for biodiversity in keeping manicured lawns, formal landscape designs, and pruned shrubs as they frequently require the use harmful pesticides, and do not provide the food or shelter for wildlife. 


\subsubsection{Restore riparian and in-stream habitats}

The restoration of riparian habitats requires taking other actions than simply replanting indigenous plants. First of all, watershed and regional factors should be considered by planners to establish healthy hydrological cycles and acquire a good quality of water. For example, the planted buffer zones must be created and maintained, stormwater must be controlled and cleaned, and new dams and reservoirs should be avoided or removed if possible. Similarly, the good management of in-stream flows from reservoirs and dams must be provided to protect wildlife habitat.

Also, new researches can be conducted on upstream and downstream natural communities in order to identify possible restoration areas and habitat types for fish, birds, and other animals. These areas should be taken into consideration by planners especially in larger river systems. Following the improvement of water quality and habitat, it will be possible to introduce native as well as new fish species to a healthy aquatic ecosystem.

\subsubsection{Use nonstructural alternatives to manage water resources}

In the past, hard engineering approach caused many damages on water quality and wildlife habitat and also triggered many flooding events. Therefore, a recent and "softer" engineering approach has emerged to offer protection from flood as well as restoration opportunities for natural river functions.

It has acquired a wide acceptance as an alternative to hard engineering-bioengineering (also known as soft engineering)- among the departments of civil engineers and public works [19].

In this soft engineering approach, the same performance standards as hard engineering are achieved; at the same time, it is possible for bioengineering to use plants and other natural materials to simulate natural forces, and in this way, to control floods, maintain water quality, provide access to recreation, reduce erosion and create wildlife habitat.

\subsubsection{Reduce hardscapes}

Hardscapes are such places as roads, parking lots, sidewalks, driveways, paved paths, roottops, and other impermeable surfaces that prevent rainwater from filtering through soil and replenishing rivers and stream as groundwater. Nearly half of all stream flows are provided by groundwater. This percentage can increase to a much higher level during drought periods [23].

The urban rivers are also adversely affected by these impermeable surfaces of hardscapes as they do not absorb stormwater. In fact, they result in considerable increases in the volume and velocity of rainwater runoff. Another adverse effect of paved surfaces is their contribution to pollution as they washes surface oils, fertilizers, heavy metals, bacteria, and other contaminants into river and streams.

Through the reduction of hardscapes and installation of natural landscapes, it can be possible to restore natural watershed functions, filter pollutant, and prevent erosion of 
banks and channelization of streambeds. The replacement of hardscape with soft, permeable surfaces, such as native grasses, shrubs, and trees in older, industrial or abandoned riverfront areas will improve environment from both aesthetic and ecological aspects.

Planners must minimize the amount of hardscapes if they cannot be avoided. The reduction of hardscapes in new development projects can offer cost efficiency for local governments, developers, and homeowners. It is expensive to install and maintain infrastructure- roads, sidewalks, sewer liner, curbs and gutters, and parking spaces.

\subsubsection{Manage stormwater on-site and use nonstructural approaches}

An ecologically designed riverfront can capture, store, and infiltrate stormwater, or otherwise, naturally treat and release it. Wildlife habitats and aesthetic value can also be obtained through systems with natural process, such as wetlands and bioswales (small linear wetland planted with riparian and water-tolerant trees). These natural systems can be used to replace the old stormwater pipes and other engineered infrastructures, most of which give high volumes of untreated stormwater directly into rivers and streams.

\subsubsection{Balance recreational and public access goals with river protection}

Riverfront communities should be provided with facilities with as many recreational usage as possible; on the other hand, some conflicting usages should be balanced (e.g. between power boats and birdwatching platforms) and possible overuse of the river corridor should be managed.

\subsubsection{Incorporate information about a river's natural resources and cultural history into the design of riverfront features, public art, and interpretive signs}

Ecological interpretation and education is especially meaningful along urban rivers because most of the original forms of ecosystems have been damaged. The history and function of rivers may not be known well by the public. A conscious and well-informed society will understand the river ecology and regeneration potentials and know how to use their river safely; therefore, communities should be informed about water quality issues and hazards to swimming and boat navigation.

\section{Baselines of urban water rehabilitation}

It is a new approach to improve ecological functions of waters and maintain their anthropogenic use at the same time. In the past uses of waters, human usage was dominant over all other uses of water. And, this had certain effects on ecological properties and restricted the consistency with other uses. In the recent times, there have efforts on the rehabilitation of urban rivers to reverse the adverse effects on ecology including the changes in hydromorphological properties and water quality, which considerably affected the availability and biodiversity of aquatic habitat [24]. 
Water rehabilitation involves cultural works as well as ecological issues in urban areas, which requires the consideration of social, economic and aesthetic aspects of issue. A good balance has to be established among all targets with respect to the sustainability principles. And a special consideration should be given to ecological concerns by the requirements of the Water Framework Directive (WFD). The site-specific conditions are effective in the creation of this balance that has to be established among these diverse and often competing requirements [24].

Considering this background, there are different scopes of rehabilitation, which can be summarized as follows [24]:

- Restoration: Restoration is aimed at reviving the pristine physical, chemical and biological states of rivers. In its simplest form, it requires a full structural and functional recovery of a pre-disturbance state.

- Renaturalisation or naturalisation: Renaturalisation or naturalisation represents a natural method of recovering the natural state of a (river-) ecosystem without really aiming the pristine, predisturbance state.

- Rehabilitation: In rehabilitation stage, it is primarily aimed to recover the partly functional and/or structural conditions of rivers or enabling a functional condition. It is generally considered with regard to ecologic state (biological, hydromorphological and physico-chemical) through structural and partly non-structural measures.

- Enhancement: Like its lexical meaning, enhancement is the improvement of the present state of rivers and its surrounding areas. In this stage, it is aimed to evaluate the ecological, social, economic and aesthetic properties.

Two terms have a special importance in the URBEM (Urban River Basin Enhancement Methods) research project: one of which is the rehabilitation in its all sense including partial functional and/or structural recovery of the former or pre-degradation conditions. The other is enhancement including the social, economic and aesthetic properties in a wider viewpoint. Actually, the term of rehabilitation would apply better to the inevitable constraints of urban rivers than the term of restoration. It cannot be always possible to obtain a pristine state of rivers in towns and cities. It becomes more appropriate to use the term of enhancement when the rehabilitation of urban waters is considered in a more comprehensive way for sustainable urban development. This involves the ecological, social, economic and aesthetic multifunctionality of urban waters with their riparian areas. Ecological conditions are given a special importance in enhancement despite in contrast to the background of the WFD [24].

It is not always possible to make a distinction between the economic advantages of restoring riverfronts and the value of restoring rivers themselves. The protection of watershed and restoration of upstream could be more effective than the activities of ecological design on riverfront. On the other hand, it cannot be forgotten that the efforts of restoring riverfront could be more effective on river condition in general [21].

However, the past experiences have demonstrated that the restoration of rivers and ecologically sensitive redevelopment efforts can have the following advantages [21]: 
- The improvement of water quality and cost effective cleanup and treatment of drinking water sources.

- The moderation of damages of flood and the costs of flood control systems.

- Low costs of stormwater management systems.

- Low costs of sprawl and related infrastructures.

- Reactivation of the downtown riverfront with new opportunities for housing, offices, and commercial services that attract new residents, businesses and visitors.

- Creation of new job opportunities for residents in the construction and commercial businesses.

- Provision of recreational opportunities, open spaces and park areas.

- Higher values of property and new tax revenues.

- Acquiring funds from state and federal governments, volunteers and broad financial support.

\section{Case studies}

\subsection{Some samples of urban river landscape throughout the world}

\subsubsection{The Mississippi River}

The places where Mississippi River pours in Minneapolis Minnesota State of USA and Mexican Gulf and the river course in Baton Rouge and New Orleans in Louisiana were investigated.

The views of riverfront in Minneapolis are given in Figure 5-6 below.

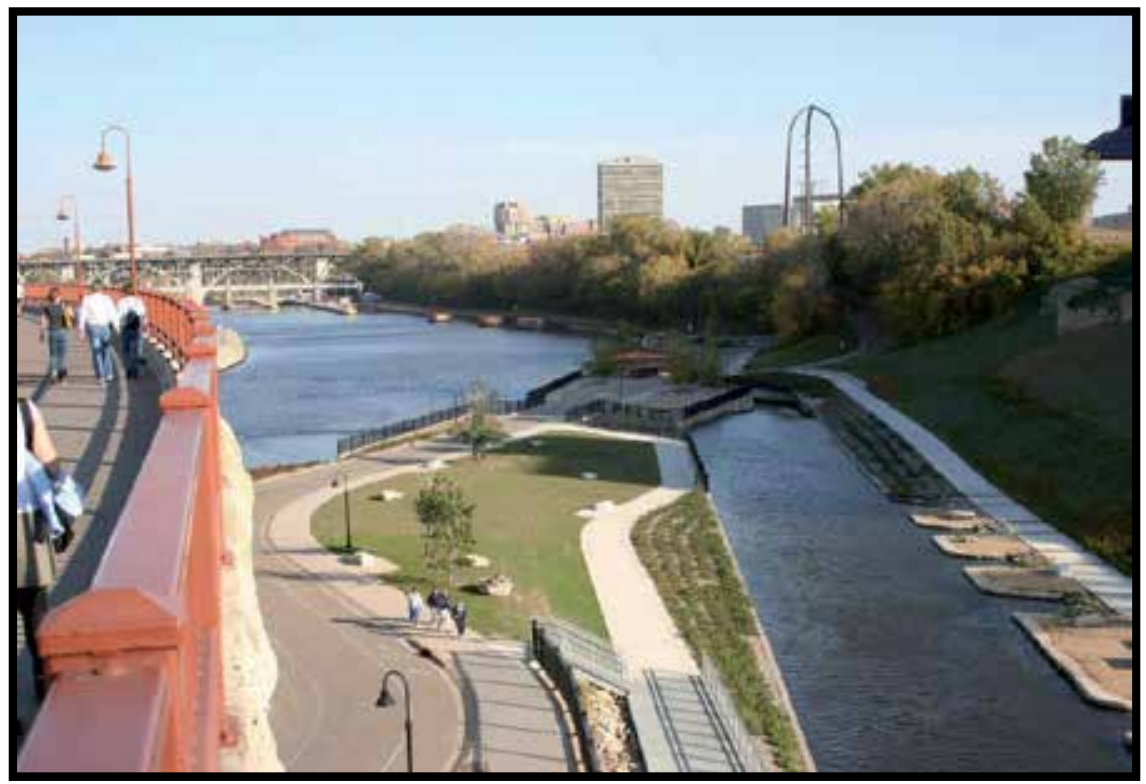

Figure 5. The view of Minneapolis Riverfront District, Minneapolis, Minnesota-USA (Original, 2006). 


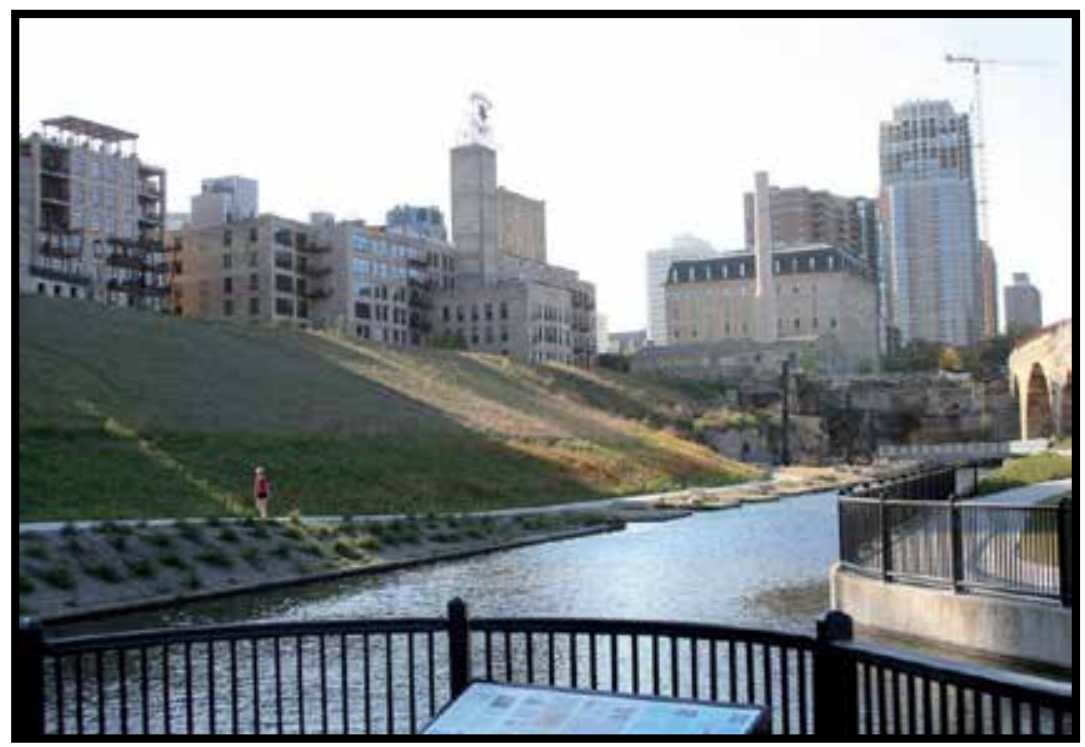

Figure 6. Minneapolis Riverfront District, Minneapolis, Minnesota-USA (Original, 2006).

The views of riverfront park areas along Mississippi River in Baton Rouge are given in Figure 7-8.

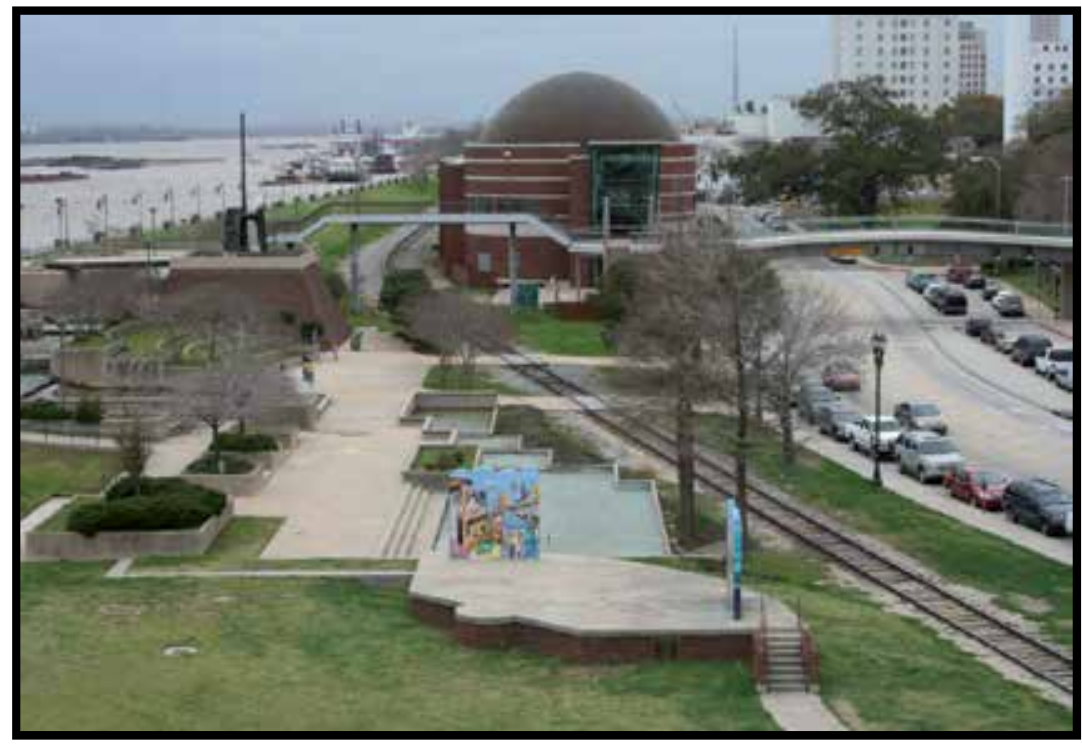

Figure 7. Park areas along Mississippi River in Baton Rouge, Louisiana-USA (Original, 2007). 


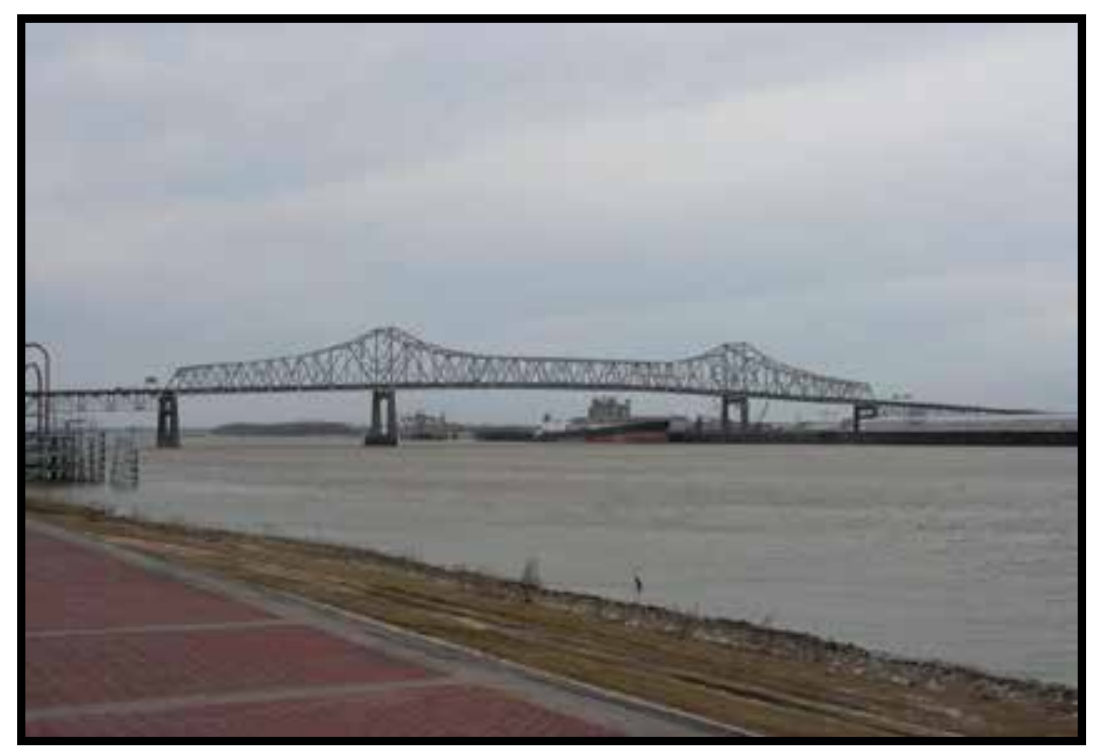

Figure 8. The view of Mississippi River in Baton Rouge, Louisiana-USA (Original, 2007).

Views of fair and exhibition spaces along Mississippi in New Orleans are given in Figure 910.

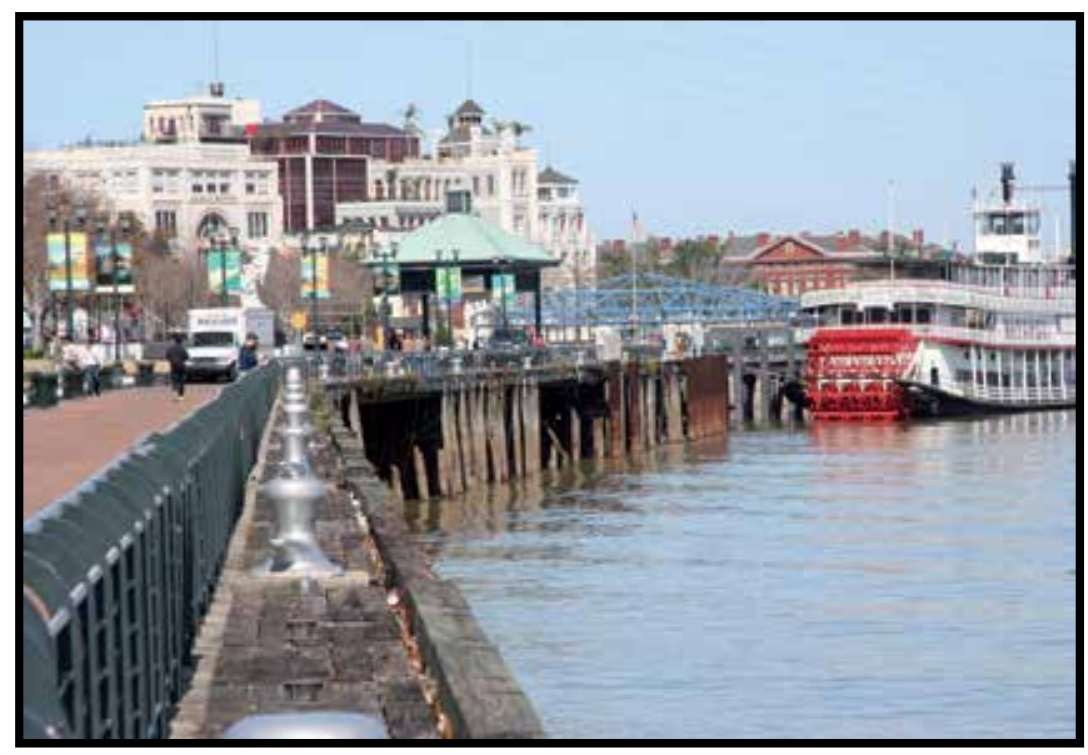

Figure 9. Fair and exhibition spaces along Mississippi in New Orleans, Louisiana-USA (Original, 2007). 


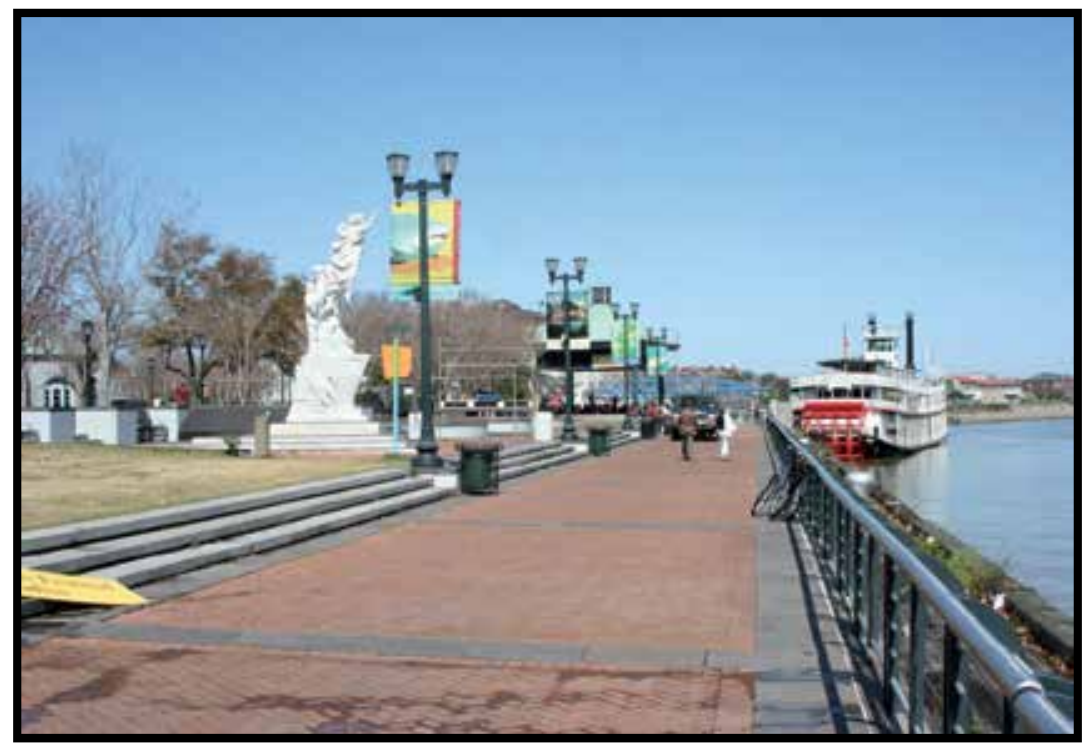

Figure 10. The view of Mississippi River in New Orleans, Louisiana-USA (Original, 2007).

\subsubsection{The San Antonio River Walk}

Streams and rivers were restored in a number of small towns and large cities to attract and improve a tourism economy [19].

The restoration of San Antonio River in San Antonio-Texas, known as San Antonio River Walk at present, has developed the tourism in the region to an extent to include the city in touristic places. The river has gained many additional downtown features such as continuous promenade following both sides of the river and shops, restaurants, and hotels facing the river. In the survey conducted on citizens of San Antonio in 1973, it was revealed that public had a strong positive response to the Project, which later even increased further to include more riverfront restoration. It was reported that almost all of the population (96.6\%) believed that the restoration created a tourism attraction and an important part of population (80\%) believed that the restoration provided economic advantages to the city [19].

The origin of River Walk was based on a flood prevention project developed following a devastating flood in 1921. The initial plan was aimed at locating the river in a larger underground culvert and paving the area into a street. This plan was adopted and considered to act like a channel to circumvent a downtown horseshoes bends in the river in order to avoid flooding in the area. And the bend was embellished by the Works Progress Administration (WPA) in 1939 [19]. San Antonio's riverfront is a small scale reminder of Amsterdam and shows the successful development of a very narrow water concourse into a major land-use development. Barges are available for various organizations to create a joyful entertainment atmosphere. The bridge element serves as a romantic element connecting sides of the city and creating an image, which allows the visitor to become completely involved with edges and land uses of the project [13]. 
With the San Antonio's River Walk, a wide variety of recreational opportunities as well as a very narrow drainage canal have been created [13], (Figure 11-12).

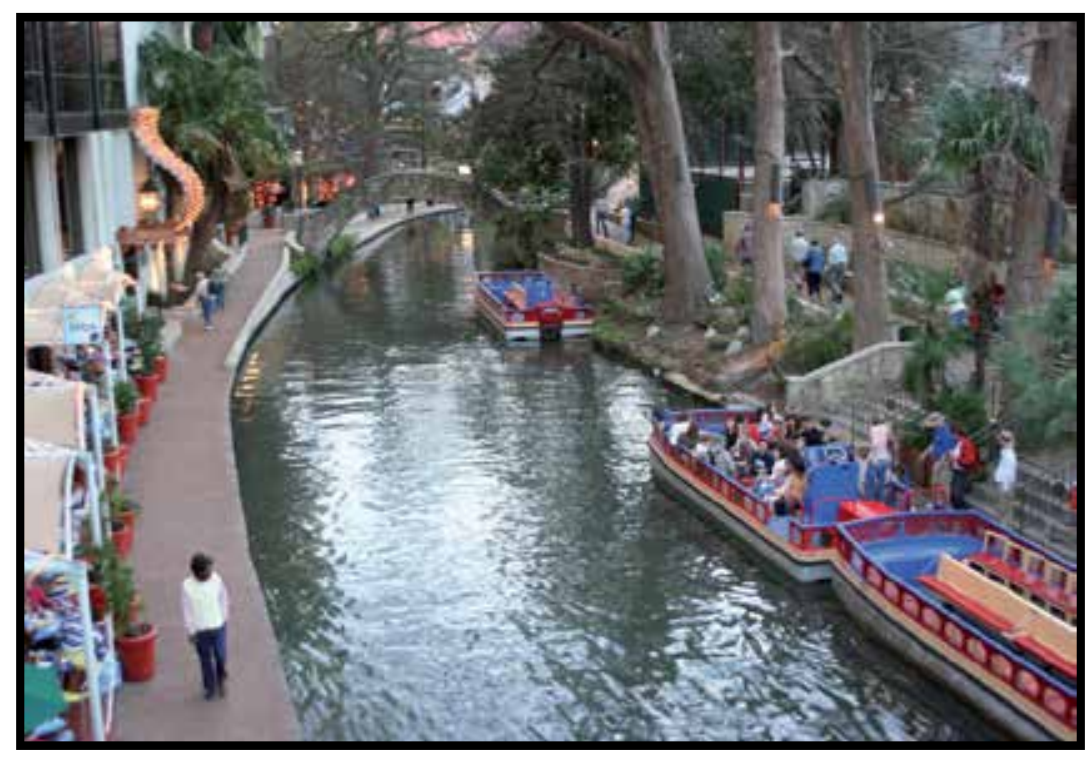

Figure 11. View of the San Antonio River Walk in San Antonio, Texas-USA (Original, 2007).

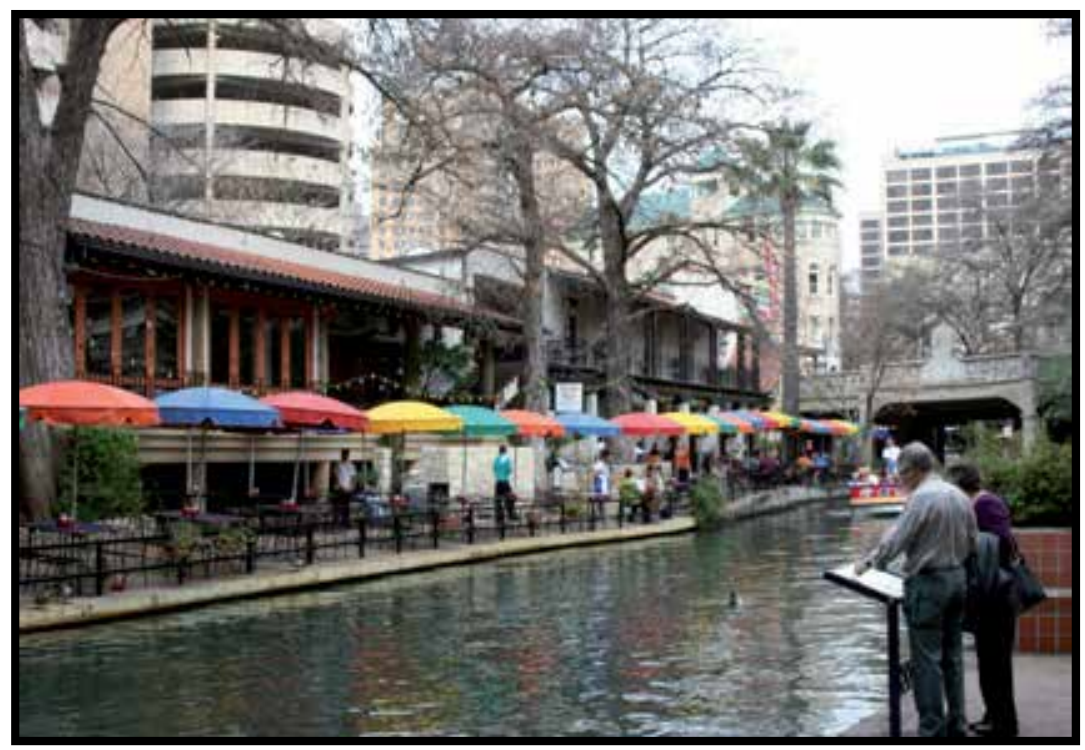

Figure 12. The San Antonio River Walk in San Antonio, Texas-USA (Original, 2007).

\subsubsection{The Nine Mile Creek}

The Nine Mile Creek extending from the Otisco Lake near Syracuse city north east to New York in USA to Onondaga Lake has a basin of $300 \mathrm{~km}^{2}$ and $28,98 \mathrm{~km}$ in length. Fishery, 
wetlands and riverfront forests are of special importance in the basin. The Nine Mile Creek provides an ideal habitat for trout production with its high quality of water and water temperature [25].

Wetlands play an important role in the protection of water quality of nine mile creek. At the same time, wetlands act like a tampon zone against floods. Various commissions (Save the Country Land Trust and Nine Mile Creek Conservation Council) actively work in the protection of many wetlands present along the corridor of Nine Mile Creek [25]. One of the unique characteristics of Nine Mile Creek is the forests along riverfront.

Just like wetlands in the basin, riverfront forests are also important for the protection of water quality of Nine Mile Creek. They control the erosion along the stream and provide food sources and shelter for most of the aquatic and fish species. The protection of all riverfront forests will positively affect the water flow and quality [25].

The important areas in greenway of Nine Mile Creek Corridor and their usages are as follows [25];

1. Baltimore Woods (trekking)

2. Disappearing Lake

3. Fishing lakes and park areas (fishing)

4. Martisco Station (historical site)

5. Camillus Valley Natural Park (trekking, fishing)

6. Erie Canal Park (trekking, fishing) (see Figure 13)

7. Canoeing and park areas (trekking, canoe access)

8. Camillus Forest Unique Space (trekking)

9. Onondaga Lake Wetlands (trekking)

In addition, the restoration application along stream is given in Figure 14.

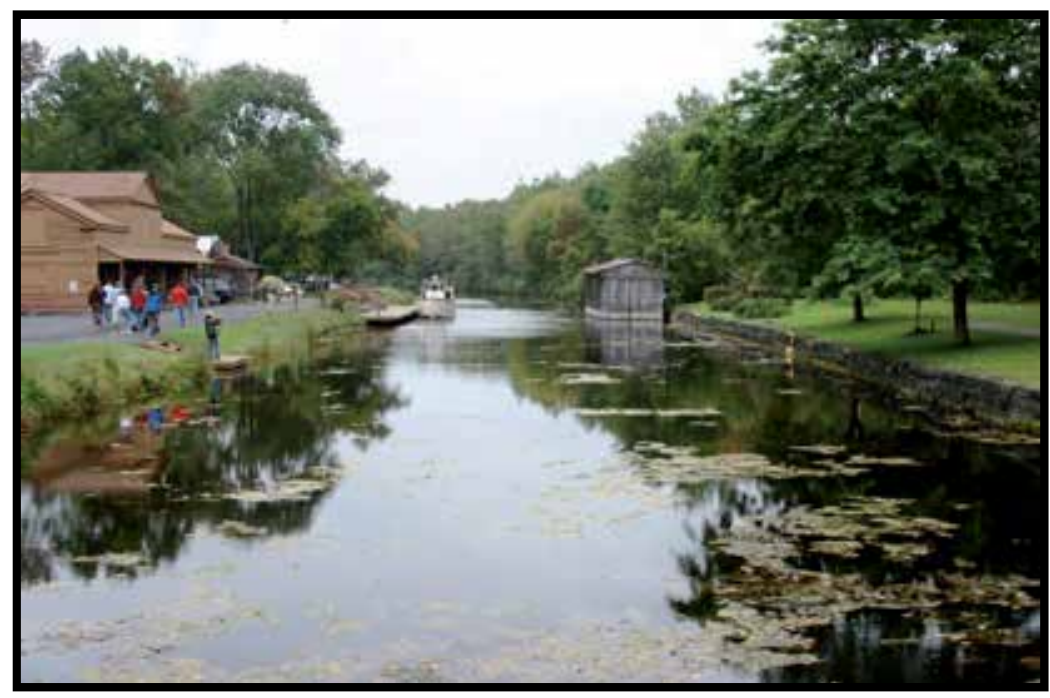

Figure 13. Erie Canal Park in Syracuse, New York-USA (Original, 2006). 


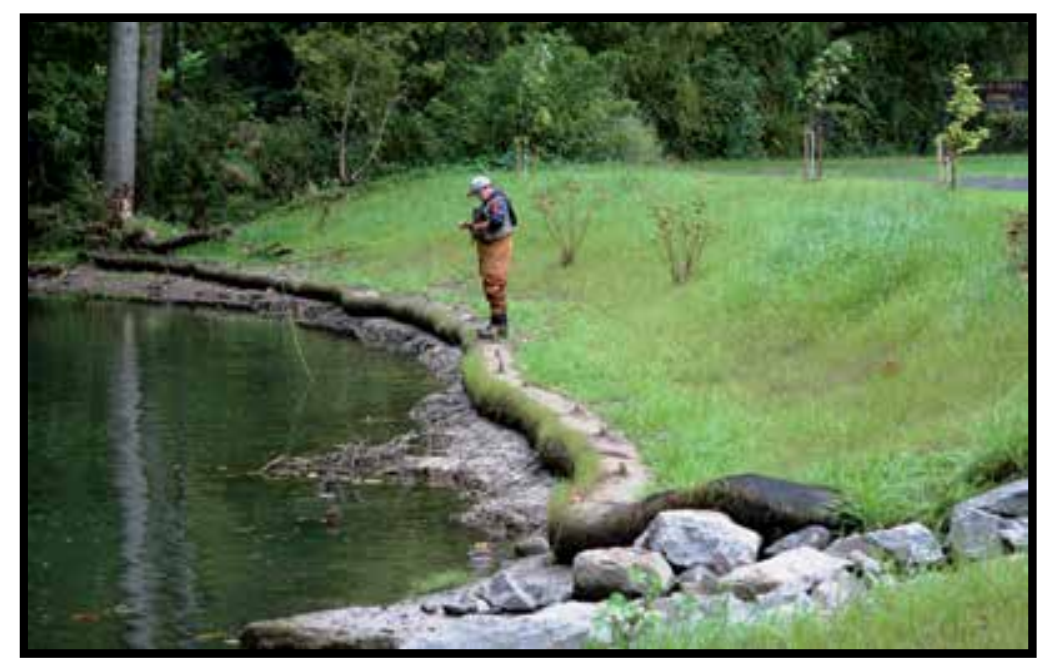

Figure 14. The Nine Mile Creek in Syracuse, New York-USA (Original, 2006).

\subsubsection{The Onondaga Creek}

The Onondaga Creek is a revitalization plan in $14.49 \mathrm{~km}$ length along the Syracuse city in New York, USA. This community-based revitalization plan designed for Onondaga Creek Basin provides guidance for widening social and economic opportunities along Onondaga Creek and improvement of habitat and water quality. It is aimed to obtain economic and ecological benefits as well as revitalization of the creek in Syracuse. The reduction of water quality along the creek, habitat changes and limited public access are the main problems related to the creek. Therefore, the following options can be realized to attract public attention to the Onondaga Creek again [26]:

- $\quad$ The efforts are still continued to increase the water quality of Onondaga Creek.

- Onondaga Creek Festivals were organized in 2004 and 2005 and there is a growing public interest.

- $\quad$ The construction of a walking trail from Armory Square of Syracuse City to Onondaga Creek is continued.

- Stabilization projects along riverfront reduce the sediment load in south tributaries of the creek.

It is quite important to provide functions attracting public preference with smart planning and restore the creek for a healthier environment in order to solve the environmental problems of the Onondaga Creek [26].

The views of Onondaga Creek across Syracuse City are given in the Figure 15-16. 


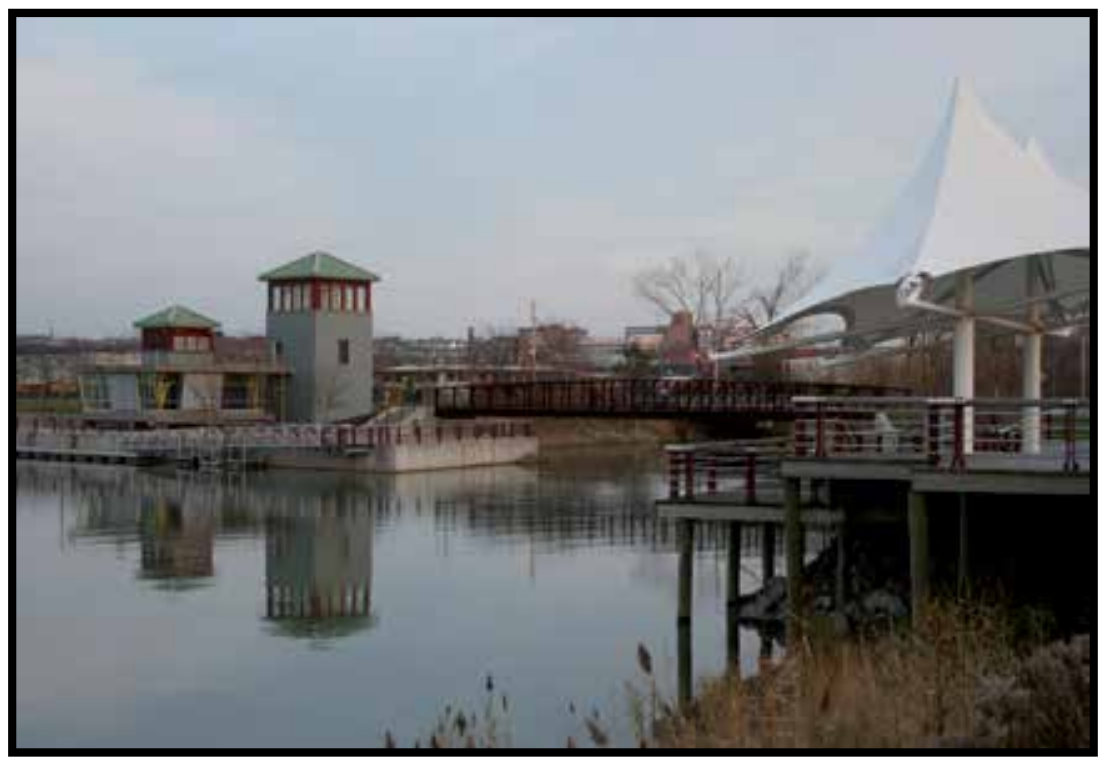

Figure 15. The Onondaga Creek riverside park in Syracuse, New York-USA (Original, 2006).

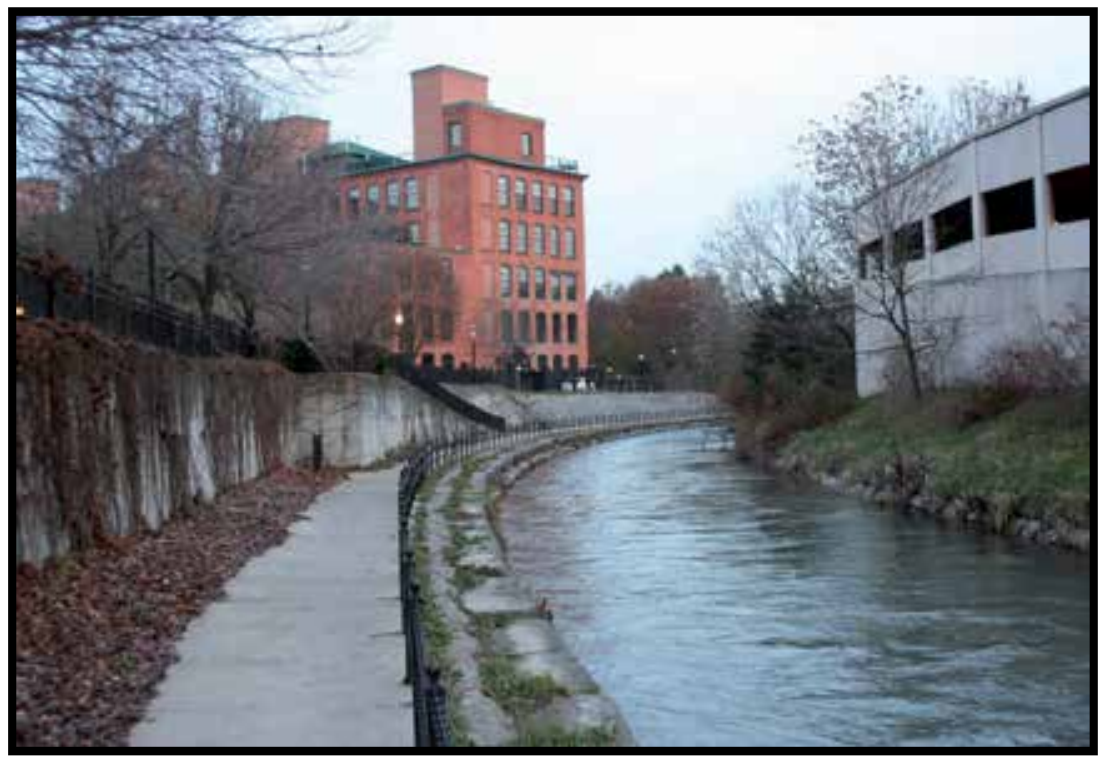

Figure 16. The Onondaga Creek in Syracuse, New York-USA (Original, 2006).

\subsubsection{The Trinity River Corridor}

The Trinity River Corridor Project in Dallas City of Texas, USA is consists of flood protection, environment management, recreation, transportation and socio-economic sections. The project is investigated in 4 regions. The following recommendations were made for these 4 regions in the project [27]; 
1. In the region of "Dallas Floodway Extension", construction of bank, wetland development, protection-improvement of area, restoration of river tributaries, fill area and public spaces within the boundaries of flood area,

2. For "Elm Fork Region", walking trails, football field, green belts, improvement of underground drainage, banks, wetlands and recreational areas,

3. For "Dallas Waterway", 2 ponds without canal connection, meandering river, water properties, wetlands, pavilion and walking trails, flood protection to create protected areas against flood water,

4. For "Great Trinity Forest", green belt, other parks and green belts, Trinity River Corridor parks, ponds, suggested wetland connection, Elm Fork region protection study, and areas like banks etc. are suggested.

The Trinity River Corridor parks in Fort Worth-Dallas city are given in Figure 17-18.

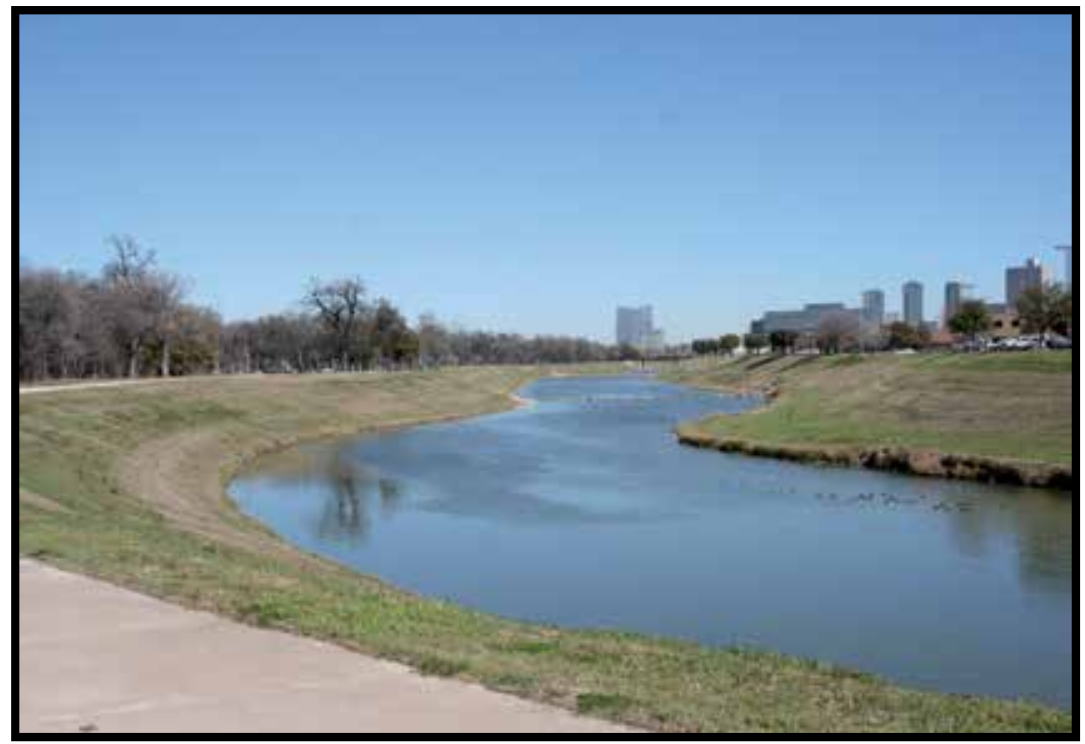

Figure 17. The Trinity River Corridor in Fort Worth-Dallas, Texas-USA (Original, 2007). 


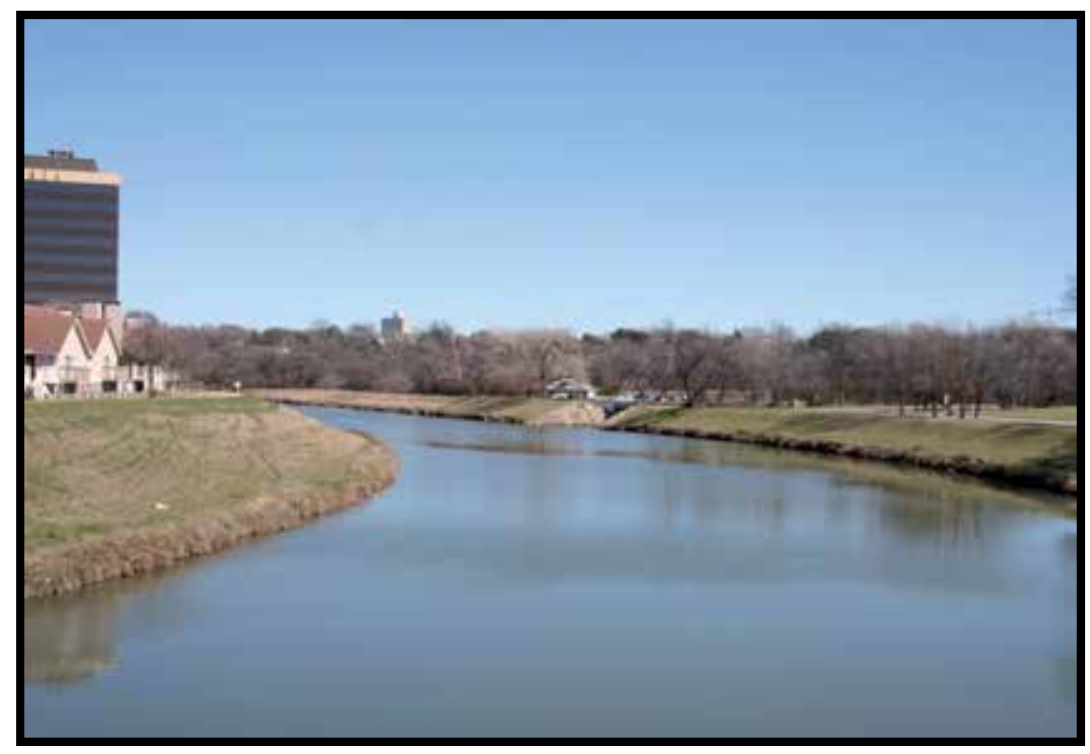

Figure 18. The Trinity River Corridor parks in Fort Worth-Dallas, Texas-USA (Original, 2007).

\subsubsection{The River Isar}

Munich is located 80 kilometers to the north from the Alps in the Munich plain, a glacial and postglacial outwash of limestone gravel. There are only a few geomorphologic features of the plain affecting urban development except for the floodplain of the river Isar with its sequence of river banks and terraces. In spite of the homogeneous appearance of the area, it contains a wide variety of habitats reflecting the interconnected ecological conditions in the Munich plain. There are only small patches of natural woodland types which are predominantly oak and the cultural landscapes such as the once extensive grassy heathlands and fenlands in the northern Munich plain. The river Isar provides a wide green passage in south to north direction passing through the city [28] (see Figure 19).

The river Isar acts like a backbone of the green structure system of the Munich city. There have been many efforts to control the wild nature of this braiding alpine river with its sudden and large floods since the first establishment of the city. And the river has been largely exploited since 1889. The main driving forces of turning the river into a bed of concrete and build canals are the protection from flood and the generation of energy, which is known as "the white gold". Almost all of the water (95\%) was cut by such means. A large water reservoir was built in the Alps in 1959, which had a deep effect on the river dynamics. Afterwards, it helped to reduce the amount of gravel and sand carried by the river, which caused continual deepening of the river bed. On the other hand, the water quality of river was not good, which then created many problems for the bathing facilities in Munich. The river Isar was called by environmentalists as a "dead river" in 1980s, and there was an evident need for a reconstruction project. For this reason, Bavarian state and the city of Munich have taken serious actions since 1989. For instance, the contract of power generating 


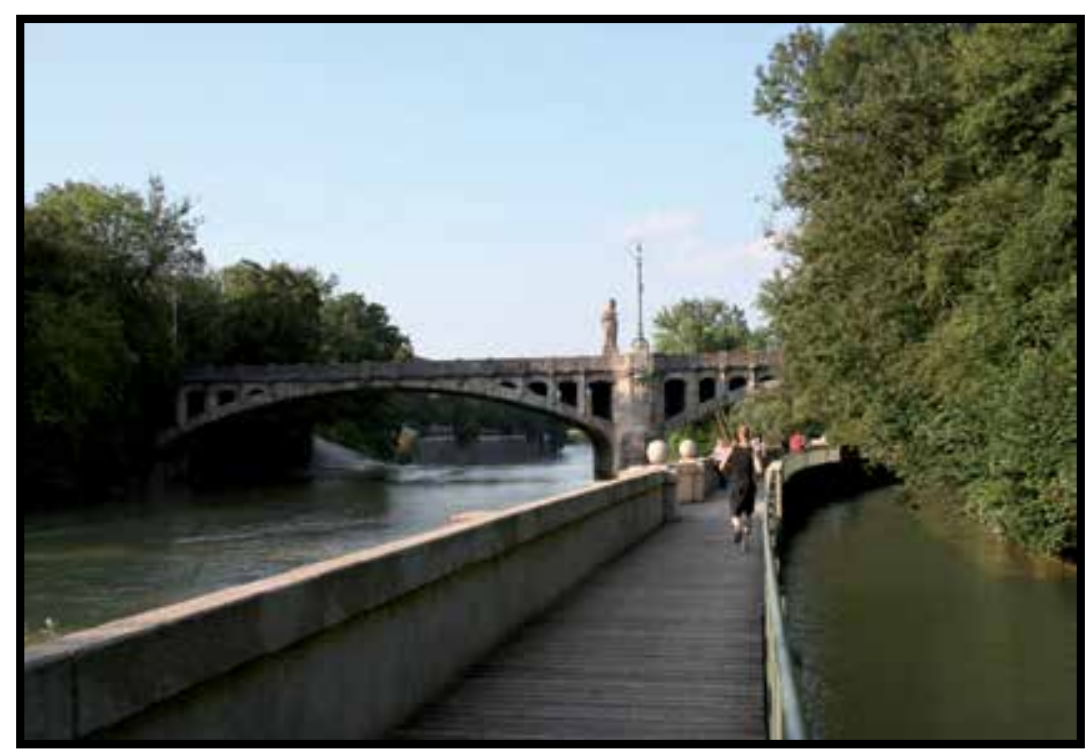

Figure 19. The River Isar in Munich-Germany (Original, 2007).

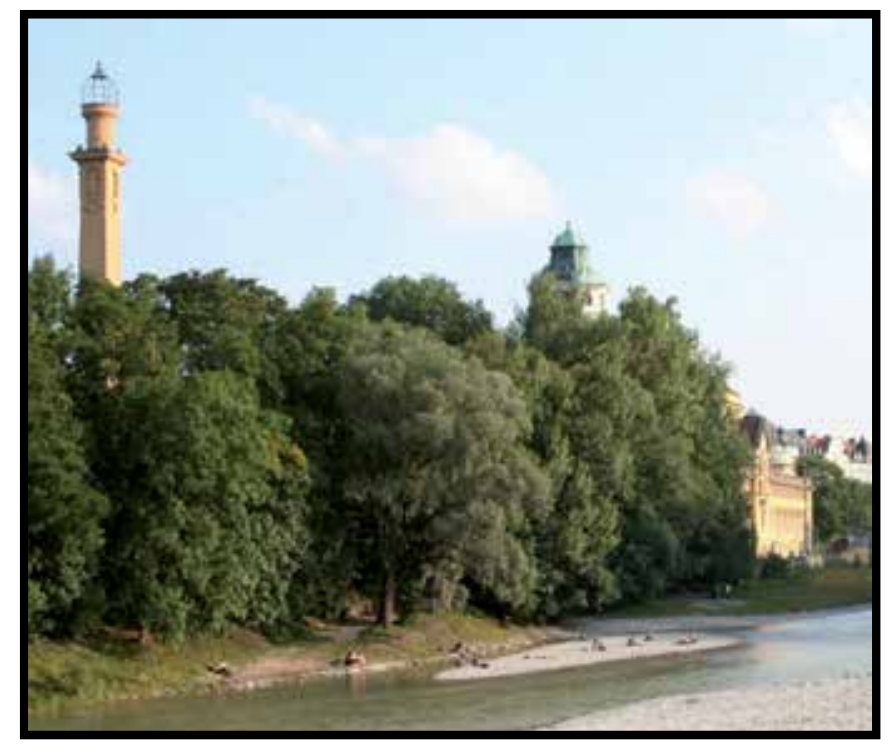

Figure 20. Gravel banks used for recreation in the River Isar in Munich-Germany (Original, 2011).

industry expired in 1993 and a renegotiation was required. Consequently, The main aim of the next planning and design processes was to increase the water flow rate from $5 \mathrm{~m}^{3} / \mathrm{sec}$ to $12 \mathrm{~m}^{3} / \mathrm{sec}$. Accordingly, the "Isarplan" was developed in 1995, which was a comprehensive and detailed plan involving every aspects of the river. A very important decision was taken by the civil board of the city of Munich in 2000 for the urban section of the river. The project primarily aimed to restructure the dams on the river Isar, increase the retention capacity of the floodplain, regain the river and its banks as living spaces, including the possibility for 
swimming without health risks and allowing natural dynamics to form and enrich the floodplain for wildlife [29].

There have been actions planned and carried out by public staff to cut trees in order to restore the dams, all of which faced strong criticism by local press in the beginning phase. However, their positive effects became apparent to public in the next summer. Consequently, the Munich citizens welcomed the second rebuilt section. The third section to redesign now provides the inner city with a prominent waterfront. Compared to the earlier sections, it has a different character in terms of morphology and function. Therefore, there is a need for well-planned and consistent solutions to improve the recreational, ecological and technical urban functions of the river. And for this purpose, there was an international competition in 2003 organized for teams of landscape architects, town planners and river engineers [29].

The Isar has a very high flow velocity and transports a huge quantity of bed load. The riverbed was improved before the rehabilitation with low drops to prevent erosion in the riverbed and reduce gravel transport. The efforts for creating a natural hydromorfologic process removed the hard confinement, replace the low drops by sills and created the input of gravel and boulders along the banks and as islands. These gravel banks will be relocated by natural processes in time. These areas are densely used by many people on recreation purposes in summer [24] (see Figure 20).

\subsubsection{The Cheonggyecheon Restoration Project}

The Cheonggyecheon Restoration Project is especially important as it is aimed to revive the historical and cultural environment of Seoul. This project is an indispensable part Seoul's urban planning but it is also a symbolic project to regain an important part of Korea's historical and natural heritage at the start of the twenty-first century. The capital city of Korea will become even more environmentally and human friendly once the project is finished. It is also expected from the project to create a new pattern for urban management in the new century and help boosting the image of Seoul [30].

The main targets of the Cheonggyecheon Restoration can be given as follows [30]:

- $\quad$ restoring history, culture and the environment in Seoul

- altering the look of city by removing repulsive structures and creating beautiful riverside landscape in downtown of Seoul

- presenting the historical and cultural heritages of Cheonggyecheon

- creating a new environmentally friendly Seoul

- reviving the economy in the downtown and northern Seoul.

The following recommendations are recommended by the Seoul Agenda 21 to construct different biological corridors and habitat network to create an eco-city [30]:

- connecting the axes of ecological green areas

- $\quad$ enhancing urban green areas (public sector) 
- transforming rivers into natural places for flora and fauna.

With the restoration of historical areas, the modern era is harmoniously integrated with the 600 years old history of Seoul as the capital city of Korea. The restored Cheonggyecheon area will attract many tourists to Seoul from all over the world. In the project, a special focus is given to the improvement of the environment for living and business, and the project is expected to help Seoul to become the financial and commercial center of the East Asia. The new look of Seoul will also increase the expectations of Seoul citizens from the future [30].

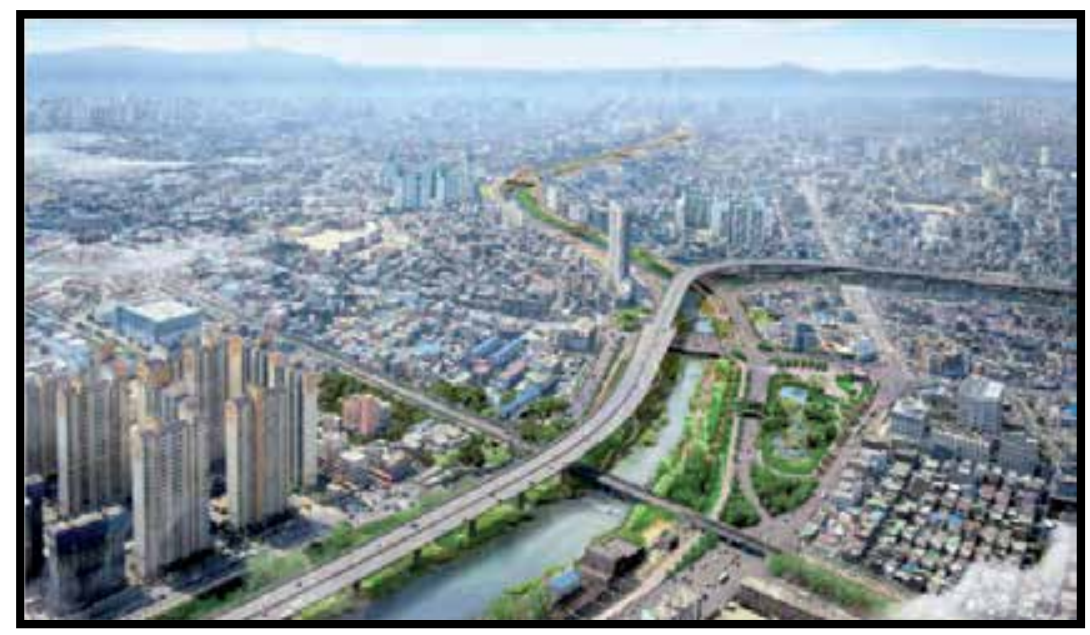

Figure 21. Digital model of Cheonggyecheon linear park [31].

\subsection{Some samples of urban river landscape in Turkey}

\subsubsection{The Porsuk Creek}

The summary information is given below about the "Landscape Planning Project for Eskişehir Urban Course of Porsuk Creek" in the Central Anatolia supported by World Bank and prepared by Memlük [32].

The project involves the green areas to be formed as a result of planning and restoration of open and green spaces $10 \mathrm{~km}$ along the Porsuk Creek and irrigation canals.

Except for a part of $1.5 \mathrm{~km}$ in city center, the entire creek remains in the natural riverbed. This natural river bed is meandering and polluted. In addition, the rehabilitation of Porsuk Creek and its tributaries was brought to agenda due to flooding events and the necessary efforts were immediately started.

As a result of these rehabilitation efforts, green areas have been formed on both sides of Porsuk Creek and its tributaries along the course within city center. Most of the large open and green spaces on both sides of creek and canal were rehabilitated. However, new riverfront tracts as well as open and green spaces created with the enforcement of new structuring and master plan are investigated in this study. 
The main theme of the project is to encourage and incite well-qualified spatial construction with the new organization and rehabilitation of the creek and canals.

As a result of the surveys, the project and its surrounding area are concluded qualified with interesting characteristics. For this reason, open spaces within the project area have been vegetated and opened for limited public use. However, the construction of fairground, picnic and commercial spaces has been avoided.

Especially, the wet space property of the project area for flora is always emphasized. The main theme of the project is to develop a landscape approach for rehabilitation and enhancement of natural structure in the area. It is aimed to attract people to this area not only for entertainment but also to experience the nature and the conditions it provides.

Consequently, below is given the recommended structure for the project designed to embellish and revive the Porsuk Creek, one of the most important parts of Eskisehir and integrated with the city.

Citizens can freely walk in the green areas along the creek and experience the water-green coherence (Figure 22-23).

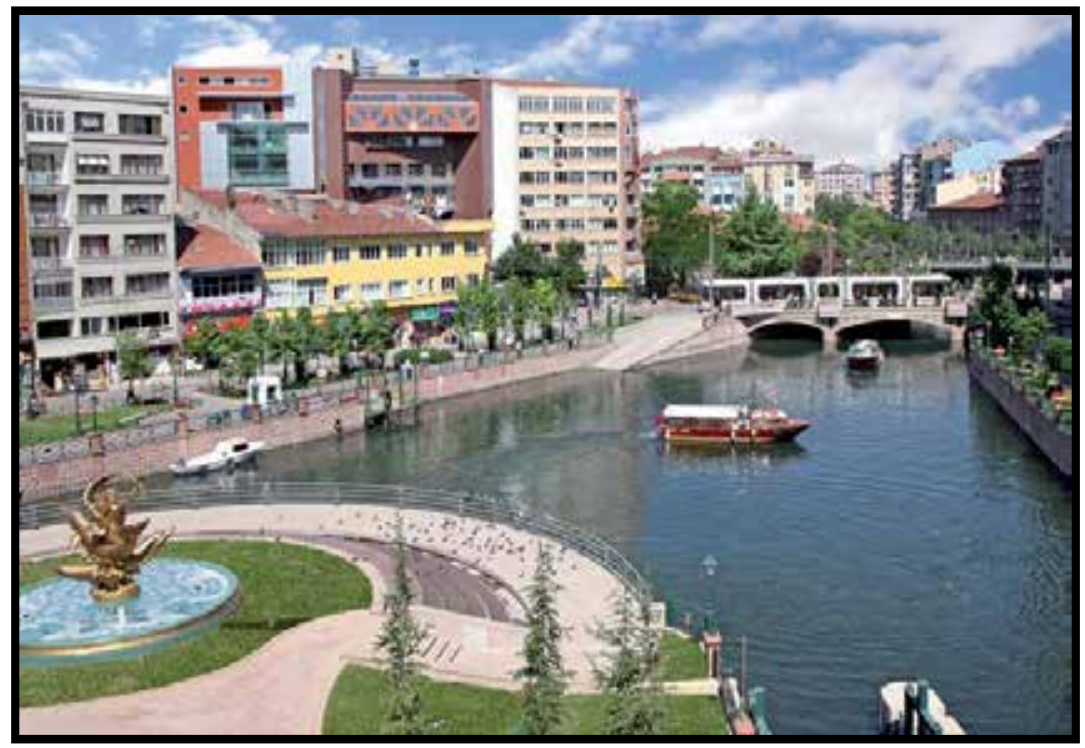

Figure 22. The Porsuk Creek riverside in Eskişehir-Turkey [33]. 


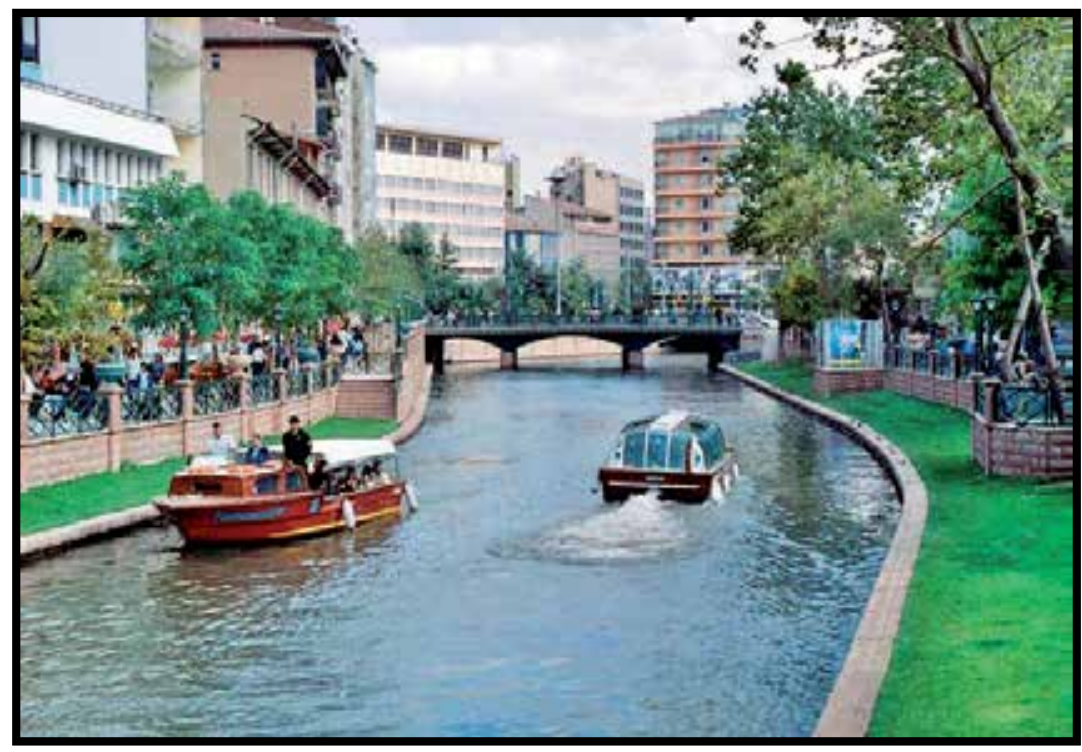

Figure 23. The Porsuk Creek in Eskişehir-Turkey [33].

In addition to forestation and vegetation, large grass-plots have been created for human use (for recreation purpose). In the project area, spaces with abundant structures have not been formed except for plazas.

Insofar as the master plan permits, walking trails and fortune balconies are given emphasis along the riverfront.

About every 100-150 m, steps between trail and canal paths are kept large enough to provide them with functionality of watching-thinking amphitheater. Rural-like fences are used to give picturesque appearance to the project area. Besides, a suggestion is made for trail forestation and canal vegetation.

With this project, Eskisehir comes into prominence as a city that offers modern standards of living comfort.

\subsubsection{The Bartm River}

The Bartın River flows through the Western Black Sea Basin in North Turkey. It is the only river in Turkey enabling $12 \mathrm{~km}$ of water transportation from the Black Sea to center of the Bartın City. Thanks to this feature, the trade made on Bartın River played an important role in the development of Bartın, which is the center of its region especially during the period of Ottoman Empire. Besides rich natural sources in Bartın City, there are also valuable cultural landscape characteristics in the city [34] (Figure 24-25). Due to these special properties of Bartın River both on regional and national scales. There are many advantages for next generations in protecting the landscape characteristics of Bartın River and landscape planning studies with regard to the rising population and urbanization pressure. The main 
focus in these studies is to meet the growing demands of population and create protection strategies from the damages of flood and protect landscape characteristics of the Bartin River [9]. Therefore, landscape characteristics of Bartın River Floodplain Corridor should be evaluated and assessed to protected its valuable natural and cultural resources and to maintain balanced land use and development (Figure 26) [4].

In this study, urban and rural landscape characteristics of research area are determined at first through Geographic Information Systems (GIS), and then some planning principles and recommendations are used to address the factors which negatively affect the river landscape and will be important to reduce flood risk, improve water transportation and connect natural, cultural and historical environments of the Bartın River in order to protect landscape and develop tourism in the region. In the study area experiencing such destructions, necessary plans are developed to protect river landscapes. The main target is to restore the Bartın River and to develop strategies to transform the riverbank and urban enhancement areas. This study is expected to contribute to national and regional economies for a long time by creating a balance between preservation and land use as well as protecting landscape characteristics of the Bartın River [4].

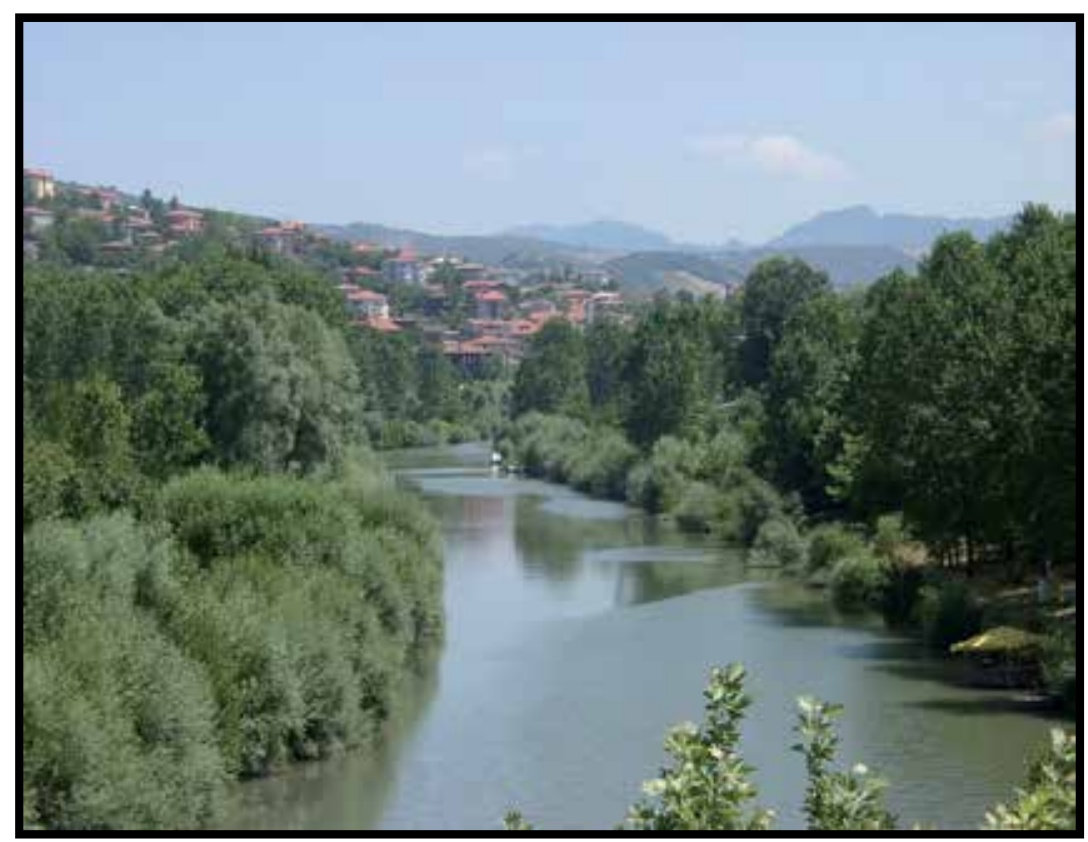

Figure 24. View of the Bartın River in Bartın-Turkey (Original, 2007). 


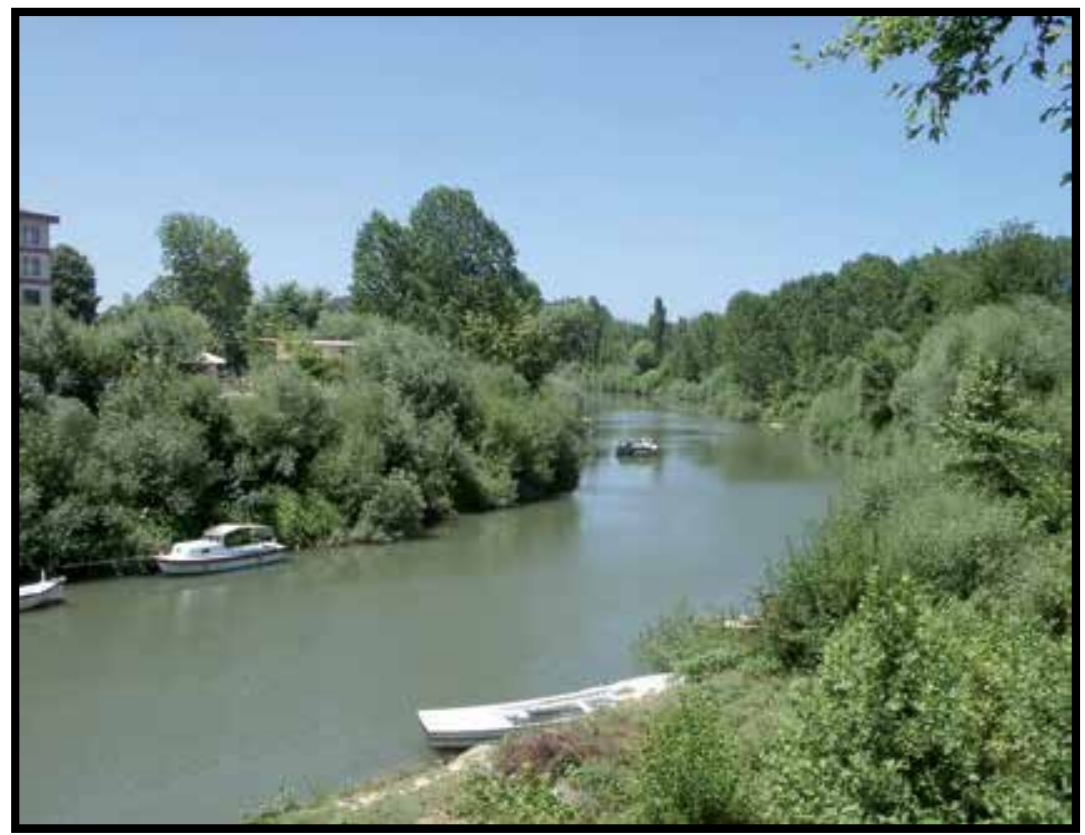

Figure 25. The Bartın River in Bartın-Turkey (Original, 2007).

A new method is developed by Cengiz [9] for determining and evaluating the landscape characteristics of Bartın River. This study can be seen as an example in planning the revitalization projects on urban river landscapes in similar hydrologic regions and further studies can be conducted based on the guidelines of this study [4].

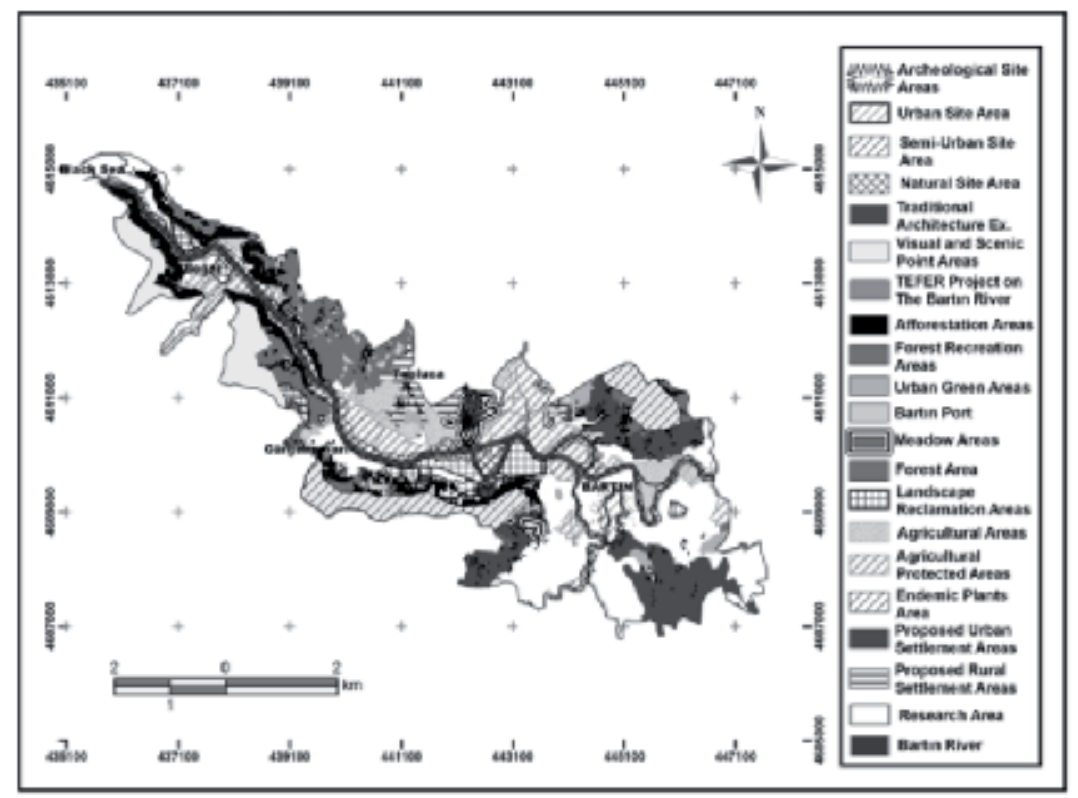

Figure 26. Alternative land use planning for the Bartın River Floodplain Corridor [4, 9]. 


\section{Discussion}

As stated by OECD [35] historical development patterns of urban centers have a general tendency of destroying ecosystem resources accounting for their own creation, development and typical characteristics. With well-planned restoration of urban river, multiple ecosystem services that have been lost or deteriorated can be recovered to some extent. Previous case studies have demonstrated the apparent benefits of these restoration works to human wellbeing such as health, economic value, life quality and contribution to regional renewal. In addition, through planning river management or urban developments for rivers with potential impacts on ecosystem, the adverse effects can be prevented or minimized and appropriate mitigation methods can also be determined to deal with damages to important and socially beneficial river functions. There has been a particular growing agreement on the value of ecosystem services for handling a wide variety of sustainability challenges including the demands of land use planning, agriculture and forestry, as well as carbon and microclimate management, and the management of fisheries, watersheds, biodiversity and tourism [5].

Base on the results of Cengiz et al. [4], the following recommendations are made for ecological planning of urban river landscape in Turkey.

- Natural and cultural landscape values of the river and historically important areas should be integrated with potential tourism centers in the region in order to improve river tourism and recreation. The main aims of river restoration studies are to provide ecological and economic benefits.

- Sustainable ecological characteristics of rivers and boundaries of flooding areas (2-5-1025-50-100-500-year floods) should be determined and dealt with in the city development plans.

- It is important to evaluate urban open and green space systems of these areas for public benefit. Therefore, it could be possible to provide protection from flood risk through specifying flooding area boundaries on river banks and also to create modern recreational places for public use in city.

- Basin Management Plans and Urban Flood Risk Management Plans should be prepared with respect to the European Water Framework Directive (WFD). Afterwards, these plans should be considered in the city development plans.

- The main objectives should be to protect, develop and use the current landscape characteristics of the river and to hand them down the next generations.

- It is quite important to plan river landscape studies for protecting landscape characteristics and alleviating the effects of rising population and urbanization pressure in order to hand them down the future generations. The main aims of landscape studies planned on different scales should be to meet increasing demands of future population growth and develop strategies for the protection of the valuable valued landscape characteristics of the river basin. Otherwise, a multifunctional river can disappear from the city landscape as it happened in many other cities of Turkey. 


\section{Author details}

Bülent Cengiz

Bartın University, Faculty of Forestry, Department of Landscape Architecture, Turkey

\section{References}

[1] Baschak LA., Brown RD. An Ecological Framework for the Planning, Design and Management of Urban River Greenways. Landscape and Urban Planning 1995;33 211225.

[2] Cook EA. Ecosystem Modeling as A Method for Designing Synthetic Fluvial Landscapes: A Case Study of the Salt River in Arizona. Landscape and Urban Planning 1991;20 291-308.

[3] Gardiner JL. River Landscapes and Sustainable Development: A Framework for Project Appraisal and Catchment Management. Landscape Research 1997;22(1) 85-114.

[4] Cengiz B., Smardon RC., Memlük Y. Assessment of River Landscapes in terms of Preservation and Usage Balance: A Case Study of The Bartın River Floodplain Corridor (Western Black Sea Region, Turkey). Fresenius Environmental Bulletin 2011;20(7) 16731684.

[5] Everard M., Moggridge HL. Rediscovering the Value of Urban Rivers. Urban Ecosystem 2012;15 293-314.

[6] Francis RA. Positioning Urban Rivers within Urban Ecology. Urban Ecosystem 2012;15 285-291.

[7] Grimm NB., Faeth SH., Golubiewski NE., Redman CL., Wu JG., Bai XM., Briggs JM. Global Change and the Ecology of Cities. Science 2008;319 756-760.

[8] Anonymous. A handbook for Stream Enhancement \& Stewardship / The Izaak Walton League of America. Blacksburg, Va. : McDonald \& Woodward Pub. Co. ; Gaithersburg, Md.: Izaak Walton League of America; 2006.

[9] Cengiz B. A research on the determination and assessment of landscape characteristics of the Bartın River. PhD thesis. Ankara University, Graduate School of Natural and Applied Sciences, Department of Landscape Architecture. Ankara; 2007. (original text in Turkish)

[10] Smardon RC., Felleman JP., Senecah S. Protecting Floodplain Resources: A Guidebook for Communities. Federal Interagency Floodplain Management Task Force, FEMA publication number 268, Wash., DC; 1995.

[11] Novaresio P. Great Rivers of the World. Barnes\&Noble. New York; 2006.

[12] Mann R. Rivers in the City. Newton Abbot, David and Charles; 1973.

[13] Torre LA. Waterfront Development. Van Nostrand Reinhold. New York; 1989.

[14] Jormala J. Urban Rivers. In: Gumiero B, Rinaldi M, Fokkens B (eds.) proceedings of the 4th ECRR International Conference on River Restoration, 16-19 June 2008, Venice, Italy; 2008. p889-890.

[15] Marsh WM. Landscape Planning: Environmental Applications, Fifth Edition. John Wiley \& Sons, Inc; 2010. 
[16] Turner T. Landscape Planning and Environmental Impact Design. 2nd edition. The Natural and Built Environment Series; 1998.

[17] Averitt E., Steiner F., Yabes RA., Patents D. An Assessment of the Verde River Corridor Project in Arizona. Landscape and Urban Planning 1994;28 161-178.

[18] Morris M. Subdivision Design in Flood Hazard Areas. Series: Report (American Planning Association. Planning Advisory Service) No: 473rd Federal Emergency Management Agency, Chicago, IL.; 1997.

[19] Riley AL. Restoring Streams in Cities: A Guide for Planners, Policymakers and Citizens. Island Press, Washington, D.C.; 1998.

[20] Hulse DW., Gregory SV. Alternative Futures as an Integrative Framework for Riparian Restoration of Large Rivers. In: Dale VH., Haeuber RA. (ed.) Applying Ecological Principles to Land Management. Springer-Verlag New York; 2001. p194-212.

[21] Otto B., McCormick K., Leccese M. Ecological Riverfront Design: Restoring Rivers, Connecting Communities. American Planning Association, Planning Advisory Service Report Number: 518-519, Chicago, IL; 2004.

[22] Turoglu H., Özdemir H. Floods and Flash Floods in Bartın Causes, Effects, PreventionMitigation. Cantay Publisher, İstanbul; 2005. (original text in Turkish)

[23] Alley WM., Thomas ER., Franke OL. Sustainability of Ground-Water Resources. U.S. Geological Survey Circular 1186. Danver; 1999.

[24] URBEM (Urban River Basin Enhancement Methods) Existing Urban River Rehabilitation Schemes. (Work package 2) Final Report. http://www.urbem.net/WP2/WP2_case_studies.pdf. (accessed 10 January 2013).

[25] Smardon RC. Nine Mile Creek Watershed an Eco-tourism Guide. Prepared by: Cornell Cooperative Extension of Onondaga County, Nine Mile Creek Conservation Council, Save The County Land Trust, Syracuse, New York; 2006.

[26] Onondaga Creek Conceptual Revitalization Plan. http://www.esf.edu/onondagacreek (accessed 20 March 2007).

[27] http://www.trinityrivercorridor.org/pdf/Master.pdf. (accessed 20 March 2007).

[28] Oppermann B., Pauleit S. The Greenstructure of Munich The need for and risk of regional cooperation. In: (Werquin AC., Duhem B., Lindholm G., Oppermann B., Pauleit S., Tjallingii S.) COST Action C11-Green Structure and Urban Planning Final Report. Belgium; 2005. p72-79.

[29] Oppermann B. Redesign of the River Isar in Munich, Germany Getting coherent quality for green structures through competitive process design? In: (Werquin AC., Duhem B., Lindholm G., Oppermann B., Pauleit S., Tjallingii S.) COST Action C11-Green Structure and Urban Planning Final Report. Belgium; 2005. p372-378.

[30] Nam-Choon K. Ecological Restoration and Revegetation Works in Korea. Landscape Ecol. Eng. 2005;1 77-83.

[31] Rinaldi BM. Landscapes of metropolitan hedonism The Cheonggyecheon Linear Park in Seoul. Journal of Landscape Architecture 2007;Autumn 60-73.

[32] Memlük Y. Landscape Planning Project for Eskişehir Urban Course of Porsuk Creek Report. Ankara; 2005.

[33] http://www.eskisehir-bld.gov.tr/eskisehir_resimler.php. (accessed 30 March 2013). 
[34] Cengiz B., Memlük Y. The Bartın River (Turkey) and its planning strategies. proceedings of the International Conference on Urban River Rehabilitation. September 21-23, 2005, Dresden, Germany; 2005. p296-302.

[35] OECD. Paying for Biodiversity: Enhancing the Cost-Effectiveness of Payments for Ecosystem Services. OECD Publishing. doi:10.1787/9789264090279-en; 2010. 


\title{
Vertical Gardens
}

\author{
Özgür Burhan Timur and Elif Karaca
}

Additional information is available at the end of the chapter

http://dx.doi.org/10.5772/55763

\section{Introduction}

\subsection{Green Walls}

Green Wall with the another name Vertical Garden is the term of used to refer to all form of vegetaded wall surfaces (Gren roof organization 2008). Green walls are not only spectacularly beautiful, but also helpful in enlivening the ambiance. Green walls can absorb heated gas in the air, lower both indoor and outdoor temperature, providing a healthier indoor air quality as well as a more beautiful space (Yeh 2012). They holds or slows rainwater, providing food and shelter for wildlife (Thompson and Sorvig 2000). As already mentioned, some plants are able to grow on walls by taking root in the substance of the wall itself. Typical of these are the small herbaceous species such as ivy-leaved toadflax, wallflower and plants such as mosses, lichens and grasses. But other species are naturally adapted to climbing up and over obstacles such as rock faces, trees and shrubs. For these to grow successfully on walls and buildings some kind of support structure is usually essential (Johnson and Newton 2004). Also Green walls can be constructed with many systems. This systems include the following structural concepts (fig 1) (Thompson and Sorvig 2000):

Gren walls can examine two major categories: Gren Facades and Living Walls. This categories can be divided into other categories (fig2). Green façades are made up of climbing plants either growing directly on a wall or in specially designed supporting structures. The plant shoot system grows up the side of the building while being rooted to the ground. On the other hand, in a living wall the modular panels are often comprised of polypropylene plastic containers, geotextiles, irrigation systems, a growing medium and vegetation (Gren roof organization 2008, Sharp R. 2007).

\section{Green facades}

Green facades are a type of green wall system in which climbing plants or cascading vegetation. Green facades can be anchored to existing walls or built as freestanding 
structures, such as fences or columns (Gonchar 2009, Green roof organization 2008, Yeh 2012).

Three green facade systems that are frequently used are Modular Trellis Panel, Grid System and Wire-Rope Net System (Green roof organization 2008, Yeh 2012).

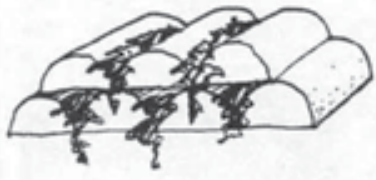

Block-rounded

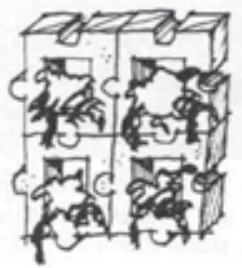

Frame

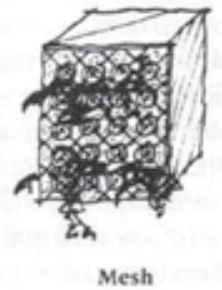

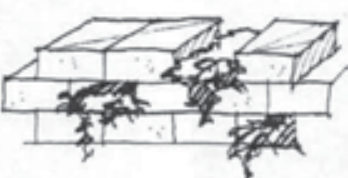

Block-staggered

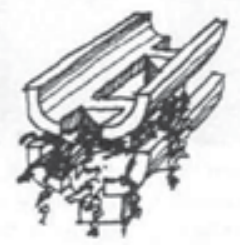

Trough

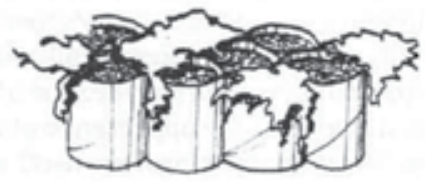

Cell

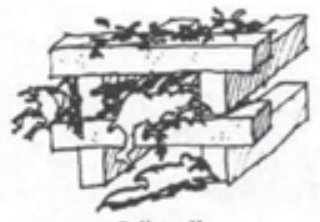

Cribwall

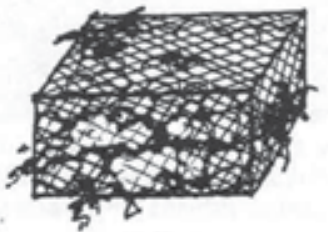

Gabion

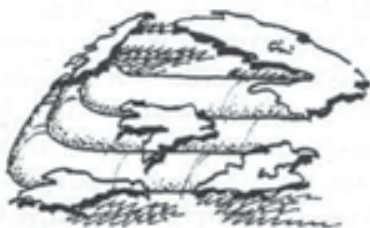

Sandbag

Block : Engineered with gaps where plants root through the wall

Crib Wall : In this system, elements of like tile, concrete, wood stacked log - cabin style

Frame : In this system, interlocking flor coverings stacked like massonry

Trough : Used soil filled tubs

Gabion : Used wire baskets filled with Stones to provide strong

Mesh : Like mini gabions

Cell : Used flexible and strong honeycombs which filled with soil

Sendbag : Make with geotextiles wrapped around soil. This systems formally called "vegetated geogrid"

Figure 1. Structural concepts of Vertical Garden (Thompson and Sorvig 2000). 


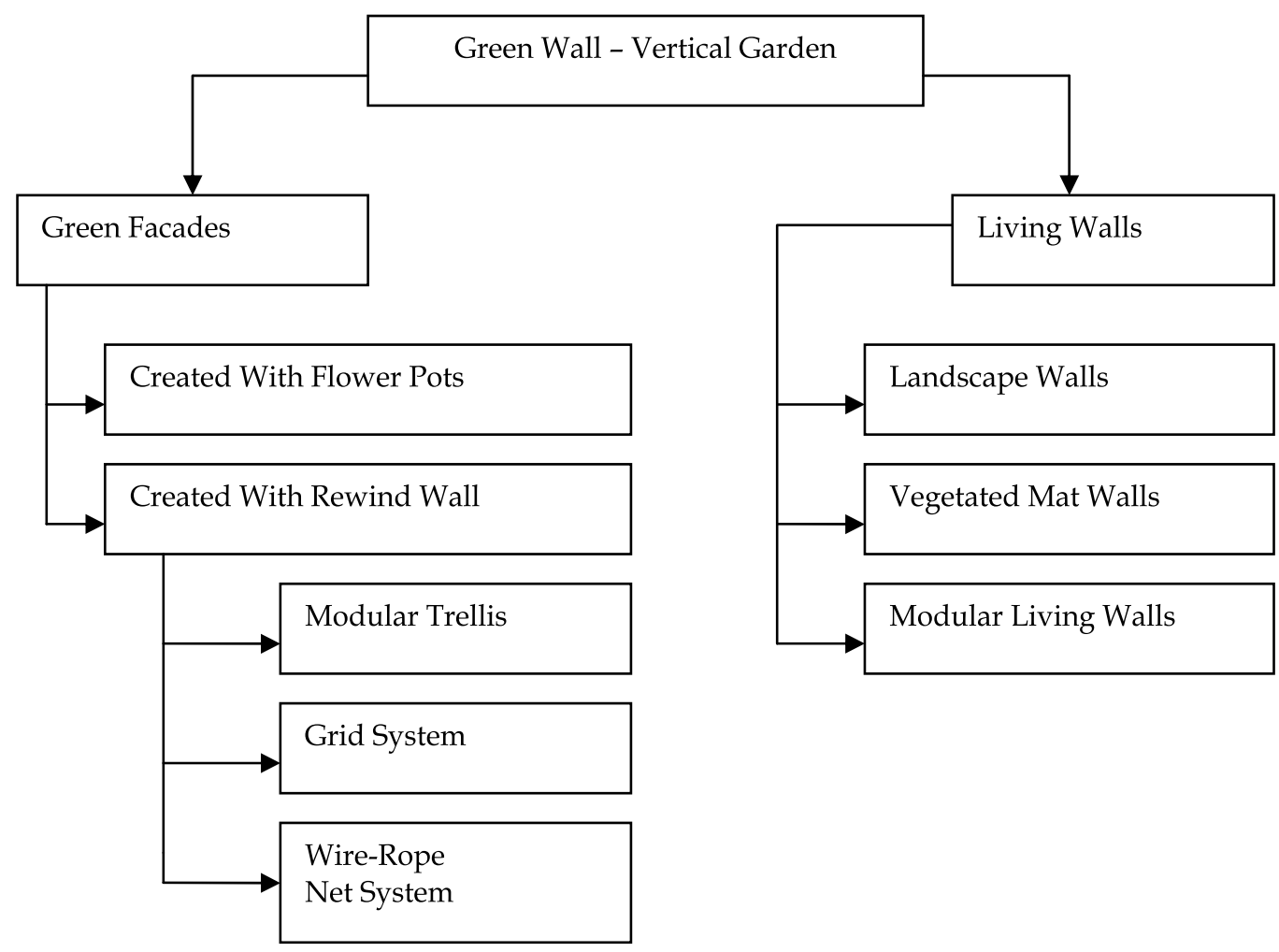

Figure 2. Types of Vertical Garden (Yeh 2012, Greenroof organization 2008,

www.landscapeurbanism.blogspot.com 2013, www.landscape-design-advisor.com 2013, Köhler 2008).

\subsection{Modular trellis panel system}

The building block of this modular system is a rigid, light weight, three-dimensional panel made from a powder coated galvanized and welded steel wire that supports plants with both a face grid and a panel depth. This system is designed to hold a green facade off the wall surface so that plant materials do not attach to the building, provides a "captive" growing environment for the plant with multiple supports for the tendrils, and helps to maintain the integrity of a building membrane. Panels can be stacked and joined to cover large areas, or formed to create shapes and curves, are made from recycledcontent steel and are recyclable (fig3, fig4). Because the panels are rigid, they can span between structures and can also be used for freestanding green walls (Gren roof organization 2008).

\subsection{Grid and wire-rope net systems}

Planning the Grid and wire-rope net systems used cables and wires (fig5, fig6). Grids are employed on green facades that are designed to support faster growing climbing plants with denser foliage. Wire-nets are often used to support slower growing plants that need the added support these systems provide at closer intervals. Both systems use high tensile steel cables, anchors and supplementary equipment. Various sizes and patterns can be 
accommodated as flexible vertical and horizontal wire-ropes are connected through cross clamps (Gren roof organization 2008, Yeh 2012).

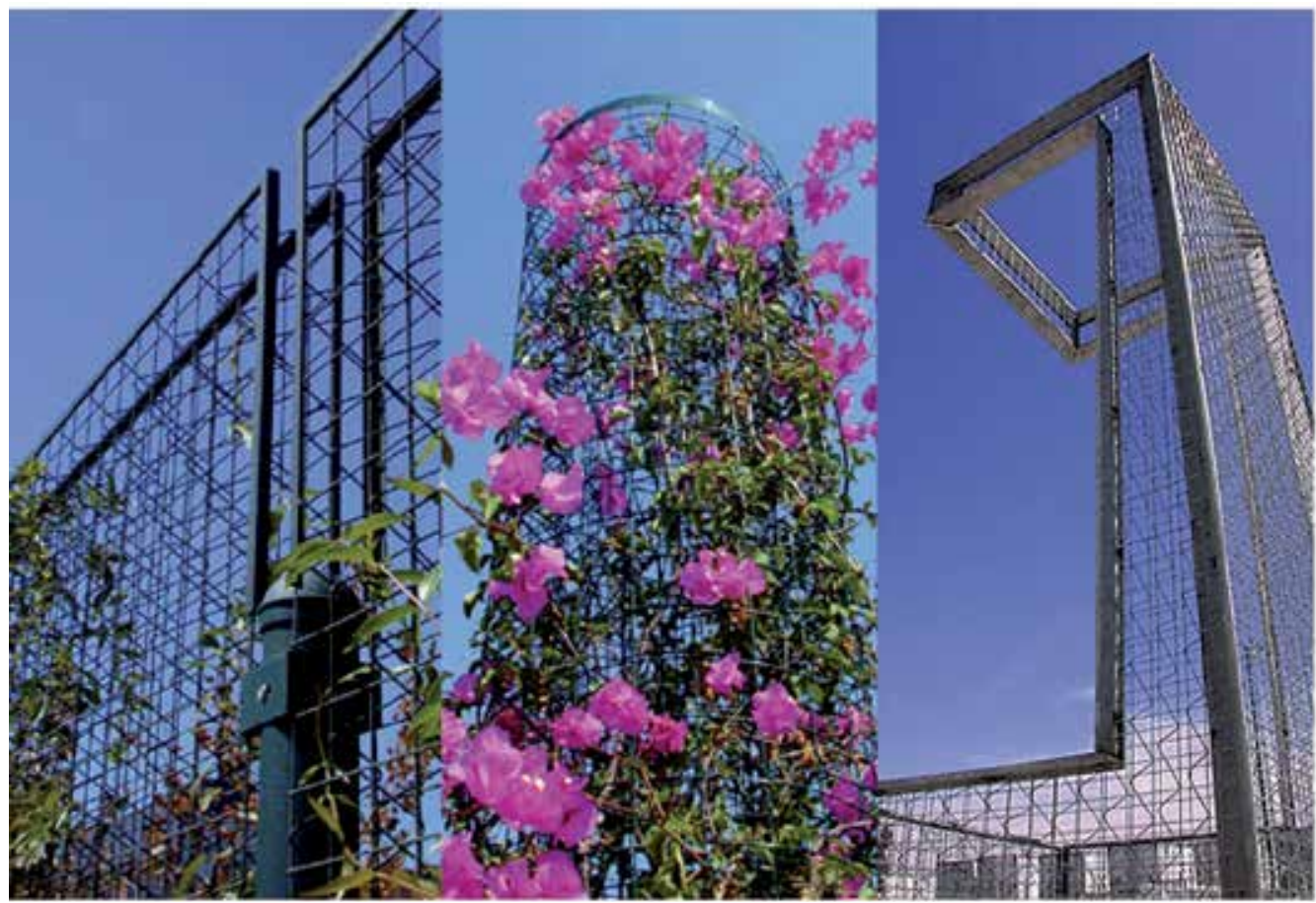

Figure 3. Freestanding trellis fence (left), coloumn trellis (bottom), custom trellis shapes (right) (www.greenscrren.com2013).

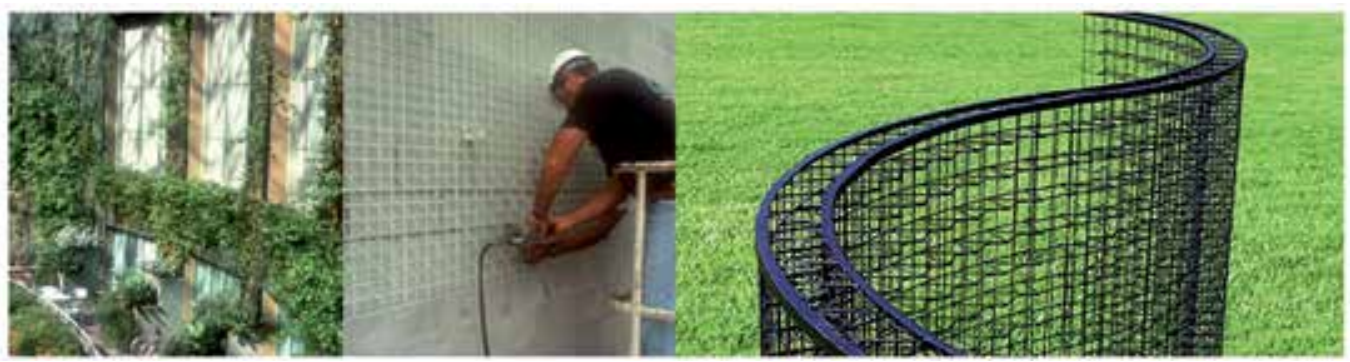

Figure 4. Modular wall hung trellis (left), curved trellis (right) (www.greenroof.com 2013). 


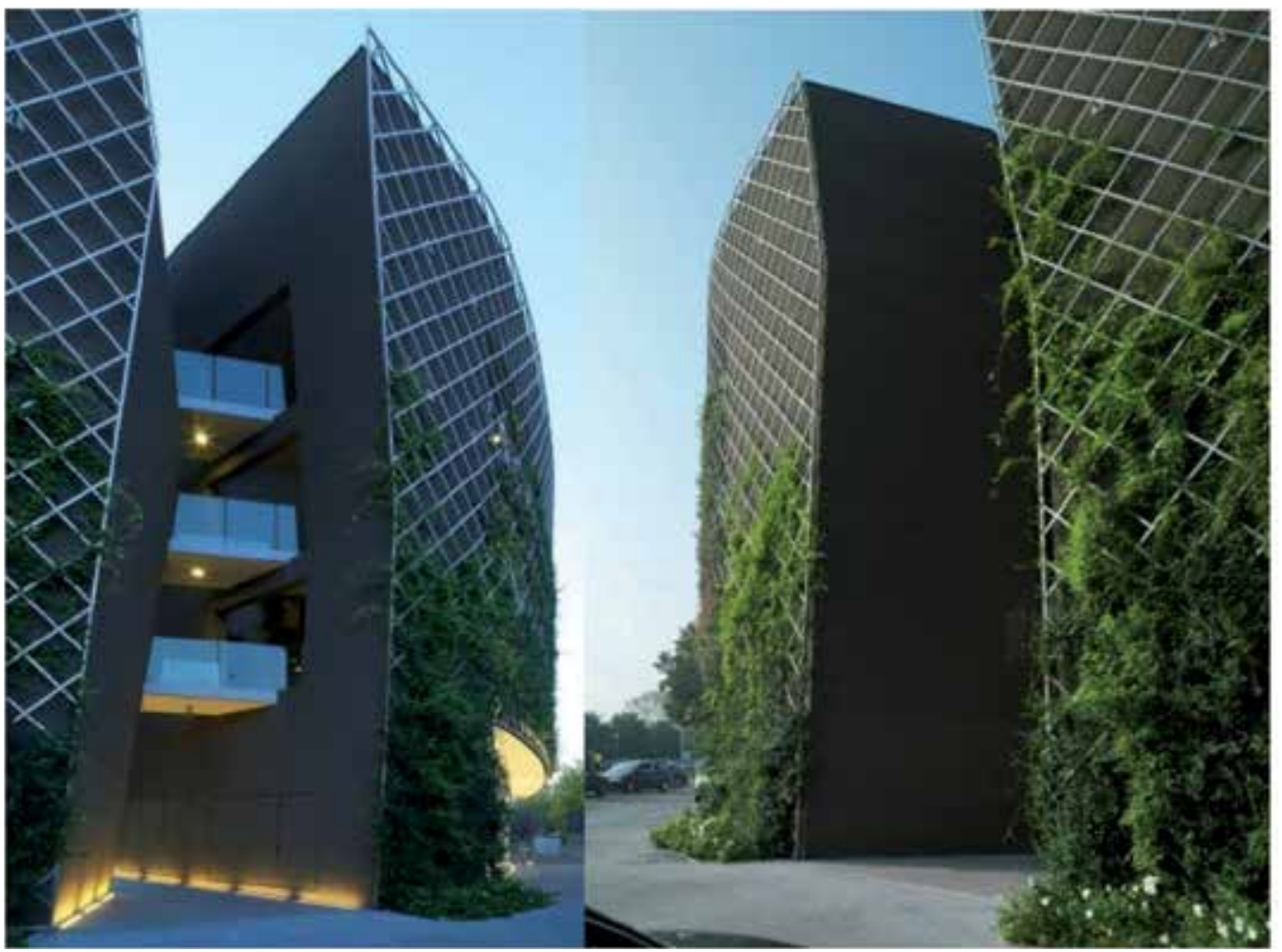

Figure 5. Grid System, Ex Ducati Office İtaly (http://preprodtest.archdaily.com 2013, http://www.archdaily.com 2013).
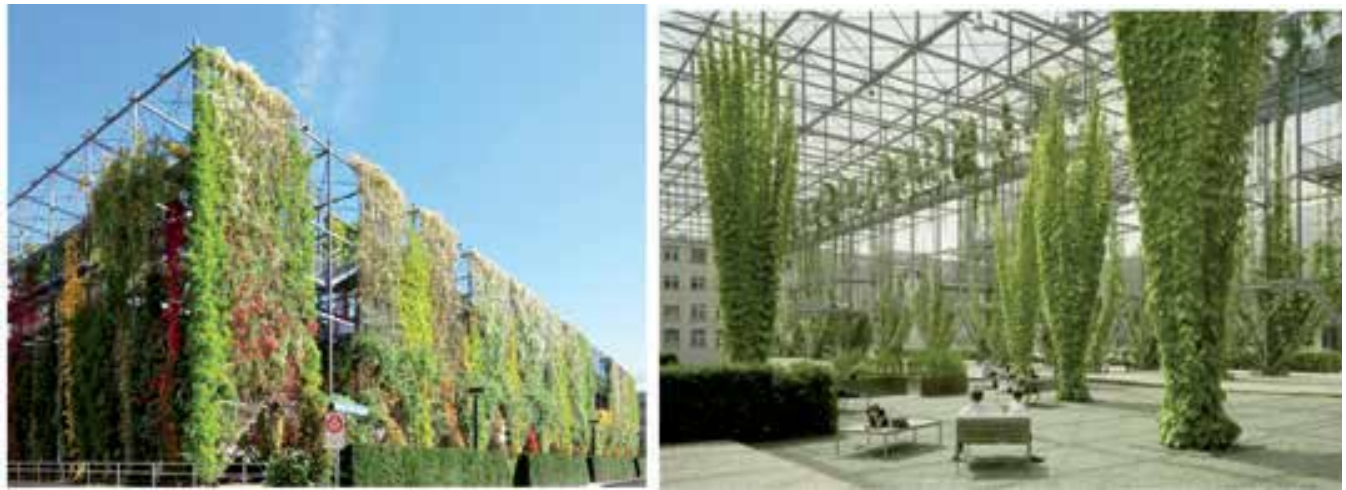

Figure 6. Grid and Wire-Rope Net Systems, MFO Park Switzerland (http://commons.wikimedia.org 2013, http://christianbarnardblog.blogspot.com 2013).

\section{Living walls}

Living walls, also called bio-walls or vertical gardens. Living wall systems are composed of pre vegetated panels, vertical modules or planted blankets These panels can be made of plastic, expanded polystyrene, synthetic fabric, clay, metal, and concrete, and support a 
great diversity and density of plant species. Living walls need more protection than green facades because of its diversity and density of vegetation. Living Walls are made with three parts: a metal frame, a PVC layer and an air layer (do not need soil). This system supports a variety of plant species, such as a mixture of vegetation, perennial flowers, low shrubs, and ferns etc (fig 7). It performs well in various climate environments. However, the selection of better species may adapt to the prevailing climatic condition, so that the maintenance of the system be made easy. Generally is used self-automated watering and nutrition system, to make maintenance of the living walls easy (Gren roof organization 2008, Yeh 2012).

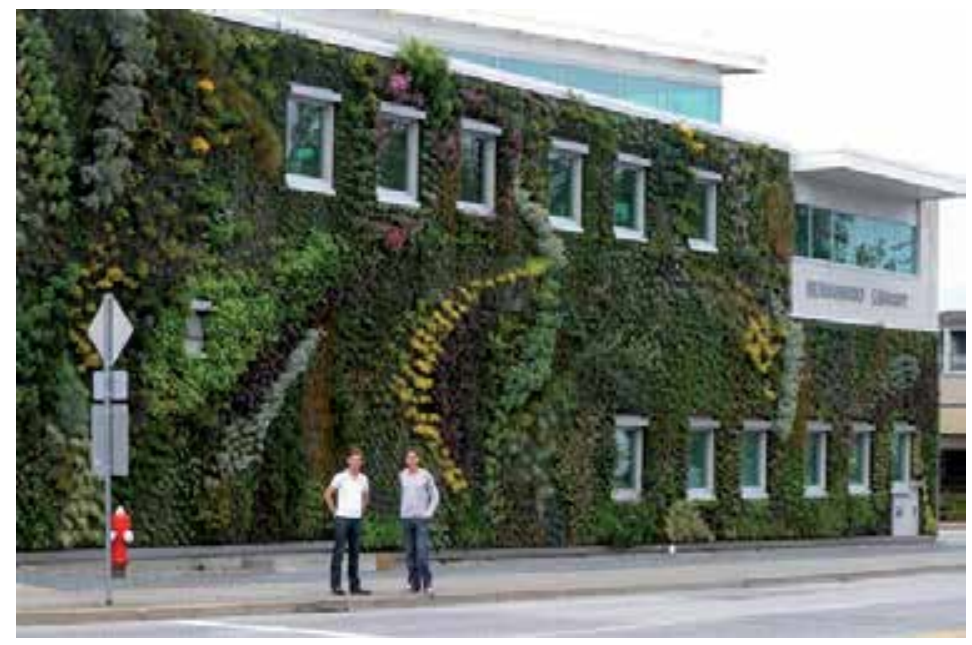

Figure 7. Living wall, Semiahmoo Library in South Surrey (http://www.vancouversun.com 2013).

\section{Landscape walls}

These walls are an evolution of landscape 'berms' and a strategic tool in an approach to 'living' architecture. Landscape walls are typically sloped as opposed to vertical and have the primary function of noise reduction and slope stabilization (fig 8). They usually are structured from some form of stacking material made of plastic or concrete with room for growing media and plants (Gren roof organization 2008).

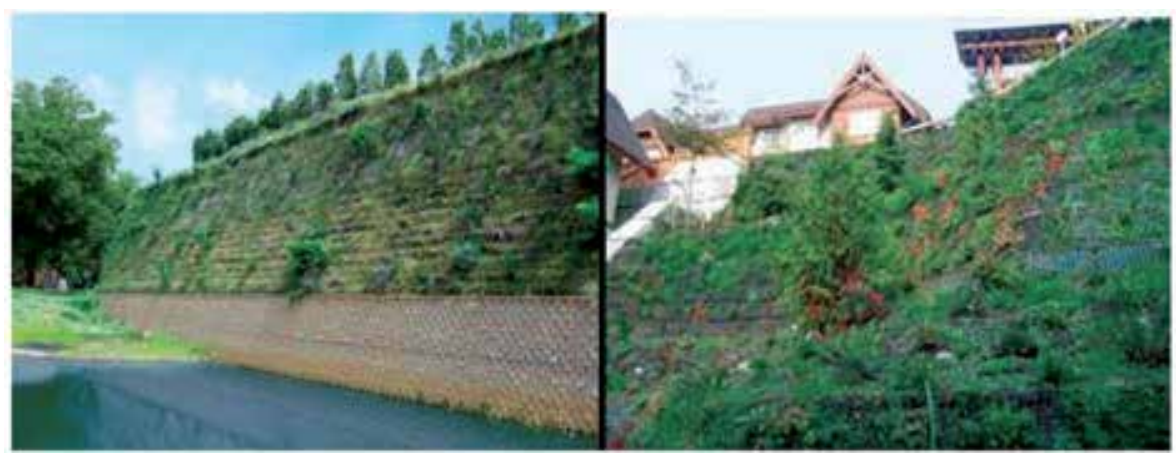

Figure 8. Landscape Walls (http://www.landscapeonline.com 2013). 


\section{Vegetated mat walls}

The 'Mur Vegetal' is a unique form of green wall pioneered by Patrick Blanc (fig 9). It is composed of two layers of synthetic fabric with pockets that physically support plants and growing media. The fabric walls are supported by a frame and backed by a waterproof membrane against the building wall because of its high moisture content. Nutrients are primarily distributed through an irrigation system that cycles water from the top of the system down (Gren roof organization 2008).
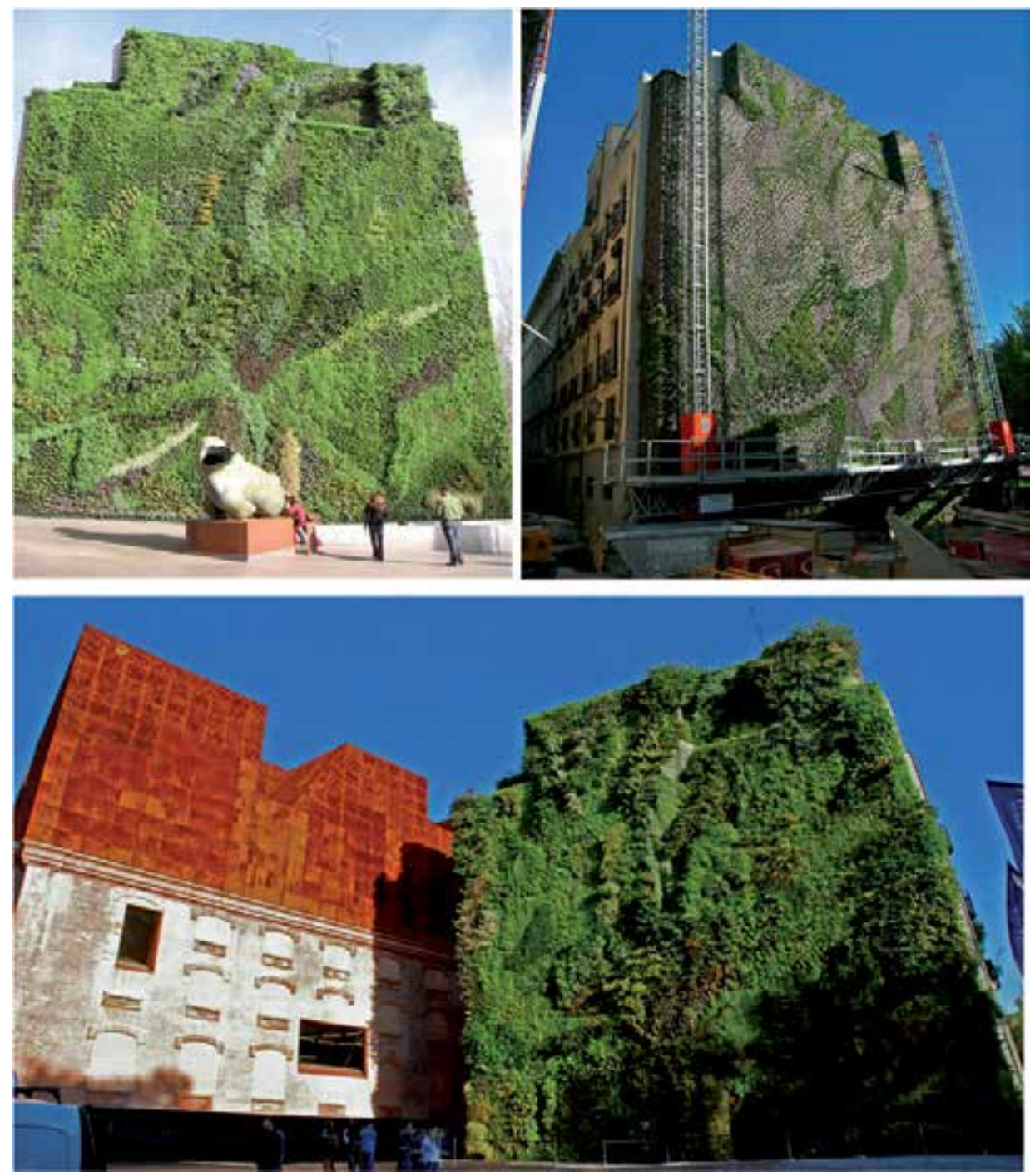

Figure 9. Vegetated Mat Walls, Madrid Spain (http://www.museumofthecity.org 2013, http://www.eyeonspain.com 2013). 


\section{Modular living walls}

A modular living wall system emerged in part from the use of modules for green roof applications, with a number of technological innovations. Modular systems consist of square or rectangular panels that hold growing media to support plant material (fig 10). (Gren roof organization 2008).
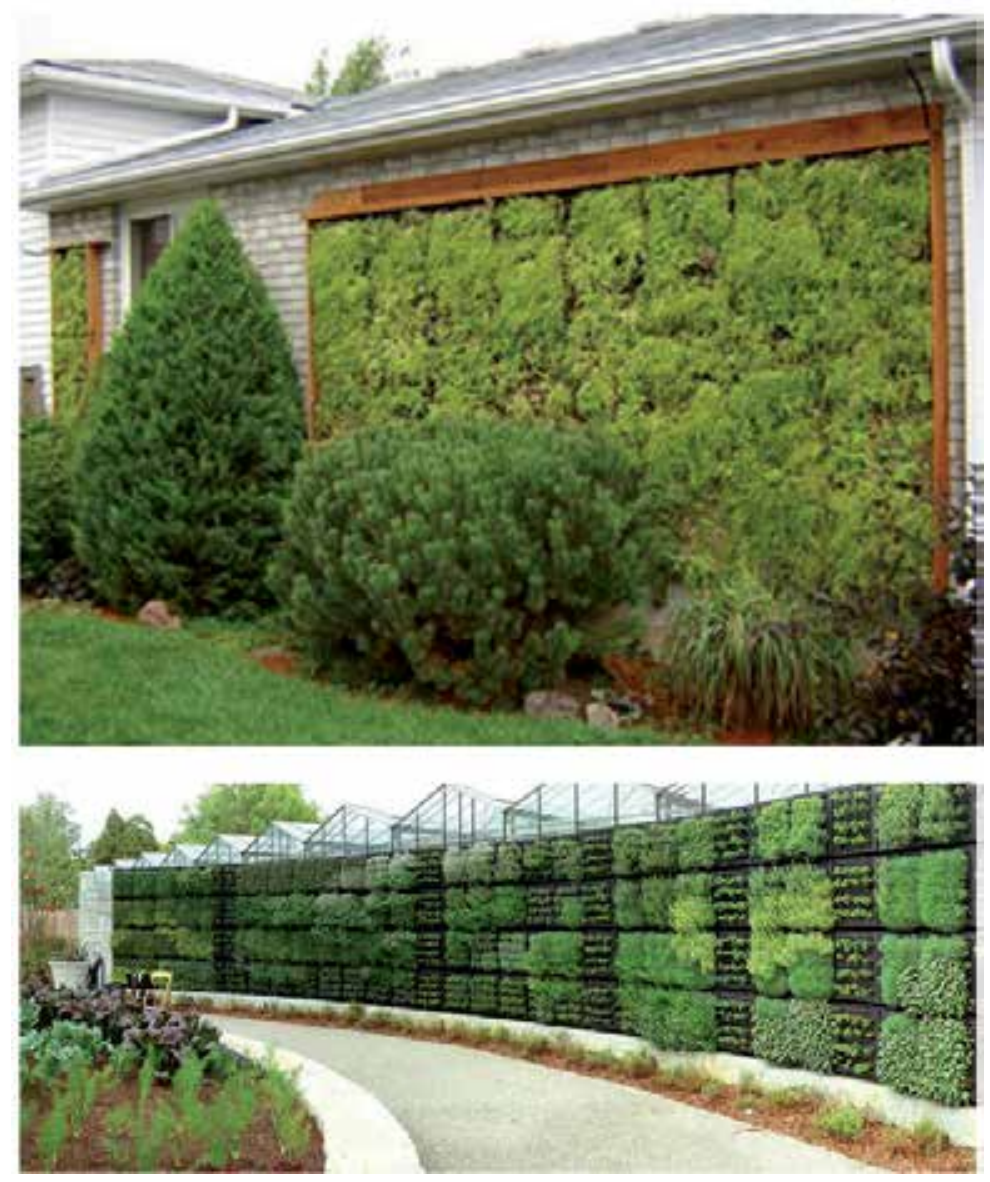

Figure 10. Modular Living Wall Canada (above), Atlanta Botanical Garden (below) (http://www.greenthinkers.org 2013, http://blog.phyllisodessey.com 2013).

\section{History of vertical garden}

The ancient concept of Gren walls was built in Babylon (fig 11) about 2500 years ago. In ancient Babylon, King Nebuchadnezzar II built the Hanging Gardens of Babylon: a wonder of the ancient world, and ancestor of the modern green wall (Ashmawy 2006, Hamilton 2009, Green roofs for healthy cities, 2008).

Between 3rd BC 17th AD Romans train grape on garden trellies and on villa walls. 
In 1920's Britania and North America promote trellis structures and self-climbing plants on houses and gardens

In 1988 started to use stainless steel cable system for green facades

Early 1990's cable and wire-rope net systems (fig 12) and modular trellis panel systems (fig 13) enter the North American marketplace.
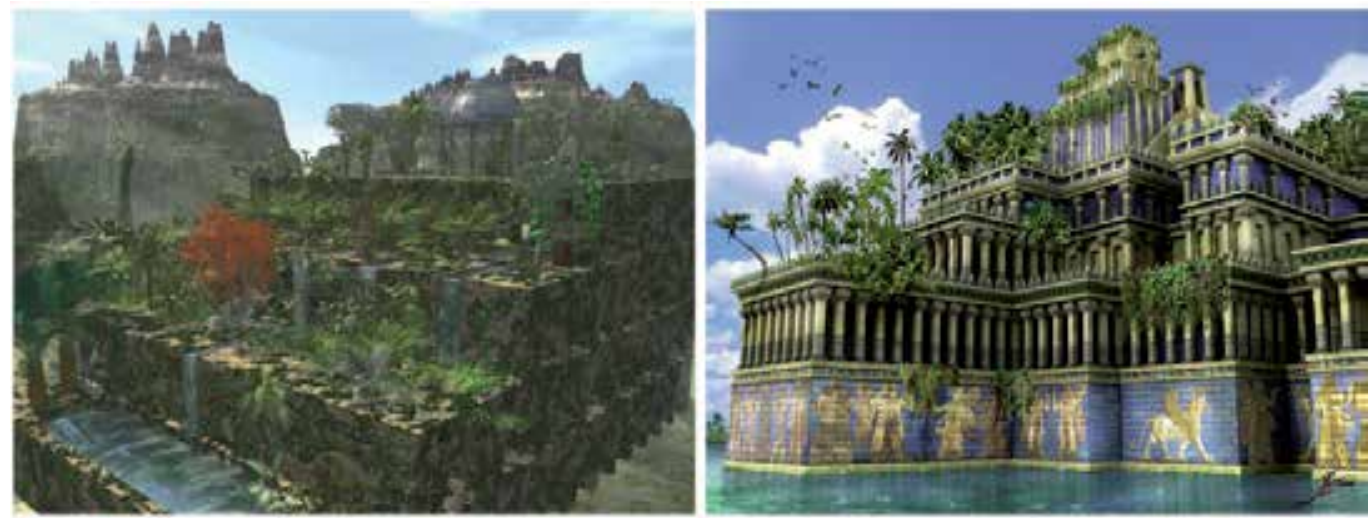

Figure 11. Babylon (http://purpleopurple.com 2013).

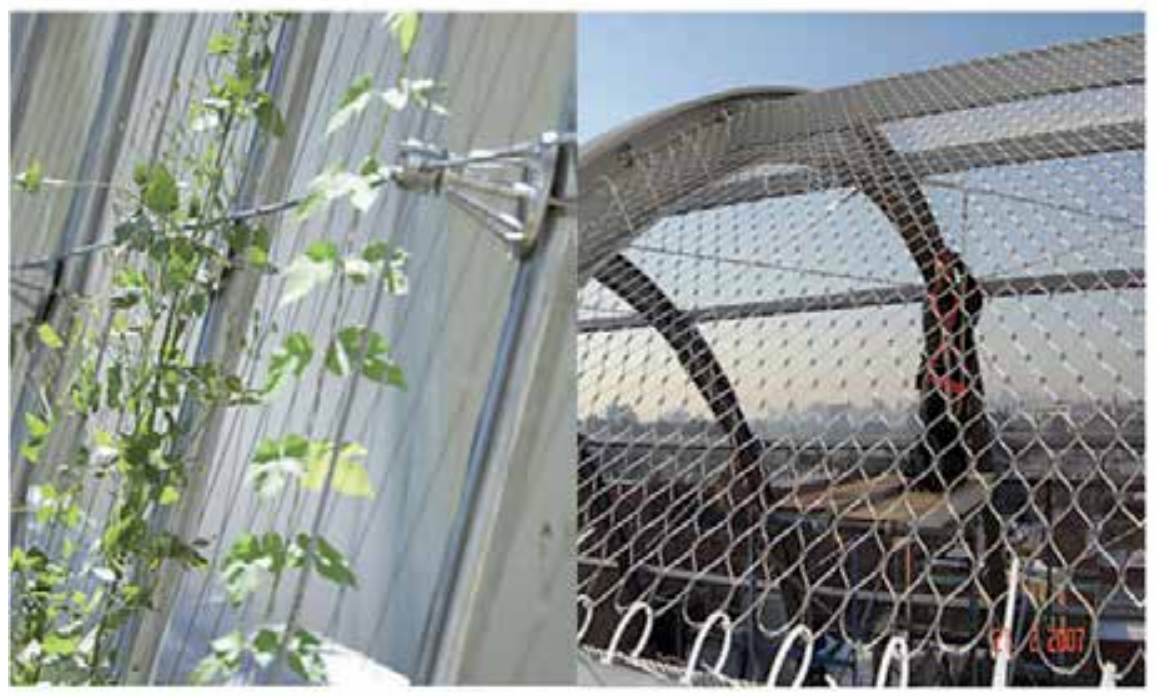

Figure 12. Cable and wire-rope net systems (Green roofs organization 2008). 


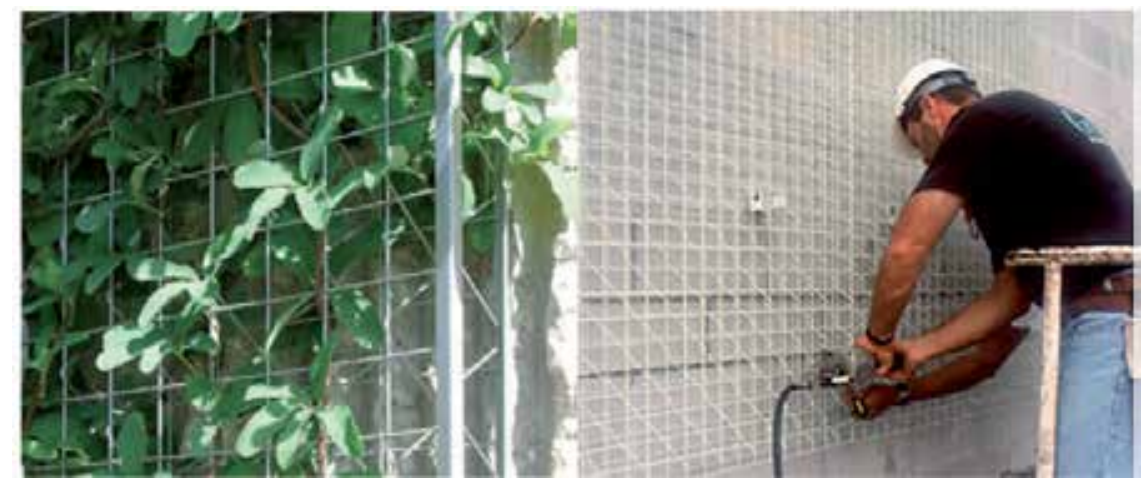

Figure 13. Modular trellis panel system (Green roofs organization 2008).

First major application of a trellis panel system had been used in Universal City Walk on California in 1993 and in 1994 (fig 14). Indoor living wall with bio filtration system installed in Canada Life Building in Toronto (fig 15) (Gren Roofs Organization 2008).
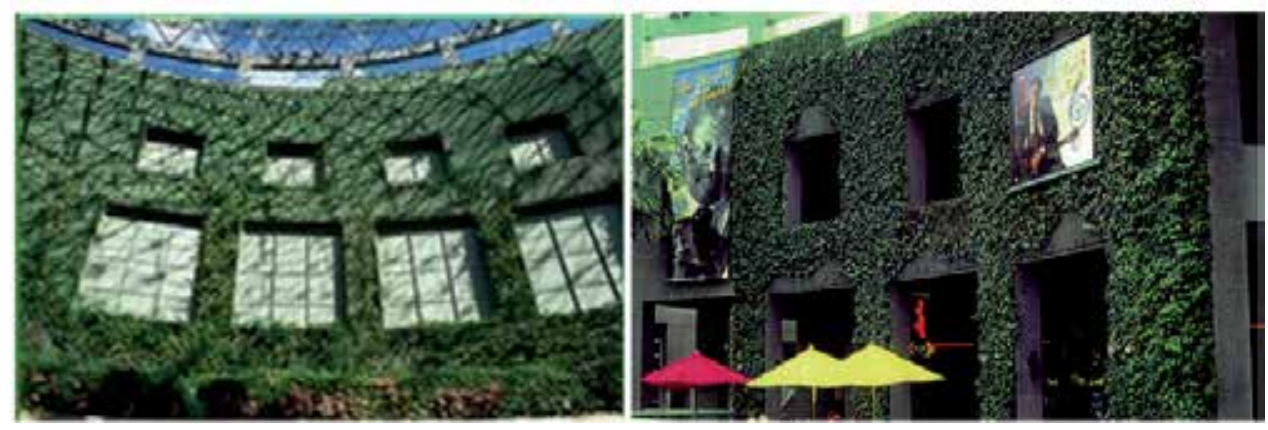

Figure 14. Universal City Walk on California (http://www.examiner.com 2013, http://pinterest.com 2013).

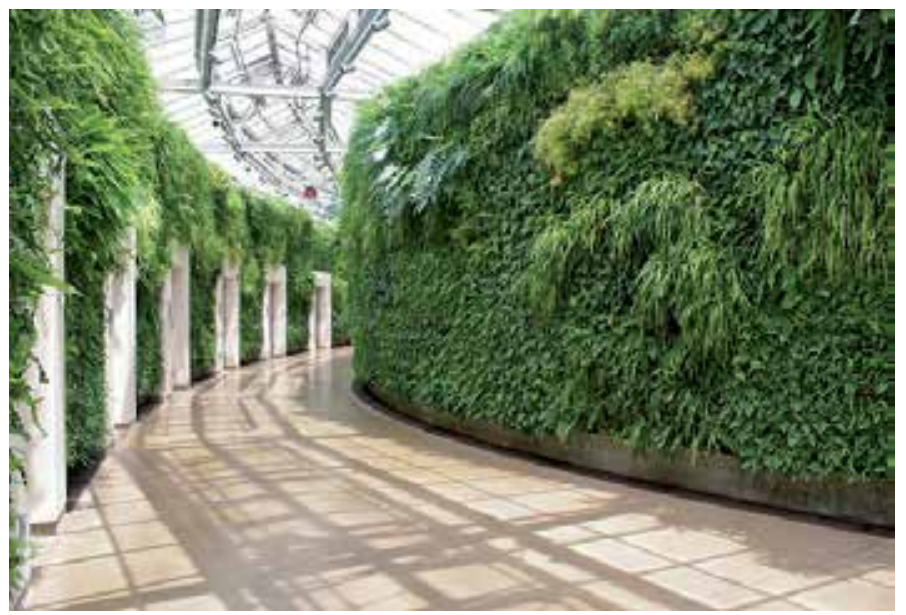

Figure 15. Longwood Gardens in Kennett Square (http://www.livingwallart.com 2013, http://gsky.com/projects 2013). 
Green walls are not only spectacularly beautiful, but also helpful in enlivening the ambiance. Green walls can absorb heated gas in the air, lower both indoor and outdoor temperature, providing a healthier indoor air quality as well as a more beautiful space. (Yeh 2012, http://www.nodai.ac.jp)

\section{Benefits of vertical gardening}

Vertical Gardens provide economic and ecologic benefits as well as aesthetic value. The benefits change with options such as different buildings, green wall technologies, plant selections and plant coverage. In this part is examined important values of Green Walls.

1. Beauty abounds and adds visual drama (fig 16)

Plants are one of the fastest, most cost effective agents for rectifying negative perceptions of an area, enhancing a buildings public profile and significantly improving the visual amenity, economic, and social conditions of the city. The application of vertical gardens is shown to increase property values by dramatically increasing the amenity of buildings, and establishing higher public acclaim, transforming them into recognisable landmarks (http://www.greenology.sg 2013)

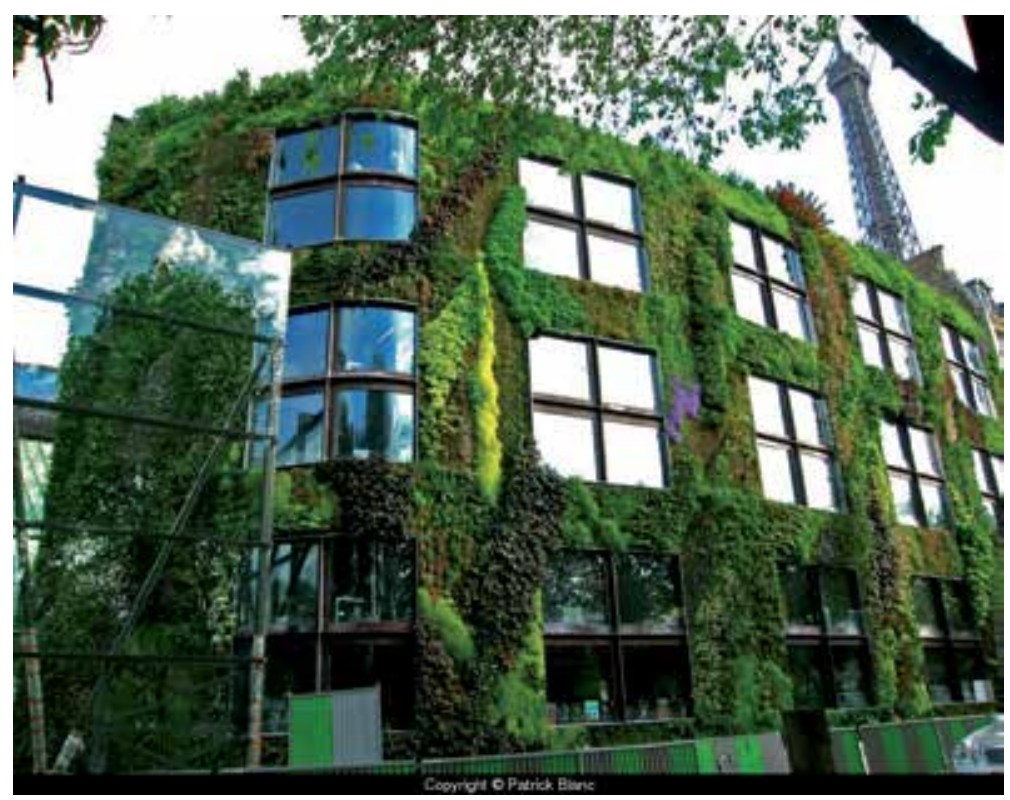

Figure 16. Quai Branly Museum (http://www.minus25.com 2013).

2. Covers up views of plain or ugly walls (fig 17) and provide building protection

Building protection is primarily produced by reducing temperature fluctuations of the building envelope. Decreased temperature fluctuations reduce the expansion and contraction of building materials and extend the building's lifespan. Green Walls shield the building envelope from ultra-violet rays and acidic rain by reducing cracking and 
carbonization of the building envelope, the buildings durability is improved and its servicelife extended (Doernach 1979, http://gsky.com).

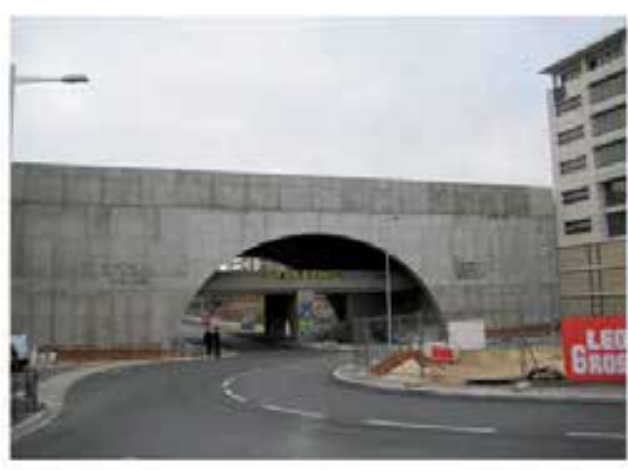

Before

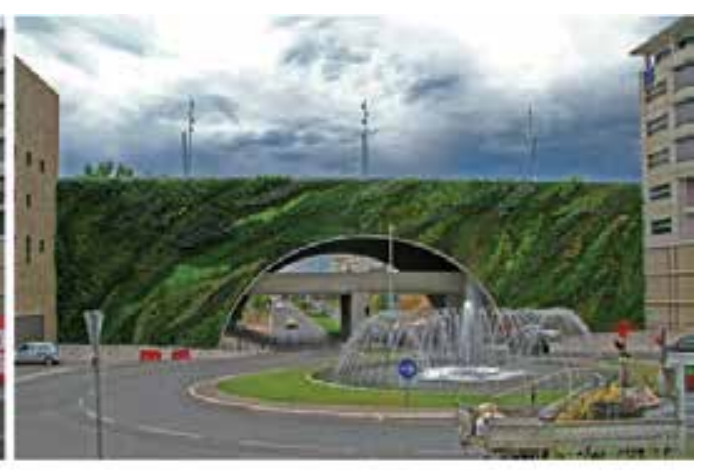

After

Figure 17. Bridge in France (http://pixpeedia.blogspot.com 2013, http://twistedsifter.com 2013).

3. Decrease voice level (fig 18)

Soil and plants which used for plantal arrengements in Vertical Gardens, have a voice absorption feature. For this reason they perform to decrease voice function which happened both in building and its close area Green Walls provide a noise buffer which significantly reduces outside noise and vibration (up to $40 \mathrm{~dB}$ ) inside our homes and workplaces. A small indoor hedge placed around a workspace will reduce noise by 5 decibels (Dunnett and Kingsbury 2004, Erdogan and Aliasghari Khabbazi 2013, http://gsky.com 2013, Jacobs 2008, Wong et al 2010).

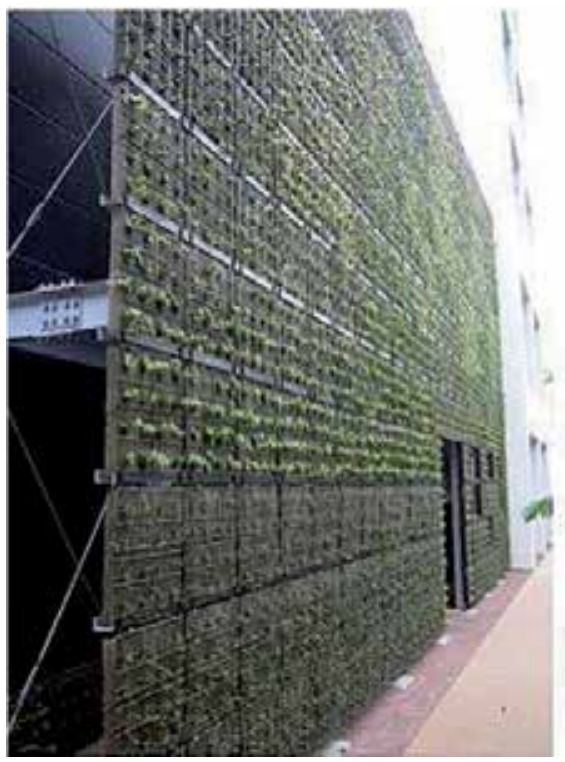

Figure 18. Living Wall for voice level (Jacobs 2008). 
4. Conserves water and watering takes less effort

One of the biggest benefits of vertical gardens is how they manage water. For starters, watering is very efficient as it is done using a drip irrigation system or a hydroponic system (fig 19). Any waste water is collected at the bottom of the garden in a special tray where it is drained away. Alternatively, it can be recycled and put back on the garden. This means that practically all the water is used up by the plants and there is very little waste. There is also no runoff into stormwater systems so natural waterways are not affected by pollutants that can be found in stormwater or waste water (fig 20) (http://www.homeim provementpages.com 2013).

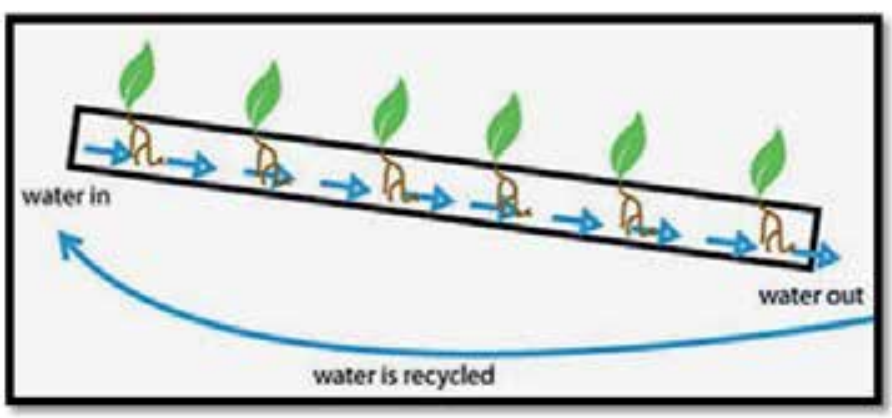

Figure 19. Hydrophonic Vertical Garden.

SOURCES
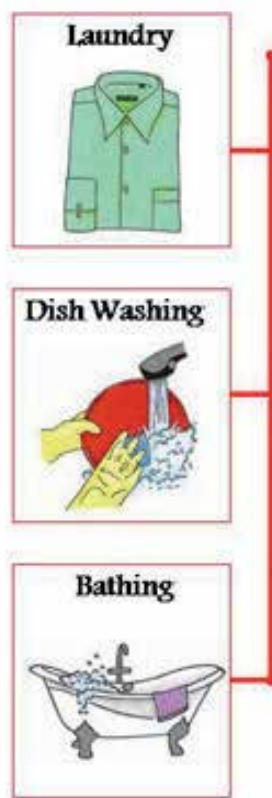

FILTRATION
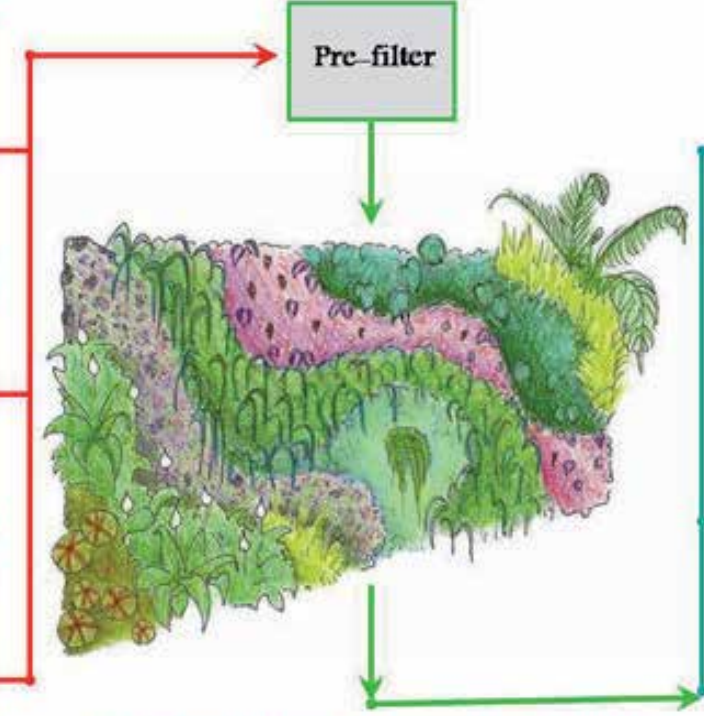

Phyloremediation of greywater by plants
RECYCLE

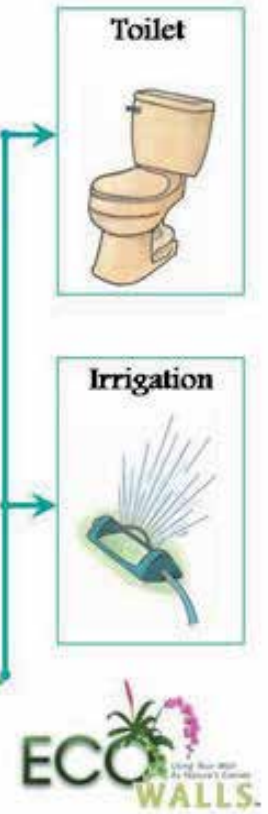

Figure 20. Greywater Treatment (http://www.greenecowalls.com 2013). 
5. Reduces CO2 levels and increases oxygen and improved air quality

A greenwall offers immediate environmental advances in reducing existing greenhouse and other volatile organic compounds from our polluted cities. Plants act as bio-purifiers and can play a dramatic role in improving the quality of city air through a number of biochemical processes by removing and breaking down airborne contaminants from both inside and outside a building. When combined with plant photosynthesis, which produces clean, oxygen rich air, it becomes easy to see the value of employing living plants as biopurifiers in polluted urban environments. Approximately 1 square foot of vegetated wall area will filter the air for approximately 100 square feet of office area. Considered in very general sense, planting one wall of any house which situated 50 houses on the street is equal to plant 50 trees on this street (Erdogan and Aliasghari Khabbazi 2013, http://www.greenology.sg 2013, Truett 2003, ).

Yet another benefit of vertical gardens is that they improve the air quality of built up areas, both inside the home and outside. This is because plants are natural filters - taking carbon dioxide from the air and replacing it with much needed oxygen (fig 21). They also help to filter pollutants from the air (fig 22). This means that the air that you breathe is much cleaner and healthier (http://www.homeimprovementpages.com.au 2013). Studies have shown that there are significantly lower concentrations of toxins in the area surrounding a living wall (Loh 2008).

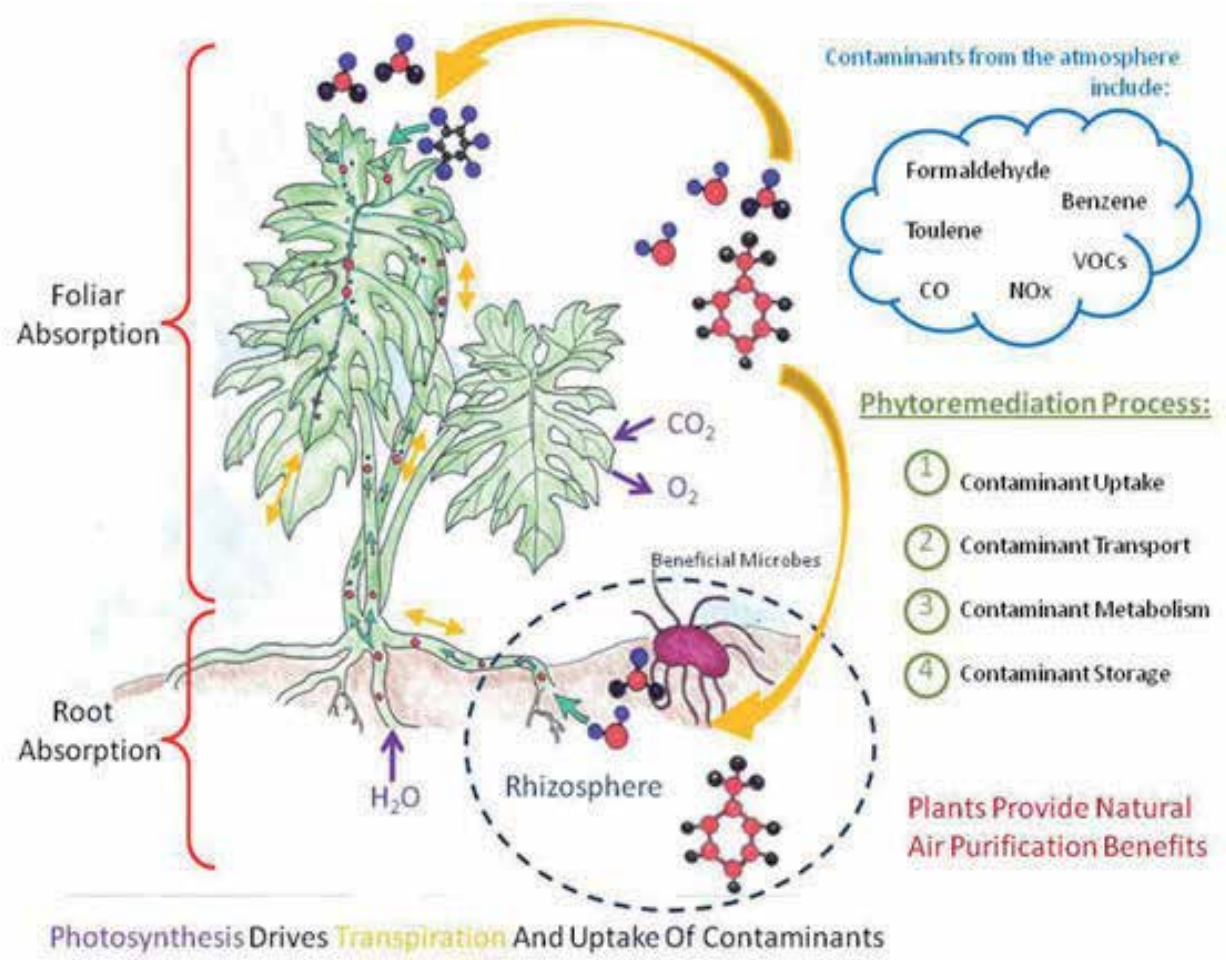

Figure 21. Indoor Air Quality (http://www.greenecowalls.com 2013) 

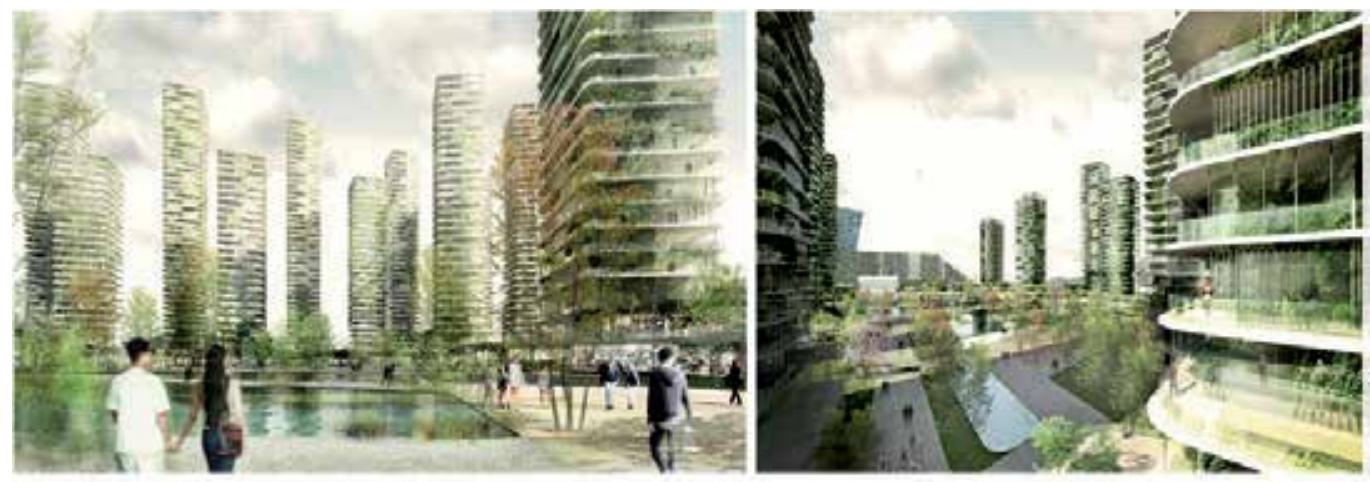

Figure 22. Dom Aquitectura Unveils Green Master Plan to Clean Air and Reduce Pollution in Huizhou, China LoriZimmer,10/12/12 (http://inhabitat.com 2013)

\section{Prevent from dust and harmful microorganisms}

Plants reduce wind-speed also they prevent dust with wet environments (fig 23) which created with their roots and leafs. By means of this event, plants bring about extinction to harmful microorganisms with on site sap and juice. Air quality improvement from plants has been shown to reduce coughs by thirty percent and dry throat and irritation by twentyfour percent also, the plants clean the office air by absorbing pollutants into their leaves and transmitting the toxin to their roots, where they are turned into food for the plant. With cleaner office air building occupants are less likely to be sick and rooms with plants contain $50 \%$ to $60 \%$ fewer of airborne molds and bacteria than rooms without plants (Fjeld at al. 1998, Kemaloğlu and Yılmaz 1991, Wolf 2002).

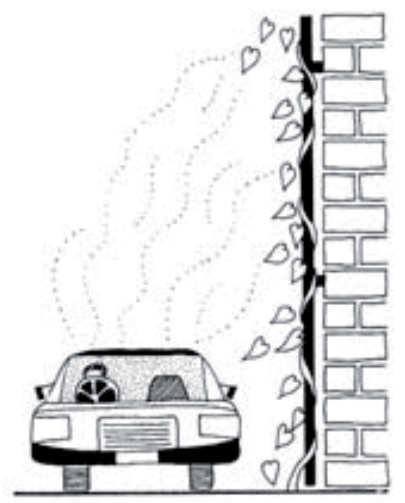

Figure 23. Drawing about prevent dust with plants (Johnston and Newton 2004).

7. Acts as natural insulation for hot and cold air and a save energy for your building.

Indirectly, living walls reduce air-conditioning requirements and energy consumption of urban buildings through cooling the city. Vegetation on walls can assist in cooling buildings in summer and insulating them in winter. In winter, evergreen species offer a degree of 
insulation by trapping a layer of air against the facade and reducing convectional heat loss. An insulating effect of up to $30 \%$ has been recorded although such a high percentage is only likely when temperatures fall close to freezing. Energy savings are less significant on wellinsulated buildings, such as those with brick cavity walls. During the summer, hot walls cause temperatures to rise inside buildings, increasing demand on cooling systems and consuming more energy. A Green Wall surface temperature is reduced when covered with plants, reducing the wall temperature and building cooling load (fig 24). Green Walls can reduce wall temperature as much as $15^{\circ} \mathrm{F}$ which results in significant air conditioning savings (Baumann 1986, Doernach 1979, http://www.marthastewart.com 2013, Johnston and Newton 2004).

In Tokyo Institute of Technology Wall tests shown here, it was discovered that Green Wall panels reduce the wall temperature by $10^{\circ} \mathrm{C}$. It was also concluded that Green Wall panel reduce energy transfer into a building by $\sim 0.24 \mathrm{kWh} / \mathrm{m}^{2}$. Green Wall energy savings calculations depend greatly on the direction the wall is facing, the sun's angle, and many other factors (http://gsky.com 2013).

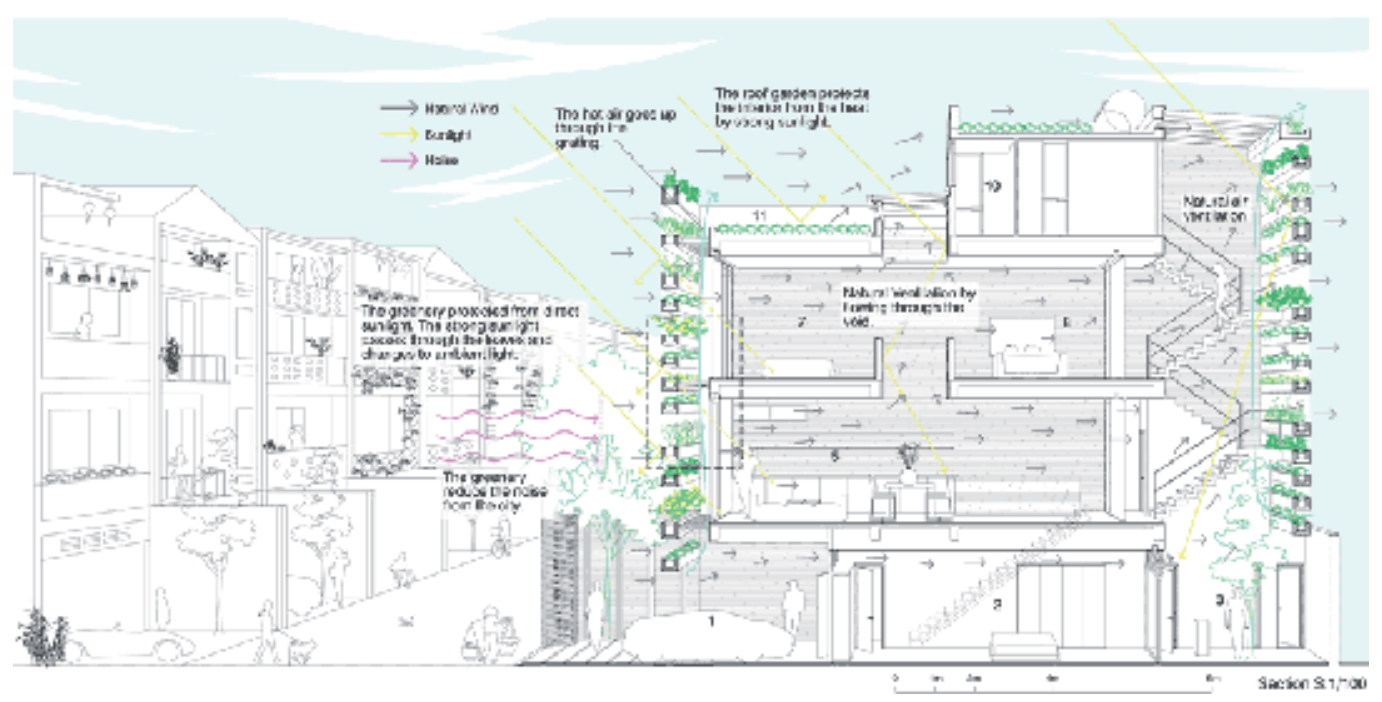

Figure 24. Stacking green (http://www.dezeen.com 2013).

8. Plants are less accessible to diseases and pests

As they grow vertically, many pests cannot even get to the plants. This means that you have very little problems with pests attacking your plants so you do not need to use pesticides or insecticides on your plants, saving you using chemicals. As well, air circulates well around the vertical garden and they also get plenty of sunshine, so there is much less risk of the plants suffering from mildew, fungus or disease (http://www.homeimprovement pages.com.au 2013).

9. Live plants decrease stress levels, create peaceful ambiance

Vertical gardens have demonstrated that restorative effect of natural scenery holds the viewer's attention (fig 25), diverts their awareness from themselves and from worrisome 
thoughts and elicits a meditation-like state. They help ease physiological and psychological pressures of city life by providing a spiritual and physical connection to nature. The beauty of a green wall (covering concrete and steel) can rejuvenate our minds and physical fatigue is greatly reduced. The presence of plants in the office not only reduce stress but also helps increase workers productivity (Peck et al 1999, http://gsky.com 2013).

Participants of Texas A\&M University and Surrey University study also reported feeling more attentive when plants were present. Participants of who worked in an environment with plants were $12 \%$ more productive and less stressed than those who worked in an environment with no plants (Gilhooley 2002).

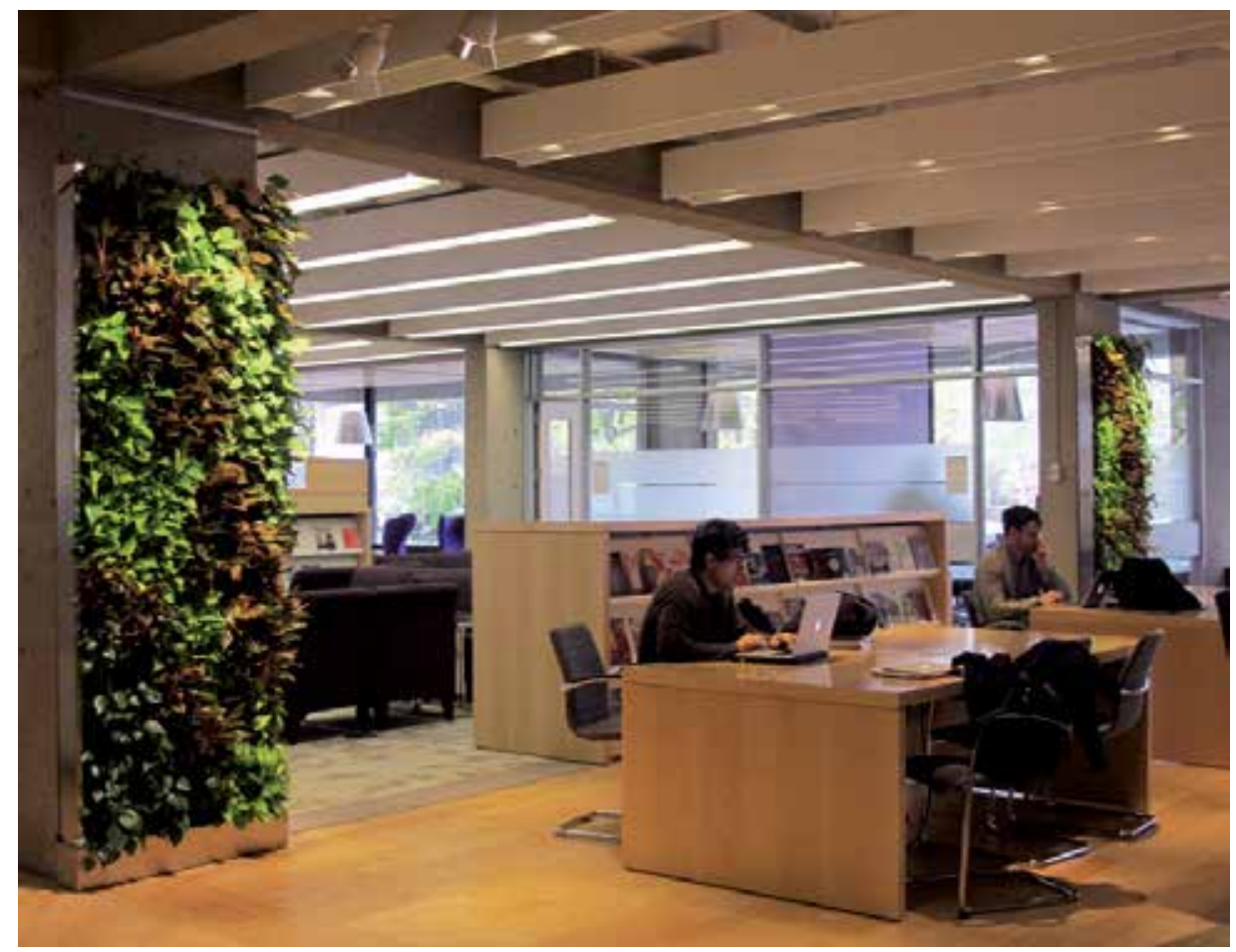

Figure 25. Living walls at Gutman Library (http://isites.harvard.edu 2013, Kim 2011)

10. Increases value and salability of your home or office building

Plants are one of the fastest, most cost effective agents for rectifying negative perceptions of an area, enhancing a buildings public profile and significantly improving the visual amenity, economic, and social conditions of the city (fig 26). The application of vertical gardens is shown to increase property values by dramatically increasing the amenity of buildings, and establishing higher public acclaim, transforming them into recognisable landmarks. American and British Studies show that having a green plant can increase the value of property by 6-15\%. (http://www.greenology.sg 2013, Peck et al, 1999) 

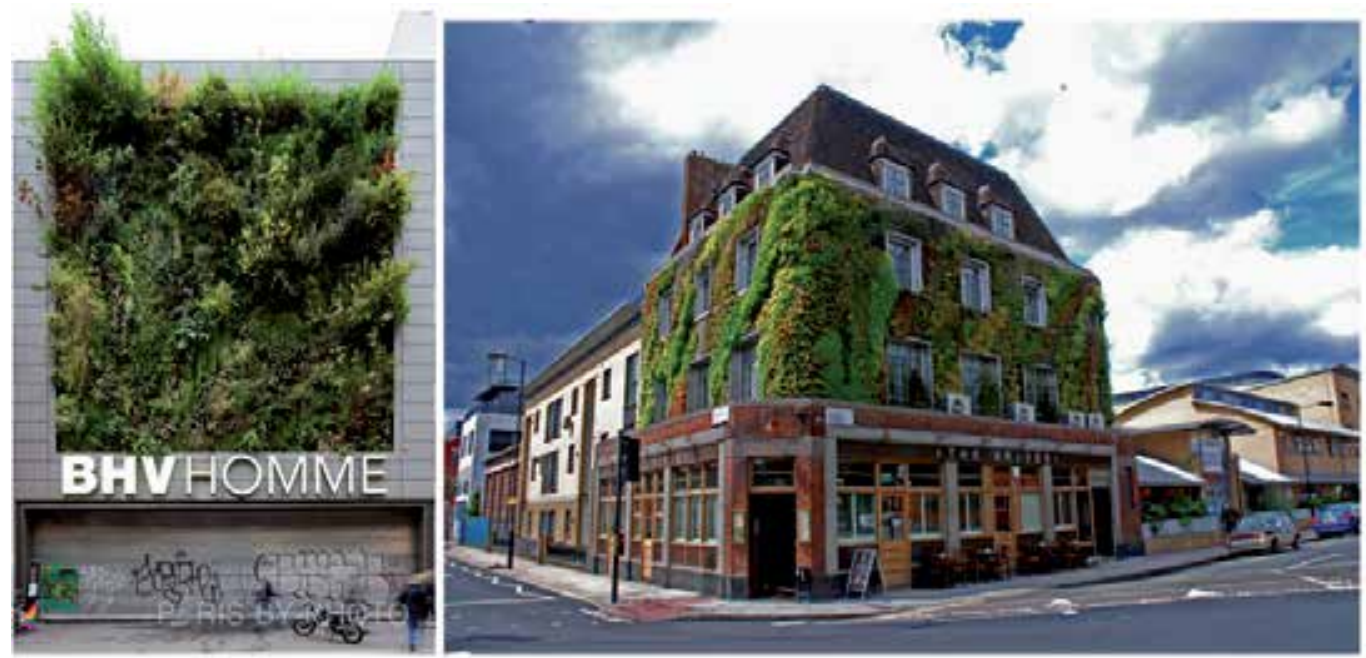

Figure 26. BHV Homme in Paris (left) (http://retailsquare.blogspot.com 2013), Pacha, The Driver, London (right) (http://twistedsifter.com 2013).

11. Help restore the places where wildlife can survive

Natural habitats are disappearing at an alarming rate, and habitat loss is the number one threat to wildlife today. Green Walls are part of the solution to help restore wildlife habitats. By carefully choosing and planting attractive plant species, a Green Wall will attract birds and butterflies (fig 27). Green Walls can be designed to provide the ideal conditions for birds, bees and butterflies to survive. It can provide water, food sources, protection, and places to bear and raise offspring (Johnston and Newton 2004, http://gsky.com 2013).

12. There are also benefits to having an outdoor living wall. They help mitigate the Urban Heat Island Effect (fig 28)

An urban heat island (UHI) is a metropolitan area which is significantly warmer than its surrounding rural area (fig 29), especially in late afternoons and nights at winter season. To avoid confusion with global warming, scientists call this phenomenon the "Urban Heat Island Effect. "There are several reasons that may explain the Heat Island Effect, but the main reason is the excessive urban development. Green walls are by far the most popular way to cooling the city. Green Walls in cooling buildings and combating the Heat Island Effect and greatly reduce this effect by absorbing a lot of the heat through the evaporation process (http://www.marthastewart.com 2013, Yamada 2008, Yeh 2012 ). 

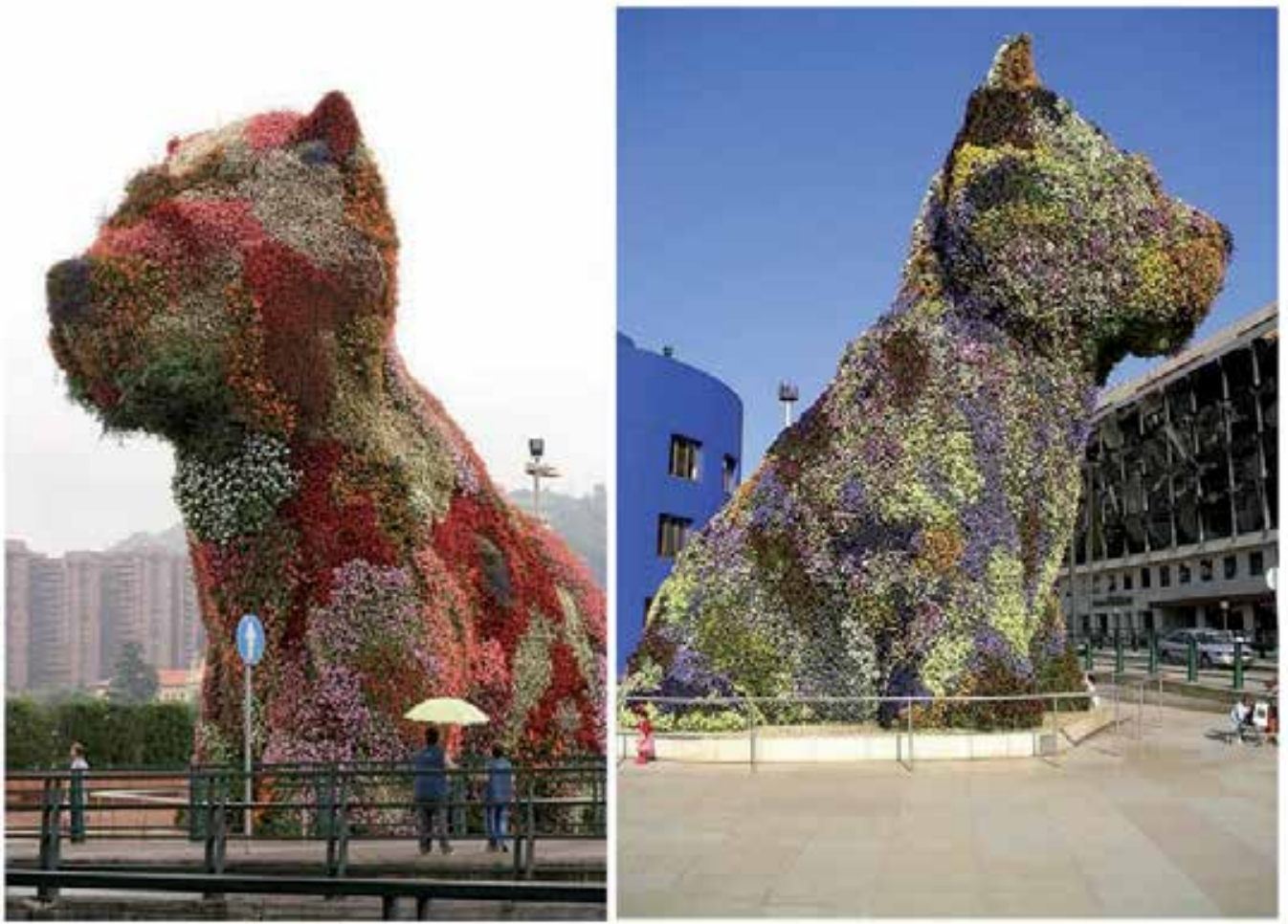

Figure 27. Guggenheim Museum, Bilbao, Spain (http://www.environmentalgraffiti.com 2013).

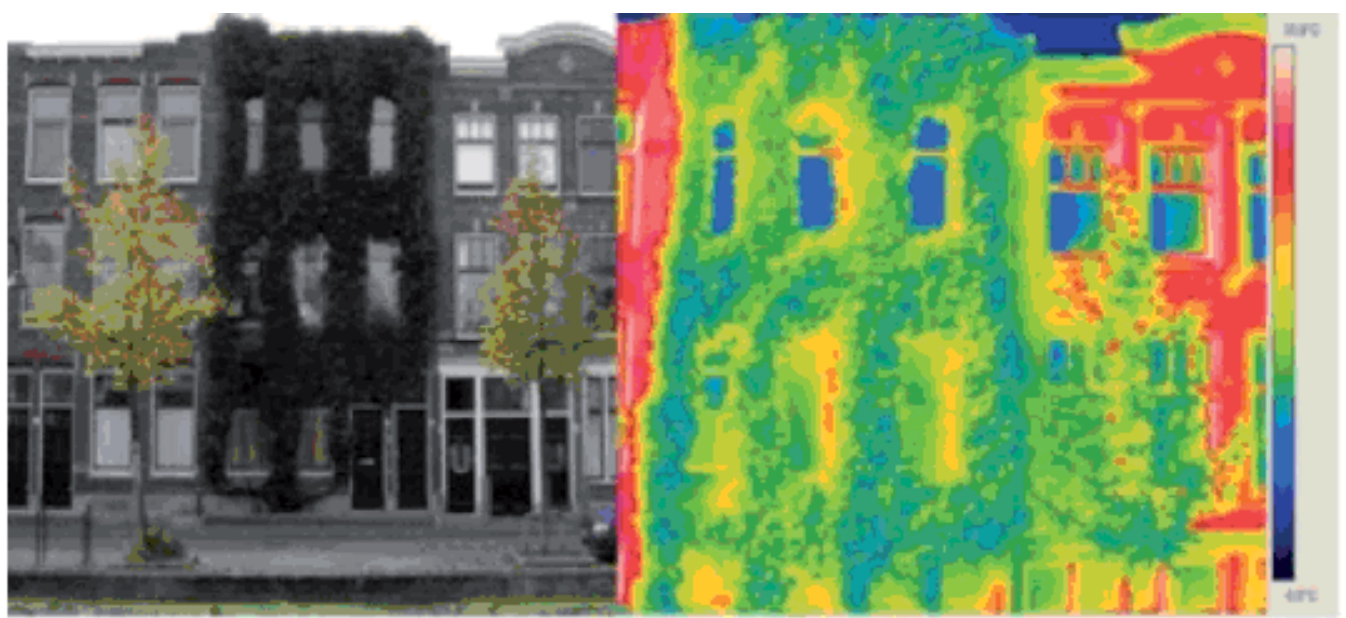

Figure 28. Urban Heat Island Effect, (Ottele, 2010). 


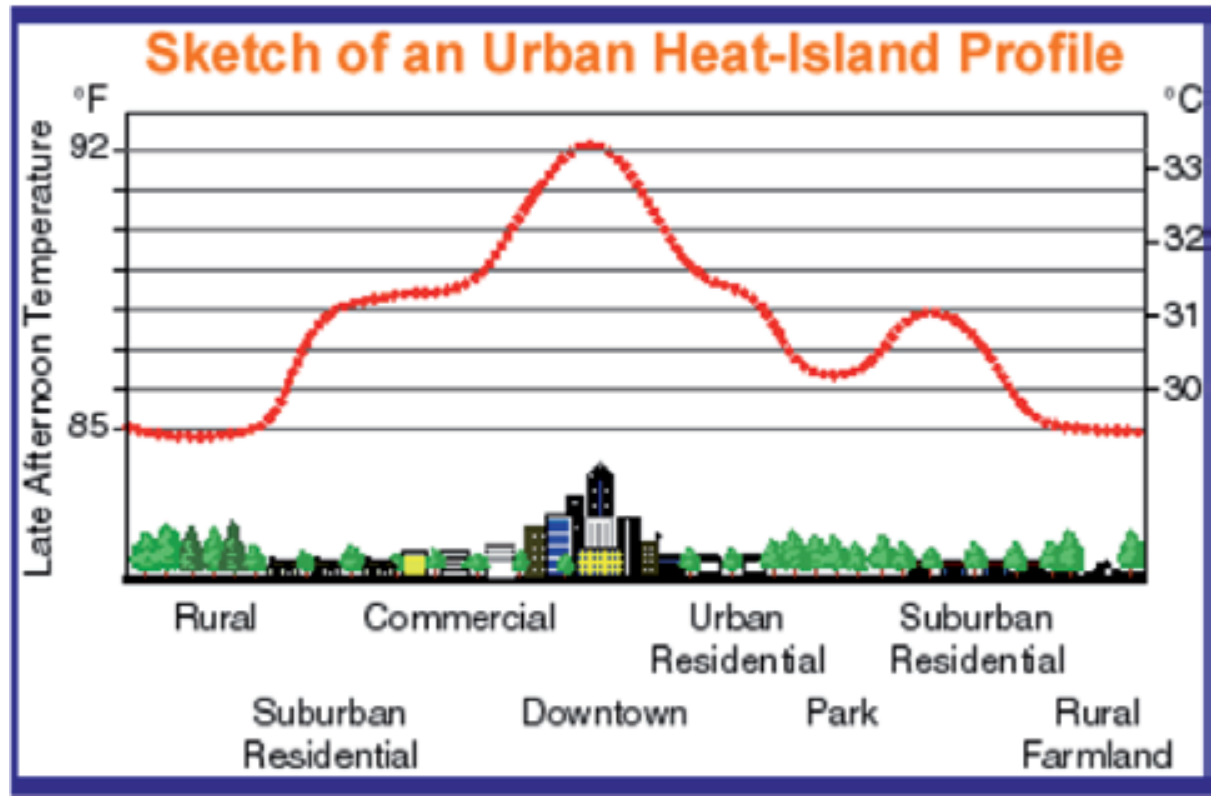

Figure 29. Urban Heat Island Profile (http://www.ssbx.org 2013, http://www.lsgi.polyu.edu.hk 2013).

\section{Some of suitable plants for vertical gardens}

A lot of plant species can be used for Vertical Gardens. For example there are 15000 plant from nearly 150 different species on the Caixa Forum Museum vertical garden who has designed Patrick Blank (http://www.greenroofs.com 2013). In this case, impossible to give all the plants one by one so in this part some plants given used for Vertical Gardens.

1. Self-clinging climbers (Generally no support needed. May need support on very smooth walls.) (Johnston and Newton 2004).

\begin{tabular}{|l|l|l|l|l|l|l|}
\hline SPECIES & $\begin{array}{l}\text { Decidius (D) } \\
\text { Evergreen (E) } \\
\text { Annual (A) }\end{array}$ & $\begin{array}{l}\text { ASPECT } \\
\text { Bold:preffered } \\
\text { Light:tolerated }\end{array}$ & $\begin{array}{l}\text { Growth } \\
\text { Rate }\end{array}$ & Soil & $\begin{array}{l}\text { Native } \\
\text { (N) } \\
\text { Exotic (E) }\end{array}$ & Speciality \\
\hline $\begin{array}{l}\text { Hedera } \\
\text { helix (fig 30) }\end{array}$ & E & N E S W & Slow & Rich & N & $\begin{array}{l}\text { Excellent wildlife plant. } \\
\text { Good nesting site for robins } \\
\text { and wrens, and hibernating } \\
\text { butterflies - esp. brimstone. } \\
\text { Nectar and pollen for bees } \\
\text { and hoverflies. }\end{array}$ \\
\hline $\begin{array}{l}\text { Parthenocissus } \\
\text { quinquefolia } \\
\text { (fig 30) }\end{array}$ & D & N E S W & Average & Any & E & $\begin{array}{l}\text { Useful for nesting birds if } \\
\text { grown on a trellis. Provides } \\
\text { nectar and pollen for bees. } \\
\text { May } \\
\text { attract nesting spotted } \\
\text { flycatcher. }\end{array}$ \\
\hline
\end{tabular}




\begin{tabular}{|l|l|l|l|l|l|l|}
\hline SPECIES & $\begin{array}{l}\text { Decidius (D) } \\
\text { Evergreen (E) } \\
\text { Annual (A) }\end{array}$ & $\begin{array}{l}\text { ASPECT } \\
\text { Bold:preffered } \\
\text { Light:tolerated }\end{array}$ & $\begin{array}{l}\text { Growth } \\
\text { Rate }\end{array}$ & Soil & $\begin{array}{l}\text { Native } \\
\text { (N) } \\
\text { Exotic (E) }\end{array}$ & Speciality \\
\hline $\begin{array}{l}\text { Parthenocissus } \\
\text { tricuspidata } \\
\text { fig 30) }\end{array}$ & D & N E S W & Fast & Any & E & \\
\hline $\begin{array}{l}\text { Hydrangea } \\
\text { petiolaris } \\
\text { (fig 31) }\end{array}$ & D & N E W & Average & $\begin{array}{l}\text { Loam } \\
\text { E }\end{array}$ & E & $\begin{array}{l}\text { Good for nesting birds and } \\
\text { produces nectar for bees and } \\
\text { other insects. }\end{array}$ \\
\hline $\begin{array}{l}\text { Euonymus } \\
\text { fortunei } \\
\text { (fig 31) }\end{array}$ & E & N E W & Slow & Any & E & \\
\hline
\end{tabular}
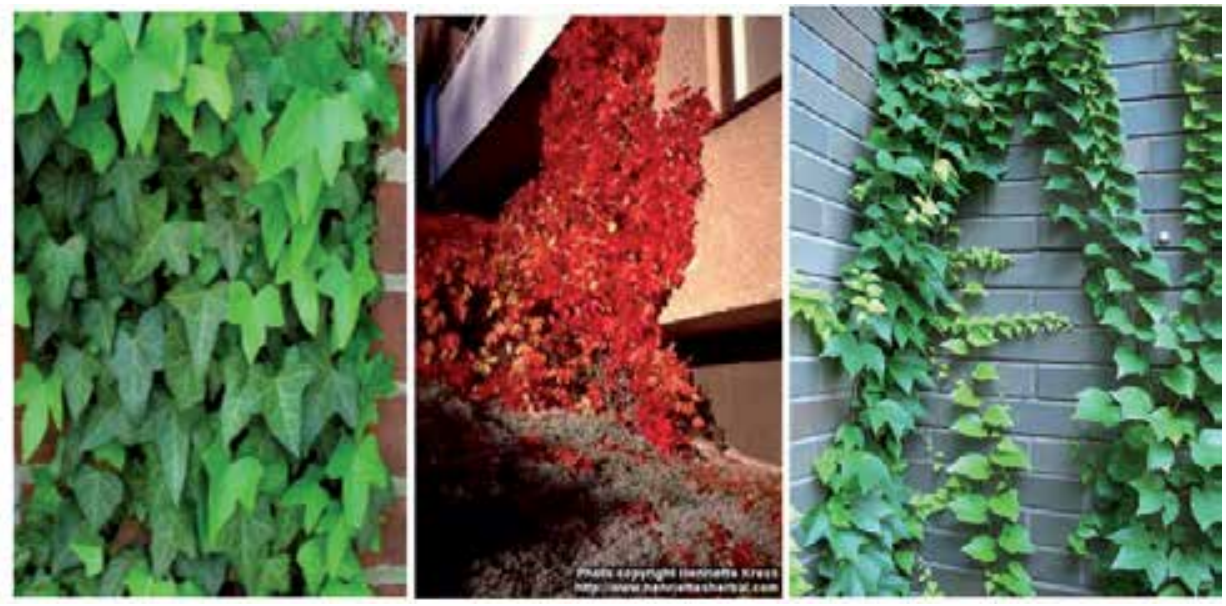

Figure 30. Hedera helix(left) (Erdoğan and Aliasghari Khabbazi 2012), Parthenocissus quinquefolia (bottom) (http://www.henriettesherbal.com 2013), Parthenocissus tricuspidata (right) (http://www.missouribotanicalgarden.org 2013)
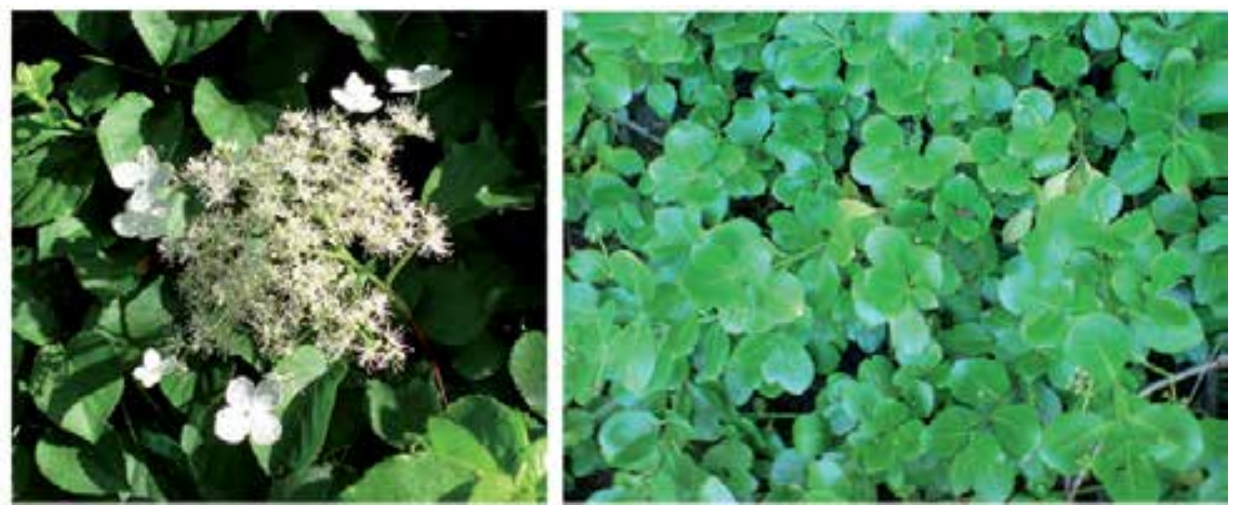

Figure 31. Hydrangea petiolaris (left) (http://www.gardenwithoutdoors.org.uk 2013), Euonymus fortunei (right) (http://commons.wikimedia.org 2013) 
2. Twining climbers (Suport needed. Thin steel wires, roughened plastic lines or timber battens running vertically will suffice for some species. Others will need a good network of wire or wooden trellis-work.) (Johnston and Newton 2004).

\begin{tabular}{|c|c|c|c|c|c|c|}
\hline SPECIES & \begin{tabular}{|l|} 
Decidius (D) \\
Evergreen \\
(E) \\
Annual (A)
\end{tabular} & \begin{tabular}{|l|} 
ASPECT \\
Bold:preffered \\
Light:tolerate \\
d
\end{tabular} & $\begin{array}{l}\text { Growth } \\
\text { Rate }\end{array}$ & Soil & \begin{tabular}{|l|} 
Native \\
$(\mathrm{N})$ \\
Exotic $(\mathrm{E})$
\end{tabular} & Speciality \\
\hline \begin{tabular}{|l|}
$\begin{array}{l}\text { Polygonum } \\
\text { bauldschianicum } \\
\text { (fig 32) }\end{array}$ \\
\end{tabular} & $\mathrm{D}$ & N E S W & Fast & Any & E & Good for nesting birds. \\
\hline $\begin{array}{l}\text { Lonicera } \\
\text { Periclymenum } \\
\text { (fig 32) }\end{array}$ & $\mathrm{D}$ & E S W & Average & $\begin{array}{l}\text { Good } \\
\text { Loam }\end{array}$ & $\mathrm{N}$ & $\begin{array}{l}\text { Must be kept bushy for } \\
\text { nesting birds. Excellent } \\
\text { for insects, especially } \\
\text { moths, due to } \\
\text { nightscented flowers. } \\
\text { Bark from older stems } \\
\text { used by nesting birds. } \\
\text { Berries eaten by birds. }\end{array}$ \\
\hline Lonicera spp. & D-E & N E S W & Average & $\begin{array}{l}\text { Good } \\
\text { Rich }\end{array}$ & E & $\begin{array}{l}\text { Several varieties are } \\
\text { useful nectar and seed } \\
\text { plants. } \\
\text { Evergreen honeysuckly } \\
\text { trained up a trellis makes } \\
\text { a good bird roosting site. }\end{array}$ \\
\hline $\begin{array}{l}\begin{array}{l}\text { Clematis vitalba } \\
\text { (fig 32) }\end{array} \\
\end{array}$ & D & E S W & Fast & $\begin{array}{l}\text { Prefers } \\
\text { Alkaline } \\
\end{array}$ & $\mathrm{N}$ & $\begin{array}{l}\text { Seeds for birds. Nesting } \\
\text { sites. Nectar for insects. }\end{array}$ \\
\hline Clematis spp. & $\mathrm{D}$ & E W & Fast & Various & E & $\begin{array}{l}\text { Useful nectar and/or seed } \\
\text { providers. Useful for } \\
\text { nesting sites if trained } \\
\text { thickly on a trellis. }\end{array}$ \\
\hline $\begin{array}{l}\text { Humulus } \\
\text { lupulus } \\
\text { (fig 33) }\end{array}$ & $\mathrm{D}$ & E S W & Fast & $\begin{array}{l}\text { Rich } \\
\text { moist }\end{array}$ & $\mathrm{N}$ & Good for bees. \\
\hline \begin{tabular}{|l|} 
Aristolochia spp. \\
(fig 33)
\end{tabular} & D & N S W & Average & Most & E & \\
\hline $\begin{array}{l}\text { Jasminum } \\
\text { officinale } \\
\text { (fig 33) }\end{array}$ & $\mathrm{D}$ & E W & Fast & $\begin{array}{l}\text { Well } \\
\text { drained }\end{array}$ & E & $\begin{array}{l}\text { Night-scented, attracting } \\
\text { moths and other night- } \\
\text { flying insects. }\end{array}$ \\
\hline $\begin{array}{l}\text { Vitis spp. } \\
\text { (fig 34) }\end{array}$ & D & E S W & $\begin{array}{l}\text { Average } \\
\text { Fast }\end{array}$ & $\begin{array}{l}\text { Rich } \\
\text { Loamy } \\
\text { Moist }\end{array}$ & E & $\begin{array}{l}\text { Provides fruit for birds } \\
\text { and nectar and pollen for } \\
\text { bees. }\end{array}$ \\
\hline $\begin{array}{l}\text { Wisteria spp } \\
\text { (fig 34) }\end{array}$ & D & E S W & Average & $\begin{array}{l}\text { Rich } \\
\text { Moist } \\
\text { Loam }\end{array}$ & E & $\begin{array}{l}\text { Excellent nectar and } \\
\text { pollen for bees. Can be } \\
\text { used by nesting. }\end{array}$ \\
\hline
\end{tabular}




\begin{tabular}{|c|c|c|c|c|c|c|}
\hline SPECIES & \begin{tabular}{|l} 
Decidius (D) \\
Evergreen \\
(E) \\
Annual (A) \\
\end{tabular} & \begin{tabular}{|l|} 
ASPECT \\
Bold:preffered \\
Light:tolerate \\
d
\end{tabular} & $\begin{array}{l}\text { Growth } \\
\text { Rate }\end{array}$ & Soil & \begin{tabular}{|l|} 
Native \\
$(\mathrm{N})$ \\
Exotic $(\mathrm{E})$
\end{tabular} & Speciality \\
\hline $\begin{array}{l}\text { Capsis radicans } \\
\text { (fig 34) }\end{array}$ & $\mathrm{D}$ & E S W & Slow & $\begin{array}{l}\text { Rich- } \\
\text { Well } \\
\text { drained }\end{array}$ & $E$ & \\
\hline $\begin{array}{l}\text { Passiflora } \\
\text { caerulea } \\
\text { (fig 35) }\end{array}$ & $\mathrm{D}$ & E S W & Fast & Any & E & $\begin{array}{l}\text { Nectar and pollen for } \\
\text { bees. }\end{array}$ \\
\hline $\begin{array}{l}\text { Lathyrus } \\
\text { odoratus } \\
\text { (fig 35) }\end{array}$ & A & $S W$ & Fast & $\begin{array}{l}\text { Rich } \\
\text { Well } \\
\text { drained }\end{array}$ & E & \\
\hline $\begin{array}{l}\text { Tropaeolum spp. } \\
\text { (fig 35) }\end{array}$ & Mainly A & E S W & Fast & Poor & $E$ & $\begin{array}{l}\text { Nectar/pollen for bees and } \\
\text { beetles. Seeds eaten by } \\
\text { birds and small } \\
\text { mammals. Food plant of } \\
\text { small and large white } \\
\text { butterflies. }\end{array}$ \\
\hline
\end{tabular}
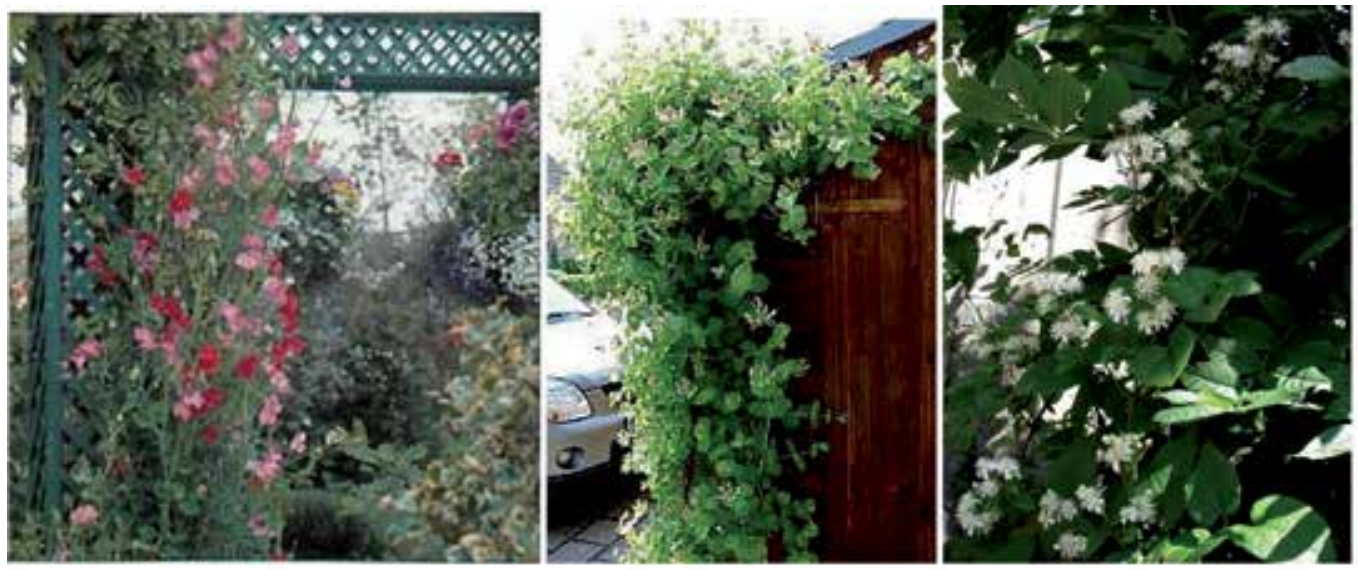

Figure 32. Polygonum bauldschianicum (left) (http://www.thegardeningbible.com 2013), Lonicera periclymenum (bottom) (http://www.about-garden.com 2013), Clematis vitalba (right) (http://www.phytoimages.siu.edu 2013) 

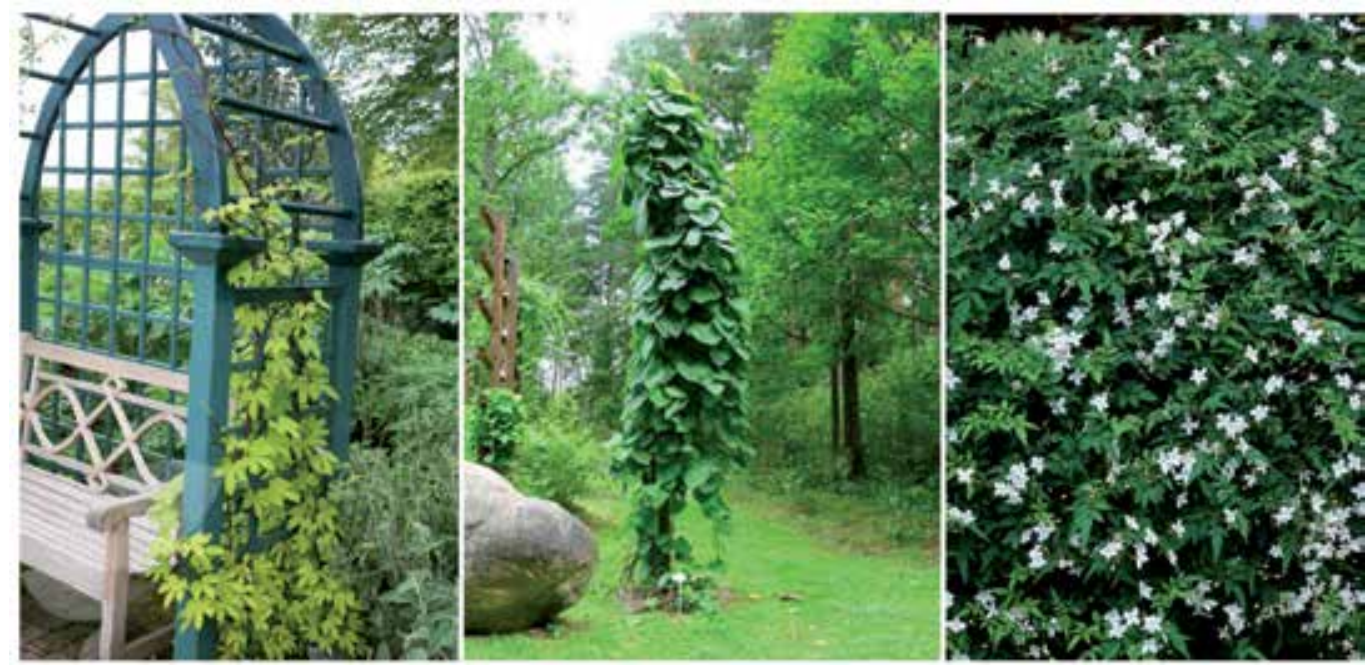

Figure 33. Humulus lupulus (left) (http://www.crocus.co.uk 2013), Aristolochia macrophylla (bottom) (http://www.pfaf.org 2013), Jasminum officinale (right) (http://www.gardenersworld.com 2013).

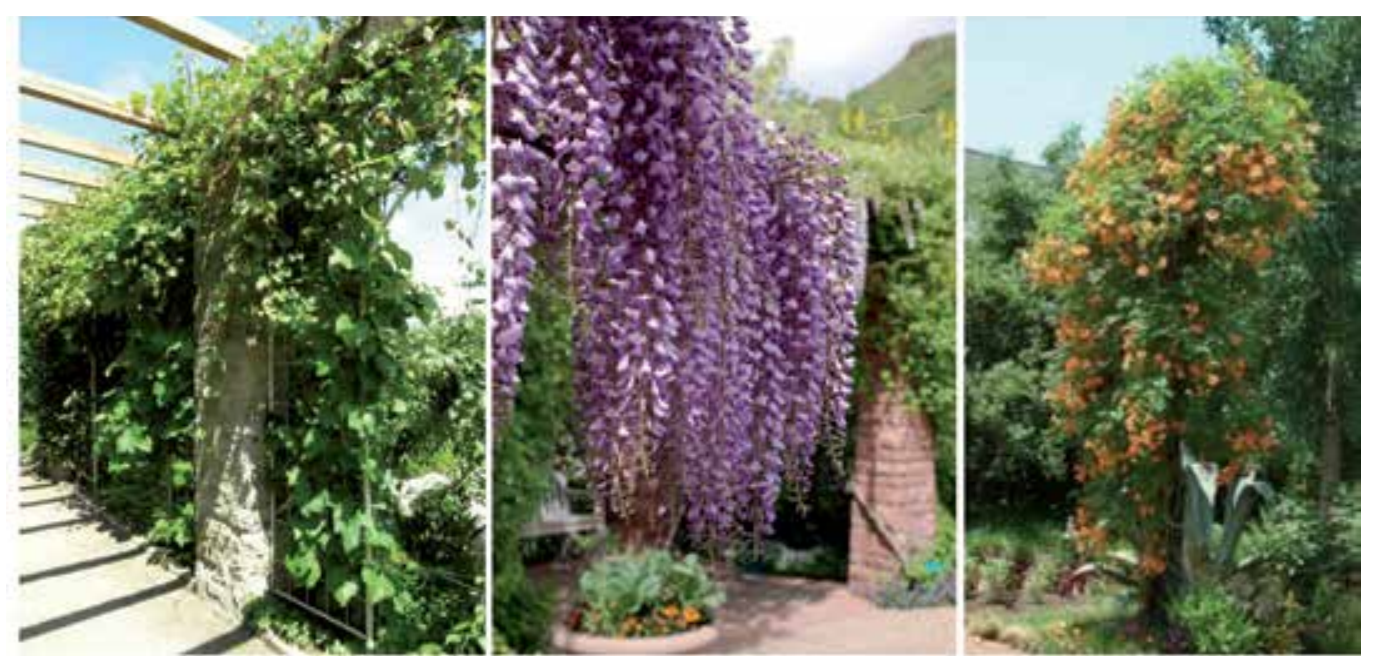

Figure 34. Vitis amurensis (left) (http://luirig.altervista.org 2013), Wisteria floribunda (bottom)

(http://www.redbuttegarden.org 2013), Capsis radicans (right) (http://www.dhz-tuinwinkel.nl 2013). 

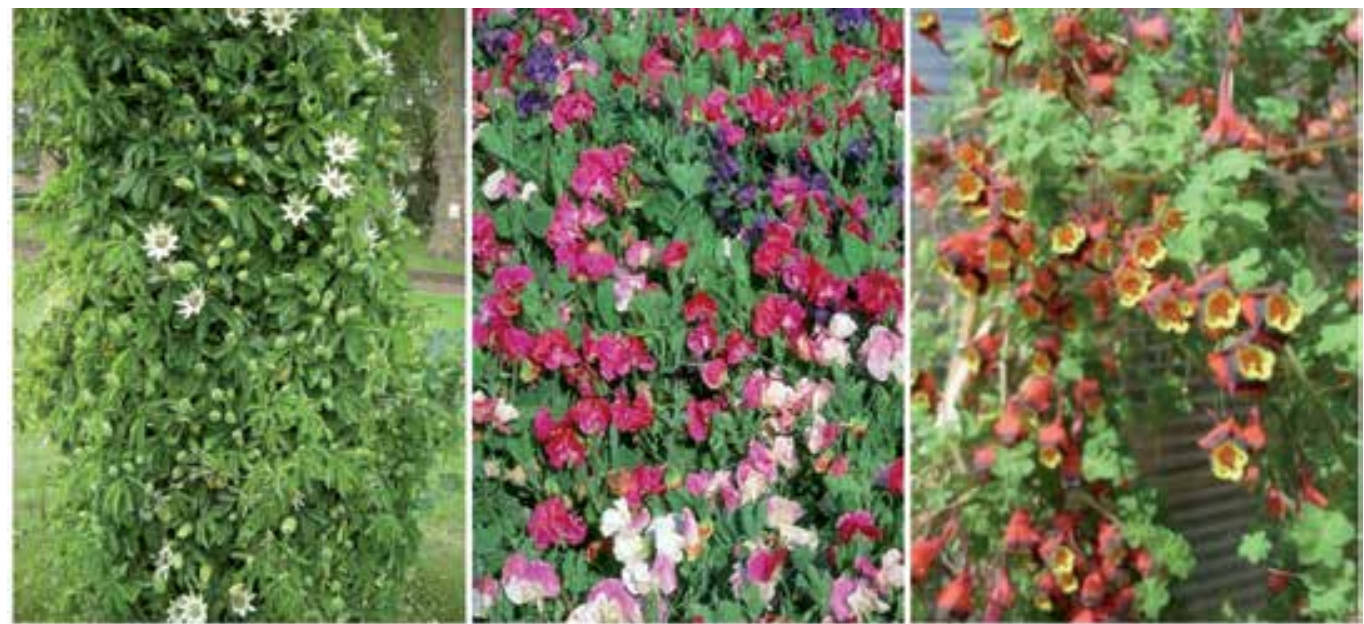

Figure 35. Passiflora caerulea (left) (http://davisla.wordpress.com 2013), Lathyrus odoratus(bottom) (http://loghouseplants.com 2013), Tropaeolum tricolorum (right) (http://www.anythinggarden.co.uk 2013).

3. Rambling shrubs (Not true climbers but can be trained on wide meshed grid structures or by tying to wall.) (Johnston and Newton 2004).

\begin{tabular}{|c|c|c|c|c|c|c|}
\hline SPECIES & $\begin{array}{l}\text { Decidius (D) } \\
\text { Evergreen } \\
(\text { E) } \\
\text { Annual (A) }\end{array}$ & $\begin{array}{l}\text { ASPECT } \\
\text { Bold:preffered } \\
\text { Light:tolerated }\end{array}$ & $\begin{array}{l}\text { Growth } \\
\text { Rate }\end{array}$ & Soil & $\begin{array}{l}\text { Native (N) } \\
\text { Exotic (E) }\end{array}$ & Speciality \\
\hline $\begin{array}{l}\text { Rubus fruiticous } \\
\text { (fig 36) }\end{array}$ & $E$ & NESW & Average & $\begin{array}{l}\text { Most } \\
\text { Like } \\
\text { asid }\end{array}$ & $\mathrm{N}$ & $\begin{array}{l}\text { Provides pollen for bees } \\
\text { and nectar for bees and } \\
\text { butterflies. Berries for } \\
\text { birds and small } \\
\text { mammals, Night- } \\
\text { scented and attracts } \\
\text { moths. } \\
\end{array}$ \\
\hline $\begin{array}{l}\text { Jasminum } \\
\text { nodiflorum } \\
\text { (fig 36) }\end{array}$ & D & N S W & Average & Most & E & \\
\hline $\begin{array}{l}\text { Rosa canina } \\
\text { (fig 36) }\end{array}$ & $\mathrm{D}$ & E S W & Average & Good & $\mathrm{N}$ & $\begin{array}{l}\text { Night-scented for } \\
\text { moths. Nectar for } \\
\text { insects, rosehips for } \\
\text { birds and small } \\
\text { mammals. } \\
\text { Good nesting cover for } \\
\text { birds. } \\
\end{array}$ \\
\hline Rosa spp. & $\mathrm{D}$ & E S W & Average & Most & $\mathrm{E}$ & $\begin{array}{l}\text { Excellent nectar for } \\
\text { bees. Nesting sites for } \\
\text { birds. }\end{array}$ \\
\hline
\end{tabular}




\begin{tabular}{|l|l|l|l|l|l|l|}
\hline SPECIES & $\begin{array}{l}\text { Decidius (D) } \\
\text { Evergreen } \\
\text { (E) } \\
\text { Annual (A) }\end{array}$ & $\begin{array}{l}\text { ASPECT } \\
\text { Bold:preffered } \\
\text { Light:tolerated }\end{array}$ & $\begin{array}{l}\text { Growth } \\
\text { Rate }\end{array}$ & Soil & $\begin{array}{l}\text { Native (N) } \\
\text { Exotic (E) }\end{array}$ & Speciality \\
\hline $\begin{array}{l}\text { Forsythia } \\
\text { suspensa (fig 37) }\end{array}$ & D & N E S W & Average & Most & E & $\begin{array}{l}\text { Nesting sites for birds, } \\
\text { as above }\end{array}$ \\
\hline $\begin{array}{l}\text { Cotoneaster spp. } \\
\text { (fig 37) }\end{array}$ & $\begin{array}{l}\text { D } \\
\text { Some E }\end{array}$ & N E & Slow & Any & E & $\begin{array}{l}\text { Thick growth may be } \\
\text { used by nesting } \\
\text { blackbirds and tbrushes. } \\
\text { Berries for birds, } \\
\text { especially blackbirds } \\
\text { and small mammals. } \\
\text { Nectar and pollen for } \\
\text { bees. }\end{array}$ \\
\hline $\begin{array}{l}\text { Pyracantha } \\
\text { atalantiodes } \\
\text { (fig 37) }\end{array}$ & E & E S W & Slow & $\begin{array}{l}\text { Most } \\
\text { Well } \\
\text { drain } \\
\text { ed }\end{array}$ & E & $\begin{array}{l}\text { Good for nesting birds } \\
\text { e.g. thrushes, and } \\
\text { provides nectar and } \\
\text { pollen for bees and } \\
\text { berries for birds, } \\
\text { particularly blackbirds. }\end{array}$ \\
\hline
\end{tabular}
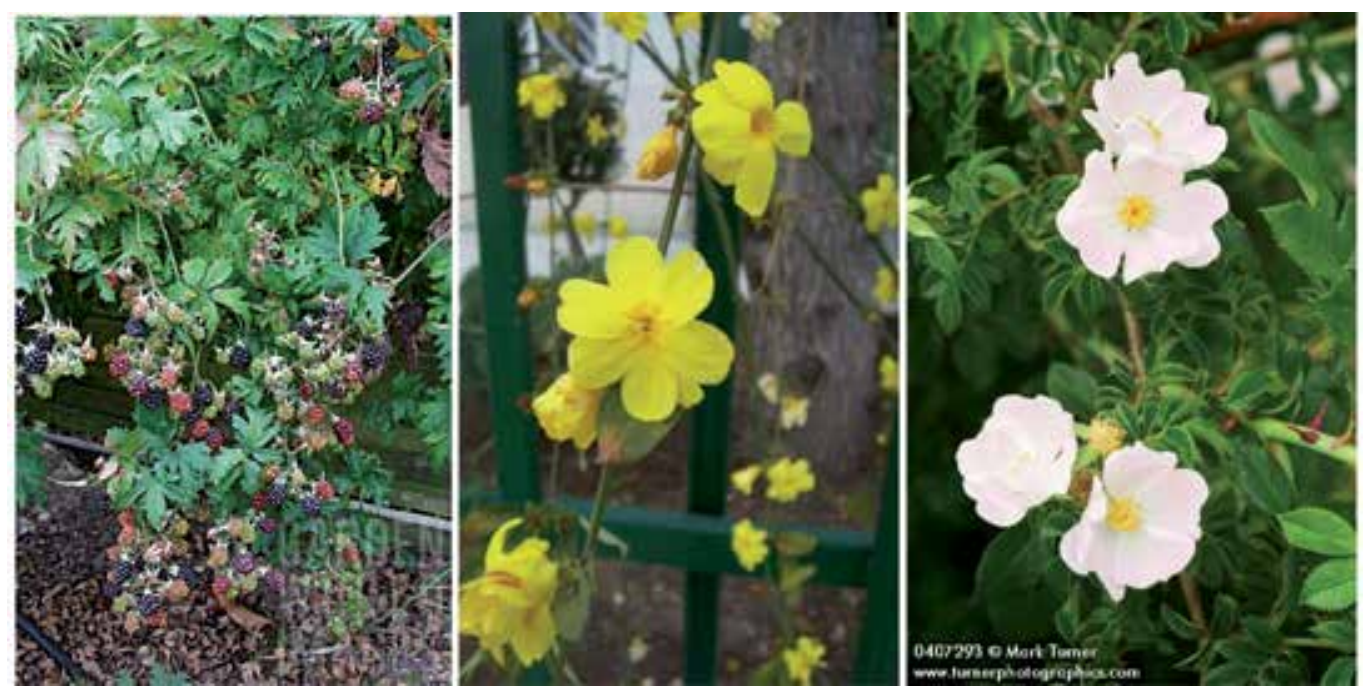

Figure 36. Figure 36. Rubus fruiticous (left) (http://www.gardenworldimages.com 2013), Jasminum nodiflorum (bottom) (http://digilander.libero.it 2013), Rosa canina (right) (http://www.pnwflowers.com 2013). 

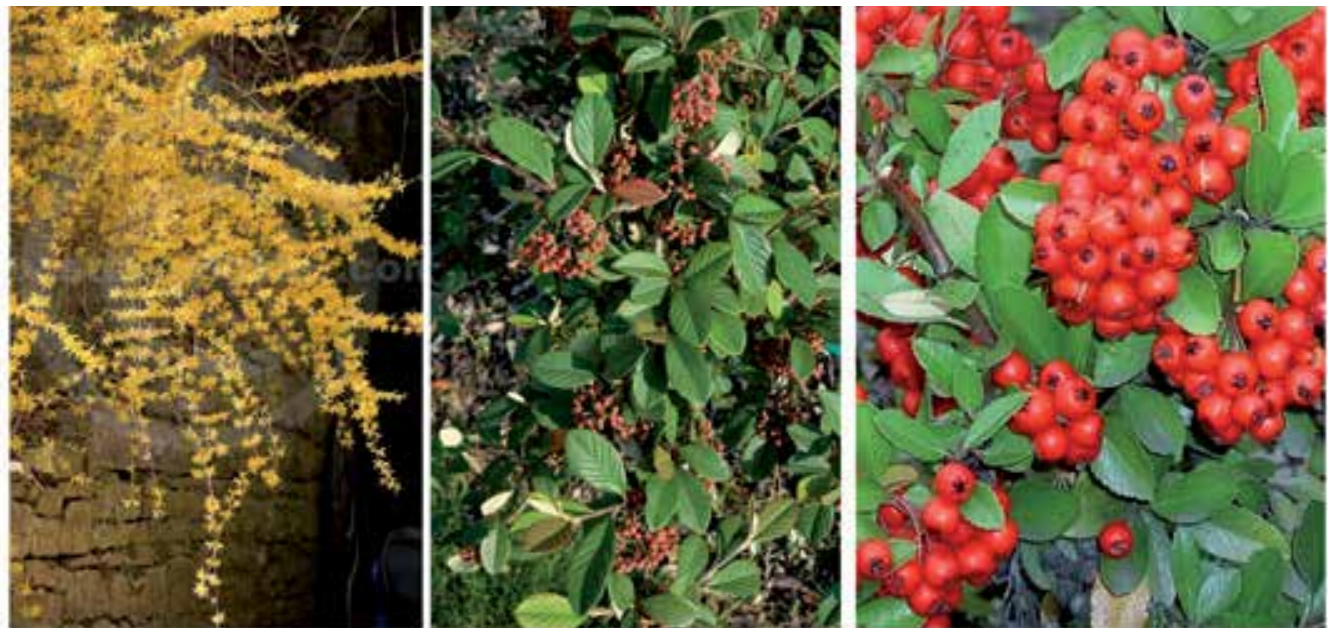

Figure 37. Forsythia suspensa (left) (http://www.stevenfoster.com 2013), Cotoneaster lacteus (bottom) (http://commons.wikimedia.org 2013), Pyracantha atalantiodes (right) (http://www.ebay.co.uk 2013).

Other typical plants for Vertical Gardens:

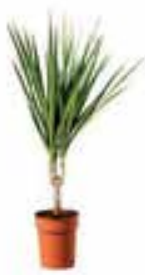

Dracansa nurginasa

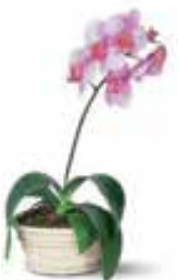

Phalaenopis spp

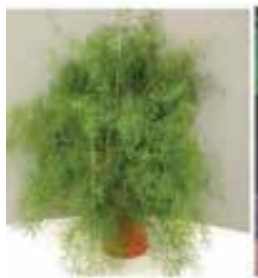

Asparagws spremeri

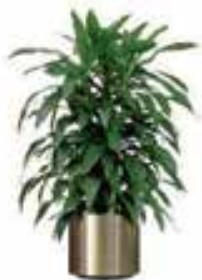

Dracoena warmeckit

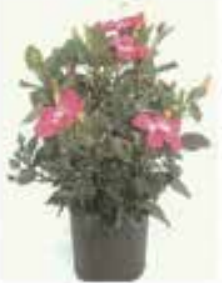

Mbiscus spp

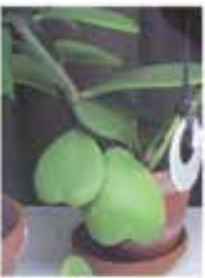

Hogr Aermii

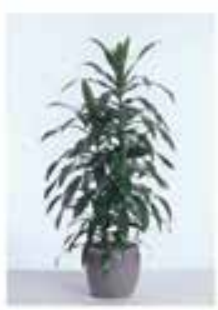

Drasaema crally

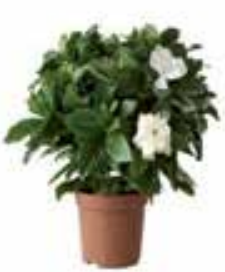

Gankenia spo

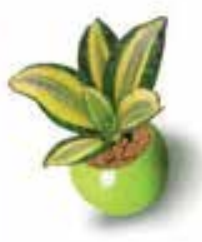

Sanseviaria hand
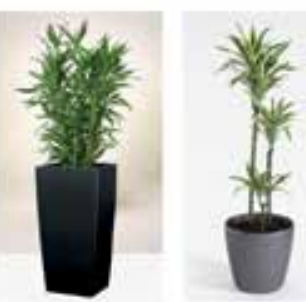

Draanena samderiana Dracucha dremewsis
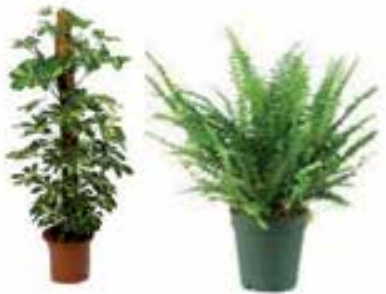

Schefleng spap.

Nephnolepsis spa
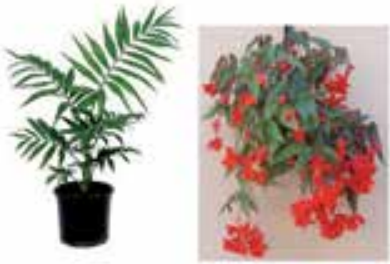

Chamacdares elcgums 

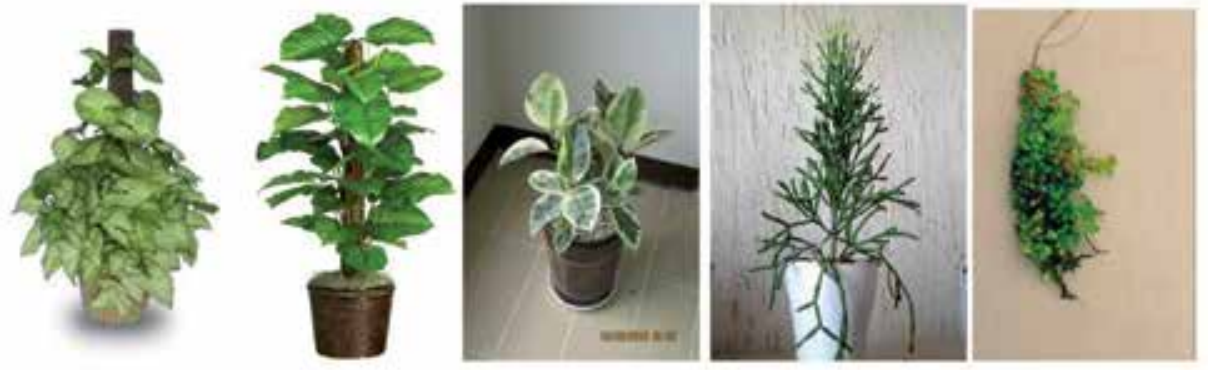

Synganium podioplyllam Philadendrown gigaunteum

Ficus elastica

Hariowa salicumioides

Solcirolia seleinolii
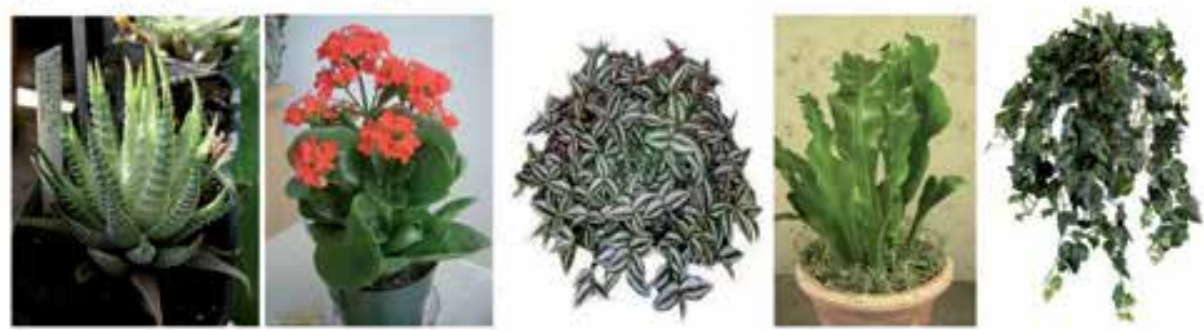

Haworthia atteniata

Kalanchoe spp.

Tradescamia sebrina

Aspleninum nidus

Chloropingram spon
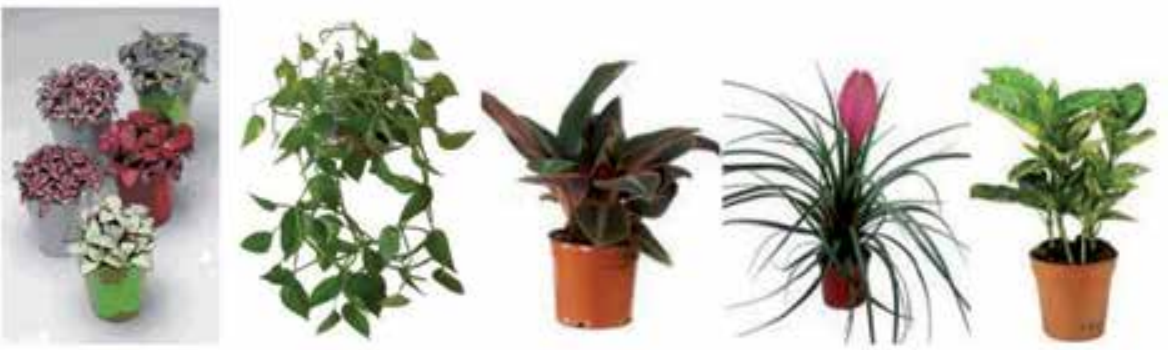

Fitonia spp.

Scindapsus anrews

Siderasis spp

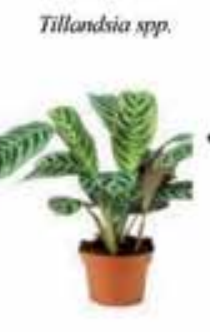

Chenouthe spp

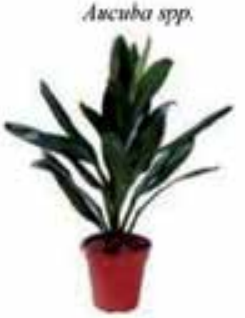

Corctylime spp.

Figure 38. Plants for Vertical Gardens (http://www.ebay.com 2013, http://www.lillealternativet.no 2013, http://www.dracaena.com 2013, http://www.ikea.com 2013, http://www.agaclar.net 2013, http://www.cicekstra.com 2013, http://www.jrexotic.com 2013, http://www.krischanphoto.com 2013, http://hobibahcemiz.net 2013, http://www.csi.eu.com 2013, http://www.flowershopnetwork.com 2013, http://nathistoc.bio.uci.edu 2013, http://www.vert-espace.fr 2013, http://commons.wikimedia.org 2013, http://www.johnstowngardencentre.ie 2013, http://www.yaban.gen.tr 2013, http://ru.wikipedia.org 2013,http://www.kaliteliresimler.com 2013, http://www.doriangreen.fr 2013, http://fr.questmachine.org 2013, http://www.floweroffice.cz 2013, http://princelandscape.com 2013, http://tuteka.wordpress.com 2013). 


\section{Applications from Turkey}

Vertical Gardens applications have been just started as a new trend by Municipalities in Turkey. Applications are continued in a lot of cities such as İstanbul, Antalya, Balıkesir, Rize.

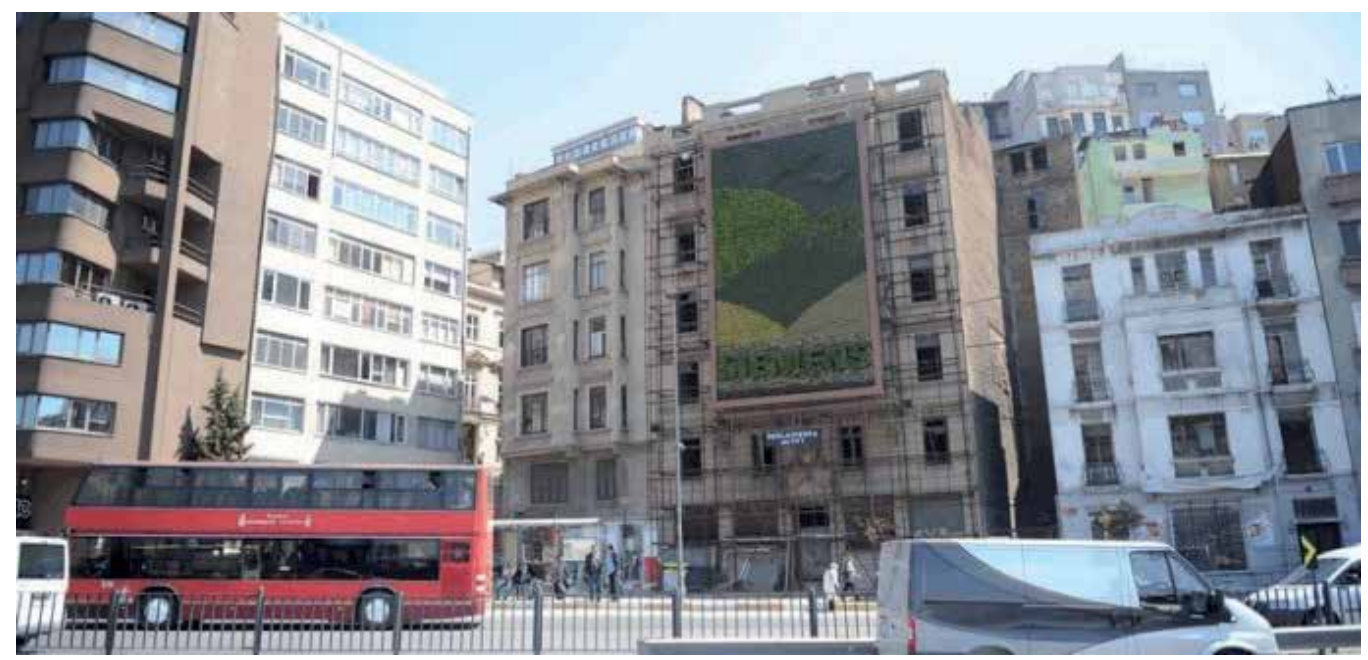

Figure 39. İstanbul Siemens Building (http://tuketicidostu.net 2013).

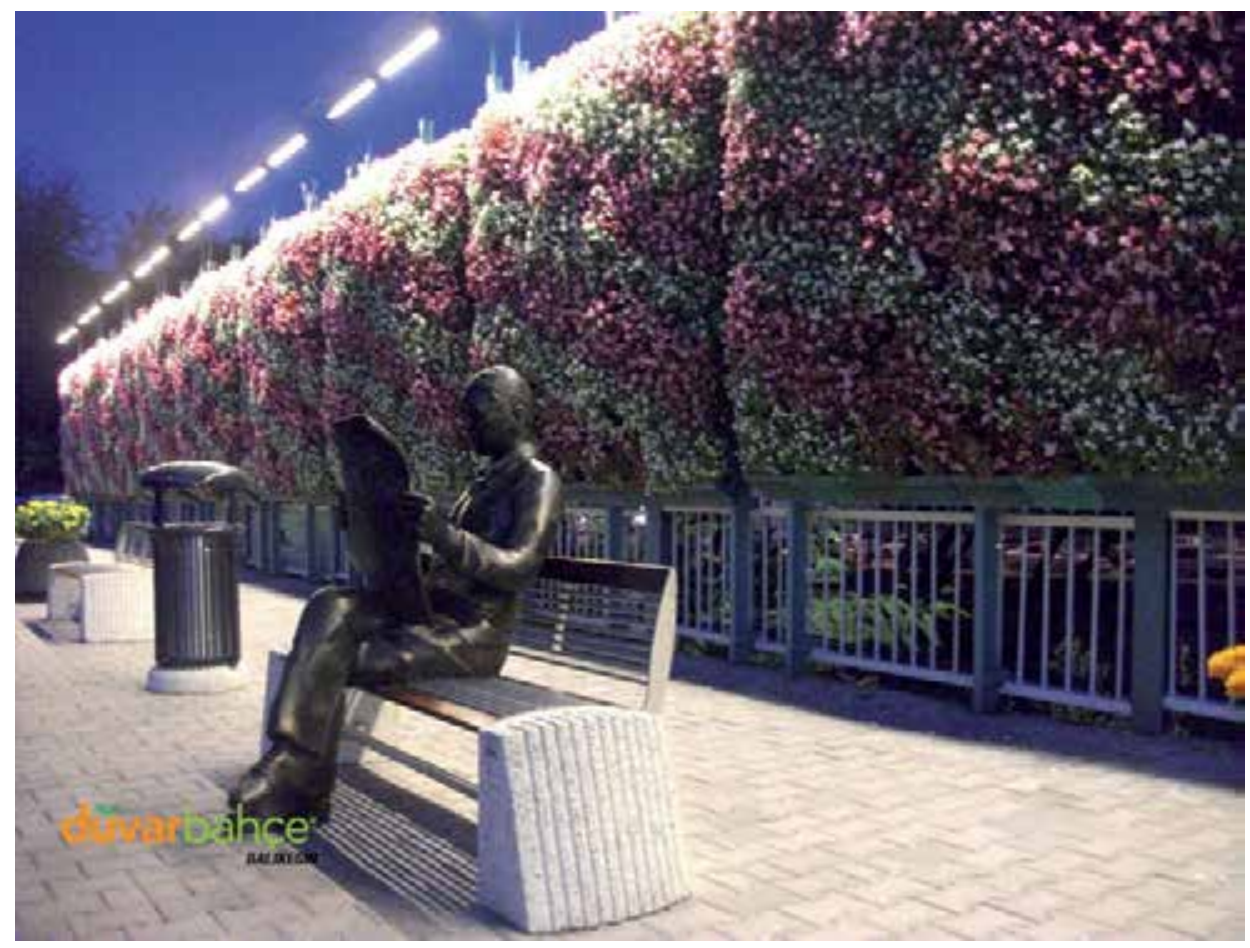

Figure 40. Application from Balıkesir (http://www.aktasplant.com 2013). 

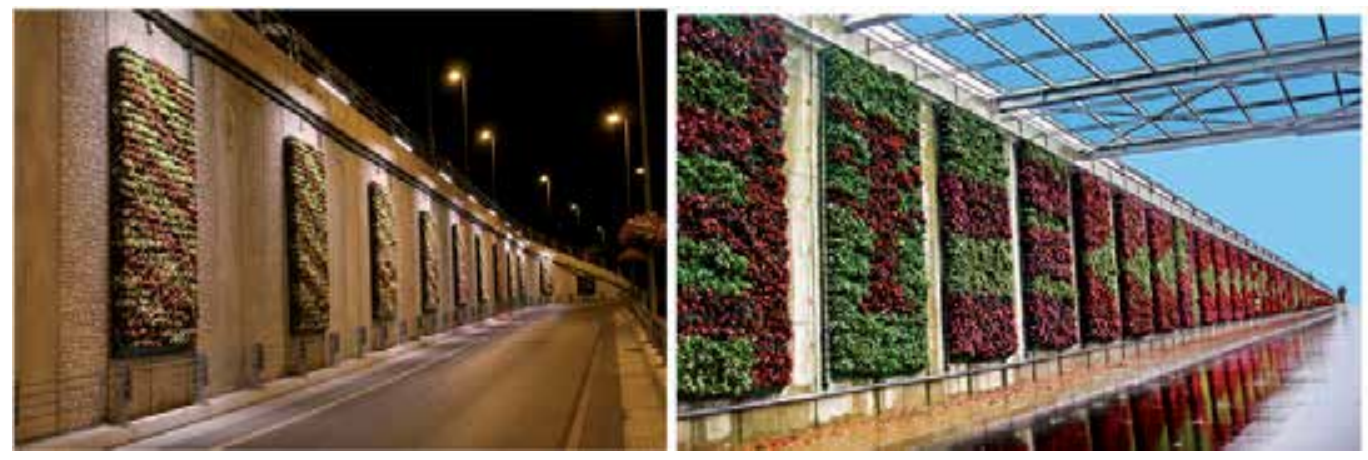

Figure 41. İstanbul airport roadside (left), Antalya airport roadside (right) (http://www.aktasplant.com 2013).

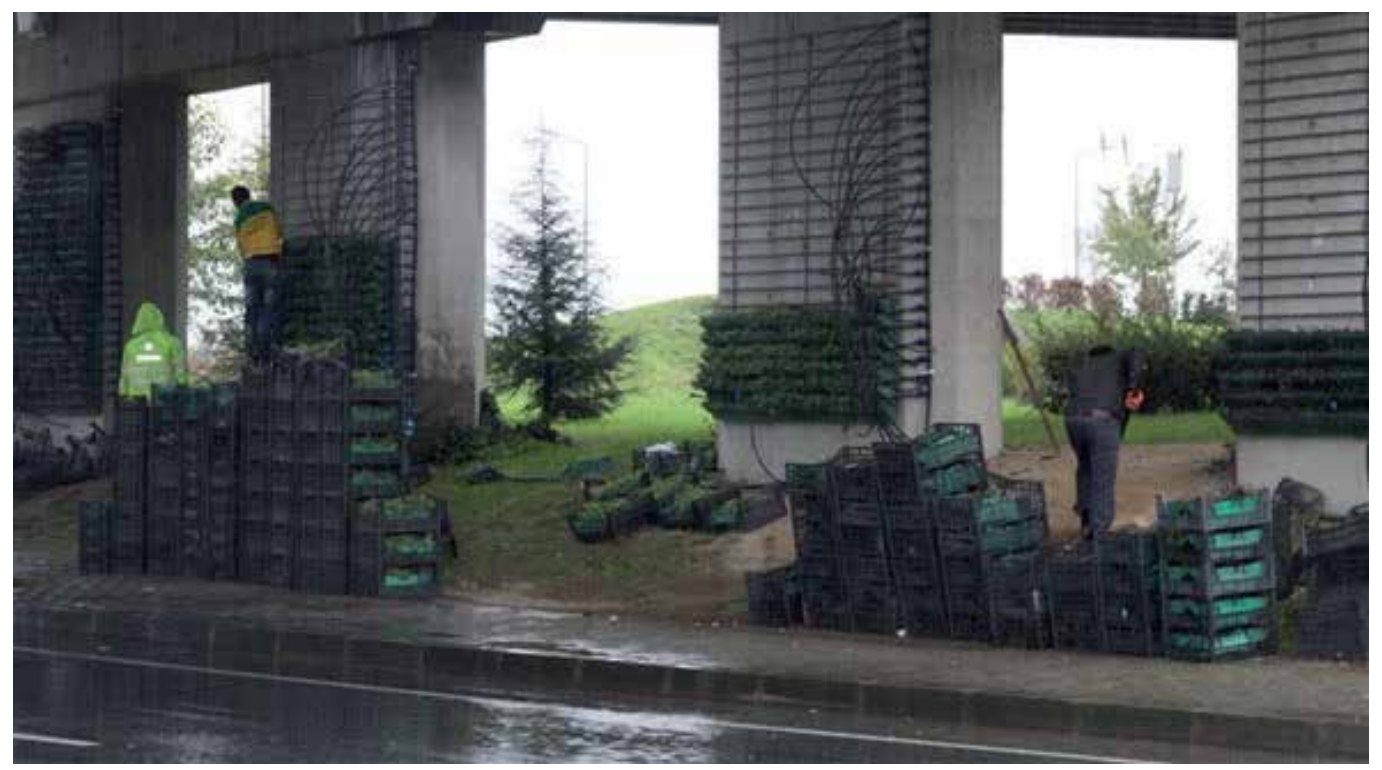

Figure 42. Viaduct pillars from Rize (http://www.zaman53.com 2013).

\section{Author details}

Özgür Burhan Timur

Çankırı Karatekin University, Faculty of Forestry, Department of Landscape Architecture, Çankırı, Turkey

Elif Karaca

Çankırı Karatekin University, Kızllırmak Vocational School, Department of Landscape, Turkey 


\section{References}

Baumann, I.R. 1986. The Constructural Importance of Climbing Plants.

Doernach, R. 1979. Uber den Nutzungen von Biotektonischen Grunsystemen. Garten und Landschaft 89(6)

Dunnett NP, Kingsbury N. 2004. Planting Green Roofs and Living Walls. Portland (OR): Timber Press.

Erdoğan, E., Aliasghari Khabbazi, P. 2013. Yapı Yüzeylerinde Bitki Kullanımı, Dikey Bahçeler ve Kent Ekolojisi, Türk Bilimsel Derlemeler Dergisi 6(1) ISSN: 1308-0040

Fjeld,T., Veiersted,B., Sandvik,1., Riise, G. \& Levy, F. 1998. The Effect of Indoor Foliage Plants on Health and Discomfort Symptoms among Office Workers. Indoor and Built Environment, 7(204)

Gilhooley,M. 2002. Green green grass of work: a little bit of green can go a long way, and we aren't talking about money. Facilities Design and Management.

http://www.iuoe.org

Gonchar, J. 2009. Vertical and verdant, living wall systems sprout on two buildings, in Paris and Vancouver, Architectural Record, McGraw-Hill Construction.

http://archrecord.construction.com/features/digital/archives/0702dignews-1.asp

Green roofs for healthy cities. 2008. Introduction to green walls technology, benefits and design. Retrieved from

http://www.greenscreen.com/Resources/download_it/IntroductionGreenWalls.pdf.

Green Roof Organization, 2008. Introduction to Green Walls Technology, Benefits \& Design. Jacobs, H. 2008. Green Plants for Green Buildings, http://greenplantsforgreenbuildings.org/about.htm

Johnston, J., Newton, J. 2004. Building Green "A guide to using plants on roofs, walls and pavements", Greater London Authority. London ISBN: 1852616377

Kemaloğlu, A. Yılmaz, O. 1991. Cephe Yeşillendirmesinin Kent Ekolojisine Katkıları. Peyzaj Mimarlığ Dergisi, Cilt 2, Sayı 30

Kim, K.S.J.W. 2011. An Investigation into the Application of Vertical Garden at the New SUB Atrium. The University of British Columbia

Köhler, M. 2008. Green Facades-A view back and some visions, Urban Ecosystem. Vol 11 p.423-436

Ottele, M., van Bohemen, H. \& Fraaij, A. 2010. Quantifying the Deposition of Particulate Matter on Climber Vegetation on Living Walls. Ecological Engineering, Volume 36, p 154-182

Peck, S., Callahan, C., Kuhn, M., and Bass, B., 1999. Greenbacks from Green roofs: Forging a New Industry in Canada, CMHC, Toronto.

Sharp,R. 2007. "6 Things You Need to Know About Green Walls", Building Design and Construction, BD\&C News, Web Article, http://www.bdcnetwork.com/article/CA6459410.html 
Thompson, J.W. and Sorving, K. 2000. Sustainable Landscape Construction, A Guide to Green Building Outdoors. Island Press, Washington D.C. p.105-131

Truett, R. 2003. 'Biofilters'. Furbish Company, Sustainable Building, http://www.furbishco.com/products/biofilters

Wolf, K.L. 2002. Retail and Urban Nature: Creating a Consumer Habitat", at the People/Plant Symposium, Amsterdam.

http://www.plantsinbuildings.com/whyplants.php?PHPSESSID=e653e7b957ce5bc2b6f

Wong, N. H., Tan, A.Y., Tan, P.Y., Chiang, K. \& Wong, N.C. 2010. Acoustics Evolution of Vertical Greenery Systems for Building Walls. Building and Environment, Volume 45

Yamada, H. 2008. How is energy usage reduced by green roof and walls, Gsky, Eco Innovations Inc. Engineering Department, Wakayama University. http://www.gsky.com/Benefits_EnergySavings_Detailed.aspx

Yeh, Y.P. 2012. Green Wall-The Creative Solution in Response to the Urban Heat Island Effect. National Chung-Hsing University

\subsection{References from web sites}

http://blog.phyllisodessey.com/2011/03/power-to-plants.html, Access: January 2013.

http://christianbarnardblog.blogspot.com/2009/05/mfo-park-zurich-switzerland.html,

Access: January 2013.

http://commons.wikimedia.org/wiki/File:MFO-Park_Oerlikon_2010-10-03_14-05-

08_ShiftN.jpg , Access: January 2013.

http://commons.wikimedia.org/wiki/File:Cotoneaster_lacteus_F.jpg, Access: January 2013.

http://commons.wikimedia.org/wiki/File:(Benved)_Euonymus_fortunei.JPG, Access: January

2013.

http://commons.wikimedia.org/wiki/File:Hoya_kerrii_with_stems.jpg, Access: January 2013. http://davisla.wordpress.com/2012/07/23/plant-of-the-week-passiflora-caerulea/, Access:

January 2013.

http://digilander.libero.it/felrig/photos/jasminum_nudiflorum.htm, Access: January 2013.

http://fr.questmachine.org/wiki/Chamaedorea_\%C3\%A9lev\%C3\%A9_ou_palmier_de_mont

agne_(Chamaedorea_elegans),_famille_des_Ar\%C3\%A9cac\%C3\%A9es, Access: January 2013.

http://greenwallandroof.wordpress.com/2011/11/17/green-facades-in-chile, Access: January

2013.

http://hobibahcemiz.net/viewtopic.php?f=39\&t=8344, Access: January 2013.

http://gsky.com/green-walls/benefits/building-protection/, Access: January 2013.

http://gsky.com/green-walls/benefits/energy-savings, Access: January 2013.

http://gsky.com/green-walls/benefits/health/, Access: January 2013.

http://gsky.com/green-walls/benefits/sound/, Access: January 2013.

http://gsky.com/green-walls/benefits/wildlife, Access: January 2013. 
http://inhabitat.com/dom-aquitectura-designs-green-master-plan-for-huizhou-china-toclean-air-and-reduce-pollution/, Access: January 2013.

http://isites.harvard.edu/icb/icb.do?keyword=k77982\&pageid=icb.page552704,

Access:

January 2013.

http://loghouseplants.com/plants/shop/lathyrus-odoratus-bijou-dwarf-sweet-pea/, Access:

January 2013.

http://luirig.altervista.org/schedenam/fnam.php?taxon=Vitis+amurensis, Access: January 2013.

http://nathistoc.bio.uci.edu/Plants\%20of\%20Upper\%20Newport\%20Bay\%20(Robert\%20De\%

20Ruff)/Urticaceae/Soleirolia\%20soleirolii.htm, Access: January 2013.

http://pinterest.com/caddetails/organic-architecture/, Access: January 2013.

http://pixpeedia.blogspot.com/2011/12/vertical-gardens-of-patrick-blanc.html,

Access:

January 2013.

http://preprodtest.archdaily.com/category/offices/page/28/, Access: January 2013.

http://princelandscape.com/onlineshop/by-categories/self-watering-plants/draceana-

sanderana-in-designer-planter.html, Access: January 2013.

http://purpleopurple.com/tourism/Architectural-wonders/hanging-gardens-of-babylon.jpg

2012, Access: January 2013.

http://retailsquare.blogspot.com/2010_11_01_archive.html, Access: January 2013.

http://ru.wikipedia.org/wiki/\%D0\%A4\%D0\%B0\%D0\%B9\%D0\%BB:Scindapsus_aureus_clean

ed.jpg, Access: January 2013.

http://tuketicidostu.net/haberler/odul/dikey-bahceler-projesi-siemense-felis-odulu-getirdi/,

Access: January 2013.

http://tuteka.wordpress.com/varios/asparagus20sprengeri/, Access: January 2013.

http://twistedsifter.com/2011/10/incredible-vertical-gardens-patrick-blanc/, Access: January

2013.

http://www.about-garden.com/se/en/fotoa-lonicera/, Access: January 2013.

http://www.agaclar.net/forum/kaktus/29357.htm, Access: January 2013.

http://www.agaclar.net/forum/orkide/3512.htm, Access: January 2013.

http://www.aktasplant.com/duvar-bahce.html, Access: January 2013.

http://www.anythinggarden.co.uk/plants-for-winter-winter-plants-discovered/tropaeolum-

tricolorum/, Access: January 2013.

http://www.archdaily.com/16863/ex-ducati-mario-cucinella-architects/869559981_mca-ex-

ducati-gallery-with-grid-for-climbing-plants-domenicali, Access: January 2013.

http://www.cicekstra.com/schefflera-gold-capella-semsiye-agaci.html, Access: January 2013. http://www.crocus.co.uk/plants/_/climbers/other-climbers/classid.1664/, Access: January

2013.

http://www.csi.eu.com/plants.aspx?range=1, Access: January 2013.

http://www.dezeen.com/2012/07/09/stacking-green-by-vo-trong-nghia/ 
http://www.dhz-tuinwinkel.nl/a-22351278/klimplanten/capsis-radicans-flamenco/, Access: January 2013.

http://www.doriangreen.fr/plante-magnetique-sanseveria-panache,fr,4,PM008.cfm, Access: January 2013.

http://www.dracaena.com/dracaena-warneckii.php, Access: January 2013.

http://www.ebay.com/itm/SILK-Philodendron-PALM-PLANT-REAL-TOUCH-Philo-51-

/140548436201, Access: January 2013.

http://www.ebay.co.uk/itm/2-PYRACANTHA-FIRE-THORN-ATALANTIODES-GARDEN-

SHRUB-PLANT-

/170860523301?pt=UK_HomeGarden_Garden_PlantsSeedsBulbs_JN\&hash=item27c814a

f25, Access: January 2013.

http://www.environmentalgraffiti.com/ecology/15-living-walls-vertical-gardens-sky-

farms/1202?image=23, Access: January 2013.

http://www.examiner.com/article/green-walls-take-planting-to-another-dimension, , Access:

January 2013.

http://www.eyeonspain.com/blogs/luislopezcortijo/8528/vertical-garden-in-spain.aspx,

Access: January 2013.

http://www.floweroffice.cz/aktnab.htm, Access: January 2013.

http://www.flowershopnetwork.com/blog/variegated-plant/ficus-elastica-variegata/, Access:

January 2013.

http://www.gardenwithoutdoors.org.uk/?q=taxonomy/term/39, Access: January 2013.

http://www.gardenersworld.com/plants/jasminum-officinale/3284.html, Access: January

2013.

http://www.gardenworldimages.com/Details.aspx?ID=29383\&TypeID=1，Access: January

2013.

http://www.greenecowalls.com/benefits_airquality.html, Access: January 2013.

http://www.greenecowalls.com/benefits_environmental_greywater.html, Access: January

2013.

http://www.greenology.sg/2011/11/benefits-of-vertical-greening-a-discussion,

Access:

January 2013.

http://www.greenroofs.com/projects/pview.php?id=1457, Access: January 2013.

http://www.greenthinkers.org/blog/2007/03/canada_blooms_elt_easy_green_r.html, Access:

January 2013.

http://www.henriettesherbal.com/pictures/p10/pages/parthenocissus-quinquefolia-6.htm,

Access: January 2013.

http://www.homeimprovementpages.com.au/article/environmental_benefits_for_vertical_g

ardens\#ixzz2EwQvIPZG, Access: January 2013.

http://www.ikea.com/us/en/catalog/products/56804359/, Access: January 2013.

http://www.ikea.com/us/en/catalog/products/80177170/, Access: January 2013. 
http://www.johnstowngardencentre.ie/fittonia--snakeskin-plant/fittoniapd.aspx, Access: January 2013.

http://www.jrexotic.com/library.html\#thumb, Access: January 2013.

http://www.landscapeonline.com/products/listing.php?id=11441, Access: January 2013.

http://www.landscape-design-advisor.com, Access: January 2013.

http://www.landscapeurbanism.blogspot.com, Access: January 2013.

http://www.lillealternativet.no/helse-a-miljo/inneklima/planteoversikt/19-helse-a-miljo/78-

syngonium-podophyllum, Access: January 2013.

http://www.livingwallart.com/category/vertical-garden-installations 2012, Access: January

2013.

http://www.lsgi.polyu.edu.hk/geomatics/article/urban_heat_island_from_satellite_images.ht ml, Access: January 2013.

http://www.kaliteliresimler.com/img7895.htm, Access: January 2013.

http://www.kaskus.co.id/thread/000000000000000000916973, Access: January 2013.

http://www.krischanphoto.com/gardens/fern/tropical/tropical.htm, Access: January

2013.

http://www.marthastewart.com/265725/vertical-gardens-or-living-walls, Access: January

2013.

http://www.missouribotanicalgarden.org/gardens-gardening/your-garden/plant-

finder/plant-details/kc/c882/parthenocissus-tricuspidata-fenway-park.aspx,

Access:

January 2013.

http://www.museumofthecity.org, Access: January 2013.

http://www.nodai.ac.jp/cip/iss/english/9th_iss/fullpaper/3-1-4nchu-yupengyeh.pdf, Access:

January 2013.

http://www.pfaf.org/user/Plant.aspx?LatinName=Aristolochia+macrophylla,

Access:

January 2013.

http://www.phytoimages.siu.edu/imgs/pelserpb/r/Ranunculaceae_Clematis_vitalba_15594.h

tml, Access: January 2013.

http://www.pnwflowers.com/flower/rosa-canina, Access: January 2013.

http://www.redbuttegarden.org/node/262, Access: January 2013.

http://www.ssbx.org/images/projects/heat_island_big.gif, Access: January 2013.

http://www.stevenfoster.com/photography/imageviewsf/forsythia/suspensa/fs10401110/con

tent/Forsythia_suspensa_4110431_large.html, Access: January 2013.

http://www.thegardeningbible.com/plants-for-the-pergola, Access: January 2013.

http://www.vancouversun.com/homes/Transforming+ugly+concrete+walls+into+beautiful+v

ertical+gardens/5107779/story.html, Access: January 2013.

http://www.vert-espace.fr/exec/fiche.asp?IDPRODUITS=485, Access: January 2013.

http://www.yaban.gen.tr/tradescantia-zebrina-telgraf-cicegi/yaban-gen-tr-tradescantia-

zebrina-telgraf-cicegi-17/, Access: January 2013. 
622 Advances in Landscape Architecture

http://www.zaman53.com/haber/35259/rizede-duvarlar-cicek-acti.html, Access: January 2013. 


\title{
Street Furniture and Amenities: Designing the User-Oriented Urban Landscape
}

\author{
Gökçen Firdevs Yücel \\ Additional information is available at the end of the chapter
}

http://dx.doi.org/10.5772/55770

\section{Introduction}

It is often difficult to understand fully how site design integrates the elements of furniture that are used for various designated purposes and create a sense of place. Such an understanding can open up creative possibilities for designers of outdoor areas and enable them to shape spaces that can succeed in achieving their aims over the long term [1].

If street furniture is properly integrated in the design of a public space, it creates an identity and develops a sense of place around it [2]. Items of street furniture comprising, for example, objects used to facilitate transportation or the use of land adjacent to a street, are commonly used in urban areas with the aim of making the street more aesthetically appealing; however, these objects, if placed near intersections, may obstruct the view of drivers, especially if crowds develop around them; and if they are close to the roadway, they should also not obstruct the sight distance of pedestrians [3].

The furniture should be selected and set up based on an analysis of the site's current and desired patterns of use, so it can serve its purpose effectively; quality furniture is costly, so it should be used only where it is really needed. There are various approaches to selecting or designing street furniture: for example, there could be a coordinated selection which gives a consistent tone to streets and walkways; or various parts of the streetscape could be designed to serve as artworks in themselves [4].

Generally speaking, there are five basic criteria involved in selecting and placing items of street furniture: function (i.e. seeing how necessary an item is and how it can serve its purpose), siting and layout (i.e. deciding where each item should be places), form and appearance (i.e. making sure there a continuity or at least a linkage between the designs of different items), durability (given expected usage), and cost [5]. 


\subsection{The significance of street furniture}

Street furnishings create the settings for resting, sitting and eating, and social encounters with others. Such settings may be of great importance to the elderly, those with limited mobility, and adults who have small children; but in addition to their functional aspect, items of urban furniture such as benches and tables in parks and squares can also be socially significant [6], as they give these sites a comforting and appealing air and draw people in together.

Appropriately selected and placed furniture can draw people to outdoor spaces and add to the pleasure of using these spaces; the main challenge is getting them outdoors, with the aim of making them feel welcome, relaxed, and involved [1]. The quality of urban spaces is indicated by their character and how well they create a sense of identity, as well as by the quality and placement of their street furniture, as can be seen in various cities: London's red telephone booths and Paris' metro entrances, for example, have become iconic and essential to these cities' identities [7]. In addition to their functional and symbolic roles, items of street furniture may also set standards and expectations of quality for the development of the areas where they are found [8] and can serve as talking points for planning [9].

\section{Furniture planning}

In order to plan the design of street furniture, one must first plan establish and define the type of space under consideration - whether it is a park, a street, a plaza, a waterfront, a recreational area, or a mall, for example. The initial defining questions are: who are the potential users of the space, for what purpose and at what times will it be used, and how will it serve users when they arrive there? [1].

Typically, installations where the furnishings have been planned and coordinated as part of a broader design concept are more successful than those where they have been selected piecemeal without taking account of users' needs, or the architectural character or weather conditions at the site.

As regards what furniture should be consistent across various sites and which unique to a particular site, this depends on the situation, but in general there can be some consistent elements, such as signage, or streetlighting (for quality of illumination, aesthetics, and to facilitate maintenance by standardizing the types of bulbs used) [10]. In brief, the goal is to create convenient, easily maintained and publicly accessible amenities that do not hinder pedestrians or traffic [11].

\subsection{Placement of street furniture}

The location of the furnishings should be based on their functions [4], and coherent with the patterns and designs of the hard surfaces at the site. The items of furniture should not give the appearance of being cluttered, so that, for example, signs are attached to a single post or column rather than being distributed in several places; group amenities such as seating 
areas or telephone booths are set up where they will be used, such as at pedestrian junctions; and features like bollards are used minimally [12].

In addition, the furniture should not be hazardous for pedestrians; if it is used along a walking area it should be aligned to make passage easier, rather than staggered like an obstacle course $[13,14]$. Varying the texture of the walking surface at key points can also help the visually impaired to find public amenities more easily [11].

\section{Street furniture design}

The furnishings of urban outdoor spaces should be designed with the needs of the disabled, children, and the elderly in mind, and also to enable triangulation - i.e. they should be linked together to stimulate social encounters and encourage people to talk to strangers.

In public spaces this stimulus can be created by the selection and arrangement of the street furniture; for instance, if benches, rubbish bins and telephones are far apart, they may have the effect of drawing people apart, whereas if they are arranged closely linked with other amenities such as a coffee cart, they tend to bring people together quite naturally.

\section{Safety and Security}

Furniture items designed for outdoor spaces must be constructed of safe materials and designed to prevent injury, without sharp edges or exposed fasteners. They are usually either attached to the ground with anchor bolts (for example, using surface mounting, i.e. attaching a bench to a concrete slab), or embedded in the ground. Naturally, the technique used for mounting should be decided on in advance, so the furniture can be made accordingly [15].

The type of furniture and its arrangement should also take into account visibility and sightlines, lighting, and accessibility issues that may be faced by women, children, the elderly and the disabled. Areas which are unsafe or pose risks should be designed taking these factors into consideration [16].

\section{Materials Used in Street Furniture}

Furniture selection and design should take into account weather effects such as sunlight, expansion and contraction, wind stress, moisture, and in some cases, salt spray, frost, or ice. The best designs usually incorporate strong, simple shapes, native materials, and natural finishes, generally in black, grays, and earth tones, accented with bright colors [17].

The most popular materials used are steel and wood; other possibilities are stone, concrete, recycled plastic and various other materials. The choice of materials depends on the context and limitations of the design; for example, whether the furniture should be resistant to vandalism, whether ventilation is needed for drying it during wet weather spells, what the weather conditions may be, how frequently the furniture is likely to be used and by whom, what the initial costs are, including mounting, the costs and ease of maintenance, and whether there is a possibility of using eco-friendly materials [15]. Site furniture should be 
made of nonflammable materials such as metal, brick, or stone, and wooden structures should be avoided in areas where there is a risk of fire [18].

Steel

Stainless steel is a popular choice of material, because it is versatile, has a high strength/weight ratio and can be shaped to fit almost any design aesthetic. It is durable, resistant to corrosion and impact, and requires no maintenance; it is also cheap compared to all the other materials in terms of life-cycle cost, and is fully recyclable.

Wood

Wood is another popular choice of material for street furniture, because it is a natural material that feels warmer in cold weather and cooler in hot weather, unlike metals. Its disadvantages are that it dries more slowly than metals after rain, needs more maintenance, and is easier to burn, break, carve graffiti into, or otherwise vandalize. Wood may be inexpensive, but the type of wood selected should depend on the location and frequency of use of the furniture. For example Pinus spp. is inexpensive and quite durable, but loses its color and longevity if it is not treated and maintained; the cost of maintaining or replacing it may outweigh the initial cost of purchasing it. Cedrus spp. weathers naturally, is non-toxic and has a pleasant odour, but it is not a hardwood, and can easily be carved into or chipped; it is therefore unsuitable for areas where there is frequent use of the furniture.

\section{Concrete}

Concrete furniture may not need to be mounted, as it is heavy; it is also difficult to vandalize (except with spray paint). Concrete has a long durability and may be aesthetically attractive if it is designed to be consistent with neighboring architecture; however, it does not drain or ventilate well after rain. Much of the concrete street furniture that exists today seems outmoded and appears to lack innovation.

Stone

Like concrete, stone is very durable, does not need to be mounted because it is heavy, and is resistant to vandalism except when spray paint is used. However, it has many of the same disadvantages: it does not ventilate or dry well after rain, and is limited in its aesthetic possibilities where design is concerned [15].

Plastic

Recycled furniture is generally made from plastics, which give it a smooth texture and appearance. The resulting furniture is highly durable, often lasting considerably longer than wood; low-maintenance; and therefore more cost-effective in the long term.

\section{Colour}

Items of street furniture should contrast significantly in color with the background where they are situated, and have a luminance contrast of at least $0.3(30 \%)$ to increase their visibility to pedestrians. This can be supplemented by colored borders in the pavement, 
which mark the edges of the street furniture and guide pedestrians around it to clear and unobstructed walking areas [19].

\section{Sustainability}

Paint or other finishing materials of furniture should be non-toxic and non-staining [14]. The use of recycled materials in street furniture enables manufacturers to conserve natural resources and reduce their carbon footprints; it also educates the users of the furniture, the public, on the importance and mental and physical benefits of recycling. In addition, such furniture items can be recycled again when they need to be replaced, further reducing damage to the environment.

Local city administrations have been increasing initiatives to ensure the sustainability of their street furniture, including raising civic awareness, in order to reduce costs and fulfil legal requirements for emissions and energy efficiency. Most of these initiatives are demonstrably effective; replacing filament light bulbs with new LED bulbs, for example, can cut the energy consumption of street lighting by $40-70 \%$.

With new, renewable energy sources other possibilities are emerging, such as, for example, converting street lamps into photovoltaic power sources which supply light, and at the same time supply energy to a city's power grid. Photovoltaic devices differ from solar panels, in that the power they generate can either be stored in batteries or added to the mains power grid [20]. In addition to this variation on solar energy generation, there are items of street furniture available that are wind-powered, or designed as photovoltaic-windpower hybrids; these items, according to their designers, optimize the use of renewable energy sources and also guarantee a power supply through two different sources of energy. Another new power source that is being explored for street furniture is geothermal energy, which arises from the subsoil; heat-controlled benches, for example, can be connected through bore holes in the earth to a geothermal system which produces a comfortable seating temperature [21].

\subsection{Seating}

Seating facilities, such as benches, should be integrated within the outdoor spaces of the city wherever people wait, meet, or socialize; in public squares, for instance, they should be coherent with other elements, so that when seats are not in use they do not create a sense of isolation or emptiness. Being able to sit within a city landscape provides an opportunity to pause, and also a tactile and more intimate contact with a place than one has when standing or walking [22].

\section{Location}

The best locations for benches are places where there is heavy pedestrian use: retail shopping corridors, transit stops, plazas, spaces outside cultural institutions, etc; poor locations are areas where there is little activity, such as in front of offices that close early or buildings without windows, and in spaces hidden from view or far away from active areas [23]. In high-activity areas there should be access to seating every $60 \mathrm{~m}$ (or every $50 \mathrm{~m}$ if there 
is intense activity) [24]; there should also be rest facilities at regular intervals of $100-200 \mathrm{~m}$, with the needs of the disabled kept in mind [11].

Benches should be set up near other amenities such as bus shelters, kiosks, news stands, waste receptacles, telephones, etc., and arranged where there is protection from the wind and to allow a choice of sitting in the sun or shade. Moveable chairs or lightweight benches allow the widest range of choices. They should be separated from the walking path by a space of $30-60 \mathrm{~cm}$, and with the seats level and having a maximum lengthwise slope of $4 \%$; if the slope is greater, the ground should be built up to create a level surface [25].

Benches set at right angles to each other create situations conducive to socialization [26], whereas if they are lined up in a row they prevent group conversation (they could be lined up in areas with an exceptional view, or where there are many people passing by). In addition, they should not be set up directly facing each other (unless they are being used to play games), because people are reluctant to make direct eye contact with strangers and will turn or sit sideways to avoid it. If pairs of benches are set up at a 90-120 angle, the space they create facilitates both socialization and sitting alone. There should also be appropriate space left beside and in front of benches to accommodate wheelchairs and walkers for the disabled without hindering pedestrians [27].

Design

In designing benches, considerations of comfort are important, but the level of comfort provided depends on how they will be used: on a shopping street, for example, people may stop briefly to rest, so comfort is less important than it is, say, in a park, where people may spend half a day in seating areas. There may also be other things to consider: for example, large slats in benches might be less comfortable than small slats, but may be more appropriate in areas where teenagers tend to sit on the back rests of the benches. In general, the selection or design of benches should take into acount all relevant conditions of use.

Appearance is another important consideration: benches should be designed to fit in with their surroundings, because a bench functions like an extension of the property it adjoins, and gives a street a sense of ownership. As a result, it is more likely that business owners will take responsibility for the care of the bench and the street, and this, on a more general level, will contribute positively to the area's safety and security [27].

Armrests and back support are normal features of seating; these provide assistance to the elderly. Back supports, contoured seats and arm rests provide comfort when sitting and support when getting up and down; these are important design elements, especially in areas where people sit for longer periods of time. Adding armrests in the center of a bench should be considered in cases where it is desirable to prevent people from sleeping on benches. When space is available, steel seating is occasionally used in circular or curved forms to give an organic feel to an area [28].

The design options for a site can be increased if the types and heights of seating (stairs, benches, seat walls, etc.) are varied [18]. The length of seating elements should be $60 \mathrm{~cm}$ per person. For benches, the recommended height of the seating surface is $42.5 \mathrm{~cm}$, with a width 
of $35-40 \mathrm{~cm}$ and the back rest extending for $50 \mathrm{~cm}$. Benches with arm and back rests provide support to users' bodies; to provide appropriate back support for users, the back rests should be $32.5-37.5 \mathrm{~cm}$ in height. Between the seating surface and the back rest there should be a $95^{\circ}-100^{\circ}$ angle, and the seating surface should slope back at an angle of $10^{\circ}$. Walls to be used as seat walls should be $37.5-60 \mathrm{~cm}$ in height $(42.5 \mathrm{~cm}$ is recommended); and the depth of a seat wall should be at least $37.5 \mathrm{~cm}$ if access is only available from one side, or $75 \mathrm{~cm}(90 \mathrm{~cm}$ is recommended) if it is available from both sides [25].

Moveable chairs to be used in open spaces are an alternative to benches and other seating elements; while these may not be ideal in every situation, they can be quite useful, as they are more comfortable than benches. While their cost varies, they are also less expensive: approximately ten moveable chairs can be purchased for the cost of one bench. In addition, users can arrange moveable furniture that they find at a site in any way they wish in order to sit closer together or further apart, in the sun or under shade.

\section{Disabilities}

For users with disabilities, some seating should be located near public toilets and telephones. In general, rest areas with benches should allow at least $1 \mathrm{~m}$ of adjoining space to accommodate wheelchairs [14]; for the same reason, table surface heights should be within the range $0.75-0.90 \mathrm{~m}$, and the minimum height under the table should be $0.6 \mathrm{~m}$ [11].

\subsection{Waste receptacles}

\section{Location}

The most common error in placing waste receptacles is putting them wherever there is an empty space, instead of in places where people will use them. If they are not placed appropriately they will remain empty while the surrounding space becomes dirtied: people will not change their habitual walking path to find a trash can, so the proper placement of these items of furniture is crucial.

Waste receptacles should be highly visible and accessible in order to minimize littering. They should be located where they are most likely to be used, in crowded areas like busy intersections, close to crosswalks, beside take-out food shops or vendors, at bus stops, in plazas, outside building entrances such as offices, department stores and homes, and near other items of street furniture like benches, seats, shelters, walls, fences and telephones [27]. Receptacles should be situated far enough away from seating areas to minimize the unpleasant effects of trash odors and insects on users; and their fronts should be set back at least $30 \mathrm{~cm}$ from walkways [25].

The number of waste receptacles to be provided depends on how many people use an area, how much litter is produced in the area, and on how efficient maintenance and sanitation programs are. On streets in the city center, 2-4 waste receptacles per block are usually sufficient: one should be at each end of the block next to the crosswalk, and one or two more in the middle of the block if there are benches or food stalls along it [13]. Trash cans are 
usually spaced at $30 \mathrm{~m}$ intervals, unless there is an increased need in a particular area; they are usually single units rather than groups of receptacles [24]. On commercial streets there should be at most one trash can every $60.96 \mathrm{~m}$; in areas where there is a lot of pedestrian traffic, the distance between receptacles can be decreased, but additional receptacles should be provided only if maintenance is provided by a private sponsor [29].

In some isolated natural areas trash cans may not be necessary, or if they are, they should be selected from a determined range; their location should not detract from the view and they should not have unnecessary decorations that clash with other items of street furniture. In these areas, discreet cigarette stubbers should be provided instead of ashtrays [28].

It should also be taken into consideration that waste receptacles will also be used at night in parks and squares; for this reason, they are most appropriately placed along lit-up pedestrian walkways or other lighted areas.

Design

Waste receptacles come in numerous forms, and may be designed with open, half-open, or closed tops, and mounted on colums (lighting, signs etc.), walls or vertical surfaces, free standing, fixed to the ground surface, moveable (generally for temporary use), built-in bins (benches, seats, walls etc.) [30,31]; however, appropriate receptacles should have certain qualities, of which the most important is that they should clearly look like places for discarding litter; if they blend in with the environment too well they will become unrecognizable. While they should certainly be compatible with other street furniture and with the local architecture, their function and purpose must be clearly recognizable.

Another important quality of a good waste receptacle is ease of use; the following characteristics are the most desirable. First, people should be able to dispose of waste without having to touch the receptacle or open a door to use it. Trash cans are most easily accessible when they are about $100 \mathrm{~cm}$ in height with the receptacle at most $40 \mathrm{~cm}$ from the outer edge [19]. The opening of the receptacle should be large enough for litter to be put in, but the size depends on the context; in parks, for example, people may dispose of larger items, so the opening should be bigger. In general, it should be at least $25 \mathrm{~cm}$ wide, so a folded newspaper or take-out food container can be put into it; if the opening is too small, items can get stuck in it and litter will be strewn in the vicinity of the receptacle. The opening should also be at most $90 \mathrm{~cm}$ above the ground to facilitate use by the disabled.

The size of the receptacle should be determined by its expected use and how often it will be emptied. Well-organized public spaces have several smaller receptacles that are emptied often, rather than one large receptacle that is only emptied at long intervals. In most areas, containers with a volume of 114-190 litres are sufficient. Wheelie bins are suitable for areas where there is a high volume of trash, if they can be emptied easily by collection equipment. In shopping centers, 120-litre wheelie bins with a framed cover over the top are required; while in town and district parks, 240-litre or 120-litre wheelie bins should be provided, depending on user needs [24]. 
Waste receptacles should be sturdy; to bear the forces of activities such as sitting, leaning, etc., that may occur beside or on top of them [13]. They should especially be able to contain all kinds of chemical and flammable materials, and should also be robust enough to withstand the impact of children climbing on them or bicycles and other motor vehicles striking them [31]. If they are attached to streetlights they should not obstruct the flow of pedestrians, and should be painted in contrasting colors to assist those with low vision [32].

It is important to know how often waste receptacles will be emptied. In areas where the receptacles are being inspected regularly, they can be lined with plastic bags. If it is expected that the receptacles will be emptied daily, they may be lidless; otherwise there may be a need for them to have a hinged lid resistant to outdoor weather conditions. Lids are also important for receptacles outdoors, to prevent the garbage from getting wet. In addition to having the waste from them collected, the receptacles themselves should also be cleaned from time to time.

The materials used for waste receptacles should be durable and resistant to vandalism, fire, rust, and stains. Among the choices of materials available are: enamels, which are graffitiand stain-resistant, but may chip easily; wood and rough-textured or porous surfaces, which are rust- and stain-resistant but easily vandalized and hard to clean; aluminum, which generally serves its purpose but may be vandalized to be used as scrap metal in some areas; and plastics, which may be problematic if they are solvent-sensitive, especially in parks, where discarded barbecue lighter fluids can erode them. Galvanized steel is a very durable material that can be used for receptacles in aeas where they may be heavily abused [27].

In view of landfill costs and the currently growing acceptance and understanding of recycling, it seems likely that the need for receptacles for recycling will increase in the future.

\subsection{Signage}

Signage systems play a number of important roles: they provide information and directions for people to find their way around a site, help maintain the site's image and coherence, and encourage learning.

\section{Location}

The location of signs significantly reinforces their message. Besides conventional signboards, maps, kiosks, and other elements may also function as signs; and placing signs at other site amenities like benches, cafes, restrooms and intersections can help create mini-destinations in larger open spaces [33].

Signage can be used for various purposes: for example, directional signs can help people keep their bearings and give them a sense of security; and in parks where there are large natural areas or no specific destinations, micro-spaces can be created with a sign, a picnic table, a telephone, or other amenities, facilitating social encounters and enabling 
communication in the event of an emergency. If the areas where signage is used incorporate other activities, these areas can enable visitors to fulfil various needs in one place, and also create a relaxing social environment in which to spend time.

Design

When people know where they are in a space and know how to get to where they want to go, they feel safer. Instead of using restrictive signs warning that something "is prohibited," a more constructive approach should be used: signage should be positive and informative, and give people the confidence to act on their own. Signage can also be used to educate people on safety issues and to encourage them to report on any dubious activities they may see.

There are four basic kinds of sign: regulatory, warning, informational and educational [34].

Regulatory signs are used for traffic control, and include stop and yield, right-of-way, speed limit and exclusion signs. Directional signs, occasionally posted in natural areas in particular, help people keep their bearings and feel located and secure; they make use of landmarks and other places of interest and are required to indicate changes in direction [19].

Warning signs indicate existing or potentially dangerous conditions; they are usually found near intersections, bridges and crossings, and can also indicate changes in the gradient or surface conditions [34]. Warning signs should make use of all the languages in areas where more than one language is commonly spoken, and should be posted at all entrances to limited, controlled, and exclusion areas. The wording should clearly indicate restricted areas, and the signs (which should not be mounted on fences with intrusion-detection equipment) should be posted at intervals of less than $30.48 \mathrm{~m}$ [35].

Informational signs inform visitors about a site; in this way they serve as outreach tools. Maps at entrances, within the site and at points along pathways can help increase users' knowledge, curiosity and interest about the area. They help visitors guide themselves, and also highlight places of interest. Maps should not be cluttered with too much or unnecessary information; they should clearly define important points.

Educational signs are a pleasurable way to get people interested in unique features of a site. Educational signage should be created with the types of audiences, their interests, and their reasons for visiting the site in mind.

Poor signage can be confusing rather than illuminating; signs should be posted off-site and at entrances, grouped on one support for clarity and ease of maintenance [24] and should include on-site directional, parking, and cautionary signs for visitors, employees, service vehicles, and pedestrians [35].

Signage should be clearly visible. Directional signs should be visible from a distance of at least $20 \mathrm{~m}$ : for clear visibility, the sign should not be further away than $47 \mathrm{~m}$ or closer than $6 \mathrm{~m}$. The design and placement of signs for pedestrian use must take into account such matters as their visibility, the size and proportions of the writing, and the relation between the writing and its background. The writing on signs should be complemented by standard 
graphic symbols to help people; directional arrows should be clearly marked. International symbols should particularly be utilized in outdoor areas used by foreign visitors.

Different materials can be used for signage: carved wooden signs are attractive in natural environments, but they are not resistant to theft and damage; metals can become bent and rusted; plastics can be broken or burned. The most damage-resistant materials are concrete and stone.

All signage should be accessible, and durable in the long term (at least 7-10 years). In areas where there is a risk of vandalism, signs on two supports should be used rather than on single supports. Signs should be easily replaceable in case of damage; and the care of signage should not be neglected.

Shape

The octagon is used only for stop signs [34]; information signboards should be rectangular, warning signboards triangular, and interdictory signboards circular [11].

\section{Colour}

There should be a strong color contrast between the text and its background, and between the sign and the surface or background against which it is seen; black text on a white background, for example, provides a good color contrast. Clashing colors, such as green text on a red background, should be avoided. The surface behind the sign should contrast with the sign to make it stand out; or if this is not feasible, the background within the sign should be increased in size [19].

\section{Lettering}

The size of the letters used on signs should be proportional to the reading distance: The character width-to-height ratio should be between 3:5 and 1:1, and the character stroke width-to-height ratio should be between 1:5 and 1:10. The letters and graphic symbols should be raised at least $1 \mathrm{~mm}$ from the background, so the visually impaired can read them by touching them. The smallest letter type should at least $15 \mathrm{~mm}$, and there should be normal spacing between words and letters.

\section{Disabilities}

The symbol for amenities for the disabled is composed of a wheelchair figure with a square background or border; the figure is distinguished from the background by contrasting colors, most commonly white for the figure and blue for the background, and the wheelchair figure should always be seen as facing right.

Signs should be accessible to wheelchair users; permanently fixed street furniture will also clearly provide more wayfinding cues for the visually impaired than landmarks [36]. Signs should not be placed behind glass because reflection may hinder visibility. Signs placed on the pedestrian path of travel are obstructive; so they should be detectable.

There is no need for large numbers of directional signs; these should be placed at main entrances and doors and where there are changes in direction or level. Fixed signs indicating 
street names should be placed at a maximum height of $2.50 \mathrm{~m}$. Maps and information panels at building entrances, along roads, and on public buildings should be set at a height of 0.9$1.8 \mathrm{~m}$; wall-mounted signs should be installed with the centre line $1.4-1.60 \mathrm{~m}$ from the finished floor level; and overhanging signs should allow a minimum clearance of $2 \mathrm{~m}$. Orientation signs and push buttons in lifts should have a text in Braille or in relief for the visually impaired [11].

Signals at crossings may be supplemented with audible or tactile messages to facilitate crossing for all users, including the visually impaired; however, audible pedestrian signals should be used judiciously, because they can create a noise problem [37].

\subsection{Lighting}

Site lighting design focuses on illuminating the environment to anticipate and respond to the needs of users of the site. The lighting elements involved in a site may have diverse functions such as wayfinding, creating social spaces, interacting with the natural and built environments, and meeting security requirements; the overall design must enable all these functions to coexist experience for users [38].

Because of security concerns, there is often a tendency to over-light parks, plazas, streets, and other public spaces; a good design plan should relate lighting to the functions of a particular space in the evening or at night. Site lighting, beyond its practical functions, should be considered in terms of how the types of lights used, their location and their intensity, affect the way a street is perceived and used [39].

Aesthetically speaking, site lighting can add colour and vibrance to an area at night; however, its primary purpose is to provide safety and security after dark. Lighting is especially important at building entrances, intersections, stairs, sudden changes in grade, dead ends, and remote walkways. Areas with high crime rates should be well lit to provide some security for those using facilities in the evenings or at night; but while it may increase people's feeling of safety, lighting may not have an effect on reducing actual crime rates.

\section{Location}

Light poles should be coordinated with other streetscape elements, and utility equipment such as pull boxes and underground trenches, both above and below ground, should be coordinated when placing lighting fixtures. Fixtures should not be placed near tree foliage that may block their light; the anticipated height and diameter of the tree canopy should be considered in relation to the height and spacing of lighting fixtures, the need for a certain level of light, and the need for uniformity. The most suitable distance between a tree and a light fixture depends upon the type of tree and on the type of light fixture; if the light from a fixture is blocked because of the existing locations of the fixture and trees, other light fixtures may be added to achieve the required level of illumination [29].

\section{Design}

The lighting of outdoor spaces should be designed carefully, taking into account placement, intensity, timing, duration, and color [18]; lighting can be provided by bollards, street lights, 
faced lights, shop windows, and other elements of the cityscape. In lighting, as in signage there is a hierarchical order of priority: at the highest priority level, activity areas and primary walkways should be lit to become the focus of pedestrian activity after dark; at the lowest level of priority one may find, for example, the decision not to light some areas at all because using them at night would be unsafe or inappropriate.

Site illumination enhances the safety of traffic and pedestrians crossing; it is used to provide warnings about hazards, and helps increase security and reduce vandalism. Within the plan of the site, it gives emphasis to focal and meeting points, and building entrances. Accent lighting can highlight fine architecture or areas of unusual significance or beauty [17].

Lighting fixtures can also be used to highlight trees and give accents to shrubbery; they can also be mounted in trees to light pathways below. When deciding on such usages, planning should take account of which trees are deciduous and which trees retain their foliage [38].

Steps or stairway lighting should provide sufficient light for people to see the stairs and differentiate between risers and treads: their visibility depends on the materials used for the steps, as well as the physical form of the stairs; dark materials require a higher level of light, and a change in color between risers and treads will increase visibility [40].

Quality and quantity of light

Appropriate light sources should be chosen, and fixtures should be designed to direct light precisely, with shielding used to prevent light trespass and glare. The intensity and color of the light should complement the elements to be illuminated. High-pressure sodium lighting, typically used in city street-light fixtures, casts a yellowish-orange glow that distorts colors, diminishes visual clarity and undermines the quality of the night-time urban environment; it should therefore be avoided. Metal halide lighting, in contrast, produces a soft, white glow that renders color accurately, provides better visual clarity, and requires less wattage for the same level of visibility. The quality of light is also influenced by the relationship between the brightness of a light source and one's distance from it: light becomes more diffuse further away from the source, so to produce the desired quality of light, the light source should be located within the range of heights specified for a given brightness.

Height of luminaires

The illumination standard set for pedestrian walkways by the Canadian Standards Association, is 0.4 footcandles, at which level a person's face can be identified from a distance of 12-15 metres [41]. Street and road lights are usually installed on 9-15m high poles, spaced $45-75 \mathrm{~m}$ apart. Fixed light poles should have durable marking strips in contrasting colors, at least $0.3 \mathrm{~m}$ long, attached along the centre line at a height of $1.4-1.6 \mathrm{~m}$ to warn visually impaired pedestrians [32]. Lamps supply an average illumination of one-half a footcandle on local roads and in all parking areas, and one footcandle on major roads and in large parking areas. Pedestrian paths require intensities varying from less than one-half footcandle for walkways to five footcandles for building entrances, steps, and intersections. Mall and walkway light poles are $3-4.5 \mathrm{~m}$ in height. Although the mounting heights of luminaires have increased in recent decades with lamp technology allowing for higher and 
brighter road lights, this is not particularly beneficial for pedestrians. If the heights of luminaires are reduced and adjusted to a pedestrian scale, more fixtures will be needed, which means the luminaires and poles and their placement can have a more positive effect on the streetscape [39].

\section{Lamp Types and Wattages}

Lamps are usually incandescent or based on mercury vapor. Fixtures where the light source is below eye level may be used to illuminate landscaping and pedestrian walks; if these are the main light sources, there should also be peripheral lighting to illuminate the immediate surroundings and create a feeling of security for passing pedestrians [42]. Excessively bright lights and frontal floodlighting should be avoided; lower-wattage light sources should be used instead. The lighting of hardscape elements from a distance can negatively affect nighttime vision, and should also be avoided. Up-lighting should only be used where it will not interfere with the pedestrians' vision [15]: when a luminaire's height is lowered, the lamp's brightness must be adjusted so as not to cause excessive glare for pedestrians, but at the same time, the wattage must also be sufficient to adequately illuminate the road [39].

Reducing light pollution

Light pollution occurs when outdoor lighting is misdirected, misplaced, unshielded, excessive, or unnecessary [18]. Light pollution, or the over-illumination of the night sky by electric lights, can be a significant problem in urban areas; it can negatively impact the normal functioning of humans and many animal species. Light pollution can be decreased if designers minimize light trespass off the site, thus reducing night-time sky glow, increasing night-time visibility, and alleviating the negative effects of light pollution on nocturnal environments. Today newer outdoor lighting products have been designed to minimize light pollution; these types of products, located strategically within the landscape, can provide adequate illumination without emitting excess light [43].

\subsection{Fountains}

\section{Location}

In open outdoor spaces, water fountains or drinking fountains provide a focal point. Flowing water has a visual and auditory appeal that creates ambience, and the sound of a water fountain can help screen out traffic sounds in seating areas [44]; drinking fountains should be available for functional reasons as well in regions where there are hot summers [45]. Care should be taken in designing water fountains for high-rise office districts, as the buildings can cause air turbulence that blows around the spray from fountains.

Design

Drinking fountains should be designed on a scale appropriate to their setting. These fountains should be accessible to children and people in wheelchairs, as well as standing adults, including those on crutches or using walkers, and the water control should be simple, with little strength required. A well-designed fountain may have a water spigot on the side for filling containers, or washing hands. 
Stone, concrete, brick and metals such as copper, bronze, cast iron and steel are suitable materials for fountains [40]. Taps may also be designed with the disabled in mind, at the usual height of $85-95 \mathrm{~cm}$. This allows sufficient space for them to be approached by users of wheelchairs, which are usually $85 \mathrm{~cm}$ in height; the approach should be on a hard surface. The basin should be cantilevered $20-30 \mathrm{~cm}$ outwards from the wall or support stand, with the drinking spigot or bubbler mounted on the outer edge of the basin. To operate the fountain, a lever-type handle should be located on the side or rim of the basin; foot pedals should only be used together with a lever for controlling the flow [46].

As wind rises, fountain height should be reduced by 10 percent for each $5 \mathrm{mph}$ of wind speed above 10mph. For critical situations a wind sensor should switch off the fountain [47].

Types of fountains

Fountains fall into three categories: rising jets, downward falls, and a combination of the two.

Rising jets are often used in public displays, and because they can rapidly change form, they can be interactive, coordinated with music or easily accessible to people; indeed, the water itself may be the spectacle, if it flows in large quantities or if advanced technologies are used. Rising jets can be seen from a distance, and coordinated lighting can change their appearance into what has been described as "never ending fireworks" [48].

Downward fall or "cascade" fountains are found in nature in the form of rivers, streams, waterfalls and rising springs. Throughout history, human beings have contained, diverted, decorated and reduced or enhanced them, and eventually used them as models, supplemented by artificial pumping systems.

An example of a combination fountain is the "splash fountain," in which people cool themselves; even if they were not designed with this in mind, fountains are often used by children for this purpose. Some fountains may be fenced in or built with raised edges to prevent access; others are designed specifically for easy access, and with nonslip surfaces so they can be used safely. In recent years, purpose-designed splash fountains have been created in open spaces in conjunction with public pools, parks, or public playgrounds. These "splash pads" have no standing water, so there is no risk of drowning in them and no supervision is needed.

\subsection{Bollards}

These are vertical barriers and are one of the most unobstrusive ways of preventing access by vehicles enroaching on to pedestrian areas.

Location

The use of bollards should be limited to areas where sidewalk structures, furniture, private property and vegetation are being damaged by vehicles trying to park; this is particularly problematic on narrow streets. Aesthetically appealing bollards may be used in locations to 
indicate special spaces like shared public paths or streets limited to pedestrians. Lighted bollards can provide additional illumination for pedestrians in median refuges.

The usual lateral distance of a bollard is about $3 \mathrm{~m}$ from the center of the street. They should be positioned alongside the the walking path so as not to obstruct pedestrians. Bollards should be installed $45 \mathrm{~cm}$ from the back edge of the curb [28].

Design

The design of bollards should be contextualized within a 'family' of streetscape elements [29]. Their size range is usually $10-25 \mathrm{~cm}$ in diameter, but decorative bollards may be larger and may differ in shape. In general, design details appear on the sides and tops of bollards, which should be articulated for this purpose; bollards should also be painted in colors that enhance other elements of the streetscape (except for gray) and to assist the visually impaired. Signs and directions may be affixed to bollards so additional signposts are unnecessary, and the bollards may be painted with white bands where appropriate [28].

The spacing between bollards is usually about $90 \mathrm{~cm}$, wide enough to allow luggage and wheelchairs to pass between them. The spacing should also be varied to follow the rhythm of the other elements that make up the streetscape - i.e. lighting fixtures, landscaping, etc. In some contexts, an area may be defined or an entryway blocked by a series of bollards. Bollard forms vary from the simple and modern to the decorative and traditional, depending on the surroundings. The simplest bollards are wooden or painted steel posts embedded in the ground; in their most practical form they demarcate parking areas, alleyways, or entrances to significant public spaces. More complex, detailed forms and refined materials are used when the intention is to blend in with the local architecture and other elements of the city and inform local identity; such forms comprise part of the public street furniture and amenities. The materials and finishes used for bollards are determined by their relation to other elements in the space under consideration [1].

Bollards comprise a wide variety of fixed or flexible elements that are used to demarcate spaces, prevent the entry of vehicles, or otherwise protect a space; they can be designed to give way to or hold up against any force. They can be removable but locked by means of locking pins or by sheer weight [14]. They should be used sparingly, and their style should be determined by their location. Thus distinctive old bollards should be kept and renovated, and new ones created in the same style, if it is still appropriate, using moulds; plastic bollards should only be used for temporary purposes. The design concept for an area should be re-thought in order to minimize the use of bollards: to reduce the need for them, reinforced slabs or stronger paved areas, as well as the use of other street furniture items or planting trees should be considered.

Permanent Bollards

Fixed bollards are also known as "static," "architectural" or "permanent" bollards. These are usually concrete, wood or metal, and cannot be moved as they are surface-mounted or embedded in the ground. They should be set $300-450 \mathrm{~mm}$ in the ground on a concrete or consolidated hardcore base and surrounded by concrete [49]. 
Rising (retractable) bollards rise up and go back down into the ground again automatically, by means of an electronic, hydraulic or pneumatic mechanism when they are activated by a hand-held remote, swipe card, or other remote device.

Security bollards are designed to withstand heavy impacts. They may be fixed or retractable, and are used to prevent terrorist or criminal attacks.

Removable bollards have a base permanently fixed to the ground, but can be unlocked with a key and lifted out when necessary.

Telescopic bollards collapse concentrically and retract to street level when they are unlocked with a key.

Lay-flat bollards, also known as "fold-down" or "collapsible" bollards, can be unlocked with a key and laid flat on the ground when required.

Bell bollards are short and bell-shaped; these are used in areas with frequent U-turns or tight turning circles, as the slope of the bell enables the wheel of a vehicle to strike it and roll around it.

Temporary \& Flexible Bollards

Qwick Kurb is the brand name of a temporary plastic curb, which is comprised of several plastic bollards or paddles strung together.

Planters can serve as environmentally friendly bollards, physically delimiting streets, widening sidewalks and restricting access for motor vehicles. If they are properly funded, managed and maintained, they can enhance the aesthetics of a public space and facilitate a community's acceptance of a new curb or median [50].

Lighted bollards provide illumination in the form of area or marker lighting. "Area lighting" illuminates the ground plane around the bollard, while "marker lighting" provides a glow indicating a bollard's location. Marker bollards are solar powered, so they do not need to be connected to the electrical grid. In cases where a light is required at a low height for visibility, a simple path light on a post may be more useful and user-friendly than a strong, lighted bollard [1].

\subsection{Public Art}

The term "public art" refers to sculptures and other artworks which are situated in public spaces outdoors and are freely and physically accessible by the public. Public art may belong to the community as a whole, but it can also be displayed in private places and serve a smaller community of interested people [51].

Public art complements and enhances the environment and brings public spaces to life; it can range from disparate objects to an entire streetscape [52]. Large-scale works can bring thematic unity to a district or demarcate a gateway to a neighborhood, while works on a human scale can provide points of visual interest for pedestrians passing by. Well-designed 
public artworks that recognize the local culture as well as broader influences can define a community, serving as landmarks that uniquely express the spirit of a place or highlight some of its functional aspects, draw people towards it, and so contribute to its growth and dynamism [15]. Public art that fits into its surroundings can thus also create a setting for breaking down barriers, generating diverse forms of social encounters and interactions, and inspiring creative expression [53].

\section{Location}

Public works of art can serve as focal points on streets and in public areas, especially at key points or intersections where there is pedestrian movement or where people tend to gather, and they can give these spaces a unique character; however, they may not be appropriate for high-traffic walking areas such as pedestrian thoroughfares, unless they function as street furniture. In addition, they can create a special sense of place in less frequented locations.

Design

Works of public art may be permanent, static or based on objects; they can also be temporary, dynamic, or evanescent; however, they should serve as pedestrian amenities [51], and the aim in the design and planning phases should be to integrate them with other elements of the streetscape such as light poles, benches, trash receptacles and utility boxes. Artworks can be centers of focus in parks or plazas, or visual "surprises" that appears as one follows a pedestrian pathway.

The materials used, whether for a modern or a more traditional sculpture will vary depending on what the sculpture expresses, their appropriateness for its composition, and the cost factors involved. In any case, public artworks should be of a reasonable quality as regards their construction, and particularly their surface finish; they should be structurally sound and designed for minimal maintenance and to resist vandalism [24]. They should also be accessible to the disabled and not hinder pathways; some may need visible warning strips around the base for this purpose.

\section{Maintenance}

If the types of street furniture and manufacturers involved at a site are consistent, maintaining or replacing worn or damaged furnishings will be less costly [54]; proper installation of items will ensure their durability, and damaged materials should be replaced with more sustainable products wherever possible [43]. The furniture should be easy to repair, and one way to facilitate this is to design it as replaceable modular parts, so that it does remain unusable for long periods pending repairs [16].

Street furniture is often vandalized by burning, slashing, carving, and spray painting, so this should be taken into account in the planning phase; some materials and styles are more resistant to vandalism. The furnishings must be durable and secure, with finishes and coatings that resist stickers, graffiti and bacteria. Thus while wood may be a cheap and aesthetically appealing choice, it is easy to carve, burn, and spray-paint, so it is not particularly resistant to vandalism compared to other alternatives. Recycled plastic is a 
popular material for street furniture, but it can be burned, carved and painted; wear due to ultraviolet radiation may be another problem (although some recycled plastic products are marketed as UV-stable), so this material may be more appropriate indoors. Steel is the material most resistant to vandalism, but it is usually the most costly: steel meshes and steel bars cannot be spray-painted, burned or slashed easily, and they also have the advantage of good ventilation so they dry rapidly after rain [15].

\section{Conclusion}

Street furniture should be available in proportion to the intensity of activity in a particular area, and carefully placed to create unobstructed paths for pedestrians without creating hazards. Furnishings include benches, waste receptacle, signs, lighting, fountain and other elements that make people feel comfortable. These elements should be coordinated and integrated so that they are both attractive and functional. However, beyond comfort, the aim of these furnishings is to provide a place with character and identity, and to encourage people to enjoy outdoor spaces. Street furniture also addresses specific needs, such as seating and shelter when one is waiting for transportation. If well planned and designed, it can also enhance the visual aspects, image and identity of a site. The quality, organisation and distribution of street furniture reflects the quality of an urban space and can also set standards and expectations for future development [8], as the aim of these furnishings is to combine and coordinate form, scale, materials and placement to create visual appeal, accessibility and safety through understanding the needs of users [55].

Besides its functional aspects, high quality in the designing of street furniture has recently become a focus of attention in urban landscape design, with emphasis placed on the integration of function and aesthetics with new materials and technologies, creative concepts and artistic application in the user-friendly cityscape. Street furniture enables a city to become closer knit as a community, a space where people can gather, share and experience life together. Visually unattractive or poorly planned street furniture defines a city through chaos, a lack of order and harmony, and the absence of community. In recent years, cities have also become very concerned about waste disposal and the stability of the environment, as can be seen in the growing tendency of using recycled street furniture; well designed street furniture enables cities to continually update outdoor spaces sustainably while being environmentally conscious at the same time.

\section{Author details}

Gökçen Firdevs Yücel

Faculty of Engineering and Architecture, Istanbul Aydin University, Istanbul, Turkey

\section{References}

[1] Main Bill, Hannah Gail Greet. Site Furnishings: A Complete Guide to the Planning, Selection and Use of Landscape Furniture and Amenities, John Wiley \& Sons; 2010. p13,14,25,151,152. 
[2] Transport \& Regional Affairs Department of the Environment. By Design, Urban Design in the Planning System: Towards Better Practice, Thomas Telford Ltd; 2000. p26.

[3] American Association of State Highway and Transportation Officials, Task Force for Roadside Safety Staff. Roadside Design Guide, 4th edition, AASHTO; 2011. p10-13.

[4] Crankshaw Ned. Creating Vibrant Public Spaces: Streetscape Design in Commercial and Historic Districts, Island Press, 2 edition; 2008. p187,188.

[5] Evyapan Gönül Aslanoğlu, Tokol Ayşegül S. Landscape design lectures, METU Faculty Of Architecture Press; 2000. p81.

[6] Deakin Mark, Mitchell Gordon, Nijkamp Peter, Vreeker Ron. Sustainable Urban Development: Volume 2; The Environmental Assessment Methods, Routledge Press; 2007. p365.

[7] Sanches Maria Gabriela, Frankel Lois. Co-design in Public Spaces: an Interdisciplinary Approach to Street Furniture Development: Design Research Society Conference 2010, University of Montreal, Montreal, Canada, http://www.drs2010.umontreal.ca/data/PDF/105.pdf (accessed January 2013).

[8] Carmona Matthew, Heath Tim, Oc Taner, Tiesdell Steve. Public Places Urban Spaces: The Dimensions of Urban Design, Published Elseiver Ltd.; 2010. p196.

[9] Gehl Jan. Cities for People, Island Press; 2010. p239.

[10] Bain Lesley, Gray Barbara, Rodgers Dave. Living Streets: Strategies for Crafting Public Space, John Wiley \& Sons; 2012. p71.

[11] United Nations. Street Furniture, Urban Design Considerations, Accessibility for the Disabled - A Design Manual for a Barrier Free Environment, Department of Economic and Social Affairs Division for Social Policy and Development, http:www.un.org/esa/socdev/enable/designm/AD1-03.htm (accessed January 2013).

[12] Biddulph, Mike. Introduction to Residential Layout, Architectural Press; 2007. p197.

[13] Traffic Signs, Marking and Street Furniture, http://www.jtc.sala.ubc.ca/reports/manual_for_streets/10\%20traffic\%20signs\%20markin g\%20and\%20street\%20furniture.pdf (accessed January 2013).

[14] Derek Lovejoy Partnership. Spon's Landscape Handbook, Taylor \& Francis; 1997. p397,398,399.

[15] Site Furnishing, Urban Green Inc., Vancouver, B.C., http://www.urbangreeninc.com/looking-for/site-furnishings/ (accessed January 2013).

[16] Toronto (Ont.). Transportation Services, Toronto (Ont.). Urban Development Services. City Planning Division, Beautiful City Sceretariat. Vibrant Streets: Toronto's Coordinated Street Furniture Program: Design and Policy Guidelines, City Planning, Clean \& Beautiful City Secretariat and Transportation Services; 2006.p21.

[17] Simonds John Ormsbee. Landscape Architecture: A Manual of Land Planning and Design, McGraw-Hill Professional; 1998. p155,158.

[18] Calkins Meg. The Sustainable Sites Handbook: A Complete Guide to the Principles, Strategies, and Best Practices for Sustainable Landscapes (Wiley Series in Sustainable Design), John Wiley \& Sons; 2012. p421,422,468,502.

[19] Planning and designing for pedestrians: guidelines. Department of Transport, 2011. http://www.transport.wa.gov.au/mediaFiles/AT_WALK_P_plan_design_pedestrians_g uidelines.pdf (accessed January 2013). p88,89,191,192. 
[20] Prasad Deo, Snow Mark. Designing With Solar Power. Images Publishing Dist Ac.; 2006.

[21] Innovation and special features of street furniture, Sustainable thinking, http://www.repsol.com/es_en/energia-casa/conciencia-sostenible/reportajes/Innovacioncuriosidades-mobiliario-urbano.aspx (accessed January 2013).

[22] Dee Catherine. Form and Fabric in Landscape Architecture, Taylor \& Francis; 2001. p196.

[23] Street Design Manual, Furniture, New York City Department of Transportation; 2009. p197.

[24] Canberra Central Design Manual. DS19 - Street and Park Furniture and Barbecues, Design Standards for Urban Infrastructure, Urban Services, http://www.tams.act.gov.au/_data/assets/pdf_file/0007/396880/ds19_bbq.pdf (accessed January 2013). p19-3,19-5,19-8.

[25] Site Design Guidelines a vocabulary for Clemson's sense of place, Clemson University, http://www.clemson.edu/facilities/campus-planning/sdg.html (accessed January 2013). p39.

[26] Loidl Hans, Bernard Stefan. Opening Spaces: Design as Landscape Architecture, Birkhauser Verlag AG; 2003. p132.

[27] Madden Kathy. Streetscape: A Guide to the Design and Management of Pedestrian Amenities in Downtowns and Neighborhood Commercial Districts, Project for Public Spaces, Inc., 1987.

[28] Public Space Design Guidelines, Furniture, London Borough of Richmond upon Thames Civic Centre, richmond.gov.uk/psdg_chpt5.pdf (accessed January 2013). p50,53,58.

[29] San Francisco Planning Department, Street Lighting, http://www.sfbetterstreets.org/find-project-types/streetscape-elements/street-lighting/ (accessed January 2013).

[30] Littlewood Michael. Landscape Detailing 3, Routledge; 1997. p.109.

[31] Harris Charles W., Dines Nicholas T., Brown Kyle. Time-saver standards for landscape architecture: design and construction data, Second edition, McGraw-Hill publishing company; 1998. p240-8.

[32] United Nations. Obstructions, Urban Design Considerations, Accessibility for the Disabled - A Design Manual for a Barrier Free Environment, Department of Economic and Social Affairs Division for Social Policy and Development, http://www.un.org/esa/socdev/enable/designm/AD1-01.htm (accessed January 2013).

[33] Project for Public Spaces. Creating Park Signage; 2009. http://www.pps.org/reference/signage/ (accessed January 2013).

[34] Flink A. Charles, Olka Kristine, Searns Robert M. Trails for the Twenty-First Century: Planning, Design, and Management Manual for Multi-Use Trails, Island Press; 2001. p88,89.

[35] Providing Protection to People and Buildings (Risk Management), FEMA; 2004. p2-41.

[36] Burton Elizabeth, Mitchell Lynne. Inclusive Urban Design: Streets For Life, Architectural Press; 2006. p91. 
[37] Zegeer Charles V. Pedestrian Facilities Users Guide: Providing Safety and Mobility, U.S. Department of Transportation Federal Highway Administration, Diane Publishing; 2002. p91.

[38] Ramsey Charles George, Sleeper Harold Reeve. Architectural Graphic Standards: Student Edition, John Wiley \& Sons; 2011. p358.

[39] Project for Public Spaces, Lighting use \& design, http://www.pps.org/parks_plazas_squares/info/amenities_bb/streetlights (accessed Jauary 2013).

[40] Hopper Leonard J. Landscape Architectural Graphic Standards, John Wiley \& Sons; 2007. p257,347.

[41] Project for Public Spaces, What role can design play in creating safer parks, http://www.pps.org/reference/what-role-can-design-play-in-creating-safer-parks/ (accessed Jauary 2013).

[42] Wood H. PaulH. Paul Wood (AuthorSite Design, Kaplan AEC Education; 2004. p108.Cook Thomas W., Vanderzanden Ann Marie. Sustainable Landscape Management, Design, Construction and Maintenance, John Wiley \& Sons, Inc.; 2011. p28,70.

[44] Marcus Clare Cooper, Francis Carolyn. People Places: Design Guidlines for Urban Open Space, John Wiley \& Sons; 1998. p50,51.

[45] Marcus Clare Cooper, Sarkissian Wendy. Housing as If People Mattered: Site Design Guidelines for Medium-Density Family Housing, University of California Press; 1992. p29.

[46] Nelischer Maurice. The handbook of Landcsape Architectural Construction, Volume two, Amer Society Landscape; 1988. p90.

[47] Littlewood Michael. Landscape Detailing 4, Routledge; 2001. p87.

[48] Hirst Bryan R., Fountains, Master Thesis. The faculty of the school of architecture, Kingston University, London, England; 1997.

[49] Littlewood Michael. Landscape Detailing 1, Routledge; 1993. p166.

[50] Transportation Alternatives (Organization), Rethinking bollards: how bollards can save lives, prevent injuries and relieve traffic congestion in New York City, New York, NY: Transportation Alternatives; 2007. p5.

[51] Coutts Glen, Jokela Timo. Art, Community and Environment: Educational Perspectives, Intellect Books; 2008. p147.

[52] Cartiere Cameron, Willis Shelly. The Practice of Public Art, Routledge; 2008. p9.

[53] Worth Margareth. Creating significance through public places art an inclusive +interdisciplinary practice, Public Art and Urban Design. Interdisciplinary and Social Perspectives Waterfronts of Art III, web version on the w@terfront nr, 4 . http://www.ub.edu/escult/epolis/WaterIII.pdf (accessed January 2013). p51.

[54] LaGro James A. Site Analysis: Linking Program and Concept in Land Planning and Design, John Wiley \& Sons; 2001. p63.

[55] Gu Ji Yong. Advances in Affective and Pleasurable Design (Advances in Human Factors and Ergonomics Series), CRC Press; 2012. p22. 


\title{
Greenways as \\ a Sustainable Urban Planning Strategy
}

\author{
Aylin Salici \\ Additional information is available at the end of the chapter
}

http://dx.doi.org/10.5772/55757

\section{Introduction}

Greenways are linear open spaces such as canals and scenic roads that are set along the riversides, hillsides or valleys, converted to a recreational use along the railways (Little, 1995).

As the last scientific sources about greenways in landscape planning are examined (President's Commission on Americans Outdoors, 1987; Little, 1990; Flink and Searns, 1993; Smith and Hellmund, 1993) the definition of "designed and managed space networks that are compatible with the concepts of sustainable space use" comes out (Ahern, 1995).

In 1970s, when the decreasing of urban open spaces became clear throughout the country, the greenways planning activities directed to preserving gained importance. Those greenways which need less open space than conventional parks, make possible various recreational activities and form a system of being associated different open and green spaces are supported by authorities and the institutions directed to protecting environment (Arslan et. al., 2007).

The most clear statement on this subject came out by President's Commission on Americans Outdoors in 1987. The commission sees the greenways as live networks like a giant circulation system. That provides people with access to open spaces close to where they live, and link together the rural and urban spaces in the American Greenways in the USA. Therefore, the commission suggested to generalize greenways which are a vision for the future as a system. It is possible to see more than 660 greenways examples implemented in the USA whose $80 \%$ of its population live in cities (Bueno et. al., 1995).

Commission draws a parallel between the evolution model of greenways and motorways or railway system. According to this idea, the motorways and railways which are firstly formed in small parts, later the left parts of them are networked by planners, being 
combined in scale of national, state and regional. Similarly, greenways are of various widths and have a network system like main roads and railways junction systems. Just the main difference is the nature has already an existing system infrastructure corridor (Fabos, 1995).

The first serious attempt in Europe is made, in 1997, by establishing European Greenway Association (EGWA). This Association define the greenways as both protecting environmental values and the network of routes that are allocated for only the motorless vehicles (on horseback, bicycling or etc.) in order to increase the health of environmental life, considering integrated management approach (Fig. 1) (European Greenways Association, 2004).

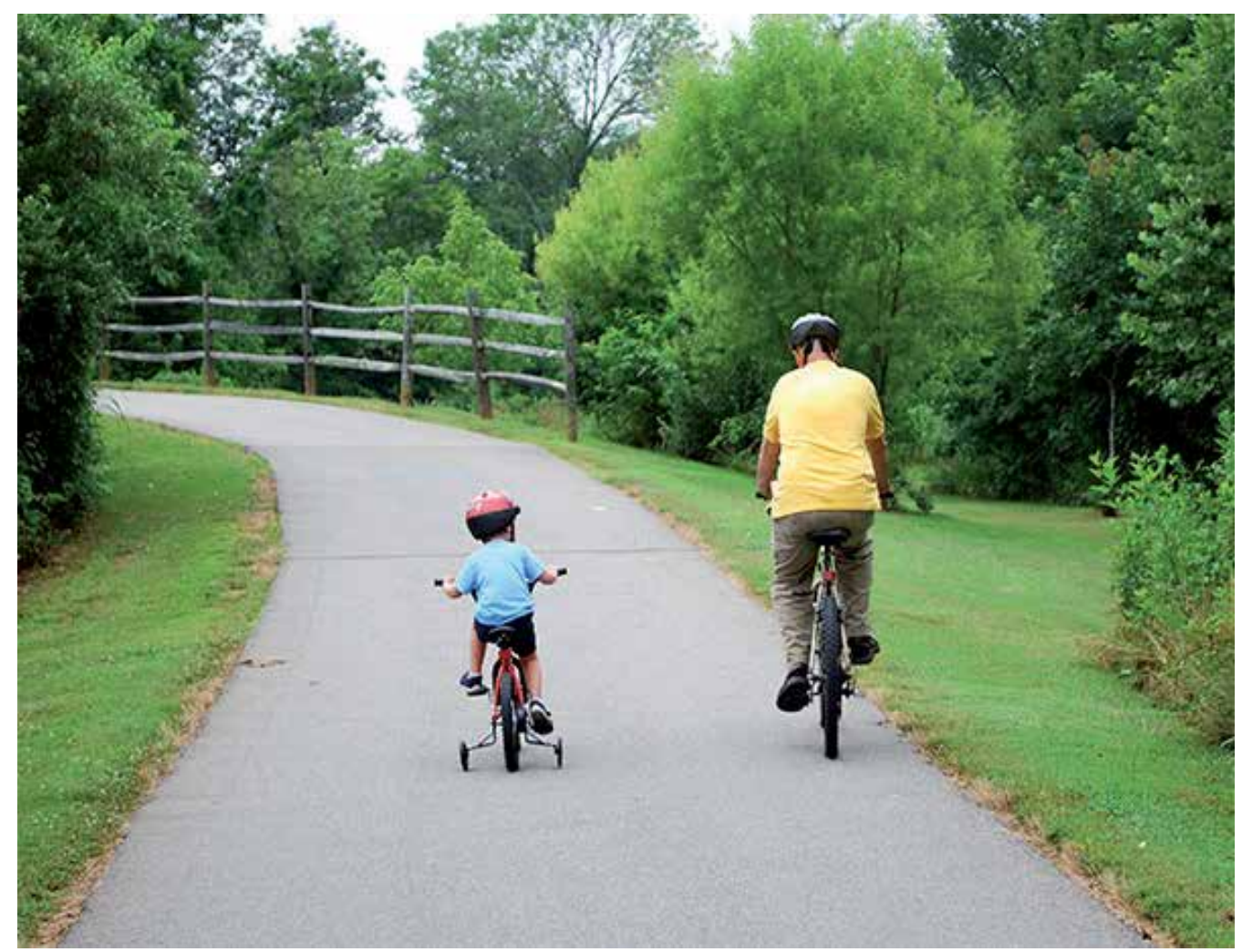

Figure 1. Salisbury Greenway Bicycle Way/ North Carolina

Greenways are defined differently in both the concept and scope. Since these greenways focus on different aims, their scopes are different (Scudo, 2006). For example, the level of aims of protection, using mainly under protection, protection mainly under using and using (like recreation) affects the forming of greenways.

Two words should be examined to make clear the definition. The full word is "Greenway". "Green" is defined as forests, riversides, natural spaces like wild life, "way" as a route or an axis. Two words together are depicted as greenway or an axis integrated with landscape (Watson et. al., 2003). 
Greenways are a general term of showing linear consistency, linking open and green spaces and providing development into urban texture. There are bicycle passages, wild life routes, improved water sides or a river far from a city or pedestrian axes forested along a bay. Within the urban landscape, greenways brought together two functions. One of them is to form open spaces which are open to public and for recreational uses, and the second one is to ensure to protect and develop natural resources (Vikipedi Özgür Ansiklopedi, 2008).

Greenways are the passages that provide linking the spaces that have the specialty of high natural resource or are of cultural aspects. These greenways are based on both land and water (http://www.chaddsfordpa.net/resources.htm).

Greenways are the greened passages which follow the ways that are out of use or used by motorless vehicles (http://www.aevv-egwa.org/site/1Template1.asp? DocID=144\&v1ID= $\&$ RevID=\&namePage=\&pageParent).

\section{Developing process of greenways}

Even if their scope is narrow, greenways whose first examples come out in the nineteenth century gave birth as an answer to the needs for the conditions of relevant period, the changing - corrupting process of landscapes in the last century and negative development of cities to the detriment of ecosystems. Changing of conditions, conceptions and tendencies lead to change of the concept and scope of greenways.

In the context of urban planning of nineteenth century, the development process of greenways classified into 3 categories. These are:

1. First Generation Greenways (the period between1700 and 1960)

2. Second Generation Greenways (the period between 1960-1985)

3. Third Generation Greenways (the period after1985)

\subsection{First generation greenways the period (between 1700 and 1960)}

First generation greenways are defined as "Green Way" and the first example of special and attractive corridors through the city (Searns, 1995). The axes that link in Europe city spaces and their surrounding are planted, boulevards and at the end of the nineteenth century, the parkways commonly used in the USA are the systems of first examples of these corridors (Ahern, 2004).

Frederick Law Olmsted developed the idea of parkway system which leads to taking shape of current greenways (Kent and Elliott, 1995). The first parkway model started with the designs of Central Park of New York city by Olmsted and Vaux (http://www. umass.edu/greenway/Greenways /2GR-def.html).

In later period, Olmsted and Vaux who are affected by the wide boulevards of Paris and Brussels designed "Prospect Park (Macdonald, 2005). One of the important aspects of this park is its characteristic of rural landscape which is fully different from central park and the general structure of the city. 
At the end of the nineteenth century and beginning of the twentieth century, first real greenways came from the system of the open spaces of the main city. This mostly is the network that is formed due to linking spatially linear spaces belong to public. The system is tied to the current topographical and hydrological models in the landscape. The Boston Park system is the most important one of these systems that Frederick Law Olmsted designed (Zube, 1995).

In 1887, The Boston Park System known as "Emerald Necklace" is the first greenway planned in the USA. Newton mentions this park system as parkway. This system that is 25 $\mathrm{km}$ length link the cities of Boston, Brooklyn to Cambridge city in Massachusetts State and Charles river to these spaces (Fabos, 2004). Olmsted also named this system as "strip park" known as parkway before (Little, 1995).

While, today, Boston Park system provide mostly recreation, transportation, water quality, flood control, nice view, wildlife, when it was first planned as a model, it was designed for linking the current conserved areas to the ecological greenways. This first design of Olmsted is adopted by various landscape architects (Ahern, 2004).

Charles Eliot, the pioneers of Landscape Architecture, suggested a comprehensive park system for Boston main city region. This corridor combined 6 wide green spaces connected to each other in the slums of main city into 3 big rivers (www.umass.edu/greenway). The suggestion of Eliot that sees rivers and their sides as the complementary of greenway system is important for the planning of greenways.

In nineteenth century, H.W.S. Cleveland, with Theodore Wirth, beside Eliot in the USA, planned greenways network for Minneapolis main city region. This parkway that provides both transportation and walking, picnic and natural hiking and is of 23-mile length is the parkway of Bronx River (Ryder, 1995).

After Bronx River parkway, parkways started to increase with this new trend and the architect Robert Moses who is affected by this trend implemented several parkways such as Hutcheson River Parkway, Taconic Parkway, Saw Mill River Parkway and Cross County Parkway, in Westchester and Bronx, and Henry Hudson Parkway in Manhattan (Arslan et.al., 2007).

The aim of Moses is to form a recreational network for New York people. Because of the transporting easiness of motorcars, as tendency for recreational spaces is getting increased. Moses especially observed that the spaces in Westchester and New Jersey have limited possibility for weekend activities. For this aim, Moses formed the Brooklyn-Queens greenways that link all the rural region which include east river, agricultural fields, sea sides, ponds, rivers and forest areas (Little, 1995).

As well as parkways concept, the green generation concept within the historic development of the greenway idea has an important place. The idea of parkways of Olmsted and Moses became the source to thought of surrounding and zoning the city, developing in the course of time. The first greenway that is The London Plan of Ebenezer Howard is defined as a 
band limiting the borders of cities and a wide band of 5-mile or more in rural areas (Searns, 1995).

In this period, other landscape architects are Henry Wright and Charles Eliot II who work on greenways. A park design which is 40 mile length and is named as " 40 -mile circle" by Wright and Eliot II is held up by other greenway planners instead of a big park design in Portland, Oregon. Moreover, that Wright include several landscape elements from river greenways to forest spaces in integrated greenway network is supported by ASLA (American Society of Landscape Architecture) (Fabos, 2004).

Another plan in this period is the first open space plan which was designed by Charles Eliot II for Massachusetts state. The comprehensive plan in statewide was named "Bay Circuit Plans". This comprehensive plan which is some $250 \mathrm{~km}$ length links several wetlands and drainage systems and surrounds Boston city (www.umass.edu/greenway).

The most important development in this period is the coupling national parks and comprehensive recreational areas and parkways and so there will be continuity between the spaces that are protected and used for recreational aim (http://www.nps. gov/aboutus/history.htm). A highlighter example of this is Blue Ridge Parkway along the Appalachian mountain (Fabos, 2004).

\subsection{Second generation greenways (the period after 1960-1985)}

First generation greenways that are parkways included in the open and green space system that links urban and rural spaces are firstly converted into the urban corridors after the second half of twentieth century.

Throughout the 1960s and 1970s, the subjects that support contemporary greenways development process in terms of environmental aspects are divided into two parts. One of them is the increasing of bicycle passages and second is the works of landscape architects in academic area.

Because the harms that motorcars coming out from 1900s do increased towards the second half of twentieth century so the demand for bicycle passage and pedestrian pathways that are motorless traffic routes. The implementation of the bicycle passage and pedestrian pathways that are a part of greenways is practiced several times in the USA and Europe. Throughout the period of 1960s-1970s, bicycle passage and pedestrian pathways named as city pathways supported the environmental conscience because they had had the goals of preserving cultural landscapes, controlling the city development and recreation (Little, 1995).

In this process that environmental conscience was increased, several landscape planning and design works that are linked to greenways would be a basis for the studies and were realized. Phil Lewis determined 220 natural and cultural resources in Wisconsin by "the method of mapping" that he found. Since these resources are especially along the river or drainage spaces, Lewis (1964) named these spaces as "environmental corridors". Lewis's mapping, analyzing and evaluating the resources provided a basis for the suggestion plan of 
"Wisconsin Heritage Pathway". "The term of environmental corridor" that was created by Lewis to protect river corridors or the spaces environmentally sensitive is used in first greenway/green space system planning in statewide. In this planning process, to protect the spaces that are environmentally sensitive, and river corridors are targeted (Fabos, 2004).

The end of 1960s is the beginning for the term of "Greenway". In this period, William $\mathrm{H}$. Whyte used the term of "Greenway" for the first time in his book entitled" "The Last Landscape" that he wrote to get rid of motorcar (Bueno et. al., 1995). The first implemented greenway project of Whyte is "Platte River Greenway" in Denver in the mid of 1970s. This corridor, 10 mile length, comprises parks, spaces having natural characteristics, canals and harbour region. There is also a stroll and bicycle route, $2.5 \mathrm{~m}$ width (Searns, 1995).

\subsection{Third generation greenways (the period after 1985)}

These greenways targeted to satisfy aesthetical and recreational needs for city dwellers with the beatified axes and corridors in addition to motorless vehicles routes. Thus, both negative effects of urbanization are reduced and alternative corridors that supply influential visual forms and greens for screening the fumes and noises of motorcars are created. This situation contributes to the spiritual healing of urban people (Searns, 1995).

This generation corridors have more comprehensive duties apart from all these characteristics of them. Third generation greenways, beyond meet people need, take on a lot of goals such as preserving habitat, reducing flood harms, increasing water quality, protecting historical sites, education, which are integrated with space and resource management concepts (Mugavin, 2004).

\section{Greenways types}

Greenways that are a part of a wide network to protect the elements which shows physical continuity in landscape are formed around railways, canals, roads that are along the hillsides and valleys, watersides and rivers.

Main concept is to keep the corridor "green" with the natural vegetation and to connect the interesting points along the river and similar systems to a "way" or line. Greenways are formed directly and indirectly for people benefits and uses. For example, a greenway can provide recreational walks, observing wild life, recognition and evaluation of the environment, river fishing and riverside protecting (Glossary of Bicycle Terms, 2008).

Greenways are divided into 6 groups according to the projections of scientists and planners who work for different goals;

Urban riverside greenways: they are the greenways that are formed by riversides in urban areas. Sometimes, the destroyed riversides which are affected by urban activities can be ameliorated by redevelopment programs. These spaces are thought as a part of greenways (Little, 1995). Beside this definition, not only riversides but the other sources that are linked to water are included greenways (Fig. 2). As a result, the greenways are formed along the 
water resources such as, flood beds, river corridors and wetlands. The aim of creating these greenways is to protect resources, ameliorate and manage (Ahern, 1995).
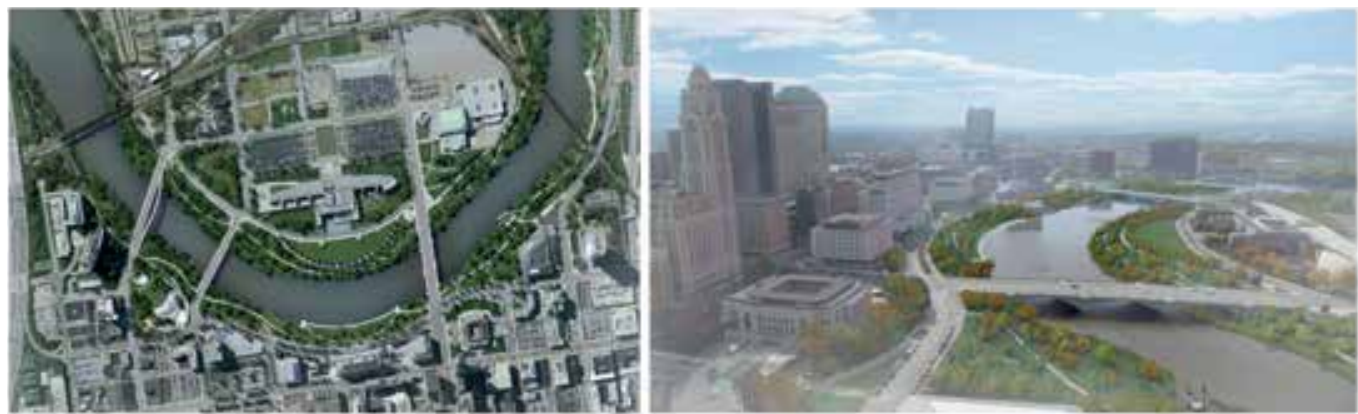

Figure 2. Scioto River Greenway

Recreational greenways: They are the spaces that have characteristics of routes and pathways of various type and go along a very long line (Little, 1995). Beside the natural corridors, canals and railway routes can be examples of that kind of spaces. These ways are formed along the routes and pathways passing through recreational spaces generally linked water and landscape resources which are of high visual value (Fabos, 1995). The recreational focuses in these pathways not only can be both urban and rural but local, regional, national and international (Fig. 3).

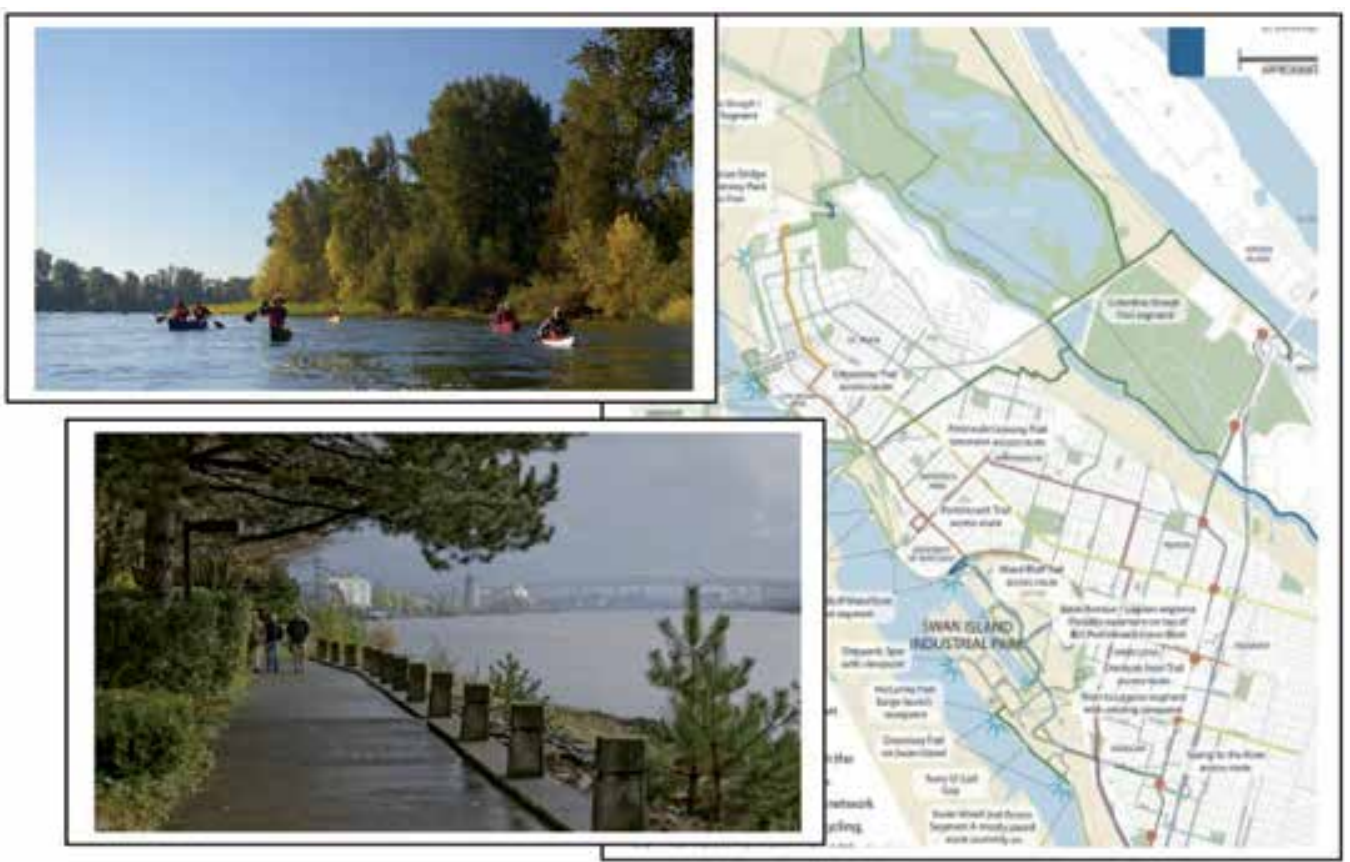

Figure 3. Willamette River Greenway, Oregon 
Natural corridors that are of Ecological importance: they are the corridors which are formed by the spaces generally along the rivers, and sometimes valley sides (Little, 1995). These kind of spaces make possible protecting wild life, migrating of species, sustaining biological diversity and natural hiking (Fabos, 1995). Ahern (1995), define ecological corridors as "ones that are linked to biodiversity" (Fig. 4).

Greenways that have visual and historical value: they are the greenways that are attract tourists, provide benefits of economical, educational and visual and supply permanent-seasonal accommodation (Fabos, 1995). They generally are the routes along the road or motorways and the routes rarely along watersides. These routes make possible seeing by getting out of vehicles and pedestrian activities in specific points (Little, 1995). Another important characteristic of these greenways is that they link cultural and historic resources (Ahern, 1995).

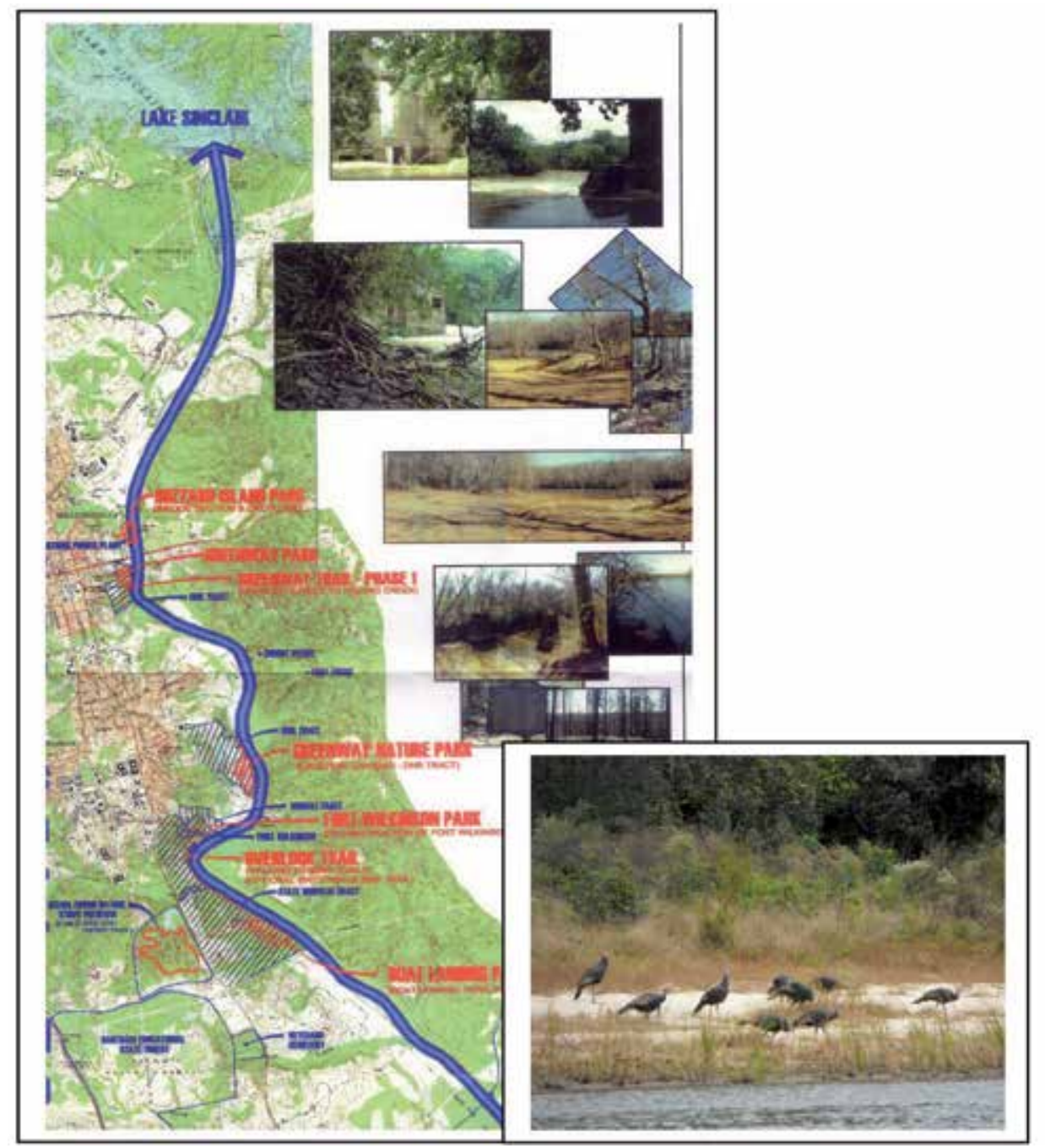

Figure 4. Oconee River Greenway, Athens, Georgia. 
The greenways that aim controlling of urban development: these greenways are formed to separate urban and rural areas and control enlargement (Ahern, 1995).

Comprehensive greenways systems and networks: they are formed by linking different kinds of open areas to greenways in urban and regional scale (Little, 1995).

\section{The functions and benefits of greenways}

Greenways have a lot of functions such as protecting water sources, reducing pollution, increasing river side habitat and biodiversity, reducing flood harms, providing recreational opportunity, supplying environmental education, alleviating noise, enhancing microclimatical effects of both cooling and decreasing pollution and reducing riverside erosion (Bischoff, 1995).

It is possible to divide the functions of greenways into two groups as rural and urban. Within the developing urban landscape, greenways have to functions: one of them is to create open spaces for people's easy reach (public access) and recreational uses and second to provide protecting and developing natural resources which are still present nowadays. In this context, the greenways that tie in with many various linear open spaces in cities and so provide developing into the textures of cities can be a bicycle passage wildlife routes, urban riverside corridor etc. These urban corridors take on some various duties such as answering to the increasing of people interest for their outside recreation, protecting the areas of habitat and wildlife, balancing between the air pollution and excessive heat changes and controlling urban development (Watson et. al., 2003).

One of the key functions of greenways is a special way that integrates the uses suitable for each other and separates the unsuitable ones from each other.

Greenways provide many benefits that increase quality of public life with using spaces for multiple goals. The recreational, ecological, environmental, cultural, aesthetical, educational and economical benefits are obtained from developing and protecting greenways.

\subsection{Environmental benefits}

The ecological characteristics of greenways make possible sustain the life of plants and animals, and cause bio-diversity to increase and be protected (Ndubisi et.al., 1995).

Several scientists believe that disintegrating of habitat is the most threatening factor to biologic diversity among the factors such as global warming, extracting metals, grazing, urban development. Disintegrating stems from the changes that human beings make. The structures like roads, canals or the activities such as agricultural development and deforesting prevent the species from their free movement. Ecologists advocate that beside the reducing obstacles, landscape greenways should be created to solve the problems. These linear connections combined habitat parts to make link species, populations and ecological processes (Bueno et. al., 1995). 
Greenways take on important duties that are of urban ecological systems. They are important to protect present natural areas hence urban ecological system for future urban development

\subsection{Educational benefits}

Greenways create practical opportunities for training users about natural landscape and cultural/historic areas, and create awareness (http://www.stlucieco.gov/greenways/ greenways.why.htm).

Greenways are like an open air class. They especially provide information about the importance of the natural environment with the children schooled (Searns, 1995).

\subsection{Economical benefits}

The economical benefits of greenways are the increasing land prices, growing tourism and increasing business and trade opportunities (Bueno et. al., 1995).

Greenways have positive effects on values of lands that are in neighboring areas. The outside recreational demands of people and increasing social interaction such as biking, walking, fishing or sightseeing cause the value of lands near to these greenways to increase (Rutgers Department of Landscape Architecture and Morris Land Conservancy, 2002).

Greenways create opportunities for economical growth, providing bicycle renting along the axis, new business areas and establishments such as shops, restaurants and health clubs.

\subsection{Aesthetics benefits}

Aesthetical quality and public perception can be increased by greenways. Greenways seems to be such a mechanism that provides a means of preserving open space while at the same time creating a "green infrastructure" to link people and places (Fabos, 1995). These greenways also create opportunities for planners and designers to form new norms in urban planning and design.

\subsection{Recreational benefits}

The greenways that are designed for recreational goals include organized sport areas, bicycle passages, walking routes, hacking courts and group activities.

These greenways as alternative transportation corridors link origins and destinations for people to go they want along the landscapes that provide sightseeing with pedestrians and cyclists (Conine et. al., 2004).

Greenways, beside developing opportunities based on natural resources in linear ways along the rural and urban landscapes, reach a dynamic recreational use, coupling the free areas that have recreational potential in urban areas on to each other. Hence a setting is 
prepared for both recreational diversity, user satisfaction and using potential, and providing city sustainability (Aydemir, 2004).

\subsection{Social benefits}

The life quality of communities is increasing due to the natural, visual value and similar characteristics of greenways. According to the research of Lee (1999), several greenways in Oakland, Chicago affect local people because of their visual characteristics. Neighboring and friendship relations of the people who use greenway is increased and so greenways became focusing points in which various activities are made (Shafer et. al., 2000).

\section{Criteria that determine greenways}

Five key words show the basic characteristics of corridors in the scope of "relating to planned, designed and ecological, cultural, aesthetical and sustainable space use concepts, and space networks which are managed for multipurpose, comprising linear elements" of greenways (Frischenbruder and Pellegrino, 2006).

According to this definition:

1. The areal shape of greenways is first linear. This characteristic of corridors provide the recreative activities like bicycle use and it provides ecological contribution by transporting material, species and nutrients in terms of wild life and cause landscape planning to have supremacy and opportunities. This characteristic is the point that the greenways differ from other landscape planning concepts.

2. The greenways that are an integrated system try to make association based on linking advantages beyond the spatial scales. Link is another key that defines greenways, contacting the different levels of scales and wholeness of bigger landscape.

3. The structure of multiple functions of greenways is required to be provided functional and spatial coherence of certain uses. Because of this characteristic, especially determining process of aims is important for planning of greenways. Determining and realizing targets can be hard for greenways that carry ecological, cultural, social and aesthetical aims. For example, because both aims contradict with each other and spatial and functional differences are required for a greenway protect both recreation and wild life, one of the special management or uses should be eliminated for their togetherness. The decisions that are the aims of greenways should reflect the social and cultural values and suggestions as well as environmental protection.

4. Greenway policy take on a complementary duty between nature protecting and economical development, beside linking to sustainable development concept. These greenways are an effort not only protecting nature but also balancing between resource use that make possible other landscape uses of people and protecting.

5. Greenways supply different spatial policies based on the advantage of integrated linear systems. These greenways also can be thought as complementary for comprehensive landscape and physical planning (Viles and Rosier, 2001). 


\section{Greenway planning}

Although the actuality of greenway concept is getting increased more and more, there are some uncertainties about how these greenways are planned. Some of the greenways are planned because they have potential for their roles in biological diversity and controlling and directing the city development, and the others because they have recreational benefits. Determining the aim is especially important for planning and designing of greenways.

One of the aims of greenway planning is environmental protecting. The greenways along the river or creek sides have effective duties such as reducing the pollution stemmed from urban and agricultural irrigation, preventing soil erosion and protecting water quality (Arendt, 2004).

Planning process targets at establishing a continuous network system that support basic ecological functions, protect important natural and cultural resources and keeping sustainability of landscape. In this respect, greenway planning head for an integrated landscape planning that try to create linear networks in a sustainable frame work (Sijmons, 1990; Kerkstra and Vrijlandt, 1990; Van Buuren, 1991; Ahern, 1995).

Greenway planning began at local scale and go on at regional scale to create greenway systems (Conine et. al., 2004). Planning process take into account the networks that are taken place in a wider landscape wholeness, and linear areas. Planning also includes an approach that provides a lot of benefits because it pays attention to areal and spatial association. In this context, greenway planning process try to provide sustainable landscapes against disintegrating, space decreasing, urban development and uncontrollable change of area use (Ahern, 1995).

\section{Implementation examples of greenways}

\subsection{The Capital Area Greenway, Raleigh, North Carolina}

The Capital Area Greenway, the first comprehensive local greenway system, is not an implementation plan that is prepared by a professional planning team or specialists. This implementation is developed as a graduate project of a student in North Carolina University. The aim of the project is to protect the natural structure of Raleigh settlement. This student suggested a greenway network through all the districts of the city instead of forming only a riverside park in his project. Today, the plan implemented protects ecosystems like wetland, suggesting recreation opportunities such as race track, bicycle passage. The Capital Area greenway is a model to 35 local scale greenways in North Carolina (Fig. 5) (Little, 1995).

\subsection{Lambro River Valley Greenway, Italy}

Lambro river and its environment are locally chosen as an exemplary space in order to form a greenway planning approach in regional scale, in Italy. It is targeted to protect the present 
natural resources, historical spaces and to create recreational spaces along the Lambro river in north of Milan by this greenway. This corridor, including the dwellings that are along the river, is a basic element formed for the motorless vehicles that couple a lot of sources in the space on to the city (Toccolini et.al., 2006).

\section{CAPITAL AREA GREENWAY}

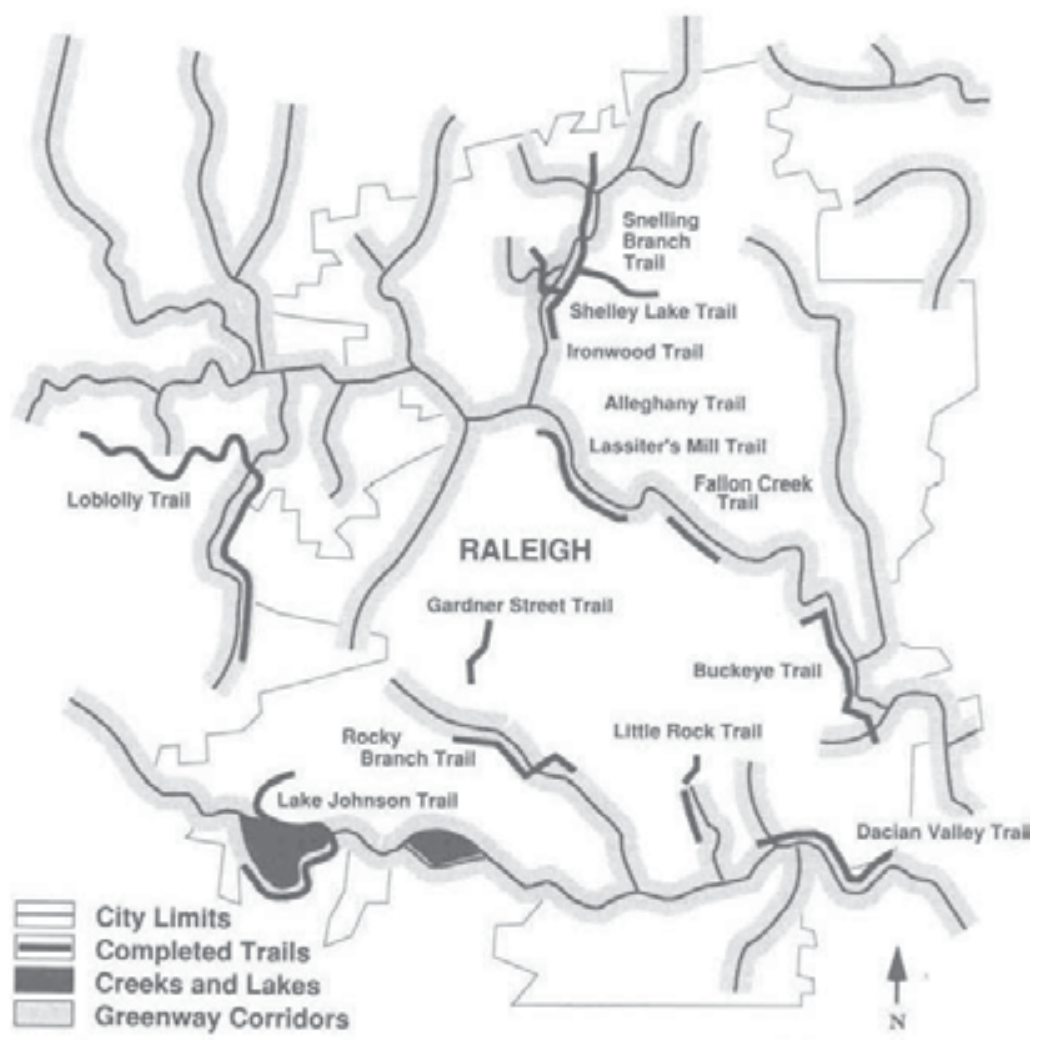

Figure 5. The Capital Area Greenway, Raleigh, North Carolina (Little 1995).

\subsection{Calgary, Fish Creek Greenway, Canada}

Fish Creek river corridor which passes through Calgary city is evaluated in the scope of greenway application in 1966 and so, in 1972, it is sequestrated by local authorities to protect these greenways and to provide possibility of recreational use of them. Calgary urban greenway is approximately of 1200 hectares with a part within the urban area of Bow River with Fish Creek River Valley. Moreover, the total length of greenway is $13 \mathrm{~km}$ and its wide $0.8 \mathrm{~km}$. Greenway forest spaces comprise pastures, river and river flood and historical spaces. Therefore, ecological characteristics are primarily taken into account in forming the corridor. Certain development centers are chosen and connections are provided between these centers in plan. Some connections are designed as bicycle and walking way. Fish Creek protect urban greenway, natural and cultural landscape values and is one of the 
successful implementations of greenway that meet public recreational needs (Taylor et. al., 1995).

\subsection{New England Vision Plan}

In this plan, to form an integrated network of greenways that combine the greenway networks of 6 states, Connecticut, Massachusetts, Maine, New Hampshire, Rhode Island and Vermont in New England region, ABD is targeted. The basic of the aim is to make sustain natural landscapes which have mountains, hills and rivers from North to South between states. When the plan that its implementation has not yet finished is completed, a greenway connections that are $57.000 \mathrm{~km}$ length between the wild life, recreational, historic and cultural areas mostly along river zones are provided (Fabos, 2004).

\subsection{The Brooklyn - Queens Greenway, Coney Island}

The aim of Brooklyn-Queens greenway planning is that ecological, cultural, recreational sources can be easily reachable and make possible various uses of it for city people (Fig. 6). Especially, wide open spaces are present for those who prefer a lot of soccer and baseball, tennis courts that are more than 100, uses that make possible various water activities along the greenway that have much rich potential in terms of recreational uses, two golf areas, two ice skate courts, funfair and passive recreations (Little, 1995).

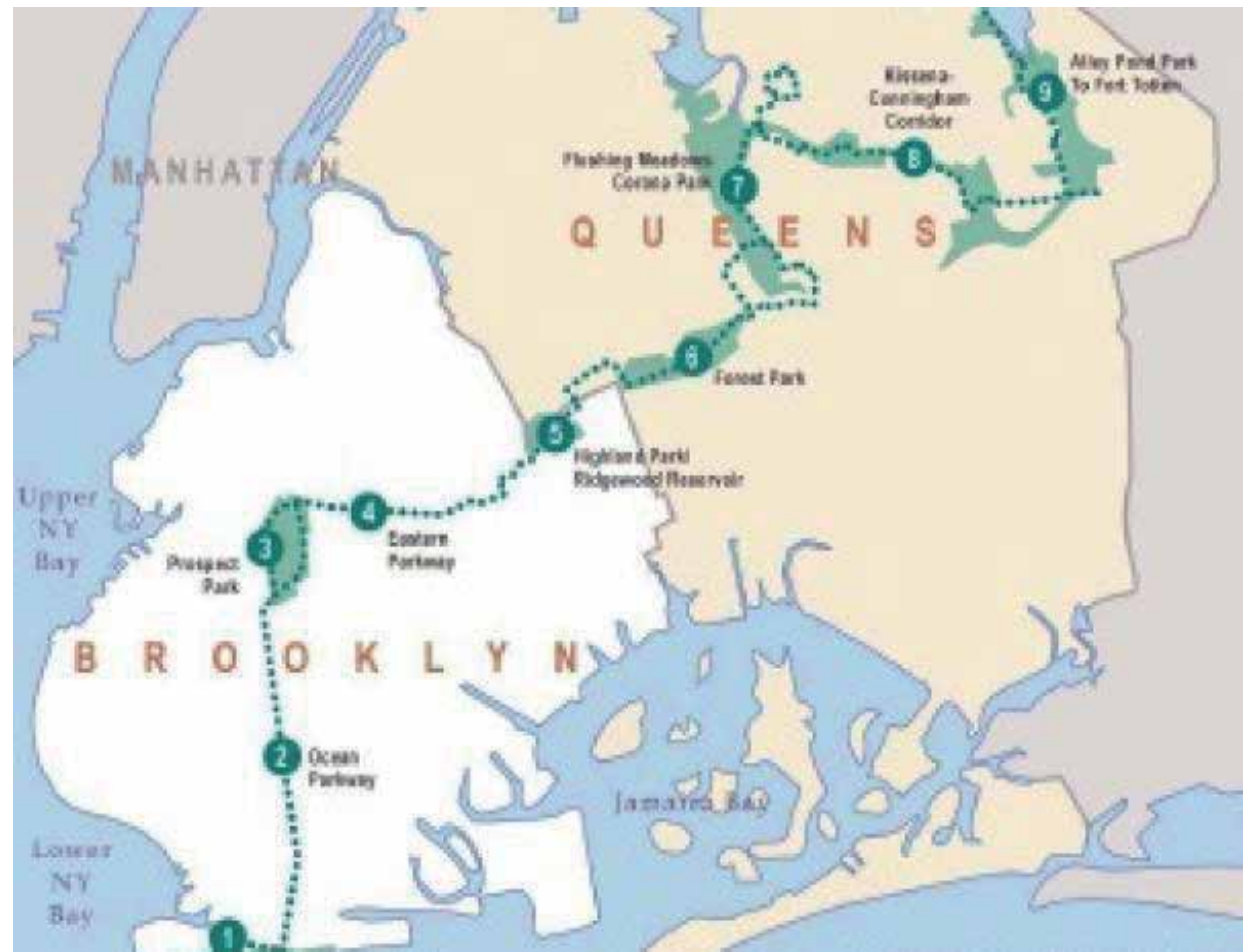

Figure 6. The Brooklyn - Queens Greenway 


\section{Author details}

Aylin Salici

Mustafa Kemal University, Architecture Faculty, Department of Landscape Architecture, Turkey

\section{References}

Ahern, J., 1995. Greenways as a Planning Strategy. Landscape and Urban Planning. Volume:33, 131-155 p.

Ahern, J., 2004. Greenways in the USA: Theory, Trends and Prospects (Jongman, R. and G., Pungetti). Ecological Networks and Greenways, Concept, Design, Implementation, Cambridge University Press, 34-55 p. ISBN 0521827760.

Arendt, R., 2004. Linked Landscapes Creating Greenway Corridors Through Conservation Subdivision Design Strategies in the Northeastern and Central United States. Landscape and Urban Planning 68, 241-269 p.

Arslan M., E. Barış, E. Erdoğan, Z. Dilaver, 2007. Yeşil Yol Planlaması: Ankara Örneği. Ankara Üniversitesi Bilimsel Araştırma Projesi Kesin Raporu, ISBN:978-975-01213-0-2 Proje Numaras1: 2000-07-11 032, 139 s.

Aydemir, S.E., 2004. Kentsel Donatılar-Açık Alanlar ve Rekreasyon Kentsel Yeşil Alanlar.

Kentsel Alanların Planlanması ve Tasarımı. Akademi Kitapevi, Trabzon, 285-337 s. ISBN: 975-95396-7-5.

Bischoff, A., 1995. Greenways as Vehicles For Expression. Landscape and Urban Planning. Volume: 33, 317-325 p.

Bueno, J. A., V. A. Tsihrintzis and L. Alvarez, 1995. South Florida Greenways: A Conceptual

Framework For The Ecological Reconnectivity of The Region. Landscape and Urban Planning. Volume: 33, 247-266 p.

Conine, A., W-N. Xiang, J. Young and D. Whitley, 2004. Planning for Multi-Purpose Greenways in Concord, North Carolina. Landscape and Urban Planning. Volume: 68, 271-287 p.

European Greenways Association, 2004. The European Greenways Good Practice Guide, Bruxelles. http://en.wikipedia.org/wiki /European_Greenways_Association.

Fabos, G.J., 1995. Introduction and Overview: The Greenway Movement, Uses And Potentials of Greenways. Landscape and Urban Planning. Volume: 33, 1-13 p.

Fabos, G.J., 2004. Greenway Planning in the United States: Its Origins and Recent Case Studies. Landscape and Urban Planning 68, 321-342 p.

Frischenbruder M.T.M. and P, Pellegrino, 2006. Using Greenways to Reclaim Nature in Brazilian Cities. Landscape and Urban Planning. Volume: 76, 67-78 p.

Glossary of Bicycle Terms, 2008.

http://adirondackresearch.com/projects/ bicycle/hglossary.html.

http://www.aevvegwa.org/site/1Template1.asp?DocID=144\&v1ID=\&RevID=\&namePage=\&p ageParent.

http://www.chaddsfordpa.net/resources.htm.

http://www.nps.gov/aboutus/history.htm 
http://www.stlucieco.gov/greenways/greenways_why.htm http://www.umass.edu/greenway

http://www.umass.edu/greenway/Greenways/2GR-def.html

Kent, R.L. and C.L. Elliott, 1995. Scenic Routes Linking and Protecting Natural and Cultural Landscape Features: A Greenway Skeleton. Landscape and Urban Planning, Volume 33, Issues 1-3, 341-355 p.

Little, C.E., 1995. Greenways for America. The Johns Hopkins University Press, London, 237 p. ISBN: 0-8018-5140-8.

Macdonald, E., 2005. Suburban Vision to Urban Reality: The Evolution of Olmsted and Vaux's Brooklyn Parkway Neighborhoods. Journal of Planning History 4:495, 295-321 p. Mugavin, D., 2004. Adelaide's Greenway: River Torrens Linear Park. Landscape and Urban Planning, Volume 68, Issues 2-3, 223-240 p.

Ndubisi, F., T. Demeo and N.D. Ditto, 1995. Environmentally Sensitive Areas: A Template For Developing Greenway Corridors. Landscape and Urban Planning. Volume: 33, 159$177 \mathrm{p}$.

Rutgers Department of Landscape Architecture and Morris Land Conservancy, 2002. High Lakes Greenway: Linking Communities with Nature. Morris Land Conservancy, Boonton, NJ., 60 p.

http://www.yorku.ca/carmelca/6101E/readings/Rutgers-HighLakesGreenway.pdf.

Ryder, B.A., 1995. Greenway Planning and Growth Management: Partners in Conservation?. Landscape and Urban Planning, Vol: 33, Issues 1-3, 417-432 p.

Scudo, K., 2006. The Greenway of Pavia: Innovations in Italian Landscape Planning. Landscape and Urban Planning 76, 112-133 p.

Searns, R.M., 1995. The Evolution of Greenways as an Adaptive Urban Landscape Form. Landscape and Urban Planning 33, 65-80 p.

Shafer, C.S., B.K. Lee, S. Turner, 2000. A Tale of Three Greenway Trails: User Perceptions Related to Quality of Life. Landscape and Urban Planning 49, 163-178 p.

Taylor, J., C. Paine and J. Fitzgibbon, 1995. From Greenbelt to Greenways: Four Canadian Case Studies. Landscape and Urban Planning. Volume: 33, 47-64 p.

Toccolini, A., Fumagalli, N. and Senes, G., 2006. Greenway Planning in Italy: The Lambro River Valley Greenways System. Landscape and Urban Planning, Volume 76, Issues 14, 98-111 p.

Vikipedia Özgür Ansiklopedi, 2008. Yeşil Yol. http://tr.wikipedia.org /wiki/Ye\%C5\%9Fil_yollar.

Viles R.L. and D.J. Rosier, 2001. How to Use in the Creation of Greenways: Case Studies in Three New Zealand Landscapes. Landscape and Urban Planning. Volume: 55, 15-27 p. Watson, D., A. Plattus, R., Shipley, 2003. Greenways. Greenways Time-Saver Standards for Urban Design, McGraw-Hill, 5.5-1 p. ISBN: 0-07-068507-X.

Zube, E.H., 1995. Greenways and The US National Park System. Landscape and Urban Planning, Volume 33, Issues 1-3, October 1995, 17-25 p. 
Section 4

\section{Landscape Ecology}





\title{
Understanding Landscape Structure Using Landscape Metrics
}

\author{
Ercan Gökyer \\ Additional information is available at the end of the chapter
}

http://dx.doi.org/10.5772/55758

\section{Introduction}

Landscapes are dynamic systems. Human affects them continuously. Depending on intensive human effects, pressure was increased on landscapes. Consequently, landscapes were altered over time.

There are negative effects of pressures on landscape and species living in the area. The negative effects are especially vulnerable more intense to the human effected landscapes. In these landscapes, fragmentation increased. Habitats have been damaged. Depending on these effects material flow and transactions of the species are limited.

Landscape ecology investigates landscape structure and changes in the landscape. Change expresses any modification occurring in the landscape over time. Landscape structure evaluates land mosaic as measure, number, size and shape.

Landscape metrics are important tools which are used to understand landscape structure and landscape changes. To use metrics, numeric data is obtained related to landscape structure. Numeric data is produced from satellite images and air photos. Also, landscape metrics are used as compatible with geographical information systems. Landscape metrics allow doing objective reviews on landscape structure.

In this study it was aimed to understand the landscape metrics. To do this, Landscape ecology and its characteristics (structure, function and change) must be emphasized. So, firstly these topics explained. After landscape metrics explained and a case study done on landscape metrics.

\section{Landscape ecology}

Landscape Ecology is a science branch in Ecology which uses the numbers. Researchers intensively investigate on landscape structure and landscape change in this science. 
Landscape is the most important research material. What is the "Landscape"? Researchers made a lot of definition on landscape.

Landscape was defined firstly by Alexander Von Humbdolt as "all of the characteristics of a land" (Farina 2000). Landscape as a heterogeneous land area composed of a cluster of interacting ecosystems that is repeated in similar from throughout (Forman and Godron 1986). Farina (2000) defines landscape as "heterogeneous land area, consisting of interaction sets between ecosystems". Landscape was defined in European Landscape Convention as "means an area, as perceived by people, whose character is the result of the action and interaction of natural and/or human factors" (http://conventions.coe.int).

Landscape became an integrative concept in many disciplines (Antrop 2005). All of Landscape definitions have in common expressions. These are (Antrop 2005):

- $\quad$ is seen as a spatial entity, having a variable extent and scale, and has territorial properties,

- $\quad$ is perceived and experienced,

- $\quad$ is composed of many very different elements and components that interact and are structured in some way,

- with a spatial organization and management that is largely influenced by humans,

- Is dynamic and changes are an inherent property of landscape.

Landscape ecology is a young but well-recognized ecological discipline dealing with the spatial distribution of organisms, patterns and processes (Farina 2010). Landscape ecology is a science branch of ecology to make contributions related to complexity studies (physical, biological, and ecological) of ecology. Landscape ecology uses numbers related to complexity studies. Also, it uses remote sensing, geographical information systems and geostatistical tools. These tools have been developed for landscape ecology studies (Farina 2000).

As simplest expression, landscape ecology investigates internal dynamics and interaction of landscapes. Landscape ecology focuses on spatial relationship of landscape elements and ecosystems, functional and structural features of the land mosaic and change that is emerged over time (Dramstad et al. 1995).

Landscape ecology has been emerged since 1980 that is useful and important for land-use planners and landscape architects. By this time, the concept of landscape ecology is seen in other disciplines. After 1980, important study areas of landscape ecology was started to be publish (Dramstad et al. 1995). The last decade has seen a growth in the number of studies and variety of topics that fall under the broad banner of landscape ecology (Farina 2010).

Landscape ecology investigates (emphasizes) the interaction between spatial pattern and ecological process, that is, the causes and consequences of spatial heterogeneity across a range of scales (Turner et al. 2001). The discipline of Landscape Ecology is rapidly emerging as a motive force, both in the domain of theoretical ecology, and in applied fields (Sanderson and Harris 2000). 
Landscape ecology recognizes that ecological units (systems) are arrayed in space in response to gradients of topography, temperature, moisture, and soils. Additional pattern is imposed by disturbances, biotic interactions, and human use of the land. Spatial arrangement, in turn, influences many ecological processes, such as the movement patterns of organisms, the spread of disturbances, and the movement of matter or energy. Landscape ecology, focusing on spatial pattern and the ecological responses to this pattern, leads to a new set of principles, distinct from the principles that govern ecosystem and population dynamics at finer scales (Turner et al. 2001).

Technological developments have also contributed to the emergence of landscape ecology. These developments include rapid advances in desktop computing power, availability of remotely sensed data such as satellite images, and development of powerful computer software packages called geographic information systems (GIS) for storing, manipulating, and displaying spatial data. New research techniques are required in landscape ecology because of the focus on spatial pattern and Dynamics and on large areas that simply cannot be thoroughly sampled or easily manipulated. For example, laboratory and plot experiments are appropriate at fine scales, but broad-scale experiments are logistically difficult, and replication is often impossible. Landscape ecologists have needed to incorporate new sources of data into their studies and creatively study natural experiments. The availability of remote imagery has made it possible to study spatial pattern over large areas and its change through time, opening new horizons for landscape analysis (Turner et al. 2001).

Landscape ecology focuses on three characteristics of the landscape (Forman and Godron 1986).

Structure: The spatial relationships among the distinctive ecosystems or elements.

Function: The interactions among the spatial features.

Change: The alteration in the structure and function of the ecological mosaic over time.

\section{Landscape structure}

Assessing landscape function and landscape change, landscape structure must be known. Connectivity and fragmentation are known with understanding landscape structure.

Landscape structure expresses the spatial pattern of landscape elements and the connections between the different ecosystems or landscape elements. Landscape structure assesses relationship between ecosystems as measure, number, size and shape (Forman and Godron 1986; Gergel and Turner 2002).

Landscape structure has two qualities. These are composition and configuration (Farina 2000).

Landscape composition: Attribute of composition is not spatial, and can't be measured. It defines the quality of the landscape patches, scattered in landscape. The composition is not a 
precise identification of the mosaic structure of the landscape. But, It is a good indicator for living environment suitability of some species (appropriate patch type for species) (Farina 2000).

Landscape configuration: Configuration refers to the spatial characteristics. It refers to spatial characteristics same as the spatial distribution of land cover (Farina 2000).

Landscape ecologists use four basic terms to define spatial structure (FISGRW 1998)

Patch: A nonlinear area (polygon) which is less abundant. It is different from the matrix.

Corridor: A special type of patch which links other patches in the matrix. Typically, a corridor is linear or elongated in shape, such as a stream corridor.

Matrix: the land cover that is dominant and interconnected over the majority of the land surface. Often the matrix is forest or agriculture, but theoretically it can be any land cover type.

Mosaic: a collection of patches, none of which are dominant enough to be interconnected throughout the landscape.

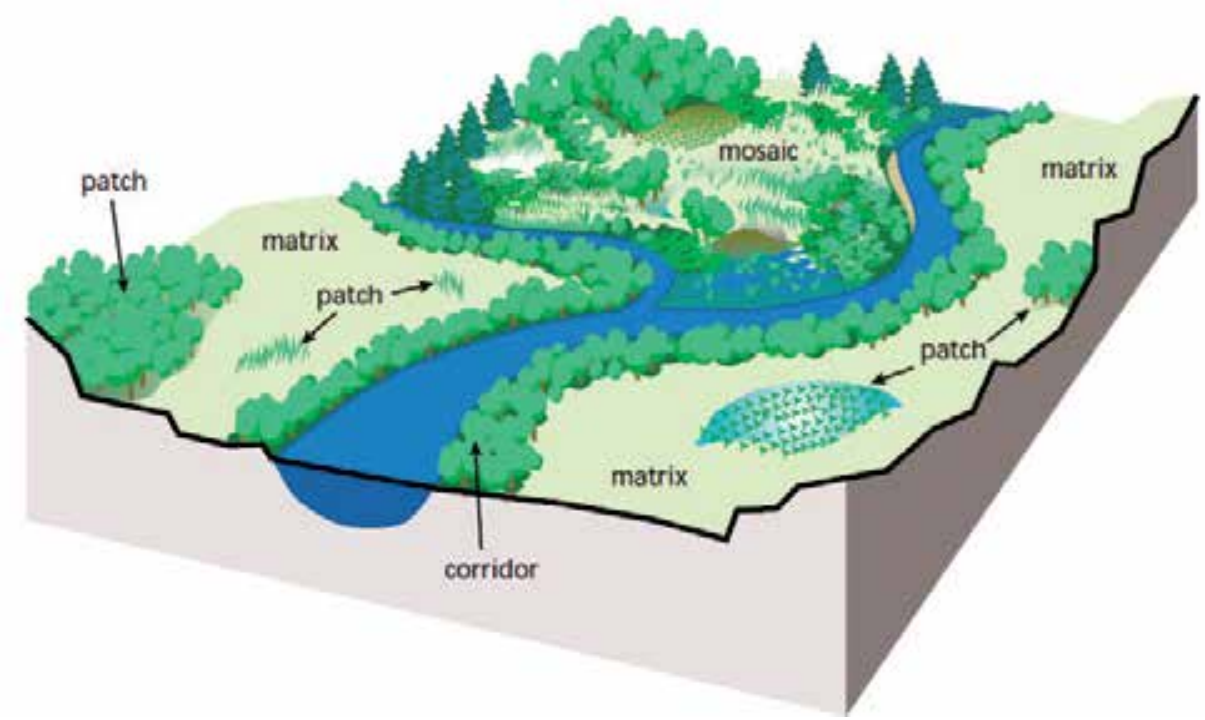

Figure 1. Basic terms to define landscape ecology (FISGRW 1998)

\section{Landscape function}

Landscape function involves flows of animals, plants, energy, mineral nutrients and interactions among these elements. The primary structural characteristics for landscape function are corridors, hedgerows, matrix and networks (Forman and Godron 1986).

Corridors have four important functions. These are; a habitat for certain type of species, movement area for species, a barrier or filter area, a source of environmental and biotic 
effects. All these functions involve flows of animals and plants; the last two functions also include flows of energy and mineral nutrients (Forman and Godron 1986).

Corridors serve as conduits and as filters for much of the movement of animals, plants, materials, and water across the landscape. Network and matrix characteristics affect transactions in contrasting ways, depending on whether the objects cross corridors or use corridors as conduits. Landscape functioning integrates flows both between adjacent ecosystems and across a landscape (Forman and Godron 1986).

Strip corridors have an interior environment and interior species. Stream corridors are most effective in controlling water and mineral nutrient flows from upland to stream when they cover both flood plain and banks, when they are wide enough above a bank to enhance the movement of upland interior species along the corridor. Networks contain alternative pathways for species movement, have differing types of intersections, enclose landscape elements, and exhibit varying mesh sizes (Forman and Godron 1986). Hedgerows are constructed to protect areas from animals. Animals damage crop in a cropland. Hedgerows network effects wind and water stream.

Various birds and mammals appear to move effectively along hedgerows. In winter (rainy season) stream flow was lower in the hedgerow landscape than in the open landscape. In the hedgerow landscape stream flow is less variable through the year (Forman and Godron 1986).

Networks are composed of corridors and notes, and trunk lines handle high-volume flows. A network is done for the movement of people it is important for other ecological features in landscape planning and management. Movement through a matrix depends on its connectivity. Species move along a connected matrix (Forman and Godron 1986).

In the landscape flows dependent on the orientation of the structure (Forman and Godron 1986). Connectivity is very important for landscape function. Sometimes landscapes have fragmented structure.

Habitat fragmentation severely threatens biodiversity and ecosystem functioning wherever humans dominated landscape. Land use planners play a significant role in determining whether and how landscapes and ecosystems are fragmented or maintain natural connectivity (ELI 2003).

\section{Landscape change}

The landscapes of today have been shaped by powerful. Ever-present forces are seen in space and time by anthropogenic activities (Sanderson and Harris, 2000). Landscapes are not static. Landscapes are impressed by Climate changes, land-use changes and human activities. It can be changed mosaic structure, shape and size of patches in a landscape. All these changes could be seen different spatial sizes and frequencies (Farina 2000).

A change can be defined as any modification occurring in a system state (from individual to biosphere) produced by a broad variety of abiotic and/or biotic factors that introduce or subtract energy and information to the system (Farina 2010). 
Changes can be considered modifications in the availability of an expected resource or pattern and the temporary or permanent impossibility for species, populations, communities, ecosystems, and land mosaics to incorporate the new conditions (Farina 2010).

To assess the current conditions of the landscape, historical process must be known. Depending on the natural and cultural influences the changes are seen over time in the landscape structure. In this case, landscape structure and relationship between ecosystems are changed. As a result of change studies, functions and conditions in the mosaic of different sized and shaped patches can be revealed (Wu and Hobbs 2000).

Changes can be integrated with the abiotic-biotic processes, and basic components of each ecosystem. Health of the system can be revealed to analyze rate, frequency, and intensity of change. Change may be occurred at different levels. Small scale systems have a higher change level from large-scale systems. It is more useful to assessment of the change at large scales (Farina 2000).

There are two main factors of landscape change. These are natural processes and human activities (especially nowadays). Both natural conditions and human needs are changed over time. Complex changes can be emerged in the landscape structure related to natural conditions and human needs (Antrop 1998; Farina 2000).

Defining change depends upon the temporal resolution of consecutive observations and data sets. Also, these differences must be observable or measurable in magnitude and this depends on the degree of detail and accuracy of the data used. Frequent and multiple observations enhance the knowledge of the dynamics of landscape processes, but became only available with the technology of remote sensing and the setting up of monitoring programs (Antrop 2005).

Landscape change can be revealed to analyze of aerial photography, land maps and satellite images through different techniques. There are some challenges related to landscape change studies. Data for previous years are different type and quality. It is difficult to get qualified data (Farina 2000).

Landscapes change 'naturally' as they are the expression of the interaction between the natural environment and man's activities. Both the natural conditions and the human needs change in time and are controlled by different but interactive factors (Antrop 1998).

Change can be expressed to made comparison of at least two different time statuses. Landscapes are mixture of the different qualifications in consists of peculiar dynamics. Depending on these dynamics, change can be emerged in different speed and scale (Antrop 1998).

Five main compelling powers are effective in the landscape change. These are listed below (Farina 2000; Bürgi et al. 2004; Antrop 2005):

- Socio-economic forces: Urbanization, industry, industrial activities.

- Political forces: Incorrect applications.

- Technological forces: Car roads, infrastructure facilities 
- Natural forces: Avalanche, landslide, flood,

- Cultural forces: Accessibility, human intervention, fire.

Accessibility is most important within the forces. Whenever people arrived in a field, they quickly start to change this field (Antrop 2005).

The nature of change also demands new thinking. Actual changes are so complex and fast it becomes hard to keep track of them. Comprehensive and integrated methods for fast inventorying and monitoring and assessment at a landscape scale are urgently needed (Antrop 2005).

\section{Landscape metrics}

Landscape metric tools were used in landscape ecology as supporting Landscape planning and landscape management decisions. Landscape metrics were used to measure the landscape structure and the complexity of this structure. The complexity of the structure of landscape structure, landscape metrics used for measuring and Mosaic structure and related information can be obtained. Thus, the characteristics of the landscape easily perceived (Farina 2000; Letiao and Ahern 2002; Wu 2004).

Calculation of the landscape structure (Jaeger 2000):

- To put forward the development of the landscape,

- To assess fragility, emerging over time.

- It was required for determining the relations among structural features, landscape function and landscape change.

Landscape metrics help to calculation composition and configuration, which have two characteristics of landscape structure. We learn knowledge on ecological processes, to use calculations related to composition and configuration (Mc Garical et al. 2002).

To perceive of Landscape composition and configuration with landscape metrics, different approaches are available. To perceive composition, metrics are used to with regard to the importance of each patch type. It was determined characteristics such as rate, richness (patch richness), regularity, dominance and diversity (patch number) with metrics related composition. It was defined physical distribution of patches in mosaic structure with landscape configuration. Metrics are size and shape, neighborhood (the distance to the nearest neighborhood) and distribution related configuration, (Farina 2000; Letiao and Ahern 2002).

Landscape metrics help us to understand changes in landscape from different perspectives (Visual, ecological, cultural). Landscape metrics have been provided contributions to the Landscape ecology studies. These contributions are listed below (Letiao and Ahern 2002; Miller et al. 2005).

- It is understood relationship between landscape structure and landscape function with Landscape metrics. Otherwise, using landscape metrics, It is estimated the effects of planning activities on ecological systems. 
- Quantifying of structural characteristics is necessary for sustainable planning. In this way, ecological processes are understood, various modeling studies are done and contributions are made to the monitoring studies in the area.

- At the same time, landscape metrics are made, to determine the changes in the landscape over time.

Landscape metrics are used in conjunction with geographic information systems (GIS). GIS has made a major contribution to the study of the landscape metrics (Johnston 1998). GIS and related technologies are used for a long time in studies related to the ecology. It offers a lot of possibilities to the users. To use landscape metrics and digital data adapted with GIS have been made contributes to the landscape planning studies (Karadeniz and Gökyer 2005). To quantify the Landscape metrics, computer programs have been developed same as Fragstats (Mc Garical and Marks 1994; Mc Garical et al. 2002), and Patch Analyst (Elkie et al. 1999).

Determination of landscape structure, Quantifying changes in this structure and determination of the structure of the landscape, with regard to the evaluation of these enhanced measures (Landscaping measures). These metrics are listed below (Elkie et al. 1999; Mc Garical and Marks 1994; Mc Garical et al. 2002):

- $\quad$ Area/Density/Edge metrics

- $\quad$ Shape metrics

- $\quad$ Core area metrics

- Isolation/Proximity metrics

- Diversity metrics

- $\quad$ Evenness metrics

- Connectivitiy metrics

- Dominance metrics

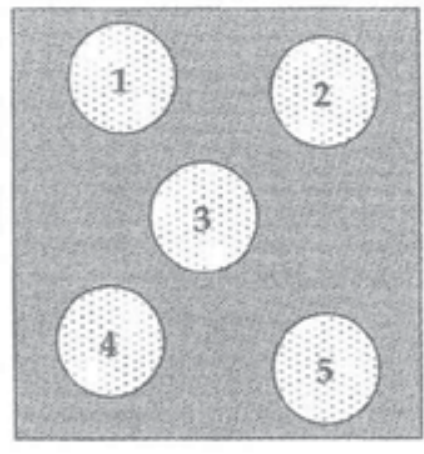

Patch level

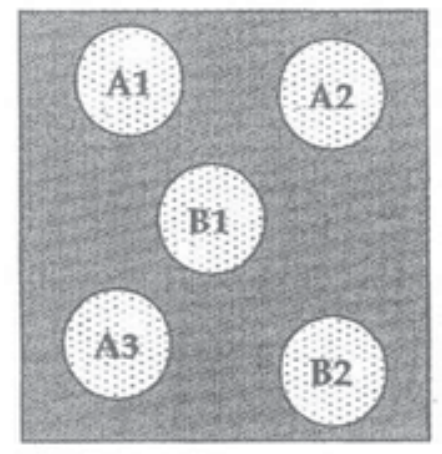

Class level

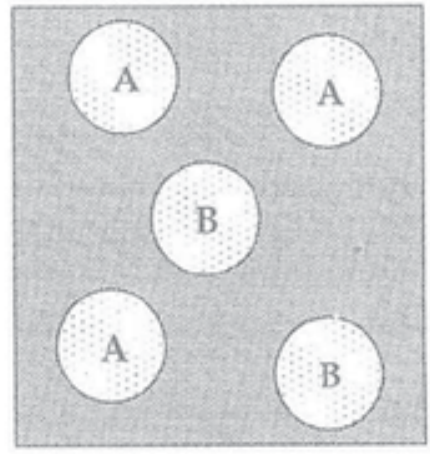

Landscape level

Figure 2. Calculation levels of landscape metrics (Farina 2000). 
Landscape metrics could be calculated to three categories (Figure 2) (Mc Garical et al. 2002; Farina 2000):

1. Patch level: To calculation ever patch type in a mosaic.

2. Class level: To calculation ever patch type class.

3. Landscape level: All of the mosaic is calculated.

\section{Case study}

In this study, Case study area is Bartın province in North part of Turkey (Figure 3). Central part of the Bartın was selected to analyze (Figure 4).

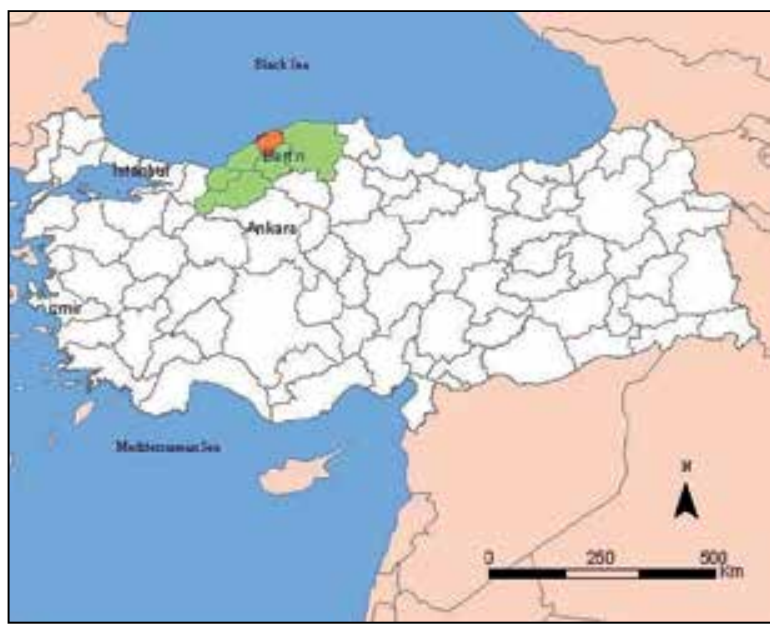

Figure 3. Bartın province in Turkey

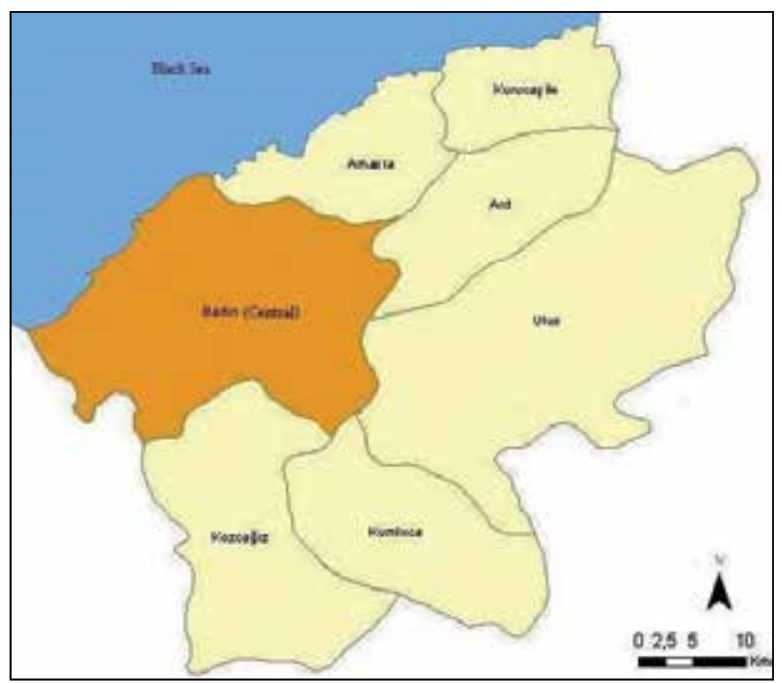

Figure 4. Case study area in Bartın province 
In this study, Land cover maps were developed using Landsat satellite images obtained in 2000 (Landsat 7 ETM) and 2010 (Landsat 5 TM). Images were formed by supervised classification method using ERDAS IMAGINE 8.4. Five land cover types are identified and used in this study. Classified maps were analyzed with neighborhood functions $(3 \times 3$ moving window). Land cover types are forest, agriculture, residential, water (river), sand (sandy areas). Classified maps (landcover maps) can be seen in figure 5-6.

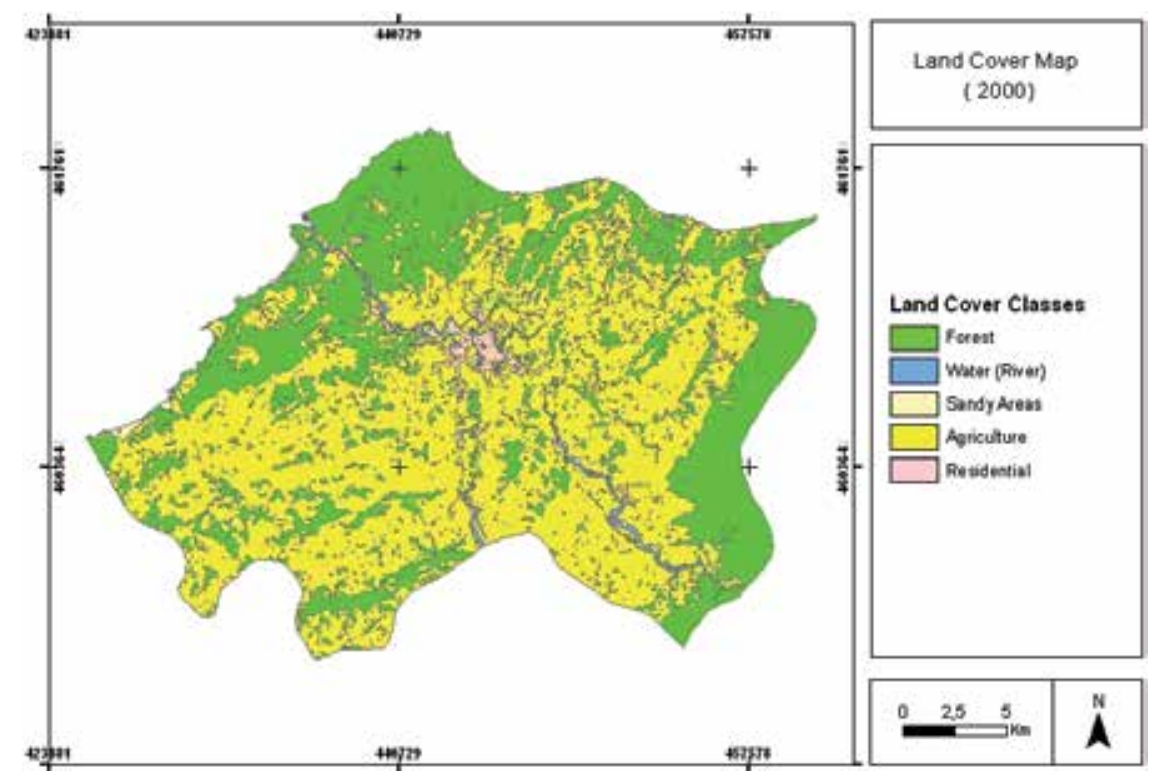

Figure 5. Land cover map for the year of 2000.

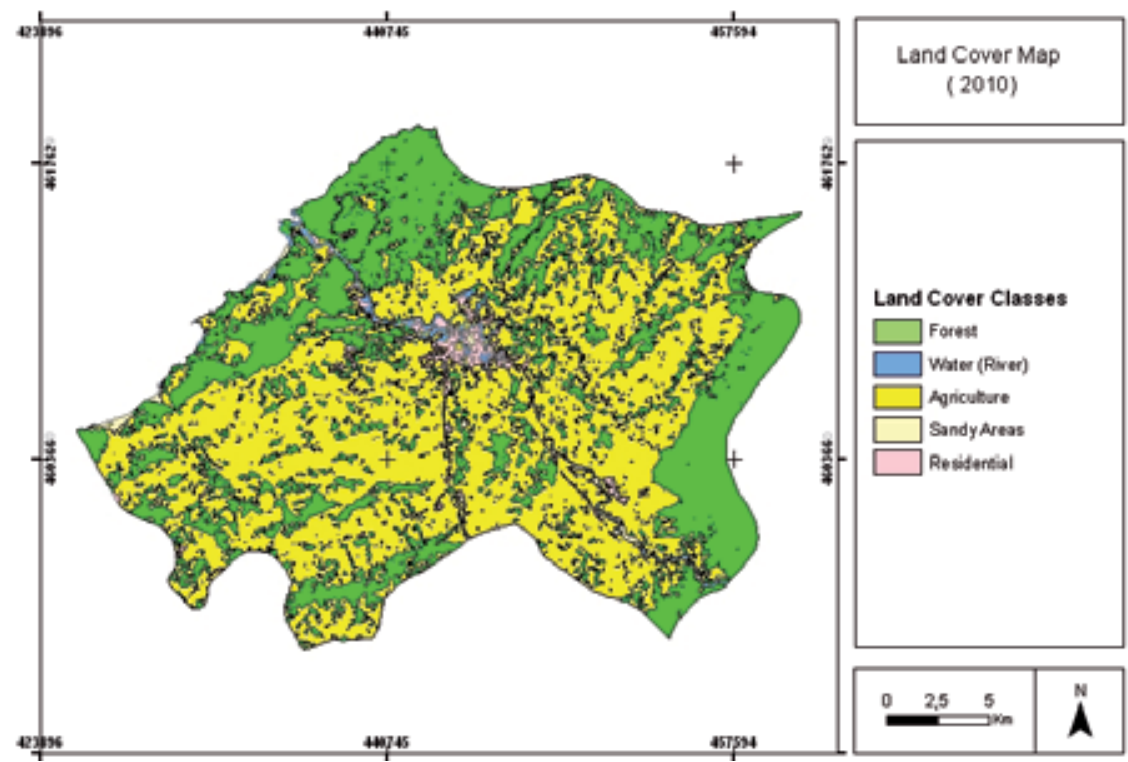

Figure 6. Land cover map for the year of 2010. 
In the study, the overall Accuracy and Kappa analysis were used to perform a classification accuracy based on error matrix analysis. For the 2000 dated image, overall classification accuracy was established as $87.12 \%$ and Kappa coefficient was computed 0.7524 . For the 2010 dated image, overall classification accuracy was established as $90.27 \%$ and Kappa coefficient was computed 0.8092 . Results of the accuracy analysis can be seen in the table1-2.

\begin{tabular}{|l|r|r|r|r|r|}
\hline Class Name & $\begin{array}{r}\text { Reference } \\
\text { Totals }\end{array}$ & $\begin{array}{r}\text { Classified } \\
\text { Totals }\end{array}$ & $\begin{array}{r}\text { Numbers } \\
\text { Correct }\end{array}$ & $\begin{array}{r}\text { Producers } \\
\text { Accuracy }\end{array}$ & $\begin{array}{r}\text { Users } \\
\text { Accuracy }\end{array}$ \\
\hline Forest & 39 & 43 & 37 & $94.87 \%$ & $86.05 \%$ \\
\hline River & 2 & 2 & 2 & $100 \%$ & $100 \%$ \\
\hline Sandy Areas & 1 & 1 & 1 & $100 \%$ & $100 \%$ \\
\hline Agriculture & 81 & 82 & 73 & $90.12 \%$ & $89.02 \%$ \\
\hline Resident & 9 & 4 & 2 & $22.22 \%$ & $50.00 \%$ \\
\hline Total & 132 & 132 & 115 & & \\
\hline
\end{tabular}

Overall Accuracy $87.12 \%$, Overall Kappa Statisics 0.7524

Table 1. Accuracy analysis results for land cover map (2000)

\begin{tabular}{|l|r|r|r|r|r|}
\hline Class Name & $\begin{array}{r}\text { Reference } \\
\text { Totals }\end{array}$ & $\begin{array}{r}\text { Classified } \\
\text { Totals }\end{array}$ & $\begin{array}{r}\text { Numbers } \\
\text { Correct }\end{array}$ & $\begin{array}{r}\text { Producers } \\
\text { Accuracy }\end{array}$ & $\begin{array}{r}\text { Users } \\
\text { Accuracy }\end{array}$ \\
\hline Forest & 47 & 38 & 38 & $80.85 \%$ & $100 \%$ \\
\hline River & 1 & 2 & 1 & $100 \%$ & $50 \%$ \\
\hline Sandy Areas & 1 & 1 & 1 & $100 \%$ & $100 \%$ \\
\hline Agriculture & 62 & 72 & 62 & $100 \%$ & $86.11 \%$ \\
\hline Resident & 2 & 1 & 1 & $50 \%$ & $100 \%$ \\
\hline Total & 113 & 113 & 102 & & \\
\hline
\end{tabular}

Overall Accuracy $90.27 \%$, Overall Kappa Statisics 0.8092

Table 2. Accuracy analysis results for land cover map (2010)

Landscape metrics were calculated using the fragstats program (Rempel et al. 2012). Results can be seen in the table 3-4.

\begin{tabular}{|l|r|r|r|r|r|r|r|r|}
\hline CalculationLevel & \multicolumn{7}{|c|}{ Calculated Parameters } \\
\hline Class Level & CA (ha) & TLA (ha) & NUMP & MPS (ha) & TE(m) & MSI & SEI & SDI \\
\hline Resident & 1382 & - & 1180 & 1.1 & 440837 & 1.3 & - & - \\
\hline Agriculture & 32834 & - & 570 & 57.6 & 1779556 & 1.4 & - & - \\
\hline Forest & 17690 & - & 1169 & 15 & 1368308 & 1.4 & - & - \\
\hline Water (River) & 550 & - & 318 & 1.7 & 171174 & 1.3 & - & - \\
\hline Sandy Areas & 244 & - & 155 & 1.6 & 64093 & 1.2 & - & - \\
\hline Landscape Level & 52703 & 52703 & 3392 & 15.5 & 3823970 & 1.3 & 0.8 & 0.5 \\
\hline
\end{tabular}

CA: Class Area, TLA: Total Landscape Area, NUMP: Patch Number, TE: Total Edge, MPS: Mean Patch Size, MSI: Mean Shape Index, SEI: Shannon Evenness Index, SDI: Shannon Diversity Index, ha: hectare, m: meter

Table 3. Calculation results for landscape metrics by the year 2000 land cover map 


\begin{tabular}{|l|r|r|r|r|r|r|r|r|}
\hline Calculation Level & \multicolumn{7}{|c|}{ Calculated Parameters } \\
\hline Class Level & CA (ha) & TLA (ha) & NUMP & MPS (ha) & TE (m) & MSI & SEI & SDI \\
\hline Resident & 1034 & - & 731 & 1.4 & 316104 & 1.3 & - & - \\
\hline Agriculture & 31429 & - & 666 & 47 & 1843999 & 1.4 & - & - \\
\hline Forest & 19031 & - & 1240 & 15 & 1543806 & 1.4 & - & - \\
\hline Water (River) & 847 & - & 722 & 1.2 & 299287 & 1.3 & - & - \\
\hline Sandy Areas & 362 & - & 279 & 1.2 & 109238 & 1.3 & - & - \\
\hline Landscape Level & 52703 & 52703 & 3638 & 14.5 & 4112437 & 1.4 & 0.9 & 0.5 \\
\hline
\end{tabular}

CA: Class Area, TLA: Total Landscape Area, NUMP: Patch Number, TE: Total Edge, MPS: Mean Patch Size, MSI: Mean Shape Index, SEI: Shannon Evenness Index, SDI: Shannon Diversity Index, ha: hectare, m: meter

Table 4. Calculation results for landscape metrics by the year 2010 land cover map

Class Area (CA): Changes can be identified over time with CA.

Number of The Patches (NUMP): Patch number can be evaluated over time with NUMP. If NUMP value increases it is understood fragmentation increases in the field. If NUMP value decreases it is understood fragmentation decreases in the field.

Mean Patch Size (MPS): MPS can be used to evaluate fragmentation. If MPS value increases it is understood fragmentation increases in the field. If MPS value decreases it is understood fragmentation decreases in the field.

Total Edge (TE): TE can be used to determine important areas for wild life. Agriculture, forestry and water are seen as important areas for wildlife in the study area. If TE is high valued these areas are suitable for edge species. TE value is used to determine suitable habitats for edge species.

Shannon Evenness Index (SEI): SEI identifies to distribution (regular or irregular) of patches in the area. If SEI value approaches 1 it is understood patches distribution are regular in the field.

Shannon Diversity Index (SDI): SDI refers to diversity of patches in the area. If SDI value is zero it is understood area consist of single patch. Distribution of patches can be identified in each other and field.

\section{Conclusions}

In the case study area landscape metrics were calculated by the year 2000 land cover and by the year 2010 land cover. In the study area;

- It is seen increase in forest areas and decrease in agricultural areas.

- Patches distribution is regular in the area.

- The distribution of the patches does not change over time in the field.

- Mean patch size is decreased over time. That describes, fragmentation is increased.

- Total edge value for forest, agriculture and river is high. So these areas are appropriate for edge species. 
In the study area, increasing to the forest areas are extremely important for wild life. Habitats and transaction fields are increased. Increasing to the fragmentation is negative for living species in the area. Because their habitats and transaction areas is restricted.

In the study area, Bartın River as corridor is important controlling water and mineral nutrient flows. Area is separated into two parts along the river. Various birds and mammals appear to move effectively along the River.

Using landscape metrics provide many facilities in landscape ecology studies. We can obtain objective results on landscape structure with the calculation of landscape metrics. Numerical results can be obtained on landscape mosaic.

Landscape structure can be analyzed over time using these results. With calculating landscape metrics, human effects can be detected on landscapes over time. Landscape health can be determined.

As a result Landscape metrics are important for landscape ecology. Metrics provide numerical data on landscape. Landscape structure and landscape change can be analyzed. Information can be obtained about landscape function using metrics.

\section{Author details}

Ercan Gökyer

Bartın University, Faculty of Forestry, Department of Landscape Architecture, Turkey

\section{References}

Antrop, M. 1998. Landscape change: plan or chaos. Landscape and Urban Planning, 41, 15516.

Antrop, M. 2005. Handling landscape change. "Landscape Change" Conference Proceedings, ECLAS 2005, Ankara, 3-15.

Bürgi, M., Anna, M. and Nina, S. 2004. Driving forces of landscape change - current and new directions. Landscape Ecology, 19, 857-868.

Dramstad, E., Olson D.J. and Forman, T.T.R. 1996. Landscape ecology principles in landscape ecology and land use planning. Island Press, USA.

ELI, 2003. Conservation Thresholds for Land Use Planners, Environmental Law Institute, Washington D.C., ISBN:1-58576-085-7, ELI project code: 003101.

Elkie, P., Rempel, R., and Carr, A. 1999. Patch analyst user's manual, a tool for quantifyıng landscape structure. Northwest Science and Technology, Ontario, Canada.

Farina, A. 2000. Landscape ecology in action. Kluwer Academic Publishers, Netherlands

Farina, A. 2010. Ecology, Cognition and Landscape, Linking Natural and Social Systems, Springer Science+Business Media B.V., Springer Dordrecht Heidelberg London New York. 
FISGRW, 1998. Stream Corridor Restoration: Principles, Proccesses and Practices by The Federal Interagency Stream Restoration Working Group (15 Federal agencies of the Us gov't) GPO Item No: 0120-A; Su Docs No.A 57.6/2=EN3/PT.653.ISBN-0-934213-59-3.

Forman, T.T.R. and Godron, M. 1986. Landscape ecology. John Wiley and Sons, USA.

Gergel, E.S. and Turner, G.M. 2002. Learning landscape ecology a practical guide to concepts and techniques. Springer Verlag, New York, USA.

http://conventions.coe.int/Treaty/en/Treaties/Html/176.htm

Jaeger, J.A. 2000. Landscape division, splitting index, and effective mesh size: new measures of landscape fragmentation. Landscape Ecology, 15, 115-130.

Johnston, A.C. 1998. Geographic information systems in ecology. Black well Science inc. USA.

Karadeniz, N. ve Gökyer, E. 2005. Quantifyıng landscape structure using g1s, case study “Gölbaşı specially protected area". Proceedings X. European Ecological Congress 08-13 November 2005.

Letiao, B.A. and Ahern, J. 2002. Applying landscape ecological concepts and metrics in sustaniable landsape planning. Landscape and Urban Planning, 59, 65-93.

McGarical, K. and Marks, B. 1994. Fragstats spatial pattern analysis program for qantifying landscape structure, Version 2.0

McGarical, K., Cushman, A.S, Neel, C.M. and Ene, E. 2002. Fragstats: Spatial pattern analysis program for categorical maps, Version 3.3

Miller, D., Morrice, J., Andersson, L., Durozard, E., Fidalgo, B., Fry, B., Gaspar, J., Gibon, A., Hassan, R., Hislop, M., Horne, P., Huet, B., Ladet, S., Lange, E., Leandro, N., Messager, P., Mottet, A., Nijnik, M., Ode, A., Pascoa, F., Pinto, L., Quine, C., Schroth, O., Schwarz, G., Shepherd, N., Tveit, S. M., Vitry, A., Watts, K. and Wissen, U. 2005. Visulation tolls for public participation in the management of landscape change. Final project report, Project Reference QLK5-CT-2002-01017, Aberdeen, 2005.

Rempel, R.S., D. Kaukinen., and A.P. Carr. 2012. Patch Analyst and Patch Grid. Ontario Ministry of Natural Resources. Centre for Northern Forest Ecosystem Research, Thunder Bay, Ontario.

Sanderson and Harris, 2000. Landscape Ecology A Top-Down Approach, Lew1s Publishers, by CRC Press LLC, N.W. Corporate Blvd., Boca Raton, Florida 33431.

Turner, G. M, Gardner, H. R, O'Neill, V. R, 2001. Landscape Ecology in Theory and Practice, Springer-Verlag New York, Inc.

Wu, J. and Hobbs, R. 2002. Key issues and research priorities in landscape ecology: an idiosyncratic synthesis. Landscape Ecology, 17, 355-365

$\mathrm{Wu}, \mathrm{J}$. 2004. Effects of changing scale on landscape pattern analysis: scaling relations. Landscape Ecology, 19, 125-138. 


\section{Urban Ecology}

\section{Canan Cengiz}

Additional information is available at the end of the chapter

http://dx.doi.org/10.5772/56314

\section{Introduction}

The growing population of urban centers necessities the study of interaction between living organisms and urban environment, which is defined as the environment surrounded by man-made structures, such as residential and commercial buildings, paved surfaces etc [1]. Within this scope, urban ecology developed as a branch of ecology in the last few decades. According to United Nations [2], in forty years' time, two-third of the world's population will be living in growing urban centers, thus it is apparent that urban ecology is fairly important.

As the ecological processes in urban environment are comparable to those outside the urban context, the methods and studies at urban ecology are similar to ecology, in general. Urban ecology dictates that local-scale dynamic interactions between socioeconomic and biophysical forces leading to development of a concept called city. Alberti et al. [3] states that distinctive ecology and ecological forcing functions for urban areas were also shaped by means of these complex interactions.

Inherently, urban ecology is an interdisciplinary field of study. The examination of complex interactions between humans and their surrounding, such as construction, production, housing, transport etc., necessitates the involvement of natural and social sciences as well as humanities and engineering. The direct consequence of this interdisciplinary nature is that urban ecology can be used not only for understanding the urban systems but also for improving the conditions of urban environments. For example, it is required to comprehend how the urban system functions and in which extent it is affected from the global and local processes so that we can analyze how to maintain the water cycle working in a region and which factors, such as the use of landscape, the effect of green spaces, climate conditions, the coexistence of species etc., affect this. Similarly, the study of urban ecology is vital if we would like to understand where and how human activity harms the urban environment or in which way we could improve the living conditions of humans without giving any damage to the urban environment. While traditional lines of urban ecology still have a close 
connection to the scientific and social context of their time as well as to the respective urban structures [4], today's urban ecology differs widely from its beginnings.

This chapter aims to examine the differences between the ecological relationships in urban areas and rural areas. The chapter analyzed landscape degradation and anthropogenic impacts, and city patterns in terms of urban ecosystems; urbanization; the necessity of the ecological areas in urban landscapes; urban climate; urban hydrology; urban soil; urban biodiversity; and, urban wildlife.

\section{Urban ecology}

Urban ecology studies the relations of mankind with each other and their surroundings including cities and urbanizing landscapes. This recent and interdisciplinary field tries to understand the coexistence of human and ecological processes in urban environment and help humans to build more sustainable living. It is a subfield of ecology and it has strong connections with many disciplines like sociology, geography, urban planning, landscape architecture, engineering, economics, anthropology, climatology and public health. Therefore, urban ecology is used to define the study of humans in urban environment, of nature in cities, and of the relationships between humans and nature [5].

As seen in Fig. 1, urban ecology can be viewed as composing of ecology 'in' cities and ecology 'of' cities to functionalize the interdisciplinary nature of it. [5-7]. The former term deals with the questions asking the effect of urbanization on the ecology of living organisms as well as the differences between the ecological processes in cities and those in other environments. The latter one is associated with the interactions between ecological and social systems in an urban environment. According to $\mathrm{Wu}$ [7], in order to investigate the relation between ecology and humans in urban habitats, the terms 'science' (ecology) and 'art' (the humanistic and holistic perspectives) should be taken into consideration for maintaining urban sustainability. Urban ecology basically concerns the relationship between the spatio-temporal patterns of urbanization and ecological processes [8].
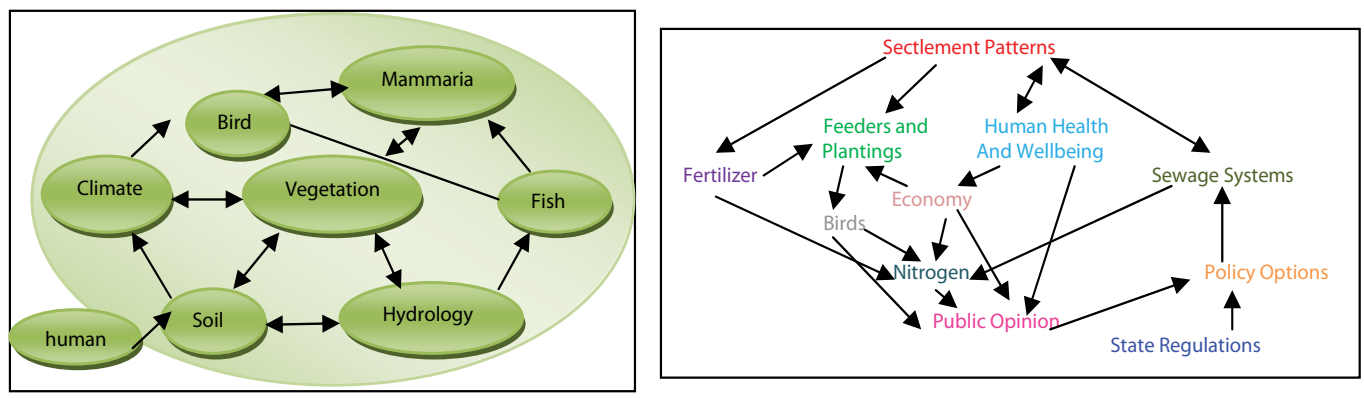

Figure 1. Charts showing the relationships for the ecology in the city (left) and ecology of the city (right) [5]. 
There is a mutual interaction between cities and ecological processes such that both are affecting to each other. This is true not only within the boundaries of the cities but also beyond them. As a result of this strong interaction, it is not possible and even useful to insulate human and natural components of urban ecological studies. Based on the definition of cities, i.e. complex phenomena emerged by human activity, new approaches are necessary to comprehend their properties [5], which can be outlined as:

1. The complex structure of the cities, a social and biophysical phenomenon, could be defined by simpler and definable structures, functions and processes.

2. The effects of the cities on the ecological and environmental processes should be well studied. While the tremendous amounts of requirements of the cities, such as energy and food, use the natural resources, the emissions and wastes produced by them are disposed to the country regions. As a result of this strong interaction, it is highly probable that the ecological processes in the Earth are strongly affected by the cities, which has not been studied yet. In fact, there is a possibility to conserve the natural resources and reduce the negative impacts of human activity on the environment with the help of the concepts emerged by the cities.

Marzluff et al. [5] pointed out that urban ecology can be viewed from three points: (1) ecology and evolution of living organisms residing in city boundaries; (2) biological, political, economic, and cultural ecology of humans in urban landscape; (3) cities resultant of the coupled relations of humans and natural processes. According to them, the third view in which human and nature are observed as interacting forces shaping the measurable patterns and processes should be followed by the field. Human factors and naturel systems with biotic and abiotic factors are coupled together since they both drive and are affected by the patterns and processes they create, see Fig. 2.

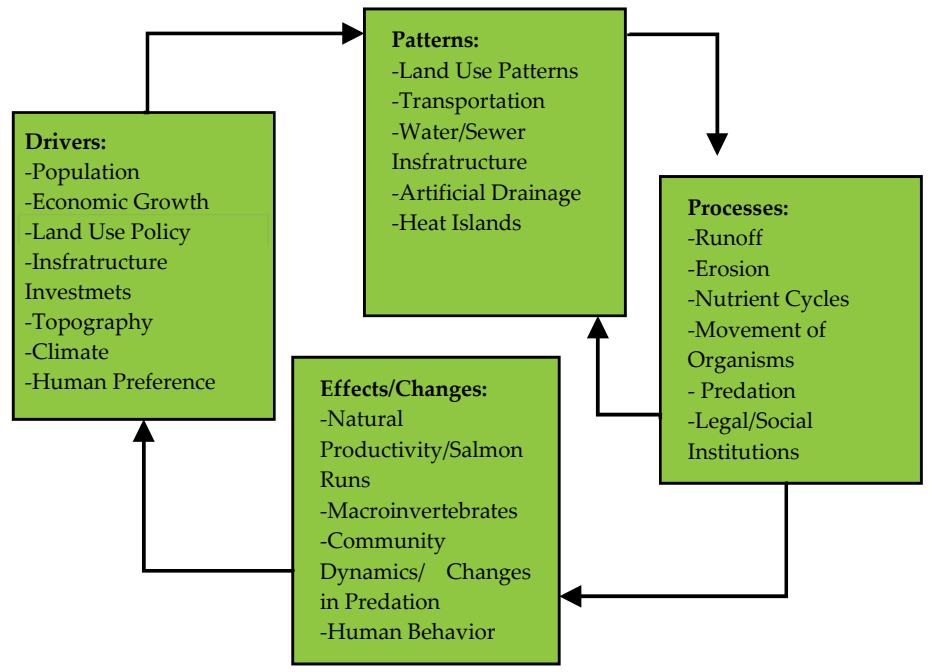

Figure 2. A scheme of urban ecology showing the relationships between humans and natural drivers which are influenced by the patterns and processes of abiotic and biotic drivers [5]. 


\section{Urban ecosystems}

According to Moll and Petit [9], "a set of interacting species and their local environment working cooperatively to stay alive" is called as ecosystem. In urban environments, it could be difficult to distinguish different forms of ecosystems. In fact, one can define the whole city as a single ecosystem, while it is also possible to consider a city is a collection of many individual ecosystems, such as parks, lakes [10], urban forests, cultivated lands, wetlands, sea and streams [10]. Here, the second approach is preferred which covers all natural green and blue areas in the city. Based on this definition, street and ponds should be considered as individual ecosystems, while actually, Bolund and Hunhammar [11] states that they are very small and could only be defined as the elements of a larger ecosystem.

According to Marzluff et al. [5], regardless of the approaches mentioned above, the whole ecosystem in a city is called urban ecosystem which includes abiotic spheres (the atmosphere, hydrosphere, lithosphere, and soil or pedosphere) and biotic spheres (often viewed as an interacting biosphere of urban plants and animals plus the socio-economic world of people, the anthroposphere.

\section{Urbanization}

Big cities, highly dense population and maximum-imperviousness are local- and regionalscale environmental effects of urbanization, which are caused by million-plus, core-oriented, high-rise concentrations [12]. Urban regions are continuing- will most probably continue in future- to be attraction centers for a number of people [8]. Accordingly, in Europe $75 \%$ of the population live in big cities, $80 \%$ will be so by the year 2020 [13]. Repercussions of the issue have yet to be grasped within society as a whole. On the other hand, how natural resources are understood, connected and used is profoundly affected by the phenomenon of urbanization. For the great majority of population, various types of urban landscape are 'familiar' environments, and it is expected to be so in future [8]. Landscape is turned into a complex structure by urbanization in terms of forms, materials and activities, which are different characteristics compared to rural landscape [14].

Human populations living in urban areas cause dramatic effects on the Earth, even though those urbanized parts cover small areas on Earth's surface. The most critical point is that urbanization affects global biodiversity and ecosystems, yet this is not understood adequately. Although there is an increasing interest in urban ecological research, and the understanding of biotic effects of urbanization is better grasped, still, the efforts to bring these issues on the agenda of policy, governance, and planning is lacking [8].

At the end of the day, urbanization has numerous effects on environment, but this does not mean that all of them are negative. Urban environment is diversified by human effects in various means; this variety of human impact changes ecosystems through urban ecosystems [15]. As a bottleneck, urban areas make environmental changes multiple level issues. Material repercussions of production and consumption modify the usage of land; and affect biodiversity, and hydro systems both locally and regionally; discharge of urban waste 
impacts on biogeochemical cycles as well as climate at the local and global scales. On the other hand, according to urbanites, the drastic changes in local environment also destroyed global environment [16]. Urban ecology concentrates on this diversity, which is characterized by the interaction between organisms and connections to human doings [8].

Ecologists did not study urban areas for the first half of the twentieth century, which is worth noting especially considering the concerns of urbanites regarding the future of urban plants and animals [16]. Sukkop [17] claimed that a systematic approach to urban ecological research started after the World War II. Central Europe and the UK can be considered as the pioneers of the oldest urban ecological research tradition. In Berlin, for example, the topic has long been studied (since 1950s) [8]. Now that, as Alberti [18] mentions, the focus on urban ecology studies has augmented, different arguments on dynamics of urban ecosystems are accrued. It is of vital importance to offer a common action that includes comprehensible definition of ecological conditions inside and outside of cities all around the world [8].

Berkes et al. [19] claimed that, in 19th and early 20th century periods environmentalists and ecologists neglected the urban landscape, as a result, the 'wilderness' or 'pristine' has been esteemed very highly over the 'human' environments. This perspective approached people as the problem itself; in this sense, removal of people from naturally resourceful areas was the only solution so as to protect the landscape. As a result, cities became the scape goat; they were reasons to destroy nature. Today, this approach is changing; many people are comfortable with the idea that cultural and biological diversity support resilience and sustainability [8].

One should take into account several urban dynamics in order to understand the relationship between urban sites and biodiversity, and develop a concept satisfying their needs [13]:

- Urbanity stands for city's life quality and character; it refers to the particular pattern of functional, structural, socio-economic and cultural interplay in urban sites. Although many enjoy urbanity, still they prefer to live near nature when they need to make a decision. In this sense, urban revitalization is an attempt to combine nature and city, especially in popular public sites.

- Urbanization is a general term for urban population increase, urban densification and/or expansion and fragmentation of urban sites. It usually leads to increase in a city's ecological footprint, and affects biodiversity and environment as a whole. On the other hand, the nature of footprint depends on the shape and structure of urbanization.

- Urban design is about describing cities' location, physical shape and the construction; therefore, it makes a number of functionalities and life styles possible. In this sense, through a successful urban design additional urban land-take and fragmentation can be reduced. What is more, urban design can provide green areas, and support biodiversity in cities. Additional green areas, recreating brown fields, promoting 'green' roofs and walls, and keeping the density and compactness in urban areas will maximize 
ecosystem activities and ecological footprint in big cities. In point of fact, by providing convenient pattern and activity plan, urban area can become more environmentally friendly areas; rather than mere threats to biodiversity.

It is important to highlight the need for an international frame of thought regarding urbanization, which has recently been experienced as a massive, unplanned course of action in landscape change in the world. Urbanization offers a diversity of altered types of land covers in residential, commercial, and industrial areas; they are generally interconnected by roads and railways, on which special green spaces are allocated. This diversity and similar structures are common all around the world; yet; how they affect biodiversity and ecosystem processes has yet to be determined. What is more, international and comparative research attempts are essential in order to develop the understanding of ecological effects of urbanization [8].

Sustainability of future can be maintained only if an ecosystem oriented approach is adopted in terms of urban planning; this approach should include equitable access to ecosystem services and proper planning [8].

\section{The necessity of the ecological areas in the urban landscapes}

The biodiversity in the cities are very much influenced by the presence of green spaces, green roofs and walls along with tree-lined streets. In order to maintain the different ecosystem services including wildlife and human populations, existence of landscapes with sufficient size, diversity and distribution is essential. The green infrastructure in the urban landscape consists of recreation parks and gardens, unmanaged natural open spaces, wetlands and rural lands. According to EEA [13], the quality of life for most urban dwellers is closely related to the amount of green areas where they live. Since these areas provide people with opportunities for social relations, recreation and experiencing nature which affect them both emotionally and physically. The structure of green spaces and biodiversity are quite different from each other in rural and urban areas as in Europe. Although different counties have different green zone policies, it is accepted that nature affects humans in a very positive way by reducing blood pressure, improving cognitive abilities and increasing happiness. Meanwhile, green areas and biodiversity are also beneficial in filtering particles, purifying water, reducing noise, and buffering climate extremes like heat waves. This means that the green areas in the cities help to reduce the temperatures which are especially important in adopting the future climate changes for the landscapes which are likely to experience high temperatures and heat waves [13]. The English Garden in Munich, Germany is a good sample for this subject (Fig 3-4).

The presence of natural flora in the cities, the establishment of habitats suitable to the animals adapted to the urban conditions and ecological studies for the protection and development of ecosystems are considered as environmentally ethical studies, as they protect the natural resources. Meanwhile, these areas are places which are increasing the quality of life in the city and allowing the social interaction of the residents [20]. 


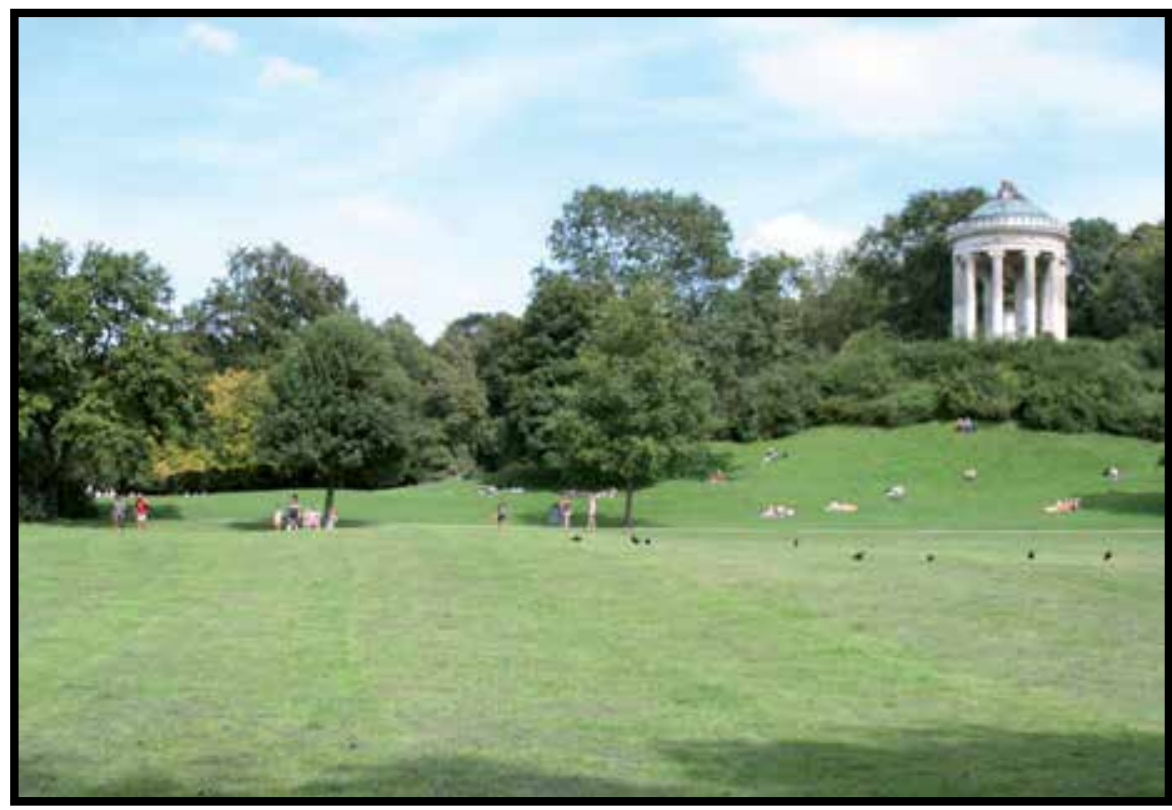

Figure 3. The English Garden in Munich-Germany (Original 2011).

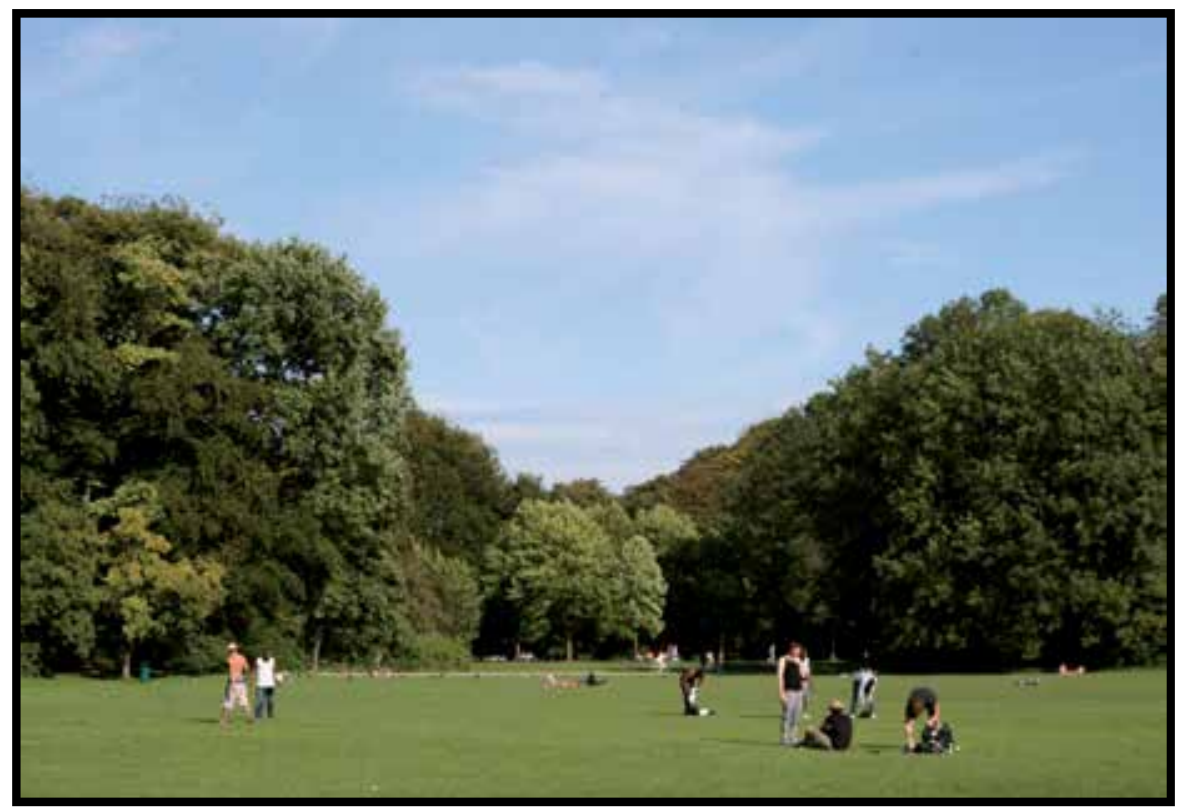

Figure 4. View of the English Garden in Munich-Germany (Original 2011).

Ecological studies and designs are significantly important for the sustainability of the mankind and natural environment. The ecological studies carried out for the establishment of the sustainability in the urban areas as well as the for the protection of the resources involve not only the construction-scale efforts performed in the urban areas but also the 
works conducted in the rural areas. In the construction-scale, the studies comprise efforts such as taking precautions for the extensive use of solar energy, recycling of the domestic waste etc [20].

\section{Urban climate}

The examination of the climatic conditions for lands differ from that of water .The complex combination of the elements of the lands, such as topography, land form, water and plants, strongly influences the climatic conditions related with solar radiation, wind precipitation, temperature and humidity. For example, the movement of air masses are strongly influenced by land forms and their topography, which are basically considered as obstacles (when they are tall) or routers (when they are in the valley-shaped) for air flow. A variety of air flow dynamics, from simple to complex, could be observed in many circumstances. Not only airflow but also humidity, temperature and absorption of solar energy are strongly affected by the properties of landscapes. The windward and leeward sides of hills affect the humidity, while height of the landscapes strongly influences the temperature. Additionally, higher levels of solar energy are absorbed at the south-facing slopes, giving small microvariations in the climate and changing the vegetation patterns [24].

Cities are generally warmer than open lands and forests as walls and roofs of the buildings and asphalt pavements have higher radiation surface than open lands yielding higher amount of solar energy absorbed. Meanwhile, the precipitation falls into the cities flow away to the sewage system through asphalt roads and squares quickly. As a result of this, the solar radiation is more effective on these surfaces than humid ground in the open lands and heat up more yielding higher degree of warming. As the terrestrial radiative heat loss from these city structures is slower, the temperature of the cities is higher. Meanwhile, evaporation of the water in the open lands also results in energy loss. For these reasons, in calm weather and invariable weather conditions, the temperature of a city could be $0.5-1.5$ ${ }^{\circ} \mathrm{C}$ higher than that of its surrounding landscape. This difference could reach to $4-5^{\circ} \mathrm{C}$ in the night period and even up to $10^{\circ} \mathrm{C}$ in the first few hours of the winter nights. Additionally the minimum temperature values could be $0.8-1.5^{\circ} \mathrm{C}$ higher than what is observed in the rural landscape. As a result of this a city can be termed as heat island. The number of frost and icy days are lower for cities. The warmer climatic conditions of the cities allow a long vegetation period for vegetables and reduce the freezing damages especially observed in the frozen nights. For this reason, the plants that do not grow normally in the climatic conditions of the open land of that region could grow in the city. The heat production in the cities and being warmer compared to their surroundings produce a low pressure region in the atmosphere. This causes a continuous flow of a wind from rural areas to the urban ones. The amounts of the dust and artificial gases in the atmosphere present on the cities are much higher than those present on the open lands and forests. Thus, these artificial materials hinder the sunshine arriving to the city. It was determined that the polluted air reduces the solar radiation by 15- $20 \%$. When the plantation is performed in the cities, the level of solar radiation increases as trees filter the polluted air and dust is partially captured by the long trees [22]. 
The effects of the elements present in the urban areas on the flow of the energy. As depicted above, a city can be considered as a hot-spot or heat island compared to its surrounding rural landscape, see Table 1 [12]. In fact, the climatic characteristics of a city can be considered for smaller scales, such that the effect of each element in the city, e.g.., streets, buildings, parks etc., could be evaluated individually.

\begin{tabular}{ll}
\hline Element & Compared to rural environs \\
\hline Contaminants & \\
Condensation nuclei & 10 times more \\
Particulates & 50 times more \\
Gaseous admixtures & $5-25$ times more \\
Radiation & \\
Total on horizontal surface & $0-20 \%$ less \\
Ultraviolet, winter & $30 \%$ less \\
Ultraviolet, summer & $5 \%$ less \\
Sunshine duration & $5-15 \%$ less \\
Cloudiness & \\
Clouds & $5-10 \%$ more \\
Fog, winter & $100 \%$ more \\
Fog, summer & $30 \%$ more \\
Precipitation & \\
Amounts & $5-15 \%$ more \\
Days with less than 5 mm & $10 \%$ more \\
Snowfall, inner city & $5-10 \%$ less \\
Snowfall, lee of city & $10 \%$ more \\
Thunderstorms & $10-15 \%$ more \\
Temperature & \\
Annual mean & $0.5-3.0^{\circ} \mathrm{C}$ more \\
Winter minimums (average) & $1-2^{\circ} \mathrm{C}$ more \\
Summer maximums & $1-3^{\circ} \mathrm{C}$ more \\
Heating degree days & $10 \%$ less \\
Relative Humidity & \\
Annual mean & $6 \%$ less \\
Winter & $2 \%$ less \\
Summer & $8 \%$ less \\
Wind Speed & \\
Annual mean & $20-30 \%$ less \\
Extreme gusts & $10-20 \%$ less \\
Calm & $5-20 \%$ more \\
\hline
\end{tabular}

Source: Landsberg [23]

Table 1. The variation of the climatic conditions in the cities [12] 
According to Marsh [14], the following factors affect the temperature of the urban areas:

1. The man-made solid-structures, walls, roofs, roads, paved areas etc., have higher heat conductivities, heat capacities and reflection capabilities than natural soils.

2. The surface area of these structures with vertical faces increases the total surface area of the landscape giving higher degree of energy, mass and momentum conversion.

3. The heat is continuously produced by equipments, such as machinery, vehicles, heating and cooling systems.

4. The amount of evaporation and the energy used for that process decreases in the cities effecting the humidity and heat of the urban areas.

5. Exposure to long-wave radiation varies due to the pollutants and dusts are given off to the atmosphere by human activity.

Urban landscapes change the direction and speed of the winds coming from surrounding. For that reason, differences occur between air flow on the cities and on the forests as well as open fields. The buildings in cites which are much taller than the average height increase the number of the calm days in the city and worsen the ventilation. These tall structures are the sources of the calm air, increased temperature and vapor pressure. In fact, this has a negative effect on the living conditions of the city resident. However, tall building do not always reduce the speed of the winds, on the contrary, it is stated that they may improve the circulation of the wind. For this, the large brows (facades) of the buildings should be perpendicular and their narrow brows should be parallel to the direction of the wind. Meanwhile, the distance between buildings should be long enough so that they do not block the motion of the wind [22].

According to Barner [24], based on the wind profile and wind tunnel experiments, the following characteristics related to wind flow are apparent [22]:

1. Depending on the height profile of the building, the speed of the wind increases at the windward brow of the building.

2. The highest value of the wind pressure, which is directly related to the speed of the wind, appears at the $2 / 3$ height of the building.

3. However, within the $2 / 3$ height of the windward brow of the building, the speed of the wind was reduced, while the turbulent flow forms due to spinning wind flow.

4. The calm air at the windward side of the building is separated form that at the opposite brow while it flows away from top and bottom parts which forms a strong air flow at the lower levels.

The effect of the buildings on the wind flow could be explained by three different examples, which represent simple and complex situations separately. The first case investigates the airflow towards an individual building. Here, when the airflow reaches to the building, an obstacle on route the airflow, its speed should increase according to the continuity of flow laws. A 2D model could clearly show that the speed of the wind on the different parts of the building is different being the highest on the windward brow of the building and across the roof. Meanwhile, air is also deflected from the brow down the face of the building (labeled 
as A in Fig. 5). Additional to those, speeds decrease and streamlines of wind spread out on the leeward side, with some descending toward the ground [14]. In the second case, two buildings of similar heights are located close to each other. Different from the first case, the streamlines of fast wind do not descend to the ground but they were maintained by the roof of the building. The direct consequence of this event is the formation of small pockets of calm air between buildings and limited intermixing of the air in between the buildings with the atmosphere (labeled B in Fig. 5). The properties of air in such pockets could be different than that of surrounding atmosphere. In the last case, the most complex one, buildings and streets are aligned such that the structure is similar to that of canyon forming channels for airflow when the wind is strong. This formation, apparently, increases the speed of the wind and yields turbulence along the walls of the canyon (labeled as C in Fig. 5) [14].

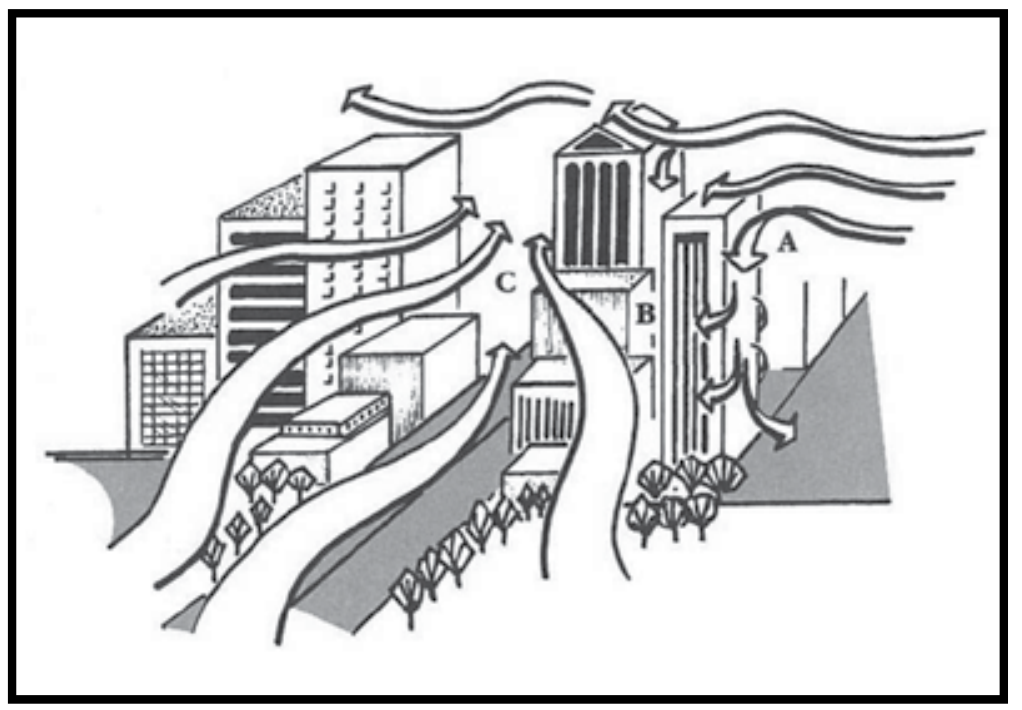

Figure 5. The flow of air in an urban area. The figure demonstrates the airflow around different structures, such as tall and short buildings, streets and their different combinations. Different cases are given here: (A) The strong flow is deflected down the building, (B) calm zone develops between buildings and (C) combination of large buildings with streets form canyons yield accelerated airflow [14].

Other than windflaws, water also significantly affects the urban climate in a way that solar energy is stored by masses of water. As the temperature of water varies much slowly than that of lands, they adjust the temperature of the lands through breezes. Meanwhile, the evaporation of water consumes energy and reduces the temperature of air, which might be called as a natural-air conditioning [21].

\section{The Urban Heat Island as a Climatic Effect of Urbanization}

There are different climatic effects of urbanization: formation of urban heat islands, increasing cloudiness, fog, dust, precipitation and downwind urban heat plume, while decreasing humidity. Apart from these small-scale effects, activities held in the boundaries 
of urban areas are the main sources of greenhouse gases, mainly $\mathrm{CO}_{2}$ and fluorocarbons, which may influence the global climate and sea levels in the following decades [12].

Among different climatic effects of urbanization, formation of heat island is one of the most apparent one. It is known that the temperature of the air in the cities is relatively higher than their surrounding rural areas, defining the urban heat islands [21]. Man-made structures, i.e. buildings, paving, vegetation and other physical elements of the city, form as active thermal elements between the ground and atmosphere. The properties of the elements in the landcovering layer, e.g., height, distribution, determine the thermal behavior of the city and the distribution of the warm air within the urban region.

There are many factors affecting the formation of the thermal heat islands, primarily, radiation and beat flows, urban boundary layer, surface heating and heat loss [14]. A sharp decrease in the temperature profile occurs on the perimeter of the city, defining the boundaries of the urban heat island which is shown in the Fig. 6 by a cliff in the profile. While the temperature may fluctuate in the heat island, which is a factor of the type of the man-made structures, beyond the boundaries of the heat island, rural landscape with much lower temperature values than those observed in the heat island emerges [14]. Such variations in the heat island are clearly shown in the Fig. 6 in a way that cool regions formed by parks and riverside while warmer parts appear as a result of the shopping centers and industrial zones.

According to Leopold [25], the use of the local-land has four distinguishable effects on the hydrology, which are relevant to each other: changes in peak-flow characteristics; changes in total runoff; changes in water quality; and changes in hydrologic amenities. It is known that stream flows, which are rainstorms characterized by heat islands, expands and becomes stronger with the growth of the cities, while stronger winds are necessary to overcome them [12].

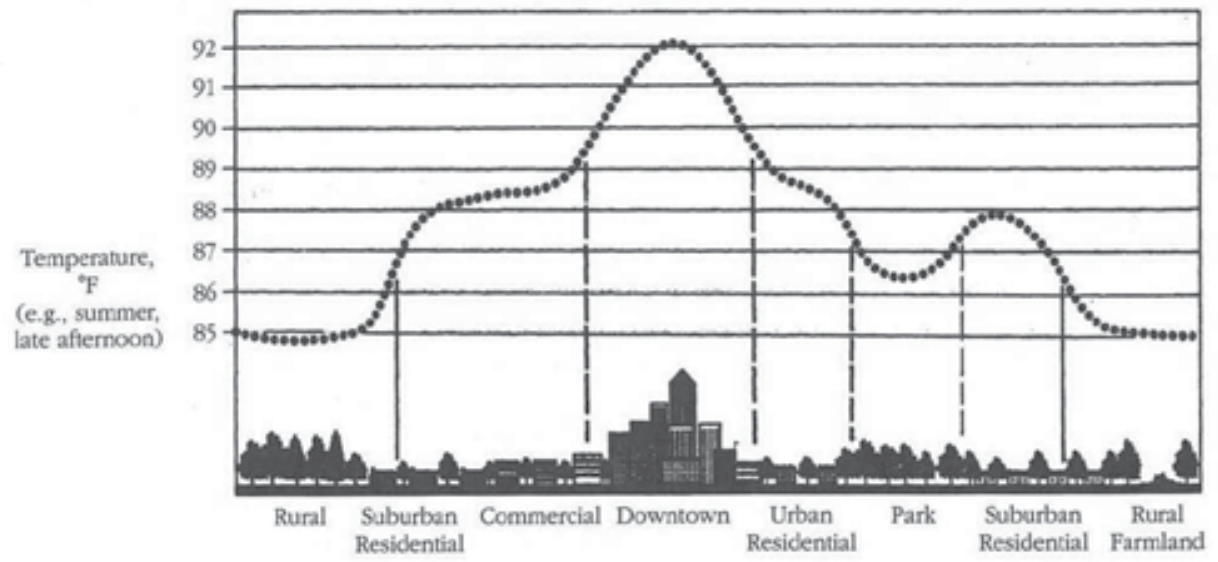

Figure 6. The schematic representation of the temperature profile of the urban heat island and its variation with the type of the elements in the urban area [14]. 
In fact, a lot of urban planners accept climate as a fundamental factor of urban planning and design; on the other hand, only few of them are able to combine variables like wind, heat, and solar radiation with decision making processes. The level of scientific understanding of microclimate is one of the most significant factors responsible for building the environment [14]. Climate is an important element for pollution control boards and regional transportation policies; whereas, for urban planner, landscape architect, and architect smallscale climatic variations are important. One can refer to the solar radiation around high buildings as an example of variation; other parameters like temperature, wind, fog, and pollution can also be seen as other variations in urban landscapes (Fig. 7).

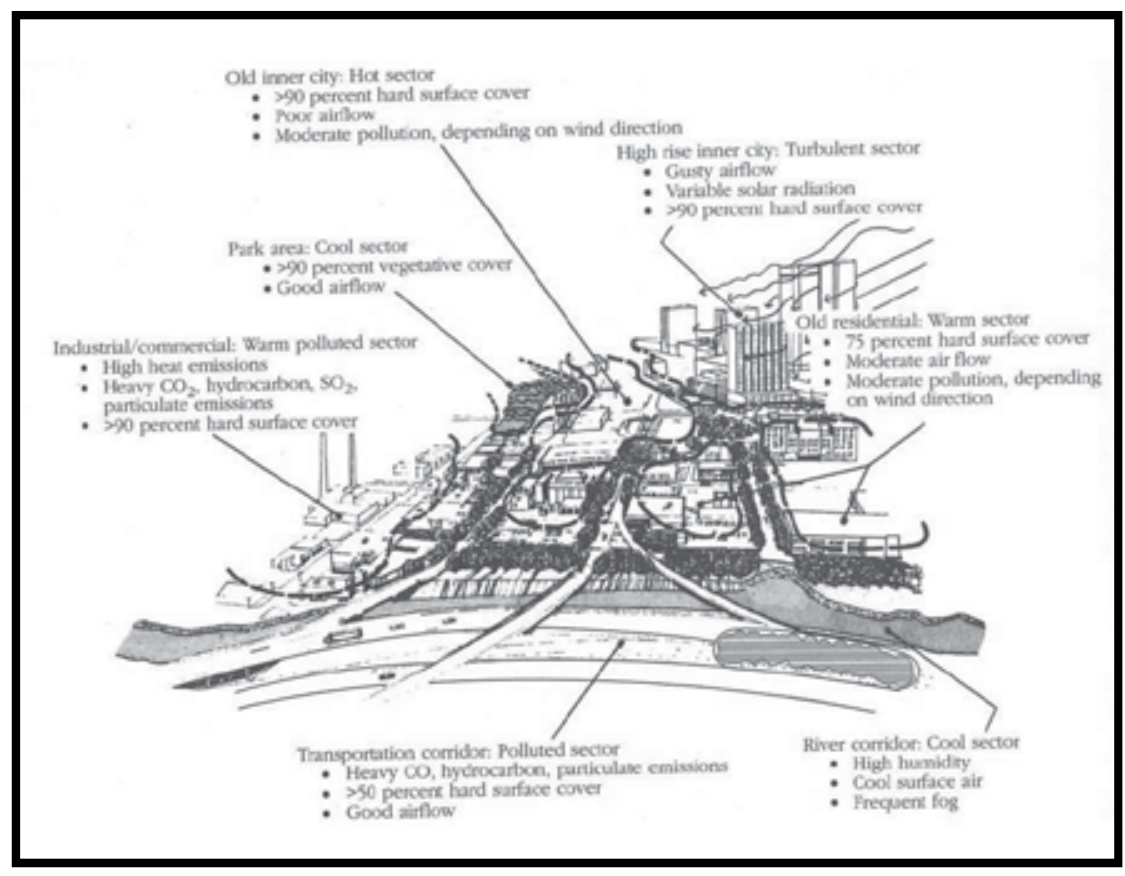

Figure 7. Climatic conditions near the ground in differnt sectors of a city. Conditions vary with surface cover, solar dadiation, airflow, and air pollution, among other things [14]

\section{Urban hydrology}

In urban design, groundwater relations and surface flow characteristics of water collection basins are of vital importance for the city's water requirement. Water economy affects heat economy as well. In cities, precipitation falling on building roofs and asphalt roads as well as city centers, are all lost because they go to sewer system through surface fall. As a result, inside the cities get dry and warmer very soon. Because precipitation waters are carried outside of the city, the level of humidity in cities is lesser than forest design. However, fog comes down frequently due to high quantity of solid structures [22].

Within the framework of urban hydrologic processes, trees as well as soils can act as an important role in terms of intercepting and retaining or slowing the flow of precipitation 
reaching the ground. It is possible that these can decrease the frequency and volume of storm water runoff, flooding damage, storm water treatment costs, and other problems in terms of water quality. According to the runoff estimates, which were conducted for an intensive storm in Dayton/OH, the tree canopy (22\%) decreased runoff by $7 \%$, and a decent increase in canopy (around 29\%) can decrease runoff by almost $12 \%$ (Sanders [26] from Nowak and Dwyer [27]). In addition, it was revealed that tree cover on pervious surfaces decreased runoff, total of $40 \%$; its effect on runoff was lesser on impervious surfaces [27].

In Europe, according to the findings obtained from research, low level humidity and more frequent fogs cause torrential rainfall repetition to increase. For this reason, it was determined that the number of days of torrential rainfall in the city is between 13 and $63 \%$ more than the open area and forest designs. Therefore, it was revealed that the city's annual rainfall is around $5-31 \%$ higher than open area and forest designs, depending on the land surface shape, height, climate characteristics, the size of the structures [24]. However, torrential rainfall and impervious surfaces inside the city cause this precipitation water to be lost in a short time; rain water does not contribute to the water economy efficiently [22].

For Bai [28], increased impervious cover is among the most significant modifications affecting streams in urban sites; it transforms hydrology and funnels accumulated pollutants from buildings, roadways, and parking lots into streams. In United States point source pollution was reduced by regulations; yet it is still an important problem in several developing countries [16]. It is crucial to remember that industrial discharges and sewage contaminate both rivers and lakes. In new design cities storm water infrastructure is separate from wastewater discharges; this is not the case in older European and American cities, where two streams are mixed and causing to acute pollution in recipient systems. The storms and low flow-discharge of cities lead to local, even regional pollution downstream, which are particularly caused by pesticides and persistent organic pollutants [16].

Urban hydrology has been altered to develop a way to manage urban runoff against flood, and to protect health and the environment. In recent years there have been important developments regarding the measurement and prediction of urban rainfall by using technologic devices such as radar and microwave networks. The predictability of urban hydrology has been improved also in order to provide models convenient with small temporal and spatial scales typical to urban and pheri urban applications. Urban storm water management has started to take into account the needs of environment and human beings. There is a strict trend towards restoring pre-development flow-regimes and water quality; also, it is believed that restoring more natural water balance would not only be an advantage to environment, but support the livability of the urban landscape. Although it was regarded as a trouble, today storm water is increasingly seen as a resource [29].

Urban runoff management has evolved with the understanding of its environmental impacts. Referred approach developed many terms such as, Sustainable Urban Drainage Systems (SUDS) [30], Water Sensitive Urban Design (WSUD) [31-32] and Low Impact Development (LID) [33]. 
These approaches have similar objectives:

1. To manage urban water cycle in a sustainable fashion (by taking into account both surface and ground water, flooding and impacts on waterways erosion),

2. To maintain or return the flow regime as much as possible back to its natural level,

3. To protect and restore, if possible, water quality (for both surface and ground water),

4. To protect and restore, if possible, the health of receiving water,

5. To conserve water resources as a resource rather than a nuisance (like, storm water),

6. To enhance urban landscape and amenity by incorporating storm water management measures, which offer multiple benefits, into the landscape [29].

\section{Urban soil}

Analyzing and determining the soil features are important in urban design for two reasons. First, it is important in terms of geologic basis for structure projects like edifice, tunnel, subway, etc. Second, it is mandatory to know the soil characteristic in growing plant. Physical features of soil, which can be listed as depth, mechanical structure, general characteristics, level of ground water, and geological basis; are not only important for tunnels and edifices, but also for all urban structures (road system, sewage, cesspool, etc). Soil is the natural environment for plants. Hence, determining soil features is of particular importance for the planned green areas in the city. For this reason, in establishing cities, favorable soils for structures should be found through soil analysis and marked on maps, and the relations between soil characteristic and how to benefit from the soil should be analyzed [22].

The soil in the areas that were left to make greenery near the building has lost its genetic characteristic and mixed with construction leftovers, cement, and concrete. Therefore, to those spots, on which green areas will be built, soil from other places are carried on trucks; they do not include concrete, but organic materials; and they are generally spread in a thin layer. For this reason, natural soil features, which are main factors of growing plant in cities, have rarely survived. As for the plants that will be grown in cities, shadows of buildings and windbreak, negative effects of salts sprayed onto the city roads in winter, and flue gas should be prior factors to consider. In this sense, plant species that will be used in urban design should have a broad ecologic tolerance; in other words, they should be durable against negative anthropogenic effects [22].

\section{Urban biodiversity}

Biodiversity provides an ecosystem system, on which the standard of living on European citizens depends, urban setting proves this successfully. Urbanites benefit from recreational, social and inspirational services of the nature, both inside and outside of cities. Yet, ecosystems are also crucial in terms of basic living conditions in cities. Thanks to its positive climatic effects, urban greenery will play an important role in adapting strategies to deal with climate change, which is expected to intensify or alter the specific urban climatic 
conditions. Urban greenery makes cities attraction centers; it prevents urban sprawl and saves space for biodiversity. In addition, as in-city services increase, the city's footprint is decreased; as a result, potential negative effects on biodiversity and environment is destroyed [13].

In addition to ecologic services, green areas -in which biologic diversity is supported- are also gaining favor in terms of public health, maintaining social cohesion, economic benefit (like the increase in real estate market thanks to the green areas), and low maintenance cost (less irrigation and fertilization by creating ecologically sustainable urban designs) [34].

Local and regional authorities have the legal power to designate conservation areas; to advocate EU's Natura 2000 networks; and, to bring biodiversity concerns urban and spatial planning agendas. Cities share the responsibility to select Natura 2000 sites. The scale of public commitment can be traced in Local Agenda 21 processes, which aim to establish sustainable societies identifying biodiversity as a precondition to build resilient cities. European Union supports advanced commitment and increased awareness by honoring the most sustainable cities, the European Green Capital Award (see the box below), and establishing a legal framework to protect biodiversity through, Natura 2000 network under the EU Habitats and Birds Directives, Air Quality Directives, the Water Framework Directive and the development of a Soil Directive [13].

Cities are crucial in terms of sheltering some rare and endangered species and habitats, which are considered to be important at the European level as well. There are a total of 97 Natura 200 sites are located in 32 major European cities. Of these cities, sixteen are capitals (for example, London, Paris, Prague, Rome and Tallinn). In addition, one or more harbors in more than half of the EU's capitals are Natura 2000 sites. Although Berlin has 15 Natura 2000 sites, most of the others have one or two. A new City Biodiversity Index (CBI) has been developed by favor of Convention on Biological Diversity (CBD) and contributions of Governments for Sustainability (ICLEI) [13].

In cities, the value of biodiversity is closely related to societies' cultural and social preferences. Biodiversity not only offers quite an amount of ecosystem services to urbanites, it also modifies negative perceptions created by cities [35].

As Walker and Salt [36] put, it is possible to perceive urban diversity within the framework of response diversity, which is the case when species and ecosystems respond differently to external interventions, even though they function collectively. For instance, urban trees intercept large amounts of precipitation, and prevent flooding; therefore, tree diversity contributes to precipitation interception's response diversity function [37]. As a result, strong biodiversity guarantees lower risk for the entire function, despite local extinction. As the cities continue to face the effects of climate change, response diversity will be an important capacity building factor in terms of resistance [37].

From the perspective of urban planning, protection of biodiversity in cities is a high-priority for both stakeholders and decision-makers. Still, when it comes to put the issue at the top priority list during the planning process, it is left behind of anthropocentric objectives such as economic development, transportation, land use and recreation [37]. 
Extensive use of native species is essential for the sake of urban biodiversity. By doing so it could be possible to carry out more sccesful landscape projects with minimum maintenance work and cost. Furthermore, a breeding and feeding environment can be created through increasing biodiversity and by using native species. Regarding sustainable cities, floristic diversity is an important topic [38].

Biotic, physical and social factors along with processes are related to biodiversity in urban ecosystems. On the other hand, ecology itself is insufficient to delineate urban ecosystems. As a result, it is advised to establish an interdicplinary approach, including natural and social sciences, that will discuss ecology-related inputs in terms of urban planning [38].

\section{Urban wildlife}

Wildlife in cities is generally undervalued. In recent years urban wetlands, abandoned industrial sites, roadside verges, vacant lots and derelict lands, ruins, allotment gardens and cemeteries - together with arboreta, residential gardens and villas, botanic gardens and individual balconies have begun to be seen as potential conservation areas for urban biodiversity [21, 39]. Dense population and infrastructure are two factors putting pressure on biodiversity in cities. What is necessary is to establish a balance between the urban green and tailor made green areas. At this point, 'double inner city development' can be used; this means to combine the existing 'made' areas with conservation, supporting the presence, character and availability of green spots and vacant spaces; and, strengthening the green infrastructure like street-trees, green walls and roofs. These will facilitate the way to access green areas in and out the city [13].

Wild fauna inside the cities can be a positive demonstration of the richness of the 'green'; on the other hand, this can be a challenge in some cases (e.g. foxes or seagulls) [13]

Rich diversities in urban landscapes can come to the fore as original communities. Urban green is an important part of urban landscape, which offers the opportunity to contact with wildlife in addition to environmental and socio-ecological benefits, regarding the quality of human life. Urban green areas are ecologically complex structures; their values can be defined in terms of goods and services within society. What is essential is to pick bioindicators that can be accessed and relied with regards to create a proper/balanced urban ecosystem, through integrating wildlife and biological parameters to human well-being [40].

\section{Discussion}

What is more, it is important to highlight that urban ecosystems do have contributions to the well-being of urban life; however, urbanites depend on global ecosystems to survive. There are some services provided by urban ecosystems in order to improve the quality of life; accordingly, air quality, lower level noise were all provided, these could not be done from distant ecosystems. The causes of these problems have yet to be solved, but their effects have been reduced. Both should be the main aim [11].

At the end of the day, the hope is that the awareness of ecosystem services will be raised, which will help to maintain a more resource-efficient city structure and design. Only then 
urban ecosystems will be respected for their contributions to life in urban areas, and gained priority when the area faces exploitation. In addition, the idea of significance of ecosystem services could result in protection of unexploited urban areas, even expanding them. One of the most important key objectives is that ecosystem services in urban areas and ecosystems are appreciated by political authorities and city planners as the cities grow in future [11].

In urban ecology studies, natural and social sciences were intermingled; the aim is to research these radically altered local environments in terms of their regional and global effects. In this rapidly urbanized world cities are the center of problems as well as solutions regarding sustainability challenges [16].

Ecologists can approach to cities as real-world laboratories; therefore, they can better understand the basic patterns and processes; and, work in collaboration with city planners, engineers, and architects in order to actualize urban policies that enhance and protect biodiversity and ecosystem function [16].

The main characteristics of cities -dense population, center of production and consumption, and waste disposal- cause the land to change and bring a number of environmental problems. These problems can be seen as sample microcosms of global environmental change addressing to the chance to develop ecology as well as global-change science. As known, human-induced activities take place on Earth, a biophysically constrained planet, and it is strongly believed that urban ecology can clarify the connection between urbanites and the biogeophysical environment they live. Ecological footprints are expanding; in this sense, the perception of issues with greater extent beyond human understanding should expand along with the broader effect of individual and collective life forms, preferences, and acts. As a consequence, it is hoped that industry and creativity, which have been located in urban centers throughout the history of man, would also be discussed as remedy, rather than problem. Last but not least, as a priority area, urban ecology has a significant mission to find solutions and develop the future of urban in a sustainable way [16].

\section{Author details}

Canan Cengiz

Bartin University, Faculty of Forestry, Department of Landscape Architecture, Turkey

\section{References}

[1] Niemela J. Ecology and Urban Planning. Biodiversity and Conservation 1999;8 119-131.

[2] United Nations 2007. World urbanization prospects: the 2007 revision. UN.

[3] Alberti M., Marzluff J. M., Shulenberger E., Bradley G., Ryan C., Zumbrunnen C. Integrating Humans into Ecology: Opportunities and Challenges for Studying Urban Ecosystems. American Institute of Biological Sciences. BioScience 2003; 53(12) 1169-1179.

[4] Weiland U., Richter M. Urban Ecology-brief History and Present Challenges. Applied Urban Ecology: A Global Framework. First Edition. Edited by Matthias Richter and Ulrike Weiland. Blackwell Publishing Ltd.; 2012. 
[5] Marzluff JM., Shulenberger E., Endlicher W., Alberti M., Bradley G., Ryan C., Simon U., ZumBrunnen C. Urban Ecology. An International Perspective on the Interaction Between Human and Nature. Springer Science and Business Media, New York; 2008.

[6] Grimm NB., Grove JM., Pickett STA., Redman CL. Integrated Approaches To LongTerm Studies of Urban Ecological Systems. BioScience 2000;50 571-584.

[7] Wu J. Making The Case For Landscape Ecology- An Effective Approach To Urban Sustainability. Landscape Journal 2008;27 41-50.

[8] Niemelä J., Breuste JH., Guntenspergen G., McIntyre NE., Elmqvist T., James P. Urban Ecology; 2011.

[9] Moll G., Petit J. The Urban Ecosystem: Putting Nature Back in The Picture. Urban Forests 1994;Oct-Nov 8-15.

[10] Rebele F. Urban Ecology and Special Features of Urban Ecosystems. Global Ecol. Biogeography Lett. 1994;4 173-187.

[11] Bolund P., Hunhammar S. Analysis Ecosystem Services in Urban Areas. Ecological Economics 1999;29 293-301.

[12] Berry BJL. Urbanization. Urban Ecology. An International Perspective on the Interaction between Humans and Nature. Springer, New York. p25-48; 2008.

[13] EEA 2010. European Enviroment Agency. 10 Messages for 2010 Urban Ecosystems. ISBN 978-92-9213-148-7 EEA, Copenhagen.

[14] Marsh WM. 2010. Landscape Planning Environmental Applications.John Wiley \& Sons, Inc.

[15] Gilbert OL. 1989. Characteristics of the Urban Flora and Fauna. Urban Ecology Reader. Instructor: Myrna Hall. Faculty of Environmental Studies, SUNY College of Environmental Science and Forestry. Syracuse, NY.

[16] Grimm NB., Faeth SH., Golubiewski NE., Redman CL., Wu JG., Bai XM., Briggs JM. Global Change and the Ecology of Cities. Science 2008;319 756-760.

[17] Sukopp H. On the early history of urban ecology in Europe. In Marzluff, J. M., Shulenberger, E., Endlicher, W., Alberti, M., Bradley, G., Ryan, C., Simon U. and ZumBrunnen, C. 2008. Urban Ecology. An International Perspective on the Interaction Between Human and Nature. pp 79-87; 2008.

[18] Alberti M. Advances in Urban Ecology: Integrating Humans and Ecological Processes in Urban Ecosystems. Springer-verlag, New York; 2008.

[19] Berkes F., Colding, J., Folke, C. (eds) 2003. Navigating Social-Ecological Systems. Building Resilience for complexity and Change. Cambridge University Press, Cambridge.

[20] Uslu A. Kent Ekolojisi. Genel Ekoloji. Editör: Sabri Gökmen. Nobel Yayın Dağıtım. Nobel Yayın No: 1160. Nobel Yayın Ve Araştırma Merkezi Yayın No: 1. Fen Ve Biyoloji Yayınları Dizisi 37. ISBN 978-9944-77-170-2; 2007.

[21] Hough M. Cities and Natural Process A Basis For Sustainability. Routledge Taylor \& Francis Group; 2004.

[22] Çepel N. Peyzaj Ekolojisi. İÜ Orman Fakültesi Yayınları, İstanbul; 1994.

[23] Landsberg Hei. The Urban Climate New York: Academic Press; 1981.

[24] Barner J. Experimentelle Landschaftsökologic. Ferdinat Enke Verlag, Stutgart; 1983.

[25] Leopold LB., Hydrology for urban land planning. Washington, D.C. :U.S. Goverment Printing Office, G.P.O. Geological Survey Circular 554; 1968 
[26] Sanders, R. A.. Urban vegetation impacts on the urban hydrology of Dayton Ohaio. Urban Ecology. 1986;9 361-376.

[27] Nowak DJ, Dwyer JF Understanding the benefits and costs of urban forest ecosystems. In: Kuser JE (ed) Handbook of urban and community forestry in the Northeast. Kluwer, New York; 2000 pp 11-25.

[28] Bai, X. and P. Shi, Pollution Control in China's Huai Basin: What Lessons for Sustainability? Environment 2006;48(7) 22-38.

[29] Fletcher TD., Andrieu H., Hamel P. Understanding, management and modelling of urban hydrology and its consequences for receiving waters: A state of the art. 2013;51 261-279.

[30] CIRIA. Sustainable urban drainage systems-design manual for Scotland and Northern Ireland. CIRIA report no. C521. Dundee, Scotland;2000

[31] Whelans C, Maunsell HG, Thompson P. Planning and management guidelines for water sensitive urban (residential) design. Perth, Western Australia: Department of Planning and Urban Development of Western Australia;1994.

[32] Wong THF. Water sensitive urban design;the journey thus far. Aust J Water Resour 2007; 110:213-22.

[33] Coffman LS. Low impact development: Smart technology for clear water-definitions, issues, roadblocks and next steps. In: Strecker EW, Huber WC, editors. $9^{\text {th }}$ International conference on urban drainage. Portland, Oregon, USA: American Society of Civil Engineers;2002. p. 16.

[34] Uslu, A ve Shakouri, N. Kentsel Peyzajda Yeşil Altyapı ve Biyolojik Çeşitliliği Destekleyecek Olanaklar. Türk Bilimsel Derlemeler Dergisi 6 (1): 46-50, 2013 ISSN: 13080040, E-ISSN: 2146-0132, www.nobel.gen.tr; 2013.

[35] Celecia, J., UNESCO's Man and the Biosphere (MAB) Programme and Urban Ecosystem Research: A Brief Overview of the Evolution and Challenges of a Three-decade International Experience. Paper prepared for the MAB Urban Group for presentation at the ad hoc Working Group to Explore Applications of the Biosphere Reserve Concept to Urban Areas and their Hinterlands, UNESCO, Paris, November, 2000.

[36] Walker B, Salt D Resilience thinking: sustaining ecosystems and people in a changing world. Island Press, Washington, DC. (2006)

[37] Ahern J 2012. Urban landscape sustainability and resilience: the promise and challenges of integrating ecology with urban planning and design. Landscape Ecology. 10.1007/s10980-012-9799-z

[38] Bekci B., Cengiz C. Cengiz, B. Evaluating Urban Biodiversity in terms of User Preferences: Urban Residential Landscapes in Bartın (Turkey). Fresenius Environmental Bulletin 2012;1(6b): 1626-1634.

[39] Heywood V., 'The Importance of Urban Environments in Maintaining Biodiversity'. In:, di Castri, F. and Younès, T., (eds.), Biodiversity, Science and Development: Towards a New Partnership. CAB International, Wallingford, Oxon, in association with the International Union of Biological Sciences; 1996, pp. 543-550.

[40] Barrico L., Azul A M, Morais MC, Coutinho AP, Freitas H, Castro P.. Biodiversity in urban ecosystems: Plants and macromycetes as indicators for conservation planning in the city of Coimbra (Portugal). Landscape and Urban Planning 2012; 106(1) 88-102. 


\title{
Landscape Engineering, Protecting Soil, and Runoff Storm Water
}

\author{
Mehmet Cetin
}

Additional information is available at the end of the chapter

http://dx.doi.org/10.5772/55812

\section{Introduction}

Landscape engineering thinks about the application of mathematics and science to the creation of convenient outdoor living areas. These outdoor living areas are a consequence of the design and the construction process made feasible by landscape architects through landscape contractors. Beside landscape engineer's interested in containing site grading and drainage, earthwork calculations, and watersheds $[1,12,13]$.

Landscape engineers employ engineering knowledge when designing and building spaces. They demand to know how to interpret contour maps which shows elevations and surface configuration by means of contour line sand and also consider how to interpret 2-D images, compute angles and grading requirements for pavements, parking lots, bridges, roads and other structures. Beside they understand the amount of fill needed for specific areas and figure out how water runoff and flow should affect their designs.

Developing and improving for landscape engineering $[1,3,13,14]$

1. Stormwater management: building up bioswales, landscape materials used to gather and install runoff, rain gardens and porous asphalt.

2. Mitigation of the urban heat island effect: diminishing the quantity of paved surfaces, building up green roofs and green walls, and using building materials with low reflectivity.

3. Wildlife habitat: protecting habitat and building up green roofs and rain gardens.

4. Social spaces: areas for walking, biking, gathering and eating.

5. Transportation: growth expanding pedestrian accessibility, limiting vehicle speeds and encouraging the use of public transportation.

All above are using for the mixing plastic with asphalt on the pavement for the above reasons. One of them we are using porous plastic asphalt on the pavement for diminishing the sounds of road, and protecting the soil, and making runoff out the structure. 
Porous plastic pavement which is a permeable pavement surface permits the action of storm water in order to infiltrate directly into the soil. It usually constructs with an underlying stone supply that temporarily stocks surface runoff before infiltrating into the subsoil. It takes the place of traditional pavement. There are various types of porous surfaces, including porous asphalt, permeable concrete and even grass or permeable pavers.

Porous plastic asphalt pavements suggest an alternative technology for stormwater management. It is varied from classical asphalt pavement designs so that the structure enables fluids to come frankly through it, decreasing or monitoring the amount of run-off from the surrounding area. By permitting precipitation and run-off to running out the structure, this pavement kind functions as an additional stormwater management technique. The mainly benefits of porous plastic asphalt pavements should contain both environmental and safety benefits including improved stormwater management, improved skid resistance, decreasing of spray to drivers and pedestrians, as well as a potential for noise decreasing. Porous plastic asphalt is applicable to many uses, including parking lots, driveways, sidewalks, bike paths, playgrounds and recreational courts. In addition, with proper maintenance, including regular vacuuming or pressure washing of the pavement surface to prevent clogging by sediments, porous asphalt can have a minimum service life of twenty years $[15,16,17,18]$.

Bitumen is a valuable binder for road construction. Different grades of bitumen which is $30 / 40,60 / 70$ and $80 / 100$ are available on the basis of their penetration values. The steady growth in high traffic intensity in terms of commercial vehicles, and the important variation in daily and weather temperature demand developed road characteristics.

Nowadays the waste plastics are to exist tremendous, as the plastic elements have been piece of daily life for using. They either blended with Municipal Solid Waste and/or dispose of landfill. If not recycled, their present disposal is either by land filling that the method has certain impact on the environment. Because of that an alternate use for the waste plastics is also the needed.

Thinner polythene carry bags are most adequately disposed of wastes, which do not draw attention the attending rag pickers to accumulate for forward recycling, for lesser value. These polythene bags are simply suitable with bitumen at specified conditions. The waste polymer bitumen mix may be prepared and a study of the properties can throw more light on their use for road laying.

Permeable pavements have been sufficient in behalf of environmental problems and corroborating sustainable green construction procedures. They are planned to support surfaces for parking lots and pedestrian roads that will permit some of the precipitation to filter into the ground, decreasing the bulk of stormwater runoff and revitalizing groundwater $[15,16,17]$. Permeable porous asphalt and concrete are the most ordinarily used elements in permeable pavements. Permeable asphalt uses practically the similar elements as conventional asphalt, order than the percent range of plastic added, and the size of the aggregate is used to stay thin, permitting for minimum particle packing [16,17]. Permeable asphalt and concrete has been successfully implemented for road, retaining walls, streets, 
driveways, sidewalks, parking lots, and slope protection for the past 30 years in many countries, including the United States [17]. None of any researchers, to the authors' knowledge, have inquired for mixing permeable plastic asphalt so far that implement plastic waste as a binder bonder for permeable pavements. This study presents an alternative sustainable technology, familiar as permeable plastic asphalt, which should be implemented for permeable pavements. Permeable plastic asphalt material is produced from plastic waste, porous aggregates, and asphalt. The research evaluated the mechanical and hydraulic characteristics of permeable plastic asphalt.

An asphaltic paving material involves $4 \%, 5 \%$ and $6 \%$ percent, of granular recycled plastic (LDPE with 1\%, 3\%, and 6\%), which supplements the porous aggregate component (aggregate size of $3 / 8,4,8,16$ ) of the mixture. The material produces a structurally superior paving material and longer lived roadbed. The plastic can contain any and all residual classes of recyclable plastic. The material produces roadbeds of higher strength with less total asphalt thickness and having greater water permeability, and is most useful for all layers below the surface layer. A process of shredding or mechanically granulating preferably forms the paving product.

A porous plastic asphalt pavement has benefit for using road users and road side environments such as decreasing road noise, developing drainage function, and driving security situation. Furthermore, the worth of porous asphalt is to support skid resistance, particularly in the wet weather, that is distinctly better than that of dense traditional asphalt [19].

Conventional asphalt was not usually acceptable in the high temperature, humid, and traffic. As a result that some of issues were occurred like the pores were clogged, strength of drainage, rutting and scattering came off by traffic loading [20]. Large percentage of air voids of the mixture is adopted in order to maintain the drainage function. Nevertheless, in the way that the proportions of air void grow, strength feature of the mixture diminish. This is the main theorem of asphalt mixture. For solving this, landscape engineers think about the plastic for design and planning as binder.

The aim of this research is to assess strength, which means the performances of porous asphalt mixtures, for testing Resilient Modulus to find Indirect Tensile Strength (ITS). Furthermore, it measures the durability of porous asphalt mixture using Marshall Immersion test.

It is the aim of this chapter (book) to outline the elementary essential parts fundamentals associate with the design, plan, and construct of pavements and to mix with plastic techniques that will allow a Landscape Engineer to plan and design a pavement to suit a variety of situations. After experiments next books chapters will be considered to help environment and nature same as protect soil and recycling. Next study will keep going to research the better experiments about permeable surfaces for using different plastic materials. As a result it gains economic, environmental, and practical design and plan for Landscape Engineering. 


\subsection{Landscape engineering}

Landscape Engineering defined that is the art of developing land for people use and entertainment in such a manner as to obtain the utmost utility including with the utmost of beauty. It is a mistake to take into consideration the subject as implicated mainly with planting trees or to visualize its main function to be the supply of some decorative camouflage for some unsightly utility. Conversely, it has to be comprehended as a most important fundamental to life, and all art, which no utility would be necessary camouflage, and that every kind of artistic proceedings, instead of being without deep, has to be natural structural. Landscape engineering verifies the fundamental utilities, not as a necessary bad, but as necessarily well. In lieu of these utilities existing in the way of the objects, which the landscape engineer is succeed in doing, they turn out a most sufficient part of her/his own initiative. Apparently, once this point of view is admitted the Landscape Engineer and the others are definitely suiting for the same thing. Landscape Engineering impresses the main ideas, concepts, and techniques that cope with the functional, visual, and ecological perspectives of grading and landform cultivation. Landscape Engineering points out introduction to the processes, principles, and techniques of site engineering $[1,3,13,21,22,23]$.

Students who pursue to study their career in Landscape Engineering programs learn about Landscape Design and Planning, Transportation Plan, Structural Landscape Design, Urban Planning, Site Planning, Ecological Design, Environmental Design, and Horticulture. Essential aims of all of subjects in Landscape Engineering pay attention to cover sustainability, and eco-friendly landscaping processes. They usually not only study with their specific area of studies like sustainable urbanism, environmental hazard management, historic preservation, ecological design but also focus in land development along with construction management, or a compound of land development and architecture [2,14].

Landscape engineer is that construction is the first step after designing and planning. Landscape engineer have to be continually consider to reach suitable adjustments between the operating cost, the construction cost, and the maintenance cost. For only during the construction period can the required savings be influenced at a minimum of expense. Landscape engineer think about completed without mention of subgrade conditions or specifications on material and method of placing while designing and planning pavement, parking lot, etc. Drains are often paid attention as releases for storm water during the catch basins although the drain is laid to accumulate the soil. With new experiment in planning is the topographical survey, usually worked out with care and precision during considers drain and protects soil.

Landscape engineer has to keep in mind when planning the pavement that it is a business proposition as well as a picture designing and planning. That the Landscape planned with an eye to operation and maintenance cost must in time, have the better financial situation to protect appearance. Meanwhile design and plans are begun; we have to never forget that budget is a factor in maintenance, whether the project is considered on the constant care principle. The complete design of the pavement is that while every element of pavement construction must be considered from the point of view of beauty and aesthetic value, the 
weight of construction, operation and maintenance must be found and recognized at the time of beginning [3,22].

A Landscape Engineer conducts and takes advantage of the strengths of nature for the benefit and satisfaction of man. For instance, if you were designing and planning a new landscape for your property and wanted to direct the winds to preserve your amusing areas, a Landscape Engineer would help you make a determination which trees to get and where to plant them; thus, the wind could avoid your patio or courtyard. Landscape engineering involves with the application of mathematics and science to the constitution of practical outdoor living areas. These areas are a conclusion of the design and the construction process made possible by landscape architects, along with landscape contractors. Other main contemplates of landscape engineer's include drainage and site grading, watersheds and earthwork calculations. It is the Landscape engineer's act to vigorously interest in the design of the landscape, hence, to significantly supervise the creation of the landscape design. Landscape engineering exemplifies the traditional engineering elements of planning, operation, management, design and construction, and assessment. Before planning and designing, Landscape engineer should consider three main areas that focus on $[4,5,24]$ :

1. Landscape plan and design that Landscape Engineers interest planning the individual landforms so that they go along with the objectives arrange in the termination design phase. It is necessity that the Landscape engineer confers with the rest of the architectural team for carrying out a sufficient visual result once the construction process is finished.

2. Termination design and plan that it implies setting targets as well as supporting the Landscape design of the project at hand. Landscape engineers who works very closely with the contractors and sub-contractors does for working with Landscape designers as well as the owner of a home or property for deciding what the desired look is considered together and the essential steps to be taken in order to success it.

3. Functioning assessment that the reason of performance evolution of the Landscape engineer results in estimating liability and financial assurance of the landscape design and plan project. Thus, performance evaluation is vital to both the closure planning progress and performance evaluation.

\subsection{Soil protection}

As we preserve air and water, which we use for breathing and drink, the soil is very important as well. The quality of soil takes care of ecosystems. Soil quality, which would be linked to water quality, is a measure of soil productivity. As a determination soil quality which particularly, the bulk of soil to operate within ecosystem borders to endure keep up environmental quality, biological productivity, and support plant and animal health $[25,26,27]$.

Soil structure and water infiltration is very important for soil quality as well as aim attention at characteristics like organic matter content overall soil biological activity, nutrient 
availability, and total organic matter levels [25,27]. Soil can be protected from erosion, landslide, and compaction by mixing plastic materials. Soil conveys very easy underground by water. Soil, which is ancient, rock broken into sand, silt and clay is the recycled and continuously transforming.

The one of ways for protect and sustainably improve of soils is mixed cover pavement with plastic materials for prevent erosions of soil. Soil tests should be recommended for mixing with compaction plastic. It is evaluated compliance with hydrologic characteristics like drainage from plastic compaction.

\subsection{Stormwater runoff}

Stormwater runoff comes off while precipitations from rain or snowmelt infiltrate the ground. Impermeable surfaces like pavement, driveways, parking lots, sidewalks, and streets restrain stormwater runoff from naturally permeate into the ground.

For understanding the impact of stormwater runoff firstly need to consider how important water cycles through the urban environment. The bulks of precipitation infiltrate forests flows slowly underground, are infiltrated in by natural progress, and eventually arrive at lakes, streams while is being its natural. When we design and plan to compress the land with roads, parking lots, and buildings, the natural progress of water infiltrate in the earth is diminished. The existing grasslands and forests are put in place of concrete, roofs, and asphalt that do not permit rain to infiltrate the earth. Rather than, the precipitations soak through as faster as directly into streams, storm drains, and all without the profit of filtration. Designing, planning and constructing with mixing plastic material help to infiltrate water on the driveway, parking lots, pavement in place of concrete or asphalt. Thus, they permit stormwater to quickly drain into the ground $[28,29,30]$.

Stormwater is water that directly results from a rainfall event is not absorbed into soil and rapidly flows downstream, increasing the level of waterways. The flow of water results from precipitation and that occurs immediately following rainfall or as a result of snowmelt. Stormwater is the portion of rainfall that does not infiltrate into the soil. Rainwater and snowmelt that runs off impermeable surfaces rather than infiltrate into the soil through a drainage system of underground pipes, stormwater carries nutrients, fine soils, plant debris, drippings from vehicles, and other substances from the drainage basin most of lakes, ponds, and wetlands are connected to the stormwater system. Water collected in a system of pipes which drain roads and industrial or trade premises Stormwater may contain contaminants present on drained surfaces.

Stormwater is concerning about two issues that are the volume and timing of runoff water and prospective polluting. Stormwater is needed to flood control and water supplies. Also stormwater lead to be water pollution for conveying the water. As a stromwater, watermanagement on the pavements should probably do urban environments self-sustaining in terms of water. Stormwater is pollution because impermeable surfaces like parking lots, roads, buildings, compacted soil do not enable rain to drain into the ground. More runoff is constituted than in the unprogressive condition. Thus, it should consume waterways like 
flooding after stormwater collection system is overwhelmed by the additional flow. So the water is out of watershed way through little drainage the soil, the storm event [31,32].

Stormwater is a problem so that it could collect chemicals waste, mud, dirt, and other pollutants and infiltrate in the storm sewer system or directly to a river, lake, coastal water, stream, or wetland. Anything, which inserts a storm sewer system, is released untilled into the waterbodies we run for fishing, swimming, and supplying drinking water.

The results of pollution of stormwater runoff could have many unfavorable effects on animals, plants, people, and fish. Sediment that could blur the water and make it complicated or unimaginable for aquatic plants to grown could demolish aquatic habitats. The pollution of stormwater usually influences drinking water sources, which could transform to imitate human health and grow drinking water treatment costs.

The solution of pollution of stormwater that is permeable pavement consists of mixing plastic. Traditional concrete and asphalt don't tolerate water to infiltrate into the ground. Rather than these surfaces depend on storm drains to switch unwanted water, Permeable pavement systems permit rain and snowmelt to saturate with, diminishing stormwater runoff [28,32]. Stormwater runoff is without filtered water that arrives at oceans, streams, and lakes by means of streaming on impermeable surfaces that contain driveways, parking lots, roads, and roofs.

\subsection{Correlation between impermeable pavement and permeable runoff}

Impermeable pavement in a watershed occurs in growth permeable runoff. The barely 10 percent impermeable pavement in a watershed would occur in stream decline.

Stormwater is pollution so that impermeable surfaces like parking lots, compacted soil, roads, buildings, do not permit rain to flows off from the land in the streams, further runoff is caused to be than in the immature condition [28,31].

This further runoff would spoil streams and rivers as well as bring about flooding after the stormwater system is overflow by the extra flow so that the water is reveled out of the watershed through the storm event, barely drains the soil, fills groundwater, or stocks stream baseflow in dry weather. Contaminant inserting surface waters during rain that is lead to contaminate runoff. Daily people activities appear in sediment of pollutants on parking lots, farm fields, driveways, roads, lawns, roofs. As soon as precipitation begins, water flow off and eventually makes its way to a lake, ocean, and river.

A traditional city block creates more than five times more runoff than the forest because of impermeable pavement. The waste of penetration from city may come out with depth groundwater changes $[28,31,32]$.

The present drainage systems, which accumulate runoff from impermeable surfaces like roads, parking lots, roofs insure that water is effectively transported to ways of water during pipes. As a matter affects little storms water occur in growth ways of water flows. Stomwater lead to some of issue that shows below. 
1. Impermeable Pavement

2. Roads, sidewalks, rooftops, overly compacted soils

3. Do not allow for natural infiltration of stormwater

4. Increase temperatures (Heat Island Effect)

5. Degradation of water quality and natural habitats

6. Flooding, erosion and may reduce groundwater levels

\subsection{Class of plastic for using contemporarily}

The simplest way for a user to label the class of plastic used in a product is to recognize the resin identification code, which is familiar with the material container code as well, is generally plotted, shaped or symbolized in or close to the middle of the bottom of the product. In accordance with the society of the plastics industry (SPI) resin identification code (or material code) is to systematize mutual plastic resins and their characteristics.

The identification of plastics made known in 1988 by The Society of the Plastics Industry Trade Association (SPI) that provides to build the companies for easy recycles make collect the consumer plastics during the common pathways for coming together recyclable stuffs from household waste. It is based on willing for plastic manufacturers, however, it has evolved into comparatively standard on plastic products sold in the U.S. and internationally. For example, the identification of plastics is in service and is affirmed by the Canadian Plastics Industry Association (CPIA) in Canada. It supports specifics on the identification by mean of its Environment, health and safety strategic unit and its Environment and Plastics Industry Council (EPIC) [7,33,34].

The aim of the identification provides to make it simpler for recycling to plastics. Furthermore, it determines consumers with an easy, handy method for identifying the class of plastic resin used to create a specific product. In conformity with SPI identifications, the number is intentionally located in an unnoticeable place on the product so that the company purpose is not to affect the consumer's buying determination, barely to assist the progress of recycling of the product.

According to SPI, there are seven different classes of plastics. Showing Figure 1, the identification numbers imprint on the bottom of plastic products that is a number inside of triangle represents to mean their identifications for recycling. Have you ever been curious about what the numbers inside the little recycling symbol mean on all of the plastic packaging and plastic products which we consume for using?

According to SPI the identification in 1988 reciprocates to the consider revising of the plenty recyclers side to side the countries. Here each class of plastics number and definition [7].

1. PETE, PET (Polyethylene Terephthalate) is clarity, strength or toughness, barrier to gas and moisture, resistance to heat. It uses for consuming plastic soft drink and water bottles, beer bottles, mouthwash bottles, peanut butter and salad dressing containers, oven able film, oven able pre-prepared food trays. 


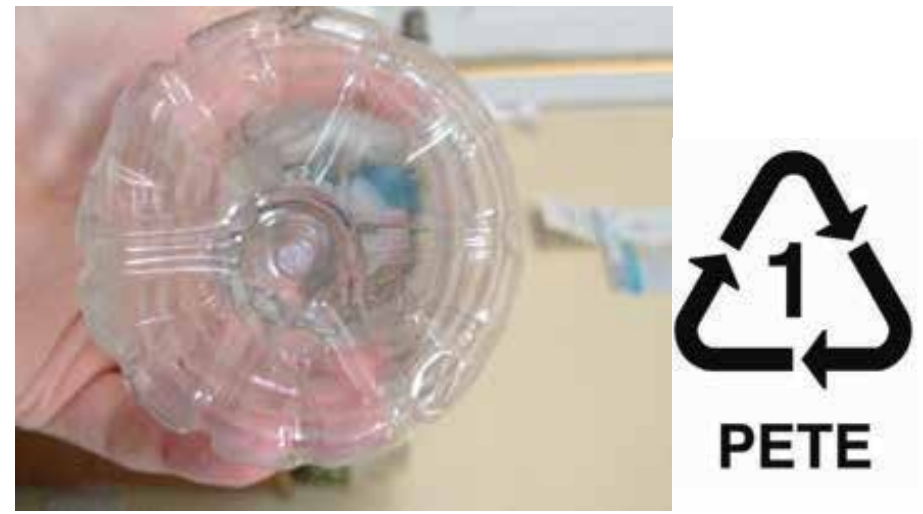

Figure 1. Samples of identification on the bottom of plastic water bottles

2. HDPE (High Density Polyethylene) is stiffness, strength or toughness, resistance to chemicals and moisture, permeability to gas, ease of processing, and ease of forming. It uses to make plenty classes of bottles. The bottles are clear, have good limit qualities and stiffness, and are quite appropriated to packaging products with a short shelf life like milk so that HDPE has good chemical resistance; it is used for packaging many household and industrial chemicals such as detergents and bleach. It uses milk, water, juice, cosmetic, shampoo, dish and laundry detergent bottles; trash and retail bags, yogurt and margarine tubs, cereal box liners.

3. V, PVC (Vinyl, Polyvinyl Chloride) is versatility, ease of blending, strength or toughness, resistance to grease or oil, resistance to chemicals, clarity. It has well chemical resistance, weather ability, flow typical features and constant electrical qualities. Products made from Vinyl can be both flexible and rigid. It uses toys, clear food and non-food packaging, shampoo bottles, medical tubing, wire and cable insulation, film and sheet; construction products such as pipes, fittings, siding, flooring, carpet backing, window frames.

4. LDPE (Low-Density Polyethylene) is ease of processing, barrier to moisture, strength or toughness, flexibility, ease of sealing. It is used efficaciously in film uses because of its flexibility toughness, and approximate transparency, making it familiar for use in uses that heat sealing is essential. Furthermore, LDPE uses to procedure some flexible lids and bottles as well as in wire and cable uses. It uses squeezable bottles (honey, mustard), coatings for paper milk cartons and hot and cold beverage cups, container lids, toys, dry cleaning, bread, and frozen food bags.

5. PP (Polypropylene) is strength or toughness, resistance to chemicals, resistance to heat, barrier to moisture, versatility, and resistance to grease or oil. It has good chemical resistance, is strong, and has a high melting point making it well for hot-fill liquids. This resin is brought to light in rigid and flexible packaging, fibers, and large pattern parts for automotive and consumer products. It uses containers for yogurt, margarine, takeout meals and deli foods, medicine bottles, bottle caps and bottles for ketchup. Furthermore, for packaging, its plenty of uses are in fibers, appliances and consumer products, containing strong applications like automotive and carpeting. 
6. PS (Polystyrene) is versatility, insulation, and clarity, easily foamed as known "styrofoam". It is clear, hard and brittle. Also, it has an approximately low melting point. General uses contain protective packaging, food packaging, bottles, and food containers. It is usually connected with rubber to make high impact polystyrene (HIPS) that is used for packaging and constant uses necessity stiffness. It uses compact disc cases, food- service applications, grocery store meat trays, egg cartons, aspirin bottles, cups, plates, and cutlery.

7. Other is dependent on resin or combination of resins. Use of this number represents which a package is made with a plastic other than the six listed above, or is made of more than one plastic and used in a multi-layer combination. It uses usually shows the exits of polycarbonate which a hard, clear plastic used to make baby bottles, water pitchers, nalgene brand water bottles, three and five-gallon reusable water bottles, food containers, some citrus juice and ketchup bottles, compact discs, cell phones, automobile parts, computers, three and five-gallon reusable water bottles, some citrus juice and catsup bottles, oven-baking bags, barrier layers and custom packaging.

\section{Development of design}

\subsection{Design factors}

The area of pavement design is vigorous in which ideas are steadily changing as new data evolve into achievable. For mixing plastic pavement that are many majority of design and plan applicable, since alternatives relating to sustainability, suitability of designs and plans alter from area to area. Especially, supplies that are applicable for construction and foundation of pavements have a higher impress on design and plan. There are, nevertheless, fundamentals of design that are mutual to all problems irrespective of other uncontrollable situation [35,36,37,38,39].

The plan and design of pavement embrace with a work of soils and paving materials, their action under load, and the plan and design of pavement to convey which load under all hydraulic and weather situations. All pavements obtain their eventual support from the underlying subgrade. As a result, a comprehension of elementary plastic materials, pavement design and soil mechanics is necessary. Landscape Engineers are familiar that efficiency of pavement that are connected to a large volume upon the types of plastic, soils over that the pavement is designed and constructed, therefore, in relationships pavement efficiency between subgrade types are built. On the whole, the experiments of mixing plastic pavement demonstrated that pavement designed and constructed over plastic displayed higher degrees of distress than those designed and implemented over traditional pavement. Frost process and unfavorable drainage situations were observed early as two of the primary reasons of pavement lapse.

However, many landscape engineers are made use of standard cross components for most pavements. It means that a road, even though it crossed several mixing plastic and soil types, was designed and implemented using a constant thickness. The foreseeing was usually confirmed on the rest of economics. Beginning of 1980s, people recognized that the 
traditional pavement affects the environment and nature. All of thriving technological elements such as cars, bike for becoming a simple life causes to influence the pavements lapse $[40,41,42,43]$.

\subsection{Conventional pavements}

AASHTO have been in charge for various tests, which roads designed and implemented in United States as well as some of state highway departments have implemented test pavements for the aim of assessment the influence of load and elements on pavement design.

There is a small suspicion that the outcomes of test results have had extreme effect on current design ideas. Furthermore, efficiency of example pavements in service has had important effect on design. This is not shocking, if one thinks that it is hard to do if not unreasonable to judge entirely design ideas in the laboratory. In addition, it has been familiar with for quite a while that reader belief in the final analysis imposes the competency in some of the design.

\subsection{Definition pavement types}

Basically, with regard to history of pavements have been classified two main types which are flexible and rigid. Flexible pavements comprise asphalt. Nowadays flexible pavement is very important with mixing plastic so that makes permeable areas.

Plan, design, and construction of permeable pavements have altered rather importantly in the last decades. On account of the current traditional plan, design, and construction pavements come up severe higher traffic levels, wheel loads, pavement lapse. A growth use of balanced is base and subbase. Balancers such as asphalt, plastic are repeatedly used to grow the structural strength of the pavement by growth rigorously. Because of the reason an extremely concentrated effort was made in the last several years to develop a more fundamentally based design analysis for asphalt.

\subsection{Permeable plastic asphalt}

Some of researchers assessed the impact of moisture susceptibility on porous asphalt samples [44]. Samples were based on wet and dry conditions and then tested for indirect tensile strength test (ITS). Results showed that ITS decreased noticeably when the sample was immersed in water.

\subsection{Purpose of plastic asphalt}

The aims of the study are need to do those. First of all; Disposal of waste plastic is a major problem, non-biodegradable, burning of these waste plastic bags causes environmental pollution. Secondly need is it mainly consists of low-density polyethylene, and to find its 
utility in bituminous mixes for road construction. Thirdly, Laboratory performance studies were conducted on bituminous mixes. Laboratory studies proved that waste plastic enhances the property of the mix, and improvement in properties of bituminous mix provides the solution for disposal in a useful way.

Waste plastics like polythene carry bags, etc. on heating usually at approximately $160^{\circ} \mathrm{C}$. According to thermo gravimetric results has demonstrated that gas evolution isn't found during the temperature rank of 130 to $180^{\circ} \mathrm{C}$. Furthermore the mellowed plastics have a binding feature. Therefore, the melted plastics can be implemented as a binder that they should be blended with binder like bitumen to improve their binding feature. As a result it should be a good modifier for the bitumen, implemented for road construction.

\subsection{Function of the mix plastic asphalt}

The growth of plastic city wastes has affected to wide and creative technologies that incorporate recycled plastics in miscellaneous uses. Scientists and Departments of Transportation have been interested in different researches regarding to the feasibility, economic and ecological impact and the complete efficiency of recycled plastic in connected landscape engineering projects. For instance, recycled thermoplastics like PET, HDPE, and LDPE, have been implemented in porous asphalt mixtures to put in place of aggregates with specified diameters $[45,46,47,48,49,50]$. Conclusion from these researches demonstrated improvement in strength, durability, and fatigue life. Nevertheless, the scale of improvement is a capacity of the plastic types and amount. The rest of researchers implemented recycled plastic strips to mechanically stabilize and aggregates by mixing plastic shreds with aggregates to compaction to defeat inadequacies in grading and diminishing the plasticity index $[51,52,53]$. The scale of enhancement was affected by many factors like the class and volume of shreds, and aggregate classes. Furthermore, creative and innovative study has cause to the development of new mixed elements using recycled plastic waste for miscellaneous uses. The mixed is produced by heating and blending the absorption elements, recycled plastic, which flakes, shared, or unprocessed, granulates and by products to a highlighted temperature. The heated combination is then compacted into a particular mold to found a final product. The features of the mixed rely on the pressure, class of recycled plastic and granulates $[54,55,56]$.

\section{Material properties}

\subsection{Recycled Low-Density Polyethylene (LDPE)}

The supplier for Recycled Low Density Polyethylene (LDPE) provided the test properties of the material with respect to density, tensile strength at break, elongation at break, impact strength, and melting point of the material as shown below Table $1[8,10]$. Recycled low-density polyethylene (LDPE), which is identification number four, was gathered together and implemented in this research. The cleaned LDPE has shredded as shown below Figure 2. 
Recycled Low-density polyethylene (LDPE) material is used extensively to produce tote bags for domestic goods. These bags become solid waste after their use for short periods and cause serious waste disposal problems. To solve this environmental problem, and at the same time to improve the drain down and other related engineering properties of the porous asphalt mixture, reclaimed from LDPE bags was used in this investigation as additive in porous asphalt mixtures. LDPE material in shredded of used is as added ingredient.

\begin{tabular}{|c|c|}
\hline \multicolumn{2}{|c|}{ Recycled Low Density Polyethylene Features (LDPE) } \\
\hline \multicolumn{2}{|c|}{ Mechanical Properties } \\
\hline Yield Strength & $15-20 \mathrm{MPa}$ \\
\hline Elongation@ break & $600-650 \%$ \\
\hline Bending Strength & $10-40 \mathrm{MPa}$ \\
\hline Young's modulus (E) & $200-400 \mathrm{MPa}$ \\
\hline Shear modulus & $100-350 \mathrm{MPa}$ \\
\hline Tensile Strength $\left(\sigma_{t}\right)$ & 8-12 MPa \\
\hline \multicolumn{2}{|c|}{ Physical Properties } \\
\hline Density & $910-928 \mathrm{~kg} / \mathrm{m}^{3}$ \\
\hline Thermal expansion & $150-200$ e- $6 / K$ \\
\hline Water absorption & $0.005-0.015 \%$ \\
\hline Melting Point & $248^{\circ} \mathrm{F} 120^{\circ} \mathrm{C}$ \\
\hline Thermal conductivity & $0.3-0.335 \mathrm{~W} / \mathrm{m} . \mathrm{K}$ \\
\hline Melting temperature & $125-136^{\circ} \mathrm{C}$ \\
\hline Maximum Temperature & $176^{\circ} \mathrm{F} 80^{\circ} \mathrm{C}$ \\
\hline Minimum Temperature & $58^{\circ} \mathrm{F} 50^{\circ} \mathrm{C}$ \\
\hline Specific heat (c) & $1800-3400 \mathrm{~J} / \mathrm{kg} . \mathrm{K}$ \\
\hline
\end{tabular}

Table 1. Recycled Low Density Polyethylene Features (LDPE)

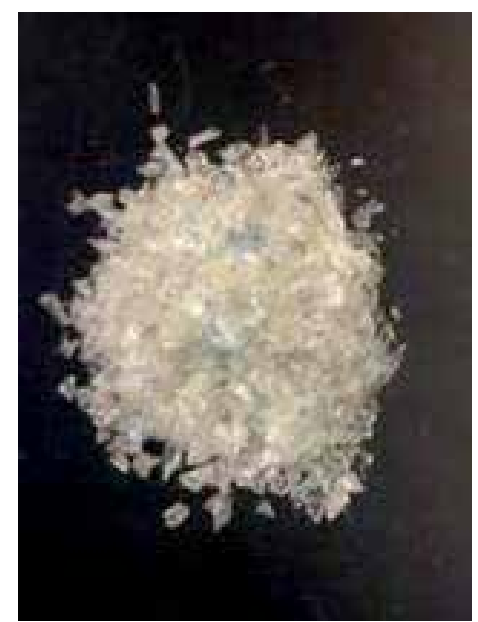

Figure 2. Shredded for recycled Low Density Polyethylene (LDPE) 


\subsection{Porous aggregate}

Crushed limestone was chosen as the course aggregate for mixing LDPE. Bulk samples were sieved in conformity with the sieve sizes for AASHTO No. 8. According to Figure 3 demonstrates the gradation for aggregates that Porous aggregates confirming to the sizes $3 / 8$ in., Nos. 4, 8, 16 (AASHTO No 8) were used for mixing with permeable plastic asphalt. Aggregates maintained on each sieve were washed, dried for 24 hours in $110^{\circ} \mathrm{C}$ in the oven and then located into their respective batches by sieve maintained. This procedure provided regenerate samples to meet AASHTO No. 8. Furthermore, it made to be better control over the gradation of each sample, so that gradation has important impact on the engineering and physical features of an aggregate mixed.

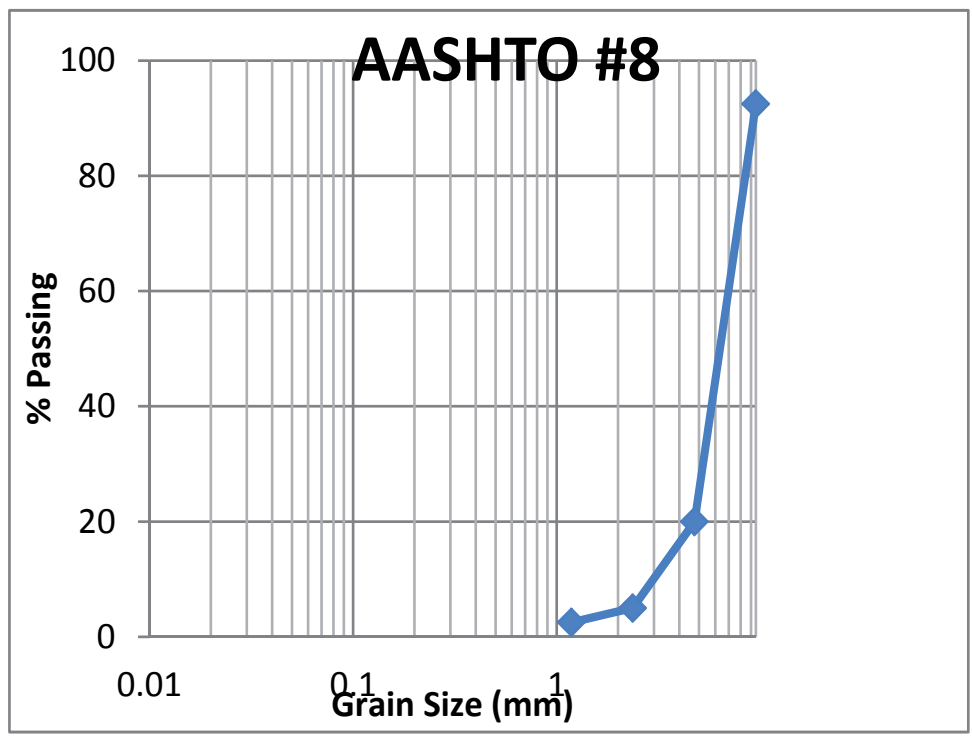

Figure 3. Grain size distribution of AASHTO No. 8

\subsection{Bitumen}

"PG 68-22" was used in the porous asphalt mixture [9]. Bitumen was mixed with Lowdensity polyethylene (LDPE) and porous aggregates. Mixes were prepared for three $(4 \%$, $5 \%$, and $6 \%$ bitumen) percentages of bitumen. Each $\%$ of bitumen has $1 \%, 3 \%$, and $6 \%$ LDPE. Obviously, four types of mixtures with three different percent of bitumen of $4 \%, 5 \%$ and $6 \%$ were used at a mixing and compacting temperature of $160^{\circ} \mathrm{C}$. These are: Without LDPE, 1\% LDPE, with 3\% LDPE, and with 6\% LDPE.

\section{Samples preparation, compaction, and tests}

\subsection{Mixing of shredded waste plastic (LDPE), aggregate and bitumen}

The aggregate mix is heated to $160^{\circ} \mathrm{C}$ in oven, and similarly the bitumen is to be heated up to a maximum of $160^{\circ} \mathrm{C}$. Plastic waste is shredding for mixing bitumen and aggregate to coat 
the plastics effectively. After that, put them in oven $160^{\circ} \mathrm{C}$ in order to mix and compact simultaneously. For protecting the moisture the spacemen, it compacted immediately after took out oven with approximately $160^{\circ} \mathrm{C}$.

\subsection{Mix Design by Marshall method Marshall test}

Use of the processed plastic bags is as an additive in bituminous concrete mixes. The processed plastic was used as an additive with heated bitumen in different proportions (ranging from 4 to $6 \%$ by weight of bitumen) and mixed well by hand, to obtain the modified bitumen. The properties of the modified bitumen were compared with ordinary bitumen.

Varying percentages of waste plastic by weight of bitumen was added into the heated aggregates. Marshall sample with varying waste plastic content was tested for stability. Maximum value of stability was considered as criteria for optimum waste plastic content. The optimum modified binder content fulfilling the Marshall Mix design criteria was found to be 4,5 , and $6 \%$ by weight of the mix, consisting of 1,3 , and $6 \%$ by weight of processed plastic added to the bitumen. In order to evaluate the ability of the mix prepared with the bitumen to withstand adverse soaking condition under water, Marshall Stability tests were conducted after soaking in water at $60^{\circ} \mathrm{C}$ for 24 hours.

\subsection{Porous plastic asphalt for preparation and compaction}

Shedder LDPE was simultaneously composed with binder and aggregates for heating and mixing approximately $160^{\circ} \mathrm{C}$ for two hours so that a uniform was achieved. Mixed plastic porous asphalt was poured and compacted into a mold, which is 4 inches diameter and 2.5 inches height, using a steel shovel. The Marshall test procedure was used for designing porous mix by compacting the sample with 50 blows on one face by Marshall hammer, at varying binder contents. The mixture design trials used asphalt content in the range of $4-6$ $\%$, by total weight of the mixture, excluding the weight of the fibers, with $1 \%$ increments. The LDPE fibers were added to the porous mixtures at a dosage rate of 1,3, and $6 \%$ based on total mixture weight. The compacted samples were extracted from the mold when they had sufficiently cooled. After compaction, samples were be kept in the hot (conditioned) and cold (unconditioned) waters. Resilient Modulus and permameter test conducted. Samples were tested for hydraulic conductivity and indirect tensile strength. Figure 4 demonstrates the preparation of the Porous plastic asphalt samples.

\subsection{Laboratory tests}

Porous plastic asphalt samples were tested for hydraulic conductivity and indirect tensile strength. Hydraulic conductivity tests were operated using a falling head approach in conformity with a proceeding particularized in the researchers $[57,58]$. The indirect tensile tests were conducted in accordance with the ASTM C 6931-07 test methods. 


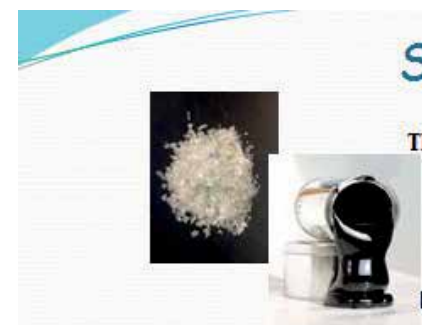

Plastic Waste (Low Density

Polyethylene-LDPE), Bitumen PG-22

Water goes through the plastic asphalt

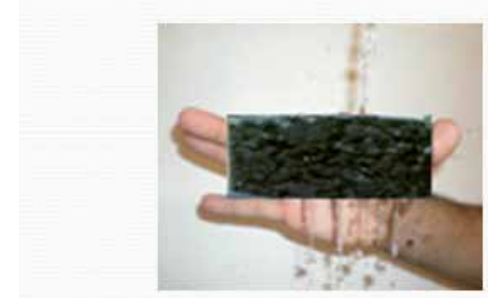

Sample Preparation

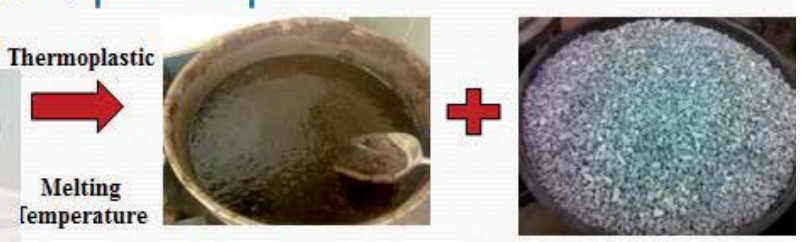

Bitumen mixed Plastic Waste (LDPE)

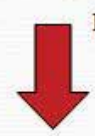

Porous Aggregates

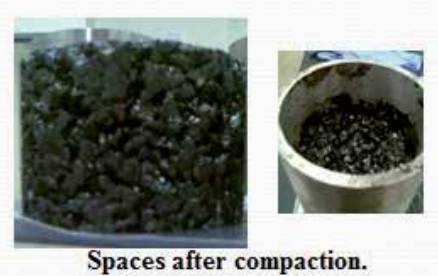

Spaces after compaction.

Figure 4. Figure 4 Sample preparation for permeable plastic asphalt that mixing of LDPE, porous aggregates, binder to create

From equation 1 calculate hydraulic conductivity for testing in the falling head permameater test. After used Permameters to measure k, use this following formula. Calculate the hydraulic conductivity of the sediment by using the following formula:

$$
k=\frac{V x L}{\left(h_{o}-h\right) A x t} x \ln \frac{h_{o}}{h}
$$

where $\quad K=$ hydraulic conductivity of the sediment sample $[\mathrm{L}] /[\mathrm{T}]$

$\mathrm{V}=$ volume of water that passed through the sample $[\mathrm{L}]^{3}$

$\mathrm{L}=$ sample length $[\mathrm{L}]$

h0 = height of top mark above outflow port [L]

$\mathrm{h}=$ height of bottom mark above outflow port [L]

$\mathrm{A}=$ cross sectional area of sample. For the NEIU permameters, this is $31.65 \mathrm{~cm}^{2}$.

$[\mathrm{L}]^{2}$

$\mathrm{t}=$ total time for discharge $[\mathrm{T}]$

The indirect tensile test that is one class of tensile strength test implemented in order to stabilize elements. The test has been run on asphalt-stabilized elements $[35,59,60,61]$. The test has many advantages, the most obvious being simplicity of test procedure. From equation 2 calculate ITS for testing in the resilient modulus (MR) test. After used with the diametrical Mr test (repetitive indirect tensile modulus test) to calculate ITS, as using the tensile strength St of the material is given by:

$$
S_{t}=\frac{2 P \max }{\pi t d}
$$

Where $\mathrm{P}=$ total applied load $(\mathrm{lb})$ 
$\mathrm{t}=$ sample thickness (in)

$\mathrm{d}=$ sample diameter (in)

\section{Test results}

\subsection{Permeability}

According to Table 2 demonstrates the hydraulic conductivity $(\mathrm{k})$ of the porous plastic asphalt samples. From Table 2, it has provided that the results of $\mathrm{k}$ diminished with the growth of porous plastic mixing. For instance, when the results of $\mathrm{k}$ mixed \%4 binders with $\% 1 \mathrm{LDPE}$ were $0.204 \mathrm{in} / \mathrm{s}$, the result of mixing \%3 LDPE was $0.193 \mathrm{in} / \mathrm{s}$. Obviously, while mixing with \% of LDPE was increasing, the result of $\mathrm{k}$ was diminishing. Figure 5 represents the results of permeability of porous plastic asphalt with mixing \%1 LDPE.

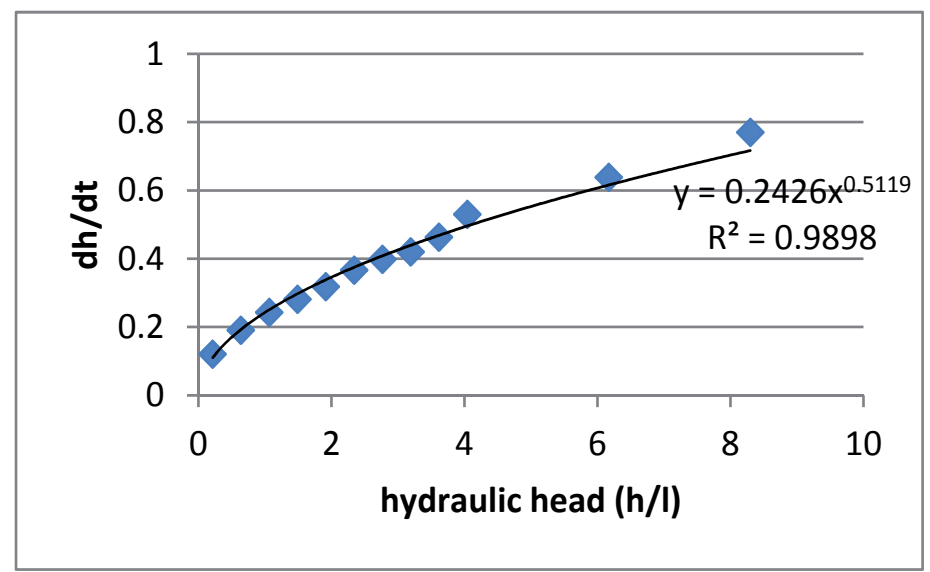

Figure 5. The results of $\mathrm{k}$ with mixing $\% 1 \mathrm{LDPE}$

\begin{tabular}{|l|l|l|}
\hline Binder & LDPE & k (in/s) \\
\hline \multirow{4}{*}{$\%$} & $\% 0$ & 0.217 \\
\cline { 2 - 3 } & $\% 1$ & 0.204 \\
\cline { 2 - 3 } & $\% 3$ & 0.193 \\
\cline { 2 - 3 } & $\% 6$ & 0.178 \\
\hline \multirow{5}{*}{5} & $\% 0$ & 0.259 \\
\cline { 2 - 3 } & $\% 1$ & 0.245 \\
\cline { 2 - 3 } & $\% 3$ & 0.234 \\
\cline { 2 - 3 } 6 & $\% 6$ & 0.223 \\
\hline \multirow{5}{*}{$\%$} & $\% 0$ & 0.301 \\
\cline { 2 - 3 } & $\% 1$ & 0.294 \\
\cline { 2 - 3 } & $\% 3$ & 0.288 \\
\cline { 2 - 3 } & $\% 6$ & 0.272 \\
\hline
\end{tabular}

Table 2. The results of hydraulic conductivity 


\subsection{Indirect Tensile Strength (ITS)}

Use this test method to determine the tensile strength of compacted bituminous mixtures. The porous plastic mixed tested as a conditioned and unconditioned. After compaction, samples were kept in the hot water (conditioned situation) and cold water (unconditioned situation). The objective of this test was to measure the water resistance of the mixture after immersion for 24 hours at $60^{\circ} \mathrm{C}$. After that, testing the resilient modulus provided the results of ITS. The purpose of results was to evaluate the resistance of porous plastic asphalt mix on plastic deformation. Furthermore, from equation 3 Tensile strength ratio (TSR) calculated that divided by conditioned to unconditioned situation. TSR $<70 \%$ considered Susceptible to Moisture. As a result it provides that the performance of strength of porous plastic asphalt. Moisture Susceptibility of Porous Plastic tested in accordance with ASTM C 693107. Samples were cured at room temperature, $100^{\circ} \mathrm{C}$ and $160^{\circ} \mathrm{C}$ for 24 hours. Samples dimension is Diameter $=4 "$, Height $=2.5^{\prime \prime}$.

$$
T S R=\frac{S 1}{S 2}
$$

Where:

$$
\begin{aligned}
& \mathrm{S} 1=\text { conditioned set }(\text { wet }) \\
& \text { S2 }=\text { unconditioned set }(\text { dry })
\end{aligned}
$$

According to Table 3 demonstrates that the results of unconditioned decreased with the growth of porous plastic mixing. For instance, when the results of mixed $\% 5$ binders with \%3 LDPE were 57 psi, the result of mixing \%6 LDPE was 54 psi. Obviously, while mixing with \% of LDPE was increasing, the results of conditioned ITS was decreasing. On the contrary, the result of conditioned increased simultaneously with the growth of porous plastic mixing. Figure 6 represents that the result of conditioned ITS diminished while

\begin{tabular}{|c|c|c|c|c|}
\hline Binder & LDPE & Unconditioned (psi) & Conditioned (psi) & TSR (con/uncon) \\
\hline \multirow{4}{*}{$\% 4$} & $\% 0$ & 67 & 45 & 0.67 \\
\hline & $\% 1$ & 58 & 52 & 0.90 \\
\hline & $\% 3$ & 46 & 56 & 1.22 \\
\hline & $\% 6$ & 41 & 63 & 1.54 \\
\hline \multirow{4}{*}{$\% 5$} & $\% 0$ & 71 & 54 & 0.76 \\
\hline & $\% 1$ & 62 & 59 & 0.95 \\
\hline & $\% 3$ & 57 & 62 & 1.09 \\
\hline & $\% 6$ & 54 & 68 & 1.26 \\
\hline \multirow{4}{*}{$\% 6$} & $\% 0$ & 73 & 63 & 0.86 \\
\hline & $\% 1$ & 69 & 67 & 0.97 \\
\hline & $\% 3$ & 66 & 71 & 1.08 \\
\hline & $\% 6$ & 61 & 75 & 1.23 \\
\hline
\end{tabular}
unconditioned ITS increased. According to the results of TSR is considered to susceptible to moisture. It provides that \%3 LDPE and over is very strength.

Table 3. The results of Indirect Tensile Strength test (ITS) 
The results of $\mathrm{k}$ and ITS of porous plastic asphalt mixtures were within the approximately predictable ranked come up in the literature for conventional asphalt showing Table 4. It is an indication that porous plastic asphalt should be used as a sustainable alternative for permeable pavements.

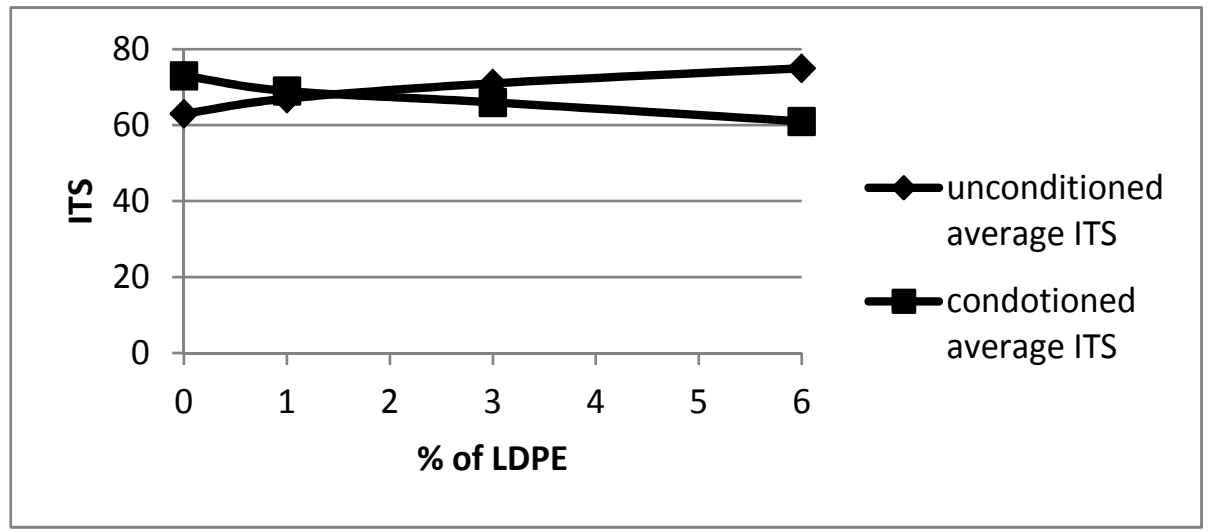

Figure 6. The results of ITS with mixing \%6 LDPE

\begin{tabular}{|c|c|}
\hline References & ITS ranges (psi) \\
\hline$[62]$ & $29.29-69.76$ \\
{$[63]$} & $18.17-38.82$ \\
{$[64]$} & $253.9-377.09$ \\
{$[65]$} & $29-65.26$ \\
{$[66]$} & $26.1-130.53$ \\
{$[19]$} & $18.30-55.90$ \\
\hline
\end{tabular}

Table 4. Summary of ITS porous asphalt from literature

\section{Discussion and conclusion}

Permeable Plastic Asphalt samples with different percentage of plastic to aggregate ratio were composed and then tested for hydraulic conductivity $(\mathrm{k})$ and indirect tensile strength (ITS). Results represented which k and ITS results of samples were within the predictable results observed in the literature for porous pavements. In addition to it was come up with that the k, ITS values diminished as the percentage of plastic waste increased. The research results of Permeable Plastic Asphalt demonstrated that Permeable Plastic Asphalt should be a sufficient recycle and stormwater runoff with important reasonable economic and ecological associations.

This research was taken in charge to evaluate the hydraulic and mechanical features of innovative porous plastic asphalt for implementing in permeable pavements. The test represented that the result of hydraulic conductivity diminished with the growth of porous plastic mixing. On the other hand, while the results of unconditioned decreased with the growth of porous plastic mixing, the result of conditioned increased simultaneously with 
the growth of porous plastic mixing. Furthermore, the results of TSR are the best result over 1 for susceptible to Moisture. The results of experiments were approximately come across that expected from literature. According to results that demonstrate porous plastic asphalt could be implement sustainable alternative pavements. It also provides also recycling.

This research concentrated on the hydraulic and mechanical properties of a permeable pavement like permeable plastic asphalt. Permeable Plastic Asphalt was composed of plastic waste, aggregates, and asphalt. Permeable Plastic Asphalt should provide a sufficient method for decreasing stormwater runoff, contributing a structural pavement sufficient for pedestrian and vehicular loadings. Furthermore, Permeable Plastic Asphalt should take the part of the currently ongoing recycling aims as a critical role that support to deflect a majority of plastic from landfills and incinerators.

The laboratory test indicates that aggregate, binder with mixing LDPE affected the results of $\mathrm{k}$ and ITS. Thus, permeability and strength of porous plastic asphalt is getting better with mixing LDPE. It proves that porous plastic asphalt help to diminish storm water runoff times diminish urban heat island effects. A new pavement increases for the sustainability of the nature that will be benefit users for many years. The design of plastic pavements contains developed pedestrian and public transportation as well as parking lot, driveway, bridges.

The results represents porous plastic asphalt should be implemented as a sustainable alternative for permeable pavements. Porous plastic asphalt is a peerless choice in that it undertakes two environmental problems that decreasing stormwater runoff and prevent to fill out with plastic waste at landfills. In the way that we keep up our way to green building and construction, porous plastic asphalt is new approach on the way to eco-friendly improvement. The innovative technology comes to grips with two environmental problems that are plastic waste and stormwater runoff. It provides to prevent a large quantity of plastic waste at landfills and incinerators, thus the plastic waste uses fro recycling. Also it decreases stormwater runoff and decreases the use of natural resources.

Permeable plastic pavement has whole with its permeability should be determined by valid void. Valid void should be directly implement to mixing ratio of permeable plastic pavement that both take control sufficiently the forming of run off and restrict urban flood.

All above results that Landscape Engineering considers that the progress of permeable plastic uses to efficiently integrate the mixing permeable plastic pavements with land use planning. Using recycling service with very powerful has approached to create pleasing environments in the world. According to test results that the advantages of plastic asphalt provide that is stronger road with increased plastic, better resistance during stormwater, without stripping and rutting, develop binder and better linking of the mix. Besides it support that is the strength of the road is increased. Using permeable plastic asphalt that is the cost of road construction diminish the maintenance cost of road gradually diminish as well. Obviously, as the plastic mix with pavement for using, the disposal of waste plastic will no longer be issue. As a result of that, using plastic helps to decrease in pores in aggregate save bitumen and help recycling. 
Consecutive chapters of this research will count profoundly on the outcomes of the test pavements mentioned above, as well as efficiency data issued in the research. Detailed representing results of the several researches projects will be debated during the research.

\section{Future research}

Effectively managing the collection, separation and processing of plastic waste can limit the environmental damages limited by eliminating the waste from our streets. Thus, we can prevent to fill the landfill with plastic waste when we mix the plastic with the other elements with soil, asphalt and cement in order to use future studies.

Laboratory tests and real life implementation will study that the life expectancy of a plastic polymer road as compared to a conventional road. Future study will need to study for expanding of life expectancy for plastic. This study proved that investigates, summarizes preliminary results, and debates key properties to be considered for future alternative pavement. Future researchers will keep going to research the better permeable pavement for economic, environmental and nature.

A long-term monitoring project to document changes in performance, evaluation of different maintenance strategies, and lifecycle costs of permeable plastic asphalts is recommended for future research. Future experience is based on designs that provide to improve future properties such as increased new materials, and developed construction and maintenance activities.

\section{Author details}

Mehmet Cetin

College of Engineering, Department of Civil and Environmental Engineering, Temple University, Philadelphia, Pennsylvania, USA

\section{Acknowledgement}

The author gratefully acknowledged Dr. Naji Khoury for his guidance and help.

\section{References}

[1] McKenna, GT. Sustainable Mine Reclamation and Landscape Engineering. PhD Thesis in Geotechnical Engineering, Department of Civil and Environmental Engineering, University of Alberta, Edmonton, 2002.

[2] American Society of Landscape Architecture. ASLA. http://www.asla.org/ppn/Article.aspx?id=1206\&terms=landscape\%20engineering (accessed 5 September 2012).

[3] American Society of Landscape Architecture. ASLA. 
http://www.asla.org/uploadedFiles/CMS/Government_Affairs/Public_Policies/Licensur e_Definition_of_Practice.pdf (accessed 5 September 2012).

[4] Zube E., Landscape Planning Education in America: Retrospect and Prospect. Landscape and Urban Planning, Volume 13, 1986, Pages 367-378, 1986.

[5] The LA Group, Landscape Architecture and Engineering P.C. http://www.thelagroup.com (accessed 8 September 2012).

[6] Valderrama A., Levine L., Yeh S., and Bloomgarden E., Financing Stormwater Retrofits in Philadelphia and Beyond, Natural Resources Defense Council (NRDC), February 2012.

http://www.nrdc.org/water/files/StormwaterFinancing-report.pdf $\quad$ (accessed 11 September 2012).

[7] The plastics industry trade association. SPI Resin Identification Code - Guide to Correct Use. Washington. DC.

http://www.plasticsindustry.org/AboutPlastics/content.cfm?ItemNumber=823\&navItem Number=1125 (accessed 2 November 2011).

[8] LDPE, Husky, 2008 Polly America, 2000 West Marshall Drive, Grand Prairie, Texas 75051, phone 800527 3322, press 7654, www.poly-america.com (accessed 2 July 2011).

[9] Asphalt 64-22 cas no 8052-42-4 PG-2010-321, NuStar Asphalt Refining, LLC, 4Paradise Rd. Paulsboro, NJ 08066 phone 8562247405.

[10] Punith V. S., and Veeraragavan A., Characterization of Ogfc Mixtures Containing Reclaimed Polyethylene Fibers. Journal of Materials in Civil Engineering, ASCE, 341, March 2011.

[11] Khan A., Gangadhar, Mohan M., and Raykar V., Effective Utilization of Waste Plastics in Asphalting of Roads. Project Report Prepared Under The Guidance of R. Suresh and H. Kumar, Dept. of Chemical Engg., R.V. College of Engineering, Bangalore, 1999.

[12] Zaro G., Nystrom K C., Bar A., Alvarez A. U., and Miranda A., Tierras Olvidadas: Chiribaya Landscape Engineering and Marginality in Southern Peru, The Society for American Archaeology, Latin American Antiquity 21(4), pp. 355-374, 2010.

[13] Corner J., Representation and Landscape: Drawing and Making in The Landscape Medium, Word \& Image 8, 246, July-Sept. 1992.

[14] American Society of Landscape Architecture. ASLA Security Design Symposium Abstracts. Chicago, IL, July 2004, http://www.asla.org/uploadedFiles/CMS/Resources/securitydesignabstractfinal.pdf (accessed 2 July 2011).

[15] Haselbach, L.M., Valavala, S., and Montes, F., Permeability Predictions for SandClogged Portland Cement Pervious Concrete Pavement Systems, Journal of Environmental Management, 81, 42-49, 2006.

[16] Huang, B., Wu, H., Shu, X., and Burdette, E.G., Laboratory Evaluation of Permeability and Strength of Polymer-Modified Pervious Concrete, Construction and Building Materials, 24, pp. 818-823, 2010.

[17] Tennis, P.D., Leming, M.L., and Akers, D.J., Pervious Concrete Pavements. Porland Cement Association. 2004. 
http://myscmap.sc.gov/marine/NERR/pdf/PerviousConcrete_pavements.pdf (accessed 2 July 2011).

[18] Montes, F., Valavaka, S., and Haselbach, L., A New Test Method for Porosity Measurements of Portland Cement Pervious Concrete, Journal of ASTM International, 2(1), 2005.

[19] Subagio B., Kosasih D., Busnial, and Tenrilangi D., Development of Stiffness Modulus and Plastic Deformation Characteristics of Porous Asphalt Mixture Using Tafpack Super ${ }^{\mathrm{TM}}$, Proceedings of the Eastern Asia Society for Transportation Studies, Vol. 5, pp. $803-812,2005$.

[20] Nakanishi H., Kawanaka T., Ziqing L., and Baocun H., Study on Improvement in Durability and Function of Porous asphalt Pavement, Road Construction, Japan, 2001.

[21] Daniels, S., and Repton H., Landscape Gardening and the Geography of Georgian England, New Haven, CT: Yale University Press, 1999.

[22] Harris D., and Hays D., On the Use and Misuse of Historic Landscape Views, in Representing Landscape Architecture, ed. Marc Treib., New York: Taylor and Francis, 22-41, 2008.

[23] Rieder K., Modeling, Physical and Virtual, in Representing Landscape Architecture, ed. Marc Treib., New York: Taylor and Francis, 2008.

[24] Waugh F. A. Landscape Engineering in the National Forests. US. Department of Agriculture Forest Service. 1918.

http://archive.org/stream/landscapeenginee00waug\#page/n1/mode/2up (accessed 5 October 2012).

[25] Doran, J.W., and T.B. Parkin. Defining and Assessing Soil Quality. In: J.W. Doran et al. (eds.) Defining Soil Quality for a Sustainable Environment. Soil Science Society of America, Madison, WI, Special Publication 35, pp. 3-22, 1994.

[26] Mollison B., Increases in Porosity Enhance Infiltration and Thus Reduce Adverse Effects of surface runoff, Permaculture: A Designer's Manual, Tagari Press, 1988.

[27] Hubbard, A. T., Encyclopedia of Surface and Colloid Science Vol 3, Santa Barbara, California Science Project, Marcel Dekker, New York, 2004.

[28] Beven K., and Robert E. Horton's Perceptual Model of Infiltration Processes, Hydrological Processes, Wiley Intersciences DOI 10:1002 hyp 5740, 2004. http://earth.boisestate.edu/jmcnamara/files/2011/10/KBeven_HP2004.pdf (accessed 23 August 2012).

[29] Stormwater Pennsylvania. http://www.stormwaterpa.org (accessed 25 August 2012).

[30] Busco D., and Lindsey G., An Annotated Bibliography of Stormwater Finance Resources, Center for Urban Policy and the Environment School of Public and Environmental Affairs Indiana University- Purdue University Indianapolis, April 29, 2002.

http://stormwaterfinance.urbancenter.iupui.edu/PDFs/Biblio\%204\%2029\%2002.pdf (accessed 26 August 2012).

[31] Lee J. H., and Bang K W., Characterization of Urban Stormwater runoff. Water Research. Volume 34, Issue 6, 1 April 2000, Pages 1773-1780 
http://www.sciencedirect.com/science/article/pii/S0043135499003255 (accessed August 2012).

[32] Dietza M. E., and Clausenb J. C., Stormwater Runoff and Export Changes with Development in a Traditional and Low Impact Subdivision. Journal of Environmental Management, Microbial and Nutrient Contaminants of Fresh and Coastal Waters, Volume 87, Issue 4, June 2008, Pages 560-566

http://www.sciencedirect.com/science/article/pii/S030147970700103X (accessed 23 August 2012).

[33] Canadian plastics industry association. http://www.plastics.ca/home/index.php (accessed 2 November 2011).

[34] Canadian plastics industry association. Environmental sustainability. http://www.plastics.ca/EnvironmentalSustainability/index.php/ (accessed 2 November 2011).

[35] Yoder E. J., and Witczak M. W. Principles of Pavement Design. Second Edition. John Wily And Sons, Inc, New York. 1975.

[36] Acum, W. E. A., and L. Fox, Computation of Load Stresses in a Three-layer Elastic System, Geotechnique, Vol. 2. pp. 293-300, 1951.

[37] McCullough, B. F., A pavement Overlay Design System Considering Wheel Loads, Temperature Changes, and Performance, Graduate Report, ITTE, University of California, Berkeley, 1970.

[38] Hveem, F. N., Pavement Deflections and Fatigue Failures, Highway Research Board Bulletin 342, 1962.

[39] Barber, E. S., Application of Triaxial Compression Test Results to the Calculation of Flexible Pavement Thickness, Proceedings, Highway Research Board, 1946.

[40] Fox, L., Computation of Traffic Stresses in a Simple Road Structure, Department of Scientific and Industrial Research, Road Research Technical Paper 9, 1948.

[41] McLeod, and Norman W., An ultimate Strength Approach to Flexible Pavement Design, Proceedings, Association of Asphalt Paving Technologist, 1954.

[42] Horner, and Raymond C., Effect of Base Course Quality on Load Transmission Through Flexible Pavements, Proceedings, Highway Research Board, 1955.

[43] Palmer, L. A., and E. S. Barber, Soil Displacement under Circular Load Areas, Proceedings, Highway Research Board, 1940.

[44] Poulikakis, L.D., and Partl, M.N., Evaluation of Moisture Susceptibility of Porous Asphalt Concrete using Water Submersion Fatigue Tests, Construction and Building Materials, 2009.

[45] Hassani, A., Ganjidoust, H., and Maghanaki, A., Use of Plastic Waste (Poly-ethylene Terephthalate) in Asphalt Concrete Mixture as Aggregate Replacement, Waste Manage Res 2005: 23: 322-327, 2005.

[46] Hinislioglu, S., and Agar, E. Use of Waste High Density Polyethylene as Bitumen Modifier in Asphalt Concrete Mix. Materials Letters, 58, 267-271, 2004.

[47] Zoorob S.E., and Suparman, L.B, Laboratory Design and Investigation of Proportion of Bituminous Composite Containing Waste Recycled Plastics Aggregate Replacement 
(Plastiphalt), CIB Symposiumon Construction and Environment Theory into Practice, Sao Paulo, Brazil, November, 2000.

[48] Zoorob, S.E., Laboratory Design and Performance of Improved Bituminous Composites Utilising Plastics Packaging Waste", Conference on Technology Watch and Innovation in Construction Industry, Belgium, Building Research Institute, Brussels, Belgium, April, 2000.

[49] Conigliaro, A., and Watson, P., Determining the Best Formulation for a Unique Asphalt Cold Patch Product Made with \# 3-7 Rigid Plastic Aggregate, Chelsea Center for Recycling and Economic Development Technical Research Program, January 2000.

[50] Mallick, R.B., and Teto, M., Evaluation of Use of Manufactured Waste Asphalt Shingles in Hot Mix Asphalt, 2000, Chelsea Center for Recycling and Economic Development Technical Research Program, July 2000.

[51] Sobhan, K., and Mashnad, M., Mechanical Stabilization of Cemented Soil-Fly Ash Mixtures with Recycled Plastic Strips, Journal of Environmental Engineering, ASCE, October 2003.

[52] Sobhan, K., Stabilized Fiber-Reinforced Pavement Base Course With Recycled Aggregate, Ph.D. Dissertation, Northwestern University, Evanston, Illinois, 303 pages, June, 1997.

[53] Cavey J. K., Krizek, R. J., Sobhan, K., and Baker, W. H., Waste Fibers in CementStabilized Recycled Aggregate Base Course Material. Transportation Research Record 1486, Transportation Research Board, Washington D.C., 97-106, 1995.

[54] Meyers, III, Swartz, J, Nathaniel, Kurczewski, N., and Kurczewski, M., Recyclable Composite Materials Articles of Manufacture and Structures and Method of using Composite Materials, U.S. Patent No. 6,984,670, 2006.

[55] Malloy, R. and Kashi, M., and Swan, C., Fly Ash/Mixed Plastic Aggregate and Products Made Therefrom, U.S. Patent No., 6,669,773, 2003.

[56] Balkum, E , Aggregate Using Recycled Plastics, U.S. Patent No. 6,488,766., 2002.

[57] Fwa, T.F., Tan, S.A., and Chuai, C.T., Permeability Measurement of Base Materials using Falling-Head Test Apparatus, Transportation Research Record, No. 1615, pp 9499, 1998.

[58] Khoury, N.N., Khoury, C.N., and Abousleiman, Y., Soil Fused with Recycled Plastic Bottles for Various Geo-Engineering Applications. ASCE Conf. Proc. 309, 42, 2008.

[59] Frocht, M. M., Photoelasticit, vol. 2 John Wiley and Sons, New York, 1957.

[60] Hadley, W. O, Hudson W. R., and Kennedy T. W., Evaluation and Prediction of The Tensile Properties of Asphalt-treated Materials, Highway Research Board Annual Meeting, Washington, D.C., 1971.

[61] Kennedy, J. W., and Hudson W. R., Application of the Indirect Tensile Test to Stabilized Materials, Highway Research Board Annual Meeting, Washington, D.C., 1968.

[62] Suresha S. N., George V., and Shankar A.U. R., Effect of Aggregate Gradations on Properties of Porous Friction Course Mixes, Material and Structure, 2010.

[63] Setyawan A., Design and Properties of Hot Mixture Porous Asphalt For Semi-Flexible Pavement Applications, Media Technic Sipil, July 2005. 
[64] Liu Q., Schlangen E., Garcia A., and Ven M. V.D., Induction Heating of Electrically Conductive Porous Asphalt Concrete. Construction and Building Materials, 2010.

[65] Shen D., Wu C., and Du J., Laboratory Investigation of Basic Oxygen Furnace Slag for Substitution of Aggregate in Porous Asphalt Mixture. Construction and Building Materials 23, 2009.

[66] Xiao F., Zhao W., Gandhi T., and Amiskhanian A. N., Influence of Antistripping Additives on Moisture Susceptibility of Warm Mix Asphalt Mixture. Journal of Materials in Civil Engineering, October 2010. 


\section{Geographic Information System}

and Remote Sensing 



\title{
Application of Geographical Information System to the Analysis of Urban Green Areas in Urban Development Plans - A Case Study of Zonguldak, Turkey
}

\author{
Yasar Bahri Ergen and Mustafa Ergen \\ Additional information is available at the end of the chapter
}

http://dx.doi.org/10.5772/55752

\section{Introduction}

One of the most rapidly growing applications of remotely sensed data is the derivation of landscape pattern metrics for the assessment of land use condition and landscape dynamics (Betts et al., 2003; Colombo et al., 2004; Egbert et al., 2002; Griffith et al., 2003; Hansen et al., 2001; Imbernon and Branthomme, 2001; Ji et al., 2008; Millington et al., 2003; Santiago et al., 2007; $\mathrm{Yu}$ and $\mathrm{Ng}$, 2006). The characteristics of green areas are generally analyzed with raster data by many scholars. In contrast with common practice, this study used vector data instead of raster data in the analysis of urban green areas in the study area. The fact that study analyzed urban development plans was the underlying reason that vector data was primarily used for this research. Geographical Information System (GIS) is one of the most useful methods for analyzing land use. All land uses for an urban development plan were considered and comparisons were made based on relative percentage of whole area. The data was derived from digitized data from an urban development. Urban green area proportion in the current city development condition was determined. Active and passive green areas were determined from an urban development plan and were prepared for analysis of trends of land use condition in the city. GIS was used as an analytical tool for this approach.

GIS data has significant utility in analysis of urban green areas in city development (Ji et al., 2008). Land use offers critical guidance to identify current landscape characteristics in urban areas. The study explored urban green areas associated with landscape features in urban areas and effectively supported an analysis of urban green area characteristics. Urban green areas can prove to be valid and useful characteristics for general landscape analysis of an urban environment. 
The fact that urban green areas improve the livability of cities has made them the focus of a great deal of attention. Urban areas completely transform the landscape into which they spread, leading to the development of entirely new land uses (Busck et al., 2006). Identification of urban green areas and developed areas are essential for monitoring and assessment of ecological consequences of changes in land use (Shi et al., 2008). The defined characteristics of urban green areas put emphasis on approaches to urban development that take urban land use patterns into consideration.

The spatial characteristics of urban areas are the most important elements of urban green areas analysis. There are many reasons to analyze urban green areas in urban development. The most important reason is to understand long-term interactions between humans and nature (Bi et al, 2011). The natural environment is under pressure from the human impacts involved in urban development processes. Urban development decisions have considerable impact in shaping current urban green areas in cities. There is no need to prove that land use is one of the important elements for analyzing urban green areas in urban development plans.

This research intended to investigate the development direction of land use with regards to urban green areas in cities. GIS technologies and analysis of proportional land use were used in this study (Bi et al, 2011). These methods were implemented on Zonguldak city as a case study. Urban green areas were determined for Zonguldak city in the urban development plan in an effort to understand current land use conditions in the city.

Consequently, the study emphasized urban landscape characteristics through the analysis of urban green areas in urban development plans. The study focused on ecological characteristics of urban areas and provided a potential approach for analyzing landscape features. The study will lead to identification land use trends and aid land use management in these areas (Bi et al, 2011).

\section{Area description ${ }^{1}$}

Located in the Western Black Sea region of Turkey, Zonguldak has an area of $8625 \mathrm{~km}^{2}$, covering $1.1 \%$ of Turkey's total land area (Figure-1) (ANONYMOUS, 2006). Zonguldak generally consists of inclined terrain due to its natural topography. Mountains in the Western Black Sea region run parallel to the coast in Zonguldak, rising sharply from the sea to elevations of up to 1976 meters (ANONYMOUS, 2006). This high mountain system provides a block between the sea and the Central Anatolian Plateaus (ANONYMOUS, 2006).

The discovery of coal in Zonguldak led to a population explosion in the region. Zonguldak was transformed from a village to a city on account of the resulting rapid economic development. In 1899, the Zonguldak coal harbor (Figure-2) was built as the hub of coal transportation in the city (ANONYMOUS, 2006). New coal washers, new employee houses and power plants steadily increased industrial productivity in Zonguldak. Zonguldak has suffered from the effects of this rapid urbanization.

\footnotetext{
${ }^{1}$ This part of article is developed from Mustafa ERGEN`s PhD dissertation
} 


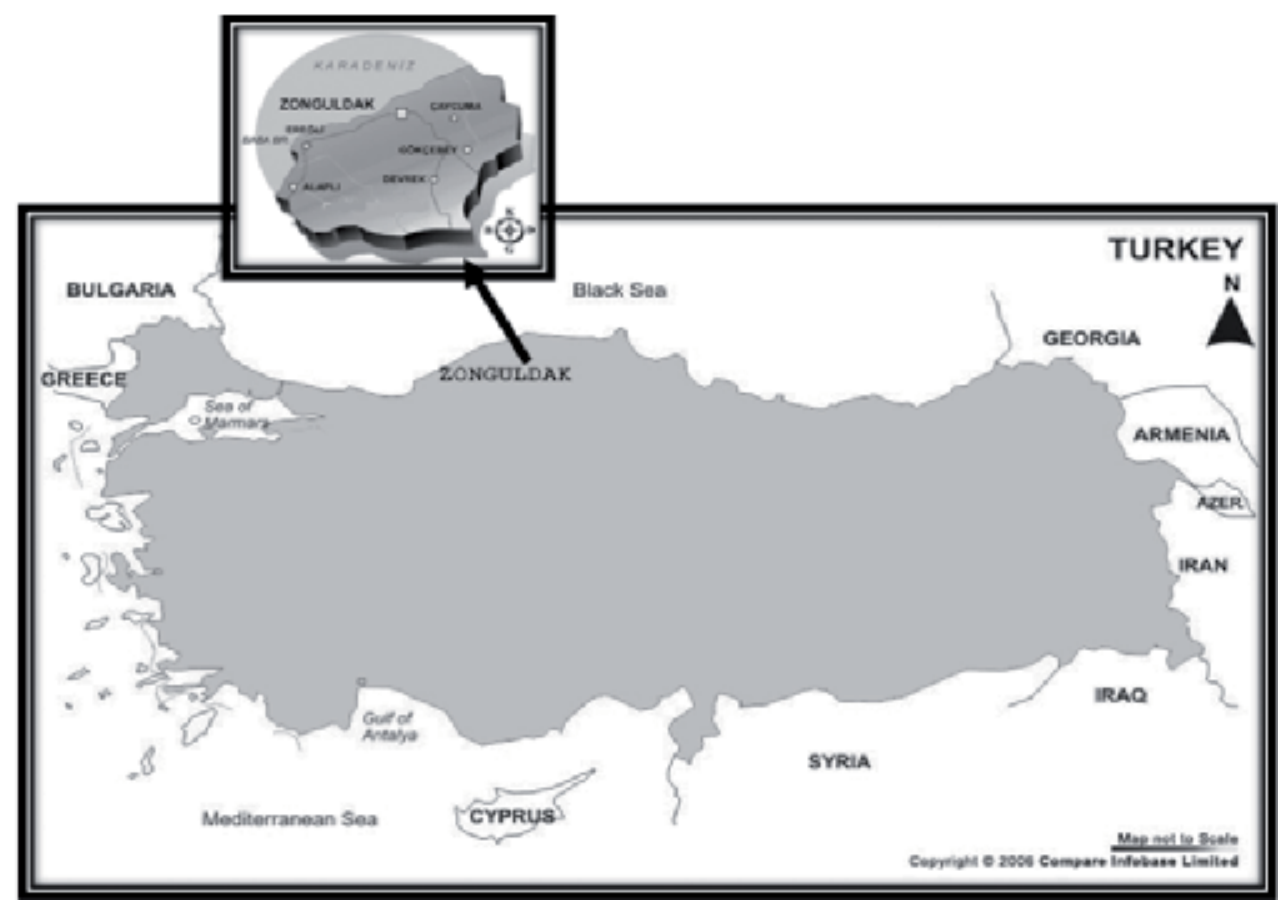

Figure 1. Location of Zonguldak City in Turkey, (The Figure is prepared by Mustafa ERGEN, 2009) Source: http://www.loadtr.com/397588- zonguldak_haritas\%C4\%B1_6.htm and http://www.mapsofworld.com/turkey/maps/turkey-outline-map.jpg,

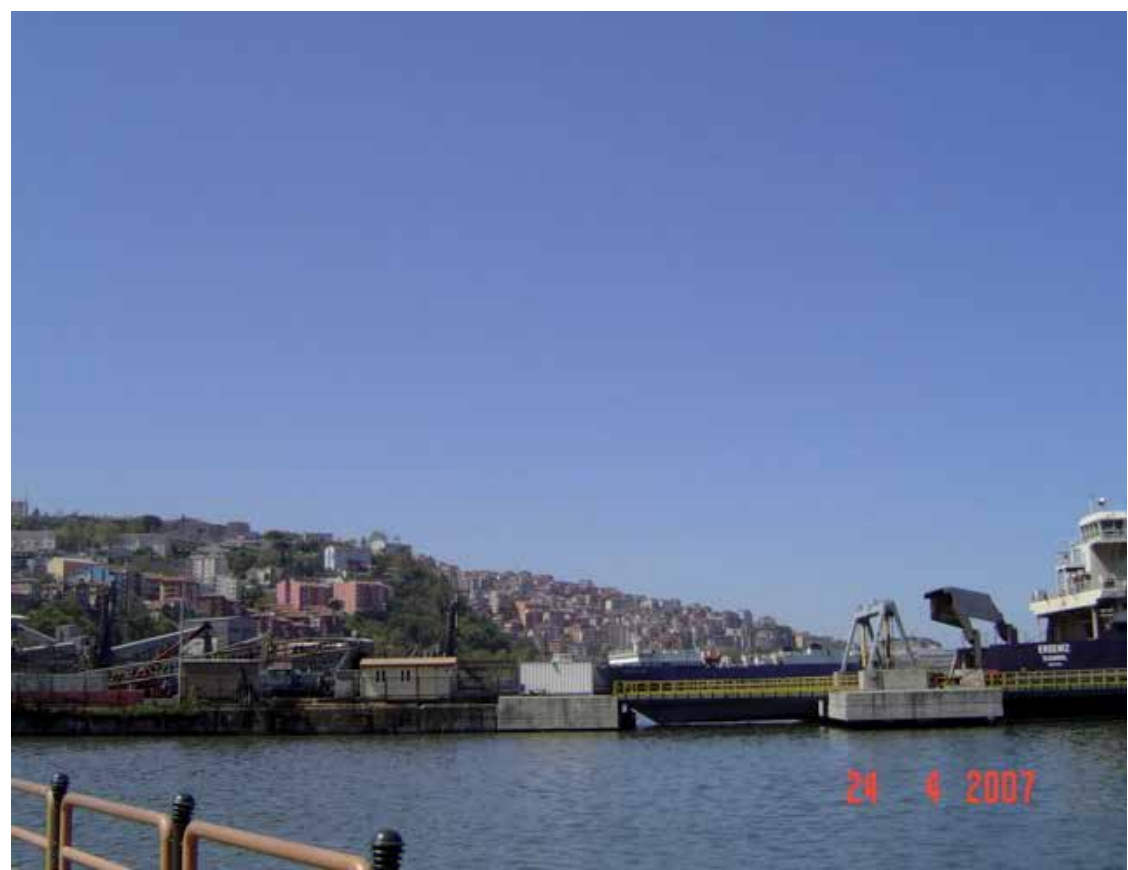

Figure 2. Zonuguldak Port Area, Source: Mustafa Ergen, 2007 (Author`s own image) 
The form and structure of Zonguldak is shaped by the coal mining industry. After the onset coal mining in the city, additional exploration accelerated the process of Zonguldak's urbanization (Figure-3). This rapid development has had an influence on natural areas and

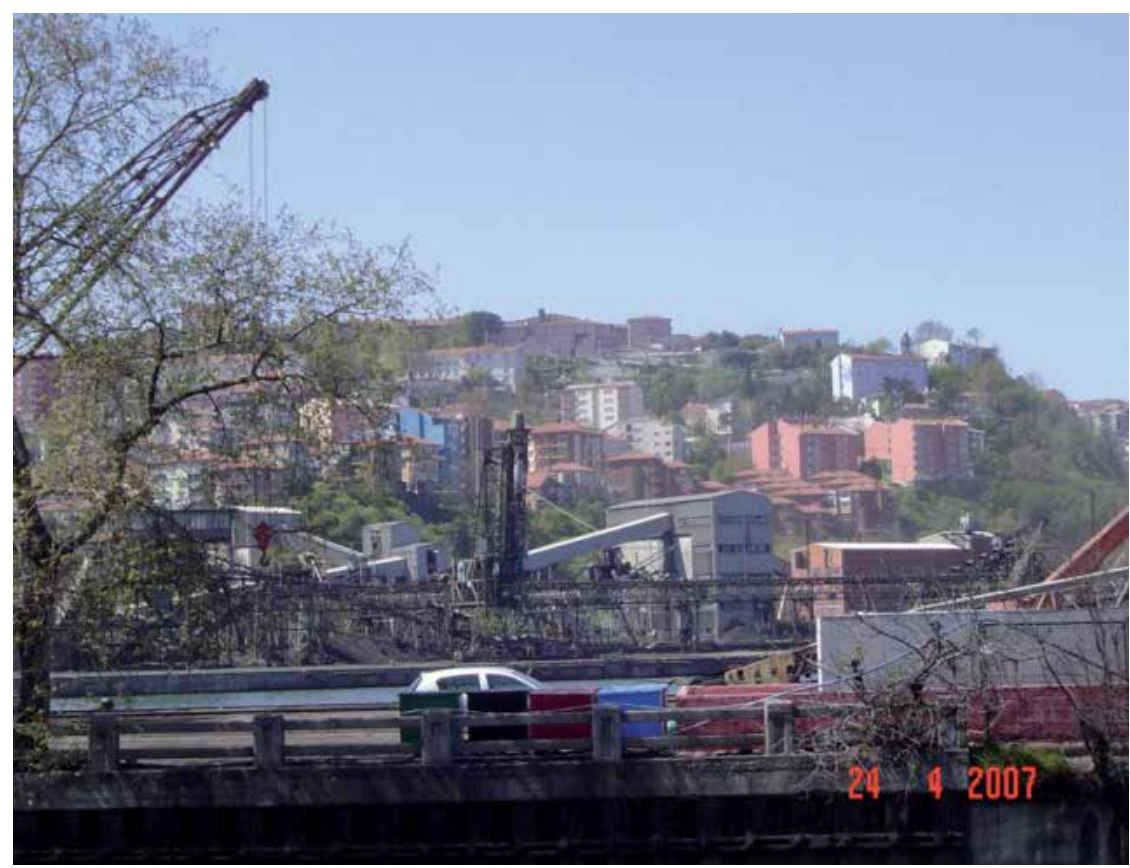

Figure 3. The View of Zonuguldak City, Source: Mustafa ERGEN, 2007 (Author`s own image)

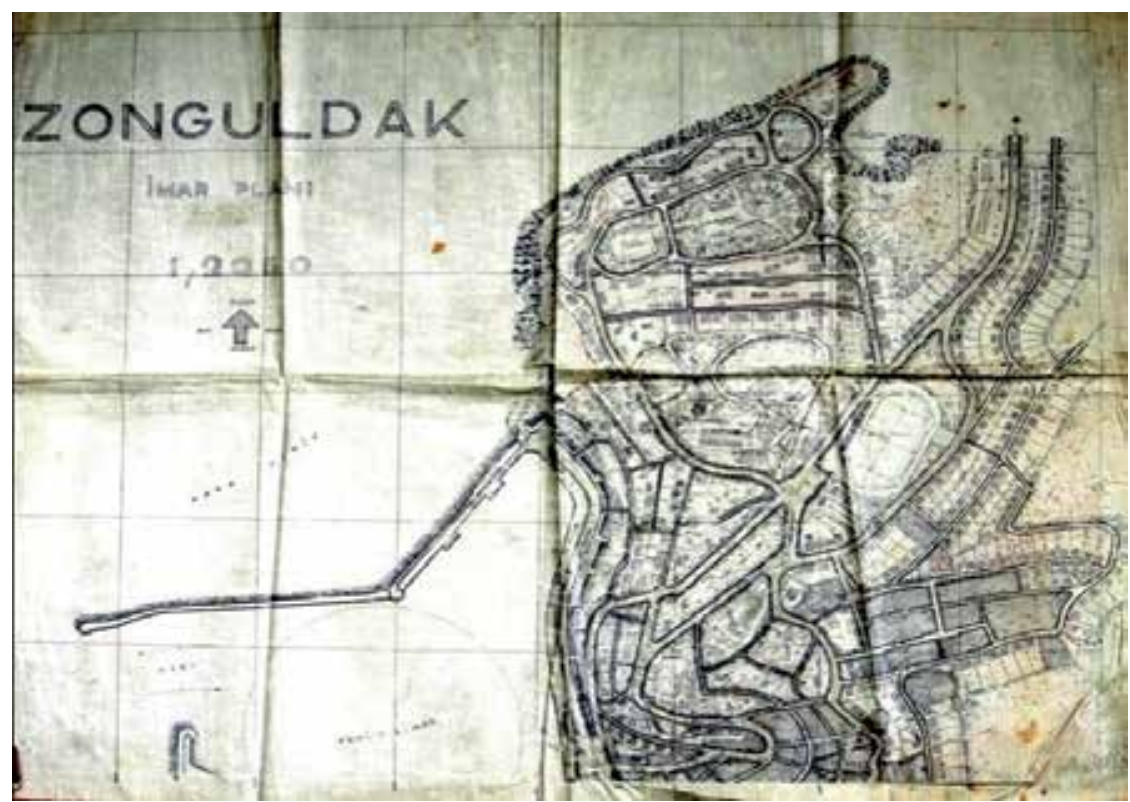

Figure 4. Development Planning Map, Source: Zonguldak Municipality, 2006 
every part of the urban area. In its history of urbanization, Zonguldak reached its greatest development during this period. There have been many regulations to attempt mitigate this unhealthy and fast urbanization. However, there was no effective approach to urban green area and land use planning during the growth of the city.

The first settlements during this growth period were formed around the port of Zonguldak, and Uzulmez, Kozlu, Asma mines in the city (ANONYMOUS, 2006). The problem of settlement areas in the city has grown in parallel with the increasing coal mining activity (Figure-4). This has had far-reaching effects on planning and urban green areas structure.

As Zonguldak city is located between the sea and mountains, its topographical properties put obstacles in the way of is development in the city. Urbanization began on flat terrain in the basin. Because attempts have been made to construct primarily on the flat terrain of Zonguldak, urban development has been concentrated in certain areas (Figure-5). This led to a problematic and unhealthy development in the early stages of urbanization in Zonguldak.
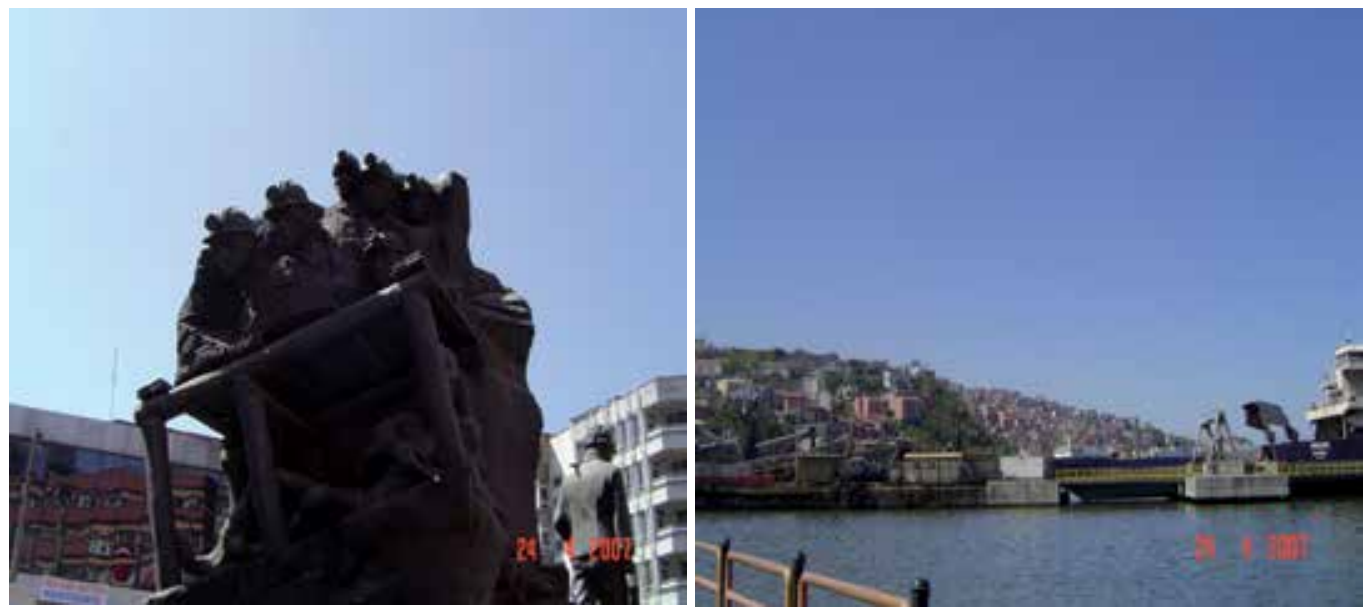

Figure 5. General View of City Center and Port Area in Zonguldak, Source: Mustafa ERGEN, 2007 (Author`s own images)

\section{Research method}

GIS is an important tool for analyzing urban green areas (Irwin, 2003). Urban green areas are currently a crucial issue in city development, now more than ever. GIS can be used to define the proportion of urban green areas in a city. These urban green areas analyses can be compared among each other and to other land uses such that an analysis can show how urban green areas can be designed and improved in urban developments.

The inclusion of urban green areas is crucial for creating livable places in cities. GIS measures various aspects of land use patterns, including topography, shapes of land use areas and future direction of development of the cities (Irwin, 2003). This study used percentage of areas calculation and arithmetic mean calculation for analyzing green areas that gives us a broad picture of green areas condition in a city development. Percentage of land use can make clear 
explanation of land use tendencies and arithmetic means can help to determine central tendency for land uses. Arithmetic mean was calculated using the below formula:

$$
A M=1 / n \sum_{i=1}^{n} a i=\frac{a_{1}}{a_{n}}+\frac{a_{2}}{a_{n}} \cdots \frac{a_{n}}{a_{n}}
$$

This study used percentage of land use and arithmetic mean to analyze urban green areas in Zonguldak city. The method measured current land use condition in terms of area calculation in the cities.

The data obtained through the digitized data of the urban development plan helped to determine the state of the urban green areas and the characteristics of the whole city. One reason for choosing to analyze percentage of land uses is that the investigation considered whole area for urban green areas. The second reason is that it gives a wide range of analysis options via the arithmetic mean for Zonguldak city.

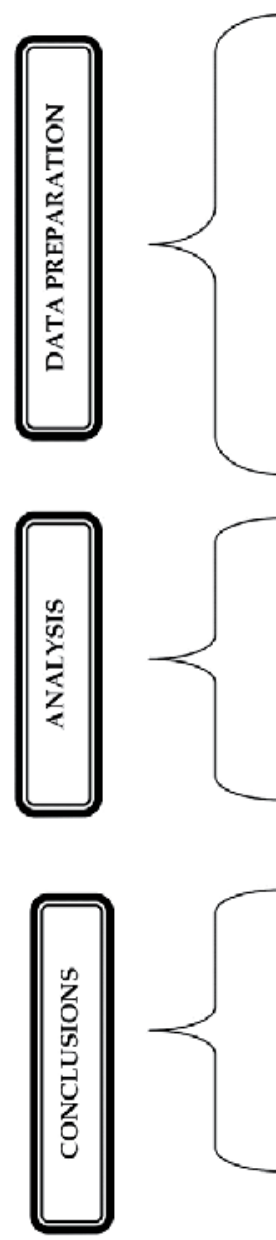

DATA WAS CONVERTED FROM NETCAD TO ARCGIS FOR ANALYSIS.

URBAN DEVELOPMENT PLAN WAS PROJECTED IN ARCGIS FOR ACQUIRING A TOTAL SOUARE METER CALCULATION.

ALL URBAN GREEN AREAS AND THE OTHER LAND USES WERE TRANSFERRED TO AN ATTRIBUTE TABLE.

ALL AREAS WERE CALCULATED IN ARCGIS AND WERE EXPORTED TO THE EXCEL FORMAT.

URBAN GREEN AREAS AND THE OTHER LAND USES WERE ANALYZED AS PERCENTAGE OF LAND USES AND USING THE ARITHMETIC MEAN.

THE ANALYSIS RESULTS WERE ANALYZED AND NEW DEVELOPMENT STRATEGIES FOR ZONGULDAK CITY ARE PRESENTED.

Figure 6. Flow chart of methodology 
The methodology was composed of three major phases; data preparation, analysis and conclusion. Data preparation included the following steps; data was converted from another program to GIS. The plan was projected for calculation in the correct units. All land uses were determined by urban green areas analysis. The data was transmitted to an excel file. The analysis converted land use measurements to arithmetic mean and the proportion of land use was determined for each use. In the he conclusion, the results were used to formulate some development strategies for Zonguldak city. The flow chart of the methodology below details the phases step by step.

\section{Results and conclusions}

Urban green areas were subdivided into Garden, Copse, Park, Forest and Graveyard lands. The areas of urban green areas were obtained from area calculations in ArcGIS. It should be noted that both urban green areas and the other land uses can be analyzed for understanding current development direction in city. The active and passive green areas were compared to one another and to the other land use areas in the analysis. The method showed that the topography of Zonguldak is the main obstacle for new development in the city. It is very important that green zones should be determined for the sustainable growth. This will offer a new direction for the city's future development. The land use map was created by ArcGIS software in this study (Figure-6). The comparison data between urban green areas and the other land uses were acquired from this map.

The urban green areas were derived by urban development plans and calculated from the same map for analysis of land usage. Forest lands and copse lands border the city development, largely due to the topography of the region.

As can be seen from the table, the other land uses grow along with total area. On the contrary, park land is underrepresented. The table shows that Copse land, Garden land and Forest land are the reasons for this situation. These lands compose most green areas in the city. This shows that the city does not have many recreational opportunities. It means that urban development has not included many recreational opportunities but that has still included enough green areas in the city.

The urban land use shows that urban green areas are dominant areas in land use. That means Zonguldak is a city with high much potential for urban green areas development. The topography is the most important reason of this situation in the city. There are not many appropriate places to settle in the city and around the city. This condition makes green areas planning in the city easier. The analysis shows that urban green areas in Zonguldak are mostly passive green areas. Although the city currently has many green areas, few of those are useful. The topography allows neither settlements nor recreational opportunities.

From the figure, it is apparent that green areas are the dominant characteristic land use in Zonguldak. It is obvious that Zonguldak has much potential for urban green areas development. Copse land and garden land are the main types of green areas in Zonguldak. The figure shows that park land is one of the less frequent land uses in the city. The reason 
is behind it that there are not adequate areas in which to design park land in the city because of the rough topography. Although the topography might not be amenable to the design of recreational opportunities, urban green areas could be the most important element of planning for Zonguldak. The figure also shows that garden land provides some degree of interaction with green areas to the people, but these are also not useful areas and are mostly converted from copse land and forest land. That means that the city does not have enough recreational opportunities in reality, such that while Zonguldak may maintain adequate ecological characteristics, it may not give an option for recreational uses.

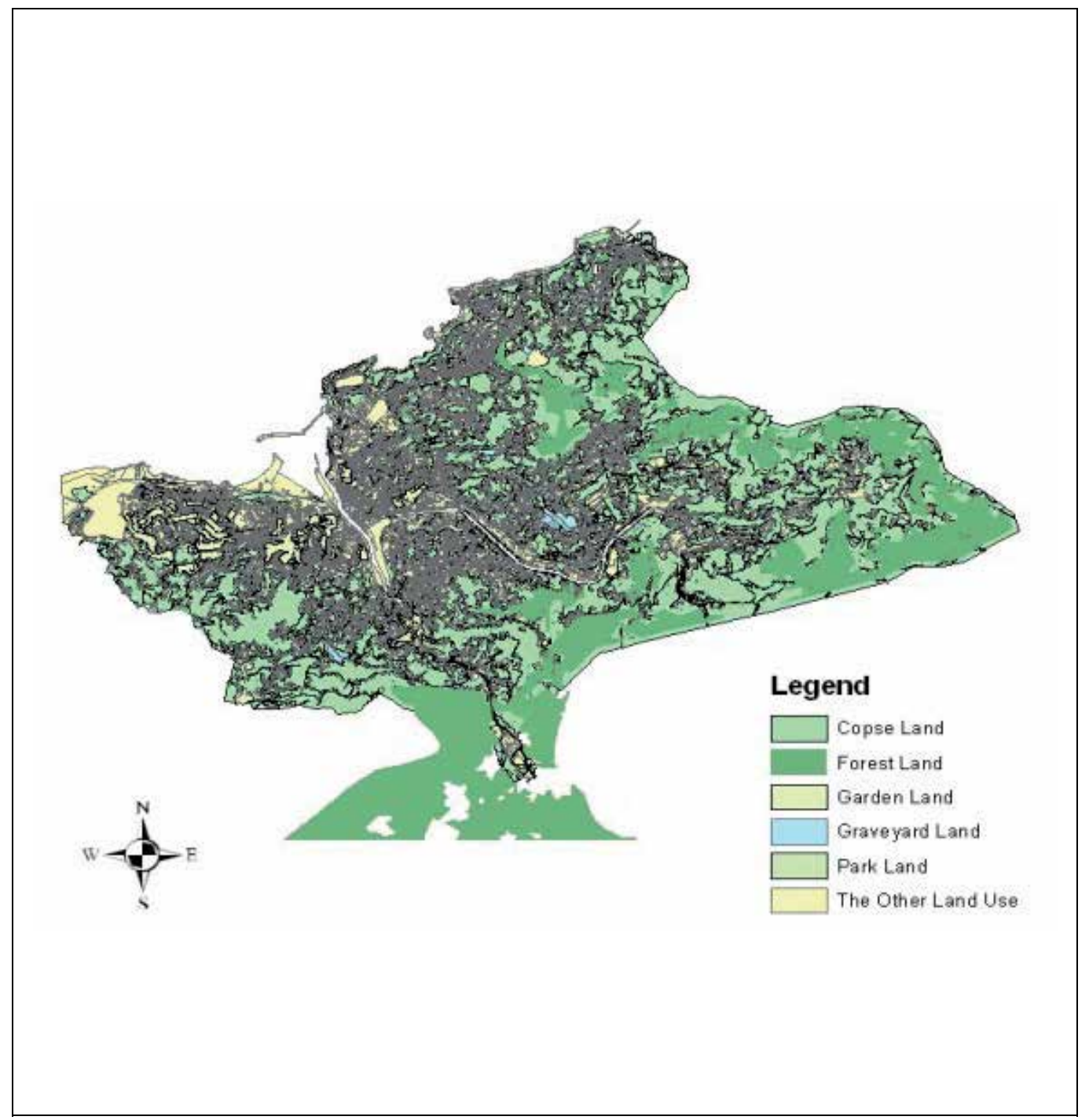

Figure 7. Zonguldak City Current Land Use Condition Depends on Urban Development Plan, Source: Anonymous, 2006 (Basic map was prepared by Modül Planlama Harita Bilgisayar İnşaat ve Ticaret Ltd. Şti with another program for Zonguldak Municipality. The map was converted and was prepared by Mustafa ERGEN for analyzing urban green areas). 


\begin{tabular}{|c|c|}
\hline Land Uses & Total Area $\mathrm{m}^{2}$ \\
\hline Copse Land & 13125850,04 \\
\hline Graveyard Land & 149400,47 \\
\hline Garden Land & 8033057,98 \\
\hline Park Land & 17373,96 \\
\hline Forest Land & 6173642,26 \\
\hline The Other Land Use & 5137810,08 \\
\hline
\end{tabular}

Table 1. Land Uses Total Areas

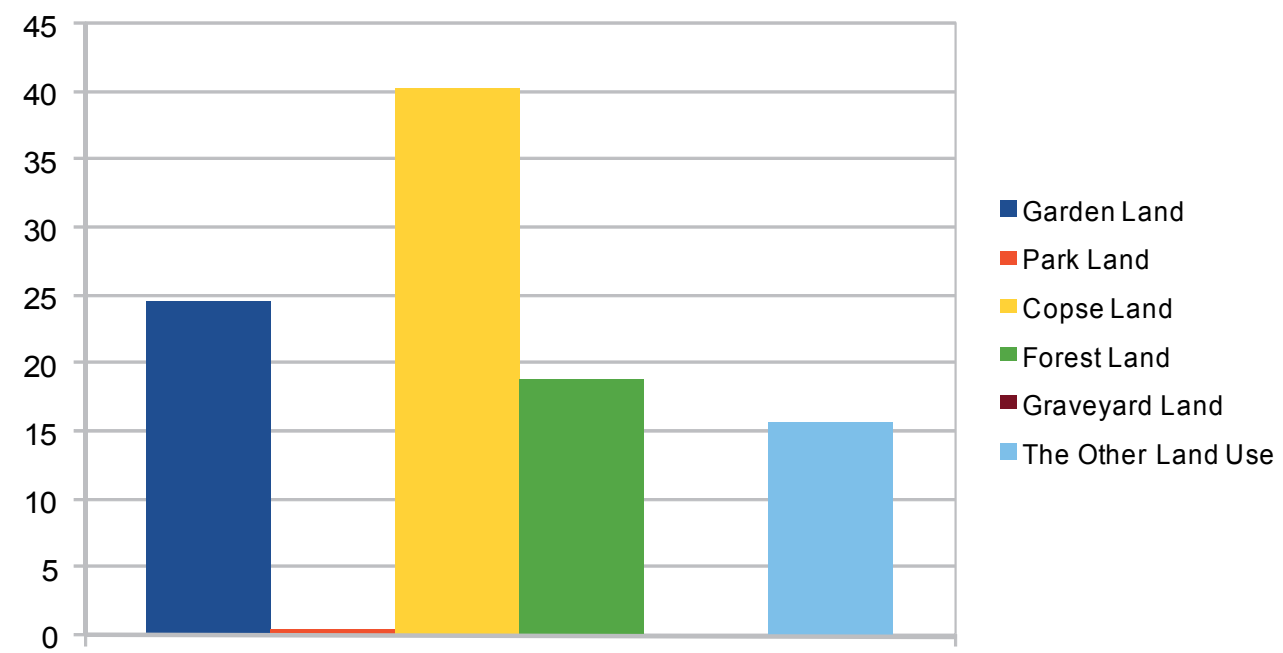

Percentage of Area

Figure 8. Proportion of Land Use Condition

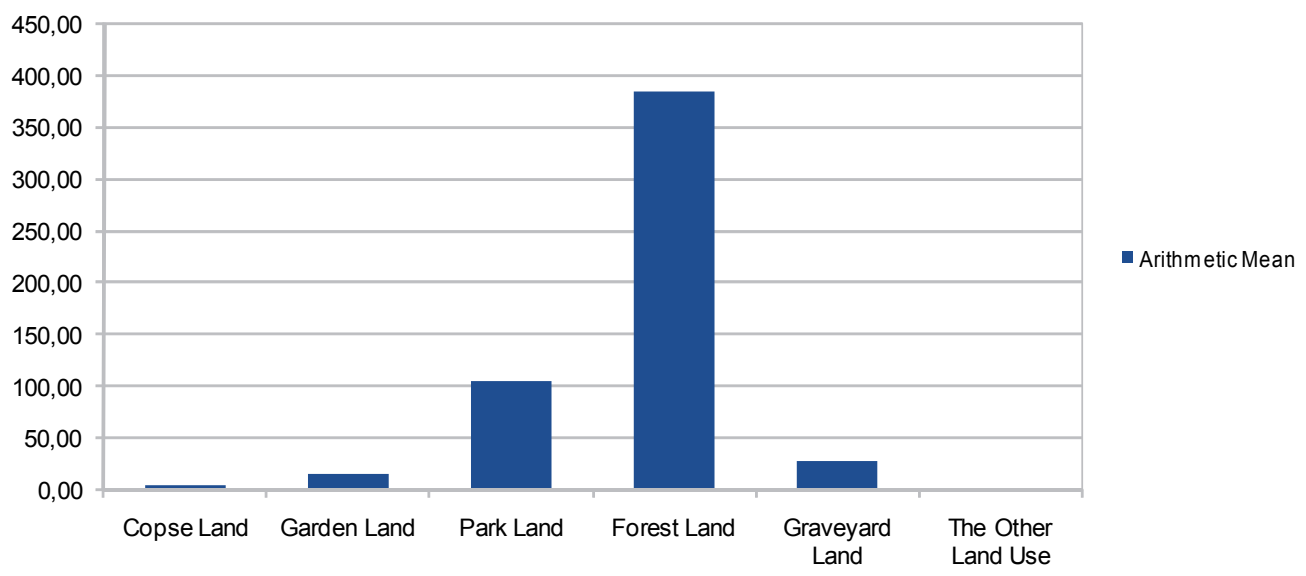

Figure 9. Arithmetic Mean of Land Uses 
It can be seen from the figure that forest land dominates the other land uses. This demonstrates that the city has adequate green areas. The figure also shows that the other land uses do not have much representation in the city. There are many reasons behind this; the most important reason mentioned above is the topographic obstacle. We may claim that development costs might be another reason for this situation. The study concludes with an obvious approach to defining several strategies for the future development of Zonguldak;

- The planning development should take the difficult topography into consideration.

- The potential development option must be defined for future development goals such as Eco-tourism.

- Achieving new development emphasizes new structures and developments in the city.

- The green potential provides new opportunities for city development such as ecological development in city.

- Eco-city development elements should be taken into consideration for new development strategies.

Consequently, this study proves that green areas are the characteristic land use in Zonguldak. Other land uses use up all the flat terrain in the city. There is no way to sprawl and develop to the other places in city development. The study showed that rough topography is main obstacle for development in Zonguldak.

The forest and copse land creates a green belt condition in city, especially in the south, south-east and east parts. This is the reason that they are also obstacles for new developments in the city. There is no clear strategy for new development to suggest. However, it introduces crucial development options in regards to urban greenery. The urban green areas are the only the option for the new developments for Zonguldak. Possible basic development approaches might be eco-tourism, recreational opportunities or open air museum.

\section{Author details}

Yasar Bahri Ergen and Mustafa Ergen

Amasya University, Faculty of Architecture, Department of Urban and Regional Planning, Amasya, Turkey

\section{References}

Anonymous, 2006, "Zonguldak Belediyesi Genel Yaklaşım Raporu”, Modül Planlama Harita Bilgisayar İnşaat ve Ticaret Ltd. Şti., Ankara

Betts, M. G., Franklin, S. E. and Taylor, R. G., 2003, “Interpretation of Landscape Pattern and Habitat Change for Local Indicator Species Using Satellite Imagery and Geographic Information System Data in New Brunsick, Canada, Canadian Forest Research 33 (10), p. 1821-1831 
Bi, H., Gao, L., Ren, Y. and Cui, Z., 2011, "Spatial and Temporal Change of Landscape Pattern in the Hilly-Gully Region of Loss Plateau", $20112^{\text {nd }}$ International Conference on Environmental Science and Technology, IPCBEE vol. 6 (2011) copy right IACSIT Press, Singapore, volume 2, p. 10-15, Available at www.ipcbee.com/vol6/no2/3-F10079.pdf, [Cited 7.12.2012]

Busck, A. G., Kristensen, S. P., Praestholm, S., Reenberg, A. and Primdahl, J., 2006, "Land System Changes in the Context of Urbanisation: Examples from the Peri-Urban Area of Greater Copnehagen", Danish Journal of Geography 106(2), p. 21-34, Available at rdgs.dk/djg/pdfs/106/2/03.pdf, [Cited 9.12.2012]

Colombo, S., Chica-Olmo, M., Abarca, F. and Eva, H., 2004, "Variographic Analysis of Tropical Forest Cover from Multi-Scale Remotely Sensed Imagery", ISPRS Journal of Photogrammetry and Remote Sensing, 58 (5-6), p. 330-341

Egbert, S. L., Park, S., Price K. P., Lee, R. Y., Wu, J. and Nellis, M. D., 2002, “Using Conservation Reserve Program Maps Derived from Satellite Imagery to Characterize Landscape Structure, Computers and Electronics in Agriculture 37 (1-3), p. 141-156

Griffith, J. A., Stehman, S. V., Sohl, L. T. and Loveland, T. R., 2003, “Detecting Trends in Landscape Pattern Metrics over a 20-Year Period Using a Sampling-Based Monitoring Programme, International Journal of Remote Sensing 24 (1), p. 175-181

Hansen, M. J., Franklin, S. E., Woudsma, C. G. and Peterson, M., 2001, “Caribou Habitat Mapping and Fragmentation Analysis Using Landsat MSS, TM and GIS Data in the North Columbia Mountains, British Columbia, Canada, Remote Sensing of Environment 77 (1), p. 50-65

Imbernon, J., Branthomme, A., 2001, "Characterization of Landscape Pattern of Deforestation in Tropical Rain Forests", International Journal of Remote Sensing 22 (9), p. 1753-1765

Irwin, G. E., 2003, “Using GIS to Model Patterns of Urban-Rural Land Use Change”, Ohio Geospatial Technology Conference for Agriculture and Natural Resources Holiday Inn Wothington, Columbus, Ohio March 24-26, 2003, Available at geospatial.osu.edu/conference/proceedings/papers/irwin_pap.pdf, [Cited 7.12.2012]

Ji, J., Yuanyuan, C., Wunian, Y. and Yanyan, K., "Analysis and Evaluation on Landscape Pattern of Songpan County with Remote Sensing and GIS", The International Archieves of the Photogrammetry, Remote Sensing and Spatial Information Science Vil. XXXVII, Part B8, Beijing, p. 1143-1148, Available at htpp://www.isprs.org/proceddings/XXXVII/congress/8_pdf/11_WG-VIII-11/25.pdf, [Cited 6.11.2011]

Millington, A. C., Velez-Liendo, X. M. and Bradely, A. V., 2003, “Scale Dependence in Multitemprol Mapping of Forest Fragmentation in Bolivia: Implacations for Explaining Temprol Trends in Landscape Ecology and Applications to Biodiversity Conservation, ISPRS Journal of Photogrammetry and Remote Sensing 57 (4), p. 289-299

Santiago, S., Sandra C., 2007, "Scaling Functions for Landscape Pattern Metrics Derived from Remotely Sensed: Are Their Subpixel Estimates Really Accurate?", ISPRS Journal of Photogrammetry and Remote Sensing 62, p. 201-216 
Shi, Y., Xiao, J. and Shen, Y., 2008, "Landscape Pattern Change and Associated Environmental Implications in Haihe River Basin, China, p. 569-573, Available at http://www.isprs.org/proceedings/XXXVII/congress/6b_pdf/28.pdf, [Cited 14.10.2011]

$\mathrm{Yu}, \mathrm{X} ., \mathrm{Ng}, \mathrm{C} ., 2006$, “An Integrated Evaluation of Landscape Change Using Remote Sensing and Landscape Metrics: A Case Study of Panyu, Guangzhou", International Journal of Remote Sensing 27 (6), 1075-1092

\section{References of images}

Anonymous, 2006, "Zonguldak Belediyesi Genel Yaklaşım Raporu”, Modül Planlama Harita Bilgisayar İnşaat ve Ticaret Ltd. Şti., Ankara

Zonguldak Municipality, 2006, "The Image was acquired by Zonguldak Municipality"

-------, ------, “Zonguldak Haritasi", Available at http://www.loadtr.com/397588zonguldak_haritas\%C4\%B1_6.htm, [Cited 8 December 2011]

------, ------, “Türkiye Haritasi”, Available at http://www.mapsofworld.com/turkey/maps/turkey-outline-map.jpg, [Cited 8 December 2011] 


\section{Socio-Cultural Landscape}





\title{
Urban Landscapes and Identity
}

\author{
Isil Kaymaz
}

Additional information is available at the end of the chapter

http://dx.doi.org/10.5772/55754

\section{Introduction}

Identity has always been a popular research subject for various disciplines, such as psychology, philosophy, sociology, human geography and anthropology. However, urbanization and globalization processes, which have caused a rapid change on our environments, have brought the concept of identity on the agenda of planners and designers in the last few decades. The major concern of the identity related research is on the sustainability of place identity.

Urbanization and globalization are obviously two major phenomena that affect our social, economic, cultural lives as well as our physical environment. Despite the broad context of the issues related to these two processes, it wouldn't be untrue to say the major global concern that has arisen from urbanization and globalization, is the sustainability of the environment. On the other hand current studies on sustainability of the urban environments mainly focus on factors like water, air, energy, and transport while urban identity is receiving attention rarely [1].

The end of the last century faced a rapid and dramatic increase in urban population worldwide, mainly because of immigration. Today more than half of the world's population lives in urban areas. According to United Nation's (UN) 2011 revision of World Urbanization Prospects, the population living in urban environments is expected to increase from 3.6 billion (2011) to 6.3 million by 2050 [2]. Therefore it seems that the urban environments will continue to grow in order to accommodate more inhabitants. Consequently, both natural and cultural landscape resources will continue to be under pressure in and around urban settlements. Besides the ecological sustainability issues, expansion of urban areas, increasing urban population and deterioration of both natural and cultural resources raise the concerns on image and identity of urban landscapes.

Today's cities are considerably multi-cultural and heterogeneous, more than ever. The influence of neo-liberalism and globalization is very prominent on the development of 
urban areas and this consequently affects identity of urban environments. Hence, management and conservation of local heritage and values have become an important aspect in urban design and planning.

Place identity is an important dimension of social and cultural life in urban areas and continuity of place identity is strongly linked to place attachment and sense of belonging. In environmental psychology, it is assumed that people intrinsically strive to develop a sense of belonging to a place. Place attachment and sense of belonging are crucial in order to establish an emotional and cognitive bond with a place, which leads to the feeling of security and sense of community. Thus, identity of a place is more than just the physical appearance, but also involves a "meaning" for the individual and the community.

Republic of Turkey is a relatively young, developing and transcontinental country which is located on mostly Anatolian peninsula. Due to its geographical context and history, modern Turkey is a multi-cultural and multi-ethnic society. Turkey's lands hosted many great civilizations such as Byzantine Empire, Seljuk Empire and Ottoman Empire; thus were shaped under the influence of many cultures. The traces of those civilizations can still be seen in the form of current settlements, in various parts of Turkey. However, Turkey's rich diversity of both cultural and natural assets has been difficult to manage and conserve, especially due to urbanization and globalization processes.

The westernization efforts during the late Ottoman Empire period continued after Republic of Turkey was established in 1923. The controlled and planned development of urban areas in the first decades of the Republic created new identities in urban areas. For instance after Ankara's proclamation as the capital city of the Republic of Turkey, which had been a small degraded and insignificant Anatolian town, it was aimed to construct Ankara as a model city for modern Turkey [3]. Besides new governmental, cultural, financial and educational buildings, and open and green spaces for recreation and leisure were constructed. All these new developments changed life-styles, as well as the perceived urban identity. However, in 1950's urbanization process gained a dramatic increase, mainly because of immigration, and expansion of urban areas subsequently became uncontrollable, not only in Ankara but across the country. Furthermore economic fluctuations and political instability had deteriorating effects on the urban environment.

One of the significant impacts on Turkish urban landscape has been the emergence of shopping malls as an urban landscape element after 1990's. On the other hand, a recent study showed that leisure time spent in shopping malls has increased in the last decade while open space use has decreased [4]. Such changes in urban environment are often due to changing lifestyles which is an important factor in identity of urban spaces. According to Erkip; "shopping malls are the most important additions to urban life in Turkey in terms of civilization, modernity, and the democratization of consumption patterns. Their impact does not seem to be limited to the field of consumption only, as they form a new identity combining global and the local" [5].

According to the latest census data of Turkish Statistical Institute, Turkey has a population of over 74 million, and $77 \%$ of the total population lives in urban environments (provinces 
and district centres) [6]. However, urbanization patterns are not the same in different parts of Turkey. Işık argues that industry, tourism (in Mediterranean region), and terror incidents (in Eastern and South-eastern Anatolia regions) are the major influences on the urbanization patterns of the Turkish cities [7]. As a result, identities of different urban spaces in Turkey change and develop in different directions and rates, which deepen "national identity" crisis in terms of spatial, social and political aspects.

Following a brief introduction on the concept of identity within the literature, this chapter will focus on the relationship between place identity and urban landscape. Concepts related to place identity, such as place attachment will also be discussed and some identity relevant examples from Turkish cities will be provided.

\section{The concept of identity}

The concept of identity has a broad context. The term is more common in social sciences and it has been employed to describe the "uniqueness" of a person or a thing from very different perspectives and purposes, such as personal identity, political identity, ethnic identity, social identity and place identity. The word identity comes from the Latin "identitas" and is defined as "the fact of being who or what a person or thing is" in the Oxford English Dictionary [8]. According to Gleason the use of the word dates back to $16^{\text {th }}$ century and until the mid of 1950 's identity is used to describe "the unity of the self" by the philosophers [9].

As Fearon points out "even though everyone knows how to use the word properly in everyday discourse, it proves quite difficult to give a short and adequate summary statement that captures the range of its present meanings" [10]. The diverse use of the concept makes it even harder to define and explain. Definition of identity has been subject to mainly sociological studies in the last few decades. However, some previous definition attempts might provide some clues to understand the basics of the identity concept, before moving to next section; spatial dimension of identity.

According to Wendt "identities are relatively stable, role-specific understandings and expectations about self" [9]. Castells defines identity as "people's source of meaning and experience" [11]. On the other hand Katzenstein points out that identity is evolving images of self and other and is mutually constructed [10]. In the encyclopaedic dictionary of "Urban Planning" (printed in Turkish) Ocakçı and Türk defines identity as the expression of distinguishing features of a being which are unique to it [12]. They also emphasize that since uniqueness of something can only be understood through its relationship with others, "being in relation" is the central form of activity which produces identity.

Erik H. Erikson, German psychologist and psychoanalyst, is one of the well-known sociologists who had a particular interest in identity. Erikson believed that while identity is shaped by the individual's experiences and tasks throughout the life cycle, it is also influenced by the social interaction [9]. On the other hand, Jenkins claims that identity is a person's capacity to know "who is who" and "what is what"; hence the concept of identity involves a comparison between things and individuals [13]. Furthermore, according to Hall, individuals assume different identities at different times and within different contexts [14]. 
This chapter does not aim to identify the concept of identity. However, given the examples of definitions, some aspects of the identity can be described as follow:

- Uniqueness of a thing or a person is central to the identity concept.

- Identity requires comparison between things of individuals.

- Meaning and experience play an important role in perception of the identity.

- Identity is never a stable construct; on the contrary it is a continuously evolving and dynamic phenomenon.

- Identity involves interaction with others.

Although the characteristics of identity concept given above might not be complete and absolute, they might be useful when integrating the concept into spatial planning and design in terms of place identity which is the subject of next section.

\section{Place attachment and place identity}

Identity is often perceived to be linked to the concepts of language, culture, minority/majority, dissimilarity, self/other, individuality and sense of belonging [13]. On the other hand "place identity" is relatively a more recent concept recognized in spatial planning and design. Moreover, it is also more difficult to explain and define place identity since "place" itself is a complicated concept.

Although space and place are often used interchangeably in Turkish language, these two words have different meanings and content in English and academic literature in environmental psychology. In his book "Space and Place: The perspective of experience", geographer $\mathrm{Yi}-\mathrm{Fu}$ Tuan suggests that "place is security" and "space is freedom" [15]. He also states that "space is an abstract term for a complex set of ideas" and "place and objects define space, giving it a geometric personality".

We need space to realize the activities that are essential for our survival. But when we assign a meaning to a space, it becomes a "place". As Halpenny puts it "place is a spatial location that is assigned meanings and values by society and individuals" [16]. Therefore meaning is a symbolic tool that links an individual with the physical environment. According to Relph, place is result of the interaction between its 3 components; physical setting, activity and meaning [17].

In environmental psychology research, many agree that development of emotional bonds with places is a prerequisite of psychological balance [18]. A sense of belonging is necessary for psychological well-being which is developed by relationships with the environment [19]. Hence, what should concern planners and designers is to understand how people and places interact and how they form a bond. That is necessary to create liveable places.

There have been many attempts to explain and define the bond between people and their physical settings in many different ways. Place identity, place attachment, and sense of place are some of the concepts that involve the relationship of humankind and his environment. All these concepts refer to the affective and cognitive relationship between 
human and the physical environment. However there is no consensus on definitions of these concepts, especially how place identity and place attachment is related to each other $[18,20]$. Both place identity and place attachment concepts have been regarded as being components of personal identity, while Stedman recognizes place attachment as an objective dimension for measuring the sense of place [17].

The emotional bonding between people and places has been defined as place attachment by Altman and Low in their work "Place Attachment" (1992) [21]. However, according to Chow and Healey (2008), place attachment is a more complex and multifaceted phenomenon which involves the interplay of not only affect and emotions, but also knowledge and beliefs, and behaviours and actions in reference to a place [20]. Scannell and Gifford (2010) defines place attachment as: "a bond between an individual or group and a place that can vary in terms of spatial level, degree of specificity, and social or physical features of the place, and is manifested through affective, cognitive, and behavioural psychological processes" [22].

Milligan (1998) states that an emotional bond with a place is formed by the meaning given to a place by the individual, as a result of his interaction with the place (Inalhan and Finch). People have feelings about places as well as beliefs and memories and they act certain ways in different places [17]. According to Riley (1992), place attachment may be primarily associated with meanings and experiences which often involve relationship with other people [19].

People's affective and cognitive responses to a place are occurred through experiencing the place. Experience is the key action in development of human-place bond. The intensity, duration, content and result of the experience may influence the individual's perception of a place. For instance, "home" is generally associated with the emotions of safety and comfort. Sayings like "there is no place like home" or "home sweet home" display the universal perception of "home" as a place with positive emotions and meanings.

The degree of attachment to a particular place depends on its ability to meet our physiological and psychological needs. Place attachment is often assumed to develop in a long period of time. However, it can also be disrupted very quickly [19].Furthermore, a person can be attached to a place either emotionally or functionally. Altman and Low (1992) attempted to define theoretical typologies of place attachment [23]. These are [23, 24]:

1. Genealogical attachment (formed through ancestors, family heritage)

2. Economic bonding (material ownership, working, etc.)

3. Attachment via loss or destruction of a place

4. Cosmological bonding (through spiritual or mythological relationship)

5. Bonding through religious or cultural activities.

6. Narratives (stories, place-naming, legends etc.)

On the other hand, Scannell and Gifford (2010) propose a framework for place attachment which consists of three dimensions [22] (Figure 1):

1. The person dimension: Who is attached? To what extent is the attachment based on individually and collectively held meanings? 
2. Psychological process: How are affect, cognition, and behaviour manifested in the attachment?

3. The place dimension: What is the attachment to? What is the nature of this place?

According to Scannell and Gifford, place attachment can occur at both the individual and group levels. Personal memories and experiences influence the degree of place attachment at the individual level. On the other hand, place attachment is built through shared historical experiences and symbolic meanings of a place [22].

Their second dimension of psychological process involves three components: (i) affect (emotional connection), (ii) cognition (memories, beliefs, meaning and knowledge), and (iii) behaviour (attachment is expressed through actions).

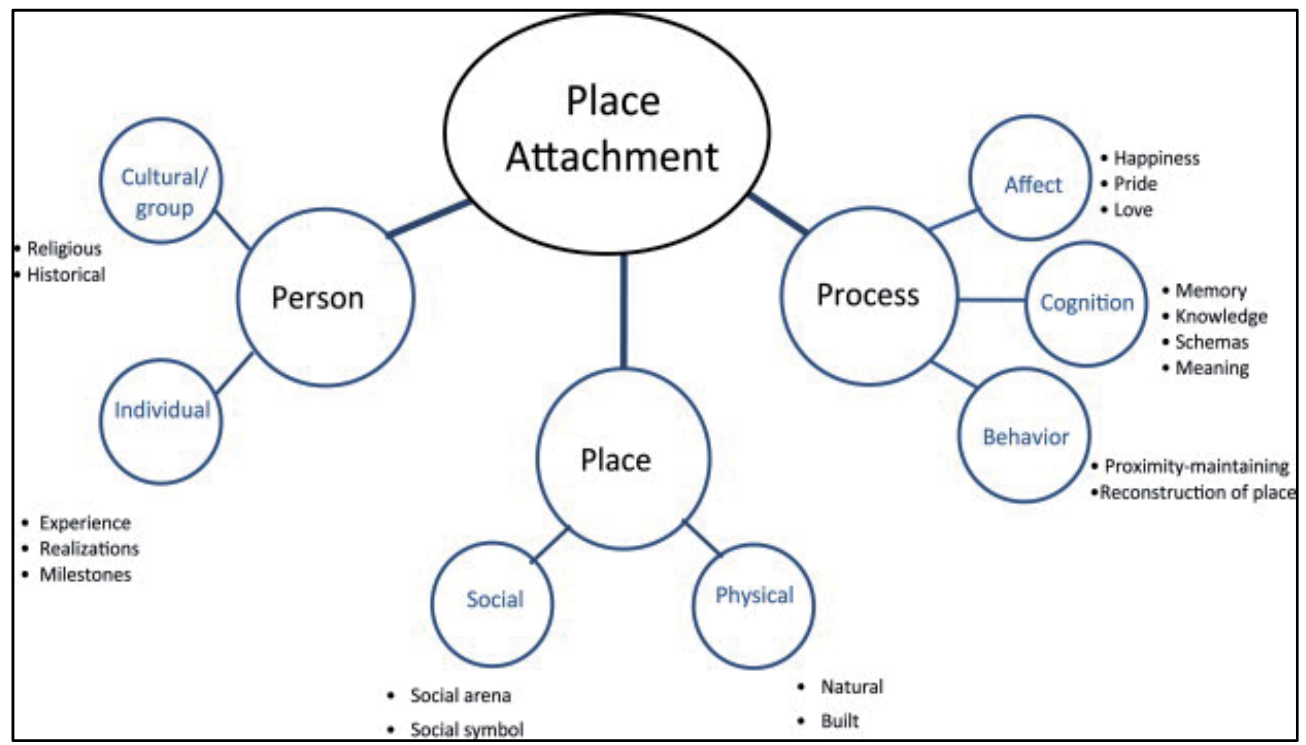

Figure 1. Scannell and Gifford's tripartite model of place attachment (Reprinted from Journal of Environmental Pschology, 30/1, Scannel L. and Gifford R., Defining place attachment: A tripartite organizing framework,1-10, 2010, with permission from Elsevier).

Place attachment has different scopes and scales in terms of place as a physical setting. Therefore the place dimension of the framework has been divided into two levels by the authors: social and physical place (natural and built) attachment. They stress out that physical characteristics of a place can be central to attachment; nevertheless "people are attached to places that facilitate social relationships and group identity".

Place attachment is influenced by many factors such as socio-demographic characteristics, environmental factors (type of involvement, familiarity to a place, activities in a place etc.), past experiences, culture, psychological factors, biological factors, and place itself [17, 23].Place attachment is also linked to environment friendly behaviour [16]. It is assumed that people, who develop positive meanings and emotions to a place, tend to protect and care for that particular place. 
As expressed before, the relationship between place attachment and place identity is still controversial among researchers. Some researchers consider place identity as a dimension of place attachment; while some others suggest that place identity is necessary for the formation of place attachment [18]. There are also researchers who assume place identity and place attachment are two separate concepts.

The term "place identity" has a duality in its meaning. In spatial planning and design, place identity is generally linked to the place itself. It refers to the distinctiveness of uniqueness of a place which is a result of the interaction between its physical features and its users. For instance Stobbelaar and Pedroli (2011) use the term "landscape identity" and they point out that the concept lacks clarity and not well- defined [25]. They define landscape identity as the perceived uniqueness of a place. Moreover they assert that perceiving has both personal and social dimension and uniqueness is based on the interaction between the physical environment and social factors.

On the contrary, in psychology "place identity" concept is a "personal" issue and linked to self-identity. One of the well-known works on place identity in psychology field is Proshansky's "The city and self-identity". In his work Proshansky (1978) defines place identity as [26]:

"those dimensions of self that define the individual's personal identity in relation to the physical environment by means of a complex pattern of conscious and unconscious ideas, beliefs, preferences, feelings, values, goals, and behavioural tendencies and skills relevant to this environment".

In summary, Proshansky's definition proposes that physical environments influence selfidentity as a result of the interaction between a person and a place. One of the well-known examples of how place affects one's identification of self is expressions like "New Yorker" or "Londoner". Similar to place attachment, place identity may also occur at different levels and scales of places; such as "European" at the continental level or "East ender" at the neighbourhood level or "Turkish" at the country level. In this respect, place identity overlaps with social identity.

While Proshansky promotes "place identity" as a separate concept, Twigger-Ross and Uzzell (1996) suggest that all aspects of identity have place-related implications and place should not be considered as a separate part of the identity [27]. They also comment that place attachment can function to support or develop aspects of identity.

Place is not merely important in developing and maintaining self identity, but it also has a significant effect on human well-being and behaviour [17]. There is a two-way relationship between a person and a place. While place influences self identity, people also tend to create, change or maintain their physical surroundings in the way which reflect themselves. Hence, the physical environment is a reflection of the identity of its users.

So far basic approaches to place attachment and place identity have been presented in this section. Next section will focus on development, maintenance of and current issues on the identity of urban landscapes from the perspective of urban planning and design. 


\section{Urban landscape and identity}

Landscape is a dynamic phenomenon which is shaped by both natural and cultural forces. Thus, change is an inherent character of any landscape. Changes in landscape may not always happen as a result of planned actions, but may also be an unexpected effect [28]. Although change of the environments does not necessarily have to result in negative ways, it is a process that is often perceived in negative terms. The magnitude and speed of the change that has been faced since the $20^{\text {th }}$ century is dramatic and environmental problems it has caused is apparent and alarming. Besides current landscape changes are characterized by the loss of diversity, coherence and identity of the existing landscapes [29].

The major forces of landscape change can be defined as [28]:

1. Socioeconomic driving forces (primarily economic factors; market economy, globalization etc.)

2. Political driving forces (political programs, laws, policies etc.)

3. Technological driving forces (information technology, developments in transportation etc.)

4. Natural driving forces (changes in climate, topography, soil characteristics etc. and natural disasters)

5. Cultural driving forces

On the other hand, Antrop (2006) is more specific and definite when defining the driving sources [30]. According to him the main driving forces of landscape change are [30]:

1. Mobility patterns related to accessibility of places

2. Urbanization process

3. Decisions affecting large areas that overrule local decisions

4. Calamities

Landscape change is a continuous and rather complex process. Dealing with it requires a multidisciplinary approach. The above factors are all in some extent linked to each other. However, landscapes are considerably complex systems where it is often difficult to understand how driving forces interact and influence each other. This section will focus on the effects of two major driving forces of landscape change on urban landscape identity; urbanization and globalization.

Urbanization has been one of the significant phenomena which has dramatically changed our physical and social environments since the second half of the last century. Antrop (2004) defines urbanization as "a complex process that transforms the rural or natural landscapes into urban and industrial ones forming star-shaped spatial patterns controlled by the physical conditions of the site and its accessibility by transportation routes" [31]. Certainly, improvements in transportation and increased mobility have led to expansion of urban areas, as well as the transformation of rural areas into urban ones. Terms like urban sprawl, urban fringe and suburbanization emerged in relation to urbanization process.

Urbanization process is mainly about industrialization and economic activities. People prefer living in urban areas rather than rural areas because they hope to achieve a better 
quality of life in cities. However, urbanization processes in developed and developing countries do not necessarily shape cities and towns the same. In most of the developing countries, planned development of urban areas cannot always "catch" the population increase rates (mainly caused by immigration from rural areas) due to insufficient development and management strategies, as well as funding. Therefore, in contrast to mostly planned urban expansion in developed countries, developing countries face with low quality environments such as slums and squatter housings. This not only affects the quality of physical environment and image of the city, but also leads to fragmentation of social coherence and social identity. As Antrop (2004) summarizes; "urbanization is primarily a complex of functional changes, followed by morphological and structural ones" [31].

Cities are not only physical constructs, but also involve social structures. The citizens are the fundamental elements of cities that keep it alive and functioning. There is a mutual relationship between a city's physical characteristics and its citizens. While the physical dimension of a city (buildings, open and green spaces, streets etc.) is shaped and formed under the influence of its citizens, it also shapes its citizens life-styles and social identity throughout the time. Cities are thus cultural heritages. As Stephenson puts it culture and identity are not merely about social relationships, but also spatial [32].

From a psychological perspective Göregenli (2005) asserts that urban identity or urban identities are a result of complex relationships between individual self, place identity and urban environments [23]. Cities are a product of continuous interaction between the physical environment and social life; their image reflects the communities' experiences, beliefs and values. Consequently identity of an urban place is the total of both physical and social distinctive features that is unique to it [12].

Meaning and sense of belonging are central to perceived urban identity. According to Lalli developing sense of belonging to a city requires coherence in urbanization process [23]. Unfortunately, today's cities are shaped under international influences and it is quite difficult to define planning and design forms which are necessary to maintain the local identity [33].

According to Lynch, identity is part of the image of a city. Although the image of a city is not necessarily the same as its identity [34], it is the physical and most instant perceived reflection of its identity. In his work "The Image of the City", Lynch (1960) defines three components of an environmental image as; (i) identity, (ii) structure and (iii) meaning [35]. The first two are more related to physical structure of the city, but meaning involves more difficult processes between the individual and the city. According to Lynch, identification of an object is the first step for a workable image. He points out that individuality or oneness, spatial or pattern relation of the object to the observer and to other objects, and finally practical or emotional meaning are the requirements of a workable image.

Lynch defines paths, edges, districts, nodes and landmarks are the five elements of a city image. He especially focuses on the legibility of the cityscape and asserts that the overall 
pattern of all city image elements determines the legibility of a city. Hence, a city's identity depends on the easiness of identifying the image which is a result of the way how its elements are composed of and interact with each other. Obviously, how human experience influences a city's image and identity is missing in Lynch's approach. Although he admits meaning is necessary for a workable image, his work basically focuses on the physical construction of the city. However, even though he is often criticized for neglecting the social dimension in his work, his work is still influencing and popular in urban planning and design.

On the other hand according to Relph, identity of a place is strongly linked to the existence of authentic sense of place [36]. Sense of place is about a person's understanding of a place; hence it involves (i) experience and (ii) a subjective dimension. Therefore the composition and characteristics of physical components of the built environment affect the sense of place perceived and interpreted by people. Rogan et al. defined three variables of sense of place; legibility, perception of and preference for the visual environment and the compatibility of the activities with human purposes [17].

Legibility is a concept that is often linked to the identity of an urban space. So what determines the legibility of a place? According to Lynch visibility, coherence and clarity are the factors that determine the degree of legibility and should be taken into account in forming the city [35]. On the other hand, these characteristics may not be sufficient alone for creating legible cities. According to Carr et al. (1992) a meaningful space has to be comfortable enough to allow an experience with it to occur and positive meanings can be created by positive connections to people [37]. Relph argues that ignoring the meanings attached to places creates inauthentic places and damage authentic ones [17]. He names this transformation as placelessness. Placelessness has become an important concern for the sustainability of the urban environments these days.

Although urbanization has some negative impacts on sustainability of the environment, what really raises the concerns on identity of urban areas is globalization process, which also influences the context of urbanization worldwide. In social sciences, globalization is studied primarily in context of economics. Since economical activities are basic to the functioning of a city, globalized economy's "global production and consumption" patterns play an important role in the change of urban environments, making them a product of "global culture". Homogenization of urban landscapes is an apparent and concerning effect of globalization process. Global brands are everywhere, not only selling or presenting or serving their products, but they also bring their unique architectural patterns, signboards etc. to wherever they open their branches. One can easily recognize a McDonalds shop or HSBC branch any city in the world. What is more concerning is the change of life-styles and thus cultural homogenization which global brands cause.

On the other hand what defines a city lays in its citizens' and visitors' minds. A city's identity is what the insiders (citizens) and outsiders (visitors) perceive, feel and remember about it. Unfortunately, what globalization causes on the image of cities through homogenization is often irreversible. 
Built heritage is definitely one of the most important aspect of the authenticity and subsequently identity of an urban environment. Cities are formed and develop throughout the time. They constantly change, develop and transform. Built heritage is the most apparent reflection of this change. It might also include symbolic meanings for the citizens and visitors, often because of the significant historical events associated with it. Buildings and structures of a city tell a story of past with meanings and cultural values involved. Therefore, built heritage is assumed to be a distinct indicator of urban identity and thus conservation of the built heritage is one of the major concerns in sustainability of urban identity. Certainly, it is impossible and senseless to protect all the "old" buildings and structures. Cities are growing faster than expected and overcapacity; hence "empty lands" are scarce and precious. It is often needed to restructure and reorganize the existing built environment. Recently some researchers have argued that urban conservation practices create morphologically standardized urban landscapes and do not contribute to place identity at all [38]. So identity concerns bring the question of "what to protect". Actually, recent research show that not only historical buildings but also contemporary and newer structures and buildings are as well associated with the city's image and identity by its citizens and visitors.

For instance Gospodini's (2004) research on place identity was conducted in Bilbao where urban landscape is formed by the combination of modern and historical architecture [38]. The findings of the research showed that both innovative design and built heritage contribute to the image and identity of the city equally, as perceived by the citizens and tourists. The Guggenheim Museum (Figure 2) in Bilbao is one of the significant examples of how innovative design schemes can contribute to urban identity. In Gospodini's research Guggenheim Museum was highly rated as a unique and distinct feature of the Bilbao's urban identity by both the inhabitants and the tourists.

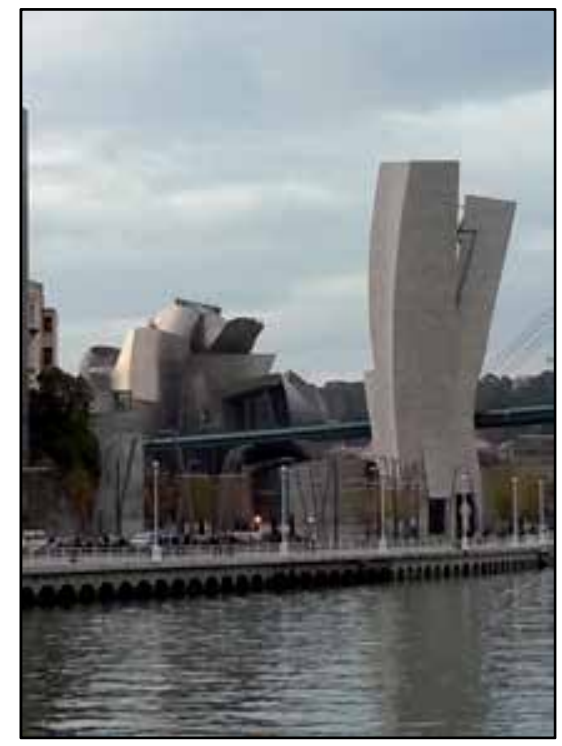

Figure 2. Guggenheim Museum in Bilbao. 
Another significant impact on urban identity is the decline in public realm. Public spaces are crucial parts of a city where social, cultural and economic activities take place. Therefore they are the heart of the cities. Public spaces bring citizens together, providing them with opportunities for relaxing, recreation, socializing, gathering, performing arts, sports activities, public art and cultural activities. In summary they liven up the city life and create a sense of community. However, public spaces decrease or lose their importance in many contemporary cities, mainly due to changing life-styles where people spend most of their time in virtual environments. But how does this affect identity of urban environments? Firstly, public spaces are where social interaction and activities occur. Secondly, public spaces are where individuals and groups experience the city most freely. Thirdly, they provide spaces where people can express themselves and be themselves. Finally, they benefit mental and physical health through the opportunities they offer, that are mentioned above. Therefore, they play an important role in developing and maintaining both selfidentity and place-identity. The loss of public spaces will not only damage social cohesion, but also reduce the quality of life of an individual.

It is hard to know how the progress of current urbanization trends will exactly shape our lives and our environments in the future. However, we can only predict the possible outcomes and so far it is only concerning.

\section{Identity issues in Turkish cities}

The characteristics of landscapes in Turkey significantly vary between its regions. For instance while Black Sea region's landscape is characterized by the plateaus, meadows, tea farms/gardens and wooden houses, landscape in Aegean region of Turkey is dominated by olive trees, maquis and stone houses. Similarly, the settlements in different regions have

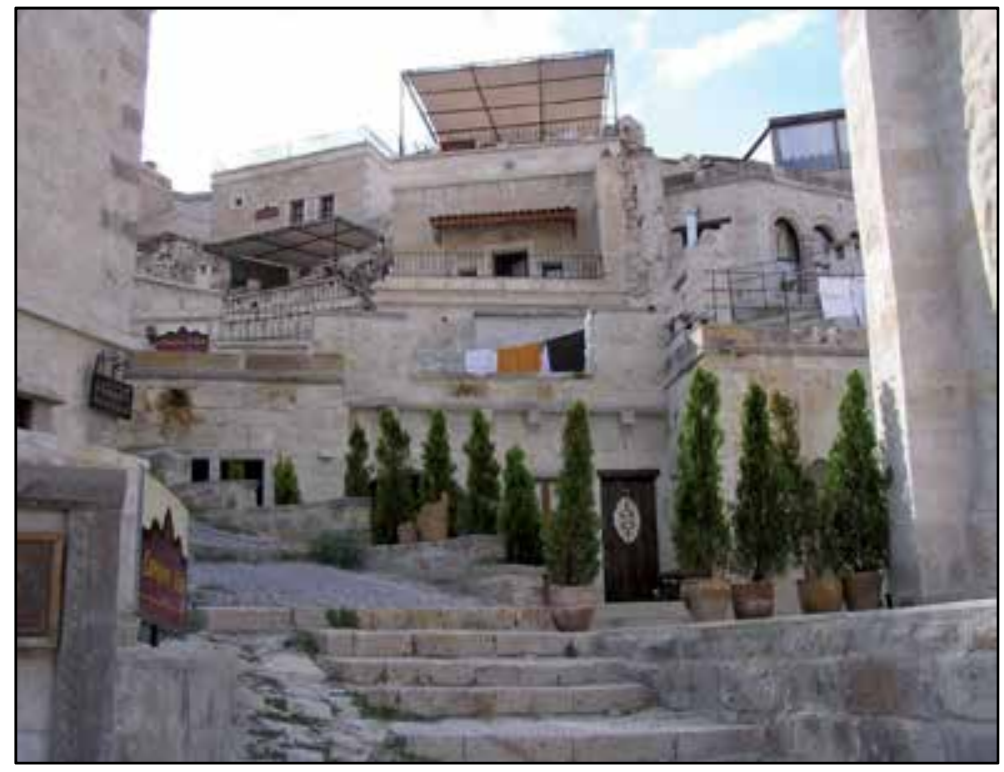

Figure 3. Local architectural identity in Göreme, Cappadocia region, Turkey. 
been shaped and formed under the influence of different physical, natural, social, cultural and economic conditions. In regions where urbanization process is relatively slower, local unique characteristics can still be seen in towns. In some towns, local landscape and built heritage is used as marketing products to attract tourists. Although tourism activities (especially mass tourism) cause irreversible impacts on local environment and resources and sometimes lead to loss of diversity and identity, there are examples where local character still exists (Figure 3).

The major problem in maintaining identity of urban environments in Turkey is the lack of awareness and sensitivity of national and local authorities. The most deteriorating actions on urban identity of Turkish cities have been decided and implemented by governmental organizations and local municipalities through urban renewal and urban transformation projects. Below some of the recent and significant examples are presented.

\section{Housing projects of TOKİ (Housing Development Administration of Turkey)}

Due to the migration from rural to urban areas In Turkey, housing developments cover 95\% of the total building production [39]. TOKI is currently the leading and the only legal authorization in development of new housing projects throughout the country. The total number of TOKI's housing projects as announced on TOKI's web page is; "in 81 cities, 800 towns, with 2522 worksites, 560866 housing units" [40]. This might seem a huge number, and it is indeed. But how does TOKI manage with so many housing projects in terms of local identity and character? The answer is quite a disappointment; the body simply ignores these issues. It rather works like a housing "factory". In fact, their vision statement is solely based on economy and financing, rather than basic principles of urban planning and design;

"TOKİ's vision for the future strives to:

- Create a model framework for quality low-cost housing,

- Prevent real estate speculation that might use low-quality materials in the construction of low-margin housing,

- Produce housing for regions in Turkey where the private sector is not active,

- Offer low and middle income groups the opportunity to finance their own homes,

- Offer rural housing opportunities that decrease the pressure on the migration to urban areas,

- Collaborate with local municipalities to create urban renewal projects and

- Create financial opportunities to finance social housing projects such as innovative income-sharing projects with the private sector" [40].

Bursa branch of the Chamber of Architects of Turkey organized a photography competition on the negative impacts of TOKİ projects in Bursa in 2011. The photographs submitted to the competition revealed the disharmony and incoherence of the housing projects within the city's existing character (Figure 4).

The main threat caused by TOKI is the standardization and homogenization of urban landscapes throughout Turkey. Although TOKİ claims that it will pay more attention to the Turkish architectural styles in its new development projects, Gür discusses that TOKI's 
"Ottoman" and "Seljuk" style architecture approaches in its projects will only be "characterless imitations" as long as TOKİ continues with projects which are unfamiliar with Anatolian culture in terms of site selection, organization of neighbourhoods, accommodation characteristics and social and cultural services.
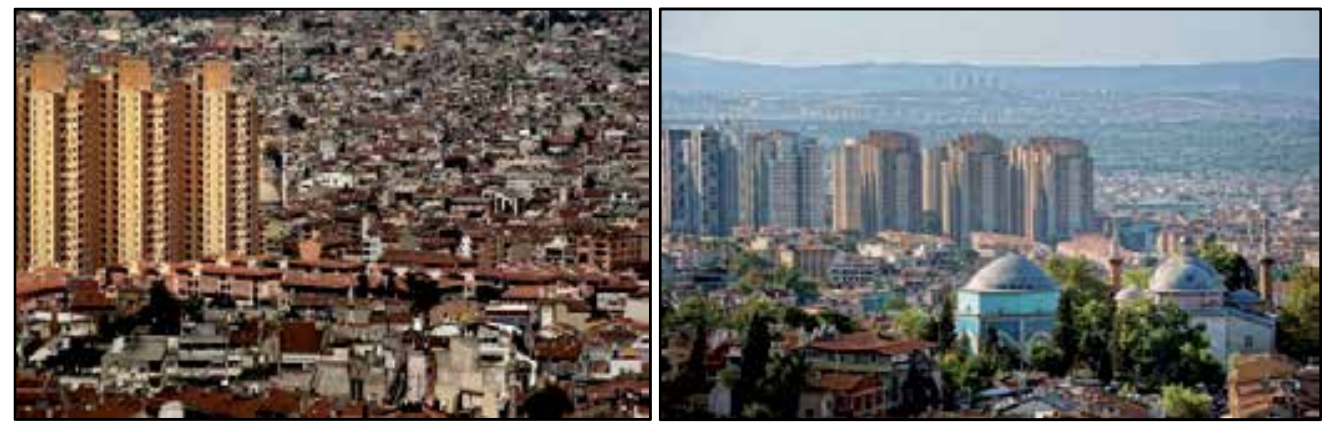

Figure 4. TOKİ housing projects in Bursa [41] (Left: $2^{\text {nd }}$ Prize Winner- Photo by Egemen Ergin, Right: Photo by Bülent Suberk).

\section{Ankara}

As explained previously in the introduction of this chapter, Ankara is the first planned city of the modern Turkey, and the prescribed identity for Ankara was a modern republican capital city. Like other metropolitan areas in Turkey, Ankara's urban environment has been affected by the impacts of immigration, uncontrolled and unplanned urbanization and globalization since 1950's. However the most destructive actions on its identity have been taken in the last two decades by the Metropolitan Municipality of Ankara.

Although it is not directly linked to identity of the urban landscape, one of the most controversial attempts to manipulate Ankara's identity was the change of Ankara's city emblem by the Metropolitan Municipality of Ankara. Ankara's old emblem was formerly the Hittite Sun which took its roots from the fact that Ankara's history goes back to Hittites. In 1995 Metropolitan Municipality of Ankara took a decision to change the emblem of the city. The new emblem was the combination of Kocatepe Mosque (construction completed in 1987) and Atakule Shopping Mall (opened in 1989). Figure 5 shows the current and the old emblem of the city.

One might argue whether the both emblems symbolize the identity of Ankara. However it is obvious that the latter one does not emphasize the "modern republican city" concept with a mosque and shopping mall in it.

Despite Ankara has struggled with more serious problems which concern quality of life and sustainability of urban environment, the change of the city emblem was only the beginning of Municipality's policies and future actions on the Ankara's urban landscape.

Ankara has suffered the negative impacts of squatter housing or as said in Turkish "gecekondu"s, especially after 1950's because of the high rates of migration. Urban renewal and urban transformation projects have been the most popular and favourite 
tools for the municipalities for the last decade. However, similar to many other attempts on the built environment, these projects have always been controversial and have received serious criticism from academicians and professional organizations. This is mainly due to the fact that urban renewal or urban transformation projects in Turkey often ignores the social, economic and cultural dimensions and based on merely the physical transformation of the environment. The gecekondus are replaced by TOKI's apartment blocks, transforming the city into homogenized units as explained before. In Figure 6, the urban transformation project (by TOKI) on North Ankara is presented. Such projects do not contribute to the social and cultural aspects of the city and moreover they are unsustainable and not incoherence with the Ankara's identity envisaged when the Republic was first established.

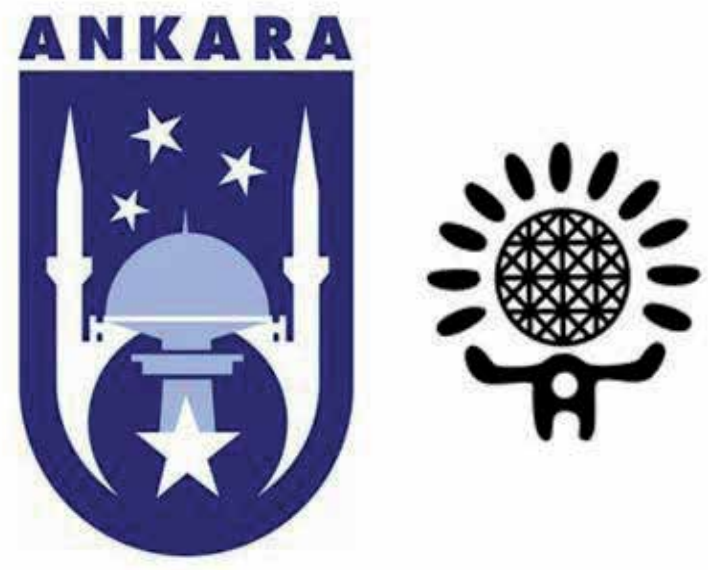

Figure 5. The current emblem of Ankara is on the left and the former is on the right [42].

Traffic is one of the other significant issues in Ankara which affects the urban quality of life. Because of the community life styles and lack of sufficient public transportation systems, traffic is a growing problem for Ankara. Besides urban expansion policies which ignored the transportation dimension has worsen the situation. Moreover, most of the governmental organizations and ministries have been moved out of the city centre and because of the lack of public transportation to these units, individual car use has been increased, especially during the peak hours. Although traffic is a common issue for many metropolitan cities, what damaged urban image and human experience in Ankara has been the construction of underground roads within the city centre which ignored the pedestrian movement and focused on vehicle traffic flow (Figure 7). The initial aim was to relieve the vehicle traffic within the city. However, building more roads underground did not solve the problem, but seriously harmed the city image. As stated before, people and social activity are necessary for the vitality of a city. Moreover, identity is developed by experiencing the environment. People experience the city best by walking and by using the public spaces. If vehicle traffic becomes the prominent priority, the city might lose its basic function and vitality. 


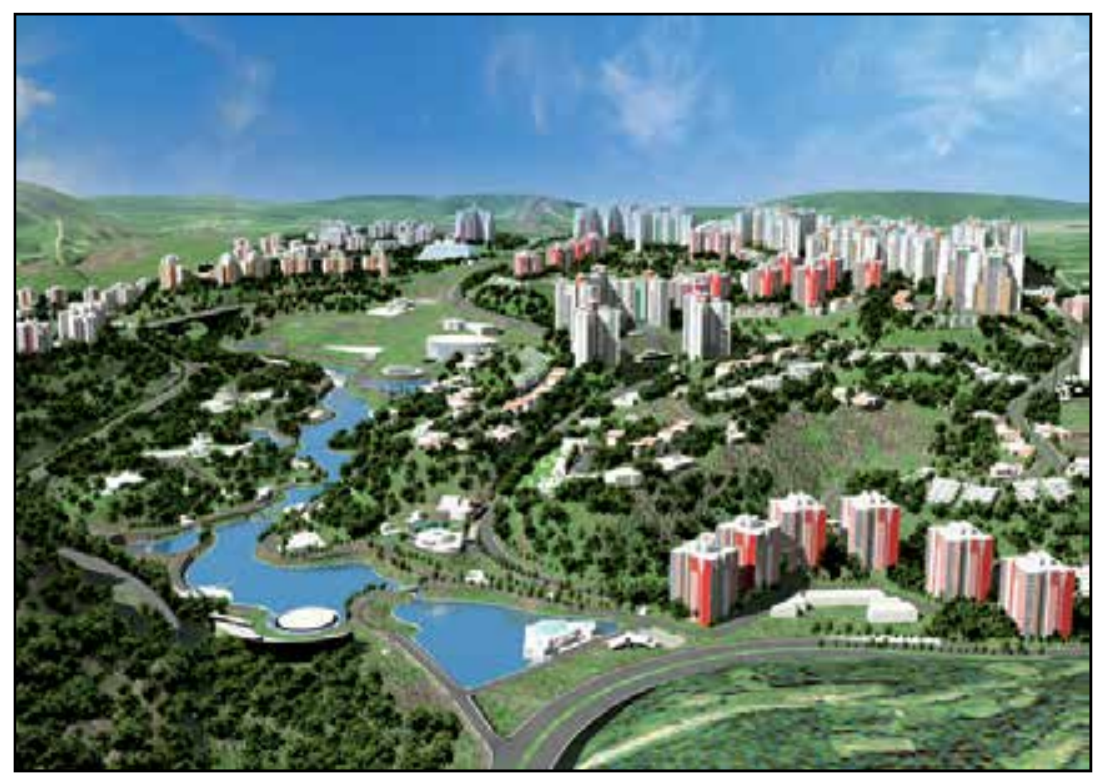

Figure 6. North Ankara urban transformation project [43].

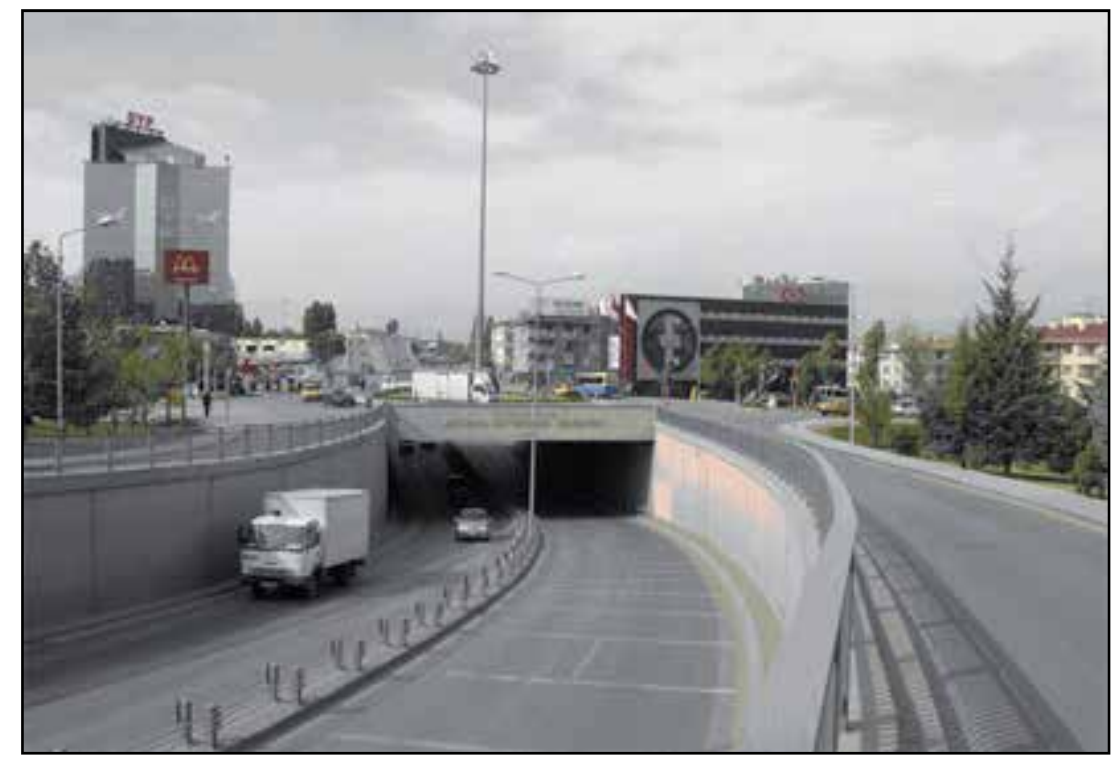

Figure 7. An underground road in Ankara [44].

Today there are more than 20 shopping malls in Ankara, which is the result of rapid growth of market economy globalization and liberalization processes. Besides the consumption based-culture they partially contributed to and supported, shopping malls have been one of the reasons of decline in use of public spaces in Ankara. Oguz and Çakc1 (2010) have found that people tend to prefer spending their leisure time in shopping malls rather than outdoor public spaces due to the services and facilities shopping malls offer [45]. However, public 
spaces are crucial parts of a city that support social integration and cohesion. They contribute to the overall city image and liven up boring city life and the built environment. They bring different social, ethnic and economic income groups together. They are where communities express themselves by gathering, protesting, etc. Therefore they play an important role in the development and maintenance of urban identity. On the other hand, public spaces have not always been paid the attention they deserved in Ankara. Today Ankara lacks of public squares which are hearts of the cities and where social interaction is the highest. The most famous and historical squares of Ankara, Kızılay and Ulus squares have become "urban junctions" which have limited pedestrian access and movement.

Ankara is a city shaped by the influences of many civilizations such as Roman Empire, Byzantine Empire, Seljuk Empire, Ottoman Empire and finally the Republic of Turkey. It has its unique topographical features, climate, vegetation and fauna, as well as built environment characteristics. There are too many aspects which can contribute to its identity. Unfortunately, today's Ankara has been losing its values and meanings belonging to its history and local character. What is more concerning is the citizens' inert response to the transformation.

Ankara's identity should be reconsidered in urban design and planning in order to emphasize Republican values and its history.

\section{İstanbul}

İstanbul is the most well known Turkish city worldwide because of its historical importance, geographical position (as a transition point between two continents, Europe and Asia) and outstanding landscape features. It is also the most crowded city in Turkey with more than 13 million inhabitants. Due to inward migration the city's population have been doubled in the last two decades. Similar to Ankara, İstanbul has been suffering uncontrolled and unplanned urban expansion which led to urban transformation and urban renewal projects, again lacking of urban identity aspect.

Haydarpaşa Train Station, constructed in 1908, has always been one of the significant landmarks of İstanbul. It has been frequently included in the opening scenes of Turkish movies, where characters arrive the first time in İstanbul and have the first glimpse of the city while standing on the stairs of Haydarpaşa Station. It has always been one of the "entrance" points to the city and an important part of the city silhouette (Figure 8). However, İstanbul Metropolitan Municipality approved an urban transformation project which will change character of Haydarpaşa Train Station and consequently İstanbul's silhouette forever; "Haydarpaşa Port Project". The project has received many criticisms but it did not prevent taking the project next level. The project will transform this historical and public site to an economy centre based on tourism and commercial activities. Such privatization trends by the authorities in urban design and planning definitely cause irreversible impacts and damages on urban character and identity. However, the government and the Metropolitan Municipality seem to be content with the project. The following paragraphs, which reflect the authorities' opinions, were taken from the İstanbul Metropolitan Municipality's website [46]. 
"The Istanbul Municipal Assembly has approved reconstruction plan for protection of the Haydarpaşa Train Station and Port, paving the way to change the entire appearance of a historical location marked for about a century by one of the architectural symbols of Istanbul's Asian side.

The municipal assembly met Sept. 14, with members representing the ruling Justice and Development Party (AKP) and the Republican People's Party (CHP), according to a report from Anatolia news agency. The project was approved with affirmative votes from the AKP members, while the CHP members voted against it.

Akif Burak Atlar, assistant secretary-general of the Istanbul City Planners Chamber said: "The Haydarpaşa Train Station may lose its public function [with this project]. We want to defend the protection of the train station feature of the Haydarpaşa building and leave it as it is for future generations, because it is part of our cultural heritage."

Commercial and tourism functions would close the building and the surrounding area to public use, he said. Haydarpaşa is planned to become the city's main tourism port, where giant cruise ships will dock.

The government deems it to be one of the most important "prestigious projects" planned for Istanbul, along with the Galata Port project on the European side of Istanbul.

Both projects were approved this year by the Cultural and Natural Heritage Conservation Board, despite having stirred great public controversy. Istanbul Mayor Kadir Topbaş had previously said that the two areas, which have cultural and historical value, would be opened to tourism."

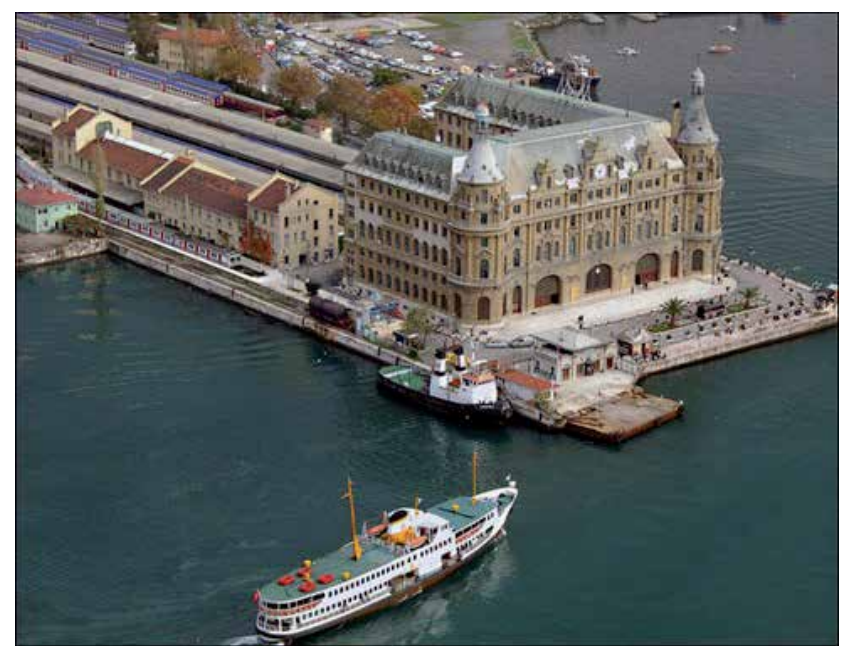

Figure 8. Haydarpaşa Train Station [47]. 
Haydarpaşa Port Project is not the only project that will change the unique character of İstanbul forever. There are many attempts by the government and the Metropolitan Municipality o change the urban landscape irreversibly. Non-governmental organizations, professional organizations and academicians are the primary opponents of these projects. Regarding these kind of projects in İstanbul, Steele and Shafik well summarize the threat İstanbul is facing [48]:

"None of these have sufficiently addressed the singular character of Istanbul as a world class city which is stepped in multiple layers of history and tradition. Its most distinctive aspect has always been its silhouette and relationship to the water. By erasing this most important feature, Planners and Developers have erased the very identity of this city. This is a tragedy."

\section{Conclusion}

Urban landscape is a complex structure which is a result of the interaction between human and his environment. It also involves a social dimension, a cultural dimension and an economic dimension. Urban landscapes are formed and shaped mainly under the influence of human activities. Therefore, they inherit communities' values, beliefs, symbolic meanings which occur and change throughout the time. They change as communities change, lifestyles change, and world economy change. Thus, they are the physical reflection of urban identity.

Similar to self identity, urban identity is also flexible and evolving. The change is an inevitable process. However, the question is how to manage the change and urban identity in today's cities which are more multi-cultural and multi-ethnic than ever. Therefore sustainability should not be limited to only natural resources, but should also include urban identity as cultural heritage. Hence there is a need for methodologies of analysis and assessment of urban identity.

The main goal of planners and designers is to create liveable places for people. "Liveability" of a place can be determined through the quality of the environment. On the other hand the quality of a place not only is determined through physical features of an environment, but also involves subjective factors. Thus, social and psychological dimension of the urban environments should be taken into account in planning and design schemes. The mutual relationship between people and their environments should be well understood and interpreted in order to create and maintain liveable places. Unfortunately, it is often too late when we realize the effects of our actions that lead to loss of coherence, diversity and change. While we put all the blame on globalization and urbanization processes, we should also acknowledge that we need to develop plans and policies that would adapt the change.

\section{Author details}

Isil Kaymaz

Department of Landscape Architecture, Ankara University, Ankara, Turkey 


\section{References}

[1] Sepe M. Place identity and placemaker: planning the urban sustainability. Journal of Urban Planning and Development, 136 (2), DOI: 10.1061/(ASCE)0733-9488(2010) 136:2(139)

[2] United Nations. World Urbanization Prospects, The 2011 revision- Highlights. New York; 2012.

[3] Türkoğlu Önge S. 2007. Spatial Representation of Power: Making the urban space of Ankara in the early Republican Period.

http://www.cliohworld.net/onlread/3/TURKOGLU_Spatial.pdf (accessed 02.12.2012).

[4] Oguz D. and Cakci I. Changes in leisure and recreational preferences: A case study of Ankara. Scientific Research and Essays, Vol.5(8), 721-729, 2010.

[5] Erkip F. The shopping mall as an emergent public space in Turkey. Environment and Planning A, 35, p.1073-1093, 2003.

[6] Turkish Statistical Institute. http://www.turkstat.gov.tr/PreHaberBultenleri.do?id=10736 (accessed: 10.12.2012).

[7] Işık Ş. Türkiye'de Kentleşme ve Kentleşme Modelleri (Urbanisation and Urbanisation models in Turkey). Ege Coğrafya Dergisi, 14, pp.57-71. 2005.

[8] Oxford English Dictionary. http://oxforddictionaries.com/ (accessed 02.12.2012).

[9] Gleason P. Identifying identity: a semantic history. The Journal of American History, Vol. 69, No. 4 (Mar., 1983), pp. 910-931

[10] Fearon J.D. What is identity (as we now use the word)?. http://www.stanford.edu/ jfearon/papers/iden1v2.pdf (accessed 21.11.2012).

[11] Castells M. Power of Identity: Economy, society, and Culture (2nd Edition). USA: WileyBlackwell; 2009.

[12] Ocakçı M., Türk Aydın T. Urban identity. The Encyclopaedic Dictionary of Urban Planning. Ed. Ersoy M. İstanbul; Ninova:2012, p.226-228.

[13] Özdemir E. Kimlik kavramı ve teorik yaklaşımlar (The concept of identity and theoretical approaches). Eğitim, Bilim, Toplum. 8(32); 9-29. 2010.

[14] Hansen N.S. Talking Identities- A critical discourse analysis of how ethnic Britons and British Muslims talk about social identities. Master Thesis. Aarhus School of Business, Aarhus University. 2009.

http://pure.au.dk/portal-asb-student/files/8344/MasterThesis.pdf (accessed 02.12.2012).

[15] Tuan Y.F. Space and Place: The perspective of experience. University of Minnesota Press, Minneapolis, 1977.

[16] Halpenny E.A. Pro-environmental behaviours and park visitors: The effect of place attachment. Journal of Environmental Psychology 2010; 30: 409-421.

[17] Najafi M., Shariff M.K.M. The concept of a place and sense of place in architectural studies. International Journal of Human and Social Sciences. 2011: 6(3); 187-193.

[18] Lewicka M. Place attachment, place identity, and place memory: restoring the forgotten city past. Journal of Environmental Psychology 2008; 28: 209-231.

[19] Inalhan G., Finch, E. Change and attachment to place. In: Finch E. (ed.) Facilities Change Management. Wiley-Blackwell; 2011. p.155-174. 
[20] Chow K., Healey M. Place attachment and place identity: First-year undergraduates making the transition from home to university. Journal of Environmental Psychology 2008; 28: 362-372.

[21] Nielsen Pincus M., Hall T., Force J.E., Wulfhorst J.D. Sociodemographic effects on place bonding. Journal of Environmental Psychology. 2010;; 30: 443-454.

[22] Scannell L., Gifford R. Defining place attachment: A tripartite organizing framework. Journal of Environmental Psychology. 2010: 30(1); 1-10.

[23] Göregenli M. Çevre Psikolojisi: İnsan Mekan İlişkileri (Environmental Psychology: People Place Relationships). İstanbul: İstanbul Bilgi Üniversitesi Yayınlarl; 2005.

[24] Sampson K.A., Goodrich C.G. Making place: identity construction and community formation through sense of place in Westland, New Zealand.

[25] Stobbelaar D.J. and Pedroli B. Perspectives on landscape identity: a conceptual challenge. Landscape Research. 2011: 36(3); 321-39.

[26] Proshansky H. M. The city and self-identity. Environment and Behavior. 1978: 10; 147170.

[27] Twigger-Ross C.L., Uzzell D.L. Place and Identity Processes. Journal of Environmental Psychology. 1996: 16; 205-220.

[28] Bürgi M., Hersperger A.M., Schneeberger N. Driving forces of landscape changecurrent and new directions. Landscape Ecology. 2004: 19; 857-868.

[29] Antrop M. Why landscapes of the past are important for the future. Landscape and Urban Planning. 2005: 70 (1-2); 21-34.

[30] Antrop M. Sustainable landscapes: contradiction, fiction or utopia? Landscape and Urban Planning. 2006: 75 (3-4); 187-197.

[31] Antrop M. Landscape change and the urbanization process in Europe. Landscape and Urban Planning. 2004 : 67 (1-2); 9-26.

[32] Stephenson J. The cultural values model: an integrated approach to values in landscapes. Landscape and Urban Planning. 2008; 84; 127-139.

[33] Brabec E. landscape change: the influence of external cultural forces. 2004. Landscape Architecture \& Regional Planning Faculty Publication Series. Paper 4. Available at: http://scholarworks.umass.edu/larp_faculty_pubs/4 (access date: 01.12.2012)

[34] Arreola D.D. Urban ethnic landscape identity. Geographical Review. 1995: 85(4); 518-34.

[35] Lynch K. The Image of the City.USA: The MIT Press; 1960.

[36] Seamon D. and Sowers J. Place and Placelessness, Edward Relph. In: Hubbard P., Kitchen R., Vallentine G. (Eds.) Key Texts in Human Geography. London: Sage; 2008. p.43-51.

[37] Carr S., Francis M., Rivlin, L. and Stone, A. Public Space. Cambridge: University Press; 1992.

[38] Gospodini A. Urban morphology and place identity in European cities: built heritage and innovative design. Journal of Urban Design 2004; 9(2) 225-248.

[39] Gür M. Kimlik Sorunu: TOKİ Konutları (The problem of identity: TOKİ houses). 6. Ulusal Çatı ve Cephe Sempozyumu, 12-13 Nisan 2012, Bursa.

[40] TOKİ. http://www.toki.gov.tr/ (accessed 28.12.2012).

[41] Bursa Branch of Turkish Chamber of Architects 
http://www.bursamimar.org.tr/icsayfa.php?catid=6\&altid=18\&indeks=457(accessed 28.12.2012).

[42] http://www.radikal.com.tr/Radikal.aspx?aType=RadikalDetayV3\&ArticleID=893201 (accessed:28.12.2012).

[43] http://www.toki.gov.tr/TR/Genel/BelgeGoster.aspx?F6E10F8892433CFFAAF6AA 849816B2EF209A85B5E49F32C4 (accessed:28.12.2012).

[44] http://www.ankara.bel.tr/ulasim-projeleri/alt-ust-gecitler-ve-koprulu-kavsaklar/cetinemec-bulvari-70-gun-alt-gecidi/ (accessed:28.12.2012).

[45] Oguz D. And Çakcı I. Changes in leisure and recreational preferences: a case study of Ankara. Scientific Research and Essays 2010: 5(8) 721-29.

[46] http://www.ibb.gov.tr/en-US/Pages/Haber.aspx?NewsID=683 (accessed 20.12.2012).

[47] http://database.emrearolat.com/2012/02/28/haydarpasa-ihalesini-ozellestirme-idaresiyapacak/ (accessed: 21.12.2012).

[48] Steele J. and Shafik R. Tensions and transformations in the master planning process of Istanbul. 14 $4^{\text {th }}$ PHS Conference. Urban Transformation: Controversies, Contrasts and Challenges.2010. http://iphs2010.com/abs/ID141.pdf (accessed 28.12.2012). 


\title{
Homegardens in Landscape Architecture - A Case Study of Hazelnut Plantations
}

\author{
Engin Eroğlu, Cengiz Acar and Ibrahim Turna \\ Additional information is available at the end of the chapter
}

http://dx.doi.org/10.5772/55750

\section{Introduction}

Landscape can be defined as from one point of view enter into the framework of a view that they produce a combination of natural and cultural assets (Council of Europe, 2000). At the same time, objects or land covers around us and how we perceive and how the relationship between nature and culture has the meaning established. Landscapes are the most important elements in building spatial identities. Landscapes, sometimes with their natural and cultural features can provide information about the way of life of the people. They are used in a sustainable manner for future generations and makes sense economically. The decisions to get to taken whether rural or urban landscape in the continuity, management and use of the quality of life of people are very important.

Landscapes are divided into three basic groups as natural, semi-natural and cultural (artificial) (Atik, 2009). Natural landscapes include areas that there is little or no human impact such as mountain forest, river, and lakes (Çepel, 1988). Semi-natural landscapes are dominated by the majority of the natural areas of land cover change in the form of areas that are too small. Urban, recreational, agricultural and industrial areas formed cultural or artificial landscapes.

Agricultural landscapes that are one of the four elements of cultural landscape (Karahan and Orhan, 2008) are the main land use form and the resulting high visibility leads to a widespread perception of rural farming. The importance of preserving agricultural landscapes is determined as (EC, 2012);

- traditional agricultural landscapes form part of the cultural and natural heritage,

- the ecological integrity and the scenic value of landscapes make rural areas attractive for the establishment of enterprises, for places to live, for tourism, and recreation businesses 
Agricultural landscapes include fruit and vegetable gardens, livestock and flower-growing businesses, watering plants. In addition, these areas have been adapted human life as field which is a recreational, a peaceful space, spending leisure time (Gökalp and Yazgan, 2013).

Agricultural landscapes are an important field in Turkey. Agricultural activities show ranging from one-year to multi-year products (Table 1).

\begin{tabular}{|l|r|}
\hline Agricultural Landscapes & Areas (da) \\
\hline $\begin{array}{l}\text { Vegetables and flower gardens } \\
\text { (Land under protective cover is included) }\end{array}$ & 5867005 \\
\hline $\begin{array}{l}\text { Fruit orchards and other permanent crops } \\
\text { (Land under protective cover is included) }\end{array}$ & 23891026 \\
\hline Poplar and willow land & 1973562 \\
\hline Unused and undeveloped potentially productive land & 19443399 \\
\hline Permanent meadow & 14493128 \\
\hline Pasture land & 131673745 \\
\hline Fallow land & 37459577 \\
\hline & Total \\
\hline
\end{tabular}

Table 1. Agricultural landscape areas in Turkey (According to values of Republic of Turkey Ministry of Food, Agriculture and Livestok in 2012)

Hazelnut plantations are in fruit orchards and other permanent crops. Hazelnut plantations cover 7138320 da in agricultural landscapes in Turkey (Table 2). Hazelnut plantations are located in northern, eastern and middle Black Sea Region of Turkey (Turna, 2012).

\begin{tabular}{|l|r|}
\hline Cities of Turkey & Areas (da) \\
\hline Artvin & 224026 \\
\hline Giresun & 1322837 \\
\hline Ordu & 2106005 \\
\hline Rize & 618472 \\
\hline Sakarya & 759062 \\
\hline Samsun & 947738 \\
\hline Trabzon & 607456 \\
\hline Düzce & 552724 \\
\hline & Total \\
\hline
\end{tabular}

Table 2. Distribution of hazelnut plantations in Turkey (According to values of Republic of Turkey Ministry of Food, Agriculture and Livestok in 2012)

In recent years, a new concept that emerged in the agricultural landscape has been the homegardens. 


\section{What is "Homegarden"?}

Homegarden is an agroforestry term for any agro-silvo pastoral activities carried out intentionally within one's houselot primarily for food, but also for medicine, side-income and landscape (Mohan, 2004).

Homegardens are unique agroforestry systems. These intensive land-use systems involving the planned management of multipurpose trees and shrubs grown in intimate association with herbaceous species (mainly annual, perennial, and seasonal agricultural crops), and livestock, are all managed within the compounds of individual homes (Fernandes and Nair, 1986 and Mohan, 2004). Homegardens provide both economic and social advantages. They, with their various agricultural crops and trees, accomplish the basic needs of the local population. In addition, homegardens provide economic benefits while remaining ecologically sound and biologically sustainable (Mohan, 2004).

There are the relationship between homegardens and landscape architecture as ecological and visual.

- As ecological, socioeconomic structure, cultural behaviors and personal preferences, seem to be the main characteristics of the appearance, function, and structure of homegardens (Christanty, 1990, Mazumdar and Mazumdar, 2012). The homegardens usually have more various plant canopy types and thus they are more complex than the urban or rural gardens. The crops, ornamental plants and trees planted in a homegarden are carefully arranged to provide for specific functions and benefits, which are primarily economic in nature. The other effects of ecological relation of homegardens to landscape architecture are their complexity of patterns, diversity of plants, naturalness or not and climatic features.

- As visual, generally, the places are where people live and threw the day unwinding. They are focal points combining people with have a range of plant richness and diversity. Most of the time, the people who live in these places is highly valued as a visual riches on offer. Therefore, the characteristic features of each garden include cultural designs (Moreno-Black et al., 1996 and Mohan, 2004).

\section{An application on homegardens in hazelnut plantations}

Homegardening is a traditional agroforestry system where a clearly bounded piece of land immediately surrounding the dwelling house is cultivated with a mixture of perennials and annuals. Can homegardens conserve biodiversity and develop landscape planning in Turkey? This is an important question, given the low forest cover in the country and peoples' high dependency on the natural production systems. The first step in assessing the conservation value of homegardens is to undertake a thorough botanical and structural survey. Total plant diversity measures the direct conservation value of homegardens, while structural features may indirectly conserve other taxa, such as birds, reptiles, amphibians, small mammals, or arthropods (Kabir and Webb 2007, Sunwar et al. 2006, Smith et al. 2006, Peyre et al. 2006, Ali 2005, Blanckaert et al. 2004, Wezel and Bender 2003). Homegardens are 
an integral part of the farming system, an adjunct to the house where selected trees, shrubs and herbs are grown for edible products and cash income (Pandey et al. 2007, Trinh et al. 2003, Ceccolini 2002).

Homegardens are a common feature in Turkey like what they are in many countries, and often exhibit remarkable variability in composition and structure in geographic regions of Turkey. The homegardens in urban in the Black Sea region in Turkey related to urban-rural are basically the determiners to form the urban and regional landscape patterns. In this region, the homegardens having minimal and limited area, the importance and functions with effective systems contains mainly the hazelnut (Corylus avellena) and tea (Camelia chinensis) plantations. The hazelnut plantations are more common than the other agricultural crops in Northern Black Sea Region of Turkey especially in Trabzon.

\subsection{Material and methods}

\section{Study Area}

This stage has been carried out within the city of Trabzon, in the northeastern Black Sea Region of Turkey (401330N-411070N; 371070E-401300E UTM) (Figure 1-2). The city of Trabzon, which covers an area of approximately $4.685 \mathrm{~km} 2$, has a population about 283.233 inhabitants making it the third largest principal city in the region (Anonymous 2008).

The aim of this study is to determine the potential of contributions of landscape planning and designing of the homegardens in Trabzon city of Turkey. Therefore, the hazelnut plantations were evaluated in Trabzon city.

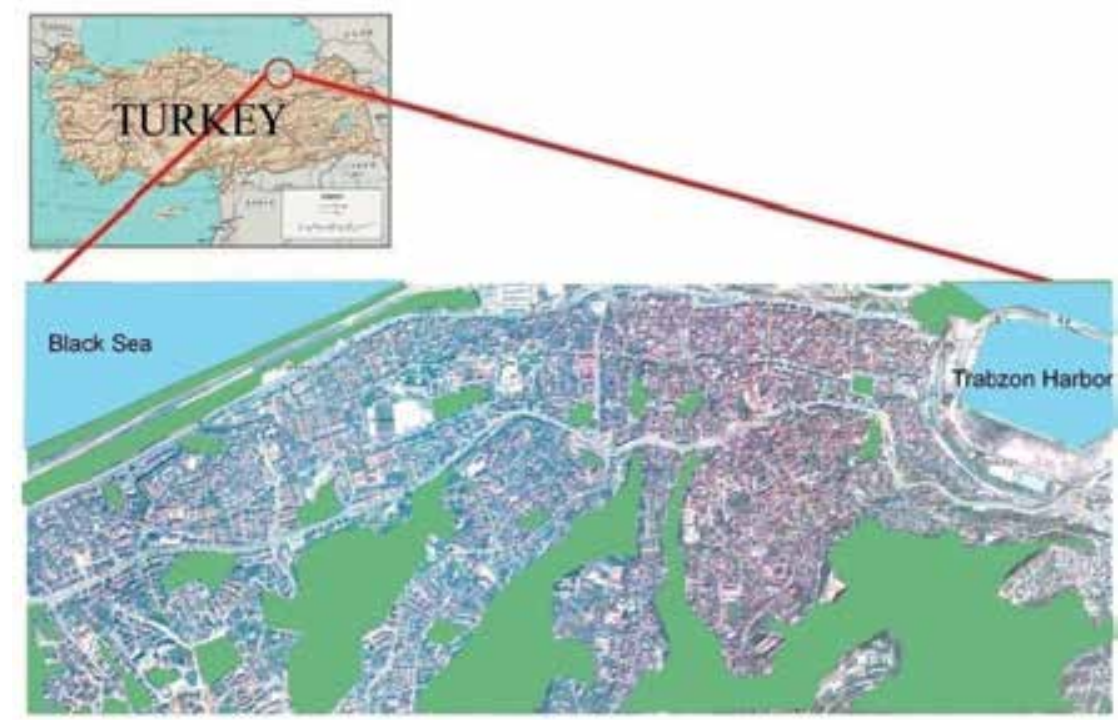

The Big Green Areas in Trabzon City Center

Figure 1. Study Area 


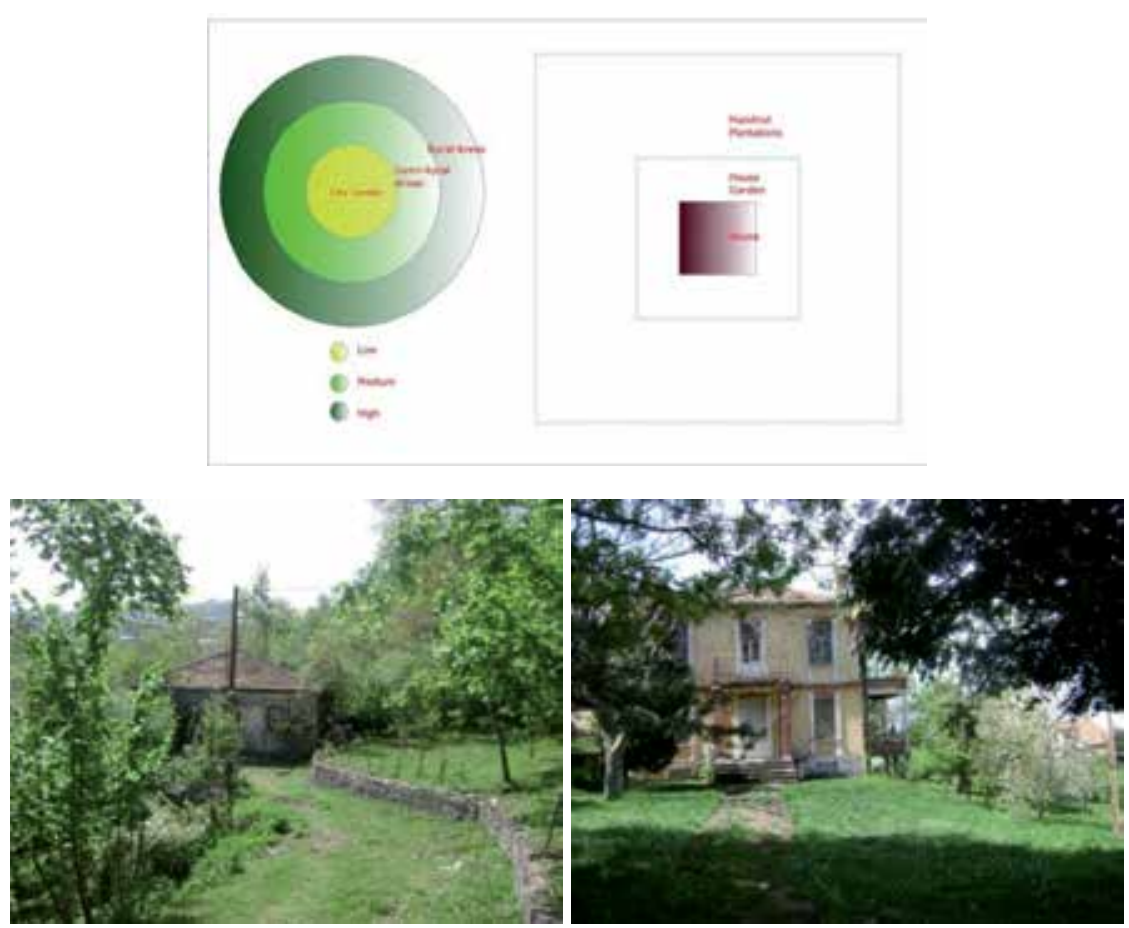

Figure 2. Disturbutions of Home Gardens and Some of the Homegardens in Trabzon City

\section{Methods}

In this study, about 30 homegardens having hazelnut plantations (Figure 3) around Trabzon were examined and plants being in these gardens were identified (Acar et al. 2007 and Tokul 2001) (Table 3).
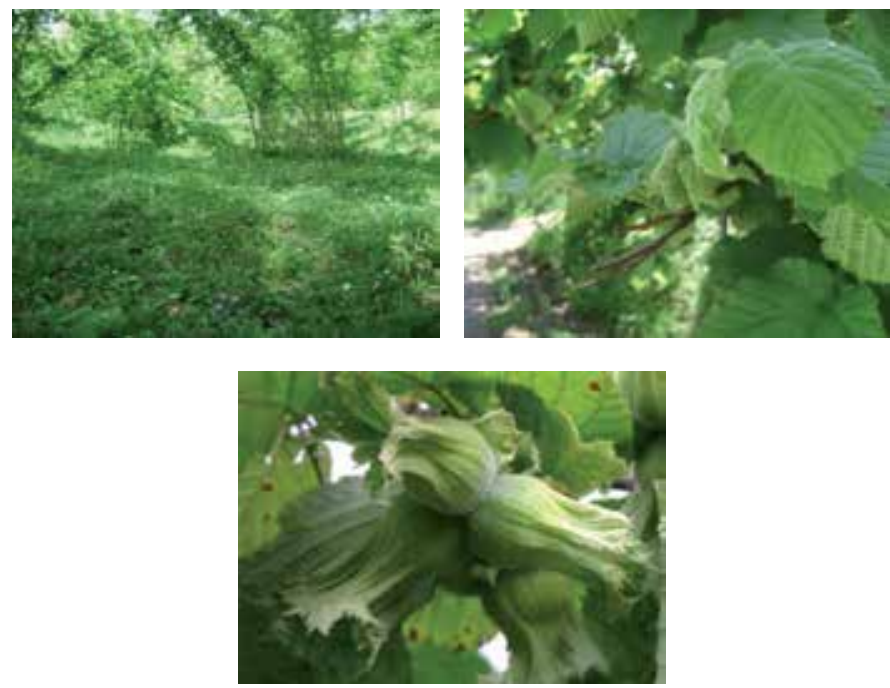

Figure 3. Hazelnut (Corylus avellana) Plantations and Hazelnut Fruits and Leaves 


\subsection{Results}

Turkey has 9 cultivated Corylus avellana taxa and they are named differently by the indigenous people (Anonymous 2007).

The species near the borders, in deeper sides and under the hazelnut plants in the research areas were identified. According to this research, totally 90 annual and biannual species (19 species near the borders, 14 inside and 57 under the hazelnut plants) were identified (Figure 4) (Table 3).

Hazelnut is one of the most important income resources among all agricultural products in Turkey and the country is number one in the list of hazelnut producers with the rate of 72 percent all over the world. Trabzon and its neighborhoods have important hazelnut plantations and most of the green areas in the urban side are these hazelnut fields (Reis, 2003).

Hazelnut plantations also include fruit trees such as Malus sp. (Apple), Prunus sp. (Plum), Pyrus sp. (Pear), Prunus persica (Peach).

Hazelnut fields are on slopes of the riverbanks in general, especially because of the geography of the Black Sea Region. Indigenous people in the area plant some trees to conserve their hazelnut fields and to make the borders of neighborhoods clear (Table 3).

\begin{tabular}{|c|c|c|c|c|c|c|c|c|}
\hline Plant Species & ᄅ્ટ & 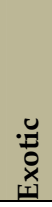 & 奇 & 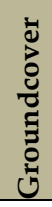 & $\frac{0}{\omega}$ & 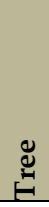 & 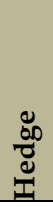 & 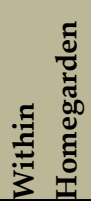 \\
\hline Acer campestre & $x$ & & & & & $x$ & $x$ & \\
\hline Achillea millefolium & $X$ & & & $X$ & & & & \\
\hline Agrimonia eupatoria & $x$ & & & $x$ & & & & \\
\hline Allium сера & $x$ & & & $x$ & & & & \\
\hline Allium porrum & $\mathrm{X}$ & & & $x$ & & & & \\
\hline Alnus glutinosa subsp. glutinosa & $x$ & & & & & $x$ & $x$ & \\
\hline Bellis perennis & $\mathrm{X}$ & & & $\mathrm{X}$ & & & & \\
\hline Brassica oleracea & $x$ & & & $x$ & & & & \\
\hline Capsella bursa-pastoris & $x$ & & & $X$ & & & & \\
\hline Carpinus betulus & $X$ & & & & & $x$ & $x$ & \\
\hline Carpinus orientalis & $x$ & & & & & $x$ & $\mathrm{X}$ & \\
\hline Chaerophyllum aureum & $x$ & & & $x$ & & & & \\
\hline Cirsium arvense & $x$ & & & $x$ & & & & \\
\hline Colchicum speciosum & $x$ & & & $x$ & & & & \\
\hline Cornus mas & $\mathrm{X}$ & & $\mathrm{X}$ & & & & $\mathrm{X}$ & $X$ \\
\hline Cornus sanguinea & $x$ & & & & $x$ & & $x$ & \\
\hline Corylus avellana & $\mathrm{X}$ & & $\mathrm{X}$ & & & & & $\mathrm{X}$ \\
\hline Crataegus monogyna & $\mathrm{X}$ & & & & $x$ & & $\mathrm{X}$ & \\
\hline Cydonia oblonga & & $X$ & & & & & & $X$ \\
\hline Dactylorhiza euxina & $\mathrm{X}$ & & & $X$ & & & & \\
\hline
\end{tabular}




\begin{tabular}{|c|c|c|c|c|c|c|c|c|}
\hline Plant Species & 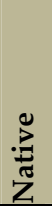 & 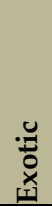 & 志 & 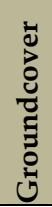 & क & ฆ & 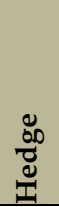 & 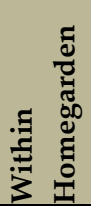 \\
\hline Daucus corota & $x$ & & & $\mathrm{X}$ & & & & \\
\hline Diospyros kaki & $X$ & & $X$ & & & & & $X$ \\
\hline Diospyros lotus & $x$ & & $x$ & & & & & $X$ \\
\hline Dryopteris dilotata & & & & $x$ & & & & \\
\hline Echium vulgare & $X$ & & & $X$ & & & & \\
\hline Euphorbia peplis & $x$ & & & $x$ & & & & \\
\hline Fagus orientalis & $x$ & & & & & $\mathrm{X}$ & $\mathrm{X}$ & \\
\hline Ficus carica & $X$ & & $X$ & & & & & $X$ \\
\hline Fragaria vesca & $\mathrm{X}$ & & & $x$ & & & & $X$ \\
\hline Fraxinus exelcior & $\mathrm{X}$ & & & & & $\mathrm{X}$ & $\mathrm{X}$ & $X$ \\
\hline Galeobdelon luteum & $x$ & & & $x$ & & & & \\
\hline Galium aparine & $X$ & & & $X$ & & & & \\
\hline Geranium purpureum & $x$ & & & $\mathrm{X}$ & & & & \\
\hline Hedera helix & $x$ & & & $\mathrm{X}$ & & & & $X$ \\
\hline Helleborus orientale & $x$ & & & $x$ & & & & $X$ \\
\hline Heracleum apiifolium & $X$ & & & $X$ & & & & \\
\hline Hypericum perforatum & $x$ & & & $x$ & & & & \\
\hline Lamium purpureum & $X$ & & & $X$ & & & & \\
\hline Laurocerasus officinalis & $x$ & & $\mathrm{X}$ & & & & $\mathrm{X}$ & $X$ \\
\hline Lysimachia verticillaris & $\mathrm{X}$ & & & $X$ & & & & \\
\hline Malus sylvestris & & $\mathrm{X}$ & $\mathrm{X}$ & & & & & $X$ \\
\hline Mercurialis perennis & $x$ & & & $x$ & & & & \\
\hline Myosoton aquaticum & $x$ & & & $x$ & & & & \\
\hline Nasturtium officinale & $x$ & & & $x$ & & & & \\
\hline Ostrya carpinifolia & $x$ & & & & & $\mathrm{X}$ & $x$ & \\
\hline Phaseolus vulgaris & $x$ & & & $x$ & & & & \\
\hline Phytolacca americana & $x$ & & & $x$ & & & & \\
\hline Picea orientalis & $x$ & & & & & $\mathrm{X}$ & $\mathrm{X}$ & $X$ \\
\hline Pimpinella rhodantha & $x$ & & & $x$ & & & & \\
\hline Pisum sativum & $x$ & & & $x$ & & & & \\
\hline Plantago major & $x$ & & & $\mathrm{X}$ & & & & \\
\hline Platanus orientalis & $x$ & & & & & $\mathrm{X}$ & $x$ & $X$ \\
\hline Polygala major & $x$ & & & $x$ & & & & \\
\hline Polygonum aviculare & $x$ & & & $\mathrm{X}$ & & & & \\
\hline Populus nigra & $x$ & & & & & $\mathrm{X}$ & $\mathrm{X}$ & $X$ \\
\hline Primula vulgaris & $x$ & & & $x$ & & & & \\
\hline Prunus avium & & $x$ & $x$ & & & & & $X$ \\
\hline Prunus cherry & & $x$ & $X$ & & & & & $X$ \\
\hline Prunus domestica & & $\mathrm{X}$ & $x$ & & & & & $X$ \\
\hline Prunus persica & & $x$ & $x$ & & & & & $x$ \\
\hline Pyrus sylvestris & & $x$ & $x$ & & & & $x$ & $X$ \\
\hline
\end{tabular}




\begin{tabular}{|c|c|c|c|c|c|c|c|c|}
\hline Plant Species & 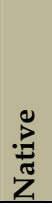 & 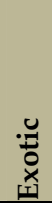 & 茞 & 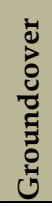 & क & 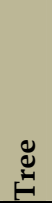 & 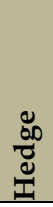 & 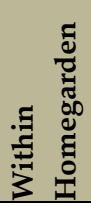 \\
\hline Quercus hartwissiana & $x$ & & & & & $x$ & $x$ & \\
\hline Ranunculus constantinopolitanus & $x$ & & & $x$ & & & & \\
\hline Raphanus raphanistrum subsp. Raphanistrum & $x$ & & & $X$ & & & & \\
\hline Rhinanthus angustifolius & $x$ & & & $x$ & & & & \\
\hline Rosa canina & $x$ & & & & $\mathrm{x}$ & & $x$ & \\
\hline Rubus fruticosus & $x$ & & & & $X$ & & $x$ & \\
\hline Rumex acetosella & $\mathrm{X}$ & & & $\mathrm{X}$ & & & & \\
\hline Rumex pulcher & $X$ & & & $X$ & & & & \\
\hline Ruscus acuelatus & $x$ & & & $x$ & & & & \\
\hline Salvia glutinosa & $\mathrm{X}$ & & & $x$ & & & & \\
\hline Sambucus ebulus & $x$ & & & $\mathrm{X}$ & & & & \\
\hline Sambucus nigra & $X$ & & & & $\mathrm{X}$ & & $\mathrm{X}$ & \\
\hline Scrophularia nodosa & $X$ & & & $X$ & & & & \\
\hline Senecio vulgaris & $x$ & & & $\mathrm{X}$ & & & & \\
\hline Stachys sp. & $\mathrm{X}$ & & & $\mathrm{X}$ & & & & \\
\hline Stelleria media & $X$ & & & $X$ & & & & \\
\hline Tanacetum parthenium & $x$ & & & $x$ & & & & \\
\hline Taraxacum crepidiforme & $x$ & & & $x$ & & & & \\
\hline Trachytemon orientalis & & & & $x$ & & & & \\
\hline Trifolium pratense & $x$ & & & $x$ & & & & \\
\hline Trifolium repens & $x$ & & & $X$ & & & & \\
\hline Tussilaga farfara & $x$ & & & $x$ & & & & \\
\hline Ulmus minor & $x$ & & & & & $\mathrm{X}$ & $x$ & $X$ \\
\hline Veronica officinalis & & & & $X$ & & & & \\
\hline Vicia cracca & $X$ & & & $X$ & & & & \\
\hline Vinca major & $X$ & & & $X$ & & & & \\
\hline Vitis sp. & & $x$ & $x$ & & & & & $x$ \\
\hline Zea mays & $x$ & & & $x$ & & & & \\
\hline
\end{tabular}

Table 3. Plant Species in Home Gardens (Hazelnut Plantations) of Trabzon City

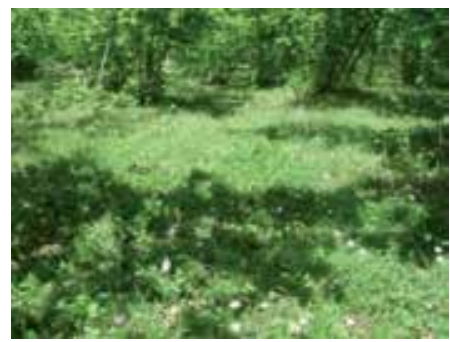

Ground cover compositions

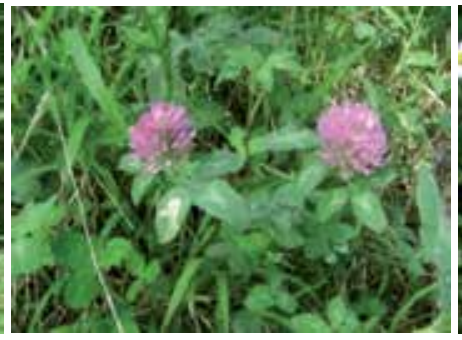

Trifolium repens

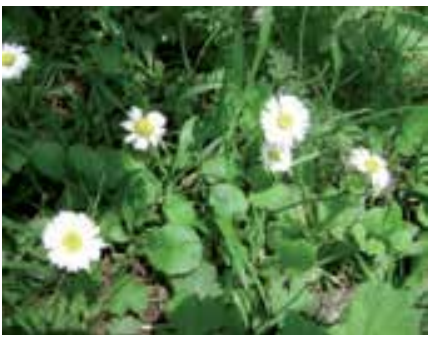

Bellis perennis 


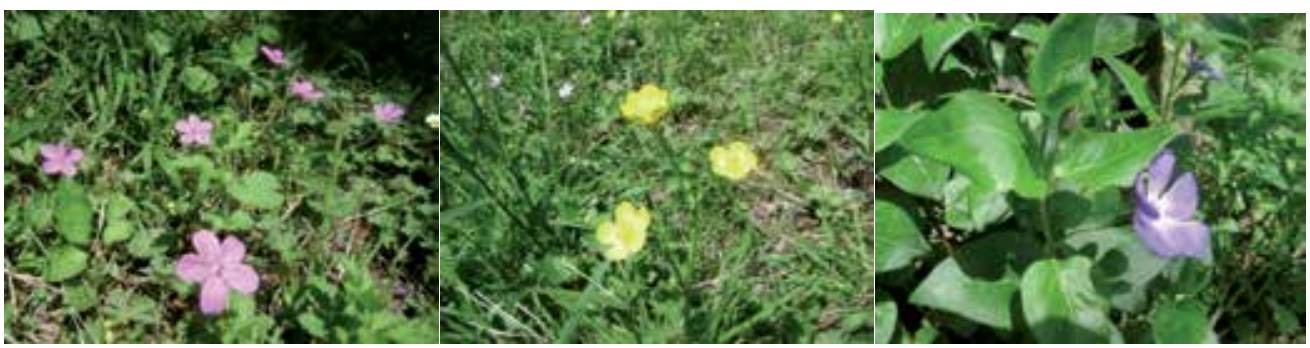

Geranium purpureum

Ranunculus constantinopolitanus

Vinca major

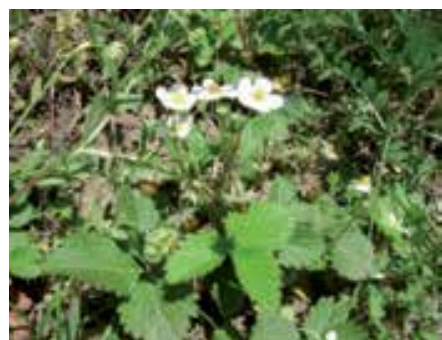

Fragaria vesca

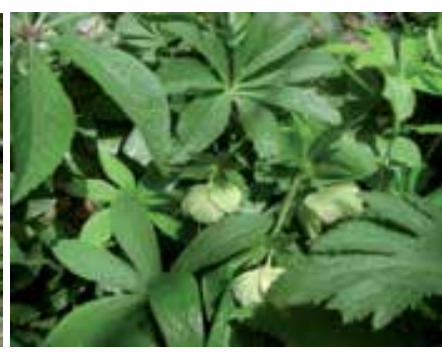

Helleborus orientale

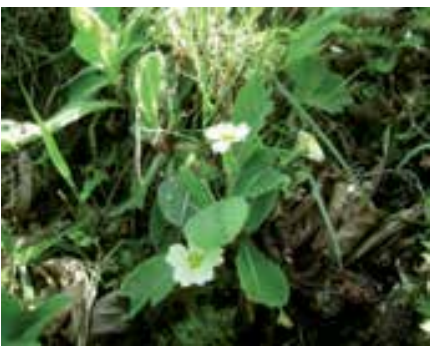

Primula vulgaris

Figure 4. Some of the Ground Covers Under the Hazelnut Plantations

\section{Conclusions}

The results of this study can be given the following items.

- Hazelnut plantations are very important income resources for the indigenous people.

- The homegardens having hazelnut plantations are the most dominate open green areas in and around Trabzon city.

- Some agricultural products such as hazelnut, tea etc. creates habitats for some other plants, which makes a serious contribution to biodiversity in urban areas.

- It is easy to claim that hazelnut fields are useful to get some fruits at the same time. That is the reason that hazelnut plantations should be supported for agroforestry studies.

- Homegardens contributes to floral diversity of landscape architecture with owned plant biodiversity.

- Especially, agricultural landscapes have different visual preferences affect people as visual effects. In this context, their diversity of size, color, texture, form effect on and visual state of landscape.

- Agricultural landscapes are in the landscape ecology concepts as patch and matrix (Forman, 1983, Forman and Godron 1986, Forman, 1995). According to Eroğlu, 2012, plant compositions that created by agricultural patches are important landscape element both visually and ecologically. Therefore, homegardens are important ecological patches and landscape elements. 
- Homegardens and agricultural landscapes are to consider landscape components with their visual and ecological potentials in optimal land use planning, landscape development plans, development plans, landscape plans and local levels in terms of design applications.

Homegardens include some cultural features such as plant material, planting style, agricultural applications and architectural structure. In order to evaluated tothese characteristics in tourism and tourism planning, they must be investigated and explored.

\section{Author details}

Engin Eroğlu

Düzce University, Faculty of Forestry, Department of Landscape Architecture, Düzce, Turkey

Cengiz Acar

Karadeniz Technical University, Faculty of Forestry, Department of Landscape Architecture, Trabzon, Turkey

İbrahim Turna

Karadeniz Technical University, Faculty of Forestry, Department of Forest Engineering, Trabzon, Turkey

\section{References}

Acar, C., Acar, H., Eroğlu, E. (2007). Evaluation of Ornamental Plant Resources to Urban Biodiversty and Cultural Changing; A Case Study of Residential Landscapes in Trabzon City (Turkey). Building and Environment. Vol. 42. Pages. 218-229.

Ali, A.M.S. (2005). Homegardens in Smallholder Farming Systems: Examples From Bangladesh. Human Ecology, Vol. 33, No. 2, April 2005 ( 2005).

Anonymous. (2007). http://www.fındık.com/yetiştiricilik.asf?sayfa=102. (accessed 12 December 2007)

Anonymous. (2008). Trabzon Valiligi, http://www.trabzon.gov.tr/index.htm, 2008 (accessed 10 January 2008).

Atik, M. (2009). Avrupa Birliğinde Doğanın Korunması ve Natura 2000, Türkiye ve Orta Doğu Amme İdaresi Enstitüsü Yayını, No: 354, Yerel Yönetimler Merkezi yayını No: 27, Sayfa: 119-134, Ankara.

Blanckaert, I., Swennen, R.L., Paredes Floresa, M., Rosas, R., Lopeza, R., Saadea, L. (2004). Floristic Composition, Plant Uses and Management Practices in Homegardens of San Rafael Coxcatl!an, Valley of Tehuac!an-Cuicatl!an, Mexico. Journal of Arid Environments 57, 39-62.

Ceccolini, L. (2002). The Homegardens of Soqotra Island, Yemen: An Example of Agroforestry Approach to Multiple Land-Use in an Isolated Location. Agroforestry Systems 56: 107-115, 
Çepel, N. (1990). Ekolojik Terimler Sözlügü. İstanbul Üniversitesi Orman Fakültesi Yayınları, 3048, ISBN 975-404-195-4, İstanbul.

Christanty, L. (1990). Homegardens in Tropical Asia, with Special Reference to Indonesia. Homegardens in Tropical America: A Review. In: K. Landauer, K and Brazil,M (eds.), Tropical Homegardens, pp 9-20. United Nations University Press, Tokyo, Japan.

Council of Europe, (2000). European Landscape Convention, Council of Europe, Strasbourg. EC, (2012). European Commission, Agricultural and Rural Development, Brussels.

Fernandes, E.C.M., Nair, P.K.R. (1986). An Evaluation of the Structure and Function of Tropical Homegardens. Agricultural Systems 21:279-310.

Forman, R.T.T., Godron, M., (19869. Landscape Ecology, Wiley, New York.

Forman, R.T.T. (1983). Corridors in a Landscape: Their Ecological Structure and Function, Ekologia (Czechoslovakia CSSR), 2,375-387.

Forman, R.T.T. (1995). Land Mosaics Ecology of Landscape and Region, Cambridge University Pres, Cambridge, U.K.

Gökalp, D.D., Yazgan, E.M. (2013). Kırsal Peyzaj Planlamada Agroturizm ve Agriturizm. KMÜ Sosyal ve Ekonomik Araştirmalar Dergïsi 15 (24): 25-29, ISSN: 1309-9132.

Kabir, E., Webb, E.L. (2008). Can Homegardens Conserve Biodiversity in Bangladesh? Biotropica 40(1): 95-103 2008.

Karahan, F., Orhan, T. (2008). Uzundere Vadisi Tarımsal Faalietlerinin Peyzaj Çeşitliliğine Etkileri. Alınteri, 15(B), 26-32, ISSN: 1307-3311.

Mazumdar, S., Mazumdar, S. (20129. Immigrant Home Gardens: Places of Religion, Culture, Ecology, and Family. Landscape and Urban Planning 105 (2012) 258-265.

Mohan, S. (2004). An Assessment of the Ecological and Socioeconomic Benefits Provided By Homegardens: A Case Study of Kerala, India. A Dissertation Presented to the Graduate School of the University of Florida in Partial Fulfillment of the Requirements for the Degree of Doctor of Philosophy. University of Florida.

Moreno-Black, G., Somnasang, P., Thamathawan, S. (1996). Cultivating Continuity and Creating Change: Women's Home Garden Practices in Northeastern Thailand. Agriculture and Human Values 13: 3-11.

Pandey C.B., Rai, R.B., Singh, L., Singh. A.K. (2007). Homegardens of Andaman and Nicobar, India. Agricultural Systems 92,1-22.

Peyre, A., Guidal A., Wiersum. K.F., Bongers, F. (2006). Dynamics of Homegarden Structure and Function in Kerala, India. Agroforestry Systems (2006) 66:101-115.

Reis, S. (2003). Çevresel Planlamalara Altlık Bir Coğrafi Bilgi Sistemi Tasarımı ve Uygulaması: Trabzon İl Bilgi Sistemi (TİBIS) Modeli", Doktora Tezi, D: Yomralığlu T., KTÜ Fen Bilimleri Enstitüsü Jeodezi ve Fotog. Müh., s.1-181, Trabzon.

Smith, R.M., Philp H.W., Ken,T., Kevin J.G. (2006). Urban Domestic Gardens (VI): Environmental Correlates of Iinvertebrate Species Richness. Biodiversity and Conservation.15:2415-2438.

Sunwar, S., Gustaf, T.C.M, Subedi, A., Bystrom, M. (2006). Homegardens in Western Nepal: Opportunities and Challenges for on-farm Managementof Agrobiodiversity. Biodiversity and Conservation (2006) 15:4211-4238. 
Tokul, A. (2001). Şalpazarı-Ağasar Deresi Havzası Tarım Arazileri ile Orman Vejetasyonunun Floristik Yönden Karşılaştırılması. KTÜ Orman Fakültesi Orman Müh. Bölümü, Orman Botaniği ABD. Bitirme Tezi, Trabzon.

Trinh, L.N., Watson, J.W., Huec, N.N., Ded, N.N., Minhe, N.V., Chuf, P., Sthapit, B.R., Eyzaguirre, P.B. (2003). Agrobiodiversity Conservation and Development in Vietnamese Home gardens. Agriculture, Ecosystems and Environment 97 317-344.

Turna, İ. (2012). Tarımsal Ormancılık Ders Notları. KTÜ Orman Fakültesi Orman Mühendisliği Bölümü Silvikültür Anabilim Dalı, Trabzon.

Wezel, A., Bender, S. (2003). Plant Species Diversity of Homegardens of Cuba and Its Significance for Household Food Supply. Agroforestry Systems 57: 39-49, 2003. 


\title{
Role of Ecotourism in Sustainable Development
}

\author{
Tuğba Kiper
}

Additional information is available at the end of the chapter

http://dx.doi.org/10.5772/55749

\section{Introduction}

Ecotourism is a sub-component of the field of sustainable tourism. Ecotourism's perceived potential as an effective tool for sustainable development is the main reason why developing countries are now embracing it and including it in their economic development and conservation strategies. Ecotourism, as an alternative tourism, involves visiting natural areas in order to learn, to study, or to carry out activities environmentally friendly, that is, a tourism based on the nature experience, which enables the economic and social development of local communities. It focuses primarily on experiencing and learning about nature, its landscape, flora, fauna and their habitats, as well as cultural artifacts from the locality. A symbiotic and complex relationship between the environment and tourist activities is possible when this philosophy can be translated into appropriate policy, careful planning and tactful practicum. Carefully planned and operated ecotourism sites, especially if it is village-based and includes local participation, is able to provide direct benefits that might offset pressure from other less sustainable activities that make use of natural and cultural resources. Eco tourism, natural resources, cultural heritage, rural lifestyle and an integrated tourism is a type of local economic activities. Therefore, ecotourism in naturel and cultural areas was carried out with a number of elements in their natural landscape and cultural landscape (water, vista, topography, vegetation, clean air), as well as in the variety of recreational activities suitable for all kinds of environments. Therefore, ecotourism and its natural assets and raw materials to create, as well as directing people to travel is an attractive force.

Ecotourism helps in community development by providing the alternate source of livelihood to local community which is more sustainable. Its aim is to conserve resources, especially biological diversity, and maintain sustainable use of resources, which an bring ecological experience to travelers, conserve the ecological environment and gain economic benefit. However, achieving the aims in ecotourism depends on whether they are environmentally and ecologically sustainable and economically applicable. Ecotourism 
helps in involving local community for the conservation of the ecology and biodiversity of the area that biodiversity in return provides the economic incentives to the local community. Eco-tourism contributes to conservation of biodiversity; sustains the well-being of local people; involves responsible action on the part of tourist and the tourism industry; promotes small and medium tourism enterprises; requires lowest possible consumption of natural resources; stresses local participation, ownership, and business opportunities, particularly for rural people; and above all includes the learning experiences.

In order for ecotourism to encourage patterns of sustainability, which can benefit local communities, protect the environment, and be economically viable, it must be comprehensive and account for the complexity of issues that have been mentioned in this paper.

This chapter has revealed that there is a need for sustainable development in tourism, and the connection between tourism and environment is much stronger than in other sectors. Ecotourism must account for social, economic and environmental implications, in order to succeed. The purpose of this study look at ways in which ecotourism and sustainable development can be evaluated; and suggest ways to improve current ecotourism practices. In parallel with this purpose, it was aimed at looking for an answer to questions of: What is Ecotourism? "What might be the effects of ecotourism?" What are the impacts and challenges of ecotourism? What are the possible benefits that ecotourism can bring? Within this scope, we focused on ecotourism's definition, its objectives, the reasons of its emergence and development, its principles, its types, its environmental, social and economic impacts; ecotourism and sustainable development and on the examination of approaches to ecotourism in Turkey and Europe.

In this section, the subjects below will be discussed.

- Introduction

- What is ecotourism and its types?

- What is sustainable development?

- Ecotourism and environmental, social and economic impacts

- Ecotourism and sustainable development relationship

- Ecotourism - examples of implementation

- Conclusion

\section{What is ecotourism and its types?}

Ecotourism, a unique subset of the tourism industry, is ,focused on the enhancement or maintenance of natural systems through tourism. Ecotourism means different things to different people. To some, it is the general term that encompasses nature-based, adventure, soft adventure, and cultural tourism. The term ecotourism was coined in 1983 by "Hctor Ceballos Lascurain" a Mexican environmentalist, and was initially used to describe naturebased travel to relatively undisturbed areas with an emphasis on education. Ecotourism guarantees the sustainable use of environmental resources, while generating economic 
opportunities for the local people (Farrell \& Runyan 2001; Bhattacharya, Chowdhury and Sarkar, 2011).

Ecotourism itself is meant to be a sustainable form of natural resource-based tourism. Even though ecotourism lacks a concrete definition, there are many wellrecognized definitions that have formed a clear picture of its core principles, which are shown in Table 1.

\begin{tabular}{|c|c|}
\hline $\begin{array}{l}\text { Ceballos Lascurain (1987) } \\
\text { (Joshi, 2011) }\end{array}$ & $\begin{array}{l}\text { Ecotourism is defined as travelling to relatively } \\
\text { undisturbed natural areas with specific objective of } \\
\text { studying, admiring and enjoying scenery and its wild } \\
\text { animals and plants as well as existing. }\end{array}$ \\
\hline $\begin{array}{l}\text { Conservation } \\
\text { International (Ziffer, 1989). }\end{array}$ & $\begin{array}{l}\text { A form of tourism inspired primarily by the natural history } \\
\text { of an area, including its indigenous cultures. The ecotourist } \\
\text { visits relatively undeveloped areas in the spirit of } \\
\text { appreciation, participation and sensitivity. The ecotourist } \\
\text { practices a non-consumptive use of wildlife and natural } \\
\text { resources and contributes to the visited areas through labor } \\
\text { or financial means aimed at directly benefiting the } \\
\text { conservation of the site and the economic well-being of the } \\
\text { local residents. }\end{array}$ \\
\hline $\begin{array}{l}\text { The National Ecotourism } \\
\text { Strategy (1994) (QuickStart } \\
\text { Guide to a Tourism Business, } \\
\text { 2006) }\end{array}$ & $\begin{array}{l}\text { Ecotourism is nature based tourism that involves education } \\
\text { and interpretation of the natural environment and is } \\
\text { managed to be ecologically sustainable. } \\
\text { This definition recognises that 'natural environment' } \\
\text { included cultural components and that 'ecologically } \\
\text { sustainable' involves an appropriate return to the local } \\
\text { community and long term conservation of the resource. }\end{array}$ \\
\hline McCormick, 1994 & $\begin{array}{l}\text { Purposeful travel to natural areas to understand the culture } \\
\text { and natural history of the environment, taking care not to } \\
\text { alter the integrity of the ecosystem, while producing } \\
\text { economic opportunities that make the conservation of } \\
\text { natural resources beneficial to local people }\end{array}$ \\
\hline $\begin{array}{l}\text { World } \\
\text { Conservation } \\
\text { Union (Brandon, 1996) }\end{array}$ & $\begin{array}{l}\text { Environmentally responsible travel and visitation to } \\
\text { relatively undisturbed natural areas, in order to enjoy and } \\
\text { appreciate nature that promotes conservation, has low } \\
\text { negative visitor impact, and provides for beneficially active } \\
\text { socio-economic involvement of local populations. }\end{array}$ \\
\hline Honey, 1999 & $\begin{array}{l}\text { Travel to fragile, pristine, and usually protected areas that } \\
\text { strive to be low impact and (usually) small scale. It helps } \\
\text { educate the traveler; provides funds for conservation; } \\
\text { directly benefits the economic development and political } \\
\text { empowerment of local communities; and fosters respect for } \\
\text { different cultures and for human rights. }\end{array}$ \\
\hline
\end{tabular}




\begin{tabular}{|l|l|}
\hline Weaver, 1999 & $\begin{array}{l}\text { Interest in ecotourism, now widespread among tourism } \\
\text { planners and marketers, is rationalized by a number of } \\
\text { popular assumptions regarding the sector's potential } \\
\text { economic, environmental, and socio-cultural benefits }\end{array}$ \\
\hline Weaver, 2001 & $\begin{array}{l}\text { Ecotourism is a form of tourism that fosters learning } \\
\text { experiences and appreciation of the natural environment, } \\
\text { or some component thereof, within its associated cultural } \\
\text { context' }\end{array}$ \\
\hline
\end{tabular}

Table 1. Definitions of ecotourism

The (International) Ecotourism Society in 1990: Responsible travel to natural areas that conserves the environment and improves the well-being of local people in 1996 by the World Conservation Union (IUCN) which describes ecotourism as: Environmentally responsible travel and visitation to natural areas, in order to enjoy and appreciate nature (and any accompanying cultural features, both past and present) that promote conservation, have a low visitor impact and provide for beneficially active socio-economic involvement of local peoples (Joshi, 2011)

Ecotourism tries to raise environmental consciousness by exploring ecology and ecosystems and by providing environmental type experiences. Taking part in ecology actively and getting first hand impressions of how ecosystems work influence peoples' ways of thinking, which finally raises awareness of conservation and protection (Ecotourism - Sustainable Tourism in National Parks and Protected Areas, 2005).

According to Patterson (2002), characteristics of an ecotourism business are that it:

- Have a low impact upon a protected area's natural resources and recreation techniques.

- Involve stakeholders (individuals, communities, ecotourists, tour operators and government institutions) in the planning, development, implementation and monitoring phases

- Limits visitation to areas, either by limiting group size and/or by the number of groups taken to an area in a season

- Supports the work of conservation groups preserving the natural area on which the

- experience is based.

- Orients customers on the region to be visited.

- Hires local people and buys supplies locally, where possible.

- Recognizes that nature is a central element to the tourist experience.

- Uses guides trained in interpretation of scientific or natural history.

- Ensures that wildlife is not harassed.

- Respects the privacy and culture of local people.

According to Chesworth (1995), Ecotourism has six characteristics. These are: a) ecotourism involves travel to relatively undisturbed natural areas and/or archeological sites, b) it focuses on learning and the quality of experience, c) it economically benefits the local communities, d) ecotourists seek to view rare species, spectacular landscapes and/or the unusual and exotic, e) ecotourists do not deplete resources but even sustain the environment 
or help undo damage to the environment, and f) ecotourists appreciate and respect local culture, traditions, etc.

It focuses primarily on experiencing and learning about nature, its landscape, flora, fauna and their habitats, as well as cultural artifacts from the locality. A symbiotic and complex relationship between the environment and tourist activities is possible when this philosophy can be translated into appropriate policy, careful planning and tactful practicum (Rahman, 2010).

While the details vary, most definitions of eco-tourism boil down to a special form of tourism that meets three criteria:

- it provides for environmental conservation;

- it includes meaningful community participation;

- $\quad$ it is profitable and can be self-sustained

As shown in Fig 1, there is just a thin line of differentiation between sustainable tourism and ecotourism, which also shows that there is as such no absolute boundary between sustainable and unsustainable tourism (Eriksson, 2003). According to Weaver (2001); Ecotourism exists within the broader classification of tourism types which, at an initial level, can be divided into 'mass tourism' and 'alternative tourism' (Figure 1). Mass tourism is seen as the more traditional form of tourism development where short-term, freemarket principles dominate and the maximization of income is paramount. The differences between mass tourism and ecotourism are shown in Table 2.

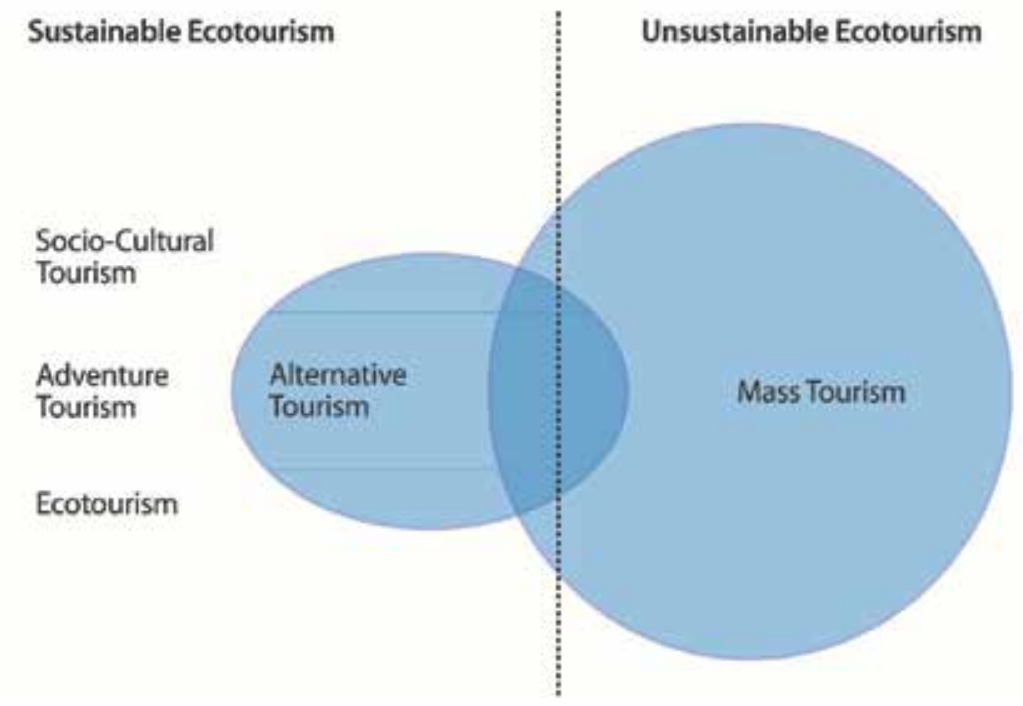

Figure 1. Conceptual model of tourism (Eriksson,2003)

Ecotourism as a very specific form is part of the broad concept of nature-based tourism, or it can be said that ecotourism describes a nature-based operation in the field of tourism. "The most obvious characteristic of Ecotourism is that it is nature based" Figure 2 (Weaver (2001); 


\begin{tabular}{|c|c|}
\hline Characteristics of mass tourism. & Characteristics of ecotourism \\
\hline Large groups of visitors & Small groups of visitors \\
\hline Urban & Rural \\
\hline Touristic general marketing activities & Eco-marketing activities. \\
\hline $\begin{array}{l}\text { Average prices for purposes of market } \\
\text { penetration }\end{array}$ & $\begin{array}{l}\text { High price with purpose of filtering the } \\
\text { market }\end{array}$ \\
\hline Impact on natural environment & Little impact on the natural environment \\
\hline Advanced control options & Limited possibilities of control \\
\hline $\begin{array}{l}\text { Management based on macroeconomic } \\
\text { principles }\end{array}$ & $\begin{array}{l}\text { Management based on local economic } \\
\text { principles }\end{array}$ \\
\hline $\begin{array}{l}\text { Anonymous relationship between visitors and } \\
\text { local community }\end{array}$ & $\begin{array}{l}\text { Personalized relationships between visitors } \\
\text { and } \\
\text { local community }\end{array}$ \\
\hline General development goals & Local development objectives \\
\hline $\begin{array}{l}\text { Behavior-oriented leisure } \\
\text { activities/entertainment, opponents to } \\
\text { education and training actions }\end{array}$ & $\begin{array}{l}\text { Loyalty in the process of training and } \\
\text { education for appropriate conduct for the } \\
\text { natural environment }\end{array}$ \\
\hline Intensive development of tourism facilities & Reduced development of tourism facilities \\
\hline
\end{tabular}

Table 2. Distinct characteristics between mass tourism and ecotourism (Dorobantu \& Nistoreanu, 2012)

\section{TOURISM}

Mass Tourism - large numbers of people seeking replication of their own culture in institutionalised settings.

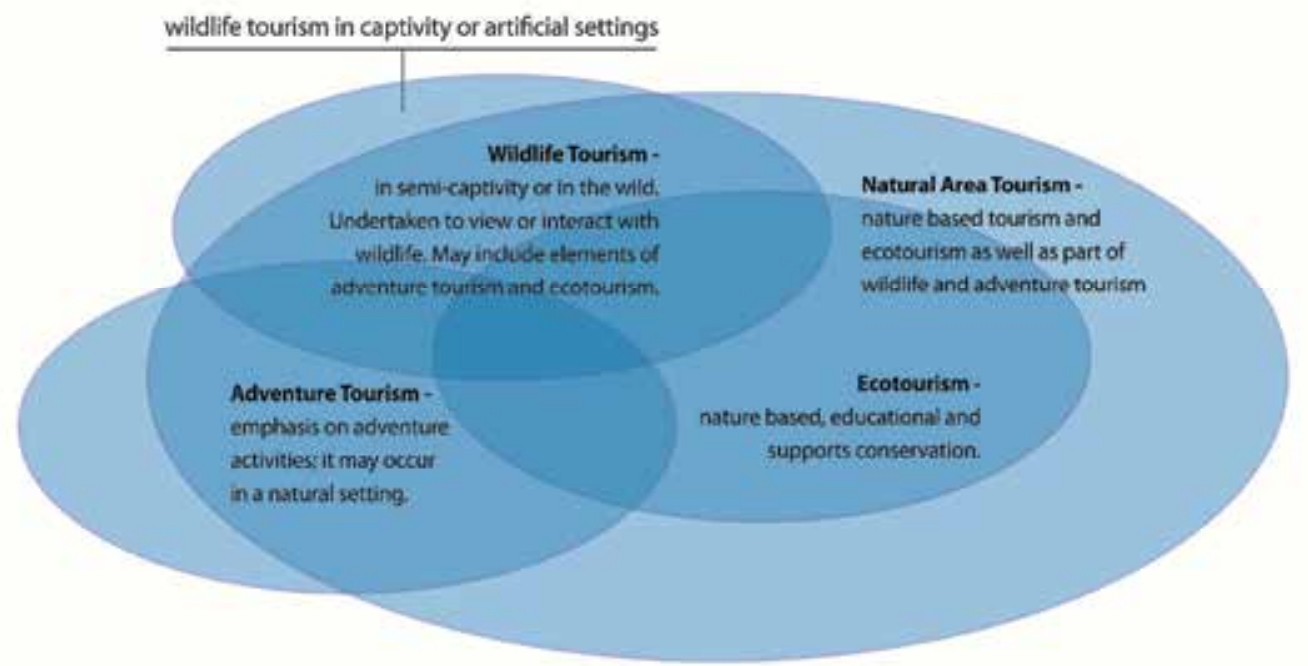

Alternative Tourism - forms of tourism generally characterised by small scale sustainable activities.

Figure 2. Relationship of ecotourism to other forms of tourism (Hill \& Gale, 2009) 
Adventure tourism is defined as: "an outdoor leisure activity that takes place in an unusual, exotic, remote or wilderness destination, involves some form of unconventional means of transportation, and tends to be associated with low or high levels of activity" (Fennel \& Dowling, 2003). According to this definition of adventure tourism and to that of ecotourism as previously stated, it seems that there are many overlapping concepts.

Ecotourism is a component of sustainable tourism. In many ways, sustainable tourism exemplifies the relationship between ecotourism and sustainable development (Sâmbotın et al., 2011; Bansal \& Kumar, 2011);

Sustainable tourism will focus on three areas:

- Quality - valuable experience for visitors and increased life quality for host communities through cultural identity, poverty reduction and environmental quality;

- Continuity - exploitation is made at the optimum level that allows the preservation and regeneration of the natural resources;

- Balance between the needs of tourism industry, environmental protection, and local communities by an equitable distribution of benefits among stakeholders

Standarts of ecotourism (Weaver \& Lawton, 2007);

a. Protection of the Ecosystem

- Maintenance of the ecosystem where the ecotourism attraction is located

- Protection and maintenance of wildlife especially endangered species

- Wildlife live harmoniously with people

b. Maintenance of the physico-chemical conditions of the area

- Maintenance of the quality of fresh water and marine resources

- No wastes overflow and contamination of the environment (water, soil and air)

c. Conservation of local culture and history

- Culture of locality is maintained

- Historical structures are maintained as part of cultural heritage

d. Infrastructures and signboards blend with the environment

e. Sustainability

- Maintenance of Carrying Capacity of the environment;

- Environmental education program is part of the ecotourism package;

- Livelihood must benefit more the local community than outside entrepreneurs;

- The local government supports the ecotourism project through ordinances and resolutions; and

- $\quad$ The Management Board (community-based) and appropriate government agencies, e.g. DENR, support the project through strict enforcement of environmental laws

- Experience and product management should follow principles and practices associated with ecological, socio-cultural and economic sustainability.

Many dimensions clearly emerge from these widely stated definitions including (Matthews, 2002) 
1. Ecotourism occurs in natural areas (most often protected areas) and/or places of unique ecological or cultural interest

2. Ecotourism contributes to conservation or preservation of the natural resources and promotes stewardship of natural and cultural resources.

3. Ecotourism should create necessary funds to promote permanent protection of ecological and socio-cultural resources

4. The local residents accrue economic and social benefits thereby contributing to project's long-term success.

5. Ecotourism incorporates environmental and cultural education.

6. Ecotourism should be effectively managed for the long-term through minimal negative impacts on the host environment.

7. Ecotourism should provide a quality tourism experience.

These principles and standards must be put in place by those who develop ecotourism products, as well as those who plan the development of an area-based ecotourism. In ecotourism branch a special place is given by the marketing concept. The importance of proper marketing is widely recognized throughout the tourism sector that today tourism market has become increasingly segmented over the methods of communication to reach consumers have multiplied and diversified (Boghean \& Boghean, 2006).

\section{What is sustainable development?}

The concept of sustainability first appeared in the public scene in the report put out by the World Commission on Environment and Development (Brundtland Commission) in 1987. The commission report advances the idea of sustainable development by noting that economic growth and environmental conservation are not only compatible but they are necessary partners. One cannot exist without the other (Harris et al., 2002).Sustainable development is high potential for any community within economic, social, cultural, ecologic and physical constraints (Bhuiyan et al., 2012). Sustainable development has been defined in many ways, but the most frequently quoted definition is from Our Common Future, also known as the Brundtland Report:

"Sustainable development is development that meets the needs of the present without compromising the ability of future generations to meet their own needs. It contains within it two key concepts (IISD, 2012):

- The concept of needs, in particular the essential needs of the world's poor, to which overriding priority should be given; and

- The idea of limitations imposed by the state of technology and social organization on the environment's ability to meet present and future needs."

Van der Merwe \& Van der Marwe (1999) add that Sustainable development is a program for changing the process of economic development so that it ensures a basic quality of life for all people and at the same time protects the ecosystems and community systems that make life possible and worthwhile. 
This was the dominant dilemma addressed by the Brundtland Commission which indicated that sustainable development should, as a minimum, address the following elements (Wall, 2007);

- Maintenance of ecological integrity and diversity;

- Meet basic human needs;

- Keep options open for future generations;

- $\quad$ Reduce injustice; and

- Increase self-determination.

It was further suggested that in order for this to occur, it would be necessary to:

- $\quad$ Revive economic growth;

- Change the quality of growth;

- Meet essential needs such as for jobs, food, energy, water and sanitation;

- Conserve and enhance the resource base;

- Reorient technology and manage risk; and

- Merge environment and economics in decision making.

Defined sustainable development as development that meets the needs of the present without compromising the ability of future generations to meet their own needs. It is often called intergenerational equality, the idea is that we should share natural resources not just with people who are alive on the planet today but also with future generations of the earth's inhabitants. Sustainable development integrates economic, social with the aforementioned environmental goals. Sustainability highlights on the resource conservation (Dixon \& Pretorius, 2001; Mebratu, 1998; Jaini, Anuar \& Daim, 2012). Dixon \& Pretorius (2001) cite the International Council for Local Environmental Initiatives (ICLEI), which emphasizes environmental, social and economic concerns as three distinct but interrelated components of sustainable development.

According to Hall (2008) sustainable development and tourism present change which refers to the movement from one state or condition to another. Whether such a transition is positive or negative depends on the original criteria by which change is measured. Sustainable tourism requires the informed participation of all relevant stakeholders, as well as strong political leadership to ensure wide participation and consensus building. Achieving it requires monitoring of impacts, introducing the necessary preventive and/or corrective measures whenever necessary. Sustainable tourism should also maintain a high level of tourist satisfaction and ensure a meaningful experience to the tourists, raising their awareness about sustainability issues and promoting sustainable tourism practices amongst them (World Tourism Organisation, 2001).

Sustainable development through ecotourism is a concerning issue in the world today. Many countries have ensured their regional development by this concept. In this concept, sustainable development may be occurred by the ecotourism and regional development (Figure 3) simultaneously in an area. Dimensions of ecotourism development refer to the environmental, economic, and social aspects of tourism development, and a suitable balance 
between these dimensions must be established to maintain its long-term sustainability (Bhuiyan et al, 2012).

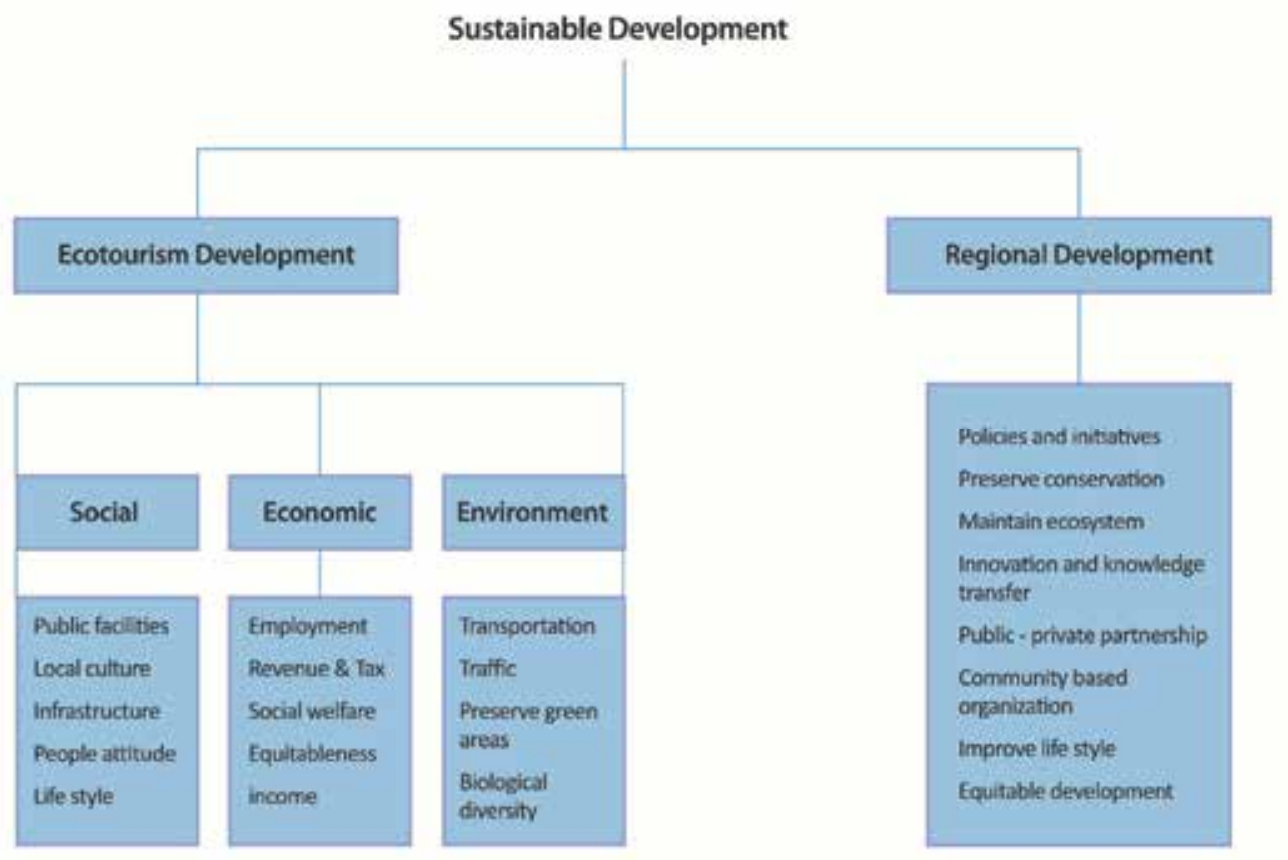

Figure 3. Sustainable development throught ecotourism (Bhuiyan et al., 2012)

\section{Ecotourism and environmental, social and economic impacts}

Tourism can be sustainable if development meets the needs of tourists and local residents while protecting future opportunities. Ecotourism offers benefits for local residents, conservation, development and educationalexperiences. Ecotourism is a sustainable form of natural resource-based tourism. It focuses primarily on experiencing and learning about nature, its landscape, flora, fauna and their habitats, as well as cultural artefacts from the locality (Dowling,1997; Fennell, 1999).

Ecotourism entails a combination of conservation and tourism (the economics related with it) to benefit local communities, especially focusing on sustainability (Myburgh \& Saayman, 2002).

Natural and cultural landscape values form a basis for ecotourism. These values are geographical position, microclimatic conditions, existence of water, natural beauties, existence of natural vegetation, existence of wildlife, surface features, geomorphologic structure, local food, festivals and pageants, traditional agricultural structure, local handicrafts, regional dress culture, historical events and people, heritage appeals, architectural variety, traditional music and folk dance, artistic activities and so on (Gerry, 2001; Lane, 1993, Lanquar, 1995; Soykan, 1999; Briassoulis, 2002, Catibog-Sinha \& Wen, 2008; Mlynarczyk, 2002; Drzewiecki, 2001; Kiper, 2006). 
Ecotourism operates for one or more of the eco-friendly alternatives for the economic use of natural resources compared with mining, hunting, farming and so on (Li, 2006). Ecotourism promotes an enhanced appreciation of natural environments and environmental education by exposing visitors and locals to nature and conservation (Bob et al., 2008).

Ecotourism is largely perceived to safeguard natural areas and thereby to contribute to the conservation of biodiversity. It focuses primarily on experiencing and learning about nature, its landscape, flora, fauna and their habitats, as well as cultural artefacts from the locality. In ecotourism planning the first issue that emerges is the environment and its conservation (Munn, 1992; Ceballos-Lascurain, 1996; Gössling, 1999; Tisdell \& Wilson, 2002; Lindsey et al., 2005; Lopez-Espinosa de los Monteros, 2002; Fung \& Wong, 2007)

An ecotourism destination must in no way be developed without planning in terms of environmental concern (Rahman, 2010). Within the ecotourism implementation existence of water resources creates advantages in terms of both visuality and utilization. Climatic features of a region influence tourism directly and indirectly and play a crucial role in the development of tourism. Plants drawing interest thanks to their size, age or appearance are other appealing components of ecotourism. Flowering plants are important resources in ecoturism. Historical, natural and folkloric values are important sources for ecotourism. According to Soykan, traditional commercial products are one of the most significant appeals leading to development of ecotourism in a region. This is because whole production process from planting to harvest and processing bear cultural differences, and most of them are performed in traditional ways (Kiper, 2011).

Ecotourism has the potential to seriously impact local communities, largely due to the tendency of ecotourists to have a greater interest in the culture and nature of the areas they visit, as compared to mass tourists (McMinn, 1997).

Ecotourism destinations are always environmentally sensitive because ecotourism activities directly involve various environmental phenomena including bird watching, trekking, mountaineering, horse riding and elephant riding within the forest wilderness trail, staying in natural caves, studying about flora and fauna, simple bush walking, fishing, animal behavior study, ecological studies (Rahman,2010). Ecotourism always incorporates various activities in nature (hiking, mountain climbing, observing the living beings in their natural habitat, etc.), but it may include cultural activities, too. Ecotourism is an important educational component, it is a chance to learn respect for nature, for the local culture, and for some it is a chance to self-reflection being inspired by the beauty of the surroundings.

\section{Ecotourism and sustainable development relationship}

Tourism is a highly complex activity and thus requires tools to assist in effective decision making to come to terms with the competing economic, social, and environmental demands of sustainable development (Fadahunsi, 2011). Table 3 indicates some interesting examples of potential risks from tourism activities, which are especially crucial in naturel and culturel areas. 


\begin{tabular}{|c|c|}
\hline Element & Examples of risks from tourism activities \\
\hline Ecosystems & $\begin{array}{l}\text { The construction of accommodation, visitor centres, } \\
\text { infrastructure, and other services has a direct impact on the } \\
\text { environment, from vegetation removal, animal disturbance elimination } \\
\text { of habitats, impacts on drainage etc. } \\
\text { - Wildlife habitat may be significantly changed (travel routes, hunting } \\
\text { areas, breeding areas, etc.) by all kinds of tourist development and use. }\end{array}$ \\
\hline Soils & $\begin{array}{l}\text { - Soil compaction can occur in certain well-used areas. } \\
\text { - Soil removal and erosion also occurs, and may continue after the } \\
\text { disturbance is gone }\end{array}$ \\
\hline Vegetation & $\begin{array}{l}\text { - Concentrated use around facilities has a negative effect on vegetation. } \\
\text { Transportation may have direct negative impacts on the environment } \\
\text { (e.g. vegetation removal, weed transmission, animal disturbance). } \\
\text { Fire frequency may change due to tourists and park tourism } \\
\text { management. }\end{array}$ \\
\hline Water & $\begin{array}{l}\text { - Increased demands for fresh water. } \\
\text { - Disposal of sewage or litter in rivers, lakes or oceans. } \\
\text { - Release of oil and fuel from ships and smaller craft. } \\
\text { Propeller-driven watercraft may affect certain aquatic plants and } \\
\text { species. }\end{array}$ \\
\hline Air & $\begin{array}{l}\text { - Motorised transportation may cause pollution from emissions (from } \\
\text { plane, train, ship or automobile). }\end{array}$ \\
\hline Wildlife & $\begin{array}{l}\text { - Hunting and fishing may change population dynamics. } \\
\text { - Hunters and fishers may demand the introduction of foreign species, } \\
\text { and increased populations of target animals. } \\
\text { - Impacts occur on insects and small invertebrates, from effect of } \\
\text { transportation, introduced species, etc } \\
\text { - Disturbance by visitors can occur for all species, including that are not } \\
\text { attracting visitors. } \\
\text { - Disturbance can be of several kinds: noise, visual or harassing } \\
\text { behaviour. } \\
\text { - The impact can last beyond the time of initial contact (e.g. before heat- } \\
\text { rate returns to normal, or before birds alight, or mammals resume } \\
\text { breeding or eating). } \\
\text { - Marine mammals may be hurt or killed by boat impacts or propeller } \\
\text { cuts. } \\
\text { Habituation to humans can cause changed wildlife behaviour, uch as } \\
\text { approaching people for food. }\end{array}$ \\
\hline
\end{tabular}

Table 3. Potential Risks from Tourism (Ecotourism - Sustainable Tourism in National Parks and Protected Areas, 2005)

Ecotourism has been regarded as a panacea for solving many of the environmental and economic problems of lessdeveloped nations. Yet, regardless of how socially and environmentally responsible ecotourism may be in theory, in practice it remains rooted in 
the tourism industry (Wall, 1997). Similarly, tourism activities generally can create various negative impacts on the surrounding environment. Increased human interference in ecologically fragile areas can cause irreversible change in the existing ecological processes. These problems can be reflected in degrading natural resources, vegetation structure and the size of the habitat patch, increasing deforestation and decreasing upstream water flow (Tourism Queenland, 2002).

Ecotourism is rooted in the concept of sustainable development, as defined by the World Commission on Environment and Development's Brundtland report (1987) (Place, 1995; King \& Stewart, 1992; McMinn, 1997; Stem et al., 2003). According to the emergence of sustainable tourism development it is proven that the milestone for its emergence was the Brundtland Report by the WCED in the year 1987. Previously, many ideas in this field had been developed at the IUCN -The World Conservation Union and referenced in the World Conservation Strategy published in 1980 (Ritchie \& Crouch, 2003). Ecotourism is often perceived as an tool for promoting sustainable development in developing countries. Ecotourism helps in community development by providing the alternate source of livelihood to local community which is more sustainable. Many view ecotourism as a viable way to protect the natural environment and create social and economic benefits for local communities. Ecotourism encompasses a spectrum of nature-based activities that foster visitor appreciation and understanding of natural and cultural heritage and are managed to be ecologically, economically and socially sustainable. Therefore, ecotourism is accepted as an alternative type of sustainable development. Ecotourism has attracted increasing attention in recentyears, not only as an alternative to mass tourism, but also as a means to promote a country's economic development and environmental conservation. Its aim is to conserve resources, especially biological diversity, and maintain sustainable use of resources, which can bring ecological experience to travelers, conserve the ecological environment and gain (Bansal \& Kumar, 2011; Godratollah et al., 2011; Tewodros, 2010). Ecotourism is increasingly being lauded as a sustainable development option for rural communities, one that is able to spur economic development (Vogt, 1997) and instill environmental protection at the same time (Cater, 2002). If the environment has not at least achieved a net benefit toward its sustainability and ecological integrity, then the activity is not ecotourism.

Many groups have proposed sets of guidelines or principles for sustainable tourism and ecotourism. Ecotourism is a sustainable version of tourism in natural areas, including at the same time elements of rural and cultural tourism. Besides subscribing to the principles of sustainable tourism, ecotourism has specific principles: it contributes actively to the conservation of natural and cultural heritage, it includes local communities in planning, development and operation activities, and it contributes to their welfare, it involves complete and interesting explanations for visitors, regarding the natural and cultural resources, it is intended mainly to individual visitors and also to small organized groups (Sâmbotın et al, 2011). According to Buchsbaum 2004; in many ways, sustainable tourism exemplifies the relationship between ecotourism and sustainable development. Many groups have proposed sets of guidelines or principles for sustainable tourism and ecotourism Tourism Concern and the World Wildlife Fund for Nature developed a wellknown list of principles and guidelines in 1991, which are presented in Table 4. 


\begin{tabular}{|c|c|}
\hline $\begin{array}{l}\text { 1. Using resources } \\
\text { sustainably }\end{array}$ & $\begin{array}{l}\text { The conservation and sustainable use of resources -natural, } \\
\text { social, cultural, -- is crucial and makes long-term business } \\
\text { sense Using resources sustainably: }\end{array}$ \\
\hline $\begin{array}{l}\text { 2. Reducing over } \\
\text { consumption and waste }\end{array}$ & $\begin{array}{l}\text { Reduction of over-consumption and waste avoids the costs } \\
\text { of restoring long-term environmental damage and } \\
\text { contributes to the quality of tourism }\end{array}$ \\
\hline 3. Maintaining Biodiversity & $\begin{array}{l}\text { Maintaining and promoting natural, social, and cultural } \\
\text { diversity is essential for long-term sustainable tourism, } \\
\text { and creates a resilient base for the industry }\end{array}$ \\
\hline $\begin{array}{l}\text { 4.Integrating tourism into } \\
\text { planning }\end{array}$ & $\begin{array}{l}\text { Tourism development which is integrated into a national } \\
\text { and local strategic planning framework and which } \\
\text { undertakes environmental impact assessments, increase } \\
\text { the long-term viability of tourism }\end{array}$ \\
\hline $\begin{array}{l}\text { 5. Supporting local } \\
\text { economies }\end{array}$ & $\begin{array}{l}\text { Tourism that supports a wide range of local economic } \\
\text { activities and which takes environmental costs and values } \\
\text { into account, both protects these economies and avoids } \\
\text { environmental damage }\end{array}$ \\
\hline $\begin{array}{l}\text { 6. Involving local } \\
\text { communities }\end{array}$ & $\begin{array}{l}\text { The full involvement of local communities in the tourism } \\
\text { sector not only benefits them and the environment but also } \\
\text { improves the quality of the tourism project }\end{array}$ \\
\hline $\begin{array}{l}\text { 7. Consulting stakeholders } \\
\text { and the public }\end{array}$ & $\begin{array}{l}\text { Consultation between the tourism industry and local } \\
\text { communities organizations and institutions is essential if } \\
\text { hey are to work alongside each other and resolve potential } \\
\text { conflicts of interest }\end{array}$ \\
\hline 8. Training Staff & $\begin{array}{l}\text { Staff training which integrates sustainable tourism into } \\
\text { work practices, along with recruitment of personnel at all } \\
\text { levels, improves the quality of the tourism product }\end{array}$ \\
\hline $\begin{array}{l}\text { 9. Marketing tourism } \\
\text { responsibly }\end{array}$ & $\begin{array}{l}\text { Marketing that provides tourists with full and responsible } \\
\text { information increases respect for the natural, social and } \\
\text { cultural environments of destination areas and enhances } \\
\text { customer satisfaction }\end{array}$ \\
\hline 10. Undertaking research & $\begin{array}{l}\text { Ongoing research and monitoring by the industry using } \\
\text { effective data collection and analysis is essential to help } \\
\text { solve problems and bring benefits to destinations, the } \\
\text { industry and consumers }\end{array}$ \\
\hline
\end{tabular}

Table 4. Principles for Sustainable Tourism (Blamey, 2001).

Medina (2005) explains that a criterion for sustainable tourism should include indicators of social and economic sustainability adding up to indicators of environmental sustainability. In addition, Wall (1997) has argued that for tourism to contribute to sustainable development it must be economically viable, environmentally sensitive and culturally 
appropriate, and the forms that this might take are likely to vary with location. The following table 5. develops sustability goals of ecotourism. Achieving sustainable tourismdefined here as tourism that is ecologically benign, economically feasible and socially acceptable-is thus contingent on environmental protection and reconciling tourism activities with local socio-economic values (Brown et al., 1997).

\begin{tabular}{|c|c|}
\hline $\begin{array}{l}\text { A: Environmental sustainability goals of } \\
\text { ecotourism }\end{array}$ & $\begin{array}{l}\text { promotes environmental protection (impact } \\
\text { assessment and environmental planning, } \\
\text { construction methods and materials, visual } \\
\text { impacts, water supply, air quality, waste } \\
\text { minimisation and litter drainage and stormwater, } \\
\text { wastewater, water conservation, energy } \\
\text { minimisation - buildings, energy minimisation- } \\
\text { transport, minimal impact on wildlife) } \\
\text { provides environmenta education } \\
\text {-increases public environmental consciousness } \\
\text {-fosters healty attitudes and behaviors towards } \\
\text { nature } \\
\text { encourages donations to contribute to the } \\
\text { protection of local natural resources air quality }\end{array}$ \\
\hline $\begin{array}{l}\text { B: Sociocultural sustainability goals of } \\
\text { ecotourism }\end{array}$ & $\begin{array}{l}\text { Promotes local peoples active participation } \\
\text { Promotes local ownership } \\
\text { Empowers local people } \\
\text {-e.g. builds up local peoples confidence/self-esteem } \\
\text { Enhances local communitys equilibrium } \\
\text { Encourages intercultural appreciation and } \\
\text { communication between host communities and } \\
\text { tourists }\end{array}$ \\
\hline $\begin{array}{l}\text { C: Economic sustainability goals of } \\
\text { ecotourism }\end{array}$ & $\begin{array}{l}\text { Contributes to lasting local economic development } \\
\text { Creates permanent jobs for local people } \\
\text { Drives the development of other related industries } \\
\text { Ungrades local infastructure } \\
\text { Profits esrned retained within local communities } \\
\text { Equal distribution of revenues } \\
\text { Promotes consumption and production } \\
\text { Finances the establishment and maintenance of } \\
\text { prodected areas } \\
\text { Uses natural resources efficiently }\end{array}$ \\
\hline
\end{tabular}

Table 5. Three systems of sustainability in ecotourism development (According to Wall 1997; Alexander and Whitehouse 2004; (Jiang 2008).

These criteria include quantification of environmental performance for most of the key environmental indicators. This allows recognition and encouragement of ecotourism product that makes measured environmental improvements which result in a more 
sustainable world (http://www.ecoroute.eu/brochures/Report_SW_Europe_draft30-042004.pdf. Review of criteria, procedures and legal framework for ecotourism in Europe).

According to Rome (1999); Ecotourism is one strategy for supporting conservation and providing income for communities in and around protected areas. It can contribute to economic development and conservation of protected areas by: a) generating revenues that can be used to sustainably manage protected areas, b) providing local employment and c) inculcating a sense of community ownership. However, without careful planning and management that balance ecological, social, and economic objectives, it may lead to environmental damage. Furthermore, envisioned as a positive approach towards sustainable development, unplanned or poorly planned and implemented tourism can have serious negative effects, offsetting the benefits it was designed to provide. Even the potential local benefits of ecotourism can lead to environmental damage to a protected area.

The core set of eight principles are that ecotourism product should: (The Green Globe 21 International Ecotourism Standard , 2004)

1. Focus on giving visitors the opportunity to personally and directly experience nature (Natural Area Focus);

2. Provide opportunities to experience nature in ways that lead to greater understanding, appreciation and enjoyment (Interpretation);

3. Represent best practice for environmentally sustainable tourism (Environmental Sustainability Practice);

4. Contribute directly to the conservation of natural areas (Contribution to Conservation);

5. Provide ongoing contributions to the local community (Benefiting Local Communities);

6. Be sensitive to, interpret and involve the culture/s existing in the area (Cultural Respect);

7. Consistently meets consumer expectations (Customer Satisfaction); and

8. Be marketed and promoted honestly and accurately so that realistic expectations are formed (Responsible Marketing).

One of the most influential ecotourism documents, the Quebec Declaration on Ecotourism (2002), produced after the World Ecotourism Summit during the International Year of Ecotourism, recognized that not only does ecotourism embrace the principles of sustainable tourism but it also embodies the following specific principles: (1) contributes actively to the conservation of natural and cultural heritage; (2) includes local and indigenous communities in its planning, development and operation, and contributes to their well-being; (3) interprets the natural and cultural heritage to visitors; (4) encourages independent travelers, as well as organized tours for small size groups. TIES' (2010) asserts that those involved in ecotourism should follow six principles: (1) minimize impact; (2) build environmental and cultural awareness and respect; (3) provide positive experiences for visitors and hosts; (4) provide direct financial benefits for conservation; (5) provide financial benefits and empowerment for local people; and (6) raise sensitivity to hosts' cultures political, and social climate)(McLaughlin, 2011). 
The participants at the World Ecotourism Summit, held in Quebec in May 2002, have acknowledged that ecotourism respects the principles of sustainable tourism referring to the economic, social and environmental impact, with some further specific principles (Sâmbotın et al, 2011);

- Ecotourism actively contribute to the conservation of natural and cultural heritage.

- Ecotourism include local communities in the activities of planning, development and operation, and it contributes to

- their welfare.

- Ecotourism involves complete and interesting explanations for visitors, regarding the natural and cultural resources.

- $\quad$ Ecotourism is intended mainly for individual visitors and small organized groups.

According to Ramwell and Henry (1996) point out four basic principles of sustainable development and sustainable ecotourism tourism development (Yogi, 2010).

- Holistic and strategic planning

- Conservation of essential ecological system

- Conservation of both human (cultural) and natural heritage

- Long term development and productivity for the future generation.

So both sustainable tourism and sustainable development focuses on the same key issues of ecology, society, and a systemic process of development that is guided by strategic planning (Yogi, 2010).

\section{Ecotourism - examples of implementation}

More tranquil, natural and original spaces are preferred to ordinary tourism centers. Likewise, individuals have begun to prefer activities, which they can particularly perform in naturel and culturel areas and with which they can learn original cultural values and be within the nature, instead of sea-sand-sun tourism. Ecotourism has increased very quickly in recent years especially in developing countries. These are highlighted in Table 6 and pertain to economic aspects, impacts on culture, environmental concerns and development. In the Tourism Strategy of Turkey-2023 and the Ninth Development Plan (2007-2013), it is aimed to utilize natural, cultural, historical and geographical values of Turkey based on conservation-use balance, to increase the share of Turkey from tourism and to promote the attractiveness of regions via alternative tourism types like ecotourism (Tourism Strategy of Turkey-2023, 2007; Ninth Development Plan, 2006).

Ecotourism is implemented differently around the world, and the impacts on native cultures vary similarly. It is universal that tourism is a crucial industry to provide economic support to developing countries. An international pact in 1996 designated the tourism industry as the paramount economic growth strategy within Central America (Moreno, 2005). At this point, "Ecotourism" activities have particularly recently become sectors which can create great changes both in socio-cultural and economic aspects. 


\begin{tabular}{|c|c|c|}
\hline & pros & cons \\
\hline Environmental & $\begin{array}{l}\text { - Low environmental impact } \\
\text { - Watching landscape, plants and } \\
\text { animals, being acquaintance with } \\
\text { local cultural activities, observing } \\
\text { through directly contacting with } \\
\text { nature, obtaining knowledge and } \\
\text { assessment will be provided via } \\
\text { ecotourism activities. } \\
\text { - The affective factor of region rises. } \\
\text { - Natural texture is protected. } \\
\text { - The opportunities of underwork } \\
\text { and bodywork rise. }\end{array}$ & $\begin{array}{l}\text { - Risk of environmental } \\
\text { degradation } \\
\text { - Environmental pollution rises } \\
\text { - The decays of natural resource } \\
\text { happen. }\end{array}$ \\
\hline Developmental & $\begin{array}{l}\text { - Provision for the development of } \\
\text { the community } \\
\text { - Capacity building within the } \\
\text { community } \\
\text { - Provision for health and family } \\
\text { planning } \\
\text { - Extending ecotourism activities year } \\
\text { round will prevent to utilize natural } \\
\text { landscape assets of the region only } \\
\text { in summer and will prevent short } \\
\text { time pressure on the sources. } \\
\text { - New investments come to region } \\
\text { - The quality of agricultural } \\
\text { production rises and in quality } \\
\text { production has its real value. }\end{array}$ & $\begin{array}{l}\text { - Failure to meet the community's } \\
\text { perception of development } \\
\text { - Advantages open to abuse by } \\
\text { community members } \\
\text { - Controversy about the motivation } \\
\text { of such programmes } \\
\text { Hotel, motel or other usages cause } \\
\text { environmental decays. } \\
\text { - Transportation density rises. }\end{array}$ \\
\hline Conse & $\begin{array}{l}\text { - Enhancement of conservation } \\
\text { objectives } \\
\text { - Monitoring of habitat and species }\end{array}$ & $\begin{array}{l}\text { - Disturbance to habitats and } \\
\text { species } \\
\text { - Threats posed by dangerous } \\
\text { animals }\end{array}$ \\
\hline Cultural aspects & $\begin{array}{l}\text { - Aw a reness of the local cultures } \\
\text { - Low cultural impact } \\
\text { - Internal migration happens with } \\
\text { tourism. } \\
\text { - Festival etc. activities rise. } \\
\text { - It supplements intersectoral } \\
\text { cooperation. } \\
\text { - Conventional culture is lived by } \\
\text { protected. }\end{array}$ & $\begin{array}{l}\text { - Misre presentation and } \\
\text { degradation of cultures } \\
\text { - Visual and noise pollution } \\
\text { happen } \\
\text { - Feasible population rise effects } \\
\text { local peoples' daily life in a } \\
\text { negative way. } \\
\text { - Conventional life style changes. }\end{array}$ \\
\hline Education & $\begin{array}{l}\text { - Education can help reduce } \\
\text { "avoidable impacts" such as } \\
\text { littering, ad hoc campfires, } \\
\text { inappropriate disposal of waste, }\end{array}$ & $\begin{array}{l}\text { - Erosion of traditional values and } \\
\text { for the guests }\end{array}$ \\
\hline
\end{tabular}




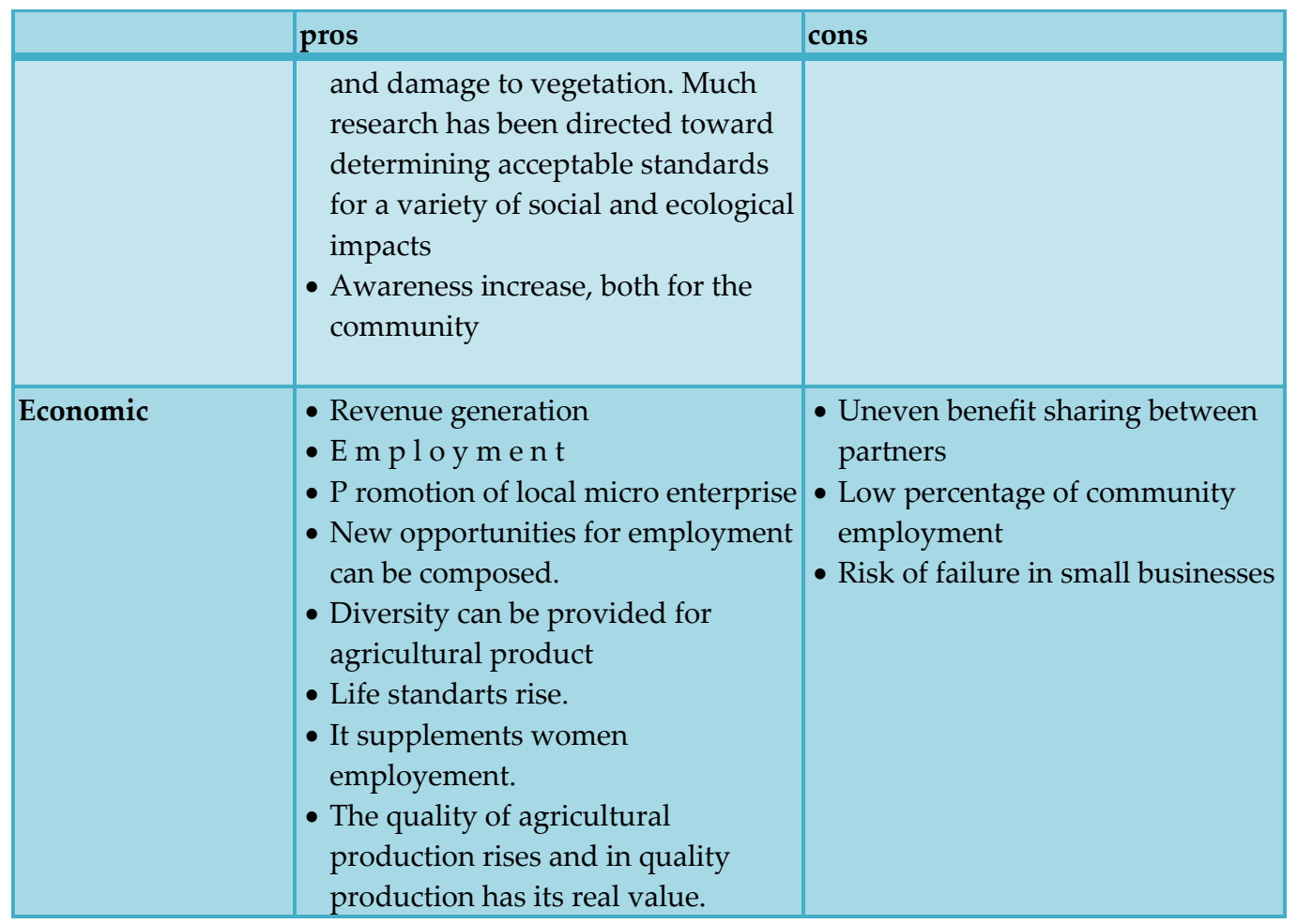

Table 6. Effects of eco-tourism in international countries (Watkin, 2003; Kiper, Özdemir, Sağlam, 2011)

Ecotourism activities have been sorted into the following categories: (Economic Development Branch BC Ministry of Sustainable Resource Management, 2003)

- $\quad$ Marine Ecotourism

- marine cruising including sailing, yacht and power cruising

- $\quad$ sea kayaking tours

- $\quad$ Land based Ecotourism

- Bicycle Touring/Mountain Biking

- Horseback Trail Riding

- Hiking/Backpacking/Trekking

- Freshwater River Rafting, Canoeing and Kayaking

- Winter Tourism (Back Country /Tour Skiing, Dog Sledding, Snow Shoeing)

- Walking, camping, boating, hunting, sight-seeing, swimming, cultural activities, observing wildlife and nature, skiing, visiting historical places, and horse riding among

The general trend in ecotourism is to increase experiences by encouraging activities such as long-distance walking, camping, boating, hunting, sight-seeing, swimming, cultural activities, bicycling, observing wildlife and nature, skiing, visiting historical places, and horse riding among others. Generally, instructive activities, for example, wildlife observation, participation in festivals, cultural activities and nature landscapes, attract most 
attention. Activities like hiking, outdoor sports, picnic, paragliding arranged according to different areas of interest influence the preferences of many visitors (Kiper, 2011; Cengiz, 2007). According to Soykan, for Europeans rural roads are natural and cultural heritages. This is because they have natural, economic and cultural identities. Some give us opportunity to familiarize with local planting patterns by passing through agricultural lands, some lie among virgin natural areas with beautiful views (e.g. forests, rivers, lakes) and some connect the settlements which have unique cultural monuments. Therefore, in many countries in Europe (specifically Austria, Switzerland and France, which have mountainous areas) long distance trekking is well-organized (Kiper, 2011).

In order for ecotourism to have a sustainable development, the analyses for determining land use suitabilities gain importance. It and other similar methods set standards or ranges of acceptable change and describe a methodology for determining these standards, measuring impacts and identifying management strategies for controlling negative impacts. They include ve includeIn recent years resources assessments have adopted oppottunity spectrum methods.

Opportunty spectrum this group includes (Fagence, 2001; Rome, 1999) ;

- $\quad \operatorname{ROS}$ (Recreation Opportunty Spectrum)

- $\quad$ TOS (Tourism Opportunty Spectrum)

- $\quad$ LAC (Limits of Acceptable Change)

- $\quad$ TA (Threshold Analysis, and more recently UET-ultimate environmental thresholds)

- ECOS (Ecotourism Opportunty Spectrum)

- $\quad$ Limits of Acceptable Change (LAC)

- Visitor Impact Management (VIM)

- Visitor Experience and Resource Protection (VERP)

- $\quad$ Tourism Optimisation Management Model (TOMM)

The ECOS model (Table 7) has been developed especially to cope with the peculiar needs of planning for ecotourism the capture of ecolpgical base-line data is the important first step.

Refinement to ECOS assesments could include

- Landscape assesments (to differentiate geographical sectors according to their principal ecotourism resources, stages of "naturalness/change, levels of ecotourist interest)

- Attractiveness indices ( to differentiate according to uniqueness, international drawing power, primacy-a measure of comparative attraction)

- Resource status (to differentiate according to the degree of disturbance of the natural resource, and any circumstance which might impede its sustainability or cause its attractiveness to be forfeited -a form of carrying capacity assesment)

- Conservation potential (including rehabilitation potential)

- Marketing assesments (combining some of the other assessments according to an aggregation of attractiveness for particular consumer/tourist market segments -to interpet the feasibility of capturing and sustaining tourist interest)

This data is then assessed or measured in terms of the capacity to be used in ecotourism, with the assessment focusing on eight important factors: 


\begin{tabular}{|l|l|}
\hline Accessibility & $\begin{array}{l}\text { - Tho the ecotourism region } \\
\text { - Tho the site }\end{array}$ \\
\hline Relationship & $\begin{array}{l}\text { - Between ecotourism and other potential uses of the same resource } \\
\text { - Complementarity, compatibility, integration, competition }\end{array}$ \\
\hline Attractions & $\begin{array}{l}\text { - Types of ecotourism experiences } \\
\text { - IN (Tropical forests, mountain areas) } \\
\text { - OF (birds, tress, wild flowers, mammals) } \\
\text { - BY (watching, filming, collecting) }\end{array}$ \\
\hline Infastructure & $\begin{array}{l}\text { - Support infastructure } \\
\text { - Support services }\end{array}$ \\
\hline $\begin{array}{l}\text { User } \\
\text { pre-requisites }\end{array}$ & $\begin{array}{l}\text { - Prior knowledge } \\
\text { - Prior skills } \\
\text { - Equipment }\end{array}$ \\
\hline Social & $\begin{array}{l}\text { - Level of interaction sought, achieved } \\
\text { - Level of interaction with local/host community sought, achieved }\end{array}$ \\
\hline Visteraction & $\begin{array}{l}\text { - Consequences of visitor access } \\
\text { - Controls on visitor access, use }\end{array}$ \\
\hline Management & $\begin{array}{l}\text { - Stakeholder involvement } \\
\text { - Decision process }\end{array}$ \\
\hline
\end{tabular}

Table 7. ECOS models (Fagence, 2001)

Also, "Multi-Criteria Decision-Making Methods" are used widely in detecting land use suitabilities. The integration of ELECTRE, to give the order of precedence of uses, with GIS, a quite important means in spatial planning studies, will enable to reach successful results. Studies for determining the suitabilities for use of a land for ecotourism will also determine the development of the land in the following years and the sustainability of its resource values.

In the eco-tourism plans, diversifying economic and ecologic activities by starting and developing organized eco-tourism practice, enhancing the life quality of the locals with the economic gains provided by eco-tourism, increasing the participation of habitat conservation, improving environmental conscious, conserving natural, cultural and historical landscape values and passing them onto the next generation and popularizing ecotourism planning with the support and participation of responsible and related organizations should be aimed. Good planning of natural and cultural elements that create resources for eco-tourism activities and their management will make important contributions to the local public. (Gültekin, 2010).

While envisioned as a positive approach towards sustainable development, unplanned or poorly planned and implemented tourism can have serious negative effects on the environment and on communities, offsetting the benefits it was designed to provide. In order to anticipate negative impacts and to prevent or mitigate them, ecotourism impacts monitoring is required. The sample of potential ecotourism monitoring indicators are shown in Table 8. 


\begin{tabular}{|c|c|}
\hline & Indicators \\
\hline Environmental & $\begin{array}{l}\text { - Species of special tourism interest - numbers recorded per time } \\
\text { or area, breeding sites } \\
\text { - Endangered species - numbers recorded per time or area, } \\
\text { breeding sites } \\
\text { - Keystone species - numbers recorded per time or area, } \\
\text { breeding sites } \\
\text { - Trail width } \\
\text { - Trail maintenance required } \\
\text { - Water quality } \\
\text { - Vegetation trampled near trails and infrastructure }\end{array}$ \\
\hline Experiential & $\begin{array}{l}\text { - Number of other people or groups encountered on trails } \\
\text { - Number and size of vehicles in parking areas } \\
\text { - Degree of solitude experienced by visitors } \\
\text { - Number of repeat visitors } \\
\text { - Tourist ratings of guides } \\
\text { - Ratings of food and accommodations }\end{array}$ \\
\hline Socio-cultural & $\begin{array}{l}\text { - Quality of historical, cultural sites } \\
\text { - Knowledge of traditional uses of flora and fauna and rituals } \\
\text { - Changes in land use near protected areas } \\
\text { - Quality and quantity of consumption } \\
\text { - Changes in dress and language } \\
\text { - Use of free time } \\
\text { - Community attitudes about tourists and tourism }\end{array}$ \\
\hline Economic & $\begin{array}{l}\text { - Number and size of vehicles in parking areasIncome levels of } \\
\text { - Residents working directly in ecotourism } \\
\text { - Residents providing ecotourism services indirectly } \\
\text { - Residents not involved with ecotourism } \\
\text { - Amount of protected area budget spent on ecotourism-related } \\
\text { - } \text { - Revenuement } \\
\text { - Amount of money spent on community improvements } \\
\text { - Changes in costs of local goods and services } \\
\text { - Rate of new construction in the area } \\
\text { - Population changes } \\
\text { - Number and volume of new businesses }\end{array}$ \\
\hline $\begin{array}{l}\text { Infrastructure } \\
\text { (or managerial) }\end{array}$ & $\begin{array}{l}\text { - Number and length of trails } \\
\text { - Amount of infrastructure development within protected area } \\
\text { - Amount of time spent in maintenance of infrastructure } \\
\text { - Lodging capacity in and around the protected area } \\
\text { - Degree of road maintenance required } \\
\text { - Methods of communication and transport }\end{array}$ \\
\hline
\end{tabular}

Table 8. A sample of potential ecotourism monitoring indicators (Rome, 1999) 


\section{Conclusion}

Various tendencies also occur in the understanding of tourism upon changing living conditions. More tranquil, natural and original spaces are preferred to ordinary tourism centers. Likewise, individuals have begun to prefer activities, which they can particularly perform in naturel and culturel areas and with which they can learn original cultural values and be within the nature, instead of sea-sand-sun tourism. At this point, "Ecotourism" activities have particularly recently become sectors which can create great changes both in socio-cultural and economic aspects. Main purpose is not only ensuring the socio-economic development but also the protection of natural and cultural landscape values to ensure awareness of nature conservation on the other hand.

Ecotourism should be seen in direct relation to nature conservation (protected areas), with preservation of the authentic and involving local communities in all stages of the process. Development process is a lengthy process, which requires a sustained effort from all those involved but can bring major benefits in the long term, contribute directly to the creation of "sustainable existing 'target area (Roxana, 2012).

Ecotourism is about (Roxana, 2012);

- environmentally responsible travel to relatively undisturbed natural areas,

- travel in order to enjoy, study and appreciate nature,

- the promotion of conservation,

- combining sustainable development with the natural environments,

- the use of natural assets and resources in ecologically sensitive areas to create unique visitor experiences with minimal impact on the area.

After research we can draw the main conclusions of this work, as it follows: (Sâmbotın, 2011)

- Ecotourism is a form of tourism developed in natural areas, whose goal is to acknowledge and to appreciate nature and local culture, which includes conservation measures and ensures an active involvement, generating benefits for the local population;

- Ecotourism clothes the sustainable tourism principles, but differs from it by aspects related to local community issues, interpretation for visitors to a particular destination, the number of visitors;

- Tourism has a complex impact on the environment, but it is also generating both cost and benefits;

- The interest of tourists for travel in natural areas (land or water) has increased recently;

- Ecotourism contributes to increased revenues from tourism, but also to the positive social effects;

- Worldwide, there are a large number of natural areas associated with a specific cultural diversity, resulting in particular through the perpetuation of the long traditions and customs;

- Tourists have a certain responsibility towards the destination visited and the environment by their choice itself, behavior and activities performed in that space, and therefore it is important to be informed about the quality and sensitivity of destinations. 
These principles should be envisaged both for lovers of this form of tourism and service providers of such eco-touristic products.

Basic purposes of ecotourism are to preserve and utilize natural and cultural resources in a sustainable way and to enable economic development of local people. However, achieving the aims in ecotourism depends on whether they are environmentally and ecologically sustainable and economically applicable. In order to achieve these, a participative tourism planning is required (Kiper, 2011). Figure 4 illustrates the multiple and diverse elements essential for ensuring that communities fulfil their role in ecotourism development (Drumm \& Moore, 2002).

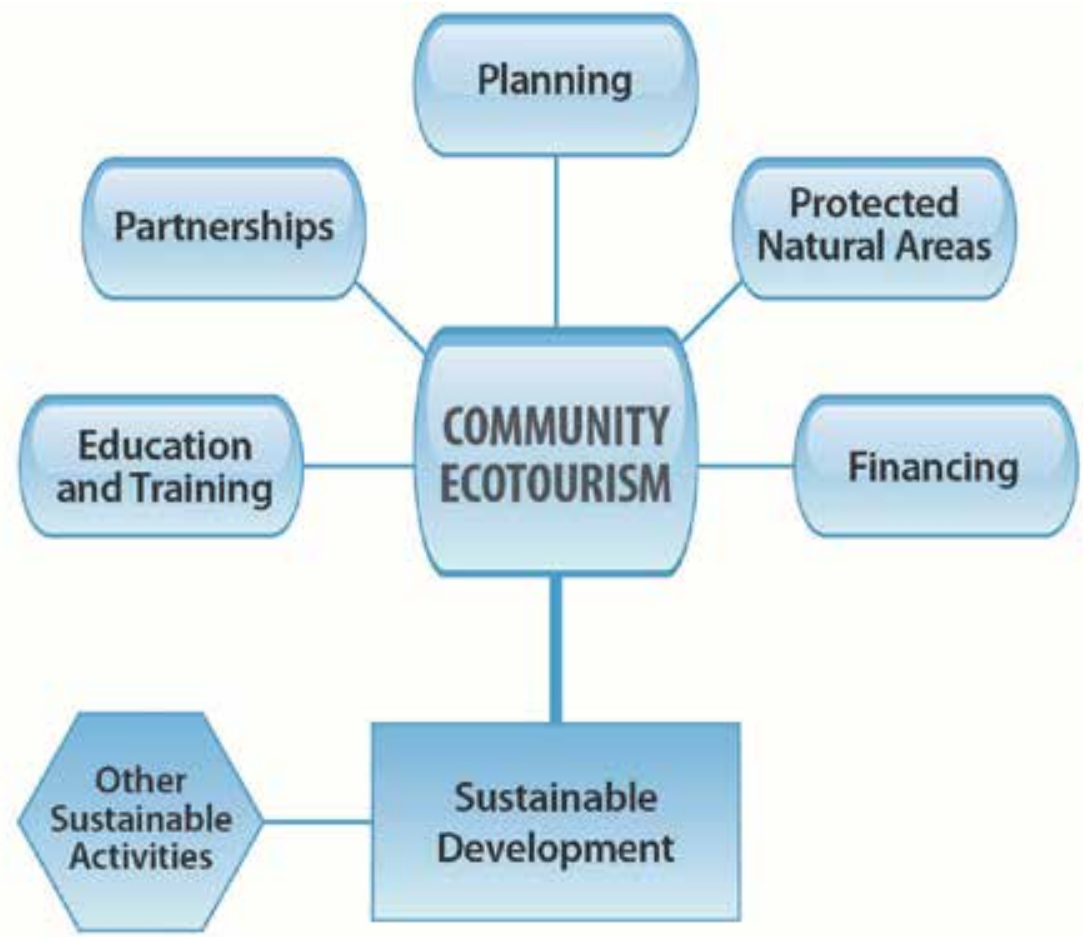

Figure 4. Essential elements for ecotourism in community setting

Now that ecotourism has reached such stature, it is especially important to scrutinize its effectiveness as a strategy for sustainable development, and search for ways to improve policies and practices. Clearly ecotourism is not a universal remedy; but its potential to promote sustainable development deserves considerable attention.

In conclusion, According to Kiper, Özdemir and Sağlam (2011); ecotourism activities which are not performed according to the purpose, the principles and the characteristics cause the disturbance in environmental, economic and socio-cultural fields due to over-intensification to be occurred especially in sensitive ecosystems like naturel and culturel areas. Therefore, in order to provide sustainability in the ecotourism, it is necessary to know environmental, social and economical effects of ecotourism activities and to consider these effects during the 
planning. Tourism planning purposes this. relationship between rational resources requirements Ensuring the sustainable use of natural (water, vista, topography, clean air, natural vegetation structure, microclimatic features of climate, marine and coastal topographic structure and motion, etc.) and cultural resources (Archeological heritage, Religious structures, Conventional architecture, Traditional social activities) to the evaluation of the physical planning decisions in the field of ecological planning strategies (Dinç and Kocan, 2012). Additionally, According to Bunruamkaew \& Murayama (2012); ecotourism development must promote educational development and create awareness in people of the need to jointly maintain the ecosystem of the area. There is a need to implement development plans and manage natural resources in a way that ensures ecological and environmental integrity. Environmental education and interpretation is the key to creating an enjoyable and meaningful ecotourism experience, and is one of the key points of differentiation between ecotourism and other tourism products. Successful interpretive components of ecotourism products will foster appreciation and support for conservation efforts, local communities and culture.

\section{Author details}

Tuğba Kiper

Namık Kemal University, Faculty of Fine Arts, Design and Architect, Department of Landscape Architecture, Turkey

\section{References}

Bansal, S.P. \& Kumar, J. 2011. Ecotourism for Community Development: A Stakeholder's Perspective in Great Himalayan National Park. International Journal of Social Ecology and Sustainable Development, 2(2), 31-40.

Bhattacharya, D., Chowdhury, B. and Sarkar,R. 2011. Irresponsible Ecotourısm Practices Flankıng The Best Natıonal Park In India: A Multıvarıate Analysıs. 2nd International Conference On Business And Economic Research (2nd Icber 2011) Proceeding, 19011928.

Bhuiyan, A.H., Siwar ,C., Ismail , S.M., Islam, R., 2012. The Role of Ecotourism for Sustainable Development In East Coast Economic Region (Ecer),Malaysıa,. / OIDA International Journal of Sustainable Development, 3 (9): 53-60. Online [Available]: http://www.ssrn.com/link/OIDA-Intl-Journal-Sustainable-Dev.html.

Blamey, R.K. 2001. Principles of Ecotourism. In David B. Weaver (Ed), Encyclopedia of Ecotourism. (5-22). New York: CABI Publishing.

Bob, U., Swart, K., Maharaj, B. and Louw, P. 2008. Nature, People and Environment: Overview of Selected Issues. Alternation, 15(1): 17-44.

Boghean, C. \& Boghean, F. 2006.Ecoturismul - Model de Valorificare Durabilă a Resurselor Turistice. Tourism Journal - Studies and Research in Tourism, 1: 43-47.

Brandon, K. 1996. Ecotourism and Conservation: A Review of Key Issues. Washington, DC: The World Bank. 
Briassoulis, H. 2002. Sustainable tourism and the question of the commons. Analysis of Tourism Research 29(4):1065-1085.

Brown, K., Turner, R.K., Hameed, H., Bateman, I. 1997. Environmental Carrying Capacity and Tourism Development In the Maldives and Nepal. Environmental Conservation, 24 (4): 316-325.

Buchsbaum, D.B. 2004. Ecotourism and Sustainable Development in Costa Rica. Major Paper Submitted to Virginia Polytechnic Institute and State University Master of Public and International Affairs.

Bunruamkaew, K. \& Murayama, Y. 2012. Land Use and Natural Resources Planning for Sustainable Ecotourism Using GIS in Surat Thani, Thailand. Sustainability , (4): 412-429.

Cater, E., 2002. Spread and Backwash Effects İn Ecotourism: Implications for Sustainable Development. International Journal of Sustainable Development, 5 (3): 265-281.

Catibog-Sinha, C. \& Wen, J. 2008. Sustainable Tourism Planning and Management Model For Rotected Natural Areas: Xishuangbanna Biosphere Reserve, South China. Asia Pacific Journal of Tourism Research, 13(2):145-162.

Ceballos-Lascurain, H. 1996. Tourism, Ecotourism and Protected areas. IUCN, Gland, Switzerland.

Cengiz, T. 2007. Tourism, an Ecological Approach in Protected Areas: Keragol-Sahara National Park, Turkey. Int J of Sustainable Development and World Ecology, 14: 260267.

Chesworth, N. 1995. Ecotourism Seminar paper delivered in the Institute of Environmental Studies and Management. UPLB. College, Laguna

Dinç, A., Kocan, N., 2012. Ecotourism Planning of Murat Mountain (Usak, Kutahya/Turkey). International Conference on Applied Life Sciences (ICALS2012), Turkey, September 1012, 2012, Online [Available]: (http://creativecommons.org/licenses/ by/3.0).

Dixon, Y. \& Pretorious, J.G. 2001. Sustainable Development. A South African Perspective. Online [Available]: http://www.helsinki.fi/imua2001/Pretorius.pdf.

Dorobantu, M.R.\& Nistoreanu, P. 2012. Rural Tourism And Ecotourism - The Main Priorities in Sustainable Development Orientations of Rural Local Communities in Romania. Economy Transdisciplinarity Cognition, 15(1): 259-266.

Dowling, R.K. 1997. Plans for the Development of Regional Ecotourism: Theory And Practice. In Tourism Planning and Policy in Australia and New Zealand: Cases, issues and practice, C.M. Hall, J. Jenkins and G. Kearsley (Eds), pp. 110-126 (Sydney: Irwin Publishers).

Drumm, A. \& Moore, A. 2002. An Introduction to Ecotourism Planning (Volume 1), Ecotourism Development, A Manual for Conser vation Planners and Managers, USA, pp.96

Drzewiecki, M. 2001. Bases of Agritourism. Centre of Organizational Progress, Bydgoszcz.

Economic Development Branch BC Ministry of Sustainable Resource Management, 2003.

Land Based Ecotourısm Winter Activities (Backcountry Skıng, Snowshoeing, Dogsledding. Stuart Gale \& Associates Pierce Lefebvre Consulting, p. 9, Online [Available]:

http://www.al. gov.bc.ca/clad/strategic_land/blocks/cabinet/tour_rec_winter.pdf. 
Ecotourism - Sustainable Tourism in National Parks and Protected Areas, 2005. Banff National Park in Canada and Nationalpark Gesause in Austria-a Camparison, pp. 170. Online [Available]: www.np-gesaeuse. at/ .../Obenaus_oJ_Ecotourism.pdf.

Eriksson, H. 2003. “Rhetoric and Marketing Device or Potential And Perfect Partnership? - A

Case Study of Kenyan Ecotourism, Umea University, pp 1-8.

Fadahunsi, J.T. 2011. Application of Geographical Information System (GIS) Technology to Tourism Management in Ile-Ife, Osun State, Nigeria The Pacific Journal of Science and Technology, 12(2): 274-283.

Fagence, M. 2001. Strategies for Developing Ecotourism in Pasific Island Countries. UNESCAP/SPTO Seminar, Fiji, p.14.

Farrell, B.H., \& Runyan D. 1991. Ecology and Tourism. Annals of Tourism Research. 18: 2640.

Fennell, D. A. \& Dowling, R.K. 2003. Ecotourism Policy and Planning. CABI Publishing: Oxon and Cambridge

Fennell, D.A. 1999. Ecotourism: An introduction (London: Routledge).

Fung, T. \& Wong, F.K. 2007. Ecotourism Planning Using Multiple Criteria Evaluation With GIS. Geocarto International, 22(2): 87-105.

Gerry, R. 2001. Cultural Attractions an European Tourism. CABI Publishing, New York.

Godratollah, B., Azlizam, A., Manohar, M., Mohd, H.I., Syed, M.H. 2011. Delphi Technique

For Generating Criteria And İndicators İn Monitoring Ecotourism Sustainability İn Northern Forests Of Iran; Case Study On Dohezar And Sehezar Watersheds. Folia Forestalia Polonica Series A, 53(2): 130-141.

Gössling, S. 1999. Ecotourism: A means to Safeguard Biodiversity and Ecosystem Functions?. Ecological Economics 29:303-320.

Gültekin, P. 2010. Determination of ecotourism potential of Duzce Uğursuyu and Aksu watersheds and landscape management. M.Sc. Thesis. The graduate school of natural and applied sciences, Düzce University, Landscape architecture department. DüzceTurkey.

Hall, C.M., 2008. Tourism Planning: Policies, Processes and Relationships. 2nd Edn., Pearson/Prentice Hall, Harlow, England, New York, ISBN: 10: 0132046520, pp: 302.

Harris R, Griffin T, Williams, P. 2002. Sustainable Tourism. A Global Perspective. Butterworth-Heinemann, p. 1-252.

Hill, J. \& Gale, T. 2009. Ecotourism and Environmental Sustainability: Principles and Practices. Published by Ashgate p.261, Britain.

Honey, M. 1999. Ecotourism and Sustainable Development. Who owns Paradise? Island Press, Washington D.C.

http://www.ecoroute.eu/brochures/Report_SW_Europe_draft30-04-2004.pdf. Review of

Criteria, Procedures And Legal Framework For Ecotourism in Europe. Labels of Tourism in Europe

IISD, 2012. What is Sustainable Development?. International Institue for Sustainable Development, Online [Available]: www.iisd.org/sd.

Jaini , N., Anuar, A.N.A., Daim, M.S., 2012. The Practice of Sustainable Tourism in Ecotourism Sites among Ecotourism Providers. Asian Social Science, 8(4): 175-179. 
Jiang, J. 2008. Evaulation of The Potential Of Ecotourism to Contribute to Local Sustainable Development. A Case Study of Tengtou Village, China. Phisophy in Development studies at Massey Universty, Master Degree, New Zealand, p. 175.

Joshi, R.L., 2011. Eco-tourism Planning and Management On Eco-tourism Destinations of Bajhang District, Nepal. M. Sc. Forestry (2010-2012), p.11. Online [Available]:

http://www.forestrynepal.org/images/ publications/ Ecotourism \%20 destination \%20bajhang.pdf.

King, D. \& Stewart, W. 1992. Ecotourism and Commodification: Protecting People and Places. Biodiversity and Conservation, 5: 293-305.

Kiper, T. 2006. Considering Safranbolu Yörükköyü Landscape Potential as the Rural Tourism. Department of Landscape Architecture (unpublished), School of Science, Ankara University, Ankara, $367 \mathrm{p}$.

Kiper, T. 2011. The Determination Of Nature Walk Routes Regarding Nature Tourism In North-Western Turkey: Şarköy District. Journal of Food, Agriculture \& Environment, 9 (3\&4):622-632.

Kiper, T., Özdemir, G., Sağlam, C., 2011. Enviromental, Socio-Cultural And Economical Effects Of Ecotourism Perceived By The Local People In The Northwestern Turkey: Kıyıköy Case. Scientific Research and Essays, 6(19): 4009-4020.

Lane, B. 1993. Sustainable Rural Tourism Strategies: A Tool For Development and Conservation In Bramwell. Proceedings of the Second International School on Rural Development, 28 June-9 July, Ireland

Lanquar, R. 1995. Tourisme et Environnement en Mediterranean. Economica, Paris.

Li, W.J. 2006. Community Decision-Making Participation In Development. Annals of Tourism Research, 33(1): 132-143.

Lindsey, P. A., Alexander, R. R., du Toit, J. T. and Mills, M. G. L. 2005. The Potential Contribution Of Ecotourism To African Wild Dog Lycaon Pictus Conservation in South Africa. Biological Conservation. 123: 339- 348.

Lopez-Espinosa de los Monteros, R. 2002. Evaluating Ecotourism In Natural Protected Areas of La Paz Bay, Baja California Sur, Mexico: Ecotourism or nature-based tourism? Biodiversity and Conservation,11: 1539-1550.

Matthews, E. J. 2002. Ecotourism: Are Current Practices Delivering Desired Outcomes? A comparative case study analysis Major Paper submitted to the Faculty of the Virginia Polytechnic Institute and State University in partial fulfillment of the requirements for the degree of Master of Urban and Regional Planning in Urban Affairs and Planning., P.106.

McCormick, K. 1994. Can Ecotourism Save the Rainforests?. Online [Available]: http://www.ran.org/ran/info_center/ecotourism.html. Rainforest Action Network.

McLaughlin, M.J. 2011. Ecotourism Assessment: Applying the Principles of Ecotourism to Paddle-Based Recreation in St. Lawrence Islands National Park and Environs. A thesis submitted to the Graduate Program in School of Environmental Studies in conformity with the requirements for the Degree of Master of Environmental Studies. Queen's University, Kingston, Ontario, Canada, pp. 142.

McMinn, S. 1997. The Challenge of Sustainable Tourism. The Environmentalist. 17: 135-141. 
Mebratu, D. 1998. Sustainability and sustainable development: Historical and conceptual overview. Environ Impact Asses and Review, 18: 493-520.

Medina, L.K. 2005. Ecotourism and Certification: Confronting The Principles And Pragmatics Of Socially Responsible Tourism. Journal of Sustainable Tourism, 13(3): 281295.

Mlynarczyk, K. 2002. Agritourism. Publishing of Warmia and Mazury University, Olsztyn.

Moreno, P. 2005. Ecotourism Along The Meso-American Caribbean Reef: The Impacts of Foreign Investment." Human Ecology, 33 (2): 217-244.

Munn, C. A. 1992. Macaw Biology and Ecotourism, Or When A Bird In The Bush Is Worth Two In The Hand. In Beissinger, S. R. and Snyder, N.F.R. (eds). New World Parrots in Crisis: Solutions from Conservation Biology. Smithsonian Institution Press, Washington, pp. 47-71.

Myburgh, E. \& Saayman, M. 2002. Ecotourism in Action. Potchefstroom: Leisure Consultants and Publications. Nationalpark Gesäuse in Austria - a Comparison,p.170, Online [Available]:

http://www.np esaeuse.at/ download / forschung/ Obenaus_oJ_Ecotourism.pdf.

Ninth Development Plan (2007-2013), 2006. Online [Available]: http:// ekutup.dpt.gov.tr/plan/plan9.pdf

Patterson, C. 2002. The Business of Ecotourism: The Complete Guide for Nature and Culture-Based Tourism Operations, Rhinelander, Wis.: Explorer's Guide Publishing Second Edition [G156.5.E26 P37/1997].

Place, S. 1995. Ecotourism for Sustainable Development: Oxymoron or Plausible Strategy? Geojournal. 35: 161-173

QuickStart Guide to a Tourism Business, 2006. Ecotourism vs Nature Based Tourism, Tourism Western Australia.

http://www.tourism.wa.gov.au/Publications\%20Library/Growing\%20Your\%20Business /Ecotourism\%20vs\%20Nature\%20Based\%20Tourism\%20v3\%20260706\%20(final).pdf.

Rahman, A., 2010. Application of Gis In Ecotourism Development: A Case Study In Sundarbans, Bangladesh, Mid-Sweden University Master Of Arts, Human Geography Focusing On Tourism, A Masters Thesis, 79 p.

Ritchie, J.R. B. \& Crouch, G.I. 2003. The Competitive Destination: A Sustainable Tourism Perspective. CABI Publishing: Oxon and Cambridge.

Rome, A. 1999. Tourism Impact Monitoring. A Review Of Methodologies And Recommendations For Developing Monitoring Programs İn Latin America. Tourism And Protected Areas Publication Series, pp.59.

Roxana, D.M. 2012. Considerations About Ecotourism and Nature-Based Tourism - Realities and Perspectives. International Journal of Academic Research in Economics and Management Sciences, 1( 5): 215-221.

Sâmbotin, D., Sâmbotin, A., Pătrăşcoiu,M., Coroian, A., Mercel, I. I. 2011. Ecoturismul Model de Valorificare Durabilă a Resurselor Turistice, Lucrări Ştiinţifice, Seria I, Vol. XIII (4).

Soykan, F. 1999. A type of A Tourism İntegrated Natural Environment and Rural Culture: Rural tourism. J. Anatolia Tourism Res. 10: 67-75. 
Stem, C., Lassoie, J., Lee, D., and Deshler, D. 2003. Community Participation in Ecotourism Benefits: The Link To Conservation Practices and Perspectives. Society and Natural Resources. 16: 387-413.

Tewodros, K.T. 2010. Geospatial Approach for Ecotourism Development: A Case of Bale Mountains National Park, Ethiopia. Master Thesis, Faculty of Natural Science, Department of Earth Sciences, Addis Ababa University, Addis Ababa, Ethiopia, 2010.

The Green Globe 21 International Ecotourism Standard, 2004. Review of criteria, procedures and legal framework for ecotourism in Europe.

http://www.ecoroute.eu/brochures/Report_SW_Europe_draft30-04-2004.pdf

Tisdell, C. \& Wilson, C. 2002. Ecotourism for the survival of sea turtles and other wildlife. Biodiversity and Conservation. 11:1521- 1538.

Tourism Queenland, 2002. Queensland Ecotourism Plan 2003-2008; Tourism Queensland: Brisbane, Australia, 2002. Online [Available]: http://www.tq.com.au/fms/tq_ corporate/ special interests /ecotourism2/Queensland \%20).

Tourism Strategy of Turkey-2023, 2007. Ministry of Culture and Tourism, Ankara, Turkey, $60 \mathrm{p}$.

Van-der-Merwe, I. \& Van-der-Merwe, J. 1999. Sustainable development at the local level: An introduction to local agenda 21. Pretoria: Department of environmental affairs and tourism

Vogt, H. 1997. The economic benefits of tourism in the marine reserve of Apo Island, Philippines. H.A. Lessios, I.G. Macintyre (Eds.), Proceedings of the Eighth International Coral Reef Symposium, vol. 2Smithsonian Tropical Research Institute, Panama, p. 21022104.

Wall, G. 1997. Is Ecotourism Sustainable?. Environmental Management, 21(4): 483-491.

Wall, G. 2007. Sustainable Development, Sustainable Tourism and Sustainable Livelihoods: Paper prepared for the 2007, International Tourism Biennial in Çanakkele, Turkey. Online [Available]: http://turizm.comu.edu.tr/conference.

Watkin, J.R. 2003. The Evolution of Ecotourism in East Africa: From an idea to an industry. IIED Wildlife and Development Series No. 15, p.29.

Weaver, D.B \& Lawton, L.J. 2007. Twenty years on: The state of contemporary ecotourism research. Tourism Management, 28: 1168-1179

Weaver, D. B. 1999. Magnitude of Ecotourism in Costa Rica and Kenya. Annals of Tourism Research, 26(4), 792-816

Weaver, D.B. 2001. Ecotourism, John Wiley \& Sons: Milton.

World Tourism Organisation, 2001. Indicators for Sustainable Development for Tourism Organisations: A Guidebook. Madrid, Spain.

Yogi, H.N. 2010. Eco-Tourısm And Sustainability - Opportunities and Challenges In The Case of Nepal. Master Thesis Department Of Sustainable Development University Of Uppsala, p.60.

Ziffer, K. 1989. Ecotourism: The Uneasy Alliance. Washington D.C., Conservation International. 


\section{The Use of Courtyards and Open Areas in the Ottoman Period in İstanbul}

\section{Gülhan Benli}

Additional information is available at the end of the chapter

http://dx.doi.org/10.5772/55797

\section{Introduction}

The courtyards of the mosques were gathering places frequently in use, public meetings always had a pleasant environment. The courts of the Imperial mosques and large building complexes called "külliye", have a regularity and symmetrical form. Evliya Çelebi [1], the famous Ottoman Turkish travel writer, tells us of the fragrance of the mosque courtyards, with fruit trees and flower beds. The types of Ottoman open space other than mosque-courts are open praying platforms;"namazgah", open air grounds promenade; "mesire" or meadows/large green areas which were called "çayır". Open praying platforms which Ottomans called "Namazgah" have regular forms, although the open spaces of the Ottoman urban model has been judged to be formless. The open areas of Ottomans were not architecturally designed; their margins are quite casual or simply enhanced by single monuments. The open air grounds, promenade (Mesire) are the actual core of the open air system. The open space when it is very large does not have a form as it is natural and has a manner of being situated in nature. They were quite widespread in public use in the 18th century and they represented a form that was latent in the preceding period.

\section{A type of open area: Külliye}

Until the mid- $16^{\text {th }}$ century, the daily life of the common people was experienced around the mosque, open market and residence. Since the social life was self-enclosed, public open spaces were not felt as required; instead the courtyards of mosques and külliyes were used as gathering places for the people. The külliyes built after the Sultan Mehmed the Conqueror conquered Constantinople, were building complexes which reached wide functional resources, possessing an urban vision, with their inherent structures of multiple functionality. These complexes which harbored various functions of religious service, education, social aid (hosting travelers, feeding the poor and providing health-care for the 
sick) and trade, were designed keeping the whole of the city in consideration. One of the characteristics of the İslamic cities, great mosque and market constituting the city-center, is also prevalent for the külliyes built in İstanbul.

Large külliyes were institutions which addressed the needs of the society, enabling social development and betterment by providing social services. Large-scale külliyes in İstanbul (Fatih Külliyesi, Süleymaniye Külliyesi, Şehzade Külliyesi, Sultanahmet Külliyesi etc.) are enormous social institutions consisting of a mosque, turbe (a sepulcher for usually religiously reputable people), hazire (a reserved burial area surrounded with fences), medrese (or 'madrassah', muslim theological school), sibyan mektebi (primary school for young boys), şifahane (hospital), imaret (public soup-kitchen), sebil (public water distribution place), fountain, market, lodging inn and a hamam (Turkish bath).

Major Ottoman Külliyes in İstanbul were located on the main road axis of the city and corresponded to the preceding Roman and Byzantine era forums; however the spatial differences in two types of spaces are the results of the differences between Byzantine and Ottoman social structures. The decisions concerning the urban life were announced to the public in mosques and mosque courtyards, thus they held the function of communication between the government and the people, well before the information age. The reactions of the community were evaluated in those public spaces, to be reported to the government. However, some courtyards were nested with the külliye of the mosque, or the neighboring market, undertaking several other functions. The surrounding shopkeepers came to the mosque for namaz, five times a day, and after the prayers, they held conversations with other shopkeepers usually about commercial, social or political issues. The children of those shopkeepers, who comes with their fathers attended to lessons of Arabic, Persian, religious rules and ethics in those mosques. In the courtyards of large, central mosques, chatters or peddlers were present through all day. These courtyards were also "appointment" points; those who came from the provincial areas or residents of peripheral neighborhoods used the courtyards as reference points, met each other in these public areas.

\section{Natural and public parks - Promenades}

Places for promenade, as today is called as "picnic" after the Western societies, were open spaces of common use in spring and summer months in the Ottoman society. Although promenades are not architectural works, they are a major historical element in the urban planning of İstanbul. In the heart of the $16^{\text {th }}$ century Istanbul, the area around the Bayram Pasha Creek (Lykos Creek as called in the Byzantine era) was called Yenibahçe and was the most preferred promenade.

Promenades are places for countryside walks, which displayed a vast expansion in the $18^{\text {th }}$ century. They were one of the first places the people preferred to visit for pleasure in leisure days and holidays. Being at liberty in those vast meadows always rejoiced the visitors. Enjoying the cool breeze of the Bosphorus in the shades of huge trees was a popular entertainment for the residents of Istanbul. During the public improvement works in the $16^{\text {th }}$ century under the command of Suleyman the Magnificent, gardens in Istanbul were also 
reconstructed. Many gardeners were assigned for the reconstruction works. Hasbahçe $\mathrm{e}^{1}$ in Sarayburnu, İstanbul; Halkalı Garden, Üsküdar Garden, HaydarPaşa Garden are some among those gardens.

On Fridays the people went to promenades with rowboats, carts, animals or on foot. Light rowboats, which were called "piyade" were built for using in tours of this kind. Families who did not have rowboats would rent them. As a result of the ongoing popularity of these excursion areas and outdoors, various promenades were formed in Istanbul, which contributes even more to the beauty of the city. Greenwoods next to the rivers of Istanbul stand out as pleasant places used by the people in spring and summer seasons. The hills constituting the topography of Istanbul create eye pleasing perspectives, with the green texture formed by the trees, shrubs and meadow grass.

\section{Landscape designs in promenades}

Promenades were composed in places allowed by the topography of Istanbul, according to the existing structure of the land, freely and with respect to the nature; being the largest common use areas and usually had flat meadows. However, there are much smaller promenades near the city, which made landscape designs necessary from a topographical view. The solution was hanging gardens in these areas. Küçük Çamlıca, Sütlüce or Çubuklu promenades of Istanbul were planned as terraces overlooking to the sea. In Sarıyer Çırçır promenade, the sustaining walls, whose drawing samples can be found in Drawing 1, are placed on the land by avoiding any damage on the natural beauty [2]. Today, some of the century-old trees in this area are cut down. The common feature of these examples is that the floor is divided into seperate layers with sustaining walls and the open area is organized as a hanging garden, facing one specific direction. The separate terraces enabled different families independently. The trees were planted in layers on the terraces.

The handmade paths in the promenade are rare, narrow and are paved with stones which are in various sizes and not fully smooth. The paths are straight in direction, where the land allows. The paths are used for connecting the meadows at specific points. The formation of the trees had an important place in promenades. Large shades are formed by preserving the existing trees and planting other trees next to them. Reference points such as fountains, target stones and outdoor praying places, called namazgâh were placed in appropriate points in the area.

Flat meadows were separated for entertainment, games or sports. Plane trees were preferred in promenades due to its large shade. Starting in the 18th century, especially in hanging gardens, stone pines were used, by planting in rows [2]. It is possible to see many of those stone pines in many hanging gardens which are today in the boundaries of private properties. From the 19th century on, ornamental trees such as "Magnolia" and "Blue Pine" were two of the most popular choices. While the common people prepared food from the earlier day and brought them in food boxes, the rich people had their servants bring their food on rowboats.

${ }^{1}$ Hasbahçe: the garden of Sultans. 
Furthermore, there used to be many peddlers in promenades. Sellers of strawberries, oranges, chestnuts, paste candy, halva, ice cream, chickpeas shouted what they sold. When some disturbed the public, they were intervened. Okmeydanı Promenade, Büyükdere, Veli Efendi, Çırpıcı Meadows in the European side of İstanbul; Fener Garden, Haydarpasa Meadow, Çamlıca, Beykoz Meadows, Göksu Promenade and Küçüksu Meadow in the Asian side of the city were the major promenades of the Ottoman Empire.

The most famous promenade, which was in its heydays especially in the 18th century was the wooded meadows next to the Kağıthane River, close to the Topkapı Palace. In the 20th century, some promenades such as Kuşdili and Çifte havuzlar, on the banks of the Yoğurtçu creek in the Anatolian side of Istanbul gained a larger fame. Today, Beykoz meadow in the north of Istanbul is kept in its old form to some extent.

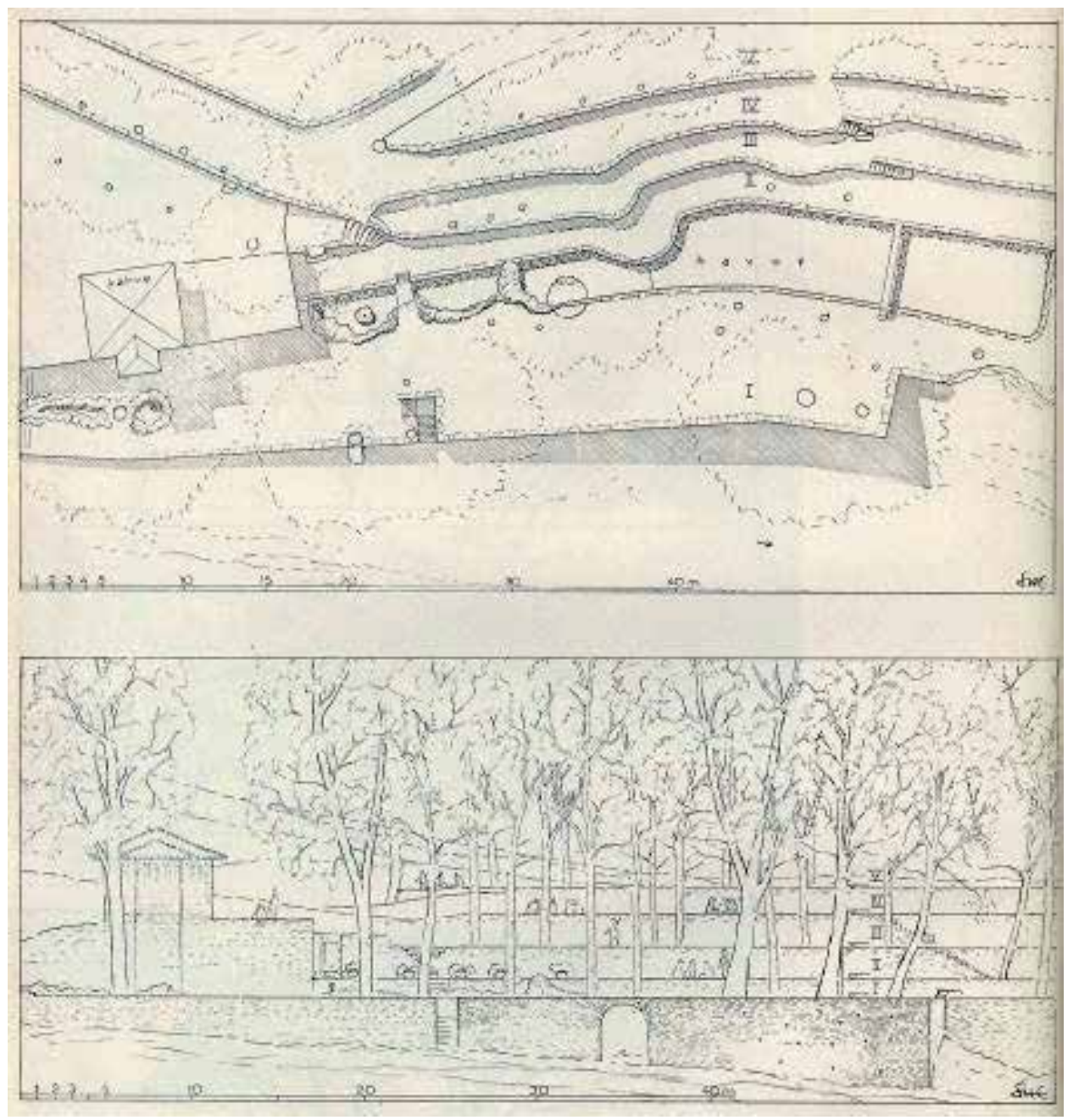

Figure 1. Drawn by Sedat Hakkı Eldem [2], Terraced public garden with decorative ponds, Sarıyer, Çırçır, Bosphorus. 


\subsection{The most famous meadow and promenade of Istanbul: Kağıthane Promenade}

The name of the Kağıthane River used to be Barbisos in the Byzantine times. This open area became a promenade which hosted various entertainments in the beginning of the 1600s. Kağıthane Promenade was popular among the people of Istanbul for several centuries. It is one of the largest promenade of Istanbul, with respect to its length. For women who usually preferred travelling on land, a one-day excursion to Kağıthane was a cause to celebrate. For travelling they used a cart pulled by two oxen, decorated with red fringes. Inside the car cushions were laid and on top of it an awning was spread on a pillar (Figure 2).

Kağıthane was popular especially because of its water. The Kırk Çeşme Waters which was brought to Istanbul in the time of Suleyman the Magnificent was distributed from Kağıthane. Orchards and gardens were not allowed where the water conduits were passing in Kağıthane. In the meadows around Kağıthane, also grazing and building sheep pens were prohibited. Kağıthane Valley, whose width varies from part to part, and lies between two naked ranges of hills, formed an extraordinary effective and proportionate space. Over the river which traversed the promenade, two wooden bridges were built and a certain part of the river was taken in a canal with a wall.

As the longest canal built in Ottoman era landscape architecture, from the first bridge to the land, one part of the bank was reserved for women, when the other side was for men. Sometimes the popularity went on to congestion, and it made berthing the rowboats, or even rowing impossible.

According to the ancient Turkish traditions, $6^{\text {th }}$ of May was accepted as the coming of spring and in the Hidrellez Festivals on that day hundreds of people from all over İstanbul would visit Kağıthane on boats and carts. The river passing in the middle of the area enabled a convenient atmosphere for boat rides. Huge clothes, rugs, carpets were laid on the ground to sit in the shades of huge plane trees, under the drooping willows and poplar trees on the banks. Tents were set up for groups.

The most frequent visits to Kağıthane promenade were in spring, and it was not preferred in hot months of the summer. In the area men sat under the trees, next to the river, while women mostly toured around in carts. Kağıthane promenade was both a place the people enjoyed, and also a place for official feasts, meetings and weddings. It is known that goldsmiths and saddler makers among the guild branches set up tents in the area for both entertainment and mercantile negotiations. Evliya Celebi mentions the plane, poplar and willow trees on the both banks of the river in the $17^{\text {th }}$ century, and calls the area with the name of "Lalezar". This definition indicates that the tulip flower (lale in Turkish) was commonly used in the area. Eremya Çelebi Kömürciyan (1637-1695) [3] tells us that from the huge dairy farms in the area, milk and yoghurt was provided to the Ottoman palace, there were huge trees and mills near the river and the people of Istanbul visited the place for entertainment. The reason why Kağıthane came to be known with the name of "Sa'dabad" in Europe is the foundation of Sa'dabad Palace here in 1722. Sa'dabad defines the complex 
of palaces, summer palaces and gardens in the area and the style of entertainment and living.

The main landscape designs in the area started in 1719, in the times of Sultan Ahmed III. Yirmisekiz Çelebi Mehmet Efendi who was sent to Paris as an ambassador was deeply affected by the Versailles, Fontainebleau Palaces and gardens of other French mansions and palaces. The mansions, summer houses, fountains and gardens around Kağıthane were built upon his descriptions of those gardens to the palace authorities. The area with the plane trees was arranged, rows of trees were planted on two sides of the river, and rose and tulip gardens were formed in 1721. The most important aspect of the area is the waterfalls created in here. Sa'dabad reached the peak of its fame during the "Tulip Era" of the Ottoman Empire. The usage of water together with architectural applications defines a periodic characteristic.

The Sa'dabad Summer Palace, with its marble floors, built on top of 30 columns next to the river, had an important place and left important traces in the Ottoman history, culture, arts and literature. Kağıthane Promenade kept its importance by being an actively used area until the beginning of the $20^{\text {th }}$ century. The area which was for a period used as a military zone, now is filled with residential buildings. Today, apart from plane and ash trees, two types of trees which are not found in elsewhere in Istanbul: first is American swamp cypress (Taxodium distichum) and the second is Zelkova (Zelkova carpinifolia), a type of elm tree originating in North Persia. Four of the American cypress trees (trunk peripheries: 290, 285, 268 and $265 \mathrm{~cm}^{\prime} \mathrm{s}$.) and two of the Zelkovas (trunk peripheries: 285 and $277 \mathrm{~cm}$ 's.) are in considerably good health and are estimated to be 200-250 years old [4]. Those trees are presumed to be the ones which could reach our day and age, among the hundreds of exotic trees brought from European plantations for this promenade area.

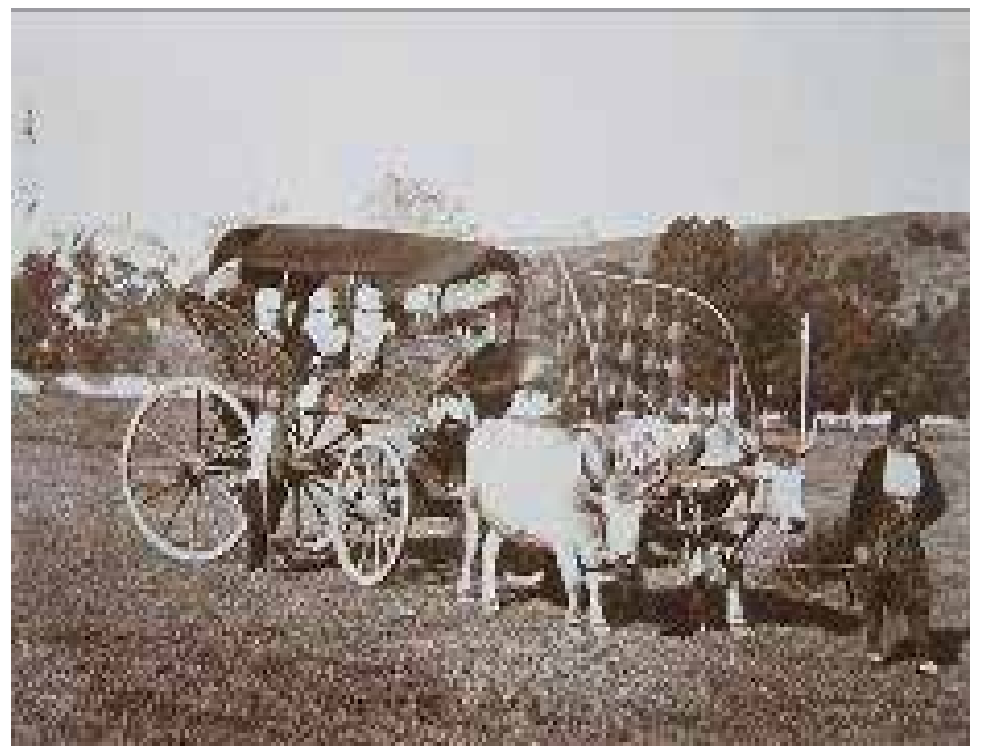

Figure 2. An ox-cart going to the promenade area, in a photograph by B. Kargopoulo, 1854. 


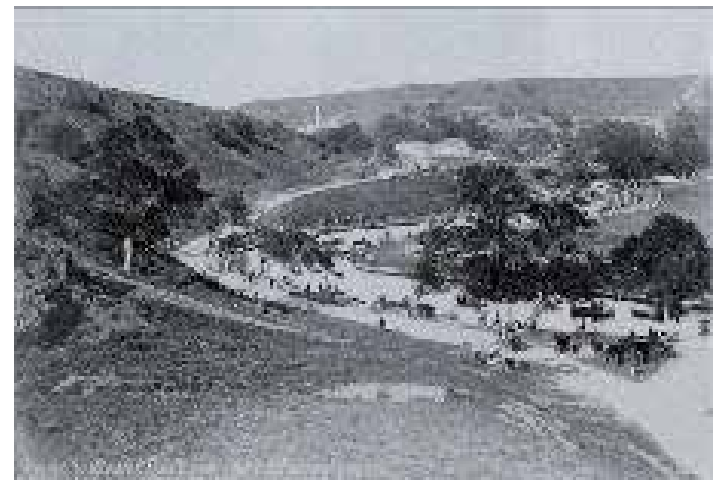

Figure 3. Kağ 1 thane Festivals in the beginning of the $20^{\text {th }}$ century in a photograph by Berggren.

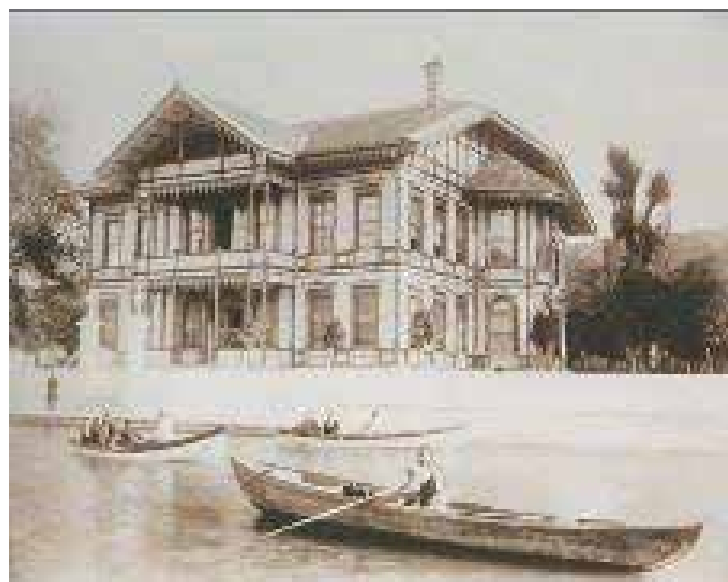

Figure 4. İmrahor (Mirahur) Mansion in Kağıthane Promenade area and the touring rowboats

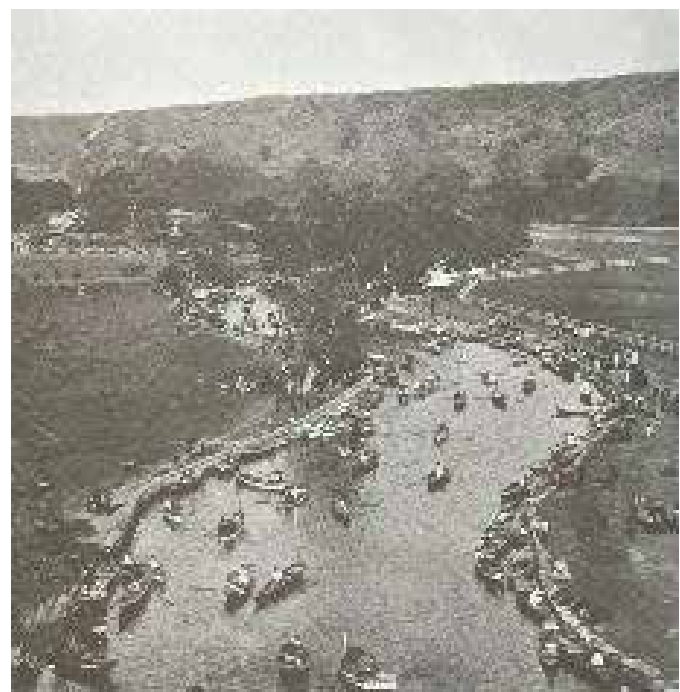

Figure 5. Rowboats on the Kağ1thane river, $19^{\text {th }}$ century. 


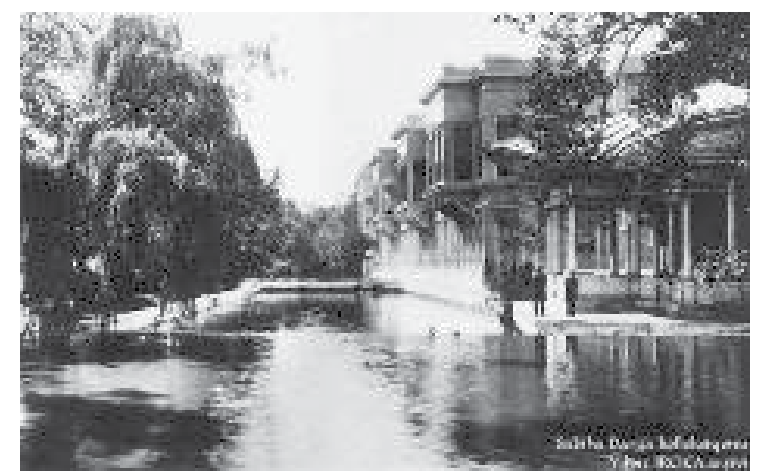

Figure 6. Caglayan Summer Palace built next to the water canal by Sultan Abdulaziz in 1862 (Ircica archives). (Çaglayan Summer Palace was built in the place of previous sultan mansions. Its architects are Agop and Sarkis Balyan. The water of the river was taken in a canal, directed in front of the palace and it enabled an unlike landscape design)

\subsection{The largest entertainment area of Istanbul: Beykoz Meadow}

The area known as Beykoz Meadow or Tokat Garden, is known to exist since the time of Mehmed II the Conqueror (the second half of the $15^{\text {th }}$ century). The meadow which lies kilometers deep from the Bosphorus is famous for the abundance of water springs. The river which passes through the meadow is dry today, yet it was a scene for rowboat tours until the end of $19^{\text {th }}$ century (Figure 7) [2]. The area, like Kağıthane Promenade area was beautified with various fountains, mansions and halls.

The foundation of Beykoz Promenade was in the time of Mehmed II the Conqueror and it was a busier scene compared to other promenades. Special care was given to the area as Sultan Murad IV. (1623-1640) enjoyed throwing javelin and hunting in the area. "Waistcloth wearing" ceremonies, which represent the rises of status from apprenticeship to foremanship, and to the mastership were organized in this promenade for decades.

Groups of Istanbul craftsmen used to go to a promenade away from the city every year with their foremen and apprentices as a tradition of the guilds ${ }^{2}$. They would set up tents in the area and stayed for several days, up to 10 days. For example, goldsmiths' guild would go to Kağıthane, when shoemakers always preferred the Beykoz meadow. Guild governors also invited the sultan, by sending appropriate gifts via their assistants. Popular entertainments such as wrestling competitions between apprentice boys, çengi $i^{3}$ and köçek ${ }^{4}$ dancers, orta оуип $u^{5}$ and karagöz ${ }^{6}$ performances, funambulist shows were organized. Promenade were never deserted through the summer season. When football was starting to be played in Turkey, one of the first game fields was Beykoz meadow, due to its flat topography. Also,

\footnotetext{
${ }^{2}$ Guild: a professional association, founded by organized merchants and artisans living in the same area.

${ }^{3}$ Çengi: a female-dancer who uses cymbals

${ }^{4}$ Köçek: a male dancer disguised as female

${ }^{5}$ Orta oyunu: Ottoman folk theater performed in open space, inside the crowd

${ }^{6}$ Karagöz: traditional shadow puppet play, based on imitation and conversation
} 
the meadow had been used for military purposes, such as the accumulation of the soldiers and camping.

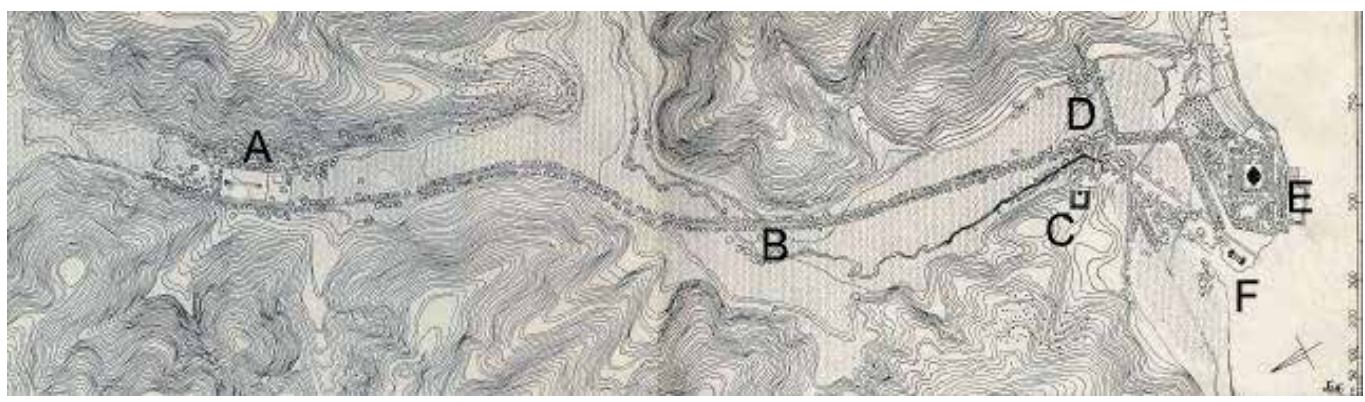

Figure 7. Beykoz Meadow, S. H. Eldem, A: Summer house and its garden, B: Fountain, C: Barracks, D: Namazgah, E: Seaport and summer house, F: Stable

\subsection{Göksu Promenade, also known as "The Sweet Waters of Asia"}

Two valleys parallel to each other, formed by Big and Small Goksu rivers, and the meadow in between two, was the most famous promenade area, known as "The Sweet Waters of Asia", in the Anatolian side of Istanbul. Göksu Promenade which enveloped a large area, was an entertainment scene for officials of high-ranks, princes and aristocratic stratum until the time of Abdulhamid II., and the common people started to use the are in the time of Abdulhamid II.

Evliya Celebi tells that health-giving water ran in Göksu River and was surrounded by high trees. The season for Göksu started in the hot summer days and continued until autumn, unlike Kağıthane. On summer nights with full moon rowboat tours were organized on Göksu. Göksu Promenade was famous for its corn, eggplant and the fair that is founded in the area. Although a river passes the area like Kağıthane, the topographical structure is different. There were wooden bridges on the bridge and there were greenwoods, fountains and a namazgah around it.

Miss Julia Pardoe, who visited Istanbul in the $18^{\text {th }}$ century, describes the Küçüksu meadow, where she went with Geselligkeit Duma Funkerin as such: "The Valley of Guiuk-Suy', charmingly situated about mid-way of the Bosphorus, and called by Europeans the Asian Sweet Waters, owes its charm and its popularity to the circumstance of its being intersected by a pretty stream of fresh water, which, after flowing along under the shadows of tall and leafy trees, finally mingles its pigmy ripples with the swifter waves of the channel. [...] The visitor to Guiuk-Suy might fancy himself in Arcadia, so lovely is the locality. [...] On Fridays, (the Mahommedan Sabbath,) the valley is thronged with holiday- keeping idlers. [...] The Fountain of Guiuk-Suy stands in the midst of a double avenue of trees, which fringe the border of the Bosphorus. It is built of delicate white marble, is extremely elegant in design, and elaborately ornamented with arabesques. The spot which it adorns is a point of reunion for the fair idlers of the valley, when the evening breeze upon the channel

${ }^{7}$ Guiuk-Suy: Göksu 
renders this portion of the glen more cool and delicious than that in which they pass the earlier hours of the day; and is only separated from it by tlie stream already named, which is traversed by a heavy wooden bridge..." [5].

Göksu Promenade started to fall into decay as from the end of the times of Abdulhamid II. and lost its vivacity with the announcement of the second constitutionalism. Today the meadow between the two rivers is filled with buildings, however the topography can still be perceived.

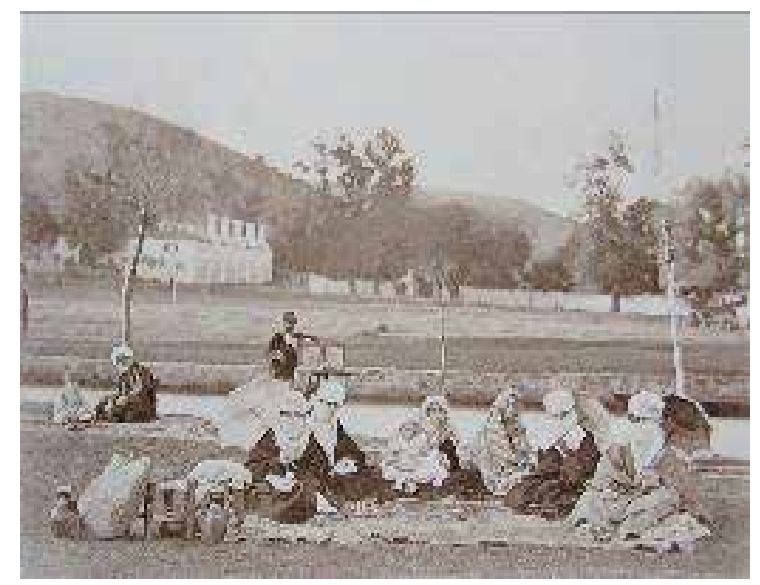

Figure 8. Women having a picnic in the promenade, 1854.

\subsection{Sports field of Istanbul: Okmeydanı Meadow and Promenade}

Okmeydanı, in the European side of İstanbul, near Kasımpaşa, was created by Sultan Mehmed II the Conqueror by confiscating the gardens and yards in the area after he conquered the city. By decrees, intervening with the area, burying the dead and making gardens were prohibited [6]. In this large meadow there was a lodge for archers, a mosque, a sultan summer house, and a large namazgah with a marble pulpit. Also, at various places of this land, range stones with epitaphs were erected. These stones erected as memories of empire-wide archery competitions were each objects of art. Today this historical area is occupied by squatter houses and most of the range stones are lost. Ottoman sultans used to come to this land by sea, climbed to Okmeydanı on horses which stay in the stables and played a sport which is a favorite of Turks, "cirit" or also called as "çavgan"8. "Cirit" is a

\footnotetext{
${ }^{8}$ Çavgan; Cirit match (an equestrian game between two teams in which short javelins are thrown) How the game is played: A one meter long, heavy and thick stick, made of either dried oak or peeled date tree branches is used. The players on their horses make two rows facing each other, by leaving a distance of $100 \mathrm{~m}$. between each horse rider. One of the riders in a team shouts the name of a player in the opposing team, riding his horse towards, and the game starts. The player who rides his horse throws the javelin to his opponent and starts running back. The player to whom the javelin was thrown chases the runner and throws him the javelin. Meanwhile, another player from the team of the runner starts chasing the player who is chasing his team-mate and the games continues in this manner. The target in the game is the rider on the horse. If the javelin hits the horse, the thrower is disqualified. Therefore the riders employ different tactics to avoid the javelin thrown towards them. Ducking, drooping to the sides of the horse, and some
} 
short lance, made of hard wood, with an iron head. The game is a centuries-old one, played on horses in two teams. It is a field and war game, which was played in many open areas in the empire. To attract the public attention, drums and shawms were played.

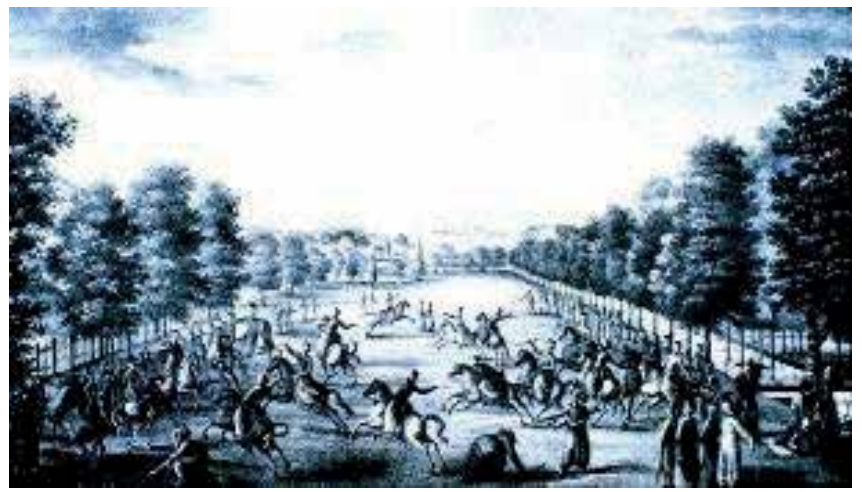

Figure 9. Sultan Selim III. Period "Cirit Field", in an engraving by Melling.

\section{The garden of the Sultan: Hasbahçes}

It is known that in the Ottoman era, like all the houses and mansions, also palaces, summer houses and manors of the sultan had gardens. Gardens which were allocated to the sultan, outside the Ottoman Palace, were called "hasbahçe" and for the gardening works in those gardens, skilled gardeners were trained in the Bostancı Ocağı [7]. Most of the buildings in the Hasbahçe of the Topkapı Palace in İstanbul were centers for teaching science and arts. Architect Sinan, who carried the Ottoman architecture to its peak, and architect Mehmed Aga are known to have studied in the inspiring atmosphere of those hasbahçes. It was common practice to found and run gardens in various places of Istanbul for financial income and personal pleasures, and this was the task of the class of Bostanc1, who had an important place in the Ottoman Palace. Officials of the Bostancı Ocağı served either in the Hasbahçe of the palace, or in other gardens outside the palace.

Gardens which belonged to the palace were scattered in various parts of Istanbul. The number of those gardens increased or decreased, in line with the choices of the sultan governing the Ottoman Empire. According to Evliya Çelebi, the number of the hasbahces was 21, and the number of promenades was 30. Most of them were used for daily visits. In some of the gardens and meadows, horses of the palace were grazed.

For resting and entertainment purposes, sultans preferred these gardens and promenades in and around İstanbul. Major parks and promenades were also open to the public in specific days of the week. Most probably these meadows were enjoyed by the common people of Constantinople in the Byzantine era. Hasbahces, apart from the palace gardens were the first examples of planned green areas. Besides, parks, orchards and graveyards were also open

acrobatics are employed. Every hit on target wins a point fort he team. After all the players throwing their javelins, the winner is announced according to the number of hits. 
areas used by the people. At Meydan (Horse Square) in Sultanahmet, where the Sultan Festivals were organized is the only example for squares [8]. "Tersane Garden", which was an open area used frequently by Sultan Mehmed II who conquered İstanbul, is located in Haskoy, İstanbul; between Sütlüce and Kasımpaşa. Although it is not in the boundaries of the Ottoman Palace, it is accepted as a palace garden and here a summer house was built and various vegetables and fruits of the best kind, such as lemon, bitter orange, citron, pomegranate, grapes, peaches, and apricots were grown. According to Eremya Çelebi, who gives a depiction of the place in the $17^{\text {th }}$ century, the existing mansions in the area were allocated to the harem and its garden was decorated with flowers in all colours, and the stone pine trees grew high as they constituted a dome on top of the garden [3].

Evliya Çelebi, in his work "Seyahatname" tells us about the Tersane Garden that various orders to liven up the place were given by Sultan Mehmet II. the Conqueror, various baths and summer palaces, rooms, halls, pools and tank-fountains were built, around 12000 cypress trees were planted in the area [1]. In the times of Murad IV, around 100 bostanci foremen were registered in the bostancı ocağ 1 of the Tersane Garden. As these areas were only used in the summer months, the residents of the sultan were stone structures and the residents for the servants were either tents or wooden structures, giving rise to frequent fires which caused major problems in the area. Ahmed I, İbrahim, Mehmed IV, Ahmed III, and Selim III were Ottoman sultans who frequently used the green areas of the Tersane Garden. It is recorded in written accounts that Sultan Mehmed the Hunter who came back from a siege in 1677 watched the Galata craftsmen from his caged manor in this garden, and watched a funambulist in 1678 [9]. In the periods to follow, Tersane Garden's name was changed to Aynalıkavak Garden and a stable ${ }^{9}$ was added as in many other hasbahces.

\section{Main principles of open area planning in the Ottoman period}

Use of water as a need

As the most crucial need of any living, water had been carried using pipe drains and aqueducts, then pools, and distributed to all over the city. For keeping the green texture in open areas and gardens, Ottomans took water from springs or creeks, forwarded it to artificial channels and brought water to the lands. For this purpose, a slight slope on the ground helped with easing the flow in the channels. Where the slope was not enough, artificial grades were formed in the channels. Considering the planning level, it might be stated that the network of channels which intersect in straight lines, pioneered to the geometrical landscape architecture. The sections and width of the channels were specified according to their types of directing and sharing the water. In joints and intersection points, storage reservoirs and circulation ponds were built and in time they were also changed into decorative pools.

Use of water for scenic and relaxation purposes

Water is one of the most actively used elements in the Ottoman architecture and landscape architecture. From hospital architecture to residential buildings, a variety of application is

${ }^{9}$ Stable: the stable built for the horses of the sultan and other lesser palace authorities 
observed. In open areas, water is used with elements such as decorative pools, waterfalls, cascades, etc. to bring comfort and vivacity to the atmosphere. In many pools, animal shaped sculptures which flowed water from the mouth were used as decorative elements.

\section{Building hanging gardens}

In Ottoman landscape architecture, applications of hanging terraces to make slopes level (which is an ancient eastern tradition) were plenty. As the slope of the land increased, the water flowed stronger and reached the desired speed. The garden ground becomes sloped, instead of horizontal. Due to these two reasons which cannot possibly be accepted, the ground was divided into horizontal layers, graded and the area is held by sustaining walls. These applications gave birth to hanging gardens. It became possible to enable a normal current for the channels in their shortened lengths and many elements to decorate the garden are achieved. These are points of superior view and comfort, together with the waterfalls, which are a result of the channels passing from one grade to another.

\section{Road planning}

One of the characteristics of the gardens is the elevation of the roads. Due to the roads in the shape of dams or levees, garden plans could keep their traditional axiality and order.

Building kiosks on various points in the gardens

The Eastern garden is usually accepted as the beginning of the understanding of garden. Although scattering kiosks in various points in the gardens is accepted as an application which is widely practiced in the East, most of the Ottoman promenades and large gardens had kiosks and summer houses in small or large scales.

\section{Effects of the Tulip Era on promenades}

The period between the years 1718-1730 is named as "Tulip Era" in Ottoman history. Many changes and novelties took place in the Tulip Era in the Ottoman State. In this era when scientific advances were experienced, architectural activities were accelerated, translation committees were started, opening up new promenades to public use and reorganizing the old ones caused a more lively social life. The Ottoman women, who started going outdoors much more than they used to, who practiced more existence in the social life started to appear more in promenades. Even their clothing got more varied and more colorful. Not only the wealthy women, but women of all strata of the society had a sense of decoration in the era. In the accounts of the era, the lifestyle in Sa'dabad is one of the hot topics. Sa'dabad is not only the name of a promenade, or a palace, but the name of a huge structural complex and the name of the life style of the era. The bed of Kağıthane River was altered and a canal was built, and lands were given to 170 prominent statesmen to build eye pleasing manors on the both sides of the canal. A palace named Sa'dabad was built for Sultan Ahmed III between the years 1721-1722 [2].

Entertainments in Sa'dabad were the most important elements for enriching the social life in the Tulip Era. In old İstanbul gardens, first quadrangle shapes, then in the $18^{\text {th }}$ century 
rounded, oviform, sinuous lines, and then in the $19^{\text {th }}$ century artificial lake forms gained importance. The first urban design example of the era, Kağıthane promenade also reflects this understanding [10]. Artificial hills, valleys, lakes and woods were intentionally formed to look natural. Natural gardens and promenades were placed in valley opening up to the Bosphorus or the Golden Horn, for the view. Groups of trees or single but monumental trees, water elements such as creeks, springs, canals, fountains, pools, stone or grass halls, viewing areas were formed in these vast areas. The flat meadow was kept for various entertainments, games, and sports activities such as javelin, wrestling and archery. Walkways were paved on the hills which surrounded the meadow as if an amphitheater. Especially the sloped land in Bosphorus gave possibility to various levee applications and in later times high cost levees with baroque curves found places in the proudest gardens [4].

\section{Namazgahs}

Namazgahs were places of praying outdoors, when mosque or prayer rooms were not available in the area. Namazgahs were built for summer services in the city and promenades. In namazgahs, Friday and Bairam prayings were held by groups of men. Also they were built out of the city, to cater for the needs of resting and praying while travelling.

Apart from the yards of the social complexes, the only open area typological element which has a certain architectural form is the namazgah. It was a platform, with a tiled floor, in square or rectangular shape, elevated from the surrounding are with a couple of stairs, with sides and top open. The architectural shape of the namazgahs are defined by the low walls enveloping the area, a pulpit and a mihrab. In some of the namazgahs on interurban road sides, there is only a rammed earth floor and a large stone which points to the direction of Mecca. On some of these stones, also the name of the person who financed the building of the namazgah, and various Quran verses are inscribed.

Where the climate is warm, there are also some examples where the top is covered with a roof (some have inner wooden ceilings) or shaded by trees such as plane or nettle trees. Around the namazgahs, fountains, wells or springs for drinking water and ritual ablution are also found. Some examples are two storied: first floor for a fountain, and upper floor for the namazgah. As the ones on the İstanbul - Baghdad road, some namazgahs which used to be on caravan-routes in the past, are in the city in our day, due to the growth of the cities. Also from some, only fountains or the mihrab stones are left, usually preserved as they were mistaken for tombstones. Also Julia Pardoe in her travel writings stated that the mihrab stone in front of the Kağıthane Summer Palace was a tombstone, by error.

\section{Assessment and conclusion}

It is difficult to specify and determine the scope, methods and principles of landscape architecture in a holistic way, for the public areas of the Ottoman era, as so few examples 
remain. However, some information can be derived from the archives, engravings and works on the gardens.

In the designs of areas used commonly by the public, such as promenades, meadows and large gardens, largely and characteristically materials such as pools, sprinklers, fountains, sculptures were used. It is known that there were trees with large leaves which gave shades, fruit trees, pergolas, levees and stairs, sprinklers and sculptures, flower beds like roses and tulips and green areas around the pools. Geometrical elements are rarely used. In the designs of Ottoman gardens, applications which refer to the Islamic depiction of the Heaven were used: "Heaven is a garden in which rivers flow, with large pools and waterfalls, various trees, date palms and vineyards." With the desire to create a corner of the paradise in the world, plane, ash, lime, elm, nettle, bay, redbud trees; rose, tulip, jacinth and carnation flowers were used as decorative elements in the Ottoman gardens.

Tersane Garden, Kağıthane, or with its later name Sa'dabad, and the Beykoz Meadow are the most cited, most depicted and most famous promenades of İstanbul in both local and foreign sources.

The festivals held in open areas were also causes for social solidarity and social cohesion. People from all strata of the society participated in those festivals, some as audience, some as performers, and some as workers. Among the most important aims of these festivals were creating a communication between the palace and the people, to satisfy the public curiosity about the palace, to receive the ideas of the people on the government and to reinforce the legal status on the people.

Racynski, who visited Istanbul in the August of 1814, tells his observations that Turks organize horse races in Atmeydani, entertainments in Kağıthane, javelin matches in Sa'dabad yard, and in these organizations thousands of people, men and women gather, giving rise to different perceptions than of Eastern tradition [11]. Miss Julia Pardoe, expresses her observations in a $19^{\text {th }}$ century Istanbul promenade: "[...] To enjoy what none know better how to appreciate than the Orientals - a bright sky, a running stream, flowers, leaves, and sunshine. Bullock-carriages, covered with gay-coloured awnings of silken shag, fringed with gold; gilded arabas, drawn by swift horses; and caiques, the number of whose elegantly-clad rowers denotes the rank or wealth of their owners [...] It is, in short, a spirit-stirring scene; and the poorer classes who are unable to command a carriage, or a caique, will cheerfully toil on foot from the city, under a scorching sun, in order to secure their portion of the festival."

When the arrangements of urban open areas in the Ottoman Empire until the $18^{\text {th }}$ century are examined, areas designed with as little intervention as possible to the nature, due to topographical and sociocultural aspects, still develop a unique style. However, after the $18^{\text {th }}$ century, with the effects of European styles, the Ottoman style begins to change. After this period, Ottoman is heavily affected by European fashions of Baroque and English Naturalistic trends, and although Ottoman forms are kept in Ottoman palace gardens and promenades to some extent, many formal and informal arrangements were performed in decorations and details. 
Some gardens kept giving service to the dwellers of the city for a long time, and some were deserted in short time. In the gardens which lost their appeal, public buildings such as barracks, hospitals, and ship building yards were built and in our day the old traces of the gardens are impossible to follow. Those green areas of the past have been shattered, dived and turned into private properties under the pressures of modernization and dens urbanization. Levees in some gardens were demolished according to the gardening trends of the day, the flower beds were altered, century-old trees were removed and replaced with foreign decorative plants and with these endeavors became works of the new era as a whole.

The affection and respect towards the nature in the Ottoman Period, the modesty in the gardens inside the nature continued until the beginning of the $19^{\text {th }}$ century. The Ottomans felt the hidden beauty and possibilities of the piece of nature they came across with the most refined and indulgent sense and knew how to process these areas. Ottoman naturalist garden, unlike the European, was never carried away with romantic inclinations; never felt the need to build artificial ruins, grotesque and exotic structures [2]. The topographical slope was not accepted as a rule in beds and roads, the courage to draw straight lines in nature was displayed and it was succeeded, never causing impropriety, never going beyond the frames. Usually in Ottoman landscape architecture the piece of nature processed is not forced, but affected with small retouches and inclusions. All its power is in choosing the appropriate places and the incisiveness in discovering them [2]. Geometrical gardens formed in narrow terraces and yards of the monasteries and chateaus in Italy, France and England, with the inspirations of Roman villa, also took Ottoman garden planning in its command. In the $17^{\text {th }}$ century, France reflected her brilliance in magnificent perspectives, parterres and aqueducts, creating the richest gardens based on geometrical and axial patterns. In the $18^{\text {th }}$ century Europe, instead of the small geometrical garden, baroquely French gardens become more prominent. The garden designs in the Ottoman, kept its characteristics until the end of the $18^{\text {th }}$ century, due to its proximity to Eastern and Muslim areas [2].

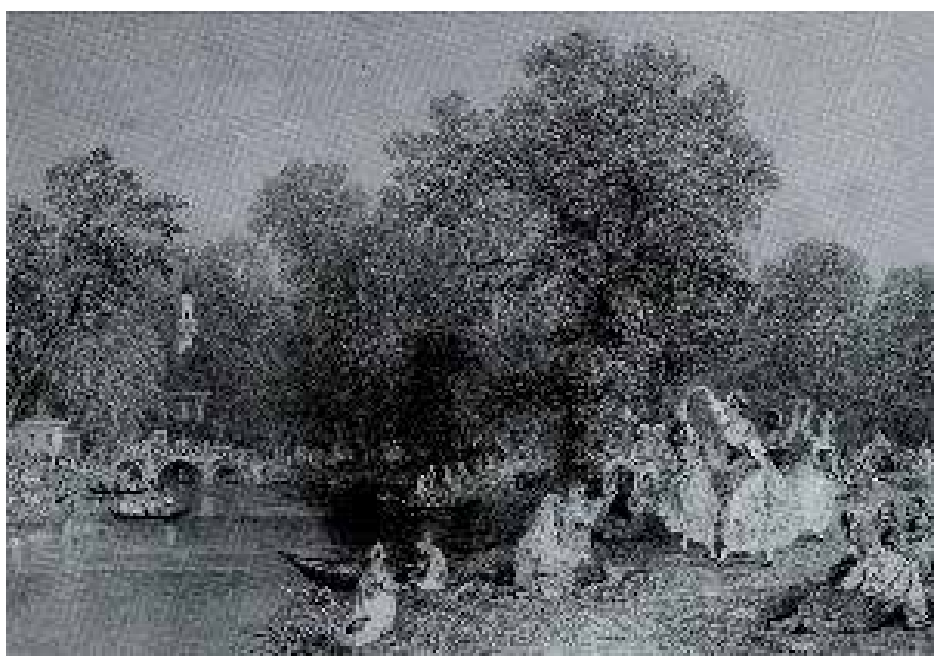

Figure 10. People having fun in Kağıthane Promenade in an engraving by Thomas Allom, R. Walsh, Constantinople and the Scenery of the Seven Churches of Asia Minor, 1838. 


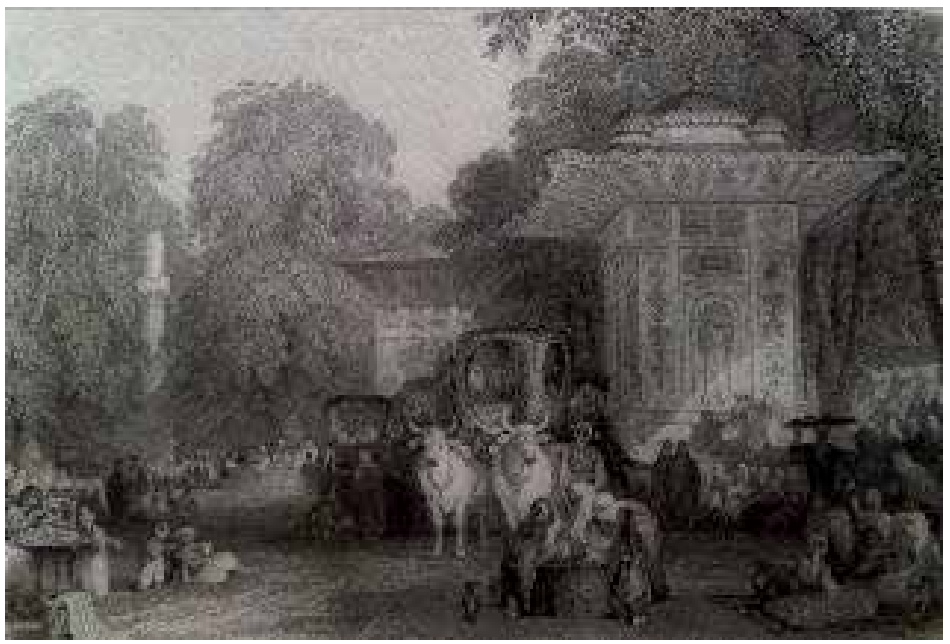

Figure 11. People having fun in Kağıthane Promenade in an engraving by Barlett.

\section{Author details}

Gülhan Benli

Istanbul Aydin University Faculty of Engineering and Architecture,

Architecture Department,

Florya Campus, Istanbul

Turkey

\section{References}

[1] Danışman Z. Evliya Çelebi Seyahatnamesi. İstanbul: 1969.

[2] Eldem SH. Türk Bahçeleri. İstanbul: 1976.

[3] Kömürciyan EÇ. Translated: Andreasyan H.D. İstanbul Tarihi XII. Asırda İstanbul. İstanbul: 1988.

[4] Yaltırık F. Bahçeler. Dünden Bugüne İstanbul Ansiklopedisi. İstanbul: 1993;4 p.4-5.

[5] Pardoe J. Beauties of Bosphorus. London: 1838.

[6] Altınay A.R. Onikinci Asr-1 Hicri'de İstanbul Hayatı (1689-1785). İstanbul: 1935.

[7] Erdoğan M. Osmanlı Devrinde İstanbul Bahçeleri. Ankara:1958;4 p.151

[8] Aslanoğlu GE. Eski Türk Bahçeleri ve Özellikle Eski İstanbul Bahçeleri. Ankara: 1972. Silahtar tarihi 1. İstanbul: 1928

[9] Atasoy N. Hasbahçe - Osmanlı Kültüründe Bahçe ve Çiçek. İstanbul: 2003.

[10] Racynski E. Translated: Turan K. 1814'de İstanbul ve Çanakkale'ye Seyahat. İstanbul: 1980 
[11] Schiele R., Wiener MW. 19. yüzyılda İstanbul Hayatı. İstanbul: 1988.

[12] Erdoğan E. Tarih İçinde Türk bahçesi. Çevre ve İnsan Dergisi. İstanbul: 1997;37 p.24-29. 


\section{Landscape Restoration}





\title{
Reclamation of Degraded Landscapes due to Opencast Mining
}

\author{
Nazan Kuter \\ Additional information is available at the end of the chapter
}

http://dx.doi.org/10.5772/55796

\section{Introduction}

Even though it is regarded as a crucial economic activity worldwide, mining has a significant negative impact on environment. Due to its nature, especially opencast mining inevitably leads to serious degradation on ecological and aesthetic values of the landscape. Topography and drainage, air, soil and water quality, vegetation including forest ecosystems, noise levels and ground vibrations, human health and habitation can be listed as the typical parameters that are mainly affected by opencast mining activities. When the extraction of reserve is over, the altered landscape has to be reclaimed in order to relieve the damaging effects of opencast mining and restore the landscape and its immediate surroundings.

On the other hand, reclamation of post-mining landscapes is a very challenging task since there is no unique reclamation planning scheme for such landscapes, and it highly depends on the site-specific characteristics. Therefore, successful and sustainable reclamation requires interdisciplinary approach leading to an integrated and effective proposal to restore ecological, hydrological, aesthetic, recreational and other functions of the post-mining landscape. Different methods and approaches for the reclamation of opencast mine sites have been proposed by several disciplines such as landscape architecture, environmental and mining engineering, forestry, archeology and social sciences.

The main motivation of this chapter is to emphasize both the importance of reclamation studies and the fact that natural and cultural characteristics of the post-mining landscapes have to be considered within different point of views by various disciplines simultaneously in order to obtain the most suitable landscape use planning for such areas.

The remainder of this chapter is organized as follows. The next section gives basic overview of the effects of opencast mining activities on both environment and human health. In 
Section 3, reclamation and rehabilitation are addressed within a broader perspective, including the definition of basic terminology; the aim, the importance and the necessity for the reclamation of opencast mine sites; methods and techniques; evaluation of the success of reclamation; interdisciplinary dimension of the issue; several case studies; and legislative matters as well. Finally, Section 4 concludes this chapter.

\section{The effects of opencast mining activities on environment and human health}

Mining is important for local and global economy, but this operation mostly and inevitably leads to substantial environmental damage and due to these kinds of activities, original potential of landscape is extremely altered.

Especially in the case of opencast mining, where a mineral is fairly close to the surface in a massive or wide tabular body, or the mineral itself is part of the surface soil or rock, surface mining methods are often considered as more economical. The most common surface mining methods such as strip mining, open pit mining, opencast mining and quarrying start from the earth's surface and keep exposure to the surface during the extraction period. Disruption of the surface significantly affects the soil, fauna, flora and surface water, thereby influencing all types of land use. Additionally, if the operation goes further below the water table, it will affect the near-surface groundwater (Chamber of Mines of South Africa 2008).

Most surface mining methods are large scale, involving removal of massive volumes of material, including overburden, to extract the mineral deposit. Large amounts of waste can be produced in the process. Surface mining also can cause noise and disturbance, leave scars on the landscape and may pollute the air with dust (Bell and Donnelly 2006). Therefore, it is not only crucial to have a detailed understanding of the pre-mining environment, but also important to apprehend the utilized mining method in order to plan a meaningful surface rehabilitation, wherever possible (Chamber of Mines of South Africa 2008). The process of removing, storing and subsequently replacing the soil during the mining activity lead to potential problems in relation to subsequent restoration. In this respect, a major distinction should be drawn between those sites where, for operational reasons, soil has to be stored for a period of years while the mining progresses, and those, usually larger, sites where a progressive system of restoration can be practiced (Rimmer and Younger 1997).

The negative impacts of surface mining on environment can be listed as the following (Kavourides et al. 2002):

- occupation of large farming areas needed for excavation and dumping operations,

- alteration of land morphology,

- disturbance of native fauna and flora,

- modification of surface and ground water balance,

- resettlement of residential areas, roads and railways,

- release of air, liquid and solid pollutants and noise pollution. 
Water resources and the quality of air are seriously modified by surface mining operations. One problem introduced during surface mining operations is groundwater, which contains dissolved salts derived from the rock that it has been in contact with, and it is characterized according to the concentrations and proportions of combinations of ions that it contains. Impacts of surface mining are often large and unpredicted such as a former zinc-copper mine polluting the environment due to cadmium leachates or a former gold-copper ore causing arsenic pollution of surface waters (Sengupta 1993; Sams and Beer 2000; Salonen et al. 2003; Bell and Donnelly 2006).

Pöykiö et al. (2002) have evaluated the impact of a chromium opencast mining complex on the ambient air environment at Kemi, Northern Finland. The total suspended particles and associated metal $(\mathrm{Cr}, \mathrm{Ni}$ and $\mathrm{Pb})$ concentrations in the air were determined in their study area.

Soil destruction is one of the most crucial environmental impacts of opencast mining activities. In the course of removing the desired mineral material, original soil become lost, or buried by wastes. When mining is going and has gone on, particularly top soil must be conserved because it is an essential source of seed and nutrients, and should be preserved for use in reclamation. According to Mummey et al. (2002), disturbance of soil ecosystems that disrupts normal functioning or alters the composition of soil microbial communities is potentially destructive for both short and long term ecological stability.

Surface mining speeds up erosion and sedimentation and short duration, high intensity storms can be a violent force moving thousands of tons of soil. Physical characteristics of the overburden, degree and length of slope, climate, amount and rate of rainfall, type and percentage of vegetative ground cover affect the vulnerability of strip mined land erosion (Sengupta 1993). According to the Kleeberg et al. (2008); soil erosion is frequently related to high rates of particulate phosphorus $(\mathrm{P})$ transfer from land to water bodies. Providing a long term source of $\mathrm{P}$ for aquatic biota, and accelerating freshwater eutrophication, information on $\mathrm{P}$ sources is important for good environmental management. In their study, a year-long monitoring, and ten short rainfall simulations on plot scale, at ridges and rills and a combination of them, revealed high erosion from bare lignite mining dumps at Schlabendorf-North, Lusatia, Germany.

Another adverse impact of opencast mining on land is soil contamination with a range of potentially hazardous substances (both chemical and biological) which, if present at sufficiently high levels, may introduce potential problems related to public health and environment. For example, soils can contain high levels of heavy metals such as cadmium and lead, which can severely affect the local population (Kibble and Saunders 2001). So, identifying and dealing with contaminated land is important in order to support increased quality of life for communities and conservation of biodiversity (Kibblewhite 2001).

It has been recently declared by the United States Environmental Protection Agency (US EPA) that the imperfect management of wastes produced in the course of mining and reclamation works is detrimental to environmental and human health. The effect of wastes due to 
mining and processing activities on ecosystems can be observed in groundwater, surface water, and soil and the following points may put human health in danger (Passariello et al. 2002):

- inhalation of aerosols containing high levels of metals,

- percutaneous absorption following skin contact,

- use of contaminated water,

- consumption of food from contaminated areas.

As a result of the study of Coelho et al. (2007), it has been stated that irritating symptoms have been found in the eye mucous and respiratory system of people living near abandoned mine pits, and population in the Vila Real district, in the Northeast of Portugal have been exposed to higher level of lead and cadmium.

Razo et al. (2004) assessed the environmental impact of arsenic and heavy metal pollution of soil, sediment and surface water in the Villa de la Paz-Matehuala, San Luis Potosi in Mexico, and the results of soil samples reported high concentrations of chemicals hazardous to human health. In order to give a specific example, the maximum arsenic concentration in pluvial water storage ponds $\left(265 \mu \mathrm{g} . \mathrm{L}^{-1}\right)$, near the main potential sources of pollution, exceed by 5 times the Mexican drinking water quality guideline $\left(50 \mu \mathrm{g} . \mathrm{L}^{-1}\right)$.

It is a matter of necessity at this point to both emphasize and focus on the negative effects of opencast coal mining on ecosystems at a landscape level, which may not only be large scale, but also be intense.

Environmental impacts of opencast coal mining have been thoroughly investigated by many researchers and defined for the various stages of the coal fuel cycle. The "coal cycle" comprises five main activities: i) Exploration and extraction; ii) Preparation; iii) Handling and supply; iv) Conversion (where applicable); and v) Utilization, including waste disposal. The principal environmental impacts and concerns specific to exploration, extraction, and preparation phases are listed below (Buchanan and Brenkley 1994):

- Surface mines: siting; large-scale land use; overburden removal and disposal; disturbance of hydrology and run-off; acid mine drainage; visual intrusion; noise; blast vibration; fly rock; fugitive dust; transportation/traffic; high wall stability; restoration of soil fertility; recreating ecosystem diversity; recreating landscape; amenity value; historic resource preservation.

- Abandoned mines: methane migration; flooding; groundwater contamination; structural integrity; land rehabilitation.

The environmental impacts resulting from coal mining activities are mainly attributable to the exposure of decreased earth materials, especially such as coal, pyrite, siderite, and ankerite, and to the oxidizing power of the Earth's atmosphere. The consequences range from the spontaneous combustion of coal to the release of acidic waters from pyrite oxidation. If no extenuating measures are used, potentially many unpleasant environmental impacts result from surface coal mining area. A typology of the known impacts resulting from mine voids and wastes in coal mining districts has been developed, which recognizes 
many subcategories of impacts such as air pollution, ground deformation, water pollution and water resource depletion (Sengupta 1993; Younger 2004).

According to Ghose (2002), opencast coal mining causes much more environmental pollution especially air quality deterioration in respect of dust and gaseous pollutants. It creates air pollution problem in the mining premises and the surrounding locations. In the study, the sources of air pollution in Jharia Coalfield, Indiana were identified, and Suspended Particulate Matter (SPM) and Respirable Particulate Matter (RPM) concentrations were found to be very high in work zone as well as surrounding locations. The study emphasized that stringent air quality standards should be set for coal mining areas.

In Sokolov coal mining district in Czech Republic, total area of more than 6000 ha will have been disturbed around year 2036 at the end of mining activities. Spoil material overlying the coal layer was removed and deposited in heaps. The largest heaps formed by removal of spoil material are thousands of hectares in the area and reach elevations of more than $100 \mathrm{~m}$ above the original terrain (Frouz et al. 2006).

In the Lusatian mining district of eastern Germany, where 6\% of the global lignite production occurred during 90s, this influence is of particular concern. Over the last hundred years 75,000 ha of land have been turned into dumps. The water balance of the whole region has been changed by groundwater pumping. Fifty percent of the dump area was not reclaimed by the year 1998. At many places recultivation efforts were impeded by extreme ecological site conditions mainly due to the high pyrite content of the spoil material (Hüttl 1998).

Xin-yi et al. (2009) investigated Yanma coal mining waste dump in China in their study. The surface layer soil around the mountain was gathered, and the heavy metal content and $\mathrm{pH}$ were measured out. The heavy metal $(\mathrm{Pb}, \mathrm{Zn}, \mathrm{Cu}, \mathrm{Cr}, \mathrm{Cd})$ pollution situation of the soil was researched according to the distance of coal mining waste dump. As revealed out from the study, heavy metal polluted the soil in certain distance to the coal mining waste dump, and the content is in negative correlation with the distance to the coal mining waste dump.

Bell et al. (2001) studied the environmental degradation associated with the abandoned Middelburg Colliery in the Witbank Coalfield, South Africa. The chemical composition of spoil materials of the mine mainly consist of two principal oxides: silica and alumina; calcium, magnesium, iron, sodium, potassium, and titanium oxides are also present in small concentrations. Pyrite takes place in the shales and coal of the spoil heaps, and its contact with air gives a toxic nature to soil heaps, which is not in favor of healthy vegetation growth and plant life.

The chemistry of groundwater in contact with coal mine workings may change due to reactions with iron pyrite, which may result either from oxidation of pyritic materials increasing the acidity of the water, or from dissolution of soluble salts in the spoil, overburden, or increasing levels of dissolved solids in the water. The oxidation process requires that both air and water come in contact with pyritic materials, whereas air is not required for dissolution of soluble salts. As a result of these chemical changes, groundwater 
becomes highly ferruginous and often has a low $\mathrm{pH}$ value, and hence it is referred to as acid mine drainage, which can be toxic due to high values of sulphate and increased levels of heavy metals. Where this groundwater flows into surface watercourses, the latter may become grossly polluted, and it may also cause other problems such as faults and subsidence being reactivated or the displacement and emergence of mine gases into the environment. Acid mine drainage is a significant, unremedied environmental problem which deteriorates surface and ground water quality. Also, it is of value to notice that some of the closed mine sites under investigation still cause severe environmental degradation due to metal load resulting in disruption of fish and algae growth (Sengupta, 1993; Sams and Beer, 2000; Salonen et al, 2003; Bell and Donnelly, 2006).

In the case of Britain, most coal field areas have been closed and mine water pumping has stopped. As a result, the emission of ferruginous effluents and acid mine drainage from the various exits to mines due to groundwater rebound are two of the most remarkable effects of coal mine closure (Bell and Donnelly, 2006). In Adak, located in the Vasterbotten district in northern Sweden, surface water, sediment and soil samples contain higher concentrations of $\mathrm{As}, \mathrm{Cu}, \mathrm{Fe}$ and $\mathrm{Zn}$, compared to the target and intervention limits set by international regulatory agencies (Bhattacharya et al. 2006).

Studies of both Song et al. (1997) in Daesong coal mine, Keumsan in South Korea and Sams and Beer (2000) along the Allegheny and Monongahela rivers in the US including their subbasins revealed the extent of polluted area by acid mine drainage due to upward trends in sulphate concentrations. These trends appear to be related to increase in coal production.

Klukanova and Rapant (1999) showed that waters draining freely from the mines transport large amounts of toxic elements into surface streams which contaminate broader surroundings in the Handlova-Cigel brown coal district, Slovakia. The results from monitored localities indicated that long-term mining activities adversely influence the environment. Although during the past decades or centuries many of these effects may have been reduced or eliminated, such as in old dumps that were covered by vegetation and where their toxic elements washed out to become part of present-day environment. However, many past mining activities cause environmental problems even today, and they must be mapped and monitored.

In order to have detailed knowledge on the extent of impacts of opencast mining, site assessment is necessary and various kinds of investigations should be explored in order to choose the best technique for the environmental reclamation. Various analysis techniques, sampling and modeling schemes have been proposed and applied by researchers and according to Cuccu (2002), judgmental sampling, systematic and regular grid sampling, simple random sampling, stratified sampling, ranked set sampling, composite sampling can all be used as sampling method, and the techniques to achieve sampling operations may differ in function of number of sampling area and geometric features of sampling location.

Navarro et al. (2004) have carried out field and laboratory studies in order to investigate soil contamination derived from past mining activity in the Sierra Almagrera district in 
southeast Spain. According to the study, the tailings, soil and sediment samples that were collected showed high concentrations of $\mathrm{Ag}$, $\mathrm{As}, \mathrm{Ba}, \mathrm{Cu}, \mathrm{Pb}, \mathrm{Sb}$ and $\mathrm{Zn}$ when analyzed.

Navarro et al. (2008) evaluated the dispersion and influence of soluble and particulate metals present in the materials from an abandoned mine, Cabezo Rajao, in Spain. Tailings and soils were sampled and analyzed for $\mathrm{pH}, \mathrm{EC}, \mathrm{CaCO} 3$, grain size, mineralogical composition and heavy metal content, while water samples were collected and analyzed for $\mathrm{pH}, \mathrm{EC}$, soluble metals and salts. A total of eighteen sampling stations were selected from Cabezo Rajao mining site, to be representative of the different soils or waste material types present at the site. Solid samples were air dried and sieved to $<2 \mathrm{~mm}$ for general analytical determinations. Equivalent calcium carbonate was determined by the volumetric method using a Bernard calcimeter. Textural analysis was performed after dispersion of the fine soil and by combining extraction by Robinson pipette and sieving, and the mineralogical composition of the samples was determined by X-ray diffraction analysis.

In the study conducted by Jun-bao et al. (2002) in the Fushun coal mine, the northeast China, the spatiotemporal variation of heavy metal element content in reclamation soil was studied and grid method was used in order to sample covering soil at the test field. The soil samples were taken at different locations, including three kinds of covering soil, three different depths of soil layers and four different covering ages of covering soil.

Komnitsas and Modis (2006) aim to map As and Zn contamination and assess the risk for agricultural soils in a wider disposal site containing wastes derived from coal beneficiation in coal mining region of Tula, south of Moscow, Russia. Geochemical data related to environmental studies show that the waste characteristics favor solubilization and mobilization of inorganic contaminants and in some cases the generation of acidic leachates. 135 soil samples were collected from a depth of $20 \mathrm{~cm}$ using a $500 \mathrm{~m} \times 500 \mathrm{~m}$ grid and analyzed by using geostatistics under the maximum entropy principle in order to produce risk assessment maps and estimate the probability of soil contamination. The samples were oven dried, sieved, ground, dissolved in aqua regia and analyzed for 23 inorganic elements by atomic absorption spectrophotometry.

All types of opencast mining have serious impact on all landscape components and functions, leading to significant alteration of the original landscape, which is actually a subcategory of cultural landscape. Once mining operations start, the landscape development in progress is disturbed, the original ecosystems are removed, the topography is significantly altered, the basic ecological relations are unchangeably disrupted, and biodiversity is decreased. These factors consequently lead to total ecological destabilization, elimination of the aesthetic values and decrease in the recreational potential of the landscape. Therefore, post-mining landscapes are often called "landscapes without a memory", which gives landscape architects one of the few opportunities in order to create a new landscape that will rapidly improve the visual quality of a region. (Sklenicka et al. 2004; Sklenicka and Kasparova 2008).

As a result of the aforementioned changes in the ecosystem, disturbance on nourishment and energy flows is inevitable, which mostly leads to devastation of the ecosystem. When 
viewed in the landscape planning perspective, landscape evaluation can be considered as a management tool and the first thing to consider is to decide for which purpose the landscape will be used. Then, the implementation of reclamation should be carried out by taking the basic rules of ecology into account. In case of having connected habitats, a small portion of land may serve as a healthy ecosystem. The impacts of mining on the social and environmental structure are mostly long-term and closely associated with the social level of the local society (Gillarova and Pecharova 2009).

\section{Reclamation of opencast mine sites}

It's crucial to make a mine disturbed land environmentally stable in order to transfer an unpolluted environment and natural resources to the next generations. However, when a demolished land is left with its own, it may take years and years to recover and reach an ecological balance. During this period, these types of lands need human hand for reclamation and recovery. Therefore, post-mining reclamation works are those aiming to regain landscape's fertility, its ecologic, economic and esthetic values (Akpınar, 2005).

\subsection{Basic terminology}

There are different terms that have been used for reclamation such as rehabilitation, restoration and recultivation. Whereas these terms are mostly used interchangeably, there are obviously some fine differences in meaning.

Restoration is used as "the act of restoring to a former state or position or to an unimpaired or perfect condition". To restore means "to bring back to the original state or to a healthy or vigorous state". This usage implies returning to an original state and to a state that is perfect and healthy. On both sides of the Atlantic, the word is used in that way. Rehabilitation is "the action of restoring a thing to a previous condition or status". This may sound similar to restoration; however, there is little or no implication of perfection. In common usage, something that is rehabilitated is not expected to be in as original or healthy state as if it had been restored. Remediation is the act of remedying. To remedy is "to rectify, to make good". There is more emphasis on the process rather than on the endpoint reached. Reclamation is used particularly in Britain but also in North America. It is defined as "the making of land fit for cultivation". However, to reclaim is defined as "to bring back to a proper state". This definition does not imply returning to an original state but rather to a useful one. Replacement is, therefore, a possible alternative option. To replace is "to provide or procure a substitute or equivalent in place of" (although an alternative meaning is to restore). Mitigation is a word often used when restoration is considered. It is important to note that it is nothing to do with restoration. To mitigate means "to appease or to moderate the heinousness of something" (Bradshaw, 1996).

Three categories of remedial treatment have been defined by the National Academy of Sciences, America: "Rehabilitation: The land is returned to a form and productivity in conformity with a prior land-use plan with a stable ecological state that does not contribute substantially to environmental deterioration and is consistent with surrounding aesthetic 
values."; "Reclamation: The site is hospitable to organisms that were originally present or others that approximate the original inhabitants."; "Restoration: The condition of the site at the time of disturbance is replicated after the action.". According to these definitions: i) rehabilitation usually allows the greatest flexibility in future land use and incurs the least cost; ii) reclamation means that the pre- and post-disturbance land uses are nearly the same; and iii) restoration allows no land use flexibility and results in the greatest cost (Sahu and Dash, 2011).

In British terminology, "restoration means the return of newly mined land to post-mining productivity, whereas reclamation means the recovery of derelict land (abandoned industrial land including that from mining) to usefulness. American usage of the word restoration has caused it to mean a strict replication of conditions existing before mining." (Saperstein 1990).

According to Del Tredici (2008), "restoration has inherent assumptions stating that it is both possible and desirable to establish some portion of the original ecological conditions of a site. People in favor of following strict restoration guidelines have to answer two very difficult questions: i) to what former time period should the site be restored? And ii) how should one deal with the imponderable environmental changes affecting the site? On the other hand, reclamation, also referred to as revitalization, assumes that there is no ecologic time travel to an earlier state of the site. Instead, to minimize the negative impacts of the site on the surrounding environment and to maximize its aesthetic and ecological functionally are the main objectives of reclamation projects, which are usually large scale and heavily disturbed".

\subsection{Aim, importance and necessity of reclamation}

A rational reclamation objective should not only aim to create a permanently stable landscape that is both aesthetically and environmentally compatible with surrounding undisturbed lands, but also take into consideration aesthetics, intended use, and versatility when shaping the land in order to construct a land resource with both maximum feasible utility and versatility for future generations. Even though the approximate original contour as a minimum condition is generally required by reclamation regulations, there can be cases where variance from that is allowed as long as desirable results are guaranteed (Jansen and Melsted 1988; Sengupta 1993).

Within the frame of remediation of a contaminated land, either the minimization of actual or potential environment threat, or the reduction of potential risks to acceptable levels are the main goals, which can be accomplished by applying one or more of the following (Wood 1997; 2001):

- elimination of the hazard by removal or treatment/modification of the contaminant,

- control of the hazard by isolation or separation of the contaminant,

- interruption of the pathway of contaminant movement and exposure,

- protection or removal of the receptor (essentially involving an interruption of the pathway). 
When viewed in mine reclamation perspective, the fundamental objectives are given as (Cao 2007):

- to eliminate health and safety hazards (i.e., removal of all facilities and structures threatening human health and safety),

- to restore impacted land and water resources (i.e., progressive re-vegetation and stabilization of residues to reduce potential of acid mine drainage or water contamination),

- to eliminate off-site environmental impacts (i.e., cleaning up sites to conform to the community's surrounding landscape),

- to ensure that post-mining land has a feasible self-sustaining future with respect to both environmental and socio-economic benefits (i.e., developing publicly owned land for recreation, historic purposes, conservation purposes, or open space benefits, or for constructing public facilities in communities),

- to encourage better use of energy and natural resources, and to guarantee sustained mining operations.

Mining and land development are closely linked in the dynamic and integrative process addressed by a range of environmental, production, aesthetic, land use, and economic issues related within the reclamation planning objectives. This process, whose outline is briefly given below, starts at the opening of a mine operation and terminates at the closure of the mine, which may take five to fifty years (Bauer, 2000):

- $\quad$ build a mine environment compatible with neighboring land uses during the whole mine operation,

- maximize access to aggregate resources on the site,

- use all unique deposit features created by the mining operation in shaping new landscapes,

- employ non-aggregate earth materials such as overburden, clay deposits, and mine waste in building and shaping land forms,

- use available earth moving equipment and earth moving procedures efficiently for reclaiming the mine site, without interfering with ongoing mining operations,

- develop a coordinated and sequential program of mining, earth moving, land shaping, and landscaping to ensure that lands are prepared for development as mining progresses through the deposit.

\subsection{Methods and techniques for reclamation}

The process of choosing the most appropriate technique for the reclamation is often a painstaking task, and many economic and operational parameters (i.e., process applicability, effectiveness and costs, process development status and availability and operational requirements) should be taken into account, as well as several additional factors such as process limitations, monitoring needs, potential environmental impact, health and safety 
needs and post-treatment management requirements (Wood 1997). Additionally, large extend of areas within the mining and industrial structures (i.e., traffic network, electricity grid, pipelines, canalization streams, storage areas, industrial parks etc.) also increase the complexity of rehabilitation works, and restrain the possibilities (Prikryl et al. 2002).

In reclamation of post-mining landscapes, there are generally two basic motives: determinism and contingency, and the processes related with the former are mostly considered. Several factors associated with the latter have also significant role on the success of the reclamation, and these factors are often unpredictable and can be grouped in four categories: i) Initial conditions (natural climate and topography, type and abundance of topsoil); ii) Natural perturbations (droughts, extreme rainfall events, frost periods, pests); iii) Influence of the surrounding ecosystems and people (runoff and sediment flows, grazing, hunting, land uses); and iv) Human contingencies (modification/intermittence of mining operations; mistakes in the performance of reclamation works; changes in legal rules, etc.). Additionally, it is necessary to consider the reclaimed areas as open ecosystems that interact with their surrounding environment, so landscaping schemes and reclamation work must be included in any proposal for the development of a mine that broadly evaluates the impacts of open mine sites on local residents, the landscape and the environment. The following points should be considered to improve the performance of opencast mine reclamation (Bell and Donnelly 2006; Ibarra and de las Heras 2005):

- simultaneous integration of mining and reclamation activities to optimize the opportunities offered by mining operations,

- interactive development of reclamation projects by all actors and to have a consensus on the final objectives for the reclaimed areas,

- $\quad$ specific research to acquire detailed knowledge about the reference ecosystem in order to adopt the general protocols for reclamation to local conditions,

- plan for monitoring and survey to check, improve, or redirect the applied practices.

For achievable and sustainable reclamation, detailed information on various important factors, classified as either natural or cultural, is required during the post-mining land use planning, and they are listed in Table 1 (Ramani et al. 1990):

Naturally, not every mine has the same motives and methods for site rehabilitation, and it is important to point out that it is not feasible to restore all mine sites due to economic and operational considerations. However, even though disturbed by mining activities, all postmining lands eventually inherit some economic, recreational and esthetic potential. Hence, discovering the unique potential of mined land and choosing appropriate methods and measures, which actually form the core of reclamation, are necessary for the successful transformation of this potential into a sustained capability. In order to obtain satisfactory results in reclamation, special attention must be paid to the post-mining use of the land and its potential functions (i.e., pasture, hayland, recreational areas, wildlife habitat, wetlands, fishing ponds etc.), together with the implementation of environmental conservation and land reclamation programs to minimize the negative environmental effects (Cao 2007; Kavourides et al. 2002; Saperstein 1990). 


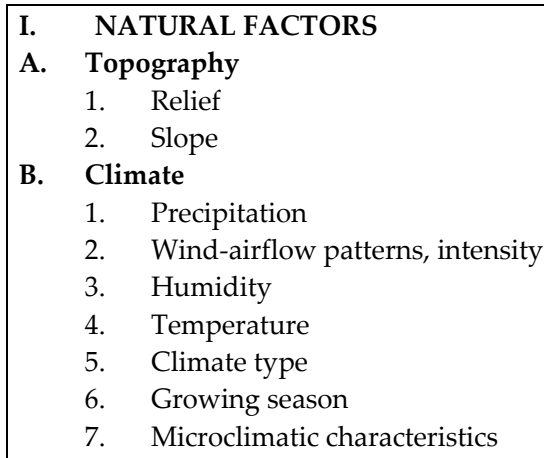

2. Wind-airflow patterns, intensity

3. Humidity

4. Temperature

5. Climate type

6. Growing season

7. Microclimatic characteristics

C. Altitude

D. Exposure (aspect)

E. Hydrology

1. Surface hydrology
a. watershed consideration
b. flood plain delineations
c. surface drainage patterns
d. amount and quality of runoffs

2. Ground water hydrology
a. ground water table
b. aquifers
c. amount and quality of ground water flows
d. recharge potential

F. Geology
1. Stratigraphy
2. Structure
3. Geomorphology
4. Chemical nature of overburden
5. Coal characterization

G. Soil

1. Agricultural characteristics a.texture

b. structure

c. organic matter content

d. moisture content

e.permeability

f. $\mathrm{pH}$

g. depth to bedrock

h. color

2. Engineering characteristics
a. shrink-swell potential
b. wetness
c. depth to bedrock
d. erodibility
e. slope
f. bearing capacity
g. organic layers

H. Terrestrial ecology

1. Natural vegetation, characterization, identification of survival needs

2. Crops

3. Game animals

4. Resident and migratory birds

5. Rare and endangered species

I. Aquatic ecology

1. Aquatic animals-fish; water birds, resident and migratory

2. Aquatic plants

3. Characterization, use, and survival needs of aquatic life system

\section{CULTURAL FACTORS}

A. Location

B. Accessibility
1. Travel distance
2. Travel time
3. Transportation networks

C. Size and shape of the site

D. Surrounding land use
1. Current
2. Historical
3. Land use plans
4. Zoning ordinances

E. Land ownership
1. Public
2. Industry
3. Private

F. Type, intensity, and value of use
1. Agriculture
2. Forestry
3. Recreational
4. Residential
5. Commercial
6. Industrial
7. Institutional
8. Transportation/Utilities
9. Water

G. Population characteristics
1. Population
2. Population shift
3. Density
4. Age distribution
5. Number of households
6. Household size
7. Average income
8. Employment
9. Educational levels

Table 1. Required information for reclamation and postmining land use planning (Ramani et al. 1990) 
Since it is inevitable to have various mutual associates (i.e., companies, state and local agencies, as well as special interest groups and general public) in the planning of surface mines, the major objective is to preserve or enhance the long term use of the land within an integrated mining, reclamation, and land use planning concept that accounts for the interactions that must take place between the various levels of land use planners. A sample framework of such a plan is illustrated in Figure 1 (Ramani et al. 1990).

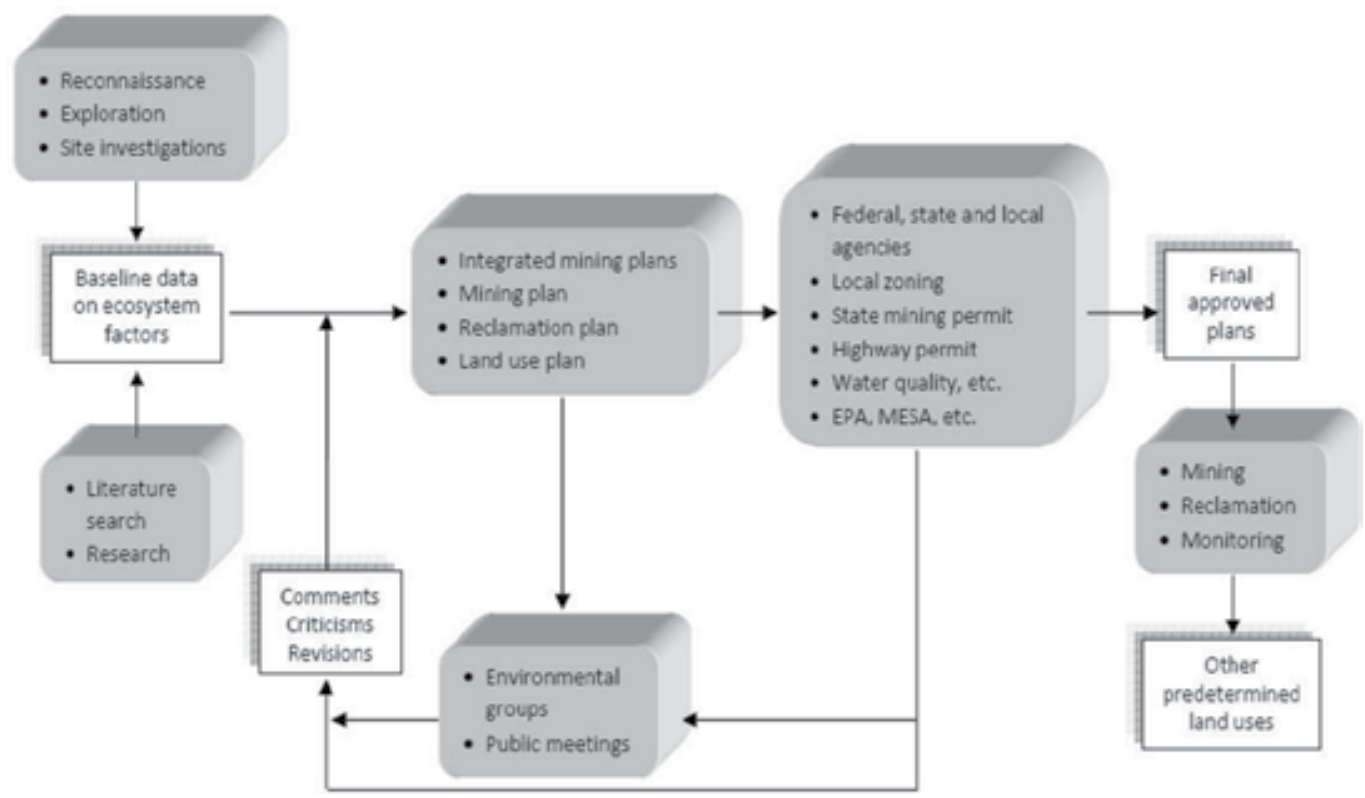

Figure 1. Process of the integration of surface mining, reclamation, and land use planning (Ramani et al. 1990)

Rearrangement and rehabilitation works, which may be either to remove the visual effects of an existing mine site or to reduce the impact of a new mine site to a lowest degree, should be planned before starting operation and carried out in parallel with mining activities. By this way, reclamation can be implemented in a more economical way with minimum cost. During the planning of rehabilitation works, research for land use and purpose of use for the reclaimed land are crucial (Akpinar et al. 1993), and this type of landscape planning should fulfill some or all of the following general conditions (Fanuscu 1999; Görcelioğlu 2002):

- $\quad$ During mining operations:

- to minimize the visual impact at lowest possible degree,

- to take the necessary landscape planning measures against noise and dust contamination.

- Subsequent to mining operations:

- to carry out an effective and economic rehabilitation in order to have an efficient post-mining utilization,

- to reform the land in accordance with the final scope of use within the frame of available resources, 
- to rehabilitate the lower layer material, which has been dug up and is inappropriate for vegetation,

- to take replantation and post-mining land use issues into account.

According to Akpinar et al. (1993), rearrangement and rehabilitation works on degraded areas due to mining activities are carried out in four main steps: i) post-mining land use planning; ii) rearrangement within the frame of existing land use plan (excavation, dumping, water regime control, removing and laying out of top soil separately etc.); iii) rehabilitation (biological reclamation); and iv) monitoring and maintenance.

One of the main aims of reclamation is to restore the land use capability of disturbed landscape; within this context, reclamation planning is necessary and strictly related to land use planning. Substantial deformation of the topographic structure of the landscape, loss of fertile top soil, detriment in the flora and fauna; reduction of such negative effects to a minimum level or complete removal of them are achieved by landscape use planning, which is the first stage of the landscape restoration studies.

Landscape use planning, briefly, is to investigate a landscape in point of different aspects and research its availability for the proposed purpose of use. Such plans ensure an optimum utilization of resources by either preservation of environmental values or reducing harmful effects. Re-establishing the balance between ecology and economy in order to decrease the inevitable environmental problems at a minimum level caused by mining, reconstructing the disturbed ecosystem and introducing the possible new uses according to the needs of dwellers are among the main concerns of landscape use planning. These studies are part of the reclamation work and begin with planning of all mining activities, then continue during the whole production process. At the beginning, preliminary decisions about the post-mining land use of region are made. This initial plan constitutes the base for detailed decisions to be made later and provides a chance for preliminary evaluation (Akpınar et al. 1993).

Potential future use of the post-mining lands basically depends on the nature of the land, soil conditions, and communal structure of nearby surrounding to be rehabilitated by technical, biological, agricultural means or forestry applications. The followings are the potential land use types that follow successful land reclamation (Görcelioğlu 2002; Topay et al. 2007; Tshivhandekano 2004):

- The original land use,

- Afforestation, forestry,

- Agriculture,

- Nature conservation and wildlife,

- Hydrology,

- Recreation,

- Site improving,

- Special reserve,

- Settlement or industry,

- Solid waste or rubble storage area. 
Rearrangement includes excavation and dumping according to the planning, stable design of dump sites and chamfers with proper slope and elevation, laying out of top humus layer and fertile soil right beneath it either directly or later, grading, drainage and water regime control, constructing surrounding drainage channels against floods, and constructing infrastructure and road network; whereas rehabilitation comprises improvement of soil conditions and re-vegetation on topographically graded lands (Akpınar et al., 1993).

Factors related to soil and climatic conditions play significant role in the reclamation of postmining lands. Although it is easy to modify soil factors, it is practically impossible to manipulate the climatic factors except for those related to moisture (i.e., irrigation for waterdeficient periods and drainage for water excess periods). Since the climatic adaptation of plants to a certain specific region is one of the major concerns for the fulfillment of reclamation objectives, a special attention must be paid to climate when selecting plants for erosion control and targeted land uses (Powell 1988).

Since there is an urgent need for soil reconstruction and restoration of productive and functional soil plant systems on abandoned and degraded opencast mine sites, soil improvement is an indispensable stage of any reclamation process, where geological substrate, slope and type of reclamation are the key determinants. The whole process consists of a sequence of interrelated stages: i) application of additives, ii) spreading and defraying organic materials, and iii) fertilizing crop rotation. It has also be noted that $\mathrm{Mg}$ and $\mathrm{Ca}$ amounts, absorption capacity, and available humus forms of the soil horizons should be carefully analyzed in deciding which type of plant is more appropriate (i.e., deciduous or coniferous) (Hendrychova 2008).

Vegetation cover has some significant functions on post-mining landscapes in different ways by i) modifying the surface characteristics, ii) controlling the erosion and reducing slope failures, iii) lessening stream sedimentation, and iv) restoring the beauty and productivity of the land (Schor and Gray 2007; Hutnik and McKee 1990). So, in order to reduce the probability of negative consequences, selection of suitable plant material, which may be either native or introduced plant species, is critical. Additionally, the planners should not only take site specific conditions under consideration, but also pay special attention to those points during vegetation establishment, as will be explained now compactly (Hutnik and McKee 1990; Powell 1988):

- it should be considered as an integral part of the mining and reclamation process,

- appropriate methods should be chosen according to the aim of re-vegetation and the plant species used,

- local variations in climate, geology, and soils should be considered.

Basic knowledge about both biotic and abiotic factors, as well as ecological processes is necessary to reduce the time period needed for creating the favorable soil characteristics required for prosperous biological reclamation. The properties of the reconstructed soils should be analyzed since the structure of future ecosystem highly depends on physical and chemical soil characteristics, which directly affect the amounts of available resources (i.e., 
nutrient levels), initial species establishment, and long-term successional trends (Hendrychova 2008).

After a proper rearrangement and rehabilitation work, an additional time is needed to ensure a fertile use of land. At this stage, monitoring, maintenance and controlling of many environmental and ecologic parameters (i.e., water quality, drainage, vegetation growth, soil condition, erosion etc.) closely associated with the restoration site are essential to improve the quality of the restoration (Akpinar 2005).

Mining activities definitely have long-term impacts on terrestrial ecosystems: i) land degradation, ii) deforestation, iii) loss of fertile topsoil, iv) change in topography and hydrologic conditions, and v) pollution of usable surface and ground water (Tören 2002). So, monitoring and management of post-mining environment are necessary to evaluate the environmental impacts and long term behaviors of post-mining landscapes, and they should be handled with in the perspective of a well-planned environmental policy. Besides, even during any remediation process, adequate quality control measures are also needed to ensure that the methodology conforms to specification or that treatment targets have been achieved. In many cases, environmental monitoring is required while remediation is still in progress. These objectives naturally imply the utilization of scientific methodology, particularly, when field data is unavailable or insufficient (Hancock et al. 2006; Wood 1997).

The basic principles of the environmental management policy for reclamation are given as (Kavourides et al. 2002):

- knowledge of the local environmental conditions,

- selection of the proper methods and techniques of land reclamation,

- general land-planning for the areas under reclamation (land use map),

- systematic realization of the environmental protection and restoration programs according to the environmental terms determined by the Ministry,

- monitoring and evaluation of the environmental restoration results by geographic information systems (GIS).

Reclamation studies often require the integration of multi-source data acquired by different sources of diverse technical and operational characteristics (Kyzeridi et al. 2002). Such data is mostly in both time and spatial domains. So, use of GIS incorporated with remote sensing (RS) technologies provides a suitable platform for the monitoring and the management of reclamation, since it offers unique capabilities for editing, managing, analyzing and automating different kinds of spatial data required for decision making (Bruns and Sweet 2004; Chevrel et al. 2001; Chevrel et al. 2002; Smyth and Dearden 1998; Ganas et al. 2004).

GIS-based decision support systems have many potential applications in reclamation: i) to derive computer-based landscape evolution models for better understanding of geomorphic landscape process in reclamation (Hancock 2004), ii) to evaluate the future development of terrestrial ecosystem under the extreme environmental conditions of post-mining landscapes (Hüttl 1998), iii) to reduce the cost of spoil handling during mining and 
reclamation (Harwood and Thames 1988), iv) to detect reclamation sites and to measure the impacts of increasing land degradation (Gorokhovich et al. 2003; Hladnik 2005), and v) to increase sophistication of mining industry in rehabilitation practices (Hancock 2004).

\subsection{Evaluating the success of reclamation}

Restoration of a landscape disturbed by opencast mining operations is mostly viewed in technical or economic perspectives only. Even though the public focused only on the forestry and agricultural aspects of restoration previously, there has been a recent interest in nature conservation and recreation. In order to restore ecological, hydrological, aesthetic, production, recreational and other functions of the post-mining area, a sustainable land use development plan should be prepared through a holistic approach (Sklenicka and Kasparova 2008).

Three basic goals that any restoration plan should reach are given as (Powell 1988):

- stabilization of newly reclaimed lands against accelerated wind and/or water erosion,

- development of target specific re-vegetation programs,

- achievable and sustainable land use by enforcing certain minimum performance standards.

The evaluation of restoration success is a tough issue, since it strictly depends on the character of the post-mining land, inherent features of ecological species involved, and the main objectives of the restoration operation. According to Pecharova et al. (2011), the process should allow spontaneous succession, or use technical restoration by sowing or planting target species and restoring or improving the site conditions.

The Society for Ecological Restoration International addresses the same issue by taking 9 ecosystem-related parameters under consideration to measure the restoration success (Hendrychova 2008):

- $\quad$ similar diversity and community structure in comparison with reference sites,

- presence of local species,

- functional groups necessary for long-term stability,

- capacity of the physical environment to sustain viable populations,

- regular functioning,

- integration with the landscape,

- removal of potential threats,

- resilience to natural disturbances,

- $\quad$ self-sustainability.

\subsection{Interdisciplinary dimension of reclamation}

All mining operations, due to their nature, have negative impacts on the cultural landscape. And opencast mining activities are not an exception, as they drastically change the former dynamic equilibrium of the landscape, leading to the formation of new ecosystems. Only the 
vegetation establishment by itself is not a proper approach. Instead, sustainable establishment of new ecosystems in the post-mining areas should be seen as an interdisciplinary challenge, in which the active participation of both science and society is highly required (Hüttl and Gerwin 2005).

The negative visual impact of the mining sites unavoidably lowers the aesthetic value of the landscape and its surroundings. So, post-mining landscape planning and rehabilitation activities should strictly consider the previous aesthetic characteristics of the land and their future development within an interdisciplinary approach (Sklenicka and Kasparova 2008).

As important as the interdisciplinary dimension of the issue, all mutual associates such as stakeholders, state officials and laws, environmental groups, engineers, landscape architectures, ecological experts, soil and social scientists should be "creatively" involved in the planning phase (Miao and Mars 2000; Saperstein 1990). By this way, significant social and environmental gains can be obtained by improving the conditions of post-mining landscapes through a relatively small investment (Garavan et.al. 2008).

When building up such a "project team", scale of the project and its complexity, special issues, and the clients' demands are the key factors to get the best results. For projects that require permitting and the preparation of mining and reclamation documents, landscape architects, mine operators, geologists, hydro-geologists, and civil engineers are possible candidates for the team (Bauer 2000).

The involvement of landscape architects in the industry has increased steadily and their role has gone far beyond the "traditional boundaries" of the profession; commonly and mistakenly thought as basic beautification and site planning duties. Based on their education and experiences, landscape architects now can easily deal with more complex sequential mining and reclamation plans, including site analysis, site and land use planning, visual analysis, grading, zoning, re-vegetation, slope stabilization, etc. They also play active roles in the permitting, regulatory, environmental assessment and community relation processes. The form, the function and the purpose of post mine landscape planning should be considered within earth science issues by landscape architects. By this way, they can approach the issue with more systematic and comprehensive manner. Landscape architects should aim to develop integrated multi-scale design approaches not only to be an equal partner in the planning process, but also to be in a position to direct the project team and undertake the responsibility for the success of reclamation planning (Arbogast 2008; Bauer 2000).

For a landscape architecture, a working knowledge on the following three points is essential for the understanding and success of reclamation planning services (Bauer 2000): i) components of mining processes associated with reclamation, ii) geologic complexities and structures within each aggregate deposit, and iii) mechanics and procedures for incorporating the mining procedures with reclamation activities. Table 2 overviews the mine reclamation studies within a multidisciplinary point of view. 


\begin{tabular}{|c|c|c|}
\hline Mine Planning Phase & Planning Activities & Areas of Specialization \\
\hline Legal requirements analysis & $\begin{array}{l}\text { Identification of regulatory } \\
\text { constraints related to land use }\end{array}$ & $\begin{array}{l}\text { Land use planner } \\
\text { Attorney or paralegal specialist }\end{array}$ \\
\hline Land and reserve acquisition & $\begin{array}{l}\text { Prepare land use / land cover } \\
\text { maps } \\
\text { Prepare land ownership map }\end{array}$ & $\begin{array}{l}\text { Land use planner } \\
\text { Landscape architect } \\
\text { Photogrammetrist/cartographer } \\
\text { Plant biologist } \\
\text { Photogrammetrist/cartographer } \\
\text { Surveyor }\end{array}$ \\
\hline Market development & Check market potential of site & $\begin{array}{l}\text { Geographer } \\
\text { Transportation engineer } \\
\text { Land use planner } \\
\end{array}$ \\
\hline Financial evaluation & \begin{tabular}{|l|} 
Check if land development \\
potential of the site will justify \\
reclamation to a higher, more \\
costly land use
\end{tabular} & $\begin{array}{l}\text { Engineering economist } \\
\text { Land use planner } \\
\text { Real estate specialist } \\
\text { Fiscal planner }\end{array}$ \\
\hline $\begin{array}{l}\text { Coal beneficiation studies and } \\
\text { plant design }\end{array}$ & $\begin{array}{l}\text { Determine the impact of waste } \\
\text { disposal on the Postmining } \\
\text { uses of land }\end{array}$ & $\begin{array}{l}\text { Mineral processing engineer } \\
\text { Environmental engineer } \\
\text { Landscape architect } \\
\text { Agronomist } \\
\text { Geologist } \\
\text { Hydrologist }\end{array}$ \\
\hline Environmental impact studies & $\begin{array}{l}\text { Evaluate the impact mining } \\
\text { will have on the site with } \\
\text { respect to capability and } \\
\text { productivity }\end{array}$ & $\begin{array}{l}\text { Mining engineer } \\
\text { Environmental engineer } \\
\text { Forest engineer } \\
\text { Agronomist } \\
\text { Geologist } \\
\text { Hydrogeologist } \\
\text { Terrestrial ecologist } \\
\text { Plant biologist } \\
\text { Agricultural engineer } \\
\text { Archeologist } \\
\text { Landscape architect } \\
\text { Land use planner } \\
\text { Social scientist }\end{array}$ \\
\hline Preliminary mine planning & $\begin{array}{l}\text { Preliminary identification of } \\
\text { postmining land uses }\end{array}$ & $\begin{array}{l}\text { Mining engineer } \\
\text { Land use planner } \\
\text { Landscape architect } \\
\text { Agronomist } \\
\text { Engineering economist }\end{array}$ \\
\hline Permits acquisition & $\begin{array}{l}\text { Land use information and } \\
\text { postmining land use plan }\end{array}$ & $\begin{array}{l}\text { Mining engineer } \\
\text { Land use planner } \\
\text { Environmental engineer } \\
\text { Agronomist }\end{array}$ \\
\hline
\end{tabular}




\begin{tabular}{|l|l|l|}
\hline Mine Planning Phase & Planning Activities & Areas of Specialization \\
\hline Administrative detail analysis & $\begin{array}{l}\text { Submitted / approval of final } \\
\text { land use plan }\end{array}$ & $\begin{array}{l}\text { Agricultural engineer } \\
\text { Hydrogeologist } \\
\text { Plant biologist } \\
\text { Engineering economist }\end{array}$ \\
\hline Detailed mine planning & Detailed land use plan design & $\begin{array}{l}\text { Land use planner (specifically } \\
\text { landscape architect) } \\
\text { Mining engineer } \\
\text { Environmental engineer } \\
\text { Civil engineer } \\
\text { Agricultural engineer } \\
\text { Agronomist } \\
\text { Hydrogeologist } \\
\text { Plant biologist } \\
\text { Engineering economist }\end{array}$ \\
& & \\
\hline
\end{tabular}

Table 2. The areas of technical expertise essential in pre-mining (Adapted from Ramani et.al. 1990; Şimşir et al. 2007)

\subsection{Case studies of reclamation}

In the $20^{\text {th }}$ century, rapid developments and new innovations in the technology and the machinery used in the mining industry have changed the whole face of landscape modification in all large mining districts of the world. Common problems in such postmining areas are the increase in water surface area and the acid mine drainage, leading to severe site conditions. Hence, prior to any reclamation study, site specific conditions due to previous mining activities should be taken into account, and the plans toward sustainable ecosystem development should be prepared accordingly. Additionally, soil fauna, mechanisms of plant succession and site specific biocoenosis should be investigated thoroughly for the successful establishment of terrestrial ecosystems on post-mining sites (Hüttl and Gerwin 2005).

Flambeau Mine, located in Wisconsin, is one of the prominent examples for the application of sustainable development principles and implementation of twenty first century materials and engineering technology to reclamation of post-mining landscapes. The implementation of sustainable development at Flambeau Mine has four main pillars: i) economic prosperity, ii) environmental protection, iii) social and community well-being, and iv) governance. The design is based upon a collaborative approach from overlapping disciplines. In addition to traditional engineers and architects, community planners, transportation planners, biodiversity specialists, energy efficiency specialists (e.g. green building) and landscape architects all contribute to the master design. The key to a successful design is to meld the wants and needs of the community with the various ideas and designs from the design team (Cherry 2008).

The study was designed, constructed, operated, and reclaimed in the 1990s. Reclamation of the site began during the fall of 1996 with the initiation of sequential backfilling of the open 
pit, which was substantially complete by the fall of 1997. During 1998, the contours of the site were reestablished, topsoil replaced, wetlands constructed, and seeding and planting were initiated. The majority of seeding and planting was completed by year and 1999 . Additionally the design constructed hiking, biking and equestrian trails for public recreational use. The pre-mining, active mining, and reclaimed site are shown in Figure 2 for a chronological comparison (Fox 2002 ; Cherry 2008).
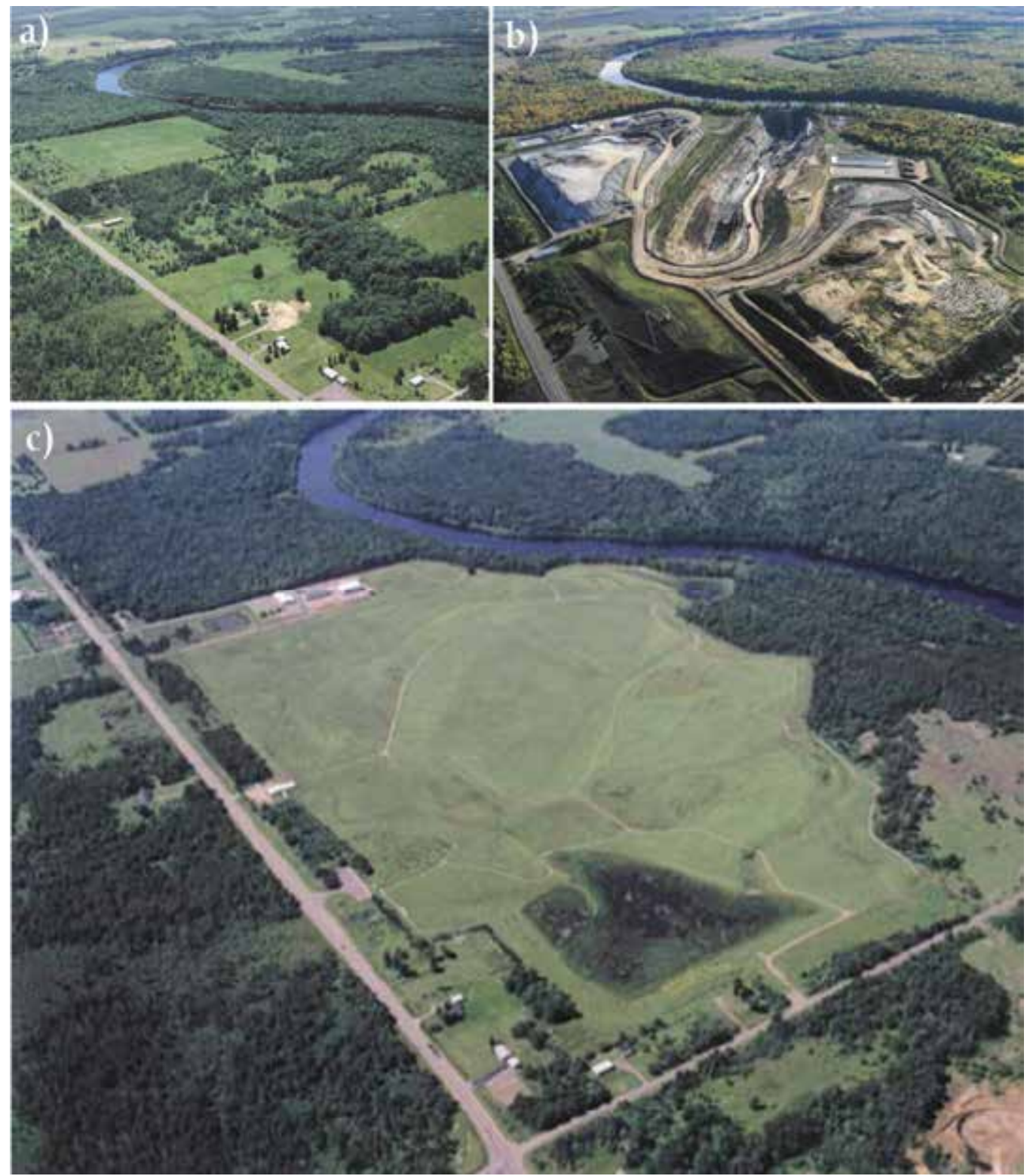

Figure 2. Flambeau Mine Site: a) before mining (1991), b) during mining (1996), and c) after mining (2002) (Fox 2002) 
The reclamation of the Flambeau Mine has included (Flambeau Reclaimed 2012):

- returning the site to its original approximate contours,

- planting clusters of trees to attract and support wildlife habitats,

- creating and restoring over 10 acres of wetland on site,

- creating over 120 acres of grassland habitat,

- constructing four miles of trails for non-motorized recreational activities.

The completion of surface contouring and return of the topsoil in 1998 were followed by the planting of native plant species necessary for the creation of prairie grasslands, woodlands and wetlands. In order to monitor and evaluate the success of the reclamation, 300 locations were randomly selected across the reclaimed Flambeau Mine. At these locations, necessary studies are performed each year in order to observe whether the performance standards (i.e., vegetative cover, planted native species, diversity and woody species survival) are met. In 2001, all necessary standards were met at the reclaimed mine site, which allowed the submittal of the Notice of Completion to the Wisconsin Department of Natural Resources. Recent surveys show a fully utilized wildlife at the reclaimed site, which provides unique and critical habitat, particularly for grassland bird species (Flambeau Reclaimed 2012).

Another outstanding example is Jarrahdale in Australia. The mining operations for bauxite at Jarrahdele started in 1963 and continued until 1998. During this period, over 160 million tons of ore was mined. Site rehabilitation studies continued for another 3 years. By 2001, all mined areas, haul roads and building sites were completely rehabilitated (Figure 3) (Alcoa 2012).
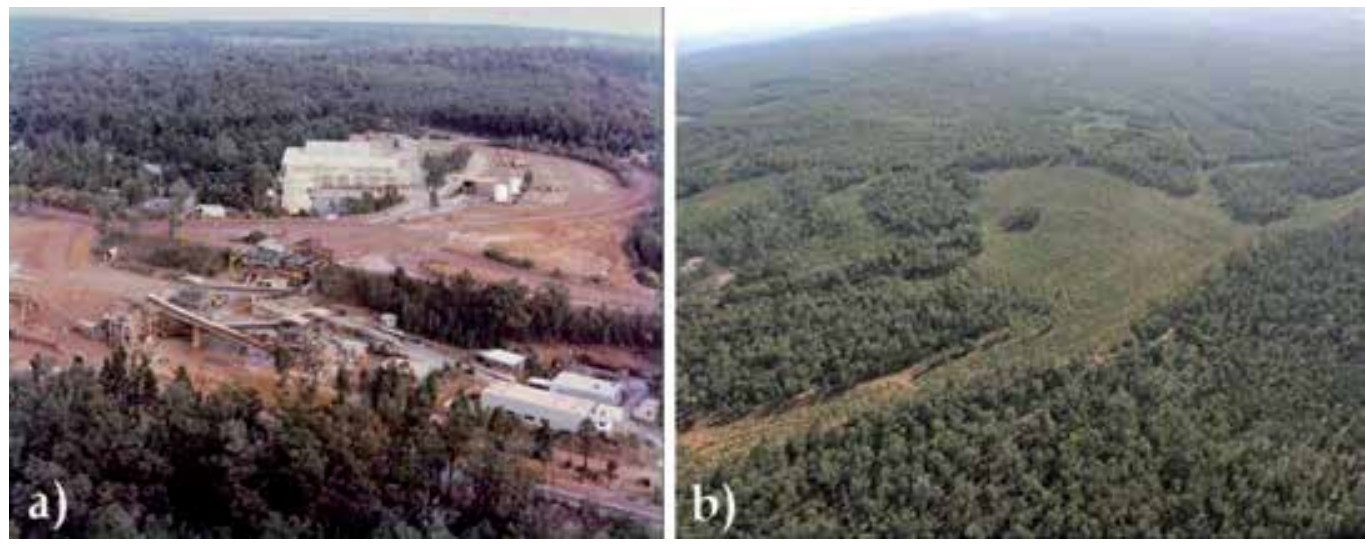

Figure 3. a) The original Jarrahdale crusher circle before its closure in 1998, and b) the same crusher circle site at Jarrahdale, after rehabilitation has been completed (Alcao 2012)

As shown in Figure 4, reclaimed mine sites are returned to productive use in a variety of ways that will serve for future generations. 

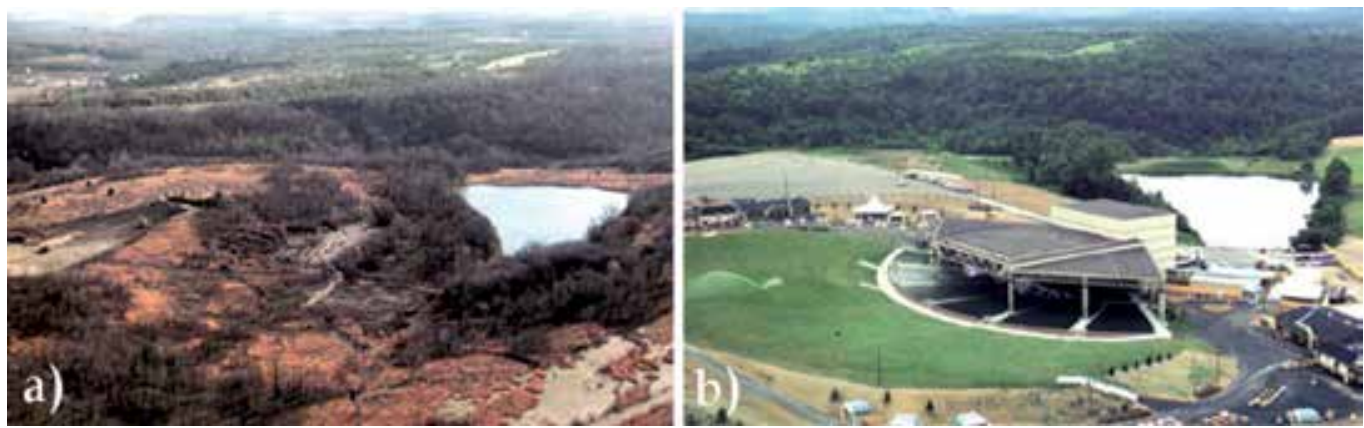

Figure 4. A site reclaimed by Starvaggi Industries in West Virginia is developed into the Star Lake Amphitheater: a) post-mining landscape, b) after the reclamation (Mineral Information Institute 2012)

In Turkey, reclamation of abandoned mine sites is generally carried out in the form afforestation (Figure 5 and 6).

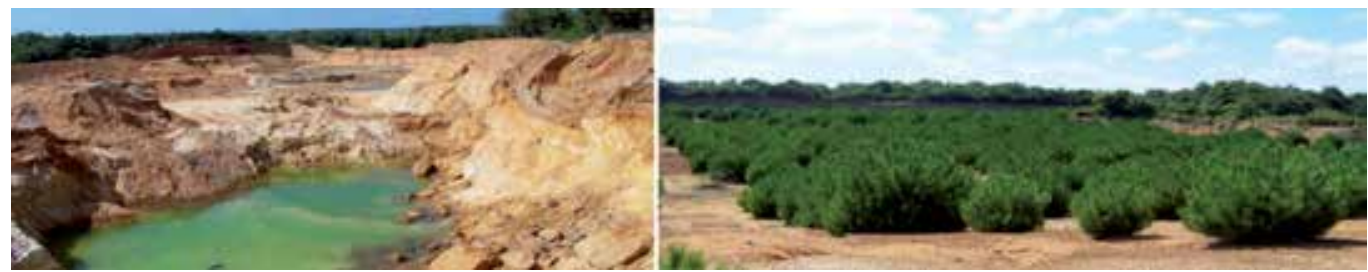

Figure 5. Afforestation operations in Şile, İstanbul (Şile Forestry Operation Directorate 2012)

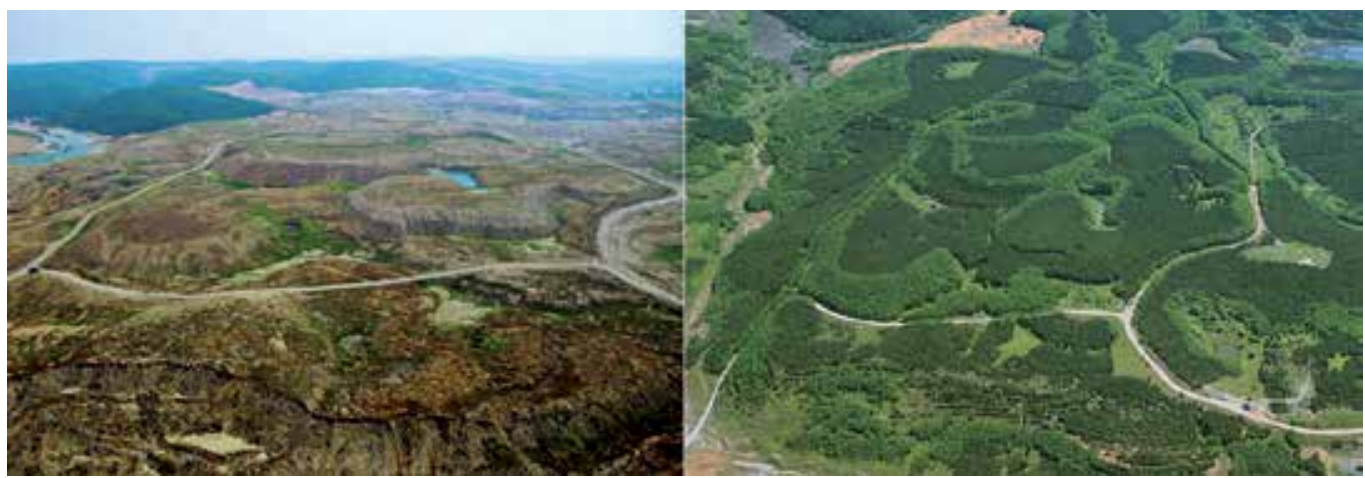

Figure 6. Afforestation in Ağaçlı, İstanbul (Kutorman 2012)

Rehabilitation and restoration operations in most of the abandoned coal mine areas are conducted by Turkish Coal Enterprises (TKI). According to General Directorate of Turkish Coal Enterprises (2011), between 1991 and 2011, nearly 7.3 million trees in various species [stone pine (Pinus pinea), black pine (Pinus nigra), red pine (Pinus brutia), cypress (Cupressus sp.), cedar (Cedrus sp.), horse chestnut (Aesculus hippocastanum), black locust (Robinia pseudoacasia), tree of heaven (Ailanthus altissima), oak (Quercus sp.), maple (Acer sp.), ash (Fraxinus sp.), etc.] were planted on 4455 hectares of post-mining lands in various establishment directorates of TKİ (Figure 7). 


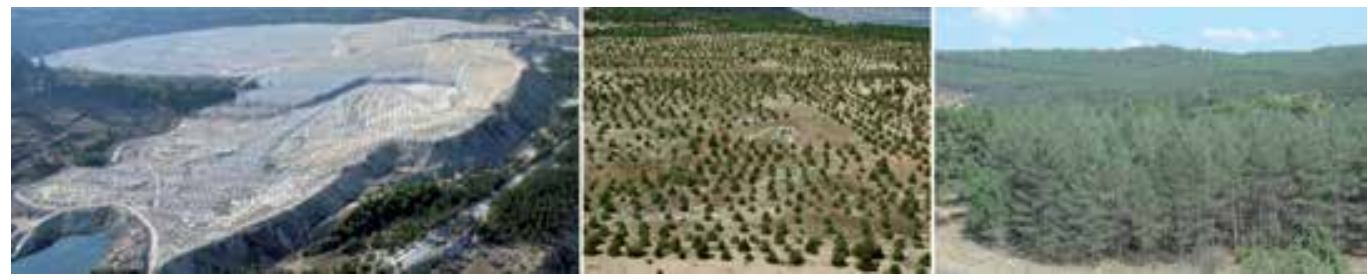

Figure 7. Afforestation of soil waste dumps by the establishment directorates of TKİ (General Directorate of Turkish Coal Enterprises 2011)

\subsection{Legislative and regulatory issues in mine reclamation}

Since the late $20^{\text {th }}$ century, reclamation has been widely accepted by both developed and developing countries as a desirable and necessary remedy in order to: i) reestablish the environmental conditions in post-mining landscapes at an acceptable level, and ii) increase their economic value to an optimum level (Cao 2007).

The law plays a critical role in reclamation of the post-mining landscape. It does not only define the legal status of the issue, but also reveals the outlook and approach of individual governments, which differ significantly in their attempts to mitigate the effects of mining disturbance.

For many of the developing countries, mining has a significant contribution to economy, which often puts a certain pressure on policy makers in order to establish an appropriate balance between national economic growth and environmental protection. Generally speaking, developing countries do not have strict environmental regulations and effective enforcement programs, and they usually address the issue within mining and environmental acts, or related national laws. Additionally, these countries mostly consider the reclamation and pollution control after the mine operations end (Cao 2007).

On the other hand, the approach in developed countries is more comprehensive and they have more stringent and effective regulations. Besides, restoration is regarded as a continuous process during mining, and mining companies have to prepare detailed environmental management plans and use expensive environmental technologies.

At this point, it would be wise to basically give examples of legislations related to mining and reclamation in several developed countries. The situation in Turkey is also overviewed briefly.

\section{USA}

With both the foundation of the Soil Conservation Service in the early 1930s and increasing local and state concerns about the degradation of land due to surface mining operations, protection of land resources became a publically important issue after World War I. This movement evolved into surface mine legislation, first in West Virginia in 1938, and then, in Indiana (1941), Illinois (1943), Pennsylvania (1945), and in Ohio (1947). Parallel to the increase in surface mining activities due to the energy crisis in the 1970s, the protection of environment gained more public interest (Doll 1988). 
In the first half of the 1970s, many states asked mine operators to provide methods for certain mine operations and requirements for reclamation. During the late 1970s and early 1980s, more compulsive regulations were imposed by the states with coal mining activities and the federal government. In this period, under the influence of Congress and pending legislation, public education campaigns by local mining associations and new research efforts by the industry to reduce the economic impact of legislated reclamation gained speed. Today, all surface mining in the US is regulated by federal or state laws (Harwood and Thames 1988).

The reclamation for the surface effects of coal mining activities (including underground operations) on public and private lands in the US is based on the Surface Mining Control and Reclamation Act (SMCRA) of 1977 (Micsak, 2008).

This principle law (i.e., SMCRA/PL 95-87) defines the federal standards for the reclamation of surface mine sites. Within the guidelines and regulatory procedures set by this law, the industry was pinned for the reclamation of surface-mined lands, which has led to major changes in mining practices and reclamation techniques. By this way, many surface-mined lands have been successfully reclaimed (Doll 1988).

Section 101(c) of SMCRA states: "Many surface mining operations result in disturbances of surface areas that burden and adversely affect commerce and the public welfare by destroying or diminishing the utility of land for commercial, industrial, residential, recreational, agricultural, and forestry purposes, by causing erosion and landslides, by contributing to floods, by polluting the water, by destroying fish and wildlife habitats, by impairing natural beauty, by damaging the property of citizens, by creating hazards dangerous to life and property by degrading the quality of life in local communities, and by counteracting governmental programs and efforts to conserve soil, water, and other natural resources." Section 101(e) of SMCRA says: "Surface mining and reclamation technology are now developed so that effective and reasonable regulation of surface coal mining operations by the States and by the Federal Government in accordance with the requirements of this Act is an appropriate and necessary means to minimize so far as practicable the adverse social, economic, and environmental effects of such mining operations." (Office of Surface Mining Reclamation and Enforcement 2012).

\section{Canada}

Each Canadian provincial government has the authority to make laws related to property, contracts, natural resources, employment, land use and planning, education, health care and municipalities. So, most laws in respect of commercial nature are enacted by provincial governments. Mining activities are mainly governed by the laws of the province or territory where a mine is physically located. Additionally, the federal government has overlapping jurisdiction in a number of areas such as taxation and the environment. The federal Canadian Environmental Assessment Act (CEAA-2012) constitutes the main legislative frame for all environmental assessment processes. It requires an environmental assessment when a federal authority proposes the mining project, provides financing or lands for the project, or issues certain permits or approvals for the project. In general, a federal environmental 
assessment is required for most major mining projects. Federal and/or provincial environmental impact assessments are required prior to commencing or expanding operations or even conducting exploration in order to decide whether or not a proposed mining project should proceed based on its environmental and social impacts. The government generally has the authority to require a public hearing and the discretion to accept a proposed mining project or reject it (Davies 2011).

\section{Australia}

The first Australian mining law dates back to 1851. Legal dimension of environmental issues associated with mine operations are defined within the various sections of Mining Act and the Environmental Protection Act, which was enacted in 1986. According to the act, any project proposal, which may potentially have a significant impact on the environment, is referred to the Environmental Protection Authority. The Environmental Protection Authority evaluates the proposal and prepares a report on whether the proposal should proceed. In relation to the minerals and the environment, four important points are always kept under consideration: i) assessment and recommendation on the environmental management related to exploration and mining proposal, ii) collaboration with the industry and the community on the environmental management of the mining industry, iii) compliance with environmental conditions during exploration and mining, and iv) cooperation with other governmental agencies in order to keep lands of high conservation under protection, and not to exclude land unnecessarily from exploration and development activity (Hunt 2009).

\section{Germany}

German mining law dates back to 1865, when the Allgemeines Berggesetz (AGB) was established. The first reclamation amendments to the mining law were enacted in 1929. Due to the increase in demand for coal after World War II, reclamation was ignored. However, beginning in 1950, reclamation efforts increased and new laws with more precise requirements were put into force in Germany (Knabe 1964). The act has been amended several times and was replaced in 1980 by the Federal German Mining Act (BGBl. IS. 1310). This act was set into force in January 1982 and revised on December 9, 2006, through slight revision to provisions of Article 11 (BGBl. IS. 2833) (Anderson 2012; Betlem et al. 2002).

\section{United Kingdom}

The main laws related to the mining and the environment in UK are i) Coal Mines Regulation Act (1908), ii) Mining Industry Act (1920), iii) Coal Act (1938), iv) The Town and Country Planning Act (Scotland) (1947), v) Coal Industry Act (1949), vi) Mineral Workings Act (1951), vii) Mines and Quarries Act (1954), viii) Opencast Coal Act (1958), ix) Mines Act (Northern Ireland) (1969), and x) Environmental Protection Act (1990) (Legislation.gov.uk 2012). English mining law operates primarily by public (administrative) law rather than by private (civil) mechanisms. The central administrative body is the Coal Authority and it was established under the Coal Industry Act (1994) during the privatization of the industry. There are lots of acts in the area of mining regulation; however, the Coal Industry Act (1994) and the Coal Mining Subsidence Act (1991) are the most pertinent ones (Betlem et al., 2002). Environmental 
Protection Act was amended by Environment Act in 1995, and Part IIA of this amendment defines a detailed framework for the identification and the compulsory remedial action for contaminated land (Legislation.gov.uk 2012).

\section{France}

The French Mining Code (Code Minier) was enacted on 21 April 1810. The old Mining Code was amended by Law No. 94- 588 of 15 July 1994, which organizes existing case law and aims at a better protection of the environment, and can be seen as revisions to bring the French Mining Code in conformity with relevant European regulations. During the development of the French environmental law in the past three decades, mechanisms for financial sanctions for those causing environmental damage have been incorporated without proper coordination in enforcement. With the Environmental Code enacted in 1999 (Code de l'Environnement), a more coherent regime was aimed by the Government. The Code addresses to several environmental issues in more than 975 articles over six chapters, combining liability clauses (Betlem et al. 2002). The central government representatives (préfets) can legislate for promoting the conservation of the habitat of listed protected species, according to a decree adopted in 1977 for the implementation of the Act (Groombridge 1992).

\section{Turkey}

In Turkey, there have been several efforts to designate the principle legal guidelines for the reclamation of post-industrial landscapes. "The Regulation on Reclamation of Lands Disturbed by Mining Activities" is an important landmark for mine closure planning in Turkey. It basically aims to establish the basic requirements for this purpose, and was published on $14^{\text {th }}$ of December, 2007, and amended on $23^{\text {rd }}$ of January, 2010. According to this regulation, reclamation plans for mining projects must be appended to the Environmental Impact Assessment (EIA) reports. A summary of related laws and regulations is given in Table 3.

\begin{tabular}{|l|l|l|l|}
\hline Laws and Regulations & $\begin{array}{l}\text { Effective } \\
\text { Date }\end{array}$ & Repealed by & Valid \\
\hline $\begin{array}{l}\text { General Hygiene Law No. } \\
1593\end{array}$ & 1930 & - & $\begin{array}{l}\text { General Hygiene Law No. } \\
1593 \text { (1930) }\end{array}$ \\
\hline Forest Law No. 6831 & 1956 & - & Forest Law No. 6831 (1956) \\
\hline $\begin{array}{l}\text { The Constitution of the } \\
\text { Republic of Turkey }\end{array}$ & 1982 & - & $\begin{array}{l}\text { The Constitution of the } \\
\text { Republic of Turkey (1982) }\end{array}$ \\
\hline $\begin{array}{l}\text { Environmental Law No. } \\
2872\end{array}$ & 1983 & - & $\begin{array}{l}\text { Environmental Law No. } \\
2872 \text { (1983) }\end{array}$ \\
\hline $\begin{array}{l}\text { National Parks Law No. } \\
2873\end{array}$ & 1983 & - & $\begin{array}{l}\text { National Parks Law No. } \\
2873 \text { (1983) }\end{array}$ \\
\hline $\begin{array}{l}\text { Regulation on Unhealthy } \\
\text { Institutions }\end{array}$ & 1983 & $\begin{array}{l}\text { Regulation on Unhealthy } \\
\text { Institutions (1995) } \\
\text { Regulation on Repealing of } \\
\text { Unhealthy Institutions } \\
\text { Regulation (2005) }\end{array}$ & Repealed (2005) \\
\hline Mining Law No. 3213 & 1985 & - & Mining Law No. 3213 (1985) \\
\hline
\end{tabular}




\begin{tabular}{|c|c|c|c|}
\hline Laws and Regulations & \begin{tabular}{|l|} 
Effective \\
Date
\end{tabular} & Repealed by & Valid \\
\hline $\begin{array}{l}\text { Regulation on Protection of } \\
\text { Air Quality }\end{array}$ & 1986 & $\begin{array}{l}\text { Regulation on Air Quality } \\
\text { Assessment and } \\
\text { Management (2008) } \\
\end{array}$ & $\begin{array}{l}\text { Regulation on Air Quality } \\
\text { Assessment and } \\
\text { Management (2008) } \\
\end{array}$ \\
\hline $\begin{array}{l}\text { Regulation on Noise } \\
\text { Control }\end{array}$ & 1986 & $\begin{array}{l}\text { Regulation on Assessment } \\
\text { and Management of } \\
\text { Environmental Noise (2005; } \\
\text { 2008; 2010) }\end{array}$ & $\begin{array}{l}\text { Regulation on Assessment } \\
\text { and Management of } \\
\text { Environmental Noise (2010) }\end{array}$ \\
\hline $\begin{array}{l}\text { Regulation on Water } \\
\text { Pollution Control }\end{array}$ & 1988 & $\begin{array}{l}\text { Regulation on Water } \\
\text { Pollution Control (2004) }\end{array}$ & $\begin{array}{l}\text { Regulation on Water } \\
\text { Pollution Control (2004) }\end{array}$ \\
\hline $\begin{array}{l}\text { Regulation on Control of } \\
\text { Solid Wastes }\end{array}$ & 1991 & - & \begin{tabular}{|l} 
Regulation on Control of \\
Solid Wastes (1991)
\end{tabular} \\
\hline $\begin{array}{l}\text { Regulation on } \\
\text { Environmental Impact } \\
\text { Assessment }\end{array}$ & 1993 & \begin{tabular}{|l} 
Regulation on \\
Environmental Impact \\
Assessment (1997; 2002; \\
2003; 2008) \\
\end{tabular} & $\begin{array}{l}\text { Regulation on } \\
\text { Environmental Impact } \\
\text { Assessment (2008) }\end{array}$ \\
\hline $\begin{array}{l}\text { Regulation on Allocation of } \\
\text { Forest Lands }\end{array}$ & 1995 & $\begin{array}{l}\text { Regulation on Permissions in } \\
\text { Forest Lands (2007) } \\
\text { Regulation on } \\
\text { Implementation of } 17 \text { th and } \\
\text { 18th Articles of the Forest } \\
\text { Law (2011) } \\
\end{array}$ & $\begin{array}{l}\text { Regulation on } \\
\text { Implementation of } 17 \text { th and } \\
\text { 18th Articles of the Forest } \\
\text { Law (2011) }\end{array}$ \\
\hline $\begin{array}{l}\text { Regulation on Control of } \\
\text { Hazardous Wastes }\end{array}$ & 1995 & $\begin{array}{l}\text { Regulation on Control of } \\
\text { Hazardous Wastes (2005) }\end{array}$ & $\begin{array}{l}\text { Regulation on Control of } \\
\text { Hazardous Wastes (2005) }\end{array}$ \\
\hline $\begin{array}{l}\text { Regulation on Control of } \\
\text { Soil Pollution }\end{array}$ & 2001 & \begin{tabular}{|l|} 
Regulation on Control of \\
Soil Pollution (2005) \\
Regulation on Control of Soil \\
Pollution and Point-Source \\
Contaminated Fields (2010) \\
\end{tabular} & $\begin{array}{l}\text { Regulation on Control of Soil } \\
\text { Pollution and Point-Source } \\
\text { Contaminated Fields (2010) }\end{array}$ \\
\hline Regulation on Noise & 2003 & - & Regulation on Noise (2003) \\
\hline \begin{tabular}{|l|} 
Regulation on the \\
Implementation of Mining \\
Law
\end{tabular} & 2005 & $\begin{array}{l}\text { Regulation on the } \\
\text { Implementation of Mining } \\
\text { Activities (2010) }\end{array}$ & $\begin{array}{l}\text { Regulation on the } \\
\text { Implementation of Mining } \\
\text { Activities (2010) }\end{array}$ \\
\hline $\begin{array}{l}\text { Regulation on Permission } \\
\text { of Mining Activities }\end{array}$ & 2005 & - & $\begin{array}{l}\text { Regulation on Permission } \\
\text { Mining Activities (2005) }\end{array}$ \\
\hline $\begin{array}{l}\text { Regulation on Reclamation } \\
\text { of Lands Disturbed by } \\
\text { Mining Activities }\end{array}$ & 2007 & $\begin{array}{l}\text { Regulation on Reclamation } \\
\text { of Lands Disturbed by } \\
\text { Mining Activities (2010) }\end{array}$ & $\begin{array}{l}\text { Regulation on Reclamation } \\
\text { of Lands Disturbed by } \\
\text { Mining Activities (2010) }\end{array}$ \\
\hline $\begin{array}{l}\text { Regulation on Protection of } \\
\text { Groundwater against } \\
\text { Pollution and Deterioration }\end{array}$ & 2012 & - & $\begin{array}{l}\text { Regulation on Protection of } \\
\text { Groundwater against } \\
\text { Pollution and Deterioration } \\
(2012)\end{array}$ \\
\hline
\end{tabular}

Table 3. The main laws and regulations related to mining and reclamation in Turkey (Official Gazette of Republic of Turkey 2012; Republic of Turkey Prime Ministry 2012; Republic of Turkey Ministry of Justice 2012; Chamber of Mining Engineers of Turkey 2012) 


\section{Concluding remarks}

One of the human footprints that cause drastic changes on environment is mining. Although it has a significant contribution to world economy and an indisputable social influence on the life of communities, its devastating negative impacts on environment cannot be disregarded. Particularly, opencast mining activities severely alter the topography and the physical conditions of the atmosphere, and inversely affect plant life, soil conditions, wildlife habitats, and water resources in the mining area and in its immediate surroundings.

As a result of above mentioned factors, post-mining landscapes lose their previous aesthetic, ecological and socioeconomic values. If effective mitigation measures are not taken to decrease the adverse environmental impacts, environmental degradation due to opencast mining operations may be irreversible.

As addressed within the chapter, the ultimate goal of reclamation is two-fold: i) to sustainably establish the aesthetic and ecological conditions of the post-mining landscape so that it become as much compatible as with surrounding undisturbed lands, and ii) to regain or enhance the productive capacity and stability of the land so that it contributes to community's economic and social welfare in a more efficient way.

Due to rapid industrialization and economic growth, the size and the content of the problems arising from negative impacts of mining activities have been changed and become more complicated than ever. So, in order to achieve successful results in reclamation studies, multidisciplinary approach enriched with the latest technological means is highly required. Of course, there is no "unique" and "magical" reclamation plan that can be directly applied on all post-mining areas, since major determinants in each reclamation study highly differ and depend on the specific characteristics of the site. Additionally, collaborative and creative involvement of all concerned parties (i.e., state and company officials, local authorities and non-governmental organizations, scientist, engineers and specialists, environmental groups etc.) is crucial for the development of permanently stable landscape use and reclamation plans. It is also necessary to emphasize that reclamation studies should begin at the earliest stages of project development, continue during mining, and proceed after the operation is completed.

The role of landscape architects in such studies has recently gone far beyond the "classical" borders of the profession. Instead of routine beautification and site planning tasks, now they often involve in large-scale complex reclamation and rehabilitation projects, and they even serve as the leader of the project team by taking the advantage of their education and practical experiences, which enables them to develop more innovative, consolidative and comprehensive approaches toward the optimum solution.

Legislative issues in mining and reclamation studies are mostly contingent to the visions of the governments. However, in order to foster efficiency and sustainability of post-mining landscapes, and to protect our valuable natural resources, much stricter global standardization on legal measures is needed in our rapidly changing world. 
Our future depends on what we do today and how we interact with nature. So, it is essential to sustainably reclaim mine-disturbed lands through comprehensive and collaborative planning that considers all key aspects. Because we borrow the nature that we live in from future generations, which is a fact that we should always recall.

\section{Author details}

Nazan Kuter

Cankiri Karatekin University, Faculty of Forestry, Department of Landscape Architecture, Cankiri, Turkey

\section{References}

Akpınar N., Kara D., Ünal E. Post surface mining land use planning. Turkey XIII. Mining Congress, 10-14 May 1993, İstanbul: Chamber of Mining Engineers of Turkey, 1993.

Akpınar N. The process of revegetation in the post-mining reclamation. The Mining and Environment Symposium, 5-6 May 2005, Ankara; 2005.

Alcoa. Jarrahdale. http://www.alcoa.com/australia/en/info_page/mining_jarrahdale.asp (accessed 18.12.2012).

Anderson S.T. The Mineral Industry of Germany. 2010 Minerals Yearbook, Germany [Advance Release], U.S. Department of the Interior U.S. Geological Survey; 2012.

Arbogast B. Interrogating a Landscape Design Agenda in the Scientifically Based Mining World. In: Berger A. (ed.) Designing the Reclaimed Landscape. London and New York: Taylor\&Francis Group; 2008. p53-60.

Bauer A.M. Reclemation Planning of Pits and Quarries. Landscape Architecture Technical Information Series (LATIS). Washington, USA: The American Society of Landscape Architects; 2000.

Bell F.G., Bullock S.E.T., Halbich T.F.J., Lindsay P. Environmental Impacts Associated with an Abandoned Mine in the Witbank Coalfield, South Africa. International Journal of Coal Geology 2001; 45: 195-216.

Bell F.G., Donnelly L.J. Mining and Its Impact on the Environment. Oxon, England: Taylor\&Francis Group; 2006.

Betlem G., Brans E., Getliffe K., Groen F. Environmental Liability \& Mining Law in Europe. Environmental Regulation of Mine Waters in the European Union (ERMITE) WP5 Report. UK; 2002.

Bhattacharya A., Routh J., Jacks G., Bhattacharya P, Mörth M. Environmental Assessment of Abandoned Mine Tailings in Adak, Vasterbotten District (Northern Sweden). Applied Geochemistry 2006; 21: 1760-1780.

Bradshaw A.D. Underlying Principles of Restoration. Can. J. Fish. Aquat. Sci. 1996; 53(1): 3-9.

Bruns D.A., Sweet T.O. Geospatial tools to support watershed environmental monitoring and reclamation: assessing mining impacts on the upper Susquehanna - Lackawanna American Heritage River. Paper presented at the Office of Surface Mining National Geospatial Conference 2004, 7-9 December 2004, Atlanta, GA.; 2004. 
Buchanan D.J., Brenkley D. Green Cool Mining. In: Hester R.E., Harrison R.M. (ed.) Mining and its Environmental Impact. Cambridge: Royal Society of Chemistry, Thomas Graham House; 1994. p71-95.

Cao X. Regulating Mine Land Reclamation in Developing Countries: The Case of China. Land Use Policy 2007; 24: 472-483.

Chamber of Mining Engineers of Turkey. Legislation. Professional Legislation http://www.maden.org.tr/mevzuat/mesleki_mevzuat.php (accessed 10 December 2012).

Chamber of Mines of South Africa. CM: Mining and Environmental Impact Guide. Gauteng Department of Agriculture, Environment and Conservation. 2008.

http://www.bullion.org.za/Departments/Environment/Downloads/Impact\%20Guide/G DACE\%20Mining\%20and\%20Environmental\%20Impact\%20Guide.pdf (accessed 02.12.2012).

Cherry J. Case Study of Successful Reclamation and Sustainable Development at Kennecott Mining Sites. In: Berger A. (ed.) Designing the Reclaimed Landscape. London and New York: Taylor\&Francis Group; 2008. p105-112.

Chevrel S. Kuosmannen V., Marsh S., Mollat H., Vosen P., Kuronen E. Hyperspectral airborne imagery for mapping mining-related contaminated areas in various European environments-first results of the mineo project. Paper presented at the International Airborne Remote Sensing Conference. 17-20 September 2001, san Francisco, California; 2001.

Chevrel S., Belocky R., Grösel K. Monitoring and Assessing the Environmental Impact of Mining in Europe Using Advanced Earth Observation Techniques - MINEO, First Results of the Alpine Test Site. In: Phillmann W., Tochtermann K. (eds.) Environemental Communication in the Information Society, EnviroInfo Vinee 2002. Part 1, p.518-526.

http://www2.brgm.fr/mineo/Publications/Enviroinfo_paper.pdf (accessed 15 December 2012).

Coelho P., Silva S., Roma-Torres J., Costa C., Henriques A., Teixeira J, Gomes M, Mayan O. Health Impact of Living Near an Abandoned Mine-Case Study: Jales Mines. International Journal of Hygiene and Environmental Health 2007; 210: 399-402.

Cuccu W. Site assessment before reclamation. In: Ciccu R. (ed.) SWEMP 2002: Proceedings of the 7 th International Symposium on Environmental Issues and Waste Management in Energy and Mineral Production, SWEMP 2002, 7-10 October 2002, Cagliari, Italy. University of Cagliari; 2002.

Davies. Investors' Guide to Mining in Canada. 2011. http://www.dwpv.com/ /media/Files/PDF/Investors-Guide-To-Mining-In-CanadaEnglish.ashx (accessed 12.12.2012).

Del Tredici P. Disturbance Ecology and Symbiosis in Mine-Reclamation Design. In: Berger A. (ed.) Designing the Reclaimed Landscape. London and New York: Taylor\&Francis Group; 2008. p13-25.

Doll E.C. Relation of Public Policy to Reclamation Goals and Responsibilities. In: Hossner L.R. (ed.) Reclamation of Surface-Mined Lands. Florida: CRC Press, Inc.; 1988. p41-53.

Fanuscu E.M. The possibilities of evaluation derelict land as urban land in Istanbul Agacli opencast coal mining area. PhD thesis. İstanbul University İstanbul; 1999.

Flambeau Reclaimed : Reclamation at the Flambeau Mine : 
http://www.flambeaumine.com/documents/factsheets/reclamation.pdf (accessed 26 October 2012).

Fox F.D. Mining and sustainable development Flambeau and Ridgeway mines - lessons learned. 2002. Presented at SME Annual Meeting, 24-26 February 2003, Cincinnati, Ohio. http://www.mining.ubc.ca/mlc/presentations_pub/sme/FoxPaper.pdf (accessed 26 October 2012).

Frouz J., Elhottova D., Kuraz V., Sourkova M. Effects of Soil Macrofauna on Other Soil Biota and Soil Formation in Reclaimed and Unreclaimed Post-mining Sites: Results of A Field Microcosm Experiment. Applied Soil Ecology 2006; 33: 308-320.

Ganas A., Aerts J., Astaras T., De Vente J., Frogoudakıs E., Lambrinos N., Riskakis C., Oikonomidis D., Filippidis A., Kassolifournaraki A. The Use of Earth Observation and Decision Support Systems in The Restoration Of Open-Cast Nickel Mines in Evia, Central Greece. International Journal of Remote Sensing 2004; 25(16), 3261-3274.

Garavan C., Breen J., Moles R., O'Regan B. A Case Study of the Health Impacts in an Abandoned Lead Mining Area, Using Children's Blood Lead Levels. International Journal of Mining, Reclamation and Environment 2008; 22(4): 265-284

General Directorate of Turkish Coal Enterprises. TKI: Annual report for 2011. http://www.tki.gov.tr/TKI/YillikFaaliyetler/c1e327f0-e193-471b-a216bb07243c3f8bfaal_2011.pdf (accessed 17.12.2012).

Ghose M.K. Air Pollution Due to Opencast Coal Mining and the Characteristics of Air-Borne Dust-an Indian Scenario. International Journal of Environmental Studies 2002; 59(2): 211-228.

Gillarova H.H., Pecharova E. An Assessment of the Environmental Impact of the Proposed Medard Lake Project. Journal of Landscape Studies 2009; 2: 33-41.

Gorokhovich Y., Reid M., Mignone E. Prioritizing Abandoned Coal Mine Reclamation Projects within the Contiguous United States Using Geographic Information System Extrapolation. Environmental Management 2003; 32(4): 527-534.

Görcelioğlu E. Landscape Reclamation Techniques. İstanbul: Emek Printing; 2002.

Groombridge B. Global Biodiversity: Status of the Earth's Living Resources. New York: Chapman \& Hall; 1992.

Hancock G.R. The Use of Landscape Evolution Models in Mining Rehabilitation Design. Environmental Geology 2004; 46: 561-573.

Hancock G.R., Grabham M.K., Martin P., Evans K.G., Bollhöfer A. A Methodology for the Assessment of Rehabilitation Success of the Post-mining Landscapes-Sediment and Radionuclide Transport at the Former Nabarlek Uranium Mine, Northern Territory, Australia. Science of the Total Environment 2006; 354: 103-119.

Harwood G.D., Thames J.L. Design and Planning Considerations in Surface-Mined Land Shaping. In: Hossner L.R. (ed.) Reclamation of Surface-Mined Lands. Florida: CRC Press, Inc.; 1988. p137-158.

Hendrychova M. Reclamation Success in Post-Mining Landscapes in the Czech Republic: A Review of Pedological and Biological Studies. Journal of Landscape Studies 2008; 1: 6378. 
Hladnik D. Spatial Structure of Disturbed Landscapes in Slovenia. Ecological Engineering 2005; 24: 17-27.

Hunt, M., Mining Law in Western Australia (4th Ed.). The Federation Press, 2009.

Hutnik R.J., McKee G.W. Reclamation (Revegetation). In: Kennedy B.A. (ed.) Surface Mining. 2nd Edition. Littleton, Colorado: Society for Mining, Metallurgy, and Exploration, Inc.; 1990. P811-817.

Hüttl R.F. Ecology of Post Strip-Mining Landscapes in Lusatia, Germany. Environmental Science and Policy 1998; 1: 129-135.

Hüttl R.F., Gerwin W. Landscape and Ecosystem Development after Disturbance by Mining. Ecological Engineering 2005; 24: 1-3.

Ibarra J.M.N., de las Heras M.M. Open-Cast Mining Reclamation. In: Mansourian S., Vallauri D., Dudley N. (ed.) Forest Restoration in Landscape: Beyond Planting Trees. New York: Springer Verlag; 2005. p370-376. Available from http://www.bf.unilj.si/fileadmin/groups/2716/downloads/\%C4\%8Clanki_vaje/Mansurian_forest_restoratio n_53_mining.pdf (access 14 October 2012).

Jansen I.J., Melsted S.W. Land Shaping and Soil Construction. In: Hossner L.R. (ed.) Reclamation of Surface-Mined Lands. Florida: CRC Press, Inc.; 1988. p125-136.

Jun-bao Y., Jing-shuang L., Jin-da W., Zhong-gen L., Xue-lin Z. Spatial-Temporal Variation of Heavy Metal Elements Content in Covering Soil of Reclamation Area in Fushun Coal Mine. Chinese Geographical Science 2002; 12(3): 268-272.

Kavourides C., Pavloudakis F., Filios P. Environmental protection and land reclamation works in West Macedonia Lignite Centre in North Greece current practice and future perspectives. In: Ciccu R. (ed.) SWEMP 2002: Proceedings of the 7 th International Symposium on Environmental Issues and Waste Management in Energy and Mineral Production, SWEMP 2002, 7-10 October 2002, Cagliari, Italy. University of Cagliari; 2002.

Kibble A.J., Saunders P.J. Contaminated Land and the Link with Health. In: Hester R.E., Harrison R.M. (ed.) Assessment and Reclamation of Contaminated Land. Cambridge: Royal Society of Chemistry, Thomas Graham House; 2001. p65-84.

Kibblewhite M. Identifying and Dealing with Contaminated Land. In: Hester R.E., Harrison R.M. (ed.) Assessment and Reclamation of Contaminated Land. Cambridge: Royal Society of Chemistry, Thomas Graham House; 2001. p45-64.

Kleeberg A., Schapp A., Biemelt D. Phosphorus and Iron Erosion from Non-Vegetated Sites in a Post-Mining Landscape, Lusatia, Germany: Impact on Aborning Mining Lakes. Catena 2008; 72: 315-324.

Klukanova A., Rapant S. Impact of Mining Activities upon the Environment of the Slovak Republic: Two Case Studies. Journal of Geochemical Exploration 1999; 66: 299-306.

Knabe W. Methods and Results of Strip-Mine Reclamation in Germany. The Ohio Journal of Science 1964; 64(2): 75-105.

Komnitsas K., Modis K. Soil Risk Assessment of As and Zn Contamination in A Coal Mining Region Using Geostatisretics. Science of the Total Environment 2006; 371: 190-196.

Kutorman. Past to present. http://www.kutorman.com/ (accessed 18.12.2012). 
Kyzeridi M., Panagiotou G.N., Peppas S. Reclamation scenarios of mined-out open pits using GIS tools. In: Ciccu R. (ed.) SWEMP 2002: Proceedings of the 7 th International Symposium on Environmental Issues and Waste Management in Energy and Mineral Production, SWEMP 2002, 7-10 October 2002, Cagliari, Italy. University of Cagliari; 2002.

Legislation.gov.uk. Search all legislation. http://www.legislation.gov.uk/ (accessed 20 December 2012)

Miao Z., Marrs R. Ecological Restoration and Land Reclamation in Open-Cast Mines in Shanxi Province, China. Journal of Environmental Management 2000; 59: 205-215.

Micsak R.W. The Legal Landscape. In: Berger A. (ed.) Designing the Reclaimed Landscape. London and New York: Taylor\&Francis Group; 2008. p154-164.

Mineral Information Institute. Mining Reclamation Success - Coal Mining Reclamation. http://www.mii.org/Rec/coal/coal.html (accessed 18.12.2012).

Mummey D.L., Stahl P.D., Buyer J.S. Microbial Biomarkers as an Indicator of Ecosystem Recovery Following Surface Mine Reclamation. Applied Soil Ecology 2002; 21: 251-259.

Navarro A., Collado D., Carbonell M., Sanchez J.A. Impact of Mining Activities on Soils in a Semi-Arid Environment: Sierra Almagrera District, SE Spain. Environmental Geochemistry and Health 2004; 26: 383-393.

Navarro M.C., Perez-Sirvent C., Martinez-Sanchez M.J., Vidal J., Tovar P.J., Bech J. Abandoned Mine Sites As A Source of Contamination by Heavy Metals: A Case Study in A Semi-Arid Zone. Journal of Geochemical Exploration 2008; 96: 183-193.

Office of Surface Mining Reclamation and Enforcement. OSM: Surface Mining Law: Public Law 95-87. Surface Mining Control and Reclamation Act of 1977 (SMCRA). http://www.osmre.gov/topic/smcra/SMCRA.pdf (accessed 13 October 2012).

Official Gazette of Republic of Turkey. http://www.resmigazete.gov.tr/default.aspx (accessed 01 December 2012).

Passariello B., Giuliano V., Quaresima S., Barbara M., Caroli S., Forte G., Carelli G., Iavicoli I. Evaluation of the Environmental Contamination at an Abandoned Mining Site. Microchemical Journal 2002; 73: 245-250.

Pecharova E., Broumova-Dusakova H., Novotna K., Svoboda, I. Function of Vegetation in New Landscape Units After Brown Coal Mining. International Journal of Mining, Reclamation and Environment 2011; 25(4): 367-376.

Powell J.L. Revegetation Options. In: Hossner L.R. (ed.) Reclamation of Surface-Mined Lands. Florida: CRC Press Inc.; 1988. p49-91.

Pöykiö R., Perämäki P., Bergstrom R., Kuokkanen T., Rönkkömäki H. Assessment of the Impact of Opencast Chrome Mining on the Ambient Air Concentrations of TSP, Cr, Ni and $\mathrm{Pb}$ Around $\mathrm{A}$ Mining Complex in Northern Finland. International Journal of Environmental Analytical Chemistry 2002; 82(5): 307-319.

Prikryl I., Svoboda I, Sklenicka P. Restoration of landscape functions at area devastated by opencast brown coal mining in the Northwest Bohemia. In: Ciccu R. (ed.) SWEMP 2002: Proceedings of the 7 th International Symposium on Environmental Issues and Waste Management in Energy and Mineral Production, SWEMP 2002, 7-10 October 2002, Cagliari, Italy. University of Cagliari; 2002. 
Ramani R.V., Sweigard R.J. Clar M.L. Reclamation (Reclamation Planning). In: Kennedy B.A. (ed.) Surface Mining. 2nd Edition. Littleton, Colorado: Society for Mining, Metallurgy, and Exploration, Inc.; 1990. p750-769.

Razo I., Carrizales L., Castro J., Diaz-Barriga F., Monroy M. Arsenic and Heavy Metal Pollution of Soil, Water and Sediments in a Semi-Arid Climate Mining Area in Mexico. Water, Air, and Soil Pollution 2004; 152: 129-152.

Republic of Turkey Ministry of Justice. Legislation. http://www.mevzuat.adalet.gov.tr/ (accessed 01 December 2012).

Republic of Turkey Prime Ministry. Legislation Information System. Regulations. http://www.mevzuat.gov.tr/Yonetmelikler.aspx (accessed 01 December 2012).

Rimmer D.L., Younger A. Land Reclamation after Coal-mining Operations. In: Hester R.E., Harrison R.M. (ed.) Contaminated Land and its Reclamation. Cambridge: Royal Society of Chemistry, Thomas Graham House; 1997. p73-90.

Sahu H.B., Dash S. Land Degradation due to Mining in India and its Mitigation Measures. Proceedings of the 2nd International Conference on Environmental Science and Technology, IPCBEE vol.6, February 26-28, 2011, Singapore: IACSIT Press; 2011.

Salonen V.P., Valpola S., Tuovinen N. Impacts of mining on the environment in Finland. Seattle Annual Meeting. 2-5 November 2003, Seattle, Washington. Paper No: 199-7, Geological Society of America Abstracts with Programs 2003; 35(6): 483.

Sams J.I., Beer K.M. Effects of Coal-Mine Drainage on Stream Water Quality in the Allegheny and Monongahela River Basins-Sulfate Transport and Trends: WaterResources Investigations Report 99-4208, Etc., Lemoyne, Pennsylvania; 2000. http://pa.water.usgs.gov/reports/wrir_99-4208.pdf (accessed 15 December 2012).

Saperstein L.W. Reclamation (Introduction). In: Kennedy B.A. (ed.) Surface Mining. 2nd Edition. Littleton, Colorado: Society for Mining, Metallurgy, and Exploration, Inc.; 1990. p749.

Schor H.J., Gray D.H. Landforming: An Environmental Approach to Hillside Development,

Mine Reclamation and Watershed Restoration. Hoboken, New Jersey: John Wiley\&Sons, Inc; 2007.

Sengupta M. Environmental Impacts of Mining Monitoring, Restoration, and Control. USA: Lewis Publishers; 1993.

Sklenicka P., Prikryl I., Svoboda I., Lhota T. Non-Productive Principles of Landscape Rehabilitation after Long-Term Opencast Mining in North-West Bohemia. The Journal of the South African Institute of Mining and Metallurgy 2004; 83-88.

Sklenicka P., Kasparova I. Restoration of Visual Values in a Post-Mining Landscape. Journal of Landscape Studies 2008; 1: 1-10.

Smyth C.R, Dearden P. Performance Standards and Monitoring Requirements of Surface Coal Mine Reclamation Success in Mountainous Jurisdictions of Western North America: A Review. Journal of Environmental Management 1998; 53: 209-229.

Song S., Min E.S., Kim M.H., Lee H.K. Pollution by Acid Mine Drainages from the Daeseong Coal Mine in Keumsan. Econ. Environ. Geol 1997; 30(2): 105-116.

Şile Forestry Operation Directorate. Current documents. Presentation 2012.

http://www.sileorman.gov.tr/ (accessed 18.12.2012). 
Şimşir F., Pamukçu Ç., Özfırat M.K. Mine Reclamation and Restoration of Nature. Dokuz Eylul University Faculty of Engineering Journal of Science and Engineering 2007; 9(2): 39-49.

Topay M, Sertkaya Aydın Ş, Koçan N. Taş Ocaklarının Peyzaja Etkileri ve Yeniden Kullanımlarına Yönelik Çözüm Önerileri: Bartın İli Örneği. Süleyman Demirel Üniversitesi Orman Fakültesi Dergisi 2007; A(2): 134-144.

Tören T. Determination of environmental impacts due to open pit coal mining activities: a case study from Turkey. In: Ciccu R. (ed.) SWEMP 2002: Proceedings of the 7 th International Symposium on Environmental Issues and Waste Management in Energy and Mineral Production, SWEMP 2002, 7-10 October 2002, Cagliari, Italy. University of Cagliari; 2002.

Tshivhandekano N.A. Documenting reclamation and closure of Ermelo coal mines (Mpumalanga Province): Implications for developing a national strategy for mine reclamation in South Africa. MSc. thesis. Master of Arts (Environment and Society), Department of Geography, Geoinformatics \& Meteorology, Faculty of Humanities, University of Pretoria South Africa; 2004.

Wood P. Remediation Methods for Contaminated Sites. In: Hester R.E., Harrison R.M. (ed.) Contaminated Land and its Reclamation. Cambridge: Royal Society of Chemistry, Thomas Graham House; 1997. p47-71.

Wood P. Remediation Methods for Contaminated Sites. In: Hester R.E., Harrison R.M. (ed.) Assessment and Reclamation of Contaminated Land. Cambridge: Royal Society of Chemistry, Thomas Graham House; 2001. p115-139.

Xin-yi W., Jian Y., Hui-xia G. Research of the Change of Heavy Metal Concentration in the Soil around the Coal Mining Waste Dump. 2009.

http://old.cgs.gov.cn/zt_more/34/zhaiyao/html/06/609.htm. (accessed 25.04.2010).

Younger P.L. Environmental Impacts of Coal Mining and Associated Wastes: A Geochemical Perspective. Geological Society 2004; 236: 169-209. 
Biodiversity and Plant Material 



\title{
Native Vegetation
}

\author{
Murat Özyavuz, Aslı B. Korkut \\ and Ayten Özyavuz
}

Additional information is available at the end of the chapter

http://dx.doi.org/10.5772/55813

\section{Introduction}

Biodiversity is the diversity of life in all its forms across the planet. The National State of the Environment Report made the following statements in defining biodiversity (Slattery, et al., 2003):

"Biodiversity is the variety of all forms of life - the different plants, animals and microorganisms, the genes they contain and the ecosystems of which they form a part".

It ranges from large scale ecosystems to the different species of flora and fauna, and to genetic differences between individuals of the same species. These three levels work together to create the complexity of life on earth. Accordingly, biodiversity is conventionally partitioned into three components: (1) genetic diversity, (2) species diversity and (3) diversity of ecosystems (Slattery, et al., 2003).

\section{Genetic diversity}

Genetic diversity is normally considered to be the range of genetic information present within a species. Genetic information is passed on to successive generations either directly in asexual reproduction or by mixing of genetic material from both parents in sexual reproduction. Genetic diversity increases the diversity of form and behavior within a species, which provides it with greater capacity to cope with changing environmental conditions or make use of completely different environments. Genetic diversity may be expressed in the form of genetic variation within individuals, within populations and/or between populations. Genetic diversity can decline if populations are lost or if the total population of the species is drastically reduced. If populations become fragmented into very small sub-populations, inbreeding depression may cause the genetic diversity to decline further (Smith, et. al., 2000). 


\section{Species diversity}

The number of species present in a location depends on the type of ecosystem. Subtropical rainforests usually contain over 100 vascular plant species in a hectare, including 30-40 tree species, whereas a hectare of cool temperate rainforest may contain only 5-10 tree species. Grassy woodlands and heaths may also be diverse with more than 100 species in a hectare, although sometimes these vegetation types contain relatively few species. However, ecosystems with relatively few species, such as temperate rainforests, can be important for species diversity if those species are unique. The diversity of various animal species assemblages varies even more than that of plants, and some groups also show distinct seasonal variation (Smith, et. al., 2000) (Figure 1.).
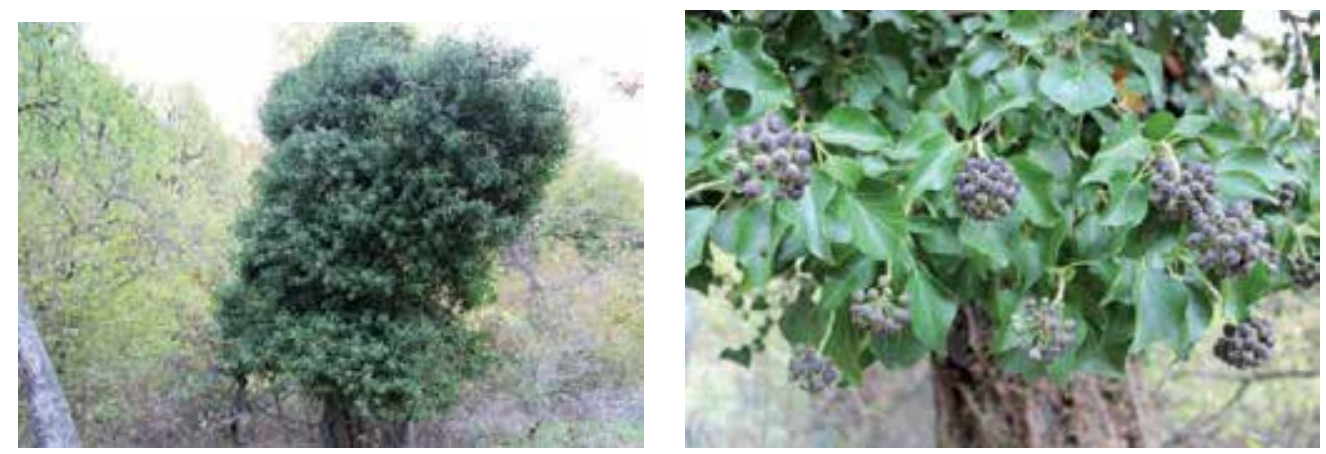

Figure 1. Hedera colchica (This plant is covered Prunus avium and has taken its place)

\section{Diversity of ecosystems}

The species in a given area interact with each other and with their environment to form complex networks known as ecosystems. These differ from place to place, thus creating ecosystem diversity. Each ecosystem differs from all others because it contains a unique combination of species (and therefore genes) and because these species interact with each other and with each environment in distinctive ways. Biodiversity is not static but is constantly changing. It is increased by genetic change and evolutionary processes and reduced by processes such as habitat degradation, a decline in flora and fauna, and the extinction of species. Diversity in all its forms (genetic, species and ecosystem) is a critical factor in the resilience of an area and its ability to respond to significant changes such as fire, food, climate and human impacts. Diversity is the key to maintaining viable populations of our native flora and fauna (Environmental Protection Authority, 2000) (Figure 2).

This is due to three major components, loss of biodiversity can result in reduction or loss of ecosystem function. Therefore, it is very important the need for conservation of biodiversity. There are four main reasons for preserving biodiversity: maintaining ecosystem processes, ethics, aesthetics and culture, and economics (Environmental Protection Authority, 2000).

Biodiversity has two key aspects:

- $\quad$ its functional value at the ecosystem level; and

- its intrinsic value at the individual species, species assemblages and genetic levels. 


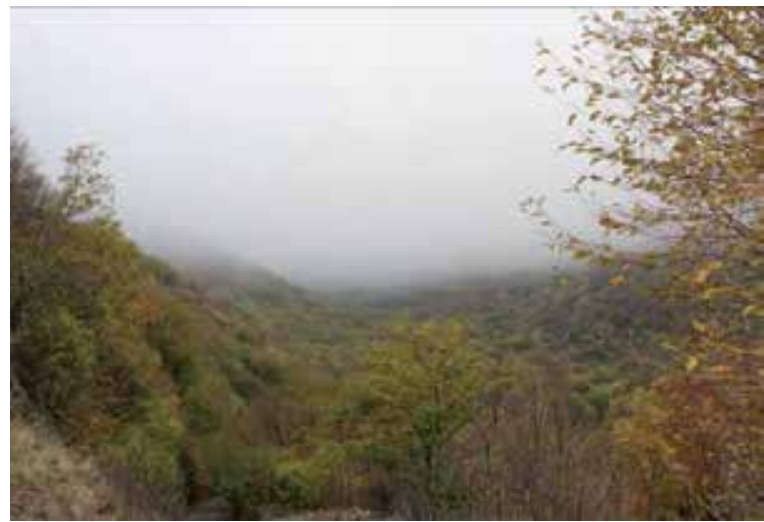

Figure 2. With a variety of important plant Ganos Mountain, Tekirdag, Turkey

The functional value is derived from the parts played by the species assemblages in supporting ecosystem processes and is expressed through the kinds of plant and animal assemblages occurring in various parts of the landscape on different soil types. In addressing this, matters requiring consideration include (Environmental Protection Authority, 2000):

- soils;

- landscape;

- species richness;

- $\quad$ species composition;

- differences in composition pre and post disturbance; and

- the ecosystem processes, linkages and how they are supported.

The intrinsic values relate to the actual species and species associations. Two species assemblages may have different intrinsic values but may still have the same functional value in terms of the part they play in maintaining ecosystem/ecological processes (Environmental Protection Authority, 2000).

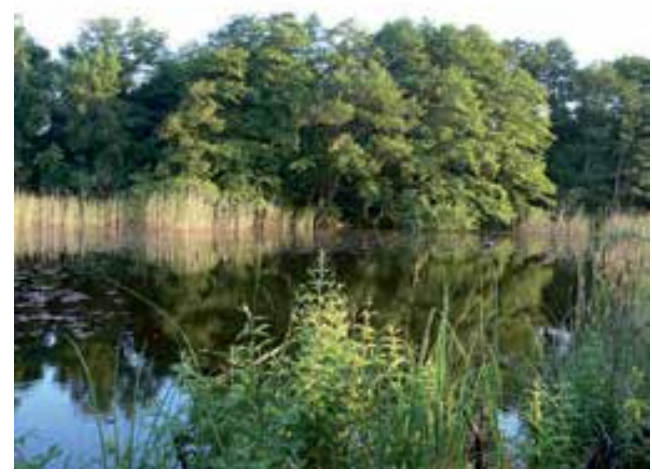

Figure 3. The Saka Lake, İğneada, Kırklareli, Turkey (It is an important area for a variety of birds and plants) 
Biodiversity provides the critical processes that make life possible, and that are often taken for granted. Healthy, functioning ecosystems are necessary to maintain the quality of the atmosphere, and to maintain and regulate the climate, fresh water, soil formation, cycling of nutrients and disposal of wastes (often referred to as ecosystem services). Biodiversity is essential for controlling pest plants, animals and diseases, for pollinating crops and for providing food, clothing and many kinds of raw materials (Environmental Protection Authority, 2000).

Biodiversity refers to the living pieces that shouldn't be discarded since we use the earth's resources to sustain us. Experience suggests to us that the first rule of intelligent tinkering is to keep all of the pieces. Because of the interconnected nature of ecosystems, the loss or addition of one species has the potential to change an ecosystem.

- High levels of biodiversity are associated with greater ecosystem stability. The more diverse a system is, the better able it is to cope with environmental stressors, such as floods or drought. Biodiversity gives us choices, options and flexibility to help us cope with variability, including long-term habitat changes.

- When a system is simplified, such as having only one species of crop or type of grass, it increases the odds that environmental stressors will have a more pronounced impact or that a disease or pest will be able to spread rapidly. Animal and plant populations with low genetic diversity are much more susceptible to stress and vulnerable to extinction.

- We all rely on the tremendous variety of species, genes and ecosystems in our world and the many benefits we receive from them - they deserve our respect and conservation.

\section{The Importance of Biodiversity}

Potential benefits of biodiversity are; health of ecosystems, their ability to maintain and regulate atmospheric quality, climate, fresh water, marine productivity, soil formation, cycling of nutrients and waste disposal, Resilience of ecosystems, their ability to respond to and recover from external shocks such as drought, flood, and climate change, cultural values (Figure 4). Biodiversity is extremely important to people and the health of ecosystems. A few of the reasons are (National Wildlife Federation, 2013):

- Biodiversity allows us to live healthy and happy lives. It provides us with an array of foods and materials and it contributes to the economy. Without a diversity of pollinators, plants, and soils, our supermarkets would have a lot less produce.

- Most medical discoveries to cure diseases and lengthen life spans were made because of research into plant and animal biology and genetics. Every time a species goes extinct or genetic diversity is lost, we will never know whether research would have given us a new vaccine or drug.

- Biodiversity is an important part of ecological services that make life livable on Earth. They include everything from cleaning water and absorbing chemicals, which wetlands do, to providing oxygen for us to breathe-one of the many things that plants do for people. 
- Biodiversity allows for ecosystems to adjust to disturbances like extreme fires and floods. If a reptile species goes extinct, a forest with 20 other reptiles is likely to adapt better than another forest with only one reptile.

- Genetic diversity prevents diseases and helps species adjust to changes in their environment.

- Simply for the wonder of it all. There are few things as beautiful and inspiring as the diversity of life that exists on Earth.

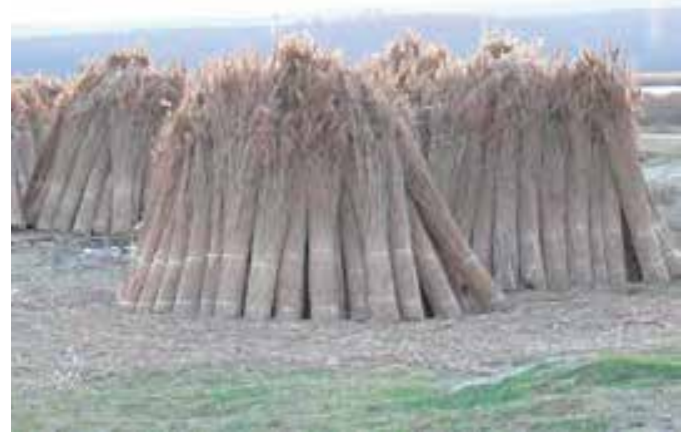

Figure 4. Reedy areas, is applied to the regular cutting program has an important economic function.

\section{Threats to Biodiversity}

Extinction is a native part of life on Earth. Over the history of the planet most of the species that ever existed, evolved and then gradually went extinct. Species go extinct because of native shifts in the environment that take place over long periods of time, such as ice ages.

Today, species are going extinct at an accelerated and dangerous rate, because of non-native environmental changes caused by human activities. Some of the activities have direct effects on species and ecosystems, such as are (National Wildlife Federation, 2013):

\section{Habitat loss/ degradation}

When an ecosystem has been dramatically changed by human activities - such as agriculture, oil and gas exploration, commercial development or water diversion - it may no longer be able to provide the food, water, cover, and places to raise young. Every day there are fewer places left that wildlife can call home (Figure 5). There are three major kinds of habitat loss are (National Wildlife Federation, 2013):

- Habitat destruction: A bulldozer pushing down trees is the iconic image of habitat destruction. Other ways that people are directly destroying habitat, include filling in wetlands, dredging rivers, mowing fields, and cutting down trees.

- Habitat fragmentation: Much of the remaining terrestrial wildlife habitat in the U.S. has been cut up into fragments by roads and development. Aquatic species' habitat has been fragmented by dams and water diversions. These fragments of habitat may not be large or connected enough to support species that need a large territory in which to find 
mates and food. The loss and fragmentation of habitat make it difficult for migratory species to find places to rest and feed along their migration routes.

- Habitat degradation: Pollution, invasive species and disruption of ecosystem processes (such as changing the intensity of fires in an ecosystem) are some of the ways habitats can become so degraded that they no longer support native wildlife.

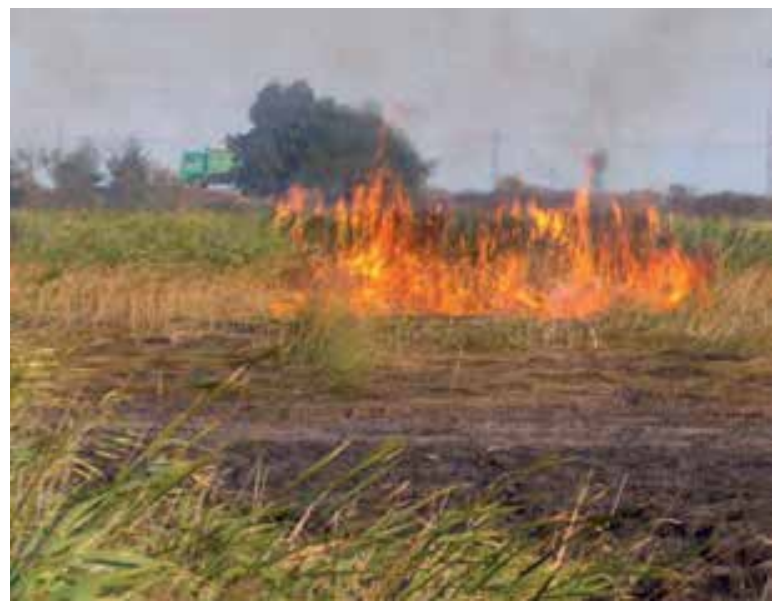

Figure 5. Applied to the wrong policies of nature conservation, local communities could lead to damage to the environment.

\section{Over exploitation (such as overfishing)}

People have always depended on wildlife and plants for food, clothing, medicine, shelter and many other needs. But today we are taking more than the native world can supply. The danger is that if we take too many individuals of a species from their native environment, the species may no longer be able to survive. The loss of one species can affect many other species in an ecosystem. Overexploitation is the over use of wildlife and plant species by people for food, clothing, pets, medicine, sport and many other purposes. The hunting, trapping, collecting and fishing of wildlife at unsustainable levels is not something new. The passenger pigeon was hunted to extinction early in the last century, and overhunting nearly caused the extinction of the American bison and several species of whales. Today, the Endangered Species Act protects some U.S. species that were in danger from overexploitation, and the Convention on International Trade in Endangered Species of Fauna and Flora (CITES) works to prevent the global trade of wildlife. But there are many species that are not protected from being illegally traded or overharvested are (National Wildlife Federation, 2013).

\section{Spread of Non-native Species/ Diseases}

Human health and economies are also at risk from invasive species. The impacts of invasive species on our native ecosystems and economy cost billions of dollars each year. Many of our commercial, agricultural, and recreational activities depend on healthy native ecosystems.

Some human activities have indirect but wide-reaching effects on biodiversity, including: 
- Climate change

- Pollution

All of these threats have put a serious strain on the diversity of species on Earth. According to the International Union for Conservation of Nature (IUCN), globally about one third of all known species are threatened with extinction. That includes $29 \%$ of all amphibians, $21 \%$ of all mammals and $12 \%$ of all birds. If we do not stop the threats to biodiversity, we could be facing another mass extinction with dire consequences to the environment and human health and livelihood are (National Wildlife Federation, 2013).

\section{Native Vegetation}

In an area without anthropogenic influences, vegetation consisting of completely native causes "native vegetation" is called. Anthropogenic impacts on vegetation by humans and animals all the destroyed (cut plants, fires, grazing, irrigation and drying of areas of life, such as climate change).

A lot of people from the intensification of economic activities in the world, after the last 50 years, especially with the increasing environmental pollution, anthropogenic influences largely been talk of a distant vegetation. The world's most secluded and found not the people living in the bodies of living things, even if the environmental pollution caused by the accumulation of many chemicals were transported. For these reasons, today, even the anthropogenic impact in less developed regions is still far from human influence.

Description of the plant natively grows only in certain areas of native vegetation, but also to be expressed in those areas should be moved by the people. Native plants in geological times in a region that region-specific climate, soil, rainfall, drought and frost, depending on the physical and biotic characteristics evolve and interact with other species in that region are found in the local plant communities. In this way, the conditions under which native plants will have certain features that makes them perfectly adapted to the characteristics and landscaping, conservation and restoration projects is extremely important to provide alternatives.

Plant sociologists, often talking about the native vegetation of different "Potential Native Vegetation". Potential Native Vegetation, all the external influences in an area (anthropogenic effects) resulting from native plant cover is removed. Generally, founded by ancient civilizations such as Turkey, passed away of native resources and areas of use, this day there are big differences between vegetation and native vegetation. However, in areas that are difficult to reach believers hardly influence the high mountains and vegetation, is equivalent to the present.

The material is of great importance for landscaping with native plants and plant communities that make us the main ones are as follows: Forests, savannah, maquis, savannahs, deserts, meadows, tundras, alpine plants, swamps. These are usually the most important plant communities that make up the earth, ecological sense, have come together and established a partnership between the livings, rather than growing the plant complied evaluated in terms of their formation and utilization conditions. 
Development of vegetation in an area and constantly remain in the area of environmental conditions that have an impact on the router. Environmental conditions, climatic conditions generally (temperature, humidity, rainfall, light, wind, etc.)., edaphic conditions (soil, water), orographic conditions (pressure area, slope, elevation, etc.)., biotic conditions (the effect of the surrounding creatures) is understood. Environment, living environment, "Biyosenoz" and the non-living environment "Ecotope" ecosystem, which together are called. Ecotopes a harmonious balance between native surroundings and has biyosenoz. At the end of the evolution of ecosystems composed of many years in this environment and vegetation is appropriate that this "Klimax" is called. There is one or more of the conditions that make the environment as a result of changes in the plant community, especially, are seen in the changing ecosystem. For these reasons, making any assessment of the vegetation in an area that should be examined thoroughly the effects of local environmental conditions and their vegetation.

Plants form the key elements stored in the primary energy production. All living things depend on other living plants. Native plants natively occur in the region in which they evolved. While non-native plants might provide some of the above benefits, native plants have many additional advantages. Because native plants are adapted to local soils and climate conditions, they generally require less watering and fertilizing than non-natives. Natives are often more resistant to insects and disease as well, and so are less likely to need pesticides. Wildlife evolved with plants; therefore, they use native plant communities for food, cover and rearing young. Using native plants helps preserve the balance and beauty of native ecosystems (Figure 6.).

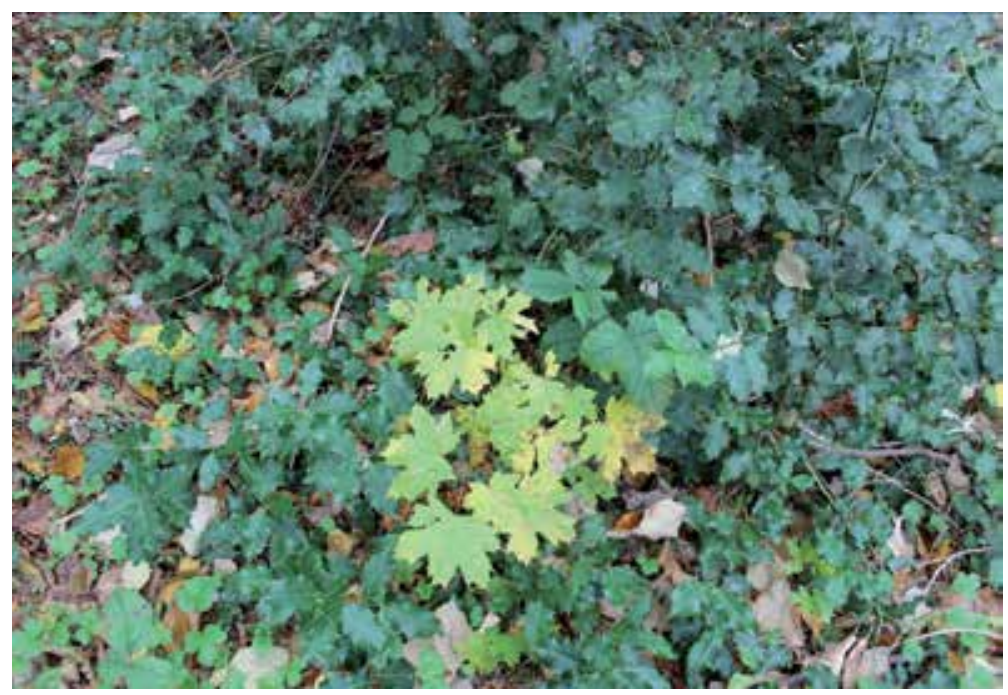

Figure 6. Different plant species in small area (Acer platanaoides, Hedera helix, Illex aquifolium, Rubus sp.)

Native species are those that occur in the region in which they evolved. Plants evolve over geologic time in response to physical and biotic processes characteristic of a region: the 
climate, soils, timing of rainfall, drought, and frost; and interactions with the other species inhabiting the local community. Thus native plants possess certain traits that make them uniquely adapted to local conditions, providing a practical and ecologically valuable alternative for landscaping, conservation and restoration projects, and as livestock forage. In addition, native plants can match the finest cultivated plants in beauty, while often surpassing non-natives in ruggedness and resistance to drought, insects and disease (Virginia Department of Conservation \& Recreation, 2012) (Figure 7.).

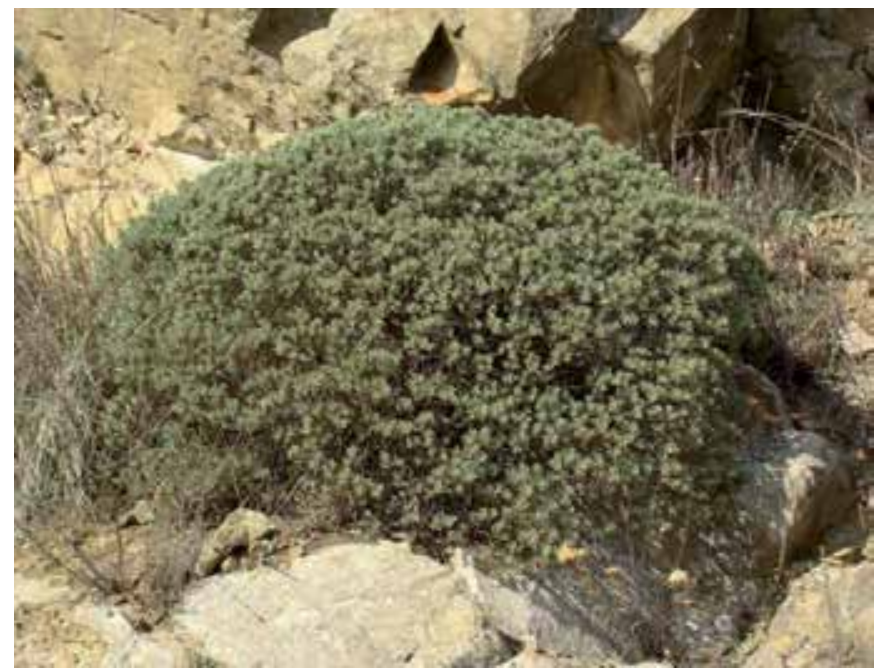

Figure 7. Thymelaea tartonraira an important plant in arid area

Native vegetation is defined differently in different jurisdictions but typically is defined to include natively occurring local vegetation (in some cases defined as vegetation that existed before a certain date), including in some jurisdictions native grasses and aquatic vegetation. The definition of terms such as 'remnant', 'regrowth', and 'thickening' is more contentious. (Productivity Commission, 2004).

\section{Potential benefits of Native vegetation}

- $\quad$ Fodder; food; seeds; wildflowers and plants; medicines; timber, including for fencing and firewood; shade; shelter; honey production; pollination and pest control services

- Tourism, recreation and visual amenity

- Habitat for native fauna (Figure 8)

- Soil and water protection (eg prevention of salinity, soil erosion or acidification)

- Biodiversity

- Carbon sinks and/or storage

- Climate

- 'Existence' and 'option' values (Productivity Commission, 2004).

In other words, native vegetation is;

- Oxygen production is the largest function. 


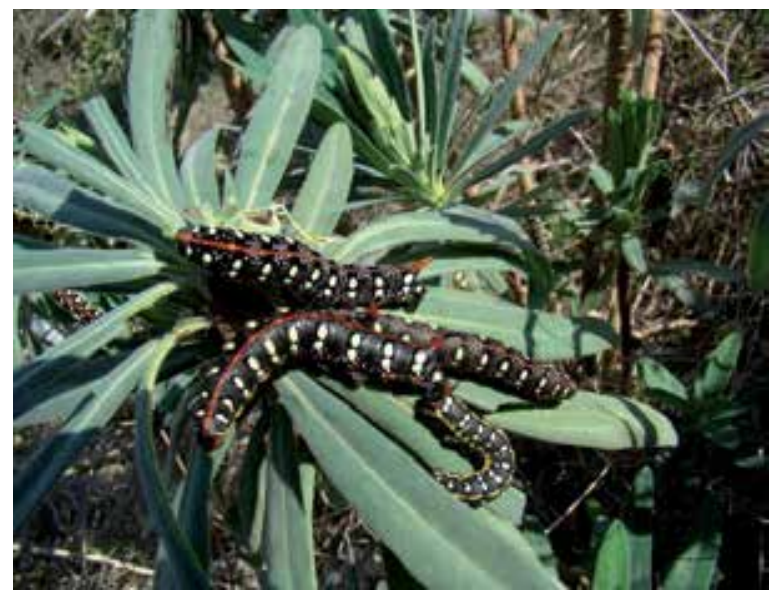

Figure 8. Larva fed on leaves of Euphorbia sp.

- The native vegetation is important in terms of microclimatic effects.

- It is important in relation to hydrological events.

- I is important in relation to soil

- It is home to wildlife

- It is high and significant economic value.

- It is important in relation to recreational (Figure 9)

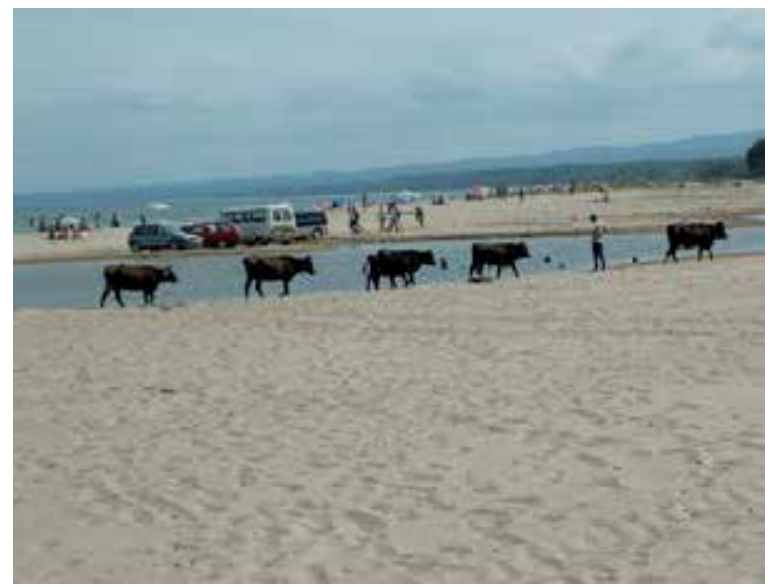

Figure 9. Sand dune areas are important for recreational activates.

Native vegetation provides many benefits principally through the protection of the land surface, amelioration or modification of local climate, maintenance of critical ecosystem processes, conservation of biodiversity, enhancement and protection of cultural and aesthetic values, and the provision of economically important products such as timber and grazing forage. However, significant degradation and loss of native vegetation has taken place since European settlement, principally as a result of human activity (Smith, et. al., 2000). 
The native vegetation is directly related to land use and environmental change and is the most easily visible and perceived part of the landscape. It is important in relation to visual effects. However, without detailed studies cannot be understood fully the relationship between other landscape elements. According to Peter et al. (2000), as well as providing essential habitat, native vegetation, including small isolated remnants and scattered trees, has an important role in providing connectivity across the landscape (Figure 10).

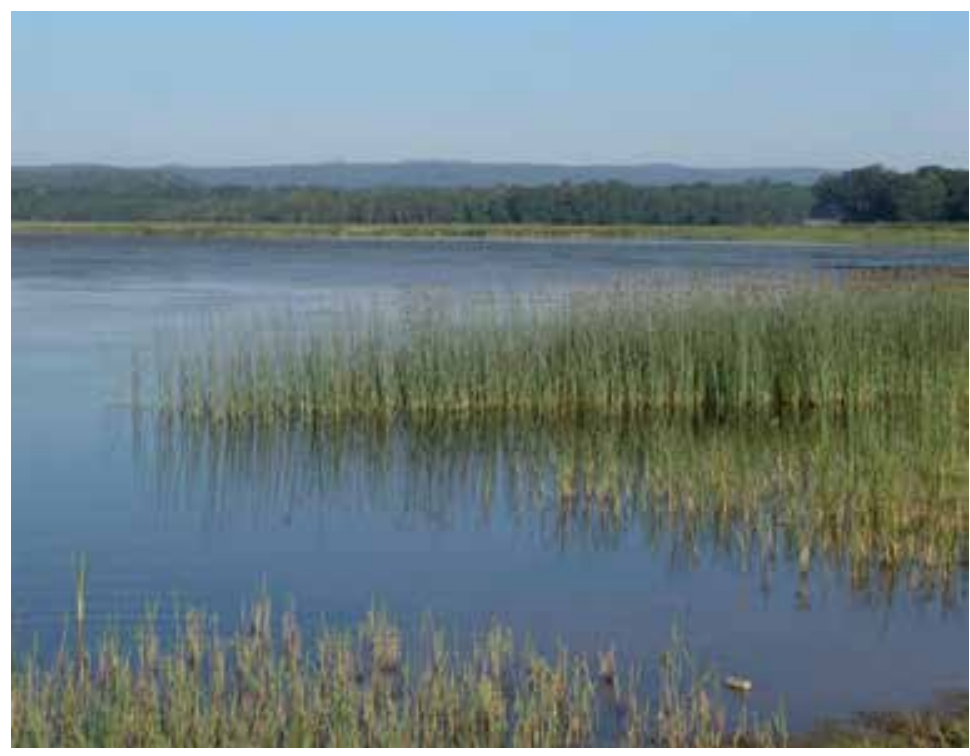

Figure 10. The Mert Lake, İğneada, Kırklareli, Turkey

According to (Smith, et. al., 2000); Connectivity concerns how easily the landscape allows plant and animal species to disperse or move through it. Adequate connectivity in the landscape reduces the probability of small isolated populations occurring, allows mobile species to access essential but dispersed resources, and may be important for species migration. Connectivity needs to be considered on a whole-of-landscape basis. This is because species movement can occur from any patch or island that is either large enough or of sufficient habitat quality to support a breeding population or among a number of smaller patches that combine to provide suitable habitat for a population. Corridors are generally considered important for providing connectivity in highly cleared and fragmented landscapes (Fahrig and Merriam 1985, Downes et al. 1997). However, there is only limited proof of their efficacy in allowing species movement and they may indeed negatively affect individual species by promoting transmission of diseases and disturbances (Simberlof and Cox 1987, Hess 1994). Nevertheless, it is generally agreed that species response to fragmentation is individualistic and that corridors enhance landscape connectivity for many species (Saunders et al. 1991, Dawson 1994, Beier and Noss 1998).

According to (Smith, et. al., 2000); Native vegetation plays an important role in many ecosystem processes. These processes include nutrient retention and cycling, carbon storage, purification of water and the maintenance of viable and diverse populations of important 
components of biodiversity such as detritivores (organisms that break down organic matter) pollinators and parasites and predators of farm pests (Figure 11). For example the life cycle of some parasitic wasps and flies depend on nearby sources of food found in native vegetation. Some species of these parasites seldom travel more than 200 metres from such sources of food (Davidson and Davidson 1992).

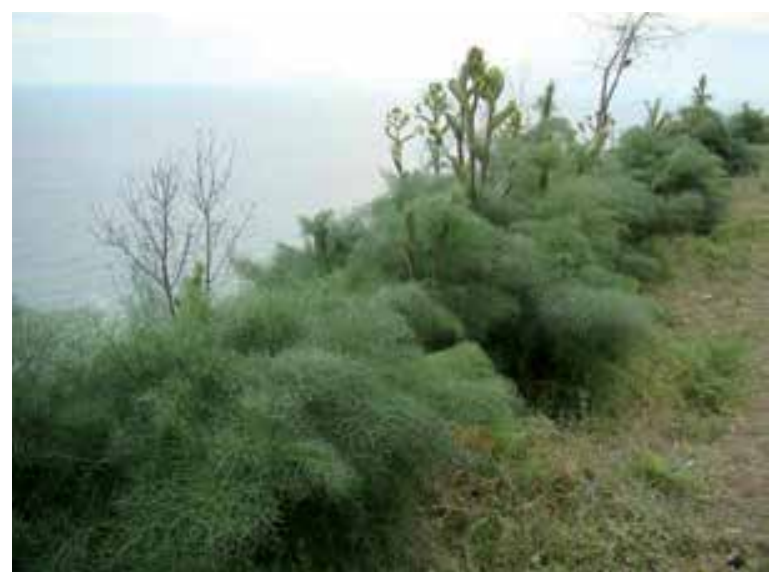

Figure 11. Ferula communis subsp.communis is used in pharmaceutical industry

Degradation and loss of native vegetation resulting from human activity has altered and disturbed many of these ecosystem processes. Broad-scale loss of vegetation cover has led to considerable land degradation by exposing the land surface to wind and rainfall, which greatly increases soil erosion. These problems are exacerbated by some agricultural management practices, which cause loss of soil organic matter and nutrient decline and, in some places, increasing soil salinity and acidity. For example, it has been estimated that some 120,000 ha of NSW are currently affected by salinity and that 7.5 million ha could potentially become salt affected (Smith, et. al., 2000).

Disturbance of ecosystem function, fragmentation of habitats, the introduction of foreign species and ecologically unsympathetic agricultural systems has been widespread. As a consequence, species decline and extinction has been marked, while altered community balance has frequently led to the unchecked and damaging spread of exotic plants and animals. Halting the decline in native vegetation cover and rectifying some of the damage that has been done is not an easy task, but is possible. Nature reserves have a vital role in this recovery but are only part of the solution. We also need sympathetic management of privately owned native vegetation, and it should be recognised that such management can offer production benefits by preserving land and water quality. Restoration of vegetation cover also provides considerable potential for improved ecosystem function, increased biodiversity and better health for the wider environment (Smith, et. al., 2000).

\section{Benefits of native vegetation}

Biodiversity conservation is an essential component of responsible environmental and native resource management. It is fundamental to quality of life and supports our economy 
and productivity, both now and in the future. Native vegetation provides habitat for native animals. It delivers a range of ecosystem services that make the land more productive and that contribute to human wellbeing. The benefits provided by native vegetation can be separated into the following categories (Victorian Government Department of Sustainability and Environment, 2012).

Use values

Use values involve people physically using or experiencing native vegetation and the attributes it provides, and deriving value from this use. These use values comprise both direct use values and indirect use values.

Direct use values. These values include benefits to agricultural production, such as enriching soils, shade for animals, pollination of plants, and native vegetation as the provider of goods such as honey, timber and pasture for grazing. Other direct uses of native vegetation include recreation and cultural uses.

Indirect use values. These values include functional benefits derived from relying on native ecosystems for life support functions including providing clean air, water and other resources, along with the conservation of biodiversity. Other benefits include resilience to climate change, and reduced susceptibility to disease and extreme weather events.

Non-use values

There are a range of benefits that flow from native vegetation that are enjoyed without contact with the native vegetation. These are known as non-use values and include existence values, option values and bequest values (Victorian Government Department of Sustainability and Environment, 2012).

- Existence values. This means the satisfaction that the community derives simply from knowing that native vegetation and biodiversity exist.

- Option values. These are benefits derived from retaining the option to use native vegetation in the future without necessarily planning to do so. These benefits include the value of waiting until a time in the future when better information is available to inform decisions about the use of native vegetation.

- Bequest values. These values derive from the knowledge that maintaining native vegetation and biodiversity will benefit future generations. (Victorian Government Department of Sustainability and Environment, 2012).

\section{Identification and classificiation of native vegetation}

The aim is to determine the extent of the formation and vegetation. Classificiation table is;

1. Floristic:As an individual species, genera, families and so on. to classify the botanical names of the form

2. Form and structure: This is based on the dominant forms (forest, pasture etc.) of plant communities by giving importance to classify plants (the most abundant, etc.)

3. Ecological: This classification, to classify plants according to habitat and some of the critical environmental parameters. 


\section{Turkey and Native Vegetation}

Biodiversity is the great wealth of the countries that have the most perceived. Turkey is the world's richest in terms of native vegetation one of the countries. Mediterranean, IranoTuranian and Euro-Siberian phytogeographical regions of Anatolia into finding and intertwined with each other, this is the main cause of wealth.

Meadows and pastures in our country is one of the most important sources of biological diversity. These are considered one of the largest renewable native resources. Turkey, in terms of plants in the world, is one of the countries in the temperate climate zone. The main reasons for this wealth, climate differences, topographical diversity, geological and geomorphological diversity, sea, lake, river, such as various water variety of environments, ranging from 0-5000 meters height differences, three different combined with the fact that the place of plant geography, east and west of Anatolia differences between the present ecological and floristic diversity in all of these ecological reflection of the diversity (Figure 12).

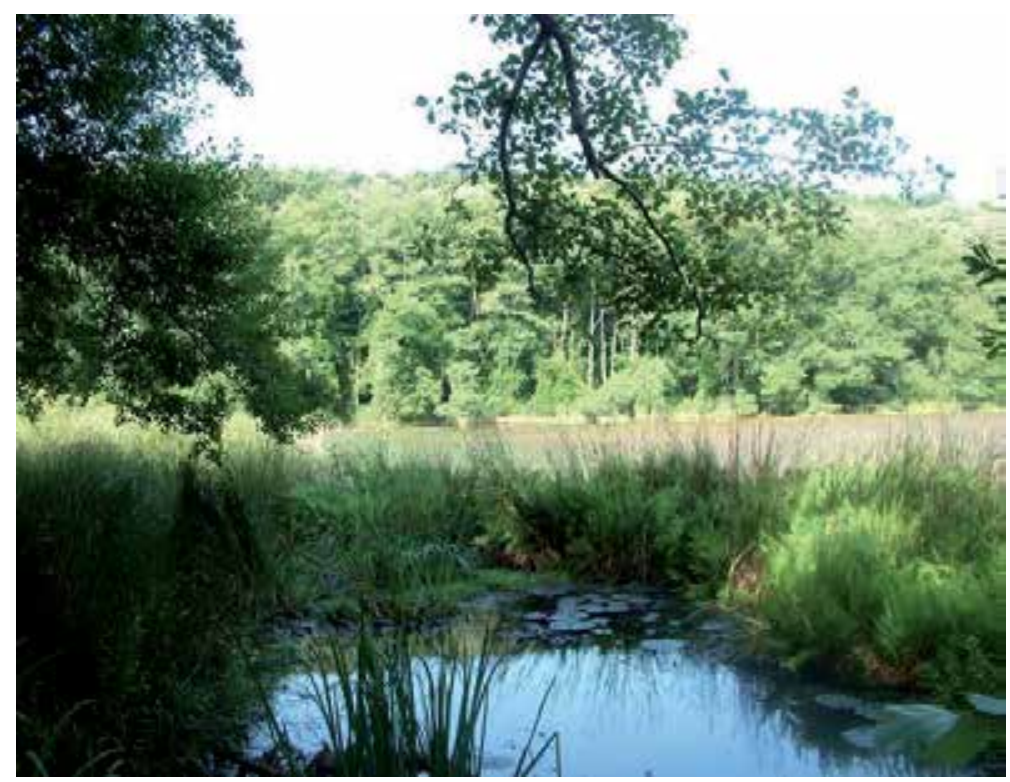

Figure 12. The Hamam Lake, İğneada, Kırklareli (the lake in forest)

Turkey, around 9000 with the type of ferns and seed plants is a country very rich in terms of flora. Whereas, flora of the European continent contains about 12,000 species. The importance of the flora of Turkey, as well as species richness is due to the high rate of endemism. There are 2750 endemic species in the European countries, Turkey, this number is around 3000 (Figure 13).

In our country, the factors leading to the formation of native vegetation regions of Anatolia, depends on the structure of a specific native. The first of these stages of the country that are turning very sharp elevation in mountainous morphological structure. Accordingly, in the 
north, north west, south of the south-westerly winds, the creation of different climates. Therefore, the vegetation varies in the vertical direction only, but also by looking also varies widely (Figure 14).

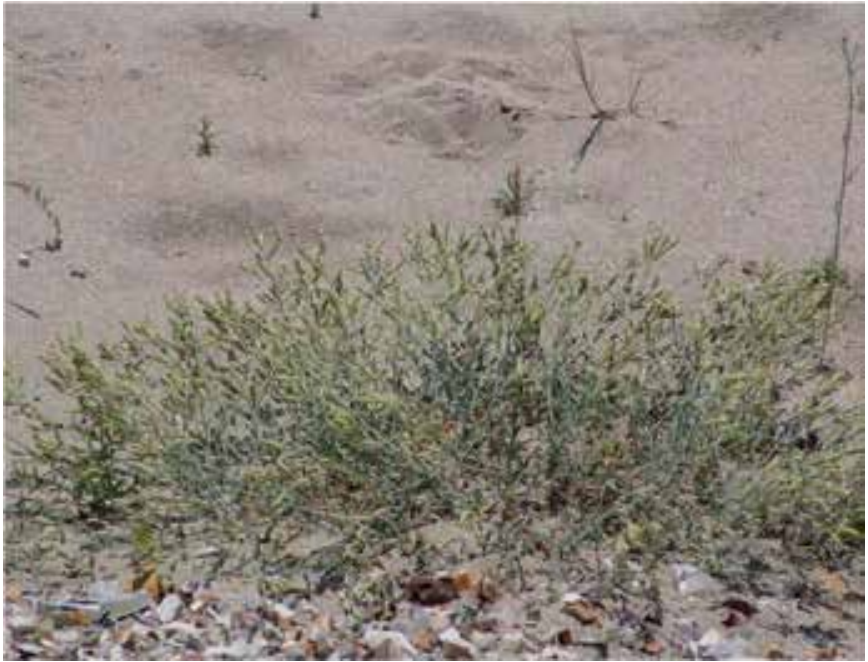

Figure 13. Silene sangaria Coode \& Cullen (endemic)

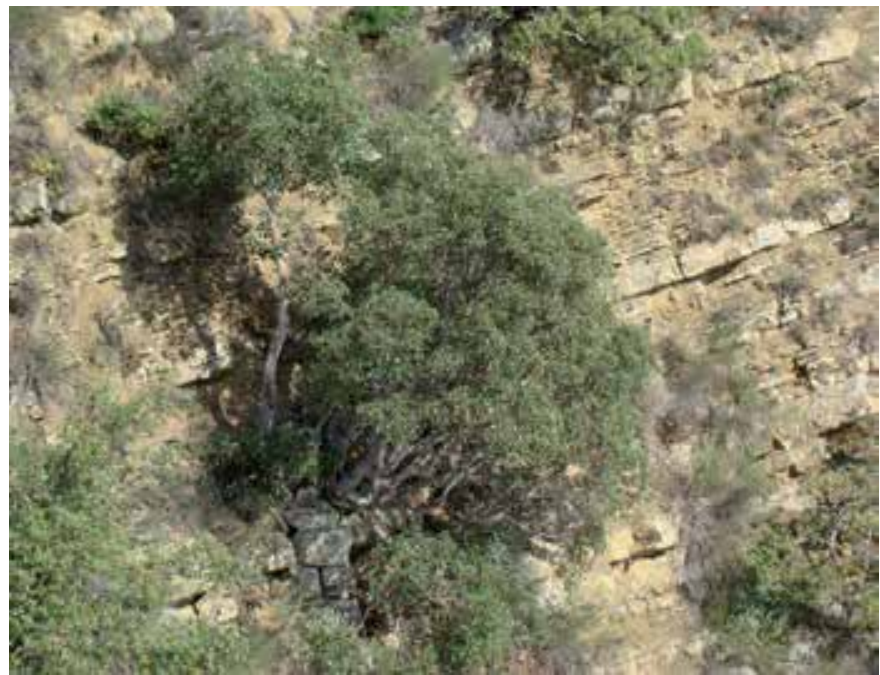

Figure 14. Arbutus andrachne L. (Southern slopes overlooking the sea), Ganos Mountains, Tekirdağ, Turkey

The native vegetation has taken over the operations supported by the complex structure of biological diversity reveals the cycle of a healthy ecosystem. For this reason, all of the physical and biotic factors in areas where native vegetation and an interaction of mutual. The native vegetation on the one hand living environments affected by factors other living and non-living, and their presence on the other hand constitute one of the most important 
factors in terms of diversity. Native plants that will blend the best of local environmental conditions, plant species, and above all a large scale ecological plantation of native plants provides significant contributions to native and biological communities. Aesthetic and functional characteristics of many native plants, as well as contribute to the efficiency of the soil, reduce erosion, and often less than many exotic plants, fertilizers, pesticides and other chemicals, such as input, show the need for maintenance measures. Plantation studies, native plants are becoming increasingly popular for many countries.

The main reasons for this interest;

Aesthetics: Beauty, interesting or rare forms and the native environment, establishing the connection.

Environment: Water use reduction, less pesticide and fertilizer use, the creation of a suitable environment for wildlife.

Maintenance: low long-term maintenance costs, and less work needed to increase the durability of the plant listed as heard.

The presence of native vegetation of the country's economy is the direct and indirect benefits of unlimited. A rich variety of plant species in the flora of Turkey, local people need to grow them, as well as industrial and scientific organizations, benefits for different purposes. Native vegetation, improving a country's climatic conditions and soil loss prevention in rural areas, preparing the ground for scientific research, forest products, food, and pharmaceutical industry is a source of units to meet the need for raw materials and fuel.

Especially important in the protection of endemics are carried out. Classes of endangered to which they belong are determined internationally, is under a lot of pressure given priority species which are in danger of extinction.

Threats to plants in Turkey are shown below. These factors are;

- Industrialization and urbanization,

Urbanization in rural areas is particularly damaging to vegetation

- Agricultural extension and excessive grazing

The native pasture areas, overgrazing, and prevents the growth of weeds as well as to the spread of cosmopolitan species are herbaceous origin. The animals eating the herbs roots up to their neck that prevents the growth of weeds and grass pastures deteriorate the quality of output. The inedible prickly weeds are spreading.

- $\quad$ Tourism

Dunes and coastal area to be occupied by tourism facilities

- Collecting plants from nature

Native plants are collected from nature for various purposes (medical, spices, ornamental, fuel, animal feed, especially bulbous plants) 
- Reclamation of Halophytic Areas

Large halophytic areas are improved, especially for agricultural purposes.

- Agricultural Control and Pollution

Unconscious use of agricultural pesticides. Especially in endemic and rare plants are damaged.

- Afforestation

Reforestation activities is changed environmental conditions of the plants. This activity is made of a plant endemic to the place where you are likely to disappearance.

- $\quad$ Fire

Fires can damage local and rare endemic species

The European continent in the Thrace Region, different climates, soil types, and due to the geographical characteristics of the floristic aspect is very rich. Although there are many different vegetation types in the Thrace Region, There are four main types:

1. Forest vegetation

2. Shrub vegetation

3. Meadow vegetation

4. Aquatic vegetation

\section{Tekirdağ and Ganos mountains}

Northwest Turkey Tekirdag, Marmara Sea, one of the three provinces in the north of the territory of the whole of Thrace, as well as two sea-coasts in Turkey is one of the six provinces. With a surface area of $6313 \mathrm{~km}{ }^{2}$, Istanbul, Tekirdag from the east, north, BSNL, west of Edirne, Canakkale south-west to the south, surrounded by the Sea of Marmara. North-east to the Black Sea is $2.5 \mathrm{~km}$ from the coast.

The geological structure of Tekirdağ is relatively young. area of the province while the sea covered the first time, the current image of the IV. from time. Increased Anatolia and Thrace, the Aegean Marmara and Black Sea basins lowered. Soils generally consist of sandstones containing clay and cemented.

Tekirdag, approximately 1,200 km long starting Karlıova 100-15000 m wide, consisting of the many faults of the North Anatolian Fault (NAF) is located near the end. $(15-25 \mathrm{~km})$. Faults may be caused by an earthquake within the boundaries of Tekirdag Province; Saros Gaziköy fault in the Sea of Marmara with the edges of the trench part of the fault. Ministry of Public Works and Settlement, dated 04.18.1996 "Seismic Zoning Map of Turkey" according to the outcrops, and Barbaros 1 Mürefte Degrees are in the earthquake area. 
Located in the southeastern part of the Balkan Peninsula in the Thrace region has a different morphological units. The most important of these morphological units in the province of Tekirdag Ganos and Koru Mountain (Figure 15).

Between these two mountainous terrain, river branches and split Ergene, mild, moderate, and sometimes pen plain steep slope lands in the south and middle parts are the high hills and sloping hillside land (Figure 16).

Ganos Mountain is located in the south of Thrace. Mountains, extends northeast-southwest direction. By Streams highly fragmented appearance. There are many hill and mountain villages in the region. Ganos Mountain is cool and a little rainy Mediterranean climate.
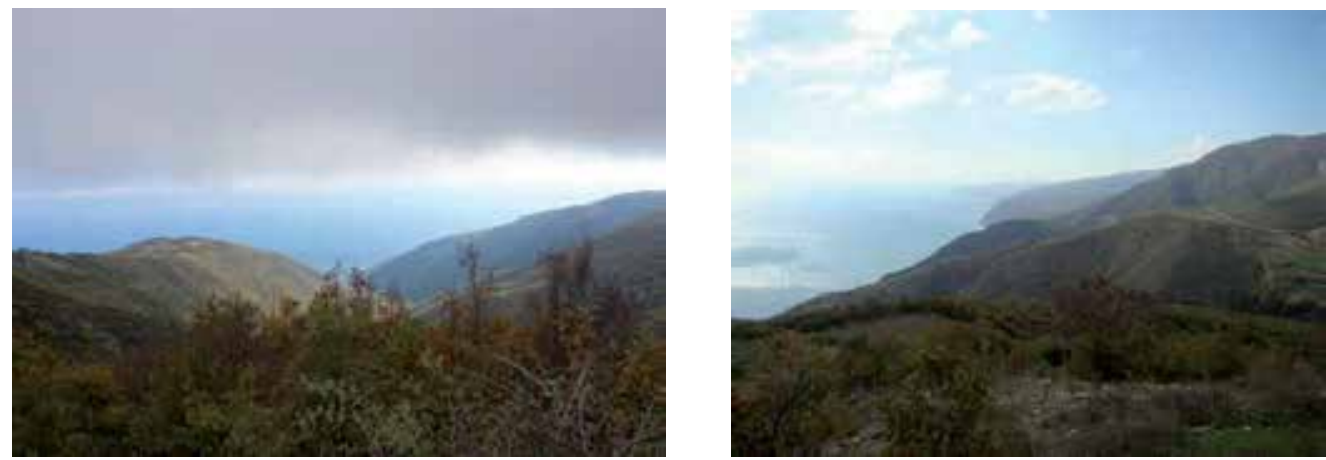

Figure 15. Morphological structure of Ganos mountains
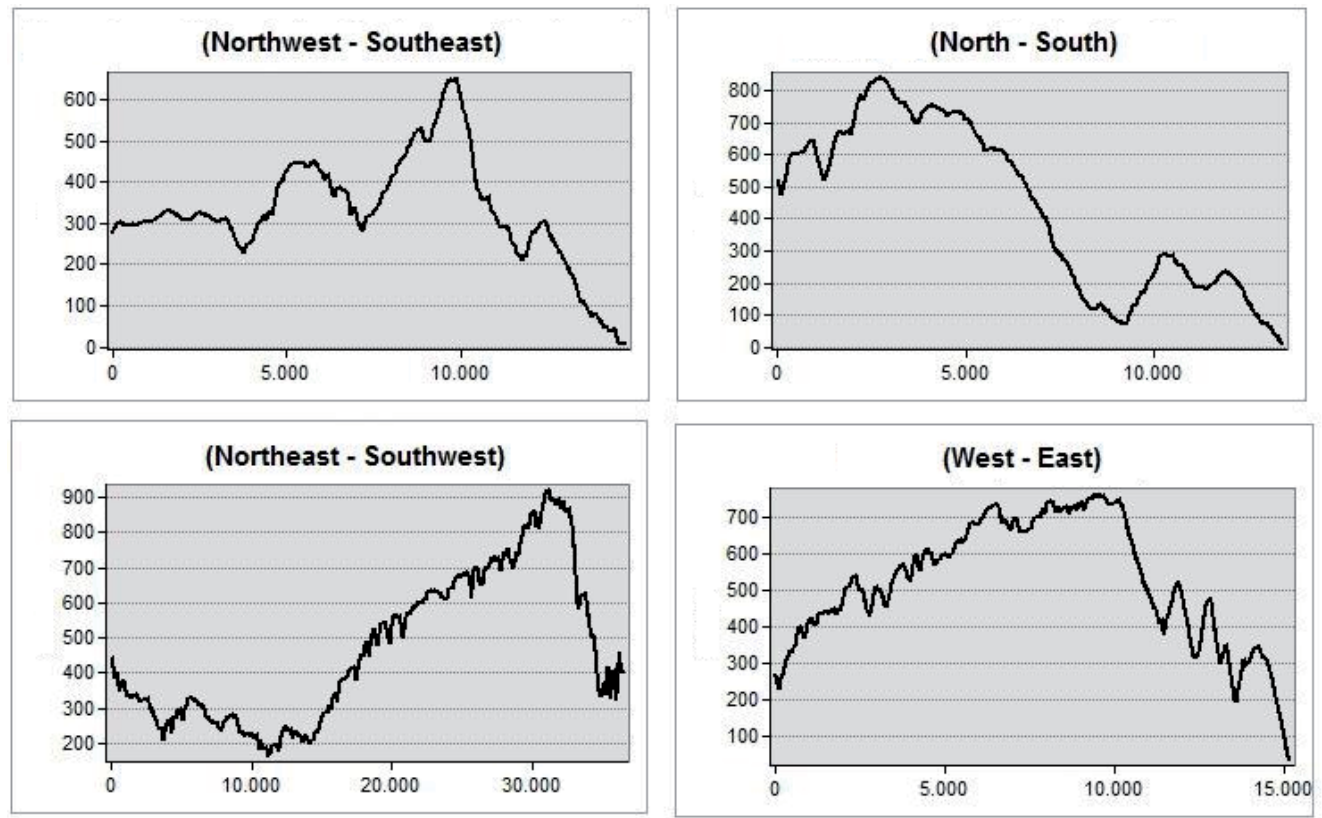

Figure 16. Profiles of Ganos Mountains, Tekirdağ, Turkey (Özyavuz, 2011) 
Therefore, there are so many taxa of Mediterranean origin. Ganos Mountain, Quercus sp. and Carpinus sp. representation of the Balkans, central Europe and the Euxine falls into the area of the dominant elements of the flora. In addition, shrubs Ganos Mountain foothills overlooking the Marmara Sea and the lowlands of the elements is observed that the pseudomaquis.

Constitute the most important Tekir Mountain the elevation of the province; $12 \mathrm{~km}$ south of the city of Tekirdag Kumbag from the start, until to Gelibolu in a row $(60 \mathrm{~km})$ stretches. The highest point Ganos Mountain. The eastern part of the province is less high. Some of the ridges on the plains is slightly wavy. One of them is around Corlu, extends east-west direction. Line is part of a water basin that serves as a teenager, and this limits the ridge to the east foot of the Strandja Tekirdag regains the west. Istrancalar (Ganos Mountains), Çerkezköy starts and rises gradually to the north.

In inland areas covering the vast and fertile plains of river valleys are broad-based. The most important of these, from the western direction Çerkezköy, Ergene river flowing through the bed with an ever-expanding Ergene Plain Hayrabolu and Cene (Beşiktepe) alluvial deposits along the creeks and Maxillofacial Hayrabolu plains.

Small and narrow coastal plains along the shores of the Marmara, the materials brought by the rivers along the coast, is a result of the accumulation. Tekirdag, Ergene Despite the fact that the basin, vegetation, rainfall, due to lack of geological structure is sparse and has a network of small streams. Irregular flow regimes of rivers, and is proportional to the amount of rainfall and the regime. In the summer, the waters decreased drying grows in winter precipitation and snow melt, or even brimming. City streams Saros Gulf, the Sea of Marmara and the Black Sea is poured. Ergene important rivers of our city with the River Corlu, Hayrabolu, Işıklar, Olukbaşı and puddles streams.

$133 \mathrm{~km}$ along the coast of the Sea of Marmara Tekirdag is the southern boundary. $2.5 \mathrm{~km}$ from the coast of the Black Sea, there are also. Marmara coast, leaving aside the small and narrow coastal plains, no generally high coasts. Marmaraereğlisi the only native harbor off the coast of Tekirdag. This is a peninsula. Marmaraereğlisi east of the port in the form of a semi-circle diameter of $1.600 \mathrm{~m}$. Northeasterly mouth open, the other winds are closed. To prevent severe winds and west southwest wind is a haven of refuge for boats.

Tekirdag province, Black Sea Kastro (Camlikoy) dating back to the bay and the bay Çilingoz high and steep rocky coastline has a view.

Does not exceed $100 \mathrm{~m}$ in the Gulf of Tekirdag depth. Self called a shallow sea. Rich in marine plants and animals. More than $1000 \mathrm{~m}$ in the Gulf Kumbağ'dan south west of the line will be drawn deeper. Fishermen here or com channel are also. And the actual currents through shoals of fish here.

Temperature averages and indices, given the general humidity, Tekirdağ province's climate is characterized as temperate semi-humid. The effect of distance and elevation coastal walks inland sea temperature and precipitation values are entered variations are small. 
Along the coast of the Sea of Marmara, summer is hot and dry, while winters are mild and rainy characteristics of the Mediterranean climate. However, the effect of the Black Sea climate lighter summer drought. During the winter season snowfalls are common. More arid inland summer is entered the semi-continental climate with cold winters more apparent.

Extending to the north of Tekirdag House Strandja more rainfall due to the mass of the northern slopes are covered with beech forests. In this section cover ormanalt rhododendrons (Rhododendron) creates. The further south, the southern slopes and, due to reduced rainfall, Fagus sp., Quercus sp. and Carpinus sp. seen that place.

Adolescents in the residential areas near the basin rarely leave the bus at the correct Quercus sp., Carpinus sp, Paliurus and Ulmus sp. populations are outstanding. These small groups of trees, whether Thrace is a testament to the inner sections of the steppe area. Thrace region, as a result of the destruction of forests to make farmland, today has the appearance of steppe land. (Anthropogen step) In this section and in the valleys of the land base poplar and willow species are common (Figure 17).
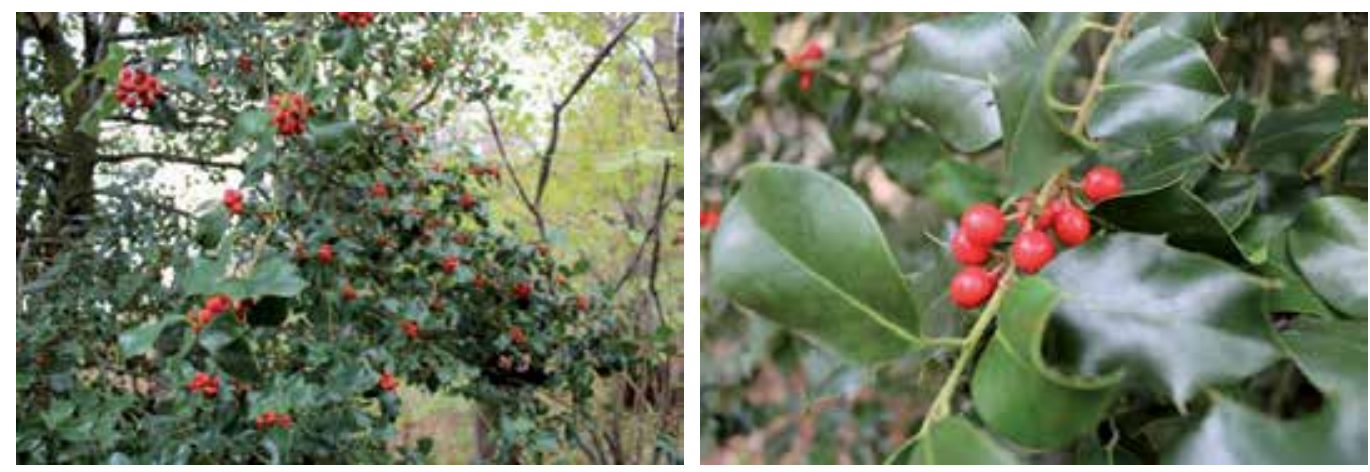

Figure 17. İlex aquifolium $L$.

The northern slopes of the mountains of southern Ganos, Carpinus sp., Quercus sp., Tilia sp., and under dense forest cover evident, due to reduced rainfall in the southern slopes are dry forests and scrub communities. Quercus sp. and Pinus sylvestris sp. forests in the Ganos Mountains communities are dominant.

\section{Conclusion}

As a result of the researches of the Ganos Mountain, 202 genera and 64 families, 305 plant taxa were included in these genera. Compositae families in terms of richness of species in this family are the most important. This is followed by Leguminosae family. Ganos Mountain taxa of flora distribution of parts of the Euro-Mediterranean elements with the elements of Sibirian comes first. Tekirdağ can be shown poor in terms of forest. Istranca mountains fall within provincial areas, in places, are oak groves. In some areas, Alnus sp, Ulmus sp. and Pinus species where observed. Typical plants are Mediterrean Climate maquis, vineyards, fruit orchards and olive groves. Plants identified in this study are shown below; 
Acer campestre L. subsp. Campestre, Alkanna tinctoria Tausch, Arbutus andrachne L, Asparagus acutifolius L., Briza maxima L., Calycotome villosa (Poir) Lk., Capparis spinosa L., Carpinus betulus L., Carpinus orientalis Miller, Cersis siliquastrum L, Cistus creticus L., Colutea cilicica Boiss.et Bal., Coronilla emerus subsp. Emeroides, Cercis siliquastrum L., Cistus creticus L., Clematis vitalba L., Colchicum autumnale L., Colutea cilicica Boiss.et Bal. Cornus mas L., Crataegus monogyna L., Cydonia oblonga Miller, Dittrichia viscosa L. Greuter, Doronicum orientale HOFFM., Emerus majus Mill., Euphorbia rigida Bieb., Euphorbia characias subsp.wulfenii, Ferula communis subsp. Communis, Fraxinus ornus L. subsp. ornus, Glaucium flavum Crantz, Hymenocarpus circinnatus L. Savi, Hypericum perforatum L., İlex aquifolium L., Jasminum fruticans L., Juncus acutus L., Juniperus oxycedrus L. subsp. oxycedrus., Phyllrea latifolia L. Prunus spinosa L. subsp. dasyphylla., Quercus frainetto Ten., Quercus infectoria Olivier, Quercus petraea (Mattuschka) Liebl. subsp. Petraea, Muscari armeniacum Leichtlın Ex Baker, Nasturtium officinale L., Paliurus spina-christi Mill., Parietaria officinalis L., Phyllirea latifolia L., Pistacia terebinthus L. Platanus orientalis L., Ruscus hypoglossum L., Salix viminalis L., Salvia triloba L., Sambucus ebulus L., Sarcopoterium spinosum (L.) SPACH., Scorpiurus muricatus L. Fiori., Seseli tortuosum L., Smilax excelsa L., Spartium junceum L., Tamus communis L., Thymelaea tartonraira L., Thymus atticus Celak., Tilia argentea Desf. (Korkut, 1987; Özyavuz, 2011)

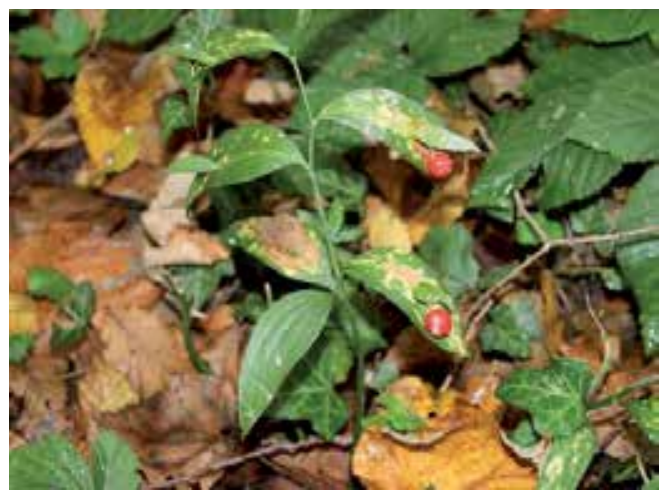

Figure 18. Ruscus hypoglossum L

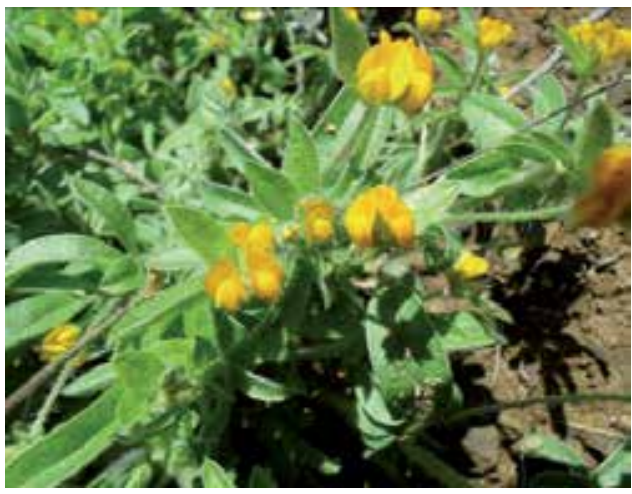

Figure 20. Hymenocarpus circinnatus L.

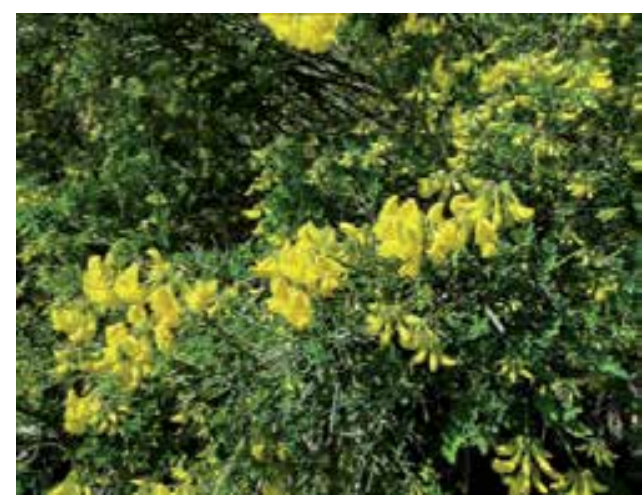

Figure 19. Emerus majus Mill.

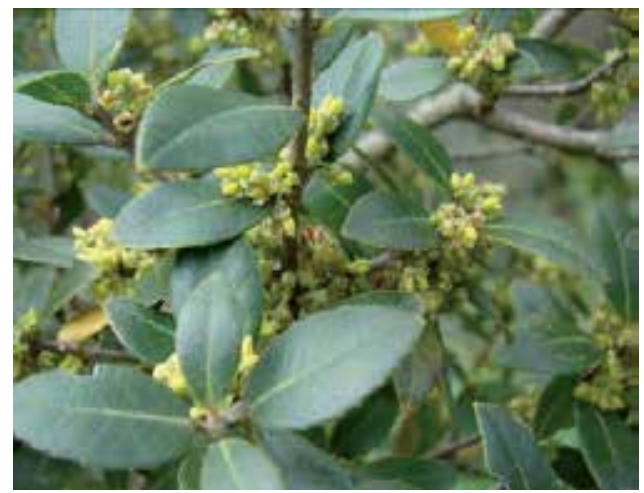

Figure 21. Phyllrea latifolia L.. 


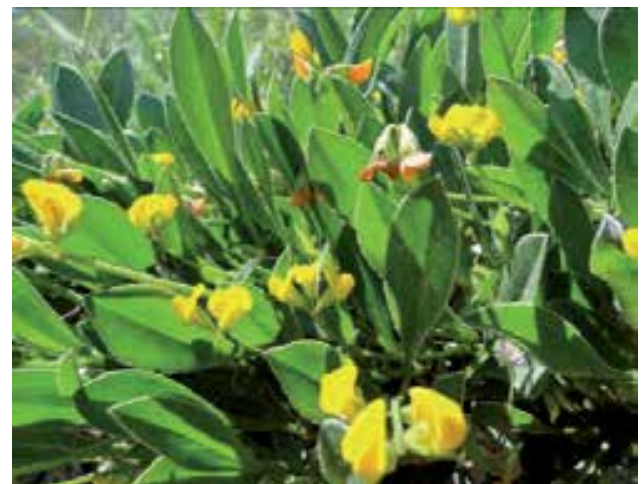

Figure 22. Scorpiurus muricatus L. Fiori.

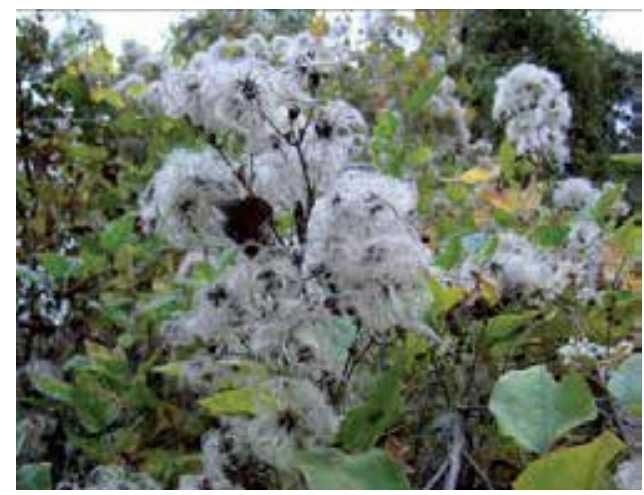

Figure 23. Clematis vitalba L.

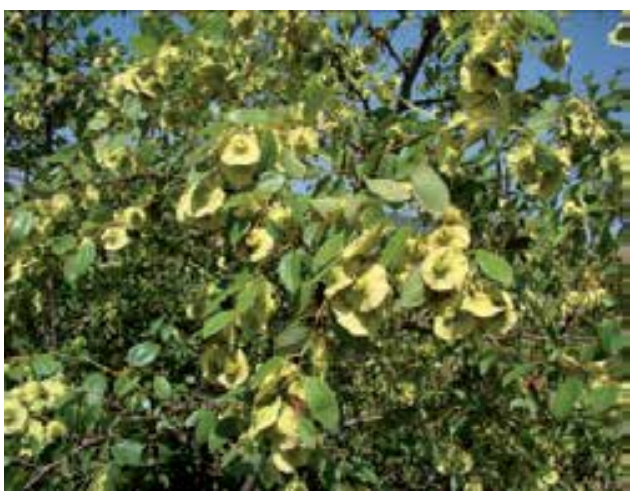

Figure 25. Paliurus spina-christi Mill
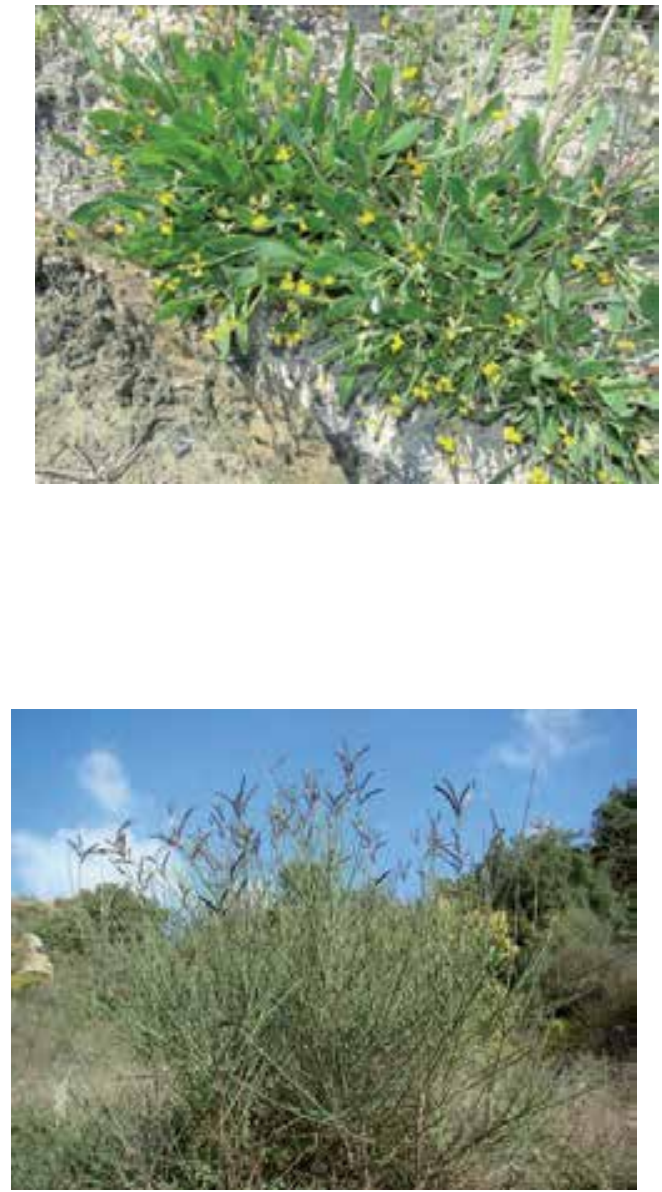

Figure 24. Spartium junceum L.

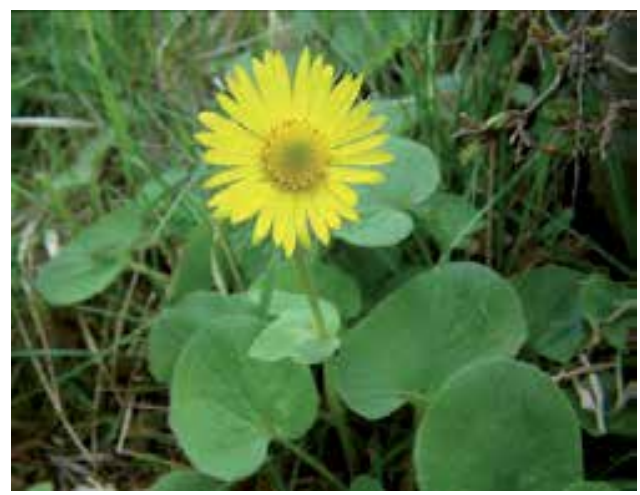

Figure 26. Doranicum orientale Hoffm. 


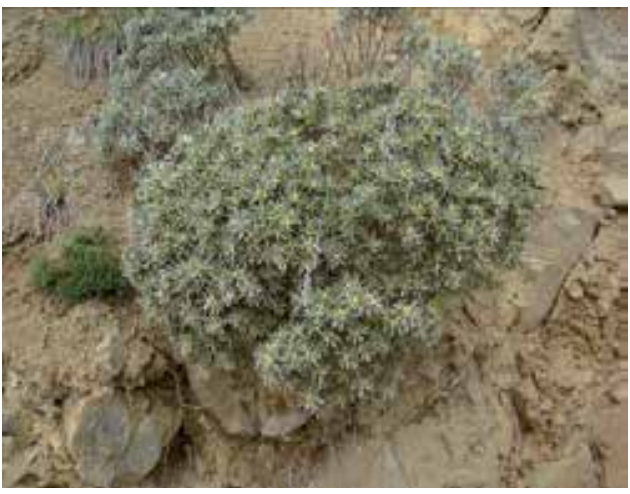

Figure 27. Thymelaea tartonraira L.

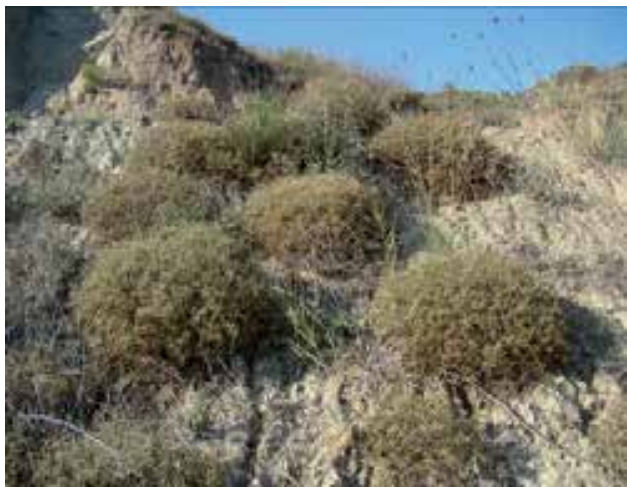

Figure 29. Sarcopoterium spinosum (L.) SPACH.

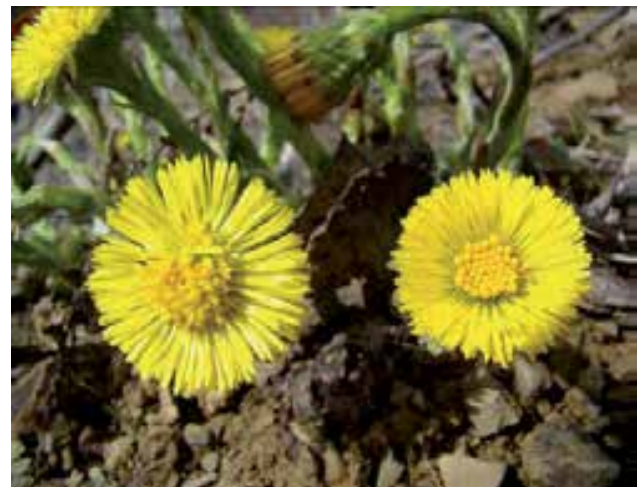

Figure 28. Tussilago farfara L..

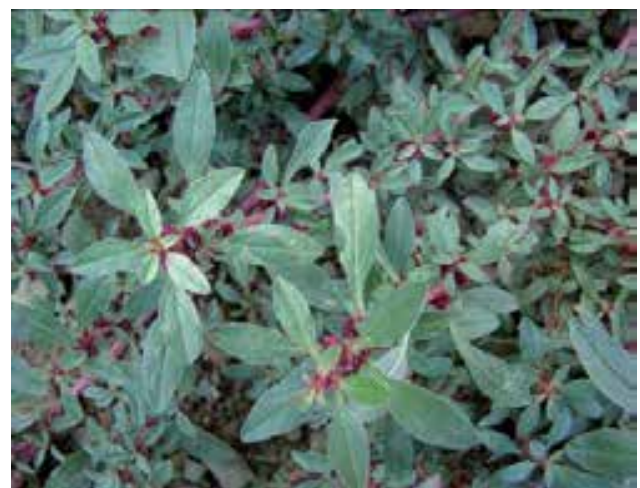

Figure 30. Parietaria $s p$.

\section{Author details}

Murat Özyavuz and Aslı B. Korkut

Namık Kemal University, Faculty of Fine Arts, Design and Architect, Department of Landscape Architecture, Turkey

Ayten Özyavuz

Namık Kemal University, Turkey

\section{References}

Environmental Protection Authority, 2000. Clearing Of Native Vegetation, With Particular Reference To The Agricultural Area, Environmental Protection Of Native Vegetation In Western Australia Position Statement No. 2, 15 p.

Korkut, A. 1987. Trakya Bölgesi Doğal Bitki Örtüsünde Peyzaj planlama Çalışmaları Yönünden Değerlendirilebilecek Bazı Bitkisel Materyalin Saptanması, TÜBİTAK Tarım ve Ormancılık Araştırma Grubu Proje no: TOAG-581, Tekirdağ. 
National Wildlife Federation, 2013. What is Biodiversity?, http://www.nwf.org/wildlife/ wildlife-conservation/biodiversity.aspx.

Özyavuz, A. 2011. Determınation of some plants grown in natural vegetatıon in Tekırdağ (kumbağ-sarköy between) Coastlıne and usage Opportunities in landscape architecture, MSc. Thesis, Namik Kemal University, Graduate School of Natural and Applied Sciences, Department of Landscape Architecture, Turkey.

Özyavuz, M. 2011. Analysis with Geographic Information Systems and Remote Sensing Techniques, Ecological Conditions of Vegetation, Ganos (Işıklar) Mountain (Tekirdağ), Journal of Tekirdag Agricultural Faculty, 8(2), p.37-48.

Peter L. Smith, Brian Wilson, Chris Nadolny, Des Lang. 2000. The ecological role of The native vegetation Of new south Wales, Native Vegetation Advisory Council, $60 \mathrm{p}$.

Productivity Commission 2004, Impacts of Native Vegetation and Biodiversity Regulations, Report no. 29, Melbourne.

Slattery, Britt E., Kathryn Reshetiloff, and Susan M. Zwicker. 2003. Native Plants for Wildlife Habitat and Conservation Landscaping: Chesapeake Bay Watershed. U.S. Fish \& Wildlife Service, Chesapeake Bay Field Office, Annapolis, MD. 82 pp.

Smith, P. L., Wilson, B., Nadolny, C. 2000. The ecological role of the native vegetation of new south Wales, Native Vegetation Advisory Council, 60 p.

Victorian Government Department of Sustainability and Environment, 2012. Future directions for native vegetation in Victoria Review of Victoria's native vegetation permitted clearing regulations, ISBN 978-1-74287-616-0 (online), $36 \mathrm{p}$.

Virginia Department of Conservation $\mathcal{E}$ Recreation, 2012. Native Plants for Conservation, Restoration, and Landscaping, http://www.dcr.virginia.gov/natural_heritagel nativeplants.shtml 


\title{
Conservation of Natural Plants and Their Use in Landscape Architecture
}

\author{
Zuhal Dilaver
}

Additional information is available at the end of the chapter

http://dx.doi.org/10.5772/55767

\section{Introduction}

Biological diversity means the diversification of living organisms in all sources including the terrestrial, marine and other aquatic ecosystems and the ecological structures that are part of these ecosystems. It refers to the differences exhibited by the living environments (habitats or, more broadly, ecosystems) of species in terms of various biotic and abiotic factors. It also refers to the differences between living things in ecosystems and between living and nonliving things, which vary according to place and time and to all of genes, species, ecosystems and functions [1].

Biological diversity can be divided into three hierarchical categories: genetic diversity, species diversity and ecosystem diversity.

Genetic Diversity means the diversity within a given species. It is measured by the genetic difference within a certain species, population, variety, sub-species or race.

Species Diversity means the diversity of the species in a particular region or in the entire world. "Species richness", i.e. the number of species in a region is the most commonly used measure in this regard.

Ecosystem Diversity is about the whole created by the community of organisms that interact with each other as an ecological unit and by their physical environment. The ecosystem consists of factors, such as fire, climate and the food cycle, which are separate from the community level and which are non-living themselves but still they affect the formation, structure and interaction of the community of living things. The conservation of biological diversity at the ecosystem level includes the conservation of the food chain and of the energy flow. At this level, it is necessary to protect not only species or groups of species but also characteristics and processes [1]. 
As human activity continues to spread throughout the earth, natural areas are changed, resulting in increasing extinctions of plants, animals, and other types of species. Currently, many experts believe such extinctions are occurring at the fastest rate in history and perhaps the fastest rate since the extinction of dinosaurs 65 million years ago. This loss of biological diversity is accelerating as desertification, deforestation (especially in the tropics), degradation of oceans and water resources, atmospheric change, and other environmental changes continue rapidly [2].

Biological diversity is important to human welfare for many reasons. Agricultural crops derive from wild species, and the high-yielding hybrids of modern agriculture depend on continuing revitalization from wild genetic stock. Furthermore, future crop species that could be used directly or modified by biotechnology are lost when entire ecosystems are wiped out. Plants are the basis of prescription drugs; a number of plants discovered in tropical rainforests or other wild areas have made significant contributions to treatment of serious diseases. Also, loss of species often means the breakdown of ecosystems that may have important roles in regulating rainfall, controlling floods, producing oxygen and storing carbon, affecting both regional and global climate [2].

At the World Summit on Sustainable Development held in 1992 in Rio de Janeiro, it was agreed that the decrease of biological diversity is a major problem and can only be prevented through international efforts. The Summit ended with the signing of important global conventions including the Convention on Biological Diversity, to which Turkey is a party by signing and ratifying it through the No. Law 4177 of 29 August 1996. The Convention entered into force in our country on 14 May 1997 [1].

The three main goals of the Convention on Biological Diversity (CBD) are:

- Conservation of biological diversity;

- Sustainable use of biological resources; and

- Fair and equitable sharing of the benefits arising from the utilization of genetic resources [1].

The Convention dictates that each country must identify its biological resources for which special protection measures are needed and which have a greater potential for sustainable use and also identify and monitor the categories and processes of actions that may have a negative effect on conservation and sustainable use [1].

\section{Biological diversity in Turkey}

Turkey displays the character of a small continent in terms of biological diversity. Among the reasons for this are the following facts:

- the country has three different types of bio climate and three Biogeographical Zones, namely Euro-Siberian, Mediterranean and Irano-Turanian,

- $\quad$ its topographic, geological, geomorphologic and soil diversity,

- the existence of different types of aquatic bodies such as the sea, lakes, rivers, and fresh water, salt water and mineral water lakes, 
- the altitude differences that range between 0 and 5,000 meters,

- the country has deep canyons and very different types of ecosystems,

- it was less affected by the glacial period in comparison with European countries,

- the existence of the Anatolian Diagonal which links Northern Anatolia to Southern Anatolia resulting in ecological and floristic differences,

- $\quad$ the country is at the point where three continents intersect [1].

The Euro-Siberian Biogeographical Zone extends throughout Northern Anatolia and through those parts of the Thracian Region which face the Black Sea. This climatic region has the highest rainfall and is largely covered with forests. The Mediterranean Biogeographical Zone, on the other hand, covers all areas on the Mediterranean cost and the western parts of Thrace and includes very different types of ecosystems. The Irano-Turanian zone is the largest of the Biogeographical Zones, starting in Central Anatolia and extending as far as Mongolia. The continental climate and steppe flora are predominant in this zone [1].

\section{Ecosystem diversity}

Turkey has agricultural, forest, mountain, steppe, wetland, coastal and marine ecosystems and different forms and combinations of these ecosystems [1].

Agricultural Ecosystems: In Turkey different agricultural ecosystems are seen in coastal regions, inner regions and transition regions. Cultivated areas, located mostly in steppe zones, constitute about 35 percent of Turkey's total surface area [1].

Steppe Ecosystems: There are about 21 million hectares of steppes and grasslands, defined as areas covered with herbaceous plants in Turkey. The steppe ecosystems are prevalent especially in Central Anatolia, in the high mountain floors of the Aegean and Mediterranean Regions and in a major part of Eastern Anatolia. The most characteristic feature of the steppe ecosystem is the predominance of annual or perennial herbaceous plants. The floristic composition of the steppe vegetation is very rich and includes many endemic plants. The steppe formation can be divided into two as "Plain Steppe" and "Mountain Steppe" in Turkey depending on the topographical structure of the area in which it lies. The plain steppe provides a habitat for species such as halophilic plants, members of the Chenopodiaceae, Juncaceae and Cyperaceae, Peganum harmala L., Veroniva cymbalaria Bodard, Thymus L. and Salvia L. The mountain steppe on the other hand, hosts the species of Astragalus L., Onobrychis cornuta (L.) Desv., Acantholimon Boiss., Asphodelus L. and Thymus L. In the Eastern Anatolia mountain steppe, Ferula L. becomes more predominant unlike in other regions. Alpine and sub-Alpine meadows cover large areas in the higher parts of the Eastern Black Sea Mountains and in the northern and northeastern parts of Eastern Anatolia [1].

Forest Ecosystems: In Turkey, forest ecosystems cover a total area of 21,188,747 hectares. Forests consisting of broad-leaved trees are more widespread in Turkey. Coniferous trees occur at all altitudes from sea level to the highest limit where forests exist. In the Aegean and Mediterranean regions, there are humid and semi-humid coniferous and dry forests 
(Quercus L, Pinus nigra Arnold and Pinus brutia Ten.) as well as shrubs and maquis. These rich forest ecosystems of Turkey provide habitats for a great number of endemic plant species, important bird species and other wildlife species. These ecosystems also include the wild relatives of many cultivated plants which are important for agricultural biological diversity [1].

Mountain Ecosystems: In Turkey, there are mountain systems formed by folding, faulting and volcanism. The types of the mountain ecosystems differ according to biogeographical regions, to patterns of formation and to altitudes [1].

Inland Waters Ecosystems: Turkey has very important inland water resources to maintain biological diversity with its rivers and lakes covering an area of about 10,000 km2. In studies conducted so far, 135 wetlands of international significance have been identified and 12 of them designated as Ramsar sites. In Turkey, there are 7 drainage basins including 26 river basins, and the ground waters are estimated at 94 billion $\mathrm{m}^{3}$. The average annual rainfall is about $640 \mathrm{~mm}$, roughly one third of which reaches water reserves and thus contributes to the maintenance of wetlands. In Turkey's wetlands, plants such as Typha L., Phragmites L, Schoenoplectus (REICHB.) PALLA and Juncus L. form large communities. In addition, there are also plants that cover the water surface such as Nymphae L. and underwater plants that grow in shallow lakes such as Phodophyllum L., Wolffia Horkel ex Schleid., Lemna L. and Ceratophyllum L., Myriophyllum L. and Potamogeton L. [1].

Coastal and Marine Ecosystems: Different characteristics of the seas surrounding Turkey, namely the Black Sea, the Marmara, the Aegean and the Eastern Mediterranean, have resulted in the diversification of the biological resources they contain. The Mediterranean, which has the highest salinity and temperature among the Turkish seas, is the area with the richest biological diversity. Coastal ecosystems are highly special ecosystems as they are important sudden transition zones (ecotones) where marine and terrestrial ecosystems intersect. Coastal ecosystems form $4.1 \%$ of the terrestrial resources that make up the country's surface area. The fact that the patterns in which mountains come down to the sea, and the coastal topography, differ from each other in the coastal areas of our country have resulted in various coastal ecosystems such as dunes, caves, deltas, lagoons, marshes and calcerous terraces. Among all these coasts, particularly the coastal areas in the Eastern Mediterranean region are rich ecosystems with very high flora and fauna diversity [1].

\section{Species diversity}

Turkey has a relatively rich flora (about 12000 species) and still a great number of species are being described (Figure 1,2,3,4). In this flora, there are a lot of interesting species such as halophytic species, semi-desert plants, carnivorous plants and nickel hyperacumulators. In Turkey, the rate of endemism is relatively high when compared with other European countries. It is about 34 percent in Turkey while it is 14.9 percent in Greece, 2.9 percent in France, 18.6 percent in Spain and 0.1 percent in Poland. The number of endemic species in Turkey is greater than 3000 [3]. 


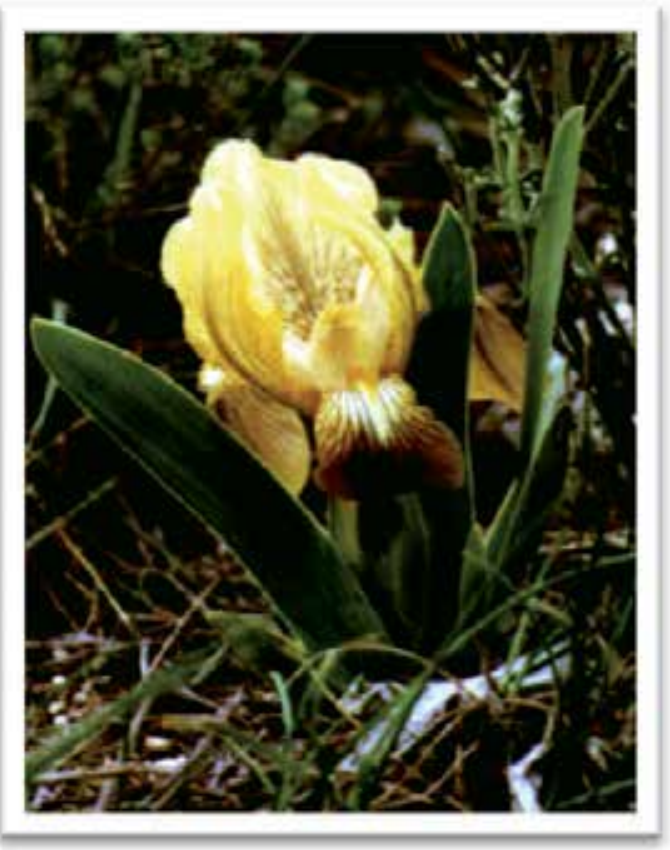

Figure 1. Iris schachtii Markgraf (Z. Dilaver)

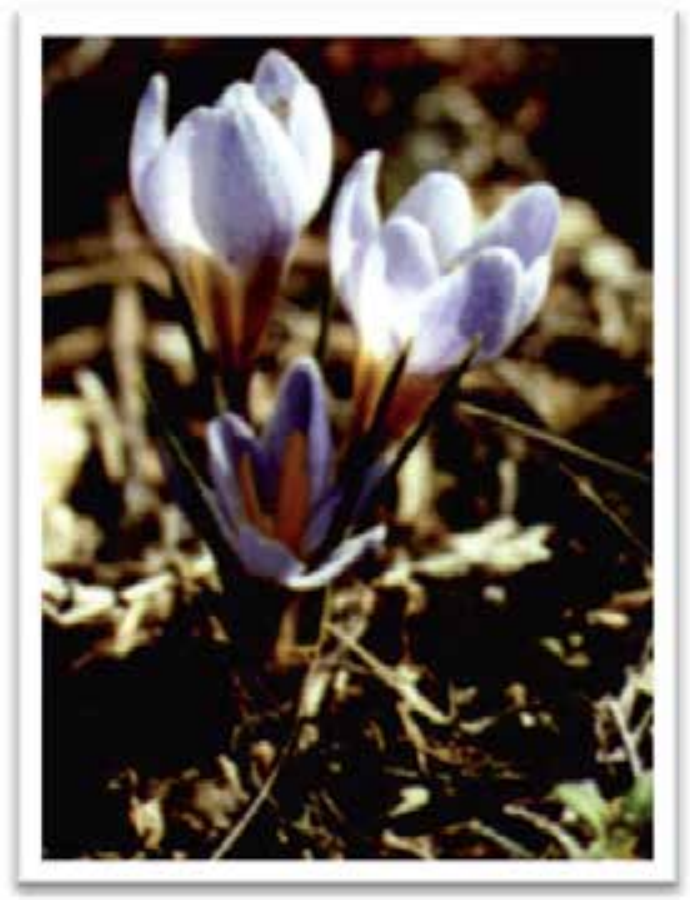

Figure 2. Crocus danfordiae Maw.(Z. Dilaver) 


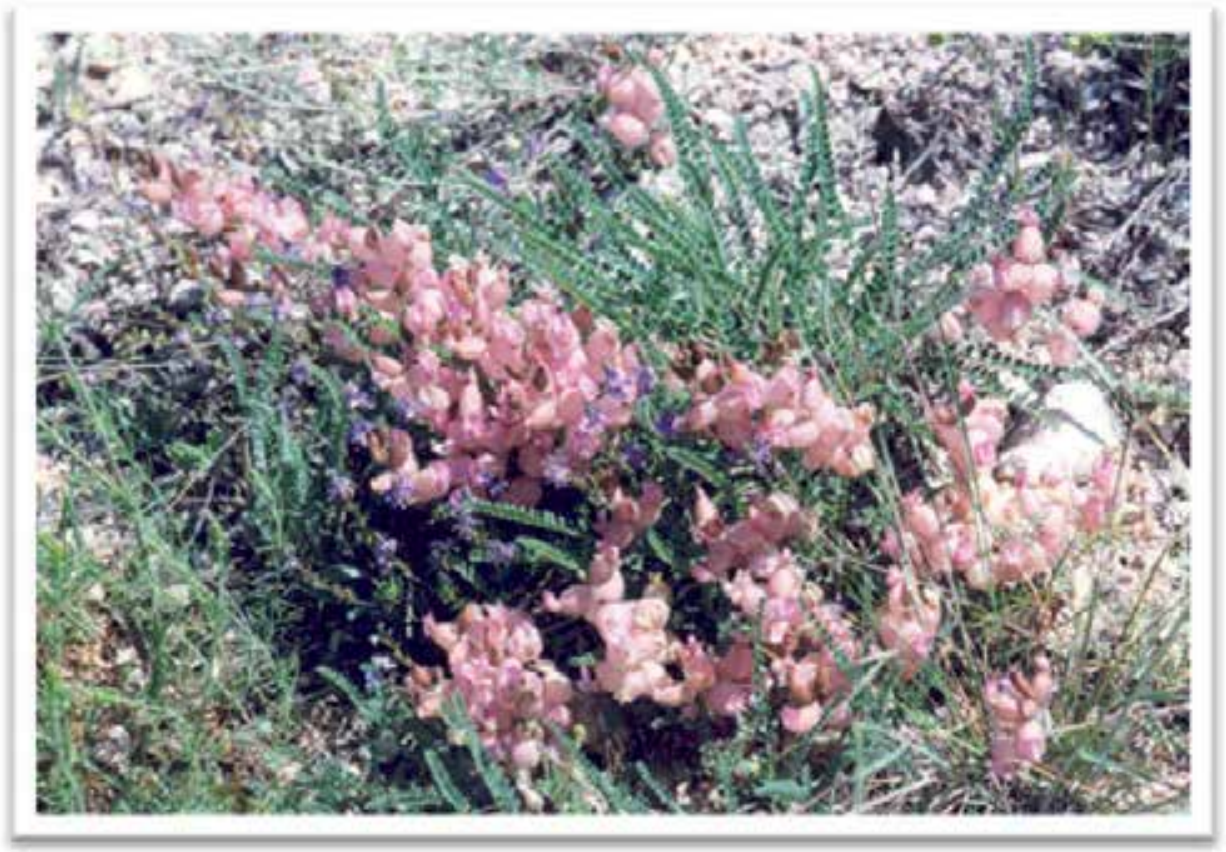

Figure 3. Astragalus anthylloides Lam. (Z. Dilaver)

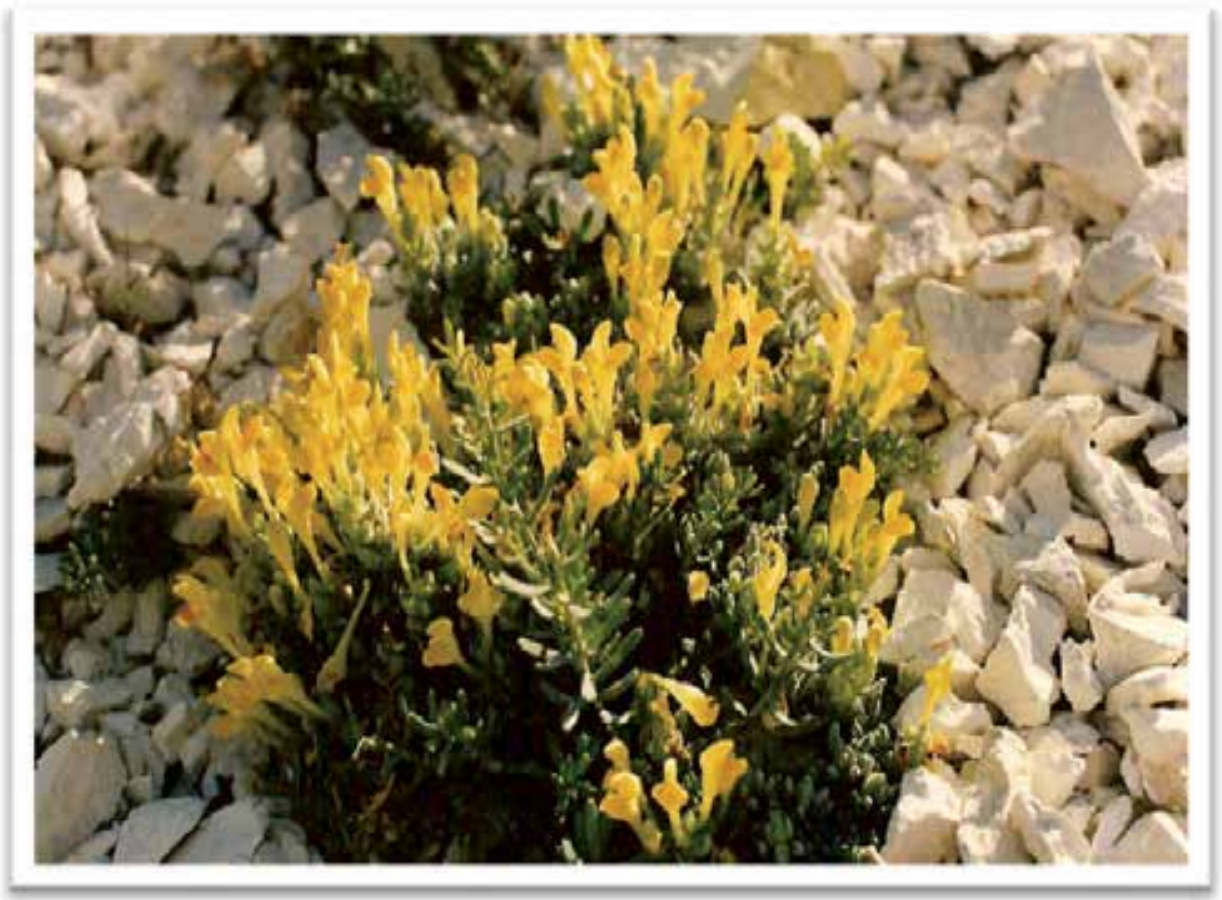

Figure 4. Scutellaria orientalis L. (Z. Dilaver) 
In terms of endemic plant species, the richest family of Turkey is Compositae, which has approximately 425 endemic species. The richest genus in terms of endemic species, on the other hand, is Astragalus L. with 250 species. It is followed by Verbascum L. with 185 species [4].

Among the phytogeographical regions, the Irano-Turanian is the region having the highest number of endemic. Mediterranean Region is the second and the Euro-Siberian Region is the third in this regard. Turkey's richest region in terms of endemic plants unique to that region alone is the Mediterranean region with 800 or so species. In Eastern Anatolia 375, in Central Anatolia 275, in Black Sea 210 and in the Aegean Region 150 endemic species grow. Marmara (70) and Southeast Anatolia (35) Regions are the poorest geographical regions of Turkey in terms of endemics. The other endemics are distributed in more than one geographical area [4].

"Red List of Threatened Species" is the most well-known study of the World Conservation Union (IUCN), which was last published in 2004. This red list is accepted to be the most comprehensive source about the latest status of threatened plant and animal species. IUCN cited the danger categories as:

1. Extinct,

2. Extinct in the wild,

3. Critically endangered

4. Endangered

5. Vulnerable

6. Lower risk

7. Data deficient

8. Not evaluated [5].

In our country, after being completed 9 volume of Flora of Turkey as a main source in 1985, a list similar with this was started to be constituted with the help of Turkish Association for Conservation of Nature and Natural Resources. It was published in 1989 with the name of "List of Rare Threatened and Endemic Plants in Turkey". After this publication, more and more floristic studies -especially the project investigating endemic plants of Turkey in detailshowed that some data in the first list should be changed or at least could be updated. Thereupon "Red Data Book of Turkish Plants" which was prepared and published in 2000 became a national list using new threat categories of IUCN. This source is because it shows Turkey's biological diversity and the status of species in terms of the danger categories. In order to protect biological diversity it is necessary to know about it and to create its database. In this study 3504 endemic and 1096 rare plants were assessed and listed in accordance with appropriate danger categories. According to this list, 46.6 percent of 3504 endemic plants and 77.4 percent of 1096 rare plants is under threat. On the other hand, 13 plant taxon in total, of which 12 was endemic, and one was rare, already extinct. While 270 endemic and 244 rare plant taxon could not be placed under a danger category because of lack of data and were listed under DD-Data deficient category [6]. 


\begin{tabular}{|c|c|c|c|c|}
\hline Plant Groups & $\begin{array}{c}\text { Defined Species/ } \\
\text { subspecies }\end{array}$ & $\begin{array}{l}\text { Endemic } \\
\text { Species }\end{array}$ & $\begin{array}{c}\text { Rare and Endangered } \\
\text { Species }\end{array}$ & Extinct species \\
\hline Algae & 2.150 & $\ldots$. & umknown & umknown \\
\hline $\begin{array}{l}\text { Lichen } \\
\text { (Lichenes) }\end{array}$ & 1000 & $\ldots$ & unknown & umknown \\
\hline $\begin{array}{l}\text { Moss } \\
\text { (Bryophytes) }\end{array}$ & 910 & 2 & 2 & unknown \\
\hline Pteridophytes Ferns & 101 & 3 & 1 & unkmown \\
\hline $\begin{array}{l}\text { Gymmospernnce } \\
\text { (Gymnosperms) }\end{array}$ & 35 & 5 & 1 & unknown \\
\hline $\begin{array}{l}\text { Monocotyledonous } \\
\text { (Monocotyledons) }\end{array}$ & 1.765 & 420 & 180 & - \\
\hline $\begin{array}{l}\text { Dicotyledonous } \\
\text { (Dicotyledons) }\end{array}$ & 9.100 & 3500 & 1100 & II \\
\hline
\end{tabular}

Table 1. Taxon numbers of species and subspecies of various plant groups; endemism, rare and endangered species, extinct species

\section{Genetic diversity}

Plant genetic diversity is of great importance for both Turkish and world agriculture. Turkey has a very special position in terms of plant genetic resources. Turkey is situated at the intersection of two important Vavilovian gene centers: Mediterranean and Near East. These two regions have a key role in the emergence of cereals and horticultural plants. Some of the cultivated plant species of Anatolian origin are the following: Linum L., Allium L., Hordeum L., Triticum L., Avena L., Cicer L., Lens Mill., Pisum L., Vitis L., Amygladus L, Prunus L., Beta L., etc. Turkey, situated where two different gene and diversity centres overlap, is the gene and origin centre of the following cultivated plants among others: Triticum L, Hordeum L, Secale L., Avena L., Linum L., Allium L., Cicer L., Lens Mill., Pisum L., Medicago L. and Vicia L. Turkey is the home of many decorative plants including Tulipa L. and Galanthus L. [1].

Turkey is also quite rich in gene resources, including the valuable gene resources of Cedrus libani A. Rich., Picea orientalis (L.) LINK and Fagus orientalis LIPSKY together with 5 Pinus L., 4 Abies Mill., 20 Quercus L. and 8 Juniperus L. species among the local forest trees of national and global importance. The important forest trees are as follows: Pinus L. species (Pinus brutia Ten., P. nigra Arnold, P. sylvestris L., P. halepensis Mill. and P. pinea L.), Abies Mill. species (Abies nordmanniana (STEV.) SPACH subsp. nordmanniana (STEV.) SPACH, $A$. nordmanniana (STEV.) SPACH subsp. bornmulleriana (mattf.) COODE ET CULLEN, $A$. nordmanniana (STEV.) SPACH subsp. equitrojani (ASCHERS. ET SINT. EX BOISS.) COOD ET C, A. cilicica (ANT. ET KOTSCHY) CARR. subsp. cilicica (ANT. ET KOTSCHY) CARR., A. cilicica (ANT. ET KOTSCHY) subsp. isaurica COODE ET CULLEN), Cedrus libani A. Rich., Fagus orientalis LIPSKY, Picea orientalis (L.) LINK, Tilia L., Alnus Mill. (2 species, a total of 6 taxons), Juniperus L. (8 species), and Quercus L. (about 20 species) [1]. 


\section{Conservation of biological diversity}

There are two different methods that are widely accepted in the world, used in order to conserve biological diversity. First of these is the "In Situ" conservation that aims at protecting the plants within their own natural growth areas. The other system is the "Ex Situ" conservation that envisages the protection of biological diversity features outside their natural living areas [7].

Despite it is possible to protect a large number of plant species by moving them to the areas outside their ecosystems by means of ex-situ conservation methods, the most important way to protect plant species is to protect them in the habitats they live. The reason for this is that all living things depend on each other in an ecosystem. No species in nature has an isolated environment and the species interact with other in many ways. Another advantage of in situ conservation is that protecting an efficient species population in its own habitat is easier when compared with ex situ conservation. As a result, ex situ conservation methods appears to be only as supporting methods alongside the in situ conservation. However, the botanical gardens allowing you to see many species of plants together and learn about are important, especially in terms of education and scientific research. Likewise, seeds and tissue banks is increasingly gaining importance with the fast growing biotechnology methods. However, in species with the physical environment as a whole to protect ecosystems, the future will be guaranteed [8].

\section{In Situ Conservation}

In the "In Situ" system, the restricted areas where the genetic material is found are protected by minimizing the human and animal effects [9].

The rapid consumption of natural resources, the increasing amount of pollution and environmental problems that have reached a global dimension have brought the obligation for countries to act in cooperation. Today, protected areas are vital component of all global and National nature conservation efforts. Many areas that have rich biodiversity and natural - cultural values have been designated as a national park and other protection statues to support conservation [10].

Protected areas are the cornerstone of biodiversity conservation; they maintain key habitats, provide refugia, allow for species migration and movement, and ensure the maintenance of natural processes across the landscape. Not only do protected areas secure biodiversity conservation, they also secure the well-being of humanity itself. Protected areas provide livelihoods for nearly 1.1 billion people are the primary source of drinking water for over a third of the world's largest cities and are a major factor in ensuring global food security. Well managed protected areas harboring participatory and equitable governance mechanisms yield significant benefits far beyond their boundaries, which can be translated into cumulative advantages across a National economy and contribute to poverty reduction and sustainable development including achievement of the Millennium Development Goals [10]. 
Definition of Protected Area According to the IUCN (1994): An area of land and/or sea especially dedicated to the protection and maintenance of biological diversity, and of natural and associated cultural resources, and managed through legal or other effective means [11].

Definition of Protected Area According to the IUCN (2008): A clearly defined geographical space, recognized, dedicated and managed, through legal or other effective means, to achieve the long-term conservation of nature with associated ecosystem services and cultural values [12].

IUCN divided the protected areas into the following categories [12]:

- $\quad$ Category I a: Strict nature reserve

Category I a - strictly protected areas set aside to protect biodiversity and also possibly geological/geomorphological features, where human visitation, use and impacts are strictly controlled and limited to ensure protection of the conservation values. Such protected areas can serve as indispensable reference areas for scientific research and monitoring.

- $\quad$ Category I b: Wilderness area

Category I b - protected areas are usually large unmodified or slightly modified areas, retaining their natural character and influence, without permanent or significant human habitation, which are protected and managed so as to preserve their natural condition.

- $\quad$ Category II: National park

Category II - protected areas are large natural or near natural areas set aside to protect largescale ecological processes, along with the complement of species and ecosystems characteristic of the area, which also provide a foundation for environmentally and culturally compatible spiritual, scientific, educational, recreational and visitor opportunities.

- Category III: Natural monument or feature

Category III - protected areas are set aside to protect a specific natural monument, which can be a landform, sea mount, submarine cavern, geological feature such as a cave or even a living feature such as an ancient grove. They are generally quite small protected areas and often have high visitor value.

- Category IV: Habitat/species management area

Category IV - protected areas aim to protect particular species or habitats and management reflects this priority. Many category IV protected areas will need regular, active interventions to address the requirements of particular species or to maintain habitats, but this is not a requirement of the category.

- Category V: Protected landscape/Seascape

Category V - protected areas where the interaction of people and nature over time has produced an area of distinct character with significant ecological, biological, cultural and 
scenic value: and where safeguarding the integrity of this interaction is vital to protecting and sustaining the area and its associated nature conservation and other values.

- Category VI: Protected area with sustainable use of natural resources

Category VI - protected areas conserve ecosystems and habitats, together with associated cultural values and traditional natural resource management systems. They are generally large, with most of the area in a natural condition, where a proportion is under sustainable natural resource management and where low-level non-industrial use of natural resources compatible with nature conservation is seen as one of the main aims of the area.

Besides these categories, it is observed that countries develop others based on their regulations and institutional structure. Also, there are other protected areas like UNESCO Biosphere Reserves, World Heritage Areas, and RAMSAR Areas. While there are protected areas managed by national legislations and specific laws that belongs to the areas, at the same time, those are affected by the international conventions and agreements which are relevant with the conservation of biodiversity and natural resources, management and sustainable use of the values and sustainable development [13].

\section{Protected Areas in Turkey}

Protection initiatives in Turkey are mostly in the form of in situ protection. There are various protected areas in Turkey which are under different institutions' authority and supervision and defined under certain laws. Turkey has signed many international conventions and protocols on Nature Protection. These conventions are;

- Convention on Biodiversity Conservation (Rio Convention) (1997)

- Cartagena Protocol (2004)

- $\quad$ CITES (1996)

- Barcelona Convention (1988)

- Bucharest Convention (1994)

- Protection of Cultural and National Heritage (1983)

- Convention on Combating Erosion (1998)

- European Landscape Convention (2000)

- Bern Convention(1984)

- Ramsar Convention (1994)

- Kyoto Protocol (2009) [14].

In accordance with these conventions, by 2011, nearly 1800 sites had been identified by the Ministry of Forest and Water as warranted protection under the 1983 law (Table 2) [14].

Turkey has 41 National Parks and approximately 37 percent of their total area is forest ecosystems (Figure 5,6,7). Besides, Turkey has 41 Nature Parks and approximately 25 percent of them are forest ecosystems (Figure 8) [15]. 


\begin{tabular}{|l|l|l|}
\hline Conservation Status & Number & Related Law \\
\hline National park & $\mathbf{4 1}$ & Law on National Parks \\
\hline Nature conservation area & 31 & Law on National Parks \\
\hline Natural monument & 106 & Law on National Parks \\
\hline Nature park & $\mathbf{4 1}$ & Law on National Parks \\
\hline Wild life reserve areas & 79 & Law on Terrestrial Hunting \\
\hline Conservation forest & $\mathbf{5 7}$ & Law on Forest \\
\hline Genetic conservation areas & 214 & Law on Forest \\
\hline Seed stands & 339 & Law on Forest \\
\hline Specially protected areas (SPAs) & $\mathbf{1 4}$ & Law on Environment \\
\hline Natural sites & $\mathbf{9 4 7}$ & $\begin{array}{l}\text { Law on Conservation of Cultural And } \\
\text { Natural Heritage }\end{array}$ \\
\hline Ramsar sites & $\mathbf{1 3}$ & $\begin{array}{l}\text { Ramsar Convention } \\
\text { By-law on Conservation of Wetlands }\end{array}$ \\
\hline Biosphere Reserve & $\mathbf{1}$ & Law on National Parks - Law on Forest \\
\hline
\end{tabular}

Table 2. Protected areas which identified by the Ministry of Forest and Water [14].

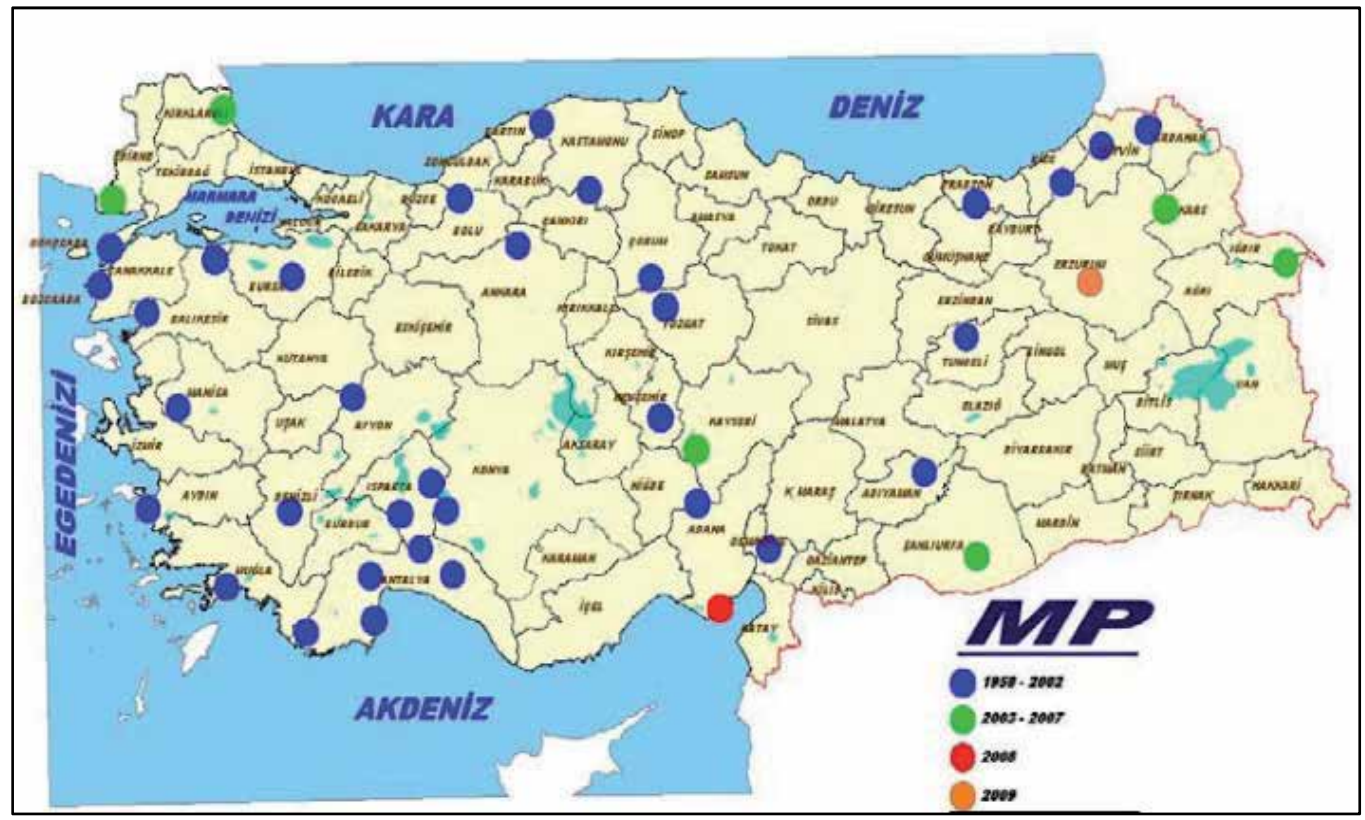

Figure 5. National Parks in Turkey [16]. 


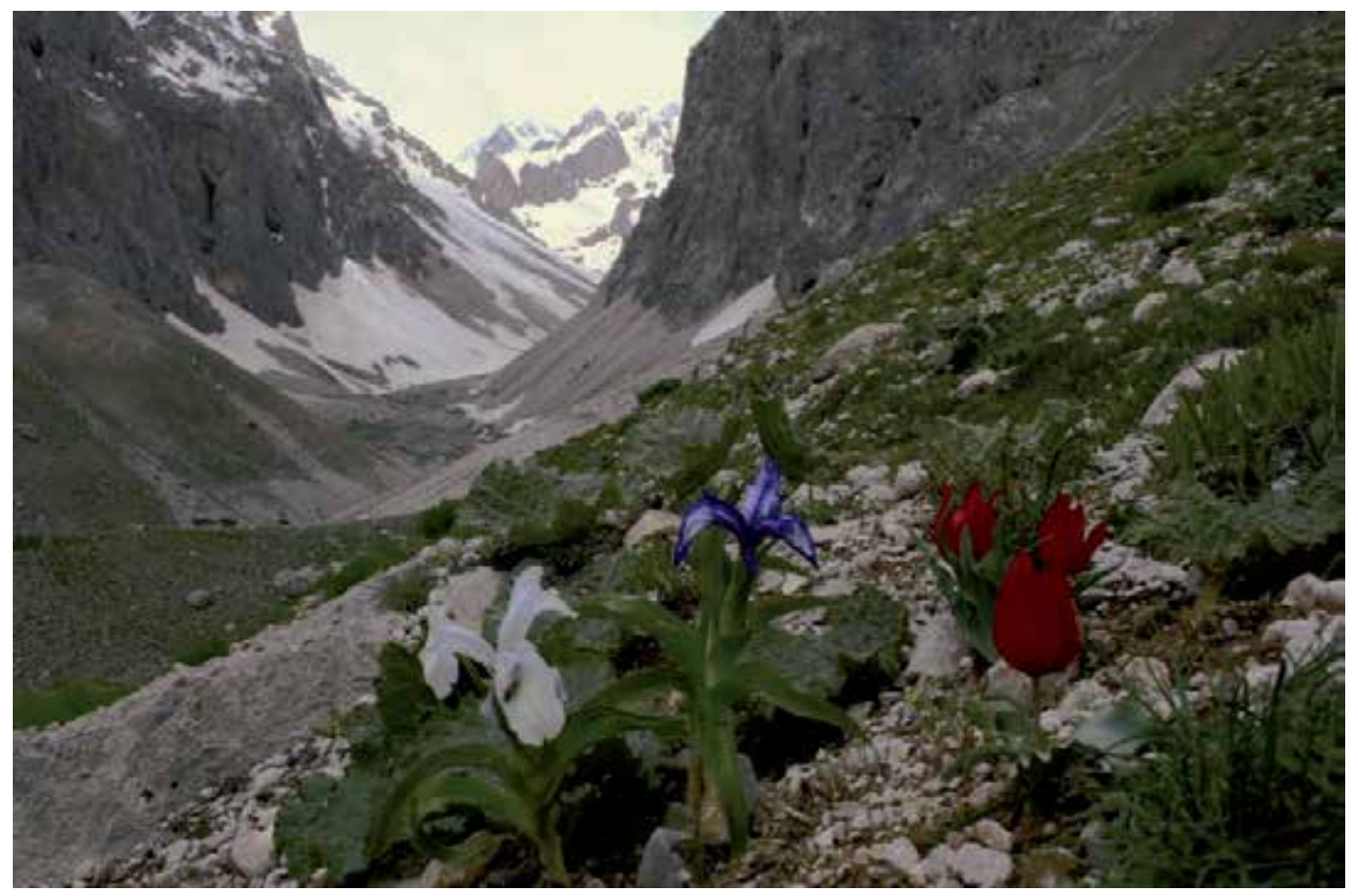

Figure 6. Munzur Valley National Park, Turkey [17].

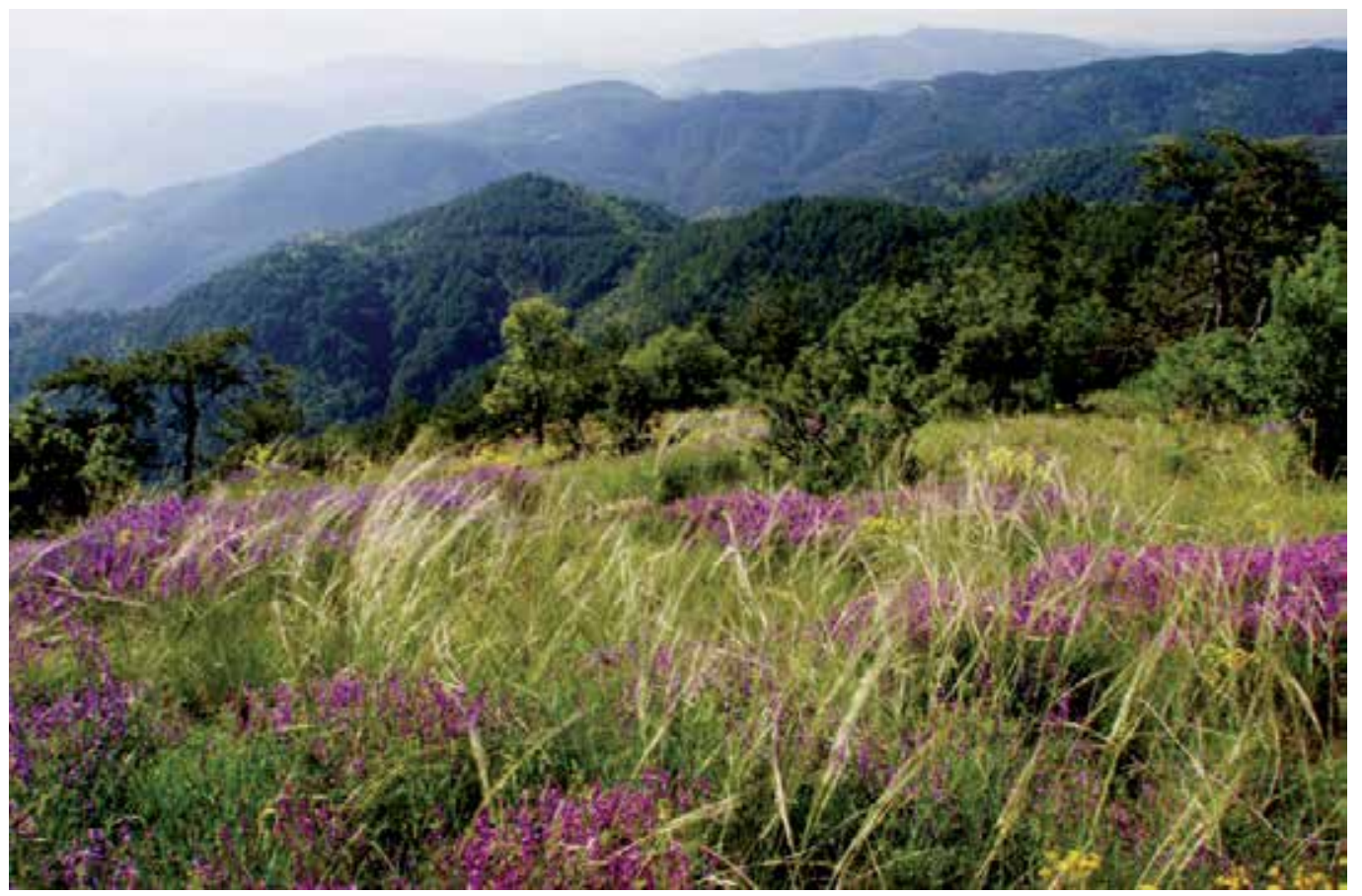

Figure 7. Soğuksu National Park, Turkey [17]. 


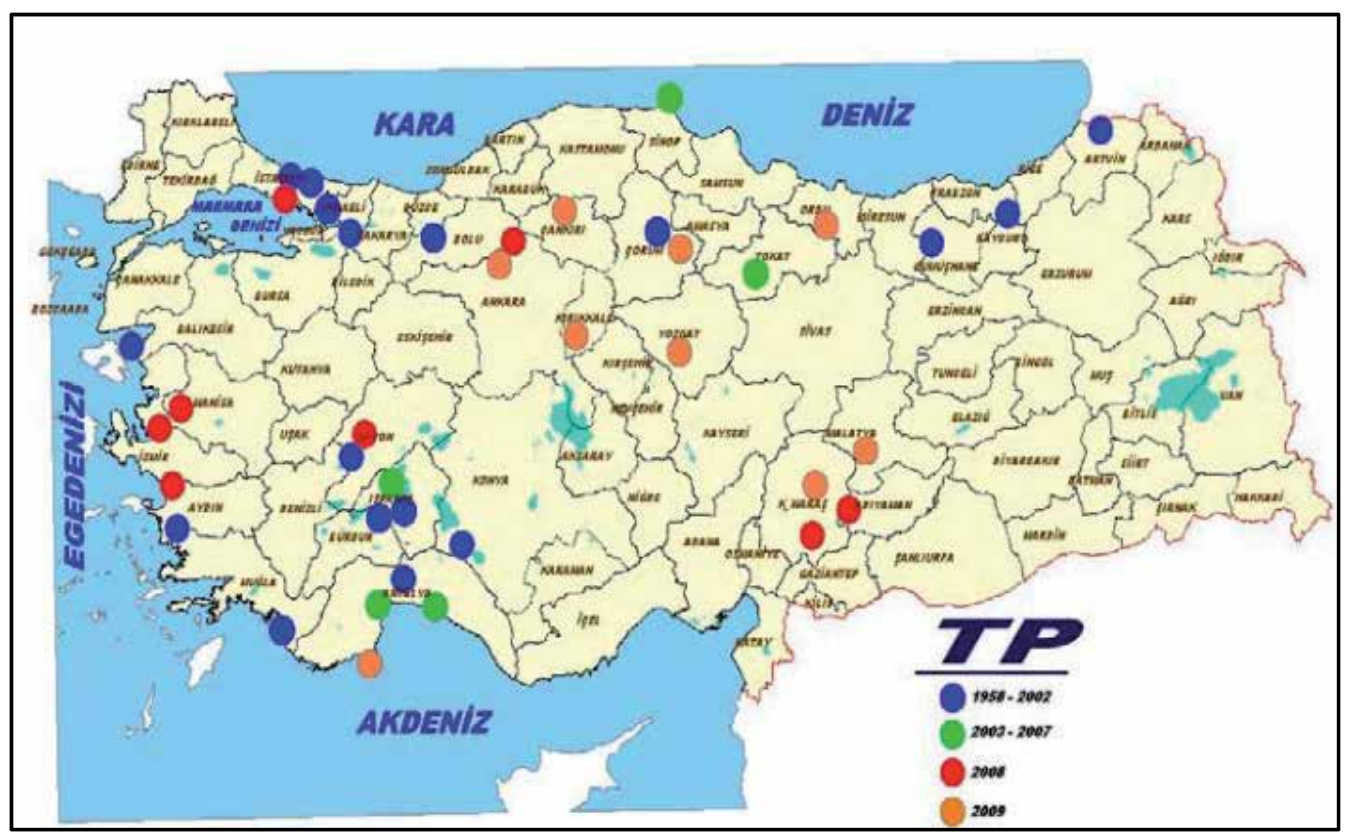

Figure 8. Nature Parks in Turkey [16].

\section{Ex Situ conservation}

This method is composed of;

- observation,

- gathering,

- storage, production and replacement,

- assessment,

- documentation,

- distribution and material exchange,

- preservation,

- education

- cooperation and organization steps [7].

Ex Situ conservation actions are an important complementary measure to In Situ habitat management. Ex situ conservation of wild plants is a central and unique role of botanic gardens. They have the appropriate facilities and staff expertise in botany and horticulture to be an 'insurance policy' against plant extinction. The Botanic Gardens ex situ program primarily employs three strategies: seed banking, tissue culture and genetic analysis of endangered plants. Seed banking is one of the most effective and useful ways of conserving genetic diversity ex situ, as the majority of wild plant species from dry land environments produce desiccation tolerant seeds that can be successfully stored for over 200 years. In most outbreeding species, the majority of the genetic diversity of the species may be captured by a single large seed sample. Conservation of population seed samples from these species 
provides insurance against loss of the wild population, whilst allowing biologists to develop germination protocols, propagation techniques etc. to support use of the species [22]. Tissue culture is the propagation, under controlled laboratory conditions, of rare and endangered plants that are difficult to propagate from seed or whose seed does not store well. Genetic analysis of rare species through various techniques, including, Microsatellites, Sequencing, AFLP (Amplified Fragment Length Polymorphism and ISSR (inter-simple sequence repeats), is helping guide preservation and restoration activities [18].

\section{Ex Situ Conservation in Turkey}

Botanic gardens, which are the most significant applications of Ex situ protection methods, have been newly developing in Turkey. The first botanic garden to be established in Turkey is Istanbul University, Alfred Heilbronn Botanic Garden. It was established in 1935 under Istanbul University, Faculty of Applied Sciences, Department of Botany and it was given its current name in 2003. In this garden, there are 5 thousand genus and 6 thousand species belonging to 127 families, which are endemic and foreign homed. There are also seed banks and herbarium units in the garden. "Istanbul Botanic Garden Seeds Catalog" was published for the first time in 1935. The garden has been exchanging seeds with 373 botanic gardens from 63 countries. Istanbul University, Center for Research and Application of Natural Resources, established in relation with the Botanic Garden, aims at preventing the loss of rare and epidemic species of Turkish plant possessions by making them live in appropriate areas and conservatories [18].

Another important botanical garden in Turkey is Nezahat Gokyigit Botanical Garden (NGBB), located in Istanbul (Figure 9). NGBB is established on 32 hectares of parkland and it was opened to public in 2002. NGBB forms a space for breath-taking offering Istanbul 12 percent of its green space, and it is also a research, education and training center [19].

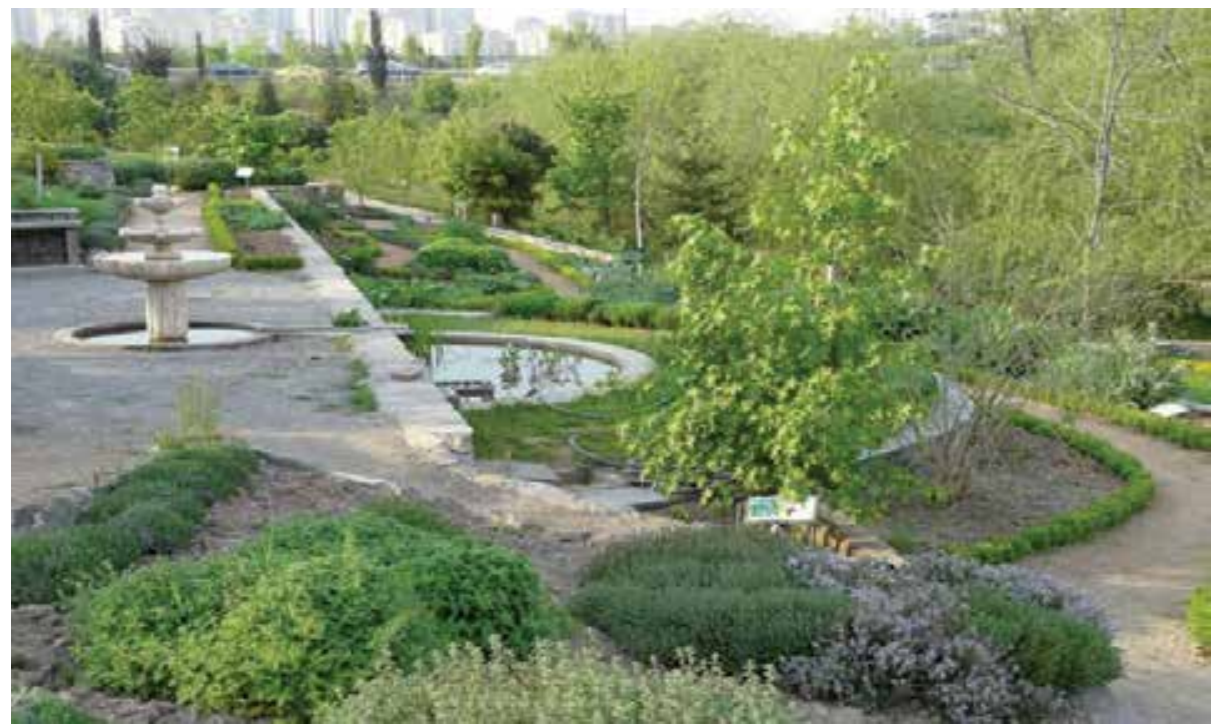

Figure 9. Nezahat Gökyigit Botanical Garden, Garden of Medicinal and Aromatic Plants [19]. 
Besides, "National Botanical Garden" is planned to be established in Ankara. The project covering an area of 2000 decare has started in 2008 and the construction work has begun in 2011.

Gene banks are also ex situ conservation units apart from the botanical gardens. Aegean Agricultural Research Institute Gene Bank and Plant Genetic Resources Unit of Field Crops Central Research Institute have been working for the conservation of genetic resources. In addition, the world's $3^{\text {rd }}$ largest gene bank (Seed Gene Bank) after the U.S. and China was established in Ankara in 2010 with a storage capacity of 250 thousand samples.

\section{Use of natural plants in landscape architecture in the scope of preserving biological diversity}

Years before, when the natural areas had not been this much damaged with the pressure from the settlement, industrial and even agricultural areas, people would find it absurd to use the natural vegetation species in plant design work. Furthermore, until recently, many natural samples were seen as weed. But today, it has been realized that especially in developed countries, cities and areas of cultural activities puts nature away from people. For this reason, people want to see natural plant samples around them in order to feel close to nature.

Alpha

The fact that the natural areas are confronted with an increasing pressure increases concerns over plants of natural vegetation. Today, some species are threatened and are in danger of extinction. For some, on the other hand, it is observed that their expansion areas are getting narrower and that they do not grow in areas where they have been previously observed. In this regard, the use of natural vegetation samples which are in danger of extinction or damaged, in landscape architecture is important. Transfer of natural samples to gardens, are important for providing these plants with protection areas, as well as for increasing the awareness of protection and their recognition by the people.

Native plants naturally occur in the region in which they evolved, while non-native plants might provide some of the above benefits, native plants have many additional advantages. Because native plants are adapted to local soils and climate conditions, they generally require less watering and fertilizing than non-natives. Natives are often more resistant to insects and disease as well, and so are less likely to need pesticides. Wildlife evolved with plants; therefore, they use native plant communities for food, cover and rearing young. Using native plants helps preserve the balance and beauty of natural ecosystems [20].

Non-native plants can be invasive. They have few or no naturally occurring measures to control them, such as insects or competitors. Invasive plants can spread rapidly and smother or out-compete native vegetation. Invasive, non-native plants are not effective in providing quality habitat [20].

Use of natural vegetation species in landscape architecture, creates a landscape harmonious with nature, and it is an application compatible with economic conditions. In this way, 
selection of plant materials that meet environmental conditions with minimal care should be preferred as an economic approach to planning.

In Turkey, due to lack of work for cultivation of natural plants, obtaining plants from nurseries is not yet possible. In this case, it is not possible to provide the supply of plants for applications, as well as natural vegetation cannot become a sector generating income. Over the years, the greatest economic gain has been derived from the plants with bulb, tuber and corm, which have been pulled out from their natural areas. However, with their extensive use in landscape architecture natural plants will be an important branch of ornamental plant industry.

\section{The utilization process of natural plants}

Anatolia, throughout the history, has been the location where many natural species were cultivated for the first time. For example, it is known that the origin of 30 percent of the field corps is Anatolia. Besides the field crops, in many parts of Turkey, many natural plant species are collected directly from nature and used for nourishment. Plants are also used for different purposes other than nourishment [3].

About 1000 species of Geophytes are grown in Turkey which constitute an important part in the biological richness of the country and majority of which have economic potential as ornamental plants and medicinal plants [21]. Collection of certain types of bulbs of these plants was initially in the form of a personal curiosity but afterwards it gained commercial importance with the collection of flower bulbs in bulk. This trade, which was conducted in Netherlands, Denmark, Switzerland, Germany, Italy and in various other European countries, reached fairly large quantities since the 1960s. While up to 15000 Galanthus L. bulbs were exported in the early 1970s after 10 years, the amount has exceeded two times of this amount. Although in some species, small-scale domestic production activities are carried out, Galanthus L., Eranthis hyemalis (L.) Salisb., Anemone blanda Schott et Kotschy, Leucojum aestivum L., Cyclamen L., Fritillaria L., et Sternbergia Waldst kit, Lilium candidum L. , Tulipa humilis Herbert L., Arum, Dracunculus Miller, Geranium tuberosum L., Colchicum speciosum Stev., Muscari Miller, Ornithogalum nutans L., Scilla bifolia L., Gladiolus L., Oxalis L., Urginea maritima (L.) Baker, Pancratium maritimum L. and Narcissus L. are largely collected from nature and became the species traded most [23]. However, in recent periods, controls over the onion pull-outs are from nature are conducted and cultivation of bulbous plants is carried out. Due to the measures taken after 1990s, the populations of geophytes sold abroad were brought back to their former levels and important progress was made in the production and exportation of Lilium candidum L., Sternbergia lutea (L.) KER-GAWL. EX SPRENGEL, Fritillaria imperialis L., F. persica L., Leucojum aestivum L. and Cyclamen hederifolium AITON abroad. [4].

Besides bulbous plants, some plant species are collected from the nature and consumed in the country or sold abroad, because of their medical and aromatic qualities. Plant species with scientifically identified medical feature and which are used by the people are numerous in the flora of Turkey. Aromatic plants such as Origanum L. and the plants used 
as tea like Salvia L. and Sideritis L. are used in small residential gardens. In addition, with the spread of theme parks, gardens of medicinal and aromatic plants are organized in parks and botanical gardens. However, due to the difficulties in finding local plant samples foreign plants are more commonly found.

The most important condition for the promotion of the use of natural plants is conducting studies for their production; cultivation, variety creation and adaptation, as well as enabling users obtain them through nurseries. In recent years, studies on this issue have been increasing.

Some research has been being carried out at Atatürk Garden Culture Central Research Institute regarding the cultivation of various ornamental plants. In 2002, within the framework of the project on "Detection, Rehabilitation and Growing Techniques of Existing Paeonia L. Species in the Flora of Turkey" which was realized by the cooperation of private sector, university and public sector, species belonging to 11 taxon out of 55 populations were collected and preserved in peony gene resources garden [21].

Another important work was the "Cultivation of Some Natural Plants and the Inclusion of New Species and Varieties in Ornamental Plants Industry" project, carried out in 2006-2009. In the framework of the project which was conducted with the participation of 7 research institutes, 8 universities and 18 private sector organizations; 1166 population have been identified covering 241 species (177 geophytes species, 20 dune, and 44 outdoor plant species). Plant samples were subjected to pre-selection, moved to cultivation areas and preserved at responsible institution. Candidates of new varieties of existing species were determined at end of the study. The work under the project is continuing with variety creation activities [21].

In addition, a project has been initiated in 2010 called "Cultivation of Turkey's Geophytes, Providing New Species and Cultivars to the New Sectors. With this work it is aimed to collect the geophytes to be exhibited in "Turkey Geophyte Garden, to develop of varieties from the collected plants and to determine the biological activities of the plants collected. [21].

\section{Conclusion}

Increasing human activity results in negative effects for the natural areas, threatening the existence of plants, animals, and other types of species. It is generally admitted that the extinctions of plant species are occurring at an unprecedented pace in recent years. Thus, conservation of biological diversity is an issue gaining greater importance in today's world.

Turkey is an important country in terms of biological diversity as it displays the character of a small continent having a rich flora. However, Turkey has been facing the same threats against its biological diversity and its conservation becomes more and more important. As described above, there are different ways and methods used for preserving plant diversity in Turkey. One method is to protect the endemic species and prevent their extinction by making use of these plants in gardens and other living environments of people. By doing so, 
there would be an important step taken for increasing people's consciousness. As people spend more time with natural plants, their protection motives and knowledge would certainly increase.

However, in order for providing these environments to people and increase their access to natural plants, more works and projects for improving cultivation and production of natural plants are needed.

\section{Author details}

Zuhal Dilaver

Ankara University, Faculty of Agriculture, Department of Landscape Architecture, Turkey

\section{References}

[1] Ministry of Environment and Forestry, The National Biological Diversity Strategy and Action Plan, General Directorate of Nature Conservation and National Parks, Department of Nature Conservation, ISBN: 978-605-393-030-3, Tasarım Ofset, Ankara. 2008.

[2] Fletcher, S.R., Biological Diversity: Issues Related to the Convention on Biodiversity, CRS Report for Congress. 1995.

[3] Avcl, M. Çeşitlilik ve Endemizm Açısından Türkiye'nin Bitki Örtüsü. İstanbul Üniversitesi Edebiyat Fakültesi Coğrafya Bölümü, Coğrafya Dergisi, Sayı 13, Sayfa 2755, İstanbul. 2005.

[4] Türkiye Çevre Vakfı, Türkiye'nin Biyolojik Zenginlikleri. TÇV Yayın No: 170, ISBN: 975-7250-79-1, Ankara. 2005.

[5] Ekim, T., Koyuncu, M., Vural, M., Duman, H., Aytaç, Z. and Adigüzel, N., Red Data Book of Turkish Plants. Türkiye Tabiatını Koruma Derneği, Van Yüzüncü Yıl Üniversitesi, ISBN: 975-93611-0-8, Ankara. 2000.

[6] Uzun, A., Palabaş, S., Terzioğlu, S., Anşin, R., Uluslararası Doğa Koruma Birliği Tehlike Kategorileri ve Türkiye Florası. Korunan Doğal Alanlar Sempozyumu Sözlü Bildiriler Kitabı, 8-10 Eylül 2005, Isparta. 2005.

[7] Dokuzoğuz, M. Bitki Genetik Kaynakları. Türkiye'nin Biyolojik Zenginlikleri. Türkiye Çevre Sorunları Vakfı Yayını, Önder Matbaa, Ankara. 1990.

[8] Kaynak, S. Biyolojik Çeşitlilik ve Çevre Koruma Rehberi. Türkiye Tabiatını Koruma Derneği, ISBN: 975-93611-1-6, Ankara. 2001.

[9] Yücel, M. Korunan Alanların Sınıflandırılması ve Uzun Devreli Gelişme Planları Yapımında Yaşanan Sorunlar. Korunan Doğal Alanlar Sempozyumu Sözlü Bildiriler Kitabı, 8-10 Eylül 2005, Isparta. 2005.

[10] Gümüş, S.C., Şen, G., Toksoy, D., Ayaz, H. and Bahat, B. Nature Conservation and National Parks in Turkey. First Serbian Forestry Congress, 11-13 November 2010, Belgrade. 2010. 
[11] IUCN, Guidelines for Protected Area Management Categories. IUCN Commission on National Parks and Protected Areas with the assistance of the World Conservation Monitoring Centre, ISBN 2-8317-0201-1, Cambridge, UK. 1994.

[12] Dudley, N. (Editor) Guidelines for Applying Protected Area Management Categories, IUCN, 86 pp., ISBN 978-2-8317-1086-0, Gland, Switzerland. 2008.

[13] Yakınkılıç, M.K., Yenilmez Arpa, N. Türkiye'deki Korunan Alanlar ve Ekoturizm. Korunan Doğal Alanlar Sempozyumu Sözlü Bildiriler Kitabı, 8-10 Eylül 2005, Isparta. 2005.

[14] Özyavuz, M. Protected Areas, Landscape Planning, Dr. Murat Ozyavuz (Ed.), ISBN: 978-953-51- 0654-8, InTech, Available from:

http://www.intechopen.com/books/landscape-planning/protected-areas, 2012.

[15] Ertürk, E. Protected Area Management in Turkey. Republic of Turkey, Ministry of Environment and Forestry, Ankara. 2011.

[16] Yalınkılıç, M.K. Protected Areas of Turkey. General Directorate of Nature Conservation and National Parks.

http://cembit.dmi.gov.tr/FILES/doc/korunan- alanlar/turkiyenin_korunan_alanlari_enUS.pdf, İstanbul. 2010.

[17] www.milliparklar.gov.tr

[18] Dilaver, Z. 2007. Conservation of Biological Diversity in the World and in Turkey. International Conference on Environment: Survival and Sustainability, Near East University, 19-24 February 2007, Proceedings, pp. 521-528, Nicosia- Turkish Republic of Northern Cyprus.

[19] http://www.ngbb.org.tr, 2013.

[20] Slattery, Britt E., Kathryn Reshetiloff, and Susan M. Zwicker. Native Plants for Wildlife Habitat and Conservation Landscaping: Chesapeake Bay Watershed. U.S. Fish \& Wildlife Service, Chesapeake Bay Field Office, Annapolis, MD. 82 pp. 2003.

[21] Kaya, E. Kır Çiçeklerimizi Etkin Değerlendiriyoruz. Plant Peyzaj ve Süs Bitkileri Dergisi, Y11:3, Sayı:6, Nisan-Temmuz 2012, Adapazarı. 2012.

[22] Wyse Jackson, P.S. and Sutherland, L.A. International Agenda for Botanic Gardens in Conservation. Botanic Gardens Conservation International, U.K. 2000.

[23] Ekim, T., Koyuncu, M., Güner, A., Erik, S., Yıldız, B. Ve Vural, M. Türkiye'nin Ekonomik Değer Taşıyan Geofitleri Üzerinde Taksonomik ve Ekolojik Araştırmalar. Orman Genel Müdürlüğü Yayın Sıra No: 669, Seri No: 65, Ankara. 1991. 


\title{
Lawns and Ground Covers in Landscape Design
}

\author{
Candan Kus Sahin \\ Additional information is available at the end of the chapter
}

http://dx.doi.org/10.5772/55768

\section{Introduction}

It is well known that the lawn is one of the basic elements of garden designs, linking together all the other planting trees, shrubs, flowers into a harmonies whole. However, a beautiful lawn has an emotional appeal that can be translated into spiritual comforts. Hence, the lawn typically offers peace and serenity, and an escape from the glare and hard surfaces of sidewalks.

In suitable growing conditions, the grasses are one of the well lawn covering materials due to uniform in color and texture, soft and resilient, easy to take care of. In many areas, grasses can provide a surface that maintenance frees than paving. They can be walked on, sat on and used for many outdoor activities and sport activities such as; football, soccer, volleyball and related practices. However, although the green of a lawn is usually grass, but not necessarily that.

It is also well established that the lawns can be made of almost any plant that spreads fairly to cover the ground, and in certain places ground covers other than grass are very popular, either as grass substitutes, or as companions for grass, to provide visual variety. However, despite the importance of the non-grass of ground covers, grass continues to be one of the favorite in open spaces and gardens. Hence, the leaves of the grasses are different in form and behavior from those of many other plants. They can grow from stem joints, first in one direction, then in another, and each leaf is divided into distinct parts. Moreover, many grasses flower in great clusters and individual flowers of which the clusters are composed are having neither fragrance nor bright color because these insect attracting characteristics are not needed. Grasses can be pollinated either by the wind or self-pollinating with their own seeds. A few-notably the bluegrasses often develop without fertilization and are able to reproduce either sexually or by a kind of self-pollination.

A fine lawn directly influences on suburban landscape practices that other ground covers have usually not considered. However, no other ground cover is as durable underfoot as a 
grass lawn, or produces as satisfying a sense of orderliness. For a while, tufted grasses and bushes as well as a multitude of hybrids that plant breeders have developed over the years. In Figure 1, typical lawn and woody plant mixtures well organized in public area and effects value of its environments
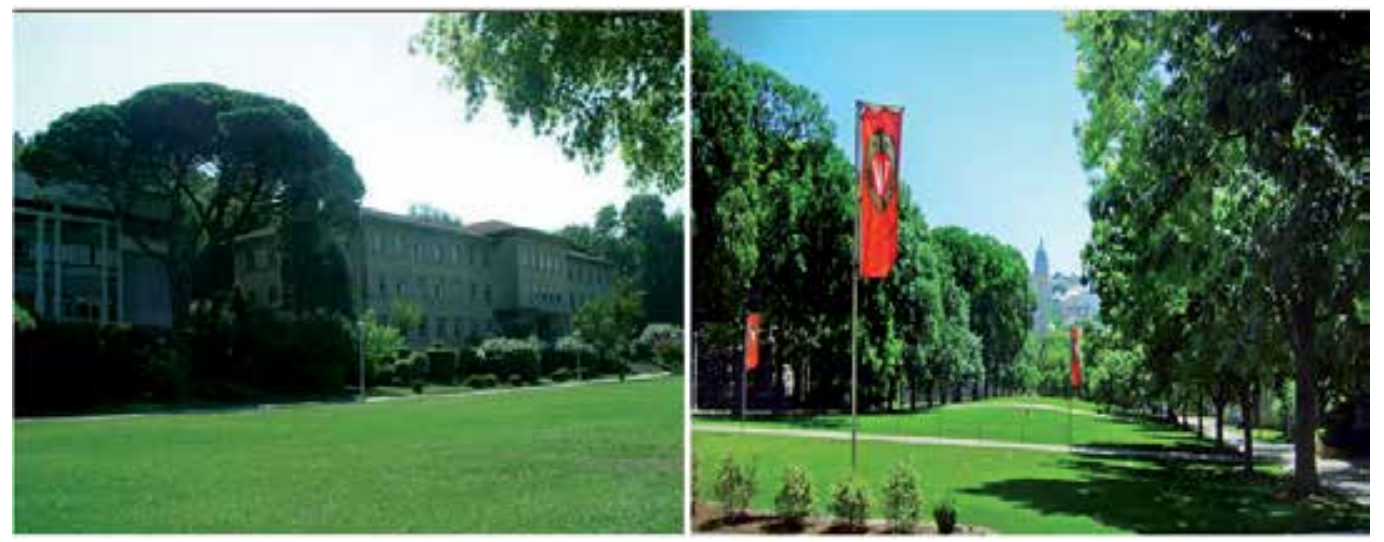

Figure 1. Typical lawn and woody plant mixtures in public area

\section{Lawn properties}

\section{Lawn variations}

The gardeners like to intervene in the plants natural distribution with their natural breeding processes whenever the demand for lawn grasses grew. However, the scientists search new grasses as well as cultivation of existing grasses and explorers the lifecycle of grasses in experiment stations to improve current strains and create hybrids. Moreover, the painstaking search for naturally produced new varieties still continues. But these days, it is becoming more practical to create improved grasses in the laboratory than before. For instance, the bluegrasses that multiply by a type of asexual reproduction; more than $90 \%$ of the time they produce viable seeds without normal fertilization.

The search for new varieties has led to lawn grasses that are better than those of even a generation ago. The way of crossing one strain with another is to catch a plant during flowers open, before the seeds start developing and at that moment to fertilize it with pollen from another plant. As a result of those, there are currently so many strains and mixtures of lawn grasses, each of which has its own advantages and drawbacks that can be a careful choice, whether is to nature the established lawn, replant a small section or start an entirely new lawn.

\section{Climate effects}

It is well known that the choice of a lawn grass is governed by a variety of things, and one of the most important things of these are climate. In the north hemisphere, the lawn grasses are usually grouped into three major climate categories; 
- Warm-climate grasses,

- Cool-climate grasses

- Dry-land grasses.

With-in these three broad categories, many individual species of grass have special preferences as to fertilizer and soil $\mathrm{pH}$.

Cool-climate grasses have usually distributed east-west on the hemisphere. However, warm climate grasses predominate in the regions close to equator. On the other hand, the dry-land grasses are usually utilized in certain areas where the lack of moisture makes it difficult or impossible to grow other strains. Moreover, the territorial imperatives of the grasses are greatly influenced by elevation. While both cool- and warm-climate grasses can provide fine lawns, the dry-land grasses are coarse in texture and generally grayish-green in color.

Cool climate grasses survive during the winter months, decay in the heat of summer, but retain some trace of green during most of the year. There are a number of varieties for cool climate grasses but three major kinds are those most often utilized;

- Blue grasses,

- Fescues,

- Bent grasses.

Regular watering and fertilizing are essential, and so is attention to the control of disease on lawns. However, the bent grass is fine and soft, it is the grass often associated with well in the gentle, cool climate. Moreover, it is also host to much well known fungus that attacks lawn grass.

Typically, many of the cool climate lawns are planted in fescue and blue grass. Fescues are sturdy grasses that demand a well sharpened lawn mower. However, fescues tolerate sun or shade and can be grown in poor sandy soil, under dry conditions and with very little fertilizer. On the other hand, the blue grass is generally considered to be one of the best all purpose lawn grass because it combines both beauty and practicality. Its color is a clear, rich green and it produces a thick, soft turf that is both pleasant to walk on. Moreover, sturdy properties of blue grass are one of the choices for the turf of football fields.

The warm climate grasses suffer in hot weather and are killed by prolonged exposure to cool temperatures. Most of them survive mild frost, but when the weather gets cool in fall they become dormant and turn brown. The four most popular warm climate grasses are;

- Bermuda grass,

- Zoysia,

- St. Augustine grass,

- Centipede grass.

Of these Bermuda grass is most widely used because it spread very rapidly in a year.

\section{Selection of grasses for mixture}

Although, a lawn of one kind yields a superbly uniform turf, unvarying in color and habit of growth, and may be exceptionally resistant to certain kinds of lawn damage, the mixture of 
the grass are usually combined together. But these have some drawbacks. Merion blue grass, for instance, requires more fertilizer than do other blue grasses. Also, a pure stand of grass makes a much more vulnerable lawn. However, one type may resist one disease or one kind of lawn trouble, its susceptibility to another leaves the lawn open to catastrophe. But, it is important to note that no single type of grass is likely to suit every part of a lawn.

Because mixture offers many advantages, but gardeners must consider their components carefully before establishing. It is well known that in mixture "nurse" grasses, fast growing types that provide a temporary cover of green until the slow growing, more permanent and more desirable grasses can develop. The commonly used for this purpose is rye grass. It comes in two forms, annual and perennial, and both have been favored upon by most turf experts. However, rye grass is cheap and its seeds are large and bulky, so that a mixture provides less grass per $\mathrm{kg}$ than finer seeds do. Gardeners usually feel that in the role of nurse grass, steal moisture and fertilizer from the more valued grasses and should properly be called a 'robber grass'. Moreover, new improved rye grass strains, have more or less removed coarse bladed and unattractive structure. These rye grasses may still steal other grasses of some food and moisture, but it has shiny dark leaves and a fine texture, and it is longer lived than the older rye grasses.

For most lawns are started from pieces of living plants. However, many of the finer varieties of warm climate grasses are hybrids. They may provide seeds, but the seeds of hybrids seldom produce new plants. Most of the warm climate grasses spread by sending out lateral stems from which new plants take root and grow at intervals. The rhizomes if they creep along the surface, are simply placed in the ground to spread and grow together, forming a lawn.

People who prefer a green lawn in winter use a technique known as over seeding. With this approach, they spread over the existing turf seeds of a cool-climate grass, usually an annual such as rye grass during the fall. The cool-climate grass quickly germinates and grows well, its green hiding the dormant brown, until warm weather returns and the permanent grass of the lawn takes over once more. One of the example as; Zoysia, which loses its green color at the autumn frost and stays brown until after the spring.

\section{Ground covers selection and blending in lawns}

Ground covers such as shrubs are as useful and decorative as grass, and sometimes more so, in many areas around the homes. However, the term "ground cover" applies to any vegetation that blankets the soil, from moss to forest. In horticulture, however, it means lowgrowing plants in close proximity, used to ornament lands that otherwise would have only grass.

For an average-size home a low-growing cover might be anything up to $30 \mathrm{~cm}$ high; for a small one it would probably not exceed $7 \mathrm{~cm}$. On the other hand, Santa Cruz fire thorn, which attains approximately $100 \mathrm{~cm}$ in height, or Tamarix juniper, which may grow $60 \mathrm{~cm}$ tall, might well qualify as a low-growing ground cover on large lands. In any event, there are no rigid rules, and overall appearance as well as actual size might make a particular 
ground cover seem perfectly suitable on an open, rolling terrain and wholly out of place in a confined area.

Plants need conditions like those they enjoy in the wild, and the ground covers that can grow best in garden are those that naturally grow in a similar habitat. If the area wish to cover lies under a heavy roof of conifers, it should be best to use such typical forest ground covers as ferns or mosses. But if the area receives full sun and is unprotected from the wind, better to put plants that grow naturally on open fields, for instance bearberry or cotoneaster.

Although nature provides ground covers for many conditions of climate, soil and moisture environment, these plants are usually categorized by their light requirements. Those growing on the forest floor and those growing in the wide open spaces even look different. As a general rule the forest habitats, the leaves of a dark green, indicating the added chlorophyll they contain to make the most of dim light for photosynthesis. However, plants that grow in full sun vary from the dark green of the cotoneaster to the red and yellow color.

There are many cultivation techniques and grass varieties. However, the choice of different grass types is limitless. Every types of grass belong to the same botanical family and within that family only a few botanically distinct groups are used for lawns. But if gardeners decide to cover ground not with grass but with the plants that are loosely categorized as ground covers, the choice broadens. Many of ground covers are distinctly different from one another in appearance and habit. Moreover, ground covers often do what grasses do and are often thought of as grass substitutes. For instance, of dichondra, ground covers commonly used for lawns in the desert or warm climate areas and cannot stand cold weather. A very tiny evergreen vine with round cup shaped leaves creates a smooth, turf sturdy surface and good enough to walk on.

Grown covers could be rough or fine, smooth or billowy, green, gray or bright color. They grow in the places where grass can grow and in other places where grass can not deep shade, rocky or moist soil, steep, rain washed slopes. However, grown covers combined with the grasses, provide the variety that enables to make grounds enjoyable and admirable.

It is well established that a well established lawn is pleasing when it is skillfully blended into the landscape. And its appearance is even more enhanced when some ground covers are blended in with the lawn itself. However, the possible variations are limited only by the availability of ivy and vines, juniper and bellflower, and all the other ground covers that can be interspersed with and contrasted with the even carpets of lawn.

One of the major advantages of many ground covers over grass is that they are colorful and decorative. The varied ornamental qualities of ground covers offer pleasing contrasts in texture and color. And they have added advantage of lasting longer than flowers. Evergreen ground covers are not only ornamental in areas where a lawn has turned brown for the winter, but their bright berries add color at the time is most welcome.

As esthetic considerations help in the selection and matching of ground covers. Boxwood and periwinkle, for example, blend naturally and have been used together. The choice of 
dichondra, which can flourish in rocky crevices, is perfect for the stone terrace, as is the use of arid-resistant for a low drive way border in the dry desert climates. However, contrasting ground covers are more effective than complementing ones, especially when the aim is to create borders upon borders, as in the case of the differing textures and zig zag patterns. In choosing a ground cover, it should be considering first the effect it may produce; then, among the plants that can achieve the effect.

A practical approach and a general rule from the point of view of landscape design are: create a border, which is planted in periwinkle, beside each path. Because periwinkle tolerates the shade of the boxwood hedge better than most grass would. However, annual periwinkle, which has rose, pink or white blossoms, is often preferred for its longer blooming season. It begins to flower soon after being set out in spring and continues to blossom until autumn.

However, apart from height distribution, ground covers vary in many ways. Evergreen ground covers such as ground covers that are herbaceous perennials-nonwoody plants die in the ground in late fall and reappear the following spring. Moreover, their foliage may range in color from the dark green through the gray green and in shape from smooth edged to serrate. Each of them does an outstanding function under the conditions for which it is best suited and each of them also deserves to be appreciated for its beauty as well as its utility.

If ground covers are chosen with well planned way, the opportunities for enriching grounds with beauty and interest are limitless. Hence, ground covers usually make a well contribution to the overall design of the landscape than grass can. A slope might look well if planted in green plants or yellow blossoms. A hot, dry area carpeted in any one of a number of plants that are capable of turning this garden liability.

However, ground covers can lighten the burden of lawn on step slopes and rocky terrain, where mowing is sometimes dangerous and where a lot of hand clipping is generally required. Hence, ground covers need to be groomed less frequently than grass needs to be mowed. The sight of a billowing surface of Sprenger asparagus is pleasing, while a billowing stand of uncut blue grass is not. The ground covers need care, and the work usually done by hand. Unlike grass, which heals quickly when stepped on, most ground covers needs further attentions.

Typically, ground covers are useful plants for trying different configurations. However, there are ground covers that can grow in wetter or drier places than grass can tolerate. Many of the ground covers usually prefer dense shade to sunlight, and over the years have acquired the ability to compete successfully with the roots of trees for the available supply of nutrients and moisture. Moreover, ground covers are a natural protect soil erosion. Hence, their roots stabilize the soil, but their thick foliage breaks the force of lashing rains and channels it into gentle dripping onto the ground beneath. They are also provided living mulch for rhododendrons, azaleas and clematis. In a bed of spring-flowering bulbs an evergreen ground cover not only sets off the blossoms, it also hides the fading leaves after the bloom is past. 
With a few exceptions, the planting procedures for ground covers are more less the same as those for grass. However, the following issues should be handled with care;

- Irrigation,

- Drainage,

- Soil preparation.

There might be fewer opportunities to alter them after the ground cover is in place. In Figure 2, typical well organized lawn in selected area and effects value of its environments
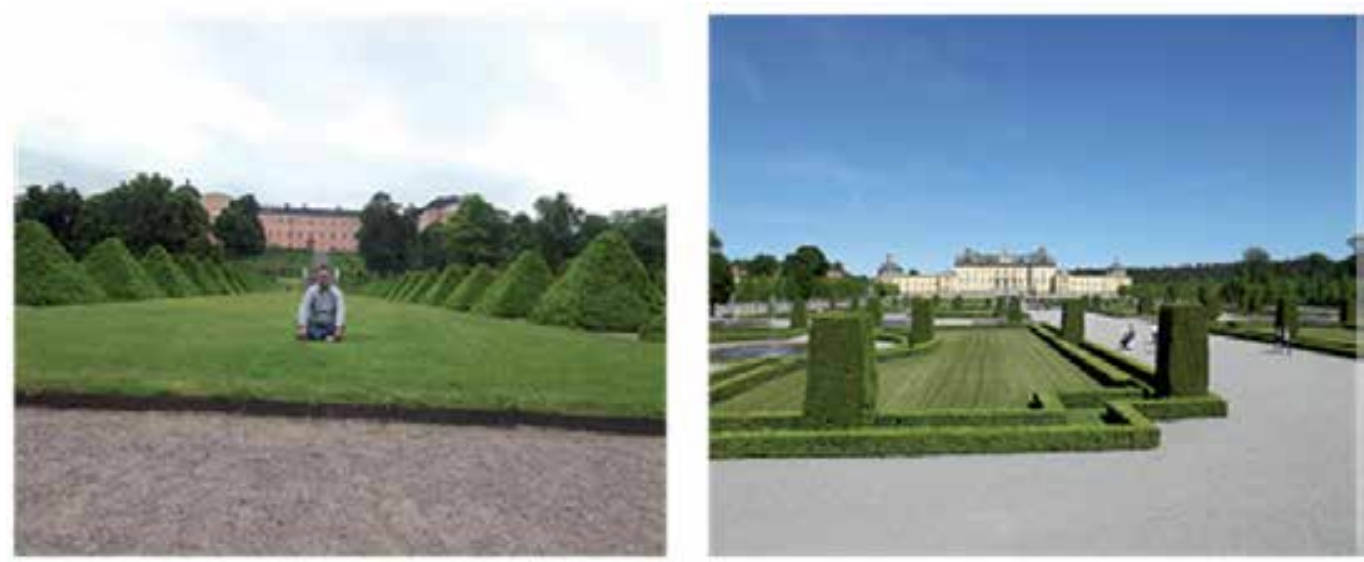

Figure 2. A well organized a lawn in historical sites

\section{Lawn and ground cover maintenance}

Maintaining a lawn involves using well planned approaches throughout the growing season. The following things should be considered all the time for a dense, healthy, wellquality lawn.

- Mowing,

- Fertilizing,

- Irrigation,

- Thatch control,

- Repearing,

- Restoring bare spots,

- Rebuilding from scratch,

However, fall lawn care somewhat depending on the location and type of grass. The cool season grasses, such as; Kentucky blue grass, fescue, and bentgrass, are as much green as in the cooler weather of spring and fall. These grasses usually sourt during the summer, the time of the year when the warm season species such as Bermuda grass, St. Augustine, and Zoysia hit their stride. But conversely, the warm season grasses turn completely brown when the temperature begins to decrease. On the orther hand, the warm season lawns, because of their earlier onset of dormancy, don't need much of autumn care. 
Although there are a few ground covers that can grow in wet or soggy soil, the majority of them prefers well drained soil. Hence, the ground covers need frequent and regular supplemental moisture and good drainage. However, with the sprinklers, the drainage should be considered when the grading is done, particularly if water does not drain off from the site naturally.

For supplemental moisture, the spray heads can be set to the proper height and should be 7$10 \mathrm{~cm}$ above the height of the ground cover at maturity and there should be enough spray heads to cover the whole bed evenly. From time to time most ground covers develop one or two stem that must be clipped off, and occasionally a rambling branch can fail to come through the winter. However, pruning unwanted stems and branches is a regular routine of ground cover care and should be performed early in the spring. Moreover, species like Aarons beard, St.-John's-worth and Algerian and English ivy generally produce a dense mat of low-growing fresh foliage. Pruning is also vital for such fast-growing, invasive vines as Hall's Japanese honeysuckle, a useful semi evergreen ground cover that has a tendency to grow so rapidly that it can very easily get quite out of hand.

The tools for grooming ground covers vary with the plant and the size of the grooming problem. For one or two dead branch, a small pruning tool can be useful, but if the clipping the surface of an entire bed, the most efficient tool is hedge shears. Low-growing ground covers like dichondra, which do not decay easily and are common grass substitutes in hot climate regions, can be cut with a rotary lawn mower. In Figure 3, ground covers, grass and shrubs shown together in a small home garden areas.
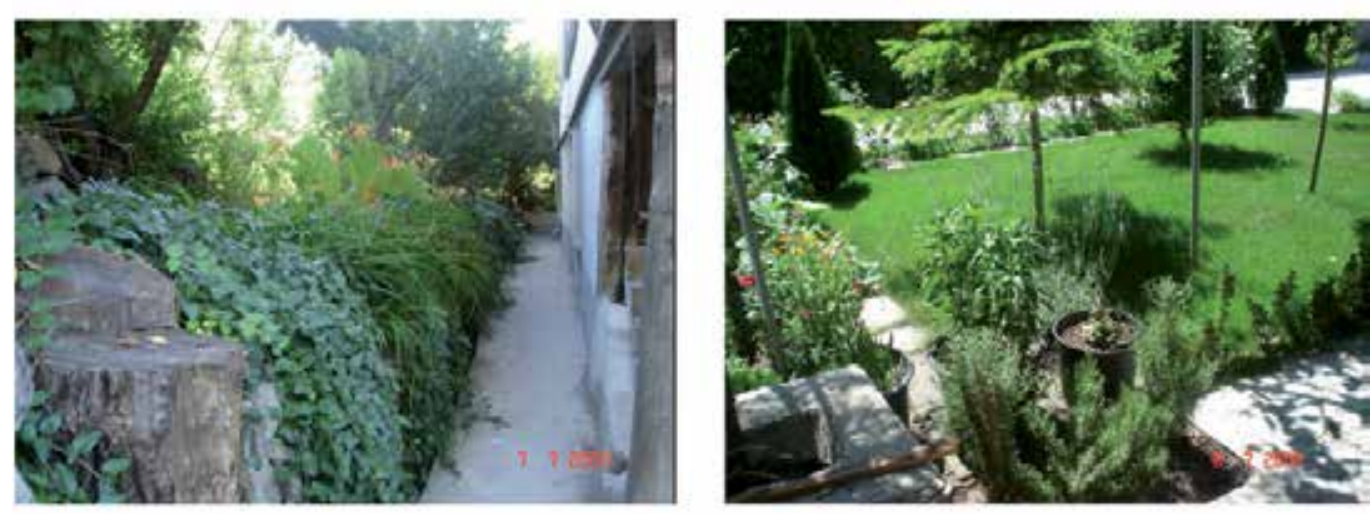

Figure 3. Ground covers, shrubs and grass together in home garden 


\section{Lawn moving}

Mowing is one of the most repetitious and time-consuming maintenance practice. It is typically influence on the turf density, uniformity and aesthetic quality of a lawn. However, lower mowing encourages broadleaf weed invasion and invasion from grassy weeds such as creeping bentgrass and annual bluegrass. Hence, low mowing produces a shallow root system, making the lawn susceptible to arid stress. But, cutting a new lawn too short could damage the young plants permanently by preventing deep root growth as well.

Weed invasion can be kept to a minimum if a lawn is mowed in a timely period, at the proper mowing height, fertilized and irrigated properly. Due to dry grass cuts cleanly, and clippings distribute more evenly, it is best to mow a lawn when the leaves are dry. Moreover, if leaves are excessively heavy, they should be rake up and remove. On the other hand, clippings include nutrients and water, breakdown rapidly and do not contribute significantly to thatch. The amount of fertilizer (especially nitrogen) can be reduced by 15$30 \%$ by leaving the clippings on.

The sensitive young plants of a new lawn need gentle treatment. However, weed killers should not be applied for about a year after sowing seed. Nor should the lawn be mowed for some time. It should be waiting until the grass is almost half again as high as its recommended mowing height such as; 7 to $10 \mathrm{~cm}$ high if it contains grasses such as bluegrasses or fescues, which should normally be moved to 5 to $8 \mathrm{~cm}$. Then mow no lower than the recommended height.

The sharp bladed mower cuts should be useful with a scissors action without pulling at the grass plants. If a rotary mower use, its blades could be very sharp; otherwise it may jar the tender plants, tear their blades and dislodge their tiny roots.

\section{Fertilizing}

Understanding and implementing a well-balanced fertilizer practices are one of the most important factors in maintaining an healthy lawn. Typically, there are three main nutrients for lawns;

- $\quad$ Nitrogen $(\mathrm{N})$ : It promotes dark green colour, leaf and blade development, and density of the turf.

- Phosphorus (P; $\mathrm{P}_{2} \mathrm{O}_{5}$ ): It is important for good root and rhizome development and promotes plant maturity.

- Potassium $\left(\mathrm{K}_{;} \mathrm{K}_{2} \mathrm{O}\right)$ : It contributes to the general vigour of the plant and promotes wear, drought tolerance and winter hardiness.

However, a lawn maintenance should be begun with a test to determine the soil's level of $\mathrm{pH}$, which determines how easily grass can get nutrients from the soil. Moreover, a soil test can provide the amount of phosphorus, potassium, sulphur or lime required. Since potassium and phosphorus, along with nitrogen, are standard ingredients in all lawn fertilizer mixtures, chances are that a soil being treated for nitrogen deficiency can also be receiving adequate amounts of the other two chemicals. 
Typically $1.5-2.0 \mathrm{~kg} / 100 \mathrm{~m}^{2}$ of nitrogen can be applied throughout the season, split into 2-4 applications. There are three numbers on the fertilizer bag represent the amount of nitrogen, phosphorus and potassium in that order. For example, the 20-5-10 fertilizer ratio represents $20 \% \mathrm{~N}, 5 \% \mathrm{P}$ and $10 \% \mathrm{~K}$ respectively. On the other hand, without a soil test, a 4-1-2 ratio (N$\mathrm{P}-\mathrm{K}$ ) such as $20-5-10 \%$ is recommended. It is important to note that nitrogen must be applied every year, while phosphorus and potassium are stable in the soil. However, on newly established lawns and sand soils, higher levels of phosphorus and potassium applications could be used.

The timing of fertilizer application is determined by the total amount of fertilizer required to use in lawn. However, late-fall practices with a quick-release nitrogen fertilizer is beneficial for home lawns. It can be applied when the lawn has stopped growing but is still green. These approaches can be effects:

- increases fall and spring root growth

- promotes a thicker lawn

- results in an early spring green-up

However, the added organic material creates a problem as it decomposes it uses up the soil's nitrogen. The practical way to compensate the loss of nitrogen is to mix in with the organic matter double the usual amount of fertilizer. In addition to the temporary deficiency in nitrogen that may be caused by the addition of organic matter, many soils typically lack other nutrients such as; iron, an important ingredient in the manufacture of chlorophyll, the green substance that makes grass grow. The acid-alkaline balance may require redressing with lime or sulfur. Iron is commonly added to soils in the form of iron sulfate. The usual dosage for iron sulfate is approximately $2 \mathrm{~kg}$ per $100 \mathrm{~m}^{2}$ land area.

\section{Irrigation}

It should be kept in mind that to ensure lawn quality, the lawn must be watered. Even a mulched lawn needs regular watering, especially during hot or windy weather. The water should fall on the ground as a gentle mist without wash the seed loose; such a fine spray can be produced by any of several types of sprinklers. However, during the growing season, grass goes dormant and turns brown if normal rainfall does not provide enough moisture. The best time for watering and better water distribution is in the early morning during a day when there is little or no wind. However, evening watering may cause disease development due to most disease causing fungi require several hours of leaf wetness for infections. Moreover, too much water can cause thatch, fertilizer leaching, increased grassy weed problems (i.e., creeping bentgrass, annual bluegrass or rough bluegrass). In contary, too little water applications can cause shallow rooting of the turf, which makes the lawn susceptible to disease, drought stress or winter injury. It is well established that the amount of water required to achieve clearly depends on soil characteristics. Hence, the water should be use with required amount to be ensure healty lawn. The lawn areas such as, slopes, areas near buildings, curbs, sidewalks and light soils needing more water while low-lying areas, shaded areas and heavy soils may not need as frequent irrigation. 


\section{Thatch control}

Thatch is simply referred to the mat of dead stems and clippings that collected along the surface of lawns. Hence, it is a layer of organic matter made up of decaying grass leaves, stems and roots that build up in between the lawn and soil surface. However, it is a common problem that has been established for several years and over watered and over fertilized lawns. Heavy watering and fertilizing could cause some new vigorous growing grasses produce such thick turf that, particularly if clippings are not raked up. Thatching associated primarily with warm-climate creeping grasses like Zoysia and Bermuda grass.

For a typical lawn, it is beneficial to have a shallow layer of dead plant material around the base of the grass plants. This layer acts as a mulch to retain moisture and keep soil temperatures cool; it discourages germination of weed seeds; and its decay adds nutrients to the soil. But when the layer becomes more than $1.5 \mathrm{~cm}$ thick, it acts like a thatched roof; air, water, soil additives and fertilizers cannot pass. It also harbours insects and diseases and can restrict grass roots from growing into the soil root zone, resulting in a shallow rooted lawn.

However, a thick lawn is one of the best prevention approach against weed invasion. A dense stand of turf can compete successfully with weed seedlings for light and nutrients. But a well maintained lawn can be defense against insect invasion due to the fact that insect damage is usually less severe on well-watered lawns. On the other hand, insects damage of lawns are usually difficult to notice and their presence goes undetected until significant destroy has been done. If the lawn remains brown or shows signs of thinning out despite watering, closer examination for insects should be made. Regular control of the lawn including leaves, stems, roots, thatch and soil will help to determine if the problem is insectrelated.

\section{Repearing}

A lawn repair practice should be begun with a test to determine the soil's pH level, which determines how grass can get nutrients from the soil. Typically, there are two equally simple corrective steps such as; raise the cutting height of the mower 1 to $3 \mathrm{~cm}$, and give the lawn an extra application of fertilizer. These practical approaches usually result in dramatic improvement. However, it is usually difficult to determine what a disaster in lawn. Some lawns do not thrive because they are planted in the wrong grasses. The lawn problem may be;

- Poor drainage,

- Tightly compacted soil

- Thatching

All these three conditions interfere with root development by cutting off the roots' supply of moisture and air, and all these are controlable. 


\section{Restoring bare spots}

If a lawn has bare patches that need seeding, Autumn is the best time to do for cool-season grasses. It is well established that it's hard to put in new seeds in the spring because the soil heats up too fast and even with watering, the root usually dry up before they get achance to develop. Warm-season grasses, however, are best sown in late spring or early summer months.

If the spots are larger than 20-30 cm across, however, new grass must be put in them. Sodding is a reliable way to cover the spots immediately. But many gardeners are put off by the high price of sod and use springs, plugs or seed. Any of these methods work well-if the suitable procedure has been followed.

Sprigged and plugged grasses spread by moving along or under the ground on lateral stems called rhizomes. Thus pieces of plant set in at intervals soon fill the bare spots between them.

\section{Rebuilding from scratch}

An old lawn, no matter how bad its appearance, still consists of a dense mat of dead and living plants together. However, when dug up of that, this turf becomes a mass of root filled parts that may not disintegrate and cannot be raked smooth. Hence, if gardener decides to establish the lawn again, it must first strip off this turf with a sod cutter, or chop it up into small pieces with a rotary tilling machine.

However, the sod cutter slices off the top of lawn, taking with it the heaviest part of the root growth, and thus practically eliminates the material that forms clods. The drawbacks of the sod cutter lead to utilize rotary tiller. Moreover, the rotary tiller does two jobs at once, chops up the turf and tills the soil. From this point onward the task of preparing the ground is practically the same for rebuilding an old lawn as for starting a new one.

If the soil has not been properly prepared with sufficient nutrituent and organic matter, sodded grass soon thins out and loses vigor. And if the soil is bumpy or uneven, the sod may conform, producing a lawn that is bumpy and uneven as well.

Sodding is an excellent way to patch persistent bare spots and to establish lawns on steep slopes and the crests of embankments, where seeds tend to wash out with the first rain. Hence, sodding provides a lawn immediately, and for this reason it is used everywhere, on cool-climate as well as warm-climate lawns. However, in laying sod the time that elapses between cutting and laying is critical for success.

\section{New lawn foundation}

The foundation of a problem-free lawn is land that has been proper drainage and watering system. However, the ground should slope gently and evenly so that rain water is carried steadily away from the land. Moreover, there should be no low spots in the lawn to collect 
and hold water as well. Most land has a general slope in one direction, and a well-planned lawn and its surroundings (house) are placed to take advantage of it. It is well established that the following steps should be considered all the time for a new, healthy lawn foundation. They are;

- Soil preparation

- Plants preparation

- Nutrition adding

- $\quad$ The Bed preparation

- The time selection for plant grass

- $\quad$ Seeds selection and sowing

- $\quad$ Springs, Plugs and Sodding

\section{Soil preparation}

The preparation of soil for lawn foundation has some steps. The first step is to loosening of the subsoil because the heavy traffic may have packed the soil hard that nothing less than a pickax can penetrate it. Obviously neither water nor roots can pass such a compacted soil. Thus, after the rough grading is done, but before the topsoil is replaced, it is recommend that the entire area be tilled with a rotary tiller to a depth of $10-15 \mathrm{~cm}$. These effects the health of the lawn subsequently planted in the area.

Organic matter, with proper fertilizer, can convert subsoil into a satisfactory growing medium for grass. Hence, in heavy clay soils organic matter opens the soil's structure, improving drainage and allowing air and water easier access to the root zone. In light, sandy soils it can acts as a sponge, soaking up and holding moisture and nutrients.

Aeration is also important step and done by a machine called an aerator (a drum-shaped device) that fitted with hollow tines, pulls plugs of soil from the lawn, leaving holes that permit movement of air, nutrients, beneficial microorganisms, and water as well as creating more growing room for the grass roots. However, when rough grading is completed and topsoil put back, the soil conditioning should be start immediately. Some organic material to improve the soil's texture, with a fertilizer may be needed to bring the soil into the proper $\mathrm{pH}$ range. Moreover, soil amendment may be needed to alter the $\mathrm{pH}$ factor at this stage. It can reduce future maintenance if in selecting a ground cover that $\mathrm{pH}$ preferences are close to the natural $\mathrm{pH}$ of the soil. Hence a numbers of organic materials are suitable for ground covers such as; well-rotted manure, spent mushroom soil, compost, leaf mold etc.. One of the most popular and most widely available types is peat moss.

A 5-8 cm layer of peat moss spread evenly on the surface and thoroughly incorporated to a depth of $15-20 \mathrm{~cm}$ could be adequate for most soils. However, it is important to note that ground covers do not have the same fertilizer requirements as grass. But it is advisable to add some nutrients to the soil to get the young plants off. Moreover, ground cover fertilizers, have less nitrogen and higher amounts of phosphorus and potassium than grass fertilizers. These produce strong roots and healthy top growth. Hence, the fertilizer should 
contain N, P and K elements in the right proportion. Spread the fertilizer evenly over the soil at the rate of 10 to $15 \mathrm{~kg}$ per $100 \mathrm{~m}^{2}$ area it in thoroughly along with the peat moss. The peat moss, fertilizer with other materials can be useful into the soil quite satisfactorily with a four-tined spading fork if the area is small; when the area to be useful is of any appreciable size, it is easier to use a rotary tiller.

After the soil is prepared, the land should be prepared for planting. However, on slopes, a diamond pattern can help prevent gullies forming during a rainfall. For that reason, there are two steps that should be taken to protect the soil around the roots of new plants.

- The first step; setting the plants into scooped-out pockets, which serve as catch basins for rainfall and act as moisture reservoirs for the young plants.

- The second step; the entire area should be mulched. The kind of mulch depends on the size and scale of the plant. Around woody plants like juniper and bearberry, coarse mulch like wood chips is suitable. On the other hand, for small creeping plants like Corsican mint or thyme, fine-textured mulch like buckwheat hulls or finely ground bark is more appropriate.

\section{Plants preparation}

It is well known that the cost of ground covers is important criteria for selection. However, although some varieties can be started from seed, for quicker results most are purchased as young plants, and plants in large numbers can be expensive. But gardeners who want to economize can purchase only enough stock for one small area, and then propagate their own new plants from that parent stock. Moreover, many ground covers root and transplant rather easily.

One of the most common form of propagation is to take cutting from the ends of the stems. A cutting should be 7-15 cm long. Strip the cutting of its lower leaves and dip the end of the cutting in a rooting hormone powder. Then plant the cutting in a $7 \mathrm{~cm}$ pot filled with coarse sand, peat moss, perlite or a mixture of equal parts of coarse sand and peat moss. Water the cutting well and then slip it, pot and all, inside a clear plastic bag that will serve for the rooting period as an individual "greenhouse." However, the place the encased cutting in a warm, partly shaded place until new growth begins, indicating that roots have formed. If a number of cuttings are being grown, they can be set in a flat, a shallow box in which seedlings are started, filled to within $2 \mathrm{~cm}$ of the top with damp rooting medium. Once the roots have formed, remove the cutting from the plastic bag or the glass-topped rooting medium, knock it out of the pot, soil mixture and plant it wherever need in the garden. It is also important to note that the ground covers should not transplant any rooted cutting outdoors later than two months before frost is expected. Hence, if in complicated situations, it is a good idea to keep the plants through the winter in a cold frame and set them out in the spring.

However, there are some ground covers that should not take cuttings until before frost, when the growth is mature. The best rooting bed for these cuttings is a flat, 7 to $10 \mathrm{~cm}$ deep, containing a mixture of equal parts of peat moss and coarse sand. If kept in a cool place (5- 
$12{ }^{\circ} \mathrm{C}$ ), they should have rooted by spring. At this point it is better to plant them outdoors in a protected spot until they have become well established; the following year they will be sturdy enough to flourish.

Another method of propagating, especially for herbaceous plants, is by division these plants develop thick crowns of roots and stems, which can be broken apart. Plant the separated sections quickly, before the roots dry, watering thoroughly, and they should flourish as additional plants in your ground-cover bed.

A third method of propagating is by layering. However, layering is best begun in early spring. To layer a woody plant, notch the underside of a stem and dust it with rooting hormone powder, then pin it against the ground with a forked stick or a loop of wire and cover it with a mound of soil. Moreover, the soil should be kept steadily damp. Roots will eventually sprout from the notched section of the stem, which can then be removed from the ground, severed from the parent plant and set out as a new plant.

\section{Nutrition adding}

Ground covers, like other plants, benefit from an annual application of fertilizer in the spring just as their season of new growth begins. As mention above, a typical fertilizer application would be $10-15 \mathrm{~kg}$ per $100 \mathrm{~m}^{2}$ used in setting out the plants. However, fertilizer should be sprinkled over the surface of the ground on a day when the foliage is completely dry, and watered in thoroughly as a result none remains on the foliage to burn it.

After that, maintenance is of minor concern for the balance of the season. About the only left is the removal of leaves that fall among ground cover plants, and they can be dispatched easily with a stream of water from a garden hose.

\section{The bed preparation}

The simplest way to get these soil supplements into the ground is to till them in all in one operation. For that, first spread them on the topsoil. Then, with a rotary tiller, go over the soil in a crisscross pattern until the added materials and existing soil are well blended to a depth of 10 or $15 \mathrm{~cm}$. After the surface dries out, it should be raked with a garden rake to remove stray roots and stones. However, this is one that many gardeners find frustrating, mainly because they do not handle the rake properly.

Raking, no matter how carefully it is done, often leaves small irregularities in the soil's surface. However, the best way to level out these high and low spots is to use a drag a ladder. The texture of the top of the soil need not be very fine; in fact, it helps if the soil clumps are a little rough, 0,3 to $2,0 \mathrm{~cm}$ in diameter, so that the grass seeds will fall into the crevices in the surface.

However, most new beds of ground cover benefit from a mulch to help hold down weeds and keep the soil moist. Not only does the mulch shade the ground to prevent weed seeds from sprouting, its soft texture also makes stray weeds easier to pull out. Moreover, weeds can be very troublesome in ground cover because they are so inaccessible, and perennial 
weeds can be a particular problem because they will continue to sprout from any stray pieces of root left in the ground. In pulling a perennial weed, always pull all of them properly.

Mulching not only keeps weeds away from ground covers but also insulates the soil, keeping it cool and moist. However, even after the ground cover has overgrown it, the mulch will continue to serve as a water absorbing medium beneath the plants. For the first year or so, a bed of ground cover will usually need a frequently watering even in areas where the annual rainfall is sufficient. This is especially important during dry spells. Moreover, mulching protects the soil and seeds from driving rain, especially on slopes, holding them in place until the grass roots are well developed.

One of the cleanest mulch for a lawn is straw. One bale of straw is enough to cover $100 \mathrm{~m}^{2}$, since only a thin layer is needed, three or four straws deep. The soil should still be visible through the mulch. However, straw has one drawback: it may contain seeds of undesirable plants. It is better, therefore, to put the straw several weeks in advance, and to open it and wet it down; this will allow any grain or weed seeds to germinate and die before using the straw on the lawn. But, it is important to notice that not use hay instead of straw. Straw is the stems of cereal grains wheat, buckwheat, oats all of which are annual plants that die after one season and there is no trouble for lawn. But hay is full of seeds of wild perennial meadow grasses and their presence can create problems for years. Moreover, salt hay is the exception which is native to shore areas and its seeds normally do not germinate in ordinary garden soil.

In windy locations, straw mulch should be anchored with string stretched between pegs and kept moist so that it will not blow away. Natural mulches like straw can be left in place to rot into the soil, or can be raked up when the seedlings are 3-4 $\mathrm{cm}$ high.

In cold climates, the aim of winter protection is not to keep the ground warm, but to prevent it from thawing and freezing, with the resultant heaving that forces plant roots out of the soil. However, one of the best protections any ground cover can have is a blanket of snow. The protective covering should not put before the ground is frozen, and do not remove it until the ground has thawed in the spring.

\section{The time selection for plant grass}

The ideal time to plant a lawn is at the beginning of a period when grass growth is most aggressive and weed growth is slow. Although, this period varies with the region and the climate, cool-climate grasses begin new growth in early spring, reach a peak of activity during the late spring and early summer, and then lapse into relative inactivity during midsummer. But by summer's end, when autumn rains begin, they grow luxuriantly again until slowed by cold weather late in the fall.

Perennial weeds such as; mouse ear, chickweed, dandelion, ground ivy and others developed in cool weather; they are in direct competition with desirable grasses throughout the year and the choice of planting time has no effect on competition from them. But annual 
weeds are easier to deal with. While many such as common chickweed, mayweed and pepper grass compete with grasses in early spring, all slow or stop their growth in fall.

In cool-climate regions, it is typically practices; one of the best possible times to sow grass seeds in cool-climates is in late summer or early fall, up to two months before the ground freezes. From that point on, it is advisable to start planting early spring. However, seeds may be sown after the ground is frozen, so that they will begin to grow with the first warm weather of spring and get an early start in their competition with weeds.

In warm-climate regions, it is better to start new lawn not with seed but with pieces of growing grass. Live grass can be installed in three forms:

- Sod, large rectangles of turf cut free of the ground,

- Plugs, which are small pieces of sod each about 5 to $10 \mathrm{~cm}$ across and $5 \mathrm{~cm}$ deep,

- Springs, which are bits of stems with several blades of grass and bits of root attached.

However, the habits of grasses dictate planting times, and variations in weed growth structure cannot easily be taken advantage of warm-climate grasses, such as Bermuda grass, Centipede grass, Zoysia grass, St. Augustine grass, Carpet grass and Bahia grass, are at their best during the hot days of summer. The time to start a new lawn in warm regions is just before this period of rapid growth begins, in the spring or early summer. Hence, grasses started then from sprigs and given proper care will become well established before they enter their dormant period and turn brown in fall.

\section{Seeds selection and sowing}

As mention above, mixtures contain some grasses that thrive in sun and others that grow in shade, since most lawns have areas of both; each type of grass eventually predominates in the area best suited to it. But before establishing a mixture, it is better to know about the nature of each of its ingredients.

Most grass seed is usually sold by weight, and the package specifies what percentage of the total weight is accounted for by each type grass, as well as how large an area the seed should cover. Kentucky bluegrass, for instance, has about 5,000,000 seeds per kg; fescues average 1,200,000 seeds per $\mathrm{kg}$; rye grasses contain only 500,000 seeds per $\mathrm{kg}$. Thus a mixture labeled 52 per cent bluegrass, 80 per cent germination; 35 per cent creeping red fescue, 80 per cent germination; 35 per cent creeping red fescue, 80 per cent germination; and 10 per cent Chewings fescue, 85 per cent germination, might seem to contain about half bluegrasses, a sun-loving type, and half fescues, which are shade tolerant (the remaining 3 per cent is inert matter). In fact the mixture contains more than four times as many useful bluegrasses as fescue seeds.

Once a seed selected, there are two important things to consider when using it. That are;

- Sow the seed as evenly as possible,

- Cover it with a very thin layer of soil.

As like spreading fertilizer; first lay down a double swath of seeds at each and of the lawn as a turn-around areas, than overlap all rows slightly to prevent bare strips. 
Seeds of fine-textured grasses, which make the most attractive lawns, should be covered with soil to a depth no greater than $2-8 \mathrm{~cm}$; more than that and the seeds may not germinate. There are two methods for covering seeds lightly; neither covers all the seeds, but the first watering will carry most of the unburied seeds down into the soil crevices.

A practical approach especially useful for small areas as; a leaf rake is inverted and dragged with slight pressure across the seeded surface; the inverted tines bury some seeds and leave behind small stripes into which others fall, to be covered when the stripes disintegrate during the first sprinkling. However, for larger areas, employs a piece of chain link fencing or a flexible wire and rubber door mat, to which a rope is attached. When it is pulled, it tumbles the soil, covering seeds as well as footprints and leaving behind a crumbly surface percipient to moisture.

Another approaches as; after seeding a lawn it has been rolled it once lightly. It is suggested that simply water the lawn; sprinkling is necessary, and it will settle the surface sufficiently in most cases.

\section{Springs, Plugs and Sodding}

Springs are cheaper than plugs. However, plugs are easier to handle. Springs are generally set $15 \mathrm{~cm}$ apart, plugs $9 \mathrm{~cm}$ apart, on a planting grid marked in the soil. Plugs are set into the ground upright, with the leaf bases level with at least part of the leafy portion above the surface. After planting, firm the surrounding soil to assure contact between the dirt and the roots, then water the lawn gently but thoroughly. Mulching is not necessary because the plants spread rapidly and soon come together. Until they do, weeds can e kept down by hoeing; using weed killing chemicals on a newly sprigged or plugged lawn is as dangerous as it is on a newly seeded one.

Sodding that are laying a growing turf in place piece by piece, is one of the fastest way to create a lawn. However, sod can be supplied from sod farms and nurseries in strips a $30 \mathrm{~cm}$ to $40 \mathrm{~cm}$ wide and up to $2.0 \mathrm{~m}$. long. Ideally, the strips should be cut from their original growing bed so that the root zone in the strips is no deeper than $2 \mathrm{~cm}$. This requirement may seem contrary to good garden practice, which ordinarily demands the deepest roots possible for transplanting. But in fact, thick sod will take a long time to push roots down into the soil beneath and take hold, while a $2 \mathrm{~cm}$ sod, given plenty of moisture, will begin to send out new feeder roots that will knit to the soil beneath it in a few days.

\section{Author details}

Candan Kus Sahin

Suleyman Demirel University, Faculty of Forestry, Department of Landscape Architecture, Turkey

\section{References}

Acartürk, R., 2001. Park ve Bahçe Peyzajında Süs Bitkileri ve Yer Örtücüler, OGEM Vakfı, Ankara. 
Avcıŏ̆lu, R., 1997. Çim Tekniği; Yeşil Alanların Ekimi Dikimi ve Bakımı. Ege Üniversitesi Matbaası, Bornova, İzmir

Bayçın Korkut, A., Şişman, E. E., Özyavuz, M., 2011. Peyzaj Mimarlığı. Verda Yayıncılık.

Crockett, J. U. 1972. Perennials, Robert M. Jones (Ed.), The Time-Life Encyclopedia of Gardening, 160 p. New York.

Crockett, J. U. 1971. Annuals. Robert M. Jones (Ed.), The Time-Life Encyclopedia of Gardening, 160 p. New York.

Ebcioğlu, N., 2004. Biryıllık ve Çokyıllık Bahçe Çiçekleri, Remzi Kitabevi, İstanbul.

Evans, H. 1986. Gardening Through Years, ISBN: 0-06-181257-9, Herper \& Row Publ. Inc., New York, 192 p.

Gülez, S., 1989. Park Bahçe ve Peyzaj Mimarisi, Karadeniz Teknik Üniversitesi Orman Fakültesi Ders Teksirleri Serisi No:29, Trabzon.

Gürsan, K., 1997. Çim Alanların Peyzaj Mimarlığındaki Önemi ve Tesisi. Atatürk Bahçe Kültürleri Merkez Araştırma Enstitüsü, Yalova.

Hill, L. and Hill, N., 1988. Successful Perennial Gardening A Practical Guide. A Garden Way Publishing Book, Storey Communications, Inc. Pownal, Vermont.

Moscow, H. 1975. Lawns and Ground Covers, Robert M. Jones (Ed.), The Time-Life Encyclopedia of Gardening, 159 p.

Newberry, L. and Handley, G. 1997. Boston Mills Press, Ontario, CA, ISBN: 1-55046-205-9, $120 \mathrm{p}$.

Orçun, E., 1972. İlkbahar ve Yaz Çiçekleri. Süs Bitkileri, Cilt II, Ders Kitabı. Ege Üniversitesi Ziraat Fakltesi Yayın No:142, Bornova, İzmir.

Peterson, A., Beckett, K.A. 1990. Reader's digest guide to creative gardening, ISBN 0276352238, 384p.

Prentice, H.K. 1990. The Gardens of Southern California, ISBN:0-87701-709-3, Chronicle Books, San Francisco, 255p.

Proctor, R., 1997. Naturalizing Bulbs. Henry Holt and Company, New York.

Sarıbaş, M., 1999. Bahçe ve Sera Çiçekleri. Ders Notu, Karaelmas Üniversitesi Yayın No:11, Bartın Orman Fakültesi Yayın No:5, Bartın.

Seçkin, Ö. B., 2003. Peyzaj Uygulama Tekniği. İstanbul Üniversitesi Yayın No:4105, Orman Fakültesi Yayın No:453, İstanbul.

Tanrıverdi, F., 2001. Peyzaj Mimarlığı Bahçe Sanatının Temel İlkeleri ve Uygulama Metodları. Atatürk Üniversitesi Ziraat Fakültesi Ofset Tesisi, Ziraat Fakültesi Yayınları No:291, Erzurum, 169-177.

Tanrıverdi, F., 1975. Peyzaj Mimarlığı Bahçe Sanatının Temel İlkeleri ve Uygulama Metotları Ders Kitabı. A.Ü. Yayın No:418, Ziraat Fakültesi Yayın No:196, Ankara.

Uluocak, N., 1994. Yerörtücü Bitkiler. Ders Kitabı. İstanbul Üniversitesi Yayın No:3824, Orman Fakültesi Yyayın No:428, İstanbul.

Uzun, G., 1999. Peyzaj Mimarlığında Çim ve Spor Alanları Yapımı. Çukurova Üniversitesi Ziraat Fakültesi Ders Kitabı No: D-20, Adana. 
924 Advances in Landscape Architecture

Vick, R. 1990. Gardening Plains \& upper Midwest, ISBN: 1-55591-068-8, Fulcrum Publihing, Golden, Colorado, 363 p. 



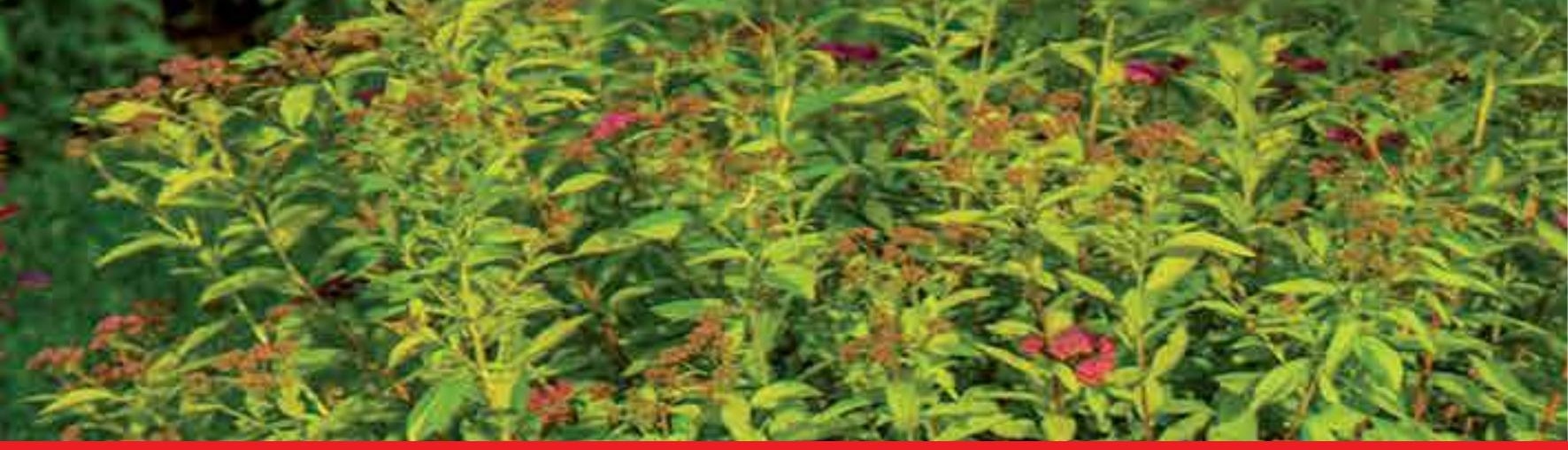

\section{Edited by Murat Özyavuz}

Landscape architecture is the design of outdoor and public spaces to achieve environmental, socio-behavioral, and/or aesthetic outcomes. It involves the systematic investigation of existing social, ecological, and geological conditions and processes in the landscape, and the design of interventions that will produce the desired outcome.

The scope of the profession includes: urban design; site planning; town or urban planning; environmental restoration; parks and recreation planning; visual resource management; green infrastructure planning and provision; and private estate and residence landscape master planning and design - all at varying scales of design, planning and management. This book contains chapters on recent developments in studies of landscape architecture. For this reason I believe the book would be useful to the relevant professional disciplines. 